\title{
The Swiss Student Life Study: Codebook
}

Timon Elmer, ETH Zürich Kieran Mepham, ETH Zürich Marion Hoffman, IAST Toulouse Zsófia Boda, University of Essex Isabel J. Raabe, University of Zürich

\section{Contents}

\section{Abstract}

\section{How to use the Codebook}

Data Availability + Collaborations

\section{Study Design}

Blocks of the Long Questionnaires

Network Items

\section{Network boundaries and participation rates}

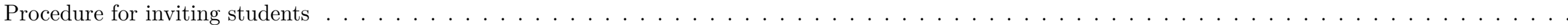

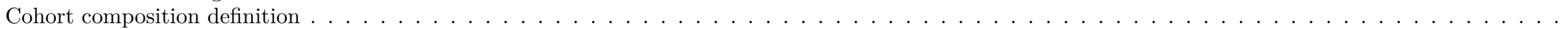

Participation rates

\section{Cohort I}

Variable Overview

Cohort II + III

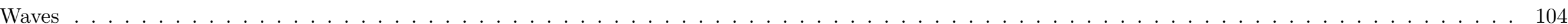

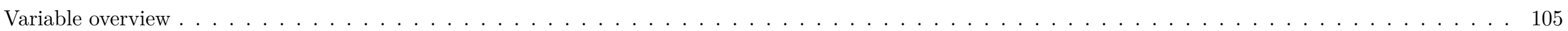

\section{References}




\section{Abstract}

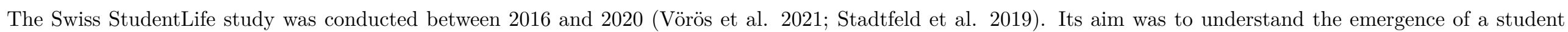

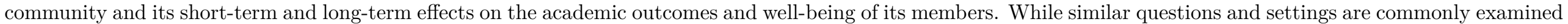

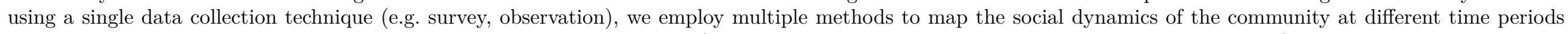

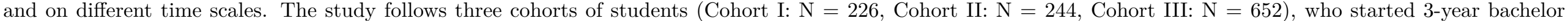

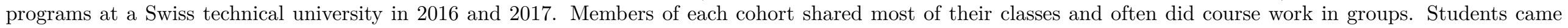

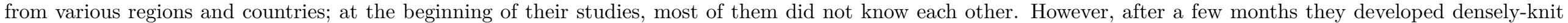

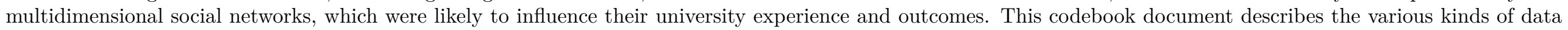
that have been collected in the context of the Swiss StudentLife Study.

\section{How to use the Codebook}

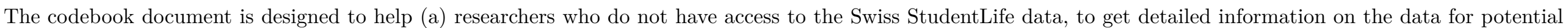
data access requests or (b) researchers who have parts of the Swiss StudentLife data to acquire more details on the measures used in collecting the data.

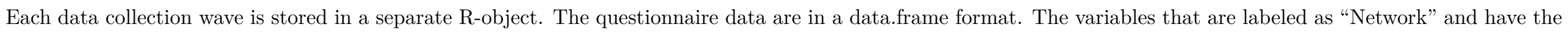

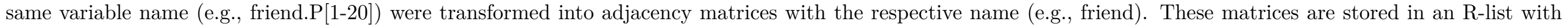
the respective wave name (e.g., net.L3, for wave 3 of the long questionnaire).

There are two types of missing codes:

- NA: The person was part of the cohort at the given timepoint but did not participate in the respective questionnaire/data-collection.

- -10: The person was not part of the cohort at the given timepoint, so he/she could not have participated in the questionnaire/data-collection.

For collaborations, the respective data can be transformed from R to other formats (e.g., csv, excel, SPSS).

\section{Data Availability + Collaborations}

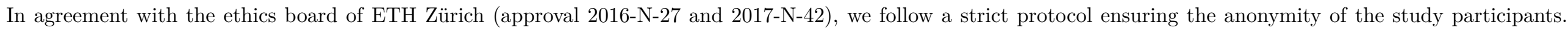
Only highly anonymized data samples are shared on publicly available servers. The data are made available to other researchers in two cases:

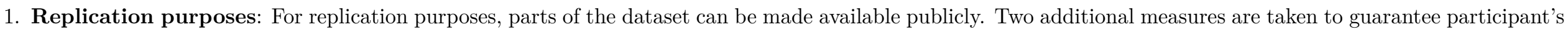

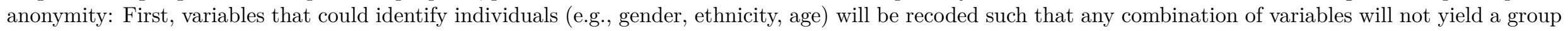

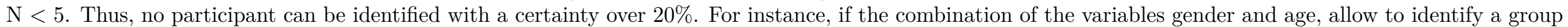

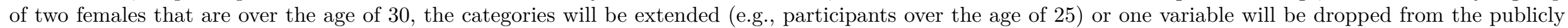

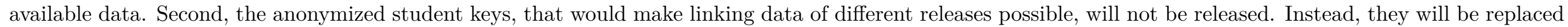
by unique keys that can only be used in a given data-subset release.

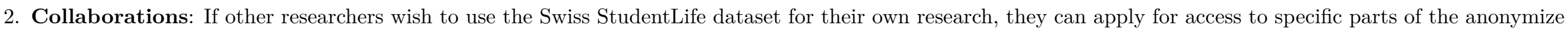
data. To do this, please fill out the following form: Data Request Form.

More information on the study design, cohort information, participation rates, and other useful details on the data collection are documented in:

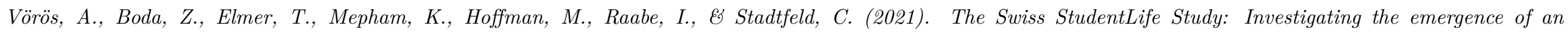
undergraduate community through dynamic, multidimensional social network data. Social Networks, 65, 71-84. 


\section{Study Design}

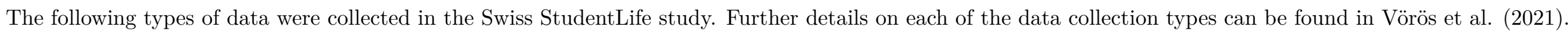

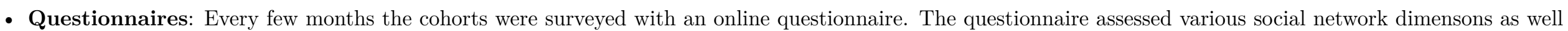

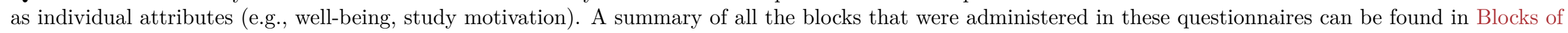

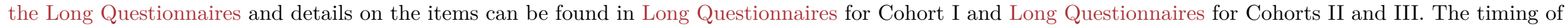

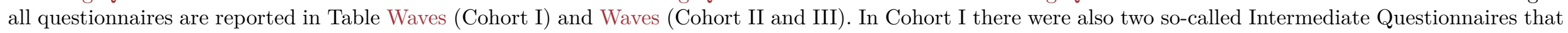

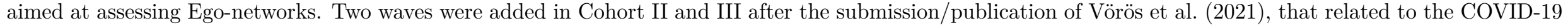
lockdown situation (Waves L11 and L12).

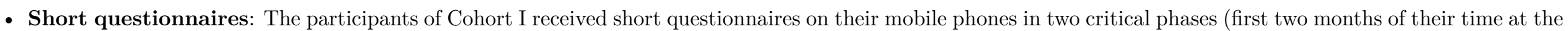

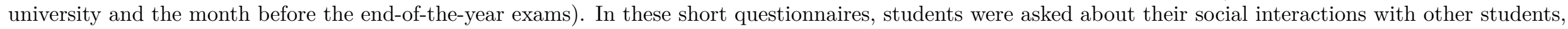

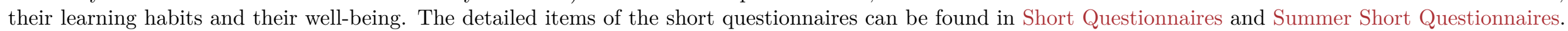
Two planned questionnaires were not administered: A6 and SS7.

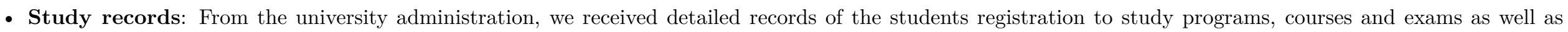

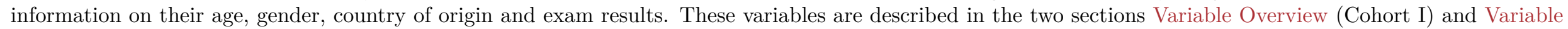
Overview (Cohorts II and III).

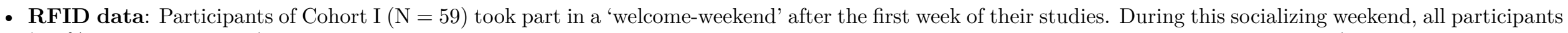

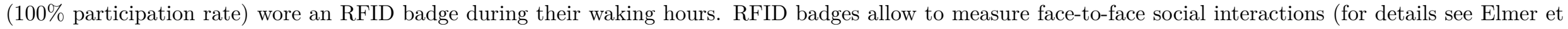
al. (2019) and Elmer and Stadtfeld (2020)).

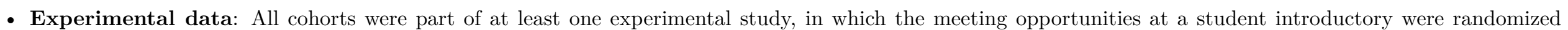
(Cohort I and II, for details see Boda et al. (2020)) and/or the seating arrangement of the introductory lecture was randomized (Cohort II and III).

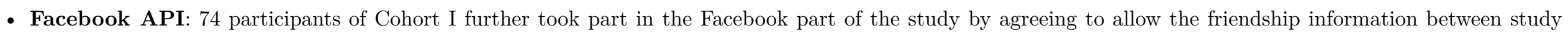

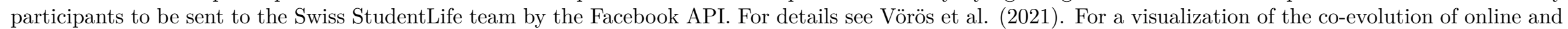
offline friendship data, see video.

\section{Blocks of the Long Questionnaires}

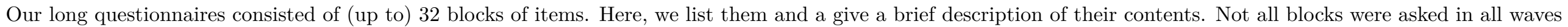
of all cohort, for details on the timing and the specific items of these blocks, see the variable lists below.

- Introduction: Introduction to the study and our informed consent sheet.

- Contact: Any details on contact details that the student wished to change (i.e. phone number, email address).

- Socio-demographic questions: As per title, questions on topics such as participants' country of origin, gender, working/financial status.

- Personal relationships: First network questions on relations, such as friendships, conflicts, and romantic relations

- Joint activities: Network questions on shared activities, such as commuting to university together, co-studying, and spending free-time together

- Social support: Network questions on emotional, instrumental, and informational social support. 
- Perceptions: Network questions on perceptions; e.g. who participants believe to be smart, who they admire, who they feel is (un)popular.

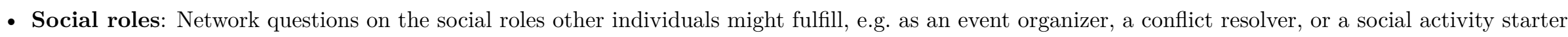

- First contact occurrence: One question on where students met those with whom they are closest for the first time.

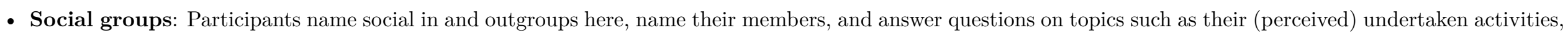
contact frequency and quality.

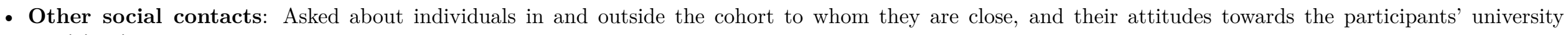
participation

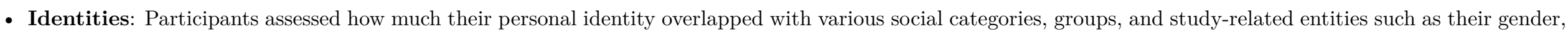
their department, and their university, using Schubert and Otten's (2002) method.

- Depression: This block contained the CESD-R depression scale (Hautzinger and Bailer 1993).

- Anxiety: This block contained the GAD-7 anxiety scale (Spitzer et al. 2006; Löwe et al. 2008).

- Stress: This block contained the PSS-10 anxiety scale (Cohen and Williamson 1988).

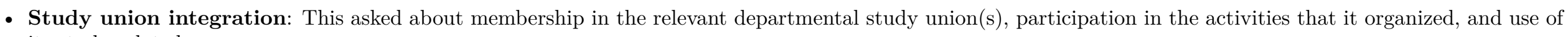
its study-related resources.

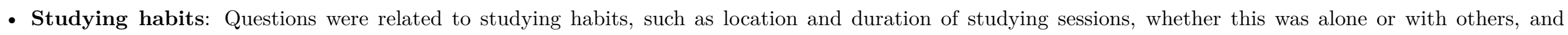
self-perceptions on the participant's studying success such as how likely they were to succeed at their next exam.

- Motivation: This block contained the SELLMO motivation scale (Spinath et al. 2002; Wilbert 2011).

- Quitting intentions: Questions on whether the participant had considered quitting their major, and why.

- Work values: Contains a module on work orientations authored for the International Social Survey Programme (2015).

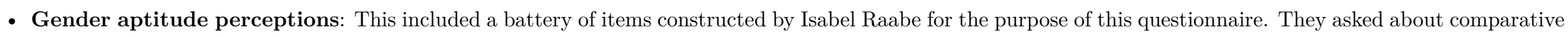

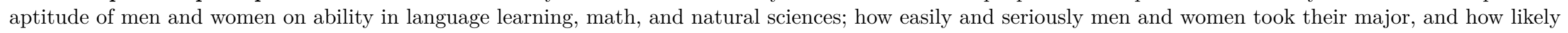
men and women were to succeed in their major.

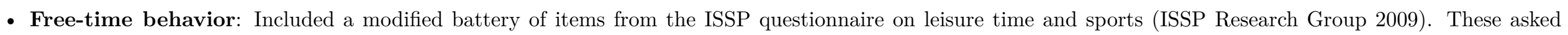

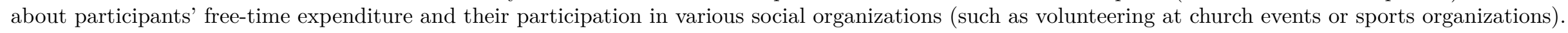

- Consumption behavior: Asked about frequency of consuming drugs, alcohol, and tobacco, and participants' frequency of partying.

- Politics: Here we asked about participants' attitudes towards varied modern political topics, upcoming referenda, and political media consumption.

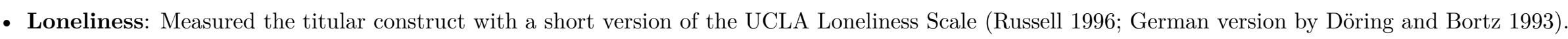

- Trait affectivity: Contained the PANAS by Watson, Clark and Tellegen (1988; German: Krohne et al. 1996).

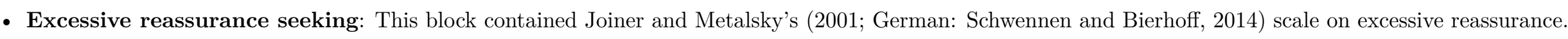

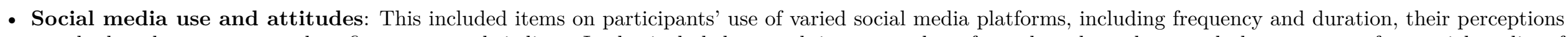

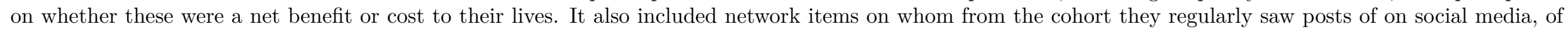
whom they saw annoying posts, and of whom they saw entertaining or useful posts.

- Self-monitoring: This block contained the Self-Monitoring scale by Lennox and Wolfe (1984; German: Schyns and Paul 2014). 


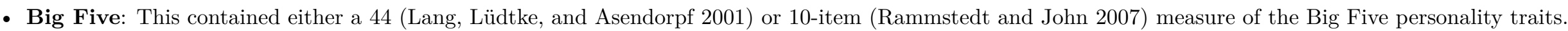

- Emotional Recognition Index: This block contained the Emotional Recognition Index task (Scherer and Scherer 2011)

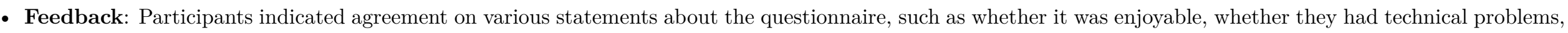
and whether the compensation was fair. Additionally, they could give text feedback here.

(taken from Vörös et al., (2021), Supplementary Information)

\section{Network Items}

\begin{tabular}{|c|c|}
\hline Variable.name & Original.item.text \\
\hline cohabit.classmates & Mit wem wohnst du im Moment? \\
\hline known.before & $\begin{array}{l}\text { Wen kanntest Du bereits vor Beginn des } \\
\text { Studiums? }\end{array}$ \\
\hline interaction & $\begin{array}{l}\text { Mit wem erlebst Du angenehme } \\
\text { Interaktionen? }\end{array}$ \\
\hline friend & $\begin{array}{l}\text { Welche Deiner Mitstudierenden würdest Du } \\
\text { als Freunde bezeichnen? }\end{array}$ \\
\hline relationship.classmat & Mit wem bist du zusammen? \\
\hline dislike & Wen magst Du nicht besonders? \\
\hline conflict & Mit wem hast Du persönliche Konflikte? \\
\hline study & $\begin{array}{l}\text { Mit wem lernst Du regelmässig gemeinsam } \\
\text { für das Studium (z.B. gemeinsames Arbeiten } \\
\text { an einem Projekt oder an Hausaufgaben oder } \\
\text { gemeinsames Lernen)? }\end{array}$ \\
\hline travel & $\begin{array}{l}\text { Wen von Deinen Mitstudierenden triffst Du } \\
\text { regelmässig auf Deinem Weg zur Universität } \\
\text { (z.B. im Bus, Tram, oder Zug)? }\end{array}$ \\
\hline freetime & $\begin{array}{l}\text { Mit wem Deiner Mitstudierenden verbringst } \\
\text { Du regelmässig Deine Freizeit? Hier kannst } \\
\text { Du an alle möglichen Freizeitaktivitäten } \\
\text { denken wie zum Beispiel, gemeinsamer Sport, } \\
\text { Filmschauen, Wandern, Kaffeetrinken, } \\
\text { Biertrinken, Tanzen, etc. }\end{array}$ \\
\hline inst.support & $\begin{array}{l}\text { Auf wen kannst Du zählen, wenn Du Hilfe } \\
\text { bei praktischen Dingen brauchst (z.B. beim } \\
\text { Erledigen von Arbeiten oder die } \\
\text { Bereitstellung finanzieller Mittel) unter } \\
\text { deinen Mitstudierenden? }\end{array}$ \\
\hline inf.support & $\begin{array}{l}\text { Auf wen von deinen Mitstudierenden kannst } \\
\text { Du zählen, wenn Du einen guten Rat oder } \\
\text { spezifische Informationen brauchst? }\end{array}$ \\
\hline
\end{tabular}

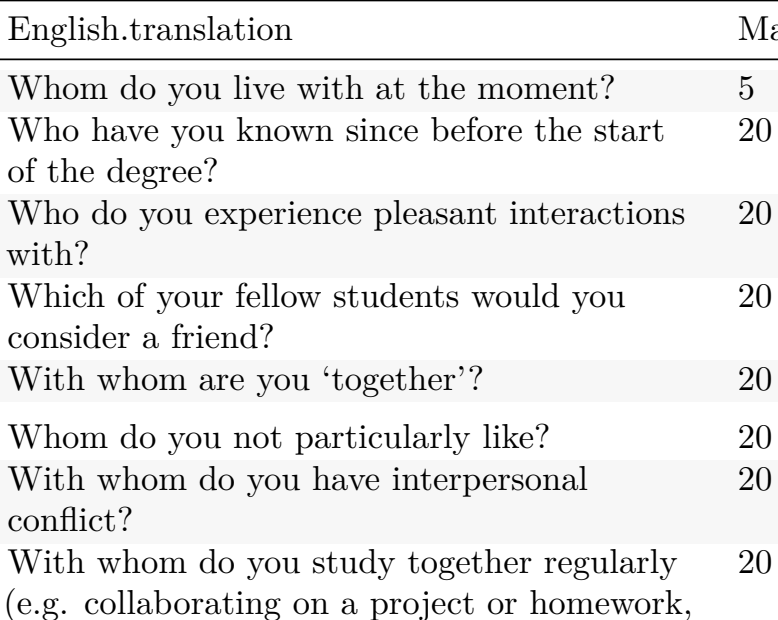
Max.alters

5

20 or communal studying)?

Whom of your fellow students do you

regularly meet on the way to University (e.g. on the bus, tram or train)?

With whom of your fellow students do you regularly spend your free time? Here you may think of all possible free-time activities

such as communal sports, watching movies, hiking, drinking a coffee or beer, dancing, etc.

Who can you count on when you need help on practical things (e.g. getting work done or borrowing money) among your fellow students?

Whom of your fellow students can you count on if you need good advice or specific information? 


\begin{tabular}{|c|c|c|c|}
\hline Variable.name & Original.item.text & English.translation & Max.alters \\
\hline e.support & $\begin{array}{l}\text { Auf wen von deinen Mitstudierenden kannst } \\
\text { Du zählen, wenn es Dir schlecht geht und Du } \\
\text { emotionale Hilfe brauchst (z.B. Trost, } \\
\text { Mitleid und Zuspruch)? }\end{array}$ & $\begin{array}{l}\text { Whom of your fellow students can you count } \\
\text { on when you are feeling low and need } \\
\text { emotional help (e.g. comfort, compassion and } \\
\text { encouragement)? }\end{array}$ & 20 \\
\hline clever & $\begin{array}{l}\text { Wer ist besonders schlau unter deinen } \\
\text { Mitstudierenden? }\end{array}$ & $\begin{array}{l}\text { Who is particularly smart among your fellow } \\
\text { students? }\end{array}$ & 5 \\
\hline funny & $\begin{array}{l}\text { Wer ist besonders lustig unter deinen } \\
\text { Mitstudierenden? }\end{array}$ & $\begin{array}{l}\text { Who is especially funny among your fellow } \\
\text { students? }\end{array}$ & 5 \\
\hline serious & $\begin{array}{l}\text { Wer von deinen Mitstudierenden nimmt das } \\
\text { Studium sehr ernst? }\end{array}$ & $\begin{array}{l}\text { Who of your fellow students takes their } \\
\text { studies very seriously? }\end{array}$ & 5 \\
\hline disturb & $\begin{array}{l}\text { Wer stört während der Vorlesungen (z.B. } \\
\text { Sprechen, lautes Essen oder andere Dinge, die } \\
\text { Mitstudierende vom Zuhören abzulenken)? }\end{array}$ & $\begin{array}{l}\text { Who disturbs during the lectures (e.g. } \\
\text { speaking, loud eating or other things that } \\
\text { distract fellow students from listening)? }\end{array}$ & 5 \\
\hline conceited & $\begin{array}{l}\text { Wer von deinen Mitstudierenden ist } \\
\text { eingebildet, hält viel von sich selbst? }\end{array}$ & $\begin{array}{l}\text { Which of your fellow students is conceited, } \\
\text { thinks a lot of himself? }\end{array}$ & 5 \\
\hline aggressive & $\begin{array}{l}\text { Wer von deinen Mitstudierenden ist } \\
\text { aggressiv? }\end{array}$ & Who of your fellow students is aggressive? & 5 \\
\hline attractive & $\begin{array}{l}\text { Wen von deinen Mitstudierenden findest Du } \\
\text { körperlich attraktiv? }\end{array}$ & $\begin{array}{l}\text { Which of your fellow students do you find } \\
\text { physically attractive? }\end{array}$ & 5 \\
\hline party & Wer von deinen Mitstudierenden feiert viel? & Who of your fellow students parties a lot? & 5 \\
\hline admire & $\begin{array}{l}\text { Wen von deinen Mitstudierenden bewunderst } \\
\text { Du? }\end{array}$ & Which of your fellow students do you admire? & 5 \\
\hline popular & $\begin{array}{l}\text { Wer von deinen Mitstudierenden ist Deiner } \\
\text { Meinung nach sehr beliebt unter Deinen } \\
\text { Mitstudierenden? }\end{array}$ & $\begin{array}{l}\text { Which of your fellow students do you think is } \\
\text { very popular among your fellow students? }\end{array}$ & 5 \\
\hline lookdown & $\begin{array}{l}\text { Auf wen Deiner Mitstudierenden schaust Du } \\
\text { hinab? }\end{array}$ & $\begin{array}{l}\text { Whom of your fellow students do you look } \\
\text { down upon? }\end{array}$ & 5 \\
\hline unpopular & $\begin{array}{l}\text { Wer von Deinen Mitstudierenden ist } \\
\text { unbeliebt? }\end{array}$ & Who of your fellow students is unpopular? & 5 \\
\hline social & $\begin{array}{l}\text { Welche Deiner Mitstudierenden würden am } \\
\text { ehesten soziale Aktivitäten starten? }\end{array}$ & $\begin{array}{l}\text { Which of your fellow students would be most } \\
\text { likely to start social activities? }\end{array}$ & 5 \\
\hline conflict.solve & $\begin{array}{l}\text { Welche Deiner Mitstudierenden wären am } \\
\text { ehesten fähig, Konflikte zwischen } \\
\text { Studierenden zu lösen? }\end{array}$ & $\begin{array}{l}\text { Which of your fellow students would be most } \\
\text { likely to resolve conflicts between students? }\end{array}$ & 5 \\
\hline organise & $\begin{array}{l}\text { Welche Deiner Mitstudierenden wären am } \\
\text { ehesten fähig, ein „Ersti-Weekend“ zu } \\
\text { organisieren? }\end{array}$ & $\begin{array}{l}\text { Which of your fellow students would be the } \\
\text { most capable of organizing a welcome } \\
\text { weekend? }\end{array}$ & 5 \\
\hline prestudy & $\begin{array}{l}\text { Mit wem warst du bei dem Student } \\
\text { Introduction Day in einer Gruppe? Versuche } \\
\text { Dich an so viele Namen wie möglich zu } \\
\text { erinnern. }\end{array}$ & $\begin{array}{l}\text { With whom were you in a group at the } \\
\text { Student Introduction Day. Please remember } \\
\text { as many names as possible. }\end{array}$ & 20 \\
\hline
\end{tabular}




\begin{tabular}{|c|c|c|c|}
\hline Variable.name & Original.item.text & English.translation & Max.alters \\
\hline prestudy.pleasant & $\begin{array}{l}\text { Mit wem hattest du angenehme } \\
\text { Interaktionen am Student Introduction Day? }\end{array}$ & $\begin{array}{l}\text { With whom did you have pleasant } \\
\text { interactions at the Student Introduction } \\
\text { Day? }\end{array}$ & 20 \\
\hline group & $\begin{array}{l}\text { Welche Deiner Mitstudierenden sind Teil der } \\
\text { Gruppe [1-5]? (die Anzahl } \\
\text { Nicht-Mitstudierenden Gruppenmitglieder } \\
\text { kann auf der nächsten Seite genannt werden) }\end{array}$ & $\begin{array}{l}\text { Which of your fellow students are part of the } \\
\text { group [1-5]? (The number of non-student } \\
\text { group members can be found on the next } \\
\text { page) }\end{array}$ & 20 \\
\hline other.group & $\begin{array}{l}\text { Kennst Du jemanden Deiner } \\
\text { Mitstudierenden, der oder die zu dieser } \\
\text { Gruppe [1-5] gehört? Bitte nenne so viele } \\
\text { Personen, wie Du kannst, aber nenne nur } \\
\text { Personen welche zur Gruppe gehören. }\end{array}$ & $\begin{array}{l}\text { Do you know any of your fellow students who } \\
\text { belong to this group [1-5]? Please name as } \\
\text { many people as you can, but name only } \\
\text { people who belong to the group. }\end{array}$ & 20 \\
\hline wkend.pleasant & $\begin{array}{l}\text { Mit wem hast Du am Welcome-Wochenende } \\
\text { angenehme Interaktionen erlebt? }\end{array}$ & $\begin{array}{l}\text { With whom did you experience pleasant } \\
\text { interactions on the welcome weekend? }\end{array}$ & 20 \\
\hline wkend.conflict & $\begin{array}{l}\text { Mit wem hattest Du am } \\
\text { Welcome-Wochenende persönliche Konflikte? }\end{array}$ & $\begin{array}{l}\text { With whom did you have personal conflicts } \\
\text { on the welcome weekend? }\end{array}$ & 20 \\
\hline political.discussion & $\begin{array}{l}\text { Mit wem Deiner Mitstudierenden tauscht Du } \\
\text { Dich über politische Themen aus? }\end{array}$ & $\begin{array}{l}\text { With whom of your fellow students do you } \\
\text { have exchanges on political topics? }\end{array}$ & 20 \\
\hline contact & $\begin{array}{l}\text { Mit welchen Deiner Mitstudierenden warst } \\
\text { Du in Kontakt während der } \\
\text { [Wintersemesterferien / } \\
\text { Sommersemesterferien]? }\end{array}$ & $\begin{array}{l}\text { With which of your fellow students were you } \\
\text { in contact during the ([winter break / } \\
\text { summer break)? }\end{array}$ & 20 \\
\hline complain & Wer beklagt sich oft? & Who often complains? & 5 \\
\hline sad & Wer ist oft traurig? & Who is often sad? & 5 \\
\hline dislike.listening.to & Wem hörst du nicht gerne zu? & Who do you not like to listen to? & 5 \\
\hline social.media & $\begin{array}{l}\text { Von wem siehst Du regelmässig Beiträge auf } \\
\text { einer Social Media Plattform (Facebook, } \\
\text { Instagram, etc.)? }\end{array}$ & $\begin{array}{l}\text { Who do you regularly see posts from on a } \\
\text { social media platform (Facebook, Instagram, } \\
\text { etc.)? }\end{array}$ & 20 \\
\hline sm.comm & $\begin{array}{l}\text { Mit welchen Deiner Mitstudierenden } \\
\text { kommunizierst Du regelmässig über Soziale } \\
\text { Medien? (ausgenommen Messaging-Apps). }\end{array}$ & $\begin{array}{l}\text { Which of your fellow students do you } \\
\text { regularly communicate with via social media? } \\
\text { (except messaging apps). }\end{array}$ & 20 \\
\hline \multirow[t]{2}{*}{ msg.comm } & $\begin{array}{l}\text { Mit welchen Deiner Mitstudierenden } \\
\text { kommunizierst Du }\end{array}$ & $\begin{array}{l}\text { Which of your fellow students do you } \\
\text { communicate with regularly via messaging } \\
\text { apps (e.g. Whatsapp, Signal, SMS)? }\end{array}$ & 20 \\
\hline & $\begin{array}{l}\text { regelmässig über Messaging-Apps (z.B. } \\
\text { Whatsapp, Signal, SMS)? }\end{array}$ & & \\
\hline sm.good & $\begin{array}{l}\text { Wer postet auf Sozialen Medien Inhalte, die } \\
\text { Du besonders gut findest? }\end{array}$ & $\begin{array}{l}\text { Who posts content on social media that you } \\
\text { particularly like? }\end{array}$ & 5 \\
\hline sm.bad & $\begin{array}{l}\text { Wer postet auf Sozialen Medien Inhalte, die } \\
\text { Du besonders schlecht findest? }\end{array}$ & $\begin{array}{l}\text { Who posts content on social media that you } \\
\text { find particularly bad? }\end{array}$ & 5 \\
\hline
\end{tabular}




\section{Network boundaries and participation rates}

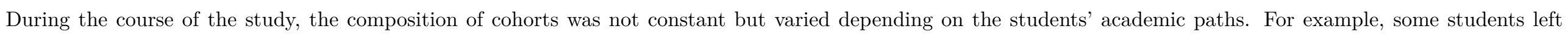

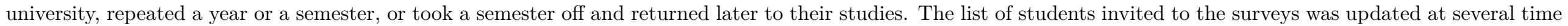

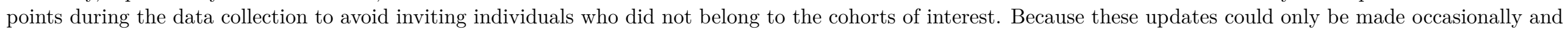

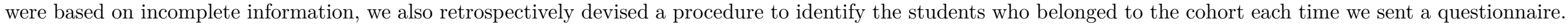

\section{Procedure for inviting students}

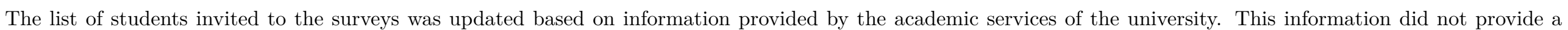

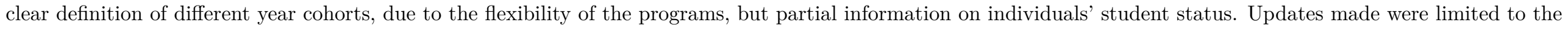
following:

- the removal of students after they asked to be taken out of our study,

- the removal of students officially dropping out of the program,

- the removal of students repeating in the following year cohort after failing the main mandatory exam at the end of the first year,

- the addition of repeaters of the previous year cohort after failing the main mandatory exam in the first year,

- the removal of students from one cohort who we judged to be more likely in the other, despite the possibility that they could be in either one.

The last step of the procedure included a fair part of guessing but was necessary to avoid sending students two questionnaires at the same time.

\section{Cohort composition definition}

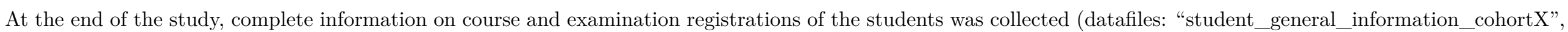

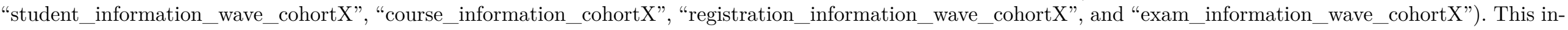

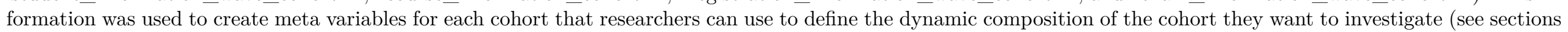
Meta for Cohort I and Meta for Cohorts II and III). Examples of the use of these variables are:

- selecting students who follow the intended curriculum by registering and passing mandatory exams

- selecting students who started studying together

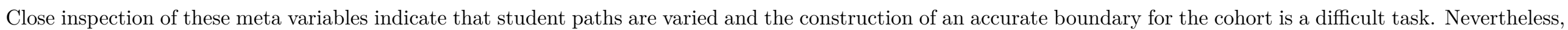

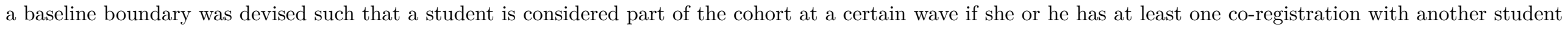

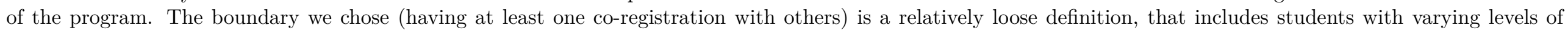

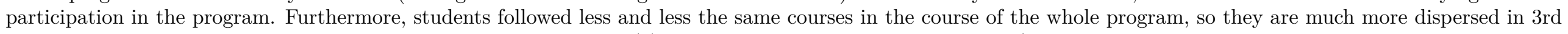

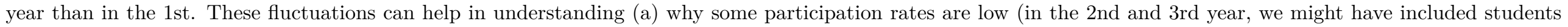
that are not really "active"in the cohort), and (b) suggest that the data from the 1st year might be more appropriate for some research. 


\section{Participation rates}

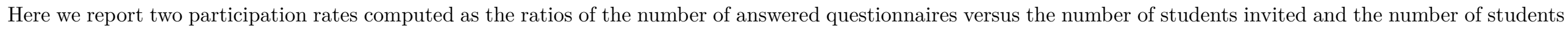

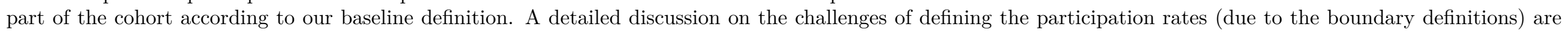
reported in Vörös et al. (2021). For Cohort I, the participation rates are the following:

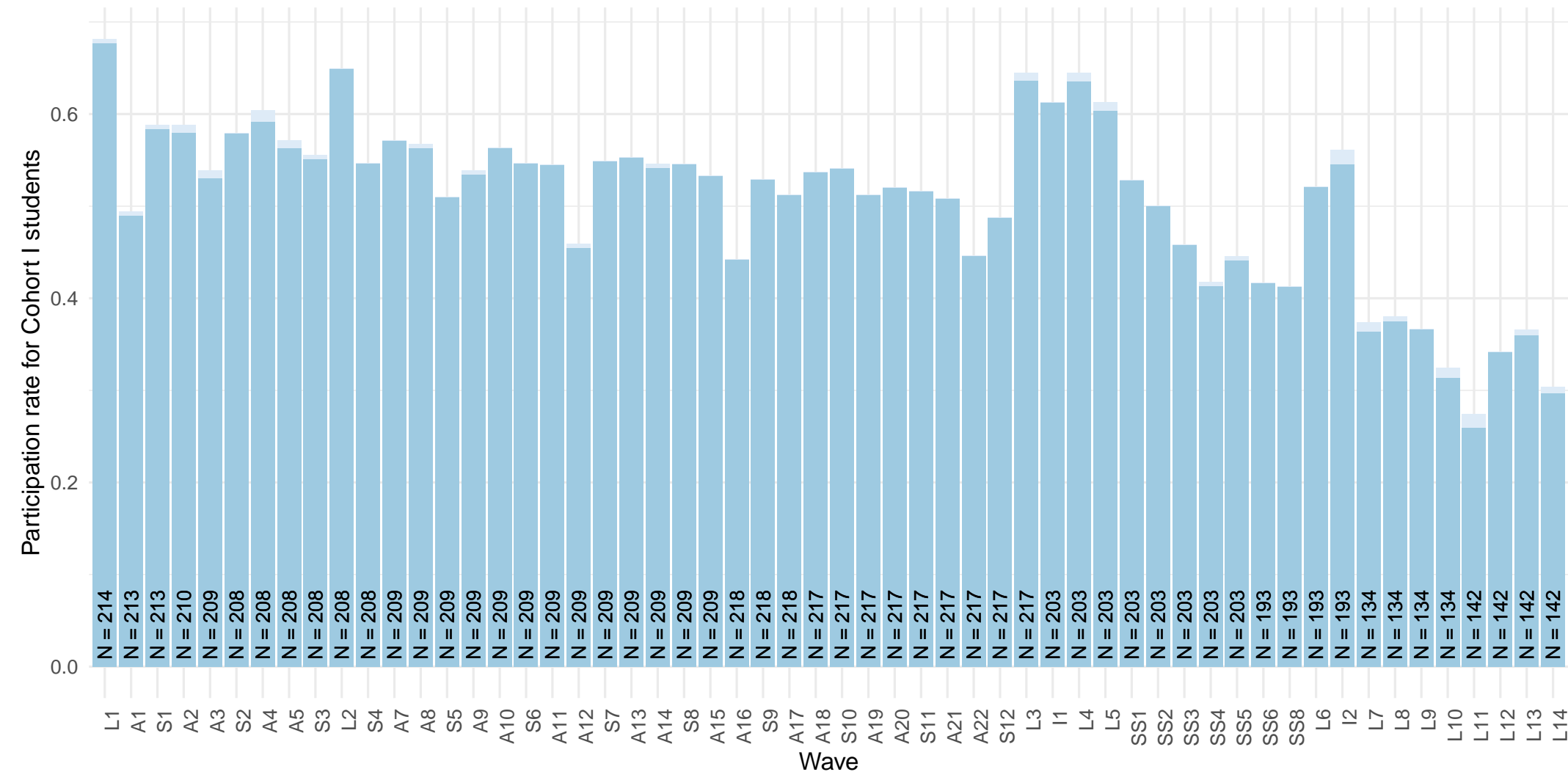


Similarly, for cohort II, participation rates are:

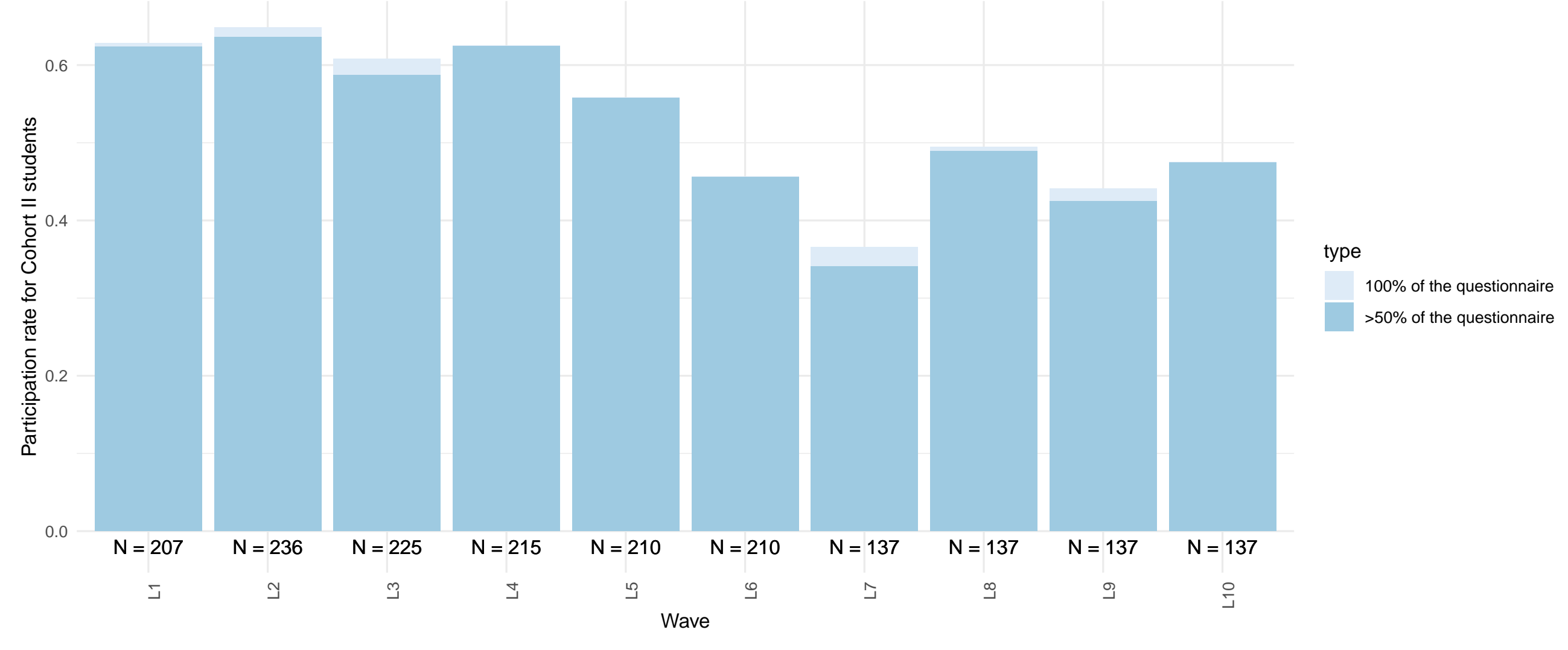


For Cohort III, the participation rates are:
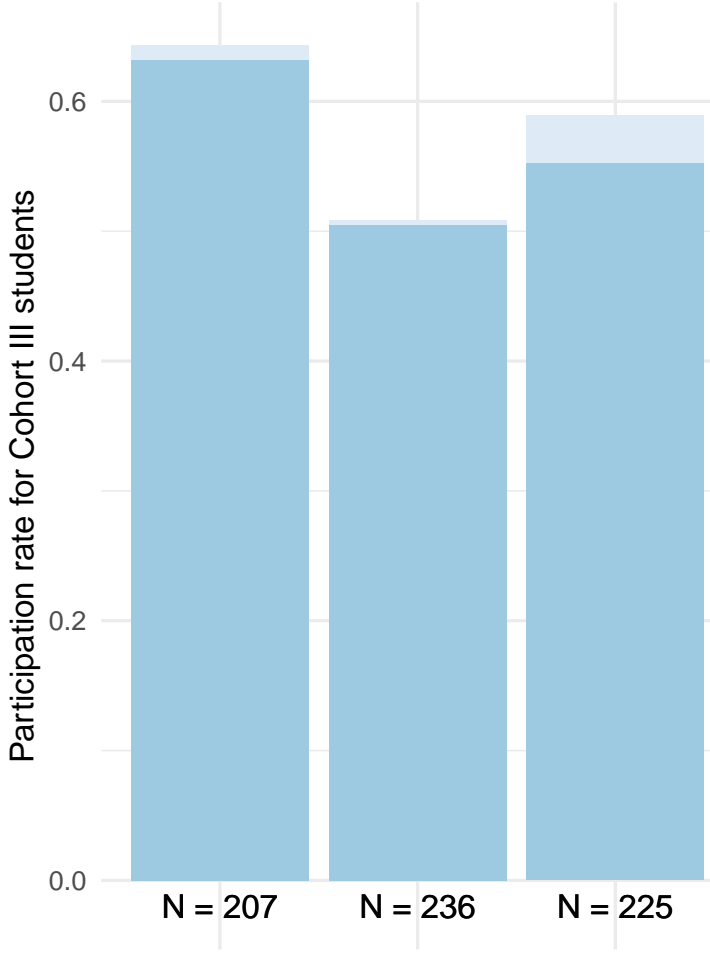

$\sqsupset$

บ

9
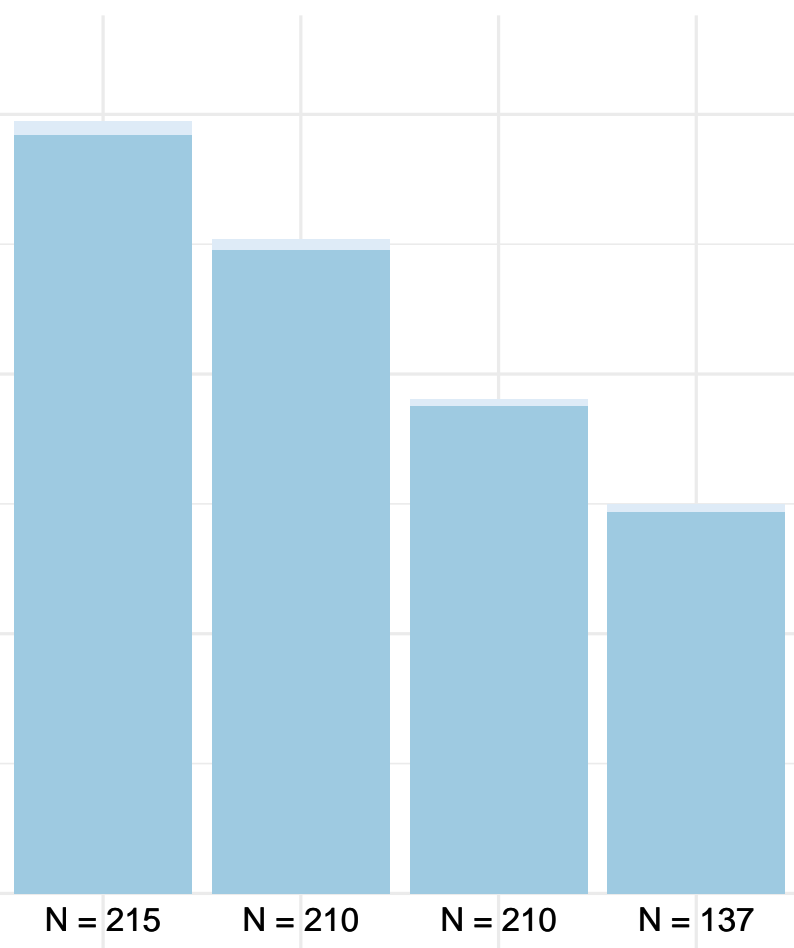

ナ

เอ

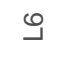

$N=137$
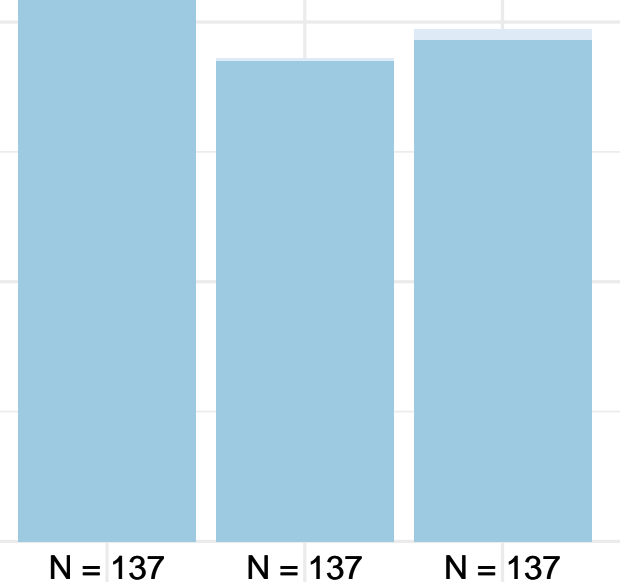

type

$100 \%$ of the questionnaire

$>50 \%$ of the questionnaire

For all cohorts, variables indicating who was invited and who belongs to the baseline cohort are available in the first Table of sections Meta for Cohort I and Meta for Cohort II and III. 


\section{Cohort I}

Cohort I $(\mathrm{N}=226)$ consisted of students starting their studies in September 2016 in a science / engineering major at a Swiss university.

\section{Waves}

\begin{tabular}{llll}
\hline WaveName & Type & Start.Date & End.Date \\
\hline L1 & Long & $2016-09-20$ & $2016-09-23$ \\
L1F & Long & $2016-09-26$ & $2016-09-29$ \\
A1 & Short (affect) & $2016-09-29$ & $2016-09-30$ \\
S1 & Short (studying) & $2016-10-02$ & $2016-10-03$ \\
A2 & Short (affect) & $2016-10-05$ & $2016-10-06$ \\
A3 & Short (affect) & $2016-10-07$ & $2016-10-08$ \\
S2 & Short (studying) & $2016-10-09$ & $2016-10-10$ \\
A4 & Short (affect) & $2016-10-10$ & $2016-10-11$ \\
A5 & Short (affect) & $2016-10-13$ & $2016-10-14$ \\
S3 & Short (studying) & $2016-10-16$ & $2016-10-17$ \\
L2 & Long & $2016-10-17$ & $2016-10-20$ \\
A6 & Short (affect) & NA & NA \\
S4 & Short (studying) & $2016-10-23$ & $2016-10-24$ \\
A7 & Short (affect) & $2016-10-25$ & $2016-10-26$ \\
A8 & Short (affect) & $2016-10-27$ & $2016-10-28$ \\
S5 & Short (studying) & $2016-10-30$ & $2016-10-31$ \\
A9 & Short (affect) & $2016-11-01$ & $2016-11-02$ \\
A10 & Short (affect) & $2016-11-03$ & $2016-11-04$ \\
S6 & Short (studying) & $2016-11-06$ & $2016-11-07$ \\
A11 & Short (affect) & $2016-11-09$ & $2016-11-10$ \\
A12 & Short (affect) & $2016-11-11$ & $2016-11-12$ \\
S7 & Short (studying) & $2016-11-13$ & $2016-11-14$ \\
A13 & Short (affect) & $2016-11-14$ & $2016-11-15$ \\
A14 & Short (affect) & $2016-11-17$ & $2016-11-18$ \\
S8 & Short (studying) & $2016-11-20$ & $2016-11-21$ \\
A15 & Short (affect) & $2016-11-22$ & $2016-11-23$ \\
A16 & Short (affect) & $2016-11-22$ & $2016-11-23$ \\
S9 & Short (studying) & $2016-11-27$ & $2016-11-28$ \\
A17 & Short (affect) & $2016-11-28$ & $2016-11-29$ \\
A18 & Short (affect) & $2016-11-30$ & $2016-12-01$ \\
S10 & Short (studying) & $2016-12-04$ & $2016-12-05$ \\
A19 & Short (affect) & $2016-12-06$ & $2016-12-07$ \\
A20 & Short (affect) & $2016-12-08$ & $2016-12-09$ \\
S11 & Short (studying) & $2016-12-11$ & $2016-12-12$ \\
& & & \\
\hline
\end{tabular}




\begin{tabular}{llll} 
(continued) & & & \\
\hline WaveName & Type & Start.Date & End.Date \\
\hline A21 & Short (affect) & $2016-12-14$ & $2016-12-15$ \\
A22 & Short (affect) & $2016-12-16$ & $2016-12-17$ \\
S12 & Short (studying) & $2016-12-18$ & $2016-12-19$ \\
L3 & Long & $2016-12-19$ & $2016-12-22$ \\
I1 & Intermediate I & $2017-02-27$ & $2017-03-03$ \\
L4 & Long & $2017-03-13$ & $2017-03-17$ \\
L5 & Long & $2017-05-29$ & $2017-06-04$ \\
SS1 & Short (studying) & $2017-07-10$ & $2017-07-11$ \\
SS2 & Short (studying) & $2017-07-17$ & $2017-07-18$ \\
SS3 & Short (studying) & $2017-07-24$ & $2017-07-25$ \\
SS4 & Short (studying) & $2017-08-07$ & $2017-08-08$ \\
SS5 & Short (studying) & $2017-08-14$ & $2017-08-15$ \\
SS6 & Short (studying) & $2017-08-21$ & $2017-08-22$ \\
SS7 & Short (studying) & NA & NA \\
SS8 & Short (studying) & $2017-08-28$ & $2017-08-29$ \\
L6 & Long & $2017-08-29$ & $2017-09-03$ \\
I2 & Intermediate II & $2017-10-02$ & $2017-10-06$ \\
L7 & Long & $2017-12-11$ & $2017-12-17$ \\
L8 & Long & $2018-03-12$ & $2018-03-18$ \\
L9 & Long & $2018-05-28$ & $2018-06-03$ \\
L10 & Long & $2018-08-23$ & $2018-08-30$ \\
L11 & Long & $2019-12-17$ & $2019-12-31$ \\
L12 & Long & $2019-04-01$ & $2019-04-06$ \\
L13 & Long & $2019-05-27$ & $2019-06-03$ \\
L14 & Long & $2019-09-16$ & $2019-09-24$ \\
\hline & & &
\end{tabular}

\section{Variable Overview}

\section{Long Questionnaires}

\begin{tabular}{|c|c|c|c|c|c|c|c|c|c|c|c|c|c|c|c|c|c|c|c|c|}
\hline VarName & VariableLabel & WordingDE & ValueLabelsDE_Linked & WordingEN & ValueLabelsEN_Linked & $\mathrm{L} 1$ & & F L2 & L3 & $\mathrm{L} 4$ & L5 & $\mathrm{L} 6$ & L7 & L8 & L9 & L10 & L11 & $1 \mathrm{~L} 12$ & $2 \mathrm{~L} 13$ & 3 L14 \\
\hline startDate & & & & & & $\mathrm{x}$ & $\mathrm{x}$ & $\mathrm{x}$ & $\mathrm{x}$ & $\mathrm{x}$ & $\mathrm{x}$ & $\mathrm{x}$ & $\mathrm{x}$ & $\mathrm{x}$ & $\mathrm{x}$ & $\mathrm{x}$ & $\mathrm{x}$ & $\mathrm{x}$ & $\mathrm{x}$ & $\mathrm{x}$ \\
\hline endDate & & & & & & $\mathrm{x}$ & $\mathrm{x}$ & $\mathrm{x}$ & $\mathrm{x}$ & $\mathrm{x}$ & $\mathrm{x}$ & $\mathrm{x}$ & $\mathrm{x}$ & $\mathrm{x}$ & $\mathrm{x}$ & $\mathrm{x}$ & $\mathrm{x}$ & $\mathrm{x}$ & $\mathrm{x}$ & $\mathrm{x}$ \\
\hline duration & & & & & & $\mathrm{x}$ & $\mathrm{x}$ & $\mathrm{x}$ & $\mathrm{x}$ & $\mathrm{x}$ & $\mathrm{x}$ & $\mathrm{x}$ & $\mathrm{x}$ & $\mathrm{x}$ & $\mathrm{x}$ & $\mathrm{x}$ & $\mathrm{x}$ & $\mathrm{x}$ & $\mathrm{x}$ & $\mathrm{x}$ \\
\hline finished & & & & & & $\mathrm{x}$ & $\mathrm{x}$ & $\mathrm{x}$ & $\mathrm{x}$ & $\mathrm{x}$ & $\mathrm{x}$ & $\mathrm{x}$ & $\mathrm{x}$ & $\mathrm{x}$ & $\mathrm{x}$ & $\mathrm{x}$ & $\mathrm{x}$ & $\mathrm{x}$ & $\mathrm{x}$ & $\mathrm{x}$ \\
\hline inform.psy & $\begin{array}{l}\text { Respondent } \\
\text { wants to be } \\
\text { informed on } \\
\text { mental } \\
\text { well-being }\end{array}$ & $\begin{array}{l}\text { Ergeben sich während } \\
\text { der Studie } \\
\text { Zufallsbefunde bezüglich } \\
\text { meiner psychischen } \\
\text { Gesundheit (z.B. } \\
\text { depressive Symptome) } \\
\text { über einem kritischen } \\
\text { Wert, möchte ich: }\end{array}$ & $\begin{array}{l}1=\text { darüber aufgeklärt } \\
\text { werden, } 2=\text { nicht darüber } \\
\text { aufgeklärt werden }\end{array}$ & $\begin{array}{l}\text { If over the course of this } \\
\text { study there are } \\
\text { incidental findings } \\
\text { regarding my mental } \\
\text { health, I would like to: } \\
\text { (free translation) }\end{array}$ & $\begin{array}{l}1=\text { be notified, } 2=\text { not } \\
\text { be notified (free } \\
\text { translation) }\end{array}$ & $\mathrm{x}$ & $\mathrm{x}$ & $\mathrm{x}$ & $\mathrm{x}$ & $\mathrm{x}$ & $\mathrm{x}$ & $\mathrm{x}$ & $\mathrm{x}$ & $\mathrm{x}$ & $\mathrm{x}$ & $\mathrm{x}$ & $\mathrm{x}$ & $\mathrm{x}$ & $\mathrm{x}$ & $\mathrm{x}$ \\
\hline
\end{tabular}




\begin{tabular}{|c|c|c|c|c|c|c|c|c|c|c|c|c|c|c|c|c|c|c|}
\hline VarName & VariableLabel & WordingDE & ValueLabelsDE_Linked & WordingEN & ValueLabelsEN_Linked & $\mathrm{L} 1$ & L1F L2 & L3 & $\mathrm{L} 4$ & L5 & L6 & L7 & L8 & L9 & & 0 L11 & L12 & L13 L14 \\
\hline birth.year & Birth year & $\begin{array}{l}\text { Wann wurdest Du } \\
\text { geboren? (Jahr) }\end{array}$ & & $\begin{array}{l}\text { When were you born? } \\
\text { (year) (free translation) }\end{array}$ & & $\mathrm{x}$ & & & & & & & & & & & & \\
\hline birth.country & Birth country & $\begin{array}{l}\text { In welchem Land bist } \\
\text { Du geboren? (Schweiz) }\end{array}$ & $1=$ Schweiz, $2=$ Andere & $\begin{array}{l}\text { Which country were you } \\
\text { born in? (Switzerland) }\end{array}$ & $\begin{array}{l}1=\text { Switzerland, } 2= \\
\text { Other }\end{array}$ & $\mathrm{x}$ & $\mathrm{x}$ & $\mathrm{x}$ & $\mathrm{x}$ & $\mathrm{x}$ & $\mathrm{x}$ & $\mathrm{x}$ & $\mathrm{x}$ & $\mathrm{x}$ & $\mathrm{x}$ & $\mathrm{x}$ & $\mathrm{x}$ & $\mathrm{x}$ \\
\hline birth.country.str & $\begin{array}{l}\text { Birth country } \\
\text { other }\end{array}$ & $\begin{array}{l}\text { In welchem Land bist } \\
\text { Du geboren? (Andere) }\end{array}$ & & $\begin{array}{l}\text { Which country were you } \\
\text { born in? (Other) }\end{array}$ & & $\mathrm{x}$ & $\mathrm{x}$ & $\mathrm{x}$ & $\mathrm{x}$ & $\mathrm{x}$ & $\mathrm{x}$ & $\mathrm{x}$ & $\mathrm{x}$ & $\mathrm{x}$ & $\mathrm{x}$ & $\mathrm{x}$ & $\mathrm{x}$ & $\mathrm{x}$ \\
\hline canton & Home canton & $\begin{array}{l}\text { Aus welchem Kanton } \\
\text { stammst du? }\end{array}$ & $\begin{array}{l}1=\text { Aargau, } 2= \\
\text { Appenzell-Ausserrhoden, } \\
3= \\
\text { Appenzell-Innerrhoden, } 4 \\
=\text { Basel-Landschaft, } 5= \\
\text { Basel-Stadt, } 6=\text { Bern, } 7 \\
=\text { Fribourg, } 8=\text { Geneva, } \\
9=\text { Glarus, } 10= \\
\text { Graubünden, } 11=\text { Jura, } \\
12=\text { Luzern, } 13= \\
\text { Neuchâtel, } 14= \\
\text { Nidwalden, } 15= \\
\text { Obwalden, } 16= \\
\text { Schaffhausen, } 17= \\
\text { Schwyz, } 18=\text { Solothurn, } \\
19=\text { St. Gallen, } 20= \\
\text { Thurgau, } 21=\text { Ticino, } 22 \\
\text { = Uri, } 23=\text { Valais, } 24= \\
\text { Vaud, } 25=\text { Zug, } 26= \\
\text { Zürich }\end{array}$ & $\begin{array}{l}\text { Which is your home } \\
\text { canton? }\end{array}$ & $\begin{array}{l}1=\text { Aargau, } 2= \\
\text { Appenzell-Ausserrhoden, } \\
3= \\
\text { Appenzell-Innerrhoden, } 4 \\
=\text { Basel-Landschaft, } 5= \\
\text { Basel-Stadt, } 6=\text { Bern, } 7 \\
=\text { Fribourg, } 8=\text { Geneva, } \\
9=\text { Glarus, } 10= \\
\text { Graubünden, } 11=\text { Jura, } \\
12=\text { Luzern, } 13= \\
\text { Neuchâtel, } 14= \\
\text { Nidwalden, } 15= \\
\text { Obwalden, } 16= \\
\text { Schaffhausen, } 17= \\
\text { Schwyz, } 18=\text { Solothurn, } \\
19=\text { St. Gallen, 20= } \\
\text { Thurgau, } 21=\text { Ticino, } 22 \\
=\text { Uri, } 23=\text { Valais, } 24= \\
\text { Vaud, } 25=\text { Zug, } 26= \\
\text { Zürich }\end{array}$ & $\mathrm{x}$ & $\mathrm{x}$ & $\mathrm{x}$ & $\mathrm{x}$ & $\mathrm{x}$ & $\mathrm{x}$ & $\mathrm{x}$ & $\mathrm{x}$ & $\mathrm{x}$ & $\mathrm{x}$ & $\mathrm{x}$ & $\mathrm{x}$ & $\mathrm{x}$ \\
\hline mig.generation & $\begin{array}{l}\text { Age of } \\
\text { migration }\end{array}$ & $\begin{array}{l}\text { Wenn nicht in der } \\
\text { Schweiz geboren: Wie } \\
\text { alt warst Du als Du in } \\
\text { die Schweiz gezogen } \\
\text { bist? }\end{array}$ & & $\begin{array}{l}\text { For those NOT born in } \\
\text { Switzerland: How old } \\
\text { were you when you } \\
\text { moved to Switzerland? }\end{array}$ & & $\mathrm{x}$ & & & & & & & & & & & & \\
\hline language.fam & $\begin{array}{l}\text { Main } \\
\text { languages } \\
\text { spoken in } \\
\text { family }\end{array}$ & $\begin{array}{l}\text { Welche Sprachen } \\
\text { sprichst Du } \\
\text { hauptsächlich mit } \\
\text { Deiner Familie? }\end{array}$ & $\begin{array}{l}1=\text { Schweizerdeutsch, } 2= \\
\text { Hochdeutsch, } 3= \\
\text { Französisch, } 4= \\
\text { Italienisch, } 5= \\
\text { Romansch, } 6=\text { Englisch, } \\
7=\text { Serbisch, } 8= \\
\text { Serbokroatisch, } 9= \\
\text { Albanisch, } 10=\text { Türkisch, } \\
11=\text { Portugiesisch, } 12= \\
\text { Spanisch }\end{array}$ & $\begin{array}{l}\text { What language do you } \\
\text { speak most of the time } \\
\text { with your family? }\end{array}$ & $\begin{array}{l}1=\text { Swiss German, } 2= \\
\text { High German, } 3=\text { French, } \\
4=\text { Italian, } 5= \\
\text { Romansch, } 6=\text { English, } 7 \\
=\text { Serbian, } 8= \\
\text { Serbo-Croatian, } 9= \\
\text { Albanian, } 10=\text { Turkish, } \\
11=\text { Portuguese, } 12= \\
\text { Spanish }\end{array}$ & $\mathrm{x}$ & & & & & & & & & & & & \\
\hline language.fam.str & $\begin{array}{l}\text { Main } \\
\text { languages } \\
\text { spoken in } \\
\text { family (other) }\end{array}$ & $\begin{array}{l}\text { Welche Sprachen } \\
\text { sprichst Du } \\
\text { hauptsächlich mit } \\
\text { Deiner Familie? } \\
\text { (Andere) }\end{array}$ & & $\begin{array}{l}\text { What language do you } \\
\text { speak most of the time } \\
\text { with your family? } \\
\text { (Other) }\end{array}$ & & $\mathrm{x}$ & & & & & & & & & & & & \\
\hline language.fri & $\begin{array}{l}\text { Main } \\
\text { languages } \\
\text { spoken with } \\
\text { friends }\end{array}$ & $\begin{array}{l}\text { Welche Sprachen } \\
\text { sprichst Du } \\
\text { hauptsächlich mit } \\
\text { Deinen Freunden? }\end{array}$ & $\begin{array}{l}1=\text { Schweizerdeutsch, } 2= \\
\text { Hochdeutsch, } 3= \\
\text { Französisch, } 4= \\
\text { Italienisch, } 5= \\
\text { Romansch, } 6=\text { Englisch, } \\
7=\text { Serbisch, } 8= \\
\text { Serbokroatisch, } 9= \\
\text { Albanisch, } 10=\text { Türkisch, } \\
11=\text { Portugiesisch, } 12= \\
\text { Spanisch }\end{array}$ & $\begin{array}{l}\text { What language do you } \\
\text { speak most of the time } \\
\text { with your friends? }\end{array}$ & $\begin{array}{l}1=\text { Swiss German, } 2= \\
\text { High German, } 3=\text { French, } \\
4=\text { Italian, } 5= \\
\text { Romansch, } 6=\text { English, } 7 \\
=\text { Serbian, } 8= \\
\text { Serbo-Croatian, } 9= \\
\text { Albanian, } 10=\text { Turkish, } \\
11=\text { Portuguese, } 12= \\
\text { Spanish }\end{array}$ & $\mathrm{x}$ & & & $\mathrm{x}$ & $\mathrm{x}$ & $\mathrm{x}$ & $\mathrm{x}$ & $\mathrm{x}$ & $\mathrm{x}$ & $\mathrm{x}$ & $\mathrm{x}$ & $\mathrm{x}$ & $\mathrm{x}$ \\
\hline home.current & Current home & $\begin{array}{l}\text { Wo wohnst Du im } \\
\text { Moment? (Bitte nenne } \\
\text { die Ortschaft, an } \\
\text { welcher Du die Mehrheit } \\
\text { deiner Zeit verbringst.) }\end{array}$ & & $\begin{array}{l}\text { Where do you live at the } \\
\text { moment? (Please think } \\
\text { about the place where } \\
\text { you spend the majority } \\
\text { of your time.) }\end{array}$ & & $\mathrm{x}$ & $\mathrm{x}$ & $\mathrm{x}$ & $\mathrm{x}$ & $\mathrm{x}$ & $\mathrm{x}$ & $\mathrm{x}$ & $\mathrm{x}$ & $\mathrm{x}$ & $\mathrm{x}$ & $\mathrm{x}$ & $\mathrm{x}$ & $\mathrm{x}$ \\
\hline sex & $\begin{array}{l}\text { Sex of } \\
\text { respondent }\end{array}$ & $\begin{array}{l}\text { Welches ist Dein } \\
\text { Geschlecht? }\end{array}$ & $\begin{array}{l}1=\text { Männlich, } 2= \\
\text { Weiblich }\end{array}$ & What is your gender? & $1=$ Male, $2=$ Female & $\mathrm{x}$ & $\mathrm{x}$ & $\mathrm{x}$ & $\mathrm{x}$ & $\mathrm{x}$ & $\mathrm{x}$ & $\mathrm{x}$ & $\mathrm{x}$ & $\mathrm{x}$ & $\mathrm{x}$ & $\mathrm{x}$ & $\mathrm{x}$ & \\
\hline
\end{tabular}




\begin{tabular}{|c|c|c|c|c|c|c|c|c|c|c|c|c|c|c|c|c|c|c|c|}
\hline VarName & VariableLabel & WordingDE & ValueLabelsDE_Linked & WordingEN & ValueLabelsEN_Linked & L1 & L1F L2 & L3 & $\mathrm{L} 4$ & L5 & L6 & L7 & L8 & L9 & L1 & o L11 & $1 \mathrm{~L} 12$ & $2 \mathrm{~L} 13$ & 3 L14 \\
\hline rel.stat & $\begin{array}{l}\text { Relationship } \\
\text { status }\end{array}$ & $\begin{array}{l}\text { Welches ist Dein } \\
\text { Beziehungsstatus? }\end{array}$ & $\begin{array}{l}1=\text { Single, } 2=\text { in einer } \\
\text { Beziehung, } 3=\text { in einer } \\
\text { eingetragenen } \\
\text { Partnerschaft, } 4= \\
\text { Verheiratet, } 5= \\
\text { Geschieden }\end{array}$ & $\begin{array}{l}\text { What is your } \\
\text { relationship status? }\end{array}$ & $\begin{array}{l}1=\text { Single, } 2=\text { in a } \\
\text { relationship, } 3=\text { in a } \\
\text { registered partnership, } 4 \\
=\text { married, } 5=\text { divorced }\end{array}$ & $\mathrm{x}$ & $\mathrm{x}$ & $\mathrm{x}$ & $\mathrm{x}$ & $\mathrm{X}$ & $\mathrm{x}$ & $\mathrm{x}$ & $\mathrm{x}$ & $\mathrm{x}$ & $\mathrm{x}$ & $\mathrm{x}$ & $\mathrm{x}$ & $\mathrm{x}$ & \\
\hline cohabit & $\begin{array}{l}\text { Cohabiting } \\
\text { with whom }\end{array}$ & $\begin{array}{l}\text { Mit wem wohnst Du im } \\
\text { Moment? }\end{array}$ & $\begin{array}{l}1=\text { Eltern, Erziehende, } 2 \\
=\text { Geschwister, } 3= \\
\text { Freunde, } 4=\text { andere } \\
\text { Studierende, } 5=\text { Andere, } \\
6=\text { Partner, } 7= \\
\text { Mitstudierende, } 8= \\
\text { Eltern, Erziehende, } 9= \\
\text { Geschwister, } 10= \\
\text { Freunde }\end{array}$ & $\begin{array}{l}\text { Who do you live with at } \\
\text { the moment? (fellow } \\
\text { students) }\end{array}$ & $\begin{array}{l}1=\text { Parents, guardians, } 2 \\
=\text { Siblings, } 3=\text { Friends, } 4 \\
=\text { other students, } 5= \\
\text { others, } 6=\text { Partner, } 7= \\
\text { Fellow students, } 8= \\
\text { Parents, guardians, } 9= \\
\text { Siblings, } 10=\text { Friends }\end{array}$ & $\mathrm{x}$ & $\mathrm{x}$ & $\mathrm{x}$ & $\mathrm{x}$ & $\mathrm{x}$ & $\mathrm{x}$ & $\mathrm{x}$ & $\mathrm{x}$ & $\mathrm{x}$ & $\mathrm{x}$ & $\mathrm{x}$ & $\mathrm{x}$ & $\mathrm{x}$ & $\mathrm{x}$ \\
\hline cohabit.str & $\begin{array}{l}\text { Cohabiting } \\
\text { with whom } \\
\text { (other) }\end{array}$ & $\begin{array}{l}\text { Mit wem wohnst Du im } \\
\text { Moment? (andere) }\end{array}$ & & $\begin{array}{l}\text { Who do you live with at } \\
\text { the moment? (Other) }\end{array}$ & & $\mathrm{x}$ & $\mathrm{x}$ & $\mathrm{x}$ & $\mathrm{x}$ & $\mathrm{X}$ & $\mathrm{x}$ & $\mathrm{x}$ & $\mathrm{x}$ & $\mathrm{x}$ & $\mathrm{x}$ & $\mathrm{x}$ & $\mathrm{x}$ & $\mathrm{X}$ & $\mathrm{x}$ \\
\hline cohabit.classmates.P1 & $\begin{array}{l}\text { Cohabiting } \\
\text { classmate } 1\end{array}$ & $\begin{array}{l}\text { Wenn Mitstudierende } \\
\text { genannt: Mit wem } \\
\text { wohnst du im Moment? }\end{array}$ & & $\begin{array}{l}\text { Who do you live with at } \\
\text { the moment? (fellow } \\
\text { students) }\end{array}$ & & $\mathrm{x}$ & $\mathrm{x}$ & $\mathrm{x}$ & $\mathrm{x}$ & $\mathrm{x}$ & $\mathrm{x}$ & $\mathrm{x}$ & $\mathrm{x}$ & $\mathrm{x}$ & $\mathrm{x}$ & $\mathrm{x}$ & $\mathrm{x}$ & $\mathrm{x}$ & $\mathrm{x}$ \\
\hline financial.sit.1 & $\begin{array}{l}\text { Financial } \\
\text { situation 1: } \\
\text { support }\end{array}$ & $\begin{array}{l}\text { Wirst Du von Deiner } \\
\text { Familie regelmässig } \\
\text { finanziell unterstützt? }\end{array}$ & $1=\mathrm{Ja}, 2=$ Nein & $\begin{array}{l}\text { Does your family } \\
\text { regularly support you } \\
\text { with money? }\end{array}$ & $1=\mathrm{Yes}, 2=\mathrm{No}$ & $\mathrm{x}$ & $\mathrm{x}$ & $\mathrm{x}$ & $\mathrm{x}$ & $\mathrm{x}$ & $\mathrm{x}$ & $\mathrm{x}$ & $\mathrm{x}$ & $\mathrm{x}$ & $\mathrm{x}$ & $\mathrm{x}$ & $\mathrm{x}$ & $\mathrm{x}$ & \\
\hline financial.sit.2 & $\begin{array}{l}\text { Financial } \\
\text { situation 2: } \\
\text { job }\end{array}$ & Hast Du einen Job? & $\begin{array}{l}1=\mathrm{Ja}, 2=\text { Teilzeit } \\
(\text { permanent }), 3=\text { Teilzeit } \\
(\text { zwischenzeitlich) }, 4= \\
\text { Nein }\end{array}$ & Do you have a job? & $\begin{array}{l}1=\text { Yes, } 2=\text { Part-time } \\
(\text { permanently }), 3= \\
\text { Part-time (temporarily), } 4 \\
=\text { No }\end{array}$ & $\mathrm{x}$ & $\mathrm{x}$ & $\mathrm{x}$ & $\mathrm{x}$ & $\mathrm{X}$ & $\mathrm{x}$ & $\mathrm{x}$ & $\mathrm{x}$ & $\mathrm{x}$ & $\mathrm{x}$ & $\mathrm{x}$ & $\mathrm{x}$ & $\mathrm{x}$ & \\
\hline financial.sit.3 & $\begin{array}{l}\text { Financial } \\
\text { situation 3: } \\
\text { hours per week }\end{array}$ & $\begin{array}{l}\text { Wie viele Stunden pro } \\
\text { Woche arbeitest Du } \\
\text { durchschnittlich? }\end{array}$ & $\begin{array}{l}1=0,2=1,3=2,4=3, \\
5=4,6=5,7=6,8=7, \\
9=8,10=9,11=10,12 \\
=11,13=12,14=13, \\
15=14,16=15,17= \\
16,18=17,19=18,20 \\
=19,21=20,22=21, \\
23=22,24=23,25= \\
24,26=25,27=26,28 \\
=27,29=28,30=29, \\
31=30,32=31,33= \\
32,34=33,35=34,36 \\
=35,37=36,38=37, \\
39=38,40=39,41=40\end{array}$ & $\begin{array}{l}\text { How many hours a week } \\
\text { do you work (on } \\
\text { average)? }\end{array}$ & $\begin{array}{l}1=0,2=1,3=2,4=3, \\
5=4,6=5,7=6,8=7, \\
9=8,10=9,11=10,12 \\
=11,13=12,14=13, \\
15=14,16=15,17= \\
16,18=17,19=18,20 \\
=19,21=20,22=21, \\
23=22,24=23,25= \\
24,26=25,27=26,28 \\
=27,29=28,30=29, \\
31=30,32=31,33= \\
32,34=33,35=34,36 \\
=35,37=36,38=37 \\
39=38,40=39,41=40\end{array}$ & $\mathrm{x}$ & $\mathrm{x}$ & $\mathrm{x}$ & $\mathrm{x}$ & $\mathrm{X}$ & $\mathrm{x}$ & $\mathrm{x}$ & $\mathrm{x}$ & $\mathrm{x}$ & $\mathrm{x}$ & $\mathrm{x}$ & $\mathrm{x}$ & $\mathrm{X}$ & \\
\hline financial.sit.4 & $\begin{array}{l}\text { Financial } \\
\text { situation } 4: \\
\text { job necessary }\end{array}$ & $\begin{array}{l}\text { Hättest Du genug } \\
\text { finanzielle Mittel um } \\
\text { auch ohne diesen Job } \\
\text { auszukommen? }\end{array}$ & $1=\mathrm{Ja}, 2=$ Nein & $\begin{array}{l}\text { Do you need this to } \\
\text { sustain yourself while } \\
\text { attending university? }\end{array}$ & $1=\mathrm{Yes}, 2=\mathrm{No}$ & $\mathrm{x}$ & $\mathrm{x}$ & $\mathrm{x}$ & $\mathrm{x}$ & $\mathrm{x}$ & $\mathrm{x}$ & $\mathrm{x}$ & $\mathrm{x}$ & $\mathrm{x}$ & $\mathrm{x}$ & $\mathrm{x}$ & $\mathrm{x}$ & $\mathrm{x}$ & \\
\hline cob.m & $\begin{array}{l}\text { Country of } \\
\text { birth (mother) }\end{array}$ & $\begin{array}{l}\text { In welchem Land ist } \\
\text { Deine Mutter geboren? } \\
\text { (Schweiz) }\end{array}$ & $1=$ Schweiz, $2=$ Andere & $\begin{array}{l}\text { In what country was } \\
\text { your mother born? } \\
\text { (Switzerland) }\end{array}$ & $\begin{array}{l}1=\text { Switzerland, } 2= \\
\text { Other }\end{array}$ & $\mathrm{x}$ & & & & & & & & & & & & & \\
\hline cob.m.str & $\begin{array}{l}\text { Country of } \\
\text { birth } \\
\text { (mother), } \\
\text { other }\end{array}$ & $\begin{array}{l}\text { In welchem Land ist } \\
\text { Deine Mutter geboren? } \\
\text { (Andere) }\end{array}$ & & $\begin{array}{l}\text { In what country was } \\
\text { your mother born? } \\
\text { (Other) }\end{array}$ & & $\mathrm{x}$ & & & & & & & & & & & & & \\
\hline cob.f & $\begin{array}{l}\text { Country of } \\
\text { birth (father) }\end{array}$ & $\begin{array}{l}\text { In welchem Land ist } \\
\text { Dein Vater geboren? } \\
\text { (Schweiz) }\end{array}$ & $1=$ Schweiz, $2=$ Andere & $\begin{array}{l}\text { In what country was } \\
\text { your father born? } \\
\text { (Switzerland) }\end{array}$ & $\begin{array}{l}1=\text { Switzerland, } 2= \\
\text { Other }\end{array}$ & $\mathrm{x}$ & & & & & & & & & & & & & \\
\hline cob.f.str & $\begin{array}{l}\text { Country of } \\
\text { birth (father), } \\
\text { other }\end{array}$ & $\begin{array}{l}\text { In welchem Land ist } \\
\text { Dein Vater geboren? } \\
\text { (Andere) }\end{array}$ & & $\begin{array}{l}\text { In what country was } \\
\text { your father born? } \\
\text { (Other) }\end{array}$ & & $\mathrm{x}$ & & & & & & & & & & & & & \\
\hline
\end{tabular}




\begin{tabular}{|c|c|c|c|c|c|c|c|c|c|c|c|c|c|c|}
\hline VarName & VariableLabel & WordingDE & ValueLabelsDE_Linked & WordingEN & ValueLabelsEN_Linked & $\mathrm{L} 1$ & L1F L2 & L3 & L4 & L5 & L6 & L7 7 & L8 L9 & L10 L11 L12 L13 L14 \\
\hline ed.att.m & $\begin{array}{l}\text { Educational } \\
\text { attainment of } \\
\text { the mother }\end{array}$ & $\begin{array}{l}\text { Welches ist der höchste } \\
\text { Bildungsabschluss } \\
\text { Deiner Mutter? }\end{array}$ & $\begin{array}{l}1=\text { Obligatorische Schule } \\
\text { nicht abgeschlossen, } 2= \\
\text { Obligatorische Schule } \\
\text { (Real, Sekundarschule, } \\
\text { Handelsschule oder } \\
\text { Fachmittelschule (1 Jahr), } \\
\text { Haushaltslehrjahr oder } \\
\text { Sprachaufenthalt), } 3= \\
\text { Sekundarstufe II (Anlehre; } \\
\text { Berufslehre; vollzeitliche } \\
\text { Berufsfachschule) } 4= \\
\text { Sekundarstufe II } \\
\text { (gymnasiale Maturität, } \\
\text { Berufsmaturität, } \\
\text { Lehrerseminar), } 5= \\
\text { Tertiärstufe } \\
\text { (Meisterdiplom, } \\
\text { eidgenössischer } \\
\text { Fachausweis; Techniker- } \\
\text { oder Fachschule; Höhere } \\
\text { Fachschule, höhere } \\
\text { technische Lehranstalt), } \\
6=\text { Tertiärstufe } \\
\text { (Universitäre Hochschule, } \\
\text { Fachhochschule, } \\
\text { Pädagogische Hochschule, } \\
\text { Eidgenössische technische } \\
\text { Hochschule) }\end{array}$ & $\begin{array}{l}\text { What is the highest level } \\
\text { of schooling completed } \\
\text { by your mother? }\end{array}$ & $\begin{array}{l}1=\text { No completed } \\
\text { mandatory education, } 2= \\
\text { Completed mandatory } \\
\text { education, } 3=\text { Lower } \\
\text { Secondary education, } 4= \\
\text { Higher Secondary } \\
\text { education, } 5=\text { Lower } \\
\text { tertiary education, } 6= \\
\text { Higher tertiary education } \\
\text { (free translation) }\end{array}$ & $\mathrm{x}$ & & & & & & & & \\
\hline ed.att.f & $\begin{array}{l}\text { Educational } \\
\text { attainment of } \\
\text { the father }\end{array}$ & $\begin{array}{l}\text { Welches ist der höchste } \\
\text { Bildungsabschluss } \\
\text { Deines Vaters? }\end{array}$ & $\begin{array}{l}1=\text { Obligatorische Schule } \\
\text { nicht abgeschlossen, } 2= \\
\text { Obligatorische Schule } \\
\text { (Real, Sekundarschule, } \\
\text { Handelsschule oder } \\
\text { Fachmittelschule (1 Jahr), } \\
\text { Haushaltslehrjahr oder } \\
\text { Sprachaufenthalt), } 3= \\
\text { Sekundarstufe II (Anlehre; } \\
\text { Berufslehre; vollzeitliche } \\
\text { Berufsfachschule) }, 4= \\
\text { Sekundarstufe II } \\
\text { (gymnasiale Maturität, } \\
\text { Berufsmaturität, } \\
\text { Lehrerseminar), } 5= \\
\text { Tertiärstufe } \\
\text { (Meisterdiplom, } \\
\text { eidgenössischer } \\
\text { Fachausweis; Techniker- } \\
\text { oder Fachschule; Höhere } \\
\text { Fachschule, höhere } \\
\text { technische Lehranstalt), } \\
6=\text { Tertiärstufe } \\
\text { (Universitäre Hochschule, } \\
\text { Fachhochschule, } \\
\text { Pädagogische Hochschule, } \\
\text { Eidgenössische technische } \\
\text { Hochschule) }\end{array}$ & $\begin{array}{l}\text { What is the highest level } \\
\text { of schooling completed } \\
\text { by your father? }\end{array}$ & $\begin{array}{l}1=\text { No completed } \\
\text { mandatory education, } 2= \\
\text { Completed mandatory } \\
\text { education, } 3=\text { Lower } \\
\text { Secondary education, } 4= \\
\text { Higher Secondary } \\
\text { education, } 5=\text { Lower } \\
\text { tertiary education, } 6= \\
\text { Higher tertiary education } \\
\text { (free translation) }\end{array}$ & $\mathrm{x}$ & & & & & & & & \\
\hline known.before.P1 & $\begin{array}{l}\text { Known before } \\
\text { the } \\
\text { programme } \\
\text { nomination: } \\
\text { Person } 1\end{array}$ & $\begin{array}{l}\text { Wen kanntest } \mathrm{Du} \\
\text { bereits vor Beginn des } \\
\text { Studiums? Nenne } 0 \text { bis } \\
20 \text { Personen }\end{array}$ & & $\begin{array}{l}\text { Whom did you know } \\
\text { before the start of the } \\
\text { year? }\end{array}$ & & $\mathrm{x}$ & & & & & & & & \\
\hline
\end{tabular}




\begin{tabular}{|c|c|c|c|c|c|c|c|c|c|c|c|c|c|c|c|c|c|c|c|c|}
\hline VarName & VariableLabel & WordingDE & ValueLabelsDE_Linked & WordingEN & ValueLabelsEN_Linked & L1 & & F L2 & L3 & $\mathrm{L} 4$ & L5 & L6 & L7 & L8 & L9 & & 0 L11 & $\mathrm{L} 12$ & L13 & 3 L14 \\
\hline interaction.P1 & $\begin{array}{l}\text { Nice } \\
\text { interaction } \\
\text { nomination: } \\
\text { Person 1 }\end{array}$ & $\begin{array}{l}\text { Mit wem erlebst Du } \\
\text { angenehme } \\
\text { Interaktionen? Nenne } 0 \\
\text { bis } 20 \text { Personen }\end{array}$ & & $\begin{array}{l}\text { Who are the people in } \\
\text { your cohort you } \\
\text { regularly or occasionally } \\
\text { interact with, and you } \\
\text { enjoy their company? }\end{array}$ & & $\mathrm{x}$ & & $\mathrm{x}$ & $\mathrm{x}$ & $\mathrm{X}$ & $\mathrm{x}$ & $\mathrm{x}$ & $\mathrm{x}$ & $\mathrm{x}$ & $\mathrm{x}$ & $\mathrm{x}$ & $\mathrm{x}$ & $\mathrm{x}$ & $\mathrm{x}$ & $\mathrm{X}$ \\
\hline friend.P1 & $\begin{array}{l}\text { Friendship } \\
\text { nomination: } \\
\text { Person } 1\end{array}$ & $\begin{array}{l}\text { Welche Deiner } \\
\text { Mitstudierenden } \\
\text { würdest Du als Freunde } \\
\text { bezeichnen? Nenne } 0 \text { bis } \\
20 \text { Personen }\end{array}$ & & $\begin{array}{l}\text { Who are the people you } \\
\text { would call a friend? }\end{array}$ & & $\mathrm{x}$ & $\mathrm{x}$ & $\mathrm{x}$ & $\mathrm{x}$ & $\mathrm{x}$ & $\mathrm{x}$ & $\mathrm{x}$ & $\mathrm{x}$ & $\mathrm{x}$ & $\mathrm{x}$ & $\mathrm{x}$ & $\mathrm{x}$ & $\mathrm{x}$ & $\mathrm{x}$ & $\mathrm{x}$ \\
\hline relationship.classmate & & $\begin{array}{l}\text { Bist Du mit einem/einer } \\
\text { deiner Mitstudierenden } \\
\text { in einer romantischen } \\
\text { Beziehung (a.k.a. } \\
\text { „zusammen")? }\end{array}$ & $1=\mathrm{Ja}, 2=$ Nein & $\begin{array}{l}\text { Are you currently dating } \\
\text { someone from your } \\
\text { cohort? }\end{array}$ & $1=$ Yes, $2=$ No & $\mathrm{x}$ & $\mathrm{x}$ & $\mathrm{x}$ & $\mathrm{x}$ & $\mathrm{x}$ & $\mathrm{x}$ & $\mathrm{x}$ & $\mathrm{x}$ & $\mathrm{x}$ & $\mathrm{x}$ & $\mathrm{x}$ & $\mathrm{x}$ & $\mathrm{x}$ & $\mathrm{x}$ & $\mathrm{x}$ \\
\hline relationship.classmate.P1 & $\begin{array}{l}\text { Relationship } \\
\text { with classmate }\end{array}$ & $\begin{array}{l}\text { Mit wem bist du } \\
\text { zusammen? }\end{array}$ & & If yes, who is it? & & $\mathrm{x}$ & $\mathrm{x}$ & $\mathrm{x}$ & $\mathrm{x}$ & $\mathrm{x}$ & $\mathrm{x}$ & $\mathrm{x}$ & $\mathrm{x}$ & $\mathrm{x}$ & $\mathrm{x}$ & $\mathrm{x}$ & $\mathrm{x}$ & $\mathrm{x}$ & $\mathrm{x}$ & $\mathrm{x}$ \\
\hline dislike.P1 & $\begin{array}{l}\text { Dislike } \\
\text { nomination: } \\
\text { Person } 1\end{array}$ & $\begin{array}{l}\text { Wen magst Du nicht } \\
\text { besonders? Nenne } 0 \text { bis } \\
20 \text { Personen }\end{array}$ & & $\begin{array}{l}\text { Who are the people in } \\
\text { your cohort whom you } \\
\text { do not like? }\end{array}$ & & $\mathrm{x}$ & $\mathrm{x}$ & $\mathrm{x}$ & $\mathrm{x}$ & $\mathrm{x}$ & $\mathrm{x}$ & $\mathrm{x}$ & $\mathrm{x}$ & $\mathrm{x}$ & $\mathrm{x}$ & $\mathrm{x}$ & $\mathrm{x}$ & $\mathrm{x}$ & $\mathrm{x}$ & $\mathrm{x}$ \\
\hline conflict.P1 & $\begin{array}{l}\text { Conflict } \\
\text { nomination: } \\
\text { Person } 1\end{array}$ & $\begin{array}{l}\text { Mit wem hast Du } \\
\text { persönliche Konflikte? } \\
\text { Nenne } 0 \text { bis } 20 \text { Personen }\end{array}$ & & $\begin{array}{l}\text { Who are the people in } \\
\text { your cohort whom you } \\
\text { have personal conflicts } \\
\text { with? }\end{array}$ & & $\mathrm{x}$ & & $\mathrm{x}$ & $\mathrm{x}$ & $\mathrm{x}$ & $\mathrm{x}$ & $\mathrm{x}$ & $\mathrm{x}$ & $\mathrm{x}$ & $\mathrm{x}$ & $\mathrm{x}$ & $\mathrm{x}$ & $\mathrm{x}$ & $\mathrm{x}$ & $\mathrm{x}$ \\
\hline study.P1 & $\begin{array}{l}\text { Study partner } \\
\text { nomination: } \\
\text { Person } 1\end{array}$ & $\begin{array}{l}\text { Mit wem lernst Du } \\
\text { regelmässig gemeinsam } \\
\text { für das Studium (z.B. } \\
\text { gemeinsames Arbeiten } \\
\text { an einem Projekt oder } \\
\text { an Hausaufgaben oder } \\
\text { gemeinsames Lernen)? } \\
\text { Nenne } 0 \text { bis } 20 \text { Personen }\end{array}$ & & $\begin{array}{l}\text { With whom do you } \\
\text { regularly spend time } \\
\text { studying together? } \\
\text { Working on a joint } \\
\text { project or homework } \\
\text { and studying in general } \\
\text { both count. }\end{array}$ & & $\mathrm{x}$ & & $\mathrm{x}$ & $\mathrm{x}$ & $\mathrm{x}$ & $\mathrm{x}$ & $\mathrm{x}$ & $\mathrm{x}$ & $\mathrm{x}$ & $\mathrm{x}$ & $\mathrm{x}$ & $\mathrm{x}$ & $\mathrm{x}$ & $\mathrm{x}$ & \\
\hline travel.P1 & $\begin{array}{l}\text { Travel } \\
\text { together to } \\
\text { university: } \\
\text { Person } 1\end{array}$ & $\begin{array}{l}\text { Wen von Deinen } \\
\text { Mitstudierenden triffst } \\
\text { Du regelmässig auf } \\
\text { Deinem Weg zur } \\
\text { Universität (z.B. im } \\
\text { Bus, Tram, oder Zug)? } \\
\text { Nenne } 0 \text { bis } 20 \text { Personen }\end{array}$ & & $\begin{array}{l}\text { With whom do you } \\
\text { regularly travel to the } \\
\text { university together (e.g. } \\
\text { on the bus, train, tram)? } \\
\text { Accidental and planned } \\
\text { meetings both count. }\end{array}$ & & $\mathrm{x}$ & & $\mathrm{x}$ & $\mathrm{x}$ & $\mathrm{x}$ & $\mathrm{x}$ & $\mathrm{x}$ & $\mathrm{x}$ & $\mathrm{x}$ & $\mathrm{x}$ & $\mathrm{x}$ & $\mathrm{x}$ & $\mathrm{x}$ & $\mathrm{x}$ & \\
\hline freetime.P1 & $\begin{array}{l}\text { Freetime } \\
\text { activities: } \\
\text { Person } 1\end{array}$ & $\begin{array}{l}\text { Mit wem Deiner } \\
\text { Mitstudierenden } \\
\text { verbringst Du } \\
\text { regelmässig Deine } \\
\text { Freizeit? Hier kannst } \\
\text { Du an alle möglichen } \\
\text { Freizeitaktivitäten } \\
\text { denken wie zum } \\
\text { Beispiel, gemeinsamer } \\
\text { Sport, Filmschauen, } \\
\text { Wandern, Kaffeetrinken, } \\
\text { Biertrinken, Tanzen, } \\
\text { etc. Nenne zwischen } 0 \\
\text { und 20 Personen. }\end{array}$ & & $\begin{array}{l}\text { With whom do you do } \\
\text { regularly spend some of } \\
\text { your leisure time } \\
\text { together? You can think } \\
\text { about any free-time } \\
\text { activity, such as doing } \\
\text { sports together, } \\
\text { watching a movie, } \\
\text { hiking, going out for a } \\
\text { coffee or beer, dancing, } \\
\text { and so on. }\end{array}$ & & $\mathrm{x}$ & & $\mathrm{x}$ & $\mathrm{x}$ & $\mathrm{x}$ & $\mathrm{x}$ & $\mathrm{x}$ & $\mathrm{x}$ & $\mathrm{x}$ & $\mathrm{x}$ & $\mathrm{x}$ & $\mathrm{x}$ & $\mathrm{x}$ & $\mathrm{x}$ & \\
\hline inst.support.P1 & $\begin{array}{l}\text { Practical help } \\
\text { nomination: } \\
\text { Person } 1\end{array}$ & $\begin{array}{l}\text { Auf wen kannst Du } \\
\text { zählen, wenn Du Hilfe } \\
\text { bei praktischen Dingen } \\
\text { brauchst (z.B. beim } \\
\text { Erledigen von Arbeiten } \\
\text { oder die Bereitstellung } \\
\text { finanzieller Mittel) unter } \\
\text { deinen Mitstudierenden? } \\
\text { Nenne zwischen } 0 \text { und } \\
20 \text { Personen. }\end{array}$ & & $\begin{array}{l}\text { Whom can you count on } \\
\text { when you need help in } \\
\text { practical things like the } \\
\text { provision of tangible } \\
\text { goods and services, or } \\
\text { tangible aid? }\end{array}$ & & $\mathrm{x}$ & & $\mathrm{x}$ & $\mathrm{x}$ & $\mathrm{x}$ & $\mathrm{x}$ & $\mathrm{x}$ & $\mathrm{x}$ & $\mathrm{x}$ & $\mathrm{x}$ & $\mathrm{x}$ & $\mathrm{x}$ & $\mathrm{x}$ & $\mathrm{x}$ & \\
\hline
\end{tabular}




\begin{tabular}{|c|c|c|c|c|c|c|c|c|c|c|c|c|c|c|c|c|c|c|c|}
\hline VarName & VariableLabel & WordingDE & ValueLabelsDE_Linked & WordingEN & ValueLabelsEN_Linked & L1 & & F L2 & L3 & $\mathrm{L} 4$ & L5 & L6 & L7 & L8 & L9 & L10 & L11 & $1 \mathrm{~L} 12$ & 2 L13 L14 \\
\hline inf.support.P1 & $\begin{array}{l}\text { Advice } \\
\text { nomination: } \\
\text { Person } 1\end{array}$ & $\begin{array}{l}\text { Auf wen von deinen } \\
\text { Mitstudierenden kannst } \\
\text { Du zählen, wenn Du } \\
\text { einen guten Rat oder } \\
\text { spezifische } \\
\text { Informationen brauchst? } \\
\text { Nenne zwischen } 0 \text { und } \\
20 \text { Personen }\end{array}$ & & $\begin{array}{l}\text { Whom can you count on } \\
\text { when you need a good } \\
\text { advice or specific } \\
\text { information? }\end{array}$ & & $\mathrm{x}$ & & $\mathrm{x}$ & $\mathrm{x}$ & $\mathrm{x}$ & $\mathrm{x}$ & $\mathrm{x}$ & $\mathrm{x}$ & $\mathrm{x}$ & $\mathrm{x}$ & $\mathrm{x}$ & $\mathrm{x}$ & $\mathrm{x}$ & $\mathrm{x}$ \\
\hline e.support.P1 & $\begin{array}{l}\text { Emotional } \\
\text { support } \\
\text { nomination: } \\
\text { Person } 1\end{array}$ & $\begin{array}{l}\text { Auf wen von deinen } \\
\text { Mitstudierenden kannst } \\
\text { Du zählen, wenn es Dir } \\
\text { schlecht geht und Du } \\
\text { emotionale Hilfe } \\
\text { brauchst (z.B. Trost, } \\
\text { Mitleid und Zuspruch)? } \\
\text { Nenne zwischen } 0 \text { und } \\
20 \text { Personen. }\end{array}$ & & $\begin{array}{l}\text { Whom can you count on } \\
\text { when you feel sad and } \\
\text { you need emotional } \\
\text { support (e.g., caring, } \\
\text { empathy and trust)? }\end{array}$ & & $\mathrm{x}$ & & $\mathrm{x}$ & $\mathrm{x}$ & $\mathrm{x}$ & $\mathrm{x}$ & $\mathrm{x}$ & $\mathrm{x}$ & $\mathrm{x}$ & $\mathrm{x}$ & $\mathrm{x}$ & $\mathrm{x}$ & $\mathrm{x}$ & $\mathrm{x}$ \\
\hline clever.P1 & $\begin{array}{l}\text { Clever } \\
\text { nomination: } \\
\text { Person } 1\end{array}$ & $\begin{array}{l}\text { Wer ist besonders schlau } \\
\text { unter deinen } \\
\text { Mitstudierenden? Nenne } \\
\text { zwischen } 0 \text { und } 5 \\
\text { Personen. }\end{array}$ & & Who is smart? & & $\mathrm{x}$ & $\mathrm{x}$ & $\mathrm{x}$ & $\mathrm{x}$ & $\mathrm{x}$ & $\mathrm{x}$ & $\mathrm{x}$ & $\mathrm{x}$ & $\mathrm{x}$ & $\mathrm{x}$ & $\mathrm{x}$ & $\mathrm{x}$ & $\mathrm{x}$ & $\mathrm{x}$ \\
\hline funny.P1 & $\begin{array}{l}\text { Funny } \\
\text { nomination: } \\
\text { Person } 1\end{array}$ & $\begin{array}{l}\text { Wer ist besonders lustig } \\
\text { unter deinen } \\
\text { Mitstudierenden? Nenne } \\
\text { zwischen } 0 \text { und } 5 \\
\text { Personen. }\end{array}$ & & Who is funny? & & $\mathrm{x}$ & $\mathrm{x}$ & $\mathrm{x}$ & $\mathrm{x}$ & $\mathrm{x}$ & $\mathrm{x}$ & $\mathrm{x}$ & $\mathrm{x}$ & $\mathrm{x}$ & $\mathrm{x}$ & $\mathrm{x}$ & $\mathrm{x}$ & $\mathrm{x}$ & $\mathrm{X}$ \\
\hline serious.P1 & $\begin{array}{l}\text { Serious about } \\
\text { studying } \\
\text { nomination: } \\
\text { Person } 1\end{array}$ & $\begin{array}{l}\text { Wer von deinen } \\
\text { Mitstudierenden nimmt } \\
\text { das Studium sehr ernst? } \\
\text { Nenne zwischen } 0 \text { und } 5 \\
\text { Personen. }\end{array}$ & & $\begin{array}{l}\text { Who takes school very } \\
\text { seriously? }\end{array}$ & & $\mathrm{x}$ & $\mathrm{x}$ & $\mathrm{x}$ & $\mathrm{x}$ & $\mathrm{x}$ & $\mathrm{x}$ & $\mathrm{x}$ & $\mathrm{x}$ & $\mathrm{x}$ & $\mathrm{x}$ & $\mathrm{x}$ & $\mathrm{x}$ & $\mathrm{x}$ & $\mathrm{x}$ \\
\hline disturb.P1 & $\begin{array}{l}\text { Disturbing } \\
\text { during } \\
\text { lectures: } \\
\text { Person } 1\end{array}$ & $\begin{array}{l}\text { Wer stört während der } \\
\text { Vorlesungen (z.B. } \\
\text { Sprechen, lautes Essen } \\
\text { oder andere Dinge, die } \\
\text { Mitstudierende vom } \\
\text { Zuhören abzulenken)? } \\
\text { Nenne zwischen } 0 \text { und } 5 \\
\text { Personen. }\end{array}$ & & $\begin{array}{l}\text { Who is disruptive in } \\
\text { classes (e.g. talking, } \\
\text { eating loudly or not } \\
\text { letting the others pay } \\
\text { attention to the teachers } \\
\text { in other ways)? }\end{array}$ & & $\mathrm{x}$ & $\mathrm{x}$ & $\mathrm{x}$ & $\mathrm{x}$ & $\mathrm{x}$ & $\mathrm{x}$ & $\mathrm{x}$ & $\mathrm{x}$ & $\mathrm{x}$ & $\mathrm{x}$ & $\mathrm{x}$ & $\mathrm{x}$ & $\mathrm{x}$ & $\mathrm{x}$ \\
\hline conceited.P1 & $\begin{array}{l}\text { Conceited/arroge } \\
\text { nomination: } \\
\text { Person } 1\end{array}$ & $\begin{array}{l}\text { Wer von deinen } \\
\text { Mitstudierenden ist } \\
\text { eingebildet, hält viel von } \\
\text { sich selbst? Nenne } \\
\text { zwischen } 0 \text { und } 5 \\
\text { Personen. }\end{array}$ & & $\begin{array}{l}\text { Who is smug, who } \\
\text { thinks highly of } \\
\text { themselves? }\end{array}$ & & $\mathrm{x}$ & $\mathrm{x}$ & $\mathrm{x}$ & $\mathrm{x}$ & $\mathrm{x}$ & $\mathrm{x}$ & $\mathrm{x}$ & $\mathrm{x}$ & $\mathrm{x}$ & $\mathrm{x}$ & $\mathrm{x}$ & $\mathrm{x}$ & $\mathrm{x}$ & $\mathrm{x}$ \\
\hline aggressive.P1 & $\begin{array}{l}\text { Aggressive } \\
\text { nomination: } \\
\text { Person } 1\end{array}$ & $\begin{array}{l}\text { Wer von deinen } \\
\text { Mitstudierenden ist } \\
\text { aggressiv? Nenne } \\
\text { zwischen } 0 \text { und } 5 \\
\text { Personen. }\end{array}$ & & Who is aggressive? & & $\mathrm{x}$ & $\mathrm{x}$ & $\mathrm{x}$ & $\mathrm{x}$ & $\mathrm{x}$ & $\mathrm{x}$ & $\mathrm{x}$ & $\mathrm{x}$ & $\mathrm{x}$ & $\mathrm{x}$ & $\mathrm{x}$ & $\mathrm{x}$ & $\mathrm{x}$ & $\mathrm{x}$ \\
\hline attractive.P1 & $\begin{array}{l}\text { Attractive } \\
\text { nomination: } \\
\text { Person } 1\end{array}$ & $\begin{array}{l}\text { Wen von deinen } \\
\text { Mitstudierenden findest } \\
\text { Du körperlich attraktiv? } \\
\text { Nenne zwischen } 0 \text { und } 5 \\
\text { Personen. }\end{array}$ & & $\begin{array}{l}\text { Who do you find } \\
\text { physically attractive? }\end{array}$ & & $\mathrm{x}$ & $\mathrm{x}$ & $\mathrm{x}$ & $\mathrm{x}$ & $\mathrm{x}$ & $\mathrm{x}$ & $\mathrm{x}$ & $\mathrm{x}$ & $\mathrm{x}$ & $\mathrm{x}$ & $\mathrm{x}$ & $\mathrm{x}$ & $\mathrm{x}$ & $\mathrm{x}$ \\
\hline party.P1 & $\begin{array}{l}\text { Party } \\
\text { nomination: } \\
\text { Person } 1\end{array}$ & $\begin{array}{l}\text { Wer von deinen } \\
\text { Mitstudierenden feiert } \\
\text { viel? Nenne zwischen } 0 \\
\text { und } 5 \text { Personen. }\end{array}$ & & Who parties a lot? & & $\mathrm{x}$ & $\mathrm{x}$ & $\mathrm{x}$ & $\mathrm{x}$ & $\mathrm{x}$ & $\mathrm{x}$ & $\mathrm{x}$ & $\mathrm{x}$ & $\mathrm{x}$ & $\mathrm{x}$ & $\mathrm{x}$ & $\mathrm{x}$ & $\mathrm{x}$ & $\mathrm{x}$ \\
\hline
\end{tabular}




\begin{tabular}{|c|c|c|c|c|c|c|c|c|c|c|c|c|c|c|c|c|c|c|c|}
\hline VarName & VariableLabel & WordingDE & ValueLabelsDE_Linked & WordingEN & ValueLabelsEN_Linked & $\mathrm{L} 1$ & L1F & F L2 & L3 & $\mathrm{L} 4$ & L5 & L6 & L7 & L8 & L9 & L10 & L11 & $\mathrm{L} 12$ & 2 L13 L14 \\
\hline admire.P1 & $\begin{array}{l}\text { Admire } \\
\text { nomination: } \\
\text { Person } 1\end{array}$ & $\begin{array}{l}\text { Wen von deinen } \\
\text { Mitstudierenden } \\
\text { bewunderst Du? Nenne } \\
\text { zwischen } 0 \text { und } 5 \\
\text { Personen. }\end{array}$ & & Who do you look up to? & & $\mathrm{x}$ & $\mathrm{x}$ & $\mathrm{x}$ & $\mathrm{x}$ & $\mathrm{x}$ & $\mathrm{x}$ & $\mathrm{x}$ & $\mathrm{x}$ & $\mathrm{x}$ & $\mathrm{x}$ & $\mathrm{x}$ & $\mathrm{x}$ & $\mathrm{x}$ & $\mathrm{x}$ \\
\hline popular.P1 & $\begin{array}{l}\text { Popular } \\
\text { nomination: } \\
\text { Person } 1\end{array}$ & $\begin{array}{l}\text { Wer von deinen } \\
\text { Mitstudierenden ist } \\
\text { Deiner Meinung nach } \\
\text { sehr beliebt unter } \\
\text { Deinen } \\
\text { Mitstudierenden? Nenne } \\
\text { zwischen 0 und 5 } \\
\text { Personen. }\end{array}$ & & $\begin{array}{l}\text { Who do you think is } \\
\text { popular in your cohort? }\end{array}$ & & $\mathrm{x}$ & $\mathrm{x}$ & $\mathrm{x}$ & $\mathrm{x}$ & $\mathrm{x}$ & $\mathrm{x}$ & $\mathrm{x}$ & $\mathrm{x}$ & $\mathrm{x}$ & $\mathrm{x}$ & $\mathrm{x}$ & $\mathrm{x}$ & $\mathrm{x}$ & $\mathrm{x}$ \\
\hline lookdown.P1 & $\begin{array}{l}\text { Looking down } \\
\text { on nomination: } \\
\text { Person } 1\end{array}$ & $\begin{array}{l}\text { Auf wen Deiner } \\
\text { Mitstudierenden schaust } \\
\text { Du hinab? Nenne } \\
\text { zwischen } 0 \text { und } 5 \\
\text { Personen. }\end{array}$ & & $\begin{array}{l}\text { Who do you look down } \\
\text { on? }\end{array}$ & & $\mathrm{x}$ & $\mathrm{x}$ & $\mathrm{x}$ & $\mathrm{x}$ & $\mathrm{x}$ & $\mathrm{x}$ & $\mathrm{x}$ & $\mathrm{x}$ & $\mathrm{x}$ & $\mathrm{x}$ & $\mathrm{x}$ & $\mathrm{x}$ & $\mathrm{x}$ & $\mathrm{x}$ \\
\hline unpopular.P1 & $\begin{array}{l}\text { Unpopular } \\
\text { nomination: } \\
\text { Person } 1\end{array}$ & $\begin{array}{l}\text { Wer von Deinen } \\
\text { Mitstudierenden ist } \\
\text { unbeliebt?Nenne } \\
\text { zwischen } 0 \text { und } 5 \\
\text { Personen. }\end{array}$ & & $\begin{array}{l}\text { Who do you think is } \\
\text { generally rejected by } \\
\text { others in your cohort? }\end{array}$ & & $\mathrm{x}$ & $\mathrm{x}$ & $\mathrm{x}$ & $\mathrm{x}$ & $\mathrm{x}$ & $\mathrm{x}$ & $\mathrm{x}$ & $\mathrm{x}$ & $\mathrm{x}$ & $\mathrm{x}$ & $\mathrm{x}$ & $\mathrm{x}$ & $\mathrm{x}$ & $\mathrm{x}$ \\
\hline social.P1 & $\begin{array}{l}\text { Starting social } \\
\text { activity } \\
\text { nomination: } \\
\text { Person } 1\end{array}$ & $\begin{array}{l}\text { Welche Deiner } \\
\text { Mitstudierenden würden } \\
\text { am ehesten soziale } \\
\text { Aktivitäten starten? } \\
\text { Nenne zwischen } 0 \text { und } 5 \\
\text { Personen. }\end{array}$ & & $\begin{array}{l}\text { Who is the one who } \\
\text { most typically initiates } \\
\text { social activities } \\
\text { involving members of } \\
\text { your cohort? }\end{array}$ & & $\mathrm{x}$ & $\mathrm{x}$ & $\mathrm{x}$ & $\mathrm{x}$ & $\mathrm{x}$ & $\mathrm{x}$ & $\mathrm{x}$ & $\mathrm{x}$ & $\mathrm{x}$ & $\mathrm{x}$ & $\mathrm{x}$ & $\mathrm{x}$ & $\mathrm{x}$ & $\mathrm{x}$ \\
\hline conflict.solve.P1 & $\begin{array}{l}\text { Solving a } \\
\text { conflict } \\
\text { nomination: } \\
\text { Person 1 }\end{array}$ & $\begin{array}{l}\text { Welche Deiner } \\
\text { Mitstudierenden wären } \\
\text { am ehesten fähig, } \\
\text { Konflikte zwischen } \\
\text { Studierenden zu lösen? } \\
\text { Nenne zwischen } 0 \text { und } 5 \\
\text { Personen. }\end{array}$ & & $\begin{array}{l}\text { Who would be able to } \\
\text { best resolve conflicts } \\
\text { among students? }\end{array}$ & & $\mathrm{x}$ & $\mathrm{x}$ & $\mathrm{x}$ & $\mathrm{x}$ & $\mathrm{X}$ & $\mathrm{x}$ & $\mathrm{X}$ & $\mathrm{x}$ & $\mathrm{x}$ & $\mathrm{x}$ & $\mathrm{x}$ & $\mathrm{X}$ & $\mathrm{x}$ & $\mathrm{X}$ \\
\hline organise.P1 & $\begin{array}{l}\text { Organisation } \\
\text { abilities } \\
\text { nomination: } \\
\text { Person } 1\end{array}$ & $\begin{array}{l}\text { Welche Deiner } \\
\text { Mitstudierenden wären } \\
\text { am ehesten fähig, ein } \\
\text { „Ersti-Weekend“" zu } \\
\text { organisieren? Nenne } \\
\text { zwischen 0 und } 5 \\
\text { Personen. }\end{array}$ & & $\begin{array}{l}\text { Who would be able to } \\
\text { best organize a "first } \\
\text { weekend"? }\end{array}$ & & $\mathrm{x}$ & $\mathrm{x}$ & $\mathrm{x}$ & $\mathrm{x}$ & $\mathrm{x}$ & $\mathrm{x}$ & $\mathrm{x}$ & $\mathrm{x}$ & $\mathrm{x}$ & $\mathrm{x}$ & $\mathrm{x}$ & $\mathrm{x}$ & $\mathrm{x}$ & $\mathrm{x}$ \\
\hline group.1 & $\begin{array}{l}\text { Group 1, } \\
\text { including } \\
\text { respondent }\end{array}$ & $\begin{array}{l}\text { Hier sind wir an } \\
\text { Gruppen interessiert, } \\
\text { von welchen Du Teil } \\
\text { bist, und welche andere } \\
\text { Deiner Mitstudierenden } \\
\text { miteinschliessen. Bitte } \\
\text { benenne Deine Gruppen } \\
\text { mit 1-2 Stichwörtern } \\
\text { (z.B. „Lerngruppe“), } \\
\text { sodass du sie für die } \\
\text { nä̈hsten Minuten } \\
\text { wiedererkennen kannst. }\end{array}$ & & $\begin{array}{l}\text { Here, we are interested } \\
\text { in groups you and other } \\
\text { fellow students are part } \\
\text { of. Please name your } \\
\text { groups with } 1-2 \text { key } \\
\text { words (e.g. "study } \\
\text { group"), so that you can } \\
\text { recognise them in the } \\
\text { next few minutes. Name } \\
0 \text { to } 5 \text { groups. (free } \\
\text { translation) }\end{array}$ & & $\mathrm{x}$ & $\mathrm{x}$ & $\mathrm{x}$ & $\mathrm{x}$ & $\mathrm{x}$ & $\mathrm{x}$ & $\mathrm{x}$ & $\mathrm{x}$ & $\mathrm{x}$ & $\mathrm{x}$ & $\mathrm{x}$ & $\mathrm{x}$ & $\mathrm{x}$ & $\mathrm{x} \quad \mathrm{X}$ \\
\hline
\end{tabular}




\begin{tabular}{|c|c|c|c|c|c|c|c|c|c|c|c|c|c|c|c|c|c|c|c|c|}
\hline VarName & VariableLabel & WordingDE & ValueLabelsDE_Linked & WordingEN & ValueLabelsEN_Linked & $\mathrm{L} 1$ & L1F & F L2 & L3 & $\mathrm{L} 4$ & L5 & L6 6 & L7 & L8 & L9 & L10 & L L11 & $1 \mathrm{~L} 12$ & $2 \mathrm{~L} 13$ & 3 L14 \\
\hline group.2 & $\begin{array}{l}\text { Group 2, } \\
\text { including } \\
\text { respondent }\end{array}$ & $\begin{array}{l}\text { Hier sind wir an } \\
\text { Gruppen interessiert, } \\
\text { von welchen Du Teil } \\
\text { bist, und welche andere } \\
\text { Deiner Mitstudierenden } \\
\text { miteinschliessen. Bitte } \\
\text { benenne Deine Gruppen } \\
\text { mit 1-2 Stichwörtern } \\
\text { (z.B. „Lerngruppe“), } \\
\text { sodass du sie für die } \\
\text { nächsten Minuten } \\
\text { wiedererkennen kannst. } \\
\text { Nenne } 0 \text { bis } 5 \text { Gruppen. }\end{array}$ & & $\begin{array}{l}\text { Here, we are interested } \\
\text { in groups you and other } \\
\text { fellow students are part } \\
\text { of. Please name your } \\
\text { groups with 1-2 key } \\
\text { words (e.g. "study } \\
\text { group"), so that you can } \\
\text { recognise them in the } \\
\text { next few minutes. Name } \\
0 \text { to } 5 \text { groups. (free } \\
\text { translation) }\end{array}$ & & $\mathrm{x}$ & $\mathrm{x}$ & $\mathrm{x}$ & $\mathrm{x}$ & $\mathrm{X}$ & $\mathrm{x}$ & $\mathrm{X}$ & $\mathrm{x}$ & $\mathrm{x}$ & $\mathrm{X}$ & $\mathrm{x}$ & $\mathrm{x}$ & $\mathrm{x}$ & $\mathrm{x}$ & $\mathrm{X}$ \\
\hline group.3 & $\begin{array}{l}\text { Group 3, } \\
\text { including } \\
\text { respondent }\end{array}$ & $\begin{array}{l}\text { Hier sind wir an } \\
\text { Gruppen interessiert, } \\
\text { von welchen Du Teil } \\
\text { bist, und welche andere } \\
\text { Deiner Mitstudierenden } \\
\text { miteinschliessen. Bitte } \\
\text { benenne Deine Gruppen } \\
\text { mit 1-2 Stichwörtern } \\
\text { (z.B. „Lerngruppe“), } \\
\text { sodass du sie für die } \\
\text { nächsten Minuten } \\
\text { wiedererkennen kannst. } \\
\text { Nenne } 0 \text { bis } 5 \text { Gruppen. }\end{array}$ & & $\begin{array}{l}\text { Here, we are interested } \\
\text { in groups you and other } \\
\text { fellow students are part } \\
\text { of. Please name your } \\
\text { groups with 1-2 key } \\
\text { words (e.g. "study } \\
\text { group"), so that you can } \\
\text { recognise them in the } \\
\text { next few minutes. Name } \\
0 \text { to } 5 \text { groups. (free } \\
\text { translation) }\end{array}$ & & $\mathrm{x}$ & $\mathrm{x}$ & $\mathrm{x}$ & $\mathrm{x}$ & $\mathrm{x}$ & $\mathrm{x}$ & $\mathrm{x}$ & $\mathrm{x}$ & $\mathrm{x}$ & $\mathrm{x}$ & $\mathrm{x}$ & $\mathrm{x}$ & $\mathrm{x}$ & $\mathrm{x}$ & $\mathrm{x}$ \\
\hline group.4 & $\begin{array}{l}\text { Group 4, } \\
\text { including } \\
\text { respondent }\end{array}$ & $\begin{array}{l}\text { Hier sind wir an } \\
\text { Gruppen interessiert, } \\
\text { von welchen Du Teil } \\
\text { bist, und welche andere } \\
\text { Deiner Mitstudierenden } \\
\text { miteinschliessen. Bitte } \\
\text { benenne Deine Gruppen } \\
\text { mit 1-2 Stichwörtern } \\
\text { (z.B. „Lerngruppe“), } \\
\text { sodass du sie für die } \\
\text { nächsten Minuten } \\
\text { wiedererkennen kannst. } \\
\text { Nenne } 0 \text { bis } 5 \text { Gruppen. }\end{array}$ & & $\begin{array}{l}\text { Here, we are interested } \\
\text { in groups you and other } \\
\text { fellow students are part } \\
\text { of. Please name your } \\
\text { groups with } 1-2 \text { key } \\
\text { words (e.g. "study } \\
\text { group"), so that you can } \\
\text { recognise them in the } \\
\text { next few minutes. Name } \\
0 \text { to } 5 \text { groups. (free } \\
\text { translation) }\end{array}$ & & $\mathrm{x}$ & $\mathrm{x}$ & $\mathrm{x}$ & $\mathrm{x}$ & $\mathrm{X}$ & $\mathrm{X}$ & $\mathrm{x}$ & $\mathrm{x}$ & $\mathrm{x}$ & $\mathrm{X}$ & $\mathrm{X}$ & $\mathrm{x}$ & $\mathrm{X}$ & $\mathrm{x}$ & $\mathrm{X}$ \\
\hline group.5 & $\begin{array}{l}\text { Group 5, } \\
\text { including } \\
\text { respondent }\end{array}$ & $\begin{array}{l}\text { Hier sind wir an } \\
\text { Gruppen interessiert, } \\
\text { von welchen Du Teil } \\
\text { bist, und welche andere } \\
\text { Deiner Mitstudierenden } \\
\text { miteinschliessen. Bitte } \\
\text { benenne Deine Gruppen } \\
\text { mit 1-2 Stichwörtern } \\
\text { (z.B. „Lerngruppe“), } \\
\text { sodass du sie für die } \\
\text { nächsten Minuten } \\
\text { wiedererkennen kannst. } \\
\text { Nenne } 0 \text { bis } 5 \text { Gruppen. }\end{array}$ & & $\begin{array}{l}\text { Here, we are interested } \\
\text { in groups you and other } \\
\text { fellow students are part } \\
\text { of. Please name your } \\
\text { groups with } 1-2 \text { key } \\
\text { words (e.g. "study } \\
\text { group"), so that you can } \\
\text { recognise them in the } \\
\text { next few minutes. Name } \\
0 \text { to } 5 \text { groups. (free } \\
\text { translation) }\end{array}$ & & $\mathrm{x}$ & $\mathrm{x}$ & $\mathrm{x}$ & $\mathrm{x}$ & $\mathrm{x}$ & $\mathrm{x}$ & $\mathrm{x}$ & $\mathrm{x}$ & $\mathrm{x}$ & $\mathrm{x}$ & $\mathrm{x}$ & $\mathrm{x}$ & $\mathrm{x}$ & $\mathrm{x}$ & $\mathrm{x}$ \\
\hline group.1.P1 & $\begin{array}{l}\text { Group 1, } \\
\text { Person } 1\end{array}$ & $\begin{array}{l}\text { Welche Deiner } \\
\text { Mitstudierenden sind } \\
\text { Teil der Gruppe 1? (die } \\
\text { Anzahl } \\
\text { Nicht-Mitstudierenden } \\
\text { Gruppenmitglieder kann } \\
\text { auf der nächsten Seite } \\
\text { genannt werden) Nenne } \\
\text { zwischen } 1 \text { und } 20 \\
\text { Personen }\end{array}$ & & $\begin{array}{l}\text { Which students from } \\
\text { your cohort are part of } \\
\text { group 1? }\end{array}$ & & $\mathrm{x}$ & $\mathrm{x}$ & $\mathrm{x}$ & $\mathrm{x}$ & $\mathrm{x}$ & $\mathrm{x}$ & $\mathrm{x}$ & $\mathrm{x}$ & $\mathrm{x}$ & $\mathrm{x}$ & $\mathrm{x}$ & $\mathrm{x}$ & $\mathrm{x}$ & $\mathrm{x}$ & $\mathrm{x}$ \\
\hline
\end{tabular}




\begin{tabular}{|c|c|c|c|c|c|c|c|c|c|c|c|c|c|c|c|c|c|c|c|c|}
\hline VarName & VariableLabel & WordingDE & ValueLabelsDE_Linked & WordingEN & ValueLabelsEN_Linked & $\mathrm{L} 1$ & & $\mathrm{~F} \mathrm{~L} 2$ & L3 & $\mathrm{L} 4$ & L5 & L6 6 & L7 & L8 & L9 & L10 & L11 & $1 \mathrm{~L} 12$ & $2 \mathrm{~L} 13$ & 3 L14 \\
\hline group.1.other & $\begin{array}{l}\text { Group } 1, \\
\text { members } \\
\text { outside the } \\
\text { study } \\
\text { programme }\end{array}$ & $\begin{array}{l}\text { Gibt es noch weitere } \\
\text { Mitglieder der Gruppe } \\
1 \text {, welche nicht mit Dir } \\
\text { studieren? }\end{array}$ & $1=\mathrm{Ja}, 2=$ Nein & $\begin{array}{l}\text { Are there further } \\
\text { members in group } 1 \text { who } \\
\text { do not study with you? } \\
\text { (free translation) }\end{array}$ & $1=\mathrm{Yes}, 2=\mathrm{No}$ & $\mathrm{x}$ & $\mathrm{x}$ & $\mathrm{x}$ & $\mathrm{x}$ & $\mathrm{X}$ & $\mathrm{x}$ & $\mathrm{x}$ & $\mathrm{x}$ & $\mathrm{x}$ & $\mathrm{x}$ & $\mathrm{x}$ & $\mathrm{x}$ & $\mathrm{x}$ & $\mathrm{x}$ & $\mathrm{x}$ \\
\hline group.1.other.number & $\begin{array}{l}\text { Group } 1, \\
\text { number } \\
\text { members } \\
\text { outside the } \\
\text { study } \\
\text { programme }\end{array}$ & $\begin{array}{l}\text { Wenn es noch weitere } \\
\text { Mitglieder in der } \\
\text { Gruppe } 1 \text { gibt, die nicht } \\
\text { mit Dir studieren, wie } \\
\text { viele? }\end{array}$ & & $\begin{array}{l}\text { How many other people } \\
\text { NOT from your cohort } \\
\text { are part of this group? }\end{array}$ & & $\mathrm{x}$ & $\mathrm{x}$ & $\mathrm{x}$ & $\mathrm{x}$ & $\mathrm{x}$ & $\mathrm{x}$ & $\mathrm{x}$ & $\mathrm{x}$ & $\mathrm{x}$ & $\mathrm{x}$ & $\mathrm{x}$ & $\mathrm{x}$ & $\mathrm{x}$ & $\mathrm{x}$ & $\mathrm{x}$ \\
\hline group.1.activity & $\begin{array}{l}\text { Group 1, } \\
\text { activity }\end{array}$ & $\begin{array}{l}\text { Welche Tätigkeiten } \\
\text { führt die Gruppe } 1 \\
\text { normalerweise } \\
\text { gemeinsam aus? }\end{array}$ & $\begin{array}{l}1=\text { Lernen, } \\
\text { Hausaufgaben, } 2= \\
\text { Arbeit, } 3=\text { Sport, } 4= \\
\text { Gespräch, } 5=\text { etwas } \\
\text { trinken gehen ("eis go } \\
\text { zieh"), } 6=\text { gemeinsamer } \\
\text { Weg (z.B. zur } \\
\text { Universität), } 1=\text { Kultur, } \\
2=\text { Andere }\end{array}$ & $\begin{array}{l}\text { What is the main } \\
\text { activity that you do } \\
\text { together? }\end{array}$ & $\begin{array}{l}1=\text { Studying,homework } \\
2=\text { work, } 3=\text { sports, } 4= \\
\text { conversation, } 5=\text { going } \\
\text { for a drink, } 6=\text { travelling }\end{array}$ & $\mathrm{x}$ & $\mathrm{x}$ & $\mathrm{x}$ & $\mathrm{x}$ & $\mathrm{x}$ & $\mathrm{x}$ & $\mathrm{x}$ & $\mathrm{x}$ & $\mathrm{x}$ & $\mathrm{x}$ & $\mathrm{x}$ & $\mathrm{x}$ & $\mathrm{x}$ & $\mathrm{x}$ & $\mathrm{x}$ \\
\hline group.1.activity.str & $\begin{array}{l}\text { Group 1, } \\
\text { activity other }\end{array}$ & $\begin{array}{l}\text { Welche Tätigkeiten } \\
\text { führt die Gruppe } 1 \\
\text { normalerweise } \\
\text { gemeinsam aus? Andere }\end{array}$ & & $\begin{array}{l}\text { What is the main } \\
\text { activity that you do } \\
\text { together? (Other) }\end{array}$ & & $\mathrm{x}$ & $\mathrm{x}$ & $\mathrm{x}$ & $\mathrm{x}$ & $\mathrm{x}$ & $\mathrm{x}$ & $\mathrm{x}$ & $\mathrm{x}$ & $\mathrm{x}$ & $\mathrm{x}$ & $\mathrm{x}$ & $\mathrm{x}$ & $\mathrm{x}$ & $\mathrm{x}$ & $\mathrm{x}$ \\
\hline group.1.freq & $\begin{array}{l}\text { Group 1, } \\
\text { frequency of } \\
\text { meeting up }\end{array}$ & $\begin{array}{l}\text { Wie oft trifft sich diese } \\
\text { Gruppe } 1 \text { normalerweise } \\
\text { für gemeinsame } \\
\text { Aktivitäten? }\end{array}$ & $\begin{array}{l}1=\text { zwei oder dreimal pro } \\
\text { Woche, } 2=\text { einmal pro } \\
\text { Woche, } 3=\text { jede zweite } \\
\text { Woche, } 4=\text { einmal pro } \\
\text { Monat, } 5=\text { weniger als } \\
\text { einmal pro Monat, } 6= \\
\text { fast jeden Tag, } 7=\text { zwei } \\
\text { oder dreimal pro Woche }\end{array}$ & $\begin{array}{l}\text { How often does this } \\
\text { group typically meet for } \\
\text { some joint activity? }\end{array}$ & $\begin{array}{l}1=\text { two or three times } \\
\text { per week, } 2=\text { one time } \\
\text { per week, } 3=\text { every } \\
\text { second week, } 4=\text { once per } \\
\text { month, } 5=\text { less than once } \\
\text { per month, } 6=\text { almost } \\
\text { every day, } 7=\text { two or } \\
\text { three times per week }\end{array}$ & $\mathrm{x}$ & $\mathrm{x}$ & $\mathrm{x}$ & $\mathrm{x}$ & $\mathrm{x}$ & $\mathrm{x}$ & $\mathrm{x}$ & $\mathrm{x}$ & $\mathrm{x}$ & $\mathrm{x}$ & $\mathrm{x}$ & $\mathrm{x}$ & $\mathrm{x}$ & $\mathrm{x}$ & $\mathrm{x}$ \\
\hline group.1.pleasant & $\begin{array}{l}\text { Group 1, } \\
\text { interactions - } \\
\text { character: } \\
\text { pleasant }\end{array}$ & $\begin{array}{l}\text { Wie empfindest Du } \\
\text { Treffen mit Gruppe 1? } \\
\text { Angenehm; unangenehm }\end{array}$ & $\begin{array}{l}1=7 \text {-Punkte Skala, sehr } \\
\text { angenehm bis sehr } \\
\text { unangenehm, } 2= \\
\text { 7-Punkte Skala, sehr } \\
\text { angenehm bis sehr } \\
\text { unangenehm, } 3= \\
\text { 7-Punkte Skala, sehr } \\
\text { angenehm bis sehr } \\
\text { unangenehm, } 4= \\
\text { 7-Punkte Skala, sehr } \\
\text { angenehm bis sehr } \\
\text { unangenehm, } 5= \\
\text { 7-Punkte Skala, sehr } \\
\text { angenehm bis sehr } \\
\text { unangenehm, } 6= \\
\text { 7-Punke Skala, sehr } \\
\text { angenehm bis sehr } \\
\text { unangenehm, } 7= \\
\text { 7-Punkte Skala, sehr } \\
\text { angenehm bis sehr } \\
\text { unangenehm }\end{array}$ & $\begin{array}{l}\text { How would you } \\
\text { characterize your typical } \\
\text { personal experience } \\
\text { when meeting with this } \\
\text { group? }\end{array}$ & $\begin{array}{l}1=7 \text { point scale, very } \\
\text { pleasant to very } \\
\text { unpleasant, } 2=7 \text { point } \\
\text { scale, very pleasant to } \\
\text { very unpleasant, } 3=7 \\
\text { point scale, very pleasant } \\
\text { to very unpleasant, } 4=7 \\
\text { point scale, very pleasant } \\
\text { to very unpleasant, } 5=7 \\
\text { point scale, very pleasant } \\
\text { to very unpleasant, } 6=7 \\
\text { point scale, very pleasant } \\
\text { to very unpleasant, } 7=7 \\
\text { point scale, very pleasant } \\
\text { to very unpleasant }\end{array}$ & $\mathrm{x}$ & $\mathrm{x}$ & $\mathrm{x}$ & $\mathrm{x}$ & $\mathrm{x}$ & $\mathrm{x}$ & $\mathrm{x}$ & $\mathrm{x}$ & $\mathrm{x}$ & $\mathrm{x}$ & $\mathrm{x}$ & $\mathrm{x}$ & $\mathrm{x}$ & $\mathrm{x}$ & $\mathrm{x}$ \\
\hline
\end{tabular}




\begin{tabular}{|c|c|c|c|c|c|c|c|c|c|c|c|c|c|c|c|c|c|c|c|c|}
\hline VarName & VariableLabel & WordingDE & ValueLabelsDE_Linked & WordingEN & ValueLabelsEN_Linked & $\mathrm{L} 1$ & & F L2 & L3 & L4 & L5 & L6 & $\mathrm{L} 7$ & L8 & L9 & L10 & L11 & $1 \mathrm{~L} 12$ & $2 \mathrm{~L} 13$ & 3 L14 \\
\hline group.1.energetic & $\begin{array}{l}\text { Group 1, } \\
\text { interactions - } \\
\text { character }\end{array}$ & $\begin{array}{l}\text { Wie empfindest Du } \\
\text { Treffen mit Gruppe } 1 \text { ? } \\
\text { Sehr ruhig; sehr } \\
\text { energiegeladen }\end{array}$ & $\begin{array}{l}1=7 \text {-Punkte Skala, sehr } \\
\text { ruhig bis sehr } \\
\text { energiegeladen, } 2= \\
7 \text {-Punkte Skala, sehr ruhig } \\
\text { bis sehr energiegeladen, } 3 \\
=7 \text {-Punkte Skala, sehr } \\
\text { ruhig bis sehr } \\
\text { energiegeladen, } 4= \\
\text { 7-Punkte Skala, sehr ruhig } \\
\text { bis sehr energiegeladen, } 5 \\
=7 \text {-Punkte Skala, sehr } \\
\text { ruhig bis sehr } \\
\text { energiegeladen, } 6= \\
7 \text {-Punkte Skala, sehr ruhig } \\
\text { bis sehr energiegeladen, } 7 \\
=7 \text {-Punkte Skala, sehr } \\
\text { ruhig bis sehr } \\
\text { energiegeladen }\end{array}$ & $\begin{array}{l}\text { How would you } \\
\text { characterize your typical } \\
\text { personal experience } \\
\text { when meeting with this } \\
\text { group? }\end{array}$ & $\begin{array}{l}1=7 \text { point scale, very } \\
\text { quiet to very energetic, } 2 \\
=7 \text { point scale, very quiet } \\
\text { to very energetic, } 3=7 \\
\text { point scale, very quiet to } \\
\text { very energetic, } 4=7 \\
\text { point scale, very quiet to } \\
\text { very energetic, } 5=7 \\
\text { point scale, very quiet to } \\
\text { very energetic, } 6=7 \\
\text { point scale, very quiet to } \\
\text { very energetic, } 7=7 \\
\text { point scale, very quiet to } \\
\text { very energetic }\end{array}$ & $\mathrm{x}$ & $\mathrm{x}$ & $\mathrm{x}$ & $\mathrm{x}$ & $\mathrm{x}$ & $\mathrm{x}$ & $\mathrm{x}$ & $\mathrm{x}$ & $\mathrm{x}$ & $\mathrm{x}$ & $\mathrm{x}$ & $\mathrm{x}$ & $\mathrm{x}$ & $\mathrm{x}$ & $\mathrm{x}$ \\
\hline group.1.personal & $\begin{array}{l}\text { Group 1, } \\
\text { interactions - } \\
\text { character }\end{array}$ & $\begin{array}{l}\text { Wie empfindest Du } \\
\text { Treffen mit Gruppe } 1 \text { ? }\end{array}$ & $\begin{array}{l}1=7 \text {-Punkte Skala, sehr } \\
\text { oberflächlich bis sehr } \\
\text { persönlich, } 2=7 \text {-Punkte } \\
\text { Skala, sehr oberflächlich } \\
\text { bis sehr persönlich, } 3= \\
\text { 7-Punkte Skala, sehr } \\
\text { oberflächlich bis sehr } \\
\text { persönlich, } 4=7 \text {-Punkte } \\
\text { Skala, sehr oberflächlich } \\
\text { bis sehr persönlich, } 5= \\
\text { 7-Punkte Skala, sehr } \\
\text { oberflächlich bis sehr } \\
\text { persönlich, } 6=7 \text {-Punkte } \\
\text { Skala, sehr oberflächlich } \\
\text { bis sehr persönlich, } 7= \\
\text { 7-Punkte Skala, sehr } \\
\text { oberflächlich bis sehr } \\
\text { persönlich }\end{array}$ & $\begin{array}{l}\text { How would you } \\
\text { characterize your typical } \\
\text { personal experience } \\
\text { when meeting with this } \\
\text { group? }\end{array}$ & $\begin{array}{l}1=7 \text { point scale, very } \\
\text { superficial to very } \\
\text { personal, } 2=7 \text { point } \\
\text { scale, very superficial to } \\
\text { very personal, } 3=7 \text { point } \\
\text { scale, very superficial to } \\
\text { very personal, } 4=7 \text { point } \\
\text { scale, very superficial to } \\
\text { very personal, } 5=7 \text { point } \\
\text { scale, very superficial to } \\
\text { very personal, } 6=7 \text { point } \\
\text { scale, very superficial to } \\
\text { very personal, } 7=7 \text { point } \\
\text { scale, very superficial to } \\
\text { very personal }\end{array}$ & $\mathrm{x}$ & $\mathrm{x}$ & $\mathrm{x}$ & $\mathrm{x}$ & $\mathrm{x}$ & $\mathrm{x}$ & $\mathrm{x}$ & $\mathrm{x}$ & $\mathrm{x}$ & $\mathrm{x}$ & $\mathrm{x}$ & $\mathrm{x}$ & $\mathrm{x}$ & $\mathrm{x}$ & $\mathrm{x}$ \\
\hline group.1.communication & $\begin{array}{l}\text { Group 1, } \\
\text { frequency of } \\
\text { meeting online }\end{array}$ & $\begin{array}{l}\text { Wie oft kommuniziert } \\
\text { die Gruppe } 1 \text { online } \\
\text { (z.B. per Whatsapp-, } \\
\text { Facebook-Gruppenchat) } \\
\text { zusätzlich zu den } \\
\text { Treffen? }\end{array}$ & $\begin{array}{l}1=\text { zwei oder dreimal pro } \\
\text { Woche, } 2=\text { einmal pro } \\
\text { Woche, } 3=\text { jede zweite } \\
\text { Woche, } 4=\text { einmal pro } \\
\text { Monat, } 5=\text { weniger als } \\
\text { einmal pro Jahr, } 6=\text { fast } \\
\text { jeden Tag, } 7=\text { nie }\end{array}$ & $\begin{array}{l}\text { How often does group } 1 \\
\text { communicate online } \\
\text { (e.g. via WhatsApp, } \\
\text { Facebook Chat) in } \\
\text { addition to the } \\
\text { meetings? }\end{array}$ & $\begin{array}{l}1=\text { second or three time } \\
\text { per week, } 2=\text { once per } \\
\text { week, } 3=\text { every second } \\
\text { week, } 4=\text { once per } \\
\text { month, } 5=\text { less than once } \\
\text { per month, } 6=\text { almost } \\
\text { every day, } 7=\text { never }\end{array}$ & $\mathrm{x}$ & $\mathrm{x}$ & $\mathrm{x}$ & $\mathrm{x}$ & $\mathrm{x}$ & $\mathrm{x}$ & $\mathrm{x}$ & $\mathrm{x}$ & $\mathrm{x}$ & $\mathrm{x}$ & $\mathrm{x}$ & $\mathrm{x}$ & $\mathrm{x}$ & $\mathrm{x}$ & $\mathrm{x}$ \\
\hline group.2.P1 & $\begin{array}{l}\text { Group 2, } \\
\text { Person 1 }\end{array}$ & $\begin{array}{l}\text { Welche Deiner } \\
\text { Mitstudierenden sind } \\
\text { Teil der Gruppe 2? (die } \\
\text { Anzahl } \\
\text { Nicht-Mitstudierenden } \\
\text { Gruppenmitglieder kann } \\
\text { auf der nächsten Seite } \\
\text { genannt werden) Nenne } \\
\text { zwischen } 1 \text { und 20 } \\
\text { Personen }\end{array}$ & & $\begin{array}{l}\text { Which students from } \\
\text { your cohort are part of } \\
\text { group 2? }\end{array}$ & & $\mathrm{x}$ & $\mathrm{x}$ & $\mathrm{x}$ & $\mathrm{x}$ & $\mathrm{x}$ & $\mathrm{x}$ & $\mathrm{x}$ & $\mathrm{x}$ & $\mathrm{x}$ & $\mathrm{x}$ & $\mathrm{x}$ & $\mathrm{x}$ & $\mathrm{x}$ & $\mathrm{x}$ & $\mathrm{x}$ \\
\hline group.2.other & $\begin{array}{l}\text { Group 2, } \\
\text { members } \\
\text { outside the } \\
\text { study } \\
\text { programme }\end{array}$ & $\begin{array}{l}\text { Gibt es noch weitere } \\
\text { Mitglieder der Gruppe } \\
2 \text {, welche nicht mit Dir } \\
\text { studieren? }\end{array}$ & $1=\mathrm{Ja}, 2=$ Nein & $\begin{array}{l}\text { Are there further } \\
\text { members in group } 2 \text { who } \\
\text { do not study with you? } \\
\text { (free translation) }\end{array}$ & $1=\mathrm{Yes}, 2=\mathrm{No}$ & $\mathrm{X}$ & $\mathrm{x}$ & $\mathrm{X}$ & $\mathrm{X}$ & $\mathrm{x}$ & $\mathrm{X}$ & $\mathrm{x}$ & $\mathrm{x}$ & $\mathrm{X}$ & $\mathrm{X}$ & $\mathrm{X}$ & $\mathrm{x}$ & $\mathrm{x}$ & $\mathrm{X}$ & $\mathrm{X}$ \\
\hline group.2.other.number & $\begin{array}{l}\text { Group 2, } \\
\text { number } \\
\text { members } \\
\text { outside the } \\
\text { study } \\
\text { programme }\end{array}$ & $\begin{array}{l}\text { Wenn es noch weitere } \\
\text { Mitglieder in der } \\
\text { Gruppe } 2 \text { gibt, die nicht } \\
\text { mit Dir studieren, wie } \\
\text { viele? }\end{array}$ & & $\begin{array}{l}\text { How many other people } \\
\text { NOT from your cohort } \\
\text { are part of this group? }\end{array}$ & & $\mathrm{x}$ & $\mathrm{x}$ & $\mathrm{x}$ & $\mathrm{x}$ & $\mathrm{x}$ & $\mathrm{x}$ & $\mathrm{x}$ & $\mathrm{x}$ & $\mathrm{x}$ & $\mathrm{x}$ & $\mathrm{x}$ & $\mathrm{x}$ & $\mathrm{x}$ & $\mathrm{x}$ & $\mathrm{x}$ \\
\hline
\end{tabular}




\begin{tabular}{|c|c|c|c|c|c|c|c|c|c|c|c|c|c|c|c|c|c|c|c|c|}
\hline VarName & VariableLabel & WordingDE & ValueLabelsDE_Linked & WordingEN & ValueLabelsEN_Linked & L1 & & F L2 & L3 & L4 & L5 & L6 & L7 & L8 & L9 & L1 & L11 & $1 \mathrm{~L} 12$ & $2 \mathrm{~L} 1$ & 3 L14 \\
\hline group.2.activity & $\begin{array}{l}\text { Group 2, } \\
\text { activity }\end{array}$ & $\begin{array}{l}\text { Welche Tätigkeiten } \\
\text { führt die Gruppe } 2 \\
\text { normalerweise } \\
\text { gemeinsam aus? }\end{array}$ & $\begin{array}{l}1=\text { Lernen, } \\
\text { Hausaufgaben, } 2= \\
\text { Arbeit, } 3=\text { Sport, } 4= \\
\text { Gespräch, } 5=\text { etwas } \\
\text { trinken gehen ("eis go } \\
\text { zieh"), } 6=\text { gemeinsamer } \\
\text { Weg (z.B. zur } \\
\text { Universität), } 1=\text { Kultur, } \\
2=\text { Andere }\end{array}$ & $\begin{array}{l}\text { What is the main } \\
\text { activity that you do } \\
\text { together? } \\
\text { (studying/homework; } \\
\text { work; sports; } \\
\text { conversation; going for a } \\
\text { drink, travelling) }\end{array}$ & $\begin{array}{l}1=\text { Studying, homework } \\
2=\text { work, } 3=\text { sports, } 4= \\
\text { conversation, } 5=\text { going } \\
\text { for a drink, } 6=\text { travelling }\end{array}$ & $\mathrm{x}$ & $\mathrm{x}$ & $\mathrm{x}$ & $\mathrm{x}$ & $\mathrm{x}$ & $\mathrm{x}$ & $\mathrm{x}$ & $\mathrm{x}$ & $\mathrm{x}$ & $\mathrm{x}$ & $\mathrm{x}$ & $\mathrm{x}$ & $\mathrm{x}$ & $\mathrm{x}$ & $\mathrm{x}$ \\
\hline group.2.activity.str & $\begin{array}{l}\text { Group 2, } \\
\text { activity other }\end{array}$ & $\begin{array}{l}\text { Welche Tätigkeiten } \\
\text { führt die Gruppe } 2 \\
\text { normalerweise } \\
\text { gemeinsam aus? Andere }\end{array}$ & & $\begin{array}{l}\text { What is the main } \\
\text { activity that you do } \\
\text { together? (Other) }\end{array}$ & & $\mathrm{x}$ & $\mathrm{x}$ & $\mathrm{x}$ & $\mathrm{x}$ & $\mathrm{x}$ & $\mathrm{x}$ & $\mathrm{x}$ & $\mathrm{x}$ & $\mathrm{x}$ & $\mathrm{x}$ & $\mathrm{x}$ & $\mathrm{x}$ & $\mathrm{x}$ & $\mathrm{x}$ & $\mathrm{x}$ \\
\hline group.2.freq & $\begin{array}{l}\text { Group 2, } \\
\text { frequency of } \\
\text { meeting up }\end{array}$ & $\begin{array}{l}\text { Wie oft trifft sich diese } \\
\text { Gruppe } 2 \text { normalerweise } \\
\text { für gemeinsame } \\
\text { Aktivitäten? }\end{array}$ & $\begin{array}{l}1=\text { zwei oder dreimal pro } \\
\text { Woche, } 2=\text { einmal pro } \\
\text { Woche, } 3=\text { jede zweite } \\
\text { Woche, } 4=\text { einmal pro } \\
\text { Monat, } 5=\text { weniger als } \\
\text { einmal pro Monat, } 6= \\
\text { fast jeden Tag, } 7=\text { zwei } \\
\text { oder dreimal pro Woche }\end{array}$ & $\begin{array}{l}\text { How often does this } \\
\text { group typically meet for } \\
\text { some joint activity? }\end{array}$ & $\begin{array}{l}1=\text { two or three times } \\
\text { per week, } 2=\text { one time } \\
\text { per week, } 3=\text { every } \\
\text { second week, } 4=\text { once per } \\
\text { month, } 5=\text { less than once } \\
\text { per month, } 6=\text { almost } \\
\text { every day, } 7=\text { two or } \\
\text { three times per week }\end{array}$ & $\mathrm{x}$ & $\mathrm{x}$ & $\mathrm{x}$ & $\mathrm{x}$ & $\mathrm{x}$ & $\mathrm{x}$ & $\mathrm{x}$ & $\mathrm{x}$ & $\mathrm{x}$ & $\mathrm{x}$ & $\mathrm{x}$ & $\mathrm{x}$ & $\mathrm{x}$ & $\mathrm{x}$ & $\mathrm{x}$ \\
\hline group.2.pleasant & $\begin{array}{l}\text { Group 2, } \\
\text { interactions - } \\
\text { character: } \\
\text { pleasant }\end{array}$ & $\begin{array}{l}\text { Wie empfindest Du } \\
\text { Treffen mit Gruppe } 2 ? \\
\text { Angenehm; unangenehm }\end{array}$ & $\begin{array}{l}1=7 \text {-Punkte Skala, sehr } \\
\text { angenehm bis sehr } \\
\text { unangenehm, } 2= \\
\text { 7-Punkte Skala, sehr } \\
\text { angenehm bis sehr } \\
\text { unangenehm, } 3= \\
\text { 7-Punkte Skala, sehr } \\
\text { angenehm bis sehr } \\
\text { unangenehm, } 4= \\
\text { 7-Punkte Skala, sehr } \\
\text { angenehm bis sehr } \\
\text { unangenehm, } 5= \\
\text { 7-Punkte Skala, sehr } \\
\text { angenehm bis sehr } \\
\text { unangenehm, } 6= \\
\text { 7-Punkte Skala, sehr } \\
\text { angenehm bis sehr } \\
\text { unangenehm, } 7= \\
\text { 7-Punkte Skala, sehr } \\
\text { angenehm bis sehr } \\
\text { unangenehm }\end{array}$ & $\begin{array}{l}\text { How would you } \\
\text { characterize your typical } \\
\text { personal experience } \\
\text { when meeting with this } \\
\text { group? }\end{array}$ & $\begin{array}{l}1=7 \text { point scale, very } \\
\text { pleasant to very } \\
\text { unpleasant, } 2=7 \text { point } \\
\text { scale, very pleasant to } \\
\text { very unpleasant, } 3=7 \\
\text { point scale, very pleasant } \\
\text { to very unpleasant, } 4=7 \\
\text { point scale, very pleasant } \\
\text { to very unpleasant, } 5=7 \\
\text { point scale, very pleasant } \\
\text { to very unpleasant, } 6=7 \\
\text { point scale, very pleasant } \\
\text { to very unpleasant, } 7=7 \\
\text { point scale, very pleasant } \\
\text { to very unpleasant }\end{array}$ & $\mathrm{x}$ & $\mathrm{x}$ & $\mathrm{x}$ & $\mathrm{x}$ & $\mathrm{x}$ & $\mathrm{x}$ & $\mathrm{x}$ & $\mathrm{x}$ & $\mathrm{x}$ & $\mathrm{x}$ & $\mathrm{x}$ & $\mathrm{x}$ & $\mathrm{x}$ & $\mathrm{x}$ & $\mathrm{x}$ \\
\hline group.2.energetic & $\begin{array}{l}\text { Group 2, } \\
\text { interactions - } \\
\text { character }\end{array}$ & $\begin{array}{l}\text { Wie empfindest Du } \\
\text { Treffen mit Gruppe 2? } \\
\text { Sehr ruhig; sehr } \\
\text { energiegeladen }\end{array}$ & $\begin{array}{l}1=7 \text {-Punkte Skala, sehr } \\
\text { ruhig bis sehr } \\
\text { energiegeladen, } 2= \\
\text { 7-Punkte Skala, sehr ruhig } \\
\text { bis sehr energiegeladen, } 3 \\
=7 \text {-Punkte Skala, sehr } \\
\text { ruhig bis sehr } \\
\text { energiegeladen, } 4= \\
\text { 7-Punkte Skala, sehr ruhig } \\
\text { bis sehr energiegeladen, } 5 \\
=7 \text {-Punkte Skala, sehr } \\
\text { ruhig bis sehr } \\
\text { energiegeladen, } 6= \\
7 \text {-Punkte Skala, sehr ruhig } \\
\text { bis sehr energiegeladen, } 7 \\
=7 \text {-Punkte Skala, sehr } \\
\text { ruhig bis sehr } \\
\text { energiegeladen }\end{array}$ & $\begin{array}{l}\text { How would you } \\
\text { characterize your typical } \\
\text { personal experience } \\
\text { when meeting with this } \\
\text { group? }\end{array}$ & $\begin{array}{l}1=7 \text { point scale, very } \\
\text { quiet to very energetic, } 2 \\
=7 \text { point scale, very quiet } \\
\text { to very energetic, } 3=7 \\
\text { point scale, very quiet to } \\
\text { very energetic, } 4=7 \\
\text { point scale, very quiet to } \\
\text { very energetic, } 5=7 \\
\text { point scale, very quiet to } \\
\text { very energetic, } 6=7 \\
\text { point scale, very quiet to } \\
\text { very energetic, } 7=7 \\
\text { point scale, very quiet to } \\
\text { very energetic }\end{array}$ & $\mathrm{x}$ & $\mathrm{x}$ & $\mathrm{x}$ & $\mathrm{x}$ & $\mathrm{x}$ & $\mathrm{x}$ & $\mathrm{x}$ & $\mathrm{x}$ & $\mathrm{x}$ & $\mathrm{x}$ & $\mathrm{x}$ & $\mathrm{x}$ & $\mathrm{x}$ & $\mathrm{x}$ & $\mathrm{x}$ \\
\hline
\end{tabular}




\begin{tabular}{|c|c|c|c|c|c|c|c|c|c|c|c|c|c|c|c|c|c|c|c|c|}
\hline VarName & VariableLabel & WordingDE & ValueLabelsDE_Linked & WordingEN & ValueLabelsEN_Linked & L1 & L11 & F L2 & L3 & $\mathrm{L} 4$ & L5 & L6 & L7 & L8 & L9 & L10 & L11 & L12 & $2 \mathrm{~L} 13$ & 3 L14 \\
\hline group.2.personal & $\begin{array}{l}\text { Group 2, } \\
\text { interactions - } \\
\text { character }\end{array}$ & $\begin{array}{l}\text { Wie empfindest Du } \\
\text { Treffen mit Gruppe 2? }\end{array}$ & $\begin{array}{l}1=7 \text {-Punkte Skala, sehr } \\
\text { oberfächlich bis sehr } \\
\text { persönlich, } 2=7 \text {-Punkte } \\
\text { Skala, sehr oberflächlich } \\
\text { bis sehr persönlich, } 3= \\
\text { 7-Punkte Skala, sehr } \\
\text { oberf̈̈̈chlich bis sehr } \\
\text { persönlich, } 4=7 \text {-Punkte } \\
\text { Skala, sehr oberflächlich } \\
\text { bis sehr persönlich, } 5= \\
\text { 7-Punkte Skala, sehr } \\
\text { oberflächlich bis sehr } \\
\text { persönlich, } 6=7 \text {-Punkte } \\
\text { Skala, sehr oberflächlich } \\
\text { bis sehr persönlich, } 7= \\
\text { 7-Punkte Skala, sehr } \\
\text { oberflächlich bis sehr } \\
\text { persönlich }\end{array}$ & $\begin{array}{l}\text { How would you } \\
\text { characterize your typical } \\
\text { personal experience } \\
\text { when meeting with this } \\
\text { group? }\end{array}$ & $\begin{array}{l}1=7 \text { point scale, very } \\
\text { superficial to very } \\
\text { personal, } 2=7 \text { point } \\
\text { scale, very superficial to } \\
\text { very personal, } 3=7 \text { point } \\
\text { scale, very superficial to } \\
\text { very personal, } 4=7 \text { point } \\
\text { scale, very superficial to } \\
\text { very personal, } 5=7 \text { point } \\
\text { scale, very superficial to } \\
\text { very personal, } 6=7 \text { point } \\
\text { scale, very superficial to } \\
\text { very personal, } 7=7 \text { point } \\
\text { scale, very superficial to } \\
\text { very personal }\end{array}$ & $\mathrm{x}$ & $\mathrm{x}$ & $\mathrm{x}$ & $\mathrm{x}$ & $\mathrm{x}$ & $\mathrm{x}$ & $\mathrm{x}$ & $\mathrm{x}$ & $\mathrm{x}$ & $\mathrm{x}$ & $\mathrm{x}$ & $\mathrm{x}$ & $\mathrm{x}$ & $\mathrm{x}$ & $\mathrm{x}$ \\
\hline group.2.communication & $\begin{array}{l}\text { Group } 2 \text {, } \\
\text { frequency of } \\
\text { meeting online }\end{array}$ & $\begin{array}{l}\text { Wie oft kommuniziert } \\
\text { die Gruppe } 2 \text { online } \\
\text { (z.B. per Whatsapp-, } \\
\text { Facebook-Gruppenchat) } \\
\text { zusätzlich zu den } \\
\text { Treffen? }\end{array}$ & $\begin{array}{l}1=\text { zwei oder dreimal pro } \\
\text { Woche, } 2=\text { einmal pro } \\
\text { Woche, } 3=\text { jede zweite } \\
\text { Woche, } 4=\text { einmal pro } \\
\text { Monat, } 5=\text { weniger als } \\
\text { einmal pro Jahr, } 6=\text { fast } \\
\text { jeden Tag, } 7=\text { nie }\end{array}$ & $\begin{array}{l}\text { How often does group } 1 \\
\text { communicate online } \\
\text { (e.g. via WhatsApp, } \\
\text { Facebook Chat) in } \\
\text { addition to the } \\
\text { meetings? }\end{array}$ & $\begin{array}{l}1=\text { second or three time } \\
\text { per week, } 2=\text { once per } \\
\text { week, } 3=\text { every second } \\
\text { week, } 4=\text { once per } \\
\text { month, } 5=\text { less than once } \\
\text { per month, } 6=\text { almost } \\
\text { every day, } 7=\text { never }\end{array}$ & $\mathrm{x}$ & $\mathrm{x}$ & $\mathrm{x}$ & $\mathrm{x}$ & $\mathrm{x}$ & $\mathrm{x}$ & $\mathrm{x}$ & $\mathrm{x}$ & $\mathrm{x}$ & $\mathrm{x}$ & $\mathrm{x}$ & $\mathrm{x}$ & $\mathrm{x}$ & $\mathrm{x}$ & $\mathrm{x}$ \\
\hline group.3.P1 & $\begin{array}{l}\text { Group 3, } \\
\text { Person 1 }\end{array}$ & $\begin{array}{l}\text { Welche Deiner } \\
\text { Mitstudierenden sind } \\
\text { Teil der Gruppe 3? (die } \\
\text { Anzahl } \\
\text { Nicht-Mitstudierenden } \\
\text { Gruppenmitglieder kann } \\
\text { auf der nächsten Seite } \\
\text { genannt werden) Nenne } \\
\text { zwischen } 1 \text { und 20 } \\
\text { Personen }\end{array}$ & & $\begin{array}{l}\text { Which students from } \\
\text { your cohort are part of } \\
\text { group 3? }\end{array}$ & & $\mathrm{x}$ & $\mathrm{x}$ & $\mathrm{x}$ & $\mathrm{x}$ & $\mathrm{x}$ & $\mathrm{X}$ & $\mathrm{x}$ & $\mathrm{x}$ & $\mathrm{x}$ & $\mathrm{X}$ & $\mathrm{x}$ & $\mathrm{x}$ & $\mathrm{x}$ & $\mathrm{x}$ & $\mathrm{x}$ \\
\hline group.3.other & $\begin{array}{l}\text { Group } 3, \\
\text { members } \\
\text { outside the } \\
\text { study } \\
\text { programme }\end{array}$ & $\begin{array}{l}\text { Gibt es noch weitere } \\
\text { Mitglieder der Gruppe } \\
\text { 3, welche nicht mit Dir } \\
\text { studieren? }\end{array}$ & $1=\mathrm{Ja}, 2=$ Nein & $\begin{array}{l}\text { Are there further } \\
\text { members in group } 3 \text { who } \\
\text { do not study with you? } \\
\text { (free translation) }\end{array}$ & $1=\mathrm{Yes}, 2=\mathrm{No}$ & $\mathrm{x}$ & $\mathrm{x}$ & $\mathrm{x}$ & $\mathrm{x}$ & $\mathrm{x}$ & $\mathrm{x}$ & $\mathrm{x}$ & $\mathrm{x}$ & $\mathrm{x}$ & $\mathrm{x}$ & $\mathrm{x}$ & $\mathrm{x}$ & $\mathrm{x}$ & $\mathrm{x}$ & $\mathrm{x}$ \\
\hline group.3.other.number & $\begin{array}{l}\text { Group } 3, \\
\text { number } \\
\text { members } \\
\text { outside the } \\
\text { study } \\
\text { programme }\end{array}$ & $\begin{array}{l}\text { Wenn es noch weitere } \\
\text { Mitglieder in der } \\
\text { Gruppe } 3 \text { gibt, die nicht } \\
\text { mit Dir studieren, wie } \\
\text { viele? }\end{array}$ & & $\begin{array}{l}\text { How many other people } \\
\text { NOT from your cohort } \\
\text { are part of this group? }\end{array}$ & & $\mathrm{x}$ & $\mathrm{x}$ & $\mathrm{x}$ & $\mathrm{x}$ & $\mathrm{x}$ & $\mathrm{x}$ & $\mathrm{x}$ & $\mathrm{x}$ & $\mathrm{x}$ & $\mathrm{x}$ & $\mathrm{x}$ & $\mathrm{x}$ & $\mathrm{x}$ & $\mathrm{x}$ & $\mathrm{x}$ \\
\hline group.3.activity & $\begin{array}{l}\text { Group } 3, \\
\text { activity }\end{array}$ & $\begin{array}{l}\text { Welche Tätigkeiten } \\
\text { führt die Gruppe } 3 \\
\text { normalerweise } \\
\text { gemeinsam aus? }\end{array}$ & $\begin{array}{l}1=\text { Lernen, } \\
\text { Hausaufgaben, } 2= \\
\text { Arbeit, } 3=\text { Sport, } 4= \\
\text { Gespräch, } 5=\text { etwas } \\
\text { trinken gehen ("eis go } \\
\text { zieh"), } 6=\text { gemeinsamer } \\
\text { Weg (z.B. zur } \\
\text { Universität), } 1=\text { Kultur, } \\
2=\text { Andere }\end{array}$ & $\begin{array}{l}\text { What is the main } \\
\text { activity that you do } \\
\text { together? } \\
\text { (studying/homework; } \\
\text { work; sports; } \\
\text { conversation; going for a } \\
\text { drink, travelling) }\end{array}$ & $\begin{array}{l}1=\text { Studying,homework, } \\
2=\text { work, } 3=\text { sports, } 4= \\
\text { conversation, } 5=\text { going } \\
\text { for a drink, } 6=\text { travelling }\end{array}$ & $\mathrm{x}$ & $\mathrm{x}$ & $\mathrm{x}$ & $\mathrm{x}$ & $\mathrm{x}$ & $\mathrm{x}$ & $\mathrm{x}$ & $\mathrm{x}$ & $\mathrm{x}$ & $\mathrm{x}$ & $\mathrm{x}$ & $\mathrm{x}$ & $\mathrm{x}$ & $\mathrm{x}$ & $\mathrm{x}$ \\
\hline group.3.activity.str & $\begin{array}{l}\text { Group } 3 \text {, } \\
\text { activity other }\end{array}$ & $\begin{array}{l}\text { Welche Tätigkeiten } \\
\text { führt die Gruppe } 3 \\
\text { normalerweise } \\
\text { gemeinsam aus? Andere }\end{array}$ & & $\begin{array}{l}\text { What is the main } \\
\text { activity that you do } \\
\text { together? (Other) }\end{array}$ & & $\mathrm{x}$ & $\mathrm{x}$ & $\mathrm{x}$ & $\mathrm{x}$ & $\mathrm{X}$ & $\mathrm{x}$ & $\mathrm{x}$ & $\mathrm{x}$ & $\mathrm{x}$ & $\mathrm{x}$ & $\mathrm{x}$ & $\mathrm{x}$ & $\mathrm{x}$ & $\mathrm{X}$ & $\mathrm{x}$ \\
\hline
\end{tabular}




\begin{tabular}{|c|c|c|c|c|c|c|c|c|c|c|c|c|c|c|c|c|c|c|c|c|}
\hline VarName & VariableLabel & WordingDE & ValueLabelsDE_Linked & WordingEN & ValueLabelsEN_Linked & $\mathrm{L} 1$ & L11 & F L2 & L3 & L4 & L5 & L6 & L7 & L8 & L9 & $\mathrm{L} 1 \mathrm{C}$ & L 11 & $\mathrm{~L} 12$ & $\mathrm{~L} 13$ & 3 L14 \\
\hline group.3.freq & $\begin{array}{l}\text { Group } 3, \\
\text { frequency of } \\
\text { meeting up }\end{array}$ & $\begin{array}{l}\text { Wie oft trifft sich diese } \\
\text { Gruppe } 3 \text { normalerweise } \\
\text { für gemeinsame } \\
\text { Aktivitäten? }\end{array}$ & $\begin{array}{l}1=\text { zwei oder dreimal pro } \\
\text { Woche, } 2=\text { einmal pro } \\
\text { Woche, } 3=\text { jede zweite } \\
\text { Woche, } 4=\text { einmal pro } \\
\text { Monat, } 5=\text { weniger als } \\
\text { einmal pro Monat, } 6= \\
\text { fast jeden Tag, } 7=\text { zwei } \\
\text { oder dreimal pro Woche }\end{array}$ & $\begin{array}{l}\text { How often does this } \\
\text { group typically meet for } \\
\text { some joint activity? }\end{array}$ & $\begin{array}{l}1=\text { two or three times } \\
\text { per week, } 2=\text { one time } \\
\text { per week, } 3=\text { every } \\
\text { second week, } 4=\text { once per } \\
\text { month, } 5=\text { less than once } \\
\text { per month, } 6=\text { almost } \\
\text { every day, } 7=\text { two or } \\
\text { three times per week }\end{array}$ & $\mathrm{x}$ & $\mathrm{x}$ & $\mathrm{x}$ & $\mathrm{x}$ & $\mathrm{x}$ & $\mathrm{x}$ & $\mathrm{x}$ & $\mathrm{x}$ & $\mathrm{x}$ & $\mathrm{x}$ & $\mathrm{x}$ & $\mathrm{x}$ & $\mathrm{x}$ & $\mathrm{x}$ & $\mathrm{x}$ \\
\hline group.3.pleasant & $\begin{array}{l}\text { Group } 3, \\
\text { interactions - } \\
\text { character: } \\
\text { pleasant }\end{array}$ & $\begin{array}{l}\text { Wie empfindest Du } \\
\text { Treffen mit Gruppe } 3 \text { ? } \\
\text { Angenehm; unangenehm }\end{array}$ & $\begin{array}{l}1=7 \text {-Punkte Skala, sehr } \\
\text { angenehm bis sehr } \\
\text { unangenehm, } 2= \\
\text { 7-Punkte Skala, sehr } \\
\text { angenehm bis sehr } \\
\text { unangenehm, } 3= \\
\text { 7-Punkte Skala, sehr } \\
\text { angenehm bis sehr } \\
\text { unangenehm, } 4= \\
\text { 7-Punkte Skala, sehr } \\
\text { angenehm bis sehr } \\
\text { unangenehm, } 5= \\
\text { 7-Punkte Skala, sehr } \\
\text { angenehm bis sehr } \\
\text { unangenehm, } 6= \\
\text { 7-Punkte Skala, sehr } \\
\text { angenehm bis sehr } \\
\text { unangenehm, } 7= \\
\text { 7-Punkte Skala, sehr } \\
\text { angenehm bis sehr } \\
\text { unangenehm }\end{array}$ & $\begin{array}{l}\text { How would you } \\
\text { characterize your typical } \\
\text { personal experience } \\
\text { when meeting with this } \\
\text { group? }\end{array}$ & $\begin{array}{l}1=7 \text { point scale, very } \\
\text { pleasant to very } \\
\text { unpleasant, } 2=7 \text { point } \\
\text { scale, very pleasant to } \\
\text { very unpleasant, } 3=7 \\
\text { point scale, very pleasant } \\
\text { to very unpleasant, } 4=7 \\
\text { point scale, very pleasant } \\
\text { to very unpleasant, } 5=7 \\
\text { point scale, very pleasant } \\
\text { to very unpleasant, } 6=7 \\
\text { point scale, very pleasant } \\
\text { to very unpleasant, } 7=7 \\
\text { point scale, very pleasant } \\
\text { to very unpleasant }\end{array}$ & $\mathrm{x}$ & $\mathrm{x}$ & $\mathrm{x}$ & $\mathrm{x}$ & $\mathrm{x}$ & $\mathrm{x}$ & $\mathrm{x}$ & $\mathrm{x}$ & $\mathrm{x}$ & $\mathrm{x}$ & $\mathrm{x}$ & $\mathrm{x}$ & $\mathrm{x}$ & $\mathrm{x}$ & $\mathrm{x}$ \\
\hline group.3.energetic & $\begin{array}{l}\text { Group } 3 \text {, } \\
\text { interactions - } \\
\text { character }\end{array}$ & $\begin{array}{l}\text { Wie empfindest Du } \\
\text { Treffen mit Gruppe } 3 \text { ? } \\
\text { Sehr ruhig; sehr } \\
\text { energiegeladen }\end{array}$ & $\begin{array}{l}1=7 \text {-Punkte Skala, sehr } \\
\text { ruhig bis sehr } \\
\text { energiegeladen, } 2= \\
7 \text {-Punkte Skala, sehr ruhig } \\
\text { bis sehr energiegeladen, } 3 \\
=7 \text {-Punkte Skala, sehr } \\
\text { ruhig bis sehr } \\
\text { energiegeladen, } 4= \\
\text { 7-Punkte Skala, sehr ruhig } \\
\text { bis sehr energiegeladen, } 5 \\
=7 \text {-Punkte Skala, sehr } \\
\text { ruhig bis sehr } \\
\text { energiegeladen, } 6= \\
\text { 7-Punkte Skala, sehr ruhig } \\
\text { bis sehr energiegeladen, } 7 \\
=7 \text {-Punkte Skala, sehr } \\
\text { ruhig bis sehr } \\
\text { energiegeladen }\end{array}$ & $\begin{array}{l}\text { How would you } \\
\text { characterize your typical } \\
\text { personal experience } \\
\text { when meeting with this } \\
\text { group? }\end{array}$ & $\begin{array}{l}1=7 \text { point scale, very } \\
\text { quiet to very energetic, } 2 \\
=7 \text { point scale, very quiet } \\
\text { to very energetic, } 3=7 \\
\text { point scale, very quiet to } \\
\text { very energetic, } 4=7 \\
\text { point scale, very quiet to } \\
\text { very energetic, } 5=7 \\
\text { point scale, very quiet to } \\
\text { very energetic, } 6=7 \\
\text { point scale, very quiet to } \\
\text { very energetic, } 7=7 \\
\text { point scale, very quiet to } \\
\text { very energetic }\end{array}$ & $\mathrm{x}$ & $\mathrm{x}$ & $\mathrm{x}$ & $\mathrm{x}$ & $\mathrm{x}$ & $\mathrm{x}$ & $\mathrm{x}$ & $\mathrm{x}$ & $\mathrm{x}$ & $\mathrm{x}$ & $\mathrm{x}$ & $\mathrm{x}$ & $\mathrm{x}$ & $\mathrm{x}$ & $\mathrm{x}$ \\
\hline
\end{tabular}




\begin{tabular}{|c|c|c|c|c|c|c|c|c|c|c|c|c|c|c|c|c|c|c|c|c|}
\hline VarName & VariableLabel & WordingDE & ValueLabelsDE_Linked & WordingEN & ValueLabelsEN_Linked & L1 & L11 & F L2 & L3 & $\mathrm{L} 4$ & L5 & L6 & L7 & L8 & L9 & L10 & L11 & L12 & $2 \mathrm{~L} 13$ & 3 L14 \\
\hline group.3.personal & $\begin{array}{l}\text { Group 3, } \\
\text { interactions - } \\
\text { character }\end{array}$ & $\begin{array}{l}\text { Wie empfindest Du } \\
\text { Treffen mit Gruppe } 3 \text { ? }\end{array}$ & $\begin{array}{l}1=7 \text {-Punkte Skala, sehr } \\
\text { oberfächlich bis sehr } \\
\text { persönlich, } 2=7 \text {-Punkte } \\
\text { Skala, sehr oberflächlich } \\
\text { bis sehr persönlich, } 3= \\
\text { 7-Punkte Skala, sehr } \\
\text { oberf̈̈̈chlich bis sehr } \\
\text { persönlich, } 4=7 \text {-Punkte } \\
\text { Skala, sehr oberflächlich } \\
\text { bis sehr persönlich, } 5= \\
\text { 7-Punkte Skala, sehr } \\
\text { oberflächlich bis sehr } \\
\text { persönlich, } 6=7 \text {-Punkte } \\
\text { Skala, sehr oberflächlich } \\
\text { bis sehr persönlich, } 7= \\
\text { 7-Punkte Skala, sehr } \\
\text { oberflächlich bis sehr } \\
\text { persönlich }\end{array}$ & $\begin{array}{l}\text { How would you } \\
\text { characterize your typical } \\
\text { personal experience } \\
\text { when meeting with this } \\
\text { group? }\end{array}$ & $\begin{array}{l}1=7 \text { point scale, very } \\
\text { superficial to very } \\
\text { personal, } 2=7 \text { point } \\
\text { scale, very superficial to } \\
\text { very personal, } 3=7 \text { point } \\
\text { scale, very superficial to } \\
\text { very personal, } 4=7 \text { point } \\
\text { scale, very superficial to } \\
\text { very personal, } 5=7 \text { point } \\
\text { scale, very superficial to } \\
\text { very personal, } 6=7 \text { point } \\
\text { scale, very superficial to } \\
\text { very personal, } 7=7 \text { point } \\
\text { scale, very superficial to } \\
\text { very personal }\end{array}$ & $\mathrm{x}$ & $\mathrm{x}$ & $\mathrm{x}$ & $\mathrm{x}$ & $\mathrm{x}$ & $\mathrm{x}$ & $\mathrm{x}$ & $\mathrm{x}$ & $\mathrm{x}$ & $\mathrm{x}$ & $\mathrm{x}$ & $\mathrm{x}$ & $\mathrm{x}$ & $\mathrm{x}$ & $\mathrm{x}$ \\
\hline group.3.communication & $\begin{array}{l}\text { Group } 3 \text {, } \\
\text { frequency of } \\
\text { meeting online }\end{array}$ & $\begin{array}{l}\text { Wie oft kommuniziert } \\
\text { die Gruppe } 3 \text { online } \\
\text { (z.B. per Whatsapp-, } \\
\text { Facebook-Gruppenchat) } \\
\text { zusätzlich zu den } \\
\text { Treffen? }\end{array}$ & $\begin{array}{l}1=\text { zwei oder dreimal pro } \\
\text { Woche, } 2=\text { einmal pro } \\
\text { Woche, } 3=\text { jede zweite } \\
\text { Woche, } 4=\text { einmal pro } \\
\text { Monat, } 5=\text { weniger als } \\
\text { einmal pro Jahr, } 6=\text { fast } \\
\text { jeden Tag, } 7=\text { nie }\end{array}$ & $\begin{array}{l}\text { How often does group } 1 \\
\text { communicate online } \\
\text { (e.g. via WhatsApp, } \\
\text { Facebook Chat) in } \\
\text { addition to the } \\
\text { meetings? }\end{array}$ & $\begin{array}{l}1=\text { second or three time } \\
\text { per week, } 2=\text { once per } \\
\text { week, } 3=\text { every second } \\
\text { week, } 4=\text { once per } \\
\text { month, } 5=\text { less than once } \\
\text { per month, } 6=\text { almost } \\
\text { every day, } 7=\text { never }\end{array}$ & $\mathrm{x}$ & $\mathrm{x}$ & $\mathrm{x}$ & $\mathrm{x}$ & $\mathrm{x}$ & $\mathrm{x}$ & $\mathrm{x}$ & $\mathrm{x}$ & $\mathrm{x}$ & $\mathrm{x}$ & $\mathrm{x}$ & $\mathrm{x}$ & $\mathrm{x}$ & $\mathrm{x}$ & $\mathrm{x}$ \\
\hline group.4.P1 & $\begin{array}{l}\text { Group 4, } \\
\text { Person } 1\end{array}$ & $\begin{array}{l}\text { Welche Deiner } \\
\text { Mitstudierenden sind } \\
\text { Teil der Gruppe 4? (die } \\
\text { Anzahl } \\
\text { Nicht-Mitstudierenden } \\
\text { Gruppenmitglieder kann } \\
\text { auf der nächsten Seite } \\
\text { genannt werden) Nenne } \\
\text { zwischen } 1 \text { und 20 } \\
\text { Personen }\end{array}$ & & $\begin{array}{l}\text { Which students from } \\
\text { your cohort are part of } \\
\text { group } 4 \text { ? }\end{array}$ & & $\mathrm{x}$ & $\mathrm{x}$ & $\mathrm{x}$ & $\mathrm{x}$ & $\mathrm{x}$ & $\mathrm{X}$ & $\mathrm{x}$ & $\mathrm{x}$ & $\mathrm{x}$ & $\mathrm{X}$ & $\mathrm{x}$ & $\mathrm{x}$ & $\mathrm{x}$ & $\mathrm{x}$ & $\mathrm{x}$ \\
\hline group.4.other & $\begin{array}{l}\text { Group } 4, \\
\text { members } \\
\text { outside the } \\
\text { study } \\
\text { programme }\end{array}$ & $\begin{array}{l}\text { Gibt es noch weitere } \\
\text { Mitglieder der Gruppe } \\
\text { 4, welche nicht mit Dir } \\
\text { studieren? }\end{array}$ & $1=\mathrm{Ja}, 2=$ Nein & $\begin{array}{l}\text { Are there further } \\
\text { members in group } 4 \text { who } \\
\text { do not study with you? } \\
\text { (free translation) }\end{array}$ & $1=\mathrm{Yes}, 2=\mathrm{No}$ & $\mathrm{x}$ & $\mathrm{x}$ & $\mathrm{x}$ & $\mathrm{x}$ & $\mathrm{x}$ & $\mathrm{x}$ & $\mathrm{x}$ & $\mathrm{x}$ & $\mathrm{x}$ & $\mathrm{x}$ & $\mathrm{x}$ & $\mathrm{x}$ & $\mathrm{x}$ & $\mathrm{x}$ & $\mathrm{x}$ \\
\hline group.4.other.number & $\begin{array}{l}\text { Group } 4, \\
\text { number } \\
\text { members } \\
\text { outside the } \\
\text { study } \\
\text { programme }\end{array}$ & $\begin{array}{l}\text { Wenn es noch weitere } \\
\text { Mitglieder in der } \\
\text { Gruppe } 4 \text { gibt, die nicht } \\
\text { mit Dir studieren, wie } \\
\text { viele? }\end{array}$ & & $\begin{array}{l}\text { How many other people } \\
\text { NOT from your cohort } \\
\text { are part of this group? }\end{array}$ & & $\mathrm{x}$ & $\mathrm{x}$ & $\mathrm{x}$ & $\mathrm{x}$ & $\mathrm{x}$ & $\mathrm{x}$ & $\mathrm{x}$ & $\mathrm{x}$ & $\mathrm{x}$ & $\mathrm{x}$ & $\mathrm{x}$ & $\mathrm{x}$ & $\mathrm{x}$ & $\mathrm{x}$ & $\mathrm{x}$ \\
\hline group.4.activity & $\begin{array}{l}\text { Group } 4, \\
\text { activity }\end{array}$ & $\begin{array}{l}\text { Welche Tätigkeiten } \\
\text { führt die Gruppe } 4 \\
\text { normalerweise } \\
\text { gemeinsam aus? }\end{array}$ & $\begin{array}{l}1=\text { Lernen, } \\
\text { Hausaufgaben, } 2= \\
\text { Arbeit, } 3=\text { Sport, } 4= \\
\text { Gespräch, } 5=\text { etwas } \\
\text { trinken gehen ("eis go } \\
\text { zieh"), } 6=\text { gemeinsamer } \\
\text { Weg (z.B. zur } \\
\text { Universität), } 1=\text { Kultur, } \\
2=\text { Andere }\end{array}$ & $\begin{array}{l}\text { What is the main } \\
\text { activity that you do } \\
\text { together? } \\
\text { (studying/homework; } \\
\text { work; sports; } \\
\text { conversation; going for a } \\
\text { drink, travelling) }\end{array}$ & $\begin{array}{l}1=\text { Studying,homework, } \\
2=\text { work, } 3=\text { sports, } 4= \\
\text { conversation, } 5=\text { going } \\
\text { for a drink, } 6=\text { travelling }\end{array}$ & $\mathrm{x}$ & $\mathrm{x}$ & $\mathrm{x}$ & $\mathrm{x}$ & $\mathrm{x}$ & $\mathrm{x}$ & $\mathrm{x}$ & $\mathrm{x}$ & $\mathrm{x}$ & $\mathrm{x}$ & $\mathrm{x}$ & $\mathrm{x}$ & $\mathrm{x}$ & $\mathrm{x}$ & $\mathrm{x}$ \\
\hline group.4.activity.str & $\begin{array}{l}\text { Group } 4 \text {, } \\
\text { activity other }\end{array}$ & $\begin{array}{l}\text { Welche Tätigkeiten } \\
\text { führt die Gruppe } 4 \\
\text { normalerweise } \\
\text { gemeinsam aus? Andere }\end{array}$ & & $\begin{array}{l}\text { What is the main } \\
\text { activity that you do } \\
\text { together? (Other) }\end{array}$ & & $\mathrm{x}$ & $\mathrm{x}$ & $\mathrm{x}$ & $\mathrm{x}$ & $\mathrm{X}$ & $\mathrm{x}$ & $\mathrm{x}$ & $\mathrm{x}$ & $\mathrm{x}$ & $\mathrm{x}$ & $\mathrm{x}$ & $\mathrm{x}$ & $\mathrm{x}$ & $\mathrm{X}$ & $\mathrm{x}$ \\
\hline
\end{tabular}




\begin{tabular}{|c|c|c|c|c|c|c|c|c|c|c|c|c|c|c|c|c|c|c|c|c|}
\hline VarName & VariableLabel & WordingDE & ValueLabelsDE_Linked & WordingEN & ValueLabelsEN_Linked & $\mathrm{L} 1$ & L11 & F L2 & L3 & L4 & L5 & L6 & L7 & L8 & L9 & $\mathrm{L} 1 \mathrm{C}$ & L 11 & $\mathrm{~L} 12$ & $\mathrm{~L} 13$ & 3 L14 \\
\hline group.4.freq & $\begin{array}{l}\text { Group } 4, \\
\text { frequency of } \\
\text { meeting up }\end{array}$ & $\begin{array}{l}\text { Wie oft trifft sich diese } \\
\text { Gruppe } 4 \text { normalerweise } \\
\text { für gemeinsame } \\
\text { Aktivitäten? }\end{array}$ & $\begin{array}{l}1=\text { zwei oder dreimal pro } \\
\text { Woche, } 2=\text { einmal pro } \\
\text { Woche, } 3=\text { jede zweite } \\
\text { Woche, } 4=\text { einmal pro } \\
\text { Monat, } 5=\text { weniger als } \\
\text { einmal pro Monat, } 6= \\
\text { fast jeden Tag, } 7=\text { zwei } \\
\text { oder dreimal pro Woche }\end{array}$ & $\begin{array}{l}\text { How often does this } \\
\text { group typically meet for } \\
\text { some joint activity? }\end{array}$ & $\begin{array}{l}1=\text { two or three times } \\
\text { per week, } 2=\text { one time } \\
\text { per week, } 3=\text { every } \\
\text { second week, } 4=\text { once per } \\
\text { month, } 5=\text { less than once } \\
\text { per month, } 6=\text { almost } \\
\text { every day, } 7=\text { two or } \\
\text { three times per week }\end{array}$ & $\mathrm{x}$ & $\mathrm{x}$ & $\mathrm{x}$ & $\mathrm{x}$ & $\mathrm{x}$ & $\mathrm{x}$ & $\mathrm{x}$ & $\mathrm{x}$ & $\mathrm{x}$ & $\mathrm{x}$ & $\mathrm{x}$ & $\mathrm{x}$ & $\mathrm{x}$ & $\mathrm{x}$ & $\mathrm{x}$ \\
\hline group.4.pleasant & $\begin{array}{l}\text { Group } 4, \\
\text { interactions - } \\
\text { character: } \\
\text { pleasant }\end{array}$ & $\begin{array}{l}\text { Wie empfindest Du } \\
\text { Treffen mit Gruppe } 4 \text { ? } \\
\text { Angenehm; unangenehm }\end{array}$ & $\begin{array}{l}1=7 \text {-Punkte Skala, sehr } \\
\text { angenehm bis sehr } \\
\text { unangenehm, } 2= \\
\text { 7-Punkte Skala, sehr } \\
\text { angenehm bis sehr } \\
\text { unangenehm, } 3= \\
\text { 7-Punkte Skala, sehr } \\
\text { angenehm bis sehr } \\
\text { unangenehm, } 4= \\
\text { 7-Punkte Skala, sehr } \\
\text { angenehm bis sehr } \\
\text { unangenehm, } 5= \\
\text { 7-Punkte Skala, sehr } \\
\text { angenehm bis sehr } \\
\text { unangenehm, } 6= \\
\text { 7-Punkte Skala, sehr } \\
\text { angenehm bis sehr } \\
\text { unangenehm, } 7= \\
\text { 7-Punkte Skala, sehr } \\
\text { angenehm bis sehr } \\
\text { unangenehm }\end{array}$ & $\begin{array}{l}\text { How would you } \\
\text { characterize your typical } \\
\text { personal experience } \\
\text { when meeting with this } \\
\text { group? }\end{array}$ & $\begin{array}{l}1=7 \text { point scale, very } \\
\text { pleasant to very } \\
\text { unpleasant, } 2=7 \text { point } \\
\text { scale, very pleasant to } \\
\text { very unpleasant, } 3=7 \\
\text { point scale, very pleasant } \\
\text { to very unpleasant, } 4=7 \\
\text { point scale, very pleasant } \\
\text { to very unpleasant, } 5=7 \\
\text { point scale, very pleasant } \\
\text { to very unpleasant, } 6=7 \\
\text { point scale, very pleasant } \\
\text { to very unpleasant, } 7=7 \\
\text { point scale, very pleasant } \\
\text { to very unpleasant }\end{array}$ & $\mathrm{x}$ & $\mathrm{x}$ & $\mathrm{x}$ & $\mathrm{x}$ & $\mathrm{x}$ & $\mathrm{x}$ & $\mathrm{x}$ & $\mathrm{x}$ & $\mathrm{x}$ & $\mathrm{x}$ & $\mathrm{x}$ & $\mathrm{x}$ & $\mathrm{x}$ & $\mathrm{x}$ & $\mathrm{x}$ \\
\hline group.4.energetic & $\begin{array}{l}\text { Group } 4, \\
\text { interactions - } \\
\text { character }\end{array}$ & $\begin{array}{l}\text { Wie empfindest Du } \\
\text { Treffen mit Gruppe } 4 \text { ? } \\
\text { Sehr ruhig; sehr } \\
\text { energiegeladen }\end{array}$ & $\begin{array}{l}1=7 \text {-Punkte Skala, sehr } \\
\text { ruhig bis sehr } \\
\text { energiegeladen, } 2= \\
7 \text {-Punkte Skala, sehr ruhig } \\
\text { bis sehr energiegeladen, } 3 \\
=7 \text {-Punkte Skala, sehr } \\
\text { ruhig bis sehr } \\
\text { energiegeladen, } 4= \\
\text { 7-Punkte Skala, sehr ruhig } \\
\text { bis sehr energiegeladen, } 5 \\
=7 \text {-Punkte Skala, sehr } \\
\text { ruhig bis sehr } \\
\text { energiegeladen, } 6= \\
\text { 7-Punkte Skala, sehr ruhig } \\
\text { bis sehr energiegeladen, } 7 \\
=7 \text {-Punkte Skala, sehr } \\
\text { ruhig bis sehr } \\
\text { energiegeladen }\end{array}$ & $\begin{array}{l}\text { How would you } \\
\text { characterize your typical } \\
\text { personal experience } \\
\text { when meeting with this } \\
\text { group? }\end{array}$ & $\begin{array}{l}1=7 \text { point scale, very } \\
\text { quiet to very energetic, } 2 \\
=7 \text { point scale, very quiet } \\
\text { to very energetic, } 3=7 \\
\text { point scale, very quiet to } \\
\text { very energetic, } 4=7 \\
\text { point scale, very quiet to } \\
\text { very energetic, } 5=7 \\
\text { point scale, very quiet to } \\
\text { very energetic, } 6=7 \\
\text { point scale, very quiet to } \\
\text { very energetic, } 7=7 \\
\text { point scale, very quiet to } \\
\text { very energetic }\end{array}$ & $\mathrm{x}$ & $\mathrm{x}$ & $\mathrm{x}$ & $\mathrm{x}$ & $\mathrm{x}$ & $\mathrm{x}$ & $\mathrm{x}$ & $\mathrm{x}$ & $\mathrm{x}$ & $\mathrm{x}$ & $\mathrm{x}$ & $\mathrm{x}$ & $\mathrm{x}$ & $\mathrm{x}$ & $\mathrm{x}$ \\
\hline
\end{tabular}




\begin{tabular}{|c|c|c|c|c|c|c|c|c|c|c|c|c|c|c|c|c|c|c|c|c|}
\hline VarName & VariableLabel & WordingDE & ValueLabelsDE_Linked & WordingEN & ValueLabelsEN_Linked & L1 & L11 & F L2 & L3 & $\mathrm{L} 4$ & L5 & L6 & L7 & L8 & L9 & L10 & L11 & L12 & $2 \mathrm{~L} 13$ & 3 L14 \\
\hline group.4.personal & $\begin{array}{l}\text { Group 4, } \\
\text { interactions - } \\
\text { character }\end{array}$ & $\begin{array}{l}\text { Wie empfindest Du } \\
\text { Treffen mit Gruppe } 4 \text { ? }\end{array}$ & $\begin{array}{l}1=7 \text {-Punkte Skala, sehr } \\
\text { oberfächlich bis sehr } \\
\text { persönlich, } 2=7 \text {-Punkte } \\
\text { Skala, sehr oberflächlich } \\
\text { bis sehr persönlich, } 3= \\
\text { 7-Punkte Skala, sehr } \\
\text { oberf̈̈̈chlich bis sehr } \\
\text { persönlich, } 4=7 \text {-Punkte } \\
\text { Skala, sehr oberflächlich } \\
\text { bis sehr persönlich, } 5= \\
\text { 7-Punkte Skala, sehr } \\
\text { oberflächlich bis sehr } \\
\text { persönlich, } 6=7 \text {-Punkte } \\
\text { Skala, sehr oberflächlich } \\
\text { bis sehr persönlich, } 7= \\
\text { 7-Punkte Skala, sehr } \\
\text { oberflächlich bis sehr } \\
\text { persönlich }\end{array}$ & $\begin{array}{l}\text { How would you } \\
\text { characterize your typical } \\
\text { personal experience } \\
\text { when meeting with this } \\
\text { group? }\end{array}$ & $\begin{array}{l}1=7 \text { point scale, very } \\
\text { superficial to very } \\
\text { personal, } 2=7 \text { point } \\
\text { scale, very superficial to } \\
\text { very personal, } 3=7 \text { point } \\
\text { scale, very superficial to } \\
\text { very personal, } 4=7 \text { point } \\
\text { scale, very superficial to } \\
\text { very personal, } 5=7 \text { point } \\
\text { scale, very superficial to } \\
\text { very personal, } 6=7 \text { point } \\
\text { scale, very superficial to } \\
\text { very personal, } 7=7 \text { point } \\
\text { scale, very superficial to } \\
\text { very personal }\end{array}$ & $\mathrm{x}$ & $\mathrm{x}$ & $\mathrm{x}$ & $\mathrm{x}$ & $\mathrm{x}$ & $\mathrm{x}$ & $\mathrm{x}$ & $\mathrm{x}$ & $\mathrm{x}$ & $\mathrm{x}$ & $\mathrm{x}$ & $\mathrm{x}$ & $\mathrm{x}$ & $\mathrm{x}$ & $\mathrm{x}$ \\
\hline group.4.communication & $\begin{array}{l}\text { Group } 4, \\
\text { frequency of } \\
\text { meeting online }\end{array}$ & $\begin{array}{l}\text { Wie oft kommuniziert } \\
\text { die Gruppe } 4 \text { online } \\
\text { (z.B. per Whatsapp-, } \\
\text { Facebook-Gruppenchat) } \\
\text { zusätzlich zu den } \\
\text { Treffen? }\end{array}$ & $\begin{array}{l}1=\text { zwei oder dreimal pro } \\
\text { Woche, } 2=\text { einmal pro } \\
\text { Woche, } 3=\text { jede zweite } \\
\text { Woche, } 4=\text { einmal pro } \\
\text { Monat, } 5=\text { weniger als } \\
\text { einmal pro Jahr, } 6=\text { fast } \\
\text { jeden Tag, } 7=\text { nie }\end{array}$ & $\begin{array}{l}\text { How often does group } 1 \\
\text { communicate online } \\
\text { (e.g. via WhatsApp, } \\
\text { Facebook Chat) in } \\
\text { addition to the } \\
\text { meetings? }\end{array}$ & $\begin{array}{l}1=\text { second or three time } \\
\text { per week, } 2=\text { once per } \\
\text { week, } 3=\text { every second } \\
\text { week, } 4=\text { once per } \\
\text { month, } 5=\text { less than once } \\
\text { per month, } 6=\text { almost } \\
\text { every day, } 7=\text { never }\end{array}$ & $\mathrm{x}$ & $\mathrm{x}$ & $\mathrm{x}$ & $\mathrm{x}$ & $\mathrm{x}$ & $\mathrm{x}$ & $\mathrm{x}$ & $\mathrm{x}$ & $\mathrm{x}$ & $\mathrm{x}$ & $\mathrm{x}$ & $\mathrm{x}$ & $\mathrm{x}$ & $\mathrm{x}$ & $\mathrm{x}$ \\
\hline group.5.P1 & $\begin{array}{l}\text { Group 5, } \\
\text { Person } 1\end{array}$ & $\begin{array}{l}\text { Welche Deiner } \\
\text { Mitstudierenden sind } \\
\text { Teil der Gruppe 5? (die } \\
\text { Anzahl } \\
\text { Nicht-Mitstudierenden } \\
\text { Gruppenmitglieder kann } \\
\text { auf der nächsten Seite } \\
\text { genannt werden) Nenne } \\
\text { zwischen } 1 \text { und 20 } \\
\text { Personen }\end{array}$ & & $\begin{array}{l}\text { Which students from } \\
\text { your cohort are part of } \\
\text { group } 5 \text { ? }\end{array}$ & & $\mathrm{x}$ & $\mathrm{x}$ & $\mathrm{x}$ & $\mathrm{x}$ & $\mathrm{x}$ & $\mathrm{x}$ & $\mathrm{x}$ & $\mathrm{x}$ & $\mathrm{x}$ & $\mathrm{X}$ & $\mathrm{x}$ & $\mathrm{x}$ & $\mathrm{x}$ & $\mathrm{x}$ & $\mathrm{x}$ \\
\hline group.5.other & $\begin{array}{l}\text { Group } 5, \\
\text { members } \\
\text { outside the } \\
\text { study } \\
\text { programme }\end{array}$ & $\begin{array}{l}\text { Gibt es noch weitere } \\
\text { Mitglieder der Gruppe } \\
5, \text { welche nicht mit Dir } \\
\text { studieren? }\end{array}$ & $1=\mathrm{Ja}, 2=$ Nein & $\begin{array}{l}\text { Are there further } \\
\text { members in group } 5 \text { who } \\
\text { do not study with you? } \\
\text { (free translation) }\end{array}$ & $1=\mathrm{Yes}, 2=\mathrm{No}$ & $\mathrm{x}$ & $\mathrm{x}$ & $\mathrm{x}$ & $\mathrm{x}$ & $\mathrm{x}$ & $\mathrm{x}$ & $\mathrm{x}$ & $\mathrm{x}$ & $\mathrm{x}$ & $\mathrm{x}$ & $\mathrm{x}$ & $\mathrm{x}$ & $\mathrm{x}$ & $\mathrm{x}$ & $\mathrm{x}$ \\
\hline group.5.other.number & $\begin{array}{l}\text { Group } 5, \\
\text { number } \\
\text { members } \\
\text { outside the } \\
\text { study } \\
\text { programme }\end{array}$ & $\begin{array}{l}\text { Wenn es noch weitere } \\
\text { Mitglieder in der } \\
\text { Gruppe } 5 \text { gibt, die nicht } \\
\text { mit Dir studieren, wie } \\
\text { viele? }\end{array}$ & & $\begin{array}{l}\text { How many other people } \\
\text { NOT from your cohort } \\
\text { are part of this group? }\end{array}$ & & $\mathrm{x}$ & $\mathrm{x}$ & $\mathrm{x}$ & $\mathrm{x}$ & $\mathrm{x}$ & $\mathrm{x}$ & $\mathrm{x}$ & $\mathrm{x}$ & $\mathrm{x}$ & $\mathrm{x}$ & $\mathrm{x}$ & $\mathrm{x}$ & $\mathrm{x}$ & $\mathrm{x}$ & $\mathrm{x}$ \\
\hline group.5.activity & $\begin{array}{l}\text { Group } 5, \\
\text { activity }\end{array}$ & $\begin{array}{l}\text { Welche Tätigkeiten } \\
\text { führt die Gruppe } 5 \\
\text { normalerweise } \\
\text { gemeinsam aus? }\end{array}$ & $\begin{array}{l}1=\text { Lernen, } \\
\text { Hausaufgaben, } 2= \\
\text { Arbeit, } 3=\text { Sport, } 4= \\
\text { Gespräch, } 5=\text { etwas } \\
\text { trinken gehen ("eis go } \\
\text { zieh"), } 6=\text { gemeinsamer } \\
\text { Weg (z.B. zur } \\
\text { Universität), } 1=\text { Kultur, } \\
2=\text { Andere }\end{array}$ & $\begin{array}{l}\text { What is the main } \\
\text { activity that you do } \\
\text { together? } \\
\text { (studying/homework; } \\
\text { work; sports; } \\
\text { conversation; going for a } \\
\text { drink, travelling) }\end{array}$ & $\begin{array}{l}1=\text { Studying,homework, } \\
2=\text { work, } 3=\text { sports, } 4= \\
\text { conversation, } 5=\text { going } \\
\text { for a drink, } 6=\text { travelling }\end{array}$ & $\mathrm{x}$ & $\mathrm{x}$ & $\mathrm{x}$ & $\mathrm{x}$ & $\mathrm{x}$ & $\mathrm{x}$ & $\mathrm{x}$ & $\mathrm{x}$ & $\mathrm{x}$ & $\mathrm{x}$ & $\mathrm{x}$ & $\mathrm{x}$ & $\mathrm{x}$ & $\mathrm{x}$ & $\mathrm{x}$ \\
\hline group.5.activity.str & $\begin{array}{l}\text { Group } 5 \text {, } \\
\text { activity other }\end{array}$ & $\begin{array}{l}\text { Welche Tätigkeiten } \\
\text { führt die Gruppe } 5 \\
\text { normalerweise } \\
\text { gemeinsam aus? Andere }\end{array}$ & & $\begin{array}{l}\text { What is the main } \\
\text { activity that you do } \\
\text { together? (Other) }\end{array}$ & & $\mathrm{x}$ & $\mathrm{x}$ & $\mathrm{x}$ & $\mathrm{x}$ & $\mathrm{X}$ & $\mathrm{x}$ & $\mathrm{x}$ & $\mathrm{x}$ & $\mathrm{x}$ & $\mathrm{x}$ & $\mathrm{x}$ & $\mathrm{x}$ & $\mathrm{x}$ & $\mathrm{X}$ & $\mathrm{x}$ \\
\hline
\end{tabular}




\begin{tabular}{|c|c|c|c|c|c|c|c|c|c|c|c|c|c|c|c|c|c|c|c|c|}
\hline VarName & VariableLabel & WordingDE & ValueLabelsDE_Linked & WordingEN & ValueLabelsEN_Linked & $\mathrm{L} 1$ & L11 & F L2 & L3 & L4 & L5 & L6 & L7 & L8 & L9 & L10 & L11 & $1 \mathrm{~L} 12$ & $2 \mathrm{~L} 13$ & 3 L14 \\
\hline group.5.freq & $\begin{array}{l}\text { Group } 5 \text {, } \\
\text { frequency of } \\
\text { meeting up }\end{array}$ & $\begin{array}{l}\text { Wie oft trifft sich diese } \\
\text { Gruppe } 5 \text { normalerweise } \\
\text { für gemeinsame } \\
\text { Aktivitäten? }\end{array}$ & $\begin{array}{l}1=\text { zwei oder dreimal pro } \\
\text { Woche, } 2=\text { einmal pro } \\
\text { Woche, } 3=\text { jede zweite } \\
\text { Woche, } 4=\text { einmal pro } \\
\text { Monat, } 5=\text { weniger als } \\
\text { einmal pro Monat, } 6= \\
\text { fast jeden Tag, } 7=\text { zwei } \\
\text { oder dreimal pro Woche }\end{array}$ & $\begin{array}{l}\text { How often does this } \\
\text { group typically meet for } \\
\text { some joint activity? }\end{array}$ & $\begin{array}{l}1=\text { two or three times } \\
\text { per week, } 2=\text { one time } \\
\text { per week, } 3=\text { every } \\
\text { second week, } 4=\text { once per } \\
\text { month, } 5=\text { less than once } \\
\text { per month, } 6=\text { almost } \\
\text { every day, } 7=\text { two or } \\
\text { three times per week }\end{array}$ & $\mathrm{x}$ & $\mathrm{x}$ & $\mathrm{x}$ & $\mathrm{x}$ & $\mathrm{x}$ & $\mathrm{x}$ & $\mathrm{x}$ & $\mathrm{x}$ & $\mathrm{x}$ & $\mathrm{x}$ & $\mathrm{x}$ & $\mathrm{x}$ & $\mathrm{x}$ & $\mathrm{x}$ & $\mathrm{x}$ \\
\hline group.5.pleasant & $\begin{array}{l}\text { Group 5, } \\
\text { interactions - } \\
\text { character: } \\
\text { pleasant }\end{array}$ & $\begin{array}{l}\text { Wie empfindest Du } \\
\text { Treffen mit Gruppe } 5 ? \\
\text { Angenehm; unangenehm }\end{array}$ & $\begin{array}{l}1=7 \text {-Punkte Skala, sehr } \\
\text { angenehm bis sehr } \\
\text { unangenehm, } 2= \\
\text { 7-Punkte Skala, sehr } \\
\text { angenehm bis sehr } \\
\text { unangenehm, } 3= \\
\text { 7-Punkte Skala, sehr } \\
\text { angenehm bis sehr } \\
\text { unangenehm, } 4= \\
\text { 7-Punkte Skala, sehr } \\
\text { angenehm bis sehr } \\
\text { unangenehm, } 5= \\
\text { 7-Punkte Skala, sehr } \\
\text { angenehm bis sehr } \\
\text { unangenehm, } 6= \\
\text { 7-Punkte Skala, sehr } \\
\text { angenehm bis sehr } \\
\text { unangenehm, } 7= \\
\text { 7-Punkte Skala, sehr } \\
\text { angenehm bis sehr } \\
\text { unangenehm }\end{array}$ & $\begin{array}{l}\text { How would you } \\
\text { characterize your typical } \\
\text { personal experience } \\
\text { when meeting with this } \\
\text { group? }\end{array}$ & $\begin{array}{l}1=7 \text { point scale, very } \\
\text { pleasant to very } \\
\text { unpleasant, } 2=7 \text { point } \\
\text { scale, very pleasant to } \\
\text { very unpleasant, } 3=7 \\
\text { point scale, very pleasant } \\
\text { to very unpleasant, } 4=7 \\
\text { point scale, very pleasant } \\
\text { to very unpleasant, } 5=7 \\
\text { point scale, very pleasant } \\
\text { to very unpleasant, } 6=7 \\
\text { point scale, very pleasant } \\
\text { to very unpleasant, } 7=7 \\
\text { point scale, very pleasant } \\
\text { to very unpleasant }\end{array}$ & $\mathrm{x}$ & $\mathrm{x}$ & $\mathrm{x}$ & $\mathrm{x}$ & $\mathrm{x}$ & $\mathrm{x}$ & $\mathrm{x}$ & $\mathrm{x}$ & $\mathrm{x}$ & $\mathrm{x}$ & $\mathrm{x}$ & $\mathrm{x}$ & $\mathrm{x}$ & $\mathrm{x}$ & $\mathrm{x}$ \\
\hline group.5.energetic & $\begin{array}{l}\text { Group 5, } \\
\text { interactions - } \\
\text { character }\end{array}$ & $\begin{array}{l}\text { Wie empfindest Du } \\
\text { Treffen mit Gruppe } 5 ? \\
\text { Sehr ruhig; sehr } \\
\text { energiegeladen }\end{array}$ & $\begin{array}{l}1=7 \text {-Punkte Skala, sehr } \\
\text { ruhig bis sehr } \\
\text { energiegeladen, } 2= \\
\text { 7-Punkte Skala, sehr ruhig } \\
\text { bis sehr energiegeladen, } 3 \\
=7 \text {-Punkte Skala, sehr } \\
\text { ruhig bis sehr } \\
\text { energiegeladen, } 4= \\
\text { 7-Punkte Skala, sehr ruhig } \\
\text { bis sehr energiegeladen, } 5 \\
=7 \text {-Punkte Skala, sehr } \\
\text { ruhig bis sehr } \\
\text { energiegeladen, } 6= \\
7 \text {-Punkte Skala, sehr ruhig } \\
\text { bis sehr energiegeladen, } 7 \\
=7 \text {-Punkte Skala, sehr } \\
\text { ruhig bis sehr } \\
\text { energiegeladen }\end{array}$ & $\begin{array}{l}\text { How would you } \\
\text { characterize your typical } \\
\text { personal experience } \\
\text { when meeting with this } \\
\text { group? }\end{array}$ & $\begin{array}{l}1=7 \text { point scale, very } \\
\text { quiet to very energetic, } 2 \\
=7 \text { point scale, very quiet } \\
\text { to very energetic, } 3=7 \\
\text { point scale, very quiet to } \\
\text { very energetic, } 4=7 \\
\text { point scale, very quiet to } \\
\text { very energetic, } 5=7 \\
\text { point scale, very quiet to } \\
\text { very energetic, } 6=7 \\
\text { point scale, very quiet to } \\
\text { very energetic, } 7=7 \\
\text { point scale, very quiet to } \\
\text { very energetic }\end{array}$ & $\mathrm{x}$ & $\mathrm{x}$ & $\mathrm{x}$ & $\mathrm{x}$ & $\mathrm{x}$ & $\mathrm{x}$ & $\mathrm{x}$ & $\mathrm{x}$ & $\mathrm{x}$ & $\mathrm{x}$ & $\mathrm{x}$ & $\mathrm{x}$ & $\mathrm{x}$ & $\mathrm{x}$ & $\mathrm{x}$ \\
\hline
\end{tabular}




\begin{tabular}{|c|c|c|c|c|c|c|c|c|c|c|c|c|c|c|c|c|c|c|c|c|}
\hline VarName & VariableLabel & WordingDE & ValueLabelsDE_Linked & WordingEN & ValueLabelsEN_Linked & L1 & & F L2 & L3 & L4 & L5 & L6 & L7 & L8 & L9 & L10 & L11 & $\mathrm{L} 12$ & $\mathrm{~L} 13$ & 3 L14 \\
\hline group.5.personal & $\begin{array}{l}\text { Group 5, } \\
\text { interactions - } \\
\text { character }\end{array}$ & $\begin{array}{l}\text { Wie empfindest Du } \\
\text { Treffen mit Gruppe } 5 \text { ? }\end{array}$ & $\begin{array}{l}1=7 \text {-Punkte Skala, sehr } \\
\text { oberfächlich bis sehr } \\
\text { persönlich, } 2=7 \text {-Punkte } \\
\text { Skala, sehr oberfl̈̈chlich } \\
\text { bis sehr persönlich, } 3= \\
\text { 7-Punkte Skala, sehr } \\
\text { oberfächlich bis sehr } \\
\text { persönlich, } 4=7 \text {-Punkte } \\
\text { Skala, sehr oberflächlich } \\
\text { bis sehr persönlich, } 5= \\
\text { 7-Punkte Skala, sehr } \\
\text { oberflächlich bis sehr } \\
\text { persönlich, } 6=7 \text {-Punkte } \\
\text { Skala, sehr oberflächlich } \\
\text { bis sehr persönlich, } 7= \\
\text { 7-Punkte Skala, sehr } \\
\text { oberfächlich bis sehr } \\
\text { persönlich }\end{array}$ & $\begin{array}{l}\text { How would you } \\
\text { characterize your typical } \\
\text { personal experience } \\
\text { when meeting with this } \\
\text { group? }\end{array}$ & $\begin{array}{l}1=7 \text { point scale, very } \\
\text { superficial to very } \\
\text { personal, } 2=7 \text { point } \\
\text { scale, very superficial to } \\
\text { very personal, } 3=7 \text { point } \\
\text { scale, very superficial to } \\
\text { very personal, } 4=7 \text { point } \\
\text { scale, very superficial to } \\
\text { very personal, } 5=7 \text { point } \\
\text { scale, very superficial to } \\
\text { very personal, } 6=7 \text { point } \\
\text { scale, very superficial to } \\
\text { very personal, } 7=7 \text { point } \\
\text { scale, very superficial to } \\
\text { very personal }\end{array}$ & $\mathrm{x}$ & $\mathrm{x}$ & $\mathrm{x}$ & $\mathrm{x}$ & $\mathrm{x}$ & $\mathrm{x}$ & $\mathrm{x}$ & $\mathrm{x}$ & $\mathrm{x}$ & $\mathrm{x}$ & $\mathrm{x}$ & $\mathrm{x}$ & $\mathrm{x}$ & $\mathrm{x}$ & $\mathrm{x}$ \\
\hline group.5.communication & $\begin{array}{l}\text { Group 5, } \\
\text { frequency of } \\
\text { meeting online }\end{array}$ & $\begin{array}{l}\text { Wie oft kommuniziert } \\
\text { die Gruppe } 5 \text { online } \\
\text { (z.B. per Whatsapp-, } \\
\text { Facebook-Gruppenchat) } \\
\text { zusätzlich zu den } \\
\text { Treffen? }\end{array}$ & $\begin{array}{l}1=\text { zwei oder dreimal pro } \\
\text { Woche, } 2=\text { einmal pro } \\
\text { Woche, } 3=\text { jede zweite } \\
\text { Woche, } 4=\text { einmal pro } \\
\text { Monat, } 5=\text { weniger als } \\
\text { einmal pro Jahr, } 6=\text { fast } \\
\text { jeden Tag, } 7=\text { nie }\end{array}$ & $\begin{array}{l}\text { How often does group } 1 \\
\text { communicate online } \\
\text { (e.g. via WhatsApp, } \\
\text { Facebook Chat) in } \\
\text { addition to the } \\
\text { meetings? }\end{array}$ & $\begin{array}{l}1=\text { second or three time } \\
\text { per week, } 2=\text { once per } \\
\text { week, } 3=\text { every second } \\
\text { week, } 4=\text { once per } \\
\text { month, } 5=\text { less than once } \\
\text { per month, } 6=\text { almost } \\
\text { every day, } 7=\text { never }\end{array}$ & $\mathrm{x}$ & $\mathrm{x}$ & $\mathrm{x}$ & $\mathrm{x}$ & $\mathrm{x}$ & $\mathrm{x}$ & $\mathrm{x}$ & $\mathrm{x}$ & $\mathrm{x}$ & $\mathrm{x}$ & $\mathrm{x}$ & $\mathrm{x}$ & $\mathrm{x}$ & $\mathrm{x}$ & $\mathrm{x}$ \\
\hline other.group.1 & $\begin{array}{l}\text { Group 1, } \\
\text { excluding } \\
\text { respondent }\end{array}$ & $\begin{array}{l}\text { Denke nun über die } \\
\text { Gruppen zwischen } \\
\text { Deinen Mitstudierenden } \\
\text { nach, welche Du } \\
\text { wahrnimmst und von } \\
\text { welchen Du nicht teil } \\
\text { bist. Bitte benenne die } \\
\text { Gruppen, zu welchen Du } \\
\text { nicht gehörst, mit 1-2 } \\
\text { Stichwörtern (z.B. } \\
\text { "Lerngruppe XY“), } \\
\text { sodass du sie für die } \\
\text { nächsten Minuten } \\
\text { wiedererkennen kannst. } \\
\text { Nenne } 0 \text { bis } 5 \text { Gruppen. }\end{array}$ & & $\begin{array}{l}\text { Now think about groups } \\
\text { that exist between your } \\
\text { fellow students which } \\
\text { you perceive, but you } \\
\text { are not part of. Please } \\
\text { name your groups with } \\
1-2 \text { key words (e.g. } \\
\text { "study group XY"), so } \\
\text { that you can recognise } \\
\text { them in the next few } \\
\text { minutes. Name } 0 \text { to } 5 \\
\text { groups. (free } \\
\text { translation) }\end{array}$ & & $\mathrm{x}$ & $\mathrm{x}$ & $\mathrm{x}$ & $\mathrm{x}$ & $\mathrm{x}$ & $\mathrm{x}$ & $\mathrm{x}$ & $\mathrm{x}$ & $\mathrm{x}$ & $\mathrm{x}$ & $\mathrm{x}$ & $\mathrm{x}$ & $\mathrm{x}$ & $\mathrm{x}$ & \\
\hline other.group.2 & $\begin{array}{l}\text { Group 2, } \\
\text { excluding } \\
\text { respondent }\end{array}$ & $\begin{array}{l}\text { Denke nun über die } \\
\text { Gruppen zwischen } \\
\text { Deinen Mitstudierenden } \\
\text { nach, welche Du } \\
\text { wahrnimmst und von } \\
\text { welchen Du nicht teil } \\
\text { bist. Bitte benenne die } \\
\text { Gruppen, zu welchen Du } \\
\text { nicht gehörst, mit 1-2 } \\
\text { Stichwörtern (z.B. } \\
\text { „Lerngruppe XY“), } \\
\text { sodass du sie für die } \\
\text { nächsten Minuten } \\
\text { wiedererkennen kannst. } \\
\text { Nenne } 0 \text { bis } 5 \text { Gruppen. }\end{array}$ & & $\begin{array}{l}\text { Now think about groups } \\
\text { that exist between your } \\
\text { fellow students which } \\
\text { you perceive, but you } \\
\text { are not part of. Please } \\
\text { name your groups with } \\
1-2 \text { key words (e.g. } \\
\text { "study group XY"), so } \\
\text { that you can recognise } \\
\text { them in the next few } \\
\text { minutes. Name } 0 \text { to } 5 \\
\text { groups. (free } \\
\text { translation) }\end{array}$ & & $\mathrm{x}$ & $\mathrm{x}$ & $\mathrm{x}$ & $\mathrm{x}$ & $\mathrm{x}$ & $\mathrm{x}$ & $\mathrm{x}$ & $\mathrm{x}$ & $\mathrm{x}$ & $\mathrm{x}$ & $\mathrm{x}$ & $\mathrm{x}$ & $\mathrm{x}$ & $\mathrm{x}$ & \\
\hline
\end{tabular}




\begin{tabular}{|c|c|c|c|c|c|c|c|c|c|c|c|c|c|c|c|c|c|c|c|}
\hline VarName & VariableLabel & WordingDE & ValueLabelsDE_Linked & WordingEN & ValueLabelsEN_Linked & L1 & L11 & $\mathrm{F} \mathrm{L} 2$ & L3 & $\mathrm{L} 4$ & L5 & L6 & L7 & L8 & L9 & L10 & L11 & $1 \mathrm{~L} 12$ & 2 L13 L14 \\
\hline other.group.3 & $\begin{array}{l}\text { Group } 3 \\
\text { excluding } \\
\text { respondent }\end{array}$ & $\begin{array}{l}\text { Denke nun über die } \\
\text { Gruppen zwischen } \\
\text { Deinen Mitstudierenden } \\
\text { nach, welche Du } \\
\text { wahrnimmst und von } \\
\text { welchen Du nicht teil } \\
\text { bist. Bitte benenne die } \\
\text { Gruppen, zu welchen Du } \\
\text { nicht gehörst, mit 1-2 } \\
\text { Stichwörtern (z.B. } \\
\text { „Lerngruppe XY“), } \\
\text { sodass du sie für die } \\
\text { nächsten Minuten } \\
\text { wiedererkennen kannst. } \\
\text { Nenne } 0 \text { bis } 5 \text { Gruppen. }\end{array}$ & & $\begin{array}{l}\text { Now think about groups } \\
\text { that exist between your } \\
\text { fellow students which } \\
\text { you perceive, but you } \\
\text { are not part of. Please } \\
\text { name your groups with } \\
1-2 \text { key words (e.g. } \\
\text { "study group XY"), so } \\
\text { that you can recognise } \\
\text { them in the next few } \\
\text { minutes. Name } 0 \text { to } 5 \\
\text { groups. (free } \\
\text { translation) }\end{array}$ & & $\mathrm{x}$ & $\mathrm{x}$ & $\mathrm{x}$ & $\mathrm{x}$ & $\mathrm{x}$ & $\mathrm{x}$ & $\mathrm{x}$ & $\mathrm{x}$ & $\mathrm{x}$ & $\mathrm{x}$ & $\mathrm{x}$ & $\mathrm{x}$ & $\mathrm{x}$ & $\mathrm{x}$ \\
\hline other.group.4 & $\begin{array}{l}\text { Group } 4, \\
\text { excluding } \\
\text { respondent }\end{array}$ & $\begin{array}{l}\text { Denke nun über die } \\
\text { Gruppen zwischen } \\
\text { Deinen Mitstudierenden } \\
\text { nach, welche Du } \\
\text { wahrnimmst und von } \\
\text { welchen Du nicht teil } \\
\text { bist. Bitte benenne die } \\
\text { Gruppen, zu welchen Du } \\
\text { nicht gehörst, mit 1-2 } \\
\text { Stichwörtern (z.B. } \\
\text { „Lerngruppe XY“), } \\
\text { sodass du sie für die } \\
\text { nächsten Minuten } \\
\text { wiedererkennen kannst. } \\
\text { Nenne } 0 \text { bis } 5 \text { Gruppen. }\end{array}$ & & $\begin{array}{l}\text { Now think about groups } \\
\text { that exist between your } \\
\text { fellow students which } \\
\text { you perceive, but you } \\
\text { are not part of. Please } \\
\text { name your groups with } \\
1-2 \text { key words (e.g. } \\
\text { "study group XY"), so } \\
\text { that you can recognise } \\
\text { them in the next few } \\
\text { minutes. Name } 0 \text { to } 5 \\
\text { groups. (free } \\
\text { translation) }\end{array}$ & & $\mathrm{x}$ & $\mathrm{x}$ & $\mathrm{x}$ & $\mathrm{x}$ & $\mathrm{X}$ & $\mathrm{x}$ & $\mathrm{x}$ & $\mathrm{x}$ & $\mathrm{x}$ & $\mathrm{x}$ & $\mathrm{x}$ & $\mathrm{x}$ & $\mathrm{x}$ & $\mathrm{X}$ \\
\hline other.group.5 & $\begin{array}{l}\text { Group 5, } \\
\text { excluding } \\
\text { respondent }\end{array}$ & $\begin{array}{l}\text { Denke nun über die } \\
\text { Gruppen zwischen } \\
\text { Deinen Mitstudierenden } \\
\text { nach, welche Du } \\
\text { wahrnimmst und von } \\
\text { welchen Du nicht teil } \\
\text { bist. Bitte benenne die } \\
\text { Gruppen, zu welchen Du } \\
\text { nicht gehörst, mit 1-2 } \\
\text { Stichwörtern (z.B. } \\
\text { „Lerngruppe XY“), } \\
\text { sodass du sie für die } \\
\text { nächsten Minuten } \\
\text { wiedererkennen kannst. } \\
\text { Nenne } 0 \text { bis } 5 \text { Gruppen. }\end{array}$ & & $\begin{array}{l}\text { Now think about groups } \\
\text { that exist between your } \\
\text { fellow students which } \\
\text { you perceive, but you } \\
\text { are not part of. Please } \\
\text { name your groups with } \\
1-2 \text { key words (e.g. } \\
\text { "study group XY"), so } \\
\text { that you can recognise } \\
\text { them in the next few } \\
\text { minutes. Name } 0 \text { to } 5 \\
\text { groups. (free } \\
\text { translation) }\end{array}$ & & $\mathrm{x}$ & $\mathrm{x}$ & $\mathrm{x}$ & $\mathrm{x}$ & $\mathrm{x}$ & $\mathrm{x}$ & $\mathrm{x}$ & $\mathrm{x}$ & $\mathrm{x}$ & $\mathrm{x}$ & $\mathrm{x}$ & $\mathrm{x}$ & $\mathrm{x}$ & $\mathrm{x}$ \\
\hline other.group.1.no & $\begin{array}{l}\text { Knowledge of } \\
\text { people in other } \\
\text { group } 1\end{array}$ & $\begin{array}{l}\text { Weißt du wie viele } \\
\text { Deiner Mitstudierenden } \\
\text { in etwa zu Gruppe } 1 \\
\text { gehören? }\end{array}$ & $1=\mathrm{Ja}, 2=$ Nein & $\begin{array}{l}\text { How many people from } \\
\text { your cohort are part of } \\
\text { group 1? }\end{array}$ & $1=\mathrm{Yes}, 2=\mathrm{No}$ & $\mathrm{x}$ & $\mathrm{x}$ & $\mathrm{x}$ & $\mathrm{x}$ & $\mathrm{x}$ & $\mathrm{x}$ & $\mathrm{x}$ & $\mathrm{x}$ & $\mathrm{x}$ & $\mathrm{x}$ & $\mathrm{x}$ & $\mathrm{x}$ & $\mathrm{x}$ & $\mathrm{x}$ \\
\hline other.group.1.no.str & $\begin{array}{l}\text { Number of } \\
\text { people in other } \\
\text { group } 1\end{array}$ & $\begin{array}{l}\text { Wie viele Deiner } \\
\text { Mitstudierenden gehören } \\
\text { in etwa zu Gruppe } 1 ?\end{array}$ & & $\begin{array}{l}\text { How many people from } \\
\text { your cohort are part of } \\
\text { group 1? }\end{array}$ & & $\mathrm{x}$ & $\mathrm{x}$ & $\mathrm{x}$ & $\mathrm{x}$ & $\mathrm{x}$ & $\mathrm{X}$ & $\mathrm{x}$ & $\mathrm{x}$ & $\mathrm{x}$ & $\mathrm{x}$ & $\mathrm{X}$ & $\mathrm{x}$ & $\mathrm{x}$ & $\mathrm{x}$ \\
\hline other.group.1.P1 & $\begin{array}{l}\text { Other group } 1 \\
\text { Person } 1\end{array}$ & $\begin{array}{l}\text { Kennst Du jemanden } \\
\text { Deiner Mitstudierenden, } \\
\text { der oder die zu dieser } \\
\text { Gruppe } 1 \text { gehört? Bitte } \\
\text { nenne so viele Personen, } \\
\text { wie Du kannst, aber } \\
\text { nenne nur Personen } \\
\text { welche zur Gruppe } \\
\text { gehören. }\end{array}$ & & $\begin{array}{l}\text { Could you name } \\
\text { students who belong to } \\
\text { group } 1 \text { ? Please name as } \\
\text { many students as you } \\
\text { remember. }\end{array}$ & & $\mathrm{x}$ & $\mathrm{x}$ & $\mathrm{x}$ & $\mathrm{x}$ & $\mathrm{x}$ & $\mathrm{x}$ & $\mathrm{x}$ & $\mathrm{x}$ & $\mathrm{x}$ & $\mathrm{x}$ & $\mathrm{x}$ & $\mathrm{x}$ & $\mathrm{x}$ & $\mathrm{x}$ \\
\hline
\end{tabular}




\begin{tabular}{|c|c|c|c|c|c|c|c|c|c|c|c|c|c|c|c|c|c|c|c|}
\hline VarName & VariableLabel & WordingDE & ValueLabelsDE_Linked & WordingEN & ValueLabelsEN_Linked & L1 & & F L2 & L3 & $\mathrm{L} 4$ & L5 & L6 & L7 & L8 & L9 & L10 & o L11 & $1 \mathrm{~L} 12$ & $2 \mathrm{~L} 13 \mathrm{~L} 14$ \\
\hline other.group.1.activity & $\begin{array}{l}\text { Other group } 1 \text {, } \\
\text { activity }\end{array}$ & $\begin{array}{l}\text { Was ist Deiner Meinung } \\
\text { nach die hauptsächliche } \\
\text { Tätigkeit, die diese } \\
\text { Gruppe } 1 \text { zusammen } \\
\text { hält (z.B. Sachen, die } \\
\text { Du Gruppenmitglieder } \\
\text { oft zusammen tun } \\
\text { siehst)? }\end{array}$ & $\begin{array}{l}1=\text { Lernen, } 2= \\
\text { Hausaufgaben, } 3= \\
\text { Arbeit, } 4=\text { Sport, } 5= \\
\text { Gespräch, } 6=\text { etwas } \\
\text { trinken gehen (,eis go } \\
\text { zieh“), } 7=\text { gemeinsamer } \\
\text { Weg (z.B. zur } \\
\text { Universität), } 8= \\
\text { Rendezvous, } 9=\text { Andere, } \\
1=\text { Kultur }\end{array}$ & $\begin{array}{l}\text { In your opinion, what is } \\
\text { it that keeps group } 1 \\
\text { together (i.e. things } \\
\text { that you see group } \\
\text { members doing together } \\
\text { often)? (free } \\
\text { translation) }\end{array}$ & $\begin{array}{l}1=\text { Studying,homework, } \\
2=\text { work, } 3=\text { sports, } 4= \\
\text { conversation, } 5=\text { going } \\
\text { for a drink, } 6= \\
\text { commuting, } 7=\text { dating, } 8 \\
=\text { other, } 9=\text { culture (free } \\
\text { translation) }\end{array}$ & $\mathrm{x}$ & $\mathrm{x}$ & $\mathrm{x}$ & $\mathrm{x}$ & $\mathrm{x}$ & $\mathrm{x}$ & $\mathrm{x}$ & $\mathrm{x}$ & $\mathrm{x}$ & $\mathrm{x}$ & $\mathrm{x}$ & $\mathrm{x}$ & $\mathrm{x}$ & $\mathrm{x}$ \\
\hline other.group.1.activity.str & $\begin{array}{l}\text { Other group 1, } \\
\text { activity other }\end{array}$ & $\begin{array}{l}\text { Was ist Deiner Meinung } \\
\text { nach die hauptsächliche } \\
\text { Tätigkeit, die diese } \\
\text { Gruppe 1 zusammen } \\
\text { hält (z.B. Sachen, die } \\
\text { Du Gruppenmitglieder } \\
\text { oft zusammen tun } \\
\text { siehst)? Andere }\end{array}$ & & & & $\mathrm{x}$ & $\mathrm{x}$ & $\mathrm{x}$ & $\mathrm{x}$ & $\mathrm{x}$ & $\mathrm{x}$ & $\mathrm{x}$ & $\mathrm{x}$ & $\mathrm{x}$ & $\mathrm{x}$ & $\mathrm{x}$ & $\mathrm{x}$ & $\mathrm{x}$ & $\mathrm{x}$ \\
\hline other.group.1.sen & $\begin{array}{l}\text { Other group } 1 \\
\text { sentiment } \\
\text { towards }\end{array}$ & $\begin{array}{l}\text { Wie empfindest Du } \\
\text { Gruppe } 1 \text { - } \\
\text { positiv/negativ? }\end{array}$ & $\begin{array}{l}1=7 \text {-Punkte Skala, sehr } \\
\text { negativ bis sehr positiv, } 2 \\
=7 \text {-Punkte Skala, sehr } \\
\text { negativ bis sehr positiv, } 3 \\
=7 \text {-Punkte Skala, sehr } \\
\text { negativ bis sehr positiv, } 4 \\
=7 \text {-Punkte Skala, sehr } \\
\text { negativ bis sehr positiv, } 5 \\
=7 \text {-Punkte Skala, sehr } \\
\text { negativ bis sehr positiv, } 6 \\
=7 \text {-Punkte Skala, sehr } \\
\text { negativ bis sehr positiv, } 7 \\
=7 \text {-Punkte Skala, sehr } \\
\text { negativ bis sehr positiv }\end{array}$ & $\begin{array}{l}\text { How do you perceive } \\
\text { group } 1 \text { - } \\
\text { positive/negative? }\end{array}$ & $\begin{array}{l}1=7 \text { item scale, very } \\
\text { negative to very positive, } \\
2=7 \text { item scale, very } \\
\text { negative to very positive, } \\
3=7 \text { item scale, very } \\
\text { negative to very positive, } \\
4=7 \text { item scale, very } \\
\text { negative to very positive, } \\
5=7 \text { item scale, very } \\
\text { negative to very positive, } \\
6=7 \text { item scale, very } \\
\text { negative to very positive, } \\
7=7 \text { item scale, very } \\
\text { negative to very positive }\end{array}$ & $\mathrm{x}$ & $\mathrm{x}$ & $\mathrm{x}$ & $\mathrm{x}$ & $\mathrm{x}$ & $\mathrm{x}$ & $\mathrm{x}$ & $\mathrm{x}$ & $\mathrm{x}$ & $\mathrm{x}$ & $\mathrm{x}$ & $\mathrm{x}$ & $\mathrm{x}$ & $\mathrm{x}$ \\
\hline other.group.1.pop & $\begin{array}{l}\text { Other group 1, } \\
\text { popularity }\end{array}$ & $\begin{array}{l}\text { Wie empfindest Du } \\
\text { Gruppe } 1 \text { - sehr } \\
\text { unbeliebt am [name } \\
\text { removed]/sehr beliebt } \\
\text { am [name removed] }\end{array}$ & $\begin{array}{l}1=7 \text {-Punkte Skala, sehr } \\
\text { unbeliebt bis sehr beliebt, } \\
2=7 \text {-Punkte Skala, sehr } \\
\text { unbeliebt bis sehr beliebt, } \\
3=7 \text {-Punkte Skala, sehr } \\
\text { unbeliebt bis sehr beliebt, } \\
4=7 \text {-Punkte Skala, sehr } \\
\text { unbeliebt bis sehr beliebt, } \\
5=7 \text {-Punkte Skala, sehr } \\
\text { unbeliebt bis sehr beliebt, } \\
6=7 \text {-Punkte Skala, sehr } \\
\text { unbeliebt bis sehr beliebt, } \\
7=7 \text {-Punkte Skala, sehr } \\
\text { unbeliebt bis sehr beliebt }\end{array}$ & $\begin{array}{l}\text { How do you perceive } \\
\text { group } 1 \text { - } \\
\text { popular/unpopular at } \\
\text { [name removed] }\end{array}$ & $\begin{array}{l}1=7 \text { item scale, very } \\
\text { unpopular to very } \\
\text { popular, } 2=7 \text { item scale, } \\
\text { very unpopular to very } \\
\text { popular, } 3=7 \text { item scale, } \\
\text { very unpopular to very } \\
\text { popular, } 4=7 \text { item scale, } \\
\text { very unpopular to very } \\
\text { popular, } 5=7 \text { item scale, } \\
\text { very unpopular to very } \\
\text { popular, } 6=7 \text { item scale, } \\
\text { very unpopular to very } \\
\text { popular, } 7=7 \text { item scale, } \\
\text { very unpopular to very } \\
\text { popular }\end{array}$ & $\mathrm{x}$ & $\mathrm{x}$ & $\mathrm{x}$ & $\mathrm{x}$ & $\mathrm{x}$ & $\mathrm{x}$ & $\mathrm{x}$ & $\mathrm{x}$ & $\mathrm{x}$ & $\mathrm{x}$ & $\mathrm{x}$ & $\mathrm{x}$ & $\mathrm{x}$ & $\mathrm{x}$ \\
\hline other.group.2.no & $\begin{array}{l}\text { Knowledge of } \\
\text { people in other } \\
\text { group } 1\end{array}$ & $\begin{array}{l}\text { Weißt du wie viele } \\
\text { Deiner Mitstudierenden } \\
\text { in etwa zu Gruppe } 2 \\
\text { gehören? }\end{array}$ & $1=\mathrm{Ja}, 2=\mathrm{Nein}$ & $\begin{array}{l}\text { How many people from } \\
\text { your cohort are part of } \\
\text { group 2? }\end{array}$ & $1=$ Yes, $2=$ No & $\mathrm{x}$ & $\mathrm{x}$ & $\mathrm{x}$ & $\mathrm{x}$ & $\mathrm{x}$ & $\mathrm{x}$ & $\mathrm{x}$ & $\mathrm{x}$ & $\mathrm{x}$ & $\mathrm{x}$ & $\mathrm{x}$ & $\mathrm{x}$ & $\mathrm{x}$ & $\mathrm{x}$ \\
\hline other.group.2.no.str & $\begin{array}{l}\text { Number of } \\
\text { people in other } \\
\text { group } 1\end{array}$ & $\begin{array}{l}\text { Wie viele Deiner } \\
\text { Mitstudierenden gehören } \\
\text { in etwa zu Gruppe } 2 ?\end{array}$ & & $\begin{array}{l}\text { How many people from } \\
\text { your cohort are part of } \\
\text { group 2? }\end{array}$ & & $\mathrm{x}$ & $\mathrm{x}$ & $\mathrm{x}$ & $\mathrm{x}$ & $\mathrm{x}$ & $\mathrm{x}$ & $\mathrm{x}$ & $\mathrm{x}$ & $\mathrm{x}$ & $\mathrm{x}$ & $\mathrm{x}$ & $\mathrm{x}$ & $\mathrm{x}$ & $\mathrm{x}$ \\
\hline other.group.2.P1 & $\begin{array}{l}\text { Other group } 2 \text {, } \\
\text { Person } 1\end{array}$ & $\begin{array}{l}\text { Kennst Du jemanden } \\
\text { Deiner Mitstudierenden, } \\
\text { der oder die zu dieser } \\
\text { Gruppe } 2 \text { gehört? Bitte } \\
\text { nenne so viele Personen, } \\
\text { wie Du kannst, aber } \\
\text { nenne nur Personen } \\
\text { welche zur Gruppe } \\
\text { gehören. }\end{array}$ & & $\begin{array}{l}\text { Could you name } \\
\text { students who belong to } \\
\text { group 2? Please name as } \\
\text { many students as you } \\
\text { remember. }\end{array}$ & & $\mathrm{x}$ & $\mathrm{x}$ & $\mathrm{x}$ & $\mathrm{x}$ & $\mathrm{x}$ & $\mathrm{x}$ & $\mathrm{x}$ & $\mathrm{x}$ & $\mathrm{x}$ & $\mathrm{x}$ & $\mathrm{x}$ & $\mathrm{x}$ & $\mathrm{x}$ & $\mathrm{x}$ \\
\hline
\end{tabular}




\begin{tabular}{|c|c|c|c|c|c|c|c|c|c|c|c|c|c|c|c|c|c|c|c|}
\hline VarName & VariableLabel & WordingDE & ValueLabelsDE_Linked & WordingEN & ValueLabelsEN_Linked & L1 & & F L2 & L3 & $\mathrm{L} 4$ & L5 & L6 & L7 & L8 & L9 & L10 & o L11 & $1 \mathrm{~L} 12$ & $2 \mathrm{~L} 13 \mathrm{~L} 14$ \\
\hline other.group.2.activity & $\begin{array}{l}\text { Other group } 2, \\
\text { activity }\end{array}$ & $\begin{array}{l}\text { Was ist Deiner Meinung } \\
\text { nach die hauptsächliche } \\
\text { Tätigkeit, die diese } \\
\text { Gruppe } 2 \text { zusammen } \\
\text { hält (z.B. Sachen, die } \\
\text { Du Gruppenmitglieder } \\
\text { oft zusammen tun } \\
\text { siehst)? }\end{array}$ & $\begin{array}{l}1=\text { Lernen, } 2= \\
\text { Hausaufgaben, } 3= \\
\text { Arbeit, } 4=\text { Sport, } 5= \\
\text { Gespräch, } 6=\text { etwas } \\
\text { trinken gehen (,eis go } \\
\text { zieh“), } 7=\text { gemeinsamer } \\
\text { Weg (z.B. zur } \\
\text { Universität), } 8= \\
\text { Rendezvous, } 9=\text { Andere, } \\
1=\text { Kultur }\end{array}$ & $\begin{array}{l}\text { In your opinion, what is } \\
\text { it that keeps group } 1 \\
\text { together (i.e. things } \\
\text { that you see group } \\
\text { members doing together } \\
\text { often)? (free } \\
\text { translation) }\end{array}$ & $\begin{array}{l}1=\text { Studying,homework, } \\
2=\text { work, } 3=\text { sports, } 4= \\
\text { conversation, } 5=\text { going } \\
\text { for a drink, } 6= \\
\text { commuting, } 7=\text { dating, } 8 \\
=\text { other, } 9=\text { culture (free } \\
\text { translation) }\end{array}$ & $\mathrm{x}$ & $\mathrm{x}$ & $\mathrm{x}$ & $\mathrm{x}$ & $\mathrm{x}$ & $\mathrm{x}$ & $\mathrm{x}$ & $\mathrm{x}$ & $\mathrm{x}$ & $\mathrm{x}$ & $\mathrm{x}$ & $\mathrm{x}$ & $\mathrm{x}$ & $\mathrm{x}$ \\
\hline other.group.2.activity.str & $\begin{array}{l}\text { Other group 2, } \\
\text { activity other }\end{array}$ & $\begin{array}{l}\text { Was ist Deiner Meinung } \\
\text { nach die hauptsächliche } \\
\text { Tätigkeit, die diese } \\
\text { Gruppe } 2 \text { zusammen } \\
\text { hält (z.B. Sachen, die } \\
\text { Du Gruppenmitglieder } \\
\text { oft zusammen tun } \\
\text { siehst)? Andere }\end{array}$ & & & & $\mathrm{x}$ & $\mathrm{x}$ & $\mathrm{x}$ & $\mathrm{x}$ & $\mathrm{x}$ & $\mathrm{x}$ & $\mathrm{x}$ & $\mathrm{x}$ & $\mathrm{x}$ & $\mathrm{x}$ & $\mathrm{x}$ & $\mathrm{x}$ & $\mathrm{x}$ & $\mathrm{X}$ \\
\hline other.group.2.sen & $\begin{array}{l}\text { Other group } 2, \\
\text { sentiment } \\
\text { towards }\end{array}$ & $\begin{array}{l}\text { Wie empfindest Du } \\
\text { Gruppe } 2 \text { - } \\
\text { positiv/negativ? }\end{array}$ & $\begin{array}{l}1=7 \text {-Punkte Skala, sehr } \\
\text { negativ bis sehr positiv, } 2 \\
=7 \text {-Punkte Skala, sehr } \\
\text { negativ bis sehr positiv, } 3 \\
=7 \text {-Punkte Skala, sehr } \\
\text { negativ bis sehr positiv, } 4 \\
=7 \text {-Punkte Skala, sehr } \\
\text { negativ bis sehr positiv, } 5 \\
=7 \text {-Punkte Skala, sehr } \\
\text { negativ bis sehr positiv, } 6 \\
=7 \text {-Punkte Skala, sehr } \\
\text { negativ bis sehr positiv, } 7 \\
=7 \text {-Punkte Skala, sehr } \\
\text { negativ bis sehr positiv }\end{array}$ & $\begin{array}{l}\text { How do you perceive } \\
\text { group } 2- \\
\text { positive/negative? }\end{array}$ & $\begin{array}{l}1=7 \text { item scale, very } \\
\text { negative to very positive, } \\
2=7 \text { item scale, very } \\
\text { negative to very positive, } \\
3=7 \text { item scale, very } \\
\text { negative to very positive, } \\
4=7 \text { item scale, very } \\
\text { negative to very positive, } \\
5=7 \text { item scale, very } \\
\text { negative to very positive, } \\
6=7 \text { item scale, very } \\
\text { negative to very positive, } \\
7=7 \text { item scale, very } \\
\text { negative to very positive }\end{array}$ & $\mathrm{x}$ & $\mathrm{x}$ & $\mathrm{x}$ & $\mathrm{x}$ & $\mathrm{x}$ & $\mathrm{x}$ & $\mathrm{x}$ & $\mathrm{x}$ & $\mathrm{x}$ & $\mathrm{x}$ & $\mathrm{x}$ & $\mathrm{x}$ & $\mathrm{x}$ & $\mathrm{x}$ \\
\hline other.group.2.pop & $\begin{array}{l}\text { Other group } 2, \\
\text { popularity }\end{array}$ & $\begin{array}{l}\text { Wie empfindest Du } \\
\text { Gruppe } 2 \text { - sehr } \\
\text { unbeliebt am [name } \\
\text { removed]/sehr beliebt } \\
\text { am [name removed] }\end{array}$ & $\begin{array}{l}1=7 \text {-Punkte Skala, sehr } \\
\text { unbeliebt bis sehr beliebt, } \\
2=7 \text {-Punkte Skala, sehr } \\
\text { unbeliebt bis sehr beliebt, } \\
3=7 \text {-Punkte Skala, sehr } \\
\text { unbeliebt bis sehr beliebt, } \\
4=7 \text {-Punkte Skala, sehr } \\
\text { unbeliebt bis sehr beliebt, } \\
5=7 \text {-Punkte Skala, sehr } \\
\text { unbeliebt bis sehr beliebt, } \\
6=7 \text {-Punkte Skala, sehr } \\
\text { unbeliebt bis sehr beliebt, } \\
7=7 \text {-Punkte Skala, sehr } \\
\text { unbeliebt bis sehr beliebt }\end{array}$ & $\begin{array}{l}\text { How do you perceive } \\
\text { group } 2- \\
\text { popular/unpopular at } \\
\text { [name removed] }\end{array}$ & $\begin{array}{l}1=7 \text { item scale, very } \\
\text { unpopular to very } \\
\text { popular, } 2=7 \text { item scale, } \\
\text { very unpopular to very } \\
\text { popular, } 3=7 \text { item scale, } \\
\text { very unpopular to very } \\
\text { popular, } 4=7 \text { item scale, } \\
\text { very unpopular to very } \\
\text { popular, } 5=7 \text { item scale, } \\
\text { very unpopular to very } \\
\text { popular, } 6=7 \text { item scale, } \\
\text { very unpopular to very } \\
\text { popular, } 7=7 \text { item scale, } \\
\text { very unpopular to very } \\
\text { popular }\end{array}$ & $\mathrm{x}$ & $\mathrm{x}$ & $\mathrm{x}$ & $\mathrm{x}$ & $\mathrm{x}$ & $\mathrm{x}$ & $\mathrm{x}$ & $\mathrm{x}$ & $\mathrm{x}$ & $\mathrm{x}$ & $\mathrm{x}$ & $\mathrm{x}$ & $\mathrm{x}$ & $\mathrm{x}$ \\
\hline other.group.3.no & $\begin{array}{l}\text { Knowledge of } \\
\text { people in other } \\
\text { group } 2\end{array}$ & $\begin{array}{l}\text { Weißt du wie viele } \\
\text { Deiner Mitstudierenden } \\
\text { in etwa zu Gruppe } 3 \\
\text { gehören? }\end{array}$ & $1=\mathrm{Ja}, 2=$ Nein & $\begin{array}{l}\text { How many people from } \\
\text { your cohort are part of } \\
\text { group 3? }\end{array}$ & $1=\mathrm{Yes}, 2=\mathrm{No}$ & $\mathrm{x}$ & $\mathrm{x}$ & $\mathrm{x}$ & $\mathrm{x}$ & $\mathrm{x}$ & $\mathrm{x}$ & $\mathrm{x}$ & $\mathrm{x}$ & $\mathrm{x}$ & $\mathrm{x}$ & $\mathrm{x}$ & $\mathrm{x}$ & $\mathrm{x}$ & $\mathrm{x}$ \\
\hline other.group.3.no.str & $\begin{array}{l}\text { Number of } \\
\text { people in other } \\
\text { group } 2\end{array}$ & $\begin{array}{l}\text { Wie viele Deiner } \\
\text { Mitstudierenden gehören } \\
\text { in etwa zu Gruppe } 3 \text { ? }\end{array}$ & & $\begin{array}{l}\text { How many people from } \\
\text { your cohort are part of } \\
\text { group 3? }\end{array}$ & & $\mathrm{x}$ & $\mathrm{x}$ & $\mathrm{x}$ & $\mathrm{x}$ & $\mathrm{x}$ & $\mathrm{x}$ & $\mathrm{x}$ & $\mathrm{x}$ & $\mathrm{x}$ & $\mathrm{x}$ & $\mathrm{x}$ & $\mathrm{x}$ & $\mathrm{x}$ & $\mathrm{x}$ \\
\hline other.group.3.P1 & $\begin{array}{l}\text { Other group } 3 \text {, } \\
\text { Person } 1\end{array}$ & $\begin{array}{l}\text { Kennst Du jemanden } \\
\text { Deiner Mitstudierenden, } \\
\text { der oder die zu dieser } \\
\text { Gruppe } 3 \text { gehört? Bitte } \\
\text { nenne so viele Personen, } \\
\text { wie Du kannst, aber } \\
\text { nenne nur Personen } \\
\text { welche zur Gruppe } \\
\text { gehören. }\end{array}$ & & $\begin{array}{l}\text { Could you name } \\
\text { students who belong to } \\
\text { group 3? Please name as } \\
\text { many students as you } \\
\text { remember. }\end{array}$ & & $\mathrm{x}$ & $\mathrm{x}$ & $\mathrm{x}$ & $\mathrm{x}$ & $\mathrm{x}$ & $\mathrm{x}$ & $\mathrm{x}$ & $\mathrm{x}$ & $\mathrm{x}$ & $\mathrm{x}$ & $\mathrm{x}$ & $\mathrm{x}$ & $\mathrm{x}$ & $\mathrm{x}$ \\
\hline
\end{tabular}




\begin{tabular}{|c|c|c|c|c|c|c|c|c|c|c|c|c|c|c|c|c|c|c|c|}
\hline VarName & VariableLabel & WordingDE & ValueLabelsDE_Linked & WordingEN & ValueLabelsEN_Linked & L1 & L11 & $\mathrm{F} \mathrm{L2}$ & L3 & $\mathrm{L} 4$ & L5 & L6 & L7 & L8 & L9 & L10 & o L11 & $1 \mathrm{~L} 12$ & $2 \mathrm{~L} 13 \mathrm{~L} 14$ \\
\hline other.group.3.activity & $\begin{array}{l}\text { Other group } 3 \text {, } \\
\text { activity }\end{array}$ & $\begin{array}{l}\text { Was ist Deiner Meinung } \\
\text { nach die hauptsächliche } \\
\text { Tätigkeit, die diese } \\
\text { Gruppe } 3 \text { zusammen } \\
\text { hält (z.B. Sachen, die } \\
\text { Du Gruppenmitglieder } \\
\text { oft zusammen tun } \\
\text { siehst)? }\end{array}$ & $\begin{array}{l}1=\text { Lernen, } 2= \\
\text { Hausaufgaben, } 3= \\
\text { Arbeit, } 4=\text { Sport, } 5= \\
\text { Gespräch, } 6=\text { etwas } \\
\text { trinken gehen (,eis go } \\
\text { zieh“), } 7=\text { gemeinsamer } \\
\text { Weg (z.B. zur } \\
\text { Universität), } 8= \\
\text { Rendezvous, } 9=\text { Andere, } \\
1=\text { Kultur }\end{array}$ & $\begin{array}{l}\text { In your opinion, what is } \\
\text { it that keeps group } 1 \\
\text { together (i.e. things } \\
\text { that you see group } \\
\text { members doing together } \\
\text { often)? (free } \\
\text { translation) }\end{array}$ & $\begin{array}{l}1=\text { Studying,homework, } \\
2=\text { work, } 3=\text { sports, } 4= \\
\text { conversation, } 5=\text { going } \\
\text { for a drink, } 6= \\
\text { commuting, } 7=\text { dating, } 8 \\
=\text { other, } 9=\text { culture (free } \\
\text { translation) }\end{array}$ & $\mathrm{x}$ & $\mathrm{x}$ & $\mathrm{x}$ & $\mathrm{x}$ & $\mathrm{x}$ & $\mathrm{x}$ & $\mathrm{x}$ & $\mathrm{x}$ & $\mathrm{x}$ & $\mathrm{x}$ & $\mathrm{x}$ & $\mathrm{x}$ & $\mathrm{x}$ & $\mathrm{x}$ \\
\hline other.group.3.activity.str & $\begin{array}{l}\text { Other group } 3, \\
\text { activity other }\end{array}$ & $\begin{array}{l}\text { Was ist Deiner Meinung } \\
\text { nach die hauptsächliche } \\
\text { Tätigkeit, die diese } \\
\text { Gruppe } 3 \text { zusammen } \\
\text { hält (z.B. Sachen, die } \\
\text { Du Gruppenmitglieder } \\
\text { oft zusammen tun } \\
\text { siehst)? Andere }\end{array}$ & & & & $\mathrm{x}$ & $\mathrm{x}$ & $\mathrm{x}$ & $\mathrm{x}$ & $\mathrm{x}$ & $\mathrm{x}$ & $\mathrm{x}$ & $\mathrm{x}$ & $\mathrm{x}$ & $\mathrm{x}$ & $\mathrm{x}$ & $\mathrm{x}$ & $\mathrm{x}$ & $\mathrm{x}$ \\
\hline other.group.3.sen & $\begin{array}{l}\text { Other group } 3 \\
\text { sentiment } \\
\text { towards }\end{array}$ & $\begin{array}{l}\text { Wie empfindest Du } \\
\text { Gruppe } 3 \text { - } \\
\text { positiv/negativ? }\end{array}$ & $\begin{array}{l}1=7 \text {-Punkte Skala, sehr } \\
\text { negativ bis sehr positiv, } 2 \\
=7 \text {-Punkte Skala, sehr } \\
\text { negativ bis sehr positiv, } 3 \\
=7 \text {-Punkte Skala, sehr } \\
\text { negativ bis sehr positiv, } 4 \\
=7 \text {-Punkte Skala, sehr } \\
\text { negativ bis sehr positiv, } 5 \\
=7 \text {-Punkte Skala, sehr } \\
\text { negativ bis sehr positiv, } 6 \\
=7 \text {-Punkte Skala, sehr } \\
\text { negativ bis sehr positiv, } 7 \\
=7 \text {-Punkte Skala, sehr } \\
\text { negativ bis sehr positiv }\end{array}$ & $\begin{array}{l}\text { How do you perceive } \\
\text { group } 3 \text { - } \\
\text { positive/negative? }\end{array}$ & $\begin{array}{l}1=7 \text { item scale, very } \\
\text { negative to very positive, } \\
2=7 \text { item scale, very } \\
\text { negative to very positive, } \\
3=7 \text { item scale, very } \\
\text { negative to very positive, } \\
4=7 \text { item scale, very } \\
\text { negative to very positive, } \\
5=7 \text { item scale, very } \\
\text { negative to very positive, } \\
6=7 \text { item scale, very } \\
\text { negative to very positive, } \\
7=7 \text { item scale, very } \\
\text { negative to very positive }\end{array}$ & $\mathrm{x}$ & $\mathrm{x}$ & $\mathrm{x}$ & $\mathrm{x}$ & $\mathrm{x}$ & $\mathrm{x}$ & $\mathrm{x}$ & $\mathrm{x}$ & $\mathrm{x}$ & $\mathrm{x}$ & $\mathrm{x}$ & $\mathrm{x}$ & $\mathrm{x}$ & $\mathrm{x}$ \\
\hline other.group.3.pop & $\begin{array}{l}\text { Other group } 3, \\
\text { popularity }\end{array}$ & $\begin{array}{l}\text { Wie empfindest Du } \\
\text { Gruppe } 3 \text { - sehr } \\
\text { unbeliebt am [name } \\
\text { removed]/sehr beliebt } \\
\text { am [name removed] }\end{array}$ & $\begin{array}{l}1=7 \text {-Punkte Skala, sehr } \\
\text { unbeliebt bis sehr beliebt, } \\
2=7 \text {-Punkte Skala, sehr } \\
\text { unbeliebt bis sehr beliebt, } \\
3=7 \text {-Punkte Skala, sehr } \\
\text { unbeliebt bis sehr beliebt, } \\
4=7 \text {-Punkte Skala, sehr } \\
\text { unbeliebt bis sehr beliebt, } \\
5=7 \text {-Punkte Skala, sehr } \\
\text { unbeliebt bis sehr beliebt, } \\
6=7 \text {-Punkte Skala, sehr } \\
\text { unbeliebt bis sehr beliebt, } \\
7=7 \text {-Punkte Skala, sehr } \\
\text { unbeliebt bis sehr beliebt }\end{array}$ & $\begin{array}{l}\text { How do you perceive } \\
\text { group } 3 \text { - } \\
\text { popular/unpopular at } \\
\text { [name removed] }\end{array}$ & $\begin{array}{l}1=7 \text { item scale, very } \\
\text { unpopular to very } \\
\text { popular, } 2=7 \text { item scale, } \\
\text { very unpopular to very } \\
\text { popular, } 3=7 \text { item scale, } \\
\text { very unpopular to very } \\
\text { popular, } 4=7 \text { item scale, } \\
\text { very unpopular to very } \\
\text { popular, } 5=7 \text { item scale, } \\
\text { very unpopular to very } \\
\text { popular, } 6=7 \text { item scale, } \\
\text { very unpopular to very } \\
\text { popular, } 7=7 \text { item scale, } \\
\text { very unpopular to very } \\
\text { popular }\end{array}$ & $\mathrm{x}$ & $\mathrm{x}$ & $\mathrm{x}$ & $\mathrm{x}$ & $\mathrm{x}$ & $\mathrm{x}$ & $\mathrm{x}$ & $\mathrm{x}$ & $\mathrm{x}$ & $\mathrm{x}$ & $\mathrm{x}$ & $\mathrm{x}$ & $\mathrm{x}$ & $\mathrm{x}$ \\
\hline other.group.4.no & $\begin{array}{l}\text { Knowledge of } \\
\text { people in other } \\
\text { group } 3\end{array}$ & $\begin{array}{l}\text { Weißt du wie viele } \\
\text { Deiner Mitstudierenden } \\
\text { in etwa zu Gruppe } 4 \\
\text { gehören? }\end{array}$ & $1=\mathrm{Ja}, 2=$ Nein & $\begin{array}{l}\text { How many people from } \\
\text { your cohort are part of } \\
\text { group } 4 \text { ? }\end{array}$ & $1=\mathrm{Yes}, 2=\mathrm{No}$ & $\mathrm{x}$ & $\mathrm{x}$ & $\mathrm{x}$ & $\mathrm{x}$ & $\mathrm{x}$ & $\mathrm{x}$ & $\mathrm{x}$ & $\mathrm{x}$ & $\mathrm{x}$ & $\mathrm{x}$ & $\mathrm{x}$ & $\mathrm{x}$ & $\mathrm{x}$ & $\mathrm{x}$ \\
\hline other.group.4.no.str & $\begin{array}{l}\text { Number of } \\
\text { people in other } \\
\text { group } 3\end{array}$ & $\begin{array}{l}\text { Wie viele Deiner } \\
\text { Mitstudierenden gehören } \\
\text { in etwa zu Gruppe } 4 ?\end{array}$ & & $\begin{array}{l}\text { How many people from } \\
\text { your cohort are part of } \\
\text { group } 4 \text { ? }\end{array}$ & & $\mathrm{x}$ & $\mathrm{x}$ & $\mathrm{x}$ & $\mathrm{x}$ & $\mathrm{x}$ & $\mathrm{x}$ & $\mathrm{x}$ & $\mathrm{x}$ & $\mathrm{x}$ & $\mathrm{x}$ & $\mathrm{x}$ & $\mathrm{x}$ & $\mathrm{x}$ & $\mathrm{x}$ \\
\hline other.group.4.P1 & $\begin{array}{l}\text { Other group } 4 \text {, } \\
\text { Person } 1\end{array}$ & $\begin{array}{l}\text { Kennst Du jemanden } \\
\text { Deiner Mitstudierenden, } \\
\text { der oder die zu dieser } \\
\text { Gruppe } 4 \text { gehört? Bitte } \\
\text { nenne so viele Personen, } \\
\text { wie Du kannst, aber } \\
\text { nenne nur Personen } \\
\text { welche zur Gruppe } \\
\text { gehören. }\end{array}$ & & $\begin{array}{l}\text { Could you name } \\
\text { students who belong to } \\
\text { group } 4 \text { ? Please name as } \\
\text { many students as you } \\
\text { remember. }\end{array}$ & & $\mathrm{x}$ & $\mathrm{x}$ & $\mathrm{x}$ & $\mathrm{x}$ & $\mathrm{x}$ & $\mathrm{x}$ & $\mathrm{x}$ & $\mathrm{x}$ & $\mathrm{x}$ & $\mathrm{x}$ & $\mathrm{x}$ & $\mathrm{x}$ & $\mathrm{x}$ & $\mathrm{x}$ \\
\hline
\end{tabular}




\begin{tabular}{|c|c|c|c|c|c|c|c|c|c|c|c|c|c|c|c|c|c|c|c|}
\hline VarName & VariableLabel & WordingDE & ValueLabelsDE_Linked & WordingEN & ValueLabelsEN_Linked & L1 & & F L2 & L3 & $\mathrm{L} 4$ & L5 & L6 & L7 & L8 & L9 & L10 & 0 L11 & $1 \mathrm{~L} 12$ & $2 \mathrm{~L} 13 \mathrm{~L} 14$ \\
\hline other.group.4.activity & $\begin{array}{l}\text { Other group } 4, \\
\text { activity }\end{array}$ & $\begin{array}{l}\text { Was ist Deiner Meinung } \\
\text { nach die hauptsächliche } \\
\text { Tätigkeit, die diese } \\
\text { Gruppe } 4 \text { zusammen } \\
\text { hält (z.B. Sachen, die } \\
\text { Du Gruppenmitglieder } \\
\text { oft zusammen tun } \\
\text { siehst)? }\end{array}$ & $\begin{array}{l}1=\text { Lernen, } 2= \\
\text { Hausaufgaben, } 3= \\
\text { Arbeit, } 4=\text { Sport, } 5= \\
\text { Gespräch, } 6=\text { etwas } \\
\text { trinken gehen (,eis go } \\
\text { zieh“), } 7=\text { gemeinsamer } \\
\text { Weg (z.B. zur } \\
\text { Universität), } 8= \\
\text { Rendezvous, } 9=\text { Andere, } \\
1=\text { Kultur }\end{array}$ & $\begin{array}{l}\text { In your opinion, what is } \\
\text { it that keeps group } 1 \\
\text { together (i.e. things } \\
\text { that you see group } \\
\text { members doing together } \\
\text { often)? (free } \\
\text { translation) }\end{array}$ & $\begin{array}{l}1=\text { Studying,homework, } \\
2=\text { work, } 3=\text { sports, } 4= \\
\text { conversation, } 5=\text { going } \\
\text { for a drink, } 6= \\
\text { commuting, } 7=\text { dating, } 8 \\
=\text { other, } 9=\text { culture (free } \\
\text { translation) }\end{array}$ & $\mathrm{x}$ & $\mathrm{x}$ & $\mathrm{x}$ & $\mathrm{x}$ & $\mathrm{x}$ & $\mathrm{x}$ & $\mathrm{x}$ & $\mathrm{x}$ & $\mathrm{x}$ & $\mathrm{x}$ & $\mathrm{x}$ & $\mathrm{x}$ & $\mathrm{x}$ & $\mathrm{x}$ \\
\hline other.group.4.activity.str & $\begin{array}{l}\text { Other group } 4, \\
\text { activity other }\end{array}$ & $\begin{array}{l}\text { Was ist Deiner Meinung } \\
\text { nach die hauptsächliche } \\
\text { Tätigkeit, die diese } \\
\text { Gruppe } 4 \text { zusammen } \\
\text { hält (z.B. Sachen, die } \\
\text { Du Gruppenmitglieder } \\
\text { oft zusammen tun } \\
\text { siehst)? Andere }\end{array}$ & & $\begin{array}{l}\text { In your opinion, what is } \\
\text { it that keeps group } 1 \\
\text { together (i.e. things } \\
\text { that you see group } \\
\text { members doing together } \\
\text { often)? Other - specify } \\
\text { (free translation) }\end{array}$ & & $\mathrm{x}$ & $\mathrm{x}$ & $\mathrm{x}$ & $\mathrm{x}$ & $\mathrm{x}$ & $\mathrm{x}$ & $\mathrm{x}$ & $\mathrm{x}$ & $\mathrm{x}$ & $\mathrm{x}$ & $\mathrm{x}$ & $\mathrm{x}$ & $\mathrm{x}$ & $\mathrm{x}$ \\
\hline other.group.4.sen & $\begin{array}{l}\text { Other group } 4, \\
\text { sentiment } \\
\text { towards }\end{array}$ & $\begin{array}{l}\text { Wie empfindest Du } \\
\text { Gruppe } 4 \text { - } \\
\text { positiv/negativ? }\end{array}$ & $\begin{array}{l}1=7 \text {-Punkte Skala, sehr } \\
\text { negativ bis sehr positiv, } 2 \\
=7 \text {-Punkte Skala, sehr } \\
\text { negativ bis sehr positiv, } 3 \\
=7 \text {-Punkte Skala, sehr } \\
\text { negativ bis sehr positiv, } 4 \\
=7 \text {-Punkte Skala, sehr } \\
\text { negativ bis sehr positiv, } 5 \\
=7 \text {-Punkte Skala, sehr } \\
\text { negativ bis sehr positiv, } 6 \\
=7 \text {-Punkte Skala, sehr } \\
\text { negativ bis sehr positiv, } 7 \\
=7 \text {-Punkte Skala, sehr } \\
\text { negativ bis sehr positiv }\end{array}$ & $\begin{array}{l}\text { How do you perceive } \\
\text { group } 4 \text { - } \\
\text { positive/negative? }\end{array}$ & $\begin{array}{l}1=7 \text { item scale, very } \\
\text { negative to very positive, } \\
2=7 \text { item scale, very } \\
\text { negative to very positive, } \\
3=7 \text { item scale, very } \\
\text { negative to very positive, } \\
4=7 \text { item scale, very } \\
\text { negative to very positive, } \\
5=7 \text { item scale, very } \\
\text { negative to very positive, } \\
6=7 \text { item scale, very } \\
\text { negative to very positive, } \\
7=7 \text { item scale, very } \\
\text { negative to very positive }\end{array}$ & $\mathrm{x}$ & $\mathrm{x}$ & $\mathrm{x}$ & $\mathrm{x}$ & $\mathrm{x}$ & $\mathrm{x}$ & $\mathrm{x}$ & $\mathrm{x}$ & $\mathrm{x}$ & $\mathrm{x}$ & $\mathrm{x}$ & $\mathrm{x}$ & $\mathrm{x}$ & $\mathrm{x}$ \\
\hline other.group.4.pop & $\begin{array}{l}\text { Other group } 4, \\
\text { popularity }\end{array}$ & $\begin{array}{l}\text { Wie empfindest Du } \\
\text { Gruppe } 4 \text { - sehr } \\
\text { unbeliebt am [name } \\
\text { removed]/sehr beliebt } \\
\text { am [name removed] }\end{array}$ & $\begin{array}{l}1=7 \text {-Punkte Skala, sehr } \\
\text { unbeliebt bis sehr beliebt, } \\
2=7 \text {-Punkte Skala, sehr } \\
\text { unbeliebt bis sehr beliebt, } \\
3=7 \text {-Punkte Skala, sehr } \\
\text { unbeliebt bis sehr beliebt, } \\
4=7 \text {-Punkte Skala, sehr } \\
\text { unbeliebt bis sehr beliebt, } \\
5=7 \text {-Punkte Skala, sehr } \\
\text { unbeliebt bis sehr beliebt, } \\
6=7 \text {-Punkte Skala, sehr } \\
\text { unbeliebt bis sehr beliebt, } \\
7=7 \text {-Punkte Skala, sehr } \\
\text { unbeliebt bis sehr beliebt }\end{array}$ & $\begin{array}{l}\text { How do you perceive } \\
\text { group } 4- \\
\text { popular/unpopular at } \\
\text { [name removed] }\end{array}$ & $\begin{array}{l}1=7 \text { item scale, very } \\
\text { unpopular to very } \\
\text { popular, } 2=7 \text { item scale, } \\
\text { very unpopular to very } \\
\text { popular, } 3=7 \text { item scale, } \\
\text { very unpopular to very } \\
\text { popular, } 4=7 \text { item scale, } \\
\text { very unpopular to very } \\
\text { popular, } 5=7 \text { item scale, } \\
\text { very unpopular to very } \\
\text { popular, } 6=7 \text { item scale, } \\
\text { very unpopular to very } \\
\text { popular, } 7=7 \text { item scale, } \\
\text { very unpopular to very } \\
\text { popular }\end{array}$ & $\mathrm{x}$ & $\mathrm{x}$ & $\mathrm{x}$ & $\mathrm{x}$ & $\mathrm{x}$ & $\mathrm{x}$ & $\mathrm{x}$ & $\mathrm{x}$ & $\mathrm{x}$ & $\mathrm{x}$ & $\mathrm{X}$ & $\mathrm{x}$ & $\mathrm{x}$ & $\mathrm{x}$ \\
\hline other.group.5.no & $\begin{array}{l}\text { Knowledge of } \\
\text { people in other } \\
\text { group } 3\end{array}$ & $\begin{array}{l}\text { Weißt du wie viele } \\
\text { Deiner Mitstudierenden } \\
\text { in etwa zu Gruppe } 5 \\
\text { gehören? }\end{array}$ & $1=\mathrm{Ja}, 2=$ Nein & $\begin{array}{l}\text { How many people from } \\
\text { your cohort are part of } \\
\text { group 5? }\end{array}$ & $1=\mathrm{Yes}, 2=\mathrm{No}$ & $\mathrm{x}$ & $\mathrm{x}$ & $\mathrm{x}$ & $\mathrm{x}$ & $\mathrm{x}$ & $\mathrm{x}$ & $\mathrm{x}$ & $\mathrm{x}$ & $\mathrm{x}$ & $\mathrm{x}$ & $\mathrm{x}$ & $\mathrm{x}$ & $\mathrm{x}$ & $\mathrm{x}$ \\
\hline other.group.5.no.str & $\begin{array}{l}\text { Number of } \\
\text { people in other } \\
\text { group } 3\end{array}$ & $\begin{array}{l}\text { Wie viele Deiner } \\
\text { Mitstudierenden gehören } \\
\text { in etwa zu Gruppe } 5 \text { ? }\end{array}$ & & $\begin{array}{l}\text { How many people from } \\
\text { your cohort are part of } \\
\text { group 5? }\end{array}$ & & $\mathrm{x}$ & $\mathrm{x}$ & $\mathrm{x}$ & $\mathrm{x}$ & $\mathrm{x}$ & $\mathrm{x}$ & $\mathrm{x}$ & $\mathrm{x}$ & $\mathrm{x}$ & $\mathrm{x}$ & $\mathrm{x}$ & $\mathrm{x}$ & $\mathrm{x}$ & $\mathrm{x}$ \\
\hline other.group.5.P1 & $\begin{array}{l}\text { Other group } 5 \text {, } \\
\text { Person } 1\end{array}$ & $\begin{array}{l}\text { Kennst Du jemanden } \\
\text { Deiner Mitstudierenden, } \\
\text { der oder die zu dieser } \\
\text { Gruppe } 5 \text { gehört? Bitte } \\
\text { nenne so viele Personen, } \\
\text { wie Du kannst, aber } \\
\text { nenne nur Personen } \\
\text { welche zur Gruppe } \\
\text { gehören. }\end{array}$ & & $\begin{array}{l}\text { Could you name } \\
\text { students who belong to } \\
\text { group } 5 \text { ? Please name as } \\
\text { many students as you } \\
\text { remember. }\end{array}$ & & $\mathrm{x}$ & $\mathrm{x}$ & $\mathrm{x}$ & $\mathrm{x}$ & $\mathrm{x}$ & $\mathrm{x}$ & $\mathrm{x}$ & $\mathrm{x}$ & $\mathrm{x}$ & $\mathrm{x}$ & $\mathrm{x}$ & $\mathrm{x}$ & $\mathrm{x}$ & $\mathrm{x}$ \\
\hline
\end{tabular}




\begin{tabular}{|c|c|c|c|c|c|c|c|c|c|c|c|c|c|c|c|c|c|c|c|c|}
\hline VarName & VariableLabel & WordingDE & ValueLabelsDE_Linked & WordingEN & ValueLabelsEN_Linked & L1 & & F L2 & L3 & $\mathrm{L} 4$ & L5 & L6 & L7 & L8 & L9 & L10 & o L11 & $1 \mathrm{~L} 12$ & $2 \mathrm{~L} 13$ & 3 L14 \\
\hline other.group.5.activity & $\begin{array}{l}\text { Other group } 5 \text {, } \\
\text { activity }\end{array}$ & $\begin{array}{l}\text { Was ist Deiner Meinung } \\
\text { nach die hauptsächliche } \\
\text { Tätigkeit, die diese } \\
\text { Gruppe } 5 \text { zusammen } \\
\text { hält (z.B. Sachen, die } \\
\text { Du Gruppenmitglieder } \\
\text { oft zusammen tun } \\
\text { siehst)? }\end{array}$ & $\begin{array}{l}1=\text { Lernen, } 2= \\
\text { Hausaufgaben, } 3= \\
\text { Arbeit, } 4=\text { Sport, } 5= \\
\text { Gespräch, } 6=\text { etwas } \\
\text { trinken gehen (,eis go } \\
\text { zieh“), } 7=\text { gemeinsamer } \\
\text { Weg (z.B. zur } \\
\text { Universität), } 8= \\
\text { Rendezvous, } 9=\text { Andere, } \\
1=\text { Kultur }\end{array}$ & $\begin{array}{l}\text { What is the main } \\
\text { activity that group } 5 \\
\text { does together? } \\
\text { studying/homework; } \\
\text { work; sports; } \\
\text { conversation; going for a } \\
\text { drink, travelling }\end{array}$ & $\begin{array}{l}1=\text { Studying,homework, } \\
2=\text { work, } 3=\text { sports, } 4= \\
\text { conversation, } 5=\text { going } \\
\text { for a drink, } 6= \\
\text { commuting, } 7=\text { dating, } 8 \\
=\text { other, } 9=\text { culture (free } \\
\text { translation) }\end{array}$ & $\mathrm{x}$ & $\mathrm{x}$ & $\mathrm{x}$ & $\mathrm{x}$ & $\mathrm{x}$ & $\mathrm{x}$ & $\mathrm{x}$ & $\mathrm{x}$ & $\mathrm{x}$ & $\mathrm{x}$ & $\mathrm{x}$ & $\mathrm{x}$ & $\mathrm{x}$ & $\mathrm{x}$ & \\
\hline other.group.5.activity.str & $\begin{array}{l}\text { Other group } 5 \text {, } \\
\text { activity other }\end{array}$ & $\begin{array}{l}\text { Was ist Deiner Meinung } \\
\text { nach die hauptsächliche } \\
\text { Tätigkeit, die diese } \\
\text { Gruppe } 5 \text { zusammen } \\
\text { hält (z.B. Sachen, die } \\
\text { Du Gruppenmitglieder } \\
\text { oft zusammen tun } \\
\text { siehst)? Andere }\end{array}$ & & $\begin{array}{l}\text { What is the main } \\
\text { activity that group } 5 \\
\text { does together? other - } \\
\text { specify }\end{array}$ & & $\mathrm{x}$ & $\mathrm{x}$ & $\mathrm{x}$ & $\mathrm{x}$ & $\mathrm{x}$ & $\mathrm{x}$ & $\mathrm{x}$ & $\mathrm{x}$ & $\mathrm{x}$ & $\mathrm{x}$ & $\mathrm{x}$ & $\mathrm{x}$ & $\mathrm{x}$ & $\mathrm{x}$ & \\
\hline other.group.5.sen & $\begin{array}{l}\text { Other group } 5 \text {, } \\
\text { sentiment } \\
\text { towards }\end{array}$ & $\begin{array}{l}\text { Wie empfindest Du } \\
\text { Gruppe } 5 \text { - } \\
\text { positiv/negativ? }\end{array}$ & $\begin{array}{l}1=7 \text {-Punkte Skala, sehr } \\
\text { negativ bis sehr positiv, } 2 \\
=7 \text {-Punkte Skala, sehr } \\
\text { negativ bis sehr positiv, } 3 \\
=7 \text {-Punkte Skala, sehr } \\
\text { negativ bis sehr positiv, } 4 \\
=7 \text {-Punkte Skala, sehr } \\
\text { negativ bis sehr positiv, } 5 \\
=7 \text {-Punkte Skala, sehr } \\
\text { negativ bis sehr positiv, } 6 \\
=7 \text {-Punkte Skala, sehr } \\
\text { negativ bis sehr positiv, } 7 \\
=7 \text {-Punkte Skala, sehr } \\
\text { negativ bis sehr positiv }\end{array}$ & $\begin{array}{l}\text { How do you perceive } \\
\text { group } 5 \text { - } \\
\text { positive/negative? }\end{array}$ & $\begin{array}{l}1=7 \text { item scale, very } \\
\text { negative to very positive, } \\
2=7 \text { item scale, very } \\
\text { negative to very positive, } \\
3=7 \text { item scale, very } \\
\text { negative to very positive, } \\
4=7 \text { item scale, very } \\
\text { negative to very positive, } \\
5=7 \text { item scale, very } \\
\text { negative to very positive, } \\
6=7 \text { item scale, very } \\
\text { negative to very positive, } \\
7=7 \text { item scale, very } \\
\text { negative to very positive }\end{array}$ & $\mathrm{x}$ & $\mathrm{x}$ & $\mathrm{x}$ & $\mathrm{x}$ & $\mathrm{x}$ & $\mathrm{x}$ & $\mathrm{x}$ & $\mathrm{x}$ & $\mathrm{x}$ & $\mathrm{x}$ & $\mathrm{x}$ & $\mathrm{x}$ & $\mathrm{x}$ & $\mathrm{x}$ & \\
\hline other.group.5.pop & $\begin{array}{l}\text { Other group } 5, \\
\text { popularity }\end{array}$ & $\begin{array}{l}\text { Wie empfindest Du } \\
\text { Gruppe } 5 \text { - sehr } \\
\text { unbeliebt am [name } \\
\text { removed]/sehr beliebt } \\
\text { am [name removed] }\end{array}$ & $\begin{array}{l}1=7 \text {-Punkte Skala, sehr } \\
\text { unbeliebt bis sehr beliebt, } \\
2=7 \text {-Punkte Skala, sehr } \\
\text { unbeliebt bis sehr beliebt, } \\
3=7 \text {-Punkte Skala, sehr } \\
\text { unbeliebt bis sehr beliebt, } \\
4=7 \text {-Punkte Skala, sehr } \\
\text { unbeliebt bis sehr beliebt, } \\
5=7 \text {-Punkte Skala, sehr } \\
\text { unbeliebt bis sehr beliebt, } \\
6=7 \text {-Punkte Skala, sehr } \\
\text { unbeliebt bis sehr beliebt, } \\
7=7 \text {-Punkte Skala, sehr } \\
\text { unbeliebt bis sehr beliebt }\end{array}$ & $\begin{array}{l}\text { How do you perceive } \\
\text { group } 5 \text { - } \\
\text { popular/unpopular at } \\
\text { [name removed] }\end{array}$ & $\begin{array}{l}1=7 \text { item scale, very } \\
\text { unpopular to very } \\
\text { popular, } 2=7 \text { item scale, } \\
\text { very unpopular to very } \\
\text { popular, } 3=7 \text { item scale, } \\
\text { very unpopular to very } \\
\text { popular, } 4=7 \text { item scale, } \\
\text { very unpopular to very } \\
\text { popular, } 5=7 \text { item scale, } \\
\text { very unpopular to very } \\
\text { popular, } 6=7 \text { item scale, } \\
\text { very unpopular to very } \\
\text { popular, } 7=7 \text { item scale, } \\
\text { very unpopular to very } \\
\text { popular }\end{array}$ & $\mathrm{x}$ & $\mathrm{x}$ & $\mathrm{x}$ & $\mathrm{x}$ & $\mathrm{x}$ & $\mathrm{x}$ & $\mathrm{x}$ & $\mathrm{x}$ & $\mathrm{x}$ & $\mathrm{x}$ & $\mathrm{x}$ & $\mathrm{x}$ & $\mathrm{x}$ & $\mathrm{x}$ & \\
\hline close.no.all & $\begin{array}{l}\text { Feeling close } \\
\text { to - number of } \\
\text { people in total }\end{array}$ & $\begin{array}{l}\text { Manche Menschen } \\
\text { fühlen sich vielen } \\
\text { Menschen sehr nahe, } \\
\text { andere nur wenigen oder } \\
\text { niemandem. Wie vielen } \\
\text { Menschen (innerhalb } \\
\text { und ausserhalb von } \\
\text { [name removed]) fühlst } \\
\text { Du Dich sehr nahe? }\end{array}$ & & $\begin{array}{l}\text { Some people feel close } \\
\text { to many people, others } \\
\text { only to few or nobody. } \\
\text { How many people } \\
\text { (within and outside } \\
\text { of [name removed]) do } \\
\text { you feel very close to? } \\
\text { (free translation) }\end{array}$ & & $\mathrm{x}$ & & $\mathrm{x}$ & $\mathrm{x}$ & $\mathrm{x}$ & $\mathrm{x}$ & $\mathrm{x}$ & $\mathrm{x}$ & $\mathrm{x}$ & $\mathrm{x}$ & $\mathrm{x}$ & $\mathrm{x}$ & $\mathrm{x}$ & $\mathrm{x}$ & $\mathrm{x}$ \\
\hline close.no.classmates & $\begin{array}{l}\text { Feeling close } \\
\text { to - number of } \\
\text { classmates }\end{array}$ & $\begin{array}{l}\text { Wieviele dieser } \\
\text { Menschen sind } \\
\text { Mitstudierende? }\end{array}$ & & $\begin{array}{l}\text { How many of these } \\
\text { people are fellow } \\
\text { students? (free } \\
\text { translation) }\end{array}$ & & $\mathrm{x}$ & & $\mathrm{x}$ & $\mathrm{x}$ & $\mathrm{x}$ & $\mathrm{x}$ & $\mathrm{x}$ & $\mathrm{x}$ & $\mathrm{x}$ & $\mathrm{x}$ & $\mathrm{x}$ & $\mathrm{x}$ & $\mathrm{x}$ & $\mathrm{x}$ & $\mathrm{x}$ \\
\hline
\end{tabular}




\begin{tabular}{|c|c|c|c|c|c|c|c|c|c|c|c|c|c|c|c|c|c|c|c|}
\hline VarName & VariableLabel & WordingDE & ValueLabelsDE_Linked & WordingEN & ValueLabelsEN_Linked & L1 & L1F L2 & L3 & $\mathrm{L} 4$ & L5 & L6 & L7 & L8 & L9 & L10 & o L11 & $1 \mathrm{~L} 12$ & $2 \mathrm{~L} 13$ & 3 L14 \\
\hline att.degree.classmates & $\begin{array}{l}\text { Attitude of } \\
\text { people towards } \\
\text { degree - } \\
\text { friends among } \\
\text { classmates }\end{array}$ & $\begin{array}{l}\text { Wie ist die Einstellung } \\
\text { von Freunden unter } \\
\text { deinen Mitstudierenden } \\
\text { zu einem } \\
\text { Universitätsabschluss? }\end{array}$ & $\begin{array}{l}1=\text { sehr negativ, } 2= \\
\text { negativ, } 3=\text { eher negativ, } \\
4=\text { neutral, } 5=\text { eher } \\
\text { positiv, } 6=\text { positiv, } 7= \\
\text { sehr positiv, } 8=\text { nicht } \\
\text { zutreffend }\end{array}$ & $\begin{array}{l}\text { What is the attitude } \\
\text { towards a university } \\
\text { degree among your } \\
\text { fellow students? (free } \\
\text { translation) }\end{array}$ & $\begin{array}{l}1=\text { very negative, } 2= \\
\text { negative, } 3=\text { rather } \\
\text { negative, } 4=\text { neutral, } 5= \\
\text { rather positive, } 6= \\
\text { positive, } 7=\text { very } \\
\text { positive, } 8=\text { not } \\
\text { applicable }\end{array}$ & $\mathrm{x}$ & $\mathrm{x}$ & $\mathrm{x}$ & $\mathrm{x}$ & $\mathrm{x}$ & $\mathrm{x}$ & $\mathrm{x}$ & $\mathrm{x}$ & $\mathrm{x}$ & $\mathrm{x}$ & $\mathrm{x}$ & $\mathrm{x}$ & $\mathrm{x}$ & $\mathrm{x}$ \\
\hline att.degree.friends & $\begin{array}{l}\text { Attitude of } \\
\text { people towards } \\
\text { degree - } \\
\text { friends not } \\
\text { among } \\
\text { classmates }\end{array}$ & $\begin{array}{l}\text { Wie ist die Einstellung } \\
\text { von Freunden die nicht } \\
\text { mit dir studieren zu } \\
\text { einem } \\
\text { Universitätsabschluss? }\end{array}$ & $\begin{array}{l}1=\text { sehr negativ, } 2= \\
\text { negativ, } 3=\text { eher negativ, } \\
4=\text { neutral, } 5=\text { eher } \\
\text { positiv, } 6=\text { positiv, } 7= \\
\text { sehr positiv, } 8=\text { nicht } \\
\text { zutreffend }\end{array}$ & $\begin{array}{l}\text { What is the attitude } \\
\text { towards a university } \\
\text { degree among your } \\
\text { friends who do not } \\
\text { study with you? (free } \\
\text { translation) }\end{array}$ & $\begin{array}{l}1=\text { very negative, } 2= \\
\text { negative, } 3=\text { rather } \\
\text { negative, } 4=\text { neutral, } 5= \\
\text { rather positive, } 6= \\
\text { positive, } 7=\text { very } \\
\text { positive, } 8=\text { not } \\
\text { applicable }\end{array}$ & $\mathrm{x}$ & $\mathrm{x}$ & $\mathrm{x}$ & $\mathrm{x}$ & $\mathrm{x}$ & $\mathrm{x}$ & $\mathrm{x}$ & $\mathrm{x}$ & $\mathrm{x}$ & $\mathrm{x}$ & $\mathrm{x}$ & $\mathrm{x}$ & $\mathrm{x}$ & $\mathrm{x}$ \\
\hline att.degree.partner & $\begin{array}{l}\text { Attitude of } \\
\text { people towards } \\
\text { degree - your } \\
\text { partner }\end{array}$ & $\begin{array}{l}\text { Wie ist die Einstellung } \\
\text { von deinem } \\
\text { Partner/deiner } \\
\text { Partnerin zu einem } \\
\text { Universitätsabschluss? }\end{array}$ & $\begin{array}{l}1=\text { sehr negativ, } 2= \\
\text { negativ, } 3=\text { eher negativ, } \\
4=\text { neutral, } 5=\text { eher } \\
\text { positiv, } 6=\text { positiv, } 7= \\
\text { sehr positiv, } 8=\text { nicht } \\
\text { zutreffend }\end{array}$ & $\begin{array}{l}\text { What is the attitude } \\
\text { towards a university } \\
\text { degree of your partner? } \\
\text { (free translation) }\end{array}$ & $\begin{array}{l}1=\text { very negative, } 2= \\
\text { negative, } 3=\text { rather } \\
\text { negative, } 4=\text { neutral, } 5= \\
\text { rather positive, } 6= \\
\text { positive, } 7=\text { very } \\
\text { positive, } 8=\text { not } \\
\text { applicable }\end{array}$ & $\mathrm{x}$ & $\mathrm{x}$ & $\mathrm{x}$ & $\mathrm{x}$ & $\mathrm{x}$ & $\mathrm{x}$ & $\mathrm{x}$ & $\mathrm{x}$ & $\mathrm{x}$ & $\mathrm{x}$ & $\mathrm{x}$ & $\mathrm{x}$ & $\mathrm{x}$ & $\mathrm{x}$ \\
\hline att.degree.family & $\begin{array}{l}\text { Attitude of } \\
\text { people towards } \\
\text { degree - your } \\
\text { family } \\
\text { members }\end{array}$ & $\begin{array}{l}\text { Wie ist die Einstellung } \\
\text { von deinen } \\
\text { Familienmitgliedern zu } \\
\text { einem } \\
\text { Universitätsabschluss? }\end{array}$ & $\begin{array}{l}1=\text { sehr negativ, } 2= \\
\text { negativ, } 3=\text { eher negativ } \\
4=\text { neutral, } 5=\text { eher } \\
\text { positiv, } 6=\text { positiv, } 7= \\
\text { sehr positiv, } 8=\text { nicht } \\
\text { zutreffend }\end{array}$ & $\begin{array}{l}\text { What is the attitude } \\
\text { towards a university } \\
\text { degree among your } \\
\text { family members? (free } \\
\text { translation) }\end{array}$ & $\begin{array}{l}1=\text { very negative, } 2= \\
\text { negative, } 3=\text { rather } \\
\text { negative, } 4=\text { neutral, } 5= \\
\text { rather positive, } 6= \\
\text { positive, } 7=\text { very } \\
\text { positive, } 8=\text { not } \\
\text { applicable }\end{array}$ & $\mathrm{x}$ & $\mathrm{x}$ & $\mathrm{x}$ & $\mathrm{x}$ & $\mathrm{x}$ & $\mathrm{x}$ & $\mathrm{x}$ & $\mathrm{x}$ & $\mathrm{x}$ & $\mathrm{x}$ & $\mathrm{x}$ & $\mathrm{x}$ & $\mathrm{x}$ & $\mathrm{x}$ \\
\hline stress.1 & $\begin{array}{l}\text { Perceived } \\
\text { Stress Scale } \\
\text { (PSS) Item 1 }\end{array}$ & $\begin{array}{l}\text { Wie oft hattest Du Dich } \\
\text { im letzten Monat } \\
\text { darüber aufgeregt, dass } \\
\text { etwas völlig } \\
\text { Unerwartetes } \\
\text { eingetreten ist? }\end{array}$ & $\begin{array}{l}0=\text { nie, } 1=\text { selten, } 2= \\
\text { manchmal, } 3=\text { häufig, } 4 \\
=\text { sehr oft }\end{array}$ & $\begin{array}{l}\text { In the last month, how } \\
\text { often have you been } \\
\text { upset because of } \\
\text { something that } \\
\text { happened unexpectedly? }\end{array}$ & $\begin{array}{l}0=\text { never, } 1=\text { seldom, } 2 \\
=\text { sometimes, } 3=\text { often, } 4 \\
=\text { all the time (free } \\
\text { translation) }\end{array}$ & $\mathrm{x}$ & $\mathrm{x}$ & $\mathrm{x}$ & $\mathrm{x}$ & $\mathrm{x}$ & $\mathrm{x}$ & $\mathrm{x}$ & $\mathrm{x}$ & $\mathrm{x}$ & $\mathrm{X}$ & $\mathrm{x}$ & $\mathrm{x}$ & $\mathrm{X}$ & $\mathrm{x}$ \\
\hline stress.2 & $\begin{array}{l}\text { Perceived } \\
\text { Stress Scale } \\
\text { (PSS) Item } 2\end{array}$ & $\begin{array}{l}\text { Wie oft hattest Du im } \\
\text { letzten Monat das } \\
\text { Gefühl, wichtige Dinge } \\
\text { in Deinem Leben nicht } \\
\text { beeinflussen zu können? }\end{array}$ & $\begin{array}{l}0=\text { nie, } 1=\text { selten, } 2= \\
\text { manchmal, } 3=\text { häufig, } 4 \\
=\text { sehr oft }\end{array}$ & $\begin{array}{l}\text { In the last month, how } \\
\text { often have you felt that } \\
\text { you were unable to } \\
\text { control the important } \\
\text { things in your life? }\end{array}$ & $\begin{array}{l}0=\text { never, } 1=\text { seldom, } 2 \\
=\text { sometimes, } 3=\text { often, } 4 \\
=\text { all the time (free } \\
\text { translation) }\end{array}$ & $\mathrm{x}$ & $\mathrm{x}$ & $\mathrm{x}$ & $\mathrm{x}$ & $\mathrm{x}$ & $\mathrm{x}$ & $\mathrm{x}$ & $\mathrm{x}$ & $\mathrm{x}$ & $\mathrm{x}$ & $\mathrm{x}$ & $\mathrm{x}$ & $\mathrm{X}$ & $\mathrm{x}$ \\
\hline stress. 3 & $\begin{array}{l}\text { Perceived } \\
\text { Stress Scale } \\
\text { (PSS) Item } 3\end{array}$ & $\begin{array}{l}\text { Wie oft hattest Du Dich } \\
\text { im letzten Monat nervös } \\
\text { und „gestresst“ gefühlt? }\end{array}$ & $\begin{array}{l}0=\text { nie, } 1=\text { selten, } 2= \\
\text { manchmal, } 3=\text { häufig, } 4 \\
=\text { sehr oft }\end{array}$ & $\begin{array}{l}\text { In the last month, how } \\
\text { often have you felt } \\
\text { nervous and "stressed"? }\end{array}$ & $\begin{array}{l}0=\text { never, } 1=\text { seldom, } 2 \\
=\text { sometimes, } 3=\text { often, } 4 \\
=\text { all the time (free } \\
\text { translation) }\end{array}$ & $\mathrm{x}$ & $\mathrm{x}$ & $\mathrm{x}$ & $\mathrm{x}$ & $\mathrm{x}$ & $\mathrm{x}$ & $\mathrm{x}$ & $\mathrm{x}$ & $\mathrm{x}$ & $\mathrm{x}$ & $\mathrm{x}$ & $\mathrm{x}$ & $\mathrm{x}$ & $\mathrm{x}$ \\
\hline stress.4 & $\begin{array}{l}\text { Perceived } \\
\text { Stress Scale } \\
\text { (PSS) Item } 4\end{array}$ & $\begin{array}{l}\text { Wie oft hattest Du Dich } \\
\text { im letzten Monat sicher } \\
\text { im Umgang mit } \\
\text { persönlichen Aufgaben } \\
\text { und Problemen gefühlt? }\end{array}$ & $\begin{array}{l}0=\text { nie, } 1=\text { selten, } 2= \\
\text { manchmal, } 3=\text { häufig, } 4 \\
=\text { sehr oft }\end{array}$ & $\begin{array}{l}\text { In the last month, how } \\
\text { often have you felt } \\
\text { confident about your } \\
\text { ability to handle your } \\
\text { personal problems? }\end{array}$ & $\begin{array}{l}0=\text { never, } 1=\text { seldom, } 2 \\
=\text { sometimes, } 3=\text { often, } 4 \\
=\text { all the time (free } \\
\text { translation) }\end{array}$ & $\mathrm{x}$ & $\mathrm{x}$ & $\mathrm{x}$ & $\mathrm{x}$ & $\mathrm{x}$ & $\mathrm{x}$ & $\mathrm{x}$ & $\mathrm{x}$ & $\mathrm{x}$ & $\mathrm{x}$ & $\mathrm{x}$ & $\mathrm{x}$ & $\mathrm{X}$ & $\mathrm{x}$ \\
\hline stress.5 & $\begin{array}{l}\text { Perceived } \\
\text { Stress Scale } \\
\text { (PSS) Item } 5\end{array}$ & $\begin{array}{l}\text { Wie oft hattest Du im } \\
\text { letzten Monat das } \\
\text { Gefühl, dass sich die } \\
\text { Dinge nach Deinen } \\
\text { Vorstellungen } \\
\text { entwickeln? }\end{array}$ & $\begin{array}{l}0=\text { nie, } 1=\text { selten, } 2= \\
\text { manchmal, } 3=\text { häufig, } 4 \\
=\text { sehr oft }\end{array}$ & $\begin{array}{l}\text { In the last month, how } \\
\text { often have you felt that } \\
\text { things were going your } \\
\text { way? }\end{array}$ & $\begin{array}{l}0=\text { never, } 1=\text { seldom, } 2 \\
=\text { sometimes, } 3=\text { often, } 4 \\
=\text { all the time (free } \\
\text { translation) }\end{array}$ & $\mathrm{x}$ & $\mathrm{x}$ & $\mathrm{x}$ & $\mathrm{x}$ & $\mathrm{x}$ & $\mathrm{x}$ & $\mathrm{x}$ & $\mathrm{x}$ & $\mathrm{x}$ & $\mathrm{x}$ & $\mathrm{x}$ & $\mathrm{x}$ & $\mathrm{x}$ & $\mathrm{x}$ \\
\hline stress.6 & $\begin{array}{l}\text { Perceived } \\
\text { Stress Scale } \\
\text { (PSS) Item } 6\end{array}$ & $\begin{array}{l}\text { Wie oft hattest Du im } \\
\text { letzten Monat das } \\
\text { Gefühl, mit all den } \\
\text { anstehenden Aufgaben } \\
\text { und Problemen nicht } \\
\text { richtig umgehen zu } \\
\text { können? }\end{array}$ & $\begin{array}{l}0=\text { nie, } 1=\text { selten, } 2= \\
\text { manchmal, } 3=\text { häufig, } 4 \\
=\text { sehr oft }\end{array}$ & $\begin{array}{l}\text { In the last month, how } \\
\text { often have you found } \\
\text { that you could not cope } \\
\text { with all the things that } \\
\text { you had to do? }\end{array}$ & $\begin{array}{l}0=\text { never, } 1=\text { seldom, } 2 \\
=\text { sometimes, } 3=\text { often, } 4 \\
=\text { all the time (free } \\
\text { translation) }\end{array}$ & $\mathrm{x}$ & $\mathrm{x}$ & $\mathrm{x}$ & $\mathrm{x}$ & $\mathrm{x}$ & $\mathrm{x}$ & $\mathrm{x}$ & $\mathrm{x}$ & $x$ & $x$ & $x$ & $x$ & $\mathrm{X}$ & $\mathrm{x}$ \\
\hline
\end{tabular}




\begin{tabular}{|c|c|c|c|c|c|c|c|c|c|c|c|c|c|c|c|c|c|c|c|}
\hline VarName & VariableLabel & WordingDE & ValueLabelsDE_Linked & WordingEN & ValueLabelsEN_Linked & L1 & L1F L2 & L3 & $\mathrm{L} 4$ & L5 & L6 & L7 & $\mathrm{L} 8$ & L9 & L10 & L11 & $\mathrm{L} 12$ & L13 & 3 L14 \\
\hline stress.7 & $\begin{array}{l}\text { Perceived } \\
\text { Stress Scale } \\
\text { (PSS) Item } 7\end{array}$ & $\begin{array}{l}\text { Wie oft hattest Du im } \\
\text { letzten Monat das } \\
\text { Gefühl, mit Ärger in } \\
\text { Deinem Leben klar zu } \\
\text { kommen? }\end{array}$ & $\begin{array}{l}0=\text { nie, } 1=\text { selten, } 2= \\
\text { manchmal, } 3=\text { häufig, } 4 \\
=\text { sehr oft }\end{array}$ & $\begin{array}{l}\text { In the last month, how } \\
\text { often have you been able } \\
\text { to control irritations in } \\
\text { your life? }\end{array}$ & $\begin{array}{l}0=\text { never, } 1=\text { seldom, } 2 \\
=\text { sometimes, } 3=\text { often, } 4 \\
=\text { all the time (free } \\
\text { translation) }\end{array}$ & $\mathrm{x}$ & $\mathrm{x}$ & $\mathrm{x}$ & $\mathrm{x}$ & $\mathrm{x}$ & $\mathrm{x}$ & $\mathrm{x}$ & $\mathrm{x}$ & $\mathrm{x}$ & $\mathrm{x}$ & $\mathrm{x}$ & $\mathrm{x}$ & $\mathrm{x}$ & $\mathrm{x}$ \\
\hline stress.8 & $\begin{array}{l}\text { Perceived } \\
\text { Stress Scale } \\
\text { (PSS) Item } 8\end{array}$ & $\begin{array}{l}\text { Wie oft hattest Du im } \\
\text { letzten Monat das } \\
\text { Gefühl, alles im Griff zu } \\
\text { haben? }\end{array}$ & $\begin{array}{l}0=\text { nie, } 1=\text { selten, } 2= \\
\text { manchmal, } 3=\text { häufig, } 4 \\
=\text { sehr oft }\end{array}$ & $\begin{array}{l}\text { In the last month, how } \\
\text { often have you felt that } \\
\text { you were on top of } \\
\text { things? }\end{array}$ & $\begin{array}{l}0=\text { never, } 1=\text { seldom, } 2 \\
=\text { sometimes, } 3=\text { often, } 4 \\
=\text { all the time (free } \\
\text { translation) }\end{array}$ & $\mathrm{x}$ & $\mathrm{x}$ & $\mathrm{x}$ & $\mathrm{x}$ & $\mathrm{x}$ & $\mathrm{x}$ & $\mathrm{x}$ & $\mathrm{x}$ & $\mathrm{x}$ & $\mathrm{x}$ & $\mathrm{x}$ & $\mathrm{x}$ & $\mathrm{X}$ & $\mathrm{x}$ \\
\hline stress.9 & $\begin{array}{l}\text { Perceived } \\
\text { Stress Scale } \\
\text { (PSS) Item } 9\end{array}$ & $\begin{array}{l}\text { Wie oft hattest Du Dich } \\
\text { im letzten Monat } \\
\text { darüber geärgert, } \\
\text { wichtige Dinge nicht } \\
\text { beeinflussen zu können? }\end{array}$ & $\begin{array}{l}0=\text { nie, } 1=\text { selten, } 2= \\
\text { manchmal, } 3=\text { häufig, } 4 \\
=\text { sehr oft }\end{array}$ & $\begin{array}{l}\text { In the last month, how } \\
\text { often have you been } \\
\text { angered because of } \\
\text { things that were outside } \\
\text { of your control? }\end{array}$ & $\begin{array}{l}0=\text { never, } 1=\text { seldom, } 2 \\
=\text { sometimes, } 3=\text { often, } 4 \\
=\text { all the time (free } \\
\text { translation) }\end{array}$ & $\mathrm{x}$ & $\mathrm{x}$ & $\mathrm{x}$ & $\mathrm{x}$ & $\mathrm{x}$ & $\mathrm{x}$ & $\mathrm{x}$ & $\mathrm{x}$ & $\mathrm{x}$ & $\mathrm{x}$ & $\mathrm{x}$ & $\mathrm{x}$ & $\mathrm{x}$ & $\mathrm{x}$ \\
\hline stress.10 & $\begin{array}{l}\text { Perceived } \\
\text { Stress Scale } \\
\text { (PSS) Item } 10\end{array}$ & $\begin{array}{l}\text { Wie oft hattest Du im } \\
\text { letzten Monat das } \\
\text { Gefühl, dass sich die } \\
\text { Probleme so aufgestaut } \\
\text { haben, dass Du diese } \\
\text { nicht mehr bewältigen } \\
\text { kannst? }\end{array}$ & $\begin{array}{l}0=\text { nie, } 1=\text { selten, } 2= \\
\text { manchmal, } 3=\text { häufig, } 4 \\
=\text { sehr oft }\end{array}$ & $\begin{array}{l}\text { In the last month, how } \\
\text { often have you felt } \\
\text { difficulties were piling } \\
\text { up so high that you } \\
\text { could not overcome } \\
\text { them? }\end{array}$ & $\begin{array}{l}0=\text { never, } 1=\text { seldom, } 2 \\
=\text { sometimes, } 3=\text { often, } 4 \\
=\text { all the time (free } \\
\text { translation) }\end{array}$ & $\mathrm{x}$ & $\mathrm{x}$ & $\mathrm{x}$ & $\mathrm{x}$ & $\mathrm{x}$ & $\mathrm{x}$ & $\mathrm{x}$ & $\mathrm{x}$ & $\mathrm{x}$ & $\mathrm{x}$ & $\mathrm{x}$ & $\mathrm{x}$ & $\mathrm{x}$ & $\mathrm{x}$ \\
\hline PA.1 & $\begin{array}{l}\text { Affect } \\
\text { (I-PANAS-SF) } \\
\text { Item } 1\end{array}$ & $\begin{array}{l}\text { Bitte gib an, wie Du } \\
\text { Dich im Allgemeinen } \\
\text { fühlst: aktiv }\end{array}$ & $\begin{array}{l}1=\text { gar nicht, } 2=\text { ein } \\
\text { bisschen, } 3= \\
\text { einigermassen, } 4= \\
\text { erheblich, } 5=\text { äusserst }\end{array}$ & $\begin{array}{l}\text { Indicate the extent you } \\
\text { have felt this way over } \\
\text { the past week: active }\end{array}$ & $\begin{array}{l}1=\text { not at all, } 2=\text { a little } \\
\text { bit, } 3=\text { somewhat, } 4= \\
\text { considerably, } 5= \\
\text { extremely (free } \\
\text { translation) }\end{array}$ & $\mathrm{x}$ & $\mathrm{x}$ & $\mathrm{x}$ & $\mathrm{x}$ & $\mathrm{x}$ & $\mathrm{x}$ & $\mathrm{x}$ & $\mathrm{x}$ & $\mathrm{x}$ & $\mathrm{x}$ & $\mathrm{x}$ & $\mathrm{x}$ & $\mathrm{x}$ & \\
\hline NA.1 & $\begin{array}{l}\text { Affect } \\
\text { (I-PANAS-SF) } \\
\text { Item } 2\end{array}$ & $\begin{array}{l}\text { Bitte gib an, wie Du } \\
\text { Dich im Allgemeinen } \\
\text { fühlst: bekümmert }\end{array}$ & $\begin{array}{l}1=\text { gar nicht, } 2=\text { ein } \\
\text { bisschen, } 3= \\
\text { einigermassen, } 4= \\
\text { erheblich, } 5=\text { äusserst }\end{array}$ & $\begin{array}{l}\text { Indicate the extent you } \\
\text { have felt this way over } \\
\text { the past week: } \\
\text { distressed }\end{array}$ & $\begin{array}{l}1=\text { not at all, } 2=\text { a little } \\
\text { bit, } 3=\text { somewhat, } 4= \\
\text { considerably, } 5= \\
\text { extremely (free } \\
\text { translation) }\end{array}$ & $\mathrm{x}$ & $\mathrm{x}$ & $\mathrm{x}$ & $\mathrm{x}$ & $\mathrm{x}$ & $\mathrm{x}$ & $\mathrm{x}$ & $\mathrm{x}$ & $\mathrm{x}$ & $\mathrm{x}$ & $\mathrm{x}$ & $\mathrm{X}$ & $\mathrm{x}$ & \\
\hline PA.2 & $\begin{array}{l}\text { Affect } \\
\text { (I-PANAS-SF) } \\
\text { Item } 3\end{array}$ & $\begin{array}{l}\text { Bitte gib an, wie Du } \\
\text { Dich im Allgemeinen } \\
\text { fühlst: interessiert }\end{array}$ & $\begin{array}{l}1=\text { gar nicht, } 2=\text { ein } \\
\text { bisschen, } 3= \\
\text { einigermassen, } 4= \\
\text { erheblich, } 5=\text { äusserst }\end{array}$ & $\begin{array}{l}\text { Indicate the extent you } \\
\text { have felt this way over } \\
\text { the past week: } \\
\text { interested }\end{array}$ & $\begin{array}{l}1=\text { not at all, } 2=\text { a little } \\
\text { bit, } 3=\text { somewhat, } 4= \\
\text { considerably, } 5= \\
\text { extremely (free } \\
\text { translation) }\end{array}$ & $\mathrm{x}$ & $\mathrm{x}$ & $\mathrm{x}$ & $\mathrm{x}$ & $\mathrm{x}$ & $\mathrm{x}$ & $\mathrm{x}$ & $\mathrm{x}$ & $\mathrm{x}$ & $\mathrm{x}$ & $\mathrm{x}$ & $\mathrm{x}$ & $\mathrm{x}$ & \\
\hline PA.3 & $\begin{array}{l}\text { Affect } \\
\text { (I-PANAS-SF) } \\
\text { Item } 4\end{array}$ & $\begin{array}{l}\text { Bitte gib an, wie Du } \\
\text { Dich im Allgemeinen } \\
\text { fühlst: freudig erregt }\end{array}$ & $\begin{array}{l}1=\text { gar nicht, } 2=\text { ein } \\
\text { bisschen, } 3= \\
\text { einigermassen, } 4= \\
\text { erheblich, } 5=\text { äusserst }\end{array}$ & $\begin{array}{l}\text { Indicate the extent you } \\
\text { have felt this way over } \\
\text { the past week: excited }\end{array}$ & $\begin{array}{l}1=\text { not at all, } 2=\text { a little } \\
\text { bit, } 3=\text { somewhat, } 4= \\
\text { considerably, } 5= \\
\text { extremely (free } \\
\text { translation) }\end{array}$ & $\mathrm{x}$ & $\mathrm{x}$ & $\mathrm{x}$ & $\mathrm{x}$ & $\mathrm{x}$ & $\mathrm{x}$ & $\mathrm{x}$ & $\mathrm{x}$ & $\mathrm{x}$ & $\mathrm{x}$ & $\mathrm{x}$ & $\mathrm{x}$ & $\mathrm{x}$ & \\
\hline NA.2 & $\begin{array}{l}\text { Affect } \\
\text { (I-PANAS-SF) } \\
\text { Item } 5\end{array}$ & $\begin{array}{l}\text { Bitte gib an, wie Du } \\
\text { Dich im Allgemeinen } \\
\text { fühlst: verärgert }\end{array}$ & $\begin{array}{l}1=\text { gar nicht, } 2=\text { ein } \\
\text { bisschen, } 3= \\
\text { einigermassen, } 4= \\
\text { erheblich, } 5=\text { äusserst }\end{array}$ & $\begin{array}{l}\text { Indicate the extent you } \\
\text { have felt this way over } \\
\text { the past week: upset }\end{array}$ & $\begin{array}{l}1=\text { not at all, } 2=\text { a little } \\
\text { bit, } 3=\text { somewhat, } 4= \\
\text { considerably, } 5= \\
\text { extremely (free } \\
\text { translation) }\end{array}$ & $\mathrm{x}$ & $\mathrm{x}$ & $\mathrm{x}$ & $\mathrm{x}$ & $\mathrm{x}$ & $\mathrm{x}$ & $\mathrm{X}$ & $\mathrm{x}$ & $\mathrm{x}$ & $\mathrm{X}$ & $\mathrm{x}$ & $\mathrm{x}$ & $\mathrm{x}$ & \\
\hline PA.4 & $\begin{array}{l}\text { Affect } \\
\text { (I-PANAS-SF) } \\
\text { Item } 6\end{array}$ & $\begin{array}{l}\text { Bitte gib an, wie Du } \\
\text { Dich im Allgemeinen } \\
\text { fühlst: stark }\end{array}$ & $\begin{array}{l}1=\text { gar nicht, } 2=\text { ein } \\
\text { bisschen, } 3= \\
\text { einigermassen }, 4= \\
\text { erheblich, } 5=\text { äusserst }\end{array}$ & $\begin{array}{l}\text { Indicate the extent you } \\
\text { have felt this way over } \\
\text { the past week: strong }\end{array}$ & $\begin{array}{l}1=\text { not at all, } 2=\text { a little } \\
\text { bit, } 3=\text { somewhat, } 4= \\
\text { considerably, } 5= \\
\text { extremely (free } \\
\text { translation) }\end{array}$ & $\mathrm{x}$ & $\mathrm{x}$ & $\mathrm{x}$ & $\mathrm{x}$ & $\mathrm{x}$ & $\mathrm{x}$ & $\mathrm{X}$ & $\mathrm{x}$ & $\mathrm{x}$ & $\mathrm{x}$ & $\mathrm{x}$ & $\mathrm{x}$ & $\mathrm{X}$ & \\
\hline NA.3 & $\begin{array}{l}\text { Affect } \\
\text { (I-PANAS-SF) } \\
\text { Item } 7\end{array}$ & $\begin{array}{l}\text { Bitte gib an, wie Du } \\
\text { Dich im Allgemeinen } \\
\text { fühlst: schuldig }\end{array}$ & $\begin{array}{l}1=\text { gar nicht, } 2=\text { ein } \\
\text { bisschen, } 3= \\
\text { einigermassen, } 4= \\
\text { erheblich, } 5=\text { äusserst }\end{array}$ & $\begin{array}{l}\text { Indicate the extent you } \\
\text { have felt this way over } \\
\text { the past week: guilty }\end{array}$ & $\begin{array}{l}1=\text { not at all, } 2=\text { a little } \\
\text { bit, } 3=\text { somewhat, } 4= \\
\text { considerably, } 5= \\
\text { extremely (free } \\
\text { translation) }\end{array}$ & $\mathrm{x}$ & $\mathrm{x}$ & $\mathrm{x}$ & $\mathrm{x}$ & $\mathrm{x}$ & $\mathrm{X}$ & $\mathrm{X}$ & $\mathrm{X}$ & $\mathrm{x}$ & $\mathrm{X}$ & $\mathrm{x}$ & $\mathrm{X}$ & $\mathrm{X}$ & \\
\hline NA.4 & $\begin{array}{l}\text { Affect } \\
\text { (I-PANAS-SF) } \\
\text { Item } 8\end{array}$ & $\begin{array}{l}\text { Bitte gib an, wie Du } \\
\text { Dich im Allgemeinen } \\
\text { fühlst: erschrocken }\end{array}$ & $\begin{array}{l}1=\text { gar nicht, } 2=\text { ein } \\
\text { bisschen, } 3= \\
\text { einigermassen, } 4= \\
\text { erheblich, } 5=\text { äusserst }\end{array}$ & $\begin{array}{l}\text { Indicate the extent you } \\
\text { have felt this way over } \\
\text { the past week: scared }\end{array}$ & $\begin{array}{l}1=\text { not at all, } 2=\text { a little } \\
\text { bit, } 3=\text { somewhat, } 4= \\
\text { considerably, } 5= \\
\text { extremely (free } \\
\text { translation) }\end{array}$ & $\mathrm{x}$ & $\mathrm{x}$ & $\mathrm{x}$ & $\mathrm{x}$ & $\mathrm{x}$ & $\mathrm{x}$ & $\mathrm{x}$ & $\mathrm{x}$ & $\mathrm{x}$ & $\mathrm{x}$ & $\mathrm{x}$ & $\mathrm{X}$ & $\mathrm{x}$ & \\
\hline
\end{tabular}




\begin{tabular}{|c|c|c|c|c|c|c|c|c|c|c|c|c|c|c|c|c|c|c|}
\hline VarName & VariableLabel & WordingDE & ValueLabelsDE_Linked & WordingEN & ValueLabelsEN_Linked & L1 & L1F L2 & L3 & $\mathrm{L} 4$ & L5 & L6 & L7 & L8 & L9 & L10 & L11 & 1. L12 & $2 \mathrm{~L} 13 \mathrm{~L} 14$ \\
\hline NA.5 & $\begin{array}{l}\text { Affect } \\
\text { (I-PANAS-SF) } \\
\text { Item } 9\end{array}$ & $\begin{array}{l}\text { Bitte gib an, wie Du } \\
\text { Dich im Allgemeinen } \\
\text { fühlst: feindselig }\end{array}$ & $\begin{array}{l}1=\text { gar nicht, } 2=\text { ein } \\
\text { bisschen, } 3= \\
\text { einigermassen, } 4= \\
\text { erheblich, } 5=\text { äusserst }\end{array}$ & $\begin{array}{l}\text { Indicate the extent you } \\
\text { have felt this way over } \\
\text { the past week: hostile }\end{array}$ & $\begin{array}{l}1=\text { not at all, } 2=\text { a little } \\
\text { bit, } 3=\text { somewhat, } 4= \\
\text { considerably, } 5= \\
\text { extremely (free } \\
\text { translation) }\end{array}$ & $\mathrm{x}$ & $\mathrm{x}$ & $\mathrm{x}$ & $\mathrm{x}$ & $\mathrm{x}$ & $\mathrm{x}$ & $\mathrm{x}$ & $\mathrm{x}$ & $\mathrm{x}$ & $\mathrm{x}$ & $\mathrm{x}$ & $\mathrm{x}$ & $\mathrm{x}$ \\
\hline PA.5 & $\begin{array}{l}\text { Affect } \\
\text { (I-PANAS-SF) } \\
\text { Item } 10\end{array}$ & $\begin{array}{l}\text { Bitte gib an, wie Du } \\
\text { Dich im Allgemeinen } \\
\text { fühlst: angeregt }\end{array}$ & $\begin{array}{l}1=\text { gar nicht, } 2=\text { ein } \\
\text { bisschen, } 3= \\
\text { einigermassen, } 4= \\
\text { erheblich, } 5=\text { äusserst }\end{array}$ & $\begin{array}{l}\text { Indicate the extent you } \\
\text { have felt this way over } \\
\text { the past week: } \\
\text { enthusiastic }\end{array}$ & $\begin{array}{l}1=\text { not at all, } 2=\text { a little } \\
\text { bit, } 3=\text { somewhat, } 4= \\
\text { considerably, } 5= \\
\text { extremely (free } \\
\text { translation) }\end{array}$ & $\mathrm{x}$ & $\mathrm{x}$ & $\mathrm{x}$ & $\mathrm{x}$ & $\mathrm{x}$ & $\mathrm{x}$ & $\mathrm{x}$ & $\mathrm{x}$ & $\mathrm{x}$ & $\mathrm{x}$ & $\mathrm{x}$ & $\mathrm{x}$ & $\mathrm{x}$ \\
\hline PA. 6 & $\begin{array}{l}\text { Affect } \\
\text { (I-PANAS-SF) } \\
\text { Item } 11\end{array}$ & $\begin{array}{l}\text { Bitte gib an, wie Du } \\
\text { Dich im Allgemeinen } \\
\text { fühlst: stolz }\end{array}$ & $\begin{array}{l}1=\text { gar nicht, } 2=\text { ein } \\
\text { bisschen, } 3= \\
\text { einigermassen, } 4= \\
\text { erheblich, } 5=\text { äusserst }\end{array}$ & $\begin{array}{l}\text { Indicate the extent you } \\
\text { have felt this way over } \\
\text { the past week: proud }\end{array}$ & $\begin{array}{l}1=\text { not at all, } 2=\text { a little } \\
\text { bit, } 3=\text { somewhat, } 4= \\
\text { considerably, } 5= \\
\text { extremely (free } \\
\text { translation) }\end{array}$ & $\mathrm{x}$ & $\mathrm{x}$ & $\mathrm{x}$ & $\mathrm{x}$ & $\mathrm{x}$ & $\mathrm{x}$ & $\mathrm{x}$ & $\mathrm{x}$ & $\mathrm{x}$ & $\mathrm{x}$ & $\mathrm{x}$ & $\mathrm{x}$ & $\mathrm{x}$ \\
\hline NA. 6 & $\begin{array}{l}\text { Affect } \\
\text { (I-PANAS-SF) } \\
\text { Item } 12\end{array}$ & $\begin{array}{l}\text { Bitte gib an, wie Du } \\
\text { Dich im Allgemeinen } \\
\text { fühlst: gereizt }\end{array}$ & $\begin{array}{l}1=\text { gar nicht, } 2=\text { ein } \\
\text { bisschen, } 3= \\
\text { einigermassen, } 4= \\
\text { erheblich, } 5=\text { äusserst }\end{array}$ & $\begin{array}{l}\text { Indicate the extent you } \\
\text { have felt this way over } \\
\text { the past week: irritable }\end{array}$ & $\begin{array}{l}1=\text { not at all, } 2=\text { a little } \\
\text { bit, } 3=\text { somewhat, } 4= \\
\text { considerably, } 5= \\
\text { extremely (free } \\
\text { translation) }\end{array}$ & $\mathrm{x}$ & $\mathrm{x}$ & $\mathrm{x}$ & $\mathrm{x}$ & $\mathrm{x}$ & $\mathrm{x}$ & $\mathrm{x}$ & $\mathrm{x}$ & $\mathrm{x}$ & $\mathrm{x}$ & $\mathrm{x}$ & $\mathrm{x}$ & $\mathrm{x}$ \\
\hline PA.7 & $\begin{array}{l}\text { Affect } \\
\text { (I-PANAS-SF) } \\
\text { Item } 13\end{array}$ & $\begin{array}{l}\text { Bitte gib an, wie Du } \\
\text { Dich im Allgemeinen } \\
\text { fühlst: begeistert }\end{array}$ & $\begin{array}{l}1=\text { gar nicht, } 2=\text { ein } \\
\text { bisschen, } 3= \\
\text { einigermassen, } 4= \\
\text { erheblich, } 5=\text { äusserst }\end{array}$ & $\begin{array}{l}\text { Indicate the extent you } \\
\text { have felt this way over } \\
\text { the past week: inspired }\end{array}$ & $\begin{array}{l}1=\text { not at all, } 2=\text { a little } \\
\text { bit, } 3=\text { somewhat, } 4= \\
\text { considerably, } 5= \\
\text { extremely (free } \\
\text { translation) }\end{array}$ & $\mathrm{x}$ & $\mathrm{x}$ & $\mathrm{x}$ & $\mathrm{x}$ & $\mathrm{x}$ & $\mathrm{x}$ & $\mathrm{X}$ & $\mathrm{x}$ & $\mathrm{x}$ & $\mathrm{x}$ & $\mathrm{x}$ & $\mathrm{x}$ & $\mathrm{x}$ \\
\hline NA. 7 & $\begin{array}{l}\text { Affect } \\
\text { (I-PANAS-SF) } \\
\text { Item } 14\end{array}$ & $\begin{array}{l}\text { Bitte gib an, wie Du } \\
\text { Dich im Allgemeinen } \\
\text { fühlst: beschämt }\end{array}$ & $\begin{array}{l}1=\text { gar nicht, } 2=\text { ein } \\
\text { bisschen, } 3= \\
\text { einigermassen, } 4= \\
\text { erheblich, } 5=\text { äusserst }\end{array}$ & $\begin{array}{l}\text { Indicate the extent you } \\
\text { have felt this way over } \\
\text { the past week: ashamed }\end{array}$ & $\begin{array}{l}1=\text { not at all, } 2=\text { a little } \\
\text { bit, } 3=\text { somewhat, } 4= \\
\text { considerably, } 5= \\
\text { extremely (free } \\
\text { translation) }\end{array}$ & $\mathrm{x}$ & $\mathrm{x}$ & $\mathrm{x}$ & $\mathrm{x}$ & $\mathrm{X}$ & $\mathrm{X}$ & $\mathrm{X}$ & $\mathrm{x}$ & $\mathrm{x}$ & $\mathrm{X}$ & $\mathrm{x}$ & $\mathrm{x}$ & $\mathrm{x}$ \\
\hline PA. 8 & $\begin{array}{l}\text { Affect } \\
\text { (I-PANAS-SF) } \\
\text { Item } 15\end{array}$ & $\begin{array}{l}\text { Bitte gib an, wie Du } \\
\text { Dich im Allgemeinen } \\
\text { fühlst: wach }\end{array}$ & $\begin{array}{l}1=\text { gar nicht, } 2=\text { ein } \\
\text { bisschen, } 3= \\
\text { einigermassen, } 4= \\
\text { erheblich, } 5=\text { äusserst }\end{array}$ & $\begin{array}{l}\text { Indicate the extent you } \\
\text { have felt this way over } \\
\text { the past week: alert }\end{array}$ & $\begin{array}{l}1=\text { not at all, } 2=\text { a little } \\
\text { bit, } 3=\text { somewhat, } 4= \\
\text { considerably, } 5= \\
\text { extremely (free } \\
\text { translation) }\end{array}$ & $\mathrm{x}$ & $\mathrm{x}$ & $\mathrm{x}$ & $\mathrm{x}$ & $\mathrm{x}$ & $\mathrm{X}$ & $\mathrm{X}$ & $\mathrm{x}$ & $\mathrm{x}$ & $\mathrm{x}$ & $\mathrm{x}$ & $\mathrm{x}$ & $\mathrm{x}$ \\
\hline NA. 8 & $\begin{array}{l}\text { Affect } \\
\text { (I-PANAS-SF) } \\
\text { Item } 16\end{array}$ & $\begin{array}{l}\text { Bitte gib an, wie Du } \\
\text { Dich im Allgemeinen } \\
\text { fühlst: nervös }\end{array}$ & $\begin{array}{l}1=\text { gar nicht, } 2=\text { ein } \\
\text { bisschen, } 3= \\
\text { einigermassen, } 4= \\
\text { erheblich, } 5=\text { äusserst }\end{array}$ & $\begin{array}{l}\text { Indicate the extent you } \\
\text { have felt this way over } \\
\text { the past week: nervous }\end{array}$ & $\begin{array}{l}1=\text { not at all, } 2=\text { a little } \\
\text { bit, } 3=\text { somewhat, } 4= \\
\text { considerably, } 5= \\
\text { extremely (free } \\
\text { translation) }\end{array}$ & $\mathrm{x}$ & $\mathrm{x}$ & $\mathrm{x}$ & $\mathrm{x}$ & $\mathrm{x}$ & $\mathrm{x}$ & $\mathrm{x}$ & $\mathrm{x}$ & $\mathrm{x}$ & $\mathrm{x}$ & $\mathrm{x}$ & $\mathrm{x}$ & $\mathrm{x}$ \\
\hline PA.9 & $\begin{array}{l}\text { Affect } \\
\text { (I-PANAS-SF) } \\
\text { Item } 17\end{array}$ & $\begin{array}{l}\text { Bitte gib an, wie Du } \\
\text { Dich im Allgemeinen } \\
\text { fühlst: entschlossen }\end{array}$ & $\begin{array}{l}1=\text { gar nicht, } 2=\text { ein } \\
\text { bisschen, } 3= \\
\text { einigermassen, } 4= \\
\text { erheblich, } 5=\text { äusserst }\end{array}$ & $\begin{array}{l}\text { Indicate the extent you } \\
\text { have felt this way over } \\
\text { the past week: } \\
\text { determined }\end{array}$ & $\begin{array}{l}1=\text { not at all, } 2=\text { a little } \\
\text { bit, } 3=\text { somewhat, } 4= \\
\text { considerably, } 5= \\
\text { extremely (free } \\
\text { translation) }\end{array}$ & $\mathrm{x}$ & $\mathrm{x}$ & $\mathrm{x}$ & $\mathrm{x}$ & $\mathrm{x}$ & $\mathrm{x}$ & $\mathrm{x}$ & $\mathrm{x}$ & $\mathrm{x}$ & $\mathrm{x}$ & $\mathrm{x}$ & $\mathrm{x}$ & $\mathrm{x}$ \\
\hline PA.10 & $\begin{array}{l}\text { Affect } \\
\text { (I-PANAS-SF) } \\
\text { Item } 18\end{array}$ & $\begin{array}{l}\text { Bitte gib an, wie Du } \\
\text { Dich im Allgemeinen } \\
\text { fühlst: aufmerksam }\end{array}$ & $\begin{array}{l}1=\text { gar nicht, } 2=\text { ein } \\
\text { bisschen, } 3= \\
\text { einigermassen, } 4= \\
\text { erheblich, } 5=\text { äusserst }\end{array}$ & $\begin{array}{l}\text { Indicate the extent you } \\
\text { have felt this way over } \\
\text { the past week: attentive }\end{array}$ & $\begin{array}{l}1=\text { not at all, } 2=\text { a little } \\
\text { bit, } 3=\text { somewhat, } 4= \\
\text { considerably, } 5= \\
\text { extremely (free } \\
\text { translation) }\end{array}$ & $\mathrm{x}$ & $\mathrm{x}$ & $\mathrm{x}$ & $\mathrm{x}$ & $\mathrm{x}$ & $\mathrm{x}$ & $\mathrm{x}$ & $\mathrm{x}$ & $\mathrm{x}$ & $\mathrm{x}$ & $\mathrm{x}$ & $\mathrm{x}$ & $\mathrm{x}$ \\
\hline NA.9 & $\begin{array}{l}\text { Affect } \\
\text { (I-PANAS-SF) } \\
\text { Item } 19\end{array}$ & $\begin{array}{l}\text { Bitte gib an, wie Du } \\
\text { Dich im Allgemeinen } \\
\text { fühlst: durcheinander }\end{array}$ & $\begin{array}{l}1=\text { gar nicht, } 2=\text { ein } \\
\text { bisschen, } 3= \\
\text { einigermassen, } 4= \\
\text { erheblich, } 5=\text { äusserst }\end{array}$ & $\begin{array}{l}\text { Indicate the extent you } \\
\text { have felt this way over } \\
\text { the past week: jittery }\end{array}$ & $\begin{array}{l}1=\text { not at all, } 2=\text { a little } \\
\text { bit, } 3=\text { somewhat, } 4= \\
\text { considerably, } 5= \\
\text { extremely (free } \\
\text { translation) }\end{array}$ & $\mathrm{x}$ & $\mathrm{x}$ & $\mathrm{x}$ & $\mathrm{x}$ & $\mathrm{x}$ & $\mathrm{x}$ & $\mathrm{x}$ & $\mathrm{x}$ & $\mathrm{x}$ & $\mathrm{x}$ & $\mathrm{x}$ & $\mathrm{x}$ & $\mathrm{x}$ \\
\hline NA.10 & $\begin{array}{l}\text { Affect } \\
\text { (I-PANAS-SF) } \\
\text { Item } 20\end{array}$ & $\begin{array}{l}\text { Bitte gib an, wie Du } \\
\text { Dich im Allgemeinen } \\
\text { fühlst: ängstlich }\end{array}$ & $\begin{array}{l}1=\text { gar nicht, } 2=\text { ein } \\
\text { bisschen, } 3= \\
\text { einigermassen, } 4= \\
\text { erheblich, } 5=\text { äusserst }\end{array}$ & $\begin{array}{l}\text { Indicate the extent you } \\
\text { have felt this way over } \\
\text { the past week: afraid }\end{array}$ & $\begin{array}{l}1=\text { not at all, } 2=\text { a little } \\
\text { bit, } 3=\text { somewhat, } 4= \\
\text { considerably, } 5= \\
\text { extremely (free } \\
\text { translation) }\end{array}$ & $\mathrm{x}$ & $\mathrm{x}$ & $\mathrm{x}$ & $\mathrm{x}$ & $\mathrm{x}$ & $\mathrm{x}$ & $\mathrm{x}$ & $\mathrm{x}$ & $\mathrm{x}$ & $\mathrm{x}$ & $\mathrm{x}$ & $\mathrm{x}$ & $\mathrm{x}$ \\
\hline
\end{tabular}




\begin{tabular}{|c|c|c|c|c|c|c|c|c|c|c|c|c|c|c|c|c|c|c|c|c|}
\hline VarName & VariableLabel & WordingDE & ValueLabelsDE_Linked & WordingEN & ValueLabelsEN_Linked & L1 & & $\mathrm{F} \mathrm{L2}$ & L3 & $\mathrm{L} 4$ & L5 & L6 & L7 & L8 & L9 & L10 & L11 & L12 & $\mathrm{L} 13$ & L14 \\
\hline depression.1 & $\begin{array}{l}\text { Depression } \\
\text { Item } 1\end{array}$ & $\begin{array}{l}\text { Während der letzten } \\
\text { Woche haben mich } \\
\text { Dinge beunruhigt, die } \\
\text { mir sonst nichts } \\
\text { ausmachen }\end{array}$ & $\begin{array}{l}0=\text { selten und überhaupt } \\
\text { nicht (weniger als einen } \\
\text { Tag lang), } 1=\text { manchmal } \\
\text { ( ein bis zwei Tage lang), } \\
2=\text { ofters ( drei bis vier } \\
\text { Tage lang), } 3=\text { meistens, } \\
\text { die ganze Zeit ( fünf oder } \\
\text { mehrere Tage lang) }\end{array}$ & $\begin{array}{l}\text { how often you have felt } \\
\text { this way in the past } \\
\text { week: I was bothered by } \\
\text { things that usually } \\
\text { don't bother me }\end{array}$ & $\begin{array}{l}0=\text { seldom and never } \\
\text { (less than a day), } 1= \\
\text { sometimes(one or two } \\
\text { days), } 2=\text { often(three or } \\
\text { four days), } 3=\text { usually, } \\
\text { all the time (five or more } \\
\text { days) (free translation) }\end{array}$ & $\mathrm{x}$ & $\mathrm{x}$ & $\mathrm{x}$ & $\mathrm{x}$ & $\mathrm{x}$ & $\mathrm{x}$ & $\mathrm{x}$ & $\mathrm{x}$ & $\mathrm{x}$ & $\mathrm{x}$ & $\mathrm{x}$ & $\mathrm{x}$ & $\mathrm{x}$ & $\mathrm{x}$ & $\mathrm{x}$ \\
\hline depression.2 & $\begin{array}{l}\text { Depression } \\
\text { Item } 2\end{array}$ & $\begin{array}{l}\text { Während der letzten } \\
\text { Woche hatte ich kaum } \\
\text { Appetit }\end{array}$ & $\begin{array}{l}0=\text { selten und überhaupt } \\
\text { nicht (weniger als einen } \\
\text { Tag lang), } 1=\text { manchmal } \\
\text { ( ein bis zwei Tage lang), } \\
2=\text { öfters ( drei bis vier } \\
\text { Tage lang), } 3 \text { = meistens, } \\
\text { die ganze Zeit ( fünf oder } \\
\text { mehrere Tage lang) }\end{array}$ & $\begin{array}{l}\text { how often you have felt } \\
\text { this way in the past } \\
\text { week: My appetite was } \\
\text { poor }\end{array}$ & $\begin{array}{l}0=\text { seldom and never } \\
\text { (less than a day), } 1= \\
\text { sometimes(one or two } \\
\text { days), } 2=\text { often(three or } \\
\text { four days), } 3=\text { usually, } \\
\text { all the time (five or more } \\
\text { days) (free translation) }\end{array}$ & $\mathrm{x}$ & $\mathrm{x}$ & $\mathrm{x}$ & $\mathrm{x}$ & $\mathrm{x}$ & $\mathrm{x}$ & $\mathrm{x}$ & $\mathrm{x}$ & $\mathrm{x}$ & $\mathrm{x}$ & $\mathrm{x}$ & $\mathrm{x}$ & $\mathrm{x}$ & $\mathrm{x}$ & $\mathrm{x}$ \\
\hline depression.3 & $\begin{array}{l}\text { Depression } \\
\text { Item } 3\end{array}$ & $\begin{array}{l}\text { Während der letzten } \\
\text { Woche konnte ich meine } \\
\text { trübsinnige Laune nicht } \\
\text { loswerden, obwohl mich } \\
\text { meine Freunde/Familie } \\
\text { versuchten, } \\
\text { aufzumuntern }\end{array}$ & $\begin{array}{l}0=\text { selten und überhaupt } \\
\text { nicht (weniger als einen } \\
\text { Tag lang), } 1=\text { manchmal } \\
\text { ( ein bis zwei Tage lang), } \\
2=\text { ofters ( drei bis vier } \\
\text { Tage lang), } 3=\text { meistens, } \\
\text { die ganze Zeit ( fünf oder } \\
\text { mehrere Tage lang) }\end{array}$ & $\begin{array}{l}\text { how often you have felt } \\
\text { this way in the past } \\
\text { week: I felt that I could } \\
\text { not shake off the blues } \\
\text { even with help from my } \\
\text { family or friends }\end{array}$ & $\begin{array}{l}0=\text { seldom and never } \\
\text { (less than a day), } 1= \\
\text { sometimes(one or two } \\
\text { days), } 2=\text { often(three or } \\
\text { four days), } 3=\text { usually, } \\
\text { all the time (five or more } \\
\text { days) (free translation) }\end{array}$ & $\mathrm{x}$ & $\mathrm{x}$ & $\mathrm{x}$ & $\mathrm{x}$ & $\mathrm{x}$ & $\mathrm{x}$ & $\mathrm{x}$ & $\mathrm{x}$ & $\mathrm{x}$ & $\mathrm{x}$ & $\mathrm{x}$ & $\mathrm{x}$ & $\mathrm{x}$ & $\mathrm{x}$ & $\mathrm{x}$ \\
\hline depression.4 & $\begin{array}{l}\text { Depression } \\
\text { Item } 4\end{array}$ & $\begin{array}{l}\text { Während der letzten } \\
\text { Woche kam ich mir } \\
\text { genauso gut vor wie } \\
\text { andere }\end{array}$ & $\begin{array}{l}0=\text { selten und überhaupt } \\
\text { nicht (weniger als einen } \\
\text { Tag lang), } 1=\text { manchmal } \\
\text { ( ein bis zwei Tage lang), } \\
2=\text { öfters ( drei bis vier } \\
\text { Tage lang), } 3=\text { meistens, } \\
\text { die ganze Zeit ( fünf oder } \\
\text { mehrere Tage lang) }\end{array}$ & $\begin{array}{l}\text { how often you have felt } \\
\text { this way in the past } \\
\text { week: I felt that I was } \\
\text { just as good as other } \\
\text { people }\end{array}$ & $\begin{array}{l}0=\text { seldom and never } \\
\text { (less than a day), } 1= \\
\text { sometimes(one or two } \\
\text { days), } 2=\text { often(three or } \\
\text { four days), } 3=\text { usually, } \\
\text { all the time (five or more } \\
\text { days) (free translation) }\end{array}$ & $\mathrm{x}$ & $\mathrm{x}$ & $\mathrm{x}$ & $\mathrm{x}$ & $\mathrm{x}$ & $\mathrm{x}$ & $\mathrm{x}$ & $\mathrm{x}$ & $\mathrm{x}$ & $\mathrm{x}$ & $\mathrm{x}$ & $\mathrm{x}$ & $\mathrm{x}$ & $\mathrm{x}$ & $\mathrm{x}$ \\
\hline depression.5 & $\begin{array}{l}\text { Depression } \\
\text { Item } 5\end{array}$ & $\begin{array}{l}\text { Während der letzten } \\
\text { Woche hatte ich Mühe, } \\
\text { mich zu konzentrieren }\end{array}$ & $\begin{array}{l}0=\text { selten und überhaupt } \\
\text { nicht (weniger als einen } \\
\text { Tag lang), } 1=\text { manchmal } \\
\text { ( ein bis zwei Tage lang), } \\
2=\text { öfters ( drei bis vier } \\
\text { Tage lang), } 3=\text { meistens, } \\
\text { die ganze Zeit ( fünf oder } \\
\text { mehrere Tage lang) }\end{array}$ & $\begin{array}{l}\text { how often you have felt } \\
\text { this way in the past } \\
\text { week: I had trouble } \\
\text { keeping my mind on } \\
\text { what I was doing }\end{array}$ & $\begin{array}{l}0=\text { seldom and never } \\
\text { (less than a day), } 1= \\
\text { sometimes(one or two } \\
\text { days), } 2=\text { often(three or } \\
\text { four days), } 3=\text { usually, } \\
\text { all the time (five or more } \\
\text { days) (free translation) }\end{array}$ & $\mathrm{x}$ & $\mathrm{x}$ & $\mathrm{x}$ & $\mathrm{x}$ & $\mathrm{x}$ & $\mathrm{x}$ & $\mathrm{x}$ & $\mathrm{x}$ & $\mathrm{x}$ & $\mathrm{x}$ & $\mathrm{x}$ & $\mathrm{x}$ & $\mathrm{x}$ & $\mathrm{x}$ & $\mathrm{x}$ \\
\hline depression.6 & $\begin{array}{l}\text { Depression } \\
\text { Item } 6\end{array}$ & $\begin{array}{l}\text { Während der letzten } \\
\text { Woche war ich deprim- } \\
\text { iert/niedergeschlagen }\end{array}$ & $\begin{array}{l}0=\text { selten und überhaupt } \\
\text { nicht (weniger als einen } \\
\text { Tag lang), } 1=\text { manchmal } \\
\text { ( ein bis zwei Tage lang), } \\
2=\text { öfters ( drei bis vier } \\
\text { Tage lang), } 3=\text { meistens, } \\
\text { die ganze Zeit ( fünf oder } \\
\text { mehrere Tage lang) }\end{array}$ & $\begin{array}{l}\text { how often you have felt } \\
\text { this way in the past } \\
\text { week: I felt depressed }\end{array}$ & $\begin{array}{l}0=\text { seldom and never } \\
\text { (less than a day), } 1= \\
\text { sometimes(one or two } \\
\text { days), } 2=\text { often(three or } \\
\text { four days), } 3=\text { usually, } \\
\text { all the time (five or more } \\
\text { days) (free translation) }\end{array}$ & $\mathrm{x}$ & $\mathrm{x}$ & $\mathrm{x}$ & $\mathrm{x}$ & $\mathrm{x}$ & $\mathrm{x}$ & $\mathrm{x}$ & $\mathrm{x}$ & $\mathrm{x}$ & $\mathrm{x}$ & $\mathrm{x}$ & $\mathrm{x}$ & $\mathrm{x}$ & $\mathrm{x}$ & $\mathrm{x}$ \\
\hline depression.7 & $\begin{array}{l}\text { Depression } \\
\text { Item } 7\end{array}$ & $\begin{array}{l}\text { Während der letzten } \\
\text { Woche war alles } \\
\text { anstrengend für mich }\end{array}$ & $\begin{array}{l}0=\text { selten und überhaupt } \\
\text { nicht (weniger als einen } \\
\text { Tag lang), } 1=\text { manchmal } \\
\text { ( ein bis zwei Tage lang), } \\
2=\text { öfters ( drei bis vier } \\
\text { Tage lang), } 3=\text { meistens, } \\
\text { die ganze Zeit ( fünf oder } \\
\text { mehrere Tage lang) }\end{array}$ & $\begin{array}{l}\text { how often you have felt } \\
\text { this way in the past } \\
\text { week: I felt that } \\
\text { everything I did was an } \\
\text { effort }\end{array}$ & $\begin{array}{l}0=\text { seldom and never } \\
\text { (less than a day), } 1= \\
\text { sometimes(one or two } \\
\text { days), } 2=\text { often(three or } \\
\text { four days), } 3=\text { usually, } \\
\text { all the time (five or more } \\
\text { days) (free translation) }\end{array}$ & $\mathrm{x}$ & $\mathrm{x}$ & $\mathrm{x}$ & $\mathrm{x}$ & $\mathrm{x}$ & $\mathrm{x}$ & $\mathrm{x}$ & $\mathrm{x}$ & $\mathrm{x}$ & $\mathrm{x}$ & $\mathrm{x}$ & $\mathrm{x}$ & $\mathrm{x}$ & $\mathrm{X}$ & $\mathrm{X}$ \\
\hline
\end{tabular}




\begin{tabular}{|c|c|c|c|c|c|c|c|c|c|c|c|c|c|c|c|c|c|c|c|c|}
\hline VarName & VariableLabel & WordingDE & ValueLabelsDE_Linked & WordingEN & ValueLabelsEN_Linked & L1 & & F L2 & L3 & $\mathrm{L} 4$ & L5 & L6 & L7 & L8 & L9 & L10 & o L11 & $1 \mathrm{~L} 12$ & $2 \mathrm{~L} 13$ & 3 L14 \\
\hline depression. 8 & $\begin{array}{l}\text { Depression } \\
\text { Item } 8\end{array}$ & $\begin{array}{l}\text { Während der letzten } \\
\text { Woche dachte ich voller } \\
\text { Hoffnung an die Zukunft }\end{array}$ & $\begin{array}{l}0=\text { selten und überhaupt } \\
\text { nicht (weniger als einen } \\
\text { Tag lang), } 1=\text { manchmal } \\
\text { ( ein bis zwei Tage lang), } \\
2=\text { öfters ( drei bis vier } \\
\text { Tage lang), } 3=\text { meistens, } \\
\text { die ganze Zeit ( fünf oder } \\
\text { mehrere Tage lang) }\end{array}$ & $\begin{array}{l}\text { how often you have felt } \\
\text { this way in the past } \\
\text { week: I felt hopeful } \\
\text { about the future }\end{array}$ & $\begin{array}{l}0=\text { seldom and never } \\
\text { (less than a day), } 1= \\
\text { sometimes(one or two } \\
\text { days), } 2=\text { often(three or } \\
\text { four days), } 3=\text { usually, } \\
\text { all the time (five or more } \\
\text { days) (free translation) }\end{array}$ & $\mathrm{x}$ & $\mathrm{x}$ & $\mathrm{x}$ & $\mathrm{x}$ & $\mathrm{x}$ & $\mathrm{x}$ & $\mathrm{x}$ & $\mathrm{X}$ & $\mathrm{x}$ & $\mathrm{x}$ & $\mathrm{x}$ & $\mathrm{x}$ & $\mathrm{x}$ & $\mathrm{x}$ & $\mathrm{x}$ \\
\hline depression.9 & $\begin{array}{l}\text { Depression } \\
\text { Item } 9\end{array}$ & $\begin{array}{l}\text { Während der letzten } \\
\text { Woche dachte ich, mein } \\
\text { Leben ist ein einziger } \\
\text { Fehlschlag }\end{array}$ & $\begin{array}{l}0=\text { selten und überhaupt } \\
\text { nicht (weniger als einen } \\
\text { Tag lang), } 1=\text { manchmal } \\
\text { ( ein bis zwei Tage lang), } \\
2=\text { öfters ( drei bis vier } \\
\text { Tage lang), } 3=\text { meistens, } \\
\text { die ganze Zeit ( fünf oder } \\
\text { mehrere Tage lang) }\end{array}$ & $\begin{array}{l}\text { how often you have felt } \\
\text { this way in the past } \\
\text { week: I thought my life } \\
\text { had been a failure }\end{array}$ & $\begin{array}{l}0=\text { seldom and never } \\
\text { (less than a day), } 1= \\
\text { sometimes(one or two } \\
\text { days), } 2=\text { often(three or } \\
\text { four days), } 3=\text { usually, } \\
\text { all the time (five or more } \\
\text { days) (free translation) }\end{array}$ & $\mathrm{x}$ & $\mathrm{x}$ & $\mathrm{x}$ & $\mathrm{x}$ & $\mathrm{x}$ & $\mathrm{x}$ & $\mathrm{x}$ & $\mathrm{x}$ & $\mathrm{x}$ & $\mathrm{x}$ & $\mathrm{x}$ & $\mathrm{x}$ & $\mathrm{x}$ & $\mathrm{x}$ & $\mathrm{x}$ \\
\hline depression.10 & $\begin{array}{l}\text { Depression } \\
\text { Item } 10\end{array}$ & $\begin{array}{l}\text { Während der letzten } \\
\text { Woche hatte ich Angst }\end{array}$ & $\begin{array}{l}0=\text { selten und überhaupt } \\
\text { nicht (weniger als einen } \\
\text { Tag lang), } 1=\text { manchmal } \\
\text { ( ein bis zwei Tage lang), } \\
2=\text { öfters ( drei bis vier } \\
\text { Tage lang), } 3=\text { meistens, } \\
\text { die ganze Zeit ( fünf oder } \\
\text { mehrere Tage lang) }\end{array}$ & $\begin{array}{l}\text { how often you have felt } \\
\text { this way in the past } \\
\text { week: I felt fearful }\end{array}$ & $\begin{array}{l}0=\text { seldom and never } \\
\text { (less than a day), } 1= \\
\text { sometimes(one or two } \\
\text { days), } 2=\text { often(three or } \\
\text { four days), } 3=\text { usually, } \\
\text { all the time (five or more } \\
\text { days) (free translation) }\end{array}$ & $\mathrm{x}$ & $\mathrm{x}$ & $\mathrm{x}$ & $\mathrm{x}$ & $\mathrm{x}$ & $\mathrm{x}$ & $\mathrm{x}$ & $\mathrm{x}$ & $\mathrm{x}$ & $\mathrm{x}$ & $\mathrm{x}$ & $\mathrm{x}$ & $\mathrm{x}$ & $\mathrm{x}$ & $\mathrm{x}$ \\
\hline depression.11 & $\begin{array}{l}\text { Depression } \\
\text { Item } 11\end{array}$ & $\begin{array}{l}\text { Während der letzten } \\
\text { Woche habe ich schlecht } \\
\text { geschlafen }\end{array}$ & $\begin{array}{l}0=\text { selten und überhaupt } \\
\text { nicht (weniger als einen } \\
\text { Tag lang), } 1=\text { manchmal } \\
\text { ( ein bis zwei Tage lang), } \\
2=\text { öfters (drei bis vier } \\
\text { Tage lang), } 3=\text { meistens, } \\
\text { die ganze Zeit ( fünf oder } \\
\text { mehrere Tage lang) }\end{array}$ & $\begin{array}{l}\text { how often you have felt } \\
\text { this way in the past } \\
\text { week: My sleep was } \\
\text { restless }\end{array}$ & $\begin{array}{l}0=\text { seldom and never } \\
\text { (less than a day), } 1= \\
\text { sometimes(one or two } \\
\text { days), } 2=\text { often(three or } \\
\text { four days), } 3=\text { usually, } \\
\text { all the time (five or more } \\
\text { days) (free translation) }\end{array}$ & $\mathrm{x}$ & $\mathrm{x}$ & $\mathrm{x}$ & $\mathrm{x}$ & $\mathrm{x}$ & $\mathrm{x}$ & $\mathrm{x}$ & $\mathrm{x}$ & $\mathrm{x}$ & $\mathrm{x}$ & $\mathrm{x}$ & $\mathrm{x}$ & $\mathrm{x}$ & $\mathrm{x}$ & $\mathrm{x}$ \\
\hline depression.12 & $\begin{array}{l}\text { Depression } \\
\text { Item } 12\end{array}$ & $\begin{array}{l}\text { Während der letzten } \\
\text { Woche war ich fröhlich } \\
\text { gestimmt }\end{array}$ & $\begin{array}{l}0=\text { selten und überhaupt } \\
\text { nicht (weniger als einen } \\
\text { Tag lang), } 1=\text { manchmal } \\
\text { ( ein bis zwei Tage lang), } \\
2=\text { öfters ( drei bis vier } \\
\text { Tage lang), } 3 \text { = meistens, } \\
\text { die ganze Zeit ( fünf oder } \\
\text { mehrere Tage lang) }\end{array}$ & $\begin{array}{l}\text { how often you have felt } \\
\text { this way in the past } \\
\text { week: I was happy }\end{array}$ & $\begin{array}{l}0=\text { seldom and never } \\
\text { (less than a day), } 1= \\
\text { sometimes(one or two } \\
\text { days), } 2=\text { often(three or } \\
\text { four days), } 3=\text { usually, } \\
\text { all the time (five or more } \\
\text { days) (free translation) }\end{array}$ & $\mathrm{x}$ & $\mathrm{x}$ & $\mathrm{x}$ & $\mathrm{x}$ & $\mathrm{x}$ & $\mathrm{x}$ & $\mathrm{x}$ & $\mathrm{x}$ & $\mathrm{x}$ & $\mathrm{x}$ & $\mathrm{x}$ & $\mathrm{x}$ & $\mathrm{x}$ & $\mathrm{x}$ & $\mathrm{x}$ \\
\hline depression.13 & $\begin{array}{l}\text { Depression } \\
\text { Item } 13\end{array}$ & $\begin{array}{l}\text { Während der letzten } \\
\text { Woche habe ich weniger } \\
\text { als sonst geredet }\end{array}$ & $\begin{array}{l}0=\text { selten und überhaupt } \\
\text { nicht (weniger als einen } \\
\text { Tag lang), } 1=\text { manchmal } \\
\text { ( ein bis zwei Tage lang), } \\
2=\text { öfters ( drei bis vier } \\
\text { Tage lang), } 3=\text { meistens, } \\
\text { die ganze Zeit ( fünf oder } \\
\text { mehrere Tage lang) }\end{array}$ & $\begin{array}{l}\text { how often you have felt } \\
\text { this way in the past } \\
\text { week: I talked less than } \\
\text { usual }\end{array}$ & $\begin{array}{l}0=\text { seldom and never } \\
\text { (less than a day), } 1= \\
\text { sometimes(one or two } \\
\text { days), } 2=\text { often(three or } \\
\text { four days), } 3=\text { usually, } \\
\text { all the time (five or more } \\
\text { days) (free translation) }\end{array}$ & $\mathrm{x}$ & $\mathrm{x}$ & $\mathrm{x}$ & $\mathrm{x}$ & $\mathrm{x}$ & $\mathrm{x}$ & $\mathrm{x}$ & $\mathrm{x}$ & $\mathrm{x}$ & $\mathrm{x}$ & $\mathrm{x}$ & $\mathrm{x}$ & $\mathrm{x}$ & $\mathrm{x}$ & $\mathrm{x}$ \\
\hline depression.14 & $\begin{array}{l}\text { Depression } \\
\text { Item } 14\end{array}$ & $\begin{array}{l}\text { Während der letzten } \\
\text { Woche fühlte ich mich } \\
\text { einsam }\end{array}$ & $\begin{array}{l}0=\text { selten und überhaupt } \\
\text { nicht (weniger als einen } \\
\text { Tag lang), } 1=\text { manchmal } \\
\text { ( ein bis zwei Tage lang), } \\
2=\text { öfters ( drei bis vier } \\
\text { Tage lang), } 3=\text { meistens, } \\
\text { die ganze Zeit ( fünf oder } \\
\text { mehrere Tage lang) }\end{array}$ & $\begin{array}{l}\text { how often you have felt } \\
\text { this way in the past } \\
\text { week: I felt lonely }\end{array}$ & $\begin{array}{l}0=\text { seldom and never } \\
\text { (less than a day), } 1= \\
\text { sometimes(one or two } \\
\text { days), } 2=\text { often(three or } \\
\text { four days), } 3=\text { usually, } \\
\text { all the time (five or more } \\
\text { days) (free translation) }\end{array}$ & $\mathrm{x}$ & $\mathrm{x}$ & $\mathrm{x}$ & $\mathrm{x}$ & $\mathrm{x}$ & $\mathrm{x}$ & $\mathrm{x}$ & $\mathrm{x}$ & $\mathrm{x}$ & $\mathrm{x}$ & $\mathrm{x}$ & $\mathrm{x}$ & $\mathrm{x}$ & $\mathrm{x}$ & $\mathrm{x}$ \\
\hline
\end{tabular}




\begin{tabular}{|c|c|c|c|c|c|c|c|c|c|c|c|c|c|c|c|c|c|c|c|c|}
\hline VarName & VariableLabel & WordingDE & ValueLabelsDE_Linked & WordingEN & ValueLabelsEN_Linked & $\mathrm{L} 1$ & L1F & F L2 & L3 & L4 & L5 & L6 & L7 & L8 & L9 & L1C & 5 L11 & $1 \mathrm{~L} 12$ & $2 \mathrm{~L} 13$ & 3 L14 \\
\hline depression. 15 & $\begin{array}{l}\text { Depression } \\
\text { Item } 15\end{array}$ & $\begin{array}{l}\text { Während der letzten } \\
\text { Woche waren die Leute } \\
\text { unfreundlich zu mir }\end{array}$ & $\begin{array}{l}0=\text { selten und überhaupt } \\
\text { nicht (weniger als einen } \\
\text { Tag lang), } 1=\text { manchmal } \\
\text { ( ein bis zwei Tage lang), } \\
2=\text { öfters ( drei bis vier } \\
\text { Tage lang), } 3=\text { meistens, } \\
\text { die ganze Zeit ( fünf oder } \\
\text { mehrere Tage lang) }\end{array}$ & $\begin{array}{l}\text { how often you have felt } \\
\text { this way in the past } \\
\text { week: People were } \\
\text { unfriendly }\end{array}$ & $\begin{array}{l}0=\text { seldom and never } \\
\text { (less than a day), } 1= \\
\text { sometimes(one or two } \\
\text { days), } 2=\text { often(three or } \\
\text { four days), } 3=\text { usually, } \\
\text { all the time (five or more } \\
\text { days) (free translation) }\end{array}$ & $\mathrm{x}$ & $\mathrm{x}$ & $\mathrm{x}$ & $\mathrm{x}$ & $\mathrm{x}$ & $\mathrm{x}$ & $\mathrm{x}$ & $\mathrm{x}$ & $\mathrm{x}$ & $\mathrm{x}$ & $\mathrm{x}$ & $\mathrm{x}$ & $\mathrm{x}$ & $\mathrm{x}$ & $\mathrm{x}$ \\
\hline depression.16 & $\begin{array}{l}\text { Depression } \\
\text { Item } 16\end{array}$ & $\begin{array}{l}\text { Während der letzten } \\
\text { Woche habe ich das } \\
\text { Leben genossen }\end{array}$ & $\begin{array}{l}0=\text { selten und überhaupt } \\
\text { nicht }(\text { weniger als einen } \\
\text { Tag lang), } 1=\text { manchmal } \\
\text { ( ein bis zwei Tage lang), } \\
2=\text { öfters ( drei bis vier } \\
\text { Tage lang), } 3=\text { meistens, } \\
\text { die ganze Zeit ( fünf oder } \\
\text { mehrere Tage lang) }\end{array}$ & $\begin{array}{l}\text { how often you have felt } \\
\text { this way in the past } \\
\text { week: I enjoyed life }\end{array}$ & $\begin{array}{l}0=\text { seldom and never } \\
\text { (less than a day), } 1= \\
\text { sometimes(one or two } \\
\text { days), } 2=\text { often(three or } \\
\text { four days), } 3=\text { usually, } \\
\text { all the time (five or more } \\
\text { days) (free translation) }\end{array}$ & $\mathrm{x}$ & $\mathrm{x}$ & $\mathrm{x}$ & $\mathrm{x}$ & $\mathrm{x}$ & $\mathrm{x}$ & $\mathrm{x}$ & $\mathrm{x}$ & $\mathrm{x}$ & $\mathrm{x}$ & $\mathrm{x}$ & $\mathrm{x}$ & $\mathrm{x}$ & $\mathrm{x}$ & $\mathrm{x}$ \\
\hline depression.17 & $\begin{array}{l}\text { Depression } \\
\text { Item } 17\end{array}$ & $\begin{array}{l}\text { Während der letzten } \\
\text { Woche musste ich } \\
\text { weinen }\end{array}$ & $\begin{array}{l}0=\text { selten und überhaupt } \\
\text { nicht (weniger als einen } \\
\text { Tag lang), } 1=\text { manchmal } \\
\text { ( ein bis zwei Tage lang), } \\
2=\text { öfters ( drei bis vier } \\
\text { Tage lang), } 3=\text { meistens, } \\
\text { die ganze Zeit ( fünf oder } \\
\text { mehrere Tage lang) }\end{array}$ & $\begin{array}{l}\text { how often you have felt } \\
\text { this way in the past } \\
\text { week: I had crying spells }\end{array}$ & $\begin{array}{l}0=\text { seldom and never } \\
\text { (less than a day), } 1= \\
\text { sometimes(one or two } \\
\text { days), } 2=\text { often(three or } \\
\text { four days), } 3=\text { usually, } \\
\text { all the time (five or more } \\
\text { days) (free translation) }\end{array}$ & $\mathrm{x}$ & $\mathrm{x}$ & $\mathrm{x}$ & $\mathrm{x}$ & $\mathrm{x}$ & $\mathrm{x}$ & $\mathrm{x}$ & $\mathrm{x}$ & $\mathrm{x}$ & $\mathrm{x}$ & $\mathrm{x}$ & $\mathrm{x}$ & $\mathrm{x}$ & $\mathrm{x}$ & $\mathrm{x}$ \\
\hline depression.18 & $\begin{array}{l}\text { Depression } \\
\text { Item } 18\end{array}$ & $\begin{array}{l}\text { Während der letzten } \\
\text { Woche war ich traurig }\end{array}$ & $\begin{array}{l}0=\text { selten und überhaupt } \\
\text { nicht (weniger als einen } \\
\text { Tag lang), } 1=\text { manchmal } \\
\text { ( ein bis zwei Tage lang), } \\
2=\text { öfters ( drei bis vier } \\
\text { Tage lang), } 3=\text { meistens, } \\
\text { die ganze Zeit ( fünf oder } \\
\text { mehrere Tage lang) }\end{array}$ & $\begin{array}{l}\text { how often you have felt } \\
\text { this way in the past } \\
\text { week: I felt sad }\end{array}$ & $\begin{array}{l}0=\text { seldom and never } \\
\text { (less than a day), } 1= \\
\text { sometimes(one or two } \\
\text { days) }, 2=\text { often(three or } \\
\text { four days) } 3=\text { usually, } \\
\text { all the time (five or more } \\
\text { days) (free translation) }\end{array}$ & $\mathrm{x}$ & $\mathrm{x}$ & $\mathrm{x}$ & $\mathrm{x}$ & $\mathrm{x}$ & $\mathrm{x}$ & $\mathrm{x}$ & $\mathrm{x}$ & $\mathrm{x}$ & $\mathrm{x}$ & $\mathrm{x}$ & $\mathrm{x}$ & $\mathrm{x}$ & $\mathrm{x}$ & $\mathrm{x}$ \\
\hline depression.19 & $\begin{array}{l}\text { Depression } \\
\text { Item } 19\end{array}$ & $\begin{array}{l}\text { Während der letzten } \\
\text { Woche hatte ich das } \\
\text { Gefühl, dass mich die } \\
\text { Leute nicht leiden } \\
\text { können }\end{array}$ & $\begin{array}{l}0=\text { selten und überhaupt } \\
\text { nicht (weniger als einen } \\
\text { Tag lang), } 1=\text { manchmal } \\
\text { ( ein bis zwei Tage lang), } \\
2=\text { ofters ( drei bis vier } \\
\text { Tage lang), } 3=\text { meistens, } \\
\text { die ganze Zeit ( fünf oder } \\
\text { mehrere Tage lang) }\end{array}$ & $\begin{array}{l}\text { how often you have felt } \\
\text { this way in the past } \\
\text { week: I felt that people } \\
\text { disliked me }\end{array}$ & $\begin{array}{l}0=\text { seldom and never } \\
\text { (less than a day), } 1= \\
\text { sometimes(one or two } \\
\text { days), } 2=\text { often(three or } \\
\text { four days), } 3=\text { usually, } \\
\text { all the time (five or more } \\
\text { days) (free translation) }\end{array}$ & $\mathrm{x}$ & $\mathrm{x}$ & $\mathrm{x}$ & $\mathrm{x}$ & $\mathrm{x}$ & $\mathrm{x}$ & $\mathrm{x}$ & $\mathrm{x}$ & $\mathrm{x}$ & $\mathrm{x}$ & $\mathrm{x}$ & $\mathrm{x}$ & $\mathrm{x}$ & $\mathrm{x}$ & $\mathrm{x}$ \\
\hline depression.20 & $\begin{array}{l}\text { Depression } \\
\text { Item } 20\end{array}$ & $\begin{array}{l}\text { Während der letzten } \\
\text { Woche konnte ich mich } \\
\text { zu nichts aufraffen }\end{array}$ & $\begin{array}{l}0=\text { selten und überhaupt } \\
\text { nicht (weniger als einen } \\
\text { Tag lang), } 1=\text { manchmal } \\
\text { ( ein bis zwei Tage lang), } \\
2=\text { öfters ( drei bis vier } \\
\text { Tage lang), } 3=\text { meistens, } \\
\text { die ganze Zeit ( fünf oder } \\
\text { mehrere Tage lang) }\end{array}$ & $\begin{array}{l}\text { how often you have felt } \\
\text { this way in the past } \\
\text { week: I could not get } \\
\text { "going" }\end{array}$ & $\begin{array}{l}0=\text { seldom and never } \\
\text { (less than a day), } 1= \\
\text { sometimes(one or two } \\
\text { days), } 2=\text { often(three or } \\
\text { four days), } 3=\text { usually, } \\
\text { all the time (five or more } \\
\text { days) (free translation) }\end{array}$ & $\mathrm{x}$ & $\mathrm{x}$ & $\mathrm{x}$ & $\mathrm{x}$ & $\mathrm{x}$ & $\mathrm{x}$ & $\mathrm{x}$ & $\mathrm{x}$ & $\mathrm{x}$ & $\mathrm{x}$ & $\mathrm{x}$ & $\mathrm{x}$ & $\mathrm{x}$ & $\mathrm{x}$ & $\mathrm{x}$ \\
\hline anxiety. 1 & Anxiety Item 1 & $\begin{array}{l}\text { Wie oft fühltest Du Dich } \\
\text { im Verlauf der letzten } \\
2 \text { Wochen durch die } \\
\text { folgenden Beschwerden } \\
\text { beeinträchtigt? } \\
\text { Nervosität, } \\
\text { Ängstlichkeit oder } \\
\text { Anspannung }\end{array}$ & $\begin{array}{l}0=\text { Überhaupt nicht, } 1= \\
\text { An einzelnen Tagen, } 2= \\
\text { An mehr als der Hälfte } \\
\text { der Tage, } 3=\text { Beinahe } \\
\text { jeden Tag }\end{array}$ & $\begin{array}{l}\text { Over the last } 2 \text { weeks, } \\
\text { how often have you been } \\
\text { bothered by the } \\
\text { following problems? } \\
\text { Feeling nervous, } \\
\text { anxious, or on edge }\end{array}$ & $\begin{array}{l}0=\text { Not at all, } 1=\text { on } \\
\text { single days, } 2=\text { on more } \\
\text { than half of the days, } 3= \\
\text { almost every day (free } \\
\text { translation) }\end{array}$ & $\mathrm{x}$ & & $\mathrm{x}$ & $\mathrm{x}$ & $\mathrm{x}$ & $\mathrm{x}$ & $\mathrm{x}$ & $\mathrm{x}$ & $\mathrm{x}$ & $\mathrm{x}$ & $\mathrm{x}$ & $\mathrm{x}$ & $\mathrm{x}$ & $\mathrm{x}$ & $\mathrm{x}$ \\
\hline anxiety. 2 & Anxiety Item 2 & $\begin{array}{l}\text { Wie oft fühltest Du Dich } \\
\text { im Verlauf der letzten } \\
2 \text { Wochen durch die } \\
\text { folgenden Beschwerden } \\
\text { beeinträchtigt? Nicht in } \\
\text { der Lage sein, Sorgen zu } \\
\text { stoppen oder zu } \\
\text { kontrollieren }\end{array}$ & $\begin{array}{l}0=\text { Überhaupt nicht, } 1= \\
\text { An einzelnen Tagen, } 2= \\
\text { An mehr als der Hälfte } \\
\text { der Tage, } 3=\text { Beinahe } \\
\text { jeden Tag }\end{array}$ & $\begin{array}{l}\text { Over the last } 2 \text { weeks, } \\
\text { how often have you been } \\
\text { bothered by the } \\
\text { following problems? Not } \\
\text { being able to stop or } \\
\text { control worrying }\end{array}$ & $\begin{array}{l}0=\text { Not at all, } 1=\text { on } \\
\text { single days, } 2=\text { on more } \\
\text { than half of the days, } 3= \\
\text { almost every day (free } \\
\text { translation) }\end{array}$ & $\mathrm{x}$ & & $\mathrm{x}$ & $\mathrm{x}$ & $\mathrm{x}$ & $\mathrm{x}$ & $\mathrm{x}$ & $\mathrm{x}$ & $\mathrm{x}$ & $\mathrm{x}$ & $\mathrm{x}$ & $\mathrm{x}$ & $\mathrm{x}$ & $\mathrm{x}$ & $\mathrm{x}$ \\
\hline
\end{tabular}




\begin{tabular}{|c|c|c|c|c|c|c|c|c|c|c|c|c|c|c|c|c|c|c|c|}
\hline VarName & VariableLabel & WordingDE & ValueLabelsDE_Linked & WordingEN & ValueLabelsEN_Linked & L1 & L1F L2 & L3 & $\mathrm{L} 4$ & L5 & L6 & L7 & L8 & L9 & L1C & o L11 & $1 \mathrm{~L} 12$ & $2 \mathrm{~L} 13$ & 3 L14 \\
\hline anxiety. 3 & Anxiety Item 3 & $\begin{array}{l}\text { Wie oft fühltest Du Dich } \\
\text { im Verlauf der letzten } \\
2 \text { Wochen durch die } \\
\text { folgenden Beschwerden } \\
\text { beeinträchtigt? } \\
\text { Übermässige Sorgen } \\
\text { bezüglich verschiedener } \\
\text { Angelegenheiten }\end{array}$ & $\begin{array}{l}0=\text { Überhaupt nicht, } 1= \\
\text { An einzelnen Tagen, } 2= \\
\text { An mehr als der Hälfte } \\
\text { der Tage, } 3=\text { Beinahe } \\
\text { jeden Tag }\end{array}$ & $\begin{array}{l}\text { Over the last } 2 \text { weeks, } \\
\text { how often have you been } \\
\text { bothered by the } \\
\text { following problems? } \\
\text { Worrying too much } \\
\text { about different things }\end{array}$ & $\begin{array}{l}0=\text { Not at all, } 1=\text { on } \\
\text { single days, } 2=\text { on more } \\
\text { than half of the days, } 3= \\
\text { almost every day (free } \\
\text { translation) }\end{array}$ & $\mathrm{x}$ & $\mathrm{x}$ & $\mathrm{x}$ & $\mathrm{x}$ & $\mathrm{x}$ & $\mathrm{x}$ & $\mathrm{x}$ & $\mathrm{x}$ & $\mathrm{x}$ & $\mathrm{x}$ & $\mathrm{x}$ & $\mathrm{x}$ & $\mathrm{X}$ & $\mathrm{x}$ \\
\hline anxiety. 4 & Anxiety Item 4 & $\begin{array}{l}\text { Wie oft fühltest Du Dich } \\
\text { im Verlauf der letzten } \\
2 \text { Wochen durch die } \\
\text { folgenden Beschwerden } \\
\text { beeinträchtigt? } \\
\text { Schwierigkeiten zu } \\
\text { entspannen }\end{array}$ & $\begin{array}{l}0=\text { Überhaupt nicht, } 1= \\
\text { An einzelnen Tagen, } 2= \\
\text { An mehr als der Hälfte } \\
\text { der Tage, } 3=\text { Beinahe } \\
\text { jeden Tag }\end{array}$ & $\begin{array}{l}\text { Over the last } 2 \text { weeks, } \\
\text { how often have you been } \\
\text { bothered by the } \\
\text { following problems? } \\
\text { Trouble relaxing }\end{array}$ & $\begin{array}{l}0=\text { Not at all, } 1=\text { on } \\
\text { single days, } 2=\text { on more } \\
\text { than half of the days, } 3= \\
\text { almost every day (free } \\
\text { translation) }\end{array}$ & $\mathrm{x}$ & $\mathrm{x}$ & $\mathrm{x}$ & $\mathrm{x}$ & $\mathrm{x}$ & $\mathrm{x}$ & $\mathrm{x}$ & $\mathrm{x}$ & $\mathrm{x}$ & $\mathrm{x}$ & $\mathrm{x}$ & $\mathrm{x}$ & $\mathrm{x}$ & $\mathrm{x}$ \\
\hline anxiety.5 & Anxiety Item 5 & $\begin{array}{l}\text { Wie oft fühltest Du Dich } \\
\text { im Verlauf der letzten } \\
2 \text { Wochen durch die } \\
\text { folgenden Beschwerden } \\
\text { beeinträchtigt? } \\
\text { Rastlosigkeit, so dass } \\
\text { Stillsitzen schwer fällt }\end{array}$ & $\begin{array}{l}0=\text { Überhaupt nicht, } 1= \\
\text { An einzelnen Tagen, } 2= \\
\text { An mehr als der Hälfte } \\
\text { der Tage, } 3=\text { Beinahe } \\
\text { jeden Tag }\end{array}$ & $\begin{array}{l}\text { Over the last } 2 \text { weeks, } \\
\text { how often have you been } \\
\text { bothered by the } \\
\text { following problems? } \\
\text { Being so restless that } \\
\text { it's hard to sit still }\end{array}$ & $\begin{array}{l}0=\text { Not at all, } 1=\text { on } \\
\text { single days, } 2=\text { on more } \\
\text { than half of the days, } 3= \\
\text { almost every day (free } \\
\text { translation) }\end{array}$ & $\mathrm{x}$ & $\mathrm{x}$ & $\mathrm{x}$ & $\mathrm{x}$ & $\mathrm{x}$ & $\mathrm{x}$ & $\mathrm{x}$ & $\mathrm{x}$ & $\mathrm{x}$ & $\mathrm{x}$ & $\mathrm{x}$ & $\mathrm{x}$ & $\mathrm{x}$ & $\mathrm{x}$ \\
\hline anxiety. 6 & Anxiety Item 6 & $\begin{array}{l}\text { Wie oft fühltest Du Dich } \\
\text { im Verlauf der letzten } \\
2 \text { Wochen durch die } \\
\text { folgenden Beschwerden } \\
\text { beeinträchtigt? Schnelle } \\
\text { Verärgerung oder } \\
\text { Gereiztheit }\end{array}$ & $\begin{array}{l}0=\text { Überhaupt nicht, } 1= \\
\text { An einzelnen Tagen, } 2= \\
\text { An mehr als der Hälfte } \\
\text { der Tage, } 3=\text { Beinahe } \\
\text { jeden Tag }\end{array}$ & $\begin{array}{l}\text { Over the last } 2 \text { weeks, } \\
\text { how often have you been } \\
\text { bothered by the } \\
\text { following problems? } \\
\text { Becoming easily } \\
\text { annoyed or irritable }\end{array}$ & $\begin{array}{l}0=\text { Not at all, } 1=\text { on } \\
\text { single days, } 2=\text { on more } \\
\text { than half of the days, } 3= \\
\text { almost every day (free } \\
\text { translation) }\end{array}$ & $\mathrm{x}$ & $\mathrm{x}$ & $\mathrm{x}$ & $\mathrm{x}$ & $\mathrm{x}$ & $\mathrm{x}$ & $\mathrm{x}$ & $\mathrm{x}$ & $\mathrm{x}$ & $\mathrm{x}$ & $\mathrm{x}$ & $\mathrm{x}$ & $\mathrm{x}$ & $\mathrm{x}$ \\
\hline anxiety. 7 & Anxiety Item 7 & $\begin{array}{l}\text { Wie oft fühltest Du Dich } \\
\text { im Verlauf der letzten } \\
2 \text { Wochen durch die } \\
\text { folgenden Beschwerden } \\
\text { beeinträchtigt? Gefühl } \\
\text { der Angst, so als würde } \\
\text { etwas Schlimmes } \\
\text { passieren }\end{array}$ & $\begin{array}{l}0=\text { Überhaupt nicht, } 1= \\
\text { An einzelnen Tagen, } 2= \\
\text { An mehr als der Hälfte } \\
\text { der Tage, } 3=\text { Beinahe } \\
\text { jeden Tag }\end{array}$ & $\begin{array}{l}\text { Over the last } 2 \text { weeks, } \\
\text { how often have you been } \\
\text { bothered by the } \\
\text { following problems? } \\
\text { Feeling afraid as if } \\
\text { something awful might } \\
\text { happen }\end{array}$ & $\begin{array}{l}0=\text { Not at all, } 1=\text { on } \\
\text { single days, } 2=\text { on more } \\
\text { than half of the days, } 3= \\
\text { almost every day (free } \\
\text { translation) }\end{array}$ & $\mathrm{x}$ & $\mathrm{x}$ & $\mathrm{x}$ & $\mathrm{x}$ & $\mathrm{x}$ & $\mathrm{x}$ & $\mathrm{x}$ & $\mathrm{x}$ & $\mathrm{x}$ & $\mathrm{x}$ & $\mathrm{x}$ & $\mathrm{x}$ & $\mathrm{x}$ & $\mathrm{x}$ \\
\hline depr.diagnosis & $\begin{array}{l}\text { Depression } \\
\text { diagnosed in } \\
\text { the past }\end{array}$ & $\begin{array}{l}\text { Hattest Du schon mal } \\
\text { eine Depression oder } \\
\text { Angststörung (Selbst- } \\
\text { oder Fremddiagnose)? }\end{array}$ & $1=\mathrm{Ja}, 2=$ Nein & $\begin{array}{l}\text { Have you ever had a } \\
\text { depression (self- or } \\
\text { other-diagnosed)? (free } \\
\text { translation) }\end{array}$ & $1=\mathrm{NA}, 2=\mathrm{NA}$ & $\mathrm{x}$ & & & & & & & & & & & & & \\
\hline psych.treatment & $\begin{array}{l}\text { Current/past } \\
\text { psychological } \\
\text { treatment }\end{array}$ & $\begin{array}{l}\text { Bist Du momentan oder } \\
\text { warst Du jemals in } \\
\text { psychologischer } \\
\text { Behandlung? }\end{array}$ & $\begin{array}{l}1=\mathrm{Ja}, \text { ich war bereits in } \\
\text { psychologischer } \\
\text { Behandlung, } 2=\mathrm{Ja} \text {, ich } \\
\text { bin momentan in } \\
\text { psychologischer } \\
\text { Behandlung, } 3=\text { Nein }\end{array}$ & $\begin{array}{l}\text { Are you currently or } \\
\text { have you ever been in } \\
\text { psychological treatment? }\end{array}$ & $\begin{array}{l}1=\text { Yes, I have been in } \\
\text { treatment }, 2=\text { Yes, I am } \\
\text { currently in treatment, } 3 \\
=\text { No }\end{array}$ & & $\mathrm{x}$ & & $\mathrm{x}$ & $\mathrm{x}$ & $\mathrm{x}$ & $\mathrm{x}$ & $\mathrm{x}$ & $\mathrm{x}$ & $\mathrm{x}$ & $\mathrm{x}$ & $\mathrm{x}$ & $\mathrm{x}$ & $\mathrm{x}$ \\
\hline reassurance.1 & $\begin{array}{l}\text { Reassurance } \\
\text { Item } 1\end{array}$ & $\begin{array}{l}\text { Bitte gib an, inwieweit } \\
\text { die folgenden Aussagen } \\
\text { auf Dich zutreffen (im } \\
\text { Allgemeinen, nicht auf } \\
\text { eine konkrete Situation } \\
\text { oder Person bezogen). } \\
\text { Ich ertappe mich öfter } \\
\text { dabei, dass ich } \\
\text { Personen, die mir nahe } \\
\text { stehen, frage, wie sie } \\
\text { wirklich über mich } \\
\text { denken. }\end{array}$ & $\begin{array}{l}1=\text { stimmt überhaupt } \\
\text { nicht, } 2=\text { stimmt nicht, } 3 \\
=\text { stimmt eher nicht, } 4= \\
\text { weder noch, } 5=\text { stimmt } \\
\text { eher, } 6=\text { stimmt, } 7= \\
\text { stimmt voll und ganz }\end{array}$ & $\begin{array}{l}\text { How well do the } \\
\text { following statements } \\
\text { describe your } \\
\text { personality? Do you } \\
\text { find yourself often } \\
\text { asking the people you } \\
\text { feel close to how they } \\
\text { truly feel about you? }\end{array}$ & $\begin{array}{l}1=\text { does not apply at all, } \\
2=\text { does not apply, } 3= \\
\text { does rather not apply, } 4= \\
\text { neither, } 5=\text { rather } \\
\text { applies, } 6=\text { applies, } 7= \\
\text { applies completely (free } \\
\text { translation) }\end{array}$ & $\mathrm{x}$ & $\mathrm{x}$ & $\mathrm{x}$ & $\mathrm{x}$ & $\mathrm{x}$ & & & & & & & & & \\
\hline
\end{tabular}




\begin{tabular}{|c|c|c|c|c|c|c|c|c|c|c|c|c|c|c|c|c|c|c|}
\hline VarName & VariableLabel & WordingDE & ValueLabelsDE_Linked & WordingEN & ValueLabelsEN_Linked & L1 & L1F L2 & L3 & L4 & L5 & L6 & $\mathrm{L} 7$ & L8 & L9 & \multicolumn{4}{|c|}{ L10 L11 L12 L13 L14 } \\
\hline reassurance. 2 & $\begin{array}{l}\text { Reassurance } \\
\text { Item } 2\end{array}$ & $\begin{array}{l}\text { Bitte gib an, inwieweit } \\
\text { die folgenden Aussagen } \\
\text { auf Dich zutreffen (im } \\
\text { Allgemeinen, nicht auf } \\
\text { eine konkrete Situation } \\
\text { oder Person bezogen). } \\
\text { Ich suche häufig von } \\
\text { Leuten, die mir nahe } \\
\text { stehen, eine } \\
\text { Zusicherung, dass ich } \\
\text { ihnen etwas bedeute. }\end{array}$ & $\begin{array}{l}1=\text { stimmt überhaupt } \\
\text { nicht, } 2=\text { stimmt nicht, } 3 \\
=\text { stimmt eher nicht, } 4= \\
\text { weder noch, } 5=\text { stimmt } \\
\text { eher, } 6=\text { stimmt, } 7= \\
\text { stimmt voll und ganz }\end{array}$ & $\begin{array}{l}\text { How well do the } \\
\text { following statements } \\
\text { describe your } \\
\text { personality? Do you } \\
\text { frequently seek } \\
\text { reassurance from the } \\
\text { people you feel close to } \\
\text { as to whether they } \\
\text { really care about you? }\end{array}$ & $\begin{array}{l}1=\text { does not apply at all, } \\
2=\text { does not apply, } 3= \\
\text { does rather not apply, } 4= \\
\text { neither, } 5=\text { rather } \\
\text { applies, } 6=\text { applies, } 7= \\
\text { applies completely (free } \\
\text { translation) }\end{array}$ & $\mathrm{x}$ & $\mathrm{x}$ & $\mathrm{x}$ & $\mathrm{x}$ & $\mathrm{x}$ & & & & & & & & \\
\hline reassurance. 3 & $\begin{array}{l}\text { Reassurance } \\
\text { Item } 3\end{array}$ & $\begin{array}{l}\text { Bitte gib an, inwieweit } \\
\text { die folgenden Aussagen } \\
\text { auf Dich zutreffen (im } \\
\text { Allgemeinen, nicht auf } \\
\text { eine konkrete Situation } \\
\text { oder Person bezogen). } \\
\text { Manchmal verärgere ich } \\
\text { mir nahe stehende } \\
\text { Personen dadurch, dass } \\
\text { ich wiederholt eine } \\
\text { Versicherung von ihnen } \\
\text { suche, dass ich ihnen } \\
\text { wirklich etwas bedeute }\end{array}$ & $\begin{array}{l}1=\text { stimmt überhaupt } \\
\text { nicht, } 2=\text { stimmt nicht, } 3 \\
=\text { stimmt eher nicht, } 4= \\
\text { weder noch, } 5=\text { stimmt } \\
\text { eher, } 6=\text { stimmt, } 7= \\
\text { stimmt voll und ganz }\end{array}$ & $\begin{array}{l}\text { How well do the } \\
\text { following statements } \\
\text { describe your } \\
\text { personality? Do the } \\
\text { people you feel close to } \\
\text { sometimes become } \\
\text { irritated with you for } \\
\text { seeking reassurance from } \\
\text { them about whether } \\
\text { they really care about } \\
\text { you? }\end{array}$ & $\begin{array}{l}1=\text { does not apply at all, } \\
2=\text { does not apply, } 3= \\
\text { does rather not apply, } 4= \\
\text { neither, } 5=\text { rather } \\
\text { applies, } 6=\text { applies, } 7= \\
\text { applies completely (free } \\
\text { translation) }\end{array}$ & $\mathrm{x}$ & $\mathrm{x}$ & $\mathrm{x}$ & $\mathrm{x}$ & $\mathrm{x}$ & & & & & & & & \\
\hline reassurance. 4 & $\begin{array}{l}\text { Reassurance } \\
\text { Item } 4\end{array}$ & $\begin{array}{l}\text { Bitte gib an, inwieweit } \\
\text { die folgenden Aussagen } \\
\text { auf Dich zutreffen (im } \\
\text { Allgemeinen, nicht auf } \\
\text { eine konkrete Situation } \\
\text { oder Person bezogen). } \\
\text { Manchmal haben Leute, } \\
\text { die mir nahe stehen, die } \\
\text { "Nase voll" davon, dass } \\
\text { ich versuche eine } \\
\text { Bestätigung von ihnen } \\
\text { zu bekommen, dass ich } \\
\text { ihnen wirklich etwas } \\
\text { bedeute.. }\end{array}$ & $\begin{array}{l}1=\text { stimmt überhaupt } \\
\text { nicht, } 2=\text { stimmt nicht, } 3 \\
=\text { stimmt eher nicht, } 4= \\
\text { weder noch, } 5=\text { stimmt } \\
\text { eher, } 6=\text { stimmt, } 7= \\
\text { stimmt voll und ganz }\end{array}$ & $\begin{array}{l}\text { How well do the } \\
\text { following statements } \\
\text { describe your } \\
\text { personality? Do the } \\
\text { people you feel close to } \\
\text { sometimes get "fed up" } \\
\text { with you for seeking } \\
\text { reassurance from them } \\
\text { about whether they } \\
\text { really care about you? }\end{array}$ & $\begin{array}{l}1=\text { does not apply at all, } \\
2=\text { does not apply, } 3= \\
\text { does rather not apply, } 4= \\
\text { neither, } 5=\text { rather } \\
\text { applies, } 6=\text { applies, } 7= \\
\text { applies completely (free } \\
\text { translation) }\end{array}$ & $\mathrm{x}$ & $\mathrm{x}$ & $\mathrm{x}$ & $\mathrm{x}$ & $\mathrm{x}$ & & & & & & & & \\
\hline social.support.1 & $\begin{array}{l}\text { Social support } \\
\text { Item } 1\end{array}$ & $\begin{array}{l}\text { Bitte gib an, inwieweit } \\
\text { die folgenden Aussagen } \\
\text { auf Dich zutreffen. Ich } \\
\text { erfahre von anderen viel } \\
\text { Verständnis und } \\
\text { Geborgenheit. }\end{array}$ & $\begin{array}{l}1=\text { trifft } \ddot{\text { überhaupt nicht }} \\
\mathrm{zu}, 2=\text { trifft nicht } \mathrm{zu}, 3= \\
\text { weder noch, } 4=\text { trifft } \mathrm{zu}, \\
5=\text { trifft voll und ganz } \mathrm{zu}\end{array}$ & $\begin{array}{l}\text { How well do the } \\
\text { following statements } \\
\text { describe you? I receive a } \\
\text { lot of understanding and } \\
\text { security from others }\end{array}$ & $\begin{array}{l}1=\text { does not apply at all, } \\
2=\text { does not apply, } 3= \\
\text { neither, } 4=\text { applies, } 5= \\
\text { applies completely (free } \\
\text { translation) }\end{array}$ & $\mathrm{x}$ & $\mathrm{x}$ & $\mathrm{x}$ & $\mathrm{x}$ & $\mathrm{x}$ & $\mathrm{x}$ & $\mathrm{x}$ & $\mathrm{x}$ & $\mathrm{x}$ & $\mathrm{x}$ & $\mathrm{x}$ & $\mathrm{x}$ & $\mathrm{x}$ \\
\hline social.support.2 & $\begin{array}{l}\text { Social support } \\
\text { Item } 2\end{array}$ & $\begin{array}{l}\text { Bitte gib an, inwieweit } \\
\text { die folgenden Aussagen } \\
\text { auf Dich zutreffen. Ich } \\
\text { habe einen sehr } \\
\text { vertrauten Menschen, } \\
\text { mit dessen Hilfe ich } \\
\text { immer rechnen kann. }\end{array}$ & $\begin{array}{l}1=\text { trifft überhaupt nicht } \\
\mathrm{zu}, 2=\text { trifft nicht } \mathrm{zu}, 3= \\
\text { weder noch, } 4=\text { trifft } \mathrm{zu} \\
5=\text { trifft voll und ganz } \mathrm{zu}\end{array}$ & $\begin{array}{l}\text { How well do the } \\
\text { following statements } \\
\text { describe you? There is } \\
\text { someone very close to } \\
\text { me whose help I can } \\
\text { always count on }\end{array}$ & $\begin{array}{l}1=\text { does not apply at all, } \\
2=\text { does not apply, } 3= \\
\text { neither, } 4=\text { applies, } 5= \\
\text { applies completely (free } \\
\text { translation) }\end{array}$ & $\mathrm{x}$ & $\mathrm{x}$ & $\mathrm{x}$ & $\mathrm{x}$ & $\mathrm{x}$ & $\mathrm{x}$ & $\mathrm{x}$ & $\mathrm{x}$ & $\mathrm{x}$ & $\mathrm{x}$ & $\mathrm{x}$ & $\mathrm{x}$ & $\mathrm{x}$ \\
\hline social.support.3 & $\begin{array}{l}\text { Social support } \\
\text { Item } 3\end{array}$ & $\begin{array}{l}\text { Bitte gib an, inwieweit } \\
\text { die folgenden Aussagen } \\
\text { auf Dich zutreffen. Bei } \\
\text { Bedarf kann ich mir } \\
\text { ohne Probleme bei } \\
\text { Freunden oder Nachbarn } \\
\text { etwas ausleihen. }\end{array}$ & $\begin{array}{l}1=\text { trifft } \ddot{\text { überhaupt nicht }} \\
\mathrm{zu}, 2=\text { trifft nicht } \mathrm{zu}, 3= \\
\text { weder noch, } 4=\text { trifft } \mathrm{zu}, \\
5=\text { trifft voll und ganz } \mathrm{zu}\end{array}$ & $\begin{array}{l}\text { How well do the } \\
\text { following statements } \\
\text { describe you? If I need } \\
\text { to, I can borrow } \\
\text { something from friends } \\
\text { or neighbors without } \\
\text { any problems }\end{array}$ & $\begin{array}{l}1=\text { does not apply at all, } \\
2=\text { does not apply, } 3= \\
\text { neither, } 4=\text { applies, } 5= \\
\text { applies completely (free } \\
\text { translation) }\end{array}$ & $\mathrm{x}$ & $\mathrm{x}$ & $\mathrm{x}$ & $\mathrm{x}$ & $\mathrm{x}$ & $\mathrm{x}$ & $\mathrm{x}$ & $\mathrm{x}$ & $\mathrm{x}$ & $\mathrm{x}$ & $\mathrm{x}$ & $\mathrm{x}$ & $\mathrm{x}$ \\
\hline social.support.4 & $\begin{array}{l}\text { Social support } \\
\text { Item } 4\end{array}$ & $\begin{array}{l}\text { Bitte gib an, inwieweit } \\
\text { die folgenden Aussagen } \\
\text { auf Dich zutreffen. Ich } \\
\text { kenne mehrere } \\
\text { Menschen, mit denen ich } \\
\text { gerne etwas unternehme. }\end{array}$ & 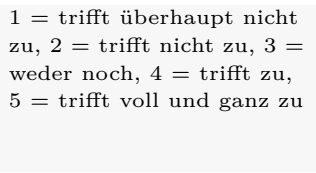 & $\begin{array}{l}\text { How well do the } \\
\text { following statements } \\
\text { describe you? I know } \\
\text { several people with } \\
\text { whom I like to do things }\end{array}$ & $\begin{array}{l}1=\text { does not apply at all, } \\
2=\text { does not apply, } 3= \\
\text { neither, } 4=\text { applies, } 5= \\
\text { applies completely (free } \\
\text { translation) }\end{array}$ & $\mathrm{x}$ & $\mathrm{x}$ & $\mathrm{x}$ & $\mathrm{x}$ & $\mathrm{x}$ & $\mathrm{x}$ & $\mathrm{x}$ & $\mathrm{x}$ & $\mathrm{x}$ & $\mathrm{x}$ & $\mathrm{x}$ & $\mathrm{x}$ & $\mathrm{x}$ \\
\hline
\end{tabular}




\begin{tabular}{|c|c|c|c|c|c|c|c|c|c|c|c|c|c|c|c|c|c|c|c|}
\hline VarName & VariableLabel & WordingDE & ValueLabelsDE_Linked & WordingEN & ValueLabelsEN_Linked & $\mathrm{L} 1$ & L1F L2 & L3 & $\mathrm{L} 4$ & L5 & L6 & L7 & L8 & L9 & L10 & o L11 & $\mathrm{L} 12$ & $2 \mathrm{~L} 13$ & L L14 \\
\hline social.support.5 & $\begin{array}{l}\text { Social support } \\
\text { Item } 5\end{array}$ & $\begin{array}{l}\text { Bitte gib an, inwieweit } \\
\text { die folgenden Aussagen } \\
\text { auf Dich zutreffen. Wenn } \\
\text { ich krank bin, kann ich } \\
\text { ohne Zögern Freunde/ } \\
\text { Angehörige bitten, } \\
\text { wichtige Dinge für mich } \\
\text { zu erledigen. }\end{array}$ & $\begin{array}{l}1=\text { trifft überhaupt nicht } \\
\mathrm{zu}, 2=\text { trifft nicht } \mathrm{zu}, 3= \\
\text { weder noch, } 4=\text { trifft } \mathrm{zu} \\
5=\text { trifft voll und ganz } \mathrm{zu}\end{array}$ & $\begin{array}{l}\text { How well do the } \\
\text { following statements } \\
\text { describe you? When I } \\
\text { am sick, I can ask } \\
\text { friends/relatives to } \\
\text { handle important things } \\
\text { for me without } \\
\text { hesitation }\end{array}$ & $\begin{array}{l}1=\text { does not apply at all, } \\
2=\text { does not apply, } 3= \\
\text { neither, } 4=\text { applies, } 5= \\
\text { applies completely (free } \\
\text { translation) }\end{array}$ & $\mathrm{x}$ & $\mathrm{x}$ & $\mathrm{x}$ & $\mathrm{X}$ & $\mathrm{x}$ & $\mathrm{x}$ & $\mathrm{x}$ & $\mathrm{x}$ & $\mathrm{X}$ & $\mathrm{x}$ & $\mathrm{x}$ & $\mathrm{x}$ & $\mathrm{x}$ & \\
\hline social.support.6 & $\begin{array}{l}\text { Social support } \\
\text { Item } 6\end{array}$ & $\begin{array}{l}\text { Bitte gib an, inwieweit } \\
\text { die folgenden Aussagen } \\
\text { auf Dich zutreffen. } \\
\text { Wenn ich mal sehr } \\
\text { bedrückt bin, weiss ich, } \\
\text { zu wem ich damit ohne } \\
\text { weiteres gehen kann. }\end{array}$ & $\begin{array}{l}1=\text { trifft überhaupt nicht } \\
\text { zu, } 2=\text { trifft nicht } \mathrm{zu}, 3= \\
\text { weder noch, } 4=\text { trifft zu, } \\
5=\text { trifft voll und ganz zu }\end{array}$ & $\begin{array}{l}\text { How well do the } \\
\text { following statements } \\
\text { describe you? If I'm } \\
\text { very depressed, I know } \\
\text { who I can turn to }\end{array}$ & $\begin{array}{l}1=\text { does not apply at all, } \\
2=\text { does not apply, } 3= \\
\text { neither, } 4=\text { applies, } 5= \\
\text { applies completely (free } \\
\text { translation) }\end{array}$ & $\mathrm{x}$ & $\mathrm{x}$ & $\mathrm{x}$ & $\mathrm{x}$ & $\mathrm{x}$ & $\mathrm{x}$ & $\mathrm{x}$ & $\mathrm{x}$ & $\mathrm{x}$ & $\mathrm{x}$ & $\mathrm{x}$ & $\mathrm{x}$ & $\mathrm{x}$ & \\
\hline identities. 1 & $\begin{array}{l}\text { Identities item } \\
1\end{array}$ & $\begin{array}{l}\text { Q14.3 - Wie } \\
\text { starkidentifizierst Du } \\
\text { Dich mit [university } \\
\text { name]? [graphical item] }\end{array}$ & $\begin{array}{l}1=1,2=2,3=3,4= \\
4,5=5,6=6,7=7\end{array}$ & $\begin{array}{l}\text { How strongly do you } \\
\text { identify with the } \\
\text { [university name]? } \\
\text { [graphical item] }\end{array}$ & $\begin{array}{l}1=1,2=2,3=3,4= \\
4,5=5,6=6,7=7\end{array}$ & $\mathrm{x}$ & $\mathrm{x}$ & $\mathrm{x}$ & $\mathrm{x}$ & $\mathrm{x}$ & $\mathrm{x}$ & $\mathrm{x}$ & $\mathrm{x}$ & $\mathrm{x}$ & $\mathrm{x}$ & $\mathrm{x}$ & $\mathrm{x}$ & $\mathrm{x}$ & $\mathrm{x}$ \\
\hline identities. 2 & $\begin{array}{l}\text { Identities item } \\
2\end{array}$ & $\begin{array}{l}\text { Wie stark identifizierst } \\
\text { Du Dich mit der } \\
\text { Gemeinschaft der } \\
\text { [department] } \\
\text { Studierenden generell? } \\
\text { [graphical item] }\end{array}$ & $\begin{array}{l}1=1,2=2,3=3,4= \\
4,5=5,6=6,7=7\end{array}$ & $\begin{array}{l}\text { How strongly do you } \\
\text { identify with the } \\
\text { community of } \\
\text { [department] students in } \\
\text { general? [graphical } \\
\text { item] }\end{array}$ & $\begin{array}{l}1=1,2=2,3=3,4= \\
4,5=5,6=6,7=7\end{array}$ & $\mathrm{x}$ & $\mathrm{x}$ & $\mathrm{x}$ & $\mathrm{X}$ & $\mathrm{x}$ & $\mathrm{x}$ & $\mathrm{x}$ & $\mathrm{x}$ & $\mathrm{x}$ & $\mathrm{x}$ & $\mathrm{x}$ & $\mathrm{x}$ & $\mathrm{x}$ & $\mathrm{x}$ \\
\hline identities. 3 & $\begin{array}{l}\text { Identities item } \\
3\end{array}$ & $\begin{array}{l}\text { Wie stark identifizierst } \\
\text { Du Dich mit der } \\
\text { Wissenschaftlichen } \\
\text { Gemeinschaft generell? } \\
\text { [graphical item] }\end{array}$ & $\begin{array}{l}1=1,2=2,3=3,4= \\
4,5=5,6=6,7=7\end{array}$ & $\begin{array}{l}\text { How strongly do you } \\
\text { identify with the } \\
\text { scientific community? } \\
\text { [graphical item] }\end{array}$ & $\begin{array}{l}1=1,2=2,3=3,4= \\
4,5=5,6=6,7=7\end{array}$ & $\mathrm{x}$ & $\mathrm{x}$ & $\mathrm{x}$ & $\mathrm{x}$ & $\mathrm{x}$ & $\mathrm{x}$ & $\mathrm{x}$ & $\mathrm{x}$ & $\mathrm{x}$ & $\mathrm{x}$ & $\mathrm{x}$ & $\mathrm{x}$ & $\mathrm{x}$ & $\mathrm{x}$ \\
\hline identities.4 & $\begin{array}{l}\text { Identities item } \\
4\end{array}$ & $\begin{array}{l}\text { Wie stark identifizierst } \\
\text { Du Dich mit der [field of } \\
\text { major] als Wissenschaft? } \\
\text { [graphical item] }\end{array}$ & $\begin{array}{l}1=1,2=2,3=3,4= \\
4,5=5,6=6,7=7\end{array}$ & $\begin{array}{l}\text { How strongly do you } \\
\text { identify with [field of } \\
\text { major] as a science? } \\
\text { [graphical item] }\end{array}$ & $\begin{array}{l}1=1,2=2,3=3,4= \\
4,5=5,6=6,7=7\end{array}$ & $\mathrm{x}$ & $\mathrm{x}$ & $\mathrm{x}$ & $\mathrm{X}$ & $\mathrm{x}$ & $\mathrm{x}$ & $\mathrm{x}$ & $\mathrm{x}$ & $\mathrm{X}$ & $\mathrm{x}$ & $\mathrm{x}$ & $\mathrm{x}$ & $\mathrm{x}$ & $\mathrm{x}$ \\
\hline identities. 5 & $\begin{array}{l}\text { Identities item } \\
5\end{array}$ & $\begin{array}{l}\text { Wie stark identifizierst } \\
\text { Du Dich mit Männern } \\
\text { generell? (wenn } \\
\text { männlich) [graphical } \\
\text { item] }\end{array}$ & $\begin{array}{l}1=1,2=2,3=3,4= \\
4,5=5,6=6,7=7\end{array}$ & $\begin{array}{l}\text { for men: How much do } \\
\text { you identify with men? } \\
\text { [graphical item] }\end{array}$ & $\begin{array}{l}1=1,2=2,3=3,4= \\
4,5=5,6=6,7=7\end{array}$ & $\mathrm{x}$ & $\mathrm{x}$ & $\mathrm{x}$ & $\mathrm{x}$ & $\mathrm{x}$ & $\mathrm{x}$ & $\mathrm{x}$ & $\mathrm{x}$ & $\mathrm{x}$ & $\mathrm{x}$ & $\mathrm{x}$ & $\mathrm{x}$ & $\mathrm{x}$ & $\mathrm{x}$ \\
\hline identities.6 & $\begin{array}{l}\text { Identities item } \\
6\end{array}$ & $\begin{array}{l}\text { Wie stark identifizierst } \\
\text { Du Dich mit Frauen } \\
\text { generell? (wenn } \\
\text { weiblich) [graphical } \\
\text { item] }\end{array}$ & $\begin{array}{l}1=1,2=2,3=3,4= \\
4,5=5,6=6,7=7\end{array}$ & $\begin{array}{l}\text { for women: How much } \\
\text { do you identify with } \\
\text { women? [graphical item] }\end{array}$ & $\begin{array}{l}1=1,2=2,3=3,4= \\
4,5=5,6=6,7=7\end{array}$ & $\mathrm{x}$ & $\mathrm{x}$ & $\mathrm{x}$ & $\mathrm{x}$ & $\mathrm{x}$ & $\mathrm{x}$ & $\mathrm{x}$ & $\mathrm{x}$ & $\mathrm{x}$ & $\mathrm{x}$ & $\mathrm{x}$ & $\mathrm{x}$ & $\mathrm{x}$ & $\mathrm{x}$ \\
\hline identities. 7 & $\begin{array}{l}\text { Identities item } \\
7\end{array}$ & $\begin{array}{l}\text { Wie stark identifizierst } \\
\text { Du Dich mit der } \\
\text { Schweiz? [graphical } \\
\text { item] }\end{array}$ & $\begin{array}{l}1=1,2=2,3=3,4= \\
4,5=5,6=6,7=7\end{array}$ & $\begin{array}{l}\text { How much do you } \\
\text { identify with } \\
\text { Switzerland? [graphical } \\
\text { item] }\end{array}$ & $\begin{array}{l}1=1,2=2,3=3,4= \\
4,5=5,6=6,7=7\end{array}$ & $\mathrm{x}$ & $\mathrm{x}$ & $\mathrm{x}$ & $\mathrm{x}$ & $\mathrm{x}$ & $\mathrm{x}$ & $\mathrm{x}$ & $\mathrm{x}$ & $\mathrm{x}$ & $\mathrm{x}$ & $\mathrm{x}$ & $\mathrm{x}$ & $\mathrm{x}$ & \\
\hline identities. 8 & $\begin{array}{l}\text { Identities item } \\
8\end{array}$ & $\begin{array}{l}\text { Wie stark identifizierst } \\
\text { Du Dich mit deinem } \\
\text { Herkunftstkanton? } \\
\text { [graphical item] }\end{array}$ & $\begin{array}{l}1=1,2=2,3=3,4= \\
4,5=5,6=6,7=7\end{array}$ & $\begin{array}{l}\text { How much do you } \\
\text { identify with members } \\
\text { of your home canton? } \\
\text { [graphical item] }\end{array}$ & $\begin{array}{l}1=1,2=2,3=3,4= \\
4,5=5,6=6,7=7\end{array}$ & $\mathrm{x}$ & $\mathrm{x}$ & $\mathrm{x}$ & $\mathrm{x}$ & $\mathrm{x}$ & $\mathrm{x}$ & $\mathrm{x}$ & $\mathrm{x}$ & $\mathrm{x}$ & $\mathrm{x}$ & $\mathrm{x}$ & $\mathrm{x}$ & $\mathrm{x}$ & \\
\hline identities. 9 & $\begin{array}{l}\text { Identities item } \\
9\end{array}$ & $\begin{array}{l}\text { Wie stark identifizierst } \\
\text { Du Dich mit anderen } \\
\text { Personen Deiner } \\
\text { Nationalität? [graphical } \\
\text { item] }\end{array}$ & $\begin{array}{l}1=1,2=2,3=3,4= \\
4,5=5,6=6,7=7\end{array}$ & $\begin{array}{l}\text { How much do you } \\
\text { identify with members } \\
\text { of your nationality? } \\
\text { [graphical item] }\end{array}$ & $\begin{array}{l}1=1,2=2,3=3,4= \\
4,5=5,6=6,7=7\end{array}$ & $\mathrm{x}$ & $\mathrm{x}$ & $\mathrm{x}$ & $\mathrm{x}$ & $\mathrm{x}$ & $\mathrm{x}$ & $\mathrm{x}$ & $\mathrm{x}$ & $\mathrm{x}$ & $\mathrm{x}$ & $\mathrm{x}$ & $\mathrm{x}$ & $\mathrm{x}$ & \\
\hline
\end{tabular}




\begin{tabular}{|c|c|c|c|c|c|c|c|c|c|c|c|c|c|c|c|c|c|c|c|}
\hline VarName & VariableLabel & WordingDE & ValueLabelsDE_Linked & WordingEN & ValueLabelsEN_Linked & $\mathrm{L} 1$ & L1F L2 & L3 & L4 & L5 & L6 & L7 & L8 & L9 & L10 & $\mathrm{L}$ L11 & $1 \mathrm{~L} 12$ & $2 \mathrm{~L} 13$ & $3 \mathrm{~L} 14$ \\
\hline behaviour.1 & $\begin{array}{l}\text { Behaviour } \\
\text { Item 1: Sport }\end{array}$ & $\begin{array}{l}\text { Wie oft machst du } \\
\text { Sport? }\end{array}$ & $\begin{array}{l}1=\text { nie, } 2=\text { sehr selten } \\
\text { (mindestens einmal im } \\
\text { Jahr), } 3=\text { manchmal } \\
(\text { mindestens einmal im } \\
\text { Monat), } 4=\text { regelmässig } \\
\text { (mindestens einmal pro } \\
\text { Woche), } 5=\text { oft } \\
\text { (mehrmals wöchentlich), } 6 \\
=\text { jeden Tag }\end{array}$ & $\begin{array}{l}\text { How often do you do } \\
\text { sports? }\end{array}$ & $\begin{array}{l}1=\text { never, } 2=\text { very rarely } \\
\text { (at least once per year), } 3 \\
=\text { sometimes (at least } \\
\text { once per month), } 4= \\
\text { regularly (at least once } \\
\text { per week), } 5=\text { often (few } \\
\text { times per week, } 6=\text { every } \\
\text { day (free translation) }\end{array}$ & $\mathrm{x}$ & $\mathrm{x}$ & $\mathrm{x}$ & $\mathrm{x}$ & $\mathrm{x}$ & $\mathrm{x}$ & $\mathrm{x}$ & $\mathrm{x}$ & $\mathrm{x}$ & $\mathrm{x}$ & $\mathrm{x}$ & $\mathrm{x}$ & $\mathrm{x}$ & $\mathrm{x}$ \\
\hline behaviour.2 & $\begin{array}{l}\text { Behaviour } \\
\text { Item 2: Tabak }\end{array}$ & $\begin{array}{l}\text { Wie oft rauchst du } \\
\text { Tabak? }\end{array}$ & $\begin{array}{l}1=\text { nie, } 2=\text { sehr selten } \\
(\text { mindestens einmal im } \\
\text { Jahr) }, 3=\text { manchmal } \\
(\text { mindestens einmal im } \\
\text { Monat), } 4=\text { regelmässig } \\
\text { (mindestens einmal pro } \\
\text { Woche), } 5=\text { oft } \\
\text { (mehrmals wöchentlich), } 6 \\
=\text { jeden Tag }\end{array}$ & $\begin{array}{l}\text { How often do you smoke } \\
\text { tobacco? }\end{array}$ & $\begin{array}{l}1=\text { never, } 2=\text { very rarely } \\
\text { (at least once per year), } 3 \\
=\text { sometimes (at least } \\
\text { once per month), } 4= \\
\text { regularly (at least once } \\
\text { per week), } 5=\text { often }(\text { few } \\
\text { times per week, } 6=\text { every } \\
\text { day (free translation) }\end{array}$ & $\mathrm{x}$ & $\mathrm{x}$ & $\mathrm{x}$ & $\mathrm{x}$ & $\mathrm{x}$ & $\mathrm{x}$ & $\mathrm{x}$ & $\mathrm{x}$ & $\mathrm{x}$ & $\mathrm{x}$ & $\mathrm{x}$ & $\mathrm{x}$ & $\mathrm{x}$ & $\mathrm{x}$ \\
\hline behaviour.3 & $\begin{array}{l}\text { Behaviour } \\
\text { Item 3: } \\
\text { Cannabis }\end{array}$ & $\begin{array}{l}\text { Wie oft rauchst du } \\
\text { Cannabis? }\end{array}$ & $\begin{array}{l}1=\text { nie, } 2=\text { sehr selten } \\
\text { (mindestens einmal im } \\
\text { Jahr), } 3=\text { manchmal } \\
(\text { mindestens einmal im } \\
\text { Monat), } 4=\text { regelmässig } \\
\text { (mindestens einmal pro } \\
\text { Woche), } 5=\text { oft } \\
\text { (mehrmals wöchentlich), } 6 \\
=\text { jeden Tag }\end{array}$ & $\begin{array}{l}\text { How often do you smoke } \\
\text { marijuana? }\end{array}$ & $\begin{array}{l}1=\text { never, } 2=\text { very rarely } \\
(\text { at least once per year) }, 3 \\
=\text { sometimes (at least } \\
\text { once per month), } 4= \\
\text { regularly (at least once } \\
\text { per week), } 5=\text { often (few } \\
\text { times per week, } 6=\text { every } \\
\text { day (free translation) }\end{array}$ & $\mathrm{x}$ & $\mathrm{x}$ & $\mathrm{x}$ & $\mathrm{x}$ & $\mathrm{x}$ & $\mathrm{x}$ & $\mathrm{x}$ & $\mathrm{x}$ & $\mathrm{x}$ & $\mathrm{x}$ & $\mathrm{x}$ & $\mathrm{x}$ & $\mathrm{x}$ & $\mathrm{x}$ \\
\hline behaviour.4 & $\begin{array}{l}\text { Behaviour } \\
\text { Item 4: } \\
\text { Alkohol }\end{array}$ & $\begin{array}{l}\text { Wie oft trinkst du } \\
\text { Alkohol? }\end{array}$ & $\begin{array}{l}1=\text { nie, } 2=\text { sehr selten } \\
\text { (mindestens einmal im } \\
\text { Jahr), } 3=\text { manchmal } \\
(\text { mindestens einmal im } \\
\text { Monat), } 4=\text { regelmässig } \\
\text { (mindestens einmal pro } \\
\text { Woche), } 5=\text { oft } \\
\text { (mehrmals wöchentlich), } 6 \\
=\text { jeden Tag }\end{array}$ & $\begin{array}{l}\text { How often do you drink } \\
\text { alcohol? }\end{array}$ & $\begin{array}{l}1=\text { never, } 2=\text { very rarely } \\
\text { (at least once per year), } 3 \\
=\text { sometimes (at least } \\
\text { once per month), } 4= \\
\text { regularly (at least once } \\
\text { per week), } 5=\text { often (few } \\
\text { times per week, } 6=\text { every } \\
\text { day (free translation) }\end{array}$ & $\mathrm{x}$ & $\mathrm{x}$ & $\mathrm{x}$ & $\mathrm{x}$ & $\mathrm{x}$ & $\mathrm{x}$ & $\mathrm{x}$ & $\mathrm{x}$ & $\mathrm{x}$ & $\mathrm{x}$ & $\mathrm{x}$ & $\mathrm{x}$ & $\mathrm{x}$ & $\mathrm{x}$ \\
\hline behaviour.5 & $\begin{array}{l}\text { Behaviour } \\
\text { Item 5: } \\
\text { Tanzclubs }\end{array}$ & $\begin{array}{l}\text { Wie oft gehst } \mathrm{du} \text { in } \\
\text { Tanzclubs? }\end{array}$ & $\begin{array}{l}1=\text { nie, } 2=\text { sehr selten } \\
(\text { mindestens einmal im } \\
\text { Jahr), } 3=\text { manchmal } \\
(\text { mindestens einmal im } \\
\text { Monat), } 4=\text { regelmässig } \\
\text { (mindestens einmal pro } \\
\text { Woche), } 5=\text { oft } \\
\text { (mehrmals wöchentlich), } 6 \\
=\text { jeden Tag }\end{array}$ & $\begin{array}{l}\text { How often do you go to } \\
\text { clubs? }\end{array}$ & $\begin{array}{l}1=\text { never, } 2=\text { very rarely } \\
\text { (at least once per year), } 3 \\
=\text { sometimes (at least } \\
\text { once per month), } 4= \\
\text { regularly (at least once } \\
\text { per week), } 5=\text { often (few } \\
\text { times per week, } 6=\text { every } \\
\text { day (free translation) }\end{array}$ & $\mathrm{x}$ & $\mathrm{x}$ & $\mathrm{x}$ & $\mathrm{x}$ & $\mathrm{x}$ & $\mathrm{x}$ & $\mathrm{x}$ & $\mathrm{x}$ & $\mathrm{x}$ & $\mathrm{x}$ & $\mathrm{x}$ & $\mathrm{x}$ & $\mathrm{x}$ & $\mathrm{x}$ \\
\hline study.1 & Study Item 1 & $\begin{array}{l}\text { Lernst Du hauptsächlich } \\
\text { alleine oder mit anderen } \\
\text { Leuten? }\end{array}$ & $\begin{array}{l}1=\text { alleine, } 2=\text { mit } \\
\text { anderen Leuten, } 3= \\
\text { beides gleich viel }\end{array}$ & $\begin{array}{l}\text { Do you study alone or } \\
\text { with other people? }\end{array}$ & $\begin{array}{l}1=\text { alone, } 2=\text { with } \\
\text { others, } 3=\text { both equally }\end{array}$ & $\mathrm{x}$ & $\mathrm{x}$ & $\mathrm{x}$ & $\mathrm{x}$ & $\mathrm{x}$ & $\mathrm{x}$ & $\mathrm{x}$ & $\mathrm{x}$ & $\mathrm{x}$ & $\mathrm{x}$ & $\mathrm{x}$ & $\mathrm{x}$ & $\mathrm{x}$ & \\
\hline study.2 & Study Item 2 & $\begin{array}{l}\text { In welchem Masse } \\
\text { würdest Du den } \\
\text { folgenden Aussagen } \\
\text { zustimmen? Ich sollte } \\
\text { mehr lernen }\end{array}$ & $\begin{array}{l}1=\text { überhaupt nicht } \\
\text { einverstanden, } 2=\text { nicht } \\
\text { einverstanden, } 3=\text { eher } \\
\text { nicht einverstanden, } 4= \\
\text { weder noch, } 5=\text { eher } \\
\text { einverstanden, } 6= \\
\text { einverstanden, } 7=\text { völlig } \\
\text { einverstanden }\end{array}$ & $\begin{array}{l}\text { To what extent would } \\
\text { you agree with the } \\
\text { following statements? I } \\
\text { should study more. (free } \\
\text { translation) }\end{array}$ & $\begin{array}{l}1=\text { don't agree at all, } 2= \\
\text { don't agree, } 3=\text { rather } \\
\text { not agree, } 4=\text { neither, } 5 \\
=\text { rather agree, } 6=\text { agree, } \\
7=\text { agree completely (free } \\
\text { translation) }\end{array}$ & $\mathrm{x}$ & $\mathrm{x}$ & $\mathrm{x}$ & $\mathrm{x}$ & $\mathrm{x}$ & $\mathrm{x}$ & $\mathrm{x}$ & $\mathrm{x}$ & $\mathrm{x}$ & $\mathrm{x}$ & $\mathrm{x}$ & $\mathrm{x}$ & $\mathrm{x}$ & \\
\hline study. 3 & Study Item 3 & $\begin{array}{l}\text { In welchem Masse } \\
\text { würdest Du den } \\
\text { folgenden Aussagen } \\
\text { zustimmen? Ich sollte } \\
\text { effizienter lernen }\end{array}$ & $\begin{array}{l}1=\text { überhaupt nicht } \\
\text { einverstanden, } 2=\text { nicht } \\
\text { einverstanden, } 3=\text { eher } \\
\text { nicht einverstanden, } 4= \\
\text { weder noch, } 5=\text { eher } \\
\text { einverstanden, } 6= \\
\text { einverstanden, } 7=\text { völlig } \\
\text { einverstanden }\end{array}$ & $\begin{array}{l}\text { To what extent would } \\
\text { you agree with the } \\
\text { following statements? I } \\
\text { should study more } \\
\text { efficiently. (free } \\
\text { translation) }\end{array}$ & $\begin{array}{l}1=\text { don't agree at all, } 2= \\
\text { don't agree, } 3=\text { rather } \\
\text { not agree, } 4=\text { neither, } 5 \\
=\text { rather agree, } 6=\text { agree, } \\
7=\text { agree completely (free } \\
\text { translation) }\end{array}$ & $\mathrm{x}$ & $\mathrm{x}$ & $\mathrm{x}$ & $\mathrm{x}$ & $\mathrm{x}$ & $\mathrm{x}$ & $\mathrm{x}$ & $\mathrm{x}$ & $\mathrm{x}$ & $\mathrm{x}$ & $\mathrm{x}$ & $\mathrm{x}$ & $\mathrm{x}$ & \\
\hline
\end{tabular}




\begin{tabular}{|c|c|c|c|c|c|c|c|c|c|c|c|c|c|c|c|c|c|c|}
\hline VarName & VariableLabel & WordingDE & ValueLabelsDE_Linked & WordingEN & ValueLabelsEN_Linked & $\mathrm{L} 1$ & L1F L2 & L3 & $\mathrm{L} 4$ & L5 & L6 6 & L7 & L8 & L9 & L10 & L11 & L12 & 2 L13 L14 \\
\hline study. 4 & Study Item 4 & $\begin{array}{l}\text { In welchem Masse } \\
\text { würdest Du den } \\
\text { folgenden Aussagen } \\
\text { zustimmen? Ich denke, } \\
\text { dass ich generell mehr } \\
\text { lerne, als die Mehrheit } \\
\text { meiner Mitstudierenden }\end{array}$ & $\begin{array}{l}1=\text { überhaupt nicht } \\
\text { einverstanden, } 2=\text { nicht } \\
\text { einverstanden, } 3=\text { eher } \\
\text { nicht einverstanden, } 4= \\
\text { weder noch, } 5=\text { eher } \\
\text { einverstanden, } 6= \\
\text { einverstanden, } 7=\text { völlig } \\
\text { einverstanden }\end{array}$ & $\begin{array}{l}\text { To what extent would } \\
\text { you agree with the } \\
\text { following statements? I } \\
\text { think that I generally } \\
\text { study more than my } \\
\text { fellow students. (free } \\
\text { translation) }\end{array}$ & $\begin{array}{l}1=\text { don't agree at all, } 2= \\
\text { don't agree, } 3=\text { rather } \\
\text { not agree, } 4=\text { neither, } 5 \\
=\text { rather agree, } 6=\text { agree } \\
7=\text { agree completely (free } \\
\text { translation) }\end{array}$ & $\mathrm{x}$ & $\mathrm{x}$ & $\mathrm{x}$ & $\mathrm{x}$ & $\mathrm{x}$ & $\mathrm{x}$ & $\mathrm{x}$ & $\mathrm{x}$ & $\mathrm{x}$ & $\mathrm{x}$ & $\mathrm{x}$ & $\mathrm{x}$ & $\mathrm{x}$ \\
\hline performance.1 & $\begin{array}{l}\text { Performance } \\
\text { Item } 1\end{array}$ & $\begin{array}{l}\text { Warst Du ein guter } \\
\text { Schüler / eine gute } \\
\text { Schülerin in Deiner } \\
\text { vorherigen Klasse? }\end{array}$ & $\begin{array}{l}1=\text { Unter den besten, } 2= \\
\text { ganz ok, } 3=\text { nicht so gut } \\
4=\text { eher bei den } \\
\text { Schlechteren }\end{array}$ & $\begin{array}{l}\text { Would you say you were } \\
\text { a good student in high } \\
\text { school? }\end{array}$ & $\begin{array}{l}1=\text { one of the best, } 2= \\
\text { quite ok, } 3=\text { not so good, } \\
4=\text { rather one of the } \\
\text { poorer (free translation) }\end{array}$ & $\mathrm{x}$ & & & & & & & & & & & & \\
\hline performance. 2 & $\begin{array}{l}\text { Performance } \\
\text { Item } 2\end{array}$ & $\begin{array}{l}\text { Wie war Deine } \\
\text { Maturanote? }\end{array}$ & & $\begin{array}{l}\text { What was your matura } \\
\text { grade? }\end{array}$ & & $\mathrm{x}$ & & & & & & & & & & & & \\
\hline performance. 3 & $\begin{array}{l}\text { Performance } \\
\text { Item } 3\end{array}$ & $\begin{array}{l}\text { Mit welcher } \\
\text { Durchschnitts - Note, } \\
\text { denkst Du, wirst du die } \\
\text { Basisjahrprüfungen } \\
\text { abschneiden? }\end{array}$ & $\begin{array}{l}1=0.0,2=0.1,3=0.2, \\
4=0.3,5=0.4,6=0.5, \\
7=0.6,8=0.7,9=0.8, \\
10=0.9,11=1.0,12= \\
1.1,13=1.2,14=1.3,15 \\
=1.4,16=1.5,17=1.6, \\
18=1.7,19=1.8,20= \\
1.9,21=2.0,22=2.1,23 \\
=2.2,24=2.3,25=2.4, \\
26=2.5,27=2.6,28= \\
2.7,29=2.8,30=2.9,31 \\
=3.0,32=3.1,33=3.2, \\
34=3.3,35=3.4,36= \\
3.5,37=3.6,38=3.7,39 \\
=3.8,40=3.9,41=4.0, \\
42=4.1,43=4.2,44= \\
4.3,45=4.4,46=4.5,47 \\
=4.6,48=4.7,49=4.8, \\
50=4.9,51=5.0,52= \\
5.1,53=5.2,54=5.3,55 \\
=5.4,56=5.5,57=5.6, \\
58=5.7,59=5.8,60= \\
5.9,1=6.0\end{array}$ & $\begin{array}{l}\text { What outcome (grade) } \\
\text { do you expect for the } \\
\text { Basisprüfung? (free } \\
\text { tanslation) }\end{array}$ & $\begin{array}{l}1=0.0,2=0.1,3=0.2, \\
4=0.3,5=0.4,6=0.5, \\
7=0.6,8=0.7,9=0.8, \\
10=0.9,11=1.0,12= \\
1.1,13=1.2,14=1.3,15 \\
=1.4,16=1.5,17=1.6, \\
18=1.7,19=1.8,20= \\
1.9,21=2.0,22=2.1,23 \\
=2.2,24=2.3,25=2.4, \\
26=2.5,27=2.6,28= \\
2.7,29=2.8,30=2.9,31 \\
=3.0,32=3.1,33=3.2, \\
34=3.3,35=3.4,36= \\
3.5,37=3.6,38=3.7,39 \\
=3.8,40=3.9,41=4.0, \\
42=4.1,43=4.2,44= \\
4.3,45=4.4,46=4.5,47 \\
=4.6,48=4.7,49=4.8 \\
50=4.9,51=5.0,52= \\
5.1,53=5.2,54=5.3,55 \\
=5.4,56=5.5,57=5.6, \\
58=5.7,59=5.8,60= \\
5.9,1=6.0\end{array}$ & $\mathrm{x}$ & & & & & & & & & & & & \\
\hline learn.obj.1 & $\begin{array}{l}\text { Learning } \\
\text { objective item } \\
1\end{array}$ & $\begin{array}{l}\text { Bei diesen Fragen geht } \\
\text { es um die Dinge, die dir } \\
\text { persönlich im Studium } \\
\text { wichtig sind. Im } \\
\text { Studium geht es mir } \\
\text { darum, neue Ideen zu } \\
\text { bekommen }\end{array}$ & $\begin{array}{l}1=\text { stimmt gar nicht, } 2= \\
\text { stimmt eher nicht, } 3= \\
\text { weder noch, } 4=\text { stimmt } \\
\text { eher, } 5=\text { stimmt genau }\end{array}$ & $\begin{array}{l}\text { In my studies it is } \\
\text { important to: get new } \\
\text { ideas. }\end{array}$ & $\begin{array}{l}1=\text { don't agree at all, } 2= \\
\text { rather not agree, } 3= \\
\text { neither, } 4=\text { rather agree, } \\
5=\text { agree completely (free } \\
\text { translation) }\end{array}$ & $\mathrm{x}$ & $\mathrm{x}$ & $\mathrm{x}$ & $\mathrm{x}$ & $\mathrm{x}$ & $\mathrm{x}$ & $\mathrm{x}$ & $\mathrm{x}$ & $\mathrm{x}$ & $\mathrm{x}$ & $\mathrm{x}$ & $\mathrm{x}$ & $\mathrm{x}$ \\
\hline app.perf.1 & $\begin{array}{l}\text { Approximate } \\
\text { performance } \\
\text { goal item } 1\end{array}$ & $\begin{array}{l}\text { Bei diesen Fragen geht } \\
\text { es um die Dinge, die dir } \\
\text { persönlich im Studium } \\
\text { wichtig sind. Im } \\
\text { Studium geht es mir } \\
\text { darum, zu zeigen, dass } \\
\text { ich bei einer Sache gut } \\
\text { bin }\end{array}$ & $\begin{array}{l}1=\text { stimmt gar nicht, } 2= \\
\text { stimmt eher nicht, } 3= \\
\text { weder noch, } 4=\text { stimmt } \\
\text { eher, } 5=\text { stimmt genau }\end{array}$ & $\begin{array}{l}\text { In my studies it is } \\
\text { important to: show that } \\
\text { I am good at things. }\end{array}$ & $\begin{array}{l}1=\text { don't agree at all, } 2= \\
\text { rather not agree, } 3= \\
\text { neither, } 4=\text { rather agree, } \\
5=\text { agree completely (free } \\
\text { translation) }\end{array}$ & $\mathrm{x}$ & $\mathrm{x}$ & $\mathrm{x}$ & $\mathrm{x}$ & $\mathrm{x}$ & $\mathrm{X}$ & $\mathrm{x}$ & $\mathrm{x}$ & $\mathrm{X}$ & $\mathrm{x}$ & $\mathrm{x}$ & $\mathrm{x}$ & $\mathrm{x}$ \\
\hline avoid.perf.1 & $\begin{array}{l}\text { Avoidance } \\
\text { performance } \\
\text { goal item } 1\end{array}$ & $\begin{array}{l}\text { Bei diesen Fragen geht } \\
\text { es um die Dinge, die dir } \\
\text { persönlich im Studium } \\
\text { wichtig sind. Im } \\
\text { Studium geht es mir } \\
\text { darum, dass andere } \\
\text { Schüler nicht denken, } \\
\text { ich sei dumm }\end{array}$ & $\begin{array}{l}1=\text { stimmt gar nicht, } 2= \\
\text { stimmt eher nicht, } 3= \\
\text { weder noch, } 4=\text { stimmt } \\
\text { eher, } 5=\text { stimmt genau }\end{array}$ & $\begin{array}{l}\text { In my studies it is } \\
\text { important that: the } \\
\text { other students don't } \\
\text { think I am stupid. }\end{array}$ & $\begin{array}{l}1=\text { don't agree at all, } 2= \\
\text { rather not agree, } 3= \\
\text { neither, } 4=\text { rather agree, } \\
5=\text { agree completely (free } \\
\text { translation) }\end{array}$ & $\mathrm{x}$ & $\mathrm{x}$ & $\mathrm{x}$ & $\mathrm{x}$ & $\mathrm{x}$ & $\mathrm{x}$ & $\mathrm{x}$ & $\mathrm{x}$ & $\mathrm{x}$ & $\mathrm{x}$ & $\mathrm{x}$ & $\mathrm{x}$ & $\mathrm{x}$ \\
\hline
\end{tabular}




\begin{tabular}{|c|c|c|c|c|c|c|c|c|c|c|c|c|c|c|c|c|c|c|}
\hline VarName & VariableLabel & WordingDE & ValueLabelsDE_Linked & WordingEN & ValueLabelsEN_Linked & L1 & L1F L2 & L3 & $\mathrm{L} 4$ & L5 & L6 & L7 & L8 & L9 & L10 & 0 L11 & $1 \mathrm{~L} 12$ & 2 L13 L14 \\
\hline work.avoid.1 & $\begin{array}{l}\text { Work } \\
\text { avoidance item } \\
1\end{array}$ & $\begin{array}{l}\text { Bei diesen Fragen geht } \\
\text { es um die Dinge, die dir } \\
\text { persönlich im Studium } \\
\text { wichtig sind. Im } \\
\text { Studium geht es mir } \\
\text { darum, keine } \\
\text { schwierigen Tests oder } \\
\text { Arbeiten zu haben }\end{array}$ & $\begin{array}{l}1=\text { stimmt gar nicht, } 2= \\
\text { stimmt eher nicht, } 3= \\
\text { weder noch, } 4=\text { stimmt } \\
\text { eher, } 5=\text { stimmt genau }\end{array}$ & $\begin{array}{l}\text { In my studies it is } \\
\text { important to have no } \\
\text { difficult tests or } \\
\text { assignments. (free } \\
\text { translation) }\end{array}$ & $\begin{array}{l}1=\text { don't agree at all, } 2= \\
\text { rather not agree, } 3= \\
\text { neither, } 4=\text { rather agree, } \\
5=\text { agree completely (free } \\
\text { translation) }\end{array}$ & $\mathrm{x}$ & $\mathrm{x}$ & $\mathrm{x}$ & $\mathrm{x}$ & $\mathrm{x}$ & $\mathrm{x}$ & $\mathrm{x}$ & $\mathrm{x}$ & $\mathrm{x}$ & $\mathrm{x}$ & $\mathrm{x}$ & $\mathrm{x}$ & $\mathrm{x}$ \\
\hline learn.obj.2 & $\begin{array}{l}\text { Learning } \\
\text { objective item } \\
2\end{array}$ & $\begin{array}{l}\text { Bei diesen Fragen geht } \\
\text { es um die Dinge, die dir } \\
\text { persönlich im Studium } \\
\text { wichtig sind. Im } \\
\text { Studium geht es mir } \\
\text { darum, etwas } \\
\text { Interessantes zu lernen }\end{array}$ & $\begin{array}{l}1=\text { stimmt gar nicht, } 2= \\
\text { stimmt eher nicht, } 3= \\
\text { weder noch, } 4=\text { stimmt } \\
\text { eher, } 5=\text { stimmt genau }\end{array}$ & $\begin{array}{l}\text { In my studies it is } \\
\text { important to: learn } \\
\text { something interesting. }\end{array}$ & $\begin{array}{l}1=\text { don't agree at all, } 2= \\
\text { rather not agree, } 3= \\
\text { neither, } 4=\text { rather agree, } \\
5=\text { agree completely (free } \\
\text { translation) }\end{array}$ & $\mathrm{x}$ & $\mathrm{x}$ & $\mathrm{x}$ & $\mathrm{x}$ & $\mathrm{x}$ & $\mathrm{x}$ & $\mathrm{x}$ & $\mathrm{x}$ & $\mathrm{x}$ & $\mathrm{x}$ & $\mathrm{x}$ & $\mathrm{x}$ & $\mathrm{x}$ \\
\hline avoid.perf.2 & $\begin{array}{l}\text { Avoidance } \\
\text { performance } \\
\text { goal item } 2\end{array}$ & $\begin{array}{l}\text { Bei diesen Fragen geht } \\
\text { es um die Dinge, die dir } \\
\text { persönlich im Studium } \\
\text { wichtig sind. Im } \\
\text { Studium geht es mir } \\
\text { darum, mich nicht zu } \\
\text { blamieren (z.B. durch } \\
\text { falsche Ergebnisse oder } \\
\text { dumme Fragen) }\end{array}$ & $\begin{array}{l}1=\text { stimmt gar nicht, } 2= \\
\text { stimmt eher nicht, } 3= \\
\text { weder noch, } 4=\text { stimmt } \\
\text { eher, } 5=\text { stimmt genau }\end{array}$ & $\begin{array}{l}\text { In my studies it is } \\
\text { important that: I don't } \\
\text { embarrass myself (e.g., } \\
\text { by wrong answers or } \\
\text { stupid questions). }\end{array}$ & $\begin{array}{l}1=\text { don't agree at all, } 2= \\
\text { rather not agree, } 3= \\
\text { neither, } 4=\text { rather agree, } \\
5=\text { agree completely (free } \\
\text { translation) }\end{array}$ & $\mathrm{x}$ & $\mathrm{x}$ & $\mathrm{x}$ & $\mathrm{x}$ & $\mathrm{x}$ & $\mathrm{x}$ & $\mathrm{x}$ & $\mathrm{x}$ & $\mathrm{x}$ & $\mathrm{x}$ & $\mathrm{X}$ & $\mathrm{x}$ & $\mathrm{x}$ \\
\hline work.avoid.2 & $\begin{array}{l}\text { Work } \\
\text { avoidance item } \\
2\end{array}$ & $\begin{array}{l}\text { Bei diesen Fragen geht } \\
\text { es um die Dinge, die dir } \\
\text { persönlich im Studium } \\
\text { wichtig sind. Im } \\
\text { Studium geht es mir } \\
\text { darum, zu Hause keine } \\
\text { Arbeiten erledigen zu } \\
\text { müssen }\end{array}$ & $\begin{array}{l}1=\text { stimmt gar nicht, } 2= \\
\text { stimmt eher nicht, } 3= \\
\text { weder noch, } 4=\text { stimmt } \\
\text { eher, } 5=\text { stimmt genau }\end{array}$ & $\begin{array}{l}\text { n my studies it is } \\
\text { important to not have } \\
\text { to work at home. (free } \\
\text { translation) }\end{array}$ & $\begin{array}{l}1=\text { don't agree at all, } 2= \\
\text { rather not agree, } 3= \\
\text { neither, } 4=\text { rather agree, } \\
5=\text { agree completely (free } \\
\text { translation) }\end{array}$ & $\mathrm{x}$ & $\mathrm{x}$ & $\mathrm{x}$ & $\mathrm{x}$ & $\mathrm{x}$ & $\mathrm{x}$ & $\mathrm{x}$ & $\mathrm{x}$ & $\mathrm{x}$ & $\mathrm{x}$ & $\mathrm{x}$ & $\mathrm{x}$ & $\mathrm{x}$ \\
\hline learn.obj.3 & $\begin{array}{l}\text { Learning } \\
\text { objective item } \\
3\end{array}$ & $\begin{array}{l}\text { Bei diesen Fragen geht } \\
\text { es um die Dinge, die dir } \\
\text { persönlich im Studium } \\
\text { wichtig sind. Im } \\
\text { Studium geht es mir } \\
\text { darum, später knifflige } \\
\text { Probleme lösen zu } \\
\text { können }\end{array}$ & $\begin{array}{l}1=\text { stimmt gar nicht, } 2= \\
\text { stimmt eher nicht, } 3= \\
\text { weder noch, } 4=\text { stimmt } \\
\text { eher, } 5=\text { stimmt genau }\end{array}$ & $\begin{array}{l}\text { In my studies it is } \\
\text { important to be able to } \\
\text { solve difficult problems } \\
\text { later. (free translation) }\end{array}$ & $\begin{array}{l}1=\text { don't agree at all, } 2= \\
\text { rather not agree, } 3= \\
\text { neither, } 4=\text { rather agree, } \\
5=\text { agree completely (free } \\
\text { translation) }\end{array}$ & $\mathrm{x}$ & $\mathrm{x}$ & $\mathrm{x}$ & $\mathrm{x}$ & $\mathrm{x}$ & $\mathrm{x}$ & $\mathrm{x}$ & $\mathrm{x}$ & $\mathrm{x}$ & $\mathrm{x}$ & $\mathrm{x}$ & $\mathrm{x}$ & $\mathrm{x}$ \\
\hline app.perf.2 & $\begin{array}{l}\text { Approximate } \\
\text { performance } \\
\text { goal item } 2\end{array}$ & $\begin{array}{l}\text { Bei diesen Fragen geht } \\
\text { es um die Dinge, die dir } \\
\text { persönlich im Studium } \\
\text { wichtig sind. Im } \\
\text { Studium geht es mir } \\
\text { darum, Arbeiten besser } \\
\text { zu schaffen als andere }\end{array}$ & $\begin{array}{l}1=\text { stimmt gar nicht, } 2= \\
\text { stimmt eher nicht, } 3= \\
\text { weder noch, } 4=\text { stimmt } \\
\text { eher, } 5=\text { stimmt genau }\end{array}$ & $\begin{array}{l}\text { In my studies it is } \\
\text { important to: do my } \\
\text { work better than others. }\end{array}$ & $\begin{array}{l}1=\text { don't agree at all, } 2= \\
\text { rather not agree, } 3= \\
\text { neither, } 4=\text { rather agree, } \\
5=\text { agree completely (free } \\
\text { translation) }\end{array}$ & $\mathrm{x}$ & $\mathrm{x}$ & $\mathrm{x}$ & $\mathrm{x}$ & $\mathrm{x}$ & $\mathrm{x}$ & $\mathrm{x}$ & $\mathrm{x}$ & $\mathrm{x}$ & $\mathrm{x}$ & $\mathrm{x}$ & $\mathrm{x}$ & $\mathrm{x}$ \\
\hline avoid.perf.3 & $\begin{array}{l}\text { Avoidance } \\
\text { performance } \\
\text { goal item } 3\end{array}$ & $\begin{array}{l}\text { Bei diesen Fragen geht } \\
\text { es um die Dinge, die dir } \\
\text { persönlich im Studium } \\
\text { wichtig sind. Im } \\
\text { Studium geht es mir } \\
\text { darum, dass niemand } \\
\text { merkt, wenn ich etwas } \\
\text { nicht verstehe }\end{array}$ & $\begin{array}{l}1=\text { stimmt gar nicht, } 2= \\
\text { stimmt eher nicht, } 3= \\
\text { weder noch, } 4=\text { stimmt } \\
\text { eher, } 5=\text { stimmt genau }\end{array}$ & $\begin{array}{l}\text { In my studies it is } \\
\text { important that: others } \\
\text { don't notice when I } \\
\text { don't understand things. }\end{array}$ & $\begin{array}{l}1=\text { don't agree at all, } 2= \\
\text { rather not agree, } 3= \\
\text { neither, } 4=\text { rather agree, } \\
5=\text { agree completely (free } \\
\text { translation) }\end{array}$ & $\mathrm{x}$ & $\mathrm{x}$ & $\mathrm{x}$ & $\mathrm{x}$ & $\mathrm{x}$ & $\mathrm{x}$ & $\mathrm{x}$ & $\mathrm{x}$ & $\mathrm{x}$ & $\mathrm{x}$ & $\mathrm{x}$ & $\mathrm{x}$ & $\mathrm{x}$ \\
\hline work.avoid.3 & $\begin{array}{l}\text { Work } \\
\text { avoidance item } \\
3\end{array}$ & $\begin{array}{l}\text { Bei diesen Fragen geht } \\
\text { es um die Dinge, die dir } \\
\text { persönlich im Studium } \\
\text { wichtig sind. Im } \\
\text { Studium geht es mir } \\
\text { darum, keine } \\
\text { schwierigen Fragen oder } \\
\text { Aufgaben lösen zu } \\
\text { müssen }\end{array}$ & $\begin{array}{l}1=\text { stimmt gar nicht, } 2= \\
\text { stimmt eher nicht, } 3= \\
\text { weder noch, } 4=\text { stimmt } \\
\text { eher, } 5=\text { stimmt genau }\end{array}$ & $\begin{array}{l}\text { In my studies it is } \\
\text { important not to have to } \\
\text { solve difficult questions } \\
\text { or assignments. (free } \\
\text { translation) }\end{array}$ & $\begin{array}{l}1=\text { don't agree at all, } 2= \\
\text { rather not agree, } 3= \\
\text { neither, } 4=\text { rather agree, } \\
5=\text { agree completely (free } \\
\text { translation) }\end{array}$ & $\mathrm{x}$ & $\mathrm{x}$ & $\mathrm{x}$ & $\mathrm{x}$ & $\mathrm{x}$ & $\mathrm{x}$ & $\mathrm{x}$ & $\mathrm{x}$ & $\mathrm{x}$ & $\mathrm{x}$ & $\mathrm{x}$ & $\mathrm{x}$ & $\mathrm{x}$ \\
\hline
\end{tabular}




\begin{tabular}{|c|c|c|c|c|c|c|c|c|c|c|c|c|c|c|c|c|c|c|}
\hline VarName & VariableLabel & WordingDE & ValueLabelsDE_Linked & WordingEN & ValueLabelsEN_Linked & $\mathrm{L} 1$ & L1F L2 & L3 & $\mathrm{L} 4$ & L5 & L6 6 & L7 & L8 & L9 & L10 & o L11 & L12 & 2 L13 L14 \\
\hline learn.obj.4 & $\begin{array}{l}\text { Learning } \\
\text { objective item } \\
4\end{array}$ & $\begin{array}{l}\text { Bei diesen Fragen geht } \\
\text { es um die Dinge, die dir } \\
\text { persönlich im Studium } \\
\text { wichtig sind. Im } \\
\text { Studium geht es mir } \\
\text { darum, komplizierte } \\
\text { Inhalte zu verstehen }\end{array}$ & $\begin{array}{l}1=\text { stimmt gar nicht, } 2= \\
\text { stimmt eher nicht, } 3= \\
\text { weder noch, } 4=\text { stimmt } \\
\text { eher, } 5=\text { stimmt genau }\end{array}$ & $\begin{array}{l}\text { In my studies it is } \\
\text { important to: } \\
\text { understand difficult } \\
\text { things. }\end{array}$ & $\begin{array}{l}1=\text { don't agree at all, } 2= \\
\text { rather not agree, } 3= \\
\text { neither, } 4=\text { rather agree, } \\
5=\text { agree completely (free } \\
\text { translation) }\end{array}$ & $\mathrm{x}$ & $\mathrm{x}$ & $\mathrm{x}$ & $\mathrm{x}$ & $\mathrm{x}$ & $\mathrm{x}$ & $\mathrm{x}$ & $\mathrm{x}$ & $\mathrm{x}$ & $\mathrm{x}$ & $\mathrm{x}$ & $\mathrm{x}$ & $\mathrm{x}$ \\
\hline app.perf.3 & $\begin{array}{l}\text { Approximate } \\
\text { performance } \\
\text { goal item } 3\end{array}$ & $\begin{array}{l}\text { Bei diesen Fragen geht } \\
\text { es um die Dinge, die dir } \\
\text { persönlich im Studium } \\
\text { wichtig sind. Im } \\
\text { Studium geht es mir } \\
\text { darum, bessere Noten zu } \\
\text { bekommen als andere }\end{array}$ & $\begin{array}{l}1=\text { stimmt gar nicht, } 2= \\
\text { stimmt eher nicht, } 3= \\
\text { weder noch, } 4=\text { stimmt } \\
\text { eher, } 5=\text { stimmt genau }\end{array}$ & $\begin{array}{l}\text { In my studies it is } \\
\text { important to: get better } \\
\text { grades than others. }\end{array}$ & $\begin{array}{l}1=\text { don't agree at all, } 2= \\
\text { rather not agree, } 3= \\
\text { neither, } 4=\text { rather agree, } \\
5=\text { agree completely (free } \\
\text { translation) }\end{array}$ & $\mathrm{x}$ & $\mathrm{x}$ & $\mathrm{x}$ & $\mathrm{x}$ & $\mathrm{x}$ & $\mathrm{x}$ & $\mathrm{x}$ & $\mathrm{x}$ & $\mathrm{x}$ & $\mathrm{x}$ & $\mathrm{x}$ & $\mathrm{x}$ & $\mathrm{x}$ \\
\hline avoid.perf.4 & $\begin{array}{l}\text { Avoidance } \\
\text { performance } \\
\text { goal item } 4\end{array}$ & $\begin{array}{l}\text { Bei diesen Fragen geht } \\
\text { es um die Dinge, die dir } \\
\text { persönlich im Studium } \\
\text { wichtig sind. Im } \\
\text { Studium geht es mir } \\
\text { darum, nicht zu zeigen, } \\
\text { falls ich weniger schlau } \\
\text { bin als andere }\end{array}$ & $\begin{array}{l}1=\text { stimmt gar nicht, } 2= \\
\text { stimmt eher nicht, } 3= \\
\text { weder noch, } 4=\text { stimmt } \\
\text { eher, } 5=\text { stimmt genau }\end{array}$ & $\begin{array}{l}\text { In my studies it is } \\
\text { important that: I don't } \\
\text { want to show that I am } \\
\text { less smart than others. }\end{array}$ & $\begin{array}{l}1=\text { don't agree at all, } 2= \\
\text { rather not agree, } 3= \\
\text { neither, } 4=\text { rather agree, } \\
5=\text { agree completely (free } \\
\text { translation) }\end{array}$ & $\mathrm{x}$ & $\mathrm{x}$ & $\mathrm{x}$ & $\mathrm{x}$ & $\mathrm{x}$ & $\mathrm{x}$ & $\mathrm{x}$ & $\mathrm{x}$ & $\mathrm{x}$ & $\mathrm{x}$ & $\mathrm{x}$ & $\mathrm{x}$ & $\mathrm{x}$ \\
\hline work.avoid.4 & $\begin{array}{l}\text { Work } \\
\text { avoidance item } \\
4\end{array}$ & $\begin{array}{l}\text { Bei diesen Fragen geht } \\
\text { es um die Dinge, die dir } \\
\text { persönlich im Studium } \\
\text { wichtig sind. Im } \\
\text { Studium geht es mir } \\
\text { darum, nicht so schwer } \\
\text { zu arbeiten }\end{array}$ & $\begin{array}{l}1=\text { stimmt gar nicht, } 2= \\
\text { stimmt eher nicht, } 3= \\
\text { weder noch, } 4=\text { stimmt } \\
\text { eher, } 5=\text { stimmt genau }\end{array}$ & $\begin{array}{l}\text { In my studies it is } \\
\text { important not to have } \\
\text { to work too hard. (free } \\
\text { translation) }\end{array}$ & $\begin{array}{l}1=\text { don't agree at all, } 2= \\
\text { rather not agree, } 3= \\
\text { neither, } 4=\text { rather agree, } \\
5=\text { agree completely (free } \\
\text { translation) }\end{array}$ & $\mathrm{x}$ & $\mathrm{x}$ & $\mathrm{x}$ & $\mathrm{x}$ & $\mathrm{x}$ & $\mathrm{x}$ & $\mathrm{x}$ & $\mathrm{x}$ & $\mathrm{x}$ & $\mathrm{x}$ & $\mathrm{x}$ & $\mathrm{x}$ & $\mathrm{x}$ \\
\hline learn.obj.5 & $\begin{array}{l}\text { Learning } \\
\text { objective item } \\
5\end{array}$ & $\begin{array}{l}\text { Bei diesen Fragen geht } \\
\text { es um die Dinge, die dir } \\
\text { persönlich im Studium } \\
\text { wichtig sind. Im } \\
\text { Studium geht es mir } \\
\text { darum, dass das } \\
\text { Gelernte für mich Sinn } \\
\text { ergibt }\end{array}$ & $\begin{array}{l}1=\text { stimmt gar nicht, } 2= \\
\text { stimmt eher nicht, } 3= \\
\text { weder noch, } 4=\text { stimmt } \\
\text { eher, } 5=\text { stimmt genau }\end{array}$ & $\begin{array}{l}\text { In my studies it is } \\
\text { important to: see that } \\
\text { what I learn makes } \\
\text { sense. }\end{array}$ & $\begin{array}{l}1=\text { don't agree at all, } 2= \\
\text { rather not agree, } 3= \\
\text { neither, } 4=\text { rather agree, } \\
5=\text { agree completely (free } \\
\text { translation) }\end{array}$ & $\mathrm{x}$ & $\mathrm{X}$ & $\mathrm{X}$ & $\mathrm{X}$ & $\mathrm{x}$ & $\mathrm{X}$ & $\mathrm{x}$ & $\mathrm{x}$ & $\mathrm{X}$ & $\mathrm{x}$ & $\mathrm{X}$ & $\mathrm{x}$ & $\mathrm{x}$ \\
\hline app.perf.4 & $\begin{array}{l}\text { Approximate } \\
\text { performance } \\
\text { goal item } 4\end{array}$ & $\begin{array}{l}\text { Bei diesen Fragen geht } \\
\text { es um die Dinge, die dir } \\
\text { persönlich im Studium } \\
\text { wichtig sind. Im } \\
\text { Studium geht es mir } \\
\text { darum, dass andere } \\
\text { denken, dass ich klug } \\
\text { bin }\end{array}$ & $\begin{array}{l}1=\text { stimmt gar nicht, } 2= \\
\text { stimmt eher nicht, } 3= \\
\text { weder noch, } 4=\text { stimmt } \\
\text { eher, } 5=\text { stimmt genau }\end{array}$ & $\begin{array}{l}\text { In my studies it is } \\
\text { important to: think that } \\
\text { I am smart. }\end{array}$ & $\begin{array}{l}1=\text { don't agree at all, } 2= \\
\text { rather not agree, } 3= \\
\text { neither, } 4=\text { rather agree, } \\
5=\text { agree completely (free } \\
\text { translation) }\end{array}$ & $\mathrm{x}$ & $\mathrm{x}$ & $\mathrm{x}$ & $\mathrm{x}$ & $\mathrm{x}$ & $\mathrm{x}$ & $\mathrm{x}$ & $\mathrm{x}$ & $\mathrm{x}$ & $\mathrm{x}$ & $\mathrm{x}$ & $\mathrm{x}$ & $\mathrm{x}$ \\
\hline avoid.perf.5 & $\begin{array}{l}\text { Avoidance } \\
\text { performance } \\
\text { goal item } 5\end{array}$ & $\begin{array}{l}\text { Bei diesen Fragen geht } \\
\text { es um die Dinge, die dir } \\
\text { persönlich im Studium } \\
\text { wichtig sind. Im } \\
\text { Studium geht es mir } \\
\text { darum, zu } \\
\text { verheimlichen, wenn ich } \\
\text { weniger weiß als andere }\end{array}$ & $\begin{array}{l}1=\text { stimmt gar nicht, } 2= \\
\text { stimmt eher nicht, } 3= \\
\text { weder noch, } 4=\text { stimmt } \\
\text { eher, } 5=\text { stimmt genau }\end{array}$ & $\begin{array}{l}\text { In my studies it is } \\
\text { important to: hide when } \\
\text { I know less than others. }\end{array}$ & $\begin{array}{l}1=\text { don't agree at all, } 2= \\
\text { rather not agree, } 3= \\
\text { neither, } 4=\text { rather agree, } \\
5=\text { agree completely (free } \\
\text { translation) }\end{array}$ & $\mathrm{x}$ & $\mathrm{x}$ & $\mathrm{x}$ & $\mathrm{X}$ & $\mathrm{x}$ & $\mathrm{x}$ & $\mathrm{x}$ & $\mathrm{x}$ & $\mathrm{X}$ & $\mathrm{x}$ & $\mathrm{x}$ & $\mathrm{x}$ & $\mathrm{x}$ \\
\hline work.avoid.5 & $\begin{array}{l}\text { Work } \\
\text { avoidance item } \\
5\end{array}$ & $\begin{array}{l}\text { Bei diesen Fragen geht } \\
\text { es um die Dinge, die dir } \\
\text { persönlich im Studium } \\
\text { wichtig sind. Im } \\
\text { Studium geht es mir } \\
\text { darum, dass die Arbeit } \\
\text { leicht ist }\end{array}$ & $\begin{array}{l}1=\text { stimmt gar nicht, } 2= \\
\text { stimmt eher nicht, } 3= \\
\text { weder noch, } 4=\text { stimmt } \\
\text { eher, } 5=\text { stimmt genau }\end{array}$ & $\begin{array}{l}\text { In my studies it is } \\
\text { important that work is } \\
\text { easy. (free translation) }\end{array}$ & $\begin{array}{l}1=\text { don't agree at all, } 2= \\
\text { rather not agree, } 3= \\
\text { neither, } 4=\text { rather agree, } \\
5=\text { agree completely (free } \\
\text { translation) }\end{array}$ & $\mathrm{x}$ & $\mathrm{x}$ & $\mathrm{x}$ & $\mathrm{x}$ & $\mathrm{x}$ & $\mathrm{x}$ & $\mathrm{x}$ & $\mathrm{x}$ & $\mathrm{x}$ & $\mathrm{x}$ & $\mathrm{x}$ & $\mathrm{x}$ & $\mathrm{x}$ \\
\hline
\end{tabular}




\begin{tabular}{|c|c|c|c|c|c|c|c|c|c|c|c|c|c|c|c|c|c|c|}
\hline VarName & VariableLabel & WordingDE & ValueLabelsDE_Linked & WordingEN & ValueLabelsEN_Linked & $\mathrm{L} 1$ & L1F L2 & L3 & $\mathrm{L} 4$ & L5 & L6 6 & L7 & L8 & L9 & L10 & L L11 & $1 \mathrm{~L} 12$ & 2 L13 L14 \\
\hline learn.obj.6 & $\begin{array}{l}\text { Learning } \\
\text { objective item } \\
6\end{array}$ & $\begin{array}{l}\text { Bei diesen Fragen geht } \\
\text { es um die Dinge, die dir } \\
\text { persönlich im Studium } \\
\text { wichtig sind. Im } \\
\text { Studium geht es mir } \\
\text { darum, zum Nachdenken } \\
\text { angeregt zu werden }\end{array}$ & $\begin{array}{l}1=\text { stimmt gar nicht, } 2= \\
\text { stimmt eher nicht, } 3= \\
\text { weder noch, } 4=\text { stimmt } \\
\text { eher, } 5=\text { stimmt genau }\end{array}$ & $\begin{array}{l}\text { In my studies it is } \\
\text { important to: be made } \\
\text { to think about things. }\end{array}$ & $\begin{array}{l}1=\text { don't agree at all, } 2= \\
\text { rather not agree, } 3= \\
\text { neither, } 4=\text { rather agree, } \\
5=\text { agree completely (free } \\
\text { translation) }\end{array}$ & $\mathrm{x}$ & $\mathrm{x}$ & $\mathrm{x}$ & $\mathrm{x}$ & $\mathrm{x}$ & $\mathrm{x}$ & $\mathrm{x}$ & $\mathrm{x}$ & $\mathrm{x}$ & $\mathrm{x}$ & $\mathrm{x}$ & $\mathrm{x}$ & $\mathrm{x}$ \\
\hline app.perf.5 & $\begin{array}{l}\text { Approximate } \\
\text { performance } \\
\text { goal item } 5\end{array}$ & $\begin{array}{l}\text { Bei diesen Fragen geht } \\
\text { es um die Dinge, die dir } \\
\text { persönlich im Studium } \\
\text { wichtig sind. Im } \\
\text { Studium geht es mir } \\
\text { darum, zu zeigen, dass } \\
\text { ich die } \\
\text { Unterrichtsinhalte } \\
\text { beherrsche }\end{array}$ & $\begin{array}{l}1=\text { stimmt gar nicht, } 2= \\
\text { stimmt eher nicht, } 3= \\
\text { weder noch, } 4=\text { stimmt } \\
\text { eher, } 5=\text { stimmt genau }\end{array}$ & $\begin{array}{l}\text { In my studies it is } \\
\text { important to: show that } \\
\text { I can do things. }\end{array}$ & $\begin{array}{l}1=\text { don't agree at all, } 2= \\
\text { rather not agree, } 3= \\
\text { neither, } 4=\text { rather agree, } \\
5=\text { agree completely (free } \\
\text { translation) }\end{array}$ & $\mathrm{x}$ & $\mathrm{x}$ & $\mathrm{x}$ & $\mathrm{x}$ & $\mathrm{x}$ & $\mathrm{x}$ & $\mathrm{x}$ & $\mathrm{x}$ & $\mathrm{x}$ & $\mathrm{x}$ & $\mathrm{x}$ & $\mathrm{x}$ & $\mathrm{x}$ \\
\hline avoid.perf.6 & $\begin{array}{l}\text { Avoidance } \\
\text { performance } \\
\text { goal item } 6\end{array}$ & $\begin{array}{l}\text { Bei diesen Fragen geht } \\
\text { es um die Dinge, die dir } \\
\text { persönlich im Studium } \\
\text { wichtig sind. Im } \\
\text { Studium geht es mir } \\
\text { darum, keine falschen } \\
\text { Antworten auf Fragen } \\
\text { des Lehrers zu geben }\end{array}$ & $\begin{array}{l}1=\text { stimmt gar nicht, } 2= \\
\text { stimmt eher nicht, } 3= \\
\text { weder noch, } 4=\text { stimmt } \\
\text { eher, } 5=\text { stimmt genau }\end{array}$ & $\begin{array}{l}\text { In my studies it is } \\
\text { important that: I don't } \\
\text { want to give wrong } \\
\text { answers to the teachers' } \\
\text { questions. }\end{array}$ & $\begin{array}{l}1=\text { don't agree at all, } 2= \\
\text { rather not agree, } 3= \\
\text { neither, } 4=\text { rather agree, } \\
5=\text { agree completely (free } \\
\text { translation) }\end{array}$ & $\mathrm{x}$ & $\mathrm{x}$ & $\mathrm{x}$ & $\mathrm{x}$ & $\mathrm{x}$ & $\mathrm{x}$ & $\mathrm{x}$ & $\mathrm{x}$ & $\mathrm{x}$ & $\mathrm{x}$ & $\mathrm{x}$ & $\mathrm{x}$ & $\mathrm{x}$ \\
\hline work.avoid.6 & $\begin{array}{l}\text { Work } \\
\text { avoidance item } \\
6\end{array}$ & $\begin{array}{l}\text { Bei diesen Fragen geht } \\
\text { es um die Dinge, die dir } \\
\text { persönlich im Studium } \\
\text { wichtig sind. Im } \\
\text { Studium geht es mir } \\
\text { darum, Aufgaben, die } \\
\text { viel Arbeit machen, } \\
\text { nicht selber erledigen zu } \\
\text { müssen }\end{array}$ & $\begin{array}{l}1=\text { stimmt gar nicht, } 2= \\
\text { stimmt eher nicht, } 3= \\
\text { weder noch, } 4=\text { stimmt } \\
\text { eher, } 5=\text { stimmt genau }\end{array}$ & $\begin{array}{l}\text { In my studies it is } \\
\text { important to not to } \\
\text { have to do tasks myself } \\
\text { that are a lot of work. } \\
\text { (free translation) }\end{array}$ & $\begin{array}{l}1=\text { don't agree at all, } 2= \\
\text { rather not agree, } 3= \\
\text { neither, } 4=\text { rather agree, } \\
5=\text { agree completely (free } \\
\text { translation) }\end{array}$ & $\mathrm{x}$ & $\mathrm{x}$ & $\mathrm{x}$ & $\mathrm{x}$ & $\mathrm{x}$ & $\mathrm{X}$ & $\mathrm{x}$ & $\mathrm{x}$ & $\mathrm{X}$ & $\mathrm{x}$ & $\mathrm{x}$ & $\mathrm{X}$ & $\mathrm{x}$ \\
\hline learn.obj.7 & $\begin{array}{l}\text { Learning } \\
\text { objective item } \\
7\end{array}$ & $\begin{array}{l}\text { Bei diesen Fragen geht } \\
\text { es um die Dinge, die dir } \\
\text { persönlich im Studium } \\
\text { wichtig sind. Im } \\
\text { Studium geht es mir } \\
\text { darum, so viel wie } \\
\text { möglich zu lernen }\end{array}$ & $\begin{array}{l}1=\text { stimmt gar nicht, } 2= \\
\text { stimmt eher nicht, } 3= \\
\text { weder noch, } 4=\text { stimmt } \\
\text { eher, } 5=\text { stimmt genau }\end{array}$ & $\begin{array}{l}\text { In my studies it is } \\
\text { important to: learn as } \\
\text { much as possible. }\end{array}$ & $\begin{array}{l}1=\text { don't agree at all, } 2= \\
\text { rather not agree, } 3= \\
\text { neither, } 4=\text { rather agree, } \\
5=\text { agree completely (free } \\
\text { translation) }\end{array}$ & $\mathrm{x}$ & $\mathrm{x}$ & $\mathrm{x}$ & $\mathrm{x}$ & $\mathrm{x}$ & $\mathrm{x}$ & $\mathrm{x}$ & $\mathrm{x}$ & $\mathrm{x}$ & $\mathrm{x}$ & $\mathrm{x}$ & $\mathrm{x}$ & $\mathrm{x}$ \\
\hline app.perf. 6 & $\begin{array}{l}\text { Approximate } \\
\text { performance } \\
\text { goal item } 6\end{array}$ & $\begin{array}{l}\text { Bei diesen Fragen geht } \\
\text { es um die Dinge, die dir } \\
\text { persönlich im Studium } \\
\text { wichtig sind. Im } \\
\text { Studium geht es mir } \\
\text { darum, das was ich kann } \\
\text { und weiß auch zu zeigen }\end{array}$ & $\begin{array}{l}1=\text { stimmt gar nicht, } 2= \\
\text { stimmt eher nicht, } 3= \\
\text { weder noch, } 4=\text { stimmt } \\
\text { eher, } 5=\text { stimmt genau }\end{array}$ & $\begin{array}{l}\text { In my studies it is } \\
\text { important to: show } \\
\text { what I can do and know. }\end{array}$ & $\begin{array}{l}1=\text { don't agree at all, } 2= \\
\text { rather not agree, } 3= \\
\text { neither, } 4=\text { rather agree, } \\
5=\text { agree completely (free } \\
\text { translation) }\end{array}$ & $\mathrm{x}$ & $\mathrm{x}$ & $\mathrm{x}$ & $\mathrm{x}$ & $\mathrm{x}$ & $\mathrm{x}$ & $\mathrm{x}$ & $\mathrm{x}$ & $\mathrm{x}$ & $\mathrm{x}$ & $\mathrm{x}$ & $\mathrm{x}$ & $\mathrm{x}$ \\
\hline avoid.perf.7 & $\begin{array}{l}\text { Avoidance } \\
\text { performance } \\
\text { goal item } 7\end{array}$ & $\begin{array}{l}\text { Bei diesen Fragen geht } \\
\text { es um die Dinge, die dir } \\
\text { persönlich im Studium } \\
\text { wichtig sind. Im } \\
\text { Studium geht es mir } \\
\text { darum, nicht durch } \\
\text { dumme Fragen } \\
\text { aufzufallen }\end{array}$ & $\begin{array}{l}1=\text { stimmt gar nicht, } 2= \\
\text { stimmt eher nicht, } 3= \\
\text { weder noch, } 4=\text { stimmt } \\
\text { eher, } 5=\text { stimmt genau }\end{array}$ & $\begin{array}{l}\text { In my studies it is } \\
\text { important that: I don't } \\
\text { want to call attention to } \\
\text { myself by asking stupid } \\
\text { questions. }\end{array}$ & $\begin{array}{l}1=\text { don't agree at all, } 2= \\
\text { rather not agree, } 3= \\
\text { neither, } 4=\text { rather agree, } \\
5=\text { agree completely (free } \\
\text { translation) }\end{array}$ & $\mathrm{x}$ & $\mathrm{x}$ & $\mathrm{x}$ & $\mathrm{x}$ & $\mathrm{x}$ & $\mathrm{x}$ & $\mathrm{x}$ & $\mathrm{x}$ & $\mathrm{x}$ & $\mathrm{x}$ & $\mathrm{x}$ & $\mathrm{x}$ & $\mathrm{x}$ \\
\hline work.avoid.7 & $\begin{array}{l}\text { Work } \\
\text { avoidance item } \\
7\end{array}$ & $\begin{array}{l}\text { Bei diesen Fragen geht } \\
\text { es um die Dinge, die dir } \\
\text { persönlich im Studium } \\
\text { wichtig sind. Im } \\
\text { Studium geht es mir } \\
\text { darum, mit wenig } \\
\text { Arbeit durch die Schule } \\
\text { zu kommen }\end{array}$ & $\begin{array}{l}1=\text { stimmt gar nicht, } 2= \\
\text { stimmt eher nicht, } 3= \\
\text { weder noch, } 4=\text { stimmt } \\
\text { eher, } 5=\text { stimmt genau }\end{array}$ & $\begin{array}{l}\text { In my studies it is } \\
\text { important to get } \\
\text { through school with } \\
\text { little work. (free } \\
\text { translation) }\end{array}$ & $\begin{array}{l}1=\text { don't agree at all, } 2= \\
\text { rather not agree, } 3= \\
\text { neither, } 4=\text { rather agree, } \\
5=\text { agree completely (free } \\
\text { translation) }\end{array}$ & $\mathrm{x}$ & $\mathrm{x}$ & $\mathrm{x}$ & $\mathrm{x}$ & $\mathrm{x}$ & $\mathrm{x}$ & $\mathrm{x}$ & $\mathrm{x}$ & $\mathrm{x}$ & $\mathrm{x}$ & $\mathrm{x}$ & $\mathrm{x}$ & $\mathrm{x}$ \\
\hline
\end{tabular}




\begin{tabular}{|c|c|c|c|c|c|c|c|c|c|c|c|c|c|c|c|c|c|c|}
\hline VarName & VariableLabel & WordingDE & ValueLabelsDE_Linked & WordingEN & ValueLabelsEN_Linked & L1 & L1F L2 & L3 & $\mathrm{L} 4$ & L5 & $\mathrm{L} 6$ & L7 & L8 & L9 & L1 & o L11 & $1 \mathrm{~L} 12$ & $2 \mathrm{~L} 13 \mathrm{~L} 14$ \\
\hline learn.obj.8 & $\begin{array}{l}\text { Learning } \\
\text { objective item } \\
8\end{array}$ & $\begin{array}{l}\text { Bei diesen Fragen geht } \\
\text { es um die Dinge, die dir } \\
\text { persönlich im Studium } \\
\text { wichtig sind. Im } \\
\text { Studium geht es mir } \\
\text { darum, die } \\
\text { Unterrichtsinhalte } \\
\text { wirklich zu verstehen }\end{array}$ & $\begin{array}{l}1=\text { stimmt gar nicht, } 2= \\
\text { stimmt eher nicht, } 3= \\
\text { weder noch, } 4=\text { stimmt } \\
\text { eher, } 5=\text { stimmt genau }\end{array}$ & $\begin{array}{l}\text { In my studies it is } \\
\text { important to: really } \\
\text { understand what is } \\
\text { taught. }\end{array}$ & $\begin{array}{l}1=\text { don't agree at all, } 2= \\
\text { rather not agree, } 3= \\
\text { neither, } 4=\text { rather agree, } \\
5=\text { agree completely (free } \\
\text { translation) }\end{array}$ & $\mathrm{x}$ & $\mathrm{x}$ & $\mathrm{x}$ & $\mathrm{x}$ & $\mathrm{x}$ & $\mathrm{x}$ & $\mathrm{x}$ & $\mathrm{X}$ & $\mathrm{x}$ & $\mathrm{x}$ & $\mathrm{x}$ & $\mathrm{x}$ & $\mathrm{X}$ \\
\hline app.perf.7 & $\begin{array}{l}\text { Approximate } \\
\text { performance } \\
\text { goal item } 7\end{array}$ & $\begin{array}{l}\text { Bei diesen Fragen geht } \\
\text { es um die Dinge, die dir } \\
\text { persönlich im Studium } \\
\text { wichtig sind. Im } \\
\text { Studium geht es mir } \\
\text { darum, dass die anderen } \\
\text { merken, dass ich in } \\
\text { Tests gut abschneide }\end{array}$ & $\begin{array}{l}1=\text { stimmt gar nicht, } 2= \\
\text { stimmt eher nicht, } 3= \\
\text { weder noch, } 4=\text { stimmt } \\
\text { eher, } 5=\text { stimmt genau }\end{array}$ & $\begin{array}{l}\text { In my studies it is } \\
\text { important to: notice } \\
\text { when I did well on a } \\
\text { test. }\end{array}$ & $\begin{array}{l}1=\text { don't agree at all, } 2= \\
\text { rather not agree, } 3= \\
\text { neither, } 4=\text { rather agree, } \\
5=\text { agree completely (free } \\
\text { translation) }\end{array}$ & $\mathrm{x}$ & $\mathrm{x}$ & $\mathrm{x}$ & $\mathrm{x}$ & $\mathrm{x}$ & $\mathrm{x}$ & $\mathrm{x}$ & $\mathrm{x}$ & $\mathrm{x}$ & $\mathrm{x}$ & $\mathrm{x}$ & $\mathrm{x}$ & $\mathrm{x}$ \\
\hline avoid.perf.8 & $\begin{array}{l}\text { Avoidance } \\
\text { performance } \\
\text { goal item } 8\end{array}$ & $\begin{array}{l}\text { Bei diesen Fragen geht } \\
\text { es um die Dinge, die dir } \\
\text { persönlich im Studium } \\
\text { wichtig sind. Im } \\
\text { Studium geht es mir } \\
\text { darum, nicht zu zeigen, } \\
\text { wenn mir eine Aufgabe } \\
\text { schwerer fällt als den } \\
\text { anderen }\end{array}$ & $\begin{array}{l}1=\text { stimmt gar nicht, } 2= \\
\text { stimmt eher nicht, } 3= \\
\text { weder noch, } 4=\text { stimmt } \\
\text { eher, } 5=\text { stimmt genau }\end{array}$ & $\begin{array}{l}\text { In my studies it is } \\
\text { important that: I don't } \\
\text { want to show when I } \\
\text { have more difficulties } \\
\text { with tasks than others. }\end{array}$ & $\begin{array}{l}1=\text { don't agree at all, } 2= \\
\text { rather not agree, } 3= \\
\text { neither, } 4=\text { rather agree, } \\
5=\text { agree completely (free } \\
\text { translation) }\end{array}$ & $\mathrm{x}$ & $\mathrm{x}$ & $\mathrm{x}$ & $\mathrm{x}$ & $\mathrm{x}$ & $\mathrm{x}$ & $\mathrm{x}$ & $\mathrm{x}$ & $\mathrm{x}$ & $\mathrm{x}$ & $\mathrm{x}$ & $\mathrm{x}$ & $\mathrm{x}$ \\
\hline work.avoid.8 & $\begin{array}{l}\text { Work } \\
\text { avoidance item } \\
8\end{array}$ & $\begin{array}{l}\text { Bei diesen Fragen geht } \\
\text { es um die Dinge, die dir } \\
\text { persönlich im Studium } \\
\text { wichtig sind. Im } \\
\text { Studium geht es mir } \\
\text { darum, den } \\
\text { Arbeitsaufwand immer } \\
\text { gering zu halten }\end{array}$ & $\begin{array}{l}1=\text { stimmt gar nicht, } 2= \\
\text { stimmt eher nicht, } 3= \\
\text { weder noch, } 4=\text { stimmt } \\
\text { eher, } 5=\text { stimmt genau }\end{array}$ & $\begin{array}{l}\text { In my studies it is } \\
\text { important to keep the } \\
\text { effort low. (free } \\
\text { translation) }\end{array}$ & $\begin{array}{l}1=\text { don't agree at all, } 2= \\
\text { rather not agree, } 3= \\
\text { neither, } 4=\text { rather agree, } \\
5=\text { agree completely (free } \\
\text { translation) }\end{array}$ & $\mathrm{x}$ & $\mathrm{x}$ & $\mathrm{x}$ & $\mathrm{x}$ & $\mathrm{x}$ & $\mathrm{x}$ & $\mathrm{x}$ & $\mathrm{x}$ & $\mathrm{x}$ & $\mathrm{x}$ & $\mathrm{X}$ & $\mathrm{x}$ & $\mathrm{X}$ \\
\hline sensitivity.1 & $\begin{array}{l}\text { Self- } \\
\text { monitoring } \\
\text { Item } 1\end{array}$ & $\begin{array}{l}\text { Im Folgenden geht es } \\
\text { um Dein Verhalten in } \\
\text { sozialen Situationen. } \\
\text { Wähle bitte die für Dich } \\
\text { am ehesten zutreffende } \\
\text { Antwort: Ich bin häufig } \\
\text { in der Lage, die wahren } \\
\text { Gefühle anderer } \\
\text { Personen in deren } \\
\text { Augen zu erkennen }\end{array}$ & $\begin{array}{l}1=\text { immer falsch, } 2= \\
\text { meist falsch, } 3= \\
\text { manchmal falsch, } 4= \\
\text { manchmal richtig, } 5= \\
\text { meist richtig, } 6=\text { immer } \\
\text { richtig }\end{array}$ & $\begin{array}{l}\text { The following questions } \\
\text { will be about your } \\
\text { behavior in social } \\
\text { situations: I am often } \\
\text { able to read people's } \\
\text { true emotions correctly } \\
\text { through their eyes. }\end{array}$ & $\begin{array}{l}1=\text { always wrong, } 2= \\
\text { usually wrong, } 3= \\
\text { sometimes wrong, } 4= \\
\text { sometimes right, } 5= \\
\text { usually right, } 6=\text { always } \\
\text { right }\end{array}$ & $\mathrm{x}$ & $\mathrm{x}$ & & $\mathrm{x}$ & $\mathrm{x}$ & & & & & & & & \\
\hline sensitivity. 2 & $\begin{array}{l}\text { Self- } \\
\text { monitoring } \\
\text { Item } 2\end{array}$ & $\begin{array}{l}\text { Im Folgenden geht es } \\
\text { um Dein Verhalten in } \\
\text { sozialen Situationen. } \\
\text { Wähle bitte die für Dich } \\
\text { am ehesten zutreffende } \\
\text { Antwort: In Gesprächen } \\
\text { bin ich für die kleinste } \\
\text { Veränderung im } \\
\text { Mienenspiel meines } \\
\text { Gegenübers sensibel. }\end{array}$ & $\begin{array}{l}1=\text { immer falsch, } 2= \\
\text { meist falsch, } 3= \\
\text { manchmal falsch, } 4= \\
\text { manchmal richtig, } 5= \\
\text { meist richtig, } 6=\text { immer } \\
\text { richtig }\end{array}$ & $\begin{array}{l}\text { The following questions } \\
\text { will be about your } \\
\text { behavior in social } \\
\text { situations: In } \\
\text { conversations, I am } \\
\text { sensitive to even the } \\
\text { slightest change in the } \\
\text { facial expression of the } \\
\text { person I'm conversing } \\
\text { with. }\end{array}$ & $\begin{array}{l}1=\text { always wrong, } 2= \\
\text { usually wrong, } 3= \\
\text { sometimes wrong, } 4= \\
\text { sometimes right, } 5= \\
\text { usually right, } 6=\text { always } \\
\text { right }\end{array}$ & $\mathrm{x}$ & $\mathrm{x}$ & & $\mathrm{x}$ & $\mathrm{x}$ & & & & & & & & \\
\hline sensitivity. 3 & $\begin{array}{l}\text { Self- } \\
\text { monitoring } \\
\text { Item } 3\end{array}$ & $\begin{array}{l}\text { Im Folgenden geht es } \\
\text { um Dein Verhalten in } \\
\text { sozialen Situationen. } \\
\text { Wähle bitte die für Dich } \\
\text { am ehesten zutreffende } \\
\text { Antwort: Meine } \\
\text { Intuition ist ziemlich } \\
\text { gut, wenn es um das } \\
\text { Verständnis der Gefühle } \\
\text { und Motive anderer geht }\end{array}$ & $\begin{array}{l}1=\text { immer falsch, } 2= \\
\text { meist falsch, } 3= \\
\text { manchmal falsch, } 4= \\
\text { manchmal richtig, } 5= \\
\text { meist richtig, } 6=\text { immer } \\
\text { richtig }\end{array}$ & $\begin{array}{l}\text { The following questions } \\
\text { will be about your } \\
\text { behavior in social } \\
\text { situations: My powers of } \\
\text { intuition are quite good } \\
\text { when it comes to } \\
\text { understanding others' } \\
\text { emotions and motives. }\end{array}$ & $\begin{array}{l}1=\text { always wrong, } 2= \\
\text { usually wrong, } 3= \\
\text { sometimes wrong, } 4= \\
\text { sometimes right, } 5= \\
\text { usually right, } 6=\text { always } \\
\text { right }\end{array}$ & $\mathrm{x}$ & $\mathrm{x}$ & & $\mathrm{x}$ & $\mathrm{x}$ & & & & & & & & \\
\hline
\end{tabular}




\begin{tabular}{|c|c|c|c|c|c|c|c|c|c|c|c|c|c|c|}
\hline VarName & VariableLabel & WordingDE & ValueLabelsDE_Linked & WordingEN & ValueLabelsEN_Linked & L1 & L1F L2 & L3 & $\mathrm{L} 4$ & L5 & L6 & L7 & L8 L9 & L10 L11 L12 L13 L14 \\
\hline sensitivity.4 & $\begin{array}{l}\text { Self- } \\
\text { monitoring } \\
\text { Item } 4\end{array}$ & $\begin{array}{l}\text { Im Folgenden geht es } \\
\text { um Dein Verhalten in } \\
\text { sozialen Situationen. } \\
\text { Wähle bitte die für Dich } \\
\text { am ehesten zutreffende } \\
\text { Antwort: Ich merke } \\
\text { gewöhnlich, wenn andere } \\
\text { einen Witz schlecht } \\
\text { finden, selbst wenn sie } \\
\text { überzeugend lachen }\end{array}$ & $\begin{array}{l}1=\text { immer falsch, } 2= \\
\text { meist falsch, } 3= \\
\text { manchmal falsch, } 4= \\
\text { manchmal richtig, } 5= \\
\text { meist richtig, } 6=\text { immer } \\
\text { richtig }\end{array}$ & $\begin{array}{l}\text { The following questions } \\
\text { will be about your } \\
\text { behavior in social } \\
\text { situations: My powers of } \\
\text { intuition are quite good } \\
\text { when it comes to } \\
\text { understanding others' } \\
\text { emotions and motives }\end{array}$ & $\begin{array}{l}1=\text { always wrong, } 2= \\
\text { usually wrong, } 3= \\
\text { sometimes wrong, } 4= \\
\text { sometimes right, } 5= \\
\text { usually right, } 6=\text { always } \\
\text { right }\end{array}$ & $\mathrm{x}$ & $\mathrm{x}$ & & $\mathrm{x}$ & $\mathrm{x}$ & & & & \\
\hline sensitivity. 5 & $\begin{array}{l}\text { Self- } \\
\text { monitoring } \\
\text { Item } 5\end{array}$ & $\begin{array}{l}\text { Im Folgenden geht es } \\
\text { um Dein Verhalten in } \\
\text { sozialen Situationen. } \\
\text { Wähle bitte die für Dich } \\
\text { am ehesten zutreffende } \\
\text { Antwort: Ich merke } \\
\text { gewöhnlich an den } \\
\text { Augen meines Zuhörers, } \\
\text { wenn ich etwas } \\
\text { Unangemessenes gesagt } \\
\text { habe }\end{array}$ & $\begin{array}{l}1=\text { immer falsch, } 2= \\
\text { meist falsch, } 3= \\
\text { manchmal falsch, } 4= \\
\text { manchmal richtig, } 5= \\
\text { meist richtig, } 6=\text { immer } \\
\text { richtig }\end{array}$ & $\begin{array}{l}\text { The following questions } \\
\text { will be about your } \\
\text { behavior in social } \\
\text { situations: I can usually } \\
\text { tell when I've said } \\
\text { something inappropriate } \\
\text { by reading it in the } \\
\text { listener's eyes. }\end{array}$ & $\begin{array}{l}1=\text { always wrong, } 2= \\
\text { usually wrong, } 3= \\
\text { sometimes wrong, } 4= \\
\text { sometimes right, } 5= \\
\text { usually right, } 6=\text { always } \\
\text { right }\end{array}$ & $\mathrm{x}$ & $\mathrm{x}$ & & $\mathrm{x}$ & $\mathrm{x}$ & & & & \\
\hline sensitivity. 6 & $\begin{array}{l}\text { Self- } \\
\text { monitoring } \\
\text { Item } 6\end{array}$ & $\begin{array}{l}\text { Im Folgenden geht es } \\
\text { um Dein Verhalten in } \\
\text { sozialen Situationen. } \\
\text { Wähle bitte die für Dich } \\
\text { am ehesten zutreffende } \\
\text { Antwort: Wenn mich } \\
\text { jemand anlügt, merke } \\
\text { ich das gewöhnlich } \\
\text { sofort an der Art seines } \\
\text { Ausdrucks }\end{array}$ & $\begin{array}{l}1=\text { immer falsch, } 2= \\
\text { meist falsch, } 3= \\
\text { manchmal falsch, } 4= \\
\text { manchmal richtig, } 5= \\
\text { meist richtig, } 6=\text { immer } \\
\text { richtig }\end{array}$ & $\begin{array}{l}\text { The following questions } \\
\text { will be about your } \\
\text { behavior in social } \\
\text { situations: If someone is } \\
\text { lying to me, I usually } \\
\text { know it at once from } \\
\text { that person's manner of } \\
\text { expression. }\end{array}$ & $\begin{array}{l}1=\text { always wrong, } 2= \\
\text { usually wrong, } 3= \\
\text { sometimes wrong, } 4= \\
\text { sometimes right, } 5= \\
\text { usually right, } 6=\text { always } \\
\text { right }\end{array}$ & $\mathrm{x}$ & $\mathrm{x}$ & & $\mathrm{x}$ & $\mathrm{x}$ & & & & \\
\hline selfpresentation.1 & $\begin{array}{l}\text { Self- } \\
\text { monitoring } \\
\text { Item } 7\end{array}$ & $\begin{array}{l}\text { Im Folgenden geht es } \\
\text { um Dein Verhalten in } \\
\text { sozialen Situationen. } \\
\text { Wähle bitte die für Dich } \\
\text { am ehesten zutreffende } \\
\text { Antwort: In sozialen } \\
\text { Situationen habe ich die } \\
\text { Fähigkeit, mein } \\
\text { Verhalten zu verändern, } \\
\text { wenn ich fühle, dass } \\
\text { etwas anderes erwartet } \\
\text { wird. }\end{array}$ & $\begin{array}{l}1=\text { immer falsch, } 2= \\
\text { meist falsch, } 3= \\
\text { manchmal falsch, } 4= \\
\text { manchmal richtig, } 5= \\
\text { meist richtig, } 6=\text { immer } \\
\text { richtig }\end{array}$ & $\begin{array}{l}\text { The following questions } \\
\text { will be about your } \\
\text { behavior in social } \\
\text { situations: In social } \\
\text { situations, I have the } \\
\text { ability to alter my } \\
\text { behavior if I feel that } \\
\text { something else is called } \\
\text { for. }\end{array}$ & $\begin{array}{l}1=\text { always wrong, } 2= \\
\text { usually wrong, } 3= \\
\text { sometimes wrong, } 4= \\
\text { sometimes right, } 5= \\
\text { usually right, } 6=\text { always } \\
\text { right }\end{array}$ & $\mathrm{x}$ & $\mathrm{x}$ & & $\mathrm{x}$ & $\mathrm{x}$ & & & & \\
\hline selfpresentation.2 & $\begin{array}{l}\text { Self- } \\
\text { monitoring } \\
\text { Item } 8\end{array}$ & $\begin{array}{l}\text { Im Folgenden geht es } \\
\text { um Dein Verhalten in } \\
\text { sozialen Situationen. } \\
\text { Wähle bitte die für Dich } \\
\text { am ehesten zutreffende } \\
\text { Antwort: In } \\
\text { Abhängigkeit davon, } \\
\text { welchen Eindruck ich } \\
\text { erwecken möchte, bin } \\
\text { ich fähig, die Art und } \\
\text { Weise, wie ich Menschen } \\
\text { gegenübertrete, zu } \\
\text { kontrollieren }\end{array}$ & $\begin{array}{l}1=\text { immer falsch, } 2= \\
\text { meist falsch, } 3= \\
\text { manchmal falsch, } 4= \\
\text { manchmal richtig, } 5= \\
\text { meist richtig, } 6=\text { immer } \\
\text { richtig }\end{array}$ & $\begin{array}{l}\text { The following questions } \\
\text { will be about your } \\
\text { behavior in social } \\
\text { situations: I have the } \\
\text { ability to control the } \\
\text { way I come across to } \\
\text { people, depending on } \\
\text { the impression I wish to } \\
\text { give them. }\end{array}$ & $\begin{array}{l}1=\text { always wrong, } 2= \\
\text { usually wrong, } 3= \\
\text { sometimes wrong, } 4= \\
\text { sometimes right, } 5= \\
\text { usually right, } 6=\text { always } \\
\text { right }\end{array}$ & $\mathrm{x}$ & $\mathrm{x}$ & & $\mathrm{x}$ & $\mathrm{x}$ & & & & \\
\hline
\end{tabular}




\begin{tabular}{|c|c|c|c|c|c|c|c|c|c|c|c|c|c|c|}
\hline VarName & VariableLabel & WordingDE & ValueLabelsDE_Linked & WordingEN & ValueLabelsEN_Linked & L1 & L1F L2 & L3 & $\mathrm{L} 4$ & L5 & L6 & L7 & L8 L9 & L10 L11 L12 L13 L14 \\
\hline selfpresentation. 3 & $\begin{array}{l}\text { Self- } \\
\text { monitoring } \\
\text { Item } 9\end{array}$ & $\begin{array}{l}\text { Im Folgenden geht es } \\
\text { um Dein Verhalten in } \\
\text { sozialen Situationen. } \\
\text { Wähle bitte die für Dich } \\
\text { am ehesten zutreffende } \\
\text { Antwort: Wenn ich das } \\
\text { Gefühl habe, dass das } \\
\text { Bild, das ich vermittle, } \\
\text { nicht wirkt, kann ich es } \\
\text { so ändern, dass es wirkt }\end{array}$ & $\begin{array}{l}1=\text { immer falsch, } 2= \\
\text { meist falsch, } 3= \\
\text { manchmal falsch, } 4= \\
\text { manchmal richtig, } 5= \\
\text { meist richtig, } 6=\text { immer } \\
\text { richtig }\end{array}$ & $\begin{array}{l}\text { The following questions } \\
\text { will be about your } \\
\text { behavior in social } \\
\text { situations: When I feel } \\
\text { that the image I am } \\
\text { portraying isn't working, } \\
\text { I can readily change it } \\
\text { to something that does. }\end{array}$ & $\begin{array}{l}1=\text { always wrong, } 2= \\
\text { usually wrong, } 3= \\
\text { sometimes wrong, } 4= \\
\text { sometimes right, } 5= \\
\text { usually right, } 6=\text { always } \\
\text { right }\end{array}$ & $\mathrm{x}$ & $\mathrm{x}$ & & $\mathrm{x}$ & $\mathrm{x}$ & & & & \\
\hline selfpresentation. 4 & $\begin{array}{l}\text { Self- } \\
\text { monitoring } \\
\text { Item } 10\end{array}$ & $\begin{array}{l}\text { Im Folgenden geht es } \\
\text { um Dein Verhalten in } \\
\text { sozialen Situationen. } \\
\text { Wähle bitte die für Dich } \\
\text { am ehesten zutreffende } \\
\text { Antwort: Ich habe } \\
\text { Schwierigkeiten, mein } \\
\text { Verhalten an } \\
\text { verschiedene Menschen } \\
\text { bzw. an verschiedene } \\
\text { Situationen anzupassen }\end{array}$ & $\begin{array}{l}1=\text { immer falsch, } 2= \\
\text { meist falsch, } 3= \\
\text { manchmal falsch, } 4= \\
\text { manchmal richtig, } 5= \\
\text { meist richtig, } 6=\text { immer } \\
\text { richtig }\end{array}$ & $\begin{array}{l}\text { The following questions } \\
\text { will be about your } \\
\text { behavior in social } \\
\text { situations: I have } \\
\text { trouble changing my } \\
\text { behavior to suit } \\
\text { different people and } \\
\text { different situations. }\end{array}$ & $\begin{array}{l}1=\text { always wrong, } 2= \\
\text { usually wrong, } 3= \\
\text { sometimes wrong, } 4= \\
\text { sometimes right, } 5= \\
\text { usually right, } 6=\text { always } \\
\text { right }\end{array}$ & $\mathrm{x}$ & $\mathrm{x}$ & & $\mathrm{x}$ & $\mathrm{x}$ & & & & \\
\hline selfpresentation.5 & $\begin{array}{l}\text { Self- } \\
\text { monitoring } \\
\text { Item } 11\end{array}$ & $\begin{array}{l}\text { Im Folgenden geht es } \\
\text { um Dein Verhalten in } \\
\text { sozialen Situationen. } \\
\text { Wähle bitte die für Dich } \\
\text { am ehesten zutreffende } \\
\text { Antwort: Ich habe } \\
\text { festgestellt, dass ich } \\
\text { mein Verhalten an die } \\
\text { Erfordernisse jeder } \\
\text { Situation, in der ich } \\
\text { mich befinde, anpassen } \\
\text { kann }\end{array}$ & $\begin{array}{l}1=\text { immer falsch, } 2= \\
\text { meist falsch, } 3= \\
\text { manchmal falsch, } 4= \\
\text { manchmal richtig, } 5= \\
\text { meist richtig, } 6=\text { immer } \\
\text { richtig }\end{array}$ & $\begin{array}{l}\text { The following questions } \\
\text { will be about your } \\
\text { behavior in social } \\
\text { situations: I have found } \\
\text { that I can adjust my } \\
\text { behavior to meet the } \\
\text { requirements of any } \\
\text { situation I find myself } \\
\text { in. }\end{array}$ & $\begin{array}{l}1=\text { always wrong, } 2= \\
\text { usually wrong, } 3= \\
\text { sometimes wrong, } 4= \\
\text { sometimes right, } 5= \\
\text { usually right, } 6=\text { always } \\
\text { right }\end{array}$ & $\mathrm{x}$ & $\mathrm{x}$ & & $\mathrm{x}$ & $\mathrm{x}$ & & & & \\
\hline selfpresentation. 6 & $\begin{array}{l}\text { Self- } \\
\text { monitoring } \\
\text { Item } 12\end{array}$ & $\begin{array}{l}\text { Im Folgenden geht es } \\
\text { um Dein Verhalten in } \\
\text { sozialen Situationen. } \\
\text { Wähle bitte die für Dich } \\
\text { am ehesten zutreffende } \\
\text { Antwort: Selbst wenn es } \\
\text { zu meinem Vorteil sein } \\
\text { könnte, habe ich } \\
\text { Schwierigkeiten, eine } \\
\text { gute Miene zu machen }\end{array}$ & $\begin{array}{l}1=\text { immer falsch, } 2= \\
\text { meist falsch, } 3= \\
\text { manchmal falsch, } 4= \\
\text { manchmal richtig, } 5= \\
\text { meist richtig, } 6=\text { immer } \\
\text { richtig }\end{array}$ & $\begin{array}{l}\text { The following questions } \\
\text { will be about your } \\
\text { behavior in social } \\
\text { situations: Even when it } \\
\text { might be to my } \\
\text { advantage, I have } \\
\text { difficulty putting up a } \\
\text { good front. }\end{array}$ & $\begin{array}{l}1=\text { always wrong, } 2= \\
\text { usually wrong, } 3= \\
\text { sometimes wrong, } 4= \\
\text { sometimes right, } 5= \\
\text { usually right, } 6=\text { always } \\
\text { right }\end{array}$ & $\mathrm{x}$ & $\mathrm{x}$ & & $\mathrm{x}$ & $\mathrm{x}$ & & & & \\
\hline selfpresentation. 7 & $\begin{array}{l}\text { Self- } \\
\text { monitoring } \\
\text { Item } 13\end{array}$ & $\begin{array}{l}\text { Im Folgenden geht es } \\
\text { um Dein Verhalten in } \\
\text { sozialen Situationen. } \\
\text { Wähle bitte die für Dich } \\
\text { am ehesten zutreffende } \\
\text { Antwort: Wenn ich } \\
\text { einmal weiß, was die } \\
\text { Situation erfordert, ist } \\
\text { es leicht für mich, meine } \\
\text { Handlungen } \\
\text { entsprechend } \\
\text { auszurichten }\end{array}$ & $\begin{array}{l}1=\text { immer falsch, } 2= \\
\text { meist falsch, } 3= \\
\text { manchmal falsch, } 4= \\
\text { manchmal richtig, } 5= \\
\text { meist richtig, } 6=\text { immer } \\
\text { richtig }\end{array}$ & $\begin{array}{l}\text { The following questions } \\
\text { will be about your } \\
\text { behavior in social } \\
\text { situations: Once I know } \\
\text { what the situation calls } \\
\text { for, it's easy for me to } \\
\text { regulate my actions } \\
\text { accordingly. }\end{array}$ & $\begin{array}{l}1=\text { always wrong, } 2= \\
\text { usually wrong, } 3= \\
\text { sometimes wrong, } 4= \\
\text { sometimes right, } 5= \\
\text { usually right, } 6=\text { always } \\
\text { right }\end{array}$ & $\mathrm{x}$ & $\mathrm{x}$ & & $\mathrm{x}$ & $\mathrm{x}$ & & & & \\
\hline extraversion. 1 & $\begin{array}{l}\text { Big Five } \\
\text { Inventory - 10 } \\
\text { (BFI10; } \\
\text { Rammstedt \& } \\
\text { John, 2007) } \\
\text { Item 1 }\end{array}$ & $\begin{array}{l}\text { Inwieweit treffen die } \\
\text { folgenden Aussagen auf } \\
\text { Dich zu? Ich bin eher } \\
\text { zurückhaltend, } \\
\text { reserviert. }\end{array}$ & $\begin{array}{l}1=\text { trifft überhaupt nicht } \\
\mathrm{zu}, 2=\text { trifft eher nicht } \\
\mathrm{zu}, 3=\text { weder noch, } 4= \\
\text { eher zutreffend, } 5=\text { trifft } \\
\text { voll und ganz zu }\end{array}$ & $\begin{array}{l}\text { I see myself as someone } \\
\text { who: is reserved }\end{array}$ & $\begin{array}{l}1=\text { does not apply at all, } \\
2=\text { does rather not apply, } \\
3=\text { neither, } 4=\text { rather } \\
\text { applies, } 5=\text { applies } \\
\text { completely (free } \\
\text { translation) }\end{array}$ & $\mathrm{x}$ & $\mathrm{x}$ & & $\mathrm{x}$ & & & & & \\
\hline
\end{tabular}




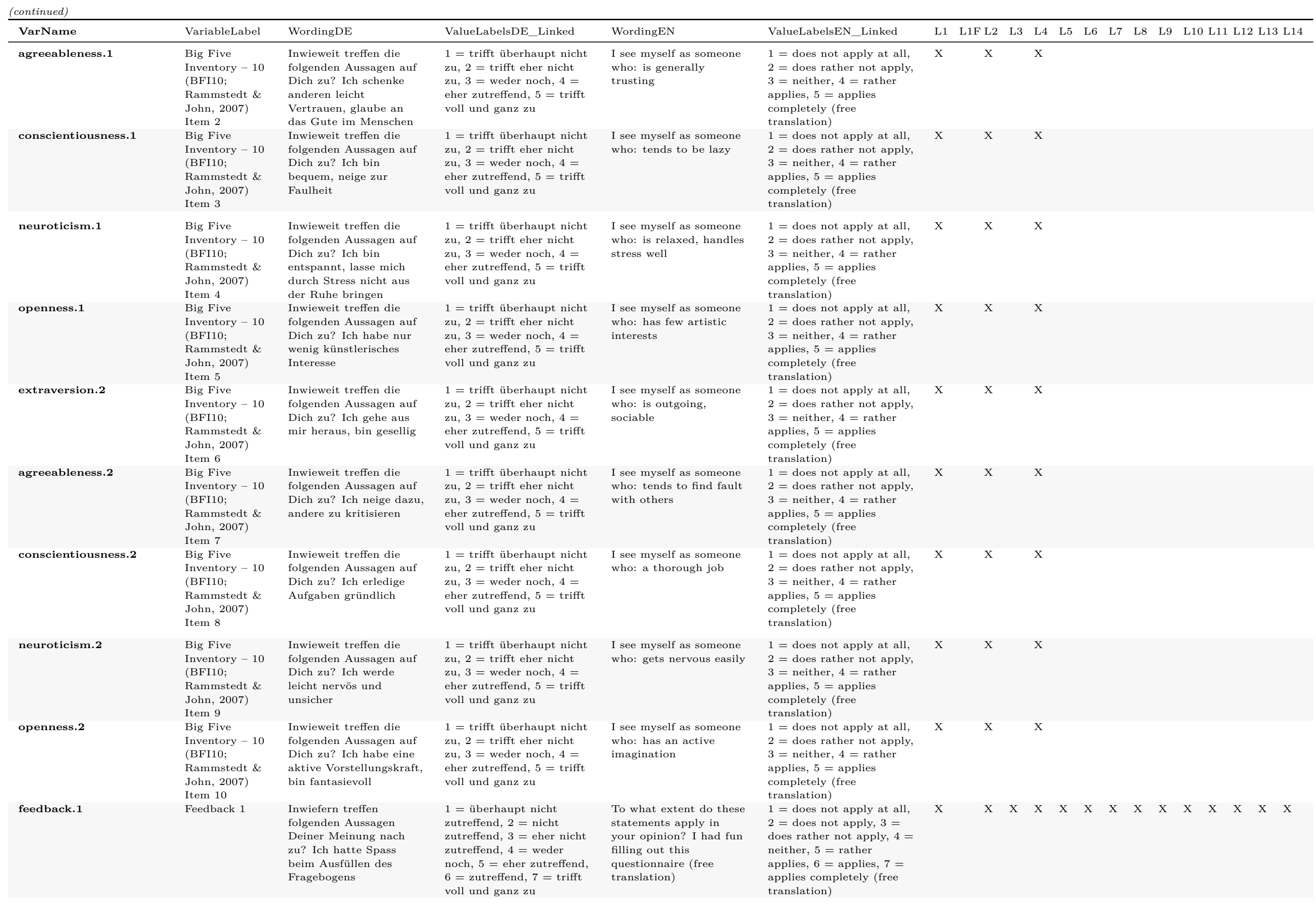




\begin{tabular}{|c|c|c|c|c|c|c|c|c|c|c|c|c|c|c|c|c|c|c|c|}
\hline VarName & VariableLabel & WordingDE & ValueLabelsDE_Linked & WordingEN & ValueLabelsEN_Linked & L1 & L1F L2 & L3 & L4 & L5 & L6 & L7 & L8 & L9 & L10 & L11 & L12 & $\mathrm{L} 13$ & L L14 \\
\hline feedback.2 & Feedback 2 & $\begin{array}{l}\text { Inwiefern treffen } \\
\text { folgenden Aussagen } \\
\text { Deiner Meinung nach } \\
\text { zu? Viele Fragen waren } \\
\text { sich zu ähnlich }\end{array}$ & $\begin{array}{l}1=\text { überhaupt nicht } \\
\text { zutreffend, } 2=\text { nicht } \\
\text { zutreffend, } 3=\text { eher nicht } \\
\text { zutreffend, } 4=\text { weder } \\
\text { noch, } 5=\text { eher zutreffend, } \\
6=\text { zutreffend, } 7=\text { trifft } \\
\text { voll und ganz zu }\end{array}$ & $\begin{array}{l}\text { To what extent do these } \\
\text { statements apply in } \\
\text { your opinion? Many } \\
\text { questions were similar } \\
\text { (free translation) }\end{array}$ & $\begin{array}{l}1=\text { does not apply at all, } \\
2=\text { does not apply, } 3= \\
\text { does rather not apply, } 4= \\
\text { neither, } 5=\text { rather } \\
\text { applies, } 6=\text { applies, } 7= \\
\text { applies completely (free } \\
\text { translation) }\end{array}$ & $\mathrm{x}$ & $\mathrm{x}$ & $\mathrm{x}$ & $\mathrm{x}$ & $\mathrm{x}$ & $\mathrm{x}$ & $\mathrm{x}$ & $\mathrm{x}$ & $\mathrm{x}$ & $\mathrm{x}$ & $\mathrm{x}$ & $\mathrm{x}$ & $\mathrm{x}$ & $\mathrm{x}$ \\
\hline feedback. 3 & Feedback 3 & $\begin{array}{l}\text { Inwiefern treffen } \\
\text { folgenden Aussagen } \\
\text { Deiner Meinung nach } \\
\text { zu? Ich hatte technische } \\
\text { Probleme beim } \\
\text { Ausfüllen des } \\
\text { Fragebogens }\end{array}$ & $\begin{array}{l}1=\text { überhaupt nicht } \\
\text { zutreffend, } 2=\text { nicht } \\
\text { zutreffend, } 3=\text { eher nicht } \\
\text { zutreffend, } 4=\text { weder } \\
\text { noch, } 5=\text { eher zutreffend, } \\
6=\text { zutreffend, } 7=\text { trifft } \\
\text { voll und ganz zu }\end{array}$ & $\begin{array}{l}\text { To what extent do these } \\
\text { statements apply in your } \\
\text { opinion? I had technical } \\
\text { problems while filling } \\
\text { our the questionnaire } \\
\text { (free translation) }\end{array}$ & $\begin{array}{l}1=\text { does not apply at all, } \\
2=\text { does not apply, } 3= \\
\text { does rather not apply, } 4= \\
\text { neither, } 5=\text { rather } \\
\text { applies, } 6=\text { applies, } 7= \\
\text { applies completely (free } \\
\text { translation) }\end{array}$ & $\mathrm{x}$ & $\mathrm{x}$ & $\mathrm{x}$ & $\mathrm{x}$ & $\mathrm{x}$ & $\mathrm{x}$ & $\mathrm{x}$ & $\mathrm{x}$ & $\mathrm{x}$ & $\mathrm{x}$ & $\mathrm{x}$ & $\mathrm{x}$ & $\mathrm{x}$ & $\mathrm{x}$ \\
\hline feedback.4 & Feedback 4 & $\begin{array}{l}\text { Inwiefern treffen } \\
\text { folgenden Aussagen } \\
\text { Deiner Meinung nach } \\
\text { zu? Ich habe mir oft } \\
\text { überlegt mit dem } \\
\text { Ausfüllen aufzuhören }\end{array}$ & $\begin{array}{l}1=\text { überhaupt nicht } \\
\text { zutreffend, } 2=\text { nicht } \\
\text { zutreffend, } 3=\text { eher nicht } \\
\text { zutreffend, } 4=\text { weder } \\
\text { noch, } 5=\text { eher zutreffend, } \\
6=\text { zutreffend, } 7=\text { trifft } \\
\text { voll und ganz zu }\end{array}$ & $\begin{array}{l}\text { To what extent do these } \\
\text { statements apply in } \\
\text { your opinion? I have } \\
\text { often considered to stop } \\
\text { filing the questionnaire } \\
\text { out (free translation) }\end{array}$ & $\begin{array}{l}1=\text { does not apply at all, } \\
2=\text { does not apply, } 3= \\
\text { does rather not apply, } 4= \\
\text { neither, } 5=\text { rather } \\
\text { applies, } 6=\text { applies, } 7= \\
\text { applies completely (free } \\
\text { translation) }\end{array}$ & $\mathrm{x}$ & $\mathrm{x}$ & $\mathrm{x}$ & $\mathrm{x}$ & $\mathrm{x}$ & $\mathrm{x}$ & $\mathrm{x}$ & $\mathrm{x}$ & $\mathrm{x}$ & $\mathrm{x}$ & $\mathrm{x}$ & $\mathrm{x}$ & $\mathrm{x}$ & $\mathrm{x}$ \\
\hline feedback.5 & Feedback 5 & $\begin{array}{l}\text { Inwiefern treffen } \\
\text { folgenden Aussagen } \\
\text { Deiner Meinung nach } \\
\text { zu? Das Dankeschön } \\
\text { von 30 CHF ist fair }\end{array}$ & $\begin{array}{l}1=\text { überhaupt nicht } \\
\text { zutreffend, } 2=\text { nicht } \\
\text { zutreffend, } 3=\text { eher nicht } \\
\text { zutreffend, } 4=\text { weder } \\
\text { noch, } 5=\text { eher zutreffend, } \\
6=\text { zutreffend, } 7=\text { trifft } \\
\text { voll und ganz zu }\end{array}$ & $\begin{array}{l}\text { To what extent do these } \\
\text { statements apply in } \\
\text { your opinion? The } \\
\text { thank-you of 30CHF is } \\
\text { fair (free translation) }\end{array}$ & $\begin{array}{l}1=\text { does not apply at all, } \\
2=\text { does not apply, } 3= \\
\text { does rather not apply, } 4= \\
\text { neither, } 5=\text { rather } \\
\text { applies, } 6=\text { applies, } 7= \\
\text { applies completely (free } \\
\text { translation) }\end{array}$ & $\mathrm{x}$ & $\mathrm{x}$ & $\mathrm{x}$ & $\mathrm{x}$ & $\mathrm{x}$ & $\mathrm{x}$ & $\mathrm{x}$ & $\mathrm{x}$ & $\mathrm{x}$ & $\mathrm{x}$ & $\mathrm{x}$ & $\mathrm{x}$ & $\mathrm{x}$ & $\mathrm{x}$ \\
\hline feedback.str & Feedback 6 & $\begin{array}{l}\text { Hast Du noch } \\
\text { Vorschläge, was wir am } \\
\text { Fragebogen / an der } \\
\text { Studie verbessern } \\
\text { können? }\end{array}$ & & $\begin{array}{l}\text { Do you have suggestions } \\
\text { on how to improve the } \\
\text { questionnaire? (free } \\
\text { translation) }\end{array}$ & & $\mathrm{x}$ & $\mathrm{x}$ & $\mathrm{x}$ & $\mathrm{x}$ & $\mathrm{x}$ & $\mathrm{x}$ & $\mathrm{x}$ & $\mathrm{x}$ & $\mathrm{x}$ & $\mathrm{x}$ & $\mathrm{x}$ & $\mathrm{x}$ & $\mathrm{x}$ & $\mathrm{x}$ \\
\hline learning. $h$ & & $\begin{array}{l}\text { Wie viele Stunden lernst } \\
\text { Du in einer normalen } \\
\text { Semesterwoche } \\
\text { (ausserhalb von } \\
\text { Vorlesungen und } \\
\text { Übungsstunden)? }\end{array}$ & & $\begin{array}{l}\text { How many hours do you } \\
\text { study in a normal week } \\
\text { in the semester } \\
\text { (excluding lectures, } \\
\text { seminars, etc.)? (free } \\
\text { translation) }\end{array}$ & & & $\mathrm{x}$ & $\mathrm{x}$ & $\mathrm{x}$ & $\mathrm{x}$ & & & & & & & & & \\
\hline learning.where & & $\begin{array}{l}\text { Wo lernst Du } \\
\text { normalerweise? }\end{array}$ & $\begin{array}{l}1=\text { Zuhause, } 2=\text { Cafés, } 3 \\
=\text { Universität, } 4= \\
\text { Bibliothek, } 5=\mathrm{Zug}, 6= \\
\text { bei Freunden, } 7= \\
\text { Anderes }\end{array}$ & $\begin{array}{l}\text { Where do you normally } \\
\text { study? (free tanslation) }\end{array}$ & $\begin{array}{l}1=\text { Home, } 2=\text { Cafe, } 3= \\
\text { University, } 4=\text { Library, } 5 \\
=\text { Train, } 6=\text { atFriends, } 7 \\
=\text { Other }\end{array}$ & & $\mathrm{x}$ & $\mathrm{x}$ & $\mathrm{x}$ & $\mathrm{x}$ & $\mathrm{x}$ & $\mathrm{x}$ & $\mathrm{x}$ & $\mathrm{x}$ & $\mathrm{x}$ & $\mathrm{x}$ & $\mathrm{x}$ & $\mathrm{x}$ & \\
\hline learning.where.str & & $\begin{array}{l}\text { Wo lernst Du } \\
\text { normalerweise? (other } \\
\text { text) }\end{array}$ & & $\begin{array}{l}\text { Where do you normally } \\
\text { study? (free tanslation) }\end{array}$ & & & $\mathrm{x}$ & $\mathrm{x}$ & $\mathrm{x}$ & $\mathrm{x}$ & $\mathrm{x}$ & $\mathrm{x}$ & $\mathrm{x}$ & $\mathrm{x}$ & $\mathrm{x}$ & $\mathrm{x}$ & $\mathrm{x}$ & $\mathrm{x}$ & \\
\hline like.studying & & $\begin{array}{l}\text { Wie gefällt Dir Dein } \\
\text { Studium an [name } \\
\text { removed]? }\end{array}$ & $\begin{array}{l}1=\text { sehr schlecht, } 2= \\
\text { schlecht, } 3=\text { mittel, } 4= \\
\text { gut, } 5=\text { very good }\end{array}$ & $\begin{array}{l}\text { How do you like your } \\
\text { studies at [name } \\
\text { removed]? (free } \\
\text { tanslation) }\end{array}$ & $\begin{array}{l}1=\text { very bad, } 2=\text { bad, } 3 \\
=\text { medium, } 4=\text { good, } 5= \\
\text { very good }\end{array}$ & & $\mathrm{x}$ & $\mathrm{x}$ & $\mathrm{x}$ & $\mathrm{x}$ & $\mathrm{x}$ & $\mathrm{x}$ & $\mathrm{x}$ & $\mathrm{x}$ & $\mathrm{x}$ & $\mathrm{x}$ & $\mathrm{x}$ & $\mathrm{x}$ & \\
\hline fb.account & & $\begin{array}{l}\text { Hast du einen } \\
\text { Facebook-Account? }\end{array}$ & $1=\mathrm{Ja}, 2=$ Nein & $\begin{array}{l}\text { Do you have a } \\
\text { facebook-account? (free } \\
\text { tanslation) }\end{array}$ & $1=\mathrm{Yes}, 2=\mathrm{No}$ & & $\mathrm{x}$ & & & $\mathrm{x}$ & & & & & & & & & \\
\hline wkend.pleasant.P1 & $\begin{array}{l}\text { Ersti-weekend: } \\
\text { pleasant } \\
\text { interaction } 1\end{array}$ & $\begin{array}{l}\text { Mit wem hast Du am } \\
\text { Ersti-Wochenende } \\
\text { angenehme } \\
\text { Interaktionen erlebt? } \\
\text { Person } 1 .\end{array}$ & & $\begin{array}{l}\text { With whom did you } \\
\text { have a pleasant } \\
\text { interaction during the } \\
\text { Ersti-weekend? Person } \\
\text { 1. }\end{array}$ & & & $\mathrm{x}$ & & & & & & & & & & & & \\
\hline
\end{tabular}




\begin{tabular}{|c|c|c|c|c|c|c|c|c|c|c|c|c|c|c|}
\hline VarName & VariableLabel & WordingDE & ValueLabelsDE_Linked & WordingEN & ValueLabelsEN_Linked & L1 & L1F L2 & L3 & $\mathrm{L} 4$ & L5 & $\mathrm{L} 6$ & L7 & L8 L9 & L10 L11 L12 L13 L14 \\
\hline wkend.conflict.P1 & $\begin{array}{l}\text { Ersti-weekend: } \\
\text { conflict } 1\end{array}$ & $\begin{array}{l}\text { Mit wem hattest Du am } \\
\text { Ersti-Wochenende } \\
\text { persönliche Konflikte? } \\
\text { Person } 1 .\end{array}$ & & $\begin{array}{l}\text { With whom did you } \\
\text { have personal conflicts } \\
\text { during the } \\
\text { Ersti-weekend? Person } \\
1 .\end{array}$ & & & $\mathrm{x}$ & & & & & & & \\
\hline drunk.fri.1 & $\begin{array}{l}\text { Alcohol } \\
\text { consumption } \\
\text { on the Friday } \\
\text { of the } \\
\text { Ersti-weekend, } \\
\text { item } 1\end{array}$ & $\begin{array}{l}\text { Wie viele } \\
\text { Alkohol-Einheiten hast } \\
\text { Du am FREITAG (des } \\
\text { Ersti-Weekends) } \\
\text { ungefähr getrunken ( } 1 \\
\text { Einheit }=0.31 \text { Bier oder } \\
\text { 1dl Wein oder } 1 / 2 \\
\text { Cocktail, etc.)? }\end{array}$ & & $\begin{array}{l}\text { How many units alcohol } \\
\text { did you drink on the } \\
\text { Friday of the } \\
\text { Ersti-weekend ? ( } 1 \text { unit } \\
=0.3 \mathrm{~L} \text { beer, } 1 \text { dl wine, } \\
1 / 2 \text { cocktail })\end{array}$ & & & $\mathrm{x}$ & & & & & & & \\
\hline drunk.fri.2 & $\begin{array}{l}\text { Alcohol } \\
\text { consumption } \\
\text { on the Friday } \\
\text { of the } \\
\text { Ersti-weekend, } \\
\text { item } 2\end{array}$ & $\begin{array}{l}\text { Inwieweit trifft die } \\
\text { folgende Aussage zu: Ich } \\
\text { war betrunken am } \\
\text { Freitag. }\end{array}$ & $\begin{array}{l}1=\text { überhaupt nicht } \\
\text { zutreffend, } 2=\text { nicht } \\
\text { zutreffend, } 3=\text { eher nicht } \\
\text { zutreffend, } 4=\text { weder } \\
\text { noch, } 5=\text { eher zutreffend, } \\
6=\text { zutreffend, } 7=\text { trifft } \\
\text { voll und ganz zu }\end{array}$ & $\begin{array}{l}\text { To what extend does the } \\
\text { following statement } \\
\text { apply: I was drunk on } \\
\text { Friday. }\end{array}$ & $\begin{array}{l}1=\text { does not apply at all, } \\
2=\text { does not apply, } 3= \\
\text { does rather not apply, } 4= \\
\text { neither, } 5=\text { rather } \\
\text { applies, } 6=\text { applies, } 7= \\
\text { applies completely (free } \\
\text { translation) }\end{array}$ & & $\mathrm{x}$ & & & & & & & \\
\hline drunk.sat.1 & $\begin{array}{l}\text { Alcohol } \\
\text { consumption } \\
\text { on the } \\
\text { Saturday of } \\
\text { the } \\
\text { Ersti-weekend, } \\
\text { item 1 }\end{array}$ & $\begin{array}{l}\text { Wie viele } \\
\text { Alkohol-Einheiten hast } \\
\text { Du am SAMSTAG (des } \\
\text { Ersti-Weekends) } \\
\text { ungefähr getrunken (1 } \\
\text { Einheit = 0.31 Bier oder } \\
\text { 1dl Wein oder } 1 / 2 \\
\text { Cocktail, etc.)? }\end{array}$ & & $\begin{array}{l}\text { How many units alcohol } \\
\text { did you drink on the } \\
\text { Saturday of the } \\
\text { Ersti-weekend ( } 1 \text { unit }= \\
0.3 \mathrm{~L} \text { beer, } 1 \mathrm{dl} \text { wine, } 1 / 2 \\
\text { cocktail) }\end{array}$ & & & $\mathrm{x}$ & & & & & & & \\
\hline drunk.sat.2 & $\begin{array}{l}\text { Alcohol } \\
\text { consumption } \\
\text { on the } \\
\text { Saturday of } \\
\text { the } \\
\text { Ersti-weekend, } \\
\text { item 2 }\end{array}$ & $\begin{array}{l}\text { Inwieweit trifft die } \\
\text { folgende Aussage zu: Ich } \\
\text { war betrunken am } \\
\text { Samstag. }\end{array}$ & $\begin{array}{l}1=\text { überhaupt nicht } \\
\text { zutreffend, } 2=\text { nicht } \\
\text { zutreffend, } 3=\text { eher nicht } \\
\text { zutreffend, } 4=\text { weder } \\
\text { noch, } 5=\text { eher zutreffend, } \\
6=\text { zutreffend, } 7=\text { trifft } \\
\text { voll und ganz zu }\end{array}$ & $\begin{array}{l}\text { To what extend does the } \\
\text { following statement } \\
\text { apply: I was drunk on } \\
\text { Saturday }\end{array}$ & $\begin{array}{l}1=\text { does not apply at all, } \\
2=\text { does not apply, } 3= \\
\text { does rather not apply, } 4= \\
\text { neither, } 5=\text { rather } \\
\text { applies, } 6=\text { applies, } 7= \\
\text { applies completely (free } \\
\text { translation) }\end{array}$ & & $\mathrm{x}$ & & & & & & & \\
\hline wkend.feedback.1 & $\begin{array}{l}\text { Feedback to } \\
\text { the } \\
\text { Ersti-weekend } \\
1\end{array}$ & $\begin{array}{l}\text { In welchem Masse } \\
\text { würdest Du den } \\
\text { folgenden Aussagen } \\
\text { zustimmen? Das } \\
\text { Erstiweekend hat mir } \\
\text { sehr gut gefallen. }\end{array}$ & $\begin{array}{l}1=\text { stimme gar nicht } \mathrm{zu}, \\
2=\text { stimme nicht } \mathrm{zu}, 3= \\
\text { stimme eher nicht } \mathrm{zu}, 4= \\
\text { weder noch, } 5=\text { stimme } \\
\text { eher } \mathrm{zu}, 6=\text { stimme } \mathrm{zu}, 7 \\
=\text { stimme voll und ganz } \\
\text { zu }\end{array}$ & $\begin{array}{l}\text { To what extent does the } \\
\text { following statement } \\
\text { apply: I very much } \\
\text { enjoyed the } \\
\text { "Ersti"-weekend. }\end{array}$ & $\begin{array}{l}1=\text { don't agree at all, } 2= \\
\text { don't agree, } 3=\text { rather } \\
\text { not agree, } 4=\text { neither, } 5 \\
=\text { rather agree, } 6=\text { agree, } \\
7=\text { agree completely (free } \\
\text { translation) }\end{array}$ & & $\mathrm{x}$ & & & & & & & \\
\hline wkend.feedback.2 & $\begin{array}{l}\text { Feedback to } \\
\text { the } \\
\text { Ersti-weekend } \\
2\end{array}$ & $\begin{array}{l}\text { In welchem Masse } \\
\text { würdest Du den } \\
\text { folgenden Aussagen } \\
\text { zustimmen? Durch das } \\
\text { Erstiweekend habe ich } \\
\text { neue Freundschaften } \\
\text { geschlossen. }\end{array}$ & $\begin{array}{l}1=\text { stimme gar nicht } \mathrm{zu}, \\
2=\text { stimme nicht } \mathrm{zu}, 3= \\
\text { stimme eher nicht } \mathrm{zu}, 4= \\
\text { weder noch, } 5=\text { stimme } \\
\text { eher } \mathrm{zu}, 6=\text { stimme } \mathrm{zu}, 7 \\
=\text { stimme voll und ganz } \\
\text { zu }\end{array}$ & $\begin{array}{l}\text { To what extent does the } \\
\text { following statement } \\
\text { apply: I made new } \\
\text { friends because of the } \\
\text { "Ersti"-weekend. }\end{array}$ & $\begin{array}{l}1=\text { don't agree at all, } 2= \\
\text { don't agree, } 3=\text { rather } \\
\text { not agree, } 4=\text { neither, } 5 \\
=\text { rather agree, } 6=\text { agree, } \\
7=\text { agree completely (free } \\
\text { translation) }\end{array}$ & & $\mathrm{x}$ & & & & & & & \\
\hline wkend.feedback.3 & $\begin{array}{l}\text { Feedback to } \\
\text { the } \\
\text { Ersti-weekend } \\
3\end{array}$ & $\begin{array}{l}\text { In welchem Masse } \\
\text { würdest Du den } \\
\text { folgenden Aussagen } \\
\text { zustimmen? Ich bin } \\
\text { jetzt von [name } \\
\text { removed] begeisterter. }\end{array}$ & $\begin{array}{l}1=\text { stimme gar nicht } \mathrm{zu}, \\
2=\text { stimme nicht } \mathrm{zu}, 3= \\
\text { stimme eher nicht } \mathrm{zu}, 4= \\
\text { weder noch, } 5=\text { stimme } \\
\text { eher zu, } 6=\text { stimme zu, } 7 \\
=\text { stimme voll und ganz } \\
\text { zu }\end{array}$ & $\begin{array}{l}\text { To what extent does the } \\
\text { following statement } \\
\text { apply: I am more } \\
\text { excited by the [name } \\
\text { removed] now. }\end{array}$ & $\begin{array}{l}1=\text { don't agree at all, } 2= \\
\text { don't agree, } 3=\text { rather } \\
\text { not agree, } 4=\text { neither, } 5 \\
=\text { rather agree, } 6=\text { agree } \\
7=\text { agree completely (free } \\
\text { translation) }\end{array}$ & & $\mathrm{x}$ & & & & & & & \\
\hline wkend.feedback.str & $\begin{array}{l}\text { Feedback to } \\
\text { the } \\
\text { Ersti-weekend } \\
4\end{array}$ & $\begin{array}{l}\text { Hast du neue Ideen oder } \\
\text { Verbesserungsvorschläge } \\
\text { für das nächste } \\
\text { Erstiweekend? }\end{array}$ & & $\begin{array}{l}\text { Do you have ideas of } \\
\text { suggestions for the next } \\
\text { "Ersti"-weekend? }\end{array}$ & & & $\mathrm{x}$ & & & & & & & \\
\hline
\end{tabular}




\begin{tabular}{|c|c|c|c|c|c|c|c|c|c|c|c|c|c|c|c|c|c|c|}
\hline VarName & VariableLabel & WordingDE & ValueLabelsDE_Linked & WordingEN & ValueLabelsEN_Linked & L1 & L1F L2 & L3 & L4 & L5 & L6 & L7 & L8 & L9 & L10 & L11 & L12 & L13 L14 \\
\hline political.discussion.P1 & $\begin{array}{l}\text { Political } \\
\text { interactions: } \\
\text { Person } 1\end{array}$ & $\begin{array}{l}\text { Mit wem Deiner } \\
\text { Mitstudierenden tauscht } \\
\text { Du Dich über politische } \\
\text { Themen aus? Person } 1\end{array}$ & & $\begin{array}{l}\text { With whom of your } \\
\text { fellow students do you } \\
\text { discuss political issues? } \\
\text { Person 1 }\end{array}$ & & & & $\mathrm{x}$ & $\mathrm{x}$ & $\mathrm{x}$ & $\mathrm{x}$ & $\mathrm{x}$ & $\mathrm{x}$ & $\mathrm{x}$ & $\mathrm{x}$ & $\mathrm{x}$ & $\mathrm{x}$ & $\mathrm{x}$ \\
\hline political.interest & $\begin{array}{l}\text { Political } \\
\text { interest }\end{array}$ & $\begin{array}{l}\text { Wie stark interessierst } \\
\text { Du Dich für Politik? } \\
\text { Würdest Du sagen, Du } \\
\text { bist ... }\end{array}$ & $\begin{array}{l}1=\text { sehr interessiert, } 2= \\
\text { ziemlich interessiert, } 3= \\
\text { kaum interessiert, } 4= \\
\text { überhaupt nicht } \\
\text { interessiert }\end{array}$ & $\begin{array}{l}\text { How interested are you } \\
\text { in politics? Would you } \\
\text { say that you are.... }\end{array}$ & $\begin{array}{l}1=\text { very interested, } 2= \\
\text { quite interested, } 3= \\
\text { barely interested, } 4=\text { not } \\
\text { interested at all }\end{array}$ & & & $\mathrm{x}$ & $\mathrm{x}$ & $\mathrm{x}$ & $\mathrm{x}$ & $\mathrm{x}$ & $\mathrm{x}$ & $\mathrm{x}$ & $\mathrm{x}$ & $\mathrm{x}$ & $\mathrm{x}$ & $\mathrm{x}$ \\
\hline political.orientation & $\begin{array}{l}\text { Political } \\
\text { orientation }\end{array}$ & $\begin{array}{l}\text { In der Politik spricht } \\
\text { man manchmal von } \\
\text { "links" und "rechts". Wo } \\
\text { auf der Skala auf dieser } \\
\text { Karte würdest Du Dich } \\
\text { selber einstufen, wenn } 0 \\
\text { für links steht und } 10 \\
\text { für rechts? }\end{array}$ & & $\begin{array}{l}\text { In politics, one } \\
\text { something talks about } \\
\text { left and right. Where } \\
\text { would you place yourself } \\
\text { on a } 10 \text {-point scale } \\
\text { (where } 0 \text { is left and } 10 \text { is } \\
\text { right)? (free translation) }\end{array}$ & & & & $\mathrm{x}$ & $\mathrm{x}$ & $\mathrm{x}$ & $\mathrm{x}$ & $\mathrm{x}$ & $\mathrm{x}$ & $\mathrm{x}$ & $\mathrm{x}$ & $\mathrm{x}$ & $\mathrm{x}$ & $\mathrm{x} \quad \mathrm{x}$ \\
\hline political.info.1 & $\begin{array}{l}\text { Political } \\
\text { information } \\
\text { source } 1\end{array}$ & $\begin{array}{l}\text { Wie häufig liest Du den } \\
\text { politischen Teil in der } \\
\text { Zeitung? }\end{array}$ & $\begin{array}{l}1=\text { Mehrmals pro Tag, } 2 \\
=\text { Einmal pro Tag, } 3= \\
5-6 \text { mal in der Woche, } 4= \\
3-4 \text { mal in der Woche, } 5= \\
1-2 \text { mal in der Woche, } 6= \\
\text { Weniger als } 1-2 \text { mal in der } \\
\text { Woche, } 7=\text { Nie }\end{array}$ & $\begin{array}{l}\text { How often do you read } \\
\text { the political part in the } \\
\text { newspaper? (free } \\
\text { translation) }\end{array}$ & $\begin{array}{l}1=\text { Several times per day, } \\
2=\text { Once per day, } 3=5 \\
\text { to } 6 \text { times per week, } 4=3 \\
\text { to } 4 \text { times per week, } 5=1 \\
\text { to } 2 \text { times per week, } 6= \\
\text { less than } 1 \text { to } 2 \text { times per } \\
\text { week, } 7=\text { never }\end{array}$ & & & $\mathrm{x}$ & $\mathrm{x}$ & $\mathrm{x}$ & $\mathrm{x}$ & $\mathrm{x}$ & $\mathrm{x}$ & $\mathrm{x}$ & $\mathrm{x}$ & $\mathrm{x}$ & $\mathrm{x}$ & $\mathrm{x}$ \\
\hline political.info.2 & $\begin{array}{l}\text { Political } \\
\text { information } \\
\text { source } 2\end{array}$ & $\begin{array}{l}\text { Wie häufig siehst Du } \\
\text { politische Nachrichten } \\
\text { am Fernsehen an? }\end{array}$ & $\begin{array}{l}1=\text { Mehrmals pro Tag, } 2 \\
=\text { Einmal pro Tag, } 3= \\
5-6 \text { mal in der Woche, } 4= \\
3-4 \text { mal in der Woche, } 5= \\
1-2 \text { mal in der Woche, } 6= \\
\text { Weniger als } 1-2 \text { mal in der } \\
\text { Woche, } 7=\text { Nie }\end{array}$ & $\begin{array}{l}\text { How often do you watch } \\
\text { political news on TV? } \\
\text { (free translation) }\end{array}$ & $\begin{array}{l}1=\text { Several times per day, } \\
2=\text { Once per day, } 3=5 \\
\text { to } 6 \text { times per week, } 4=3 \\
\text { to } 4 \text { times per week, } 5=1 \\
\text { to } 2 \text { times per week, } 6= \\
\text { less than } 1 \text { to } 2 \text { times per } \\
\text { week, } 7=\text { never }\end{array}$ & & & $\mathrm{x}$ & $\mathrm{x}$ & $\mathrm{x}$ & $\mathrm{x}$ & $\mathrm{x}$ & $\mathrm{x}$ & $\mathrm{x}$ & $\mathrm{x}$ & $\mathrm{x}$ & $\mathrm{x}$ & $\mathrm{x}$ \\
\hline political.info.3 & $\begin{array}{l}\text { Political } \\
\text { information } \\
\text { source } 3\end{array}$ & $\begin{array}{l}\text { Wie häufig hörst Du } \\
\text { politische Nachrichten } \\
\text { im Radio? }\end{array}$ & $\begin{array}{l}1=\text { Mehrmals pro Tag, } 2 \\
=\text { Einmal pro Tag, } 3= \\
5-6 \text { mal in der Woche, } 4= \\
3-4 \text { mal in der Woche, } 5= \\
1-2 \text { mal in der Woche, } 6= \\
\text { Weniger als } 1-2 \text { mal in der } \\
\text { Woche, } 7=\text { Nie }\end{array}$ & $\begin{array}{l}\text { How often do you listen } \\
\text { do you listen to political } \\
\text { news on the radio? (free } \\
\text { translation) }\end{array}$ & $\begin{array}{l}1=\text { Several times per day, } \\
2=\text { Once per day, } 3=5 \\
\text { to } 6 \text { times per week, } 4=3 \\
\text { to } 4 \text { times per week, } 5=1 \\
\text { to } 2 \text { times per week, } 6= \\
\text { less than } 1 \text { to } 2 \text { times per } \\
\text { week, } 7=\text { never }\end{array}$ & & & $\mathrm{x}$ & $\mathrm{x}$ & $\mathrm{x}$ & $\mathrm{x}$ & $\mathrm{x}$ & $\mathrm{x}$ & $\mathrm{x}$ & $\mathrm{x}$ & $\mathrm{x}$ & $\mathrm{x}$ & $\mathrm{x}$ \\
\hline political.info.4 & $\begin{array}{l}\text { Political } \\
\text { information } \\
\text { source } 4\end{array}$ & $\begin{array}{l}\text { Wie häufig liest Du } \\
\text { politische Artikel auf } \\
\text { Nachrichtenseiten im } \\
\text { Internet? }\end{array}$ & $\begin{array}{l}1=\text { Mehrmals pro Tag, } 2 \\
=\text { Einmal pro Tag, } 3= \\
5-6 \text { mal in der Woche, } 4= \\
3-4 \text { mal in der Woche, } 5= \\
1-2 \text { mal in der Woche, } 6= \\
\text { Weniger als } 1-2 \text { mal in der } \\
\text { Woche, } 7=\text { Nie }\end{array}$ & $\begin{array}{l}\text { How often do you lead } \\
\text { political articles online? } \\
\text { (free translation) }\end{array}$ & $\begin{array}{l}1=\text { Several times per day, } \\
2=\text { Once per day, } 3=5 \\
\text { to } 6 \text { times per week, } 4=3 \\
\text { to } 4 \text { times per week, } 5=1 \\
\text { to } 2 \text { times per week, } 6= \\
\text { less than } 1 \text { to } 2 \text { times per } \\
\text { week, } 7=\text { never }\end{array}$ & & & $\mathrm{x}$ & $\mathrm{x}$ & $\mathrm{x}$ & $\mathrm{x}$ & $\mathrm{x}$ & $\mathrm{x}$ & $\mathrm{x}$ & $\mathrm{x}$ & $\mathrm{x}$ & $\mathrm{x}$ & $\mathrm{x}$ \\
\hline political.info.5 & $\begin{array}{l}\text { Political } \\
\text { information } \\
\text { source } 5\end{array}$ & $\begin{array}{l}\text { Wie häufig nutzt Du } \\
\text { Soziale Medien (wie } \\
\text { Facebook oder Twitter) } \\
\text { um politische } \\
\text { Nachrichten oder } \\
\text { Informationen zu } \\
\text { erhalten? }\end{array}$ & $\begin{array}{l}1=\text { Mehrmals pro Tag, } 2 \\
=\text { Einmal pro Tag, } 3= \\
5-6 \text { mal in der Woche, } 4= \\
3-4 \text { mal in der Woche, } 5= \\
1-2 \text { mal in der Woche, } 6= \\
\text { Weniger als } 1-2 \text { mal in der } \\
\text { Woche, } 7=\text { Nie }\end{array}$ & $\begin{array}{l}\text { How often do you use } \\
\text { social media (like } \\
\text { Facebook or Twitter) to } \\
\text { access political } \\
\text { information? }\end{array}$ & $\begin{array}{l}1=\text { Several times per day, } \\
2=\text { Once per day, } 3=5 \\
\text { to } 6 \text { times per week, } 4=3 \\
\text { to } 4 \text { times per week, } 5=1 \\
\text { to } 2 \text { times per week, } 6= \\
\text { less than } 1 \text { to } 2 \text { times per } \\
\text { week, } 7=\text { never }\end{array}$ & & & $\mathrm{x}$ & $\mathrm{x}$ & $\mathrm{x}$ & $\mathrm{x}$ & $\mathrm{x}$ & $\mathrm{x}$ & $\mathrm{x}$ & $\mathrm{x}$ & $\mathrm{x}$ & $\mathrm{x}$ & $\mathrm{x}$ \\
\hline political.info.6 & $\begin{array}{l}\text { Political } \\
\text { information } \\
\text { source } 6\end{array}$ & $\begin{array}{l}\text { Wie häufig nutzt Du } \\
\text { Aggregatorseiten (wie } \\
\text { Reddit oder Digg) um } \\
\text { politische Nachrichten } \\
\text { oder Informationen zu } \\
\text { erhalten? }\end{array}$ & $\begin{array}{l}1=\text { Mehrmals pro Tag, } 2 \\
=\text { Einmal pro Tag, } 3= \\
5-6 \text { mal in der Woche, } 4= \\
3-4 \text { mal in der Woche, } 5= \\
1-2 \text { mal in der Woche, } 6= \\
\text { Weniger als } 1-2 \text { mal in der } \\
\text { Woche, } 7=\text { Nie }\end{array}$ & $\begin{array}{l}\text { How often do you use } \\
\text { aggregators (like Reddit } \\
\text { or Digg) to access } \\
\text { political information? }\end{array}$ & $\begin{array}{l}1=\text { Several times per day, } \\
2=\text { Once per day, } 3=5 \\
\text { to } 6 \text { times per week, } 4=3 \\
\text { to } 4 \text { times per week, } 5=1 \\
\text { to } 2 \text { times per week, } 6= \\
\text { less than } 1 \text { to } 2 \text { times per } \\
\text { week, } 7=\text { never }\end{array}$ & & & $\mathrm{x}$ & $\mathrm{x}$ & $\mathrm{x}$ & $\mathrm{x}$ & $\mathrm{x}$ & $\mathrm{x}$ & $\mathrm{x}$ & $\mathrm{x}$ & $\mathrm{x}$ & $\mathrm{x}$ & $\mathrm{x}$ \\
\hline
\end{tabular}




\begin{tabular}{|c|c|c|c|c|c|c|c|c|c|c|c|c|c|c|c|c|c|c|c|}
\hline VarName & VariableLabel & WordingDE & ValueLabelsDE_Linked & WordingEN & ValueLabelsEN_Linked & L1 & L1F L2 & L3 & $\mathrm{L} 4$ & L5 & L6 & L7 & $\mathrm{L} 8$ & L9 & $\mathrm{L} 10$ & L11 & $1 \mathrm{~L} 12$ & $2 \mathrm{~L} 13$ & 3 L14 \\
\hline political.info.7 & $\begin{array}{l}\text { Political } \\
\text { information } \\
\text { source } 7\end{array}$ & $\begin{array}{l}\text { Wie häufig nutzt } \mathrm{Du} \\
\text { andere Internetquellen } \\
\text { um politische } \\
\text { Nachrichten oder } \\
\text { Informationen zu } \\
\text { erhalten? }\end{array}$ & $\begin{array}{l}1=\text { Mehrmals pro Tag, } 2 \\
=\text { Einmal pro Tag, } 3= \\
5-6 \text { mal in der Woche, } 4= \\
3-4 \text { mal in der Woche, } 5= \\
1-2 \text { mal in der Woche, } 6= \\
\text { Weniger als } 1-2 \text { mal in der } \\
\text { Woche, } 7=\mathrm{Nie}\end{array}$ & $\begin{array}{l}\text { How often do you use } \\
\text { other online resources to } \\
\text { access political } \\
\text { information? }\end{array}$ & $\begin{array}{l}1=\text { Several times per day, } \\
2=\text { Once per day, } 3=5 \\
\text { to } 6 \text { times per week, } 4=3 \\
\text { to } 4 \text { times per week, } 5=1 \\
\text { to } 2 \text { times per week, } 6= \\
\text { less than } 1 \text { to } 2 \text { times per } \\
\text { week, } 7=\text { never }\end{array}$ & & & $\mathrm{x}$ & $\mathrm{x}$ & $\mathrm{x}$ & $\mathrm{x}$ & $\mathrm{x}$ & $\mathrm{x}$ & $\mathrm{x}$ & $\mathrm{x}$ & $\mathrm{x}$ & $\mathrm{x}$ & $\mathrm{x}$ & \\
\hline political.info.7.other & $\begin{array}{l}\text { Political } \\
\text { information } \\
\text { source } 7 \text { - } \\
\text { other }\end{array}$ & $\begin{array}{l}\text { Du hast angegeben, dass } \\
\text { Du auch andere } \\
\text { Internetquellen benutzt } \\
\text { um politische } \\
\text { Nachrichten oder } \\
\text { Informationen zu } \\
\text { erhalten, welche sind } \\
\text { diese? }\end{array}$ & & $\begin{array}{l}\text { You said that you are } \\
\text { also using other online } \\
\text { resources to access } \\
\text { political information - } \\
\text { which ones? }\end{array}$ & & & & $\mathrm{x}$ & $\mathrm{x}$ & $\mathrm{X}$ & $\mathrm{x}$ & $\mathrm{x}$ & $\mathrm{x}$ & $\mathrm{x}$ & $\mathrm{x}$ & $\mathrm{x}$ & $\mathrm{x}$ & $\mathrm{x}$ & \\
\hline thermometer.1 & $\begin{array}{l}\text { Thermometer - } \\
\text { left }\end{array}$ & $\begin{array}{l}\text { Unten dargestellt sind } \\
\text { sogenannte } \\
\text { "Gefühlsthermometer". } \\
\text { Bitte gibt an, wie Du } \\
\text { Dich gegenüber den } \\
\text { folgenden politischen } \\
\text { Gruppen fühlst, wobei } \\
0^{\circ} \text { die "kältesten“ oder } \\
\text { negativsten Gefühle } \\
\text { darstellt, und } 100^{\circ} \text { die } \\
\text { "wärmsten" oder } \\
\text { positivsten Gefühle. } \\
\text { Neutrale Gefühle sind } \\
\text { durch } 50^{\circ} \text { dargestellt. } \\
\text { Links: }\end{array}$ & $\begin{array}{l}1=0^{\circ}, 2=10^{\circ}, 3=20^{\circ} \\
4=30^{\circ}, 5=40^{\circ}, 6=50^{\circ} \\
7=60^{\circ}, 8=70^{\circ}, 9=80^{\circ} \\
10=90^{\circ}, 11=100^{\circ}\end{array}$ & $\begin{array}{l}\text { Below are so called } \\
\text { 'feeling thermometers'. } \\
\text { Please indicate how } \\
\text { warmly you feel towards } \\
\text { the following political } \\
\text { groups, where } 0^{\circ} \\
\text { indicates the most } \\
\text { negative, or coldest } \\
\text { feelings, and } 100^{\circ} \\
\text { indicates the most } \\
\text { positive, or warmest } \\
\text { feelings. Neutral feelings } \\
\text { are indicated by } 50^{\circ} \text { : } \\
\text { The Left. }\end{array}$ & $\begin{array}{l}1=0^{\circ}, 2=10^{\circ}, 3=20^{\circ} \\
4=30^{\circ}, 5=40^{\circ}, 6=50^{\circ} \\
7=60^{\circ}, 8=70^{\circ}, 9=80^{\circ} \\
10=90^{\circ}, 11=100^{\circ}\end{array}$ & & & $\mathrm{x}$ & $\mathrm{x}$ & $\mathrm{x}$ & $\mathrm{x}$ & $\mathrm{x}$ & $\mathrm{x}$ & $\mathrm{x}$ & $\mathrm{x}$ & $\mathrm{x}$ & $\mathrm{x}$ & $\mathrm{x}$ & $\mathrm{x}$ \\
\hline thermometer.2 & $\begin{array}{l}\text { Thermometer - } \\
\text { center }\end{array}$ & $\begin{array}{l}\text { Unten dargestellt sind } \\
\text { sogenannte } \\
\text { "Gefühlsthermometer". } \\
\text { Bitte gibt an, wie Du } \\
\text { Dich gegenüber den } \\
\text { folgenden politischen } \\
\text { Gruppen fühlst, wobei } \\
0^{\circ} \text { die ,kältesten“ oder } \\
\text { negativsten Gefühle } \\
\text { darstellt, und } 100^{\circ} \text { die } \\
\text { "wärmsten" oder } \\
\text { positivsten Gefühle. } \\
\text { Neutrale Gefühle sind } \\
\text { durch } 50^{\circ} \text { dargestellt. } \\
\text { Mitte: }\end{array}$ & $\begin{array}{l}1=0^{\circ}, 2=10^{\circ}, 3=20^{\circ} \\
4=30^{\circ}, 5=40^{\circ}, 6=50^{\circ} \\
7=60^{\circ}, 8=70^{\circ}, 9=80^{\circ} \\
10=90^{\circ}, 11=100^{\circ}\end{array}$ & $\begin{array}{l}\text { Below are so called } \\
\text { 'feeling thermometers'. } \\
\text { Please indicate how } \\
\text { warmly you feel towards } \\
\text { the following political } \\
\text { groups, where } 0^{\circ} \\
\text { indicates the most } \\
\text { negative, or coldest } \\
\text { feelings, and } 100^{\circ} \\
\text { indicates the most } \\
\text { positive, or warmest } \\
\text { feelings. Neutral feelings } \\
\text { are indicated by } 50^{\circ} \text { : } \\
\text { The Centre. }\end{array}$ & $\begin{array}{l}1=0^{\circ}, 2=10^{\circ}, 3=20^{\circ} \\
4=30^{\circ}, 5=40^{\circ}, 6=50^{\circ} \\
7=60^{\circ}, 8=70^{\circ}, 9=80^{\circ} \\
10=90^{\circ}, 11=100^{\circ}\end{array}$ & & & $\mathrm{x}$ & $\mathrm{x}$ & $\mathrm{X}$ & $\mathrm{x}$ & $\mathrm{x}$ & $\mathrm{x}$ & $\mathrm{x}$ & $\mathrm{x}$ & $\mathrm{x}$ & $\mathrm{x}$ & $\mathrm{X}$ & $\mathrm{x}$ \\
\hline thermometer.3 & $\begin{array}{l}\text { Thermometer - } \\
\text { right }\end{array}$ & $\begin{array}{l}\text { Unten dargestellt sind } \\
\text { sogenannte } \\
\text { "Gefühlsthermometer". } \\
\text { Bitte gibt an, wie Du } \\
\text { Dich gegenüber den } \\
\text { folgenden politischen } \\
\text { Gruppen fühlst, wobei } \\
0^{\circ} \text { die ,kältesten“ oder } \\
\text { negativsten Gefühle } \\
\text { darstellt, und } 100^{\circ} \text { die } \\
\text { "wärmsten" oder } \\
\text { positivsten Gefühle. } \\
\text { Neutrale Gefühle sind } \\
\text { durch } 50^{\circ} \text { dargestellt. } \\
\text { Rechts: }\end{array}$ & $\begin{array}{l}1=0^{\circ}, 2=10^{\circ}, 3=20^{\circ} \\
4=30^{\circ}, 5=40^{\circ}, 6=50^{\circ} \\
7=60^{\circ}, 8=70^{\circ}, 9=80^{\circ} \\
10=90^{\circ}, 11=100^{\circ}\end{array}$ & $\begin{array}{l}\text { Below are so called } \\
\text { 'feeling thermometers' } \\
\text { Please indicate how } \\
\text { warmly you feel towards } \\
\text { the following political } \\
\text { groups, where } 0^{\circ} \\
\text { indicates the most } \\
\text { negative, or coldest } \\
\text { feelings, and } 100^{\circ} \\
\text { indicates the most } \\
\text { positive, or warmest } \\
\text { feelings. Neutral feelings } \\
\text { are indicated by } 50^{\circ} \text { : } \\
\text { The Right. }\end{array}$ & $\begin{array}{l}1=0^{\circ}, 2=10^{\circ}, 3=20^{\circ} \\
4=30^{\circ}, 5=40^{\circ}, 6=50^{\circ} \\
7=60^{\circ}, 8=70^{\circ}, 9=80^{\circ}, \\
10=90^{\circ}, 11=100^{\circ}\end{array}$ & & & $\mathrm{x}$ & $\mathrm{x}$ & $\mathrm{x}$ & $\mathrm{x}$ & $\mathrm{x}$ & $\mathrm{x}$ & $\mathrm{x}$ & $\mathrm{x}$ & $\mathrm{x}$ & $\mathrm{x}$ & $\mathrm{x}$ & $\mathrm{x}$ \\
\hline
\end{tabular}




\begin{tabular}{|c|c|c|c|c|c|c|c|c|c|c|c|c|c|c|c|c|c|c|}
\hline VarName & VariableLabel & WordingDE & ValueLabelsDE_Linked & WordingEN & ValueLabelsEN_Linked & $\mathrm{L} 1$ & L1F L2 & L3 & $\mathrm{L} 4$ & L5 & L6 & L7 & L8 & L9 & $\mathrm{L} 10$ & L11 & $\mathrm{L} 12$ & 2 L13 L14 \\
\hline student.association.membe & $\begin{array}{l}\text { eilembership } \\
\text { student } \\
\text { organisation }\end{array}$ & $\begin{array}{l}\text { Bist Du Mitglied beim } \\
\text { [name removed]? Du } \\
\text { bist automatisch } \\
\text { Mitglied wenn Du bei } \\
\text { Deiner Einschreibung im } \\
\text { [name removed] } \\
\text { angeklickt hast }\end{array}$ & $1=\mathrm{Ja}, 2=$ Nein & $\begin{array}{l}\text { Are you a member of } \\
\text { the [name removed]? } \\
\text { You are a member if you } \\
\text { clicked on [name } \\
\text { removed]. }\end{array}$ & $1=\mathrm{Yes}, 2=\mathrm{No}$ & & & $\mathrm{x}$ & $\mathrm{x}$ & $\mathrm{x}$ & $\mathrm{x}$ & $\mathrm{x}$ & $\mathrm{x}$ & $\mathrm{x}$ & $\mathrm{x}$ & $\mathrm{x}$ & $\mathrm{x}$ & $\mathrm{x}$ \\
\hline student.association.event & $\begin{array}{l}\text { Participation } \\
\text { in student } \\
\text { organisation } \\
\text { events - other }\end{array}$ & $\begin{array}{l}\text { An welchen der } \\
\text { folgenden [name re- } \\
\text { moved]Veranstaltungen } \\
\text { hast Du teilgenommen? } \\
\text { Andere }\end{array}$ & & $\begin{array}{l}\text { Did you participate in } \\
\text { the following events? } \\
\text { Other (free translation) }\end{array}$ & & & & $\mathrm{x}$ & $\mathrm{x}$ & $\mathrm{x}$ & $\mathrm{x}$ & $\mathrm{x}$ & $\mathrm{x}$ & $\mathrm{x}$ & & $\mathrm{x}$ & $\mathrm{x}$ & $\mathrm{x}$ \\
\hline student.association.materi & $\begin{array}{l}\text { iallsage of study } \\
\text { material }\end{array}$ & $\begin{array}{l}\text { Hast Du bereits die von } \\
\text { der [name removed] } \\
\text { online zur Verfügung } \\
\text { gestellten Materialien } \\
\text { zur } \\
\text { Prüfungsvorbereitung } \\
\text { verwendet } \\
\text { (Altklausuren, } \\
\text { Prüfungsprotokolle von } \\
\text { mündlichen Prüfungen } \\
\text { etc.)? }\end{array}$ & $1=\mathrm{Ja}, 2=$ Nein & $\begin{array}{l}\text { Have you already used } \\
\text { the study material } \\
\text { (previous exams, } \\
\text { examination protocolls, } \\
\text { etc.) provided by } \\
\text { BAMK (Bachelor- und } \\
\text { Masterprüfungskommis- } \\
\text { sion)? (free } \\
\text { translation) }\end{array}$ & $1=\mathrm{Yes}, 2=\mathrm{No}$ & & & $\mathrm{x}$ & $\mathrm{x}$ & $\mathrm{x}$ & $\mathrm{x}$ & $\mathrm{x}$ & $\mathrm{x}$ & $\mathrm{x}$ & & $\mathrm{x}$ & $\mathrm{x}$ & $\mathrm{x}$ \\
\hline music.genres & $\begin{array}{l}\text { Favourite } \\
\text { music genres }\end{array}$ & $\begin{array}{l}\text { Welche Musikgenres } \\
\text { magst Du am Liebsten? }\end{array}$ & $\begin{array}{l}4=\text { Alternative, } 5= \\
\text { Blues, } 6=\text { Country, } 7= \\
\text { Dance, } 8=\text { Electronische } \\
\text { Musik, } 9=\text { Folk } \& \\
\text { Americana, } 10=\text { Funk, } 11 \\
=\text { Hip Hop, } 12=\text { Indie, } 13 \\
=\text { Jazz, } 14=\text { Klassik, } 15 \\
=\text { Latino, } 16=\text { Metal, } 17 \\
=\text { New Age, } 18=\text { Pop, } 19 \\
=\text { Punk, } 20=\text { Reggae, } 21 \\
\text { = RnB, } 22=\text { Rock, } 23= \\
\text { Soul, } 24= \\
\text { Singer-Songwriter, } 25= \\
\text { Volksmusik, } 26=\text { Andere } \\
1,27=\text { Andere } 2,28= \\
\text { Andere 3 }\end{array}$ & $\begin{array}{l}\text { Which are your } \\
\text { favourite music genres? }\end{array}$ & $\begin{array}{l}4=\text { Alternative, } 5= \\
\text { Blues, } 6=\text { Country, } 7= \\
\text { Dance, } 8=\text { Electronische } \\
\text { Musik, } 9=\text { Folk \& } \\
\text { Americana, } 10=\text { Funk, } 11 \\
=\text { Hip Hop, } 12=\text { Indie, } 13 \\
=\text { Jazz, } 14=\text { Classical, } 15 \\
=\text { Latino, } 16=\text { Metal, } 17 \\
=\text { New Age, } 18=\text { Pop, } 19 \\
=\text { Punk, } 20=\text { Reggae, } 21 \\
\text { = RnB, } 22=\text { Rock, } 23= \\
\text { Soul, } 24= \\
\text { Singer-Songwriter, } 25= \\
\text { Volksmusik, } 26=\text { Other } 1, \\
27=\text { Other } 2,28=\text { Other } \\
3\end{array}$ & & & $\mathrm{x}$ & & $\mathrm{x}$ & $\mathrm{x}$ & $\mathrm{x}$ & $\mathrm{x}$ & $\mathrm{x}$ & $\mathrm{x}$ & $\mathrm{x}$ & $\mathrm{x}$ & $\mathrm{x}$ \\
\hline music.genres.str1 & $\begin{array}{l}\text { Favourite } \\
\text { music genres - } \\
\text { other } 1\end{array}$ & $\begin{array}{l}\text { Welche Musikgenres } \\
\text { magst Du am Liebsten? } \\
\text { Andere } 1\end{array}$ & & $\begin{array}{l}\text { Which are your } \\
\text { favourite music genres? } \\
\text { Other } 1\end{array}$ & & & & $\mathrm{x}$ & & $\mathrm{x}$ & $\mathrm{x}$ & $\mathrm{x}$ & $\mathrm{x}$ & $\mathrm{x}$ & $\mathrm{x}$ & $\mathrm{x}$ & $\mathrm{x}$ & $\mathrm{x}$ \\
\hline music.genres.str2 & $\begin{array}{l}\text { Favourite } \\
\text { music genres - } \\
\text { other } 2\end{array}$ & $\begin{array}{l}\text { Welche Musikgenres } \\
\text { magst Du am Liebsten? } \\
\text { Andere } 2\end{array}$ & & $\begin{array}{l}\text { Which are your } \\
\text { favourite music genres? } \\
\text { Other } 2\end{array}$ & & & & $\mathrm{x}$ & & $\mathrm{x}$ & $\mathrm{x}$ & $\mathrm{x}$ & $\mathrm{x}$ & $\mathrm{x}$ & $\mathrm{x}$ & $\mathrm{x}$ & $\mathrm{x}$ & $\mathrm{x}$ \\
\hline music.genres.str3 & $\begin{array}{l}\text { Favourite } \\
\text { music genres - } \\
\text { other } 3\end{array}$ & $\begin{array}{l}\text { Welche Musikgenres } \\
\text { magst Du am Liebsten? } \\
\text { Andere } 3\end{array}$ & & $\begin{array}{l}\text { Which are your } \\
\text { favourite music genres? } \\
\text { Other } 3\end{array}$ & & & & $\mathrm{x}$ & & $\mathrm{x}$ & $\mathrm{x}$ & $\mathrm{x}$ & $\mathrm{x}$ & $\mathrm{x}$ & $\mathrm{x}$ & $\mathrm{x}$ & $\mathrm{x}$ & $\mathrm{x}$ \\
\hline
\end{tabular}




\begin{tabular}{|c|c|c|c|c|c|c|c|c|c|c|c|c|c|c|c|c|c|c|}
\hline VarName & VariableLabel & WordingDE & ValueLabelsDE_Linked & WordingEN & ValueLabelsEN_Linked & L1 & L1F L2 & L3 & $\mathrm{L} 4$ & L5 & L6 & L7 & L8 & L9 & L10 & L11 & $1 \mathrm{~L} 12$ & 2 L13 L14 \\
\hline movie.genres & $\begin{array}{l}\text { Favourite } \\
\text { movie genres }\end{array}$ & $\begin{array}{l}\text { Welche Film-Genres } \\
\text { magst Du am Liebsten? }\end{array}$ & $\begin{array}{l}4=\text { Action, } 5= \\
\text { Abenteuer, } 6= \\
\text { Animation, } 7= \\
\text { Biographie, } 8=\text { Komödie, } \\
9=\text { Krimi, } 10= \\
\text { Dokumentation, } 11= \\
\text { Drama, } 12= \\
\text { Familienfilm, } 13= \\
\text { Fantasy, } 14=\text { Film Noir, } \\
15=\text { Historienfilm, } 16= \\
\text { Horror, } 17=\text { Musikfilm, } \\
18=\text { Musical, } 19= \\
\text { Mystery, } 20=\text { Romanze, } \\
21=\text { Science Fiction, } 22= \\
\text { Sport, } 23=\text { Thriller, } 24= \\
\text { Kriegsilm, } 25=\text { Western, } \\
26=\text { Andere } 1,27= \\
\text { Andere } 2,28=\text { Andere } 3\end{array}$ & $\begin{array}{l}\text { Which are your } \\
\text { favourite movie genres? }\end{array}$ & $\begin{array}{l}4=\text { Action, } 5= \\
\text { Adventure, } 6=\text { Animated, } \\
7=\text { Biography, } 8= \\
\text { Comedy, } 9=\text { Crime, } 10= \\
\text { Documentary, } 11= \\
\text { Drama, } 12=\text { Familiy, } 13 \\
=\text { Fantasy, } 14=\text { Film } \\
\text { Noir, } 15=\text { History, } 16= \\
\text { Horror, } 17=\text { Music Film, } \\
18=\text { Musical, } 19= \\
\text { Mystery, } 20=\text { Romance, } \\
21=\text { Science Fiction, } 22 \\
=\text { Sport, } 23=\text { Thriller, } 24 \\
=\text { War films, } 25= \\
\text { Western, } 26=\text { Other } 1,27 \\
=\text { Other } 2,28=\text { Other } 3\end{array}$ & & & $\mathrm{x}$ & & $\mathrm{x}$ & $\mathrm{x}$ & $\mathrm{x}$ & $\mathrm{x}$ & $\mathrm{x}$ & $\mathrm{x}$ & $\mathrm{x}$ & $\mathrm{x}$ & $\mathrm{x}$ \\
\hline movie.genres.str1 & $\begin{array}{l}\text { Favourite } \\
\text { movie genres - } \\
\text { other } 1\end{array}$ & $\begin{array}{l}\text { Welche Film-Genres } \\
\text { magst Du am Liebsten? } \\
\text { Andere } 1\end{array}$ & & $\begin{array}{l}\text { Which are your } \\
\text { favourite movie genres? } \\
\text { Other } 1\end{array}$ & & & & $\mathrm{x}$ & & $\mathrm{x}$ & $\mathrm{x}$ & $\mathrm{x}$ & $\mathrm{x}$ & $\mathrm{x}$ & $\mathrm{x}$ & $\mathrm{x}$ & $\mathrm{x}$ & $\mathrm{x}$ \\
\hline movie.genres.str2 & $\begin{array}{l}\text { Favourite } \\
\text { movie genres - } \\
\text { other } 2\end{array}$ & $\begin{array}{l}\text { Welche Film-Genres } \\
\text { magst Du am Liebsten? } \\
\text { Andere } 2\end{array}$ & & $\begin{array}{l}\text { Which are your } \\
\text { favourite movie genres? } \\
\text { Other } 2\end{array}$ & & & & $\mathrm{x}$ & & $\mathrm{x}$ & $\mathrm{x}$ & $\mathrm{x}$ & $\mathrm{x}$ & $\mathrm{x}$ & $\mathrm{x}$ & $\mathrm{x}$ & $\mathrm{x}$ & $\mathrm{x}$ \\
\hline movie.genres.str3 & $\begin{array}{l}\text { Favourite } \\
\text { movie genres - } \\
\text { other } 3\end{array}$ & $\begin{array}{l}\text { Welche Film-Genres } \\
\text { magst Du am Liebsten? } \\
\text { Andere } 3\end{array}$ & & $\begin{array}{l}\text { Which are your } \\
\text { favourite movie genres? } \\
\text { Other } 3\end{array}$ & & & & $\mathrm{x}$ & & $\mathrm{x}$ & $\mathrm{x}$ & $\mathrm{x}$ & $\mathrm{x}$ & $\mathrm{x}$ & $\mathrm{x}$ & $\mathrm{x}$ & $\mathrm{x}$ & $\mathrm{x}$ \\
\hline Final.exam.1 & $\begin{array}{l}\text { View of final } \\
\text { exam } 1\end{array}$ & $\begin{array}{l}\text { Ich bin sicher, dass ich } \\
\text { die Basisprüfung am } \\
\text { Ende des ersten Jahres } \\
\text { bestehen werde. }\end{array}$ & $\begin{array}{l}1=\text { trifft überhaupt nicht } \\
\text { zu, } 2=\text { trifft nicht } \mathrm{zu}, 3= \\
\text { trifft eher nicht } \mathrm{zu}, 4= \\
\text { weder noch, } 5=\text { eher } \\
\text { zutreffend, } 6=\text { trifft } \mathrm{zu}, 7 \\
=\text { trifft voll und ganz zu }\end{array}$ & $\begin{array}{l}\text { I am certain that I am } \\
\text { going to pass the final } \\
\text { exam at the end of the } \\
\text { first year. }\end{array}$ & $\begin{array}{l}1=\text { does not apply at all, } \\
2=\text { does not apply, } 3= \\
\text { does rather not apply, } 4= \\
\text { neither, } 5=\text { rather } \\
\text { applies, } 6=\text { applies, } 7= \\
\text { applies completely (free } \\
\text { translation) }\end{array}$ & & & $\mathrm{x}$ & $\mathrm{x}$ & $\mathrm{x}$ & & & & & & & & \\
\hline Final.exam.2 & $\begin{array}{l}\text { View of final } \\
\text { exam } 2\end{array}$ & $\begin{array}{l}\text { Ich fühle mich gestresst, } \\
\text { wenn ich an die } \\
\text { Basisprüfung denke. }\end{array}$ & $\begin{array}{l}1=\text { trifft überhaupt nicht } \\
\text { zu, } 2=\text { trifft nicht zu, } 3= \\
\text { trifft eher nicht } \mathrm{zu}, 4= \\
\text { weder noch, } 5=\text { eher } \\
\text { zutreffend, } 6=\text { trifft zu, } 7 \\
=\text { trifft voll und ganz zu }\end{array}$ & $\begin{array}{l}\text { I am stressed when I } \\
\text { think about the final } \\
\text { exam. }\end{array}$ & $\begin{array}{l}1=\text { does not apply at all, } \\
2=\text { does not apply, } 3= \\
\text { does rather not apply, } 4= \\
\text { neither, } 5=\text { rather } \\
\text { applies, } 6=\text { applies, } 7= \\
\text { applies completely (free } \\
\text { translation) }\end{array}$ & & & $\mathrm{x}$ & $\mathrm{x}$ & $\mathrm{X}$ & & & & & & & & \\
\hline Final.exam.3 & $\begin{array}{l}\text { View of final } \\
\text { exam } 3\end{array}$ & $\begin{array}{l}\text { Mir ist völlig klar, } \\
\text { welche Themen ich } \\
\text { beherrschen musst, um } \\
\text { die Basisprüfung zu } \\
\text { bestehen. }\end{array}$ & $\begin{array}{l}1=\text { trifft überhaupt nicht } \\
\text { zu, } 2=\text { trifft nicht } \mathrm{zu}, 3= \\
\text { trifft eher nicht } \mathrm{zu}, 4= \\
\text { weder noch, } 5=\text { eher } \\
\text { zutreffend, } 6=\text { trifft } \mathrm{zu}, 7 \\
=\text { trifft voll und ganz zu }\end{array}$ & $\begin{array}{l}\text { It is clear to me which } \\
\text { topics I have to know } \\
\text { about to pass the final } \\
\text { exam. }\end{array}$ & $\begin{array}{l}1=\text { does not apply at all, } \\
2=\text { does not apply, } 3= \\
\text { does rather not apply, } 4= \\
\text { neither, } 5=\text { rather } \\
\text { applies, } 6=\text { applies, } 7= \\
\text { applies completely (free } \\
\text { translation) }\end{array}$ & & & $\mathrm{x}$ & $\mathrm{x}$ & $\mathrm{x}$ & & & & & & & & \\
\hline Final.exam.4 & $\begin{array}{l}\text { View of final } \\
\text { exam } 4\end{array}$ & $\begin{array}{l}\text { Die Studierenden am } \\
\text { [name removed] } \\
\text { unterstützen sich } \\
\text { gegenseitig bei der } \\
\text { Vorbereitung auf die } \\
\text { Basisprüfung. }\end{array}$ & $\begin{array}{l}1=\text { trifft überhaupt nicht } \\
\text { zu, } 2=\text { trifft nicht } \mathrm{zu}, 3= \\
\text { trifft eher nicht } \mathrm{zu}, 4= \\
\text { weder noch, } 5=\text { eher } \\
\text { zutreffend, } 6=\text { trifft } \mathrm{zu}, 7 \\
=\text { trifft voll und ganz zu }\end{array}$ & $\begin{array}{l}\text { The students at [name } \\
\text { removed] support each } \\
\text { other in the preparation } \\
\text { of the final exam. }\end{array}$ & $\begin{array}{l}1=\text { does not apply at all, } \\
2=\text { does not apply, } 3= \\
\text { does rather not apply, } 4= \\
\text { neither, } 5=\text { rather } \\
\text { applies, } 6=\text { applies, } 7= \\
\text { applies completely (free } \\
\text { translation) }\end{array}$ & & & $\mathrm{x}$ & $\mathrm{x}$ & $\mathrm{x}$ & & & & & & & & \\
\hline intention.quit & $\begin{array}{l}\text { Intention to } \\
\text { quit }\end{array}$ & $\begin{array}{l}\text { Ich habe mir oft } \\
\text { überlegt das Studium } \\
\text { am [name removed] } \\
\text { abzubrechen (z.B. zu } \\
\text { einem anderen [name } \\
\text { removed] wechseln, die } \\
\text { Uni wechseln oder } \\
\text { aufhören zu studieren) }\end{array}$ & $\begin{array}{l}1=\text { stimmt überhaupt } \\
\text { nicht, } 2=\text { stimmt nicht, } 3 \\
=\text { stimmt eher nicht, } 4= \\
\text { weder noch, } 5=\text { stimmt } \\
\text { eher, } 6=\text { stimmt, } 7= \\
\text { stimmt voll und ganz }\end{array}$ & $\begin{array}{l}\text { I have frequently } \\
\text { considered quitting my } \\
\text { studies at [name } \\
\text { removed] (e.g. change to } \\
\text { another[name removed] } \\
\text { departement, different } \\
\text { university or quit } \\
\text { university) }\end{array}$ & $\begin{array}{l}1=\text { does not apply at all, } \\
2=\text { does not apply, } 3= \\
\text { does rather not apply, } 4= \\
\text { neither, } 5=\text { rather } \\
\text { applies, } 6=\text { applies, } 7= \\
\text { applies completely (free } \\
\text { translation) }\end{array}$ & & & & & $\mathrm{x}$ & $\mathrm{x}$ & $\mathrm{x}$ & $\mathrm{x}$ & $\mathrm{x}$ & $\mathrm{x}$ & $\mathrm{x}$ & $\mathrm{x}$ & $\mathrm{x}$ \\
\hline
\end{tabular}




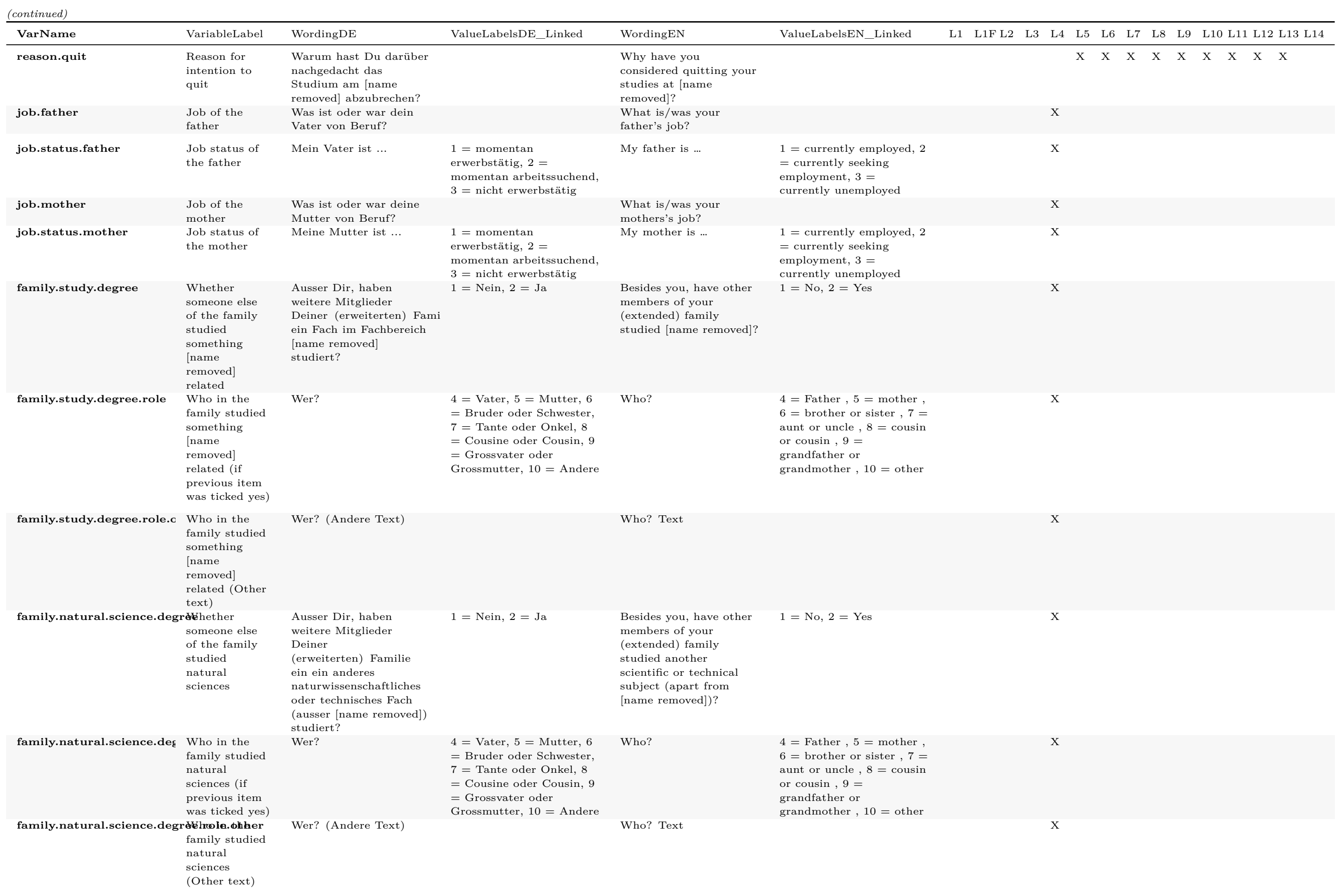




\begin{tabular}{|c|c|c|c|c|c|c|c|c|c|c|c|c|c|c|c|}
\hline VarName & VariableLabel & WordingDE & ValueLabelsDE_Linked & WordingEN & ValueLabelsEN_Linked & $\mathrm{L} 1$ & L1F L2 & L3 & $\mathrm{L} 4$ & L5 & L6 & L7 & $\mathrm{L} 8$ & L9 & L10 L11 L12 L13 L14 \\
\hline attitude.parents. 1 & $\begin{array}{l}\text { Importance of } \\
\text { studying for } \\
\text { parents }\end{array}$ & $\begin{array}{l}\text { Meinen Eltern ist es } \\
\text { wichtig, dass ich } \\
\text { studiere. (4) }\end{array}$ & $\begin{array}{l}4=\text { überhaupt nicht } \\
\text { zutreffend, } 5=\text { nicht } \\
\text { zutreffend, } 6=\text { eher nicht } \\
\text { zutreffend, } 7=\text { weder } \\
\text { noch, } 8=\text { eher zutreffend, } \\
9=\text { zutreffend, } 10=\text { trifft } \\
\text { voll und ganz zu }\end{array}$ & $\begin{array}{l}\text { It is important to my } \\
\text { parents that I study }\end{array}$ & $\begin{array}{l}4=\text { not at all }, 5=\text { not } \\
\text { applicable }, 6=\text { rather } \\
\text { not applicable }, 7= \\
\text { neither nor }, 8=\text { rather } \\
\text { applicable }, 9=\text { applicable } \\
10=\text { fully applies }\end{array}$ & & & & $\mathrm{x}$ & & & & & & \\
\hline attitude.parents. 2 & $\begin{array}{l}\text { Importance of } \\
\text { studying a } \\
\text { natural or } \\
\text { technical } \\
\text { science for } \\
\text { parents }\end{array}$ & $\begin{array}{l}\text { Meinen Eltern ist es } \\
\text { wichtig, dass ich eine } \\
\text { Naturwissenschaft oder } \\
\text { ein technisches Fach } \\
\text { studiere. (5) }\end{array}$ & $\begin{array}{l}4=\text { überhaupt nicht } \\
\text { zutreffend, } 5=\text { nicht } \\
\text { zutreffend, } 6=\text { eher nicht } \\
\text { zutreffend, } 7=\text { weder } \\
\text { noch, } 8=\text { eher zutreffend, } \\
9=\text { zutreffend, } 10=\text { trifft } \\
\text { voll und ganz zu }\end{array}$ & $\begin{array}{l}\text { It is important to my } \\
\text { parents that I study a } \\
\text { natural science or } \\
\text { technical subject }\end{array}$ & $\begin{array}{l}4=\text { not at all }, 5=\text { not } \\
\text { applicable }, 6=\text { rather } \\
\text { not applicable }, 7= \\
\text { neither nor }, 8=\text { rather } \\
\text { applicable, } 9=\text { applicable } \\
10=\text { fully applies }\end{array}$ & & & & $\mathrm{x}$ & & & & & & \\
\hline attitude.parents. 3 & $\begin{array}{l}\text { Importance of } \\
\text { studying } \\
\text { [name } \\
\text { removed] for } \\
\text { parents }\end{array}$ & $\begin{array}{l}\text { Meinen Eltern ist es } \\
\text { wichtig, dass ich ein } \\
\text { Fach im Fachbereich } \\
\text { [name removed] } \\
\text { studiere. (6) }\end{array}$ & $\begin{array}{l}4=\text { überhaupt nicht } \\
\text { zutreffend, } 5=\text { nicht } \\
\text { zutreffend, } 6=\text { eher nicht } \\
\text { zutreffend, } 7=\text { weder } \\
\text { noch, } 8=\text { eher zutreffend, } \\
9=\text { zutreffend, } 10=\text { trifft } \\
\text { voll und ganz zu }\end{array}$ & $\begin{array}{l}\text { It is important to my } \\
\text { parents that I study a } \\
\text { [name removed]-related } \\
\text { subject }\end{array}$ & $\begin{array}{l}4=\text { not at all }, 5=\text { not } \\
\text { applicable }, 6=\text { rather } \\
\text { not applicable }, 7= \\
\text { neither nor }, 8=\text { rather } \\
\text { applicable }, 9=\text { applicable } \\
, 10=\text { fully applies }\end{array}$ & & & & $\mathrm{x}$ & & & & & & \\
\hline attitude.parents. 4 & $\begin{array}{l}\text { Degree to } \\
\text { which parents } \\
\text { would prefere } \\
\text { if participant } \\
\text { studied } \\
\text { something else }\end{array}$ & $\begin{array}{l}\text { Meine Eltern würden es } \\
\text { bevorzugen, wenn ich } \\
\text { ein anderes Fach } \\
\text { studierte. ( } 7 \text { ) }\end{array}$ & $\begin{array}{l}4=\text { überhaupt nicht } \\
\text { zutreffend, } 5=\text { nicht } \\
\text { zutreffend, } 6=\text { eher nicht } \\
\text { zutreffend, } 7=\text { weder } \\
\text { noch, } 8=\text { eher zutreffend, } \\
9=\text { zutreffend, } 10=\text { trifft } \\
\text { voll und ganz zu }\end{array}$ & $\begin{array}{l}\text { My parents would prefer } \\
\text { it if I studied a different } \\
\text { subject }\end{array}$ & $\begin{array}{l}4=\text { not at all }, 5=\text { not } \\
\text { applicable }, 6=\text { rather } \\
\text { not applicable }, 7= \\
\text { neither nor }, 8=\text { rather } \\
\text { applicable }, 9=\text { applicable } \\
, 10=\text { fully applies }\end{array}$ & & & & $\mathrm{x}$ & & & & & & \\
\hline attitude.parents. 5 & $\begin{array}{l}\text { Degree to } \\
\text { which parents } \\
\text { would prefere } \\
\text { if participant } \\
\text { worked instead } \\
\text { of studied }\end{array}$ & $\begin{array}{l}\text { Meine Eltern hätten es } \\
\text { bevorzugt, wenn ich eine } \\
\text { Arbeitsstelle } \\
\text { angenommen hätte, } \\
\text { statt ein Studium zu } \\
\text { beginnen. (8) }\end{array}$ & $\begin{array}{l}4=\text { überhaupt nicht } \\
\text { zutreffend, } 5=\text { nicht } \\
\text { zutreffend, } 6=\text { eher nicht } \\
\text { zutreffend, } 7=\text { weder } \\
\text { noch, } 8=\text { eher zutreffend, } \\
9=\text { zutreffend, } 10=\text { trifft } \\
\text { voll und ganz zu }\end{array}$ & $\begin{array}{l}\text { My parents would have } \\
\text { preferred it if I had } \\
\text { taken on a job instead } \\
\text { of starting a degree }\end{array}$ & $\begin{array}{l}4=\text { not at all }, 5=\text { not } \\
\text { applicable }, 6=\text { rather } \\
\text { not applicable }, 7= \\
\text { neither nor }, 8=\text { rather } \\
\text { applicable }, 9=\text { applicable } \\
10=\text { fully applies }\end{array}$ & & & & $\mathrm{x}$ & & & & & & \\
\hline extraversion.long. 1 & $\begin{array}{l}\text { Big Five } \\
\text { Inventory } \\
\text { (Lang et al., } \\
\text { 2001), Item 1 }\end{array}$ & $\begin{array}{l}\text { Ich sehe mich selbst als } \\
\text { jemand, der gesprächig } \\
\text { ist, sich gerne unterhält }\end{array}$ & $\begin{array}{l}1=\text { trifft überhaupt nicht } \\
\mathrm{zu}, 2=\text { trifft eher nicht } \\
\mathrm{zu}, 3=\text { weder noch, } 4= \\
\text { eher zutreffend, } 5=\text { trifft } \\
\text { voll und ganz zu }\end{array}$ & & $\begin{array}{l}1=\text { does not apply at all } \\
2=\text { does not apply }, 3= \\
\text { neither nor }, 4=\text { applies } \\
5=\text { fully applies }\end{array}$ & & & & & $\mathrm{x}$ & & & & & \\
\hline agreeableness.long. 1 & $\begin{array}{l}\text { Big Five } \\
\text { Inventory } \\
\text { (Lang et al., } \\
2001 \text { ), Item } 2\end{array}$ & $\begin{array}{l}\text { dazu neigt, andere zu } \\
\text { kritisieren. }\end{array}$ & $\begin{array}{l}1=\text { trifft überhaupt nicht } \\
\mathrm{zu}, 2=\text { trifft eher nicht } \\
\mathrm{zu}, 3=\text { weder noch, } 4= \\
\text { eher zutreffend, } 5=\text { trifft } \\
\text { voll und ganz zu }\end{array}$ & & $\begin{array}{l}1=\text { does not apply at all } \\
2=\text { does not apply }, 3= \\
\text { neither nor }, 4=\text { applies } \\
5=\text { fully applies }\end{array}$ & & & & & $\mathrm{x}$ & & & & & \\
\hline conscientiousness.long. 1 & $\begin{array}{l}\text { Big Five } \\
\text { Inventory } \\
\text { (Lang et al., } \\
2001 \text { ), Item } 3\end{array}$ & $\begin{array}{l}\text { Aufgaben gründlich } \\
\text { erledigt }\end{array}$ & $\begin{array}{l}1=\text { trifft überhaupt nicht } \\
\mathrm{zu}, 2=\text { trifft eher nicht } \\
\mathrm{zu}, 3=\text { weder noch, } 4= \\
\text { eher zutreffend, } 5=\text { trifft } \\
\text { voll und ganz zu }\end{array}$ & & $\begin{array}{l}1=\text { does not apply at all } \\
2=\text { does not apply }, 3= \\
\text { neither nor }, 4=\text { applies } \\
5=\text { fully applies }\end{array}$ & & & & & $\mathrm{x}$ & & & & & \\
\hline neuroticism.long. 1 & $\begin{array}{l}\text { Big Five } \\
\text { Inventory } \\
\text { (Lang et al., } \\
2001 \text { ), Item } 4\end{array}$ & $\begin{array}{l}\text { deprimiert, } \\
\text { niedergeschlagen ist }\end{array}$ & $\begin{array}{l}1=\text { trifft überhaupt nicht } \\
\mathrm{zu}, 2=\text { trifft eher nicht } \\
\mathrm{zu}, 3=\text { weder noch, } 4= \\
\text { eher zutreffend, } 5=\text { trifft } \\
\text { voll und ganz zu }\end{array}$ & & $\begin{array}{l}1=\text { does not apply at all } \\
2=\text { does not apply }, 3= \\
\text { neither nor }, 4=\text { applies } \\
5=\text { fully applies }\end{array}$ & & & & & $\mathrm{x}$ & & & & & \\
\hline openness.long.1 & $\begin{array}{l}\text { Big Five } \\
\text { Inventory } \\
\text { (Lang et al., } \\
\text { 2001), Item 5 }\end{array}$ & $\begin{array}{l}\text { originell ist, neue Ideen } \\
\text { entwickelt }\end{array}$ & $\begin{array}{l}1=\text { trifft überhaupt nicht } \\
\mathrm{zu}, 2=\text { trifft eher nicht } \\
\mathrm{zu}, 3=\text { weder noch, } 4= \\
\text { eher zutreffend, } 5=\text { trifft } \\
\text { voll und ganz zu }\end{array}$ & & $\begin{array}{l}1=\text { does not apply at all } \\
2=\text { does not apply }, 3= \\
\text { neither nor }, 4=\text { applies } \\
5=\text { fully applies }\end{array}$ & & & & & $\mathrm{x}$ & & & & & \\
\hline
\end{tabular}




\begin{tabular}{|c|c|c|c|c|c|c|c|c|c|c|c|c|c|c|}
\hline VarName & VariableLabel & WordingDE & ValueLabelsDE_Linked & WordingEN & ValueLabelsEN_Linked & L1 & L1F L2 & L3 & $\mathrm{L} 4$ & L5 & $\mathrm{L} 6$ & L7 L8 & L9 & L10 L11 L12 L13 L14 \\
\hline extraversion.long. 2 & $\begin{array}{l}\text { Big Five } \\
\text { Inventory } \\
\text { (Lang et al., } \\
\text { 2001), Item 6 }\end{array}$ & $\begin{array}{l}\text { eher zurückhaltend und } \\
\text { reserviert ist }\end{array}$ & $\begin{array}{l}1=\text { trifft überhaupt nicht } \\
\text { zu, } 2=\text { trifft eher nicht } \\
\text { zu, } 3=\text { weder noch, } 4= \\
\text { eher zutreffend, } 5=\text { trifft } \\
\text { voll und ganz zu }\end{array}$ & & $\begin{array}{l}1=\text { does not apply at all } \\
2=\text { does not apply }, 3= \\
\text { neither nor }, 4=\text { applies } \\
5=\text { fully applies }\end{array}$ & & & & & $\mathrm{x}$ & & & & \\
\hline agreeableness.long. 2 & $\begin{array}{l}\text { Big Five } \\
\text { Inventory } \\
\text { (Lang et al., } \\
\text { 2001), Item } 7\end{array}$ & $\begin{array}{l}\text { hilfsbereit und selbstlos } \\
\text { gegenüber anderen ist }\end{array}$ & $\begin{array}{l}1=\text { trifft überhaupt nicht } \\
\text { zu, } 2=\text { trifft eher nicht } \\
\text { zu, } 3=\text { weder noch, } 4= \\
\text { eher zutreffend, } 5=\text { trifft } \\
\text { voll und ganz zu }\end{array}$ & & $\begin{array}{l}1=\text { does not apply at all } \\
2=\text { does not apply }, 3= \\
\text { neither nor }, 4=\text { applies } \\
5=\text { fully applies }\end{array}$ & & & & & $\mathrm{x}$ & & & & \\
\hline conscientiousness.long.2 & $\begin{array}{l}\text { Big Five } \\
\text { Inventory } \\
\text { (Lang et al., } \\
\text { 2001), Item } 8\end{array}$ & etwas achtlos sein kann & $\begin{array}{l}1=\text { trifft überhaupt nicht } \\
\text { zu, } 2=\text { trifft eher nicht } \\
\text { zu, } 3=\text { weder noch, } 4= \\
\text { eher zutreffend, } 5=\text { trifft } \\
\text { voll und ganz zu }\end{array}$ & & $\begin{array}{l}1=\text { does not apply at all } \\
2=\text { does not apply }, 3= \\
\text { neither nor }, 4=\text { applies } \\
5=\text { fully applies }\end{array}$ & & & & & $\mathrm{x}$ & & & & \\
\hline neuroticism.long.2 & $\begin{array}{l}\text { Big Five } \\
\text { Inventory } \\
\text { (Lang et al., } \\
\text { 2001), Item } 9\end{array}$ & $\begin{array}{l}\text { entspannt ist, sich durch } \\
\text { Stress nicht aus der } \\
\text { Ruhe bringen lässt }\end{array}$ & $\begin{array}{l}1=\text { trifft überhaupt nicht } \\
\text { zu, } 2=\text { trifft eher nicht } \\
\text { zu, } 3=\text { weder noch, } 4= \\
\text { eher zutreffend, } 5=\text { trifft } \\
\text { voll und ganz zu }\end{array}$ & & $\begin{array}{l}1=\text { does not apply at all } \\
2=\text { does not apply }, 3= \\
\text { neither nor }, 4=\text { applies } \\
5=\text { fully applies }\end{array}$ & & & & & $\mathrm{x}$ & & & & \\
\hline openness.long. 2 & $\begin{array}{l}\text { Big Five } \\
\text { Inventory } \\
\text { (Lang et al., } \\
2001 \text { ), Item } 10\end{array}$ & vielseitig interessiert ist & $\begin{array}{l}1=\text { trifft überhaupt nicht } \\
\text { zu, } 2=\text { trifft eher nicht } \\
\text { zu, } 3=\text { weder noch, } 4= \\
\text { eher zutreffend, } 5=\text { trifft } \\
\text { voll und ganz zu }\end{array}$ & & $\begin{array}{l}1=\text { does not apply at all } \\
2=\text { does not apply }, 3= \\
\text { neither nor }, 4=\text { applies } \\
5=\text { fully applies }\end{array}$ & & & & & $\mathrm{x}$ & & & & \\
\hline extraversion.long. 3 & $\begin{array}{l}\text { Big Five } \\
\text { Inventory } \\
\text { (Lang et al., } \\
\text { 2001), Item } 11\end{array}$ & $\begin{array}{l}\text { voller Energie und } \\
\text { Tatendrang ist }\end{array}$ & $\begin{array}{l}1=\text { trifft überhaupt nicht } \\
\text { zu, } 2=\text { trifft eher nicht } \\
\text { zu, } 3=\text { weder noch, } 4= \\
\text { eher zutreffend, } 5=\text { trifft } \\
\text { voll und ganz zu }\end{array}$ & & $\begin{array}{l}1=\text { does not apply at all } \\
2=\text { does not apply }, 3= \\
\text { neither nor }, 4=\text { applies } \\
5=\text { fully applies }\end{array}$ & & & & & $\mathrm{x}$ & & & & \\
\hline agreeableness.long. 3 & $\begin{array}{l}\text { Big Five } \\
\text { Inventory } \\
\text { (Lang et al., } \\
2001), \text { Item } 12\end{array}$ & $\begin{array}{l}\text { häufig in Streitereien } \\
\text { verwickelt ist }\end{array}$ & $\begin{array}{l}1=\text { trifft überhaupt nicht } \\
\mathrm{zu}, 2=\text { trifft eher nicht } \\
\mathrm{zu}, 3=\text { weder noch, } 4= \\
\text { eher zutreffend, } 5=\text { trifft } \\
\text { voll und ganz zu }\end{array}$ & & $\begin{array}{l}1=\text { does not apply at all } \\
2=\text { does not apply }, 3= \\
\text { neither nor }, 4=\text { applies } \\
5=\text { fully applies }\end{array}$ & & & & & $\mathrm{x}$ & & & & \\
\hline conscientiousness.long. 3 & $\begin{array}{l}\text { Big Five } \\
\text { Inventory } \\
\text { (Lang et al., } \\
2001 \text { ), Item } 13\end{array}$ & $\begin{array}{l}\text { zuverlässig und } \\
\text { gewissenhaft arbeitet }\end{array}$ & $\begin{array}{l}1=\text { trifft überhaupt nicht } \\
\mathrm{zu}, 2=\text { trifft eher nicht } \\
\mathrm{zu}, 3=\text { weder noch, } 4= \\
\text { eher zutreffend, } 5=\text { trifft } \\
\text { voll und ganz zu }\end{array}$ & & $\begin{array}{l}1=\text { does not apply at all } \\
2=\text { does not apply }, 3= \\
\text { neither nor }, 4=\text { applies } \\
5=\text { fully applies }\end{array}$ & & & & & $\mathrm{x}$ & & & & \\
\hline neuroticism.long.3 & $\begin{array}{l}\text { Big Five } \\
\text { Inventory } \\
\text { (Lang et al., } \\
\text { 2001), Item } 14\end{array}$ & $\begin{array}{l}\text { leicht angespannt } \\
\text { reagiert }\end{array}$ & $\begin{array}{l}1=\text { trifft überhaupt nicht } \\
\text { zu, } 2=\text { trifft eher nicht } \\
\text { zu, } 3=\text { weder noch, } 4= \\
\text { eher zutreffend, } 5=\text { trifft } \\
\text { voll und ganz zu }\end{array}$ & & $\begin{array}{l}1=\text { does not apply at all } \\
2=\text { does not apply }, 3= \\
\text { neither nor }, 4=\text { applies } \\
5=\text { fully applies }\end{array}$ & & & & & $\mathrm{x}$ & & & & \\
\hline openness.long. 3 & $\begin{array}{l}\text { Big Five } \\
\text { Inventory } \\
\text { (Lang et al., } \\
\text { 2001), Item } 15\end{array}$ & $\begin{array}{l}\text { tiefsinnig ist, gerne über } \\
\text { Sachen nachdenkt }\end{array}$ & $\begin{array}{l}1=\text { trifft überhaupt nicht } \\
\mathrm{zu}, 2=\text { trifft eher nicht } \\
\mathrm{zu}, 3=\text { weder noch, } 4= \\
\text { eher zutreffend, } 5=\text { trifft } \\
\text { voll und ganz zu }\end{array}$ & & $\begin{array}{l}1=\text { does not apply at all } \\
2=\text { does not apply }, 3= \\
\text { neither nor }, 4=\text { applies } \\
5=\text { fully applies }\end{array}$ & & & & & $\mathrm{X}$ & & & & \\
\hline extraversion.long. 4 & $\begin{array}{l}\text { Big Five } \\
\text { Inventory } \\
\text { (Lang et al., } \\
2001 \text { ), Item } 16\end{array}$ & $\begin{array}{l}\text { begeisterungsfähig ist } \\
\text { und andere mitreißen } \\
\text { kann }\end{array}$ & $\begin{array}{l}1=\text { trifft überhaupt nicht } \\
\mathrm{zu}, 2=\text { trifft eher nicht } \\
\mathrm{zu}, 3=\text { weder noch, } 4= \\
\text { eher zutreffend, } 5=\text { trifft } \\
\text { voll und ganz } \mathrm{zu}\end{array}$ & & $\begin{array}{l}1=\text { does not apply at all } \\
2=\text { does not apply }, 3= \\
\text { neither nor }, 4=\text { applies } \\
5=\text { fully applies }\end{array}$ & & & & & $\mathrm{x}$ & & & & \\
\hline agreeableness.long.4 & $\begin{array}{l}\text { Big Five } \\
\text { Inventory } \\
\text { (Lang et al., } \\
2001 \text { ), Item } 17\end{array}$ & $\begin{array}{l}\text { nicht nachtragend ist, } \\
\text { anderen leicht vergibt }\end{array}$ & $\begin{array}{l}1=\text { trifft überhaupt nicht } \\
\mathrm{zu}, 2=\text { trifft eher nicht } \\
\mathrm{zu}, 3=\text { weder noch, } 4= \\
\text { eher zutreffend, } 5=\text { trifft } \\
\text { voll und ganz zu }\end{array}$ & & $\begin{array}{l}1=\text { does not apply at all } \\
2=\text { does not apply }, 3= \\
\text { neither nor }, 4=\text { applies } \\
5=\text { fully applies }\end{array}$ & & & & & $\mathrm{X}$ & & & & \\
\hline
\end{tabular}




\begin{tabular}{|c|c|c|c|c|c|c|c|c|c|c|c|c|c|c|}
\hline VarName & VariableLabel & WordingDE & ValueLabelsDE_Linked & WordingEN & ValueLabelsEN_Linked & L1 & L1F L2 & L3 & L4 & L5 & L6 & L7 & L8 L9 & L10 L11 L12 L13 L14 \\
\hline conscientiousness.long. 4 & $\begin{array}{l}\text { Big Five } \\
\text { Inventory } \\
\text { (Lang et al., } \\
2001 \text { ), Item } 18\end{array}$ & $\begin{array}{l}\text { dazu neigt, unordentlich } \\
\text { zu sein }\end{array}$ & $\begin{array}{l}1=\text { trifft überhaupt nicht } \\
\mathrm{zu}, 2=\text { trifft eher nicht } \\
\mathrm{zu}, 3=\text { weder noch, } 4= \\
\text { eher zutreffend, } 5=\text { trifft } \\
\text { voll und ganz zu }\end{array}$ & & $\begin{array}{l}1=\text { does not apply at all } \\
2=\text { does not apply }, 3= \\
\text { neither nor }, 4=\text { applies } \\
5=\text { fully applies }\end{array}$ & & & & & $\mathrm{x}$ & & & & \\
\hline neuroticism.long.4 & $\begin{array}{l}\text { Big Five } \\
\text { Inventory } \\
\text { (Lang et al., } \\
\text { 2001), Item } 19\end{array}$ & sich viele Sorgen macht & $\begin{array}{l}1=\text { trifft überhaupt nicht } \\
\mathrm{zu}, 2=\text { trifft eher nicht } \\
\mathrm{zu}, 3=\text { weder noch, } 4= \\
\text { eher zutreffend, } 5=\text { trifft } \\
\text { voll und ganz zu }\end{array}$ & & $\begin{array}{l}1=\text { does not apply at all } \\
2=\text { does not apply }, 3= \\
\text { neither nor }, 4=\text { applies } \\
5=\text { fully applies }\end{array}$ & & & & & $\mathrm{x}$ & & & & \\
\hline openness.long. 4 & $\begin{array}{l}\text { Big Five } \\
\text { Inventory } \\
\text { (Lang et al., } \\
\text { 2001), Item } 20\end{array}$ & $\begin{array}{l}\text { eine lebhafte } \\
\text { Vorstellungskraft hat, } \\
\text { phantasievoll ist }\end{array}$ & $\begin{array}{l}1=\text { trifft überhaupt nicht } \\
\mathrm{zu}, 2=\text { trifft eher nicht } \\
\mathrm{zu}, 3=\text { weder noch, } 4= \\
\text { eher zutreffend, } 5=\text { trifft } \\
\text { voll und ganz zu }\end{array}$ & & $\begin{array}{l}1=\text { does not apply at all } \\
2=\text { does not apply }, 3= \\
\text { neither nor }, 4=\text { applies } \\
5=\text { fully applies }\end{array}$ & & & & & $\mathrm{x}$ & & & & \\
\hline extraversion.long.5 & $\begin{array}{l}\text { Big Five } \\
\text { Inventory } \\
\text { (Lang et al., } \\
2001 \text { ), Item } 21\end{array}$ & $\begin{array}{l}\text { eher still und wortkarg } \\
\text { ist }\end{array}$ & $\begin{array}{l}1=\text { trifft überhaupt nicht } \\
\mathrm{zu}, 2=\text { trifft eher nicht } \\
\mathrm{zu}, 3=\text { weder noch, } 4= \\
\text { eher zutreffend, } 5=\text { trifft } \\
\text { voll und ganz zu }\end{array}$ & & $\begin{array}{l}1=\text { does not apply at all } \\
2=\text { does not apply }, 3= \\
\text { neither nor }, 4=\text { applies } \\
5=\text { fully applies }\end{array}$ & & & & & $\mathrm{x}$ & & & & \\
\hline agreeableness.long. 5 & $\begin{array}{l}\text { Big Five } \\
\text { Inventory } \\
\text { (Lang et al., } \\
\text { 2001), Item } 22\end{array}$ & $\begin{array}{l}\text { anderen Vertrauen } \\
\text { schenkt }\end{array}$ & $\begin{array}{l}1=\text { trifft überhaupt nicht } \\
\mathrm{zu}, 2=\text { trifft eher nicht } \\
\mathrm{zu}, 3=\text { weder noch, } 4= \\
\text { eher zutreffend, } 5=\text { trifft } \\
\text { voll und ganz } \mathrm{zu}\end{array}$ & & $\begin{array}{l}1=\text { does not apply at all } \\
2=\text { does not apply }, 3= \\
\text { neither nor }, 4=\text { applies } \\
5=\text { fully applies }\end{array}$ & & & & & $\mathrm{x}$ & & & & \\
\hline conscientiousness.long. 5 & $\begin{array}{l}\text { Big Five } \\
\text { Inventory } \\
\text { (Lang et al., } \\
\text { 2001), Item } 23\end{array}$ & $\begin{array}{l}\text { bequem ist und zur } \\
\text { Faulheit neigt }\end{array}$ & $\begin{array}{l}1=\text { trifft überhaupt nicht } \\
\mathrm{zu}, 2=\text { trifft eher nicht } \\
\mathrm{zu}, 3=\text { weder noch, } 4= \\
\text { eher zutreffend, } 5=\text { trifft } \\
\text { voll und ganz zu }\end{array}$ & & $\begin{array}{l}1=\text { does not apply at all } \\
2=\text { does not apply }, 3= \\
\text { neither nor }, 4=\text { applies } \\
5=\text { fully applies }\end{array}$ & & & & & $\mathrm{x}$ & & & & \\
\hline neuroticism.long. 5 & $\begin{array}{l}\text { Big Five } \\
\text { Inventory } \\
\text { (Lang et al., } \\
\text { 2001), Item } 24\end{array}$ & $\begin{array}{l}\text { ausgeglichen ist, nicht } \\
\text { leicht aus der Fassung } \\
\text { zu bringen }\end{array}$ & $\begin{array}{l}1=\text { trifft überhaupt nicht } \\
\mathrm{zu}, 2=\text { trifft eher nicht } \\
\mathrm{zu}, 3=\text { weder noch, } 4= \\
\text { eher zutreffend, } 5=\text { trifft } \\
\text { voll und ganz } \mathrm{zu}\end{array}$ & & $\begin{array}{l}1=\text { does not apply at all } \\
2=\text { does not apply }, 3= \\
\text { neither nor }, 4=\text { applies } \\
5=\text { fully applies }\end{array}$ & & & & & $\mathrm{x}$ & & & & \\
\hline openness.long.5 & $\begin{array}{l}\text { Big Five } \\
\text { Inventory } \\
\text { (Lang et al., } \\
2001 \text { ), Item } 25\end{array}$ & $\begin{array}{l}\text { erfinderisch und } \\
\text { einfallsreich ist }\end{array}$ & $\begin{array}{l}1=\text { trifft überhaupt nicht } \\
\mathrm{zu}, 2=\text { trifft eher nicht } \\
\mathrm{zu}, 3=\text { weder noch, } 4= \\
\text { eher zutreffend, } 5=\text { trifft } \\
\text { voll und ganz zu }\end{array}$ & & $\begin{array}{l}1=\text { does not apply at all } \\
2=\text { does not apply }, 3= \\
\text { neither nor }, 4=\text { applies } \\
5=\text { fully applies }\end{array}$ & & & & & $\mathrm{x}$ & & & & \\
\hline extraversion.long. 6 & $\begin{array}{l}\text { Big Five } \\
\text { Inventory } \\
\text { (Lang et al., } \\
\text { 2001), Item } 26\end{array}$ & $\begin{array}{l}\text { durchsetzungsfähig und } \\
\text { energisch ist }\end{array}$ & $\begin{array}{l}1=\text { trifft überhaupt nicht } \\
\mathrm{zu}, 2=\text { trifft eher nicht } \\
\mathrm{zu}, 3=\text { weder noch, } 4= \\
\text { eher zutreffend, } 5=\text { trifft } \\
\text { voll und ganz zu }\end{array}$ & & $\begin{array}{l}1=\text { does not apply at all } \\
2=\text { does not apply }, 3= \\
\text { neither nor }, 4=\text { applies } \\
5=\text { fully applies }\end{array}$ & & & & & $\mathrm{x}$ & & & & \\
\hline agreeableness.long. 6 & $\begin{array}{l}\text { Big Five } \\
\text { Inventory } \\
\text { (Lang et al., } \\
\text { 2001), Item } 27\end{array}$ & $\begin{array}{l}\text { sich kalt und distanziert } \\
\text { verhalten kann }\end{array}$ & $\begin{array}{l}1=\text { trifft überhaupt nicht } \\
\mathrm{zu}, 2=\text { trifft eher nicht } \\
\mathrm{zu}, 3=\text { weder noch, } 4= \\
\text { eher zutreffend, } 5=\text { trifft } \\
\text { voll und ganz } \mathrm{zu}\end{array}$ & & $\begin{array}{l}1=\text { does not apply at all } \\
2=\text { does not apply } 3= \\
\text { neither nor }, 4=\text { applies } \\
5=\text { fully applies }\end{array}$ & & & & & $\mathrm{x}$ & & & & \\
\hline conscientiousness.long. 6 & $\begin{array}{l}\text { Big Five } \\
\text { Inventory } \\
\text { (Lang et al., } \\
\text { 2001), Item } 28\end{array}$ & $\begin{array}{l}\text { nicht aufgibt ehe die } \\
\text { Aufgabe erledigt ist }\end{array}$ & $\begin{array}{l}1=\text { trifft überhaupt nicht } \\
\mathrm{zu}, 2=\text { trifft eher nicht } \\
\mathrm{zu}, 3=\text { weder noch, } 4= \\
\text { eher zutreffend, } 5=\text { trifft } \\
\text { voll und ganz } \mathrm{zu}\end{array}$ & & $\begin{array}{l}1=\text { does not apply at all } \\
2=\text { does not apply }, 3= \\
\text { neither nor }, 4=\text { applies } \\
5=\text { fully applies }\end{array}$ & & & & & $\mathrm{x}$ & & & & \\
\hline neuroticism.long. 6 & $\begin{array}{l}\text { Big Five } \\
\text { Inventory } \\
\text { (Lang et al., } \\
2001 \text { ), Item } 29\end{array}$ & $\begin{array}{l}\text { launisch sein kann, } \\
\text { schwankende } \\
\text { Stimmungen hat }\end{array}$ & $\begin{array}{l}1=\text { trifft überhaupt nicht } \\
\mathrm{zu}, 2=\text { trifft eher nicht } \\
\mathrm{zu}, 3=\text { weder noch, } 4= \\
\text { eher zutreffend, } 5=\text { trifft } \\
\text { voll und ganz zu }\end{array}$ & & $\begin{array}{l}1=\text { does not apply at all } \\
2=\text { does not apply }, 3= \\
\text { neither nor }, 4=\text { applies } \\
5=\text { fully applies }\end{array}$ & & & & & $\mathrm{x}$ & & & & \\
\hline
\end{tabular}




\begin{tabular}{|c|c|c|c|c|c|c|c|c|c|c|c|c|c|c|c|}
\hline VarName & VariableLabel & WordingDE & ValueLabelsDE_Linked & WordingEN & ValueLabelsEN_Linked & L1 & L1F L2 & L3 & L4 & L5 & $\mathrm{L} 6$ & $\mathrm{~L} 7$ & L8 & L9 & L10 L11 L12 L13 L14 \\
\hline openness.long. 6 & $\begin{array}{l}\text { Big Five } \\
\text { Inventory } \\
\text { (Lang et al., } \\
2001), \text { Item } 30\end{array}$ & $\begin{array}{l}\text { künstlerische und } \\
\text { ästhetische Eindrücke } \\
\text { schätzt }\end{array}$ & $\begin{array}{l}1=\text { trifft überhaupt nicht } \\
\mathrm{zu}, 2=\text { trifft eher nicht } \\
\mathrm{zu}, 3=\text { weder noch, } 4= \\
\text { eher zutreffend, } 5=\text { trifft } \\
\text { voll und ganz zu }\end{array}$ & & $\begin{array}{l}1=\text { does not apply at all } \\
2=\text { does not apply }, 3= \\
\text { neither nor }, 4=\text { applies } \\
5=\text { fully applies }\end{array}$ & & & & & $\mathrm{x}$ & & & & & \\
\hline extraversion.long. 7 & $\begin{array}{l}\text { Big Five } \\
\text { Inventory } \\
\text { (Lang et al., } \\
\text { 2001), Item } 31\end{array}$ & $\begin{array}{l}\text { manchmal schüchtern } \\
\text { und gehemmt ist }\end{array}$ & $\begin{array}{l}1=\text { trifft überhaupt nicht } \\
\mathrm{zu}, 2=\text { trifft eher nicht } \\
\mathrm{zu}, 3=\text { weder noch, } 4= \\
\text { eher zutreffend, } 5=\text { trifft } \\
\text { voll und ganz zu }\end{array}$ & & $\begin{array}{l}1=\text { does not apply at all } \\
2=\text { does not apply }, 3= \\
\text { neither nor }, 4=\text { applies } \\
5=\text { fully applies }\end{array}$ & & & & & $\mathrm{x}$ & & & & & \\
\hline agreeableness.long. 7 & $\begin{array}{l}\text { Big Five } \\
\text { Inventory } \\
\text { (Lang et al., } \\
\text { 2001), Item } 32\end{array}$ & $\begin{array}{l}\text { rücksichtsvoll und } \\
\text { einfühlsam zu anderen } \\
\text { ist }\end{array}$ & $\begin{array}{l}1=\text { trifft überhaupt nicht } \\
\mathrm{zu}, 2=\text { trifft eher nicht } \\
\mathrm{zu}, 3=\text { weder noch, } 4= \\
\text { eher zutreffend, } 5=\text { trifft } \\
\text { voll und ganz zu }\end{array}$ & & $\begin{array}{l}1=\text { does not apply at all } \\
2=\text { does not apply }, 3= \\
\text { neither nor }, 4=\text { applies } \\
5=\text { fully applies }\end{array}$ & & & & & $\mathrm{x}$ & & & & & \\
\hline conscientiousness.long. 7 & $\begin{array}{l}\text { Big Five } \\
\text { Inventory } \\
\text { (Lang et al., } \\
\text { 2001), Item } 33\end{array}$ & $\begin{array}{l}\text { tüchtig ist und flott } \\
\text { arbeitet }\end{array}$ & $\begin{array}{l}1=\text { trifft überhaupt nicht } \\
\mathrm{zu}, 2=\text { trifft eher nicht } \\
\mathrm{zu}, 3=\text { weder noch, } 4= \\
\text { eher zutreffend, } 5=\text { trifft } \\
\text { voll und ganz zu }\end{array}$ & & $\begin{array}{l}1=\text { does not apply at all } \\
2=\text { does not apply }, 3= \\
\text { neither nor }, 4=\text { applies } \\
5=\text { fully applies }\end{array}$ & & & & & $\mathrm{x}$ & & & & & \\
\hline neuroticism.long. 7 & $\begin{array}{l}\text { Big Five } \\
\text { Inventory } \\
\text { (Lang et al., } \\
\text { 2001), Item } 34\end{array}$ & $\begin{array}{l}\text { ruhig bleibt, selbst in } \\
\text { angespannten } \\
\text { Situationen }\end{array}$ & $\begin{array}{l}1=\text { trifft überhaupt nicht } \\
\mathrm{zu}, 2=\text { trifft eher nicht } \\
\mathrm{zu}, 3=\text { weder noch, } 4= \\
\text { eher zutreffend, } 5=\text { trifft } \\
\text { voll und ganz } \mathrm{zu}\end{array}$ & & $\begin{array}{l}1=\text { does not apply at all } \\
2=\text { does not apply }, 3= \\
\text { neither nor }, 4=\text { applies } \\
5=\text { fully applies }\end{array}$ & & & & & $\mathrm{x}$ & & & & & \\
\hline openness.long. 7 & $\begin{array}{l}\text { Big Five } \\
\text { Inventory } \\
\text { (Lang et al., } \\
\text { 2001), Item } 35\end{array}$ & $\begin{array}{l}\text { routinemässige und } \\
\text { einfache Aufgaben } \\
\text { bevorzugt }\end{array}$ & $\begin{array}{l}1=\text { trifft überhaupt nicht } \\
\mathrm{zu}, 2=\text { trifft eher nicht } \\
\mathrm{zu}, 3=\text { weder noch, } 4= \\
\text { eher zutreffend, } 5=\text { trifft } \\
\text { voll und ganz zu }\end{array}$ & & $\begin{array}{l}1=\text { does not apply at all } \\
2=\text { does not apply }, 3= \\
\text { neither nor }, 4=\text { applies } \\
5=\text { fully applies }\end{array}$ & & & & & $\mathrm{x}$ & & & & & \\
\hline extraversion.long. 8 & $\begin{array}{l}\text { Big Five } \\
\text { Inventory } \\
\text { (Lang et al., } \\
2001 \text { ), Item } 36\end{array}$ & $\begin{array}{l}\text { aus sich herausgeht, } \\
\text { gesellig ist }\end{array}$ & $\begin{array}{l}1=\text { triff überhaupt nicht } \\
\text { zu, } 2=\text { trifft eher nicht } \\
\text { zu, } 3=\text { weder noch, } 4= \\
\text { eher zutreffend, } 5=\text { trifft } \\
\text { voll und ganz zu }\end{array}$ & & $\begin{array}{l}1=\text { does not apply at all } \\
2=\text { does not apply }, 3= \\
\text { neither nor }, 4=\text { applies } \\
5=\text { fully applies }\end{array}$ & & & & & $\mathrm{x}$ & & & & & \\
\hline agreeableness.long. 8 & $\begin{array}{l}\text { Big Five } \\
\text { Inventory } \\
\text { (Lang et al., } \\
\text { 2001), Item } 37\end{array}$ & $\begin{array}{l}\text { schroff und abweisend } \\
\text { zu anderen sein kann }\end{array}$ & $\begin{array}{l}1=\text { trifft überhaupt nicht } \\
\mathrm{zu}, 2=\text { trifft eher nicht } \\
\mathrm{zu}, 3=\text { weder noch, } 4= \\
\text { eher zutreffend, } 5=\text { trifft } \\
\text { voll und ganz zu }\end{array}$ & & $\begin{array}{l}1=\text { does not apply at all } \\
2=\text { does not apply }, 3= \\
\text { neither nor }, 4=\text { applies } \\
5=\text { fully applies }\end{array}$ & & & & & $\mathrm{x}$ & & & & & \\
\hline conscientiousness.long. 8 & $\begin{array}{l}\text { Big Five } \\
\text { Inventory } \\
\text { (Lang et al., } \\
\text { 2001), Item } 38\end{array}$ & $\begin{array}{l}\text { Pläne macht und diese } \\
\text { auch durchführt }\end{array}$ & $\begin{array}{l}1=\text { trifft überhaupt nicht } \\
\mathrm{zu}, 2=\text { trifft eher nicht } \\
\mathrm{zu}, 3=\text { weder noch, } 4= \\
\text { eher zutreffend, } 5=\text { trifft } \\
\text { voll und ganz } \mathrm{zu}\end{array}$ & & $\begin{array}{l}1=\text { does not apply at all } \\
2=\text { does not apply }, 3= \\
\text { neither nor }, 4=\text { applies } \\
5=\text { fully applies }\end{array}$ & & & & & $\mathrm{x}$ & & & & & \\
\hline neuroticism.long. 8 & $\begin{array}{l}\text { Big Five } \\
\text { Inventory } \\
\text { (Lang et al., } \\
\text { 2001), Item } 39\end{array}$ & $\begin{array}{l}\text { leicht nervös und } \\
\text { unsicher wird. }\end{array}$ & $\begin{array}{l}1=\text { trifft überhaupt nicht } \\
\mathrm{zu}, 2=\text { trifft eher nicht } \\
\mathrm{zu}, 3=\text { weder noch, } 4= \\
\text { eher zutreffend, } 5=\text { trifft } \\
\text { voll und ganz zu }\end{array}$ & & $\begin{array}{l}1=\text { does not apply at all } \\
2=\text { does not apply }, 3= \\
\text { neither nor }, 4=\text { applies } \\
5=\text { fully applies }\end{array}$ & & & & & $\mathrm{x}$ & & & & & \\
\hline openness.long. 8 & $\begin{array}{l}\text { Big Five } \\
\text { Inventory } \\
\text { (Lang et al., } \\
\text { 2001), Item } 40\end{array}$ & $\begin{array}{l}\text { gerne Überlegungen } \\
\text { anstellt, mit Ideen spielt }\end{array}$ & $\begin{array}{l}1=\text { trifft überhaupt nicht } \\
\mathrm{zu}, 2=\text { trifft eher nicht } \\
\mathrm{zu}, 3=\text { weder noch, } 4= \\
\text { eher zutreffend, } 5=\text { trifft } \\
\text { voll und ganz } \mathrm{zu}\end{array}$ & & $\begin{array}{l}1=\text { does not apply at all } \\
2=\text { does not apply }, 3= \\
\text { neither nor }, 4=\text { applies } \\
5=\text { fully applies }\end{array}$ & & & & & $\mathrm{x}$ & & & & & \\
\hline openness.long.9 & $\begin{array}{l}\text { Big Five } \\
\text { Inventory } \\
\text { (Lang et al., } \\
\text { 2001), Item } 41\end{array}$ & $\begin{array}{l}\text { nur wenig künstlerische } \\
\text { Interessen hat }\end{array}$ & $\begin{array}{l}1=\text { trifft überhaupt nicht } \\
\mathrm{zu}, 2=\text { trifft eher nicht } \\
\mathrm{zu}, 3=\text { weder noch, } 4= \\
\text { eher zutreffend, } 5=\text { trifft } \\
\text { voll und ganz zu }\end{array}$ & & $\begin{array}{l}1=\text { does not apply at all } \\
2=\text { does not apply }, 3= \\
\text { neither nor }, 4=\text { applies } \\
5=\text { fully applies }\end{array}$ & & & & & $\mathrm{x}$ & & & & & \\
\hline
\end{tabular}




\begin{tabular}{|c|c|c|c|c|c|c|c|c|c|c|c|c|c|c|c|c|c|c|}
\hline VarName & VariableLabel & WordingDE & ValueLabelsDE_Linked & WordingEN & ValueLabelsEN_Linked & L1 & L1F L2 & L3 & $\mathrm{L} 4$ & L5 & L6 & L7 & L8 & L9 & & $0 \mathrm{~L} 11$ & 1 L12 & $2 \mathrm{~L} 13 \mathrm{~L} 14$ \\
\hline agreeableness.long. 9 & $\begin{array}{l}\text { Big Five } \\
\text { Inventory } \\
\text { (Lang et al., } \\
2001 \text { ), Item } 42\end{array}$ & $\begin{array}{l}\text { sich kooperativ verhält, } \\
\text { Zusammenarbeit dem } \\
\text { Wettbewerb vorzieht }\end{array}$ & $\begin{array}{l}1=\text { trifft überhaupt nicht } \\
\mathrm{zu}, 2=\text { trifft eher nicht } \\
\mathrm{zu}, 3=\text { weder noch, } 4= \\
\text { eher zutreffend, } 5=\text { trifft } \\
\text { voll und ganz zu }\end{array}$ & & $\begin{array}{l}1=\text { does not apply at all } \\
2=\text { does not apply }, 3= \\
\text { neither nor }, 4=\text { applies } \\
5=\text { fully applies }\end{array}$ & & & & & $\mathrm{x}$ & & & & & & & & \\
\hline conscientiousness.long.9 & $\begin{array}{l}\text { Big Five } \\
\text { Inventory } \\
\text { (Lang et al., } \\
\text { 2001), Item } 43\end{array}$ & $\begin{array}{l}\text { leicht ablenkbar ist, } \\
\text { nicht bei der Sache } \\
\text { bleibt }\end{array}$ & $\begin{array}{l}1=\text { trifft überhaupt nicht } \\
\mathrm{zu}, 2=\text { trifft eher nicht } \\
\mathrm{zu}, 3=\text { weder noch, } 4= \\
\text { eher zutreffend, } 5=\text { trifft } \\
\text { voll und ganz zu }\end{array}$ & & $\begin{array}{l}1=\text { does not apply at all } \\
2=\text { does not apply }, 3= \\
\text { neither nor }, 4=\text { applies } \\
5=\text { fully applies }\end{array}$ & & & & & $\mathrm{x}$ & & & & & & & & \\
\hline openness.long.10 & $\begin{array}{l}\text { Big Five } \\
\text { Inventory } \\
\text { (Lang et al., } \\
\text { 2001), Item } 44\end{array}$ & $\begin{array}{l}\text { sich gut in Musik, Kunst } \\
\text { und Literatur auskennt }\end{array}$ & $\begin{array}{l}1=\text { trifft überhaupt nicht } \\
\mathrm{zu}, 2=\text { trifft eher nicht } \\
\mathrm{zu}, 3=\text { weder noch, } 4= \\
\text { eher zutreffend, } 5=\text { trifft } \\
\text { voll und ganz zu }\end{array}$ & & $\begin{array}{l}1=\text { does not apply at all } \\
2=\text { does not apply }, 3= \\
\text { neither nor }, 4=\text { applies } \\
5=\text { fully applies }\end{array}$ & & & & & $\mathrm{x}$ & & & & & & & & \\
\hline complain.P1 & $\begin{array}{l}\text { Who } \\
\text { complains a } \\
\text { lot? Person } 1\end{array}$ & $\begin{array}{l}\text { Wer beklagt sich oft? } \\
\text { Nenne zwischen } 0 \text { und } 5 \\
\text { Personen. }\end{array}$ & & Who complains a lot? & & & & & & $\mathrm{x}$ & $\mathrm{x}$ & $\mathrm{x}$ & $\mathrm{x}$ & $\mathrm{x}$ & $\mathrm{x}$ & $\mathrm{x}$ & $\mathrm{x}$ & $\mathrm{x}$ \\
\hline sad.P1 & $\begin{array}{l}\text { Who is sad a } \\
\text { lot? Person } 1\end{array}$ & $\begin{array}{l}\text { Wer ist oft traurig? } \\
\text { Nenne zwischen } 0 \text { und } 5 \\
\text { Personen. }\end{array}$ & & Who is sad a lot? & & & & & & $\mathrm{x}$ & $\mathrm{x}$ & $\mathrm{x}$ & $\mathrm{x}$ & $\mathrm{x}$ & $\mathrm{x}$ & $\mathrm{x}$ & $\mathrm{x}$ & $\mathrm{x}$ \\
\hline dislike.listening.to.P1 & $\begin{array}{l}\text { Whom do you } \\
\text { disklike to } \\
\text { listen to? } \\
\text { Person } 1\end{array}$ & $\begin{array}{l}\text { Wem hörst du nicht } \\
\text { gerne zu? Nenne } \\
\text { zwischen } 0 \text { und } 5 \\
\text { Personen. }\end{array}$ & & $\begin{array}{l}\text { Whom do you dislike to } \\
\text { listen to? }\end{array}$ & & & & & & $\mathrm{x}$ & $\mathrm{x}$ & $\mathrm{x}$ & $\mathrm{x}$ & $\mathrm{x}$ & $\mathrm{x}$ & $\mathrm{x}$ & $\mathrm{x}$ & $\mathrm{X}$ \\
\hline support.types. 1 & $\begin{array}{l}\text { Type of } \\
\text { support } 1\end{array}$ & $\begin{array}{l}\text { Ich brauche oft Hilfe mit } \\
\text { praktischen Dingen, wie } \\
\text { z.B. beim Erledigen von } \\
\text { Arbeiten oder die } \\
\text { Bereitstellung } \\
\text { finanzieller Mittel oder } \\
\text { weitere konkrete Hilfe, } \\
\text { von meinen } \\
\text { Mitstudenten. }\end{array}$ & $\begin{array}{l}1=\text { trifft überhaupt nicht } \\
\text { zu, } 2=\text { trifft nicht } \mathrm{zu}, 3= \\
\text { trifft eher nicht zu, } 4= \\
\text { weder noch, } 5=\text { trifft } \\
\text { eher zu, } 6=\text { trifft zu, } 7= \\
\text { trifft voll und ganz zu }\end{array}$ & $\begin{array}{l}\text { I often feel like I need to } \\
\text { receive help in practical } \\
\text { things like the provision } \\
\text { of tangible goods and } \\
\text { services, or tangible aid } \\
\text { from the people I study } \\
\text { with. }\end{array}$ & $\begin{array}{l}1=\text { don't agree at all, } 2= \\
\text { don't agree, } 3=\text { rather } \\
\text { not agree, } 4=\text { neither, } 5 \\
=\text { rather agree, } 6=\text { agree, } \\
7=\text { agree completely }\end{array}$ & & & & & $\mathrm{x}$ & & & & & & & & \\
\hline support.types.2 & $\begin{array}{l}\text { Type of } \\
\text { support } 2\end{array}$ & $\begin{array}{l}\text { Ich brauche oft guten } \\
\text { Rat oder spezifische } \\
\text { Informationen von } \\
\text { meinen Mitstudenten }\end{array}$ & $\begin{array}{l}1=\text { trifft überhaupt nicht } \\
\text { zu, } 2=\text { trifft nicht } \mathrm{zu}, 3= \\
\text { trifft eher nicht } \mathrm{zu}, 4= \\
\text { weder noch, } 5=\text { trifft } \\
\text { eher zu, } 6=\text { trifft } \mathrm{zu}, 7= \\
\text { trifft voll und ganz zu }\end{array}$ & $\begin{array}{l}\text { I often feel like I need to } \\
\text { receive good advice or } \\
\text { specific information } \\
\text { from the people I study } \\
\text { with. }\end{array}$ & $\begin{array}{l}1=\text { don't agree at all, } 2= \\
\text { don't agree, } 3=\text { rather } \\
\text { not agree, } 4=\text { neither, } 5 \\
=\text { rather agree, } 6=\text { agree } \\
7=\text { agree completely }\end{array}$ & & & & & $\mathrm{x}$ & & & & & & & & \\
\hline support.types.3 & $\begin{array}{l}\text { Type of } \\
\text { support } 3\end{array}$ & $\begin{array}{l}\text { Ich brauche oft } \\
\text { emotionale } \\
\text { Unterstützung von } \\
\text { meinen Mitstudenten } \\
\text { (z.B. Anteilnahme, } \\
\text { Empathie und } \\
\text { Vertrauen). }\end{array}$ & $\begin{array}{l}1=\text { trifft überhaupt nicht } \\
\text { zu, } 2=\text { trifft nicht zu, } 3= \\
\text { trifft eher nicht zu, } 4= \\
\text { weder noch, } 5=\text { trifft } \\
\text { eher zu, } 6=\text { trifft zu, } 7= \\
\text { trifft voll und ganz zu }\end{array}$ & $\begin{array}{l}\text { I often feel like I need to } \\
\text { receive emotional } \\
\text { support (e.g., caring, } \\
\text { empathy and trust) from } \\
\text { the people I study with. }\end{array}$ & $\begin{array}{l}1=\text { don't agree at all, } 2= \\
\text { don't agree, } 3=\text { rather } \\
\text { not agree, } 4=\text { neither, } 5 \\
=\text { rather agree, } 6=\text { agree, } \\
7=\text { agree completely }\end{array}$ & & & & & $\mathrm{x}$ & & & & & & & & \\
\hline support.types.4 & $\begin{array}{l}\text { Type of } \\
\text { support } 4\end{array}$ & $\begin{array}{l}\text { Ich kann auf meine } \\
\text { Mitstudenten zählen, } \\
\text { wenn ich Hilfe mit } \\
\text { praktischen Dingen } \\
\text { (z.B. beim Erledigen } \\
\text { von Arbeiten oder die } \\
\text { Bereitstellung } \\
\text { finanzieller Mittel oder } \\
\text { weitere konkrete Hilfe } \\
\text { benötige). }\end{array}$ & $\begin{array}{l}1=\text { trifft überhaupt nicht } \\
\text { zu, } 2=\text { trifft nicht } \mathrm{zu}, 3= \\
\text { trifft eher nicht } \mathrm{zu}, 4= \\
\text { weder noch, } 5=\text { trifft } \\
\text { eher zu, } 6=\text { trifft } \mathrm{zu}, 7= \\
\text { trifft voll und ganz zu }\end{array}$ & $\begin{array}{l}\text { I feel like I get the help } \\
\text { I need in practical } \\
\text { things like the provision } \\
\text { of tangible goods and } \\
\text { services, or tangible aid } \\
\text { from the people I study } \\
\text { with. }\end{array}$ & $\begin{array}{l}1=\text { don't agree at all, } 2= \\
\text { don't agree, } 3=\text { rather } \\
\text { not agree, } 4=\text { neither, } 5 \\
=\text { rather agree, } 6=\text { agree, } \\
7=\text { agree completely }\end{array}$ & & & & & $\mathrm{x}$ & & & & & & & & \\
\hline
\end{tabular}




\begin{tabular}{|c|c|c|c|c|c|c|c|c|c|c|c|c|c|c|c|c|c|c|}
\hline VarName & VariableLabel & WordingDE & ValueLabelsDE_Linked & WordingEN & ValueLabelsEN_Linked & L1 & L1F L2 & L3 & $\mathrm{L} 4$ & L5 & L6 & L7 & L8 & L9 & & L11 & $1 \mathrm{~L} 12$ & $2 \mathrm{~L} 13 \mathrm{~L} 14$ \\
\hline support.types.5 & $\begin{array}{l}\text { Type of } \\
\text { support } 5\end{array}$ & $\begin{array}{l}\text { Ich kann auf meine } \\
\text { Mitstudenten zählen, } \\
\text { wenn ich guten Rat oder } \\
\text { spezifische } \\
\text { Informationen benötige }\end{array}$ & $\begin{array}{l}1=\text { trifft überhaupt nicht } \\
\text { zu, } 2=\text { trifft nicht } \mathrm{zu}, 3= \\
\text { trifft eher nicht } \mathrm{zu}, 4= \\
\text { weder noch, } 5=\text { trifft } \\
\text { eher zu, } 6=\text { trifft } \mathrm{zu}, 7= \\
\text { trifft voll und ganz zu }\end{array}$ & $\begin{array}{l}\text { I feel like I get the } \\
\text { advice or information I } \\
\text { need from the people I } \\
\text { study with. }\end{array}$ & $\begin{array}{l}1=\text { don't agree at all, } 2= \\
\text { don't agree, } 3=\text { rather } \\
\text { not agree, } 4=\text { neither, } 5 \\
=\text { rather agree, } 6=\text { agree, } \\
7=\text { agree completely }\end{array}$ & & & & & $\mathrm{x}$ & & & & & & & & \\
\hline support.types.6 & $\begin{array}{l}\text { Type of } \\
\text { support } 6\end{array}$ & $\begin{array}{l}\text { Ich kann auf meine } \\
\text { Mitstudenten zählen, } \\
\text { wenn ich emotionale } \\
\text { Unterstützung (z.B. } \\
\text { Anteilnahme, Empathie } \\
\text { und Vertrauen) benötige }\end{array}$ & $\begin{array}{l}1=\text { trifft überhaupt nicht } \\
\text { zu, } 2=\text { trifft nicht } \mathrm{zu}, 3= \\
\text { trifft eher nicht zu, } 4= \\
\text { weder noch, } 5=\text { trifft } \\
\text { eher zu, } 6=\text { trifft } \mathrm{zu}, 7= \\
\text { trifft voll und ganz zu }\end{array}$ & $\begin{array}{l}\text { I feel like I get the } \\
\text { emotional support (e.g., } \\
\text { caring, empathy and } \\
\text { trust) I need from the } \\
\text { people I study with. }\end{array}$ & $\begin{array}{l}1=\text { don't agree at all, } 2= \\
\text { don't agree, } 3=\text { rather } \\
\text { not agree, } 4=\text { neither, } 5 \\
=\text { rather agree, } 6=\text { agree, } \\
7=\text { agree completely }\end{array}$ & & & & & $\mathrm{x}$ & & & & & & & & \\
\hline erstiweekend.attend & $\begin{array}{l}\text { Would have } \\
\text { liked to } \\
\text { participate in } \\
\text { ersti-weekend }\end{array}$ & $\begin{array}{l}\text { Welche Aussage } \\
\text { bezüglich des [name } \\
\text { removed] trifft auf Dich } \\
\text { zu? }\end{array}$ & $\begin{array}{l}1=\text { Ich habe daran } \\
\text { teilgenommen, } 2=\text { Ich } \\
\text { hätte gerne daran } \\
\text { teilgenommen, habe aber } \\
\text { keinen Platz mehr } \\
\text { bekommen, } 3=\text { Im } \\
\text { Nachhinein hätte ich } \\
\text { gerne daran } \\
\text { teilgenommen, wollte es } \\
\text { aber zum } \\
\text { Anmeldezeitpunkt noch } \\
\text { nicht, } 4=\text { Ich wollte nicht } \\
\text { daran teilnehmen }\end{array}$ & $\begin{array}{l}\text { Regarding the } \\
\text { ersti-weekend, which } \\
\text { statement applies to } \\
\text { you? }\end{array}$ & $\begin{array}{l}1 \text { = I participated, } 2=\mathrm{I} \\
\text { would have liked to } \\
\text { participate, but I didn't } \\
\text { get a spot, } 3=\text { in } \\
\text { hindshight, I would have } \\
\text { liked to participate, but I } \\
\text { didn't want to when I had } \\
\text { to register, } 4=\text { I didn't } \\
\text { want to participate }\end{array}$ & & & & & $\mathrm{x}$ & & & & & & & & \\
\hline $\begin{array}{l}\text { work.values } \\
\text {.extrinsic.orientation.1 }\end{array}$ & $\begin{array}{l}\text { Work values } \\
\text { item } 1\end{array}$ & $\begin{array}{l}\text { Wie wichtig ist für } \\
\text { Deine Berufswahl eine } \\
\text { sichere Berufsstellung? }\end{array}$ & $\begin{array}{l}1=\text { trifft überhaupt nicht } \\
\text { zu, } 2=\text { trifft nicht zu, } 3= \\
\text { trifft eher nicht zu, } 4= \\
\text { weder noch, } 5=\text { trifft } \\
\text { eher zu, } 6=\text { trifft zu, } 7= \\
\text { trifft voll und ganz zu }\end{array}$ & $\begin{array}{l}\text { When choosing a job, } \\
\text { how important is job } \\
\text { security? }\end{array}$ & $\begin{array}{l}1=\text { don't agree at all, } 2= \\
\text { don't agree, } 3=\text { rather } \\
\text { not agree, } 4=\text { neither, } 5 \\
=\text { rather agree, } 6=\text { agree } \\
7=\text { agree completely }\end{array}$ & & & & & $\mathrm{x}$ & $\mathrm{x}$ & $\mathrm{x}$ & $\mathrm{x}$ & $\mathrm{x}$ & $\mathrm{x}$ & $\mathrm{x}$ & $\mathrm{x}$ & $\mathrm{X}$ \\
\hline $\begin{array}{l}\text { work.values } \\
\text {.extrinsic.orientation.2 }\end{array}$ & $\begin{array}{l}\text { Work values } \\
\text { item } 2\end{array}$ & ein hohes Einkommen? & $\begin{array}{l}1=\text { trifft überhaupt nicht } \\
\text { zu, } 2=\text { trifft nicht } \mathrm{zu}, 3= \\
\text { trifft eher nicht } \mathrm{zu}, 4= \\
\text { weder noch, } 5=\text { trifft } \\
\text { eher } \mathrm{zu}, 6=\text { trifft } \mathrm{zu}, 7= \\
\text { trifft voll und ganz zu }\end{array}$ & High income? & $\begin{array}{l}1=\text { don't agree at all, } 2= \\
\text { don't agree, } 3=\text { rather } \\
\text { not agree, } 4=\text { neither, } 5 \\
=\text { rather agree, } 6=\text { agree, } \\
7=\text { agree completely }\end{array}$ & & & & & $\mathrm{x}$ & $\mathrm{x}$ & $\mathrm{x}$ & $\mathrm{x}$ & $\mathrm{x}$ & $\mathrm{x}$ & $\mathrm{x}$ & $\mathrm{x}$ & $\mathrm{x}$ \\
\hline $\begin{array}{l}\text { work.values } \\
\text {.extrinsic.orientation.3 }\end{array}$ & $\begin{array}{l}\text { Work values } \\
\text { item } 3\end{array}$ & $\begin{array}{l}\text { gute } \\
\text { Aufstiegsmöglichkeiten? }\end{array}$ & $\begin{array}{l}1=\text { trifft überhaupt nicht } \\
\text { zu, } 2=\text { trifft nicht zu, } 3= \\
\text { trifft eher nicht zu, } 4= \\
\text { weder noch, } 5=\text { trifft } \\
\text { eher zu, } 6=\text { trifft zu, } 7= \\
\text { trifft voll und ganz zu }\end{array}$ & Good career prospects? & $\begin{array}{l}1=\text { don't agree at all, } 2= \\
\text { don't agree, } 3=\text { rather } \\
\text { not agree, } 4=\text { neither, } 5 \\
=\text { rather agree, } 6=\text { agree, } \\
7=\text { agree completely }\end{array}$ & & & & & $\mathrm{x}$ & $\mathrm{x}$ & $\mathrm{x}$ & $\mathrm{x}$ & $\mathrm{x}$ & $\mathrm{x}$ & $\mathrm{x}$ & $\mathrm{x}$ & $\mathrm{x}$ \\
\hline $\begin{array}{l}\text { work.values } \\
\text {.extrinsic.orientation.4 }\end{array}$ & $\begin{array}{l}\text { Work values } \\
\text { item } 4\end{array}$ & $\begin{array}{l}\text { ein Beruf, der anerkannt } \\
\text { ist und geachtet wird? }\end{array}$ & $\begin{array}{l}1=\text { trifft überhaupt nicht } \\
\text { zu, } 2=\text { trifft nicht zu, } 3= \\
\text { trifft eher nicht zu, } 4= \\
\text { weder noch, } 5=\text { trifft } \\
\text { eher zu, } 6=\text { trifft zu, } 7= \\
\text { trifft voll und ganz zu }\end{array}$ & $\begin{array}{l}\text { That the job is } \\
\text { recognised and } \\
\text { well-esteemed? }\end{array}$ & $\begin{array}{l}1=\text { don't agree at all, } 2= \\
\text { don't agree, } 3=\text { rather } \\
\text { not agree, } 4=\text { neither, } 5 \\
=\text { rather agree, } 6=\text { agree, } \\
7=\text { agree completely }\end{array}$ & & & & & $\mathrm{x}$ & $\mathrm{x}$ & $\mathrm{x}$ & $\mathrm{x}$ & $\mathrm{x}$ & $\mathrm{x}$ & $\mathrm{x}$ & $\mathrm{x}$ & $\mathrm{X}$ \\
\hline $\begin{array}{l}\text { work.values } \\
\text {.external.orientation.1 }\end{array}$ & $\begin{array}{l}\text { Work values } \\
\text { item } 5\end{array}$ & $\begin{array}{l}\text { ein Beruf, der einem viel } \\
\text { Freizeit lässt? }\end{array}$ & $\begin{array}{l}1=\text { trifft überhaupt nicht } \\
\text { zu, } 2=\text { trifft nicht zu, } 3= \\
\text { trifft eher nicht zu, } 4= \\
\text { weder noch, } 5=\text { trifft } \\
\text { eher zu, } 6=\text { trifft zu, } 7= \\
\text { trifft voll und ganz zu }\end{array}$ & $\begin{array}{l}\text { That it leaves much free } \\
\text { time? }\end{array}$ & $\begin{array}{l}1=\text { don't agree at all, } 2= \\
\text { don't agree, } 3=\text { rather } \\
\text { not agree, } 4=\text { neither, } 5 \\
=\text { rather agree, } 6=\text { agree, } \\
7=\text { agree completely }\end{array}$ & & & & & $\mathrm{x}$ & $\mathrm{x}$ & $\mathrm{x}$ & $\mathrm{x}$ & $\mathrm{x}$ & $\mathrm{x}$ & $\mathrm{x}$ & $\mathrm{x}$ & $\mathrm{x}$ \\
\hline $\begin{array}{l}\text { work.values } \\
\text {.intrinsic.orientation.1 }\end{array}$ & $\begin{array}{l}\text { Work values } \\
\text { item } 6\end{array}$ & $\begin{array}{l}\text { eine interessante } \\
\text { Tätigkeit? }\end{array}$ & $\begin{array}{l}1=\text { trifft überhaupt nicht } \\
\text { zu, } 2=\text { trifft nicht zu, } 3= \\
\text { trifft eher nicht zu, } 4= \\
\text { weder noch, } 5=\text { trifft } \\
\text { eher zu, } 6=\text { trifft zu, } 7= \\
\text { trifft voll und ganz zu }\end{array}$ & $\begin{array}{l}\text { That the work is } \\
\text { interesting? }\end{array}$ & $\begin{array}{l}1=\text { don't agree at all, } 2= \\
\text { don't agree, } 3=\text { rather } \\
\text { not agree, } 4=\text { neither, } 5 \\
=\text { rather agree, } 6=\text { agree, } \\
7=\text { agree completely }\end{array}$ & & & & & $\mathrm{x}$ & $\mathrm{x}$ & $\mathrm{x}$ & $\mathrm{x}$ & $\mathrm{x}$ & $\mathrm{x}$ & $\mathrm{x}$ & $\mathrm{x}$ & $\mathrm{x}$ \\
\hline
\end{tabular}




\begin{tabular}{|c|c|c|c|c|c|c|c|c|c|c|c|c|c|c|c|c|c|c|}
\hline VarName & VariableLabel & WordingDE & ValueLabelsDE_Linked & WordingEN & ValueLabelsEN_Linked & L1 & L1F L2 & L3 & $\mathrm{L} 4$ & L5 & L6 & L7 & L8 & L9 & L10 & o L11 & 1 L12 & $2 \mathrm{~L} 13 \mathrm{~L} 14$ \\
\hline $\begin{array}{l}\text { work.values } \\
\text {.intrinsic.orientation.2 }\end{array}$ & $\begin{array}{l}\text { Work values } \\
\text { item } 7\end{array}$ & $\begin{array}{l}\text { eine Tätigkeit bei der } \\
\text { man selbstständig } \\
\text { arbeiten kann? }\end{array}$ & $\begin{array}{l}1=\text { trifft überhaupt nicht } \\
\text { zu, } 2=\text { trifft nicht } \mathrm{zu}, 3= \\
\text { trifft eher nicht } \mathrm{zu}, 4= \\
\text { weder noch, } 5=\text { trifft } \\
\text { eher zu, } 6=\text { trifft } \mathrm{zu}, 7= \\
\text { trifft voll und ganz zu }\end{array}$ & $\begin{array}{l}\text { That you can work } \\
\text { independently? }\end{array}$ & $\begin{array}{l}1=\text { don't agree at all, } 2= \\
\text { don't agree, } 3=\text { rather } \\
\text { not agree, } 4=\text { neither, } 5 \\
=\text { rather agree, } 6=\text { agree, } \\
7=\text { agree completely }\end{array}$ & & & & & $\mathrm{x}$ & $\mathrm{x}$ & $\mathrm{x}$ & $\mathrm{x}$ & $\mathrm{x}$ & $\mathrm{x}$ & $\mathrm{x}$ & $\mathrm{x}$ & $\mathrm{x}$ \\
\hline $\begin{array}{l}\text { work.values } \\
\text {.social.orientation.1 }\end{array}$ & $\begin{array}{l}\text { Work values } \\
\text { item } 8\end{array}$ & $\begin{array}{l}\text { viel Kontakt zu anderen } \\
\text { Menschen? }\end{array}$ & $\begin{array}{l}1=\text { trifft überhaupt nicht } \\
\text { zu, } 2=\text { trifft nicht zu, } 3= \\
\text { trifft eher nicht zu, } 4= \\
\text { weder noch, } 5=\text { trifft } \\
\text { eher zu, } 6=\text { trifft zu, } 7= \\
\text { trifft voll und ganz zu }\end{array}$ & $\begin{array}{l}\text { Much contact to other } \\
\text { people? }\end{array}$ & $\begin{array}{l}1=\text { don't agree at all, } 2= \\
\text { don't agree, } 3=\text { rather } \\
\text { not agree, } 4=\text { neither, } 5 \\
=\text { rather agree, } 6=\text { agree } \\
7=\text { agree completely }\end{array}$ & & & & & $\mathrm{x}$ & $\mathrm{X}$ & $\mathrm{x}$ & $\mathrm{x}$ & $\mathrm{x}$ & $\mathrm{X}$ & $\mathrm{X}$ & $\mathrm{X}$ & $\mathrm{X}$ \\
\hline $\begin{array}{l}\text { work.values } \\
\text {.social.orientation.2 }\end{array}$ & $\begin{array}{l}\text { Work values } \\
\text { item } 9\end{array}$ & $\begin{array}{l}\text { ein Beruf, der für die } \\
\text { Gesellschaft wichtig ist? }\end{array}$ & $\begin{array}{l}1=\text { trifft überhaupt nicht } \\
\text { zu, } 2=\text { trifft nicht zu, } 3= \\
\text { trifft eher nicht zu, } 4= \\
\text { weder noch, } 5=\text { trifft } \\
\text { eher zu, } 6=\text { trifft zu, } 7= \\
\text { trifft voll und ganz zu }\end{array}$ & $\begin{array}{l}\text { That the job is } \\
\text { important for society? }\end{array}$ & $\begin{array}{l}1=\text { don't agree at all, } 2= \\
\text { don't agree, } 3=\text { rather } \\
\text { not agree, } 4=\text { neither, } 5 \\
=\text { rather agree, } 6=\text { agree, } \\
7=\text { agree completely }\end{array}$ & & & & & $\mathrm{x}$ & $\mathrm{X}$ & $\mathrm{x}$ & $\mathrm{x}$ & $\mathrm{X}$ & $\mathrm{X}$ & $\mathrm{X}$ & $\mathrm{X}$ & $\mathrm{X}$ \\
\hline $\begin{array}{l}\text { work.values } \\
\text {.external.orientation.2 }\end{array}$ & $\begin{array}{l}\text { Work values } \\
\text { item } 10\end{array}$ & $\begin{array}{l}\text { sichere und gesunde } \\
\text { Arbeitsbedingungen? }\end{array}$ & $\begin{array}{l}1=\text { trifft überhaupt nicht } \\
\text { zu, } 2=\text { trifft nicht zu, } 3= \\
\text { trifft eher nicht zu, } 4= \\
\text { weder noch, } 5=\text { trifft } \\
\text { eher zu, } 6=\text { trifft zu, } 7= \\
\text { trifft voll und ganz zu }\end{array}$ & $\begin{array}{l}\text { Safe and healthy work } \\
\text { conditions? }\end{array}$ & $\begin{array}{l}1=\text { don't agree at all, } 2= \\
\text { don't agree, } 3=\text { rather } \\
\text { not agree, } 4=\text { neither, } 5 \\
=\text { rather agree, } 6=\text { agree, } \\
7=\text { agree completely }\end{array}$ & & & & & $\mathrm{x}$ & $\mathrm{x}$ & $\mathrm{x}$ & $\mathrm{x}$ & $\mathrm{x}$ & $\mathrm{x}$ & $\mathrm{x}$ & $\mathrm{x}$ & $\mathrm{x}$ \\
\hline $\begin{array}{l}\text { work.values } \\
\text {.external.orientation.3 }\end{array}$ & $\begin{array}{l}\text { Work values } \\
\text { item } 11\end{array}$ & $\begin{array}{l}\text { ein Beruf, der einem } \\
\text { genügend Zeit für } \\
\text { familiäre } \\
\text { Verpflichtungen lässt? }\end{array}$ & $\begin{array}{l}1=\text { trifft überhaupt nicht } \\
\text { zu, } 2=\text { trifft nicht zu, } 3= \\
\text { trifft eher nicht zu, } 4= \\
\text { weder noch, } 5=\text { trifft } \\
\text { eher zu, } 6=\text { trifft zu, } 7= \\
\text { trifft voll und ganz zu }\end{array}$ & $\begin{array}{l}\text { That the job leaves } \\
\text { enough time for family } \\
\text { duties? }\end{array}$ & $\begin{array}{l}1=\text { don't agree at all, } 2= \\
\text { don't agree, } 3=\text { rather } \\
\text { not agree, } 4=\text { neither, } 5 \\
=\text { rather agree, } 6=\text { agree, } \\
7=\text { agree completely }\end{array}$ & & & & & $\mathrm{x}$ & $\mathrm{x}$ & $\mathrm{x}$ & $\mathrm{x}$ & $\mathrm{x}$ & $\mathrm{x}$ & $\mathrm{x}$ & $\mathrm{x}$ & $\mathrm{x}$ \\
\hline $\begin{array}{l}\text { work.values } \\
\text {.social.orientation.3 }\end{array}$ & $\begin{array}{l}\text { Work values } \\
\text { item } 12\end{array}$ & $\begin{array}{l}\text { ein Beruf, bei dem man } \\
\text { anderen Menschen } \\
\text { helfen kann? }\end{array}$ & $\begin{array}{l}1=\text { trifft überhaupt nicht } \\
\text { zu, } 2=\text { trifft nicht } \mathrm{zu}, 3= \\
\text { trifft eher nicht } \mathrm{zu}, 4= \\
\text { weder noch, } 5=\text { trifft } \\
\text { eher } \mathrm{zu}, 6=\text { trifft } \mathrm{zu}, 7= \\
\text { trifft voll und ganz zu }\end{array}$ & $\begin{array}{l}\text { That you can help } \\
\text { others in this job? }\end{array}$ & $\begin{array}{l}1=\text { don't agree at all, } 2= \\
\text { don't agree, } 3=\text { rather } \\
\text { not agree, } 4=\text { neither, } 5 \\
=\text { rather agree, } 6=\text { agree, } \\
7=\text { agree completely }\end{array}$ & & & & & $\mathrm{x}$ & $\mathrm{x}$ & $\mathrm{x}$ & $\mathrm{x}$ & $\mathrm{x}$ & $\mathrm{x}$ & $\mathrm{x}$ & $\mathrm{x}$ & $\mathrm{x}$ \\
\hline gender.perceptions. 1 & $\begin{array}{l}\text { Gender } \\
\text { perception and } \\
\text { aptitude item } \\
1\end{array}$ & $\begin{array}{l}\text { Im Folgenden sind } \\
\text { einige Fragen die sich } \\
\text { darauf beziehen, ob } \\
\text { Männer und Frauen sich } \\
\text { in verschiedenen } \\
\text { Hinsichten } \\
\text { unterscheiden. Bitte gib } \\
\text { an, inwiefern Du den } \\
\text { folgenden Aussagen } \\
\text { zustimmst. Männer sind } \\
\text { besser in } \\
\text { Naturwissenschaften als } \\
\text { Frauen. }\end{array}$ & $\begin{array}{l}1=\text { stimmt überhaupt } \\
\text { nicht, } 2=\text { stimmt nicht, } 3 \\
=\text { stimmt eher nicht, } 4= \\
\text { weder noch, } 5=\text { stimmt } \\
\text { eher, } 6=\text { stimmt, } 7= \\
\text { stimmt voll und ganz }\end{array}$ & $\begin{array}{l}\text { Men are better in maths } \\
\text { than women. }\end{array}$ & $\begin{array}{l}1=\text { don't agree at all, } 2= \\
\text { don't agree, } 3=\text { rather } \\
\text { not agree, } 4=\text { neither, } 5 \\
=\text { rather agree, } 6=\text { agree, } \\
7=\text { agree completely }\end{array}$ & & & & & $\mathrm{x}$ & $\mathrm{x}$ & $\mathrm{x}$ & $\mathrm{x}$ & $\mathrm{x}$ & $\mathrm{x}$ & $\mathrm{x}$ & $\mathrm{x}$ & $\mathrm{x}$ \\
\hline gender.perceptions.2 & $\begin{array}{l}\text { Gender } \\
\text { perception and } \\
\text { aptitude item } \\
2\end{array}$ & $\begin{array}{l}\text { Frauen sind besser in } \\
\text { Naturwissenschaften als } \\
\text { Männer. }\end{array}$ & $\begin{array}{l}1=\text { stimmt überhaupt } \\
\text { nicht, } 2=\text { stimmt nicht, } 3 \\
=\text { stimmt eher nicht, } 4= \\
\text { weder noch, } 5=\text { stimmt } \\
\text { eher, } 6=\text { stimmt, } 7= \\
\text { stimmt voll und ganz }\end{array}$ & $\begin{array}{l}\text { Women are better in } \\
\text { maths than men. }\end{array}$ & $\begin{array}{l}1=\text { don't agree at all, } 2= \\
\text { don't agree, } 3=\text { rather } \\
\text { not agree, } 4=\text { neither, } 5 \\
=\text { rather agree, } 6=\text { agree, } \\
7=\text { agree completely }\end{array}$ & & & & & $\mathrm{x}$ & $\mathrm{x}$ & $\mathrm{x}$ & $\mathrm{x}$ & $\mathrm{x}$ & $\mathrm{x}$ & $\mathrm{x}$ & $\mathrm{x}$ & $\mathrm{x}$ \\
\hline gender.perceptions.3 & $\begin{array}{l}\text { Gender } \\
\text { perception and } \\
\text { aptitude item } \\
3\end{array}$ & $\begin{array}{l}\text { Männer sind besser in } \\
\text { Mathematik als Frauen. }\end{array}$ & $\begin{array}{l}1=\text { stimmt überhaupt } \\
\text { nicht, } 2=\text { stimmt nicht, } 3 \\
=\text { stimmt eher nicht, } 4= \\
\text { weder noch, } 5=\text { stimmt } \\
\text { eher, } 6=\text { stimmt, } 7= \\
\text { stimmt voll und ganz }\end{array}$ & $\begin{array}{l}\text { Men are better in } \\
\text { science than women. }\end{array}$ & $\begin{array}{l}1=\text { don't agree at all, } 2= \\
\text { don't agree, } 3=\text { rather } \\
\text { not agree, } 4=\text { neither, } 5 \\
=\text { rather agree, } 6=\text { agree, } \\
7=\text { agree completely }\end{array}$ & & & & & $\mathrm{x}$ & $\mathrm{x}$ & $\mathrm{x}$ & $\mathrm{x}$ & $\mathrm{x}$ & $\mathrm{x}$ & $\mathrm{x}$ & $\mathrm{x}$ & $\mathrm{x}$ \\
\hline
\end{tabular}




\begin{tabular}{|c|c|c|c|c|c|c|c|c|c|c|c|c|c|c|c|c|c|c|}
\hline VarName & VariableLabel & WordingDE & ValueLabelsDE_Linked & WordingEN & ValueLabelsEN_Linked & L1 & L1F L2 & L3 & $\mathrm{L} 4$ & L5 & L6 & L7 & L8 & L9 & L10 & o L11 & 1 L12 & $2 \mathrm{~L} 13 \mathrm{~L} 14$ \\
\hline gender.perceptions. 4 & $\begin{array}{l}\text { Gender } \\
\text { perception and } \\
\text { aptitude item } \\
4\end{array}$ & $\begin{array}{l}\text { Frauen sind besser in } \\
\text { Mathematik als Männer. }\end{array}$ & $\begin{array}{l}1=\text { stimmt überhaupt } \\
\text { nicht, } 2=\text { stimmt nicht, } 3 \\
=\text { stimmt eher nicht, } 4= \\
\text { weder noch, } 5=\text { stimmt } \\
\text { eher, } 6=\text { stimmt, } 7= \\
\text { stimmt voll und ganz }\end{array}$ & $\begin{array}{l}\text { Women are better in } \\
\text { science than men. }\end{array}$ & $\begin{array}{l}1=\text { don't agree at all, } 2= \\
\text { don't agree, } 3=\text { rather } \\
\text { not agree, } 4=\text { neither, } 5 \\
=\text { rather agree, } 6=\text { agree, } \\
7=\text { agree completely }\end{array}$ & & & & & $\mathrm{x}$ & $\mathrm{x}$ & $\mathrm{x}$ & $\mathrm{x}$ & $\mathrm{x}$ & $\mathrm{x}$ & $\mathrm{x}$ & $\mathrm{x}$ & $\mathrm{x}$ \\
\hline gender.perceptions.5 & $\begin{array}{l}\text { Gender } \\
\text { perception and } \\
\text { aptitude item } \\
5\end{array}$ & $\begin{array}{l}\text { Männer sind besser in } \\
\text { Sprachen als Frauen. }\end{array}$ & $\begin{array}{l}1=\text { stimmt überhaupt } \\
\text { nicht, } 2=\text { stimmt nicht, } 3 \\
=\text { stimmt eher nicht, } 4= \\
\text { weder noch, } 5=\text { stimmt } \\
\text { eher, } 6=\text { stimmt, } 7= \\
\text { stimmt voll und ganz }\end{array}$ & $\begin{array}{l}\text { Men are better in } \\
\text { languages than women. }\end{array}$ & $\begin{array}{l}1=\text { don't agree at all, } 2= \\
\text { don't agree, } 3=\text { rather } \\
\text { not agree, } 4=\text { neither, } 5 \\
=\text { rather agree, } 6=\text { agree, } \\
7=\text { agree completely }\end{array}$ & & & & & $\mathrm{x}$ & $\mathrm{x}$ & $\mathrm{x}$ & $\mathrm{x}$ & $\mathrm{x}$ & $\mathrm{x}$ & $\mathrm{x}$ & $\mathrm{x}$ & $\mathrm{x}$ \\
\hline gender.perceptions. 6 & $\begin{array}{l}\text { Gender } \\
\text { perception and } \\
\text { aptitude item } \\
6\end{array}$ & $\begin{array}{l}\text { Männer sind besser in } \\
\text { Sprachen als Frauen. }\end{array}$ & $\begin{array}{l}1=\text { stimmt überhaupt } \\
\text { nicht, } 2=\text { stimmt nicht, } 3 \\
=\text { stimmt eher nicht, } 4= \\
\text { weder noch, } 5=\text { stimmt } \\
\text { eher, } 6=\text { stimmt, } 7= \\
\text { stimmt voll und ganz }\end{array}$ & $\begin{array}{l}\text { Women are better in } \\
\text { languages than men. }\end{array}$ & $\begin{array}{l}1=\text { don't agree at all, } 2= \\
\text { don't agree, } 3=\text { rather } \\
\text { not agree, } 4=\text { neither, } 5 \\
=\text { rather agree, } 6=\text { agree, } \\
7=\text { agree completely }\end{array}$ & & & & & $\mathrm{x}$ & $\mathrm{x}$ & $\mathrm{x}$ & $\mathrm{x}$ & $\mathrm{x}$ & $\mathrm{x}$ & $\mathrm{X}$ & $\mathrm{x}$ & $\mathrm{x}$ \\
\hline gender.perceptions.cohort. & $\begin{array}{l}\text { Gender } \\
\text { perceptions in } \\
\text { cohort item } 1\end{array}$ & $\begin{array}{l}\text { Nun geht es darum, ob } \\
\text { die männlichen und } \\
\text { weiblichen Studenten in } \\
\text { deinem Fach sich in } \\
\text { verschiedenen } \\
\text { Hinsichten } \\
\text { unterscheiden. Bitte gib } \\
\text { an, inwiefern Du den } \\
\text { folgenden Aussagen } \\
\text { zustimmst. Meine } \\
\text { männlichen } \\
\text { Mitstudierenden } \\
\text { verstehen Inhalte } \\
\text { leichter als die } \\
\text { weiblichen Studenten. }\end{array}$ & $\begin{array}{l}1=\text { stimmt überhaupt } \\
\text { nicht, } 2=\text { stimmt nicht, } 3 \\
=\text { stimmt eher nicht, } 4= \\
\text { weder noch, } 5=\text { stimmt } \\
\text { eher, } 6=\text { stimmt, } 7= \\
\text { stimmt voll und ganz }\end{array}$ & $\begin{array}{l}\text { Now it is about whether } \\
\text { the male and female } \\
\text { students in your subject } \\
\text { differ in some regards. } \\
\text { Please indicate to what } \\
\text { extent you agree with } \\
\text { the following } \\
\text { statements: My male } \\
\text { fellow-students } \\
\text { understand the contents } \\
\text { easier than my female } \\
\text { fellow students. }\end{array}$ & $\begin{array}{l}1=\text { don't agree at all, } 2= \\
\text { don't agree, } 3=\text { rather } \\
\text { not agree, } 4=\text { neither, } 5 \\
=\text { rather agree, } 6=\text { agree, } \\
7=\text { agree completely }\end{array}$ & & & & & $\mathrm{x}$ & $\mathrm{x}$ & $\mathrm{x}$ & $\mathrm{x}$ & $\mathrm{x}$ & $\mathrm{x}$ & $\mathrm{x}$ & $\mathrm{x}$ & $\mathrm{x}$ \\
\hline gender.perceptions.cohor & $\begin{array}{l}\text { Gender } \\
\text { perceptions in } \\
\text { cohort item } 2\end{array}$ & $\begin{array}{l}\text { Meine weiblichen } \\
\text { Mitstudierenden } \\
\text { verstehen Inhalte } \\
\text { leichter als die } \\
\text { männlichen Studenten }\end{array}$ & $\begin{array}{l}1=\text { stimmt überhaupt } \\
\text { nicht, } 2=\text { stimmt nicht, } 3 \\
=\text { stimmt eher nicht, } 4= \\
\text { weder noch, } 5=\text { stimmt } \\
\text { eher, } 6=\text { stimmt, } 7= \\
\text { stimmt voll und ganz }\end{array}$ & $\begin{array}{l}\text { My female } \\
\text { fellow-students } \\
\text { understand the contents } \\
\text { easier than my male } \\
\text { fellow students. }\end{array}$ & $\begin{array}{l}1=\text { don't agree at all, } 2= \\
\text { don't agree, } 3=\text { rather } \\
\text { not agree, } 4=\text { neither, } 5 \\
=\text { rather agree, } 6=\text { agree, } \\
7=\text { agree completely }\end{array}$ & & & & & $\mathrm{x}$ & $\mathrm{x}$ & $\mathrm{x}$ & $\mathrm{x}$ & $\mathrm{x}$ & $\mathrm{x}$ & $\mathrm{x}$ & $\mathrm{x}$ & $\mathrm{x}$ \\
\hline gender.perceptions.cohort. & $\begin{array}{l}\text { Siender } \\
\text { perceptions in } \\
\text { cohort item } 3\end{array}$ & $\begin{array}{l}\text { Meine männlichen } \\
\text { Mitstudierenden nehmen } \\
\text { ihr Studium ernster als } \\
\text { die weiblichen Studenten } \\
\text { (e.g. lernen mehr, } \\
\text { schwänzen seltener } \\
\text { Vorlesungen, etc.) }\end{array}$ & $\begin{array}{l}1=\text { stimmt überhaupt } \\
\text { nicht, } 2=\text { stimmt nicht, } 3 \\
=\text { stimmt eher nicht, } 4= \\
\text { weder noch, } 5=\text { stimmt } \\
\text { eher, } 6=\text { stimmt, } 7= \\
\text { stimmt voll und ganz }\end{array}$ & $\begin{array}{l}\text { My male fellow-students } \\
\text { are take their studies } \\
\text { more seriously than the } \\
\text { female ones (e.g. they } \\
\text { study more, skip fewer } \\
\text { lectures, etc.) }\end{array}$ & $\begin{array}{l}1=\text { don't agree at all, } 2= \\
\text { don't agree, } 3=\text { rather } \\
\text { not agree, } 4=\text { neither, } 5 \\
=\text { rather agree, } 6=\text { agree, } \\
7=\text { agree completely }\end{array}$ & & & & & $\mathrm{x}$ & $\mathrm{x}$ & $\mathrm{x}$ & $\mathrm{x}$ & $\mathrm{x}$ & $\mathrm{x}$ & $\mathrm{x}$ & $\mathrm{x}$ & $\mathrm{x}$ \\
\hline gender.perceptions.cohor & $\begin{array}{l}\text { Gender } \\
\text { perceptions in } \\
\text { cohort item } 4\end{array}$ & $\begin{array}{l}\text { Meine weiblichen } \\
\text { Mitstudierenden nehmen } \\
\text { ihr Studium ernster als } \\
\text { die männlichen } \\
\text { Studenten (e.g. lernen } \\
\text { mehr, schwänzen } \\
\text { seltener Vorlesungen, } \\
\text { etc.) }\end{array}$ & $\begin{array}{l}1=\text { stimmt überhaupt } \\
\text { nicht, } 2=\text { stimmt nicht, } 3 \\
=\text { stimmt eher nicht, } 4= \\
\text { weder noch, } 5=\text { stimmt } \\
\text { eher, } 6=\text { stimmt, } 7= \\
\text { stimmt voll und ganz }\end{array}$ & $\begin{array}{l}\text { My female } \\
\text { fellow-students are take } \\
\text { their studies more } \\
\text { seriously than the male } \\
\text { ones (e.g. they study } \\
\text { more, skip fewer } \\
\text { lectures, etc.) }\end{array}$ & $\begin{array}{l}1=\text { don't agree at all, } 2= \\
\text { don't agree, } 3=\text { rather } \\
\text { not agree, } 4=\text { neither, } 5 \\
=\text { rather agree, } 6=\text { agree, } \\
7=\text { agree completely }\end{array}$ & & & & & $\mathrm{x}$ & $\mathrm{x}$ & $\mathrm{x}$ & $\mathrm{x}$ & $\mathrm{x}$ & $\mathrm{x}$ & $\mathrm{x}$ & $\mathrm{x}$ & $\mathrm{x}$ \\
\hline gender.perceptions.11 & $\begin{array}{l}\text { Gender } \\
\text { perceptions in } \\
\text { cohort item } 5\end{array}$ & $\begin{array}{l}\text { Meine männlichen } \\
\text { Mitstudierenden haben } \\
\text { bessere Chancen die } \\
\text { Basisprüfung zu } \\
\text { bestehen als die } \\
\text { weiblichen. }\end{array}$ & $\begin{array}{l}1=\text { stimmt überhaupt } \\
\text { nicht, } 2=\text { stimmt nicht, } 3 \\
=\text { stimmt eher nicht, } 4= \\
\text { weder noch, } 5=\text { stimmt } \\
\text { eher, } 6=\text { stimmt, } 7= \\
\text { stimmt voll und ganz }\end{array}$ & $\begin{array}{l}\text { My male fellow-students } \\
\text { have better chances to } \\
\text { pass the Basisprüfung } \\
\text { than the female ones. }\end{array}$ & $\begin{array}{l}1=\text { don't agree at all, } 2= \\
\text { don't agree, } 3=\text { rather } \\
\text { not agree, } 4=\text { neither, } 5 \\
=\text { rather agree, } 6=\text { agree, } \\
7=\text { agree completely }\end{array}$ & & & & & $\mathrm{x}$ & $\mathrm{x}$ & $\mathrm{x}$ & & & & & & \\
\hline
\end{tabular}




\begin{tabular}{|c|c|c|c|c|c|c|c|c|c|c|c|c|c|c|c|c|c|c|}
\hline VarName & VariableLabel & WordingDE & ValueLabelsDE_Linked & WordingEN & ValueLabelsEN_Linked & L1 & L1F L2 & L3 & $\mathrm{L} 4$ & L5 & L6 & $\mathrm{L} 7$ & L8 & L9 & & 0 L11 & $\mathrm{L} 12$ & 2 L13 L14 \\
\hline gender.perceptions.12 & $\begin{array}{l}\text { Gender } \\
\text { perceptions in } \\
\text { cohort item } 6\end{array}$ & $\begin{array}{l}\text { Meine weiblichen } \\
\text { Mitstudierenden haben } \\
\text { bessere Chancen die } \\
\text { Basisprüfung zu } \\
\text { bestehen als die } \\
\text { männlichen }\end{array}$ & $\begin{array}{l}1=\text { stimmt überhaupt } \\
\text { nicht, } 2=\text { stimmt nicht, } 3 \\
=\text { stimmt eher nicht, } 4= \\
\text { weder noch, } 5=\text { stimmt } \\
\text { eher, } 6=\text { stimmt, } 7= \\
\text { stimmt voll und ganz }\end{array}$ & $\begin{array}{l}\text { My female } \\
\text { fellow-students have } \\
\text { better chances to pass } \\
\text { the Basisprüfung than } \\
\text { the male ones. }\end{array}$ & $\begin{array}{l}1=\text { don't agree at all, } 2= \\
\text { don't agree, } 3=\text { rather } \\
\text { not agree, } 4=\text { neither, } 5 \\
=\text { rather agree, } 6=\text { agree, } \\
7=\text { agree completely }\end{array}$ & & & & & $\mathrm{x}$ & $\mathrm{x}$ & $\mathrm{x}$ & & & & & & \\
\hline gender.perceptions.13 & $\begin{array}{l}\text { Gender } \\
\text { perceptions in } \\
\text { cohort item } 7\end{array}$ & $\begin{array}{l}\text { Meine männlichen } \\
\text { Mitstudierenden haben } \\
\text { bessere } \\
\text { Karriereaussichten als } \\
\text { die weiblichen }\end{array}$ & $\begin{array}{l}1=\text { stimmt überhaupt } \\
\text { nicht, } 2=\text { stimmt nicht, } 3 \\
=\text { stimmt eher nicht, } 4= \\
\text { weder noch, } 5=\text { stimmt } \\
\text { eher, } 6=\text { stimmt, } 7= \\
\text { stimmt voll und ganz }\end{array}$ & $\begin{array}{l}\text { My male fellow-students } \\
\text { have better career } \\
\text { prospects than the } \\
\text { female ones. }\end{array}$ & $\begin{array}{l}1=\text { don't agree at all, } 2= \\
\text { don't agree, } 3=\text { rather } \\
\text { not agree, } 4=\text { neither, } 5 \\
=\text { rather agree, } 6=\text { agree, } \\
7=\text { agree completely }\end{array}$ & & & & & $\mathrm{x}$ & $\mathrm{x}$ & $\mathrm{x}$ & $\mathrm{x}$ & $\mathrm{x}$ & $\mathrm{x}$ & $\mathrm{x}$ & $\mathrm{x}$ & $\mathrm{x}$ \\
\hline gender.perceptions. 14 & $\begin{array}{l}\text { Gender } \\
\text { perceptions in } \\
\text { cohort item } 8\end{array}$ & $\begin{array}{l}\text { Meine weiblichen } \\
\text { Mitstudierenden haben } \\
\text { bessere } \\
\text { Karriereaussichten als } \\
\text { die männlichen. }\end{array}$ & $\begin{array}{l}1=\text { stimmt überhaupt } \\
\text { nicht, } 2=\text { stimmt nicht, } 3 \\
=\text { stimmt eher nicht, } 4= \\
\text { weder noch, } 5=\text { stimmt } \\
\text { eher, } 6=\text { stimmt, } 7= \\
\text { stimmt voll und ganz }\end{array}$ & $\begin{array}{l}\text { My female } \\
\text { fellow-students have } \\
\text { better career prospects } \\
\text { than the male ones. }\end{array}$ & $\begin{array}{l}1=\text { don't agree at all, } 2= \\
\text { don't agree, } 3=\text { rather } \\
\text { not agree, } 4=\text { neither, } 5 \\
=\text { rather agree, } 6=\text { agree, } \\
7=\text { agree completely }\end{array}$ & & & & & $\mathrm{x}$ & $\mathrm{x}$ & $\mathrm{x}$ & $\mathrm{x}$ & $\mathrm{x}$ & $\mathrm{x}$ & $\mathrm{x}$ & $\mathrm{x}$ & $\mathrm{x}$ \\
\hline attention.check & $\begin{array}{l}\text { Checking that } \\
\text { students are } \\
\text { paying } \\
\text { attention }\end{array}$ & $\begin{array}{l}\text { Um sicherzustellen, dass } \\
\text { Dein Webbrowser } \\
\text { korrekt funktioniert und } \\
\text { dass alle Antworten } \\
\text { aufgezeichnet werden, } \\
\text { klicke bitte auf â€žtrifft } \\
\text { zuâ€œ. }\end{array}$ & $\begin{array}{l}1=\text { stimmt überhaupt } \\
\text { nicht, } 2=\text { stimmt nicht, } 3 \\
=\text { stimmt eher nicht, } 4= \\
\text { weder noch, } 5=\text { stimmt } \\
\text { eher, } 6=\text { stimmt, } 7= \\
\text { stimmt voll und ganz }\end{array}$ & $\begin{array}{l}\text { To ensure that your web } \\
\text { browser is functioning } \\
\text { correctly, please click on } \\
\text { option }\end{array}$ & $\begin{array}{l}1=\text { don't agree at all, } 2= \\
\text { don't agree, } 3=\text { rather } \\
\text { not agree, } 4=\text { neither, } 5 \\
=\text { rather agree, } 6=\text { agree, } \\
7=\text { agree completely }\end{array}$ & & & & & & $\mathrm{x}$ & $\mathrm{x}$ & $\mathrm{x}$ & $\mathrm{x}$ & $\mathrm{x}$ & $\mathrm{x}$ & $\mathrm{x}$ & $\mathrm{x}$ \\
\hline first.contact & $\begin{array}{l}\text { When students } \\
\text { met } \\
\text { cohortmates } \\
\text { whom they are } \\
\text { closest to }\end{array}$ & $\begin{array}{l}\text { Mit denjenigen } \\
\text { Mitstudenten, denen ich } \\
\text { mich am nächsten fühle, } \\
\text { habe ich mich zum } \\
\text { ersten Mal unterhalten... } \\
\text { (mehrere Antworten } \\
\text { möglich) }\end{array}$ & $\begin{array}{l}1=\text { am Student } \\
\text { Introduciton Day Event, } 2 \\
=\text { in der ersten Vorlesung } \\
\text { am Erstitag, } 3=\text { später } \\
\text { am Erstitag, } 4=\text { in der } \\
\text { ersten Studienwoche, } 5= \\
\text { am Erstiwochenende, } 6= \\
\text { in einer regulären } \\
\text { Vorlesung, } 7=\text { zu einem } \\
\text { anderen Zeitpunkt: }\end{array}$ & $\begin{array}{l}\text { With those students, to } \\
\text { whom I feel closest, I } \\
\text { first interacted... } \\
\text { (multiple answers } \\
\text { possible) }\end{array}$ & $\begin{array}{l}1=\text { at the Student } \\
\text { Introduction Day, } 2=\text { at } \\
\text { the first lecture on the } \\
\text { first day, } 3=\text { later on the } \\
\text { first day, } 4=\text { in the first } \\
\text { week of studies, } 5=\text { at } \\
\text { the first weekend, } 6=\text { in a } \\
\text { regular lecture, } 7=\text { at } \\
\text { another time point: }\end{array}$ & & & & & & $\mathrm{x}$ & $\mathrm{x}$ & $\mathrm{x}$ & $\mathrm{x}$ & $\mathrm{x}$ & $\mathrm{x}$ & $\mathrm{x}$ & $\mathrm{x}$ \\
\hline first.contact.other & other option & $\begin{array}{l}\text { Mit denjenigen } \\
\text { Mitstudenten, denen ich } \\
\text { mich am nächsten fühle, } \\
\text { habe ich mich zum } \\
\text { ersten Mal unterhalten... } \\
\text { (mehrere Antworten } \\
\text { möglich) }\end{array}$ & & $\begin{array}{l}\text { With those students, to } \\
\text { whom I feel closest, I } \\
\text { first interacted... } \\
\text { (multiple answers } \\
\text { possible) }\end{array}$ & & & & & & & $\mathrm{x}$ & $\mathrm{x}$ & $\mathrm{x}$ & $\mathrm{x}$ & $\mathrm{x}$ & $\mathrm{x}$ & $\mathrm{x}$ & $\mathrm{x}$ \\
\hline exam.prep.1 & $\begin{array}{l}\text { Participation } \\
\text { in exam prep - } \\
\text { [name } \\
\text { removed] }\end{array}$ & $\begin{array}{l}\text { In welchem Mass hast } \\
\text { du an den Prüfungsvor- } \\
\text { bereitungskursen [name } \\
\text { removed] teilgenommen? } \\
\text { - [name removed] }\end{array}$ & $\begin{array}{l}1=\text { Gar nicht }, 2=, 3= \\
4=, 5=\text { teilweise } 6= \\
7=\text { immer }\end{array}$ & $\begin{array}{l}\text { To what extent did you } \\
\text { take part in the exam } \\
\text { preparation courses of } \\
\text { the [name removed] - } \\
\text { [name removed] }\end{array}$ & $\begin{array}{l}1=\text { never, } 2=, 3=, 4= \\
, 5=, 6=\text { sometimes, } 7 \\
=, 1=, 2=\text { always }\end{array}$ & & & & & & $\mathrm{x}$ & & & & & & & \\
\hline exam.prep.2 & $\begin{array}{l}\text { Participation } \\
\text { in exam prep - } \\
\text { [name } \\
\text { removed] }\end{array}$ & $\begin{array}{l}\text { In welchem Mass hast } \\
\text { du an den Prüfungsvor- } \\
\text { bereitungskursen [name } \\
\text { removed] teilgenommen? } \\
\text { - [name removed] }\end{array}$ & $\begin{array}{l}1=\text { Gar nicht }, 2=, 3= \\
4=, 5=\text { teilweise, } 6= \\
7=\text { immer }\end{array}$ & $\begin{array}{l}\text { To what extent did you } \\
\text { take part in the exam } \\
\text { preparation courses of } \\
\text { the [name removed] - } \\
\text { [name removed] }\end{array}$ & $\begin{array}{l}1=\text { never, } 2=\text { sometimes } \\
3=\text { always, } 4=\text { never }, 5 \\
=\text { sometimes, } 6=\text { always } \\
7=\text { never }\end{array}$ & & & & & & $\mathrm{x}$ & & & & & & & \\
\hline exam.prep.3 & $\begin{array}{l}\text { Participation } \\
\text { in exam prep - } \\
\text { [name } \\
\text { removed] }\end{array}$ & $\begin{array}{l}\text { In welchem Mass hast } \\
\text { du an den Prüfungsvor- } \\
\text { bereitungskursen [name } \\
\text { removed] teilgenommen? } \\
\text { - [name removed] }\end{array}$ & $\begin{array}{l}1=\text { Gar nicht }, 2=, 3= \\
4=, 5=\text { teilweise, } 6= \\
7=\text { immer }\end{array}$ & $\begin{array}{l}\text { To what extent did you } \\
\text { take part in the exam } \\
\text { preparation courses of } \\
\text { the [name removed] - } \\
\text { [name removed] }\end{array}$ & $\begin{array}{l}1=\text { never, } 2=\text { sometimes } \\
3=\text { always, } 4=\text { never }, 5 \\
=\text { sometimes, } 6=\text { always } \\
7=\text { never }\end{array}$ & & & & & & $\mathrm{x}$ & & & & & & & \\
\hline exam.prep.4 & $\begin{array}{l}\text { Participation } \\
\text { in exam prep - } \\
\text { [name } \\
\text { removed] }\end{array}$ & $\begin{array}{l}\text { In welchem Mass hast } \\
\text { du an den Prüfungsvor- } \\
\text { bereitungskursen [name } \\
\text { removed] teilgenommen? } \\
\text { - [name removed] }\end{array}$ & $\begin{array}{l}1=\text { Gar nicht }, 2=, 3= \\
4=, 5=\text { teilweise, } 6= \\
7=\text { immer }\end{array}$ & $\begin{array}{l}\text { To what extent did you } \\
\text { take part in the exam } \\
\text { preparation courses of } \\
\text { the [name removed] - } \\
\text { [name removed] }\end{array}$ & $\begin{array}{l}1=\text { never, } 2=\text { sometimes } \\
3=\text { always, } 4=\text { never }, 5 \\
=\text { sometimes, } 6=\text { always } \\
7=\text { never }\end{array}$ & & & & & & $\mathrm{x}$ & & & & & & & \\
\hline
\end{tabular}




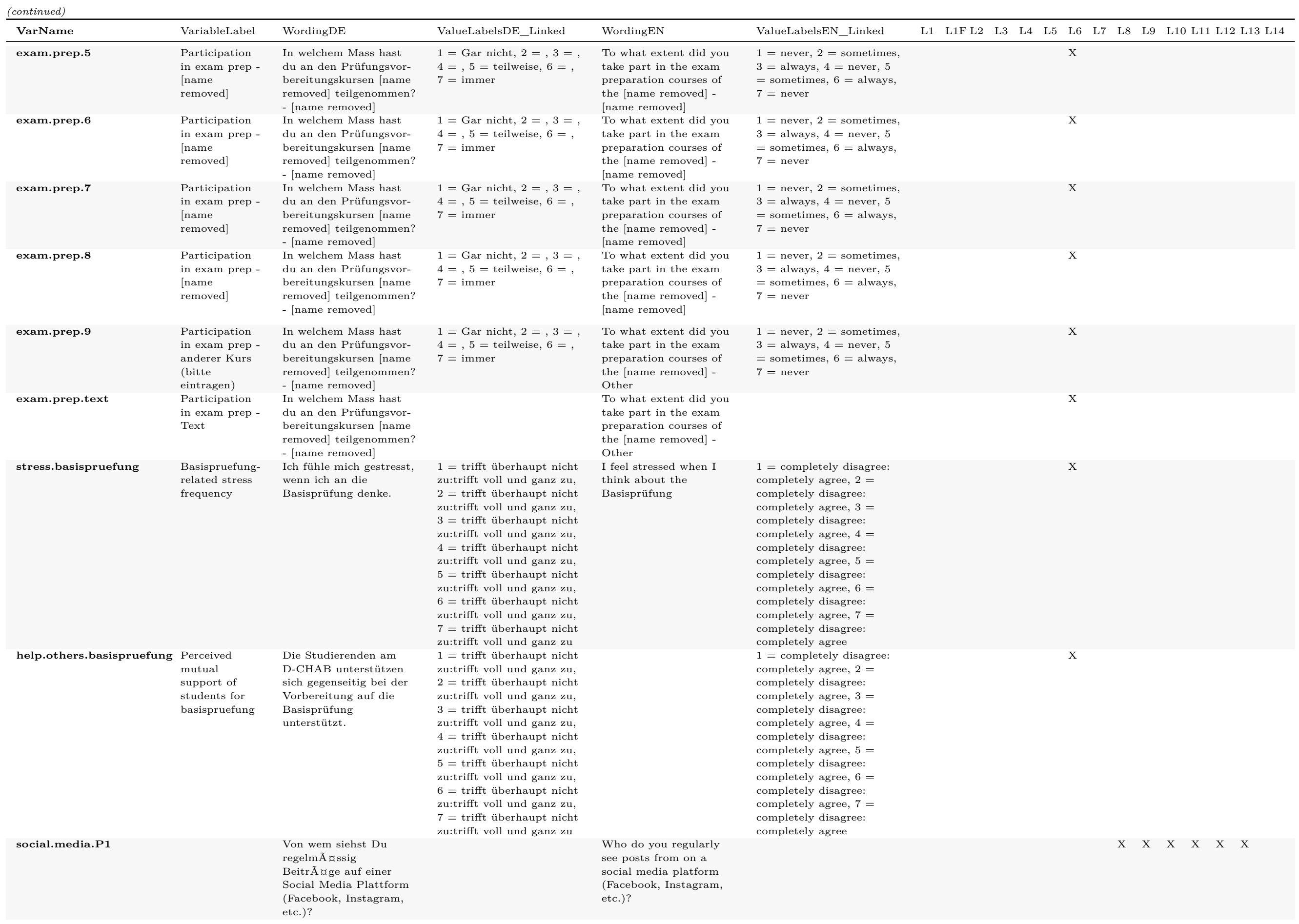




\begin{tabular}{|c|c|c|c|c|c|c|c|c|c|c|c|c|c|c|c|c|c|c|c|}
\hline VarName & VariableLabel & WordingDE & ValueLabelsDE_Linked & WordingEN & ValueLabelsEN_Linked & L1 & L1F L2 & L3 & $\mathrm{L} 4$ & L5 & L6 & $\mathrm{L} 7$ & L8 & L9 & L10 & o L11 & $1 \mathrm{~L} 12$ & $2 \mathrm{~L} 1$ & 3 L14 \\
\hline loneliness.intimate.1 & $\begin{array}{l}\text { german } \\
\text { version of the } \\
\text { short UCLA } \\
\text { Loneliness } \\
\text { scale } \\
\text { (Luhmann et } \\
\text { al., 2016) }\end{array}$ & $\begin{array}{l}\text { Wie hÃ aufig hast Du } \\
\text { das Gef } \tilde{A}^{1 / 4 h l} \text {, dass Dir } \\
\text { Gesellschaft fehlt? }\end{array}$ & $\begin{array}{l}1=\text { nie, } 2=\text { selten, } 3= \\
\text { manchmal, } 4=\text { oft }\end{array}$ & $\begin{array}{l}\text { How often do you feel } \\
\text { that you lack } \\
\text { companionship? (I) }\end{array}$ & $\begin{array}{l}1=\text { never, } 2=\text { rarely, } 3= \\
\text { sometimes, } 4=\text { often }\end{array}$ & & & & & & & & & $\mathrm{x}$ & $\mathrm{x}$ & $\mathrm{x}$ & $\mathrm{x}$ & $\mathrm{x}$ & $\mathrm{x}$ \\
\hline loneliness.collective. 1 & $\begin{array}{l}\text { german } \\
\text { version of the } \\
\text { short UCLA } \\
\text { Loneliness } \\
\text { scale } \\
\text { (Luhmann et } \\
\text { al., 2016) }\end{array}$ & 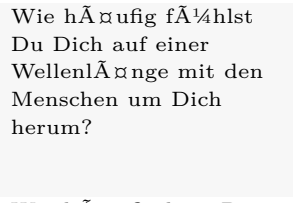 & $\begin{array}{l}1=\text { nie, } 2=\text { selten, } 3= \\
\text { manchmal, } 4=\text { oft }\end{array}$ & $\begin{array}{l}\text { How often do you feel } \\
\text { that you are 'in tune' } \\
\text { with the people around } \\
\text { you? (Ca) }\end{array}$ & $\begin{array}{l}1=\text { never, } 2=\text { rarely, } 3= \\
\text { sometimes, } 4=\text { often }\end{array}$ & & & & & & & & & $\mathrm{x}$ & $\mathrm{x}$ & $\mathrm{x}$ & $\mathrm{x}$ & $\mathrm{x}$ & $\mathrm{x}$ \\
\hline loneliness.relational.1 & $\begin{array}{l}\text { german } \\
\text { version of the } \\
\text { short UCLA } \\
\text { Loneliness } \\
\text { scale } \\
\text { (Luhmann et } \\
\text { al., 2016) }\end{array}$ & $\begin{array}{l}\text { Wie hÃ qufig hast Du } \\
\text { das Gef } \tilde{A}^{1 / 4 h l} \text {, dass es } \\
\text { Menschen gibt, mit } \\
\text { denen Du reden kannst? }\end{array}$ & $\begin{array}{l}1=\text { nie, } 2=\text { selten, } 3= \\
\text { manchmal, } 4=\text { oft }\end{array}$ & $\begin{array}{l}\text { How often do you feel } \\
\text { that there are people } \\
\text { you can talk to? (Ra) }\end{array}$ & $\begin{array}{l}1=\text { never, } 2=\text { rarely, } 3= \\
\text { sometimes, } 4=\text { often }\end{array}$ & & & & & & & & & $\mathrm{x}$ & $\mathrm{x}$ & $\mathrm{x}$ & $\mathrm{x}$ & $\mathrm{x}$ & $\mathrm{x}$ \\
\hline loneliness.intimate. 2 & $\begin{array}{l}\text { german } \\
\text { version of the } \\
\text { short UCLA } \\
\text { Loneliness } \\
\text { scale } \\
\text { (Luhmann et } \\
\text { al., 2016) }\end{array}$ & $\begin{array}{l}\text { Wie hÃ dufig f } \tilde{A}^{1 / 4 h l s t} \\
\text { Du Dich ausgeschlossen? }\end{array}$ & $\begin{array}{l}1=\text { nie, } 2=\text { selten, } 3= \\
\text { manchmal, } 4=\text { oft }\end{array}$ & $\begin{array}{l}\text { How often do you feel } \\
\text { left out? (I) }\end{array}$ & $\begin{array}{l}1=\text { never, } 2=\text { rarely, } 3= \\
\text { sometimes, } 4=\text { often }\end{array}$ & & & & & & & & & $\mathrm{x}$ & $\mathrm{x}$ & $\mathrm{x}$ & $\mathrm{x}$ & $\mathrm{x}$ & $\mathrm{x}$ \\
\hline loneliness.relational.2 & $\begin{array}{l}\text { german } \\
\text { version of the } \\
\text { short UCLA } \\
\text { Loneliness } \\
\text { scale } \\
\text { (Luhmann et } \\
\text { al., 2016) }\end{array}$ & $\begin{array}{l}\text { Wie hÃ qufig f } \tilde{A}^{1 / 4 h l s t} \\
\text { Du, dass es Menschen } \\
\text { gibt, an die Du Dich } \\
\text { wenden kannst? }\end{array}$ & $\begin{array}{l}1=\text { nie, } 2=\text { selten, } 3= \\
\text { manchmal, } 4=\text { oft }\end{array}$ & $\begin{array}{l}\text { How often do you feel } \\
\text { that there are people } \\
\text { you can turn to? (Ra) }\end{array}$ & $\begin{array}{l}1=\text { never, } 2=\text { rarely, } 3= \\
\text { sometimes, } 4=\text { often }\end{array}$ & & & & & & & & & $\mathrm{x}$ & $\mathrm{X}$ & $\mathrm{x}$ & $\mathrm{x}$ & $\mathrm{x}$ & $\mathrm{x}$ \\
\hline loneliness.collective.2 & $\begin{array}{l}\text { german } \\
\text { version of the } \\
\text { short UCLA } \\
\text { Loneliness } \\
\text { scale } \\
\text { (Luhmann et } \\
\text { al., 2016) }\end{array}$ & $\begin{array}{l}\text { Wie hÃ aufig hast Du } \\
\text { das Gef } \tilde{A}^{1 / 4 h l} \text {, dass Du } \\
\text { mit den Menschen um } \\
\text { Dich herum vieles } \\
\text { gemeinsam hast? }\end{array}$ & $\begin{array}{l}1=\text { nie, } 2=\text { selten, } 3= \\
\text { manchmal, } 4=\text { oft }\end{array}$ & $\begin{array}{l}\text { How often do you feel } \\
\text { that you have a lot in } \\
\text { common with the people } \\
\text { around you? (Ca) }\end{array}$ & $\begin{array}{l}1=\text { never, } 2=\text { rarely, } 3= \\
\text { sometimes, } 4=\text { often }\end{array}$ & & & & & & & & & $\mathrm{x}$ & $\mathrm{x}$ & $\mathrm{x}$ & $\mathrm{x}$ & $\mathrm{x}$ & $\mathrm{x}$ \\
\hline loneliness.relational.3 & $\begin{array}{l}\text { german } \\
\text { version of the } \\
\text { short UCLA } \\
\text { Loneliness } \\
\text { scale } \\
\text { (Luhmann et } \\
\text { al., 2016) }\end{array}$ & $\begin{array}{l}\text { Wie hÃ a ufig f } \tilde{A}^{1} / 4 h l s t \\
\text { Du Dich anderen } \\
\text { Menschen nah? }\end{array}$ & $\begin{array}{l}1=\text { nie, } 2=\text { selten, } 3= \\
\text { manchmal, } 4=\text { oft }\end{array}$ & $\begin{array}{l}\text { How often do you feel } \\
\text { close to people? (Ra) }\end{array}$ & $\begin{array}{l}1=\text { never, } 2=\text { rarely, } 3= \\
\text { sometimes, } 4=\text { often }\end{array}$ & & & & & & & & & $\mathrm{x}$ & $\mathrm{x}$ & $\mathrm{x}$ & $\mathrm{x}$ & $\mathrm{x}$ & $\mathrm{x}$ \\
\hline loneliness.intimate. 3 & $\begin{array}{l}\text { german } \\
\text { version of the } \\
\text { short UCLA } \\
\text { Loneliness } \\
\text { scale } \\
\text { (Luhmann et } \\
\text { al., 2016) }\end{array}$ & $\begin{array}{l}\text { Wie hÃ a ufig f } \tilde{A}^{1} / 4 \text { hlst } \\
\text { Du Dich isoliert von } \\
\text { anderen Menschen? }\end{array}$ & $\begin{array}{l}1=\text { nie, } 2=\text { selten, } 3= \\
\text { manchmal, } 4=\text { oft }\end{array}$ & $\begin{array}{l}\text { How often do you feel } \\
\text { iso- lated from others? } \\
\text { (I) }\end{array}$ & $\begin{array}{l}1=\text { never, } 2=\text { rarely, } 3= \\
\text { sometimes, } 4=\text { often }\end{array}$ & & & & & & & & & $\mathrm{x}$ & $\mathrm{x}$ & $\mathrm{x}$ & $\mathrm{x}$ & $\mathrm{x}$ & $\mathrm{x}$ \\
\hline loneliness.collective. 3 & $\begin{array}{l}\text { german } \\
\text { version of the } \\
\text { short UCLA } \\
\text { Loneliness } \\
\text { scale } \\
\text { (Luhmann et } \\
\text { al., 2016) }\end{array}$ & $\begin{array}{l}\text { Wie hÃ aufig hast Du } \\
\text { das Gef } \tilde{A}^{1 / 4 h l} \text {, zu einer } \\
\text { Gruppe von Freunden } \\
\text { dazu zu geh } \tilde{\uparrow} \text { Iren? }\end{array}$ & $\begin{array}{l}1=\text { nie, } 2=\text { selten, } 3= \\
\text { manchmal, } 4=\text { oft }\end{array}$ & $\begin{array}{l}\text { How often do you feel } \\
\text { part of a group of } \\
\text { friends? (Ca) }\end{array}$ & $\begin{array}{l}1=\text { never, } 2=\text { rarely, } 3= \\
\text { sometimes, } 4=\text { often }\end{array}$ & & & & & & & & & $\mathrm{x}$ & $\mathrm{x}$ & $\mathrm{x}$ & $\mathrm{x}$ & $\mathrm{x}$ & $\mathrm{x}$ \\
\hline
\end{tabular}




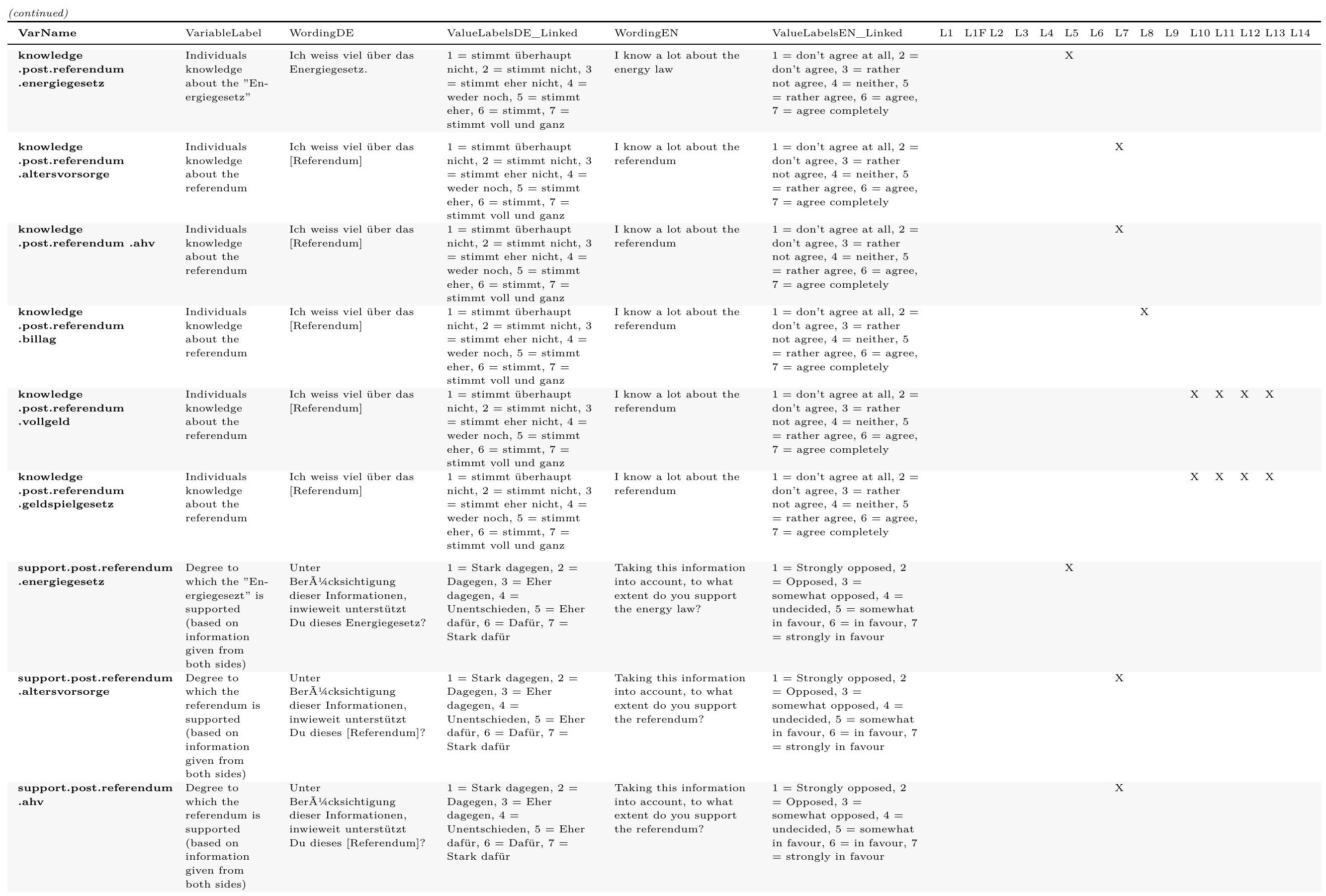




\begin{tabular}{|c|c|c|c|c|c|c|c|c|c|c|c|c|c|c|c|c|c|c|}
\hline VarName & VariableLabel & WordingDE & ValueLabelsDE_Linked & WordingEN & ValueLabelsEN_Linked & L1 & L1F L2 & L3 & L4 & L5 & L6 & $\mathrm{L} 7$ & L8 & L9 & L10 & o L11 & 1 L12 & $2 \mathrm{~L} 13 \mathrm{~L} 14$ \\
\hline $\begin{array}{l}\text { support.post.referendum } \\
\text {.billag }\end{array}$ & $\begin{array}{l}\text { Degree to } \\
\text { which the } \\
\text { referendum is } \\
\text { supported } \\
\text { (based on } \\
\text { information } \\
\text { given from } \\
\text { both sides) }\end{array}$ & $\begin{array}{l}\text { Unter } \\
\text { Ber } \tilde{A}^{1 / 4} \text { cksichtigung } \\
\text { dieser Informationen, } \\
\text { inwieweit unterstützt } \\
\text { Du dieses [Referendum]? }\end{array}$ & $\begin{array}{l}1=\text { Stark dagegen, } 2= \\
\text { Dagegen, } 3=\text { Eher } \\
\text { dagegen, } 4= \\
\text { Unentschieden, } 5=\text { Eher } \\
\text { dafür, } 6=\text { Dafür, } 7= \\
\text { Stark dafür }\end{array}$ & $\begin{array}{l}\text { Taking this information } \\
\text { into account, to what } \\
\text { extent do you support } \\
\text { the referendum? }\end{array}$ & $\begin{array}{l}1=\text { Strongly opposed, } 2 \\
=\text { Opposed, } 3= \\
\text { somewhat opposed, } 4= \\
\text { undecided, } 5=\text { somewhat } \\
\text { in favour, } 6=\text { in favour, } 7 \\
=\text { strongly in favour }\end{array}$ & & & & & & & & $\mathrm{x}$ & & & & & \\
\hline $\begin{array}{l}\text { support.post.referendum } \\
\text {.billag }\end{array}$ & $\begin{array}{l}\text { Degree to } \\
\text { which the } \\
\text { referendum is } \\
\text { supported } \\
\text { (based on } \\
\text { information } \\
\text { given from } \\
\text { both sides) }\end{array}$ & $\begin{array}{l}\text { Unter } \\
\text { Ber } \tilde{A}^{1 / 4} \text { cksichtigung } \\
\text { dieser Informationen, } \\
\text { inwieweit unterstützt } \\
\text { Du dieses [Referendum]? }\end{array}$ & $\begin{array}{l}1=\text { Stark dagegen, } 2= \\
\text { Dagegen, } 3=\text { Eher } \\
\text { dagegen, } 4= \\
\text { Unentschieden, } 5=\text { Eher } \\
\text { dafür, } 6=\text { Dafür, } 7= \\
\text { Stark dafür }\end{array}$ & $\begin{array}{l}\text { Taking this information } \\
\text { into account, to what } \\
\text { extent do you support } \\
\text { the referendum? }\end{array}$ & $\begin{array}{l}1=\text { Strongly opposed, } 2 \\
=\text { Opposed, } 3= \\
\text { somewhat opposed, } 4= \\
\text { undecided, } 5=\text { somewhat } \\
\text { in favour, } 6=\text { in favour, } 7 \\
=\text { strongly in favour }\end{array}$ & & & & & & & & & & $\mathrm{x}$ & $\mathrm{x}$ & $\mathrm{x}$ & $\mathrm{x}$ \\
\hline $\begin{array}{l}\text { support.post.referendum } \\
\text {.billag }\end{array}$ & $\begin{array}{l}\text { Degree to } \\
\text { which the } \\
\text { referendum is } \\
\text { supported } \\
\text { (based on } \\
\text { information } \\
\text { given from } \\
\text { both sides) }\end{array}$ & $\begin{array}{l}\text { Unter } \\
\text { Ber } \tilde{A}^{1 / 4} \text { cksichtigung } \\
\text { dieser Informationen, } \\
\text { inwieweit unterstützt } \\
\text { Du dieses [Referendum]? }\end{array}$ & $\begin{array}{l}1=\text { Stark dagegen, } 2= \\
\text { Dagegen, } 3=\text { Eher } \\
\text { dagegen, } 4= \\
\text { Unentschieden, } 5=\text { Eher } \\
\text { dafür, } 6=\text { Dafür, } 7= \\
\text { Stark dafür }\end{array}$ & $\begin{array}{l}\text { Taking this information } \\
\text { into account, to what } \\
\text { extent do you support } \\
\text { the referendum? }\end{array}$ & $\begin{array}{l}1=\text { Strongly opposed, } 2 \\
=\text { Opposed, } 3= \\
\text { somewhat opposed, } 4= \\
\text { undecided, } 5=\text { somewhat } \\
\text { in favour, } 6=\text { in favour, } 7 \\
=\text { strongly in favour }\end{array}$ & & & & & & & & & & $\mathrm{x}$ & $\mathrm{x}$ & $\mathrm{x}$ & $\mathrm{x}$ \\
\hline $\begin{array}{l}\text { vote.post.referendum } \\
\text {.energiegesetz }\end{array}$ & $\begin{array}{l}\text { Vote in the } \\
\text { energy } \\
\text { referendum }\end{array}$ & $\begin{array}{l}\text { Hast Du über das } \\
\text { Referendum gegen das } \\
\text { Energiegesetz } \\
\text { abgestimmt? }\end{array}$ & $\begin{array}{l}1=\mathrm{Ja}, \text { ich habe gegen das } \\
\text { Energiegesetz abgestimmt, } \\
2=\mathrm{Ja} \text {, ich habe für das } \\
\text { Energiegesetz abgestimmt, } \\
3=\text { Nein, ich habe nicht } \\
\text { abgestimmt, obwohl ich } \\
\text { stimmberechtigt bin, } 4= \\
\text { Nein, ich bin nicht } \\
\text { stimmberechtigt }\end{array}$ & $\begin{array}{l}\text { Did you vote in the } \\
\text { referendum against the } \\
\text { energy law? }\end{array}$ & $\begin{array}{l}1=\text { Yes, I voted against } \\
\text { the energy law, } 2=\text { Yes, I } \\
\text { voted for the energy law, } \\
3=\text { No, I did not vote, } \\
\text { although I do have the } \\
\text { right to vote, } 4=\text { No, I do } \\
\text { not have the right to } \\
\text { vote. }\end{array}$ & & & & & $\mathrm{x}$ & & & & & & & & \\
\hline $\begin{array}{l}\text { vote.post.referendum } \\
\text {.billag }\end{array}$ & Vote & $\begin{array}{l}\text { Hast Du über das } \\
\text { Referendum [name of } \\
\text { referendum] } \\
\text { abgestimmt? }\end{array}$ & $\begin{array}{l}1=\mathrm{Ja}, \text { ich habe gegen das } \\
\text { Energiegesetz abgestimmt, } \\
2=\mathrm{Ja} \text {, ich habe für das } \\
\text { Energiegesetz abgestimmt, } \\
3=\text { Nein, ich habe nicht } \\
\text { abgestimmt, obwohl ich } \\
\text { stimmberechtigt bin, } 4= \\
\text { Nein, ich bin nicht } \\
\text { stimmberechtigt }\end{array}$ & $\begin{array}{l}\text { Did you vote in the } \\
\text { referendum [name of the } \\
\text { referendum]? }\end{array}$ & $\begin{array}{l}1=\text { Yes, I voted against } \\
\text { the energy law, } 2=\text { Yes, I } \\
\text { voted for the energy law, } \\
3=\text { No, I did not vote, } \\
\text { although I do have the } \\
\text { right to vote, } 4=\text { No, I do } \\
\text { not have the right to } \\
\text { vote. }\end{array}$ & & & & & & & & $\mathrm{x}$ & & & & & \\
\hline $\begin{array}{l}\text { vote.post.referendum } \\
\text {.altersvorsorge }\end{array}$ & Vote & $\begin{array}{l}\text { Hast Du über das } \\
\text { Referendum [name of } \\
\text { referendum] } \\
\text { abgestimmt? }\end{array}$ & $\begin{array}{l}1=\mathrm{Ja} \text {, ich habe gegen das } \\
\text { Energiegesetz abgestimmt, } \\
2=\mathrm{Ja} \text {, ich habe für das } \\
\text { Energiegesetz abgestimmt, } \\
3=\text { Nein, ich habe nicht } \\
\text { abgestimmt, obwohl ich } \\
\text { stimmberechtigt bin, } 4= \\
\text { Nein, ich bin nicht } \\
\text { stimmberechtigt }\end{array}$ & $\begin{array}{l}\text { Did you vote in the } \\
\text { referendum [name of the } \\
\text { referendum]? }\end{array}$ & $\begin{array}{l}1=\text { Yes, I voted against } \\
\text { the energy law, } 2=\text { Yes, I } \\
\text { voted for the energy law, } \\
3=\text { No, I did not vote, } \\
\text { although I do have the } \\
\text { right to vote, } 4=\text { No, I do } \\
\text { not have the right to } \\
\text { vote. }\end{array}$ & & & & & & & $\mathrm{x}$ & & & & & & \\
\hline $\begin{array}{l}\text { vote.post.referendum } \\
\text {.ahv }\end{array}$ & Vote & $\begin{array}{l}\text { Hast Du über das } \\
\text { Referendum [name of } \\
\text { referendum] } \\
\text { abgestimmt? }\end{array}$ & $\begin{array}{l}1=\mathrm{Ja} \text {, ich habe gegen das } \\
\text { Energiegesetz abgestimmt, } \\
2=\mathrm{Ja} \text {, ich habe für das } \\
\text { Energiegesetz abgestimmt, } \\
3=\text { Nein, ich habe nicht } \\
\text { abgestimmt, obwohl ich } \\
\text { stimmberechtigt bin, } 4= \\
\text { Nein, ich bin nicht } \\
\text { stimmberechtigt }\end{array}$ & $\begin{array}{l}\text { Did you vote in the } \\
\text { referendum [name of the } \\
\text { referendum]? }\end{array}$ & $\begin{array}{l}1=\text { Yes, I voted against } \\
\text { the energy law, } 2=\text { Yes, I } \\
\text { voted for the energy law, } \\
3=\text { No, I did not vote, } \\
\text { although I do have the } \\
\text { right to vote, } 4=\text { No, I do } \\
\text { not have the right to } \\
\text { vote. }\end{array}$ & & & & & & & $\mathrm{x}$ & & & & & & \\
\hline
\end{tabular}




\begin{tabular}{|c|c|c|c|c|c|c|c|c|c|c|c|c|c|c|c|c|c|c|}
\hline VarName & VariableLabel & WordingDE & ValueLabelsDE_Linked & WordingEN & ValueLabelsEN_Linked & L1 & L1F L2 & L3 & $\mathrm{L} 4$ & L5 & L6 & $\mathrm{L} 7$ & L8 & L9 & L1C & 0 L11 & $1 \mathrm{~L} 12$ & 2 L13 L14 \\
\hline $\begin{array}{l}\text { vote.post.referendum } \\
\text {.vollgeld }\end{array}$ & Vote & $\begin{array}{l}\text { Hast Du über das } \\
\text { Referendum [name of } \\
\text { referendum] } \\
\text { abgestimmt? }\end{array}$ & $\begin{array}{l}1=\mathrm{Ja} \text {, ich habe gegen das } \\
\text { Energiegesetz abgestimmt, } \\
2=\mathrm{Ja} \text {, ich habe für das } \\
\text { Energiegesetz abgestimmt, } \\
3=\text { Nein, ich habe nicht } \\
\text { abgestimmt, obwohl ich } \\
\text { stimmberechtigt bin, } 4= \\
\text { Nein, ich bin nicht } \\
\text { stimmberechtigt }\end{array}$ & $\begin{array}{l}\text { Did you vote in the } \\
\text { referendum [name of the } \\
\text { referendum]? }\end{array}$ & $\begin{array}{l}1=\text { Yes, I voted against } \\
\text { the energy law, } 2=\text { Yes, I } \\
\text { voted for the energy law, } \\
3=\text { No, I did not vote, } \\
\text { although I do have the } \\
\text { right to vote, } 4=\text { No, I do } \\
\text { not have the right to } \\
\text { vote. }\end{array}$ & & & & & & & & & & $\mathrm{x}$ & $\mathrm{x}$ & $\mathrm{x}$ & $\mathrm{x}$ \\
\hline $\begin{array}{l}\text { vote.post.referendum } \\
\text {.geldspielgesetz }\end{array}$ & Vote & $\begin{array}{l}\text { Hast Du über das } \\
\text { Referendum [name of } \\
\text { referendum] } \\
\text { abgestimmt? }\end{array}$ & $\begin{array}{l}1=\mathrm{Ja} \text {, ich habe gegen das } \\
\text { Energiegesetz abgestimmt, } \\
2=\mathrm{Ja} \text {, ich habe für das } \\
\text { Energiegesetz abgestimmt, } \\
3=\text { Nein, ich habe nicht } \\
\text { abgestimmt, obwohl ich } \\
\text { stimmberechtigt bin, } 4= \\
\text { Nein, ich bin nicht } \\
\text { stimmberechtigt }\end{array}$ & $\begin{array}{l}\text { Did you vote in the } \\
\text { referendum [name of the } \\
\text { referendum]? }\end{array}$ & $\begin{array}{l}1=\text { Yes, I voted against } \\
\text { the energy law, } 2=\text { Yes, I } \\
\text { voted for the energy law, } \\
3=\text { No, I did not vote, } \\
\text { although I do have the } \\
\text { right to vote, } 4=\text { No, I do } \\
\text { not have the right to } \\
\text { vote. }\end{array}$ & & & & & & & & & & $\mathrm{x}$ & $\mathrm{x}$ & $\mathrm{X}$ & $\mathrm{X}$ \\
\hline $\begin{array}{l}\text { knowledge } \\
\text { ·pre.referendum } \\
\text {.energiegesetz }\end{array}$ & $\begin{array}{l}\text { Individuals } \\
\text { knowledge } \\
\text { about the "En- } \\
\text { ergiegesetz" }\end{array}$ & $\begin{array}{l}\text { Ich weiss viel über das } \\
\text { Energiegesetz. }\end{array}$ & $\begin{array}{l}1=\text { stimmt überhaupt } \\
\text { nicht, } 2=\text { stimmt nicht, } 3 \\
=\text { stimmt eher nicht, } 4= \\
\text { weder noch, } 5=\text { stimmt } \\
\text { eher, } 6=\text { stimmt, } 7= \\
\text { stimmt voll und ganz }\end{array}$ & $\begin{array}{l}\text { I know a lot about the } \\
\text { energy law }\end{array}$ & $\begin{array}{l}1=\text { don't agree at all, } 2= \\
\text { don't agree, } 3=\text { rather } \\
\text { not agree, } 4=\text { neither, } 5 \\
=\text { rather agree, } 6=\text { agree, } \\
7=\text { agree completely }\end{array}$ & & & & $\mathrm{x}$ & & & & & & & & & \\
\hline $\begin{array}{l}\text { knowledge } \\
\text { ·pre.referendum } \\
\text {.altersvorsorge }\end{array}$ & $\begin{array}{l}\text { Individuals } \\
\text { knowledge } \\
\text { about the } \\
\text { [Referendum] }\end{array}$ & $\begin{array}{l}\text { Ich weiss viel über das } \\
\text { [Referendum] }\end{array}$ & $\begin{array}{l}1=\text { stimmt überhaupt } \\
\text { nicht, } 2=\text { stimmt nicht, } 3 \\
=\text { stimmt eher nicht, } 4= \\
\text { weder noch, } 5=\text { stimmt } \\
\text { eher, } 6=\text { stimmt, } 7= \\
\text { stimmt voll und ganz }\end{array}$ & $\begin{array}{l}\text { I know a lot about the } \\
\text { [Referendum] }\end{array}$ & $\begin{array}{l}1=\text { don't agree at all, } 2= \\
\text { don't agree, } 3=\text { rather } \\
\text { not agree, } 4=\text { neither, } 5 \\
=\text { rather agree, } 6=\text { agree, } \\
7=\text { agree completely }\end{array}$ & & & & & & $\mathrm{x}$ & & & & & & & \\
\hline $\begin{array}{l}\text { knowledge } \\
\text {.pre.referendum .ahv }\end{array}$ & $\begin{array}{l}\text { Individuals } \\
\text { knowledge } \\
\text { about the } \\
\text { [Referendum] }\end{array}$ & $\begin{array}{l}\text { Ich weiss viel über das } \\
\text { [Referendum] }\end{array}$ & $\begin{array}{l}1=\text { stimmt überhaupt } \\
\text { nicht, } 2=\text { stimmt nicht, } 3 \\
=\text { stimmt eher nicht, } 4= \\
\text { weder noch, } 5=\text { stimmt } \\
\text { eher, } 6=\text { stimmt, } 7= \\
\text { stimmt voll und ganz }\end{array}$ & $\begin{array}{l}\text { I know a lot about the } \\
\text { [Referendum] }\end{array}$ & $\begin{array}{l}1=\text { don't agree at all, } 2= \\
\text { don't agree, } 3=\text { rather } \\
\text { not agree, } 4=\text { neither, } 5 \\
=\text { rather agree, } 6=\text { agree, } \\
7=\text { agree completely }\end{array}$ & & & & & & $\mathrm{x}$ & & & & & & & \\
\hline $\begin{array}{l}\text { knowledge } \\
\text {.pre.referendum .billag }\end{array}$ & $\begin{array}{l}\text { Individuals } \\
\text { knowledge } \\
\text { about the } \\
\text { [Referendum] }\end{array}$ & $\begin{array}{l}\text { Ich weiss viel über das } \\
\text { [Referendum] }\end{array}$ & $\begin{array}{l}1=\text { stimmt überhaupt } \\
\text { nicht, } 2=\text { stimmt nicht, } 3 \\
=\text { stimmt eher nicht, } 4= \\
\text { weder noch, } 5=\text { stimmt } \\
\text { eher, } 6=\text { stimmt, } 7= \\
\text { stimmt voll und ganz }\end{array}$ & $\begin{array}{l}\text { I know a lot about the } \\
\text { [Referendum] }\end{array}$ & $\begin{array}{l}1=\text { don't agree at all, } 2= \\
\text { don't agree, } 3=\text { rather } \\
\text { not agree, } 4=\text { neither, } 5 \\
=\text { rather agree, } 6=\text { agree, } \\
7=\text { agree completely }\end{array}$ & & & & & & & $\mathrm{x}$ & & & & & & \\
\hline $\begin{array}{l}\text { knowledge } \\
\text { ·pre.referendum } \\
\text {.vollgeld }\end{array}$ & $\begin{array}{l}\text { Individuals } \\
\text { knowledge } \\
\text { about the } \\
\text { [Referendum] }\end{array}$ & $\begin{array}{l}\text { Ich weiss viel über das } \\
\text { [Referendum] }\end{array}$ & $\begin{array}{l}1=\text { stimmt überhaupt } \\
\text { nicht, } 2=\text { stimmt nicht, } 3 \\
=\text { stimmt eher nicht, } 4= \\
\text { weder noch, } 5=\text { stimmt } \\
\text { eher, } 6=\text { stimmt, } 7= \\
\text { stimmt voll und ganz }\end{array}$ & $\begin{array}{l}\text { I know a lot about the } \\
\text { [Referendum] }\end{array}$ & $\begin{array}{l}1=\text { don't agree at all, } 2= \\
\text { don't agree, } 3=\text { rather } \\
\text { not agree, } 4=\text { neither, } 5 \\
=\text { rather agree, } 6=\text { agree, } \\
7=\text { agree completely }\end{array}$ & & & & & & & & & $\mathrm{x}$ & & & & \\
\hline $\begin{array}{l}\text { knowledge } \\
\text { ·pre.referendum } \\
\text {.geldspielgesetz }\end{array}$ & $\begin{array}{l}\text { Individuals } \\
\text { knowledge } \\
\text { about the } \\
\text { [Referendum] }\end{array}$ & $\begin{array}{l}\text { Ich weiss viel über das } \\
\text { [Referendum] }\end{array}$ & $\begin{array}{l}1=\text { stimmt überhaupt } \\
\text { nicht, } 2=\text { stimmt nicht, } 3 \\
=\text { stimmt eher nicht, } 4= \\
\text { weder noch, } 5=\text { stimmt } \\
\text { eher, } 6=\text { stimmt, } 7= \\
\text { stimmt voll und ganz }\end{array}$ & $\begin{array}{l}\text { I know a lot about the } \\
\text { [Referendum] }\end{array}$ & $\begin{array}{l}1=\text { don't agree at all, } 2= \\
\text { don't agree, } 3=\text { rather } \\
\text { not agree, } 4=\text { neither, } 5 \\
=\text { rather agree, } 6=\text { agree, } \\
7=\text { agree completely }\end{array}$ & & & & & & & & & $\mathrm{x}$ & & & & \\
\hline $\begin{array}{l}\text { knowledge } \\
\text { ·pre.referendum } \\
\text {.ernahrung }\end{array}$ & $\begin{array}{l}\text { Individuals } \\
\text { knowledge } \\
\text { about the } \\
\text { [Referendum] }\end{array}$ & $\begin{array}{l}\text { Ich weiss viel über das } \\
\text { [Referendum] }\end{array}$ & $\begin{array}{l}1=\text { stimmt überhaupt } \\
\text { nicht, } 2=\text { stimmt nicht, } 3 \\
=\text { stimmt eher nicht, } 4= \\
\text { weder noch, } 5=\text { stimmt } \\
\text { eher, } 6=\text { stimmt, } 7= \\
\text { stimmt voll und ganz }\end{array}$ & $\begin{array}{l}\text { I know a lot about the } \\
\text { [Referendum] }\end{array}$ & $\begin{array}{l}1=\text { don't agree at all, } 2= \\
\text { don't agree, } 3=\text { rather } \\
\text { not agree, } 4=\text { neither, } 5 \\
=\text { rather agree, } 6=\text { agree, } \\
7=\text { agree completely }\end{array}$ & & & & & & & & & & $\mathrm{x}$ & $\mathrm{x}$ & $\mathrm{X}$ & $\mathrm{X}$ \\
\hline
\end{tabular}




\begin{tabular}{|c|c|c|c|c|c|c|c|c|c|c|c|c|c|c|c|c|c|c|}
\hline VarName & VariableLabel & WordingDE & ValueLabelsDE_Linked & WordingEN & ValueLabelsEN_Linked & L1 & L1F L2 & L3 & $\mathrm{L} 4$ & L5 & L6 6 & $\mathrm{~L} 7$ & L8 & L9 & L10 & L11 & L12 & L13 L14 \\
\hline $\begin{array}{l}\text { knowledge } \\
\text {.pre.referendum } \\
\text { fairfood }\end{array}$ & $\begin{array}{l}\text { Individuals } \\
\text { knowledge } \\
\text { about the } \\
\text { [Referendum] }\end{array}$ & $\begin{array}{l}\text { Ich weiss viel über das } \\
\text { [Referendum] }\end{array}$ & $\begin{array}{l}1=\text { stimmt überhaupt } \\
\text { nicht, } 2=\text { stimmt nicht, } 3 \\
=\text { stimmt eher nicht, } 4= \\
\text { weder noch, } 5=\text { stimmt } \\
\text { eher, } 6=\text { stimmt, } 7= \\
\text { stimmt voll und ganz }\end{array}$ & $\begin{array}{l}\text { I know a lot about the } \\
\text { [Referendum] }\end{array}$ & $\begin{array}{l}1=\text { don't agree at all, } 2= \\
\text { don't agree, } 3=\text { rather } \\
\text { not agree, } 4=\text { neither, } 5 \\
=\text { rather agree, } 6=\text { agree, } \\
7=\text { agree completely }\end{array}$ & & & & & & & & & & $\mathrm{x}$ & $\mathrm{x}$ & $\mathrm{x}$ & $\mathrm{x}$ \\
\hline $\begin{array}{l}\text { knowledge } \\
\text {.pre.referendum .velo }\end{array}$ & $\begin{array}{l}\text { Individuals } \\
\text { knowledge } \\
\text { about the } \\
\text { [Referendum] }\end{array}$ & $\begin{array}{l}\text { Ich weiss viel über das } \\
\text { [Referendum] }\end{array}$ & $\begin{array}{l}1=\text { stimmt überhaupt } \\
\text { nicht, } 2=\text { stimmt nicht, } 3 \\
=\text { stimmt eher nicht, } 4= \\
\text { weder noch, } 5=\text { stimmt } \\
\text { eher, } 6=\text { stimmt, } 7= \\
\text { stimmt voll und ganz }\end{array}$ & $\begin{array}{l}\text { I know a lot about the } \\
\text { [Referendum] }\end{array}$ & $\begin{array}{l}1=\text { don't agree at all, } 2= \\
\text { don't agree, } 3=\text { rather } \\
\text { not agree, } 4=\text { neither, } 5 \\
=\text { rather agree, } 6=\text { agree } \\
7=\text { agree completely }\end{array}$ & & & & & & & & & & $\mathrm{x}$ & $\mathrm{x}$ & $\mathrm{x}$ & $\mathrm{x}$ \\
\hline $\begin{array}{l}\text { support.pre.referendum } \\
\text {.energiegesetz }\end{array}$ & $\begin{array}{l}\text { Degree to } \\
\text { which the "En- } \\
\text { ergiegesezt" is } \\
\text { supported } \\
\text { (based on } \\
\text { information } \\
\text { given from } \\
\text { both sides) }\end{array}$ & $\begin{array}{l}\text { Unter } \\
\text { Ber } \tilde{A}^{1} / 4 \text { cksichtigung } \\
\text { dieser Informationen, } \\
\text { inwieweit unterstützt } \\
\text { Du dieses Energiegesetz? }\end{array}$ & $\begin{array}{l}1=\text { Stark dagegen, } 2= \\
\text { Dagegen, } 3=\text { Eher } \\
\text { dagegen, } 4= \\
\text { Unentschieden, } 5=\text { Eher } \\
\text { dafür, } 6=\text { Dafür, } 7= \\
\text { Stark dafür }\end{array}$ & $\begin{array}{l}\text { Taking this information } \\
\text { into account, to what } \\
\text { extent do you support } \\
\text { the energy law? }\end{array}$ & $\begin{array}{l}1=\text { Strongly opposed, } 2 \\
=\text { Opposed, } 3= \\
\text { somewhat opposed, } 4= \\
\text { undecided, } 5=\text { somewhat } \\
\text { in favour, } 6=\text { in favour, } 7 \\
=\text { strongly in favour }\end{array}$ & & & & $\mathrm{x}$ & & & & & & & & & \\
\hline $\begin{array}{l}\text { support.pre.referendum } \\
\text {.ahv }\end{array}$ & $\begin{array}{l}\text { Degree to } \\
\text { which the } \\
\text { [Referendum] } \\
\text { is supported } \\
\text { (based on } \\
\text { information } \\
\text { given from } \\
\text { both sides) }\end{array}$ & $\begin{array}{l}\text { Unter } \\
\text { Ber } \tilde{A}^{1 / 4} \text { cksichtigung } \\
\text { dieser Informationen, } \\
\text { inwieweit unterstützt } \\
\text { Du dieses Energiegesetz? }\end{array}$ & $\begin{array}{l}1=\text { Stark dagegen, } 2= \\
\text { Dagegen, } 3=\text { Eher } \\
\text { dagegen, } 4= \\
\text { Unentschieden, } 5=\text { Eher } \\
\text { dafür, } 6=\text { Dafür, } 7= \\
\text { Stark dafür }\end{array}$ & $\begin{array}{l}\text { Taking this information } \\
\text { into account, to what } \\
\text { extent do you support } \\
\text { the [Referendum]? }\end{array}$ & $\begin{array}{l}1=\text { Strongly opposed, } 2 \\
=\text { Opposed, } 3= \\
\text { somewhat opposed, } 4= \\
\text { undecided, } 5=\text { somewhat } \\
\text { in favour, } 6=\text { in favour, } 7 \\
=\text { strongly in favour }\end{array}$ & & & & & & $\mathrm{x}$ & & & & & & & \\
\hline $\begin{array}{l}\text { support.pre.referendum } \\
\text {.geldspielgesetz }\end{array}$ & $\begin{array}{l}\text { Degree to } \\
\text { which the } \\
\text { [Referendum] } \\
\text { is supported } \\
\text { (based on } \\
\text { information } \\
\text { given from } \\
\text { both sides) }\end{array}$ & $\begin{array}{l}\text { Unter } \\
\text { Ber } \tilde{A}^{1} / 4 \text { cksichtigung } \\
\text { dieser Informationen, } \\
\text { inwieweit unterstützt } \\
\text { Du dieses Energiegesetz? }\end{array}$ & $\begin{array}{l}1=\text { Stark dagegen, } 2= \\
\text { Dagegen, } 3=\text { Eher } \\
\text { dagegen, } 4= \\
\text { Unentschieden, } 5=\text { Eher } \\
\text { dafür, } 6=\text { Dafür, } 7= \\
\text { Stark dafür }\end{array}$ & $\begin{array}{l}\text { Taking this information } \\
\text { into account, to what } \\
\text { extent do you support } \\
\text { the [Referendum]? }\end{array}$ & $\begin{array}{l}1=\text { Strongly opposed, } 2 \\
=\text { Opposed, } 3= \\
\text { somewhat opposed, } 4= \\
\text { undecided, } 5=\text { somewhat } \\
\text { in favour, } 6=\text { in favour, } 7 \\
=\text { strongly in favour }\end{array}$ & & & & & & & & & $\mathrm{x}$ & & & & \\
\hline $\begin{array}{l}\text { support.pre.referendum } \\
\text {.altersvorsorge }\end{array}$ & $\begin{array}{l}\text { Degree to } \\
\text { which the } \\
\text { [Referendum] } \\
\text { is supported } \\
\text { (based on } \\
\text { information } \\
\text { given from } \\
\text { both sides) }\end{array}$ & $\begin{array}{l}\text { Unter } \\
\text { Ber } \tilde{A}^{1} / 4 \text { cksichtigung } \\
\text { dieser Informationen, } \\
\text { inwieweit unterstützt } \\
\text { Du dieses Energiegesetz? }\end{array}$ & $\begin{array}{l}1=\text { Stark dagegen, } 2= \\
\text { Dagegen, } 3=\text { Eher } \\
\text { dagegen, } 4= \\
\text { Unentschieden, } 5=\text { Eher } \\
\text { dafür, } 6=\text { Dafür, } 7= \\
\text { Stark dafür }\end{array}$ & $\begin{array}{l}\text { Taking this information } \\
\text { into account, to what } \\
\text { extent do you support } \\
\text { the [Referendum]? }\end{array}$ & $\begin{array}{l}1=\text { Strongly opposed, } 2 \\
=\text { Opposed, } 3= \\
\text { somewhat opposed, } 4= \\
\text { undecided, } 5=\text { somewhat } \\
\text { in favour, } 6=\text { in favour, } 7 \\
=\text { strongly in favour }\end{array}$ & & & & & & $\mathrm{x}$ & & & & & & & \\
\hline $\begin{array}{l}\text { support.pre.referendum } \\
\text {.billag }\end{array}$ & $\begin{array}{l}\text { Degree to } \\
\text { which the } \\
\text { [Referendum] } \\
\text { is supported } \\
\text { (based on } \\
\text { information } \\
\text { given from } \\
\text { both sides) }\end{array}$ & $\begin{array}{l}\text { Unter } \\
\text { Ber } \tilde{A}^{1 / 4} \text { cksichtigung } \\
\text { dieser Informationen, } \\
\text { inwieweit unterstützt } \\
\text { Du dieses Energiegesetz? }\end{array}$ & $\begin{array}{l}1=\text { Stark dagegen, } 2= \\
\text { Dagegen, } 3=\text { Eher } \\
\text { dagegen, } 4= \\
\text { Unentschieden, } 5=\text { Eher } \\
\text { dafür, } 6=\text { Dafür, } 7= \\
\text { Stark dafür }\end{array}$ & $\begin{array}{l}\text { Taking this information } \\
\text { into account, to what } \\
\text { extent do you support } \\
\text { the [Referendum]? }\end{array}$ & $\begin{array}{l}1=\text { Strongly opposed, } 2 \\
=\text { Opposed, } 3= \\
\text { somewhat opposed, } 4= \\
\text { undecided, } 5=\text { somewhat } \\
\text { in favour, } 6=\text { in favour, } 7 \\
=\text { strongly in favour }\end{array}$ & & & & & & & $\mathrm{x}$ & & & & & & \\
\hline $\begin{array}{l}\text { support.pre.referendum } \\
\text {.vollgeld }\end{array}$ & $\begin{array}{l}\text { Degree to } \\
\text { which the } \\
\text { [Referendum] } \\
\text { is supported } \\
\text { (based on } \\
\text { information } \\
\text { given from } \\
\text { both sides) }\end{array}$ & $\begin{array}{l}\text { Unter } \\
\text { BerÃ } \tilde{A}^{1 / 4 k s i c h t i g u n g} \\
\text { dieser Informationen, } \\
\text { inwieweit unterstützt } \\
\text { Du dieses Energiegesetz? }\end{array}$ & $\begin{array}{l}1=\text { Stark dagegen, } 2= \\
\text { Dagegen, } 3=\text { Eher } \\
\text { dagegen, } 4= \\
\text { Unentschieden, } 5=\text { Eher } \\
\text { dafür, } 6=\text { Dafür, } 7= \\
\text { Stark dafür }\end{array}$ & $\begin{array}{l}\text { Taking this information } \\
\text { into account, to what } \\
\text { extent do you support } \\
\text { the [Referendum]? }\end{array}$ & $\begin{array}{l}1 \text { = Strongly opposed, } 2 \\
=\text { Opposed, } 3= \\
\text { somewhat opposed, } 4= \\
\text { undecided, } 5=\text { somewhat } \\
\text { in favour, } 6=\text { in favour, } 7 \\
=\text { strongly in favour }\end{array}$ & & & & & & & & & $\mathrm{x}$ & & & & \\
\hline
\end{tabular}




\begin{tabular}{|c|c|c|c|c|c|c|c|c|c|c|c|c|c|c|c|c|c|c|}
\hline VarName & VariableLabel & WordingDE & ValueLabelsDE_Linked & WordingEN & ValueLabelsEN_Linked & L1 & L1F L2 & L3 & L4 & L5 & L6 & $\mathrm{L} 7$ & L8 & L9 & L10 & L11 & $\mathrm{L} 12$ & 2 L13 L14 \\
\hline $\begin{array}{l}\text { support.pre.referendum } \\
\text {.ernahrung }\end{array}$ & $\begin{array}{l}\text { Degree to } \\
\text { which the } \\
\text { [Referendum] } \\
\text { is supported } \\
\text { (based on } \\
\text { information } \\
\text { given from } \\
\text { both sides) }\end{array}$ & $\begin{array}{l}\text { Unter } \\
\text { Ber } \tilde{A}^{1 / 4} / \text { cksichtigung } \\
\text { dieser Informationen, } \\
\text { inwieweit unterstützt } \\
\text { Du dieses Energiegesetz? }\end{array}$ & $\begin{array}{l}1=\text { Stark dagegen, } 2= \\
\text { Dagegen, } 3=\text { Eher } \\
\text { dagegen, } 4= \\
\text { Unentschieden, } 5=\text { Eher } \\
\text { dafür, } 6=\text { Dafür, } 7= \\
\text { Stark dafür }\end{array}$ & $\begin{array}{l}\text { Taking this information } \\
\text { into account, to what } \\
\text { extent do you support } \\
\text { the [Referendum]? }\end{array}$ & $\begin{array}{l}1=\text { Strongly opposed, } 2 \\
=\text { Opposed, } 3= \\
\text { somewhat opposed, } 4= \\
\text { undecided, } 5=\text { somewhat } \\
\text { in favour, } 6=\text { in favour, } 7 \\
=\text { strongly in favour }\end{array}$ & & & & & & & & & & $\mathrm{x}$ & $\mathrm{x}$ & $\mathrm{x}$ & $\mathrm{x}$ \\
\hline $\begin{array}{l}\text { support.pre.referendum } \\
\text {.fairfood }\end{array}$ & $\begin{array}{l}\text { Degree to } \\
\text { which the } \\
\text { [Referendum] } \\
\text { is supported } \\
\text { (based on } \\
\text { information } \\
\text { given from } \\
\text { both sides) }\end{array}$ & $\begin{array}{l}\text { Unter } \\
\text { BerÃ } \tilde{1}^{1 / 4 k s i c h t i g u n g} \\
\text { dieser Informationen, } \\
\text { inwieweit unterstützt } \\
\text { Du dieses Energiegesetz? }\end{array}$ & $\begin{array}{l}1=\text { Stark dagegen, } 2= \\
\text { Dagegen, } 3=\text { Eher } \\
\text { dagegen, } 4= \\
\text { Unentschieden, } 5=\text { Eher } \\
\text { dafür, } 6=\text { Dafür, } 7= \\
\text { Stark dafür }\end{array}$ & $\begin{array}{l}\text { Taking this information } \\
\text { into account, to what } \\
\text { extent do you support } \\
\text { the [Referendum]? }\end{array}$ & $\begin{array}{l}1 \text { = Strongly opposed, } 2 \\
=\text { Opposed, } 3= \\
\text { somewhat opposed, } 4= \\
\text { undecided, } 5=\text { somewhat } \\
\text { in favour, } 6=\text { in favour, } 7 \\
=\text { strongly in favour }\end{array}$ & & & & & & & & & & $\mathrm{X}$ & $\mathrm{X}$ & $\mathrm{X}$ & $\mathrm{X}$ \\
\hline $\begin{array}{l}\text { support.pre.referendum } \\
\text {.velo }\end{array}$ & $\begin{array}{l}\text { Degree to } \\
\text { which the } \\
\text { [Referendum] } \\
\text { is supported } \\
\text { (based on } \\
\text { information } \\
\text { given from } \\
\text { both sides) }\end{array}$ & $\begin{array}{l}\text { Unter } \\
\text { Ber } \tilde{A}^{1 / 4} \text { cksichtigung } \\
\text { dieser Informationen, } \\
\text { inwieweit unterstützt } \\
\text { Du dieses Energiegesetz? }\end{array}$ & $\begin{array}{l}1=\text { Stark dagegen, } 2= \\
\text { Dagegen, } 3=\text { Eher } \\
\text { dagegen, } 4= \\
\text { Unentschieden, } 5=\text { Eher } \\
\text { dafür, } 6=\text { Dafür, } 7= \\
\text { Stark dafür }\end{array}$ & $\begin{array}{l}\text { Taking this information } \\
\text { into account, to what } \\
\text { extent do you support } \\
\text { the [Referendum]? }\end{array}$ & $\begin{array}{l}1=\text { Strongly opposed, } 2 \\
=\text { Opposed, } 3= \\
\text { somewhat opposed, } 4= \\
\text { undecided, } 5=\text { somewhat } \\
\text { in favour, } 6=\text { in favour, } 7 \\
=\text { strongly in favour }\end{array}$ & & & & & & & & & & $\mathrm{x}$ & $\mathrm{x}$ & $\mathrm{x}$ & $\mathrm{x}$ \\
\hline $\begin{array}{l}\text { vote.pre.referendum } \\
\text {.energiegesetz }\end{array}$ & $\begin{array}{l}\text { Asks if } \\
\text { participant } \\
\text { wants to vote } \\
\text { about the "En- } \\
\text { ergiegesetz" }\end{array}$ & $\begin{array}{l}\text { Hast Du vor über das } \\
\text { Referendum gegen das } \\
\text { Energiegesetz } \\
\text { abzustimmen? }\end{array}$ & $\begin{array}{l}1=\mathrm{Ja} \text {, ich stimme gegen } \\
\text { das Energiegesetz ab, } 2= \\
\mathrm{Ja} \text {, ich stimme für das } \\
\text { Energiegesetz ab, } 3= \\
\text { Nein, ich stimme nicht, } 4 \\
=\text { Kann nicht abstimmen }\end{array}$ & $\begin{array}{l}\text { Do you plan to vote in } \\
\text { the referendum against } \\
\text { the energy law? }\end{array}$ & $\begin{array}{l}1=\text { Yes, } I \text { am voting } \\
\text { against the energy law, } 2 \\
=\text { Yes, I am voting for the } \\
\text { energy law, } 3=\text { No, I am } \\
\text { not voting, } 4=\mathrm{I} \text { do not } \\
\text { have the right to vote. }\end{array}$ & & & & $\mathrm{x}$ & & & & & & & & & \\
\hline $\begin{array}{l}\text { vote.pre.referendum } \\
\text {.ahv }\end{array}$ & $\begin{array}{l}\text { Asks if } \\
\text { participant } \\
\text { wants to vote } \\
\text { about the } \\
\text { [Referendum] }\end{array}$ & $\begin{array}{l}\text { Hast Du vor über das } \\
\text { Referendum gegen das } \\
\text { [Referendum] } \\
\text { abzustimmen? }\end{array}$ & $\begin{array}{l}1=\mathrm{Ja}, \text { ich stimme gegen } \\
\text { das [Referendum] ab, } 2= \\
\mathrm{Ja}, \text { ich stimme für das } \\
\text { [Referendum] ab, } 3= \\
\text { Nein, ich stimme nicht, } 4 \\
=\text { Kann nicht abstimmen }\end{array}$ & $\begin{array}{l}\text { Do you plan to vote in } \\
\text { the referendum against } \\
\text { the [Referendum]? }\end{array}$ & $\begin{array}{l}1=\text { Yes, I am voting } \\
\text { against the [Referendum], } \\
2=\text { Yes, I am voting for } \\
\text { the [Referendum], } 3=\text { No, } \\
\text { I am not voting, } 4=\mathrm{I} \text { do } \\
\text { not have the right to } \\
\text { vote. }\end{array}$ & & & & & & $\mathrm{x}$ & & & & & & & \\
\hline $\begin{array}{l}\text { vote.pre.referendum } \\
\text {.altersvorsorge }\end{array}$ & $\begin{array}{l}\text { Asks if } \\
\text { participant } \\
\text { wants to vote } \\
\text { about the } \\
\text { [Referendum] }\end{array}$ & $\begin{array}{l}\text { Hast Du vor über das } \\
\text { Referendum gegen das } \\
\text { [Referendum] } \\
\text { abzustimmen? }\end{array}$ & $\begin{array}{l}1=\mathrm{Ja}, \text { ich stimme gegen } \\
\text { das [Referendum] ab, } 2= \\
\mathrm{Ja} \text {, ich stimme für das } \\
\text { [Referendum] ab, } 3= \\
\text { Nein, ich stimme nicht, } 4 \\
=\text { Kann nicht abstimmen }\end{array}$ & $\begin{array}{l}\text { Do you plan to vote in } \\
\text { the referendum against } \\
\text { the [Referendum]? }\end{array}$ & $\begin{array}{l}1=\text { Yes, I am voting } \\
\text { against the }[\text { Referendum], } \\
2=\text { Yes, I am voting for } \\
\text { the [Referendum], } 3=\text { No, } \\
I \text { am not voting, } 4=\mathrm{I} \text { do } \\
\text { not have the right to } \\
\text { vote. }\end{array}$ & & & & & & $\mathrm{X}$ & & & & & & & \\
\hline $\begin{array}{l}\text { vote.pre.referendum } \\
\text {.geldspielgesetz }\end{array}$ & $\begin{array}{l}\text { Asks if } \\
\text { participant } \\
\text { wants to vote } \\
\text { about the } \\
\text { [Referendum] }\end{array}$ & $\begin{array}{l}\text { Hast Du vor über das } \\
\text { Referendum gegen das } \\
\text { [Referendum] } \\
\text { abzustimmen? }\end{array}$ & $\begin{array}{l}1=\mathrm{Ja} \text {, ich stimme gegen } \\
\text { das [Referendum] ab, } 2= \\
\mathrm{Ja}, \text { ich stimme für das } \\
{[\text { Referendum] ab, } 3=} \\
\text { Nein, ich stimme nicht, } 4 \\
=\text { Kann nicht abstimmen }\end{array}$ & $\begin{array}{l}\text { Do you plan to vote in } \\
\text { the referendum against } \\
\text { the [Referendum]? }\end{array}$ & $\begin{array}{l}1=\text { Yes, I am voting } \\
\text { against the [Referendum], } \\
2=\text { Yes, I am voting for } \\
\text { the }[\text { Referendum }], 3=\text { No, } \\
\text { I am not voting, } 4=\mathrm{I} \text { do } \\
\text { not have the right to } \\
\text { vote. }\end{array}$ & & & & & & & & & $\mathrm{x}$ & & & & \\
\hline $\begin{array}{l}\text { vote.pre.referendum } \\
\text {.billag }\end{array}$ & $\begin{array}{l}\text { Asks if } \\
\text { participant } \\
\text { wants to vote } \\
\text { about the } \\
\text { [Referendum] }\end{array}$ & $\begin{array}{l}\text { Hast Du vor über das } \\
\text { Referendum gegen das } \\
\text { [Referendum] } \\
\text { abzustimmen? }\end{array}$ & $\begin{array}{l}1=\mathrm{Ja}, \text { ich stimme gegen } \\
\text { das [Referendum] ab, } 2= \\
\mathrm{Ja}, \text { ich stimme für das } \\
{[\text { Referendum] ab, } 3=} \\
\text { Nein, ich stimme nicht, } 4 \\
=\text { Kann nicht abstimmen }\end{array}$ & $\begin{array}{l}\text { Do you plan to vote in } \\
\text { the referendum against } \\
\text { the [Referendum]? }\end{array}$ & $\begin{array}{l}1=\text { Yes, I am voting } \\
\text { against the [Referendum], } \\
2=\text { Yes, I am voting for } \\
\text { the [Referendum], } 3=\text { No, } \\
\text { I am not voting, } 4=\mathrm{I} \text { do } \\
\text { not have the right to } \\
\text { vote. }\end{array}$ & & & & & & & $\mathrm{X}$ & & & & & & \\
\hline
\end{tabular}




\begin{tabular}{|c|c|c|c|c|c|c|c|c|c|c|c|c|c|c|c|c|c|c|}
\hline VarName & VariableLabel & WordingDE & ValueLabelsDE_Linked & WordingEN & ValueLabelsEN_Linked & L1 & L1F L2 & L3 & $\mathrm{L} 4$ & L5 & L6 & L7 & L8 & L9 & & 10 L11 & $\mathrm{L} 12$ & 2 L13 L14 \\
\hline $\begin{array}{l}\text { vote.pre.referendum } \\
\text {.vollgeld }\end{array}$ & $\begin{array}{l}\text { Asks if } \\
\text { participant } \\
\text { wants to vote } \\
\text { about the } \\
\text { [Referendum] }\end{array}$ & $\begin{array}{l}\text { Hast Du vor über das } \\
\text { Referendum gegen das } \\
\text { [Referendum] } \\
\text { abzustimmen? }\end{array}$ & $\begin{array}{l}1=\mathrm{Ja}, \text { ich stimme gegen } \\
\text { das [Referendum] ab, } 2= \\
\mathrm{Ja}, \text { ich stimme für das } \\
{[\text { Referendum] ab, } 3=} \\
\text { Nein, ich stimme nicht, } 4 \\
=\text { Kann nicht abstimmen }\end{array}$ & $\begin{array}{l}\text { Do you plan to vote in } \\
\text { the referendum against } \\
\text { the [Referendum]? }\end{array}$ & $\begin{array}{l}1=\text { Yes, I am voting } \\
\text { against the [Referendum], } \\
2=\text { Yes, I am voting for } \\
\text { the [Referendum] } 3=\text { No, } \\
\text { I am not voting, } 4=\mathrm{I} \text { do } \\
\text { not have the right to } \\
\text { vote. }\end{array}$ & & & & & & & & & $\mathrm{x}$ & & & & \\
\hline $\begin{array}{l}\text { vote.pre.referendum } \\
\text { ernahrung }\end{array}$ & $\begin{array}{l}\text { Asks if } \\
\text { participant } \\
\text { wants to vote } \\
\text { about the } \\
\text { [Referendum] }\end{array}$ & $\begin{array}{l}\text { Hast Du vor über das } \\
\text { Referendum gegen das } \\
\text { [Referendum] } \\
\text { abzustimmen? }\end{array}$ & $\begin{array}{l}1=\mathrm{Ja} \text {, ich stimme gegen } \\
\text { das [Referendum] ab, } 2= \\
\mathrm{Ja}, \text { ich stimme für das } \\
\text { [Referendum] ab, } 3= \\
\text { Nein, ich stimme nicht, } 4 \\
=\text { Kann nicht abstimmen }\end{array}$ & $\begin{array}{l}\text { Do you plan to vote in } \\
\text { the referendum against } \\
\text { the [Referendum]? }\end{array}$ & $\begin{array}{l}1=\text { Yes, I am voting } \\
\text { against the [Referendum], } \\
2=\text { Yes, I am voting for } \\
\text { the }[\text { Referendum], } 3=\text { No, } \\
\text { I am not voting, } 4=\mathrm{I} \text { do } \\
\text { not have the right to } \\
\text { vote. }\end{array}$ & & & & & & & & & & $\mathrm{x}$ & $\mathrm{x}$ & $\mathrm{x}$ & $\mathrm{x}$ \\
\hline $\begin{array}{l}\text { vote.pre.referendum } \\
\text {.fairfood }\end{array}$ & $\begin{array}{l}\text { Asks if } \\
\text { participant } \\
\text { wants to vote } \\
\text { about the } \\
\text { [Referendum] }\end{array}$ & $\begin{array}{l}\text { Hast Du vor über das } \\
\text { Referendum gegen das } \\
\text { [Referendum] } \\
\text { abzustimmen? }\end{array}$ & $\begin{array}{l}1=\mathrm{Ja}, \text { ich stimme gegen } \\
\text { das [Referendum] ab, } 2= \\
\mathrm{Ja}, \text { ich stimme für das } \\
\text { [Referendum] ab, } 3= \\
\text { Nein, ich stimme nicht, } 4 \\
=\text { Kann nicht abstimmen }\end{array}$ & $\begin{array}{l}\text { Do you plan to vote in } \\
\text { the referendum against } \\
\text { the [Referendum]? }\end{array}$ & $\begin{array}{l}1=\text { Yes, I am voting } \\
\text { against the }[\text { Referendum], } \\
2=\text { Yes, I am voting for } \\
\text { the [Referendum], } 3=\text { No, } \\
\text { I am not voting, } 4=\mathrm{I} \text { do } \\
\text { not have the right to } \\
\text { vote. }\end{array}$ & & & & & & & & & & $\mathrm{x}$ & $\mathrm{x}$ & $\mathrm{x}$ & $\mathrm{x}$ \\
\hline $\begin{array}{l}\text { vote.pre.referendum } \\
\text {.velo }\end{array}$ & $\begin{array}{l}\text { Asks if } \\
\text { participant } \\
\text { wants to vote } \\
\text { about the } \\
\text { [Referendum] }\end{array}$ & $\begin{array}{l}\text { Hast Du vor über das } \\
\text { Referendum gegen das } \\
\text { [Referendum] } \\
\text { abzustimmen? }\end{array}$ & $\begin{array}{l}1=\mathrm{Ja}, \text { ich stimme gegen } \\
\text { das [Referendum] ab, } 2= \\
\mathrm{Ja} \text {, ich stimme für das } \\
\text { [Referendum] ab, } 3= \\
\text { Nein, ich stimme nicht, } 4 \\
=\text { Kann nicht abstimmen }\end{array}$ & $\begin{array}{l}\text { Do you plan to vote in } \\
\text { the referendum against } \\
\text { the [Referendum]? }\end{array}$ & $\begin{array}{l}1=\text { Yes, I am voting } \\
\text { against the }[\text { Referendum], } \\
2=\text { Yes, I am voting for } \\
\text { the }[\text { Referendum], } 3=\text { No, } \\
\text { I am not voting, } 4=\mathrm{I} \text { do } \\
\text { not have the right to } \\
\text { vote. }\end{array}$ & & & & & & & & & & $\mathrm{x}$ & $\mathrm{x}$ & $\mathrm{x}$ & $\mathrm{x}$ \\
\hline $\begin{array}{l}\text { media.referendum } \\
\text {.newspaper }\end{array}$ & & & & & & & & & & & & & & & $\mathrm{x}$ & $\mathrm{x}$ & $\mathrm{x}$ & $\mathrm{x}$ \\
\hline media.referendum .tv & & & & & & & & & & & & & & & $\mathrm{x}$ & $\mathrm{x}$ & $\mathrm{x}$ & $\mathrm{x}$ \\
\hline $\begin{array}{l}\text { media.referendum } \\
\text {.radio }\end{array}$ & & & & & & & & & & & & & & & $\mathrm{x}$ & $\mathrm{x}$ & $\mathrm{x}$ & $\mathrm{x}$ \\
\hline $\begin{array}{l}\text { media.referendum } \\
\text {.internet }\end{array}$ & & & & & & & & & & & & & & & $\mathrm{x}$ & $\mathrm{x}$ & $\mathrm{x}$ & $\mathrm{x}$ \\
\hline $\begin{array}{l}\text { media.referendum } \\
\text {.social.media }\end{array}$ & & & & & & & & & & & & & & & $\mathrm{x}$ & $\mathrm{x}$ & $\mathrm{x}$ & $\mathrm{x}$ \\
\hline $\begin{array}{l}\text { media.referendum } \\
\text { aggregator }\end{array}$ & & & & & & & & & & & & & & & $\mathrm{x}$ & $\mathrm{x}$ & $\mathrm{x}$ & $\mathrm{x}$ \\
\hline $\begin{array}{l}\text { media.referendum } \\
\text {.other }\end{array}$ & & & & & & & & & & & & & & & $\mathrm{x}$ & $\mathrm{x}$ & $\mathrm{x}$ & $\mathrm{x}$ \\
\hline $\begin{array}{l}\text { media.referendum } \\
\text {.other.text }\end{array}$ & & & & & & & & & & & & & & & $\mathrm{x}$ & $\mathrm{x}$ & $\mathrm{x}$ & $\mathrm{x}$ \\
\hline acc.1 & & $\begin{array}{l}\text { Ich habe einen Account } \\
\text { - Facebook }\end{array}$ & $1=\mathrm{Ja}, 2=$ Nein & $\begin{array}{l}\text { I have an account - } \\
\text { Facebook }\end{array}$ & $1=\mathrm{Yes}, 2=\mathrm{No}$ & & & & & & & & & & & $\mathrm{x}$ & $\mathrm{x}$ & $\mathrm{x}$ \\
\hline acc. 2 & & $\begin{array}{l}\text { Ich habe einen Account } \\
\text { - Facebook Messenger }\end{array}$ & $1=\mathrm{Ja}, 2=$ Nein & $\begin{array}{l}\text { I have an account - } \\
\text { Facebook Messenger }\end{array}$ & $1=\mathrm{Yes}, 2=\mathrm{No}$ & & & & & & & & & & & $\mathrm{x}$ & $\mathrm{x}$ & $\mathrm{x}$ \\
\hline acc. 3 & & $\begin{array}{l}\text { Ich habe einen Account } \\
\text { - WhatsApp }\end{array}$ & $1=\mathrm{Ja}, 2=$ Nein & $\begin{array}{l}\text { I have an account - } \\
\text { WhatsApp }\end{array}$ & $1=\mathrm{Yes}, 2=\mathrm{No}$ & & & & & & & & & & & $\mathrm{x}$ & $\mathrm{x}$ & $\mathrm{x}$ \\
\hline acc. 4 & & $\begin{array}{l}\text { Ich habe einen Account } \\
\text { - Instagram }\end{array}$ & $1=\mathrm{Ja}, 2=$ Nein & $\begin{array}{l}\text { I have an account - } \\
\text { Instagram }\end{array}$ & $1=\mathrm{Yes}, 2=\mathrm{No}$ & & & & & & & & & & & $\mathrm{x}$ & $\mathrm{x}$ & $\mathrm{x}$ \\
\hline acc. 5 & & $\begin{array}{l}\text { Ich habe einen Account } \\
\text { - Twitter }\end{array}$ & $1=\mathrm{Ja}, 2=$ Nein & $\begin{array}{l}\text { I have an account - } \\
\text { Twitter }\end{array}$ & $1=\mathrm{Yes}, 2=\mathrm{No}$ & & & & & & & & & & & $\mathrm{x}$ & $\mathrm{x}$ & $\mathrm{x}$ \\
\hline acc. 6 & & $\begin{array}{l}\text { Ich habe einen Account } \\
\text { - Snapchat }\end{array}$ & $1=\mathrm{Ja}, 2=$ Nein & $\begin{array}{l}\text { I have an account - } \\
\text { Snapchat }\end{array}$ & $1=$ Yes, $2=$ No & & & & & & & & & & & $\mathrm{x}$ & $\mathrm{x}$ & $\mathrm{x}$ \\
\hline acc. 7 & & $\begin{array}{l}\text { Ich habe einen Account } \\
\text { - Reddit }\end{array}$ & $1=\mathrm{Ja}, 2=$ Nein & $\begin{array}{l}\text { I have an account - } \\
\text { Reddit }\end{array}$ & $1=\mathrm{Yes}, 2=\mathrm{No}$ & & & & & & & & & & & $\mathrm{x}$ & $\mathrm{x}$ & $\mathrm{x}$ \\
\hline acc. 8 & & $\begin{array}{l}\text { Ich habe einen Account } \\
\text { - Linkedin }\end{array}$ & $1=\mathrm{Ja}, 2=$ Nein & $\begin{array}{l}\text { I have an account - } \\
\text { Linkedin }\end{array}$ & $1=\mathrm{Yes}, 2=\mathrm{No}$ & & & & & & & & & & & $\mathrm{x}$ & $\mathrm{x}$ & $\mathrm{x}$ \\
\hline acc. 9 & & $\begin{array}{l}\text { Ich habe einen Account } \\
\text { - Signal }\end{array}$ & $1=\mathrm{Ja}, 2=$ Nein & $\begin{array}{l}\text { I have an account } \\
\text { signal }\end{array}$ & $1=\mathrm{Yes}, 2=\mathrm{No}$ & & & & & & & & & & & $\mathrm{x}$ & $\mathrm{x}$ & $\mathrm{x}$ \\
\hline
\end{tabular}




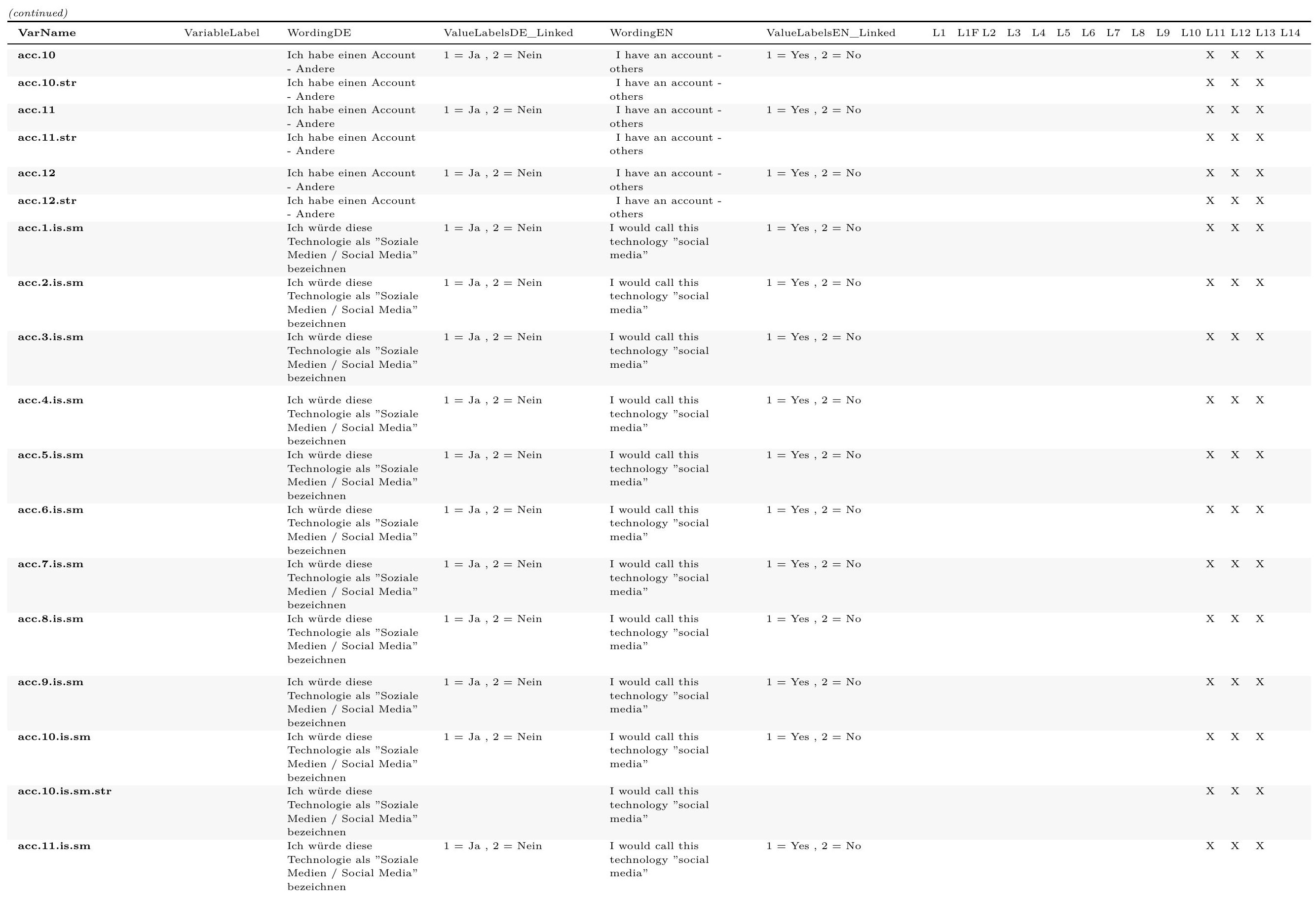




\begin{tabular}{|c|c|c|c|c|c|c|c|c|c|c|c|c|c|c|c|c|c|}
\hline VarName & VariableLabel & WordingDE & ValueLabelsDE_Linked & WordingEN & ValueLabelsEN_Linked & $\mathrm{L} 1$ & L1F L2 & L3 & $\mathrm{L} 4$ & L5 & L6 & L7 & L8 & L9 & L10 L11 & $1 \mathrm{~L} 12$ & 2 L13 L14 \\
\hline acc.11.is.sm.str & & $\begin{array}{l}\text { Ich würde diese } \\
\text { Technologie als "Soziale } \\
\text { Medien / Social Media" } \\
\text { bezeichnen }\end{array}$ & & $\begin{array}{l}\text { I would call this } \\
\text { technology "social } \\
\text { media" }\end{array}$ & & & & & & & & & & & $\mathrm{x}$ & $\mathrm{x}$ & $\mathrm{x}$ \\
\hline acc.12.is.sm & & $\begin{array}{l}\text { Ich würde diese } \\
\text { Technologie als "Soziale } \\
\text { Medien / Social Media" } \\
\text { bezeichnen }\end{array}$ & $1=\mathrm{Ja}, 2=$ Nein & $\begin{array}{l}\text { I would call this } \\
\text { technology "social } \\
\text { media" }\end{array}$ & $1=\mathrm{Yes}, 2=\mathrm{No}$ & & & & & & & & & & $\mathrm{x}$ & $\mathrm{x}$ & $\mathrm{x}$ \\
\hline acc.12.is.sm.str & & $\begin{array}{l}\text { Ich würde diese } \\
\text { Technologie als "Soziale } \\
\text { Medien / Social Media" } \\
\text { bezeichnen }\end{array}$ & & $\begin{array}{l}\text { I would call this } \\
\text { technology "social } \\
\text { media" }\end{array}$ & & & & & & & & & & & $\mathrm{x}$ & $\mathrm{x}$ & $\mathrm{x}$ \\
\hline acc.1.freq & & $\begin{array}{l}\text { Wie oft bist Du pro Tag } \\
\text { auf dieser Plattform? }\end{array}$ & & $\begin{array}{l}\text { How many times a day } \\
\text { are you on this } \\
\text { platform? }\end{array}$ & & & & & & & & & & & $\mathrm{x}$ & $\mathrm{x}$ & $\mathrm{x}$ \\
\hline acc.2.freq & & $\begin{array}{l}\text { Wie oft bist Du pro Tag } \\
\text { auf dieser Plattform? }\end{array}$ & & $\begin{array}{l}\text { How many times a day } \\
\text { are you on this } \\
\text { platform? }\end{array}$ & & & & & & & & & & & $\mathrm{x}$ & $\mathrm{x}$ & $\mathrm{x}$ \\
\hline acc.3.freq & & $\begin{array}{l}\text { Wie oft bist Du pro Tag } \\
\text { auf dieser Plattform? }\end{array}$ & & $\begin{array}{l}\text { How many times a day } \\
\text { are you on this } \\
\text { platform? }\end{array}$ & & & & & & & & & & & $\mathrm{x}$ & $\mathrm{x}$ & $\mathrm{x}$ \\
\hline acc.4.freq & & $\begin{array}{l}\text { Wie oft bist Du pro Tag } \\
\text { auf dieser Plattform? }\end{array}$ & & $\begin{array}{l}\text { How many times a day } \\
\text { are you on this } \\
\text { platform? }\end{array}$ & & & & & & & & & & & $\mathrm{x}$ & $\mathrm{x}$ & $\mathrm{x}$ \\
\hline acc.5.freq & & $\begin{array}{l}\text { Wie oft bist Du pro Tag } \\
\text { auf dieser Plattform? }\end{array}$ & & $\begin{array}{l}\text { How many times a day } \\
\text { are you on this } \\
\text { platform? }\end{array}$ & & & & & & & & & & & $\mathrm{x}$ & $\mathrm{x}$ & $\mathrm{x}$ \\
\hline acc.6.freq & & $\begin{array}{l}\text { Wie oft bist Du pro Tag } \\
\text { auf dieser Plattform? }\end{array}$ & & $\begin{array}{l}\text { How many times a day } \\
\text { are you on this } \\
\text { platform? }\end{array}$ & & & & & & & & & & & $\mathrm{x}$ & $\mathrm{x}$ & $\mathrm{x}$ \\
\hline acc.7.freq & & $\begin{array}{l}\text { Wie oft bist Du pro Tag } \\
\text { auf dieser Plattform? }\end{array}$ & & $\begin{array}{l}\text { How many times a day } \\
\text { are you on this } \\
\text { platform? }\end{array}$ & & & & & & & & & & & $\mathrm{x}$ & $\mathrm{x}$ & $\mathrm{x}$ \\
\hline acc.8.freq & & $\begin{array}{l}\text { Wie oft bist Du pro Tag } \\
\text { auf dieser Plattform? }\end{array}$ & & $\begin{array}{l}\text { How many times a day } \\
\text { are you on this } \\
\text { platform? }\end{array}$ & & & & & & & & & & & $\mathrm{x}$ & $\mathrm{x}$ & $\mathrm{x}$ \\
\hline acc.9.freq & & $\begin{array}{l}\text { Wie oft bist Du pro Tag } \\
\text { auf dieser Plattform? }\end{array}$ & & $\begin{array}{l}\text { How many times a day } \\
\text { are you on this } \\
\text { platform? }\end{array}$ & & & & & & & & & & & $\mathrm{x}$ & $\mathrm{x}$ & $\mathrm{x}$ \\
\hline acc.10.freq.str & & $\begin{array}{l}\text { Wie oft bist Du pro Tag } \\
\text { auf dieser Plattform? }\end{array}$ & & $\begin{array}{l}\text { How many times a day } \\
\text { are you on this } \\
\text { platform? }\end{array}$ & & & & & & & & & & & $\mathrm{x}$ & $\mathrm{x}$ & $\mathrm{x}$ \\
\hline acc.10.freq & & $\begin{array}{l}\text { Wie oft bist Du pro Tag } \\
\text { auf dieser Plattform? }\end{array}$ & & $\begin{array}{l}\text { How many times a day } \\
\text { are you on this } \\
\text { platform? }\end{array}$ & & & & & & & & & & & $\mathrm{x}$ & $\mathrm{x}$ & $\mathrm{x}$ \\
\hline acc.11.freq.str & & $\begin{array}{l}\text { Wie oft bist Du pro Tag } \\
\text { auf dieser Plattform? }\end{array}$ & & $\begin{array}{l}\text { How many times a day } \\
\text { are you on this } \\
\text { platform? }\end{array}$ & & & & & & & & & & & $\mathrm{x}$ & $\mathrm{x}$ & $\mathrm{x}$ \\
\hline acc.freq. 11 & & $\begin{array}{l}\text { Wie oft bist Du pro Tag } \\
\text { auf dieser Plattform? }\end{array}$ & & $\begin{array}{l}\text { How many times a day } \\
\text { are you on this } \\
\text { platform? }\end{array}$ & & & & & & & & & & & $\mathrm{x}$ & $\mathrm{x}$ & $\mathrm{x}$ \\
\hline acc.12.freq.str & & $\begin{array}{l}\text { Wie oft bist Du pro Tag } \\
\text { auf dieser Plattform? }\end{array}$ & & $\begin{array}{l}\text { How many times a day } \\
\text { are you on this } \\
\text { platform? }\end{array}$ & & & & & & & & & & & $\mathrm{x}$ & $\mathrm{x}$ & $\mathrm{x}$ \\
\hline acc.12.freq & & $\begin{array}{l}\text { Wie oft bist Du pro Tag } \\
\text { auf dieser Plattform? }\end{array}$ & & $\begin{array}{l}\text { How many times a day } \\
\text { are you on this } \\
\text { platform? }\end{array}$ & & & & & & & & & & & $\mathrm{x}$ & $\mathrm{x}$ & $\mathrm{x}$ \\
\hline acc.1.duration & & $\begin{array}{l}\text { Wieviel Zeit verbringst } \\
\text { Du auf dieser Plattform? }\end{array}$ & & $\begin{array}{l}\text { How much time do you } \\
\text { spend on this platform? }\end{array}$ & & & & & & & & & & & $\mathrm{x}$ & $\mathrm{x}$ & $\mathrm{x}$ \\
\hline acc.2.duration & & $\begin{array}{l}\text { Wieviel Zeit verbringst } \\
\text { Du auf dieser Plattform? }\end{array}$ & & $\begin{array}{l}\text { How much time do you } \\
\text { spend on this platform? }\end{array}$ & & & & & & & & & & & $\mathrm{x}$ & $\mathrm{x}$ & $\mathrm{x}$ \\
\hline
\end{tabular}




\begin{tabular}{|c|c|c|c|c|c|c|c|c|c|c|c|c|c|c|c|c|c|}
\hline VarName & VariableLabel & WordingDE & ValueLabelsDE_Linked & WordingEN & ValueLabelsEN_Linked & $\mathrm{L} 1$ & L1F L2 & L3 & $\mathrm{L} 4$ & L5 & L6 & $\mathrm{L} 7$ & L8 & L9 & L10 L11 & $\mathrm{L} 12$ & L13 L14 \\
\hline acc.3.duration & & $\begin{array}{l}\text { Wieviel Zeit verbringst } \\
\text { Du auf dieser Plattform? }\end{array}$ & & $\begin{array}{l}\text { How much time do you } \\
\text { spend on this platform? }\end{array}$ & & & & & & & & & & & $\mathrm{x}$ & $\mathrm{x}$ & $\mathrm{x}$ \\
\hline acc.4.duration & & $\begin{array}{l}\text { Wieviel Zeit verbringst } \\
\text { Du auf dieser Plattform? }\end{array}$ & & $\begin{array}{l}\text { How much time do you } \\
\text { spend on this platform? }\end{array}$ & & & & & & & & & & & $\mathrm{x}$ & $\mathrm{x}$ & $\mathrm{x}$ \\
\hline acc.5.duration & & $\begin{array}{l}\text { Wieviel Zeit verbringst } \\
\text { Du auf dieser Plattform? }\end{array}$ & & $\begin{array}{l}\text { How much time do you } \\
\text { spend on this platform? }\end{array}$ & & & & & & & & & & & $\mathrm{x}$ & $\mathrm{x}$ & $\mathrm{x}$ \\
\hline acc.6.duration & & $\begin{array}{l}\text { Wieviel Zeit verbringst } \\
\text { Du auf dieser Plattform? }\end{array}$ & & $\begin{array}{l}\text { How much time do you } \\
\text { spend on this platform? }\end{array}$ & & & & & & & & & & & $\mathrm{x}$ & $\mathrm{x}$ & $\mathrm{x}$ \\
\hline acc.7.duration & & $\begin{array}{l}\text { Wieviel Zeit verbringst } \\
\text { Du auf dieser Plattform? }\end{array}$ & & $\begin{array}{l}\text { How much time do you } \\
\text { spend on this platform? }\end{array}$ & & & & & & & & & & & $\mathrm{x}$ & $\mathrm{x}$ & $\mathrm{x}$ \\
\hline acc.8.duration & & $\begin{array}{l}\text { Wieviel Zeit verbringst } \\
\text { Du auf dieser Plattform? }\end{array}$ & & $\begin{array}{l}\text { How much time do you } \\
\text { spend on this platform? }\end{array}$ & & & & & & & & & & & $\mathrm{x}$ & $\mathrm{x}$ & $\mathrm{x}$ \\
\hline acc.9.duration & & $\begin{array}{l}\text { Wieviel Zeit verbringst } \\
\text { Du auf dieser Plattform? }\end{array}$ & & $\begin{array}{l}\text { How much time do you } \\
\text { spend on this platform? }\end{array}$ & & & & & & & & & & & $\mathrm{x}$ & $\mathrm{x}$ & $\mathrm{x}$ \\
\hline acc.10.duration.str & & $\begin{array}{l}\text { Wieviel Zeit verbringst } \\
\text { Du auf dieser Plattform? }\end{array}$ & & $\begin{array}{l}\text { How much time do you } \\
\text { spend on this platform? }\end{array}$ & & & & & & & & & & & $\mathrm{x}$ & $\mathrm{x}$ & $\mathrm{x}$ \\
\hline acc.10.duration & & $\begin{array}{l}\text { Wieviel Zeit verbringst } \\
\text { Du auf dieser Plattform? }\end{array}$ & & $\begin{array}{l}\text { How much time do you } \\
\text { spend on this platform? }\end{array}$ & & & & & & & & & & & $\mathrm{x}$ & $\mathrm{x}$ & $\mathrm{x}$ \\
\hline acc.11.duration.str & & $\begin{array}{l}\text { Wieviel Zeit verbringst } \\
\text { Du auf dieser Plattform? }\end{array}$ & & $\begin{array}{l}\text { How much time do you } \\
\text { spend on this platform? }\end{array}$ & & & & & & & & & & & $\mathrm{x}$ & $\mathrm{x}$ & $\mathrm{x}$ \\
\hline acc.11.duration & & $\begin{array}{l}\text { Wieviel Zeit verbringst } \\
\text { Du auf dieser Plattform? }\end{array}$ & & $\begin{array}{l}\text { How much time do you } \\
\text { spend on this platform? }\end{array}$ & & & & & & & & & & & $\mathrm{x}$ & $\mathrm{x}$ & $\mathrm{x}$ \\
\hline acc.12.duration.str & & $\begin{array}{l}\text { Wieviel Zeit verbringst } \\
\text { Du auf dieser Plattform? }\end{array}$ & & $\begin{array}{l}\text { How much time do you } \\
\text { spend on this platform? }\end{array}$ & & & & & & & & & & & $\mathrm{x}$ & $\mathrm{x}$ & $\mathrm{x}$ \\
\hline acc.12.duration & & $\begin{array}{l}\text { Wieviel Zeit verbringst } \\
\text { Du auf dieser Plattform? }\end{array}$ & & $\begin{array}{l}\text { How much time do you } \\
\text { spend on this platform? }\end{array}$ & & & & & & & & & & & $\mathrm{x}$ & $\mathrm{x}$ & $\mathrm{x}$ \\
\hline acc.1.post & & $\begin{array}{l}\text { Wie oft postest Du } \\
\text { eigene Inhalte auf dieser } \\
\text { Plattform? }\end{array}$ & & $\begin{array}{l}\text { How often do you post } \\
\text { your own content on } \\
\text { this platform? }\end{array}$ & & & & & & & & & & & $\mathrm{x}$ & $\mathrm{x}$ & $\mathrm{x}$ \\
\hline acc.2.post & & $\begin{array}{l}\text { Wie oft postest Du } \\
\text { eigene Inhalte auf dieser } \\
\text { Plattform? }\end{array}$ & & $\begin{array}{l}\text { How often do you post } \\
\text { your own content on } \\
\text { this platform? }\end{array}$ & & & & & & & & & & & $\mathrm{x}$ & $\mathrm{x}$ & $\mathrm{x}$ \\
\hline acc.3.post & & $\begin{array}{l}\text { Wie oft postest Du } \\
\text { eigene Inhalte auf dieser } \\
\text { Plattform? }\end{array}$ & & $\begin{array}{l}\text { How often do you post } \\
\text { your own content on } \\
\text { this platform? }\end{array}$ & & & & & & & & & & & $\mathrm{x}$ & $\mathrm{x}$ & $\mathrm{x}$ \\
\hline acc.4.post & & $\begin{array}{l}\text { Wie oft postest Du } \\
\text { eigene Inhalte auf dieser } \\
\text { Plattform? }\end{array}$ & & $\begin{array}{l}\text { How often do you post } \\
\text { your own content on } \\
\text { this platform? }\end{array}$ & & & & & & & & & & & $\mathrm{x}$ & $\mathrm{x}$ & $\mathrm{x}$ \\
\hline acc.5.post & & $\begin{array}{l}\text { Wie oft postest Du } \\
\text { eigene Inhalte auf dieser } \\
\text { Plattform? }\end{array}$ & & $\begin{array}{l}\text { How often do you post } \\
\text { your own content on } \\
\text { this platform? }\end{array}$ & & & & & & & & & & & $\mathrm{x}$ & $\mathrm{x}$ & $\mathrm{x}$ \\
\hline acc.6.post & & $\begin{array}{l}\text { Wie oft postest Du } \\
\text { eigene Inhalte auf dieser } \\
\text { Plattform? }\end{array}$ & & $\begin{array}{l}\text { How often do you post } \\
\text { your own content on } \\
\text { this platform? }\end{array}$ & & & & & & & & & & & $\mathrm{x}$ & $\mathrm{x}$ & $\mathrm{x}$ \\
\hline acc.7.post & & $\begin{array}{l}\text { Wie oft postest Du } \\
\text { eigene Inhalte auf dieser } \\
\text { Plattform? }\end{array}$ & & $\begin{array}{l}\text { How often do you post } \\
\text { your own content on } \\
\text { this platform? }\end{array}$ & & & & & & & & & & & $\mathrm{x}$ & $\mathrm{x}$ & $\mathrm{x}$ \\
\hline acc.8.post & & $\begin{array}{l}\text { Wie oft postest Du } \\
\text { eigene Inhalte auf dieser } \\
\text { Plattform? }\end{array}$ & & $\begin{array}{l}\text { How often do you post } \\
\text { your own content on } \\
\text { this platform? }\end{array}$ & & & & & & & & & & & $\mathrm{x}$ & $\mathrm{x}$ & $\mathrm{x}$ \\
\hline acc.9.post & & $\begin{array}{l}\text { Wie oft postest } \mathrm{Du} \\
\text { eigene Inhalte auf dieser } \\
\text { Plattform? }\end{array}$ & & $\begin{array}{l}\text { How often do you post } \\
\text { your own content on } \\
\text { this platform? }\end{array}$ & & & & & & & & & & & $\mathrm{x}$ & $\mathrm{x}$ & $\mathrm{x}$ \\
\hline acc.10.post.str & & $\begin{array}{l}\text { Wie oft postest } \mathrm{Du} \\
\text { eigene Inhalte auf dieser } \\
\text { Plattform? }\end{array}$ & & $\begin{array}{l}\text { How often do you post } \\
\text { your own content on } \\
\text { this platform? }\end{array}$ & & & & & & & & & & & $\mathrm{x}$ & $\mathrm{x}$ & $\mathrm{x}$ \\
\hline acc.10.post & & $\begin{array}{l}\text { Wie oft postest Du } \\
\text { eigene Inhalte auf dieser } \\
\text { Plattform? }\end{array}$ & & $\begin{array}{l}\text { How often do you post } \\
\text { your own content on } \\
\text { this platform? }\end{array}$ & & & & & & & & & & & $\mathrm{x}$ & $\mathrm{x}$ & $\mathrm{x}$ \\
\hline
\end{tabular}




\begin{tabular}{|c|c|c|c|c|c|c|c|c|c|c|c|c|c|c|c|c|c|}
\hline VarName & VariableLabel & WordingDE & ValueLabelsDE_Linked & WordingEN & ValueLabelsEN_Linked & L1 & L1F L2 & L3 & $\mathrm{L} 4$ & L5 & L6 6 & L7 & L8 & L9 & L10 L11 & $1 \mathrm{~L} 12$ & $2 \mathrm{~L} 13 \mathrm{~L} 14$ \\
\hline acc.11.post.str & & $\begin{array}{l}\text { Wie oft postest Du } \\
\text { eigene Inhalte auf dieser } \\
\text { Plattform? }\end{array}$ & & $\begin{array}{l}\text { How often do you post } \\
\text { your own content on } \\
\text { this platform? }\end{array}$ & & & & & & & & & & & $\mathrm{x}$ & $\mathrm{x}$ & $\mathrm{x}$ \\
\hline acc.11.post & & $\begin{array}{l}\text { Wie oft postest Du } \\
\text { eigene Inhalte auf dieser } \\
\text { Plattform? }\end{array}$ & & $\begin{array}{l}\text { How often do you post } \\
\text { your own content on } \\
\text { this platform? }\end{array}$ & & & & & & & & & & & $\mathrm{x}$ & $\mathrm{x}$ & $\mathrm{x}$ \\
\hline acc.12.post.str & & $\begin{array}{l}\text { Wie oft postest } \mathrm{Du} \\
\text { eigene Inhalte auf dieser } \\
\text { Plattform? }\end{array}$ & & $\begin{array}{l}\text { How often do you post } \\
\text { your own content on } \\
\text { this platform? }\end{array}$ & & & & & & & & & & & $\mathrm{x}$ & $\mathrm{x}$ & $\mathrm{x}$ \\
\hline acc.12.post & & $\begin{array}{l}\text { Wie oft postest Du } \\
\text { eigene Inhalte auf dieser } \\
\text { Plattform? }\end{array}$ & & $\begin{array}{l}\text { How often do you post } \\
\text { your own content on } \\
\text { this platform? }\end{array}$ & & & & & & & & & & & $\mathrm{x}$ & $\mathrm{x}$ & $\mathrm{x}$ \\
\hline acc.1.comm & & $\begin{array}{l}\text { Ich verwende diese } \\
\text { Plattform um mit } \\
\text { Mitstudierenden zu } \\
\text { kommunizieren }\end{array}$ & $1=\mathrm{Ja}, 2=\mathrm{Nein}$ & $\begin{array}{l}\text { I use this platform to } \\
\text { communicate with fellow } \\
\text { students }\end{array}$ & $1=\mathrm{Yes}, 2=\mathrm{No}$ & & & & & & & & & & $\mathrm{x}$ & $\mathrm{x}$ & $\mathrm{x}$ \\
\hline acc.2.comm & & $\begin{array}{l}\text { Ich verwende diese } \\
\text { Plattform um mit } \\
\text { Mitstudierenden zu } \\
\text { kommunizieren }\end{array}$ & $1=\mathrm{Ja}, 2=\mathrm{Nein}$ & $\begin{array}{l}\text { I use this platform to } \\
\text { communicate with fellow } \\
\text { students }\end{array}$ & $1=\mathrm{Yes}, 2=\mathrm{No}$ & & & & & & & & & & $\mathrm{x}$ & $\mathrm{x}$ & $\mathrm{x}$ \\
\hline acc.3.comm & & $\begin{array}{l}\text { Ich verwende diese } \\
\text { Plattform um mit } \\
\text { Mitstudierenden zu } \\
\text { kommunizieren }\end{array}$ & $1=\mathrm{Ja}, 2=$ Nein & $\begin{array}{l}\text { I use this platform to } \\
\text { communicate with fellow } \\
\text { students }\end{array}$ & $1=\mathrm{Yes}, 2=\mathrm{No}$ & & & & & & & & & & $\mathrm{x}$ & $\mathrm{x}$ & $\mathrm{x}$ \\
\hline acc.4.comm & & $\begin{array}{l}\text { Ich verwende diese } \\
\text { Plattform um mit } \\
\text { Mitstudierenden zu } \\
\text { kommunizieren }\end{array}$ & $1=\mathrm{Ja}, 2=$ Nein & $\begin{array}{l}\text { I use this platform to } \\
\text { communicate with fellow } \\
\text { students }\end{array}$ & $1=\mathrm{Yes}, 2=\mathrm{No}$ & & & & & & & & & & $\mathrm{x}$ & $\mathrm{x}$ & $\mathrm{x}$ \\
\hline acc.5.comm & & $\begin{array}{l}\text { Ich verwende diese } \\
\text { Plattform um mit } \\
\text { Mitstudierenden zu } \\
\text { kommunizieren }\end{array}$ & $1=\mathrm{Ja}, 2=$ Nein & $\begin{array}{l}\text { I use this platform to } \\
\text { communicate with fellow } \\
\text { students }\end{array}$ & $1=\mathrm{Yes}, 2=\mathrm{No}$ & & & & & & & & & & $\mathrm{x}$ & $\mathrm{x}$ & $\mathrm{x}$ \\
\hline acc.6.comm & & $\begin{array}{l}\text { Ich verwende diese } \\
\text { Plattform um mit } \\
\text { Mitstudierenden zu } \\
\text { kommunizieren }\end{array}$ & $1=\mathrm{Ja}, 2=$ Nein & $\begin{array}{l}\text { I use this platform to } \\
\text { communicate with fellow } \\
\text { students }\end{array}$ & $1=\mathrm{Yes}, 2=\mathrm{No}$ & & & & & & & & & & $\mathrm{x}$ & $\mathrm{x}$ & $\mathrm{x}$ \\
\hline acc.7.comm & & $\begin{array}{l}\text { Ich verwende diese } \\
\text { Plattform um mit } \\
\text { Mitstudierenden zu } \\
\text { kommunizieren }\end{array}$ & $1=\mathrm{Ja}, 2=$ Nein & $\begin{array}{l}\text { I use this platform to } \\
\text { communicate with fellow } \\
\text { students }\end{array}$ & $1=\mathrm{Yes}, 2=\mathrm{No}$ & & & & & & & & & & $\mathrm{x}$ & $\mathrm{x}$ & $\mathrm{x}$ \\
\hline acc.8.comm & & $\begin{array}{l}\text { Ich verwende diese } \\
\text { Plattform um mit } \\
\text { Mitstudierenden zu } \\
\text { kommunizieren }\end{array}$ & $1=\mathrm{Ja}, 2=$ Nein & $\begin{array}{l}\text { I use this platform to } \\
\text { communicate with fellow } \\
\text { students }\end{array}$ & $1=\mathrm{Yes}, 2=\mathrm{No}$ & & & & & & & & & & $\mathrm{x}$ & $\mathrm{x}$ & $\mathrm{x}$ \\
\hline acc.9.comm & & $\begin{array}{l}\text { Ich verwende diese } \\
\text { Plattform um mit } \\
\text { Mitstudierenden zu } \\
\text { kommunizieren }\end{array}$ & $1=\mathrm{Ja}, 2=\mathrm{Nein}$ & $\begin{array}{l}\text { I use this platform to } \\
\text { communicate with fellow } \\
\text { students }\end{array}$ & $1=\mathrm{Yes}, 2=\mathrm{No}$ & & & & & & & & & & $\mathrm{x}$ & $\mathrm{x}$ & $\mathrm{x}$ \\
\hline acc.10.comm & & $\begin{array}{l}\text { Ich verwende diese } \\
\text { Plattform um mit } \\
\text { Mitstudierenden zu } \\
\text { kommunizieren }\end{array}$ & $1=\mathrm{Ja}, 2=$ Nein & $\begin{array}{l}\text { I use this platform to } \\
\text { communicate with fellow } \\
\text { students }\end{array}$ & $1=\mathrm{Yes}, 2=\mathrm{No}$ & & & & & & & & & & $\mathrm{x}$ & $\mathrm{x}$ & $\mathrm{x}$ \\
\hline acc.10.comm.str & & $\begin{array}{l}\text { Ich verwende diese } \\
\text { Plattform um mit } \\
\text { Mitstudierenden zu } \\
\text { kommunizieren }\end{array}$ & & $\begin{array}{l}\text { I use this platform to } \\
\text { communicate with fellow } \\
\text { students }\end{array}$ & & & & & & & & & & & $\mathrm{x}$ & $\mathrm{x}$ & $\mathrm{x}$ \\
\hline acc.11.comm & & $\begin{array}{l}\text { Ich verwende diese } \\
\text { Plattform um mit } \\
\text { Mitstudierenden zu } \\
\text { kommunizieren }\end{array}$ & $1=\mathrm{Ja}, 2=$ Nein & $\begin{array}{l}\text { I use this platform to } \\
\text { communicate with fellow } \\
\text { students }\end{array}$ & $1=\mathrm{Yes}, 2=\mathrm{No}$ & & & & & & & & & & $\mathrm{x}$ & $\mathrm{x}$ & $\mathrm{x}$ \\
\hline
\end{tabular}




\begin{tabular}{|c|c|c|c|c|c|c|c|c|c|c|c|c|c|c|c|c|c|}
\hline VarName & VariableLabel & WordingDE & ValueLabelsDE_Linked & WordingEN & ValueLabelsEN_Linked & L1 & L1F L2 & L3 & $\mathrm{L} 4$ & L5 & $\mathrm{L} 6$ & $\mathrm{~L} 7$ & $\mathrm{~L} 8$ & L9 & L10 L11 & $\mathrm{L} 12$ & L13 L14 \\
\hline acc.11.comm.str & & $\begin{array}{l}\text { Ich verwende diese } \\
\text { Plattform um mit } \\
\text { Mitstudierenden zu } \\
\text { kommunizieren }\end{array}$ & & $\begin{array}{l}\text { I use this platform to } \\
\text { communicate with fellow } \\
\text { students }\end{array}$ & & & & & & & & & & & $\mathrm{x}$ & $\mathrm{x}$ & $\mathrm{x}$ \\
\hline acc.12.comm & & $\begin{array}{l}\text { Ich verwende diese } \\
\text { Plattform um mit } \\
\text { Mitstudierenden zu } \\
\text { kommunizieren }\end{array}$ & $1=\mathrm{Ja}, 2=$ Nein & $\begin{array}{l}\text { I use this platform to } \\
\text { communicate with fellow } \\
\text { students }\end{array}$ & $1=\mathrm{Yes}, 2=\mathrm{No}$ & & & & & & & & & & $\mathrm{x}$ & $\mathrm{x}$ & $\mathrm{x}$ \\
\hline acc.12.comm.str & & $\begin{array}{l}\text { Ich verwende diese } \\
\text { Plattform um mit } \\
\text { Mitstudierenden zu } \\
\text { kommunizieren }\end{array}$ & & $\begin{array}{l}\text { I use this platform to } \\
\text { communicate with fellow } \\
\text { students }\end{array}$ & & & & & & & & & & & $\mathrm{x}$ & $\mathrm{x}$ & $\mathrm{x}$ \\
\hline sm.perception.1 & & $\begin{array}{l}\text { Soziale Medien sind } \\
\text { wichtig, um soziale } \\
\text { Events zwischen den } \\
\text { Studierenden des } \\
\text { Departements zu } \\
\text { organisieren }\end{array}$ & & $\begin{array}{l}\text { Social media are } \\
\text { important to organize } \\
\text { social events between } \\
\text { the students of the } \\
\text { department }\end{array}$ & & & & & & & & & & & $\mathrm{x}$ & $\mathrm{x}$ & $\mathrm{x}$ \\
\hline sm.perception.2 & & $\begin{array}{l}\text { Soziale Medien sind } \\
\text { wichtig, um [name } \\
\text { removed] } \\
\text { Lernmaterialien } \\
\text { auszutauschen und zu } \\
\text { diskutieren }\end{array}$ & & $\begin{array}{l}\text { Social media are } \\
\text { important for } \\
\text { exchanging and } \\
\text { discussing [name } \\
\text { removed] learning } \\
\text { materials }\end{array}$ & & & & & & & & & & & $\mathrm{x}$ & $\mathrm{x}$ & $\mathrm{x}$ \\
\hline sm.perception.3 & & $\begin{array}{l}\text { Soziale Medien sind } \\
\text { wichtig, um } \\
\text { Freundschaften } \\
\text { innerhalb des } \\
\text { Departements zu pflegen }\end{array}$ & & $\begin{array}{l}\text { Social media are } \\
\text { important to maintain } \\
\text { friendships within the } \\
\text { department }\end{array}$ & & & & & & & & & & & $\mathrm{x}$ & $\mathrm{x}$ & $\mathrm{x}$ \\
\hline sm.perception.4 & & $\begin{array}{l}\text { Soziale Medien sind } \\
\text { wichtig, um } \\
\text { Freundschaften } \\
\text { ausserhalb [name } \\
\text { removed] zu pflegen }\end{array}$ & & $\begin{array}{l}\text { Social media are } \\
\text { important to maintain } \\
\text { friendships outside of } \\
\text { [name removed] }\end{array}$ & & & & & & & & & & & $\mathrm{x}$ & $\mathrm{x}$ & $\mathrm{x}$ \\
\hline sm.perception.5 & & $\begin{array}{l}\text { Wenn ich einen Tag lang } \\
\text { keinen Zugang zu } \\
\text { Sozialen Medien habe, } \\
\text { fühle ich mich gestresst }\end{array}$ & & $\begin{array}{l}\text { If I don't have access } \\
\text { to social media for a } \\
\text { day, I feel stressed }\end{array}$ & & & & & & & & & & & $\mathrm{x}$ & $\mathrm{x}$ & $\mathrm{x}$ \\
\hline sm.perception.6 & & $\begin{array}{l}\text { Wenn ich einen Tag lang } \\
\text { keinen Zugang zu } \\
\text { Sozialen Medien habe } \\
\text { fühle ich mich erleichtert }\end{array}$ & & $\begin{array}{l}\text { If I don't have access } \\
\text { to social media for a } \\
\text { day, I feel relieved }\end{array}$ & & & & & & & & & & & $\mathrm{x}$ & $\mathrm{x}$ & $\mathrm{x}$ \\
\hline sm.more.less & & $\begin{array}{l}\text { Ich würde Soziale } \\
\text { Medien gerne... }\end{array}$ & & $\begin{array}{l}\text { I would like to social } \\
\text { media ... }\end{array}$ & & & & & & & & & & & $\mathrm{x}$ & $\mathrm{x}$ & $\mathrm{x}$ \\
\hline sm.better.worse & & $\begin{array}{l}\text { Durch Soziale Medien ist } \\
\text { mein Leben insgesamt... }\end{array}$ & & $\begin{array}{l}\text { Through social media, } \\
\text { my life as a whole is ... }\end{array}$ & & & & & & & & & & & $\mathrm{x}$ & $\mathrm{x}$ & $\mathrm{x}$ \\
\hline sm.comm.P1 & & $\begin{array}{l}\text { Mit welchen Deiner } \\
\text { Mitstudierenden } \\
\text { kommunizierst Du } \\
\text { regelmässig über Soziale } \\
\text { Medien? (ausgenommen } \\
\text { Messaging-Apps). } \\
\text { Nenne zwischen } 0 \text { und } \\
20 \text { Personen }\end{array}$ & & $\begin{array}{l}\text { Which of your fellow } \\
\text { students do you } \\
\text { communicate with } \\
\text { regularly on social } \\
\text { media? (except } \\
\text { messaging apps). Name } \\
\text { between } 0 \text { and } 20 \text { people }\end{array}$ & & & & & & & & & & & $\mathrm{x}$ & $\mathrm{x}$ & $\mathrm{x}$ \\
\hline
\end{tabular}




\begin{tabular}{|c|c|c|c|c|c|c|c|c|c|c|c|c|c|c|c|c|c|}
\hline VarName & VariableLabel & WordingDE & ValueLabelsDE_Linked & WordingEN & ValueLabelsEN_Linked & L1 & L1F L2 & L3 & $\mathrm{L} 4$ & L5 & L6 & $\mathrm{L} 7$ & $\mathrm{~L} 8$ & L9 & L10 L11 & $1 \mathrm{~L} 12$ & $2 \mathrm{~L} 13 \mathrm{~L} 14$ \\
\hline msg.comm.P1 & & $\begin{array}{l}\text { Mit welchen Deiner } \\
\text { Mitstudierenden } \\
\text { kommunizierst } \\
\text { Duregelmässig über } \\
\text { Messaging-Apps (z.B. } \\
\text { Whatsapp, Signal, } \\
\text { SMS)? Nenne bitte } \\
\text { zwischen } 0 \text { und } 20 \\
\text { Personen. }\end{array}$ & & $\begin{array}{l}\text { Which of your fellow } \\
\text { students do you } \\
\text { communicate with } \\
\text { regularly via messaging } \\
\text { apps (e.g. Whatsapp, } \\
\text { Signal, SMS)? Please } \\
\text { name between } 0 \text { and } 20 \\
\text { people. }\end{array}$ & & & & & & & & & & & $\mathrm{x}$ & $\mathrm{x}$ & $\mathrm{x}$ \\
\hline sm.good.P1 & & $\begin{array}{l}\text { Wer postet auf Sozialen } \\
\text { Medien Inhalte, die Du } \\
\text { besonders gut findest? }\end{array}$ & & $\begin{array}{l}\text { Who posts content on } \\
\text { social media that you } \\
\text { particularly like? }\end{array}$ & & & & & & & & & & & $\mathrm{x}$ & $\mathrm{x}$ & $\mathrm{x}$ \\
\hline sm.bad.P1 & & $\begin{array}{l}\text { Wer postet auf Sozialen } \\
\text { Medien Inhalte, die Du } \\
\text { besonders schlecht } \\
\text { findest? }\end{array}$ & & $\begin{array}{l}\text { Who posts content on } \\
\text { social media that you } \\
\text { find particularly bad? }\end{array}$ & & & & & & & & & & & $\mathrm{x}$ & $\mathrm{x}$ & $\mathrm{X}$ \\
\hline describe.best.friend. 1 & & $\begin{array}{l}\text { Von diesen Personen } \\
\text { denke nun an Deinen } \\
\text { engsten Freund oder } \\
\text { Deine engste Freundin. } \\
\text { Welche Begriffe } \\
\text { beschreiben Deine } \\
\text { Beziehung zu dieser } \\
\text { Person am Besten (ein } \\
\text { Wort oder Ausdruck pro } \\
\text { Feld)? }\end{array}$ & & $\begin{array}{l}\text { Of these people, think of } \\
\text { your closest friend. } \\
\text { What terms best } \\
\text { describe your } \\
\text { relationship with that } \\
\text { person (one word or } \\
\text { phrase per field)? }\end{array}$ & & & & & & & & & & & & & $\mathrm{x}$ \\
\hline describe.best.friend.2 & & $\begin{array}{l}\text { Von diesen Personen } \\
\text { denke nun an Deinen } \\
\text { engsten Freund oder } \\
\text { Deine engste Freundin. } \\
\text { Welche Begriffe } \\
\text { beschreiben Deine } \\
\text { Beziehung zu dieser } \\
\text { Person am Besten (ein } \\
\text { Wort oder Ausdruck pro } \\
\text { Feld)? }\end{array}$ & & $\begin{array}{l}\text { Of these people, think of } \\
\text { your closest friend. } \\
\text { What terms best } \\
\text { describe your } \\
\text { relationship with that } \\
\text { person (one word or } \\
\text { phrase per field)? }\end{array}$ & & & & & & & & & & & & & $\mathrm{x}$ \\
\hline describe.best.friend.3 & & $\begin{array}{l}\text { Von diesen Personen } \\
\text { denke nun an Deinen } \\
\text { engsten Freund oder } \\
\text { Deine engste Freundin. } \\
\text { Welche Begriffe } \\
\text { beschreiben Deine } \\
\text { Beziehung zu dieser } \\
\text { Person am Besten (ein } \\
\text { Wort oder Ausdruck pro } \\
\text { Feld)? }\end{array}$ & & $\begin{array}{l}\text { Of these people, think of } \\
\text { your closest friend. } \\
\text { What terms best } \\
\text { describe your } \\
\text { relationship with that } \\
\text { person (one word or } \\
\text { phrase per field)? }\end{array}$ & & & & & & & & & & & & & $\mathrm{x}$ \\
\hline describe.best.friend.4 & & $\begin{array}{l}\text { Von diesen Personen } \\
\text { denke nun an Deinen } \\
\text { engsten Freund oder } \\
\text { Deine engste Freundin. } \\
\text { Welche Begriffe } \\
\text { beschreiben Deine } \\
\text { Beziehung zu dieser } \\
\text { Person am Besten (ein } \\
\text { Wort oder Ausdruck pro } \\
\text { Feld)? }\end{array}$ & & $\begin{array}{l}\text { Of these people, think of } \\
\text { your closest friend. } \\
\text { What terms best } \\
\text { describe your } \\
\text { relationship with that } \\
\text { person (one word or } \\
\text { phrase per field)? }\end{array}$ & & & & & & & & & & & & & $\mathrm{x}$ \\
\hline
\end{tabular}




\begin{tabular}{|c|c|c|c|c|c|c|c|c|c|c|c|c|c|c|}
\hline VarName & VariableLabel & WordingDE & ValueLabelsDE_Linked & WordingEN & ValueLabelsEN_Linked & L1 & L1F L2 & L3 & $\mathrm{L} 4$ & L5 & L6 & L7 L8 & L9 & L10 L11 L12 L13 L14 \\
\hline describe.best.friend.5 & & $\begin{array}{l}\text { Von diesen Personen } \\
\text { denke nun an Deinen } \\
\text { engsten Freund oder } \\
\text { Deine engste Freundin. } \\
\text { Welche Begriffe } \\
\text { beschreiben Deine } \\
\text { Beziehung zu dieser } \\
\text { Person am Besten (ein } \\
\text { Wort oder Ausdruck pro } \\
\text { Feld)? }\end{array}$ & & $\begin{array}{l}\text { Of these people, think of } \\
\text { your closest friend. } \\
\text { What terms best } \\
\text { describe your } \\
\text { relationship with that } \\
\text { person (one word or } \\
\text { phrase per field)? }\end{array}$ & & & & & & & & & & $\mathrm{x}$ \\
\hline closeness.best.friend & & & & & & & & & & & & & & $\mathrm{x}$ \\
\hline talk.to.best.friend & & & & & & & & & & & & & & $\mathrm{x}$ \\
\hline friend.may 17.P1 & & $\begin{array}{l}\text { Welche Deiner } \\
\text { Mitstudierenden hast } \\
\text { Du am Ende des } 1 . \\
\text { Studienjahres (Ende } \\
\text { Mai 2017) als Freunde } \\
\text { bezeichnet? }\end{array}$ & & $\begin{array}{l}\text { Which of your fellow } \\
\text { students did you refer to } \\
\text { as friends at the end of } \\
\text { the first year of study } \\
\text { (end of May 2017)? }\end{array}$ & & & & & & & & & & $\mathrm{x}$ \\
\hline friend.may $18 . P 1$ & & $\begin{array}{l}\text { Welche Deiner } \\
\text { Mitstudierenden hast } \\
\text { Du am Ende des } 2 . \\
\text { Studienjahres (Ende } \\
\text { Mai 2018) als Freunde } \\
\text { bezeichnet? }\end{array}$ & & $\begin{array}{l}\text { Which of your fellow } \\
\text { students did you refer to } \\
\text { as friends at the end of } \\
\text { the second year (end of } \\
\text { May 2018)? }\end{array}$ & & & & & & & & & & $\mathrm{x}$ \\
\hline perception.integration & & $\begin{array}{l}\text { Im Vergleich zu den } \\
\text { anderen Studierenden } \\
\text { war ich insgesamt gut } \\
\text { integriert in meinem } \\
\text { Studiengang. }\end{array}$ & $\begin{array}{l}1=\text { überhaupt nicht } \\
\text { einverstanden }, 2=\text { nicht } \\
\text { einverstanden }, 3=\text { eher } \\
\text { nicht einverstanden , } 4= \\
\text { weder noch, } 5=\text { eher } \\
\text { einverstanden, } 6= \\
\text { einverstanden, }, 7=\text { völlig } \\
\text { einverstanden }\end{array}$ & $\begin{array}{l}\text { Compared to the other } \\
\text { students, I was generally } \\
\text { well integrated into my } \\
\text { degree program. }\end{array}$ & $\begin{array}{l}1=\mathrm{NA}, 2=\mathrm{NA}, 3=\mathrm{NA} \\
4=\mathrm{NA}, 5=\mathrm{NA}, 6=\mathrm{NA} \\
7=\mathrm{NA}\end{array}$ & & & & & & & & & $\mathrm{x}$ \\
\hline cohort.timetogehter & & $\begin{array}{l}\text { Die Studierenden in } \\
\text { meinem Jahrgang ... } \\
\text { haben ihre Freizeit } \\
\text { miteinander verbracht. }\end{array}$ & $\begin{array}{l}1=\text { überhaupt nicht } \\
\text { einverstanden, } 2=\text { nicht } \\
\text { einverstanden, } 3=\text { eher } \\
\text { nicht einverstanden , } 4= \\
\text { weder noch, } 5=\text { eher } \\
\text { einverstanden, } 6= \\
\text { einverstanden, } 7=\text { völlig } \\
\text { einverstanden }\end{array}$ & $\begin{array}{l}\text { The students in my year } \\
\ldots \text { spent their free time } \\
\text { together. }\end{array}$ & $\begin{array}{l}1=\mathrm{NA}, 2=\mathrm{NA}, 3=\mathrm{NA} \\
4=\mathrm{NA}, 5=\mathrm{NA}, 6=\mathrm{NA} \\
7=\mathrm{NA}\end{array}$ & & & & & & & & & $\mathrm{x}$ \\
\hline cohort.support & & $\begin{array}{l}\text { Die Studierenden in } \\
\text { meinem Jahrgang ... } \\
\text { haben sich gegenseitig } \\
\text { im Studium unterstützt. }\end{array}$ & $\begin{array}{l}1=\text { überhaupt nicht } \\
\text { einverstanden }, 2=\text { nicht } \\
\text { einverstanden }, 3=\text { eher } \\
\text { nicht einverstanden }, 4= \\
\text { weder noch, } 5=\text { eher } \\
\text { einverstanden, } 6= \\
\text { einverstanden, } 7=\text { völlig } \\
\text { einverstanden }\end{array}$ & $\begin{array}{l}\text { The students in my class } \\
\ldots \text { supported each other } \\
\text { in their studies. }\end{array}$ & $\begin{array}{l}1=\mathrm{NA}, 2=\mathrm{NA}, 3=\mathrm{NA} \\
4=\mathrm{NA}, 5=\mathrm{NA}, 6=\mathrm{NA} \\
7=\mathrm{NA}\end{array}$ & & & & & & & & & $\mathrm{x}$ \\
\hline cohort.private.support & & $\begin{array}{l}\text { Die Studierenden in } \\
\text { meinem Jahrgang ... } \\
\text { haben sich gegenseitig } \\
\text { bei privaten Problemen } \\
\text { und Sorgen unterstützt. }\end{array}$ & $\begin{array}{l}1=\text { überhaupt nicht } \\
\text { einverstanden }, 2=\text { nicht } \\
\text { einverstanden }, 3=\text { eher } \\
\text { nicht einverstanden }, 4= \\
\text { weder noch, } 5=\text { eher } \\
\text { einverstanden, } 6= \\
\text { einverstanden, } 7=\text { völlig } \\
\text { einverstanden }\end{array}$ & $\begin{array}{l}\text { The students in my class } \\
\ldots \text { supported each other } \\
\text { with private problems } \\
\text { and concerns. }\end{array}$ & $\begin{array}{l}1=\mathrm{NA}, 2=\mathrm{NA}, 3=\mathrm{NA} \\
4=\mathrm{NA}, 5=\mathrm{NA}, 6=\mathrm{NA} \\
7=\mathrm{NA}\end{array}$ & & & & & & & & & $\mathrm{x}$ \\
\hline
\end{tabular}




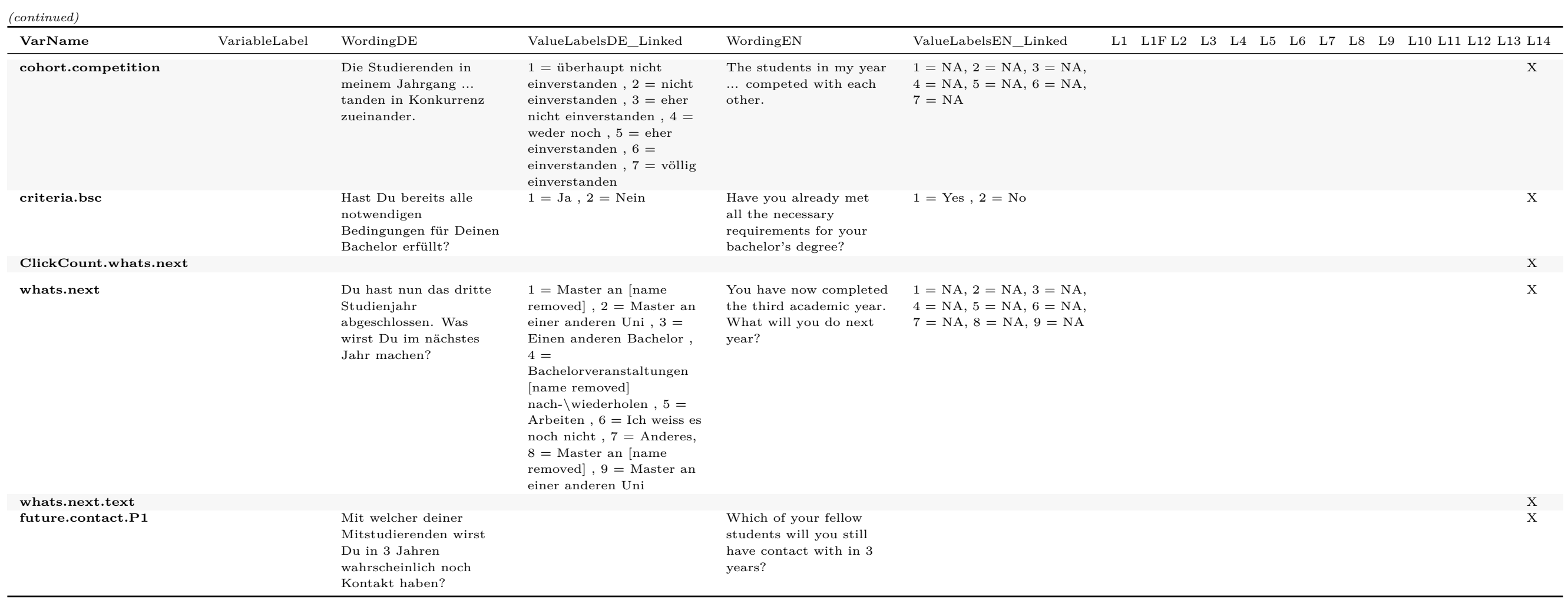




\section{Short Questionnaires}

\begin{tabular}{|c|c|c|c|c|c|c|c|}
\hline VarName & VariableLabel & WordingDE & ValueLabelsDE_Linked & WordingEN & ValueLabelsEN_Linked & Affect & Studying \\
\hline duration & $\begin{array}{l}\text { Duration to } \\
\text { finish } \\
\text { questionnaire }\end{array}$ & & & & & $\mathrm{x}$ & $\mathrm{x}$ \\
\hline finished & $\begin{array}{l}\text { Finished } \\
\text { questionnaire }\end{array}$ & & & & & $\mathrm{x}$ & $\mathrm{x}$ \\
\hline stress. 1 & $\begin{array}{l}\text { Stress (PSS-4) } \\
\text { Item } 1\end{array}$ & $\begin{array}{l}\text { Wie oft hattest Du heute das } \\
\text { Gefühl, wichtige Dinge in } \\
\text { Deinem Leben nicht } \\
\text { beeinflussen zu können? }\end{array}$ & $\begin{array}{l}1=\text { nie, } 2=\text { selten, } 3= \\
\text { manchmal, } 4=\text { häufig, } 5= \\
\text { sehr oft }\end{array}$ & $\begin{array}{l}\text { Today, how often have you } \\
\text { felt that you were unable to } \\
\text { control the important things } \\
\text { in your life? }\end{array}$ & $\begin{array}{l}1=\text { never, } 2=\text { almost never, } \\
3=\text { sometimes, } 4=\text { fairly } \\
\text { often, } 5=\text { very often }\end{array}$ & $\mathrm{x}$ & \\
\hline stress.2 & $\begin{array}{l}\text { Stress (PSS- } 4) \\
\text { Item } 2\end{array}$ & $\begin{array}{l}\text { Wie oft hast Du Dich heute } \\
\text { sicher im Umgang mit } \\
\text { persönlichen Aufgaben und } \\
\text { Problemen gefühlt? }\end{array}$ & $\begin{array}{l}1=\text { nie, } 2=\text { selten, } 3= \\
\text { manchmal, } 4=\text { häufig, } 5= \\
\text { sehr oft }\end{array}$ & $\begin{array}{l}\text { Today, how often have you } \\
\text { felt confident about your } \\
\text { ability to handle your } \\
\text { personal problems? }\end{array}$ & $\begin{array}{l}1=\text { never, } 2=\text { almost never } \\
3=\text { sometimes, } 4=\text { fairly } \\
\text { often, } 5=\text { very often }\end{array}$ & $\mathrm{x}$ & \\
\hline stress. 3 & $\begin{array}{l}\text { Stress (PSS-4) } \\
\text { Item } 3\end{array}$ & $\begin{array}{l}\text { Wie oft hattest Du heute das } \\
\text { Gefühl, dass sich die Dinge } \\
\text { nach Deinen Vorstellungen } \\
\text { entwickeln? }\end{array}$ & $\begin{array}{l}1=\text { nie, } 2=\text { selten, } 3= \\
\text { manchmal, } 4=\text { häufig, } 5= \\
\text { sehr oft }\end{array}$ & $\begin{array}{l}\text { Today, how often have you } \\
\text { felt that things were going } \\
\text { your way? }\end{array}$ & $\begin{array}{l}1=\text { never, } 2=\text { almost never } \\
3=\text { sometimes, } 4=\text { fairly } \\
\text { often, } 5=\text { very often }\end{array}$ & $\mathrm{x}$ & \\
\hline stress.4 & $\begin{array}{l}\text { Stress (PSS-4) } \\
\text { Item } 4\end{array}$ & $\begin{array}{l}\text { Wie oft hattest Du heute das } \\
\text { Gefühl, dass sich die } \\
\text { Probleme so aufgestaut } \\
\text { haben, dass Du diese nicht } \\
\text { mehr bewältigen kannst? }\end{array}$ & $\begin{array}{l}1=\text { nie, } 2=\text { selten, } 3= \\
\text { manchmal, } 4=\text { häufig, } 5= \\
\text { sehr oft }\end{array}$ & $\begin{array}{l}\text { Today, how often have you } \\
\text { felt difficulties were piling up } \\
\text { so high that you could not } \\
\text { overcome them? }\end{array}$ & $\begin{array}{l}1=\text { never, } 2=\text { almost never } \\
3=\text { sometimes, } 4=\text { fairly } \\
\text { often, } 5=\text { very often }\end{array}$ & $\mathrm{x}$ & \\
\hline stress.general & $\begin{array}{l}\text { Stress single } \\
\text { Item }\end{array}$ & $\begin{array}{l}\text { Wie oft hast Du Dich heute } \\
\text { nervös und „gestresst" } \\
\text { gefühlt? }\end{array}$ & $\begin{array}{l}1=\text { nie, } 2=\text { selten, } 3= \\
\text { manchmal, } 4=\text { häufig, } 5= \\
\text { sehr oft }\end{array}$ & $\begin{array}{l}\text { Today, how often have you } \\
\text { felt nervous and "stressed"? } \\
\text { (free translation) }\end{array}$ & $\begin{array}{l}1=\text { never, } 2=\text { almost never, } \\
3=\text { sometimes, } 4=\text { fairly } \\
\text { often, } 5=\text { very often }\end{array}$ & $\mathrm{x}$ & \\
\hline PA.1 & $\begin{array}{l}\text { Affect } \\
\text { (I-PANAS-SF) } \\
\text { Item } 1\end{array}$ & $\begin{array}{l}\text { Gib bitte an, wie Du Dich } \\
\text { heute gefühlt hast: aktiv }\end{array}$ & $\begin{array}{l}1=\text { gar nicht, } 2=\text { ein } \\
\text { bisschen, } 3=\text { einigermassen, } \\
4=\text { erheblich, } 5=\text { äusserst }\end{array}$ & $\begin{array}{l}\text { Indicate the extent you have } \\
\text { felt this way over the past } \\
\text { week: active }\end{array}$ & $\begin{array}{l}1=\text { very slightly or not at all, } \\
2=\text { a little, } 3=\text { moderately, } 4 \\
=\text { quite a bit }, 5=\text { extremely }\end{array}$ & $\mathrm{x}$ & \\
\hline NA.1 & $\begin{array}{l}\text { Affect } \\
\text { (I-PANAS-SF) } \\
\text { Item } 2\end{array}$ & $\begin{array}{l}\text { Gib bitte an, wie Du Dich } \\
\text { heute gefühlt hast: ängstlich }\end{array}$ & $\begin{array}{l}1=\text { gar nicht }, 2=\text { ein } \\
\text { bisschen, } 3=\text { einigermassen, } \\
4=\text { erheblich, } 5=\text { äusserst }\end{array}$ & $\begin{array}{l}\text { Indicate the extent you have } \\
\text { felt this way over the past } \\
\text { week: afraid }\end{array}$ & $\begin{array}{l}1=\text { very slightly or not at all, } \\
2=\text { a little, } 3=\text { moderately, } 4 \\
=\text { quite a bit }, 5=\text { extremely }\end{array}$ & $\mathrm{x}$ & \\
\hline PA.2 & $\begin{array}{l}\text { Affect } \\
\text { (I-PANAS-SF) } \\
\text { Item } 3\end{array}$ & $\begin{array}{l}\text { Gib bitte an, wie Du Dich } \\
\text { heute gefühlt hast: wach }\end{array}$ & $\begin{array}{l}1=\text { gar nicht, } 2=\text { ein } \\
\text { bisschen, } 3=\text { einigermassen, } \\
4=\text { erheblich, } 5=\text { äusserst }\end{array}$ & $\begin{array}{l}\text { Indicate the extent you have } \\
\text { felt this way over the past } \\
\text { week: alert }\end{array}$ & $\begin{array}{l}1=\text { very slightly or not at all, } \\
2=\text { a little, } 3=\text { moderately, } 4 \\
=\text { quite a bit, } 5=\text { extremely }\end{array}$ & $\mathrm{x}$ & \\
\hline NA.2 & $\begin{array}{l}\text { Affect } \\
\text { (I-PANAS-SF) } \\
\text { Item } 4\end{array}$ & $\begin{array}{l}\text { Gib bitte an, wie Du Dich } \\
\text { heute gefühlt hast: nervös }\end{array}$ & $\begin{array}{l}1=\text { gar nicht, } 2=\text { ein } \\
\text { bisschen, } 3=\text { einigermassen, } \\
4=\text { erheblich, } 5=\text { äusserst }\end{array}$ & $\begin{array}{l}\text { Indicate the extent you have } \\
\text { felt this way over the past } \\
\text { week: nervous }\end{array}$ & $\begin{array}{l}1=\text { very slightly or not at all, } \\
2=\text { a little, } 3=\text { moderately, } 4 \\
=\text { quite a bit }, 5=\text { extremely }\end{array}$ & $\mathrm{x}$ & \\
\hline PA.3 & $\begin{array}{l}\text { Affect } \\
\text { (I-PANAS-SF) } \\
\text { Item } 5\end{array}$ & $\begin{array}{l}\text { Gib bitte an, wie Du Dich } \\
\text { heute gefühlt hast: } \\
\text { aufmerksam }\end{array}$ & $\begin{array}{l}1=\text { gar nicht, } 2=\text { ein } \\
\text { bisschen, } 3=\text { einigermassen, } \\
4=\text { erheblich, } 5=\text { äusserst }\end{array}$ & $\begin{array}{l}\text { Indicate the extent you have } \\
\text { felt this way over the past } \\
\text { week: attentive }\end{array}$ & $\begin{array}{l}1=\text { very slightly or not at all, } \\
2=\text { a little, } 3=\text { moderately, } 4 \\
=\text { quite a bit }, 5=\text { extremely }\end{array}$ & $\mathrm{x}$ & \\
\hline NA.3 & $\begin{array}{l}\text { Affect } \\
\text { (I-PANAS-SF) } \\
\text { Item } 6\end{array}$ & $\begin{array}{l}\text { Gib bitte an, wie Du Dich } \\
\text { heute gefühlt hast: feindselig }\end{array}$ & $\begin{array}{l}1=\text { gar nicht, } 2=\text { ein } \\
\text { bisschen, } 3=\text { einigermassen, } \\
4=\text { erheblich, } 5=\text { äusserst }\end{array}$ & $\begin{array}{l}\text { Indicate the extent you have } \\
\text { felt this way over the past } \\
\text { week: hostile }\end{array}$ & $\begin{array}{l}1=\text { very slightly or not at all, } \\
2=\text { a little, } 3=\text { moderately, } 4 \\
=\text { quite a bit }, 5=\text { extremely }\end{array}$ & $\mathrm{x}$ & \\
\hline PA.4 & $\begin{array}{l}\text { Affect } \\
\text { (I-PANAS-SF) } \\
\text { Item } 7\end{array}$ & $\begin{array}{l}\text { Gib bitte an, wie Du Dich } \\
\text { heute gefühlt hast: } \\
\text { entschlossen }\end{array}$ & $\begin{array}{l}1=\text { gar nicht, } 2=\text { ein } \\
\text { bisschen, } 3=\text { einigermassen, } \\
4=\text { erheblich, } 5=\text { äusserst }\end{array}$ & $\begin{array}{l}\text { Indicate the extent you have } \\
\text { felt this way over the past } \\
\text { week: determined }\end{array}$ & $\begin{array}{l}1=\text { very slightly or not at all, } \\
2=\text { a little, } 3=\text { moderately, } 4 \\
=\text { quite a bit }, 5=\text { extremely }\end{array}$ & $\mathrm{x}$ & \\
\hline NA.4 & $\begin{array}{l}\text { Affect } \\
\text { (I-PANAS-SF) } \\
\text { Item } 8\end{array}$ & $\begin{array}{l}\text { Gib bitte an, wie Du Dich } \\
\text { heute gefühlt hast: beschämt }\end{array}$ & $\begin{array}{l}1=\text { gar nicht, } 2=\text { ein } \\
\text { bisschen, } 3=\text { einigermassen, } \\
4=\text { erheblich, } 5=\text { äusserst }\end{array}$ & $\begin{array}{l}\text { Indicate the extent you have } \\
\text { felt this way over the past } \\
\text { week: ashamed }\end{array}$ & $\begin{array}{l}1=\text { very slightly or not at all, } \\
2=\text { a little, } 3=\text { moderately, } 4 \\
=\text { quite a bit }, 5=\text { extremely }\end{array}$ & $\mathrm{x}$ & \\
\hline PA.5 & $\begin{array}{l}\text { Affect } \\
\text { (I-PANAS-SF) } \\
\text { Item } 9\end{array}$ & $\begin{array}{l}\text { Gib bitte an, wie Du Dich } \\
\text { heute gefühlt hast: begeistert }\end{array}$ & $\begin{array}{l}1=\text { gar nicht, } 2=\text { ein } \\
\text { bisschen, } 3=\text { einigermassen, } \\
4=\text { erheblich, } 5=\text { äusserst }\end{array}$ & $\begin{array}{l}\text { Indicate the extent you have } \\
\text { felt this way over the past } \\
\text { week: inspired }\end{array}$ & $\begin{array}{l}1=\text { very slightly or not at all, } \\
2=\text { a little, } 3=\text { moderately, } 4 \\
=\text { quite a bit }, 5=\text { extremely }\end{array}$ & $\mathrm{x}$ & \\
\hline NA.5 & $\begin{array}{l}\text { Affect } \\
\text { (I-PANAS-SF) } \\
\text { Item } 10\end{array}$ & $\begin{array}{l}\text { Gib bitte an, wie Du Dich } \\
\text { heute gefühlt hast: verärgert }\end{array}$ & $\begin{array}{l}1=\text { gar nicht, } 2=\text { ein } \\
\text { bisschen, } 3=\text { einigermassen, } \\
4=\text { erheblich, } 5=\text { äusserst }\end{array}$ & $\begin{array}{l}\text { Indicate the extent you have } \\
\text { felt this way over the past } \\
\text { week: upset }\end{array}$ & $\begin{array}{l}1=\text { very slightly or not at all, } \\
2=\text { a little, } 3=\text { moderately, } 4 \\
=\text { quite a bit }, 5=\text { extremely }\end{array}$ & $\mathrm{x}$ & \\
\hline
\end{tabular}




\begin{tabular}{|c|c|c|c|c|c|c|c|}
\hline VarName & VariableLabel & WordingDE & ValueLabelsDE_Linked & WordingEN & ValueLabelsEN_Linked & Affect & Studying \\
\hline interaction $A$ & Interaction A & $\begin{array}{l}\text { Bitte denke nun an } \\
\text { Situationen, in welchen Du } \\
\text { heute mit Mitstudierenden } \\
\text { interagiert hast. [...] Bitte } \\
\text { benenne Deine Interaktionen } \\
\text { mit 1-2 Stichwörtern (z.B. } \\
\text { „Kaffee trinken mit Clara“), } \\
\text { sodass du sie für die nächsten } \\
\text { Minuten wiedererkennen } \\
\text { kannst }\end{array}$ & & $\begin{array}{l}\text { Please think about the } \\
\text { situations in which you talked } \\
\text { to or did something together } \\
\text { with other people TODAY. } \\
{[\ldots] \text { Please name your }} \\
\text { interactions with } 1 \text { or } 2 \text { key } \\
\text { words so that you recognise } \\
\text { them in the next few minutes }\end{array}$ & & $\mathrm{x}$ & \\
\hline interactionB & Interaction B & $\begin{array}{l}\text { Bitte denke nun an } \\
\text { Situationen, in welchen Du } \\
\text { heute mit Mitstudierenden } \\
\text { interagiert hast. [...] Bitte } \\
\text { benenne Deine Interaktionen } \\
\text { mit 1-2 Stichwörtern sodass } \\
\text { du sie für die nächsten } \\
\text { Minuten wiedererkennen } \\
\text { kannst }\end{array}$ & & $\begin{array}{l}\text { Please think about the } \\
\text { situations in which you talked } \\
\text { to or did something together } \\
\text { with other people TODAY. } \\
\text { [...] Please name your } \\
\text { interactions with } 1 \text { or } 2 \text { key } \\
\text { words so that you recognise } \\
\text { them in the next few minutes }\end{array}$ & & $\mathrm{x}$ & \\
\hline interactionC & Interaction $\mathrm{C}$ & $\begin{array}{l}\text { Bitte denke nun an } \\
\text { Situationen, in welchen Du } \\
\text { heute mit Mitstudierenden } \\
\text { interagiert hast. [...] Bitte } \\
\text { benenne Deine Interaktionen } \\
\text { mit 1-2 Stichwörtern sodass } \\
\text { du sie für die nächsten } \\
\text { Minuten wiedererkennen } \\
\text { kannst }\end{array}$ & & $\begin{array}{l}\text { Please think about the } \\
\text { situations in which you talked } \\
\text { to or did something together } \\
\text { with other people TODAY. } \\
\text { [...] Please name your } \\
\text { interactions with } 1 \text { or } 2 \text { key } \\
\text { words so that you recognise } \\
\text { them in the next few minutes }\end{array}$ & & $\mathrm{x}$ & \\
\hline interactionD & Interaction D & $\begin{array}{l}\text { Bitte denke nun an } \\
\text { Situationen, in welchen Du } \\
\text { heute mit Mitstudierenden } \\
\text { interagiert hast. [...] Bitte } \\
\text { benenne Deine Interaktionen } \\
\text { mit 1-2 Stichwörtern sodass } \\
\text { du sie für die nächsten } \\
\text { Minuten wiedererkennen } \\
\text { kannst }\end{array}$ & & $\begin{array}{l}\text { Please think about the } \\
\text { situations in which you talked } \\
\text { to or did something together } \\
\text { with other people TODAY. } \\
{[\ldots . .] \text { Please name your }} \\
\text { interactions with } 1 \text { or } 2 \text { key } \\
\text { words so that you recognise } \\
\text { them in the next few minutes }\end{array}$ & & $\mathrm{x}$ & \\
\hline interactionE & Interaction $\mathrm{E}$ & $\begin{array}{l}\text { Bitte denke nun an } \\
\text { Situationen, in welchen Du } \\
\text { heute mit Mitstudierenden } \\
\text { interagiert hast. [...] Bitte } \\
\text { benenne Deine Interaktionen } \\
\text { mit } 1-2 \text { Stichwörtern sodass } \\
\text { du sie für die nächsten } \\
\text { Minuten wiedererkennen } \\
\text { kannst }\end{array}$ & & $\begin{array}{l}\text { Please think about the } \\
\text { situations in which you talked } \\
\text { to or did something together } \\
\text { with other people TODAY. } \\
{[\ldots .] \text { Please name your }} \\
\text { interactions with } 1 \text { or } 2 \text { key } \\
\text { words so that you recognise } \\
\text { them in the next few minutes }\end{array}$ & & $\mathrm{x}$ & \\
\hline interactionA.Type & $\begin{array}{l}\text { Interaction A } \\
\text { Type }\end{array}$ & $\begin{array}{l}\text { Was für eine Situation war } \\
\text { Situation A? }\end{array}$ & $\begin{array}{l}1=\text { Lernen, Hausaufgaben, } 2 \\
=\text { Arbeit, } 3=\text { Sport, } 4= \\
\text { Gespräch, } 5=\text { einen trinken } \\
\text { gehen, } 6=\text { gemeinsamer Weg, } \\
7=\text { Date, Rendezvous, } 8= \\
\text { Freizeit Aktivität, } 9= \\
\text { Andere }(\text { mehrere Antworten } \\
\text { möglich) }\end{array}$ & $\begin{array}{l}\text { What was the nature of } \\
\text { situation A? }\end{array}$ & $\begin{array}{l}1=\text { studying,homework, } 2= \\
\text { work, } 3=\text { sports, } 4= \\
\text { conversation, } 5=\text { going for a } \\
\text { drink, } 6=\text { travelling, } 7= \\
\text { date, } 8=\text { other pastime, } 9= \\
\text { other }\end{array}$ & $\mathrm{x}$ & \\
\hline interactionA.P1 & $\begin{array}{l}\text { Interaction A - } \\
\text { who was } \\
\text { present, } \\
\text { person } 1\end{array}$ & $\begin{array}{l}\text { Wer war an Interaktion A } \\
\text { beteiligt? (Person 1) }\end{array}$ & & $\begin{array}{l}\text { Who was present in situation } \\
\mathrm{A} \text { ? (person 1) }\end{array}$ & & $\mathrm{x}$ & \\
\hline interactionA.StartHour & $\begin{array}{l}\text { Interaction A - } \\
\text { start time, } \\
\text { hour }\end{array}$ & $\begin{array}{l}\text { Von wann bis wann hat } \\
\text { Interaktion A stattgefunden? }\end{array}$ & & $\begin{array}{l}\text { At what time did situation A } \\
\text { happen? }\end{array}$ & & $\mathrm{x}$ & \\
\hline
\end{tabular}




\begin{tabular}{|c|c|c|c|}
\hline VarName & VariableLabel & WordingDE & ValueLabelsDE_Linked \\
\hline interactionA.StartMinute & $\begin{array}{l}\text { Interaction A - } \\
\text { start time, } \\
\text { minute }\end{array}$ & $\begin{array}{l}\text { Von wann bis wann hat } \\
\text { Interaktion A stattgefunden? }\end{array}$ & \\
\hline interactionA.EndHour & $\begin{array}{l}\text { Interaction A - } \\
\text { end time, hour }\end{array}$ & $\begin{array}{l}\text { Von wann bis wann hat } \\
\text { Interaktion A stattgefunden? }\end{array}$ & \\
\hline interactionA.EndMinute & $\begin{array}{l}\text { Interaction A - } \\
\text { end time, } \\
\text { minute }\end{array}$ & $\begin{array}{l}\text { Von wann bis wann hat } \\
\text { Interaktion A stattgefunden? }\end{array}$ & \\
\hline interactionA.Pleasant & $\begin{array}{l}\text { Interaction A - } \\
\text { character: } \\
\text { pleasant }\end{array}$ & $\begin{array}{l}\text { Wie hast Du Situation A } \\
\text { empfunden? }\end{array}$ & $\begin{array}{l}1=7 \text {-Punkte Skala, sehr } \\
\text { angenehm bis sehr } \\
\text { unangenehm, } 2=7 \text {-Punkte } \\
\text { Skala, sehr angenehm bis sehr } \\
\text { unangenehm, } 3=7 \text {-Punkte } \\
\text { Skala, sehr angenehm bis sehr } \\
\text { unangenehm, } 4=7 \text {-Punkte } \\
\text { Skala, sehr angenehm bis sehr } \\
\text { unangenehm, } 5=7 \text {-Punkte } \\
\text { Skala, sehr angenehm bis sehr } \\
\text { unangenehm, } 6=7 \text {-Punkte } \\
\text { Skala, sehr angenehm bis sehr } \\
\text { unangenehm, } 7=7 \text {-Punkte } \\
\text { Skala, sehr angenehm bis sehr } \\
\text { unangenehm }\end{array}$ \\
\hline interactionA.Energetic & $\begin{array}{l}\text { Interaction A - } \\
\text { character }\end{array}$ & $\begin{array}{l}\text { Wie hast Du Situation A } \\
\text { empfunden? }\end{array}$ & $\begin{array}{l}1=7 \text {-Punkte Skala, sehr } \\
\text { ruhig bis sehr energiegeladen, } \\
2=7 \text {-Punkte Skala, sehr } \\
\text { ruhig bis sehr energiegeladen, } \\
3=7 \text {-Punkte Skala, sehr } \\
\text { ruhig bis sehr energiegeladen, } \\
4=7 \text {-Punkte Skala, sehr } \\
\text { ruhig bis sehr energiegeladen, } \\
5=7 \text {-Punkte Skala, sehr } \\
\text { ruhig bis sehr energiegeladen, } \\
6=7 \text {-Punkte Skala, sehr } \\
\text { ruhig bis sehr energiegeladen, } \\
7=7 \text {-Punkte Skala, sehr } \\
\text { ruhig bis sehr energiegeladen }\end{array}$ \\
\hline interactionA.Personal & $\begin{array}{l}\text { Interaction A - } \\
\text { character }\end{array}$ & $\begin{array}{l}\text { Wie hast Du Situation A } \\
\text { empfunden? }\end{array}$ & $\begin{array}{l}1=7 \text {-Punkte Skala, sehr } \\
\text { oberfächlich bis sehr } \\
\text { persönlich, } 2=7 \text {-Punkte } \\
\text { Skala, sehr oberflächlich bis } \\
\text { sehr persönlich, } 3=7 \text {-Punkte } \\
\text { Skala, sehr oberflächlich bis } \\
\text { sehr persönlich, } 4=7 \text {-Punkte } \\
\text { Skala, sehr oberflächlich bis } \\
\text { sehr persönlich, } 5=7 \text {-Punkte } \\
\text { Skala, sehr oberflächlich bis } \\
\text { sehr persönlich, } 6=7 \text {-Punkte } \\
\text { Skala, sehr oberflächlich bis } \\
\text { sehr persönlich, } 7=7 \text {-Punkte } \\
\text { Skala, sehr oberflächlich bis } \\
\text { sehr persönlich }\end{array}$ \\
\hline interactionB.Type & $\begin{array}{l}\text { Interaction B } \\
\text { Type }\end{array}$ & $\begin{array}{l}\text { Was für eine Situation war } \\
\text { Situation B? }\end{array}$ & $\begin{array}{l}1=\text { Lernen, Hausaufgaben, } 2 \\
=\text { Arbeit, } 3=\text { Sport, } 4= \\
\text { Gespräch, } 5=\text { einen trinken } \\
\text { gehen, } 6=\text { gemeinsamer Weg, } \\
7=\text { Date, Rendezvous, } 8= \\
\text { Freizeit Aktivität, } 9= \\
\text { Andere (mehrere Antworten } \\
\text { möglich) }\end{array}$ \\
\hline
\end{tabular}

WordingEN

ValueLabelsEN_Linked

At what time did situation A

happen?

At what time did situation A

$\mathrm{x}$

appen?

At what time did situation A

How would you characterize

$1=7$ point scale, very
pleasant to very unpleasant, 2

$\mathrm{x}$

situation A based on your

$=7$ point scale, very pleasant

$=7$ point scale, very pleas
to very unpleasant, $3=7$

point scale, very pleasant to

very unpleasant, $4=7$ point

very unpleasant, $4=7$ pein

unpleasant, $5=7$ point scale

very pleasant to very

unpleasant, $6=7$ point scale

very pleasant to very

unpleasant, $7=7$ point scale,

very pleasant to very

unpleasant

How would you characterize

situation A based on your

$1=7$ point scale, very quiet

to very energetic, $2=7$ point

scale, very quiet to very

energetic, $3=7$ point scale,

very quiet to very energetic, 4

$=7$ point scale, very quiet to
very energetic, $5=7$ point

scale, very quiet to very

energetic, $6=7$ point scale,

very quiet to very energetic, 7
$=7$ point scale, very quiet to

very energetic

How would you characterize

situation A based on your

personal experience?

$1=7$ point scale, very

superficial to very personal,

$=7$ point scale, very

superficial to very personal,

$=7$ point scale, very

superficial to very personal,

$=7$ point scale, very

7 point scale, versonal, 5

$=7$ point scale, very

7 point tole, personal, 6

-7 point scale, very

7 point to very personal, 7

superficial to very personal

What was the nature of

1 = studying,homework, $2=$

work, $3=$ sports, $4=$

conversation, $5=$ going for

drink, $6=$ travelling, $7=$

date, $8=$ other pastime, $9=$

other 


\begin{tabular}{|c|c|c|c|}
\hline VarName & VariableLabel & WordingDE & ValueLabelsDE_Linked \\
\hline interactionB.P1 & $\begin{array}{l}\text { Interaction B - } \\
\text { who was } \\
\text { present, } \\
\text { person } 1\end{array}$ & $\begin{array}{l}\text { Wer war an Interaktion B } \\
\text { beteiligt? (Person 1) }\end{array}$ & \\
\hline interactionB.StartHour & $\begin{array}{l}\text { Interaction B - } \\
\text { start time, } \\
\text { hour }\end{array}$ & $\begin{array}{l}\text { Von wann bis wann hat } \\
\text { Interaktion B stattgefunden? }\end{array}$ & \\
\hline interactionB.StartMinute & $\begin{array}{l}\text { Interaction B - } \\
\text { start time, } \\
\text { minute }\end{array}$ & $\begin{array}{l}\text { Von wann bis wann hat } \\
\text { Interaktion B stattgefunden? }\end{array}$ & \\
\hline interactionB.EndHour & $\begin{array}{l}\text { Interaction B - } \\
\text { end time, hour }\end{array}$ & $\begin{array}{l}\text { Von wann bis wann hat } \\
\text { Interaktion B stattgefunden? }\end{array}$ & \\
\hline interactionB.EndMinute & $\begin{array}{l}\text { Interaction B - } \\
\text { end time, } \\
\text { minute }\end{array}$ & $\begin{array}{l}\text { Von wann bis wann hat } \\
\text { Interaktion B stattgefunden? }\end{array}$ & \\
\hline interactionB.Pleasant & $\begin{array}{l}\text { Interaction B - } \\
\text { character: } \\
\text { pleasant }\end{array}$ & $\begin{array}{l}\text { Wie hast Du Situation B } \\
\text { empfunden? }\end{array}$ & $\begin{array}{l}1=7 \text {-Punkte Skala, sehr } \\
\text { angenehm bis sehr } \\
\text { unangenehm, } 2=7 \text {-Punkte } \\
\text { Skala, sehr angenehm bis sehr } \\
\text { unangenehm, } 3=7 \text {-Punkte } \\
\text { Skala, sehr angenehm bis sehr } \\
\text { unangenehm, } 4=7 \text {-Punkte } \\
\text { Skala, sehr angenehm bis sehr } \\
\text { unangenehm, } 5=7 \text {-Punkte } \\
\text { Skala, sehr angenehm bis sehr } \\
\text { unangenehm, } 6=7 \text {-Punkte } \\
\text { Skala, sehr angenehm bis sehr } \\
\text { unangenehm, } 7=7 \text {-Punkte } \\
\text { Skala, sehr angenehm bis sehr } \\
\text { unangenehm }\end{array}$ \\
\hline interactionB.Energetic & $\begin{array}{l}\text { Interaction B - } \\
\text { character }\end{array}$ & $\begin{array}{l}\text { Wie hast Du Situation B } \\
\text { empfunden? }\end{array}$ & $\begin{array}{l}1=7 \text {-Punkte Skala, sehr } \\
\text { ruhig bis sehr energiegeladen, } \\
2=7 \text {-Punkte Skala, sehr } \\
\text { ruhig bis sehr energiegeladen, } \\
3=7 \text {-Punkte Skala, sehr } \\
\text { ruhig bis sehr energiegeladen, } \\
4=7 \text {-Punkte Skala, sehr } \\
\text { ruhig bis sehr energiegeladen, } \\
5=7 \text {-Punkte Skala, sehr } \\
\text { ruhig bis sehr energiegeladen, } \\
6=7 \text {-Punkte Skala, sehr } \\
\text { ruhig bis sehr energiegeladen, } \\
7=7 \text {-Punkte Skala, sehr } \\
\text { ruhig bis sehr energiegeladen }\end{array}$ \\
\hline interactionB.Personal & $\begin{array}{l}\text { Interaction B - } \\
\text { character }\end{array}$ & $\begin{array}{l}\text { Wie hast Du Situation B } \\
\text { empfunden? }\end{array}$ & $\begin{array}{l}1=7 \text {-Punkte Skala, sehr } \\
\text { oberfächlich bis sehr } \\
\text { persönlich, } 2=7 \text {-Punkte } \\
\text { Skala, sehr oberflächlich bis } \\
\text { sehr persönlich, } 3=7 \text {-Punkte } \\
\text { Skala, sehr oberflächlich bis } \\
\text { sehr persönlich, } 4=7 \text {-Punkte } \\
\text { Skala, sehr oberflächlich bis } \\
\text { sehr persönlich, } 5=7 \text {-Punkte } \\
\text { Skala, sehr oberflächlich bis } \\
\text { sehr persönlich, } 6=7 \text {-Punkte } \\
\text { Skala, sehr oberflächlich bis } \\
\text { sehr persönlich, } 7=7 \text {-Punkte } \\
\text { Skala, sehr oberflächlich bis } \\
\text { sehr persönlich }\end{array}$ \\
\hline
\end{tabular}

ValueLabelsEN_Linked

Who was present in situation

B? (person 1)

At what time did situation B happen?

At what time did situation B happen?

At what time did situation B happen?

At what time did situation B happen?

How would you characterize situation B based on your personal experience?

$1=7$ point scale, very

pleasant to very unpleasant, 2

$=7$ point scale, very pleasant

point scale, very pleasant to

very unpleasant, $4=7$ point

scale, very pleasant to very

unpleasant, $5=7$ point scale,

very pleasant to very

unpleasant, $6=7$ point scale,

very pleasant to very

unpleasant, $7=7$ point scale

very pleasant to very

unpleasant

How would you characterize situation B based on your

$1=7$ point scale, very quiet to very energetic, $2=7$ poin scale, very quiet to very

energetic, $3=7$ point scale,

very quiet to very energetic, 4

$=7$ point scale, very quiet to

very energetic, $5=7$ poin

scale, very quiet to very

energetic, $6=7$ point scale,

very quiet to very energetic, 7

$=7$ point scale, very quiet to very energetic

How would you characteriz personal experience?

$1=7$ point scale, very

superficial to very personal,

$=7$ point scale, very

superficial to very personal,

$=7$ point scale, very

superficial to very personal,

$=7$ point scale, very

superficial to very personal, 5

$=7$ point scale, very

superficial to very personal,

$=7$ point scale, very

superficial to very personal,

$=7$ point scale, very

superficial to very personal $\mathrm{x}$

$\mathrm{x}$

5




\begin{tabular}{|c|c|c|c|c|c|c|c|}
\hline VarName & VariableLabel & WordingDE & ValueLabelsDE_Linked & WordingEN & ValueLabelsEN_Linked & Affect & Studying \\
\hline interactionC.Type & $\begin{array}{l}\text { Interaction C } \\
\text { Type }\end{array}$ & $\begin{array}{l}\text { Was für eine Situation war } \\
\text { Situation C? }\end{array}$ & $\begin{array}{l}1=\text { Lernen, Hausaufgaben, } 2 \\
=\text { Arbeit, } 3=\text { Sport, } 4= \\
\text { Gespräch, } 5=\text { einen trinken } \\
\text { gehen, } 6=\text { gemeinsamer Weg, } \\
7=\text { Date, Rendezvous, } 8= \\
\text { Freizeit Aktivität, } 9= \\
\text { Andere (mehrere Antworten } \\
\text { möglich) }\end{array}$ & $\begin{array}{l}\text { What was the nature of } \\
\text { situation } C \text { ? }\end{array}$ & $\begin{array}{l}1=\text { studying,homework, } 2= \\
\text { work, } 3=\text { sports, } 4= \\
\text { conversation, } 5=\text { going for a } \\
\text { drink, } 6=\text { travelling, } 7= \\
\text { date, } 8=\text { other pastime, } 9= \\
\text { other }\end{array}$ & $\mathrm{x}$ & \\
\hline interactionC.P1 & $\begin{array}{l}\text { Interaction C - } \\
\text { who was } \\
\text { present, } \\
\text { person } 1\end{array}$ & $\begin{array}{l}\text { Wer war an Interaktion C } \\
\text { beteiligt? (Person 1) }\end{array}$ & & $\begin{array}{l}\text { Who was present in situation } \\
\text { C? (person } 1)\end{array}$ & & $\mathrm{x}$ & \\
\hline interactionC.StartHour & $\begin{array}{l}\text { Interaction C - } \\
\text { start time, } \\
\text { hour }\end{array}$ & $\begin{array}{l}\text { Von wann bis wann hat } \\
\text { Interaktion C stattgefunden? }\end{array}$ & & $\begin{array}{l}\text { At what time did situation } \mathrm{C} \\
\text { happen? }\end{array}$ & & $\mathrm{x}$ & \\
\hline interactionC.StartMinute & $\begin{array}{l}\text { Interaction } \mathrm{C}- \\
\text { start time, } \\
\text { minute }\end{array}$ & $\begin{array}{l}\text { Von wann bis wann hat } \\
\text { Interaktion } \mathrm{C} \text { stattgefunden? }\end{array}$ & & $\begin{array}{l}\text { At what time did situation C } \\
\text { happen? }\end{array}$ & & $\mathrm{x}$ & \\
\hline interactionC.EndHour & $\begin{array}{l}\text { Interaction } \mathrm{C} \text { - } \\
\text { end time, hour }\end{array}$ & $\begin{array}{l}\text { Von wann bis wann hat } \\
\text { Interaktion } \mathrm{C} \text { stattgefunden? }\end{array}$ & & $\begin{array}{l}\text { At what time did situation } \mathrm{C} \\
\text { happen? }\end{array}$ & & $\mathrm{x}$ & \\
\hline interactionC.EndMinute & $\begin{array}{l}\text { Interaction } \mathrm{C} \text { - } \\
\text { end time, } \\
\text { minute }\end{array}$ & $\begin{array}{l}\text { Von wann bis wann hat } \\
\text { Interaktion C stattgefunden? }\end{array}$ & & $\begin{array}{l}\text { At what time did situation C } \\
\text { happen? }\end{array}$ & & $\mathrm{x}$ & \\
\hline interactionC.Pleasant & $\begin{array}{l}\text { Interaction C - } \\
\text { character: } \\
\text { pleasant }\end{array}$ & $\begin{array}{l}\text { Wie hast Du Situation C } \\
\text { empfunden? }\end{array}$ & $\begin{array}{l}1=7 \text {-Punkte Skala, sehr } \\
\text { angenehm bis sehr } \\
\text { unangenehm, } 2=7 \text {-Punkte } \\
\text { Skala, sehr angenehm bis sehr } \\
\text { unangenehm, } 3=7 \text {-Punkte } \\
\text { Skala, sehr angenehm bis sehr } \\
\text { unangenehm, } 4=7 \text {-Punkte } \\
\text { Skala, sehr angenehm bis sehr } \\
\text { unangenehm, } 5=7 \text {-Punkte } \\
\text { Skala, sehr angenehm bis sehr } \\
\text { unangenehm, } 6=7 \text {-Punkte } \\
\text { Skala, sehr angenehm bis sehr } \\
\text { unangenehm, } 7=7 \text {-Punkte } \\
\text { Skala, sehr angenehm bis sehr } \\
\text { unangenehm }\end{array}$ & $\begin{array}{l}\text { How would you characterize } \\
\text { situation C based on your } \\
\text { personal experience? }\end{array}$ & $\begin{array}{l}1=7 \text { point scale, very } \\
\text { pleasant to very unpleasant, } 2 \\
=7 \text { point scale, very pleasant } \\
\text { to very unpleasant, } 3=7 \\
\text { point scale, very pleasant to } \\
\text { very unpleasant, } 4=7 \text { point } \\
\text { scale, very pleasant to very } \\
\text { unpleasant, } 5=7 \text { point scale, } \\
\text { very pleasant to very } \\
\text { unpleasant, } 6=7 \text { point scale, } \\
\text { very pleasant to very } \\
\text { unpleasant, } 7=7 \text { point scale, } \\
\text { very pleasant to very } \\
\text { unpleasant }\end{array}$ & $\mathrm{x}$ & \\
\hline interactionC.Energetic & $\begin{array}{l}\text { Interaction C - } \\
\text { character }\end{array}$ & $\begin{array}{l}\text { Wie hast Du Situation C } \\
\text { empfunden? }\end{array}$ & $\begin{array}{l}1=7 \text {-Punkte Skala, sehr } \\
\text { ruhig bis sehr energiegeladen, } \\
2=7 \text {-Punkte Skala, sehr } \\
\text { ruhig bis sehr energiegeladen, } \\
3=7 \text {-Punkte Skala, sehr } \\
\text { ruhig bis sehr energiegeladen, } \\
4=7 \text {-Punkte Skala, sehr } \\
\text { ruhig bis sehr energiegeladen, } \\
5=7 \text {-Punkte Skala, sehr } \\
\text { ruhig bis sehr energiegeladen, } \\
6=7 \text {-Punkte Skala, sehr } \\
\text { ruhig bis sehr energiegeladen, } \\
7=7 \text {-Punkte Skala, sehr } \\
\text { ruhig bis sehr energiegeladen }\end{array}$ & $\begin{array}{l}\text { How would you characterize } \\
\text { situation C based on your } \\
\text { personal experience? }\end{array}$ & $\begin{array}{l}1=7 \text { point scale, very quiet } \\
\text { to very energetic, } 2=7 \text { point } \\
\text { scale, very quiet to very } \\
\text { energetic, } 3=7 \text { point scale, } \\
\text { very quiet to very energetic, } 4 \\
=7 \text { point scale, very quiet to } \\
\text { very energetic, } 5=7 \text { point } \\
\text { scale, very quiet to very } \\
\text { energetic, } 6=7 \text { point scale, } \\
\text { very quiet to very energetic, } 7 \\
=7 \text { point scale, very quiet to } \\
\text { very energetic }\end{array}$ & $\mathrm{x}$ & \\
\hline
\end{tabular}




\begin{tabular}{|c|c|c|c|c|c|c|c|}
\hline VarName & VariableLabel & WordingDE & ValueLabelsDE_Linked & WordingEN & ValueLabelsEN_Linked & Affect & Studying \\
\hline interactionC.Personal & $\begin{array}{l}\text { Interaction C - } \\
\text { character }\end{array}$ & $\begin{array}{l}\text { Wie hast Du Situation C } \\
\text { empfunden? }\end{array}$ & $\begin{array}{l}1=7 \text {-Punkte Skala, sehr } \\
\text { oberflächlich bis sehr } \\
\text { persönlich, } 2=7 \text {-Punkte } \\
\text { Skala, sehr oberflächlich bis } \\
\text { sehr persönlich, } 3=7 \text {-Punkte } \\
\text { Skala, sehr oberflächlich bis } \\
\text { sehr persönlich, } 4=7 \text {-Punkte } \\
\text { Skala, sehr oberflächlich bis } \\
\text { sehr persönlich, } 5=7 \text {-Punkte } \\
\text { Skala, sehr oberflächlich bis } \\
\text { sehr persönlich, } 6=7 \text {-Punkte } \\
\text { Skala, sehr oberflächlich bis } \\
\text { sehr persönlich, } 7=7 \text {-Punkte } \\
\text { Skala, sehr oberflächlich bis } \\
\text { sehr persönlich }\end{array}$ & $\begin{array}{l}\text { How would you characterize } \\
\text { situation C based on your } \\
\text { personal experience? }\end{array}$ & $\begin{array}{l}1=7 \text { point scale, very } \\
\text { superficial to very personal, } 2 \\
=7 \text { point scale, very } \\
\text { superficial to very personal, } 3 \\
=7 \text { point scale, very } \\
\text { superficial to very personal, } 4 \\
=7 \text { point scale, very } \\
\text { superficial to very personal, } 5 \\
=7 \text { point scale, very } \\
\text { superficial to very personal, } 6 \\
=7 \text { point scale, very } \\
\text { superficial to very personal, } 7 \\
=7 \text { point scale, very } \\
\text { superficial to very personal }\end{array}$ & $\mathrm{x}$ & \\
\hline interactionD.Type & $\begin{array}{l}\text { Interaction D } \\
\text { Type }\end{array}$ & $\begin{array}{l}\text { Was für eine Situation war } \\
\text { Situation D? }\end{array}$ & $\begin{array}{l}1=\text { Lernen, Hausaufgaben, } 2 \\
=\text { Arbeit, } 3=\text { Sport, } 4= \\
\text { Gespräch, } 5=\text { einen trinken } \\
\text { gehen, } 6=\text { gemeinsamer Weg, } \\
7=\text { Date, Rendezvous, } 8= \\
\text { Freizeit Aktivität, } 9= \\
\text { Andere (mehrere Antworten } \\
\text { möglich) }\end{array}$ & $\begin{array}{l}\text { What was the nature of } \\
\text { situation D? }\end{array}$ & $\begin{array}{l}1=\text { studying,homework, } 2= \\
\text { work, } 3=\text { sports, } 4= \\
\text { conversation, } 5=\text { going for a } \\
\text { drink, } 6=\text { travelling, } 7= \\
\text { date, } 8=\text { other pastime, } 9= \\
\text { other }\end{array}$ & $\mathrm{x}$ & \\
\hline interactionD.P1 & $\begin{array}{l}\text { Interaction D - } \\
\text { who was } \\
\text { present, } \\
\text { person } 1\end{array}$ & $\begin{array}{l}\text { Wer war an Interaktion D } \\
\text { beteiligt? (Person } 1 \text { ) }\end{array}$ & & $\begin{array}{l}\text { Who was present in situation } \\
\text { D? (person 1) }\end{array}$ & & $\mathrm{x}$ & \\
\hline interactionD.StartHour & $\begin{array}{l}\text { Interaction D - } \\
\text { start time, } \\
\text { hour }\end{array}$ & $\begin{array}{l}\text { Von wann bis wann hat } \\
\text { Interaktion A stattgefunden? }\end{array}$ & & $\begin{array}{l}\text { At what time did situation D } \\
\text { happen? }\end{array}$ & & $\mathrm{x}$ & \\
\hline interactionD.StartMinut $\epsilon$ & $\begin{array}{l}\text { Interaction D - } \\
\text { start time, } \\
\text { minute }\end{array}$ & $\begin{array}{l}\text { Von wann bis wann hat } \\
\text { Interaktion A stattgefunden? }\end{array}$ & & $\begin{array}{l}\text { At what time did situation D } \\
\text { happen? }\end{array}$ & & $\mathrm{x}$ & \\
\hline interactionD.EndHour & $\begin{array}{l}\text { Interaction D - } \\
\text { end time, hour }\end{array}$ & $\begin{array}{l}\text { Von wann bis wann hat } \\
\text { Interaktion A stattgefunden? }\end{array}$ & & $\begin{array}{l}\text { At what time did situation D } \\
\text { happen? }\end{array}$ & & $\mathrm{x}$ & \\
\hline interactionD.EndMinute & $\begin{array}{l}\text { Interaction D - } \\
\text { end time, } \\
\text { minute }\end{array}$ & $\begin{array}{l}\text { Von wann bis wann hat } \\
\text { Interaktion A stattgefunden? }\end{array}$ & & $\begin{array}{l}\text { At what time did situation D } \\
\text { happen? }\end{array}$ & & $\mathrm{x}$ & \\
\hline interactionD.Pleasant & $\begin{array}{l}\text { Interaction D - } \\
\text { character: } \\
\text { pleasant }\end{array}$ & $\begin{array}{l}\text { Wie hast Du Situation A } \\
\text { empfunden? }\end{array}$ & $\begin{array}{l}1=7 \text {-Punkte Skala, sehr } \\
\text { angenehm bis sehr } \\
\text { unangenehm, } 2=7 \text {-Punkte } \\
\text { Skala, sehr angenehm bis sehr } \\
\text { unangenehm, } 3=7 \text {-Punkte } \\
\text { Skala, sehr angenehm bis sehr } \\
\text { unangenehm, } 4=7 \text {-Punkte } \\
\text { Skala, sehr angenehm bis sehr } \\
\text { unangenehm, } 5=7 \text {-Punkte } \\
\text { Skala, sehr angenehm bis sehr } \\
\text { unangenehm, } 6=7 \text {-Punkte } \\
\text { Skala, sehr angenehm bis sehr } \\
\text { unangenehm, } 7=7 \text {-Punkte } \\
\text { Skala, sehr angenehm bis sehr } \\
\text { unangenehm }\end{array}$ & $\begin{array}{l}\text { How would you characterize } \\
\text { situation D based on your } \\
\text { personal experience? }\end{array}$ & $\begin{array}{l}1=7 \text { point scale, very } \\
\text { pleasant to very unpleasant, } 2 \\
=7 \text { point scale, very pleasant } \\
\text { to very unpleasant, } 3=7 \\
\text { point scale, very pleasant to } \\
\text { very unpleasant, } 4=7 \text { point } \\
\text { scale, very pleasant to very } \\
\text { unpleasant, } 5=7 \text { point scale, } \\
\text { very pleasant to very } \\
\text { unpleasant, } 6=7 \text { point scale, } \\
\text { very pleasant to very } \\
\text { unpleasant, } 7=7 \text { point scale, } \\
\text { very pleasant to very } \\
\text { unpleasant }\end{array}$ & $\mathrm{x}$ & \\
\hline
\end{tabular}




\begin{tabular}{|c|c|c|c|c|c|c|c|}
\hline VarName & VariableLabel & WordingDE & ValueLabelsDE_Linked & WordingEN & ValueLabelsEN_Linked & Affect & Studying \\
\hline interactionD.Energetic & $\begin{array}{l}\text { Interaction D - } \\
\text { character }\end{array}$ & $\begin{array}{l}\text { Wie hast Du Situation A } \\
\text { empfunden? }\end{array}$ & $\begin{array}{l}1=7 \text {-Punkte Skala, sehr } \\
\text { ruhig bis sehr energiegeladen, } \\
2=7 \text {-Punkte Skala, sehr } \\
\text { ruhig bis sehr energiegeladen, } \\
3=7 \text {-Punkte Skala, sehr } \\
\text { ruhig bis sehr energiegeladen, } \\
4=7 \text {-Punkte Skala, sehr } \\
\text { ruhig bis sehr energiegeladen, } \\
5=7 \text {-Punkte Skala, sehr } \\
\text { ruhig bis sehr energiegeladen, } \\
6=7 \text {-Punkte Skala, sehr } \\
\text { ruhig bis sehr energiegeladen, } \\
7=7 \text {-Punkte Skala, sehr } \\
\text { ruhig bis sehr energiegeladen }\end{array}$ & $\begin{array}{l}\text { How would you characterize } \\
\text { situation D based on your } \\
\text { personal experience? }\end{array}$ & $\begin{array}{l}1=7 \text { point scale, very quiet } \\
\text { to very energetic, } 2=7 \text { point } \\
\text { scale, very quiet to very } \\
\text { energetic, } 3=7 \text { point scale, } \\
\text { very quiet to very energetic, } 4 \\
=7 \text { point scale, very quiet to } \\
\text { very energetic, } 5=7 \text { point } \\
\text { scale, very quiet to very } \\
\text { energetic, } 6=7 \text { point scale, } \\
\text { very quiet to very energetic, } 7 \\
=7 \text { point scale, very quiet to } \\
\text { very energetic }\end{array}$ & $\mathrm{x}$ & \\
\hline interactionD.Personal & $\begin{array}{l}\text { Interaction D - } \\
\text { character }\end{array}$ & $\begin{array}{l}\text { Wie hast Du Situation A } \\
\text { empfunden? }\end{array}$ & $\begin{array}{l}1=7 \text {-Punkte Skala, sehr } \\
\text { oberflächlich bis sehr } \\
\text { persönlich, } 2=7 \text {-Punkte } \\
\text { Skala, sehr oberflächlich bis } \\
\text { sehr persönlich, } 3=7 \text {-Punkte } \\
\text { Skala, sehr oberflächlich bis } \\
\text { sehr persönlich, } 4=7 \text {-Punkte } \\
\text { Skala, sehr oberflächlich bis } \\
\text { sehr persönlich, } 5=7 \text {-Punkte } \\
\text { Skala, sehr oberflächlich bis } \\
\text { sehr persönlich, } 6=7 \text {-Punkte } \\
\text { Skala, sehr oberflächlich bis } \\
\text { sehr persönlich, } 7=7 \text {-Punkte } \\
\text { Skala, sehr oberflächlich bis } \\
\text { sehr persönlich }\end{array}$ & $\begin{array}{l}\text { How would you characterize } \\
\text { situation D based on your } \\
\text { personal experience? }\end{array}$ & $\begin{array}{l}1=7 \text { point scale, very } \\
\text { superficial to very personal, } 2 \\
=7 \text { point scale, very } \\
\text { superficial to very personal, } 3 \\
=7 \text { point scale, very } \\
\text { superficial to very personal, } 4 \\
=7 \text { point scale, very } \\
\text { superficial to very personal, } 5 \\
=7 \text { point scale, very } \\
\text { superficial to very personal, } 6 \\
=7 \text { point scale, very } \\
\text { superficial to very personal, } 7 \\
=7 \text { point scale, very } \\
\text { superficial to very personal }\end{array}$ & $\mathrm{x}$ & \\
\hline interactionE.Type & $\begin{array}{l}\text { Interaction E } \\
\text { Type }\end{array}$ & $\begin{array}{l}\text { Was für eine Situation war } \\
\text { Situation E? }\end{array}$ & $\begin{array}{l}1=\text { Lernen, Hausaufgaben, } 2 \\
=\text { Arbeit, } 3=\text { Sport, } 4= \\
\text { Gespräch, } 5=\text { einen trinken } \\
\text { gehen, } 6=\text { gemeinsamer Weg, } \\
7=\text { Date, Rendezvous, } 8= \\
\text { Freizeit Aktivität, } 9= \\
\text { Andere (mehrere Antworten } \\
\text { möglich) }\end{array}$ & $\begin{array}{l}\text { What was the nature of } \\
\text { situation E? }\end{array}$ & $\begin{array}{l}1=\text { studying,homework, } 2= \\
\text { work, } 3=\text { sports, } 4= \\
\text { conversation, } 5=\text { going for a } \\
\text { drink, } 6=\text { travelling, } 7= \\
\text { date, } 8=\text { other pastime, } 9= \\
\text { other }\end{array}$ & $\mathrm{x}$ & \\
\hline interactionE.P1 & $\begin{array}{l}\text { Interaction E - } \\
\text { who was } \\
\text { present, } \\
\text { person } 1\end{array}$ & $\begin{array}{l}\text { Wer war an Interaktion } \mathrm{E} \\
\text { beteiligt? (Person } 1 \text { ) }\end{array}$ & & $\begin{array}{l}\text { Who was present in situation } \\
\text { E? (person } 1)\end{array}$ & & $\mathrm{x}$ & \\
\hline interactionE.StartHour & $\begin{array}{l}\text { Interaction E - } \\
\text { start time, } \\
\text { hour }\end{array}$ & $\begin{array}{l}\text { Von wann bis wann hat } \\
\text { Interaktion A stattgefunden? }\end{array}$ & & $\begin{array}{l}\text { At what time did situation } \mathrm{E} \\
\text { happen? }\end{array}$ & & $\mathrm{x}$ & \\
\hline interactionE.StartMinute & $\begin{array}{l}\text { Interaction } \mathrm{E}- \\
\text { start time, } \\
\text { minute }\end{array}$ & $\begin{array}{l}\text { Von wann bis wann hat } \\
\text { Interaktion A stattgefunden? }\end{array}$ & & $\begin{array}{l}\text { At what time did situation } \mathrm{E} \\
\text { happen? }\end{array}$ & & $\mathrm{x}$ & \\
\hline interactionE.EndHour & $\begin{array}{l}\text { Interaction E - } \\
\text { end time, hour }\end{array}$ & $\begin{array}{l}\text { Von wann bis wann hat } \\
\text { Interaktion A stattgefunden? }\end{array}$ & & $\begin{array}{l}\text { At what time did situation } \mathrm{E} \\
\text { happen? }\end{array}$ & & $\mathrm{x}$ & \\
\hline interactionE.EndMinute & $\begin{array}{l}\text { Interaction } \mathrm{E}- \\
\text { end time, } \\
\text { minute }\end{array}$ & $\begin{array}{l}\text { Von wann bis wann hat } \\
\text { Interaktion A stattgefunden? }\end{array}$ & & $\begin{array}{l}\text { At what time did situation } \mathrm{E} \\
\text { happen? }\end{array}$ & & $\mathrm{x}$ & \\
\hline
\end{tabular}




\begin{tabular}{|c|c|c|c|c|c|c|c|}
\hline VarName & VariableLabel & WordingDE & ValueLabelsDE_Linked & WordingEN & ValueLabelsEN_Linked & Affect & Studying \\
\hline interactionE.Pleasant & $\begin{array}{l}\text { Interaction E - } \\
\text { character: } \\
\text { pleasant }\end{array}$ & $\begin{array}{l}\text { Wie hast Du Situation A } \\
\text { empfunden? }\end{array}$ & $\begin{array}{l}1=7 \text {-Punkte Skala, sehr } \\
\text { angenehm bis sehr } \\
\text { unangenehm, } 2=7 \text {-Punkte } \\
\text { Skala, sehr angenehm bis sehr } \\
\text { unangenehm, } 3=7 \text {-Punkte } \\
\text { Skala, sehr angenehm bis sehr } \\
\text { unangenehm, } 4=7 \text {-Punkte } \\
\text { Skala, sehr angenehm bis sehr } \\
\text { unangenehm, } 5=7 \text {-Punkte } \\
\text { Skala, sehr angenehm bis sehr } \\
\text { unangenehm, } 6=7 \text {-Punkte } \\
\text { Skala, sehr angenehm bis sehr } \\
\text { unangenehm, } 7=7 \text {-Punkte } \\
\text { Skala, sehr angenehm bis sehr } \\
\text { unangenehm }\end{array}$ & $\begin{array}{l}\text { How would you characterize } \\
\text { situation E based on your } \\
\text { personal experience? }\end{array}$ & $\begin{array}{l}1=7 \text { point scale, very } \\
\text { pleasant to very unpleasant, } 2 \\
=7 \text { point scale, very pleasant } \\
\text { to very unpleasant, } 3=7 \\
\text { point scale, very pleasant to } \\
\text { very unpleasant, } 4=7 \text { point } \\
\text { scale, very pleasant to very } \\
\text { unpleasant, } 5=7 \text { point scale, } \\
\text { very pleasant to very } \\
\text { unpleasant, } 6=7 \text { point scale, } \\
\text { very pleasant to very } \\
\text { unpleasant, } 7=7 \text { point scale, } \\
\text { very pleasant to very } \\
\text { unpleasant }\end{array}$ & $\mathrm{x}$ & \\
\hline interactionE.Energetic & $\begin{array}{l}\text { Interaction E - } \\
\text { character }\end{array}$ & $\begin{array}{l}\text { Wie hast Du Situation A } \\
\text { empfunden? }\end{array}$ & $\begin{array}{l}1=7 \text {-Punkte Skala, sehr } \\
\text { ruhig bis sehr energiegeladen, } \\
2=7 \text {-Punkte Skala, sehr } \\
\text { ruhig bis sehr energiegeladen, } \\
3=7 \text {-Punkte Skala, sehr } \\
\text { ruhig bis sehr energiegeladen, } \\
4=7 \text {-Punkte Skala, sehr } \\
\text { ruhig bis sehr energiegeladen, } \\
5=7 \text {-Punkte Skala, sehr } \\
\text { ruhig bis sehr energiegeladen, } \\
6=7 \text {-Punkte Skala, sehr } \\
\text { ruhig bis sehr energiegeladen, } \\
7=7 \text {-Punkte Skala, sehr } \\
\text { ruhig bis sehr energiegeladen }\end{array}$ & $\begin{array}{l}\text { How would you characterize } \\
\text { situation E based on your } \\
\text { personal experience? }\end{array}$ & $\begin{array}{l}1=7 \text { point scale, very quiet } \\
\text { to very energetic, } 2=7 \text { point } \\
\text { scale, very quiet to very } \\
\text { energetic, } 3=7 \text { point scale, } \\
\text { very quiet to very energetic, } 4 \\
=7 \text { point scale, very quiet to } \\
\text { very energetic, } 5=7 \text { point } \\
\text { scale, very quiet to very } \\
\text { energetic, } 6=7 \text { point scale, } \\
\text { very quiet to very energetic, } 7 \\
=7 \text { point scale, very quiet to } \\
\text { very energetic }\end{array}$ & $\mathrm{x}$ & \\
\hline interactionE.Personal & $\begin{array}{l}\text { Interaction E - } \\
\text { character }\end{array}$ & $\begin{array}{l}\text { Wie hast Du Situation A } \\
\text { empfunden? }\end{array}$ & $\begin{array}{l}1=7 \text {-Punkte Skala, sehr } \\
\text { oberfl̈chlich bis sehr } \\
\text { persönlich, } 2=7 \text {-Punkte } \\
\text { Skala, sehr oberfächlich bis } \\
\text { sehr persönlich, } 3=7 \text {-Punkte } \\
\text { Skala, sehr oberflächlich bis } \\
\text { sehr persönlich, } 4=7 \text {-Punkte } \\
\text { Skala, sehr oberflächlich bis } \\
\text { sehr persönlich, } 5=7 \text {-Punkte } \\
\text { Skala, sehr oberflächlich bis } \\
\text { sehr persönlich, } 6=7 \text {-Punkte } \\
\text { Skala, sehr oberflächlich bis } \\
\text { sehr persönlich, } 7=7 \text {-Punkte } \\
\text { Skala, sehr oberflächlich bis } \\
\text { sehr persönlich }\end{array}$ & $\begin{array}{l}\text { How would you characterize } \\
\text { situation E based on your } \\
\text { personal experience? }\end{array}$ & $\begin{array}{l}1=7 \text { point scale, very } \\
\text { superficial to very personal, } 2 \\
=7 \text { point scale, very } \\
\text { superficial to very personal, } 3 \\
=7 \text { point scale, very } \\
\text { superficial to very personal, } 4 \\
=7 \text { point scale, very } \\
\text { superficial to very personal, } 5 \\
=7 \text { point scale, very } \\
\text { superficial to very personal, } 6 \\
=7 \text { point scale, very } \\
\text { supericial to very personal, } 7 \\
=7 \text { point scale, very } \\
\text { superficial to very personal }\end{array}$ & $\mathrm{x}$ & \\
\hline time.studied.hrs & Hours studied & $\begin{array}{l}\text { Wie viele Stunden hast Du } \\
\text { diese Woche für Dein } \\
\text { Studium gelernt (ausserhalb } \\
\text { von Vorlesungen oder } \\
\text { Übungsstunden)? }\end{array}$ & & $\begin{array}{l}\text { How many hours did you } \\
\text { study this week for your } \\
\text { degree (apart from lectures } \\
\text { and practicals)? }\end{array}$ & & & $\mathrm{x}$ \\
\hline time.studied.min & $\begin{array}{l}\text { Minutes } \\
\text { studied }\end{array}$ & $\begin{array}{l}\text { Wie viele Minuten hast Du } \\
\text { diese Woche für Dein } \\
\text { Studium gelernt (ausserhalb } \\
\text { von Vorlesungen oder } \\
\text { Übungsstunden)? }\end{array}$ & & $\begin{array}{l}\text { How many minutes did you } \\
\text { study this week for your } \\
\text { degree (apart from lectures } \\
\text { and practicals)? }\end{array}$ & & & $\mathrm{x}$ \\
\hline
\end{tabular}




\begin{tabular}{|c|c|c|c|c|c|c|c|}
\hline VarName & VariableLabel & WordingDE & ValueLabelsDE_Linked & WordingEN & ValueLabelsEN_Linked & Affect & Studying \\
\hline study.1 & $\begin{array}{l}\text { Self- } \\
\text { assessment } \\
\text { study } \\
\text { behaviour } \\
\text { (item 1) }\end{array}$ & $\begin{array}{l}3 \text { In welchem Masse würdest } \\
\text { Du den folgenden Aussagen } \\
\text { zustimmen (in Bezug auf } \\
\text { diese Woche)? Ich hätte mehr } \\
\text { lernen sollen. }\end{array}$ & $\begin{array}{l}1=7 \text {-Punkte Skala, sehr } \\
\text { angenehm bis sehr } \\
\text { unangenehm, } 2=7 \text {-Punkte } \\
\text { Skala, sehr angenehm bis sehr } \\
\text { unangenehm, } 3=7 \text {-Punkte } \\
\text { Skala, sehr angenehm bis sehr } \\
\text { unangenehm, } 4=7 \text {-Punkte } \\
\text { Skala, sehr angenehm bis sehr } \\
\text { unangenehm, } 5=7 \text {-Punkte } \\
\text { Skala, sehr angenehm bis sehr } \\
\text { unangenehm, } 6=7 \text {-Punkte } \\
\text { Skala, sehr angenehm bis sehr } \\
\text { unangenehm, } 7=7 \text {-Punkte } \\
\text { Skala, sehr angenehm bis sehr } \\
\text { unangenehm }\end{array}$ & $\begin{array}{l}\text { To what extent would you } \\
\text { agree with the following } \\
\text { statements (regarding this } \\
\text { week)? I should have studied } \\
\text { more. }\end{array}$ & $\begin{array}{l}1=7 \text { point scale, very } \\
\text { pleasant to very unpleasant, } 2 \\
=7 \text { point scale, very pleasant } \\
\text { to very unpleasant, } 3=7 \\
\text { point scale, very pleasant to } \\
\text { very unpleasant, } 4=7 \text { point } \\
\text { scale, very pleasant to very } \\
\text { unpleasant, } 5=7 \text { point scale, } \\
\text { very pleasant to very } \\
\text { unpleasant, } 6=7 \text { point scale, } \\
\text { very pleasant to very } \\
\text { unpleasant, } 7=7 \text { point scale, } \\
\text { very pleasant to very } \\
\text { unpleasant }\end{array}$ & & $\mathrm{x}$ \\
\hline study. 2 & $\begin{array}{l}\text { Self- } \\
\text { assessment } \\
\text { study } \\
\text { behaviour } \\
\text { (item 2) }\end{array}$ & $\begin{array}{l}3 \text { In welchem Masse würdest } \\
\text { Du den folgenden Aussagen } \\
\text { zustimmen (in Bezug auf } \\
\text { diese Woche)? Ich hätte } \\
\text { effizienter lernen sollen. }\end{array}$ & $\begin{array}{l}1=7 \text {-Punkte Skala, sehr } \\
\text { ruhig bis sehr energiegeladen, } \\
2=7 \text {-Punkte Skala, sehr } \\
\text { ruhig bis sehr energiegeladen, } \\
3=7 \text {-Punkte Skala, sehr } \\
\text { ruhig bis sehr energiegeladen, } \\
4=7 \text {-Punkte Skala, sehr } \\
\text { ruhig bis sehr energiegeladen, } \\
5=7 \text {-Punkte Skala, sehr } \\
\text { ruhig bis sehr energiegeladen, } \\
6=7 \text {-Punkte Skala, sehr } \\
\text { ruhig bis sehr energiegeladen, } \\
7=7 \text {-Punkte Skala, sehr } \\
\text { ruhig bis sehr energiegeladen }\end{array}$ & $\begin{array}{l}\text { To what extent would you } \\
\text { agree with the following } \\
\text { statements (regarding this } \\
\text { week)? I should have studied } \\
\text { more efficiently. }\end{array}$ & $\begin{array}{l}1=7 \text { point scale, very quiet } \\
\text { to very energetic, } 2=7 \text { point } \\
\text { scale, very quiet to very } \\
\text { energetic, } 3=7 \text { point scale, } \\
\text { very quiet to very energetic, } 4 \\
=7 \text { point scale, very quiet to } \\
\text { very energetic, } 5=7 \text { point } \\
\text { scale, very quiet to very } \\
\text { energetic, } 6=7 \text { point scale, } \\
\text { very quiet to very energetic, } 7 \\
=7 \text { point scale, very quiet to } \\
\text { very energetic }\end{array}$ & & $\mathrm{x}$ \\
\hline study. 3 & $\begin{array}{l}\text { Self- } \\
\text { assessment } \\
\text { study } \\
\text { behaviour } \\
\text { (item 3) }\end{array}$ & $\begin{array}{l}3 \text { In welchem Masse würdest } \\
\text { Du den folgenden Aussagen } \\
\text { zustimmen (in Bezug auf } \\
\text { diese Woche)? Ich denke, } \\
\text { dass ich mehr gelernt habe } \\
\text { als die Mehrheit meiner } \\
\text { Mitstundenten. }\end{array}$ & $\begin{array}{l}1=7 \text {-Punkte Skala, sehr } \\
\text { oberflächlich bis sehr } \\
\text { persönlich, } 2=7 \text {-Punkte } \\
\text { Skala, sehr oberflächlich bis } \\
\text { sehr persönlich, } 3=7 \text {-Punkte } \\
\text { Skala, sehr oberflächlich bis } \\
\text { sehr persönlich, } 4=7 \text {-Punkte } \\
\text { Skala, sehr oberflächlich bis } \\
\text { sehr persönlich, } 5=7 \text {-Punkte } \\
\text { Skala, sehr oberflächlich bis } \\
\text { sehr persönlich, } 6=7 \text {-Punkte } \\
\text { Skala, sehr oberfl̈̈chlich bis } \\
\text { sehr persönlich, } 7=7 \text {-Punkte } \\
\text { Skala, sehr oberflächlich bis } \\
\text { sehr persönlich }\end{array}$ & $\begin{array}{l}\text { To what extent would you } \\
\text { agree with the following } \\
\text { statements (regarding this } \\
\text { week)? I think I studied more } \\
\text { than the majority of my } \\
\text { classmates. }\end{array}$ & $\begin{array}{l}1=7 \text { point scale, very } \\
\text { superficial to very personal, } 2 \\
=7 \text { point scale, very } \\
\text { superficial to very personal, } 3 \\
=7 \text { point scale, very } \\
\text { superficial to very personal, } 4 \\
=7 \text { point scale, very } \\
\text { superficial to very personal, } 5 \\
=7 \text { point scale, very } \\
\text { superficial to very personal, } 6 \\
=7 \text { point scale, very } \\
\text { superficial to very personal, } 7 \\
=7 \text { point scale, very } \\
\text { superficial to very personal }\end{array}$ & & $\mathrm{x}$ \\
\hline FirstClick.p19 & $\begin{array}{l}\text { First Click on } \\
\text { Page } 1\end{array}$ & & & & & & $\mathrm{x}$ \\
\hline LastClick.p19 & $\begin{array}{l}\text { Last Click on } \\
\text { Page } 1\end{array}$ & & & & & & $\mathrm{x}$ \\
\hline PageSubmit.p19 & $\begin{array}{l}\text { Time until } \\
\text { Page } 1 \\
\text { submitted }\end{array}$ & & & & & & $\mathrm{x}$ \\
\hline ClickCount.p19 & $\begin{array}{l}\text { Number of } \\
\text { Clicks on Page } \\
1\end{array}$ & & & & & & $\mathrm{x}$ \\
\hline studywith.P1 & $\begin{array}{l}\text { Studied with } \\
\text { last week - } \\
\text { Person } 1\end{array}$ & $\begin{array}{l}\text { Manchmal lernt man } \\
\text { gemeinsam mit anderen } \\
\text { Studierenden, manchmal lernt } \\
\text { man alleine. Mit wem von } \\
\text { Deinen Mitstudierenden hast } \\
\text { Du diese Woche gelernt? } \\
\text { Nenne } 0 \text { bis } 10 \text { Personen }\end{array}$ & & $\begin{array}{l}\text { Sometimes one studies alone, } \\
\text { sometimes with others. Who } \\
\text { of your classmates did you } \\
\text { study with this week? Please } \\
\text { name } 0 \text { to } 10 \text { people. }\end{array}$ & & & $\mathrm{x}$ \\
\hline
\end{tabular}




\section{Summer Short Questionnaires}

\begin{tabular}{|c|c|c|c|c|c|c|}
\hline VarName & VariableLabel & WordingDE & ValueLabelsDE_Linked & WordingEN & ValueLabelsEN_Linked & SS1 \\
\hline startDate & Start date & & & & & $\mathrm{x}$ \\
\hline endDate & End date & & & & & $\mathrm{x}$ \\
\hline duration & $\begin{array}{l}\text { Time to } \\
\text { complete }\end{array}$ & & & & & $\mathrm{x}$ \\
\hline finished & Completed? & & & & & $\mathrm{x}$ \\
\hline interact.P1 & $\begin{array}{l}\text { Most } \\
\text { important } \\
\text { interaction } \\
\text { partner, last } \\
\text { week: P1 }\end{array}$ & $\begin{array}{l}\text { Bitte denke an Situationen, } \\
\text { in welchen Du letzte Woche } \\
\text { mit Mitstudierenden } \\
\text { interagiert hast. Benenne } \\
\text { Deine wichtigsten } \\
\text { Interaktionspartner: - Name } 1\end{array}$ & & & & $\mathrm{x}$ \\
\hline studyHrsMo & $\begin{array}{l}\text { Hours studied: } \\
\text { Monday }\end{array}$ & $\begin{array}{l}\text { Wie viele Stunden hast Du } \\
\text { am Montag gelernt? } \\
\text { Ausgenommen sind } \\
\text { Prüfungsvorbereitungskurse. } \\
\text { - Stunden }\end{array}$ & & & & $\mathrm{x}$ \\
\hline study AloneMo & $\begin{array}{l}\text { Studied alone: } \\
\text { Monday }\end{array}$ & $\begin{array}{l}\text { Hast du am Montag } \\
\text { ausschliesslich alleine gelernt? }\end{array}$ & $1=\mathrm{Ja}, 2=$ Nein & & $1=\mathrm{NA}, 2=\mathrm{NA}$ & $\mathrm{x}$ \\
\hline studyTogetherMo.P1 & $\begin{array}{l}\text { Studied } \\
\text { together } \\
\text { Monday: P1 }\end{array}$ & $\begin{array}{l}\text { Mit wem hast du am Montag } \\
\text { zusammen gelernt, und in } \\
\text { welcher Weise? }\end{array}$ & & & & $\mathrm{x}$ \\
\hline studyCollabMo.P1 & $\begin{array}{l}\text { Studied } \\
\text { collaboratively } \\
\text { on Monday: } \\
\text { P1 }\end{array}$ & $\begin{array}{l}\text { Mit wem hast du am Montag } \\
\text { zusammen gelernt, und in } \\
\text { welcher Weise? }\end{array}$ & & & & $\mathrm{x}$ \\
\hline studyExtMo & $\begin{array}{l}\text { Studied with } \\
\text { non-cohort } \\
\text { members: } \\
\text { Monday }\end{array}$ & $\begin{array}{l}\text { Hast du am Montag mit } \\
\text { Leuten gelernt, die nicht mit } \\
\text { Dir zusammen studieren? }\end{array}$ & $\begin{array}{l}1=\text { Nein, } 2=\mathrm{Ja} \text {, zusammen } \\
\text { (in selben Ort), } 3=\mathrm{Ja}, \\
\text { kollaborativ (gemeinsame } \\
\text { Diskussionen) }\end{array}$ & & $1=\mathrm{NA}, 2=\mathrm{NA}, 3=\mathrm{NA}$ & $\mathrm{x}$ \\
\hline studyHrsTu & $\begin{array}{l}\text { Hours studied: } \\
\text { Tuesday }\end{array}$ & $\begin{array}{l}\text { Wie viele Stunden hast Du } \\
\text { am Dienstag gelernt? } \\
\text { Ausgenommen sind } \\
\text { Prüfungsvorbereitungskurse. } \\
\text { - Stunden }\end{array}$ & & & & $\mathrm{x}$ \\
\hline study AloneTu & $\begin{array}{l}\text { Studied alone: } \\
\text { Tuesday }\end{array}$ & $\begin{array}{l}\text { Hast du am Dienstag } \\
\text { ausschliesslich alleine gelernt? }\end{array}$ & $1=\mathrm{Ja}, 2=$ Nein & & $1=\mathrm{NA}, 2=\mathrm{NA}$ & $\mathrm{x}$ \\
\hline studyTogetherTu.P1 & $\begin{array}{l}\text { Studied } \\
\text { together } \\
\text { Tuesday: P1 }\end{array}$ & $\begin{array}{l}\text { Mit wem hast du am } \\
\text { Dienstag zusammen gelernt, } \\
\text { und in welcher Weise? - } \\
\text { Q5.5\#1 - Name } 1\end{array}$ & & & & $\mathrm{x}$ \\
\hline studyCollabTu.P1 & $\begin{array}{l}\text { Studied } \\
\text { collaboratively } \\
\text { on Tuesday: } \\
\text { P1 }\end{array}$ & $\begin{array}{l}\text { Mit wem hast du am } \\
\text { Dienstag zusammen gelernt, } \\
\text { und in welcher Weise? - } \\
\text { Q5.5\#2 - Name } 1\end{array}$ & & & & $\mathrm{x}$ \\
\hline studyExtTu & $\begin{array}{l}\text { Studied with } \\
\text { non-cohort } \\
\text { members: } \\
\text { Tuesday }\end{array}$ & $\begin{array}{l}\text { Hast du am Dienstag mit } \\
\text { Leuten gelernt, die nicht mit } \\
\text { Dir zusammen studieren? }\end{array}$ & $\begin{array}{l}1=\text { Nein, } 2=\mathrm{Ja} \text {, zusammen } \\
(\text { in selben Ort), } 3=\mathrm{Ja}, \\
\text { kollaborativ (gemeinsame } \\
\text { Diskussionen) }\end{array}$ & & $1=\mathrm{NA}, 2=\mathrm{NA}, 3=\mathrm{NA}$ & $\mathrm{x}$ \\
\hline studyHrsWe & $\begin{array}{l}\text { Hours studied: } \\
\text { Wednesday }\end{array}$ & $\begin{array}{l}\text { Wie viele Stunden hast Du } \\
\text { am Mittwoch gelernt? } \\
\text { Ausgenommen sind } \\
\text { Prüfungsvorbereitungskurse. } \\
\text { - Stunden }\end{array}$ & & & & $\mathrm{x}$ \\
\hline study AloneWe & $\begin{array}{l}\text { Studied alone: } \\
\text { Wednesday }\end{array}$ & $\begin{array}{l}\text { Hast du am Mittwoch } \\
\text { ausschliesslich alleine gelernt? }\end{array}$ & $1=\mathrm{Ja}, 2=$ Nein & & $1=\mathrm{NA}, 2=\mathrm{NA}$ & $\mathrm{x}$ \\
\hline studyTogetherWe.P1 & $\begin{array}{l}\text { Studied } \\
\text { together } \\
\text { Wednesday: } \\
\text { P1 }\end{array}$ & $\begin{array}{l}\text { Mit wem hast du am } \\
\text { Mittwoch zusammen gelernt, } \\
\text { und in welcher Weise? - } \\
\text { Q6.5\#1 - Name } 1\end{array}$ & & & & $\mathrm{x}$ \\
\hline
\end{tabular}




\begin{tabular}{|c|c|c|c|c|c|c|}
\hline VarName & VariableLabel & WordingDE & ValueLabelsDE_Linked & WordingEN & ValueLabelsEN_Linked & SS1 \\
\hline studyCollabWe.P1 & $\begin{array}{l}\text { Studied } \\
\text { collaboratively } \\
\text { on Wednesday: } \\
\text { P1 }\end{array}$ & $\begin{array}{l}\text { Mit wem hast du am } \\
\text { Mittwoch zusammen gelernt, } \\
\text { und in welcher Weise? - } \\
\text { Q6.5\#2 - Name } 1\end{array}$ & & & & $\mathrm{x}$ \\
\hline studyExtWe & $\begin{array}{l}\text { Studied with } \\
\text { non-cohort } \\
\text { members: } \\
\text { Wednesday }\end{array}$ & $\begin{array}{l}\text { Hast du am Mittwoch mit } \\
\text { Leuten gelernt, die nicht mit } \\
\text { Dir zusammen studieren? }\end{array}$ & $\begin{array}{l}1=\text { Nein, } 2=\mathrm{Ja} \text {, zusammen } \\
\text { (in selben Ort), } 3=\mathrm{Ja} \text {, } \\
\text { kollaborativ (gemeinsame } \\
\text { Diskussionen) }\end{array}$ & & $1=\mathrm{NA}, 2=\mathrm{NA}, 3=\mathrm{NA}$ & $\mathrm{x}$ \\
\hline studyHrsTh & $\begin{array}{l}\text { Hours studied: } \\
\text { Thursday }\end{array}$ & $\begin{array}{l}\text { Wie viele Stunden hast } \mathrm{Du} \\
\text { am Donnerstag gelernt? } \\
\text { Ausgenommen sind } \\
\text { Prüfungsvorbereitungskurse. } \\
\text { - Stunden }\end{array}$ & & & & $\mathrm{x}$ \\
\hline studyAloneTh & $\begin{array}{l}\text { Studied alone: } \\
\text { Thursday }\end{array}$ & $\begin{array}{l}\text { Hast du am Donnerstag } \\
\text { ausschliesslich alleine gelernt? }\end{array}$ & $1=\mathrm{Ja}, 2=$ Nein & & $1=\mathrm{NA}, 2=\mathrm{NA}$ & $\mathrm{x}$ \\
\hline studyTogetherTh.P1 & $\begin{array}{l}\text { Studied } \\
\text { together } \\
\text { Thursday: P1 }\end{array}$ & $\begin{array}{l}\text { Mit wem hast du am } \\
\text { Donnerstag zusammen } \\
\text { gelernt, und in welcher } \\
\text { Weise? - Q7.5\#1 - Name 1 }\end{array}$ & & & & $\mathrm{x}$ \\
\hline studyCollabTh.P1 & $\begin{array}{l}\text { Studied } \\
\text { collaboratively } \\
\text { on Thursday: } \\
\text { P1 }\end{array}$ & $\begin{array}{l}\text { Mit wem hast du am } \\
\text { Donnerstag zusammen } \\
\text { gelernt, und in welcher } \\
\text { Weise? - Q7.5\#2 - Name 1 }\end{array}$ & & & & $\mathrm{x}$ \\
\hline studyHrsFr & $\begin{array}{l}\text { Hours studied: } \\
\text { Friday }\end{array}$ & $\begin{array}{l}\text { Wie viele Stunden hast Du } \\
\text { am Freitag gelernt? } \\
\text { Ausgenommen sind } \\
\text { Prüfungsvorbereitungskurse. } \\
\text { - Stunden }\end{array}$ & & & & $\mathrm{x}$ \\
\hline study AloneFr & $\begin{array}{l}\text { Studied alone: } \\
\text { Friday }\end{array}$ & $\begin{array}{l}\text { Hast du am Freitag } \\
\text { ausschliesslich alleine gelernt? }\end{array}$ & $1=\mathrm{Ja}, 2=$ Nein & & $1=\mathrm{NA}, 2=\mathrm{NA}$ & $\mathrm{x}$ \\
\hline studyTogetherFr.P1 & $\begin{array}{l}\text { Studied } \\
\text { together } \\
\text { Friday: P1 }\end{array}$ & $\begin{array}{l}\text { Mit wem hast du am Freitag } \\
\text { zusammen gelernt, und in } \\
\text { welcher Weise? - Q8.5\#1 - } \\
\text { Name } 1\end{array}$ & & & & $\mathrm{x}$ \\
\hline studyCollabFr.P1 & $\begin{array}{l}\text { Studied } \\
\text { collaboratively } \\
\text { on Friday: P1 }\end{array}$ & $\begin{array}{l}\text { Mit wem hast du am Freitag } \\
\text { zusammen gelernt, und in } \\
\text { welcher Weise? - Q8.5\#2 - } \\
\text { Name } 1\end{array}$ & & & & $\mathrm{x}$ \\
\hline studyExtFr & $\begin{array}{l}\text { Studied with } \\
\text { non-cohort } \\
\text { members: } \\
\text { Friday }\end{array}$ & $\begin{array}{l}\text { Hast du am Freitag mit } \\
\text { Leuten gelernt, die nicht mit } \\
\text { Dir zusammen studieren? }\end{array}$ & $\begin{array}{l}1=\text { Nein, } 2=\mathrm{Ja} \text {, zusammen } \\
\text { (in selben Ort), } 3=\mathrm{Ja} \text {, } \\
\text { kollaborativ (gemeinsame } \\
\text { Diskussionen) }\end{array}$ & & $1=\mathrm{NA}, 2=\mathrm{NA}, 3=\mathrm{NA}$ & $\mathrm{X}$ \\
\hline studyAloneSa & $\begin{array}{l}\text { Studied alone: } \\
\text { Saturday }\end{array}$ & $\begin{array}{l}\text { Hast du am Samstag } \\
\text { ausschliesslich alleine gelernt? }\end{array}$ & $1=\mathrm{Ja}, 2=$ Nein & & $1=\mathrm{NA}, 2=\mathrm{NA}$ & $\mathrm{x}$ \\
\hline studyTogetherSa.P1 & $\begin{array}{l}\text { Studied } \\
\text { together } \\
\text { Saturday: P1 }\end{array}$ & $\begin{array}{l}\text { Mit wem hast du am Samstag } \\
\text { zusammen gelernt, und in } \\
\text { welcher Weise? - Q9.5\#1 - } \\
\text { Name 1 }\end{array}$ & & & & $\mathrm{x}$ \\
\hline studyCollabSa.P1 & $\begin{array}{l}\text { Studied } \\
\text { collaboratively } \\
\text { on Saturday: } \\
\text { P1 }\end{array}$ & $\begin{array}{l}\text { Mit wem hast du am Samstag } \\
\text { zusammen gelernt, und in } \\
\text { welcher Weise? - Q9.5\#2 - } \\
\text { Name 1 }\end{array}$ & & & & $\mathrm{x}$ \\
\hline
\end{tabular}




\begin{tabular}{|c|c|c|c|c|c|c|}
\hline VarName & VariableLabel & WordingDE & ValueLabelsDE_Linked & WordingEN & ValueLabelsEN_Linked & SS1 \\
\hline studyExtSa & $\begin{array}{l}\text { Studied with } \\
\text { non-cohort } \\
\text { members: } \\
\text { Saturday }\end{array}$ & $\begin{array}{l}\text { Hast du am Samstag mit } \\
\text { Leuten gelernt, die nicht mit } \\
\text { Dir zusammen studieren? }\end{array}$ & $\begin{array}{l}1=\text { Nein, } 2=\mathrm{Ja} \text {, zusammen } \\
\text { (in selben Ort), } 3=\mathrm{Ja}, \\
\text { kollaborativ (gemeinsame } \\
\text { Diskussionen) }\end{array}$ & & $1=\mathrm{NA}, 2=\mathrm{NA}, 3=\mathrm{NA}$ & $\mathrm{x}$ \\
\hline studyHrsSu & $\begin{array}{l}\text { Hours studied: } \\
\text { Sunday }\end{array}$ & $\begin{array}{l}\text { Wie viele Stunden hast } \mathrm{Du} \\
\text { am Sonntag gelernt? } \\
\text { Ausgenommen sind } \\
\text { Prüfungsvorbereitungskurse. } \\
\text { - Stunden }\end{array}$ & & & & $\mathrm{x}$ \\
\hline study AloneSu & $\begin{array}{l}\text { Studied alone: } \\
\text { Sunday }\end{array}$ & $\begin{array}{l}\text { Hast du am Sonntag } \\
\text { ausschliesslich alleine gelernt? }\end{array}$ & $1=\mathrm{Ja}, 2=$ Nein & & $1=\mathrm{NA}, 2=\mathrm{NA}$ & $\mathrm{x}$ \\
\hline studyTogetherSu.P1 & $\begin{array}{l}\text { Studied } \\
\text { together } \\
\text { Sunday: P1 }\end{array}$ & $\begin{array}{l}\text { Mit wem hast du am Sonntag } \\
\text { zusammen gelernt, und in } \\
\text { welcher Weise? - Q10.5\#1 - } \\
\text { Name 1 }\end{array}$ & & & & $\mathrm{x}$ \\
\hline studyCollabSu.P1 & $\begin{array}{l}\text { Studied } \\
\text { collaboratively } \\
\text { on Sunday: P1 }\end{array}$ & $\begin{array}{l}\text { Mit wem hast du am Sonntag } \\
\text { zusammen gelernt, und in } \\
\text { welcher Weise? - Q10.5\#2 - } \\
\text { Name } 1\end{array}$ & & & & $\mathrm{x}$ \\
\hline studyExtSu & $\begin{array}{l}\text { Studied with } \\
\text { non-cohort } \\
\text { members: } \\
\text { Sunday }\end{array}$ & $\begin{array}{l}\text { Hast du am Sonntag mit } \\
\text { Leuten gelernt, die nicht mit } \\
\text { Dir zusammen studieren? }\end{array}$ & $\begin{array}{l}1=\text { Nein, } 2=\mathrm{Ja} \text {, zusammen } \\
\text { (in selben Ort), } 3=\mathrm{Ja}, \\
\text { kollaborativ (gemeinsame } \\
\text { Diskussionen) }\end{array}$ & & $1=\mathrm{NA}, 2=\mathrm{NA}, 3=\mathrm{NA}$ & $\mathrm{x}$ \\
\hline StudyQuality.1 & $\begin{array}{l}\text { Should have } \\
\text { studied more }\end{array}$ & $\begin{array}{l}\text { In welchem Masse würdest } \\
\text { Du den folgenden Aussagen } \\
\text { zustimmen (in Bezug auf die } \\
\text { vergangene Woche)? - Ich } \\
\text { hätte mehr lernen sollen. }\end{array}$ & $\begin{array}{l}1=\text { überhaupt nicht } \\
\text { einverstanden, } 2=2,3=3,4 \\
=4,5=5,6=6,7=\text { völlig } \\
\text { einverstanden }\end{array}$ & & $\begin{array}{l}1=\mathrm{NA}, 2=\mathrm{NA}, 3=\mathrm{NA}, 4 \\
=\mathrm{NA}, 5=\mathrm{NA}, 6=\mathrm{NA}, 7= \\
\mathrm{NA}\end{array}$ & $\mathrm{x}$ \\
\hline StudyQuality.2 & $\begin{array}{l}\text { Should have } \\
\text { studied more } \\
\text { efficiently }\end{array}$ & $\begin{array}{l}\text { In welchem Masse würdest } \\
\text { Du den folgenden Aussagen } \\
\text { zustimmen (in Bezug auf die } \\
\text { vergangene Woche)? - Ich } \\
\text { hätte effizienter lernen sollen. }\end{array}$ & $\begin{array}{l}1=\text { überhaupt nicht } \\
\text { einverstanden, } 2=2,3=3,4 \\
=4,5=5,6=6,7=\text { völlig } \\
\text { einverstanden }\end{array}$ & & $\begin{array}{l}1=\mathrm{NA}, 2=\mathrm{NA}, 3=\mathrm{NA}, 4 \\
=\mathrm{NA}, 5=\mathrm{NA}, 6=\mathrm{NA}, 7= \\
\mathrm{NA}\end{array}$ & $\mathrm{x}$ \\
\hline studyQuality.3 & $\begin{array}{l}\text { Studied more } \\
\text { than others }\end{array}$ & $\begin{array}{l}\text { In welchem Masse würdest } \\
\text { Du den folgenden Aussagen } \\
\text { zustimmen (in Bezug auf die } \\
\text { vergangene Woche)? - Ich } \\
\text { denke, dass ich mehr gelernt } \\
\text { habe als die Mehrheit meiner } \\
\text { Mitstudierenden. }\end{array}$ & $\begin{array}{l}1=\text { überhaupt nicht } \\
\text { einverstanden, } 2=2,3=3,4 \\
=4,5=5,6=6,7=\text { völlig } \\
\text { einverstanden }\end{array}$ & & $\begin{array}{l}1=\mathrm{NA}, 2=\mathrm{NA}, 3=\mathrm{NA}, 4 \\
=\mathrm{NA}, 5=\mathrm{NA}, 6=\mathrm{NA}, 7= \\
\mathrm{NA}\end{array}$ & $\mathrm{x}$ \\
\hline stress.3 & $\begin{array}{l}\text { How } \\
\text { frequently } \\
\text { stressed past } \\
\text { week }\end{array}$ & $\begin{array}{l}\text { Wie oft hast du dich in der } \\
\text { letzten Woche nervös und } \\
\text { "gestresst" gefühlt? }\end{array}$ & $\begin{array}{l}1=\text { nie, } 2=\text { selten, } 3= \\
\text { manchmal, } 4=\text { häufig, } 5= \\
\text { sehr oft }\end{array}$ & & $\begin{array}{l}1=\mathrm{NA}, 2=\mathrm{NA}, 3=\mathrm{NA}, 4 \\
=\mathrm{NA}, 5=\mathrm{NA}\end{array}$ & $\mathrm{x}$ \\
\hline
\end{tabular}




\section{Meta}

For cohort I, specific information related to students' academic status at each wave is contained in data.frames with the following variables:

\begin{tabular}{|c|c|c|}
\hline VarName & Type & Description \\
\hline student_id & character & identifier of the student (used in other tables) \\
\hline is_invited & boolean & $\begin{array}{l}\text { indicator for whether the student received an invitation at this } \\
\text { specific wave }\end{array}$ \\
\hline is_alter & boolean & $\begin{array}{l}\text { indicator for whether the student was mentionned as a posisble } \\
\text { alter in network items at this specific wave }\end{array}$ \\
\hline is_in_cohort & boolean & $\begin{array}{l}\text { indicator for whether the student is considered to be part of the } \\
\text { cohort at this specific wave (having at least one course } \\
\text { registration with another member of the cohort) }\end{array}$ \\
\hline is_enrolled & boolean & $\begin{array}{l}\text { indicator for whether the student was officially enrolled in the } \\
\text { program at this specific wave }\end{array}$ \\
\hline number_courses_total & numeric & $\begin{array}{l}\text { number of courses to which the student was registered at this } \\
\text { specific wave }\end{array}$ \\
\hline number_courses_department & numeric & $\begin{array}{l}\text { number of courses of the department attached to the study } \\
\text { program to which the student was registered at this specific wave }\end{array}$ \\
\hline $\begin{array}{l}\text { number_courses_year1_mandatory } \\
\text { _program1 }\end{array}$ & numeric & $\begin{array}{l}\text { number of courses that were mandatory in the first year of the } \\
\text { first subprogram to which the student was registered at this } \\
\text { specific wave }\end{array}$ \\
\hline $\begin{array}{l}\text { number_courses_year1_mandatory } \\
\text { _program2 }\end{array}$ & numeric & $\begin{array}{l}\text { number of courses that were mandatory in the first year of the } \\
\text { second subprogram to which the student was registered at this } \\
\text { specific wave }\end{array}$ \\
\hline $\begin{array}{l}\text { number_courses_year1_mandatory } \\
\text { _program3 }\end{array}$ & numeric & $\begin{array}{l}\text { number of courses that were mandatory in the first year of the } \\
\text { third subprogram to which the student was registered at this } \\
\text { specific wave }\end{array}$ \\
\hline $\begin{array}{l}\text { number_courses_year1_mandatory } \\
\text { _program4 }\end{array}$ & numeric & $\begin{array}{l}\text { number of courses that were mandatory in the first year of the } \\
\text { fourth subprogram to which the student was registered at this } \\
\text { specific wave }\end{array}$ \\
\hline $\begin{array}{l}\text { number_courses_year2_mandatory } \\
\text { _program1 }\end{array}$ & numeric & $\begin{array}{l}\text { number of courses that were mandatory in the second year of the } \\
\text { first subprogram to which the student was registered at this } \\
\text { specific wave }\end{array}$ \\
\hline $\begin{array}{l}\text { number_courses_year2_mandatory } \\
\text { _program2 }\end{array}$ & numeric & $\begin{array}{l}\text { number of courses that were mandatory in the second year of the } \\
\text { second subprogram to which the student was registered at this } \\
\text { specific wave }\end{array}$ \\
\hline $\begin{array}{l}\text { number_courses_year2_mandatory } \\
\text { _program3 }\end{array}$ & numeric & $\begin{array}{l}\text { number of courses that were mandatory in the secdon year of the } \\
\text { third subprogram to which the student was registered at this } \\
\text { specific wave }\end{array}$ \\
\hline $\begin{array}{l}\text { number_courses_year2_mandatory } \\
\text { _program4 }\end{array}$ & numeric & $\begin{array}{l}\text { number of courses that were mandatory in the second year of the } \\
\text { fourth subprogram to which the student was registered at this } \\
\text { specific wave }\end{array}$ \\
\hline
\end{tabular}




\begin{tabular}{|c|c|c|}
\hline VarName & Type & Description \\
\hline $\begin{array}{l}\text { number_courses_year3_mandatory } \\
\text { _program1 }\end{array}$ & numeric & $\begin{array}{l}\text { number of courses that were mandatory in the third year of the } \\
\text { first subprogram to which the student was registered at this } \\
\text { specific wave }\end{array}$ \\
\hline $\begin{array}{l}\text { number_courses_year3_mandatory } \\
\text { _program2 }\end{array}$ & numeric & $\begin{array}{l}\text { number of courses that were mandatory in the third year of the } \\
\text { second subprogram to which the student was registered at this } \\
\text { specific wave }\end{array}$ \\
\hline $\begin{array}{l}\text { number_courses_year3_mandatory } \\
\text { _program3 }\end{array}$ & numeric & $\begin{array}{l}\text { number of courses that were mandatory in the third year of the } \\
\text { third subprogram to which the student was registered at this } \\
\text { specific wave }\end{array}$ \\
\hline $\begin{array}{l}\text { number_courses_year3_mandatory } \\
\text { _program4 }\end{array}$ & numeric & $\begin{array}{l}\text { number of courses that were mandatory in the third year of the } \\
\text { fourth subprogram to which the student was registered at this } \\
\text { specific wave }\end{array}$ \\
\hline number_students_coregistered & numeric & $\begin{array}{l}\text { number of other students with whom the student had at least } \\
\text { one course in common }\end{array}$ \\
\hline number_coregistrations_total & numeric & $\begin{array}{l}\text { number of co-registrations with all other students (i.e., the sum } \\
\text { over all other students of the number of common courses) }\end{array}$ \\
\hline number_exams_year1_total & numeric & $\begin{array}{l}\text { number of exams offered in first year to which the student was } \\
\text { registered at this specific wave }\end{array}$ \\
\hline $\begin{array}{l}\text { number_exams_year1_mandatory } \\
\text { _program1 }\end{array}$ & numeric & $\begin{array}{l}\text { number of exams that were mandatory in the first year of the } \\
\text { first subprogram to which the student was registered at this } \\
\text { specific wave }\end{array}$ \\
\hline $\begin{array}{l}\text { number_exams_year1_mandatory } \\
\text { _program } 2\end{array}$ & numeric & $\begin{array}{l}\text { number of exams that were mandatory in the first year of the } \\
\text { second subprogram to which the student was registered at this } \\
\text { specific wave }\end{array}$ \\
\hline $\begin{array}{l}\text { number_exams_year1_mandatory } \\
\text { _program3 }\end{array}$ & numeric & $\begin{array}{l}\text { number of exams that were mandatory in the first year of the } \\
\text { third subprogram to which the student was registered at this } \\
\text { specific wave }\end{array}$ \\
\hline $\begin{array}{l}\text { number_exams_year1_mandatory } \\
\text { _program } 4\end{array}$ & numeric & $\begin{array}{l}\text { number of exams that were mandatory in the first year of the } \\
\text { fourth subprogram to which the student was registered at this } \\
\text { specific wave }\end{array}$ \\
\hline number_exams_year2_total & numeric & $\begin{array}{l}\text { number of exams offered in second year to which the student was } \\
\text { registered at this specific wave }\end{array}$ \\
\hline $\begin{array}{l}\text { number_exams_year2_mandatory } \\
\text { _program } 1\end{array}$ & numeric & $\begin{array}{l}\text { number of exams that were mandatory in the first year of the } \\
\text { first subprogram to which the student was registered at this } \\
\text { specific wave }\end{array}$ \\
\hline $\begin{array}{l}\text { number_exams_year2_mandatory } \\
\text { _program } 2\end{array}$ & numeric & $\begin{array}{l}\text { number of exams that were mandatory in the first year of the } \\
\text { second subprogram to which the student was registered at this } \\
\text { specific wave }\end{array}$ \\
\hline $\begin{array}{l}\text { number_exams_year2_mandatory } \\
\text { _program } 3\end{array}$ & numeric & $\begin{array}{l}\text { number of exams that were mandatory in the first year of the } \\
\text { third subprogram to which the student was registered at this } \\
\text { specific wave }\end{array}$ \\
\hline
\end{tabular}




\begin{tabular}{|c|c|c|}
\hline VarName & Type & Description \\
\hline $\begin{array}{l}\text { number_exams_year2_mandatory } \\
\text { program4 }\end{array}$ & numeric & $\begin{array}{l}\text { number of exams that were mandatory in the first year of the } \\
\text { fourth subprogram to which the student was registered at this } \\
\text { specific wave }\end{array}$ \\
\hline number_exams_year3_total & numeric & $\begin{array}{l}\text { number of exams offered in third year to which the student was } \\
\text { registered at this specific wave }\end{array}$ \\
\hline $\begin{array}{l}\text { number_exams_year3_mandatory } \\
\text { _program1 }\end{array}$ & numeric & $\begin{array}{l}\text { number of exams that were mandatory in the first year of the } \\
\text { first subprogram to which the student was registered at this } \\
\text { specific wave }\end{array}$ \\
\hline $\begin{array}{l}\text { number_exams_year3_mandatory } \\
\text { _program2 }\end{array}$ & numeric & $\begin{array}{l}\text { number of exams that were mandatory in the first year of the } \\
\text { second subprogram to which the student was registered at this } \\
\text { specific wave }\end{array}$ \\
\hline $\begin{array}{l}\text { number_exams_year3_mandatory } \\
\text { program3 }\end{array}$ & numeric & $\begin{array}{l}\text { number of exams that were mandatory in the first year of the } \\
\text { third subprogram to which the student was registered at this } \\
\text { specific wave }\end{array}$ \\
\hline $\begin{array}{l}\text { number_exams_year3_mandatory } \\
\text { _program4 }\end{array}$ & numeric & $\begin{array}{l}\text { number of exams that were mandatory in the first year of the } \\
\text { fourth subprogram to which the student was registered at this } \\
\text { specific wave }\end{array}$ \\
\hline number_labs_year2 & numeric & $\begin{array}{l}\text { number of exams considered as lab exams offered in second year } \\
\text { to which the student was registered at this specific wave }\end{array}$ \\
\hline number_labs_year3 & numeric & $\begin{array}{l}\text { number of exams considered as lab exams offered in third year to } \\
\text { which the student was registered at this specific wave }\end{array}$ \\
\hline number_exams_year1_passed & numeric & $\begin{array}{l}\text { number of exams offered in first year that the student passed in } \\
\text { the semester of this specific wave }\end{array}$ \\
\hline number_exams_year2_passed & numeric & $\begin{array}{l}\text { number of exams offered in second year that the student passed } \\
\text { in the semester of this specific wave }\end{array}$ \\
\hline number_exams_year3_passed & numeric & $\begin{array}{l}\text { number of exams offered in third year that the student passed in } \\
\text { the semester of this specific wave }\end{array}$ \\
\hline block_year1_passed & boolean & $\begin{array}{l}\text { indicator for whether the student passed the exam block offered } \\
\text { in first year (i.e., qualification exam) in the semester of this } \\
\text { specific wave }\end{array}$ \\
\hline number_blocks_year2_passed & numeric & $\begin{array}{l}\text { number of exam blocks offered in second year that the student } \\
\text { passed in the semester of this specific wave }\end{array}$ \\
\hline number_blocks_year3_passed & numeric & $\begin{array}{l}\text { number of exam blocks offered in third year that the student } \\
\text { passed in the semester of this specific wave }\end{array}$ \\
\hline
\end{tabular}

General information on students contains the following: 


\begin{tabular}{|c|c|c|}
\hline VarName & Type & Description \\
\hline student_id & character & identifier of the student (used in other tables) \\
\hline birthdate & date & date of birth of the student (format: yyyy-mm-dd) \\
\hline gender & character & gender of the student ( $M=$ male, $W=$ female $)$ \\
\hline country_of_origin & character & $\begin{array}{l}\text { country provided as residence of the student when entering the } \\
\text { university (in German) }\end{array}$ \\
\hline entry_semester & character & $\begin{array}{l}\text { semester in which the student entered the university (can be in } \\
\text { any program) }\end{array}$ \\
\hline qualification_exam_semester & character & $\begin{array}{l}\text { semester in which the student last took the first year } \\
\text { qualification exam in the program of interest (empty if the } \\
\text { student did not took the exam) }\end{array}$ \\
\hline qualification_exam_program & character & $\begin{array}{l}\text { program in which the student last took the first year } \\
\text { qualification exam in the program of interest (for cohorts } 1 \text { and } 2 \text {, } \\
\text { this value can be } 1,2,3 \text {, or } 4 \text { depending on the sub-program they } \\
\text { are enrolled in the main program, for cohort } 3 \text { it can only be } 1 \text {, } \\
\text { and the variable is empty if the student did not took the exam) }\end{array}$ \\
\hline qualification_exam_grade & numeric & $\begin{array}{l}\text { grade obtained when the student last took the first year } \\
\text { qualification exam in the program of interest (passing the exam } \\
\text { requires a value above } 3 \text {, the variable is empty if the student did } \\
\text { not took the exam) }\end{array}$ \\
\hline first_program & character & $\begin{array}{l}\text { program in which the student entered the university (for cohorts } \\
1 \text { and } 2 \text {, this value can be } 1,2,3,4 \text {, depending on the } \\
\text { sub-program they are enrolled in the main program, for cohort } 3 \\
\text { it can only be } 1 \text {, and the variable is "other" if the student } \\
\text { entered in another program) }\end{array}$ \\
\hline last_program & character & $\begin{array}{l}\text { program in which the student was at the end of the study, i.e. } \\
\text { Fall } 2019 \text { (for cohorts } 1 \text { and } 2 \text {, this value can be } 1,2,3,4 \text {, } \\
\text { depending on the sub-program they are enrolled in the main } \\
\text { program, for cohort } 3 \text { it can only be } 1 \text {, and the variable is "other" } \\
\text { if the student entered in another program) }\end{array}$ \\
\hline switching_semester & character & $\begin{array}{l}\text { semester in which the student switched from the first program to } \\
\text { the last program (can be "unknown" if it was not possible to } \\
\text { reconstruct) }\end{array}$ \\
\hline leaving_date & date & $\begin{array}{l}\text { date at which the student officially left the university (can be } \\
\text { empty if the student was still registered in Fall 2019) }\end{array}$ \\
\hline
\end{tabular}

For this cohort, the following objects are available to describe the academic paths of students and the cohort boundaries:

\begin{tabular}{lll}
\hline Object & Type & Description \\
\hline student_general_information_cohort1 & data frame & $\begin{array}{l}\text { table containing general information related to the academic } \\
\text { path of each student who was invited to participate in the study }\end{array}$
\end{tabular}




\begin{tabular}{|c|c|c|}
\hline Object & Type & Description \\
\hline student_information_wave_cohort1 & $\begin{array}{l}\text { list of } 58 \\
\text { data frames }\end{array}$ & $\begin{array}{l}\text { list containing } 58 \text { data frames (one for each wave of } \\
\text { questionnaire) containing the information related to the students } \\
\text { academic status at the time the questionnaires were sent }\end{array}$ \\
\hline course_information_cohort1 & data frame & $\begin{array}{l}\text { table containing information related to the courses and exams } \\
\text { students could register to }\end{array}$ \\
\hline registration_information_wave_cohort1 & $\begin{array}{l}\text { list of } 58 \\
\text { matrices }\end{array}$ & $\begin{array}{l}\text { list containing } 58 \text { matrices (one for each wave of questionnaire) } \\
\text { representing the bipartite network of students registrations to } \\
\text { different couses (in this network, } 0=\text { no registration, } 1= \\
\text { registration) }\end{array}$ \\
\hline exam_information_wave_cohort1 & $\begin{array}{l}\text { list of } 58 \\
\text { matrices }\end{array}$ & $\begin{array}{l}\text { list containing } 58 \text { matrices (one for each wave of questionnaire) } \\
\text { representing the bipartite network of students registrations to } \\
\text { different couses }\end{array}$ \\
\hline
\end{tabular}

Information related to courses and exams offered for this cohort can be found in the following table:

\begin{tabular}{|c|c|c|}
\hline VarName & Type & Description \\
\hline course_code & character & $\begin{array}{l}\text { identifier of a course and the exam linked to this course (if it } \\
\text { exists) }\end{array}$ \\
\hline is_exam & boolean & indicator of whether an exam is linked to the course \\
\hline department_course & boolean & $\begin{array}{l}\text { indicator of whether the course was proposed in the department } \\
\text { attached to the study program }\end{array}$ \\
\hline present_in_year1 & boolean & $\begin{array}{l}\text { indicator of whether the exam linked to the course was proposed } \\
\text { to first year students }\end{array}$ \\
\hline mandatory_in_year1_program1 & boolean & $\begin{array}{l}\text { indicator of whether the course was mentionned as mandatory in } \\
\text { first year in the official curriculum of the first sub-program }\end{array}$ \\
\hline mandatory_in_year1_program2 & boolean & $\begin{array}{l}\text { indicator of whether the course was mentionned as mandatory in } \\
\text { first year in the official curriculum of the second sub-program }\end{array}$ \\
\hline mandatory_in_year1_program3 & boolean & $\begin{array}{l}\text { indicator of whether the course was mentionned as mandatory in } \\
\text { first year in the official curriculum of the third sub-program }\end{array}$ \\
\hline mandatory_in_year1_program4 & boolean & $\begin{array}{l}\text { indicator of whether the course was mentionned as mandatory in } \\
\text { first year in the official curriculum of the fourth sub-program }\end{array}$ \\
\hline present_in_year2 & boolean & $\begin{array}{l}\text { indicator of whether the exam linked to the course was proposed } \\
\text { to second year students }\end{array}$ \\
\hline mandatory_in_year2_program 1 & boolean & $\begin{array}{l}\text { indicator of whether the course was mentionned as mandatory in } \\
\text { second year in the official curriculum of the first sub-program }\end{array}$ \\
\hline mandatory_in_year2_program2 & boolean & $\begin{array}{l}\text { indicator of whether the course was mentionned as mandatory in } \\
\text { second year in the official curriculum of the second sub-program }\end{array}$ \\
\hline mandatory_in_year2_program 3 & boolean & $\begin{array}{l}\text { indicator of whether the course was mentionned as mandatory in } \\
\text { second year in the official curriculum of the third sub-program }\end{array}$ \\
\hline
\end{tabular}




\begin{tabular}{|c|c|c|}
\hline VarName & Type & Description \\
\hline mandatory_in_year2_program 4 & boolean & $\begin{array}{l}\text { indicator of whether the course was mentionned as mandatory in } \\
\text { second year in the official curriculum of the fourth sub-program }\end{array}$ \\
\hline lab_in_year2 & boolean & $\begin{array}{l}\text { indicator of whether the exam linked to the course was } \\
\text { considered as a lab exam in second year }\end{array}$ \\
\hline present_in_year3 & boolean & $\begin{array}{l}\text { indicator of whether the exam linked to the course was proposed } \\
\text { to third year students }\end{array}$ \\
\hline mandatory_in_year3_program1 & boolean & $\begin{array}{l}\text { indicator of whether the course was mentionned as mandatory in } \\
\text { third year in the official curriculum of the first sub-program }\end{array}$ \\
\hline mandatory_in_year3_program2 & boolean & $\begin{array}{l}\text { indicator of whether the course was mentionned as mandatory in } \\
\text { third year in the official curriculum of the second sub-program }\end{array}$ \\
\hline mandatory_in_year3_program3 & boolean & $\begin{array}{l}\text { indicator of whether the course was mentionned as mandatory in } \\
\text { third year in the official curriculum of the third sub-program }\end{array}$ \\
\hline mandatory_in_year3_program4 & boolean & $\begin{array}{l}\text { indicator of whether the course was mentionned as mandatory in } \\
\text { third year in the official curriculum of the fourth sub-program }\end{array}$ \\
\hline lab_in_year3 & boolean & $\begin{array}{l}\text { indicator of whether the exam linked to the course was } \\
\text { considered as a lab exam in third year }\end{array}$ \\
\hline
\end{tabular}

\section{Cohort II + III}

Cohort II $(\mathrm{N}=244)$ and III $(\mathrm{N}=652)$ consisted of students starting their studies in September 2017 in a science / engineering major at a Swiss university.

\section{Waves}

\begin{tabular}{llll}
\hline WaveName & Type & Start.Date & End.Date \\
\hline L1 & Long & 19.09 .2017 (Cohort II), 21.09.2017 (Cohort III) & 22.09 .2017 (Cohort II), 27.09.2017 (Cohort III) \\
L2 & Long & 16.10 .2017 (Cohort II), 23.10.2017 (Cohort III) & 22.10 .2017 (Cohort II), 29.10.2017 (Cohort III) \\
L3 & Long & 11.12 .2017 & 17.12 .2017 \\
L4 & Long & 19.03 .2018 & 28.03 .2018 \\
L5 & Long & 28.05 .2018 & 08.06 .2018 \\
L6 & Long & 28.08 .2018 & 03.09 .2018 \\
L7 & Long & 17.12 .2018 & 07.01 .2019 \\
L8 & Long & 01.04 .2019 & 08.04 .2019 \\
L9 & Long & 27.05 .2019 & 05.06 .2019 \\
L10 & Long & 16.09 .2019 & 25.09 .2019 \\
L11 & Long & 01.04 .2020 & 08.04 .2020 \\
L12 & Long & NA & NA \\
NA & NA & NA & NA \\
NA & NA & NA & NA \\
\hline
\end{tabular}




\section{Variable overview}

\section{Long Questionnaires}

\begin{tabular}{|c|c|c|c|c|c|c|c|c|c|c|c|c|c|c|c|c|c|}
\hline VarName & VariableLabel & WordingDE & ValueLabelsDE_Linked & WordingEN & ValueLabelsEN_Linked & L1 & $\mathrm{L} 2$ & L3 & $\mathrm{L} 4$ & L5 & $\mathrm{L} 6$ & L7 & L8 & L9 & L10 & L11 & $\mathrm{L} 12$ \\
\hline startDate & & & & & & $\mathrm{x}$ & $\mathrm{x}$ & $\mathrm{x}$ & $\mathrm{x}$ & $\mathrm{x}$ & $\mathrm{x}$ & $\mathrm{x}$ & $\mathrm{x}$ & $\mathrm{x}$ & $\mathrm{x}$ & $\mathrm{x}$ & $\mathrm{x}$ \\
\hline endDate & & & & & & $\mathrm{x}$ & $\mathrm{x}$ & $\mathrm{x}$ & $\mathrm{x}$ & $\mathrm{X}$ & $\mathrm{x}$ & $\mathrm{X}$ & $\mathrm{x}$ & $\mathrm{x}$ & $\mathrm{x}$ & $\mathrm{X}$ & $\mathrm{X}$ \\
\hline duration & & & & & & $\mathrm{x}$ & $\mathrm{x}$ & $\mathrm{x}$ & $\mathrm{x}$ & $\mathrm{x}$ & $\mathrm{x}$ & $\mathrm{x}$ & $\mathrm{x}$ & $\mathrm{x}$ & $\mathrm{x}$ & $\mathrm{x}$ & $\mathrm{x}$ \\
\hline finished & & & & & & $\mathrm{x}$ & $\mathrm{x}$ & $\mathrm{x}$ & $\mathrm{x}$ & $\mathrm{x}$ & $\mathrm{x}$ & $\mathrm{x}$ & $\mathrm{x}$ & $\mathrm{x}$ & $\mathrm{x}$ & $\mathrm{x}$ & $\mathrm{x}$ \\
\hline inform.psy & & $\begin{array}{l}\text { Ergeben sich während der } \\
\text { Studie } \\
\text { Zufallsbefundebezüglich } \\
\text { meiner psychischen } \\
\text { Gesundheit (z.B. depressive } \\
\text { Symptome) über } \\
\text { einemkritischen Wert, } \\
\text { möchte ich ... }\end{array}$ & $\begin{array}{l}1=\text { darüber aufgeklärt } \\
\text { werden, } 2=\text { nicht darüber } \\
\text { aufgeklärt werden }\end{array}$ & $\begin{array}{l}\text { If findings regarding my } \\
\text { mental health (for } \\
\text { instance, depressive } \\
\text { symptoms) are above a } \\
\text { critical value, I would } \\
\text { like }\end{array}$ & $\begin{array}{l}1=\text { to be informed about } \\
\text { it, } 2=\text { not to be informed } \\
\text { about it }\end{array}$ & $\mathrm{x}$ & $\mathrm{x}$ & $\mathrm{x}$ & $\mathrm{x}$ & $\mathrm{x}$ & $\mathrm{x}$ & $\mathrm{x}$ & $\mathrm{x}$ & $\mathrm{x}$ & $\mathrm{x}$ & $\mathrm{x}$ & $\mathrm{x}$ \\
\hline birth.year & Birth year & $\begin{array}{l}\text { Wann wurdest Du geboren? } \\
\text { (Jahr) }\end{array}$ & & $\begin{array}{l}\text { When were you born? } \\
\text { (year) }\end{array}$ & & $\mathrm{x}$ & & & & & & & & & & & \\
\hline birth.country & Birth country & $\begin{array}{l}\text { In welchem Land bist Du } \\
\text { geboren? (Schweiz) }\end{array}$ & $1=$ Schweiz, $2=$ Andere & $\begin{array}{l}\text { Which country were you } \\
\text { born in? (Switzerland) }\end{array}$ & $\begin{array}{l}1=\text { Switzerland, } 2= \\
\text { Other }\end{array}$ & $\mathrm{x}$ & $\mathrm{x}$ & $\mathrm{x}$ & $\mathrm{x}$ & $\mathrm{x}$ & $\mathrm{x}$ & $\mathrm{x}$ & $\mathrm{x}$ & $\mathrm{x}$ & $\mathrm{X}$ & $\mathrm{x}$ & $\mathrm{x}$ \\
\hline birth.country.str & $\begin{array}{l}\text { Birth country } \\
\text { other }\end{array}$ & $\begin{array}{l}\text { In welchem Land bist Du } \\
\text { geboren? (Andere) }\end{array}$ & & $\begin{array}{l}\text { Which country were you } \\
\text { born in? (Other) }\end{array}$ & & $\mathrm{x}$ & $\mathrm{x}$ & $\mathrm{x}$ & $\mathrm{x}$ & $\mathrm{x}$ & $\mathrm{x}$ & $\mathrm{x}$ & $\mathrm{x}$ & $\mathrm{x}$ & $\mathrm{x}$ & $\mathrm{x}$ & $\mathrm{x}$ \\
\hline age.migration & $\begin{array}{l}\text { Age of } \\
\text { migration }\end{array}$ & $\begin{array}{l}\text { Wenn nicht in der Schweiz } \\
\text { geboren: Wie alt warst Du } \\
\text { als Du in die Schweiz } \\
\text { gezogen bist? }\end{array}$ & $\begin{array}{l}0=0,1=1,2=2,3=3,4 \\
=4,5=5,6=6,7=7,8= \\
8,9=9,10=10,11=11,12 \\
=12,13=13,14=14,15= \\
15,16=16,17=17,18=18 \\
19=19,20=20,21=21,22 \\
=22,23=23,24=24,25= \\
25,26=26,27=27,28= \\
28,29=29,30=30,31= \\
31,32=32,33=33,34= \\
34,35=35,36=36,37= \\
37,38=38,39=39,40=40\end{array}$ & $\begin{array}{l}\text { If not born in } \\
\text { Switzerland: How old } \\
\text { were you when you } \\
\text { moved to Switzerland? }\end{array}$ & $\begin{array}{l}0=0,1=1,2=2,3=3, \\
4=4,5=5,6=6,7=7, \\
8=8,9=9,10=10,11 \\
=11,12=12,13=13 \\
14=14,15=15,16= \\
16,17=17,18=18,19 \\
=19,20=20,21=21 \\
22=22,23=23,24= \\
24,25=25,26=26,27 \\
=27,28=28,29=29 \\
30=30,31=31,32= \\
32,33=33,34=34,35 \\
=35,36=36,37=37 \\
38=38,39=39,40=40\end{array}$ & $\mathrm{x}$ & & & & & & & & & & & \\
\hline kanton & Home kanton & $\begin{array}{l}\text { Aus welchem Kanton } \\
\text { stammst du? }\end{array}$ & $\begin{array}{l}1=\text { Aargau, } 2= \\
\text { Appenzell-Ausserrhoden, } 3= \\
\text { Appenzell-Innerrhoden, } 4= \\
\text { Basel-Landschaft, } 5= \\
\text { Basel-Stadt, } 6=\text { Bern, } 7= \\
\text { Fribourg, } 8=\text { Geneva, } 9= \\
\text { Glarus, } 10=\text { Graubünden, } 11 \\
=\text { Jura, } 12=\text { Luzern, } 13= \\
\text { Neuchâtel, } 14=\text { Nidwalden, } \\
15=\text { Obwalden, } 16= \\
\text { Schaffhausen, } 17=\text { Schwyz, } \\
18=\text { Solothurn, } 19=\text { St. } \\
\text { Gallen, } 20=\text { Thurgau, } 21= \\
\text { Ticino, } 22=\text { Uri, } 23=\text { Valais, } \\
24=\text { Vaud, } 25=\text { Zug, } 26= \\
\text { Zürich }\end{array}$ & $\begin{array}{l}\text { Which is your home } \\
\text { canton? }\end{array}$ & $\begin{array}{l}1=\text { Aargau, } 2= \\
\text { Appenzell-Ausserrhoden, } \\
3= \\
\text { Appenzell-Innerrhoden, } 4 \\
=\text { Basel-Landschaft, } 5= \\
\text { Basel-Stadt, } 6=\text { Bern, } 7 \\
=\text { Fribourg, } 8=\text { Geneva, } \\
9=\text { Glarus, } 10= \\
\text { Graubünden, } 11=\text { Jura, } \\
12=\text { Luzern, } 13= \\
\text { Neuchâtel, } 14= \\
\text { Nidwalden, } 15= \\
\text { Obwalden, } 16= \\
\text { Schaffhausen, } 17= \\
\text { Schwyz, } 18=\text { Solothurn, } \\
19=\text { St. Gallen, } 20= \\
\text { Thurgau, } 21=\text { Ticino, } 22 \\
=\text { Uri, } 23=\text { Valais, } 24= \\
\text { Vaud, } 25=\text { Zug, } 26= \\
\text { Zürich }\end{array}$ & $\mathrm{x}$ & $\mathrm{x}$ & $\mathrm{x}$ & $\mathrm{x}$ & $\mathrm{x}$ & $\mathrm{x}$ & $\mathrm{x}$ & $\mathrm{x}$ & $\mathrm{x}$ & $\mathrm{x}$ & $\mathrm{x}$ & $\mathrm{x}$ \\
\hline language.fam.1 & $\begin{array}{l}\text { Main } \\
\text { languages } \\
\text { spoken in } \\
\text { family }\end{array}$ & $\begin{array}{l}\text { Q3.7_1 - Welche Sprachen } \\
\text { sprichst Du hauptsächlich } \\
\text { mit Deiner Familie? - } \\
\text { Selected Choice - } \\
\text { Schweizerdeutsch }\end{array}$ & & $\begin{array}{l}\text { What language do you } \\
\text { speak most of the time } \\
\text { with your family? - } \\
\text { Selected Choice - Swiss } \\
\text { German }\end{array}$ & & $\mathrm{x}$ & & & & & & & & & & & \\
\hline
\end{tabular}




\begin{tabular}{|c|c|c|c|c|c|c|c|c|c|c|c|c|c|c|c|}
\hline VarName & VariableLabel & WordingDE & ValueLabelsDE_Linked & WordingEN & ValueLabelsEN_Linked & $\mathrm{L} 1$ & L2 & L3 & L4 & L5 & $\mathrm{L} 6$ & $\mathrm{~L} 7$ & $\mathrm{~L} 8$ & L9 & $\mathrm{L} 10 \mathrm{~L} 11 \mathrm{~L} 12$ \\
\hline language.fam.2 & $\begin{array}{l}\text { Main } \\
\text { languages } \\
\text { spoken in } \\
\text { family }\end{array}$ & $\begin{array}{l}\text { Q3.7_2 - Welche Sprachen } \\
\text { sprichst Du hauptsächlich } \\
\text { mit Deiner Familie? - } \\
\text { Selected Choice - } \\
\text { Hochdeutsch }\end{array}$ & & $\begin{array}{l}\text { What language do you } \\
\text { speak most of the time } \\
\text { with your family? - } \\
\text { Selected Choice - High } \\
\text { German }\end{array}$ & & $\mathrm{x}$ & & & & & & & & & \\
\hline language.fam. 3 & $\begin{array}{l}\text { Main } \\
\text { languages } \\
\text { spoken in } \\
\text { family }\end{array}$ & $\begin{array}{l}\text { Q3.7_3 - Welche Sprachen } \\
\text { sprichst Du hauptsächlich } \\
\text { mit Deiner Familie? - } \\
\text { Selected Choice - } \\
\text { Französisch }\end{array}$ & & $\begin{array}{l}\text { What language do you } \\
\text { speak most of the time } \\
\text { with your family? - } \\
\text { Selected Choice - French }\end{array}$ & & $\mathrm{x}$ & & & & & & & & & \\
\hline language.fam.4 & $\begin{array}{l}\text { Main } \\
\text { languages } \\
\text { spoken in } \\
\text { family }\end{array}$ & $\begin{array}{l}\text { Q3.7_4 - Welche Sprachen } \\
\text { sprichst Du hauptsächlich } \\
\text { mit Deiner Familie? - } \\
\text { Selected Choice - Italienisch }\end{array}$ & & $\begin{array}{l}\text { What language do you } \\
\text { speak most of the time } \\
\text { with your family? - } \\
\text { Selected Choice - Italian }\end{array}$ & & $\mathrm{x}$ & & & & & & & & & \\
\hline language.fam.5 & $\begin{array}{l}\text { Main } \\
\text { languages } \\
\text { spoken in } \\
\text { family }\end{array}$ & $\begin{array}{l}\text { Q3.7_5 - Welche Sprachen } \\
\text { sprichst Du hauptsächlich } \\
\text { mit Deiner Familie? - } \\
\text { Selected Choice - Romansch }\end{array}$ & & $\begin{array}{l}\text { What language do you } \\
\text { speak most of the time } \\
\text { with your family? - } \\
\text { Selected Choice - } \\
\text { Romansch }\end{array}$ & & $\mathrm{x}$ & & & & & & & & & \\
\hline language.fam.6 & $\begin{array}{l}\text { Main } \\
\text { languages } \\
\text { spoken in } \\
\text { family }\end{array}$ & $\begin{array}{l}\text { Q3.7_6 - Welche Sprachen } \\
\text { sprichst Du hauptsächlich } \\
\text { mit Deiner Familie? - } \\
\text { Selected Choice - Englisch }\end{array}$ & & $\begin{array}{l}\text { What language do you } \\
\text { speak most of the time } \\
\text { with your family? - } \\
\text { Selected Choice - } \\
\text { English }\end{array}$ & & $\mathrm{x}$ & & & & & & & & & \\
\hline language.fam.7 & $\begin{array}{l}\text { Main } \\
\text { languages } \\
\text { spoken in } \\
\text { family }\end{array}$ & $\begin{array}{l}\text { Q3.7_7 - Welche Sprachen } \\
\text { sprichst Du hauptsächlich } \\
\text { mit Deiner Familie? - } \\
\text { Selected Choice - Serbisch }\end{array}$ & & $\begin{array}{l}\text { What language do you } \\
\text { speak most of the time } \\
\text { with your family? - } \\
\text { Selected Choice - } \\
\text { Serbian }\end{array}$ & & $\mathrm{x}$ & & & & & & & & & \\
\hline language.fam.8 & $\begin{array}{l}\text { Main } \\
\text { languages } \\
\text { spoken in } \\
\text { family }\end{array}$ & $\begin{array}{l}\text { Q3.7_8 - Welche Sprachen } \\
\text { sprichst Du hauptsächlich } \\
\text { mit Deiner Familie? - } \\
\text { Selected Choice - Albanisch }\end{array}$ & & $\begin{array}{l}\text { What language do you } \\
\text { speak most of the time } \\
\text { with your family? - } \\
\text { Selected Choice - } \\
\text { Albanian }\end{array}$ & & $\mathrm{x}$ & & & & & & & & & \\
\hline language.fam.9 & $\begin{array}{l}\text { Main } \\
\text { languages } \\
\text { spoken in } \\
\text { family }\end{array}$ & $\begin{array}{l}\text { Q3.7_9 - Welche Sprachen } \\
\text { sprichst Du hauptsächlich } \\
\text { mit Deiner Familie? - } \\
\text { Selected Choice - Türkisch }\end{array}$ & & $\begin{array}{l}\text { What language do you } \\
\text { speak most of the time } \\
\text { with your family? - } \\
\text { Selected Choice - } \\
\text { Turkish }\end{array}$ & & $\mathrm{x}$ & & & & & & & & & \\
\hline language.fam.10 & $\begin{array}{l}\text { Main } \\
\text { languages } \\
\text { spoken in } \\
\text { family }\end{array}$ & $\begin{array}{l}\text { Q3.7_10 - Welche Sprachen } \\
\text { sprichst Du hauptsächlich } \\
\text { mit Deiner Familie? - } \\
\text { Selected Choice - } \\
\text { Portugiesisch }\end{array}$ & & $\begin{array}{l}\text { What language do you } \\
\text { speak most of the time } \\
\text { with your family? - } \\
\text { Selected Choice - } \\
\text { Portuguese }\end{array}$ & & $\mathrm{x}$ & & & & & & & & & \\
\hline language.fam.11 & $\begin{array}{l}\text { Main } \\
\text { languages } \\
\text { spoken in } \\
\text { family }\end{array}$ & $\begin{array}{l}\text { Q3.7_11 - Welche Sprachen } \\
\text { sprichst Du hauptsächlich } \\
\text { mit Deiner Familie? - } \\
\text { Selected Choice - Spanisch }\end{array}$ & & $\begin{array}{l}\text { What language do you } \\
\text { speak most of the time } \\
\text { with your family? - } \\
\text { Selected Choice - } \\
\text { Spanish }\end{array}$ & & $\mathrm{x}$ & & & & & & & & & \\
\hline language.fam.12 & $\begin{array}{l}\text { Main } \\
\text { languages } \\
\text { spoken in } \\
\text { family (other) }\end{array}$ & $\begin{array}{l}\text { Q3.7_12 - Welche Sprachen } \\
\text { sprichst Du hauptsächlich } \\
\text { mit Deiner Familie? - } \\
\text { Selected Choice - Andere: }\end{array}$ & & $\begin{array}{l}\text { What language do you } \\
\text { speak most of the time } \\
\text { with your family? - } \\
\text { Selected Choice - Other }\end{array}$ & & $\mathrm{x}$ & & & & & & & & & \\
\hline language.fam.13 & $\begin{array}{l}\text { Main } \\
\text { languages } \\
\text { spoken in } \\
\text { family (other) }\end{array}$ & $\begin{array}{l}\text { Q3.7_13 - Welche Sprachen } \\
\text { sprichst Du hauptsächlich } \\
\text { mit Deiner Familie? - } \\
\text { Selected Choice - } \\
\text { Serbokroatisch }\end{array}$ & & $\begin{array}{l}\text { What language do you } \\
\text { speak most of the time } \\
\text { with your family? - } \\
\text { Selected Choice - } \\
\text { Serbo-Croatian }\end{array}$ & & $\mathrm{X}$ & & & & & & & & & \\
\hline language.fam.12.str & $\begin{array}{l}\text { Main } \\
\text { languages } \\
\text { spoken in } \\
\text { family (other) }\end{array}$ & $\begin{array}{l}\text { Q3.7_12_TEXT - Welche } \\
\text { Sprachen sprichst Du } \\
\text { hauptsächlich mit Deiner } \\
\text { Familie? - Andere: - Text }\end{array}$ & & $\begin{array}{l}\text { What language do you } \\
\text { speak most of the time } \\
\text { with your family? } \\
\text {-Other: -Text }\end{array}$ & & $\mathrm{x}$ & & & & & & & & & \\
\hline
\end{tabular}




\begin{tabular}{|c|c|c|c|c|c|c|c|c|c|c|c|c|c|c|c|}
\hline VarName & VariableLabel & WordingDE & ValueLabelsDE_Linked & WordingEN & ValueLabelsEN_Linked & L1 & $\mathrm{L} 2$ & L3 & $\mathrm{L} 4$ & L5 & L6 & L7 & L8 & L9 & L10 L11 L12 \\
\hline language.fri.1 & & $\begin{array}{l}\text { Q3.5_1 - Welche Sprachen } \\
\text { sprichst Du hauptsächlich } \\
\text { mit Deinen Freunden? - } \\
\text { Selected Choice - } \\
\text { Schweizerdeutsch }\end{array}$ & & $\begin{array}{l}\text { What language do you } \\
\text { speak most of the time } \\
\text { with your friends? - } \\
\text { Selected Choice - Swiss } \\
\text { German }\end{array}$ & & $\mathrm{x}$ & $\mathrm{x}$ & $\mathrm{x}$ & $\mathrm{x}$ & $\mathrm{x}$ & $\mathrm{x}$ & $\mathrm{x}$ & $\mathrm{x}$ & $\mathrm{x}$ & $\mathrm{x}$ \\
\hline language.fri.2 & & $\begin{array}{l}\text { Q3.5_2 - Welche Sprachen } \\
\text { sprichst Du hauptsächlich } \\
\text { mit Deinen Freunden? - } \\
\text { Selected Choice - } \\
\text { Hochdeutsch }\end{array}$ & & $\begin{array}{l}\text { What language do you } \\
\text { speak most of the time } \\
\text { with your friends? - } \\
\text { Selected Choice - High } \\
\text { German }\end{array}$ & & $\mathrm{x}$ & $\mathrm{x}$ & $\mathrm{x}$ & $\mathrm{x}$ & $\mathrm{x}$ & $\mathrm{x}$ & $\mathrm{x}$ & $\mathrm{x}$ & $\mathrm{x}$ & $\mathrm{x}$ \\
\hline language.fri.3 & & $\begin{array}{l}\text { Q3.5_3 - Welche Sprachen } \\
\text { sprichst Du hauptsächlich } \\
\text { mit Deinen Freunden? - } \\
\text { Selected Choice - } \\
\text { Französisch }\end{array}$ & & $\begin{array}{l}\text { What language do you } \\
\text { speak most of the time } \\
\text { with your friends? - } \\
\text { Selected Choice - French }\end{array}$ & & $\mathrm{x}$ & $\mathrm{x}$ & $\mathrm{x}$ & $\mathrm{x}$ & $\mathrm{x}$ & $\mathrm{x}$ & $\mathrm{x}$ & $\mathrm{x}$ & $\mathrm{x}$ & $\mathrm{x}$ \\
\hline language.fri.4 & & $\begin{array}{l}\text { Q3.5_4 - Welche Sprachen } \\
\text { sprichst Du hauptsächlich } \\
\text { mit Deinen Freunden? - } \\
\text { Selected Choice - Italienisch }\end{array}$ & & $\begin{array}{l}\text { What language do you } \\
\text { speak most of the time } \\
\text { with your friends? - } \\
\text { Selected Choice - Italian }\end{array}$ & & $\mathrm{x}$ & $\mathrm{x}$ & $\mathrm{x}$ & $\mathrm{x}$ & $\mathrm{x}$ & $\mathrm{x}$ & $\mathrm{x}$ & $\mathrm{x}$ & $\mathrm{x}$ & $\mathrm{x}$ \\
\hline language.fri.5 & & $\begin{array}{l}\text { Q3.5_5 - Welche Sprachen } \\
\text { sprichst Du hauptsächlich } \\
\text { mit Deinen Freunden? - } \\
\text { Selected Choice - Romansch }\end{array}$ & & $\begin{array}{l}\text { What language do you } \\
\text { speak most of the time } \\
\text { with your friends? - } \\
\text { Selected Choice - } \\
\text { Romansch }\end{array}$ & & $\mathrm{x}$ & $\mathrm{x}$ & $\mathrm{x}$ & $\mathrm{x}$ & $\mathrm{x}$ & $\mathrm{x}$ & $\mathrm{x}$ & $\mathrm{x}$ & $\mathrm{x}$ & $\mathrm{x}$ \\
\hline language.fri.6 & & $\begin{array}{l}\text { Q3.5_6 - Welche Sprachen } \\
\text { sprichst Du hauptsächlich } \\
\text { mit Deinen Freunden? - } \\
\text { Selected Choice - Englisch }\end{array}$ & & $\begin{array}{l}\text { What language do you } \\
\text { speak most of the time } \\
\text { with your friends? - } \\
\text { Selected Choice - } \\
\text { English }\end{array}$ & & $\mathrm{x}$ & $\mathrm{x}$ & $\mathrm{x}$ & $\mathrm{x}$ & $\mathrm{x}$ & $\mathrm{x}$ & $\mathrm{x}$ & $\mathrm{x}$ & $\mathrm{x}$ & $\mathrm{x}$ \\
\hline language.fri. 7 & & $\begin{array}{l}\text { Q3.5_7 - Welche Sprachen } \\
\text { sprichst Du hauptsächlich } \\
\text { mit Deinen Freunden? - } \\
\text { Selected Choice - Serbisch }\end{array}$ & & $\begin{array}{l}\text { What language do you } \\
\text { speak most of the time } \\
\text { with your friends? - } \\
\text { Selected Choice - } \\
\text { Serbian }\end{array}$ & & $\mathrm{x}$ & $\mathrm{x}$ & $\mathrm{x}$ & $\mathrm{x}$ & $\mathrm{x}$ & $\mathrm{x}$ & $\mathrm{x}$ & $\mathrm{x}$ & $\mathrm{x}$ & $\mathrm{x}$ \\
\hline language.fri.8 & & $\begin{array}{l}\text { Q3.5_8 - Welche Sprachen } \\
\text { sprichst Du hauptsächlich } \\
\text { mit Deinen Freunden? - } \\
\text { Selected Choice - Albanisch }\end{array}$ & & $\begin{array}{l}\text { What language do you } \\
\text { speak most of the time } \\
\text { with your friends? - } \\
\text { Selected Choice - } \\
\text { Albanian }\end{array}$ & & $\mathrm{x}$ & $\mathrm{x}$ & $\mathrm{x}$ & $\mathrm{x}$ & $\mathrm{x}$ & $\mathrm{x}$ & $\mathrm{x}$ & $\mathrm{x}$ & $\mathrm{x}$ & $\mathrm{x}$ \\
\hline language.fri.9 & & $\begin{array}{l}\text { Q3.5_9 - Welche Sprachen } \\
\text { sprichst Du hauptsächlich } \\
\text { mit Deinen Freunden? - } \\
\text { Selected Choice - Türkisch }\end{array}$ & & $\begin{array}{l}\text { What language do you } \\
\text { speak most of the time } \\
\text { with your friends? - } \\
\text { Selected Choice - } \\
\text { Turkish }\end{array}$ & & $\mathrm{x}$ & $\mathrm{x}$ & $\mathrm{x}$ & $\mathrm{x}$ & $\mathrm{x}$ & $\mathrm{x}$ & $\mathrm{x}$ & $\mathrm{x}$ & $\mathrm{x}$ & $\mathrm{x}$ \\
\hline language.fri.10 & & $\begin{array}{l}\text { Q3.5_10- Welche Sprachen } \\
\text { sprichst Du hauptsächlich } \\
\text { mit Deinen Freunden? - } \\
\text { Selected Choice - } \\
\text { Portugiesisch }\end{array}$ & & $\begin{array}{l}\text { What language do you } \\
\text { speak most of the time } \\
\text { with your friends? - } \\
\text { Selected Choice - } \\
\text { Portuguese }\end{array}$ & & $\mathrm{x}$ & $\mathrm{x}$ & $\mathrm{x}$ & $\mathrm{x}$ & $\mathrm{x}$ & $\mathrm{x}$ & $\mathrm{x}$ & $\mathrm{x}$ & $\mathrm{x}$ & $\mathrm{x}$ \\
\hline language.fri.11 & & $\begin{array}{l}\text { Q3.5_11 - Welche Sprachen } \\
\text { sprichst Du hauptsächlich } \\
\text { mit Deinen Freunden? - } \\
\text { Selected Choice - Spanisch }\end{array}$ & & $\begin{array}{l}\text { What language do you } \\
\text { speak most of the time } \\
\text { with your friends? - } \\
\text { Selected Choice - } \\
\text { Spanish }\end{array}$ & & $\mathrm{x}$ & $\mathrm{x}$ & $\mathrm{x}$ & $\mathrm{x}$ & $\mathrm{x}$ & $\mathrm{x}$ & $\mathrm{x}$ & $\mathrm{x}$ & $\mathrm{x}$ & $\mathrm{x}$ \\
\hline language.fri.12 & & $\begin{array}{l}\text { Q3.5_12 - Welche Sprachen } \\
\text { sprichst Du hauptsächlich } \\
\text { mit Deinen Freunden? - } \\
\text { Selected Choice - Andere: }\end{array}$ & & $\begin{array}{l}\text { What language do you } \\
\text { speak most of the time } \\
\text { with your friends? - } \\
\text { Selected Choice - Other }\end{array}$ & & $\mathrm{x}$ & $\mathrm{x}$ & $\mathrm{x}$ & $\mathrm{x}$ & $\mathrm{x}$ & $\mathrm{x}$ & $\mathrm{x}$ & $\mathrm{x}$ & $\mathrm{x}$ & $\mathrm{x}$ \\
\hline
\end{tabular}




\begin{tabular}{|c|c|c|c|c|c|c|c|c|c|c|c|c|c|c|c|c|c|}
\hline VarName & VariableLabel & WordingDE & ValueLabelsDE_Linked & WordingEN & ValueLabelsEN_Linked & $\mathrm{L} 1$ & L2 & L3 & L4 & L5 & L6 & L7 & L8 & L9 & L10 & L11 & $\mathrm{L} 12$ \\
\hline language.fri.13 & & $\begin{array}{l}\text { Q3.5_13 - Welche Sprachen } \\
\text { sprichst Du hauptsächlich } \\
\text { mit Deinen Freunden? - } \\
\text { Selected Choice - } \\
\text { Serbokroatisch }\end{array}$ & & $\begin{array}{l}\text { What language do you } \\
\text { speak most of the time } \\
\text { with your friends? - } \\
\text { Selected Choice - } \\
\text { Serbo-Croatian }\end{array}$ & & $\mathrm{x}$ & $\mathrm{x}$ & $\mathrm{x}$ & $\mathrm{x}$ & $\mathrm{x}$ & $\mathrm{x}$ & $\mathrm{x}$ & $\mathrm{x}$ & $\mathrm{x}$ & $\mathrm{x}$ & & \\
\hline language.fri.12.str & & $\begin{array}{l}\text { Q3.5_12_TEXT - Welche } \\
\text { Sprachen sprichst Du } \\
\text { hauptsächlich mit Deinen } \\
\text { Freunden? - Andere: - Text }\end{array}$ & & $\begin{array}{l}\text { What language do you } \\
\text { speak most of the time } \\
\text { with your friends? } \\
\text {-Other: -Text }\end{array}$ & & $\mathrm{x}$ & $\mathrm{x}$ & $\mathrm{x}$ & $\mathrm{x}$ & $\mathrm{x}$ & $\mathrm{x}$ & $\mathrm{x}$ & $\mathrm{x}$ & $\mathrm{x}$ & $\mathrm{x}$ & & \\
\hline home.current & & $\begin{array}{l}\text { Q3.10 - Wo wohnst Du im } \\
\text { Moment? (Bitte nenne die } \\
\text { Ortschaft, an welcher Du } \\
\text { die Mehrheit deiner Zeit } \\
\text { verbringst.) }\end{array}$ & & $\begin{array}{l}\text { Where do you live at the } \\
\text { moment? (Please think } \\
\text { about the place where } \\
\text { you spend the majority } \\
\text { of your time.) }\end{array}$ & & $\mathrm{x}$ & $\mathrm{x}$ & $\mathrm{x}$ & $\mathrm{x}$ & $\mathrm{x}$ & $\mathrm{x}$ & $\mathrm{x}$ & $\mathrm{x}$ & $\mathrm{x}$ & $\mathrm{x}$ & $\mathrm{x}$ & $\mathrm{x}$ \\
\hline sex & & $\begin{array}{l}\text { Q3.11 - Welches ist Dein } \\
\text { Geschlecht? }\end{array}$ & 1 = Männlich, 2 = Weiblich & What is your gender? & $1=$ male, $2=$ female & $\mathrm{x}$ & $\mathrm{x}$ & $\mathrm{x}$ & $\mathrm{x}$ & $\mathrm{x}$ & $\mathrm{x}$ & $\mathrm{x}$ & $\mathrm{x}$ & $\mathrm{x}$ & $\mathrm{x}$ & & \\
\hline $\begin{array}{l}\text { postal.code } \\
\text { rel.stat }\end{array}$ & & $\begin{array}{l}\text { Q3.12 - Welches ist Dein } \\
\text { Beziehungsstatus? }\end{array}$ & $\begin{array}{l}1=\text { Single, } 2=\text { in einer } \\
\text { Beziehung, } 3=\text { in einer } \\
\text { eingetragenen Partnerschaft, } \\
4=\text { Verheiratet, } 5= \\
\text { Geschieden }\end{array}$ & $\begin{array}{l}\text { What is your } \\
\text { relationship status? }\end{array}$ & $\begin{array}{l}1=\text { Single, } 2=\text { in a } \\
\text { relationship, } 3=\text { in a } \\
\text { registered partnership, } 4 \\
=\text { married, } 5=\text { divorced }\end{array}$ & $\mathrm{x}$ & $\mathrm{x}$ & $\mathrm{x}$ & $\mathrm{x}$ & $\mathrm{x}$ & $\mathrm{x}$ & $\mathrm{x}$ & $\mathrm{x}$ & $\mathrm{x}$ & $\mathrm{x}$ & $\begin{array}{l}\mathrm{x} \\
\mathrm{x}\end{array}$ & $\begin{array}{l}\mathrm{x} \\
\mathrm{x}\end{array}$ \\
\hline cohabit.1 & & $\begin{array}{l}\text { Q3.13_1 - Mit wem wohnst } \\
\text { Du im Moment? - Selected } \\
\text { Choice - Eltern / } \\
\text { Erziehende }\end{array}$ & & $\begin{array}{l}\text { Who do you live with at } \\
\text { the moment? - Selected } \\
\text { Choice - parents }\end{array}$ & & $\mathrm{x}$ & $\mathrm{x}$ & $\mathrm{x}$ & $\mathrm{x}$ & $\mathrm{x}$ & $\mathrm{x}$ & $\mathrm{x}$ & $\mathrm{x}$ & $\mathrm{x}$ & $\mathrm{x}$ & $\mathrm{x}$ & $\mathrm{x}$ \\
\hline cohabit.2 & & $\begin{array}{l}\text { Q3.13_2 - Mit wem wohnst } \\
\text { Du im Moment? - Selected } \\
\text { Choice - Geschwister }\end{array}$ & & $\begin{array}{l}\text { Who do you live with at } \\
\text { the moment? - Selected } \\
\text { Choice - siblings }\end{array}$ & & $\mathrm{x}$ & $\mathrm{x}$ & $\mathrm{x}$ & $\mathrm{x}$ & $\mathrm{X}$ & $\mathrm{x}$ & $\mathrm{x}$ & $\mathrm{x}$ & $\mathrm{x}$ & $\mathrm{x}$ & $\mathrm{x}$ & $\mathrm{x}$ \\
\hline cohabit.3 & & $\begin{array}{l}\text { Q3.13_3 - Mit wem wohnst } \\
\text { Du im Moment? - Selected } \\
\text { Choice - Freunde }\end{array}$ & & $\begin{array}{l}\text { Who do you live with at } \\
\text { the moment? - Selected } \\
\text { Choice - friends }\end{array}$ & & $\mathrm{x}$ & $\mathrm{x}$ & $\mathrm{x}$ & $\mathrm{x}$ & $\mathrm{x}$ & $\mathrm{x}$ & $\mathrm{x}$ & $\mathrm{x}$ & $\mathrm{x}$ & $\mathrm{x}$ & $\mathrm{x}$ & $\mathrm{x}$ \\
\hline cohabit.4 & & $\begin{array}{l}\text { Q3.13_4 - Mit wem wohnst } \\
\text { Du im Moment? - Selected } \\
\text { Choice - Anderen } \\
\text { Studierenden }\end{array}$ & & $\begin{array}{l}\text { Who do you live with at } \\
\text { the moment? - Selected } \\
\text { Choice - other students }\end{array}$ & & $\mathrm{x}$ & $\mathrm{x}$ & $\mathrm{x}$ & $\mathrm{x}$ & $\mathrm{x}$ & $\mathrm{x}$ & $\mathrm{x}$ & $\mathrm{x}$ & $\mathrm{x}$ & $\mathrm{x}$ & $\mathrm{x}$ & $\mathrm{x}$ \\
\hline cohabit.5 & & $\begin{array}{l}\text { Q3.13_5 - Mit wem wohnst } \\
\text { Du im Moment? - Selected } \\
\text { Choice - Andere }\end{array}$ & & $\begin{array}{l}\text { Who do you live with at } \\
\text { the moment? - Selected } \\
\text { Choice - (Other) }\end{array}$ & & $\mathrm{x}$ & $\mathrm{x}$ & $\mathrm{x}$ & $\mathrm{x}$ & $\mathrm{x}$ & $\mathrm{x}$ & $\mathrm{x}$ & $\mathrm{x}$ & $\mathrm{x}$ & $\mathrm{x}$ & $\mathrm{x}$ & $\mathrm{x}$ \\
\hline cohabit. 6 & & $\begin{array}{l}\text { Q3.13_6 - Mit wem wohnst } \\
\text { Du im Moment? - Selected } \\
\text { Choice - Partner }\end{array}$ & & $\begin{array}{l}\text { Who do you live with at } \\
\text { the moment? - Selected } \\
\text { Choice - partners }\end{array}$ & & $\mathrm{x}$ & $\mathrm{x}$ & $\mathrm{x}$ & $\mathrm{x}$ & $\mathrm{x}$ & $\mathrm{x}$ & $\mathrm{x}$ & $\mathrm{x}$ & $\mathrm{x}$ & $\mathrm{x}$ & $\mathrm{x}$ & $\mathrm{x}$ \\
\hline cohabit. 7 & & $\begin{array}{l}\text { Q3.13_10 - Mit wem } \\
\text { wohnst Du im Moment? - } \\
\text { Selected Choice - } \\
\text { Mitstudierenden }\end{array}$ & & $\begin{array}{l}\text { Who do you live with at } \\
\text { the moment? - Selected } \\
\text { Choice - fellow students }\end{array}$ & & $\mathrm{x}$ & $\mathrm{x}$ & $\mathrm{x}$ & $\mathrm{x}$ & $\mathrm{x}$ & $\mathrm{x}$ & $\mathrm{x}$ & $\mathrm{x}$ & $\mathrm{x}$ & $\mathrm{x}$ & $\mathrm{x}$ & $\mathrm{x}$ \\
\hline cohabit. 8 & & & & & & & & & & & & & & & & $\mathrm{X}$ & $\mathrm{x}$ \\
\hline cohabit.5.str & & $\begin{array}{l}\text { Q3.13_5_TEXT - Mit wem } \\
\text { wohnst Du im Moment? - } \\
\text { Andere - Text }\end{array}$ & & $\begin{array}{l}\text { TEXT - Who do you } \\
\text { live with at the } \\
\text { moment? - Other - Text }\end{array}$ & & $\mathrm{x}$ & $\mathrm{x}$ & $\mathrm{x}$ & $\mathrm{x}$ & $\mathrm{x}$ & $\mathrm{x}$ & $\mathrm{x}$ & $\mathrm{x}$ & $\mathrm{x}$ & $\mathrm{x}$ & $\mathrm{x}$ & $\mathrm{x}$ \\
\hline cohabit.classmates.P1 & & $\begin{array}{l}\text { Q3.14_1 - Mit wem Deiner } \\
\text { Mitstudierenden wohnst Du } \\
\text { zusammen?Nenne zwischen } \\
1 \text { und } 5 \text { Personen. - Name } 1\end{array}$ & & $\begin{array}{l}\text { Whom of your fellow } \\
\text { students do you live } \\
\text { with at the moment? } \\
\text { Name between } 0 \text { and } 5 \\
\text { people. - Name } 1\end{array}$ & & $\mathrm{x}$ & $\mathrm{x}$ & $\mathrm{x}$ & $\mathrm{x}$ & $\mathrm{x}$ & $\mathrm{x}$ & $\mathrm{x}$ & $\mathrm{x}$ & $\mathrm{x}$ & $\mathrm{x}$ & $\mathrm{x}$ & $\mathrm{x}$ \\
\hline financial.sit.1 & & $\begin{array}{l}\text { Q3.16 - Wirst Du von } \\
\text { Deiner Familie regelmässig } \\
\text { finanziell unterstützt? }\end{array}$ & $1=\mathrm{Ja}, 2=\mathrm{Nein}$ & $\begin{array}{l}\text { Does your family } \\
\text { financially support you } \\
\text { regularly? }\end{array}$ & $1=\mathrm{Yes}, 2=\mathrm{No}$ & $\mathrm{x}$ & $\mathrm{x}$ & $\mathrm{x}$ & $\mathrm{x}$ & $\mathrm{x}$ & $\mathrm{x}$ & $\mathrm{x}$ & $\mathrm{x}$ & $\mathrm{x}$ & $\mathrm{x}$ & & \\
\hline financial.sit.2 & & Q3.17 - Hast Du einen Job? & $\begin{array}{l}1=\mathrm{Ja}, 2=\text { Teilzeit } \\
(\text { permanent }), 3=\text { Teilzeit } \\
\text { (zwischenzeitlich), } 4=\text { Nein }\end{array}$ & Do you have a job? & $\begin{array}{l}1=\text { Yes, } 2=\text { Part-time } \\
(\text { permanently), } 3= \\
\text { Part-time (temporarily), } 4 \\
=\text { No }\end{array}$ & $\mathrm{x}$ & $\mathrm{x}$ & $\mathrm{x}$ & $\mathrm{x}$ & $\mathrm{x}$ & $\mathrm{x}$ & $\mathrm{x}$ & $\mathrm{x}$ & $\mathrm{x}$ & $\mathrm{x}$ & & \\
\hline
\end{tabular}




\begin{tabular}{|c|c|c|c|c|c|c|c|c|c|c|c|c|c|c|c|}
\hline VarName & VariableLabel & WordingDE & ValueLabelsDE_Linked & WordingEN & ValueLabelsEN_Linked & L1 & $\mathrm{L} 2$ & L3 & $\mathrm{L} 4$ & L5 & $\mathrm{L} 6$ & L7 & L8 & L9 & L10 L11 L12 \\
\hline financial.sit.3 & & $\begin{array}{l}\text { Q3.18 - Wie viele Stunden } \\
\text { pro Woche arbeitest Du } \\
\text { durchschnittlich? }\end{array}$ & $\begin{array}{l}1=0,2=1,3=2,4=3,5 \\
=4,6=5,7=6,8=7,9= \\
8,10=9,11=10,12=11, \\
13=12,14=13,15=14,16 \\
=15,17=16,18=17,19= \\
18,20=19,21=20,22=21, \\
23=22,24=23,25=24,26 \\
=25,27=26,28=27,29= \\
28,30=29,31=30,32= \\
31,33=32,34=33,35= \\
34,36=35,37=36,38= \\
37,39=38,40=39,41=40\end{array}$ & $\begin{array}{l}\text { How many hours a week } \\
\text { do you work (on } \\
\text { average)? }\end{array}$ & $\begin{array}{l}1=0,2=1,3=2,4=3, \\
5=4,6=5,7=6,8=7, \\
9=8,10=9,11=10,12 \\
=11,13=12,14=13, \\
15=14,16=15,17= \\
16,18=17,19=18,20 \\
=19,21=20,22=21, \\
23=22,24=23,25= \\
24,26=25,27=26,28 \\
=27,29=28,30=29 \\
31=30,32=31,33= \\
32,34=33,35=34,36 \\
=35,37=36,38=37 \\
39=38,40=39,41=40\end{array}$ & $\mathrm{x}$ & $\mathrm{x}$ & $\mathrm{x}$ & $\mathrm{x}$ & $\mathrm{x}$ & $\mathrm{x}$ & $\mathrm{x}$ & $\mathrm{x}$ & $\mathrm{x}$ & $\mathrm{x}$ \\
\hline financial.sit.4 & & $\begin{array}{l}\text { Q3.19 - Hättest Du genug } \\
\text { finanzielle Mittel um auch } \\
\text { ohne diesen Job } \\
\text { auszukommen? }\end{array}$ & $1=\mathrm{Ja}, 2=$ Nein & $\begin{array}{l}\text { Do you need this to } \\
\text { sustain yourself while } \\
\text { attending university? }\end{array}$ & $1=\mathrm{Yes}, 2=\mathrm{No}$ & $\mathrm{x}$ & $\mathrm{x}$ & $\mathrm{x}$ & $\mathrm{x}$ & $\mathrm{x}$ & $\mathrm{x}$ & $\mathrm{x}$ & $\mathrm{x}$ & $\mathrm{x}$ & $\mathrm{x}$ \\
\hline cob.parent1 & & $\begin{array}{l}\text { Q3.22 - In welchem Land } \\
\text { sind Deine Eltern geboren? } \\
\text { Erster Elternteil: - Selected } \\
\text { Choice }\end{array}$ & $1=$ Schweiz, $2=$ Andere & $\begin{array}{l}\text { In which country was } \\
\text { your first parent born? } \\
\text { (Switzerland) }\end{array}$ & $\begin{array}{l}1=\text { Switzerland, } 2= \\
\text { Other }\end{array}$ & $\mathrm{x}$ & & & & & & & & & \\
\hline cob.parent1.str & & $\begin{array}{l}\text { Q3.22_2_TEXT - In } \\
\text { welchem Land sind Deine } \\
\text { Eltern geboren? Erster } \\
\text { Elternteil: - Anderes: - Text }\end{array}$ & & $\begin{array}{l}\text { In which country was } \\
\text { your first parent born? } \\
\text { (Other) }\end{array}$ & & $\mathrm{x}$ & & & & & & & & & \\
\hline cob.parent2 & & $\begin{array}{l}\text { Q3.23 - Zweiter Elternteil: - } \\
\text { Selected Choice }\end{array}$ & $1=$ Schweiz, $2=$ Andere & $\begin{array}{l}\text { In which country was } \\
\text { your second parent } \\
\text { born? (Switzerland) }\end{array}$ & $\begin{array}{l}1=\text { Switzerland, } 2= \\
\text { Other }\end{array}$ & $\mathrm{x}$ & & & & & & & & & \\
\hline cob.parent2.str & & $\begin{array}{l}\text { Q3.23_2_TEXT - Zweiter } \\
\text { Elternteil: - Anderes: - Text }\end{array}$ & & $\begin{array}{l}\text { In which country was } \\
\text { your second parent } \\
\text { born? (Other) }\end{array}$ & & $\mathrm{x}$ & & & & & & & & & \\
\hline ed.att.parent1 & & $\begin{array}{l}\text { Q3.24 - Welches ist der } \\
\text { höchste Bildungsabschluss } \\
\text { Deines ersten Elternteils? }\end{array}$ & $\begin{array}{l}1=\text { Obligatorische Schule } \\
\text { nicht abgeschlossen }, 2= \\
\text { Obligatorische Schule (Real, } \\
\text { Sekundarschule, } \\
\text { Handelsschule oder } \\
\text { Fachmittelschule (1 Jahr), } \\
\text { Haushaltslehrjahr oder } \\
\text { Sprachaufenthalt), } 3= \\
\text { Sekundarstufe II (Anlehre; } \\
\text { Berufslehre; vollzeitliche } \\
\text { Berufsfachschule), } 4= \\
\text { Sekundarstufe II (gymnasiale } \\
\text { Maturität, Berufsmaturität, } \\
\text { Lehrerseminar), } 5= \\
\text { Tertiärstufe (Meisterdiplom, } \\
\text { eidgenössischer Fachausweis; } \\
\text { Techniker- oder Fachschule; } \\
\text { Höhere Fachschule, höhere } \\
\text { technische Lehranstalt), } 6= \\
\text { Tertiärstufe (Universitäre } \\
\text { Hochschule, Fachhochschule, } \\
\text { Pädagogische Hochschule, } \\
\text { Eidgenössische technische } \\
\text { Hochschule) }\end{array}$ & $\begin{array}{l}\text { What is the highest level } \\
\text { of schooling completed } \\
\text { by your first parent? }\end{array}$ & $\begin{array}{l}1=\text { No completed } \\
\text { mandatory education, } 2= \\
\text { Completed mandatory } \\
\text { education, } 3=\text { Lower } \\
\text { Secondary education, } 4= \\
\text { Higher Secondary } \\
\text { education, } 5=\text { Lower } \\
\text { tertiary education, } 6= \\
\text { Higher tertiary education } \\
\text { (free translation) }\end{array}$ & $\mathrm{x}$ & & & & & & & & & \\
\hline
\end{tabular}




\begin{tabular}{|c|c|c|c|c|c|c|c|c|c|c|c|c|c|c|}
\hline VariableLabel & WordingDE & ValueLabelsDE_Linked & WordingEN & ValueLabelsEN_Linked & L1 & $\mathrm{L} 2$ & L3 & L4 & L5 & L6 & L7 & L8 & L9 & L10 L11 L12 \\
\hline ed.att.parent2 & $\begin{array}{l}\text { Q3.25 - Welches ist der } \\
\text { höchste Bildungsabschluss } \\
\text { Deines zweiten Elternteils? }\end{array}$ & $\begin{array}{l}1=\text { Obligatorische Schule } \\
\text { nicht abgeschlossen }, 2= \\
\text { Obligatorische Schule (Real, } \\
\text { Sekundarschule, } \\
\text { Handelsschule oder } \\
\text { Fachmittelschule (1 Jahr), } \\
\text { Haushaltslehrjahr oder } \\
\text { Sprachaufenthalt) }, 3= \\
\text { Sekundarstufe II (Anlehre; } \\
\text { Berufslehre; vollzeitliche } \\
\text { Berufsfachschule), } 4= \\
\text { Sekundarstufe II (gymnasiale } \\
\text { Maturität, Berufsmaturität, } \\
\text { Lehrerseminar), } 5= \\
\text { Tertiärstufe (Meisterdiplom, } \\
\text { eidgenössischer Fachausweis; } \\
\text { Techniker- oder Fachschule; } \\
\text { Höhere Fachschule, höhere } \\
\text { technische Lehranstalt), } 6= \\
\text { Tertiärstufe (Universitäre } \\
\text { Hochschule, Fachhochschule, } \\
\text { Pädagogische Hochschule, } \\
\text { Eidgenössische technische } \\
\text { Hochschule) }\end{array}$ & $\begin{array}{l}\text { What is the highest level } \\
\text { of schooling completed } \\
\text { by your second parent? }\end{array}$ & $\begin{array}{l}1=\text { No completed } \\
\text { mandatory education, } 2= \\
\text { Completed mandatory } \\
\text { education, } 3=\text { Lower } \\
\text { Secondary education, } 4= \\
\text { Higher Secondary } \\
\text { education, } 5=\text { Lower } \\
\text { tertiary education, } 6= \\
\text { Higher tertiary education } \\
\text { (free translation) }\end{array}$ & $\mathrm{x}$ & & & & & & & & & \\
\hline family.subject.degree & $\begin{array}{l}\text { Q3.27 - Ausser Dir, haben } \\
\text { weitere Mitglieder Deiner } \\
\text { (erweiterten) Familie ein } \\
\text { Fach im Fachbereich [name } \\
\text { removed] studiert? }\end{array}$ & $1=\mathrm{Nein}, 2=\mathrm{Ja}$ & $\begin{array}{l}\text { Have any members of } \\
\text { your (extended) family } \\
\text { studied the subject area } \\
\text { of [name removed], } \\
\text { besides you? }\end{array}$ & $1=$ No, $2=$ Yes & $\mathrm{x}$ & & & & & & & & & \\
\hline family.subject.degree.role.1 & $\begin{array}{l}\text { Q3.28_4 - Wer? - Selected } \\
\text { Choice - Vater oder Mutter }\end{array}$ & & $\begin{array}{l}\text { Who of your family } \\
\text { members studied the } \\
\text { subject area of [name } \\
\text { removed]? - Selected } \\
\text { Choice - father or } \\
\text { mother }\end{array}$ & & $\mathrm{x}$ & & & & & & & & & \\
\hline family.subject.degree.rol $\epsilon$ & $\begin{array}{l}\text { Q3.28_6 - Wer? - Selected } \\
\text { Choice - Bruder oder } \\
\text { Schwester }\end{array}$ & & $\begin{array}{l}\text { Who of your family } \\
\text { members studied the } \\
\text { subject area of [name } \\
\text { removed]? - Selected } \\
\text { Choice - brother or } \\
\text { sister }\end{array}$ & & $\mathrm{x}$ & & & & & & & & & \\
\hline family.subject.degree.role. 3 & $\begin{array}{l}\text { Q3.28_7 - Wer? - Selected } \\
\text { Choice - Tante oder Onkel }\end{array}$ & & $\begin{array}{l}\text { Who of your family } \\
\text { members studied the } \\
\text { subject area of [name } \\
\text { removed]? - Selected } \\
\text { Choice - aunt or uncle }\end{array}$ & & $\mathrm{x}$ & & & & & & & & & \\
\hline family.subject.degree.role & $\begin{array}{l}\text { Q3.28_8 - Wer? - Selected } \\
\text { Choice - Cousine oder } \\
\text { Cousin }\end{array}$ & & $\begin{array}{l}\text { Who of your family } \\
\text { members studied the } \\
\text { subject area of [name } \\
\text { removed]? - Selected } \\
\text { Choice - cousin (m) or } \\
\text { cousin (f) }\end{array}$ & & $\mathrm{x}$ & & & & & & & & & \\
\hline family.subject.degree.role.5 & $\begin{array}{l}\text { Q3.28_9 - Wer? - Selected } \\
\text { Choice - Grossvater oder } \\
\text { Grossmutter }\end{array}$ & & $\begin{array}{l}\text { Who of your family } \\
\text { members studied the } \\
\text { subject area of [name } \\
\text { removed]? - Selected } \\
\text { Choice - grandfather or } \\
\text { grandmother }\end{array}$ & & $\mathrm{x}$ & & & & & & & & & \\
\hline family.subject.degree.role & $\begin{array}{l}\text { Q3.28_10 - Wer? - Selected } \\
\text { Choice - Andere }\end{array}$ & & $\begin{array}{l}\text { Who of your family } \\
\text { members studied the } \\
\text { subject area of [name } \\
\text { removed]? (Other) }\end{array}$ & & $\mathrm{x}$ & & & & & & & & & \\
\hline
\end{tabular}




\begin{tabular}{|c|c|c|c|c|c|c|c|c|c|c|c|c|c|c|}
\hline VariableLabel & WordingDE & ValueLabelsDE_Linked & WordingEN & ValueLabelsEN_Linked & L1 & $\mathrm{L} 2$ & L3 & L4 & L5 & $\mathrm{L} 6$ & L7 & L8 & L9 & L10 L11 L12 \\
\hline family.subject.degree.role.6.str & $\begin{array}{l}\text { Q3.28_10_TEXT - Wer? - } \\
\text { Andere - Text }\end{array}$ & & $\begin{array}{l}\text { TEXT_Who of your } \\
\text { family members studied } \\
\text { the subject area of } \\
\text { [name removed]? - } \\
\text { Other }\end{array}$ & & $\mathrm{x}$ & & & & & & & & & \\
\hline family.natural.science.dę & $\begin{array}{l}\text { Q3.29 - Ausser Dir, haben } \\
\text { weitere Mitglieder Deiner } \\
\text { (erweiterten) Familie ein } \\
\text { anderes } \\
\text { naturwissenschaftliches oder } \\
\text { technisches Fach (ausser } \\
\text { [name removed]) studiert? }\end{array}$ & $1=$ Nein, $2=\mathrm{Ja}$ & $\begin{array}{l}\text { Have any members of } \\
\text { your (extended) family, } \\
\text { besides you, studied } \\
\text { another technical or } \\
\text { natural science subject } \\
\text { area, excluding [name } \\
\text { removed]? }\end{array}$ & $1=$ No, $2=$ Yes & $\mathrm{x}$ & & & & & & & & & \\
\hline family.natural.science.degree.role.1 & $\begin{array}{l}\text { Q3.30_4 - Wer? - Selected } \\
\text { Choice - Vater oder Mutter }\end{array}$ & & $\begin{array}{l}\text { Who of your family } \\
\text { members, besides you, } \\
\text { studied another } \\
\text { technical or natural } \\
\text { science subject area, } \\
\text { excluding [name } \\
\text { removed]? - Selected } \\
\text { Choice - father or } \\
\text { mother }\end{array}$ & & $\mathrm{x}$ & & & & & & & & & \\
\hline family.natural.science.dę & $\begin{array}{l}\text { Q3.30_6 - Wer? - Selected } \\
\text { Choice - Bruder oder } \\
\text { Schwester }\end{array}$ & & $\begin{array}{l}\text { Who of your family } \\
\text { members, besides you, } \\
\text { studied another } \\
\text { technical or natural } \\
\text { science subject area, } \\
\text { excluding [name } \\
\text { removed]? - Selected } \\
\text { Choice - brother or } \\
\text { sister }\end{array}$ & & $\mathrm{x}$ & & & & & & & & & \\
\hline family.natural.science.degree.role. 3 & $\begin{array}{l}\text { Q3.30_7 - Wer? - Selected } \\
\text { Choice - Tante oder Onkel }\end{array}$ & & $\begin{array}{l}\text { Who of your family } \\
\text { members, besides you, } \\
\text { studied another } \\
\text { technical or natural } \\
\text { science subject area, } \\
\text { excluding [name } \\
\text { removed]? - Selected } \\
\text { Choice - aunt or uncle }\end{array}$ & & $\mathrm{x}$ & & & & & & & & & \\
\hline family.natural.science.de६ & $\begin{array}{l}\text { Q3.30_8 - Wer? - Selected } \\
\text { Choice - Cousine oder } \\
\text { Cousin }\end{array}$ & & $\begin{array}{l}\text { Who of your family } \\
\text { members, besides you, } \\
\text { studied another } \\
\text { technical or natural } \\
\text { science subject area, } \\
\text { excluding [name } \\
\text { removed]? - Selected } \\
\text { Choice - cousin (m) or } \\
\text { cousin (f) }\end{array}$ & & $\mathrm{x}$ & & & & & & & & & \\
\hline family.natural.science.degree.role.5 & $\begin{array}{l}\text { Q3.30_9 - Wer? - Selected } \\
\text { Choice - Grossvater oder } \\
\text { Grossmutter }\end{array}$ & & $\begin{array}{l}\text { Who of your family } \\
\text { members, besides you, } \\
\text { studied another } \\
\text { technical or natural } \\
\text { science subject area, } \\
\text { excluding [name } \\
\text { removed]? - Selected } \\
\text { Choice - grandfather or } \\
\text { grandmother }\end{array}$ & & $\mathrm{x}$ & & & & & & & & & \\
\hline family.natural.science.de६ & $\begin{array}{l}\text { Q3.30_10 - Wer? - Selected } \\
\text { Choice - Andere }\end{array}$ & & $\begin{array}{l}\text { Who of your family } \\
\text { members, besides you, } \\
\text { studied another } \\
\text { technical or natural } \\
\text { science subject area, } \\
\text { excluding [name } \\
\text { removed]? (Other) }\end{array}$ & & $\mathrm{x}$ & & & & & & & & & \\
\hline
\end{tabular}



science subject area excluding [name

attitude.parents.

attitude.parents.

attitude.parents. 4

attitude.parents. 5 - Meine Eltern hätten es

political.orientation

Q3.34 - In derPolitik sprich

interaction.P1
Q3.32 4 - Inwieweit treffen die folgenden Aussagen zu? Meinen Eltern ist es wichtig, dass ich studiere.

Q3.32 5 - Inwieweit treffen die folgenden Aussagen zu? - Meinen Eltern ist e wichtig, dass ich eine Naturwissenschaft oder ei

Q3.32 6 - Inwieweit treffen die folgenden Aussagen zu? - Meinen Eltern ist es wichtig, dass ich ein Fach im Fachbereich [nam removed] studiere.

Q3.32_7 - Inwieweit treffen die folgenden Aussagen zu? - Meine Eltern würden es bevorzugen, wenn ich ei anderes Fach studierte.

Q3.32_8 - Inwieweit treffen die folgenden Aussagen zu? bevorzugt, wenn ich eine Arbeitsstelle angenommen hätte, statt ein Studium zu beginnen man manchmal von "links" und "rechts". Wo würdest Du Dich selber

instufen,wenn 0 für links steht und 10 für rechts?

Wen kanntest Du bereits vor Deinem Start an [name removed], also vor dem Semesterbeginn und de [name removed]?Nen
zwischen 0 und 20 zwischen 0 und 20
Personen. - Name 1

4 = überhaupt nicht zutreffend, $5=$ nicht zutreffend, $6=$ eher nicht zutreffend, 7 = weder noch, 8 $=$ eher zutreffend, $9=$ zutreffend, 10
und ganz zu

und ganz zu
$4=$ überhaupt nich zutreffend, $5=$ nicht zutreffend, $7=$ weder noch, $=$ eher zutreffend, $9=$ zutreffend, $10=$ trifft voll und ganz zu

$4=$ überhaupt nicht zutreffend, $5=$ nicht zutreffend, $7=$ weder noch, 8 $=$ eher zutreffend, $9=$ zutreffend, $10=$ trifft voll und ganz zu

$4=$ überhaupt nicht zutreffend, $5=$ nicht zutreffend, $6=$ eher nicht zutreffend, $7=$ weder noch, $=$ eher zutreffend, $9=$ zutreffend, $10=$ trifft voll und ganz zu

$4=$ überhaupt nicht zutreffend, $5=$ nicht zutreffend, $6=$ eher nicht zutreffend, 7 = weder noch, 8 $=$ eher zutreffend, $9=$ zutreffend, $10=$ trifft vol und ganz zu

Q4.5_1 - Mit wem erlebs

Du angenehme

Interaktionen?Nenne

zwischen 0 und 20

Personen. - Name zutreffend, $6=$ eher nicht zutreffend, $6=$ eher nicht
It is important to my

higher education

$4=$ not at all, $5=$ not

applicable, $6=$ rather

not applicable, $7=$

neither nor , $8=$ rather

applicable, $9=$ applicable

$10=$ fully applies

It is important to my parents, that I pursue natural or technical

$4=$ not at all , $5=$ not applicable, $6=$ rather not applicable, $7=$ applicar, $8=$ rather $10=$ fully applies

It is important to my parents, that I pursu higher education applicable, $6=$ rather not applicable, $7=$

neither nor , $8=$ rather applicable , $9=$ applicable , $10=$ fully applies

It is important to my the subject area of [name removed]

$4=$ not at all , $5=$ not applicable, $6=$ rathe not applicable, $7=$ neither nor, $8=$ rather applicable, $9=$ applicable $10=$ fully applies

My parents would have employment, rather

$4=$ not at all, $5=$ not applicable , $6=$ rathe

not applicable, $7=$

neither nor, $8=$ rather applicable, $9=$ applicable $10=$ fully applies

In politics, people ofte talk of "left" and "right". Where would you place yourself on a 10-point scale (where 0 is left and 10 is right)? Whom did you know before the start of the and 20 people. - Name 1

With whom do you have pleasant interactions? Name between 0 and 20 people. - Name 1 


\begin{tabular}{|c|c|c|c|c|c|c|c|c|c|c|c|c|c|c|c|c|c|}
\hline VarName & VariableLabel & WordingDE & ValueLabelsDE_Linked & WordingEN & ValueLabelsEN_Linked & L1 & $\mathrm{L} 2$ & L3 & $\mathrm{L} 4$ & L5 & L6 & L7 & L8 & L9 & L10 & L11 & L12 \\
\hline friend.P1 & & $\begin{array}{l}\text { Q4.7_1 - Welche Deiner } \\
\text { Mitstudierenden würdest } \\
\text { Du als Freunde } \\
\text { bezeichnen?Nenne zwischen } \\
0 \text { und } 20 \text { Personen. - Name } \\
1\end{array}$ & & $\begin{array}{l}\text { Which of your fellow } \\
\text { students would you call } \\
\text { a friend? Name between } \\
0 \text { and } 20 \text { people. - Name } \\
1\end{array}$ & & $\mathrm{x}$ & $\mathrm{x}$ & $\mathrm{x}$ & $\mathrm{x}$ & $\mathrm{x}$ & $\mathrm{x}$ & $\mathrm{x}$ & $\mathrm{x}$ & $\mathrm{x}$ & $\mathrm{x}$ & $\mathrm{x}$ & $\mathrm{x}$ \\
\hline relationship.classmate & & $\begin{array}{l}\text { Q4.9 - Bist Du mit } \\
\text { einem/einer deiner } \\
\text { Mitstudierenden in einer } \\
\text { romantischenBeziehung } \\
\text { ("zusammen")? }\end{array}$ & $1=\mathrm{Ja}, 2=$ Nein & $\begin{array}{l}\text { Are you in a } \\
\text { relationship with one of } \\
\text { your fellow students? }\end{array}$ & $1=\mathrm{Yes}, 2=\mathrm{No}$ & $\mathrm{x}$ & $\mathrm{x}$ & $\mathrm{x}$ & $\mathrm{x}$ & $\mathrm{x}$ & $\mathrm{x}$ & $\mathrm{x}$ & $\mathrm{x}$ & $\mathrm{x}$ & $\mathrm{x}$ & $\mathrm{x}$ & $\mathrm{x}$ \\
\hline relationship.classmate.P1 & & Q4.10 - Mit wem? & & with whom? & & $\mathrm{x}$ & $\mathrm{x}$ & $\mathrm{x}$ & $\mathrm{x}$ & $\mathrm{x}$ & $\mathrm{x}$ & $\mathrm{x}$ & $\mathrm{x}$ & $\mathrm{x}$ & $\mathrm{x}$ & $\mathrm{x}$ & $\mathrm{x}$ \\
\hline dislike.P1 & & $\begin{array}{l}\text { Q4.12_1 - Wen magst Du } \\
\text { nicht besonders?Nenne } \\
\text { zwischen } 0 \text { und } 20 \\
\text { Personen. - Name } 1\end{array}$ & & $\begin{array}{l}\text { Whom do you not } \\
\text { particularly like? Name } \\
\text { between } 0 \text { and } 20 \\
\text { people. - Name } 1\end{array}$ & & $\mathrm{x}$ & $\mathrm{x}$ & $\mathrm{x}$ & $\mathrm{x}$ & $\mathrm{X}$ & $\mathrm{x}$ & $\mathrm{x}$ & $\mathrm{X}$ & $\mathrm{X}$ & $\mathrm{x}$ & $\mathrm{X}$ & $\mathrm{X}$ \\
\hline conflict.P1 & & $\begin{array}{l}\text { Q4.14_1 - Mit wem hast Du } \\
\text { persönliche Konflikte?Nenne } \\
\text { zwischen } 0 \text { und } 20 \\
\text { Personen. - Name } 1\end{array}$ & & $\begin{array}{l}\text { With whom do you have } \\
\text { personal conflicts? } \\
\text { Name between } 0 \text { and } 20 \\
\text { people. - Name } 1\end{array}$ & & $\mathrm{x}$ & $\mathrm{x}$ & $\mathrm{x}$ & $\mathrm{x}$ & $\mathrm{x}$ & $\mathrm{x}$ & $\mathrm{x}$ & $\mathrm{x}$ & $\mathrm{x}$ & $\mathrm{x}$ & & \\
\hline study.P1 & & $\begin{array}{l}\text { Q5.3_1 - Mitwem lernst Du } \\
\text { regelmässig gemeinsam für } \\
\text { das Studium (z.B. } \\
\text { gemeinsames Arbeitenan } \\
\text { einem Projekt oder an } \\
\text { Hausaufgaben oder } \\
\text { gemeinsames } \\
\text { Lernen)?Nenne zwischen } 0 \\
\text { und } 20 \text { Personen. - Name } 1\end{array}$ & & $\begin{array}{l}\text { With whom do you } \\
\text { regularly spend time } \\
\text { studying together? } \\
\text { Working on a joint } \\
\text { project or homework } \\
\text { and revising lecture } \\
\text { materials together both } \\
\text { count }\end{array}$ & & $\mathrm{x}$ & $\mathrm{x}$ & $\mathrm{x}$ & $\mathrm{x}$ & $\mathrm{x}$ & $\mathrm{x}$ & $\mathrm{x}$ & $\mathrm{x}$ & $\mathrm{x}$ & $\mathrm{x}$ & $\mathrm{x}$ & $\mathrm{x}$ \\
\hline travel.P1 & & $\begin{array}{l}\text { Q5.5_1 - Wenvon Deinen } \\
\text { Mitstudierenden triffst Du } \\
\text { regelmässig auf Deinem } \\
\text { Weg zurUniversität (z.B. im } \\
\text { Bus, Tram, oder } \\
\text { Zug)?Nenne zwischen } 0 \text { und } \\
20 \text { Personen. - Name } 1\end{array}$ & & $\begin{array}{l}\text { Whom do you regularly } \\
\text { meet on your way to } \\
\text { university (e.g. on the } \\
\text { bus, train, or tram)? } \\
\text { Name between } 0 \text { and } 20 \\
\text { people. - Name } 1\end{array}$ & & $\mathrm{x}$ & $\mathrm{x}$ & $\mathrm{x}$ & $\mathrm{x}$ & $\mathrm{x}$ & $\mathrm{x}$ & $\mathrm{x}$ & $\mathrm{x}$ & $\mathrm{x}$ & $\mathrm{x}$ & & \\
\hline freetime.P1 & & $\begin{array}{l}\text { Q5.7_1 - Mit wem Deiner } \\
\text { Mitstudierenden verbringst } \\
\text { Du regelmässig Deine } \\
\text { Freizeit?Hier kannst Du an } \\
\text { alle möglichen } \\
\text { Freizeitaktivitäten denken } \\
\text { wie zum } \\
\text { Beispiel,gemeinsamer Sport, } \\
\text { Filmschauen, Wandern, } \\
\text { Kaffeetrinken, Biertrinken, } \\
\text { Tanzen,etc.Nenne zwischen } \\
0 \text { und } 20 \text { Personen. - Name } \\
1\end{array}$ & & $\begin{array}{l}\text { With whom of your } \\
\text { fellow students do you } \\
\text { regularly spend your } \\
\text { leisure time? Here you } \\
\text { may think of any } \\
\text { possible leisure activity, } \\
\text { such as group sports, } \\
\text { watching movies, hiking, } \\
\text { having a coffee, having a } \\
\text { beer, dancing and so on. } \\
\text { Name between } 0 \text { and } 20 \\
\text { people. - Name } 1\end{array}$ & & $\mathrm{x}$ & $\mathrm{x}$ & $\mathrm{x}$ & $\mathrm{x}$ & $\mathrm{x}$ & $\mathrm{x}$ & $\mathrm{x}$ & $\mathrm{x}$ & $\mathrm{x}$ & $\mathrm{x}$ & & \\
\hline pol.discussion.P1 & & $\begin{array}{l}\text { Q5.9_1 - Mit wem Deiner } \\
\text { Mitstudierenden tauscht Du } \\
\text { Dich über politische } \\
\text { Themen aus? Nenne } \\
\text { zwischen } 0 \text { und } 20 \\
\text { Personen. - Name } 1\end{array}$ & & $\begin{array}{l}\text { With whom do you } \\
\text { regularly discuss } \\
\text { political topcs? Name } \\
\text { between } 0 \text { and } 20 \\
\text { people. - Name } 1\end{array}$ & & $\mathrm{x}$ & $\mathrm{x}$ & $\mathrm{x}$ & $\mathrm{x}$ & $\mathrm{x}$ & $\mathrm{x}$ & $\mathrm{x}$ & $\mathrm{x}$ & $\mathrm{x}$ & $\mathrm{x}$ & $\mathrm{x}$ & $\mathrm{x}$ \\
\hline
\end{tabular}




\begin{tabular}{|c|c|c|c|c|c|c|c|c|c|c|c|c|c|c|c|c|c|}
\hline VarName & VariableLabel & WordingDE & ValueLabelsDE_Linked & WordingEN & ValueLabelsEN_Linked & L1 & $\mathrm{L} 2$ & L3 & $\mathrm{L} 4$ & L5 & L6 6 & L7 & L8 & L9 & L10 & 0 L11 & 1 L12 \\
\hline inst.support.P1 & & $\begin{array}{l}\text { Q6.2_1 - Aufwen kannst Du } \\
\text { zählen, wenn Du Hilfe bei } \\
\text { praktischen Dingen } \\
\text { brauchst (z.B. } \\
\text { beimErledigen von Arbeiten } \\
\text { oder die Bereitstellung } \\
\text { finanzieller Mittel) unter } \\
\text { deinen } \\
\text { Mitstudierenden?Nenne } \\
\text { zwischen } 0 \text { und } 20 \\
\text { Personen. - Name } 1\end{array}$ & & $\begin{array}{l}\text { Whom can you count on } \\
\text { when you need help } \\
\text { with practical things } \\
\text { (such as working on } \\
\text { tasks or providing } \\
\text { financial help) among } \\
\text { your fellow students? } \\
\text { Name between } 0 \text { and } 20 \\
\text { people. - Name } 1\end{array}$ & & $\mathrm{x}$ & $\mathrm{x}$ & $\mathrm{x}$ & $\mathrm{x}$ & $\mathrm{x}$ & $\mathrm{x}$ & $\mathrm{x}$ & $\mathrm{x}$ & $\mathrm{x}$ & $\mathrm{x}$ & $\mathrm{x}$ & $\mathrm{x}$ \\
\hline inf.support.P1 & & $\begin{array}{l}\text { Q6.4_1 - Aufwen von } \\
\text { deinen Mitstuderienden } \\
\text { kannst Du zählen, wenn Du } \\
\text { einen guten Rat oder } \\
\text { spezifische Informationen- } \\
\text { brauchst?Nenne zwischen } 0 \\
\text { und } 20 \text { Personen. - Name } 1\end{array}$ & & $\begin{array}{l}\text { Whom can you count on } \\
\text { when you need good } \\
\text { advice or specific } \\
\text { information? Name } \\
\text { between } 0 \text { and } 20 \\
\text { people. - Name } 1\end{array}$ & & $\mathrm{x}$ & $\mathrm{x}$ & $\mathrm{x}$ & $\mathrm{x}$ & $\mathrm{x}$ & $\mathrm{x}$ & $\mathrm{x}$ & $\mathrm{x}$ & $\mathrm{x}$ & $\mathrm{x}$ & $\mathrm{x}$ & $\mathrm{x}$ \\
\hline e.support.P1 & & $\begin{array}{l}\text { Q6.6_1 - Auf wen von } \\
\text { deinen Mitstudierenden } \\
\text { kannst Du zählen, wenn es } \\
\text { Dir schlecht geht und Du } \\
\text { emotionaleHilfe brauchst } \\
\text { (z.B. Trost, Mitleid und } \\
\text { Zuspruch)?Nenne zwischen } \\
0 \text { und } 20 \text { Personen. - Name } \\
1\end{array}$ & & $\begin{array}{l}\text { Whom can you count on } \\
\text { when you're feeling bad } \\
\text { and you need emotional } \\
\text { support (e.g., } \\
\text { consolation, empathy } \\
\text { and encouragement)? } \\
\text { Name between } 0 \text { and } 20 \\
\text { people. - Name } 1\end{array}$ & & $\mathrm{x}$ & $\mathrm{x}$ & $\mathrm{x}$ & $\mathrm{x}$ & $\mathrm{x}$ & $\mathrm{x}$ & $\mathrm{x}$ & $\mathrm{x}$ & $\mathrm{x}$ & $\mathrm{x}$ & $\mathrm{x}$ & $\mathrm{x}$ \\
\hline clever.P1 & & $\begin{array}{l}\text { Q7.3_1 - Werist besonders } \\
\text { schlau unter deinen } \\
\text { Mitstudierenden?Nenne } \\
\text { zwischen } 0 \text { und } 5 \text { Personen. } \\
\text { - Name } 1\end{array}$ & & $\begin{array}{l}\text { Who is particularly } \\
\text { smart among your fellow } \\
\text { students? Name } \\
\text { between } 0 \text { and } 5 \text { people. } \\
\text { - Name } 1\end{array}$ & & $\mathrm{x}$ & $\mathrm{x}$ & $\mathrm{x}$ & $\mathrm{x}$ & $\mathrm{x}$ & $\mathrm{x}$ & $\mathrm{x}$ & $\mathrm{x}$ & $\mathrm{x}$ & $\mathrm{x}$ & & \\
\hline funny.P1 & & $\begin{array}{l}\text { Q7.4_1 - Werist besonders } \\
\text { lustig unter deinen } \\
\text { Mitstudierenden?Nenne } \\
\text { zwischen } 0 \text { und } 5 \text { Personen. } \\
\text { - Name } 1\end{array}$ & & $\begin{array}{l}\text { Who is particularly } \\
\text { funny among your fellow } \\
\text { students? Name } \\
\text { between } 0 \text { and } 5 \text { people. } \\
\text { - Name } 1\end{array}$ & & $\mathrm{x}$ & $\mathrm{x}$ & $\mathrm{x}$ & $\mathrm{x}$ & $\mathrm{x}$ & $\mathrm{x}$ & $\mathrm{x}$ & $\mathrm{x}$ & $\mathrm{x}$ & $\mathrm{x}$ & & \\
\hline serious.P1 & & $\begin{array}{l}\text { Q7.5_1 - Wer von deinen } \\
\text { Mitstudierenden nimmt das } \\
\text { Studium sehr ernst?Nenne } \\
\text { zwischen } 0 \text { und } 5 \text { Personen. } \\
\text { - Name } 1\end{array}$ & & $\begin{array}{l}\text { Who takes school very } \\
\text { seriously among your } \\
\text { fellow students? Name } \\
\text { between } 0 \text { and } 5 \text { people. } \\
\text { - Name } 1\end{array}$ & & $\mathrm{x}$ & $\mathrm{x}$ & $\mathrm{x}$ & $\mathrm{x}$ & $\mathrm{x}$ & $\mathrm{x}$ & $\mathrm{x}$ & $\mathrm{x}$ & $\mathrm{x}$ & $\mathrm{x}$ & & \\
\hline disturb.P1 & & $\begin{array}{l}\text { Q7.7_1 - Wer stört } \\
\text { während der Vorlesungen } \\
\text { (z.B. Sprechen, lautes Essen } \\
\text { oderandere Dinge, die } \\
\text { Mitstudierende vom } \\
\text { Zuhören abzulenken)?Nenne } \\
\text { zwischen 0 und 5 Personen. } \\
\text { - Name 1 }\end{array}$ & & $\begin{array}{l}\text { Who is disruptive in } \\
\text { classes (e.g. talking, } \\
\text { eating loudly or not } \\
\text { letting the others pay } \\
\text { attention to the teachers } \\
\text { in other ways)? Name } \\
\text { between } 0 \text { and } 5 \text { people. } \\
\text { - Name } 1\end{array}$ & & $\mathrm{x}$ & $\mathrm{x}$ & $\mathrm{x}$ & $\mathrm{x}$ & $\mathrm{x}$ & $\mathrm{x}$ & $\mathrm{x}$ & $\mathrm{x}$ & $\mathrm{x}$ & $\mathrm{x}$ & & \\
\hline conceited.P1 & & $\begin{array}{l}\text { Q7.8_1 - Wer von deinen } \\
\text { Mitstudierenden ist } \\
\text { eingebildet, hält viel von } \\
\text { sich selbst?Nenne zwischen } \\
0 \text { und } 5 \text { Personen. - Name } 1\end{array}$ & & $\begin{array}{l}\text { Who is smug, who } \\
\text { thinks highly of } \\
\text { themselves among your } \\
\text { fellow students? Name } \\
\text { between } 0 \text { and } 5 \text { people. } \\
\text { - Name } 1\end{array}$ & & $\mathrm{x}$ & $\mathrm{x}$ & $\mathrm{x}$ & $\mathrm{x}$ & $\mathrm{x}$ & $\mathrm{x}$ & $\mathrm{x}$ & $\mathrm{x}$ & $\mathrm{x}$ & $\mathrm{x}$ & & \\
\hline aggressive.P1 & & $\begin{array}{l}\text { Q7.9_1 - Wer von deinen } \\
\text { Mitstudierenden ist } \\
\text { aggressiv?Nenne zwischen } 0 \\
\text { und } 5 \text { Personen. - Name } 1\end{array}$ & & $\begin{array}{l}\text { Who is aggressive } \\
\text { among your fellow } \\
\text { students? Name } \\
\text { between } 0 \text { and } 5 \text { people. } \\
\text { - Name } 1\end{array}$ & & $\mathrm{x}$ & $\mathrm{x}$ & $\mathrm{x}$ & $\mathrm{x}$ & $\mathrm{x}$ & $\mathrm{x}$ & $\mathrm{x}$ & $\mathrm{x}$ & $\mathrm{x}$ & $\mathrm{x}$ & & \\
\hline
\end{tabular}




\begin{tabular}{|c|c|c|c|c|c|c|c|c|c|c|c|c|c|c|}
\hline VariableLabel & WordingDE & ValueLabelsDE_Linked & WordingEN & ValueLabelsEN_Linked & L1 & $\mathrm{L} 2$ & L3 & $\mathrm{L} 4$ & L5 & $\mathrm{L} 6$ & L7 & L8 & L9 & L10 L11 L12 \\
\hline attractive.P1 & $\begin{array}{l}\text { Q7.11_1 - Wen von deinen } \\
\text { Mitstudierenden findest Du } \\
\text { körperlich attraktiv?Nenne } \\
\text { zwischen } 0 \text { und } 5 \text { Personen. } \\
\text { - Name } 1\end{array}$ & & $\begin{array}{l}\text { Who do you find } \\
\text { physically attractive } \\
\text { among your fellow } \\
\text { students? Name } \\
\text { between } 0 \text { and } 5 \text { people. } \\
\text { - Name } 1\end{array}$ & & $\mathrm{x}$ & $\mathrm{x}$ & $\mathrm{x}$ & $\mathrm{x}$ & $\mathrm{x}$ & $\mathrm{x}$ & $\mathrm{x}$ & $\mathrm{x}$ & $\mathrm{x}$ & $\mathrm{x}$ \\
\hline party.P1 & $\begin{array}{l}\text { Q7.12_1 - Wer von deinen } \\
\text { Mitstudierenden feiert } \\
\text { viel?Nenne zwischen } 0 \text { und } \\
5 \text { Personen. - Name } 1\end{array}$ & & $\begin{array}{l}\text { Who parties a lot among } \\
\text { your fellow students? } \\
\text { Name between } 0 \text { and } 5 \\
\text { people. - Name } 1\end{array}$ & & $\mathrm{x}$ & $\mathrm{x}$ & $\mathrm{x}$ & $\mathrm{x}$ & $\mathrm{x}$ & $\mathrm{x}$ & $\mathrm{x}$ & $\mathrm{x}$ & $\mathrm{x}$ & $\mathrm{x}$ \\
\hline admire.P1 & $\begin{array}{l}\text { Q7.14_1 - Wen von deinen } \\
\text { Mitstudierenden } \\
\text { bewunderst Du?Nenne } \\
\text { zwischen } 0 \text { und } 5 \text { Personen. } \\
\text { - Name } 1\end{array}$ & & $\begin{array}{l}\text { Who do you look up to } \\
\text { among your fellow } \\
\text { students? Name } \\
\text { between } 0 \text { and } 5 \text { people. } \\
\text { - Name } 1\end{array}$ & & $\mathrm{x}$ & $\mathrm{x}$ & $\mathrm{x}$ & $\mathrm{x}$ & $\mathrm{x}$ & $\mathrm{x}$ & $\mathrm{x}$ & $\mathrm{x}$ & $\mathrm{x}$ & $\mathrm{x}$ \\
\hline popular.P1 & $\begin{array}{l}\text { Q7.15_1 - Wer von deinen } \\
\text { Mitstudierenden ist Deiner } \\
\text { Meinung nach sehr beliebt } \\
\text { unter Deinen } \\
\text { Mitstudierenden?Nenne } \\
\text { zwischen } 0 \text { und } 5 \text { Personen. } \\
\text { - Name } 1\end{array}$ & & $\begin{array}{l}\text { Who do you think is } \\
\text { popular among your } \\
\text { fellow students? Name } \\
\text { between } 0 \text { and } 5 \text { people. } \\
\text { - Name } 1\end{array}$ & & $\mathrm{x}$ & $\mathrm{x}$ & $\mathrm{x}$ & $\mathrm{x}$ & $\mathrm{x}$ & $\mathrm{x}$ & $\mathrm{x}$ & $\mathrm{x}$ & $\mathrm{x}$ & $\mathrm{x}$ \\
\hline lookdown.P1 & $\begin{array}{l}\text { Q7.17_1 - Auf wen Deiner } \\
\text { Mitstudierenden schaust Du } \\
\text { hinab?Nenne zwischen 0 } \\
\text { und } 5 \text { Personen. - Name } 1\end{array}$ & & $\begin{array}{l}\text { Who do you look down } \\
\text { on among your fellow } \\
\text { students? Name } \\
\text { between } 0 \text { and } 5 \text { people. } \\
\text { - Name } 1\end{array}$ & & $\mathrm{x}$ & $\mathrm{x}$ & $\mathrm{x}$ & $\mathrm{x}$ & $\mathrm{x}$ & $\mathrm{x}$ & $\mathrm{x}$ & $\mathrm{x}$ & $\mathrm{x}$ & $\mathrm{x}$ \\
\hline unpopular.P1 & $\begin{array}{l}\text { Q7.18_1 - Wer von Deinen } \\
\text { Mitstudierenden ist } \\
\text { unbeliebt?Nenne zwischen } 0 \\
\text { und } 5 \text { Personen. - Name } 1\end{array}$ & & $\begin{array}{l}\text { Who among your fellow } \\
\text { students is unpopular? } \\
\text { Name between } 0 \text { and } 5 \\
\text { people. - Name } 1\end{array}$ & & $\mathrm{x}$ & $\mathrm{x}$ & $\mathrm{x}$ & $\mathrm{x}$ & $\mathrm{x}$ & $\mathrm{x}$ & $\mathrm{x}$ & $\mathrm{x}$ & $\mathrm{x}$ & $\mathrm{x}$ \\
\hline complain.P1 & $\begin{array}{l}\text { Q7.20_1 - Wer beklagt sich } \\
\text { oft?Nenne zwischen } 0 \text { und } 5 \\
\text { Personen. - Name } 1\end{array}$ & & $\begin{array}{l}\text { Who complains a lot? } \\
\text { Name between } 0 \text { and } 5 \\
\text { people. - Name } 1\end{array}$ & & $\mathrm{x}$ & $\mathrm{x}$ & $\mathrm{x}$ & $\mathrm{x}$ & $\mathrm{x}$ & $\mathrm{x}$ & $\mathrm{x}$ & $\mathrm{x}$ & $\mathrm{x}$ & $\mathrm{x}$ \\
\hline dislike.listening.to.P1 & $\begin{array}{l}\text { Q7.21_1 - Wem hörst du } \\
\text { nicht gerne zu?Nenne } \\
\text { zwischen } 0 \text { und } 5 \text { Personen. } \\
\text { - Name } 1\end{array}$ & & $\begin{array}{l}\text { Whom do you dislike } \\
\text { listening to among your } \\
\text { fellow students? Name } \\
\text { between } 0 \text { and } 5 \text { people. } \\
\text { - Name } 1\end{array}$ & & $\mathrm{x}$ & $\mathrm{x}$ & $\mathrm{X}$ & $\mathrm{x}$ & $\mathrm{x}$ & $\mathrm{x}$ & $\mathrm{x}$ & $\mathrm{x}$ & $\mathrm{x}$ & $\mathrm{x}$ \\
\hline social.P1 & $\begin{array}{l}\text { Q8.3_1 - Welche Deiner } \\
\text { Mitstudierenden würdenam } \\
\text { ehesten soziale Aktivitäten } \\
\text { starten?Nenne zwischen } 0 \\
\text { und } 5 \text { Personen. - Name } 1\end{array}$ & & $\begin{array}{l}\text { Who is most likely to } \\
\text { initiate social activities } \\
\text { among your fellow } \\
\text { students? Name } \\
\text { between } 0 \text { and } 5 \text { people. } \\
\text { - Name } 1\end{array}$ & & $\mathrm{x}$ & $\mathrm{x}$ & $\mathrm{x}$ & $\mathrm{x}$ & $\mathrm{x}$ & $\mathrm{x}$ & $\mathrm{x}$ & $\mathrm{x}$ & $\mathrm{x}$ & $\mathrm{x}$ \\
\hline conflict.solve.P1 & $\begin{array}{l}\text { Q8.4_1 - Welche Deiner } \\
\text { Mitstudierenden wären am } \\
\text { ehesten fähig,Konflikte } \\
\text { zwischen Studierenden zu } \\
\text { lösen?Nenne zwischen } 0 \text { und } \\
5 \text { Personen. - Name 1 }\end{array}$ & & $\begin{array}{l}\text { Who would be best able } \\
\text { to resolve conflicts } \\
\text { among your fellow } \\
\text { students? Name } \\
\text { between } 0 \text { and } 5 \text { people. } \\
\text { - Name } 1\end{array}$ & & $\mathrm{x}$ & $\mathrm{x}$ & $\mathrm{x}$ & $\mathrm{x}$ & $\mathrm{x}$ & $\mathrm{x}$ & $\mathrm{x}$ & $\mathrm{x}$ & $\mathrm{x}$ & $\mathrm{x}$ \\
\hline organise.P1 & $\begin{array}{l}\text { Q8.5_1 - Welche Deiner } \\
\text { Mitstudierenden wärenam } \\
\text { ehesten fähig, ein } \\
\text { "Ersti-Weekend" zu } \\
\text { organisieren?Nenne } \\
\text { zwischen } 0 \text { und } 5 \text { Personen. } \\
\text { - Name } 1\end{array}$ & & $\begin{array}{l}\text { Who would be best able } \\
\text { to organize a "first } \\
\text { weekend" among your } \\
\text { fellow students? Name } \\
\text { between } 0 \text { and } 5 \text { people. } \\
\text { - Name } 1\end{array}$ & & $\mathrm{x}$ & $\mathrm{x}$ & $\mathrm{x}$ & $\mathrm{x}$ & $\mathrm{x}$ & $\mathrm{x}$ & $\mathrm{x}$ & $\mathrm{x}$ & $\mathrm{x}$ & $\mathrm{x}$ \\
\hline participate.student.intro.day & $\begin{array}{l}\text { Hast Du an einem der } \\
\text { Student Introduction Day } \\
\text { Events teilgenommen? }\end{array}$ & & $\begin{array}{l}\text { Did you participate in } \\
\text { one of the Student } \\
\text { Introduction Day } \\
\text { events? }\end{array}$ & & $\mathrm{x}$ & & & & & & & & & \\
\hline
\end{tabular}




\begin{tabular}{|c|c|c|c|c|c|c|c|c|c|c|c|c|c|c|}
\hline VariableLabel & WordingDE & ValueLabelsDE_Linked & WordingEN & ValueLabelsEN_Linked & L1 & L2 & L3 & L4 & L5 & L6 6 & L7 & L8 & L9 & L10 L11 L12 \\
\hline student.intro.day.P1 & $\begin{array}{l}\text { Q8.8_1 - Mit wem warst du } \\
\text { bei dem Student } \\
\text { Introduction Day in einer } \\
\text { Gruppe? Versuche Dich an } \\
\text { so viele Namen wie möglich } \\
\text { zu erinnern. Nenne zwischen } \\
0 \text { und } 20 \text { Personen. - Name } \\
1\end{array}$ & & $\begin{array}{l}\text { Whom were you in a } \\
\text { group with at the } \\
\text { Student Introduction } \\
\text { Day? Try to remember } \\
\text { as many names as } \\
\text { possible. Try to } \\
\text { remember as many } \\
\text { names as possible. } \\
\text { Name between } 0 \text { and } 20 \\
\text { people. - Name } 1\end{array}$ & & $\mathrm{x}$ & & & & & & & & & \\
\hline student.intro.day.pleasant.P1 & $\begin{array}{l}\text { Q8.9_1 - Mit wem hattest } \\
\text { du angenehme Interaktionen } \\
\text { am Student Introduction } \\
\text { Day?Nenne zwischen } 0 \text { und } \\
20 \text { Personen. - Name } 1\end{array}$ & & $\begin{array}{l}\text { Whom did you have } \\
\text { pleasant interactions } \\
\text { with at the Student } \\
\text { Introduction Day? } \\
\text { Name between } 0 \text { and } 20 \\
\text { people. - Name } 1\end{array}$ & & $\mathrm{x}$ & & & & & & & & & \\
\hline group.1 & $\begin{array}{l}\text { Q9.3_1 - Bitte benenne } \\
\text { Deine Gruppen mit 1-2 } \\
\text { Stichwörtern } \\
\text { (z.B."Lerngruppe"), sodass } \\
\text { du sie für die nächsten } \\
\text { Minuten wiedererkennen } \\
\text { kannst. Nenne } 0 \text { bis } 5 \\
\text { Gruppen. - Gruppe } 1\end{array}$ & & $\begin{array}{l}\text { Here, we are interested } \\
\text { in groups you and other } \\
\text { fellow students are part } \\
\text { of. Please name your } \\
\text { groups with 1-2 key } \\
\text { words (e.g. "study } \\
\text { group"), so that you can } \\
\text { recognise them in the } \\
\text { next few minutes. Name } \\
0 \text { to } 5 \text { groups. - group } 1\end{array}$ & & $\mathrm{x}$ & $\mathrm{x}$ & $\mathrm{x}$ & $\mathrm{x}$ & $\mathrm{x}$ & $\mathrm{x}$ & $\mathrm{x}$ & $\mathrm{x}$ & $\mathrm{x}$ & $\mathrm{x}$ \\
\hline group.2 & $\begin{array}{l}\text { Q9.3_3 - Bitte benenne } \\
\text { Deine Gruppen mit 1-2 } \\
\text { Stichwörtern } \\
\text { (z.B."Lerngruppe"), sodass } \\
\text { du sie für die nächsten } \\
\text { Minuten wiedererkennen } \\
\text { kannst. Nenne } 0 \text { bis } 5 \\
\text { Gruppen. - Gruppe 2 }\end{array}$ & & $\begin{array}{l}\text { Here, we are interested } \\
\text { in groups you and other } \\
\text { fellow students are part } \\
\text { of. Please name your } \\
\text { groups with 1-2 key } \\
\text { words (e.g. "study } \\
\text { group"), so that you can } \\
\text { recognise them in the } \\
\text { next few minutes. Name } \\
0 \text { to } 5 \text { groups. - group } 2\end{array}$ & & $\mathrm{x}$ & $\mathrm{x}$ & $\mathrm{x}$ & $\mathrm{x}$ & $\mathrm{x}$ & $\mathrm{x}$ & $\mathrm{x}$ & $\mathrm{x}$ & $\mathrm{x}$ & $\mathrm{x}$ \\
\hline group.3 & $\begin{array}{l}\text { Q9.3_4 - Bitte benenne } \\
\text { Deine Gruppen mit 1-2 } \\
\text { Stichwörtern } \\
\text { (z.B."Lerngruppe"), sodass } \\
\text { du sie für die nächsten } \\
\text { Minuten wiedererkennen } \\
\text { kannst. Nenne } 0 \text { bis } 5 \\
\text { Gruppen. - Gruppe } 3\end{array}$ & & $\begin{array}{l}\text { Here, we are interested } \\
\text { in groups you and other } \\
\text { fellow students are part } \\
\text { of. Please name your } \\
\text { groups with } 1-2 \text { key } \\
\text { words (e.g. "study } \\
\text { group"), so that you can } \\
\text { recognise them in the } \\
\text { next few minutes. Name } \\
0 \text { to } 5 \text { groups. - group } 3\end{array}$ & & $\mathrm{x}$ & $\mathrm{x}$ & $\mathrm{x}$ & $\mathrm{x}$ & $\mathrm{x}$ & $\mathrm{x}$ & $\mathrm{x}$ & $\mathrm{x}$ & $\mathrm{x}$ & $\mathrm{x}$ \\
\hline group.4 & $\begin{array}{l}\text { Q9.3_5 - Bitte benenne } \\
\text { Deine Gruppen mit 1-2 } \\
\text { Stichwörtern } \\
\text { (z.B."Lerngruppe"), sodass } \\
\text { du sie für die nächsten } \\
\text { Minuten wiedererkennen } \\
\text { kannst. Nenne } 0 \text { bis } 5 \\
\text { Gruppen. - Gruppe } 4\end{array}$ & & $\begin{array}{l}\text { Here, we are interested } \\
\text { in groups you and other } \\
\text { fellow students are part } \\
\text { of. Please name your } \\
\text { groups with 1-2 key } \\
\text { words (e.g. "study } \\
\text { group"), so that you can } \\
\text { recognise them in the } \\
\text { next few minutes. Name } \\
0 \text { to } 5 \text { groups. - group } 4\end{array}$ & & $\mathrm{x}$ & $\mathrm{x}$ & $\mathrm{x}$ & $\mathrm{x}$ & $\mathrm{x}$ & $\mathrm{x}$ & $\mathrm{x}$ & $\mathrm{x}$ & $\mathrm{x}$ & $\mathrm{x}$ \\
\hline
\end{tabular}




\begin{tabular}{|c|c|c|c|c|c|c|c|c|c|c|c|c|c|c|c|}
\hline VarName & VariableLabel & WordingDE & ValueLabelsDE_Linked & WordingEN & ValueLabelsEN_Linked & $\mathrm{L} 1$ & $\mathrm{~L} 2$ & L3 & L4 & L5 & $\mathrm{L} 6$ & L7 & L8 & L9 & L10 L11 L12 \\
\hline group.5 & & $\begin{array}{l}\text { Q9.3_6 - Bitte benenne } \\
\text { Deine Gruppen mit 1-2 } \\
\text { Stichwörtern } \\
\text { (z.B."Lerngruppe"), sodass } \\
\text { du sie für die nächsten } \\
\text { Minuten wiedererkennen } \\
\text { kannst. Nenne } 0 \text { bis } 5 \\
\text { Gruppen. - Gruppe } 5\end{array}$ & & $\begin{array}{l}\text { Here, we are interested } \\
\text { in groups you and other } \\
\text { fellow students are part } \\
\text { of. Please name your } \\
\text { groups with } 1-2 \text { key } \\
\text { words (e.g. "study } \\
\text { group"), so that you can } \\
\text { recognise them in the } \\
\text { next few minutes. Name } \\
0 \text { to } 5 \text { groups. - group } 5\end{array}$ & & $\mathrm{x}$ & $\mathrm{x}$ & $\mathrm{x}$ & $\mathrm{x}$ & $\mathrm{x}$ & $\mathrm{x}$ & $\mathrm{x}$ & $\mathrm{x}$ & $\mathrm{x}$ & $\mathrm{x}$ \\
\hline group.1.P1 & & $\begin{array}{l}\text { 1_Q10.2_1 - Welche Deiner } \\
\text { Mitstudierenden sind Teil } \\
\text { der Gruppe "[Field-1]"? } \\
\text { (die Anzahl von } \\
\text { Gruppenmitgliedern, die } \\
\text { nicht mit Dir studierendem } \\
\text { kann auf der nächsten Seite } \\
\text { genannt werden)Nenne } \\
\text { zwischen } 1 \text { und 20 Personen. } \\
\text { - Gruppe } 1 \text { - Name 1 }\end{array}$ & & $\begin{array}{l}\text { Whom among your } \\
\text { fellow students is part of } \\
\text { the group } \\
\text { "< } \\
\text { numboupname }>\text { "? (the } \\
\text { members ghoup are not } \\
\text { fellow students can be } \\
\text { reported on the next } \\
\text { page). Name between } 0 \\
\text { and } 20 \text { people. - Group } \\
1 \text { - Name } 1\end{array}$ & & $\mathrm{x}$ & $\mathrm{x}$ & $\mathrm{x}$ & $\mathrm{x}$ & $\mathrm{x}$ & $\mathrm{x}$ & $\mathrm{x}$ & $\mathrm{x}$ & $\mathrm{x}$ & $\mathrm{x}$ \\
\hline group.1.other & & $\begin{array}{l}\text { 1_Q10.4 - Gibt es noch } \\
\text { weitere Mitglieder dieser } \\
\text { Gruppe, welche nicht mit } \\
\text { Dir studieren? - Gruppe } 1 \text { - } \\
\text { Gibt es noch weitere } \\
\text { Mitglieder dieser Gruppe, } \\
\text { welche nicht mit Dir } \\
\text { studieren? - Selected Choice }\end{array}$ & $\begin{array}{l}1=\text { Wenn ja, wieviele sind } \\
\text { dies?, } 2=\text { Nein }\end{array}$ & $\begin{array}{l}\text { Are there further } \\
\text { members in who do not } \\
\text { study with you? - } \\
\text { Group } 1\end{array}$ & $\begin{array}{l}1=\text { If yes, how many?, } 2 \\
=\text { No }\end{array}$ & $\mathrm{x}$ & $\mathrm{x}$ & $\mathrm{x}$ & $\mathrm{x}$ & $\mathrm{x}$ & $\mathrm{x}$ & $\mathrm{x}$ & $\mathrm{x}$ & $\mathrm{x}$ & $\mathrm{x}$ \\
\hline group.1.other.number & & $\begin{array}{l}\text { 1_Q10.4_1_TEXT - Gibt } \\
\text { es noch weitere Mitglieder } \\
\text { dieser Gruppe, welche nicht } \\
\text { mit Dir studieren? - } \\
\text { Gruppe } 1 \text { - Wenn ja, } \\
\text { wieviele sind dies? - Text }\end{array}$ & & $\begin{array}{l}\text { How many other people } \\
\text { NOT from your cohort } \\
\text { are part of this group? - } \\
\text { Group } 1\end{array}$ & & $\mathrm{x}$ & $\mathrm{x}$ & $\mathrm{x}$ & $\mathrm{x}$ & $\mathrm{x}$ & $\mathrm{x}$ & $\mathrm{x}$ & $\mathrm{x}$ & $\mathrm{x}$ & $\mathrm{x}$ \\
\hline group.1.activity.1 & & $\begin{array}{l}\text { 1_Q10.5_1 - Welche } \\
\text { Tätigkeiten führt die } \\
\text { Gruppe "[Field-1]" } \\
\text { normalerweise gemeinsam } \\
\text { aus? - Gruppe 1 - Welche } \\
\text { Tätigkeiten führt die } \\
\text { Gruppe "[Field-1]" } \\
\text { normalerweise gemeinsam } \\
\text { aus? - Selected Choice - } \\
\text { Lernen/Hausaufgaben }\end{array}$ & & $\begin{array}{l}\text { What activities does the } \\
\text { group "<groupname>" } \\
\text { usually do together? - } \\
\text { Group 1 - Selected } \\
\text { Choice - } \\
\text { studying/homework }\end{array}$ & & $\mathrm{x}$ & $\mathrm{x}$ & $\mathrm{x}$ & $\mathrm{x}$ & $\mathrm{x}$ & $\mathrm{x}$ & $\mathrm{x}$ & $\mathrm{x}$ & $\mathrm{x}$ & $\mathrm{x}$ \\
\hline group.1.activity.2 & & $\begin{array}{l}\text { 1_Q10.5_2 - Welche } \\
\text { Tätigkeiten führt die } \\
\text { Gruppe "[Field-1]" } \\
\text { normalerweise gemeinsam } \\
\text { aus? - Gruppe 1 - Welche } \\
\text { Tätigkeiten führt die } \\
\text { Gruppe "[Field-1]" } \\
\text { normalerweise gemeinsam } \\
\text { aus? - Selected Choice - } \\
\text { Arbeit }\end{array}$ & & $\begin{array}{l}\text { What activities does the } \\
\text { group "< } \\
\text { usually do tognamether? - } \\
\text { Group } 1 \text { - Selected } \\
\text { Choice - work }\end{array}$ & & $\mathrm{x}$ & $\mathrm{x}$ & $\mathrm{x}$ & $\mathrm{x}$ & $\mathrm{x}$ & $\mathrm{x}$ & $\mathrm{x}$ & $\mathrm{x}$ & $\mathrm{x}$ & $\mathrm{x}$ \\
\hline
\end{tabular}




\begin{tabular}{|c|c|c|c|c|c|c|c|c|c|c|c|c|c|c|c|}
\hline VarName & VariableLabel & WordingDE & ValueLabelsDE_Linked & WordingEN & ValueLabelsEN_Linked & $\mathrm{L} 1$ & $\mathrm{~L} 2$ & L3 & $\mathrm{L} 4$ & L5 & L6 & L7 & L8 & L9 & L10 L11 L12 \\
\hline group.1.activity.3 & & $\begin{array}{l}\text { 1_Q10.5_3 - Welche } \\
\text { Tätigkeiten führt die } \\
\text { Gruppe "[Field-1]" } \\
\text { normalerweise gemeinsam } \\
\text { aus? - Gruppe 1 - Welche } \\
\text { Tätigkeiten führt die } \\
\text { Gruppe "[Field-1]" } \\
\text { normalerweise gemeinsam } \\
\text { aus? - Selected Choice - } \\
\text { Sport }\end{array}$ & & $\begin{array}{l}\text { What activities does the } \\
\text { group "< groupname>" } \\
\text { usually do together? - } \\
\text { Group } 1 \text { - Selected } \\
\text { Choice - sports }\end{array}$ & & $\mathrm{x}$ & $\mathrm{x}$ & $\mathrm{x}$ & $\mathrm{x}$ & $\mathrm{x}$ & $\mathrm{x}$ & $\mathrm{x}$ & $\mathrm{x}$ & $\mathrm{x}$ & $\mathrm{x}$ \\
\hline group.1.activity.4 & & $\begin{array}{l}\text { 1_Q10.5_4 - Welche } \\
\text { Tätigkeiten führt die } \\
\text { Gruppe "[Field-1]" } \\
\text { normalerweise gemeinsam } \\
\text { aus? - Gruppe 1 - Welche } \\
\text { Tätigkeiten führt die } \\
\text { Gruppe "[Field-1]" } \\
\text { normalerweise gemeinsam } \\
\text { aus? - Selected Choice - } \\
\text { Gespräch }\end{array}$ & & $\begin{array}{l}\text { What activities does the } \\
\text { group "< }<\text { groupname>" } \\
\text { usually do together? - } \\
\text { Group } 1 \text { - Selected } \\
\text { Choice - conversation }\end{array}$ & & $\mathrm{x}$ & $\mathrm{x}$ & $\mathrm{x}$ & $\mathrm{x}$ & $\mathrm{x}$ & $\mathrm{x}$ & $\mathrm{x}$ & $\mathrm{x}$ & $\mathrm{x}$ & $\mathrm{x}$ \\
\hline group.1.activity.5 & & $\begin{array}{l}\text { 1_Q10.5_5 - Welche } \\
\text { Tätigkeiten führt die } \\
\text { Gruppe "[Field-1]" } \\
\text { normalerweise gemeinsam } \\
\text { aus? - Gruppe } 1 \text { - Welche } \\
\text { Tätigkeiten führt die } \\
\text { Gruppe "[Field-1]" } \\
\text { normalerweise gemeinsam } \\
\text { aus? - Selected Choice - } \\
\text { etwas trinken gehen ("eis go } \\
\text { zieh") }\end{array}$ & & $\begin{array}{l}\text { What activities does the } \\
\text { group "<groupname>" } \\
\text { usually do together? - } \\
\text { Group } 1 \text { - Selected } \\
\text { Choice - going for drinks }\end{array}$ & & $\mathrm{x}$ & $\mathrm{x}$ & $\mathrm{x}$ & $\mathrm{x}$ & $\mathrm{x}$ & $\mathrm{x}$ & $\mathrm{x}$ & $\mathrm{x}$ & $\mathrm{x}$ & $\mathrm{x}$ \\
\hline group.1.activity. 6 & & $\begin{array}{l}\text { 1_Q10.5_6 - Welche } \\
\text { Tätigkeiten führt die } \\
\text { Gruppe "[Field-1]" } \\
\text { normalerweise gemeinsam } \\
\text { aus? - Gruppe } 1 \text { - Welche } \\
\text { Tätigkeiten führt die } \\
\text { Gruppe "[Field-1]" } \\
\text { normalerweise gemeinsam } \\
\text { aus? - Selected Choice - } \\
\text { gemeinsamer Weg (z.B. zur } \\
\text { Universität) }\end{array}$ & & $\begin{array}{l}\text { What activities does the } \\
\text { group "< }<\text { groupname>" } \\
\text { usually do together? - } \\
\text { Group } 1 \text { - Selected } \\
\text { Choice - commute }\end{array}$ & & $\mathrm{x}$ & $\mathrm{x}$ & $\mathrm{x}$ & $\mathrm{x}$ & $\mathrm{x}$ & $\mathrm{x}$ & $\mathrm{x}$ & $\mathrm{x}$ & $\mathrm{x}$ & $\mathrm{x}$ \\
\hline group.1.activity.7 & & $\begin{array}{l}\text { 1_Q10.5_7 - Welche } \\
\text { Tätigkeiten führt die } \\
\text { Gruppe "[Field-1]" } \\
\text { normalerweise gemeinsam } \\
\text { aus? - Gruppe } 1 \text { - Welche } \\
\text { Tätigkeiten führt die } \\
\text { Gruppe "[Field-1]" } \\
\text { normalerweise gemeinsam } \\
\text { aus? - Selected Choice - } \\
\text { Andere }\end{array}$ & & $\begin{array}{l}\text { What activities does the } \\
\text { group "< } \\
\text { usually do tognether? - } \\
\text { Group } 1 \text { - Selected } \\
\text { Choice - Other }\end{array}$ & & $\mathrm{x}$ & $\mathrm{x}$ & $\mathrm{x}$ & $\mathrm{x}$ & $\mathrm{x}$ & $\mathrm{x}$ & $\mathrm{x}$ & $\mathrm{x}$ & $\mathrm{x}$ & $\mathrm{x}$ \\
\hline group.1.activity. 8 & & $\begin{array}{l}\text { 1_Q10.5_8 - Welche } \\
\text { Tätigkeiten führt die } \\
\text { Gruppe "[Field-1]" } \\
\text { normalerweise gemeinsam } \\
\text { aus? - Gruppe 1 - Welche } \\
\text { Tätigkeiten führt die } \\
\text { Gruppe "[Field-1]" } \\
\text { normalerweise gemeinsam } \\
\text { aus? - Selected Choice - } \\
\text { Kultur }\end{array}$ & & $\begin{array}{l}\text { What activities does the } \\
\text { group "< groupname>" } \\
\text { usually do together? - } \\
\text { Group } 1 \text { - Selected } \\
\text { Choice - cultural } \\
\text { activities }\end{array}$ & & $\mathrm{x}$ & $\mathrm{x}$ & $\mathrm{x}$ & $\mathrm{x}$ & $\mathrm{x}$ & $\mathrm{x}$ & $\mathrm{x}$ & $\mathrm{x}$ & $\mathrm{x}$ & $\mathrm{x}$ \\
\hline
\end{tabular}




\begin{tabular}{|c|c|c|c|c|c|c|c|c|c|c|c|c|c|c|c|}
\hline VarName & VariableLabel & WordingDE & ValueLabelsDE_Linked & WordingEN & ValueLabelsEN_Linked & L1 & $\mathrm{L} 2$ & L3 & $\mathrm{L} 4$ & L5 & L6 & L7 & L8 & L9 & L10 L11 L12 \\
\hline group.1.activity.9 & & $\begin{array}{l}\text { 1_Q10.5_10 - Welche } \\
\text { Tätigkeiten führt die } \\
\text { Gruppe "[Field-1]" } \\
\text { normalerweise gemeinsam } \\
\text { aus? - Gruppe 1 - Welche } \\
\text { Tätigkeiten führt die } \\
\text { Gruppe "[Field-1]" } \\
\text { normalerweise gemeinsam } \\
\text { aus? - Selected Choice - } \\
\text { über politische Themen } \\
\text { sprechen }\end{array}$ & & $\begin{array}{l}\text { What activities does the } \\
\text { group "< } \\
\text { usually do tognether? - } \\
\text { Group } 1 \text { - Selected } \\
\text { Choice - discussing } \\
\text { politics }\end{array}$ & & $\mathrm{x}$ & $\mathrm{x}$ & $\mathrm{x}$ & $\mathrm{x}$ & $\mathrm{x}$ & $\mathrm{x}$ & $\mathrm{x}$ & $\mathrm{x}$ & $\mathrm{x}$ & $\mathrm{x}$ \\
\hline group.1.activity.9.str & & $\begin{array}{l}\text { 1_Q10.5_7_TEXT - } \\
\text { Welche Tätigkeiten führt } \\
\text { die Gruppe "[Field-1]" } \\
\text { normalerweise gemeinsam } \\
\text { aus? - Gruppe 1 - Andere - } \\
\text { Text }\end{array}$ & & $\begin{array}{l}\text { TEXT_What activities } \\
\text { does the group } \\
\text { "< groupname>" usually } \\
\text { do together? - Group } 1 \text { - } \\
\text { Other - text }\end{array}$ & & $\mathrm{x}$ & $\mathrm{x}$ & $\mathrm{x}$ & $\mathrm{x}$ & $\mathrm{x}$ & $\mathrm{x}$ & $\mathrm{x}$ & $\mathrm{x}$ & $\mathrm{x}$ & $\mathrm{x}$ \\
\hline group.1.freq & & $\begin{array}{l}\text { 1_Q10.6 - Gruppe 1 - } \\
\text { Wieoft trifft sich diese } \\
\text { Gruppe "[Field-1]" } \\
\text { normalerweise für } \\
\text { gemeinsame Aktivitäten? }\end{array}$ & $\begin{array}{l}1=\text { zwei oder dreimal pro } \\
\text { Woche, } 2=\text { einmal pro } \\
\text { Woche, } 3=\text { jede zweite } \\
\text { Woche, } 4=\text { einmal pro } \\
\text { Monat, } 5=\text { weniger als } \\
\text { einmal pro Monat, } 6 \text { = fast } \\
\text { jeden Tag }\end{array}$ & $\begin{array}{l}\text { How often does this } \\
\text { group typically meet for } \\
\text { some joint activity? - } \\
\text { Group } 1\end{array}$ & $\begin{array}{l}1=\text { two or three times } \\
\text { per week, } 2=\text { one time } \\
\text { per week, } 3=\text { every } \\
\text { second week, } 4=\text { once per } \\
\text { month, } 5=\text { less than once } \\
\text { per month, } 6=\text { almost } \\
\text { every day }\end{array}$ & $\mathrm{x}$ & $\mathrm{x}$ & $\mathrm{x}$ & $\mathrm{x}$ & $\mathrm{x}$ & $\mathrm{x}$ & $\mathrm{x}$ & $\mathrm{x}$ & $\mathrm{x}$ & $\mathrm{x}$ \\
\hline group.1.pleasant & & $\begin{array}{l}\text { 1_Q10.7_1 - Wie } \\
\text { empfindest Du persönlich } \\
\text { typischerweiseTreffen mit } \\
\text { dieser Gruppe "[Field-1]"? - } \\
\text { Gruppe } 1 \text { - sehr } \\
\text { unangenehm:sehr angenehm }\end{array}$ & $\begin{array}{l}0=7 \text {-Punkte Skala, sehr } \\
\text { angenehm bis sehr } \\
\text { unangenehm, } 1=7 \text {-Punkte } \\
\text { Skala, sehr angenehm bis sehr } \\
\text { unangenehm, } 2=7 \text {-Punkte } \\
\text { Skala, sehr angenehm bis sehr } \\
\text { unangenehm, } 3=7 \text {-Punkte } \\
\text { Skala, sehr angenehm bis sehr } \\
\text { unangenehm, } 4=7 \text {-Punkte } \\
\text { Skala, sehr angenehm bis sehr } \\
\text { unangenehm, } 5=7 \text {-Punkte } \\
\text { Skala, sehr angenehm bis sehr } \\
\text { unangenehm, } 6=7 \text {-Punkte } \\
\text { Skala, sehr angenehm bis sehr } \\
\text { unangenehm }\end{array}$ & $\begin{array}{l}\text { How would you } \\
\text { characterize your typical } \\
\text { personal experience } \\
\text { when meeting with this } \\
\text { group? }\end{array}$ & $\begin{array}{l}0=7 \text { point scale, very } \\
\text { pleasant to very } \\
\text { unpleasant, } 1=7 \text { point } \\
\text { scale, very pleasant to } \\
\text { very unpleasant, } 2=7 \\
\text { point scale, very pleasant } \\
\text { to very unpleasant, } 3=7 \\
\text { point scale, very pleasant } \\
\text { to very unpleasant, } 4=7 \\
\text { point scale, very pleasant } \\
\text { to very unpleasant, } 5=7 \\
\text { point scale, very pleasant } \\
\text { to very unpleasant, } 6=7 \\
\text { point scale, very pleasant } \\
\text { to very unpleasant }\end{array}$ & $\mathrm{x}$ & $\mathrm{x}$ & $\mathrm{x}$ & $\mathrm{x}$ & $\mathrm{x}$ & $\mathrm{x}$ & $\mathrm{x}$ & $\mathrm{x}$ & $\mathrm{x}$ & $\mathrm{x}$ \\
\hline group.1.energetic & & $\begin{array}{l}\text { 1_Q10.7_2-Wie } \\
\text { empfindest Du persönlich } \\
\text { typischerweiseTreffen mit } \\
\text { dieser Gruppe "[Field-1]"? - } \\
\text { Gruppe } 1 \text { - sehr ruhig:sehr } \\
\text { energiegeladen }\end{array}$ & $\begin{array}{l}0=7 \text {-Punkte Skala, sehr } \\
\text { ruhig bis sehr energiegeladen, } \\
1=7 \text {-Punkte Skala, sehr } \\
\text { ruhig bis sehr energiegeladen, } \\
2=7 \text {-Punkte Skala, sehr } \\
\text { ruhig bis sehr energiegeladen, } \\
3=7 \text {-Punkte Skala, sehr } \\
\text { ruhig bis sehr energiegeladen, } \\
4=7 \text {-Punkte Skala, sehr } \\
\text { ruhig bis sehr energiegeladen, } \\
5=7 \text {-Punkte Skala, sehr } \\
\text { ruhig bis sehr energiegeladen, } \\
6=7 \text {-Punkte Skala, sehr } \\
\text { ruhig bis sehr energiegeladen }\end{array}$ & $\begin{array}{l}\text { How would you } \\
\text { characterize your typical } \\
\text { personal experience } \\
\text { when meeting with this } \\
\text { group? - Group } 1\end{array}$ & $\begin{array}{l}0=7 \text { point scale, very } \\
\text { quiet to very energetic, } 1 \\
=7 \text { point scale, very quiet } \\
\text { to very energetic, } 2=7 \\
\text { point scale, very quiet to } \\
\text { very energetic, } 3=7 \\
\text { point scale, very quiet to } \\
\text { very energetic, } 4=7 \\
\text { point scale, very quiet to } \\
\text { very energetic, } 5=7 \\
\text { point scale, very quiet to } \\
\text { very energetic, } 6=7 \\
\text { point scale, very quiet to } \\
\text { very energetic }\end{array}$ & $\mathrm{x}$ & $\mathrm{x}$ & $\mathrm{x}$ & $\mathrm{x}$ & $\mathrm{x}$ & $\mathrm{x}$ & $\mathrm{x}$ & $\mathrm{x}$ & $\mathrm{x}$ & $\mathrm{x}$ \\
\hline
\end{tabular}




\begin{tabular}{|c|c|c|c|c|c|c|c|c|c|c|c|c|c|c|c|}
\hline VarName & VariableLabel & WordingDE & ValueLabelsDE_Linked & WordingEN & ValueLabelsEN_Linked & L1 & $\mathrm{L} 2$ & L3 & $\mathrm{L} 4$ & L5 & $\mathrm{L} 6$ & L7 & L8 & L9 & L10 L11 L12 \\
\hline group.1.personal & & $\begin{array}{l}\text { 1_Q10.7_3 - Wie } \\
\text { empfindest Du persönlich } \\
\text { typischerweiseTreffen mit } \\
\text { dieser Gruppe "[Field-1]"? - } \\
\text { Gruppe } 1 \text { - sehr } \\
\text { oberflächlich:sehr persönlich }\end{array}$ & $\begin{array}{l}0=7 \text {-Punkte Skala, sehr } \\
\text { oberfl̈̈chlich bis sehr } \\
\text { persönlich, } 1=7 \text {-Punkte } \\
\text { Skala, sehr oberflächlich bis } \\
\text { sehr persönlich, } 2=7 \text {-Punkte } \\
\text { Skala, sehr oberflächlich bis } \\
\text { sehr persönlich, } 3=7 \text {-Punkte } \\
\text { Skala, sehr oberflächlich bis } \\
\text { sehr persönlich, } 4=7 \text {-Punkte } \\
\text { Skala, sehr oberflächlich bis } \\
\text { sehr persönlich, } 5=7 \text {-Punkte } \\
\text { Skala, sehr oberflächlich bis } \\
\text { sehr persönlich, } 6=7 \text {-Punkte } \\
\text { Skala, sehr oberflächlich bis } \\
\text { sehr persönlich }\end{array}$ & $\begin{array}{l}\text { How would you } \\
\text { characterize your typical } \\
\text { personal experience } \\
\text { when meeting with this } \\
\text { group? - Group } 1\end{array}$ & $\begin{array}{l}0=7 \text { point scale, very } \\
\text { superficial to very } \\
\text { personal, } 1=7 \text { point } \\
\text { scale, very superficial to } \\
\text { very personal, } 2=7 \text { point } \\
\text { scale, very superficial to } \\
\text { very personal, } 3=7 \text { point } \\
\text { scale, very superficial to } \\
\text { very personal, } 4=7 \text { point } \\
\text { scale, very superficial to } \\
\text { very personal, } 5=7 \text { point } \\
\text { scale, very superficial to } \\
\text { very personal, } 6=7 \text { point } \\
\text { scale, very superficial to } \\
\text { very personal }\end{array}$ & $\mathrm{x}$ & $\mathrm{x}$ & $\mathrm{x}$ & $\mathrm{x}$ & $\mathrm{x}$ & $\mathrm{x}$ & $\mathrm{x}$ & $\mathrm{x}$ & $\mathrm{x}$ & $\mathrm{x}$ \\
\hline group.1.communication & & $\begin{array}{l}\text { 1_Q10.8 - Gruppe 1 - } \\
\text { Wieoft kommuniziert die } \\
\text { Gruppe "[Field-1]" online } \\
\text { (z.B. per Whatsapp-, } \\
\text { Facebook-Gruppenchat) } \\
\text { zusätzlich zu den Treffen? }\end{array}$ & $\begin{array}{l}1=\text { zwei oder dreimal pro } \\
\text { Woche, } 2=\text { einmal pro } \\
\text { Woche, } 3=\text { jede zweite } \\
\text { Woche, } 4=\text { einmal pro } \\
\text { Monat, } 5=\text { weniger als } \\
\text { einmal pro Jahr, } 6=\text { fast } \\
\text { jeden Tag, } 7=\text { nie, } 8=\text { zwei } \\
\text { oder dreimal pro Woche, } 9= \\
\text { einmal pro Woche, } 10=\text { jede } \\
\text { zweite Woche, } 11=\text { einmal } \\
\text { pro Monat, } 12=\text { weniger als } \\
\text { einmal pro Jahr }\end{array}$ & $\begin{array}{l}\text { How often does this } \\
\text { group communicate } \\
\text { online (e.g. via } \\
\text { WhatsApp, Facebook } \\
\text { Chat) in addition to the } \\
\text { meetings? - Group } 1\end{array}$ & $\begin{array}{l}1=\text { second or three time } \\
\text { per week, } 2=\text { once per } \\
\text { week, } 3=\text { every second } \\
\text { week, } 4=\text { once per } \\
\text { month, } 5=\text { less than once } \\
\text { per month, } 6=\text { almost } \\
\text { every day, } 7=\text { never, } 8= \\
\text { second or three time per } \\
\text { week, } 9=\text { once per week, } \\
10=\text { every second week, } \\
11=\text { once per month, } 12 \\
=\text { less than once per } \\
\text { month }\end{array}$ & $\mathrm{x}$ & $\mathrm{x}$ & $\mathrm{x}$ & $\mathrm{x}$ & $\mathrm{x}$ & $\mathrm{x}$ & $\mathrm{x}$ & $\mathrm{x}$ & $\mathrm{x}$ & $\mathrm{x}$ \\
\hline group.1.identification & & $\begin{array}{l}\text { 1_Q10.9 - Gruppe 1 - Wir } \\
\text { zeigen Dir jeweils zwei } \\
\text { Kreise, vondenen } \\
\text { repräsentiert der eine Dich } \\
\text { (blau) und der andere eine } \\
\text { bestimmte Gruppe(rot). } \\
\text { Bitte wähle immer das Bild } \\
\text { mit den zwei Kreisen, von } \\
\text { dem Du denkst, } \\
\text { esrepräsentiere Dein eigenes } \\
\text { Level an Identifikation mit } \\
\text { dieser Gruppe am } \\
\text { Besten.Wie } \\
\text { starkidentifizierst Du Dich } \\
\text { mit der der Gruppe } \\
\text { "[Field-1]"? }\end{array}$ & & $\begin{array}{l}\text { Group } 1 \text { - We will } \\
\text { present you two circles, } \\
\text { of which one represents } \\
\text { you (blue) and the other } \\
\text { represents a certain } \\
\text { group (red). Please } \\
\text { choose the picture which } \\
\text { you think best } \\
\text { represents your own } \\
\text { level of identification } \\
\text { with this group. How } \\
\text { strongly do you identify } \\
\text { with this group? }\end{array}$ & & $\mathrm{x}$ & $\mathrm{x}$ & $\mathrm{x}$ & $\mathrm{x}$ & $\mathrm{x}$ & $\mathrm{x}$ & $\mathrm{x}$ & $\mathrm{x}$ & $\mathrm{x}$ & $\mathrm{x}$ \\
\hline group.2.P1 & & $\begin{array}{l}\text { 3_Q10.2_1 - Welche Deiner } \\
\text { Mitstudierenden sind Teil } \\
\text { der Gruppe "[Field-1]"? } \\
\text { (die Anzahl von } \\
\text { Gruppenmitgliedern, die } \\
\text { nicht mit Dir studierendem } \\
\text { kann auf der nächsten Seite } \\
\text { genannt werden) Nenne } \\
\text { zwischen } 1 \text { und } 20 \text { Personen. } \\
\text { - Gruppe 2 - Name 1 }\end{array}$ & & $\begin{array}{l}\text { Whom among your } \\
\text { fellow students is part of } \\
\text { the group } \\
\text { "< } \\
\text { numbeupname }>\text { ? (the } \\
\text { members whoup are not } \\
\text { fellow students can be } \\
\text { reported on the next } \\
\text { page). Name between } 0 \\
\text { and } 20 \text { people. - Group } \\
2 \text { - Name1 }\end{array}$ & & $\mathrm{x}$ & $\mathrm{x}$ & $\mathrm{x}$ & $\mathrm{x}$ & $\mathrm{x}$ & $\mathrm{x}$ & $\mathrm{x}$ & $\mathrm{x}$ & $\mathrm{x}$ & $\mathrm{x}$ \\
\hline group.2.other & & $\begin{array}{l}\text { 3_Q10.4 - Gibt es noch } \\
\text { weitere Mitglieder dieser } \\
\text { Gruppe, welche nicht mit } \\
\text { Dir studieren? - Gruppe 2 - } \\
\text { Gibt es noch weitere } \\
\text { Mitglieder dieser Gruppe, } \\
\text { welche nicht mit Dir } \\
\text { studieren? - Selected Choice }\end{array}$ & $\begin{array}{l}1=\text { Wenn ja, wieviele sind } \\
\text { dies?, } 2=\text { Nein }\end{array}$ & $\begin{array}{l}\text { Are there further } \\
\text { members in who do not } \\
\text { study with you? - } \\
\text { Group } 2\end{array}$ & $\begin{array}{l}1=\text { If yes, how many?, } 2 \\
=\text { No }\end{array}$ & $\mathrm{x}$ & $\mathrm{x}$ & $\mathrm{x}$ & $\mathrm{x}$ & $\mathrm{x}$ & $\mathrm{x}$ & $\mathrm{x}$ & $\mathrm{x}$ & $\mathrm{x}$ & $\mathrm{x}$ \\
\hline
\end{tabular}




\begin{tabular}{|c|c|c|c|c|c|c|c|c|c|c|c|c|c|c|c|}
\hline VarName & VariableLabel & WordingDE & ValueLabelsDE_Linked & WordingEN & ValueLabelsEN_Linked & L1 & $\mathrm{L} 2$ & L3 & $\mathrm{L} 4$ & L5 & L6 6 & L7 & L8 & L9 & L10 L11 L12 \\
\hline group.2.other.number & & $\begin{array}{l}\text { 3_Q10.4_1_TEXT - Gibt } \\
\text { es noch weitere Mitglieder } \\
\text { dieser Gruppe, welche nicht } \\
\text { mit Dir studieren? - } \\
\text { Gruppe 2 - Wenn ja, } \\
\text { wieviele sind dies? - Text }\end{array}$ & & $\begin{array}{l}\text { How many other people } \\
\text { NOT from your cohort } \\
\text { are part of this group? - } \\
\text { Group } 2\end{array}$ & & $\mathrm{x}$ & $\mathrm{x}$ & $\mathrm{x}$ & $\mathrm{x}$ & $\mathrm{x}$ & $\mathrm{x}$ & $\mathrm{x}$ & $\mathrm{x}$ & $\mathrm{x}$ & $\mathrm{x}$ \\
\hline group.2.activity.1 & & $\begin{array}{l}\text { 3_Q10.5_1 - Welche } \\
\text { Tätigkeiten führt die } \\
\text { Gruppe "[Field-1]" } \\
\text { normalerweise gemeinsam } \\
\text { aus? - Gruppe } 2 \text { - Welche } \\
\text { Tätigkeiten führt die } \\
\text { Gruppe "[Field-1]" } \\
\text { normalerweise gemeinsam } \\
\text { aus? - Selected Choice - } \\
\text { Lernen/Hausaufgaben }\end{array}$ & & $\begin{array}{l}\text { What activities does the } \\
\text { group "< } \\
\text { usually do tognether? - } \\
\text { Group } 2 \text { - Selected } \\
\text { Choice - } \\
\text { studying/homework }\end{array}$ & & $\mathrm{x}$ & $\mathrm{x}$ & $\mathrm{x}$ & $\mathrm{x}$ & $\mathrm{x}$ & $\mathrm{x}$ & $\mathrm{x}$ & $\mathrm{x}$ & $\mathrm{x}$ & $\mathrm{x}$ \\
\hline group.2.activity.2 & & $\begin{array}{l}\text { 3_Q10.5_2 - Welche } \\
\text { Tätigkeiten führt die } \\
\text { Gruppe "[Field-1]" } \\
\text { normalerweise gemeinsam } \\
\text { aus? - Gruppe } 2 \text { - Welche } \\
\text { Tätigkeiten führt die } \\
\text { Gruppe "[Field-1]" } \\
\text { normalerweise gemeinsam } \\
\text { aus? - Selected Choice - } \\
\text { Arbeit }\end{array}$ & & $\begin{array}{l}\text { What activities does the } \\
\text { group "< } \\
\text { usually do tognether? - } \\
\text { Group } 2 \text { - Selected } \\
\text { Choice - work }\end{array}$ & & $\mathrm{x}$ & $\mathrm{x}$ & $\mathrm{x}$ & $\mathrm{x}$ & $\mathrm{x}$ & $\mathrm{x}$ & $\mathrm{x}$ & $\mathrm{x}$ & $\mathrm{x}$ & $\mathrm{x}$ \\
\hline group.2.activity.3 & & $\begin{array}{l}\text { 3_Q10.5_3 - Welche } \\
\text { Tätigkeiten füht die } \\
\text { Gruppe "[Field-1]" } \\
\text { normalerweise gemeinsam } \\
\text { aus? - Gruppe } 2 \text { - Welche } \\
\text { Tätigkeiten führt die } \\
\text { Gruppe "[Field-1]" } \\
\text { normalerweise gemeinsam } \\
\text { aus? - Selected Choice - } \\
\text { Sport }\end{array}$ & & $\begin{array}{l}\text { What activities does the } \\
\text { group "< groupname>" } \\
\text { usually do together? - } \\
\text { Group } 2 \text { - Selected } \\
\text { Choice - sports }\end{array}$ & & $\mathrm{x}$ & $\mathrm{x}$ & $\mathrm{x}$ & $\mathrm{x}$ & $\mathrm{x}$ & $\mathrm{x}$ & $\mathrm{x}$ & $\mathrm{x}$ & $\mathrm{x}$ & $\mathrm{x}$ \\
\hline group.2.activity.4 & & $\begin{array}{l}\text { 3_Q10.5_4 - Welche } \\
\text { Tätigkeiten führt die } \\
\text { Gruppe "[Field-1]" } \\
\text { normalerweise gemeinsam } \\
\text { aus? - Gruppe } 2 \text { - Welche } \\
\text { Tätigkeiten führt die } \\
\text { Gruppe "[Field-1]" } \\
\text { normalerweise gemeinsam } \\
\text { aus? - Selected Choice - } \\
\text { Gespräch }\end{array}$ & & $\begin{array}{l}\text { What activities does the } \\
\text { group "< } \\
\text { usually do tognether? }> \\
\text { Group } 2 \text { - Selected } \\
\text { Choice - conversation }\end{array}$ & & $\mathrm{x}$ & $\mathrm{x}$ & $\mathrm{x}$ & $\mathrm{x}$ & $\mathrm{x}$ & $\mathrm{x}$ & $\mathrm{x}$ & $\mathrm{x}$ & $\mathrm{x}$ & $\mathrm{x}$ \\
\hline group.2.activity.5 & & $\begin{array}{l}\text { 3_Q10.5_5 - Welche } \\
\text { Tätigkeiten führt die } \\
\text { Gruppe "[Field-1]" } \\
\text { normalerweise gemeinsam } \\
\text { aus? - Gruppe 2 - Welche } \\
\text { Tätigkeiten führt die } \\
\text { Gruppe "[Field-1]" } \\
\text { normalerweise gemeinsam } \\
\text { aus? - Selected Choice - } \\
\text { etwas trinken gehen ("eis go } \\
\text { zieh") }\end{array}$ & & $\begin{array}{l}\text { What activities does the } \\
\text { group "< groupname>" } \\
\text { usually do together? - } \\
\text { Group } 2 \text { - Selected } \\
\text { Choice - going for drinks }\end{array}$ & & $\mathrm{x}$ & $\mathrm{x}$ & $\mathrm{X}$ & $\mathrm{X}$ & $\mathrm{X}$ & $\mathrm{X}$ & $\mathrm{x}$ & $\mathrm{x}$ & $\mathrm{x}$ & $\mathrm{x}$ \\
\hline
\end{tabular}




\begin{tabular}{|c|c|c|c|c|c|c|c|c|c|c|c|c|c|c|c|}
\hline VarName & VariableLabel & WordingDE & ValueLabelsDE_Linked & WordingEN & ValueLabelsEN_Linked & L1 & $\mathrm{L} 2$ & L3 & $\mathrm{L} 4$ & L5 & L6 & L7 & L8 & L9 & L10 L11 L12 \\
\hline group.2.activity. 6 & & $\begin{array}{l}\text { 3_Q10.5_6 - Welche } \\
\text { Tätigkeiten führt die } \\
\text { Gruppe "[Field-1]" } \\
\text { normalerweise gemeinsam } \\
\text { aus? - Gruppe 2 - Welche } \\
\text { Tätigkeiten führt die } \\
\text { Gruppe "[Field-1]" } \\
\text { normalerweise gemeinsam } \\
\text { aus? - Selected Choice - } \\
\text { gemeinsamer Weg (z.B. zur } \\
\text { Universität) }\end{array}$ & & $\begin{array}{l}\text { What activities does the } \\
\text { group "< } \\
\text { usually do toupname }>\text { " } \\
\text { Group } 2 \text { - Selected } \\
\text { Choice - commute }\end{array}$ & & $\mathrm{x}$ & $\mathrm{x}$ & $\mathrm{x}$ & $\mathrm{x}$ & $\mathrm{x}$ & $\mathrm{x}$ & $\mathrm{x}$ & $\mathrm{x}$ & $\mathrm{x}$ & $\mathrm{x}$ \\
\hline group.2.activity.7 & & $\begin{array}{l}\text { 3_Q10.5_7 - Welche } \\
\text { Tätigkeiten führt die } \\
\text { Gruppe "[Field-1]" } \\
\text { normalerweise gemeinsam } \\
\text { aus? - Gruppe 2 - Welche } \\
\text { Tätigkeiten führt die } \\
\text { Gruppe "[Field-1]" } \\
\text { normalerweise gemeinsam } \\
\text { aus? - Selected Choice - } \\
\text { Andere }\end{array}$ & & $\begin{array}{l}\text { What activities does the } \\
\text { group "< } \\
\text { usually do togetherer? - } \\
\text { Group } 2 \text { - Selected } \\
\text { Choice - Other }\end{array}$ & & $\mathrm{x}$ & $\mathrm{x}$ & $\mathrm{x}$ & $\mathrm{x}$ & $\mathrm{x}$ & $\mathrm{x}$ & $\mathrm{x}$ & $\mathrm{x}$ & $\mathrm{x}$ & $\mathrm{x}$ \\
\hline group.2.activity. 8 & & $\begin{array}{l}\text { 3_Q10.5_8 - Welche } \\
\text { Tätigkeiten führt die } \\
\text { Gruppe "[Field-1]" } \\
\text { normalerweise gemeinsam } \\
\text { aus? - Gruppe 2 - Welche } \\
\text { Tätigkeiten führt die } \\
\text { Gruppe "[Field-1]" } \\
\text { normalerweise gemeinsam } \\
\text { aus? - Selected Choice - } \\
\text { Kultur }\end{array}$ & & $\begin{array}{l}\text { What activities does the } \\
\text { group "<groupname>" } \\
\text { usually do together? - } \\
\text { Group } 2 \text { - Selected } \\
\text { Choice - cultural } \\
\text { activities }\end{array}$ & & $\mathrm{x}$ & $\mathrm{x}$ & $\mathrm{x}$ & $\mathrm{x}$ & $\mathrm{x}$ & $\mathrm{x}$ & $\mathrm{x}$ & $\mathrm{x}$ & $\mathrm{x}$ & $\mathrm{x}$ \\
\hline group.2.activity.9 & & $\begin{array}{l}\text { 3_Q10.5_10 - Welche } \\
\text { Tätigkeiten führt die } \\
\text { Gruppe "[Field-1]" } \\
\text { normalerweise gemeinsam } \\
\text { aus? - Gruppe 2 - Welche } \\
\text { Tätigkeiten führt die } \\
\text { Gruppe "[Field-1]" } \\
\text { normalerweise gemeinsam } \\
\text { aus? - Selected Choice - } \\
\text { über politische Themen } \\
\text { sprechen }\end{array}$ & & $\begin{array}{l}\text { What activities does the } \\
\text { group "< } \\
\text { usually do toupname >" } \\
\text { Group } 2 \text { - Selected } \\
\text { Choice - discussing } \\
\text { politics }\end{array}$ & & $\mathrm{x}$ & $\mathrm{x}$ & $\mathrm{x}$ & $\mathrm{x}$ & $\mathrm{x}$ & $\mathrm{x}$ & $\mathrm{x}$ & $\mathrm{x}$ & $\mathrm{x}$ & $\mathrm{x}$ \\
\hline group.2.activity.7.str & & $\begin{array}{l}\text { 3_Q10.5_7_TEXT - } \\
\text { Welche Tätigkeiten führt } \\
\text { die Gruppe "[Field-1]" } \\
\text { normalerweise gemeinsam } \\
\text { aus? - Gruppe 2 - Andere - } \\
\text { Text }\end{array}$ & & $\begin{array}{l}\text { TEXT_What activities } \\
\text { does the group } \\
\text { "<groupname>" usually } \\
\text { do together? - Group } 2 \text { - } \\
\text { Other - text }\end{array}$ & & $\mathrm{x}$ & $\mathrm{x}$ & $\mathrm{x}$ & $\mathrm{x}$ & $\mathrm{x}$ & $\mathrm{x}$ & $\mathrm{x}$ & $\mathrm{x}$ & $\mathrm{x}$ & $\mathrm{x}$ \\
\hline group.2.freq & & $\begin{array}{l}\text { 3_Q10.6 - Gruppe 2- } \\
\text { Wieoft trifft sich diese } \\
\text { Gruppe "[Field-1]" } \\
\text { normalerweise für } \\
\text { gemeinsame Aktivitäten? }\end{array}$ & $\begin{array}{l}1=\text { zwei oder dreimal pro } \\
\text { Woche, } 2=\text { einmal pro } \\
\text { Woche, } 3=\text { jede zweite } \\
\text { Woche, } 4=\text { einmal pro } \\
\text { Monat, } 5=\text { weniger als } \\
\text { einmal pro Monat, } 6=\text { fast } \\
\text { jeden Tag }\end{array}$ & $\begin{array}{l}\text { How often does this } \\
\text { group typically meet for } \\
\text { some joint activity? - } \\
\text { Group } 2\end{array}$ & $\begin{array}{l}1=\text { two or three times } \\
\text { per week, } 2=\text { one time } \\
\text { per week, } 3=\text { every } \\
\text { second week, } 4=\text { once per } \\
\text { month, } 5=\text { less than once } \\
\text { per month, } 6=\text { almost } \\
\text { every day }\end{array}$ & $\mathrm{x}$ & $\mathrm{x}$ & $\mathrm{x}$ & $\mathrm{x}$ & $\mathrm{x}$ & $\mathrm{x}$ & $\mathrm{x}$ & $\mathrm{x}$ & $\mathrm{x}$ & $\mathrm{x}$ \\
\hline
\end{tabular}




\begin{tabular}{|c|c|c|c|c|c|c|c|c|c|c|c|c|c|c|c|}
\hline VarName & VariableLabel & WordingDE & ValueLabelsDE_Linked & WordingEN & ValueLabelsEN_Linked & L1 & $\mathrm{L} 2$ & L3 & $\mathrm{L} 4$ & L5 & L6 & L7 & L8 & L9 & L10 L11 L12 \\
\hline group.2.pleasant & & $\begin{array}{l}\text { 3_Q10.7_1 - Wie } \\
\text { empfindest Du persönlich } \\
\text { typischerweise Treffen mit } \\
\text { dieser Gruppe "[Field-1]"? - } \\
\text { Gruppe } 2 \text { - sehr } \\
\text { unangenehm:sehr angenehm }\end{array}$ & $\begin{array}{l}0=7 \text {-Punkte Skala, sehr } \\
\text { angenehm bis sehr } \\
\text { unangenehm, } 1=7 \text {-Punkte } \\
\text { Skala, sehr angenehm bis sehr } \\
\text { unangenehm, } 2=7 \text {-Punkte } \\
\text { Skala, sehr angenehm bis sehr } \\
\text { unangenehm, } 3=7 \text {-Punkte } \\
\text { Skala, sehr angenehm bis sehr } \\
\text { unangenehm, } 4=7 \text {-Punkte } \\
\text { Skala, sehr angenehm bis sehr } \\
\text { unangenehm, } 5=7 \text {-Punkte } \\
\text { Skala, sehr angenehm bis sehr } \\
\text { unangenehm, } 6=7 \text {-Punkte } \\
\text { Skala, sehr angenehm bis sehr } \\
\text { unangenehm }\end{array}$ & $\begin{array}{l}\text { How would you } \\
\text { characterize your typical } \\
\text { personal experience } \\
\text { when meeting with this } \\
\text { group? - Group } 2 \text { - very } \\
\text { pleasant : very } \\
\text { unpleasant }\end{array}$ & $\begin{array}{l}0=7 \text { point scale, very } \\
\text { pleasant to very } \\
\text { unpleasant, } 1=7 \text { point } \\
\text { scale, very pleasant to } \\
\text { very unpleasant, } 2=7 \\
\text { point scale, very pleasant } \\
\text { to very unpleasant, } 3=7 \\
\text { point scale, very pleasant } \\
\text { to very unpleasant, } 4=7 \\
\text { point scale, very pleasant } \\
\text { to very unpleasant, } 5=7 \\
\text { point scale, very pleasant } \\
\text { to very unpleasant, } 6=7 \\
\text { point scale, very pleasant } \\
\text { to very unpleasant }\end{array}$ & $\mathrm{x}$ & $\mathrm{x}$ & $\mathrm{x}$ & $\mathrm{x}$ & $\mathrm{x}$ & $\mathrm{x}$ & $\mathrm{x}$ & $\mathrm{x}$ & $\mathrm{x}$ & $\mathrm{x}$ \\
\hline group.2.energetic & & $\begin{array}{l}\text { 3_Q10.7_2 - Wie } \\
\text { empfindest Du persönlich } \\
\text { typischerweise Treffen mit } \\
\text { dieser Gruppe "[Field-1]"? - } \\
\text { Gruppe 2 - sehr ruhig:sehr } \\
\text { energiegeladen }\end{array}$ & $\begin{array}{l}0=7 \text {-Punkte Skala, sehr } \\
\text { ruhig bis sehr energiegeladen, } \\
1=7 \text {-Punkte Skala, sehr } \\
\text { ruhig bis sehr energiegeladen, } \\
2=7 \text {-Punkte Skala, sehr } \\
\text { ruhig bis sehr energiegeladen, } \\
3=7 \text {-Punkte Skala, sehr } \\
\text { ruhig bis sehr energiegeladen, } \\
4=7 \text {-Punkte Skala, sehr } \\
\text { ruhig bis sehr energiegeladen, } \\
5=7 \text {-Punkte Skala, sehr } \\
\text { ruhig bis sehr energiegeladen, } \\
6=7 \text {-Punkte Skala, sehr } \\
\text { ruhig bis sehr energiegeladen }\end{array}$ & $\begin{array}{l}\text { How would you } \\
\text { characterize your typical } \\
\text { personal experience } \\
\text { when meeting with this } \\
\text { group? - Group } 2 \text { - very } \\
\text { quiet : very energetic }\end{array}$ & $\begin{array}{l}0=7 \text { point scale, very } \\
\text { quiet to very energetic, } 1 \\
=7 \text { point scale, very quiet } \\
\text { to very energetic, } 2=7 \\
\text { point scale, very quiet to } \\
\text { very energetic, } 3=7 \\
\text { point scale, very quiet to } \\
\text { very energetic, } 4=7 \\
\text { point scale, very quiet to } \\
\text { very energetic, } 5=7 \\
\text { point scale, very quiet to } \\
\text { very energetic, } 6=7 \\
\text { point scale, very quiet to } \\
\text { very energetic }\end{array}$ & $\mathrm{x}$ & $\mathrm{x}$ & $\mathrm{x}$ & $\mathrm{x}$ & $\mathrm{x}$ & $\mathrm{x}$ & $\mathrm{X}$ & $\mathrm{x}$ & $\mathrm{x}$ & $\mathrm{x}$ \\
\hline group.2.personal & & $\begin{array}{l}\text { 3_Q10.7_3 - Wie } \\
\text { empfindest Du persönlich } \\
\text { typischerweise Treffen mit } \\
\text { dieser Gruppe "[Field-1]"? - } \\
\text { Gruppe } 2 \text { - sehr } \\
\text { oberflächlich:sehr persönlich }\end{array}$ & $\begin{array}{l}0=7 \text {-Punkte Skala, sehr } \\
\text { oberfächlich bis sehr } \\
\text { persönlich, } 1=7 \text {-Punkte } \\
\text { Skala, sehr oberflächlich bis } \\
\text { sehr persönlich, } 2=7 \text {-Punkte } \\
\text { Skala, sehr oberflächlich bis } \\
\text { sehr persönlich, } 3=7 \text {-Punkte } \\
\text { Skala, sehr oberflächlich bis } \\
\text { sehr persönlich, } 4=7 \text {-Punkte } \\
\text { Skala, sehr oberflächlich bis } \\
\text { sehr persönlich, } 5=7 \text {-Punkte } \\
\text { Skala, sehr oberflächlich bis } \\
\text { sehr persönlich, } 6=7 \text {-Punkte } \\
\text { Skala, sehr oberflächlich bis } \\
\text { sehr persönlich }\end{array}$ & $\begin{array}{l}\text { How would you } \\
\text { characterize your typical } \\
\text { personal experience } \\
\text { when meeting with this } \\
\text { group? - Group } 2 \text { - very } \\
\text { superficial : very } \\
\text { personal }\end{array}$ & $\begin{array}{l}0=7 \text { point scale, very } \\
\text { superficial to very } \\
\text { personal, } 1=7 \text { point } \\
\text { scale, very superficial to } \\
\text { very personal, } 2=7 \text { point } \\
\text { scale, very superficial to } \\
\text { very personal, } 3=7 \text { point } \\
\text { scale, very superficial to } \\
\text { very personal, } 4=7 \text { point } \\
\text { scale, very superficial to } \\
\text { very personal, } 5=7 \text { point } \\
\text { scale, very superficial to } \\
\text { very personal, } 6=7 \text { point } \\
\text { scale, very superficial to } \\
\text { very personal }\end{array}$ & $\mathrm{x}$ & $\mathrm{x}$ & $\mathrm{x}$ & $\mathrm{x}$ & $\mathrm{x}$ & $\mathrm{x}$ & $\mathrm{x}$ & $\mathrm{x}$ & $\mathrm{x}$ & $\mathrm{x}$ \\
\hline group.2.communication & & $\begin{array}{l}\text { 3_Q10.8 - Gruppe 2 - Wie } \\
\text { oft kommuniziert die } \\
\text { Gruppe "[Field-1]" online } \\
\text { (z.B. per Whatsapp-, } \\
\text { Facebook-Gruppenchat) } \\
\text { zusätzlich zu den Treffen? }\end{array}$ & $\begin{array}{l}1=\text { zwei oder dreimal pro } \\
\text { Woche, } 2=\text { einmal pro } \\
\text { Woche, } 3=\text { jede zweite } \\
\text { Woche, } 4=\text { einmal pro } \\
\text { Monat, } 5=\text { weniger als } \\
\text { einmal pro Jahr, } 6=\text { fast } \\
\text { jeden Tag, } 7=\text { nie, } 8=\text { zwei } \\
\text { oder dreimal pro Woche, } 9= \\
\text { einmal pro Woche, } 10=\text { jede } \\
\text { zweite Woche, } 11=\text { einmal } \\
\text { pro Monat, } 12=\text { weniger als } \\
\text { einmal pro Jahr }\end{array}$ & $\begin{array}{l}\text { How often does this } \\
\text { group communicate } \\
\text { online (e.g. via } \\
\text { WhatsApp, Facebook } \\
\text { Chat) in addition to the } \\
\text { meetings? - Group } 2\end{array}$ & $\begin{array}{l}1=\text { second or three time } \\
\text { per week, } 2=\text { once per } \\
\text { week, } 3=\text { every second } \\
\text { week, } 4=\text { once per } \\
\text { month, } 5=\text { less than once } \\
\text { per month, } 6=\text { almost } \\
\text { every day, } 7=\text { never, } 8= \\
\text { second or three time per } \\
\text { week, } 9=\text { once per week, } \\
10=\text { every second week, } \\
11=\text { once per month, } 12 \\
=\text { less than once per } \\
\text { month }\end{array}$ & $\mathrm{x}$ & $\mathrm{x}$ & $\mathrm{x}$ & $\mathrm{x}$ & $\mathrm{x}$ & $\mathrm{x}$ & $\mathrm{x}$ & $\mathrm{x}$ & $\mathrm{x}$ & $\mathrm{x}$ \\
\hline
\end{tabular}




\begin{tabular}{|c|c|c|c|c|c|c|c|c|c|c|c|c|c|c|c|}
\hline VarName & VariableLabel & WordingDE & ValueLabelsDE_Linked & WordingEN & ValueLabelsEN_Linked & $\mathrm{L} 1$ & L2 & L3 & $\mathrm{L} 4$ & L5 & L6 & L7 & L8 & L9 & L10 L11 L12 \\
\hline group.2.identification & & $\begin{array}{l}\text { 3_Q10.9 - Gruppe 2 - Wir } \\
\text { zeigen Dir jeweils zwei } \\
\text { Kreise, von denen } \\
\text { repräsentiert der eine Dich } \\
\text { (blau) und der andere eine } \\
\text { bestimmte Gruppe (rot). } \\
\text { Bitte wähle immer das Bild } \\
\text { mit den zwei Kreisen, von } \\
\text { dem Du denkst, es } \\
\text { repräsentiere Dein eigenes } \\
\text { Level an Identifikation mit } \\
\text { dieser Gruppe am Besten. } \\
\text { Wie stark identifizierst Du } \\
\text { Dich mit der der Gruppe } \\
\text { "[Field-1]"? }\end{array}$ & & $\begin{array}{l}\text { Group } 2 \text { - We will } \\
\text { present you two circles, } \\
\text { of which one represents } \\
\text { you (blue) and the other } \\
\text { represents a certain } \\
\text { group (red). Please } \\
\text { choose the picture which } \\
\text { you think best } \\
\text { represents your own } \\
\text { level of identification } \\
\text { with this group. How } \\
\text { strongly do you identify } \\
\text { with this group? }\end{array}$ & & $\mathrm{x}$ & $\mathrm{x}$ & $\mathrm{x}$ & $\mathrm{x}$ & $\mathrm{x}$ & $\mathrm{x}$ & $\mathrm{x}$ & $\mathrm{x}$ & $\mathrm{x}$ & $\mathrm{x}$ \\
\hline group.3.P1 & & $\begin{array}{l}\text { 4_Q10.2_1 - Welche Deiner } \\
\text { Mitstudierenden sind Teil } \\
\text { der Gruppe "[Field-1]"? } \\
\text { (die Anzahl von } \\
\text { Gruppenmitgliedern, die } \\
\text { nicht mit Dir studierendem } \\
\text { kann auf der nächsten Seite } \\
\text { genannt werden) Nenne } \\
\text { zwischen } 1 \text { und } 20 \text { Personen. } \\
\text { - Gruppe } 3 \text { - Name 1 }\end{array}$ & & $\begin{array}{l}\text { Whom among your } \\
\text { fellow students is part of } \\
\text { the group } \\
\text { "< groupname }>\text { "? (the } \\
\text { number of group } \\
\text { members who are not } \\
\text { fellow students can be } \\
\text { reported on the next } \\
\text { page). Name between } 0 \\
\text { and } 20 \text { people. - Group } \\
3 \text { - Name } 1\end{array}$ & & $\mathrm{x}$ & $\mathrm{x}$ & $\mathrm{x}$ & $\mathrm{x}$ & $\mathrm{x}$ & $\mathrm{x}$ & $\mathrm{x}$ & $\mathrm{x}$ & $\mathrm{x}$ & $\mathrm{x}$ \\
\hline group.3.other & & $\begin{array}{l}\text { 4_Q10.4 - Gibt es noch } \\
\text { weitere Mitglieder dieser } \\
\text { Gruppe, welche nicht mit } \\
\text { Dir studieren? - Gruppe } 3 \text { - } \\
\text { Gibt es noch weitere } \\
\text { Mitglieder dieser Gruppe, } \\
\text { welche nicht mit Dir } \\
\text { studieren? - Selected Choice }\end{array}$ & $\begin{array}{l}1=\text { Wenn ja, wieviele sind } \\
\text { dies?, } 2=\text { Nein }\end{array}$ & $\begin{array}{l}\text { Are there further } \\
\text { members in who do not } \\
\text { study with you? - } \\
\text { Group } 3\end{array}$ & $\begin{array}{l}1=\text { If yes, how many?, } 2 \\
=\text { No }\end{array}$ & $\mathrm{x}$ & $\mathrm{x}$ & $\mathrm{x}$ & $\mathrm{x}$ & $\mathrm{x}$ & $\mathrm{x}$ & $\mathrm{x}$ & $\mathrm{x}$ & $\mathrm{x}$ & $\mathrm{x}$ \\
\hline group.3.other.number & & $\begin{array}{l}\text { 4_Q10.4_1_TEXT - Gibt } \\
\text { es noch weitere Mitglieder } \\
\text { dieser Gruppe, welche nicht } \\
\text { mit Dir studieren? - } \\
\text { Gruppe } 3 \text { - Wenn ja, } \\
\text { wieviele sind dies? - Text }\end{array}$ & & $\begin{array}{l}\text { How many other people } \\
\text { NOT from your cohort } \\
\text { are part of this group? - } \\
\text { Group } 3\end{array}$ & & $\mathrm{x}$ & $\mathrm{x}$ & $\mathrm{x}$ & $\mathrm{x}$ & $\mathrm{x}$ & $\mathrm{x}$ & $\mathrm{x}$ & $\mathrm{x}$ & $\mathrm{x}$ & $\mathrm{x}$ \\
\hline group.3.activity. 1 & & $\begin{array}{l}\text { 4_Q10.5_1 - Welche } \\
\text { Tätigkeiten führt die } \\
\text { Gruppe "[Field-1]" } \\
\text { normalerweise gemeinsam } \\
\text { aus? - Gruppe } 3 \text { - Welche } \\
\text { Tätigkeiten füht die } \\
\text { Gruppe "[Field-1]" } \\
\text { normalerweise gemeinsam } \\
\text { aus? - Selected Choice - } \\
\text { Lernen/Hausaufgaben }\end{array}$ & & $\begin{array}{l}\text { What activities does the } \\
\text { group "< groupname>" } \\
\text { usually do together? - } \\
\text { Group } 3 \text { - Selected } \\
\text { Choice - } \\
\text { studying/homework }\end{array}$ & & $\mathrm{x}$ & $\mathrm{x}$ & $\mathrm{x}$ & $\mathrm{x}$ & $\mathrm{x}$ & $\mathrm{x}$ & $\mathrm{x}$ & $\mathrm{x}$ & $\mathrm{x}$ & $\mathrm{x}$ \\
\hline group.3.activity.2 & & $\begin{array}{l}\text { 4_Q10.5_2 - Welche } \\
\text { Tätigkeiten führt die } \\
\text { Gruppe "[Field-1]" } \\
\text { normalerweise gemeinsam } \\
\text { aus? - Gruppe } 3 \text { - Welche } \\
\text { Tätigkeiten führt die } \\
\text { Gruppe "[Field-1]" } \\
\text { normalerweise gemeinsam } \\
\text { aus? - Selected Choice - } \\
\text { Arbeit }\end{array}$ & & $\begin{array}{l}\text { What activities does the } \\
\text { group "< groupname>" } \\
\text { usually do together? - } \\
\text { Group } 3 \text { - Selected } \\
\text { Choice - work }\end{array}$ & & $\mathrm{x}$ & $\mathrm{x}$ & $\mathrm{x}$ & $\mathrm{x}$ & $\mathrm{x}$ & $\mathrm{x}$ & $\mathrm{x}$ & $\mathrm{x}$ & $\mathrm{x}$ & $\mathrm{x}$ \\
\hline
\end{tabular}




\begin{tabular}{|c|c|c|c|c|c|c|c|c|c|c|c|c|c|c|c|}
\hline VarName & VariableLabel & WordingDE & ValueLabelsDE_Linked & WordingEN & ValueLabelsEN_Linked & L1 & L2 & L3 & L4 & L5 & $\mathrm{L} 6$ & L7 & L8 & L9 & L10 L11 L12 \\
\hline group.3.activity.3 & & $\begin{array}{l}\text { 4_Q10.5_3 - Welche } \\
\text { Tätigkeiten führt die } \\
\text { Gruppe "[Field-1]" } \\
\text { normalerweise gemeinsam } \\
\text { aus? - Gruppe } 3 \text { - Welche } \\
\text { Tätigkeiten führt die } \\
\text { Gruppe "[Field-1]" } \\
\text { normalerweise gemeinsam } \\
\text { aus? - Selected Choice - } \\
\text { Sport }\end{array}$ & & $\begin{array}{l}\text { What activities does the } \\
\text { group "<groupname>" } \\
\text { usually do together? - } \\
\text { Group } 3 \text { - Selected } \\
\text { Choice - sports }\end{array}$ & & $\mathrm{x}$ & $\mathrm{x}$ & $\mathrm{x}$ & $\mathrm{x}$ & $\mathrm{x}$ & $\mathrm{x}$ & $\mathrm{x}$ & $\mathrm{x}$ & $\mathrm{x}$ & $\mathrm{x}$ \\
\hline group.3.activity.4 & & $\begin{array}{l}\text { 4_Q10.5_4 - Welche } \\
\text { Tätigkeiten führt die } \\
\text { Gruppe "[Field-1]" } \\
\text { normalerweise gemeinsam } \\
\text { aus? - Gruppe 3 - Welche } \\
\text { Tätigkeiten führt die } \\
\text { Gruppe "[Field-1]" } \\
\text { normalerweise gemeinsam } \\
\text { aus? - Selected Choice - } \\
\text { Gespräch }\end{array}$ & & $\begin{array}{l}\text { What activities does the } \\
\text { group "< groupname>" } \\
\text { usually do together? - } \\
\text { Group } 3 \text { - Selected } \\
\text { Choice - conversation }\end{array}$ & & $\mathrm{x}$ & $\mathrm{x}$ & $\mathrm{x}$ & $\mathrm{x}$ & $\mathrm{x}$ & $\mathrm{x}$ & $\mathrm{x}$ & $\mathrm{x}$ & $\mathrm{x}$ & $\mathrm{x}$ \\
\hline group.3.activity.5 & & $\begin{array}{l}\text { 4_Q10.5_5 - Welche } \\
\text { Tätigkeiten führt die } \\
\text { Gruppe "[Field-1]" } \\
\text { normalerweise gemeinsam } \\
\text { aus? - Gruppe } 3 \text { - Welche } \\
\text { Tätigkeiten führt die } \\
\text { Gruppe "[Field-1]" } \\
\text { normalerweise gemeinsam } \\
\text { aus? - Selected Choice - } \\
\text { twas trinken gehen ("eis go } \\
\text { zieh") }\end{array}$ & & $\begin{array}{l}\text { What activities does the } \\
\text { group "< groupname>" } \\
\text { usually do together? - } \\
\text { Group } 3 \text { - Selected } \\
\text { Choice - going for drinks }\end{array}$ & & $\mathrm{x}$ & $\mathrm{x}$ & $\mathrm{X}$ & $\mathrm{x}$ & $\mathrm{X}$ & $\mathrm{x}$ & $\mathrm{x}$ & $\mathrm{x}$ & $\mathrm{x}$ & $\mathrm{x}$ \\
\hline group.3.activity.6 & & $\begin{array}{l}\text { 4_Q10.5_6 - Welche } \\
\text { Tätigkeiten führt die } \\
\text { Gruppe "[Field-1]" } \\
\text { normalerweise gemeinsam } \\
\text { aus? - Gruppe } 3 \text { - Welche } \\
\text { Tätigkeiten führt die } \\
\text { Gruppe "[Field-1]" } \\
\text { normalerweise gemeinsam } \\
\text { aus? - Selected Choice - } \\
\text { gemeinsamer Weg (z.B. zur } \\
\text { Universität) }\end{array}$ & & $\begin{array}{l}\text { What activities does the } \\
\text { group "< groupname>" } \\
\text { usually do together? - } \\
\text { Group } 3 \text { - Selected } \\
\text { Choice - commute }\end{array}$ & & $\mathrm{x}$ & $\mathrm{x}$ & $\mathrm{x}$ & $\mathrm{x}$ & $\mathrm{x}$ & $\mathrm{x}$ & $\mathrm{x}$ & $\mathrm{x}$ & $\mathrm{x}$ & $\mathrm{x}$ \\
\hline group.3.activity. 7 & & $\begin{array}{l}\text { 4_Q10.5_7 - Welche } \\
\text { Tätigkeiten füht die } \\
\text { Gruppe "[Field-1]" } \\
\text { normalerweise gemeinsam } \\
\text { aus? - Gruppe } 3 \text { - Welche } \\
\text { Tätigkeiten führt die } \\
\text { Gruppe "[Field-1]" } \\
\text { normalerweise gemeinsam } \\
\text { aus? - Selected Choice - } \\
\text { Andere }\end{array}$ & & $\begin{array}{l}\text { What activities does the } \\
\text { group "< } \\
\text { usually do toupnamether? - } \\
\text { Group } 3 \text { - Selected } \\
\text { Choice - Other }\end{array}$ & & $\mathrm{x}$ & $\mathrm{x}$ & $\mathrm{x}$ & $\mathrm{x}$ & $\mathrm{x}$ & $\mathrm{x}$ & $\mathrm{x}$ & $\mathrm{x}$ & $\mathrm{x}$ & $\mathrm{x}$ \\
\hline group.3.activity. 8 & & $\begin{array}{l}\text { 4_Q10.5_8 - Welche } \\
\text { Tätigkeiten füht die } \\
\text { Gruppe "[Field-1]" } \\
\text { normalerweise gemeinsam } \\
\text { aus? - Gruppe } 3 \text { - Welche } \\
\text { Tätigkeiten führt die } \\
\text { Gruppe "[Field-1]" } \\
\text { normalerweise gemeinsam } \\
\text { aus? - Selected Choice - } \\
\text { Kultur }\end{array}$ & & $\begin{array}{l}\text { What activities does the } \\
\text { group "< } \\
\text { usually do tognether? - } \\
\text { Group } 3 \text { - Selected } \\
\text { Choice - cultural } \\
\text { activities }\end{array}$ & & $\mathrm{x}$ & $\mathrm{x}$ & $\mathrm{x}$ & $\mathrm{x}$ & $\mathrm{x}$ & $\mathrm{x}$ & $\mathrm{x}$ & $\mathrm{x}$ & $\mathrm{x}$ & $\mathrm{x}$ \\
\hline
\end{tabular}




\begin{tabular}{|c|c|c|c|c|c|c|c|c|c|c|c|c|c|c|c|}
\hline VarName & VariableLabel & WordingDE & ValueLabelsDE_Linked & WordingEN & ValueLabelsEN_Linked & L1 & $\mathrm{L} 2$ & L3 & $\mathrm{L} 4$ & L5 & L6 & L7 & L8 & L9 & L10 L11 L12 \\
\hline group.3.activity. 9 & & $\begin{array}{l}\text { 4_Q10.5_10-Welche } \\
\text { Tätigkeiten führt die } \\
\text { Gruppe "[Field-1]" } \\
\text { normalerweise gemeinsam } \\
\text { aus? - Gruppe } 3 \text { - Welche } \\
\text { Tätigkeiten führt die } \\
\text { Gruppe "[Field-1]" } \\
\text { normalerweise gemeinsam } \\
\text { aus? - Selected Choice - } \\
\text { über politische Themen } \\
\text { sprechen }\end{array}$ & & $\begin{array}{l}\text { What activities does the } \\
\text { group "< } \\
\text { usually do toupname }>\text { " } \\
\text { Group } 3 \text { - Selected } \\
\text { Choice - discussing } \\
\text { politics }\end{array}$ & & $\mathrm{x}$ & $\mathrm{x}$ & $\mathrm{x}$ & $\mathrm{x}$ & $\mathrm{x}$ & $\mathrm{x}$ & $\mathrm{x}$ & $\mathrm{x}$ & $\mathrm{x}$ & $\mathrm{x}$ \\
\hline group.3.activity.7.str & & $\begin{array}{l}\text { 4_Q10.5_7_TEXT - } \\
\text { Welche Tätigkeiten führt } \\
\text { die Gruppe "[Field-1]" } \\
\text { normalerweise gemeinsam } \\
\text { aus? - Gruppe } 3 \text { - Andere - } \\
\text { Text }\end{array}$ & & $\begin{array}{l}\text { TEXT_What activities } \\
\text { does the group } \\
\text { "<groupname > usually } \\
\text { do together? - Group } 3 \text { - } \\
\text { Other - text }\end{array}$ & & $\mathrm{x}$ & $\mathrm{x}$ & $\mathrm{x}$ & $\mathrm{x}$ & $\mathrm{x}$ & $\mathrm{x}$ & $\mathrm{x}$ & $\mathrm{x}$ & $\mathrm{x}$ & $\mathrm{x}$ \\
\hline group.3.freq & & $\begin{array}{l}\text { 4_Q10.6 - Gruppe } 3 \text { - } \\
\text { Wieoft trifft sich diese } \\
\text { Gruppe "[Field-1]" } \\
\text { normalerweise für } \\
\text { gemeinsame Aktivitäten? }\end{array}$ & $\begin{array}{l}1=\text { zwei oder dreimal pro } \\
\text { Woche, } 2=\text { einmal pro } \\
\text { Woche, } 3=\text { jede zweite } \\
\text { Woche, } 4=\text { einmal pro } \\
\text { Monat, } 5=\text { weniger als } \\
\text { einmal pro Monat, } 6=\text { fast } \\
\text { jeden Tag }\end{array}$ & $\begin{array}{l}\text { How often does this } \\
\text { group typically meet for } \\
\text { some joint activity? - } \\
\text { Group } 3\end{array}$ & $\begin{array}{l}1=\text { two or three times } \\
\text { per week, } 2=\text { one time } \\
\text { per week, } 3=\text { every } \\
\text { second week, } 4=\text { once per } \\
\text { month, } 5=\text { less than once } \\
\text { per month, } 6=\text { almost } \\
\text { every day }\end{array}$ & $\mathrm{x}$ & $\mathrm{x}$ & $\mathrm{x}$ & $\mathrm{x}$ & $\mathrm{x}$ & $\mathrm{x}$ & $\mathrm{x}$ & $\mathrm{x}$ & $\mathrm{x}$ & $\mathrm{x}$ \\
\hline group.3.pleasant & & $\begin{array}{l}\text { 4_Q10.7_1 - Wie } \\
\text { empfindest Du persönlich } \\
\text { typischerweiseTreffen mit } \\
\text { dieser Gruppe "[Field-1]"? - } \\
\text { Gruppe } 3 \text { - sehr } \\
\text { unangenehm:sehr angenehm }\end{array}$ & $\begin{array}{l}0=7 \text {-Punkte Skala, sehr } \\
\text { angenehm bis sehr } \\
\text { unangenehm, } 1=7 \text {-Punkte } \\
\text { Skala, sehr angenehm bis sehr } \\
\text { unangenehm, } 2=7 \text {-Punkte } \\
\text { Skala, sehr angenehm bis sehr } \\
\text { unangenehm, } 3=7 \text {-Punkte } \\
\text { Skala, sehr angenehm bis sehr } \\
\text { unangenehm, } 4=7 \text {-Punkte } \\
\text { Skala, sehr angenehm bis sehr } \\
\text { unangenehm, } 5=7 \text {-Punkte } \\
\text { Skala, sehr angenehm bis sehr } \\
\text { unangenehm, } 6=7 \text {-Punkte } \\
\text { Skala, sehr angenehm bis sehr } \\
\text { unangenehm }\end{array}$ & $\begin{array}{l}\text { How would you } \\
\text { characterize your typical } \\
\text { personal experience } \\
\text { when meeting with this } \\
\text { group? - Group } 3 \text { - very } \\
\text { pleasant : very } \\
\text { unpleasant }\end{array}$ & $\begin{array}{l}0=7 \text { point scale, very } \\
\text { pleasant to very } \\
\text { unpleasant, } 1=7 \text { point } \\
\text { scale, very pleasant to } \\
\text { very unpleasant, } 2=7 \\
\text { point scale, very pleasant } \\
\text { to very unpleasant, } 3=7 \\
\text { point scale, very pleasant } \\
\text { to very unpleasant, } 4=7 \\
\text { point scale, very pleasant } \\
\text { to very unpleasant, } 5=7 \\
\text { point scale, very pleasant } \\
\text { to very unpleasant, } 6=7 \\
\text { point scale, very pleasant } \\
\text { to very unpleasant }\end{array}$ & $\mathrm{x}$ & $\mathrm{x}$ & $\mathrm{x}$ & $\mathrm{x}$ & $\mathrm{x}$ & $\mathrm{x}$ & $\mathrm{x}$ & $\mathrm{x}$ & $\mathrm{x}$ & $\mathrm{x}$ \\
\hline group.3.energetic & & $\begin{array}{l}\text { 4_Q10.7_2 - Wie } \\
\text { empfindest Du persönlich } \\
\text { typischerweiseTreffen mit } \\
\text { dieser Gruppe "[Field-1]"? - } \\
\text { Gruppe } 3 \text { - sehr ruhig:sehr } \\
\text { energiegeladen }\end{array}$ & $\begin{array}{l}0=7 \text {-Punkte Skala, sehr } \\
\text { ruhig bis sehr energiegeladen, } \\
1=7 \text {-Punkte Skala, sehr } \\
\text { ruhig bis sehr energiegeladen, } \\
2=7 \text {-Punkte Skala, sehr } \\
\text { ruhig bis sehr energiegeladen, } \\
3=7 \text {-Punkte Skala, sehr } \\
\text { ruhig bis sehr energiegeladen, } \\
4=7 \text {-Punkte Skala, sehr } \\
\text { ruhig bis sehr energiegeladen, } \\
5=7 \text {-Punkte Skala, sehr } \\
\text { ruhig bis sehr energiegeladen, } \\
6=7 \text {-Punkte Skala, sehr } \\
\text { ruhig bis sehr energiegeladen }\end{array}$ & $\begin{array}{l}\text { How would you } \\
\text { characterize your typical } \\
\text { personal experience } \\
\text { when meeting with this } \\
\text { group? - Group } 3 \text { - very } \\
\text { quiet : very energetic }\end{array}$ & $\begin{array}{l}0=7 \text { point scale, very } \\
\text { quiet to very energetic, } 1 \\
=7 \text { point scale, very quiet } \\
\text { to very energetic, } 2=7 \\
\text { point scale, very quiet to } \\
\text { very energetic, } 3=7 \\
\text { point scale, very quiet to } \\
\text { very energetic, } 4=7 \\
\text { point scale, very quiet to } \\
\text { very energetic, } 5=7 \\
\text { point scale, very quiet to } \\
\text { very energetic, } 6=7 \\
\text { point scale, very quiet to } \\
\text { very energetic }\end{array}$ & $\mathrm{x}$ & $\mathrm{x}$ & $\mathrm{x}$ & $\mathrm{x}$ & $\mathrm{x}$ & $\mathrm{x}$ & $\mathrm{x}$ & $\mathrm{x}$ & $\mathrm{x}$ & $\mathrm{x}$ \\
\hline
\end{tabular}




\begin{tabular}{|c|c|c|c|c|c|c|c|c|c|c|c|c|c|c|c|}
\hline VarName & VariableLabel & WordingDE & ValueLabelsDE_Linked & WordingEN & ValueLabelsEN_Linked & L1 & $\mathrm{L} 2$ & L3 & $\mathrm{L} 4$ & L5 & $\mathrm{L} 6$ & L7 & L8 & L9 & L10 L11 L12 \\
\hline group.3.personal & & $\begin{array}{l}\text { 4_Q10.7_3 - Wie } \\
\text { empfindest Du persönlich } \\
\text { typischerweiseTreffen mit } \\
\text { dieser Gruppe "[Field-1]"? - } \\
\text { Gruppe } 3 \text { - sehr } \\
\text { oberflächlich:sehr persönlich }\end{array}$ & $\begin{array}{l}0=7 \text {-Punkte Skala, sehr } \\
\text { oberfl̈̈chlich bis sehr } \\
\text { persönlich, } 1=7 \text {-Punkte } \\
\text { Skala, sehr oberflächlich bis } \\
\text { sehr persönlich, } 2=7 \text {-Punkte } \\
\text { Skala, sehr oberflächlich bis } \\
\text { sehr persönlich, } 3=7 \text {-Punkte } \\
\text { Skala, sehr oberflächlich bis } \\
\text { sehr persönlich, } 4=7 \text {-Punkte } \\
\text { Skala, sehr oberflächlich bis } \\
\text { sehr persönlich, } 5=7 \text {-Punkte } \\
\text { Skala, sehr oberfächlich bis } \\
\text { sehr persönlich, } 6=7 \text {-Punkte } \\
\text { Skala, sehr oberflächlich bis } \\
\text { sehr persönlich }\end{array}$ & $\begin{array}{l}\text { How would you } \\
\text { characterize your typical } \\
\text { personal experience } \\
\text { when meeting with this } \\
\text { group? - Group } 3 \text { - very } \\
\text { superficial : very } \\
\text { personal }\end{array}$ & $\begin{array}{l}0=7 \text { point scale, very } \\
\text { superficial to very } \\
\text { personal, } 1=7 \text { point } \\
\text { scale, very superficial to } \\
\text { very personal, } 2=7 \text { point } \\
\text { scale, very superficial to } \\
\text { very personal, } 3=7 \text { point } \\
\text { scale, very superficial to } \\
\text { very personal, } 4=7 \text { point } \\
\text { scale, very superficial to } \\
\text { very personal, } 5=7 \text { point } \\
\text { scale, very superficial to } \\
\text { very personal, } 6=7 \text { point } \\
\text { scale, very superficial to } \\
\text { very personal }\end{array}$ & $\mathrm{x}$ & $\mathrm{x}$ & $\mathrm{x}$ & $\mathrm{x}$ & $\mathrm{x}$ & $\mathrm{x}$ & $\mathrm{x}$ & $\mathrm{x}$ & $\mathrm{x}$ & $\mathrm{x}$ \\
\hline group.3.communication & & $\begin{array}{l}\text { 4_Q10.8 - Gruppe } 3 \text { - } \\
\text { Wieoft kommuniziert die } \\
\text { Gruppe "[Field-1]" online } \\
\text { (z.B. per Whatsapp-, } \\
\text { Facebook-Gruppenchat) } \\
\text { zusätzlich zu den Treffen? }\end{array}$ & $\begin{array}{l}1=\text { zwei oder dreimal pro } \\
\text { Woche, } 2=\text { einmal pro } \\
\text { Woche, } 3=\text { jede zweite } \\
\text { Woche, } 4=\text { einmal pro } \\
\text { Monat, } 5=\text { weniger als } \\
\text { einmal pro Jahr, } 6=\text { fast } \\
\text { jeden Tag, } 7=\text { nie, } 8=\text { zwei } \\
\text { oder dreimal pro Woche, } 9= \\
\text { einmal pro Woche, } 10=\text { jede } \\
\text { zweite Woche, } 11=\text { einmal } \\
\text { pro Monat, } 12=\text { weniger als } \\
\text { einmal pro Jahr }\end{array}$ & $\begin{array}{l}\text { How often does this } \\
\text { group communicate } \\
\text { online (e.g. via } \\
\text { WhatsApp, Facebook } \\
\text { Chat) in addition to the } \\
\text { meetings? - Group } 3\end{array}$ & $\begin{array}{l}1=\text { second or three time } \\
\text { per week, } 2=\text { once per } \\
\text { week, } 3=\text { every second } \\
\text { week, } 4=\text { once per } \\
\text { month, } 5=\text { less than once } \\
\text { per month, } 6=\text { almost } \\
\text { every day, } 7=\text { never, } 8= \\
\text { second or three time per } \\
\text { week, } 9=\text { once per week, } \\
10=\text { every second week, } \\
11=\text { once per month, } 12 \\
=\text { less than once per } \\
\text { month }\end{array}$ & $\mathrm{x}$ & $\mathrm{x}$ & $\mathrm{x}$ & $\mathrm{x}$ & $\mathrm{x}$ & $\mathrm{x}$ & $\mathrm{x}$ & $\mathrm{x}$ & $\mathrm{x}$ & $\mathrm{x}$ \\
\hline group.3.identification & & $\begin{array}{l}\text { 4_Q10.9 - Gruppe } 3 \text { - Wir } \\
\text { zeigen Dir jeweils zwei } \\
\text { Kreise, vondenen } \\
\text { repräsentiert der eine Dich } \\
\text { (blau) und der andere eine } \\
\text { bestimmte Gruppe(rot). } \\
\text { Bitte wähle immer das Bild } \\
\text { mit den zwei Kreisen, von } \\
\text { dem Du denkst, } \\
\text { esrepräsentiere Dein eigenes } \\
\text { Level an Identifikation mit } \\
\text { dieser Gruppe am } \\
\text { Besten.Wie } \\
\text { starkidentifizierst Du Dich } \\
\text { mit der der Gruppe } \\
\text { "[Field-1]"? }\end{array}$ & & $\begin{array}{l}\text { Group } 3 \text { - We will } \\
\text { present you two circles, } \\
\text { of which one represents } \\
\text { you (blue) and the other } \\
\text { represents a certain } \\
\text { group (red). Please } \\
\text { choose the picture which } \\
\text { you think best } \\
\text { represents your own } \\
\text { level of identification } \\
\text { with this group. How } \\
\text { strongly do you identify } \\
\text { with this group? }\end{array}$ & & $\mathrm{x}$ & $\mathrm{x}$ & $\mathrm{x}$ & $\mathrm{x}$ & $\mathrm{x}$ & $\mathrm{x}$ & $\mathrm{x}$ & $\mathrm{x}$ & $\mathrm{x}$ & $\mathrm{x}$ \\
\hline group.4.P1 & & $\begin{array}{l}\text { 5_Q10.2_1 - Welche Deiner } \\
\text { Mitstudierenden sind Teil } \\
\text { der Gruppe "[Field-1]"? } \\
\text { (die Anzahl von } \\
\text { Gruppenmitgliedern, die } \\
\text { nicht mit Dir studierendem } \\
\text { kann auf der nächsten Seite } \\
\text { genannt werden)Nenne } \\
\text { zwischen } 1 \text { und 20 Personen. } \\
\text { - Gruppe } 4 \text { - Name } 1\end{array}$ & & $\begin{array}{l}\text { Whom among your } \\
\text { fellow students is part of } \\
\text { the group } \\
\text { "< } \\
\text { numbeupname }>\text { ? (the } \\
\text { members whoup are not } \\
\text { fellow students can be } \\
\text { reported on the next } \\
\text { page). Name between } 0 \\
\text { and } 20 \text { people. - Group } \\
4-\text { Name } 1\end{array}$ & & $\mathrm{x}$ & $\mathrm{x}$ & $\mathrm{x}$ & $\mathrm{x}$ & $\mathrm{x}$ & $\mathrm{x}$ & $\mathrm{x}$ & $\mathrm{x}$ & $\mathrm{x}$ & $\mathrm{x}$ \\
\hline group.4.other & & $\begin{array}{l}\text { 5_Q10.4 - Gibt es noch } \\
\text { weitere Mitglieder dieser } \\
\text { Gruppe, welche nicht mit } \\
\text { Dir studieren? - Gruppe } 4 \text { - } \\
\text { Gibt es noch weitere } \\
\text { Mitglieder dieser Gruppe, } \\
\text { welche nicht mit Dir } \\
\text { studieren? - Selected Choice }\end{array}$ & $\begin{array}{l}1=\text { Wenn ja, wieviele sind } \\
\text { dies?, } 2=\text { Nein }\end{array}$ & $\begin{array}{l}\text { Are there further } \\
\text { members in who do not } \\
\text { study with you? - } \\
\text { Group } 4\end{array}$ & $\begin{array}{l}1=\text { If yes, how many?, } 2 \\
=\text { No }\end{array}$ & $\mathrm{x}$ & $\mathrm{x}$ & $\mathrm{x}$ & $\mathrm{x}$ & $\mathrm{x}$ & $\mathrm{x}$ & $\mathrm{x}$ & $\mathrm{x}$ & $\mathrm{x}$ & $\mathrm{x}$ \\
\hline
\end{tabular}




\begin{tabular}{|c|c|c|c|c|c|c|c|c|c|c|c|c|c|c|c|}
\hline VarName & VariableLabel & WordingDE & ValueLabelsDE_Linked & WordingEN & ValueLabelsEN_Linked & $\mathrm{L} 1$ & $\mathrm{~L} 2$ & L3 & $\mathrm{L} 4$ & L5 & L6 & L7 & L8 & L9 & L10 L11 L12 \\
\hline group.4.other.number & & $\begin{array}{l}\text { 5_Q10.4_1_TEXT - Gibt } \\
\text { es noch weitere Mitglieder } \\
\text { dieser Gruppe, welche nicht } \\
\text { mit Dir studieren? - } \\
\text { Gruppe 4 - Wenn ja, } \\
\text { wieviele sind dies? - Text }\end{array}$ & & $\begin{array}{l}\text { How many other people } \\
\text { NOT from your cohort } \\
\text { are part of this group? - } \\
\text { Group } 4\end{array}$ & & $\mathrm{x}$ & $\mathrm{x}$ & $\mathrm{x}$ & $\mathrm{x}$ & $\mathrm{x}$ & $\mathrm{x}$ & $\mathrm{x}$ & $\mathrm{x}$ & $\mathrm{x}$ & $\mathrm{x}$ \\
\hline group.4.activity.1 & & $\begin{array}{l}\text { 5_Q10.5_1 - Welche } \\
\text { Tätigkeiten führt die } \\
\text { Gruppe "[Field-1]" } \\
\text { normalerweise gemeinsam } \\
\text { aus? - Gruppe } 4 \text { - Welche } \\
\text { Tätigkeiten führt die } \\
\text { Gruppe "[Field-1]" } \\
\text { normalerweise gemeinsam } \\
\text { aus? - Selected Choice - } \\
\text { Lernen/Hausaufgaben }\end{array}$ & & $\begin{array}{l}\text { What activities does the } \\
\text { group "< groupname>" } \\
\text { usually do together? - } \\
\text { Group } 4 \text { - Selected } \\
\text { Choice - } \\
\text { studying/homework }\end{array}$ & & $\mathrm{x}$ & $\mathrm{x}$ & $\mathrm{x}$ & $\mathrm{x}$ & $\mathrm{x}$ & $\mathrm{x}$ & $\mathrm{x}$ & $\mathrm{x}$ & $\mathrm{x}$ & $\mathrm{x}$ \\
\hline group.4.activity.2 & & $\begin{array}{l}\text { 5_Q10.5_2 - Welche } \\
\text { Tätigkeiten führt die } \\
\text { Gruppe "[Field-1]" } \\
\text { normalerweise gemeinsam } \\
\text { aus? - Gruppe 4 - Welche } \\
\text { Tätigkeiten führt die } \\
\text { Gruppe "[Field-1]" } \\
\text { normalerweise gemeinsam } \\
\text { aus? - Selected Choice - } \\
\text { Arbeit }\end{array}$ & & $\begin{array}{l}\text { What activities does the } \\
\text { group "< groupname>" } \\
\text { usually do together? - } \\
\text { Group } 4 \text { - Selected } \\
\text { Choice - work }\end{array}$ & & $\mathrm{x}$ & $\mathrm{x}$ & $\mathrm{x}$ & $\mathrm{x}$ & $\mathrm{x}$ & $\mathrm{x}$ & $\mathrm{x}$ & $\mathrm{x}$ & $\mathrm{x}$ & $\mathrm{x}$ \\
\hline group.4.activity.3 & & $\begin{array}{l}\text { 5_Q10.5_3 - Welche } \\
\text { Tätigkeiten füht die } \\
\text { Gruppe "[Field-1]" } \\
\text { normalerweise gemeinsam } \\
\text { aus? - Gruppe } 4 \text { - Welche } \\
\text { Tätigkeiten führt die } \\
\text { Gruppe "[Field-1]" } \\
\text { normalerweise gemeinsam } \\
\text { aus? - Selected Choice - } \\
\text { Sport }\end{array}$ & & $\begin{array}{l}\text { What activities does the } \\
\text { group "< } \\
\text { usually do tognamether? - } \\
\text { Group } 4 \text { - Selected } \\
\text { Choice - sports }\end{array}$ & & $\mathrm{x}$ & $\mathrm{x}$ & $\mathrm{x}$ & $\mathrm{x}$ & $\mathrm{x}$ & $\mathrm{x}$ & $\mathrm{x}$ & $\mathrm{x}$ & $\mathrm{x}$ & $\mathrm{x}$ \\
\hline group.4.activity. 4 & & $\begin{array}{l}\text { 5_Q10.5_4 - Welche } \\
\text { Tätigkeiten führt die } \\
\text { Gruppe "[Field-1]" } \\
\text { normalerweise gemeinsam } \\
\text { aus? - Gruppe } 4 \text { - Welche } \\
\text { Tätigkeiten führt die } \\
\text { Gruppe "[Field-1]" } \\
\text { normalerweise gemeinsam } \\
\text { aus? - Selected Choice - } \\
\text { Gespräch }\end{array}$ & & $\begin{array}{l}\text { What activities does the } \\
\text { group "< } \\
\text { usually do tognether? }> \\
\text { Group } 4 \text { - Selected } \\
\text { Choice - conversation }\end{array}$ & & $\mathrm{x}$ & $\mathrm{x}$ & $\mathrm{x}$ & $\mathrm{x}$ & $\mathrm{x}$ & $\mathrm{x}$ & $\mathrm{x}$ & $\mathrm{x}$ & $\mathrm{x}$ & $\mathrm{x}$ \\
\hline group.4.activity.5 & & $\begin{array}{l}\text { 5_Q10.5_5 - Welche } \\
\text { Tätigkeiten führt die } \\
\text { Gruppe "[Field-1]" } \\
\text { normalerweise gemeinsam } \\
\text { aus? - Gruppe 4 - Welche } \\
\text { Tätigkeiten führt die } \\
\text { Gruppe "[Field-1]" } \\
\text { normalerweise gemeinsam } \\
\text { aus? - Selected Choice - } \\
\text { etwas trinken gehen ("eis go } \\
\text { zieh") }\end{array}$ & & $\begin{array}{l}\text { What activities does the } \\
\text { group "< } \\
\text { usually do to together? }> \\
\text { Group } 4 \text { - Selected } \\
\text { Choice - going for drinks }\end{array}$ & & $\mathrm{x}$ & $\mathrm{x}$ & $\mathrm{x}$ & $\mathrm{x}$ & $\mathrm{x}$ & $\mathrm{x}$ & $\mathrm{x}$ & $\mathrm{x}$ & $\mathrm{x}$ & $\mathrm{x}$ \\
\hline
\end{tabular}




\begin{tabular}{|c|c|c|c|c|c|c|c|c|c|c|c|c|c|c|c|}
\hline VarName & VariableLabel & WordingDE & ValueLabelsDE_Linked & WordingEN & ValueLabelsEN_Linked & L1 & $\mathrm{L} 2$ & L3 & L4 & L5 & L6 & L7 & L8 & L9 & L10 L11 L12 \\
\hline group.4.activity. 6 & & $\begin{array}{l}\text { 5_Q10.5_6 - Welche } \\
\text { Tätigkeiten führt die } \\
\text { Gruppe "[Field-1]" } \\
\text { normalerweise gemeinsam } \\
\text { aus? - Gruppe } 4 \text { - Welche } \\
\text { Tätigkeiten führt die } \\
\text { Gruppe "[Field-1]" } \\
\text { normalerweise gemeinsam } \\
\text { aus? - Selected Choice - } \\
\text { gemeinsamer Weg (z.B. zur } \\
\text { Universität) }\end{array}$ & & $\begin{array}{l}\text { What activities does the } \\
\text { group "< } \\
\text { usually do toupname }>\text { " } \\
\text { Group } 4 \text { - Selected } \\
\text { Choice - commute }\end{array}$ & & $\mathrm{x}$ & $\mathrm{x}$ & $\mathrm{x}$ & $\mathrm{x}$ & $\mathrm{x}$ & $\mathrm{x}$ & $\mathrm{x}$ & $\mathrm{x}$ & $\mathrm{x}$ & $\mathrm{x}$ \\
\hline group.4.activity. 7 & & $\begin{array}{l}\text { 5_Q10.5_7 - Welche } \\
\text { Tätigkeiten führt die } \\
\text { Gruppe "[Field-1]" } \\
\text { normalerweise gemeinsam } \\
\text { aus? - Gruppe } 4 \text { - Welche } \\
\text { Tätigkeiten führt die } \\
\text { Gruppe "[Field-1]" } \\
\text { normalerweise gemeinsam } \\
\text { aus? - Selected Choice - } \\
\text { Andere }\end{array}$ & & $\begin{array}{l}\text { What activities does the } \\
\text { group "< } \\
\text { usually do togetherere }>\text { - } \\
\text { Group } 4 \text { - Selected } \\
\text { Choice - Other }\end{array}$ & & $\mathrm{x}$ & $\mathrm{x}$ & $\mathrm{x}$ & $\mathrm{x}$ & $\mathrm{x}$ & $\mathrm{x}$ & $\mathrm{x}$ & $\mathrm{x}$ & $\mathrm{x}$ & $\mathrm{x}$ \\
\hline group.4.activity. 8 & & $\begin{array}{l}\text { 5_Q10.5_8 - Welche } \\
\text { Tätigkeiten führt die } \\
\text { Gruppe "[Field-1]" } \\
\text { normalerweise gemeinsam } \\
\text { aus? - Gruppe } 4 \text { - Welche } \\
\text { Tätigkeiten führt die } \\
\text { Gruppe "[Field-1]" } \\
\text { normalerweise gemeinsam } \\
\text { aus? - Selected Choice - } \\
\text { Kultur }\end{array}$ & & $\begin{array}{l}\text { What activities does the } \\
\text { group "< groupname>" } \\
\text { usually do together? - } \\
\text { Group } 4 \text { - Selected } \\
\text { Choice - cultural } \\
\text { activities }\end{array}$ & & $\mathrm{x}$ & $\mathrm{x}$ & $\mathrm{x}$ & $\mathrm{x}$ & $\mathrm{x}$ & $\mathrm{x}$ & $\mathrm{x}$ & $\mathrm{x}$ & $\mathrm{x}$ & $\mathrm{x}$ \\
\hline group.4.activity.9 & & $\begin{array}{l}\text { 5_Q10.5_10 - Welche } \\
\text { Tätigkeiten führt die } \\
\text { Gruppe "[Field-1]" } \\
\text { normalerweise gemeinsam } \\
\text { aus? - Gruppe 4 - Welche } \\
\text { Tätigkeiten führt die } \\
\text { Gruppe "[Field-1]" } \\
\text { normalerweise gemeinsam } \\
\text { aus? - Selected Choice - } \\
\text { über politische Themen } \\
\text { sprechen }\end{array}$ & & $\begin{array}{l}\text { What activities does the } \\
\text { group "<groupname>" } \\
\text { usually do together? - } \\
\text { Group } 4 \text { - Selected } \\
\text { Choice - discussing } \\
\text { politics }\end{array}$ & & $\mathrm{x}$ & $\mathrm{x}$ & $\mathrm{x}$ & $\mathrm{x}$ & $\mathrm{x}$ & $\mathrm{x}$ & $\mathrm{x}$ & $\mathrm{x}$ & $\mathrm{x}$ & $\mathrm{x}$ \\
\hline group.4.activity.7.str & & $\begin{array}{l}\text { 5_Q10.5_7_TEXT - } \\
\text { Welche Tätigkeiten führt } \\
\text { die Gruppe "[Field-1]" } \\
\text { normalerweise gemeinsam } \\
\text { aus? - Gruppe } 4 \text { - Andere - } \\
\text { Text }\end{array}$ & & $\begin{array}{l}\text { TEXT_What activities } \\
\text { does the group } \\
\text { "< groupname }>\text { usually } \\
\text { do together? - Group } 4 \text { - } \\
\text { Other - text }\end{array}$ & & $\mathrm{x}$ & $\mathrm{x}$ & $\mathrm{x}$ & $\mathrm{x}$ & $\mathrm{x}$ & $\mathrm{x}$ & $\mathrm{x}$ & $\mathrm{x}$ & $\mathrm{x}$ & $\mathrm{x}$ \\
\hline group.4.freq & & $\begin{array}{l}\text { 5_Q10.6 - Gruppe } 4 \text { - } \\
\text { Wieoft trifft sich diese } \\
\text { Gruppe "[Field-1]" } \\
\text { normalerweise für } \\
\text { gemeinsame Aktivitäten? }\end{array}$ & $\begin{array}{l}1=\text { zwei oder dreimal pro } \\
\text { Woche, } 2=\text { einmal pro } \\
\text { Woche, } 3=\text { jede zweite } \\
\text { Woche, } 4=\text { einmal pro } \\
\text { Monat, } 5=\text { weniger als } \\
\text { einmal pro Monat, } 6=\text { fast } \\
\text { jeden Tag }\end{array}$ & $\begin{array}{l}\text { How often does this } \\
\text { group typically meet for } \\
\text { some joint activity? - } \\
\text { Group } 4\end{array}$ & $\begin{array}{l}1=\text { two or three times } \\
\text { per week, } 2=\text { one time } \\
\text { per week, } 3=\text { every } \\
\text { second week, } 4=\text { once per } \\
\text { month, } 5=\text { less than once } \\
\text { per month, } 6=\text { almost } \\
\text { every day }\end{array}$ & $\mathrm{x}$ & $\mathrm{x}$ & $\mathrm{x}$ & $\mathrm{x}$ & $\mathrm{x}$ & $\mathrm{x}$ & $\mathrm{x}$ & $\mathrm{x}$ & $\mathrm{x}$ & $\mathrm{x}$ \\
\hline
\end{tabular}




\begin{tabular}{|c|c|c|c|c|c|c|c|c|c|c|c|c|c|c|c|}
\hline VarName & VariableLabel & WordingDE & ValueLabelsDE_Linked & WordingEN & ValueLabelsEN_Linked & L1 & $\mathrm{L} 2$ & L3 & $\mathrm{L} 4$ & L5 & L6 & L7 & L8 & L9 & L10 L11 L12 \\
\hline group.4.pleasant & & $\begin{array}{l}\text { 5_Q10.7_1 - Wie } \\
\text { empfindest Du persönlich } \\
\text { typischerweiseTreffen mit } \\
\text { dieser Gruppe "[Field-1]"? - } \\
\text { Gruppe 4 - sehr } \\
\text { unangenehm:sehr angenehm }\end{array}$ & $\begin{array}{l}0=7 \text {-Punkte Skala, sehr } \\
\text { angenehm bis sehr } \\
\text { unangenehm, } 1=7 \text {-Punkte } \\
\text { Skala, sehr angenehm bis sehr } \\
\text { unangenehm, } 2=7 \text {-Punkte } \\
\text { Skala, sehr angenehm bis sehr } \\
\text { unangenehm, } 3=7 \text {-Punkte } \\
\text { Skala, sehr angenehm bis sehr } \\
\text { unangenehm, } 4=7 \text {-Punkte } \\
\text { Skala, sehr angenehm bis sehr } \\
\text { unangenehm, } 5=7 \text {-Punkte } \\
\text { Skala, sehr angenehm bis sehr } \\
\text { unangenehm, } 6=7 \text {-Punkte } \\
\text { Skala, sehr angenehm bis sehr } \\
\text { unangenehm }\end{array}$ & $\begin{array}{l}\text { How would you } \\
\text { characterize your typical } \\
\text { personal experience } \\
\text { when meeting with this } \\
\text { group? - Group } 4 \text { - very } \\
\text { pleasant : very } \\
\text { unpleasant }\end{array}$ & $\begin{array}{l}0=7 \text { point scale, very } \\
\text { pleasant to very } \\
\text { unpleasant, } 1=7 \text { point } \\
\text { scale, very pleasant to } \\
\text { very unpleasant, } 2=7 \\
\text { point scale, very pleasant } \\
\text { to very unpleasant, } 3=7 \\
\text { point scale, very pleasant } \\
\text { to very unpleasant, } 4=7 \\
\text { point scale, very pleasant } \\
\text { to very unpleasant, } 5=7 \\
\text { point scale, very pleasant } \\
\text { to very unpleasant, } 6=7 \\
\text { point scale, very pleasant } \\
\text { to very unpleasant }\end{array}$ & $\mathrm{x}$ & $\mathrm{x}$ & $\mathrm{x}$ & $\mathrm{x}$ & $\mathrm{x}$ & $\mathrm{x}$ & $\mathrm{x}$ & $\mathrm{x}$ & $\mathrm{x}$ & $\mathrm{x}$ \\
\hline group.4.energetic & & $\begin{array}{l}\text { 5_Q10.7_2 - Wie } \\
\text { empfindest Du persönlich } \\
\text { typischerweiseTreffen mit } \\
\text { dieser Gruppe "[Field-1]"? - } \\
\text { Gruppe 4 - sehr ruhig:sehr } \\
\text { energiegeladen }\end{array}$ & $\begin{array}{l}0=7 \text {-Punkte Skala, sehr } \\
\text { ruhig bis sehr energiegeladen, } \\
1=7 \text {-Punkte Skala, sehr } \\
\text { ruhig bis sehr energiegeladen, } \\
2=7 \text {-Punkte Skala, sehr } \\
\text { ruhig bis sehr energiegeladen, } \\
3=7 \text {-Punkte Skala, sehr } \\
\text { ruhig bis sehr energiegeladen, } \\
4=7 \text {-Punkte Skala, sehr } \\
\text { ruhig bis sehr energiegeladen, } \\
5=7 \text {-Punkte Skala, sehr } \\
\text { ruhig bis sehr energiegeladen, } \\
6=7 \text {-Punkte Skala, sehr } \\
\text { ruhig bis sehr energiegeladen }\end{array}$ & $\begin{array}{l}\text { How would you } \\
\text { characterize your typical } \\
\text { personal experience } \\
\text { when meeting with this } \\
\text { group? - Group } 4 \text { - very } \\
\text { quiet : very energetic }\end{array}$ & $\begin{array}{l}0=7 \text { point scale, very } \\
\text { quiet to very energetic, } 1 \\
=7 \text { point scale, very quiet } \\
\text { to very energetic, } 2=7 \\
\text { point scale, very quiet to } \\
\text { very energetic, } 3=7 \\
\text { point scale, very quiet to } \\
\text { very energetic, } 4=7 \\
\text { point scale, very quiet to } \\
\text { very energetic, } 5=7 \\
\text { point scale, very quiet to } \\
\text { very energetic, } 6=7 \\
\text { point scale, very quiet to } \\
\text { very energetic }\end{array}$ & $\mathrm{x}$ & $\mathrm{x}$ & $\mathrm{x}$ & $\mathrm{x}$ & $\mathrm{x}$ & $\mathrm{x}$ & $\mathrm{x}$ & $\mathrm{x}$ & $\mathrm{x}$ & $\mathrm{x}$ \\
\hline group.4.personal & & $\begin{array}{l}\text { 5_Q10.7_3 - Wie } \\
\text { empfindest Du persönlich } \\
\text { typischerweiseTreffen mit } \\
\text { dieser Gruppe "[Field-1]"? - } \\
\text { Gruppe } 4 \text { - sehr } \\
\text { oberflächlich:sehr persönlich }\end{array}$ & $\begin{array}{l}0=7 \text {-Punkte Skala, sehr } \\
\text { oberfächlich bis sehr } \\
\text { persönlich, } 1=7 \text {-Punkte } \\
\text { Skala, sehr oberfächlich bis } \\
\text { sehr persönlich, } 2=7 \text {-Punkte } \\
\text { Skala, sehr oberflächlich bis } \\
\text { sehr persönlich, } 3=7 \text {-Punkte } \\
\text { Skala, sehr oberflächlich bis } \\
\text { sehr persönlich, } 4=7 \text {-Punkte } \\
\text { Skala, sehr oberflächlich bis } \\
\text { sehr persönlich, } 5=7 \text {-Punkte } \\
\text { Skala, sehr oberflächlich bis } \\
\text { sehr persönlich, } 6=7 \text {-Punkte } \\
\text { Skala, sehr oberflächlich bis } \\
\text { sehr persönlich }\end{array}$ & $\begin{array}{l}\text { How would you } \\
\text { characterize your typical } \\
\text { personal experience } \\
\text { when meeting with this } \\
\text { group? - Group } 4 \text { - very } \\
\text { superficial : very } \\
\text { personal }\end{array}$ & $\begin{array}{l}0=7 \text { point scale, very } \\
\text { superficial to very } \\
\text { personal, } 1=7 \text { point } \\
\text { scale, very superficial to } \\
\text { very personal, } 2=7 \text { point } \\
\text { scale, very superficial to } \\
\text { very personal, } 3=7 \text { point } \\
\text { scale, very superficial to } \\
\text { very personal, } 4=7 \text { point } \\
\text { scale, very superficial to } \\
\text { very personal, } 5=7 \text { point } \\
\text { scale, very superficial to } \\
\text { very personal, } 6=7 \text { point } \\
\text { scale, very superficial to } \\
\text { very personal }\end{array}$ & $\mathrm{x}$ & $\mathrm{x}$ & $\mathrm{x}$ & $\mathrm{x}$ & $\mathrm{x}$ & $\mathrm{x}$ & $\mathrm{x}$ & $\mathrm{x}$ & $\mathrm{x}$ & $\mathrm{x}$ \\
\hline group.4.communication & & $\begin{array}{l}\text { 5_Q10.8 - Gruppe } 4 \text { - } \\
\text { Wieoft kommuniziert die } \\
\text { Gruppe "[Field-1]" online } \\
\text { (z.B. per Whatsapp-, } \\
\text { Facebook-Gruppenchat) } \\
\text { zusätzlich zu den Treffen? }\end{array}$ & $\begin{array}{l}1=\text { zwei oder dreimal pro } \\
\text { Woche, } 2=\text { einmal pro } \\
\text { Woche, } 3=\text { jede zweite } \\
\text { Woche, } 4=\text { einmal pro } \\
\text { Monat, } 5=\text { weniger als } \\
\text { einmal pro Jahr, } 6=\text { fast } \\
\text { jeden Tag, } 7=\text { nie, } 8=\text { zwei } \\
\text { oder dreimal pro Woche, } 9= \\
\text { einmal pro Woche, } 10=\text { jede } \\
\text { zweite Woche, } 11=\text { einmal } \\
\text { pro Monat, } 12=\text { weniger als } \\
\text { einmal pro Jahr }\end{array}$ & $\begin{array}{l}\text { How often does this } \\
\text { group communicate } \\
\text { online (e.g. via } \\
\text { WhatsApp, Facebook } \\
\text { Chat) in addition to the } \\
\text { meetings? - Group } 4\end{array}$ & $\begin{array}{l}1=\text { second or three time } \\
\text { per week, } 2=\text { once per } \\
\text { week, } 3=\text { every second } \\
\text { week, } 4=\text { once per } \\
\text { month, } 5=\text { less than once } \\
\text { per month, } 6=\text { almost } \\
\text { every day, } 7=\text { never, } 8= \\
\text { second or three time per } \\
\text { week, } 9=\text { once per week, } \\
10=\text { every second week, } \\
11=\text { once per month, } 12 \\
=\text { less than once per } \\
\text { month }\end{array}$ & $\mathrm{x}$ & $\mathrm{x}$ & $\mathrm{x}$ & $\mathrm{x}$ & $\mathrm{x}$ & $\mathrm{x}$ & $\mathrm{x}$ & $\mathrm{x}$ & $\mathrm{x}$ & $\mathrm{x}$ \\
\hline
\end{tabular}




\begin{tabular}{|c|c|c|c|c|c|c|c|c|c|c|c|c|c|c|c|}
\hline VarName & VariableLabel & WordingDE & ValueLabelsDE_Linked & WordingEN & ValueLabelsEN_Linked & $\mathrm{L} 1$ & L2 & L3 & $\mathrm{L} 4$ & L5 & L6 & L7 & L8 & L9 & L10 L11 L12 \\
\hline group.4.identification & & $\begin{array}{l}\text { 5_Q10.9 - Gruppe 4 - Wir } \\
\text { zeigen Dir jeweils zwei } \\
\text { Kreise, vondenen } \\
\text { repräsentiert der eine Dich } \\
\text { (blau) und der andere eine } \\
\text { bestimmte Gruppe(rot). } \\
\text { Bitte wähle immer das Bild } \\
\text { mit den zwei Kreisen, von } \\
\text { dem Du denkst, } \\
\text { esrepräsentiere Dein eigenes } \\
\text { Level an Identifikation mit } \\
\text { dieser Gruppe am } \\
\text { Besten.Wie } \\
\text { starkidentifizierst Du Dich } \\
\text { mit der der Gruppe } \\
\text { "[Field-1]"? }\end{array}$ & & $\begin{array}{l}\text { Group } 4 \text { - We will } \\
\text { present you two circles, } \\
\text { of which one represents } \\
\text { you (blue) and the other } \\
\text { represents a certain } \\
\text { group (red). Please } \\
\text { choose the picture which } \\
\text { you think best } \\
\text { represents your own } \\
\text { level of identification } \\
\text { with this group. How } \\
\text { strongly do you identify } \\
\text { with this group? }\end{array}$ & & $\mathrm{x}$ & $\mathrm{x}$ & $\mathrm{x}$ & $\mathrm{x}$ & $\mathrm{x}$ & $\mathrm{x}$ & $\mathrm{x}$ & $\mathrm{x}$ & $\mathrm{x}$ & $\mathrm{x}$ \\
\hline group.5.P1 & & $\begin{array}{l}\text { 6_Q10.2_1 - Welche Deiner } \\
\text { Mitstudierenden sind Teil } \\
\text { der Gruppe "[Field-1]"? } \\
\text { (die Anzahl von } \\
\text { Gruppenmitgliedern, die } \\
\text { nicht mit Dir studierendem } \\
\text { kann auf der nächsten Seite } \\
\text { genannt werden)Nenne } \\
\text { zwischen } 11 \text { und } 20 \text { Personen. } \\
\text { - Gruppe } 5 \text { - Name } 1\end{array}$ & & $\begin{array}{l}\text { Whom among your } \\
\text { fellow students is part of } \\
\text { the group } \\
\text { "< } \\
\text { numbupname }>\text { "? (the } \\
\text { members whoup are not } \\
\text { fellow students can be } \\
\text { reported on the next } \\
\text { page). Name between } 0 \\
\text { and } 20 \text { people. - Group } \\
5 \text { - Name } 1\end{array}$ & & $\mathrm{x}$ & $\mathrm{x}$ & $\mathrm{x}$ & $\mathrm{x}$ & $\mathrm{x}$ & $\mathrm{x}$ & $\mathrm{x}$ & $\mathrm{x}$ & $\mathrm{x}$ & $\mathrm{x}$ \\
\hline group.5.other & & $\begin{array}{l}\text { 6_Q10.4 - Gibt es noch } \\
\text { weitere Mitglieder dieser } \\
\text { Gruppe, welche nicht mit } \\
\text { Dir studieren? - Gruppe 5 - } \\
\text { Gibt es noch weitere } \\
\text { Mitglieder dieser Gruppe, } \\
\text { welche nicht mit Dir } \\
\text { studieren? - Selected Choice }\end{array}$ & $\begin{array}{l}1=\text { Wenn ja, wieviele sind } \\
\text { dies?, } 2=\text { Nein }\end{array}$ & $\begin{array}{l}\text { Are there further } \\
\text { members in who do not } \\
\text { study with you? - } \\
\text { Group } 1\end{array}$ & $\begin{array}{l}1=\text { If yes, how many?, } 2 \\
=\text { No }\end{array}$ & $\mathrm{x}$ & $\mathrm{x}$ & $\mathrm{x}$ & $\mathrm{x}$ & $\mathrm{x}$ & $\mathrm{x}$ & $\mathrm{x}$ & $\mathrm{x}$ & $\mathrm{x}$ & $\mathrm{x}$ \\
\hline group.5.other.number & & $\begin{array}{l}\text { 6_Q10.4_1_TEXT - Gibt } \\
\text { es noch weitere Mitglieder } \\
\text { dieser Gruppe, welche nicht } \\
\text { mit Dir studieren? - } \\
\text { Gruppe } 5 \text { - Wenn ja, } \\
\text { wieviele sind dies? - Text }\end{array}$ & & $\begin{array}{l}\text { How many other people } \\
\text { NOT from your cohort } \\
\text { are part of this group? - } \\
\text { Group } 1\end{array}$ & & $\mathrm{x}$ & $\mathrm{x}$ & $\mathrm{x}$ & $\mathrm{x}$ & $\mathrm{x}$ & $\mathrm{x}$ & $\mathrm{x}$ & $\mathrm{x}$ & $\mathrm{x}$ & $\mathrm{x}$ \\
\hline group.5.activity. 1 & & $\begin{array}{l}\text { 6_Q10.5_1 - Welche } \\
\text { Tätigkeiten führt die } \\
\text { Gruppe "[Field-1]" } \\
\text { normalerweise gemeinsam } \\
\text { aus? - Gruppe } 5 \text { - Welche } \\
\text { Tätigkeiten führt die } \\
\text { Gruppe "[Field-1]" } \\
\text { normalerweise gemeinsam } \\
\text { aus? - Selected Choice - } \\
\text { Lernen/Hausaufgaben }\end{array}$ & & $\begin{array}{l}\text { What activities does the } \\
\text { group "< groupname>" } \\
\text { usually do together? - } \\
\text { Group } 1 \text { - Selected } \\
\text { Choice - } \\
\text { studying/homework }\end{array}$ & & $\mathrm{x}$ & $\mathrm{x}$ & $\mathrm{x}$ & $\mathrm{x}$ & $\mathrm{x}$ & $\mathrm{x}$ & $\mathrm{x}$ & $\mathrm{x}$ & $\mathrm{x}$ & $\mathrm{x}$ \\
\hline group.5.activity.2 & & $\begin{array}{l}\text { 6_Q10.5_2 - Welche } \\
\text { Tätigkeiten führt die } \\
\text { Gruppe "[Field-1]" } \\
\text { normalerweise gemeinsam } \\
\text { aus? - Gruppe } 5 \text { - Welche } \\
\text { Tätigkeiten führt die } \\
\text { Gruppe "[Field-1]" } \\
\text { normalerweise gemeinsam } \\
\text { aus? - Selected Choice - } \\
\text { Arbeit }\end{array}$ & & $\begin{array}{l}\text { What activities does the } \\
\text { group "< } \\
\text { usually do togetherame }>\text { - } \\
\text { Group } 1 \text { - Selected } \\
\text { Choice - work }\end{array}$ & & $\mathrm{x}$ & $\mathrm{x}$ & $\mathrm{x}$ & $\mathrm{x}$ & $\mathrm{x}$ & $\mathrm{x}$ & $\mathrm{x}$ & $\mathrm{x}$ & $\mathrm{x}$ & $\mathrm{x}$ \\
\hline
\end{tabular}




\begin{tabular}{|c|c|c|c|c|c|c|c|c|c|c|c|c|c|c|c|}
\hline VarName & VariableLabel & WordingDE & ValueLabelsDE_Linked & WordingEN & ValueLabelsEN_Linked & $\mathrm{L} 1$ & $\mathrm{~L} 2$ & L3 & L4 & L5 & $\mathrm{L} 6$ & L7 & L8 & L9 & L10 L11 L12 \\
\hline group.5.activity.3 & & $\begin{array}{l}\text { 6_Q10.5_3 - Welche } \\
\text { Tätigkeiten führt die } \\
\text { Gruppe "[Field-1]" } \\
\text { normalerweise gemeinsam } \\
\text { aus? - Gruppe } 5 \text { - Welche } \\
\text { Tätigkeiten führt die } \\
\text { Gruppe "[Field-1]" } \\
\text { normalerweise gemeinsam } \\
\text { aus? - Selected Choice - } \\
\text { Sport }\end{array}$ & & $\begin{array}{l}\text { What activities does the } \\
\text { group "< } \\
\text { usually do togetherer? - } \\
\text { Group } 1 \text { - Selected } \\
\text { Choice - sports }\end{array}$ & & $\mathrm{x}$ & $\mathrm{x}$ & $\mathrm{x}$ & $\mathrm{x}$ & $\mathrm{x}$ & $\mathrm{x}$ & $\mathrm{x}$ & $\mathrm{x}$ & $\mathrm{x}$ & $\mathrm{x}$ \\
\hline group.5.activity.4 & & $\begin{array}{l}\text { 6_Q10.5_4 - Welche } \\
\text { Tätigkeiten führt die } \\
\text { Gruppe "[Field-1]" } \\
\text { normalerweise gemeinsam } \\
\text { aus? - Gruppe } 5 \text { - Welche } \\
\text { Tätigkeiten führt die } \\
\text { Gruppe "[Field-1]" } \\
\text { normalerweise gemeinsam } \\
\text { aus? - Selected Choice - } \\
\text { Gespräch }\end{array}$ & & $\begin{array}{l}\text { What activities does the } \\
\text { group "< groupname>" } \\
\text { usually do together? - } \\
\text { Group } 1 \text { - Selected } \\
\text { Choice - conversation }\end{array}$ & & $\mathrm{x}$ & $\mathrm{x}$ & $\mathrm{x}$ & $\mathrm{x}$ & $\mathrm{x}$ & $\mathrm{x}$ & $\mathrm{x}$ & $\mathrm{x}$ & $\mathrm{x}$ & $\mathrm{x}$ \\
\hline group.5.activity.5 & & $\begin{array}{l}\text { 6_Q10.5_5 - Welche } \\
\text { Tätigkeiten führt die } \\
\text { Gruppe "[Field-1]" } \\
\text { normalerweise gemeinsam } \\
\text { aus? - Gruppe } 5 \text { - Welche } \\
\text { Tätigkeiten führt die } \\
\text { Gruppe "[Field-1]" } \\
\text { normalerweise gemeinsam } \\
\text { aus? - Selected Choice - } \\
\text { etwas trinken gehen ("eis go } \\
\text { zieh") }\end{array}$ & & $\begin{array}{l}\text { What activities does the } \\
\text { group "< groupname>" } \\
\text { usually do together? - } \\
\text { Group } 1 \text { - Selected } \\
\text { Choice - going for drinks }\end{array}$ & & $\mathrm{x}$ & $\mathrm{x}$ & $\mathrm{x}$ & $\mathrm{x}$ & $\mathrm{x}$ & $\mathrm{x}$ & $\mathrm{x}$ & $\mathrm{x}$ & $\mathrm{x}$ & $\mathrm{x}$ \\
\hline group.5.activity.6 & & $\begin{array}{l}\text { 6_Q10.5_6 - Welche } \\
\text { Tätigkeiten führt die } \\
\text { Gruppe "[Field-1]" } \\
\text { normalerweise gemeinsam } \\
\text { aus? - Gruppe } 5 \text { - Welche } \\
\text { Tätigkeiten führt die } \\
\text { Gruppe "[Field-1]" } \\
\text { normalerweise gemeinsam } \\
\text { aus? - Selected Choice - } \\
\text { gemeinsamer Weg (z.B. zur } \\
\text { Universität) }\end{array}$ & & $\begin{array}{l}\text { What activities does the } \\
\text { group "< } \\
\text { usually do togetherer? - } \\
\text { Group } 1 \text { - Selected } \\
\text { Choice - commute }\end{array}$ & & $\mathrm{x}$ & $\mathrm{x}$ & $\mathrm{x}$ & $\mathrm{x}$ & $\mathrm{x}$ & $\mathrm{x}$ & $\mathrm{x}$ & $\mathrm{x}$ & $\mathrm{x}$ & $\mathrm{x}$ \\
\hline group.5.activity.7 & & $\begin{array}{l}\text { 6_Q10.5_7 - Welche } \\
\text { Tätigkeiten führt die } \\
\text { Gruppe "[Field-1]" } \\
\text { normalerweise gemeinsam } \\
\text { aus? - Gruppe } 5 \text { - Welche } \\
\text { Tätigkeiten führt die } \\
\text { Gruppe "[Field-1]" } \\
\text { normalerweise gemeinsam } \\
\text { aus? - Selected Choice - } \\
\text { Andere }\end{array}$ & & $\begin{array}{l}\text { What activities does the } \\
\text { group "< } \\
\text { usually do togetherer? - } \\
\text { Group } 1 \text { - Selected } \\
\text { Choice - Other }\end{array}$ & & $\mathrm{x}$ & $\mathrm{x}$ & $\mathrm{x}$ & $\mathrm{x}$ & $\mathrm{x}$ & $\mathrm{x}$ & $\mathrm{x}$ & $\mathrm{x}$ & $\mathrm{x}$ & $\mathrm{x}$ \\
\hline group.5.activity.8 & & $\begin{array}{l}\text { 6_Q10.5_8 - Welche } \\
\text { Tätigkeiten führt die } \\
\text { Gruppe "[Field-1]" } \\
\text { normalerweise gemeinsam } \\
\text { aus? - Gruppe } 5 \text { - Welche } \\
\text { Tätigkeiten führt die } \\
\text { Gruppe "[Field-1]" } \\
\text { normalerweise gemeinsam } \\
\text { aus? - Selected Choice - } \\
\text { Kultur }\end{array}$ & & $\begin{array}{l}\text { What activities does the } \\
\text { group "< groupname>" } \\
\text { usually do together? - } \\
\text { Group } 1 \text { - Selected } \\
\text { Choice - cultural } \\
\text { activities }\end{array}$ & & $\mathrm{x}$ & $\mathrm{x}$ & $\mathrm{x}$ & $\mathrm{x}$ & $\mathrm{x}$ & $\mathrm{x}$ & $\mathrm{x}$ & $\mathrm{x}$ & $\mathrm{x}$ & $\mathrm{x}$ \\
\hline
\end{tabular}




\begin{tabular}{|c|c|c|c|c|c|c|c|c|c|c|c|c|c|c|c|}
\hline VarName & VariableLabel & WordingDE & ValueLabelsDE_Linked & WordingEN & ValueLabelsEN_Linked & L1 & $\mathrm{L} 2$ & L3 & $\mathrm{L} 4$ & L5 & L6 6 & L7 & L8 & L9 & L10 L11 L12 \\
\hline group.5.activity. 9 & & $\begin{array}{l}\text { 6_Q10.5_10 - Welche } \\
\text { Tätigkeiten führt die } \\
\text { Gruppe "[Field-1]" } \\
\text { normalerweise gemeinsam } \\
\text { aus? - Gruppe } 5 \text { - Welche } \\
\text { Tätigkeiten führt die } \\
\text { Gruppe "[Field-1]" } \\
\text { normalerweise gemeinsam } \\
\text { aus? - Selected Choice - } \\
\text { über politische Themen } \\
\text { sprechen }\end{array}$ & & $\begin{array}{l}\text { What activities does the } \\
\text { group "< groupname>" } \\
\text { usually do together? - } \\
\text { Group } 1 \text { - Selected } \\
\text { Choice - discussing } \\
\text { politics }\end{array}$ & & $\mathrm{x}$ & $\mathrm{x}$ & $\mathrm{x}$ & $\mathrm{x}$ & $\mathrm{x}$ & $\mathrm{x}$ & $\mathrm{x}$ & $\mathrm{x}$ & $\mathrm{x}$ & $\mathrm{x}$ \\
\hline group.5.activity.7.str & & $\begin{array}{l}\text { 6_Q10.5_7_TEXT - } \\
\text { Welche Tätigkeiten führt } \\
\text { die Gruppe "[Field-1]" } \\
\text { normalerweise gemeinsam } \\
\text { aus? - Gruppe } 5 \text { - Andere - } \\
\text { Text }\end{array}$ & & $\begin{array}{l}\text { TEXT_What activities } \\
\text { does the group } \\
\text { "< } \\
\text { do toupname }>\text { " usually } \\
\text { Other - text - Group } 1 \text { - }\end{array}$ & & $\mathrm{x}$ & $\mathrm{x}$ & $\mathrm{x}$ & $\mathrm{x}$ & $\mathrm{x}$ & $\mathrm{x}$ & $\mathrm{x}$ & $\mathrm{x}$ & $\mathrm{x}$ & $\mathrm{x}$ \\
\hline group.5.freq & & $\begin{array}{l}\text { 6_Q10.6 - Gruppe } 5 \text { - } \\
\text { Wieoft trifft sich diese } \\
\text { Gruppe "[Field-1]" } \\
\text { normalerweise für } \\
\text { gemeinsame Aktivitäten? }\end{array}$ & $\begin{array}{l}1=\text { zwei oder dreimal pro } \\
\text { Woche, } 2=\text { einmal pro } \\
\text { Woche, } 3=\text { jede zweite } \\
\text { Woche, } 4=\text { einmal pro } \\
\text { Monat, } 5=\text { weniger als } \\
\text { einmal pro Monat, } 6=\text { fast } \\
\text { jeden Tag }\end{array}$ & $\begin{array}{l}\text { How often does this } \\
\text { group typically meet for } \\
\text { some joint activity? - } \\
\text { Group } 1\end{array}$ & $\begin{array}{l}1=\text { two or three times } \\
\text { per week, } 2=\text { one time } \\
\text { per week, } 3=\text { every } \\
\text { second week, } 4=\text { once per } \\
\text { month, } 5=\text { less than once } \\
\text { per month, } 6=\text { almost } \\
\text { every day }\end{array}$ & $\mathrm{x}$ & $\mathrm{x}$ & $\mathrm{x}$ & $\mathrm{x}$ & $\mathrm{x}$ & $\mathrm{x}$ & $\mathrm{x}$ & $\mathrm{x}$ & $\mathrm{x}$ & $\mathrm{x}$ \\
\hline group.5.pleasant & & $\begin{array}{l}\text { 6_Q10.7_1 - Wie } \\
\text { empfindest Du persönlich } \\
\text { typischerweiseTreffen mit } \\
\text { dieser Gruppe "[Field-1]"? - } \\
\text { Gruppe } 5 \text { - sehr } \\
\text { unangenehm:sehr angenehm }\end{array}$ & $\begin{array}{l}0=7 \text {-Punkte Skala, sehr } \\
\text { angenehm bis sehr } \\
\text { unangenehm, } 1=7 \text {-Punkte } \\
\text { Skala, sehr angenehm bis sehr } \\
\text { unangenehm, } 2=7 \text {-Punkte } \\
\text { Skala, sehr angenehm bis sehr } \\
\text { unangenehm, } 3=7 \text {-Punkte } \\
\text { Skala, sehr angenehm bis sehr } \\
\text { unangenehm, } 4=7 \text {-Punkte } \\
\text { Skala, sehr angenehm bis sehr } \\
\text { unangenehm, } 5=7 \text {-Punkte } \\
\text { Skala, sehr angenehm bis sehr } \\
\text { unangenehm, } 6=7 \text {-Punkte } \\
\text { Skala, sehr angenehm bis sehr } \\
\text { unangenehm }\end{array}$ & $\begin{array}{l}\text { How would you } \\
\text { characterize your typical } \\
\text { personal experience } \\
\text { when meeting with this } \\
\text { group? }\end{array}$ & $\begin{array}{l}0=7 \text { point scale, very } \\
\text { pleasant to very } \\
\text { unpleasant, } 1=7 \text { point } \\
\text { scale, very pleasant to } \\
\text { very unpleasant, } 2=7 \\
\text { point scale, very pleasant } \\
\text { to very unpleasant, } 3=7 \\
\text { point scale, very pleasant } \\
\text { to very unpleasant, } 4=7 \\
\text { point scale, very pleasant } \\
\text { to very unpleasant, } 5=7 \\
\text { point scale, very pleasant } \\
\text { to very unpleasant, } 6=7 \\
\text { point scale, very pleasant } \\
\text { to very unpleasant }\end{array}$ & $\mathrm{x}$ & $\mathrm{x}$ & $\mathrm{x}$ & $\mathrm{x}$ & $\mathrm{x}$ & $\mathrm{x}$ & $\mathrm{x}$ & $\mathrm{x}$ & $\mathrm{x}$ & $\mathrm{x}$ \\
\hline group.5.energetic & & $\begin{array}{l}\text { 6_Q10.7_2 - Wie } \\
\text { empfindest Du persönlich } \\
\text { typischerweiseTreffen mit } \\
\text { dieser Gruppe "[Field-1]"? - } \\
\text { Gruppe 5 - sehr ruhig:sehr } \\
\text { energiegeladen }\end{array}$ & $\begin{array}{l}0=7 \text {-Punkte Skala, sehr } \\
\text { ruhig bis sehr energiegeladen, } \\
1=7 \text {-Punkte Skala, sehr } \\
\text { ruhig bis sehr energiegeladen, } \\
2=7 \text {-Punkte Skala, sehr } \\
\text { ruhig bis sehr energiegeladen, } \\
3=7 \text {-Punkte Skala, sehr } \\
\text { ruhig bis sehr energiegeladen, } \\
4=7 \text {-Punkte Skala, sehr } \\
\text { ruhig bis sehr energiegeladen, } \\
5=7 \text {-Punkte Skala, sehr } \\
\text { ruhig bis sehr energiegeladen, } \\
6=7 \text {-Punkte Skala, sehr } \\
\text { ruhig bis sehr energiegeladen }\end{array}$ & $\begin{array}{l}\text { How would you } \\
\text { characterize your typical } \\
\text { personal experience } \\
\text { when meeting with this } \\
\text { group? - Group } 1\end{array}$ & $\begin{array}{l}0=7 \text { point scale, very } \\
\text { quiet to very energetic, } 1 \\
=7 \text { point scale, very quiet } \\
\text { to very energetic, } 2=7 \\
\text { point scale, very quiet to } \\
\text { very energetic, } 3=7 \\
\text { point scale, very quiet to } \\
\text { very energetic, } 4=7 \\
\text { point scale, very quiet to } \\
\text { very energetic, } 5=7 \\
\text { point scale, very quiet to } \\
\text { very energetic, } 6=7 \\
\text { point scale, very quiet to } \\
\text { very energetic }\end{array}$ & $\mathrm{x}$ & $\mathrm{x}$ & $\mathrm{x}$ & $\mathrm{x}$ & $\mathrm{x}$ & $\mathrm{x}$ & $\mathrm{x}$ & $\mathrm{x}$ & $\mathrm{x}$ & $\mathrm{x}$ \\
\hline
\end{tabular}




\begin{tabular}{|c|c|c|c|c|c|c|c|c|c|c|c|c|c|c|c|}
\hline VarName & VariableLabel & WordingDE & ValueLabelsDE_Linked & WordingEN & ValueLabelsEN_Linked & $\mathrm{L} 1$ & $\mathrm{~L} 2$ & L3 & $\mathrm{L} 4$ & L5 & L6 & $\mathrm{L} 7$ & L8 & L9 & L10 L11 L12 \\
\hline group.5.personal & & $\begin{array}{l}\text { 6_Q10.7_3 - Wie } \\
\text { empfindest Du persönlich } \\
\text { typischerweiseTreffen mit } \\
\text { dieser Gruppe "[Field-1]"? - } \\
\text { Gruppe } 5 \text { - sehr } \\
\text { oberflächlich:sehr persönlich }\end{array}$ & $\begin{array}{l}0=7 \text {-Punkte Skala, sehr } \\
\text { oberflächlich bis sehr } \\
\text { persönlich, } 1=7 \text {-Punkte } \\
\text { Skala, sehr oberflächlich bis } \\
\text { sehr persönlich, } 2=7 \text {-Punkte } \\
\text { Skala, sehr oberflächlich bis } \\
\text { sehr persönlich, } 3=7 \text {-Punkte } \\
\text { Skala, sehr oberflächlich bis } \\
\text { sehr persönlich, } 4=7 \text {-Punkte } \\
\text { Skala, sehr oberflächlich bis } \\
\text { sehr persönlich, } 5=7 \text {-Punkte } \\
\text { Skala, sehr oberflächlich bis } \\
\text { sehr persönlich, } 6=7 \text {-Punkte } \\
\text { Skala, sehr oberflächlich bis } \\
\text { sehr persönlich }\end{array}$ & $\begin{array}{l}\text { How would you } \\
\text { characterize your typical } \\
\text { personal experience } \\
\text { when meeting with this } \\
\text { group? - Group } 1\end{array}$ & $\begin{array}{l}0=7 \text { point scale, very } \\
\text { superficial to very } \\
\text { personal, } 1=7 \text { point } \\
\text { scale, very superficial to } \\
\text { very personal, } 2=7 \text { point } \\
\text { scale, very superficial to } \\
\text { very personal, } 3=7 \text { point } \\
\text { scale, very superficial to } \\
\text { very personal, } 4=7 \text { point } \\
\text { scale, very superficial to } \\
\text { very personal, } 5=7 \text { point } \\
\text { scale, very superficial to } \\
\text { very personal, } 6=7 \text { point } \\
\text { scale, very superficial to } \\
\text { very personal }\end{array}$ & $\mathrm{x}$ & $\mathrm{x}$ & $\mathrm{x}$ & $\mathrm{x}$ & $\mathrm{x}$ & $\mathrm{x}$ & $\mathrm{x}$ & $\mathrm{x}$ & $\mathrm{x}$ & $\mathrm{x}$ \\
\hline group.5.communication & & $\begin{array}{l}\text { 6_Q10.8 - Gruppe } 5 \text { - } \\
\text { Wieoft kommuniziert die } \\
\text { Gruppe "[Field-1]" online } \\
\text { (z.B. per Whatsapp-, } \\
\text { Facebook-Gruppenchat) } \\
\text { zusätzlich zu den Treffen? }\end{array}$ & $\begin{array}{l}1=\text { zwei oder dreimal pro } \\
\text { Woche, } 2=\text { einmal pro } \\
\text { Woche, } 3=\text { jede zweite } \\
\text { Woche, } 4=\text { einmal pro } \\
\text { Monat, } 5=\text { weniger als } \\
\text { einmal pro Jahr, } 6=\text { fast } \\
\text { jeden Tag, } 7=\text { nie, } 8=\text { zwei } \\
\text { oder dreimal pro Woche, } 9= \\
\text { einmal pro Woche, } 10=\text { jede } \\
\text { zweite Woche, } 11=\text { einmal } \\
\text { pro Monat, } 12=\text { weniger als } \\
\text { einmal pro Jahr }\end{array}$ & $\begin{array}{l}\text { How often does this } \\
\text { group communicate } \\
\text { online (e.g. via } \\
\text { WhatsApp, Facebook } \\
\text { Chat) in addition to the } \\
\text { meetings? - Group } 1\end{array}$ & $\begin{array}{l}1=\text { second or three time } \\
\text { per week, } 2=\text { once per } \\
\text { week, } 3=\text { every second } \\
\text { week, } 4=\text { once per } \\
\text { month, } 5=\text { less than once } \\
\text { per month, } 6=\text { almost } \\
\text { every day, } 7=\text { never, } 8= \\
\text { second or three time per } \\
\text { week, } 9=\text { once per week, } \\
10=\text { every second week, } \\
11=\text { once per month, } 12 \\
=\text { less than once per } \\
\text { month }\end{array}$ & $\mathrm{x}$ & $\mathrm{x}$ & $\mathrm{x}$ & $\mathrm{x}$ & $\mathrm{x}$ & $\mathrm{X}$ & $\mathrm{x}$ & $\mathrm{x}$ & $\mathrm{x}$ & $\mathrm{x}$ \\
\hline group.5.identification & & $\begin{array}{l}\text { 6_Q10.9 - Gruppe 5 - Wir } \\
\text { zeigen Dir jeweils zwei } \\
\text { Kreise, vondenen } \\
\text { repräsentiert der eine Dich } \\
\text { (blau) und der andere eine } \\
\text { bestimmte Gruppe(rot). } \\
\text { Bitte wähle immer das Bild } \\
\text { mit den zwei Kreisen, von } \\
\text { dem Du denkst, } \\
\text { esrepräsentiere Dein eigenes } \\
\text { Level an Identifikation mit } \\
\text { dieser Gruppe am } \\
\text { Besten.Wie } \\
\text { starkidentifizierst Du Dich } \\
\text { mit der der Gruppe } \\
\text { "[Field-1]"? }\end{array}$ & & $\begin{array}{l}\text { Group } 1 \text { - We will } \\
\text { present you two circles, } \\
\text { of which one represents } \\
\text { you (blue) and the other } \\
\text { represents a certain } \\
\text { group (red). Please } \\
\text { choose the picture which } \\
\text { you think best } \\
\text { represents your own } \\
\text { level of identification } \\
\text { with this group. How } \\
\text { strongly do you identify } \\
\text { with this group? }\end{array}$ & & $\mathrm{x}$ & $\mathrm{x}$ & $\mathrm{x}$ & $\mathrm{x}$ & $\mathrm{x}$ & $\mathrm{x}$ & $\mathrm{x}$ & $\mathrm{x}$ & $\mathrm{x}$ & $\mathrm{x}$ \\
\hline other.group.1 & & $\begin{array}{l}\text { Q11.3_1 - Bitte benenne } \\
\text { die Gruppen, zu welchen Du } \\
\text { nicht gehörst, mit 1-2 } \\
\text { Stichwörtern (z.B. } \\
\text { "Lerngruppe XY"), sodass } \\
\text { du sie für die nächsten } \\
\text { Minuten wiedererkennen } \\
\text { kannst. Nenne } 0 \text { bis } 5 \\
\text { Gruppen. - Gruppe } 1\end{array}$ & & $\begin{array}{l}\text { Here, we are interested } \\
\text { in groups you and other } \\
\text { fellow students are part } \\
\text { of. Please name your } \\
\text { groups with } 1-2 \text { key } \\
\text { words (e.g. "study } \\
\text { group"), so that you can } \\
\text { recognise them in the } \\
\text { next few minutes. Name } \\
0 \text { to } 5 \text { groups. - group } 1\end{array}$ & & $\mathrm{x}$ & $\mathrm{x}$ & $\mathrm{x}$ & $\mathrm{x}$ & $\mathrm{x}$ & $\mathrm{x}$ & $\mathrm{x}$ & $\mathrm{x}$ & $\mathrm{x}$ & $\mathrm{x}$ \\
\hline other.group.2 & & $\begin{array}{l}\text { Q11.3_2 - Bitte benenne } \\
\text { die Gruppen, zu welchen Du } \\
\text { nicht gehörst, mit 1-2 } \\
\text { Stichwörtern (z.B. } \\
\text { "Lerngruppe XY"), sodass } \\
\text { du sie für die nächsten } \\
\text { Minuten wiedererkennen } \\
\text { kannst. Nenne } 0 \text { bis } 5 \\
\text { Gruppen. - Gruppe 2 }\end{array}$ & & $\begin{array}{l}\text { Here, we are interested } \\
\text { in groups you and other } \\
\text { fellow students are part } \\
\text { of. Please name your } \\
\text { groups with } 1-2 \text { key } \\
\text { words (e.g. "study } \\
\text { group"), so that you can } \\
\text { recognise them in the } \\
\text { next few minutes. Name } \\
0 \text { to } 5 \text { groups. - group } 2\end{array}$ & & $\mathrm{x}$ & $\mathrm{x}$ & $\mathrm{x}$ & $\mathrm{x}$ & $\mathrm{x}$ & $\mathrm{x}$ & $\mathrm{x}$ & $\mathrm{x}$ & $\mathrm{x}$ & $\mathrm{x}$ \\
\hline
\end{tabular}




\begin{tabular}{|c|c|c|c|c|c|c|c|c|c|c|c|c|c|c|c|}
\hline VarName & VariableLabel & WordingDE & ValueLabelsDE_Linked & WordingEN & ValueLabelsEN_Linked & L1 & L2 & L3 & $\mathrm{L} 4$ & L5 & L6 & L7 & L8 & L9 & L10 L11 L12 \\
\hline other.group.3 & & $\begin{array}{l}\text { Q11.3_3 - Bitte benenne } \\
\text { die Gruppen, zu welchen Du } \\
\text { nicht gehörst, mit 1-2 } \\
\text { Stichwörtern (z.B. } \\
\text { "Lerngruppe XY"), sodass } \\
\text { du sie für die nächsten } \\
\text { Minuten wiedererkennen } \\
\text { kannst. Nenne } 0 \text { bis } 5 \\
\text { Gruppen. - Gruppe } 3\end{array}$ & & $\begin{array}{l}\text { Here, we are interested } \\
\text { in groups you and other } \\
\text { fellow students are part } \\
\text { of. Please name your } \\
\text { groups with } 1-2 \text { key } \\
\text { words (e.g. "study } \\
\text { group"), so that you can } \\
\text { recognise them in the } \\
\text { next few minutes. Name } \\
0 \text { to } 5 \text { groups. - group } 3\end{array}$ & & $\mathrm{x}$ & $\mathrm{x}$ & $\mathrm{x}$ & $\mathrm{x}$ & $\mathrm{x}$ & $\mathrm{x}$ & $\mathrm{x}$ & $\mathrm{x}$ & $\mathrm{x}$ & $\mathrm{x}$ \\
\hline other.group. 4 & & $\begin{array}{l}\text { Q11.3_4 - Bitte benenne } \\
\text { die Gruppen, zu welchen Du } \\
\text { nicht gehörst, mit 1-2 } \\
\text { Stichwörtern (z.B. } \\
\text { "Lerngruppe XY"), sodass } \\
\text { du sie für die nächsten } \\
\text { Minuten wiedererkennen } \\
\text { kannst. Nenne 0 bis } 5 \\
\text { Gruppen. - Gruppe } 4\end{array}$ & & $\begin{array}{l}\text { Here, we are interested } \\
\text { in groups you and other } \\
\text { fellow students are part } \\
\text { of. Please name your } \\
\text { groups with 1-2 key } \\
\text { words (e.g. "study } \\
\text { group"), so that you can } \\
\text { recognise them in the } \\
\text { next few minutes. Name } \\
0 \text { to } 5 \text { groups. - group } 4\end{array}$ & & $\mathrm{x}$ & $\mathrm{x}$ & $\mathrm{x}$ & $\mathrm{x}$ & $\mathrm{x}$ & $\mathrm{x}$ & $\mathrm{x}$ & $\mathrm{x}$ & $\mathrm{x}$ & $\mathrm{x}$ \\
\hline other.group.5 & & $\begin{array}{l}\text { Q11.3_5 - Bitte benenne } \\
\text { die Gruppen, zu welchen Du } \\
\text { nicht gehörst, mit 1-2 } \\
\text { Stichwörtern (z.B. } \\
\text { "Lerngruppe XY"), sodass } \\
\text { du sie für die nächsten } \\
\text { Minuten wiedererkennen } \\
\text { kannst. Nenne } 0 \text { bis } 5 \\
\text { Gruppen. - Gruppe } 5\end{array}$ & & $\begin{array}{l}\text { Here, we are interested } \\
\text { in groups you and other } \\
\text { fellow students are part } \\
\text { of. Please name your } \\
\text { groups with } 1-2 \text { key } \\
\text { words (e.g. "study } \\
\text { group"), so that you can } \\
\text { recognise them in the } \\
\text { next few minutes. Name } \\
0 \text { to } 5 \text { groups. - group } 5\end{array}$ & & $\mathrm{x}$ & $\mathrm{x}$ & $\mathrm{x}$ & $\mathrm{x}$ & $\mathrm{x}$ & $\mathrm{x}$ & $\mathrm{x}$ & $\mathrm{x}$ & $\mathrm{x}$ & $\mathrm{x}$ \\
\hline other.group.1.no & & $\begin{array}{l}\text { 1_Q12.2 - Wieviele Deiner } \\
\text { Mitstudierenden gehören in } \\
\text { etwa zu dieser Gruppe } \\
\text { "[Field-1]"? - Gruppe } 1 \text { - } \\
\text { Wieviele Deiner } \\
\text { Mitstudierenden gehören in } \\
\text { etwa zu dieser Gruppe } \\
\text { "[Field-1]"? - Selected } \\
\text { Choice }\end{array}$ & $\begin{array}{l}1=\text { Anzahl: }, 2=\text { Keine } \\
\text { Ahnung }\end{array}$ & $\begin{array}{l}\text { How students from your } \\
\text { cohort are } \\
\text { approximately part of } \\
\text { this group? - Group } 1\end{array}$ & $\begin{array}{l}1=\text { Number: }, 2=\text { No } \\
\text { idea }\end{array}$ & $\mathrm{x}$ & $\mathrm{x}$ & $\mathrm{x}$ & $\mathrm{x}$ & $\mathrm{x}$ & $\mathrm{x}$ & $\mathrm{x}$ & $\mathrm{x}$ & $\mathrm{x}$ & $\mathrm{x}$ \\
\hline other.group.1.no.str & & $\begin{array}{l}\text { 1_Q12.2_1_TEXT - } \\
\text { Wieviele Deiner } \\
\text { Mitstudierenden gehören in } \\
\text { etwa zu dieser Gruppe } \\
\text { "[Field-1]"? - Gruppe } 1 \text { - } \\
\text { Anzahl: - Text }\end{array}$ & & $\begin{array}{l}\text { How students from your } \\
\text { cohort are } \\
\text { approximately part of } \\
\text { this group? - Group } 1 \text { - } \\
\text { Amount: - Text }\end{array}$ & & $\mathrm{x}$ & $\mathrm{x}$ & $\mathrm{x}$ & $\mathrm{x}$ & $\mathrm{x}$ & $\mathrm{x}$ & $\mathrm{x}$ & $\mathrm{x}$ & $\mathrm{x}$ & $\mathrm{x}$ \\
\hline other.group.1.P1 & & $\begin{array}{l}\text { 1_Q12.4_1 - Kennst Du } \\
\text { jemanden Deiner } \\
\text { Mitstudierenden, der oder } \\
\text { die zu dieser Gruppe } \\
\text { "[Field-1]" gehört? Bitte } \\
\text { nenne so viele Personen, wie } \\
\text { Du kannst, aber nenne nur } \\
\text { Personen welche zur } \\
\text { Gruppe gehören. - Gruppe } \\
\text { 1- Name 1 }\end{array}$ & & $\begin{array}{l}\text { Whom among your } \\
\text { fellow students is part of } \\
\text { the group } \\
\text { "< groupname }>\text { "? (the } \\
\text { number of group } \\
\text { members who are not } \\
\text { fellow students can be } \\
\text { reported on the next } \\
\text { page). Name between } 0 \\
\text { and } 20 \text { people. - Group } \\
1 \text { - Name } 1\end{array}$ & & $\mathrm{x}$ & $\mathrm{x}$ & $\mathrm{x}$ & $\mathrm{x}$ & $\mathrm{x}$ & $\mathrm{X}$ & $\mathrm{x}$ & $\mathrm{x}$ & $\mathrm{x}$ & $\mathrm{x}$ \\
\hline
\end{tabular}




\begin{tabular}{|c|c|c|c|c|c|c|c|c|c|c|c|c|c|c|c|}
\hline VarName & VariableLabel & WordingDE & ValueLabelsDE_Linked & WordingEN & ValueLabelsEN_Linked & $\mathrm{L} 1$ & $\mathrm{~L} 2$ & L3 & $\mathrm{L} 4$ & L5 & L6 & L7 & L8 & L9 & L10 L11 L12 \\
\hline other.group.1.activity.1 & & $\begin{array}{l}\text { 1_Q13.6_1 - Was ist } \\
\text { Deiner Meinung nach die } \\
\text { hauptsächliche Tätigkeit, } \\
\text { die diese Gruppe "[Field-1]" } \\
\text { zusammen hält (z.B. } \\
\text { Sachen, die Du } \\
\text { Gruppenmitglieder oft } \\
\text { zusammen tun siehst)? - } \\
\text { Gruppe 1 - Was ist Deiner } \\
\text { Meinung nach die } \\
\text { hauptsächliche Tätigkeit, } \\
\text { die diese Gruppe "[Field-1]" } \\
\text { zusammen hält (z.B. } \\
\text { Sachen, die Du } \\
\text { Gruppenmitglieder oft } \\
\text { zusammen tun siehst)? - } \\
\text { Selected Choice - } \\
\text { Lernen/Hausaufgaben }\end{array}$ & & $\begin{array}{l}\text { In your opinion, what is } \\
\text { the main activity that } \\
\text { keeps this group } \\
\text { "<groupname>" } \\
\text { together (e.g. things } \\
\text { that you often see the } \\
\text { group members doing } \\
\text { together)? - Group 1- } \\
\text { Selected Choice - } \\
\text { studying/homework }\end{array}$ & & $\mathrm{x}$ & $\mathrm{x}$ & $\mathrm{x}$ & $\mathrm{x}$ & $\mathrm{x}$ & $\mathrm{x}$ & $\mathrm{x}$ & $\mathrm{x}$ & $\mathrm{x}$ & $\mathrm{x}$ \\
\hline other.group.1.activity.2 & & $\begin{array}{l}\text { 1_Q13.6_2 - Was ist } \\
\text { Deiner Meinung nach die } \\
\text { hauptsächliche Tätigkeit, } \\
\text { die diese Gruppe "[Field-1]" } \\
\text { zusammen hält (z.B. } \\
\text { Sachen, die Du } \\
\text { Gruppenmitglieder oft } \\
\text { zusammen tun siehst)? - } \\
\text { Gruppe 1 - Was ist Deiner } \\
\text { Meinung nach die } \\
\text { hauptsächliche Tätigkeit, } \\
\text { die diese Gruppe "[Field-1]" } \\
\text { zusammen hält (z.B. } \\
\text { Sachen, die Du } \\
\text { Gruppenmitglieder oft } \\
\text { zusammen tun siehst)? - } \\
\text { Selected Choice - Arbeit }\end{array}$ & & $\begin{array}{l}\text { In your opinion, what is } \\
\text { the main activity that } \\
\text { keeps this group } \\
\text { "<groupname>" } \\
\text { together (e.g. things } \\
\text { that you often see the } \\
\text { group members doing } \\
\text { together)? - Group 1- } \\
\text { Selected Choice - work }\end{array}$ & & $\mathrm{x}$ & $\mathrm{x}$ & $\mathrm{x}$ & $\mathrm{x}$ & $\mathrm{x}$ & $\mathrm{x}$ & $\mathrm{x}$ & $\mathrm{x}$ & $\mathrm{x}$ & $\mathrm{x}$ \\
\hline other.group.1.activity.3 & & $\begin{array}{l}\text { 1_Q13.6_3 - Was ist } \\
\text { Deiner Meinung nach die } \\
\text { hauptsächliche Tätigkeit, } \\
\text { die diese Gruppe "[Field-1]" } \\
\text { zusammen hält (z.B. } \\
\text { Sachen, die Du } \\
\text { Gruppenmitglieder oft } \\
\text { zusammen tun siehst)? - } \\
\text { Gruppe 1 - Was ist Deiner } \\
\text { Meinung nach die } \\
\text { hauptsächliche Tätigkeit, } \\
\text { die diese Gruppe "[Field-1]" } \\
\text { zusammen hält (z.B. } \\
\text { Sachen, die Du } \\
\text { Gruppenmitglieder oft } \\
\text { zusammen tun siehst)? - } \\
\text { Selected Choice - Sport }\end{array}$ & & $\begin{array}{l}\text { In your opinion, what is } \\
\text { the main activity that } \\
\text { keeps this group } \\
\text { "<groupname>" } \\
\text { together (e.g. things } \\
\text { that you often see the } \\
\text { group members doing } \\
\text { together)? - Group 1- } \\
\text { Selected Choice - sports }\end{array}$ & & $\mathrm{x}$ & $\mathrm{x}$ & $\mathrm{x}$ & $\mathrm{x}$ & $\mathrm{x}$ & $\mathrm{x}$ & $\mathrm{x}$ & $\mathrm{x}$ & $\mathrm{x}$ & $\mathrm{x}$ \\
\hline
\end{tabular}




\begin{tabular}{|c|c|c|c|c|c|c|c|c|c|c|c|c|c|c|c|}
\hline VarName & VariableLabel & WordingDE & ValueLabelsDE_Linked & WordingEN & ValueLabelsEN_Linked & $\mathrm{L} 1$ & $\mathrm{~L} 2$ & L3 & L4 & L5 & L6 & L7 & L8 & L9 & L10 L11 L12 \\
\hline other.group.1.activity.4 & & $\begin{array}{l}\text { 1_Q13.6_4 - Was ist } \\
\text { Deiner Meinung nach die } \\
\text { hauptsächliche Tätigkeit, } \\
\text { die diese Gruppe "[Field-1]" } \\
\text { zusammen hält (z.B. } \\
\text { Sachen, die Du } \\
\text { Gruppenmitglieder oft } \\
\text { zusammen tun siehst)? - } \\
\text { Gruppe } 1 \text { - Was ist Deiner } \\
\text { Meinung nach die } \\
\text { hauptsächliche Tätigkeit, } \\
\text { die diese Gruppe "[Field-1]" } \\
\text { zusammen hält (z.B. } \\
\text { Sachen, die Du } \\
\text { Gruppenmitglieder oft } \\
\text { zusammen tun siehst)? - } \\
\text { Selected Choice - Gespräch }\end{array}$ & & $\begin{array}{l}\text { In your opinion, what is } \\
\text { the main activity that } \\
\text { keeps this group } \\
\text { "< groupname>" } \\
\text { together (e.g. things } \\
\text { that you often see the } \\
\text { group members doing } \\
\text { together)? - Group 1- } \\
\text { Selected Choice - } \\
\text { chatting }\end{array}$ & & $\mathrm{x}$ & $\mathrm{x}$ & $\mathrm{x}$ & $\mathrm{x}$ & $\mathrm{x}$ & $\mathrm{x}$ & $\mathrm{x}$ & $\mathrm{x}$ & $\mathrm{x}$ & $\mathrm{x}$ \\
\hline other.group.1.activity.5 & & $\begin{array}{l}\text { 1_Q13.6_5 - Was ist } \\
\text { Deiner Meinung nach die } \\
\text { hauptsächliche Tätigkeit, } \\
\text { die diese Gruppe "[Field-1]" } \\
\text { zusammen hält (z.B. } \\
\text { Sachen, die Du } \\
\text { Gruppenmitglieder oft } \\
\text { zusammen tun siehst)? - } \\
\text { Gruppe 1 - Was ist Deiner } \\
\text { Meinung nach die } \\
\text { hauptsächliche Tätigkeit, } \\
\text { die diese Gruppe "[Field-1]" } \\
\text { zusammen hält (z.B. } \\
\text { Sachen, die Du } \\
\text { Gruppenmitglieder oft } \\
\text { zusammen tun siehst)? - } \\
\text { Selected Choice - etwas } \\
\text { trinken gehen ("eis go } \\
\text { zieh") }\end{array}$ & & $\begin{array}{l}\text { In your opinion, what is } \\
\text { the main activity that } \\
\text { keeps this group } \\
\text { "<groupname>" } \\
\text { together (e.g. things } \\
\text { that you often see the } \\
\text { group members doing } \\
\text { together)? - Group 1- } \\
\text { Selected Choice - having } \\
\text { drinks }\end{array}$ & & $\mathrm{x}$ & $\mathrm{x}$ & $\mathrm{x}$ & $\mathrm{x}$ & $\mathrm{x}$ & $\mathrm{x}$ & $\mathrm{x}$ & $\mathrm{x}$ & $\mathrm{x}$ & $\mathrm{x}$ \\
\hline other.group.1.activity. 6 & & $\begin{array}{l}\text { 1_Q13.6_6 - Was ist } \\
\text { Deiner Meinung nach die } \\
\text { hauptsächliche Tätigkeit, } \\
\text { die diese Gruppe "[Field-1]" } \\
\text { zusammen hält (z.B. } \\
\text { Sachen, die Du } \\
\text { Gruppenmitglieder oft } \\
\text { zusammen tun siehst)? - } \\
\text { Gruppe 1 - Was ist Deiner } \\
\text { Meinung nach die } \\
\text { hauptsächliche Tätigkeit, } \\
\text { die diese Gruppe "[Field-1]" } \\
\text { zusammen hält (z.B. } \\
\text { Sachen, die Du } \\
\text { Gruppenmitglieder oft } \\
\text { zusammen tun siehst)? - } \\
\text { Selected Choice - } \\
\text { gemeinsamer Weg (z.B. zur } \\
\text { Universität) }\end{array}$ & & $\begin{array}{l}\text { In your opinion, what is } \\
\text { the main activity that } \\
\text { keeps this group } \\
\text { "<groupname>" } \\
\text { together (e.g. things } \\
\text { that you often see the } \\
\text { group members doing } \\
\text { together)? - Group 1- } \\
\text { Selected Choice - } \\
\text { commute }\end{array}$ & & $\mathrm{x}$ & $\mathrm{x}$ & $\mathrm{x}$ & $\mathrm{x}$ & $\mathrm{x}$ & $\mathrm{x}$ & $\mathrm{x}$ & $\mathrm{x}$ & $\mathrm{x}$ & $\mathrm{x}$ \\
\hline
\end{tabular}




\begin{tabular}{|c|c|c|c|c|c|c|c|c|c|c|c|c|c|c|c|}
\hline VarName & VariableLabel & WordingDE & ValueLabelsDE_Linked & WordingEN & ValueLabelsEN_Linked & L1 & $\mathrm{L} 2$ & L3 & $\mathrm{L} 4$ & L5 & L6 & L7 & L8 & L9 & L10 L11 L12 \\
\hline other.group.1.activity.7 & & $\begin{array}{l}\text { 1_Q13.6_7 - Was ist } \\
\text { Deiner Meinung nach die } \\
\text { hauptsächliche Tätigkeit, } \\
\text { die diese Gruppe "[Field-1]" } \\
\text { zusammen hält (z.B. } \\
\text { Sachen, die Du } \\
\text { Gruppenmitglieder oft } \\
\text { zusammen tun siehst)? - } \\
\text { Gruppe } 1 \text { - Was ist Deiner } \\
\text { Meinung nach die } \\
\text { hauptsächliche Tätigkeit, } \\
\text { die diese Gruppe "[Field-1]" } \\
\text { zusammen hält (z.B. } \\
\text { Sachen, die Du } \\
\text { Gruppenmitglieder oft } \\
\text { zusammen tun siehst)? - } \\
\text { Selected Choice - } \\
\text { Rendezvous }\end{array}$ & & $\begin{array}{l}\text { In your opinion, what is } \\
\text { the main activity that } \\
\text { keeps this group } \\
\text { "< }<\text { groupname }>\text { " } \\
\text { together (e.g. things } \\
\text { that you often see the } \\
\text { group members doing } \\
\text { together)? - Group 1- } \\
\text { Selected Choice - dating }\end{array}$ & & $\mathrm{x}$ & $\mathrm{x}$ & $\mathrm{x}$ & $\mathrm{x}$ & $\mathrm{x}$ & $\mathrm{x}$ & $\mathrm{x}$ & $\mathrm{x}$ & $\mathrm{x}$ & $\mathrm{x}$ \\
\hline other.group.1.activity.8 & & $\begin{array}{l}\text { 1_Q13.6_8 - Was ist } \\
\text { Deiner Meinung nach die } \\
\text { hauptsächliche Tätigkeit, } \\
\text { die diese Gruppe "[Field-1]" } \\
\text { zusammen hält (z.B. } \\
\text { Sachen, die Du } \\
\text { Gruppenmitglieder oft } \\
\text { zusammen tun siehst)? - } \\
\text { Gruppe 1 - Was ist Deiner } \\
\text { Meinung nach die } \\
\text { hauptsächliche Tätigkeit, } \\
\text { die diese Gruppe "[Field-1]" } \\
\text { zusammen hält (z.B. } \\
\text { Sachen, die Du } \\
\text { Gruppenmitglieder oft } \\
\text { zusammen tun siehst)? - } \\
\text { Selected Choice - über } \\
\text { politische Themen sprechen }\end{array}$ & & $\begin{array}{l}\text { In your opinion, what is } \\
\text { the main activity that } \\
\text { keeps this group } \\
\text { "<groupname }>\text { " } \\
\text { together (e.g. things } \\
\text { that you often see the } \\
\text { group members doing } \\
\text { together)? - Group 1- } \\
\text { Selected Choice - } \\
\text { political discussion }\end{array}$ & & & & $\mathrm{x}$ & $\mathrm{x}$ & $\mathrm{x}$ & $\mathrm{x}$ & $\mathrm{x}$ & $\mathrm{x}$ & $\mathrm{x}$ & $\mathrm{x}$ \\
\hline other.group.1.activity.otr & & $\begin{array}{l}\text { 1_Q13.6_11 - Was ist } \\
\text { Deiner Meinung nach die } \\
\text { hauptsächliche Tätigkeit, } \\
\text { die diese Gruppe "[Field-1]" } \\
\text { zusammen hält (z.B. } \\
\text { Sachen, die Du } \\
\text { Gruppenmitglieder oft } \\
\text { zusammen tun siehst)? - } \\
\text { Gruppe 1 - Was ist Deiner } \\
\text { Meinung nach die } \\
\text { hauptsächliche Tätigkeit, } \\
\text { die diese Gruppe "[Field-1]" } \\
\text { zusammen hält (z.B. } \\
\text { Sachen, die Du } \\
\text { Gruppenmitglieder oft } \\
\text { zusammen tun siehst)? - } \\
\text { Selected Choice - Anderes }\end{array}$ & & $\begin{array}{l}\text { In your opinion, what is } \\
\text { the main activity that } \\
\text { keeps this group } \\
\text { "<groupname>" } \\
\text { together (e.g. things } \\
\text { that you often see the } \\
\text { group members doing } \\
\text { together)? - Group 1- } \\
\text { Selected Choice - other }\end{array}$ & & $\mathrm{x}$ & $\mathrm{x}$ & $\mathrm{x}$ & $\mathrm{x}$ & $\mathrm{x}$ & $\mathrm{x}$ & $\mathrm{x}$ & $\mathrm{x}$ & $\mathrm{x}$ & $\mathrm{x}$ \\
\hline
\end{tabular}




\begin{tabular}{|c|c|c|c|c|c|c|c|c|c|c|c|c|c|c|c|}
\hline VarName & VariableLabel & WordingDE & ValueLabelsDE_Linked & WordingEN & ValueLabelsEN_Linked & L1 & $\mathrm{L} 2$ & L3 & $\mathrm{L} 4$ & L5 & L6 & L7 & L8 & L9 & L10 L11 L12 \\
\hline other.group.1.activity.9 & & $\begin{array}{l}\text { 1_Q13.6_9 - Was ist } \\
\text { Deiner Meinung nach die } \\
\text { hauptsächliche Tätigkeit, } \\
\text { die diese Gruppe "[Field-1]" } \\
\text { zusammen hält (z.B. } \\
\text { Sachen, die Du } \\
\text { Gruppenmitglieder oft } \\
\text { zusammen tun siehst)? - } \\
\text { Gruppe 1 - Was ist Deiner } \\
\text { Meinung nach die } \\
\text { hauptsächliche Tätigkeit, } \\
\text { die diese Gruppe "[Field-1]" } \\
\text { zusammen hält (z.B. } \\
\text { Sachen, die Du } \\
\text { Gruppenmitglieder oft } \\
\text { zusammen tun siehst)? - } \\
\text { Selected Choice - Kultur }\end{array}$ & & $\begin{array}{l}\text { In your opinion, what is } \\
\text { the main activity that } \\
\text { keeps this group } \\
\text { "<groupname>" } \\
\text { together (e.g. things } \\
\text { that you often see the } \\
\text { group members doing } \\
\text { together)? - Group } 1- \\
\text { Selected Choice - culture }\end{array}$ & & $\mathrm{x}$ & $\mathrm{x}$ & $\mathrm{x}$ & $\mathrm{x}$ & $\mathrm{x}$ & $\mathrm{x}$ & $\mathrm{x}$ & $\mathrm{x}$ & $\mathrm{x}$ & $\mathrm{x}$ \\
\hline other.group.1.activity.otr & & $\begin{array}{l}\text { 1_Q13.6_11_TEXT - Was } \\
\text { ist Deiner Meinung nach die } \\
\text { hauptsächliche Tätigkeit, } \\
\text { die diese Gruppe "[Field-1]" } \\
\text { zusammen hält (z.B. } \\
\text { Sachen, die Du } \\
\text { Gruppenmitglieder oft } \\
\text { zusammen tun siehst)? - } \\
\text { Gruppe 1 - Anderes - Text }\end{array}$ & & $\begin{array}{l}\text { In your opinion, what is } \\
\text { the main activity that } \\
\text { keeps this group } \\
\text { "<groupname>" } \\
\text { together (e.g. things } \\
\text { that you often see the } \\
\text { group members doing } \\
\text { together)? - Group 1 - } \\
\text { Other - TEXT }\end{array}$ & & $\mathrm{x}$ & $\mathrm{x}$ & $\mathrm{x}$ & $\mathrm{x}$ & $\mathrm{x}$ & $\mathrm{x}$ & $\mathrm{x}$ & $\mathrm{x}$ & $\mathrm{x}$ & $\mathrm{x}$ \\
\hline other.group.1.sen & & $\begin{array}{l}\text { 1_Q13.7_1 - Wie } \\
\text { empfindest Du die Gruppe } \\
\text { "[Field-1]"? - Gruppe } 1 \text { - } \\
\text { sehr negativ:sehr positiv }\end{array}$ & $\begin{array}{l}0=\text { sehr negativ:sehr positiv } \\
1=\text { sehr negativ:sehr positiv } \\
2=\text { sehr negativ:sehr positiv } \\
3=\text { sehr negativ:sehr positiv } \\
4=\text { sehr negativ:sehr positiv } \\
5=\text { sehr negativ:sehr positiv } \\
6=\text { sehr negativ:sehr positiv }\end{array}$ & $\begin{array}{l}\text { How would you } \\
\text { characterize this group } \\
1 ? \text { - Group } 1 \text { - very } \\
\text { positive : very negative }\end{array}$ & $\begin{array}{l}0=\text { very positive }: \text { very } \\
\text { negative, } 1=\text { very } \\
\text { positive }: \text { very negative, } 2 \\
=\text { very positive }: \text { very } \\
\text { negative, } 3=\text { very } \\
\text { positive }: \text { very negative, } 4 \\
=\text { very positive }: \text { very } \\
\text { negative, } 5=\text { very } \\
\text { positive }: \text { very negative, } 6 \\
=\text { very positive }: \text { very } \\
\text { negative }\end{array}$ & $\mathrm{x}$ & $\mathrm{x}$ & $\mathrm{x}$ & $\mathrm{x}$ & $\mathrm{x}$ & $\mathrm{x}$ & $\mathrm{x}$ & $\mathrm{x}$ & $\mathrm{x}$ & $\mathrm{x}$ \\
\hline other.group.1.pop & & $\begin{array}{l}\text { 1_Q13.7_2 - Wie } \\
\text { empfindest Du die Gruppe } \\
\text { "[Field-1]"? - Gruppe 1 - } \\
\text { sehr unbeliebt am } \\
\text { Departement:sehr beliebt } \\
\text { am Departement }\end{array}$ & $\begin{array}{l}0=\text { sehr unbeliebt am } \\
\text { Departement:sehr beliebt am } \\
\text { Departement, } 1=\text { sehr } \\
\text { unbeliebt am } \\
\text { Departement:sehr beliebt am } \\
\text { Departement, } 2=\text { sehr } \\
\text { unbeliebt am } \\
\text { Departement:sehr beliebt am } \\
\text { Departement, } 3=\text { sehr } \\
\text { unbeliebt am } \\
\text { Departement:sehr beliebt am } \\
\text { Departement, } 4=\text { sehr } \\
\text { unbeliebt am } \\
\text { Departement:sehr beliebt am } \\
\text { Departement, } 5=\text { sehr } \\
\text { unbeliebt am } \\
\text { Departement:sehr beliebt am } \\
\text { Departement, } 6 \text { = sehr } \\
\text { unbeliebt am } \\
\text { Departement:sehr beliebt am } \\
\text { Departement }\end{array}$ & $\begin{array}{l}\text { How would you } \\
\text { characterize this group } \\
1 ? \text { - Group } 1 \text { - very } \\
\text { unpopular with the } \\
\text { department : very } \\
\text { popular with the } \\
\text { department }\end{array}$ & $\begin{array}{l}0=\text { very unpopular with } \\
\text { the department }: \text { very } \\
\text { popular with the } \\
\text { department, } 1=\text { very } \\
\text { unpopular with the } \\
\text { department }: \text { very popular } \\
\text { with the department, } 2= \\
\text { very unpopular with the } \\
\text { department : very popular } \\
\text { with the department, } 3= \\
\text { very unpopular with the } \\
\text { department : very popular } \\
\text { with the department, } 4= \\
\text { very unpopular with the } \\
\text { department : very popular } \\
\text { with the department, } 5= \\
\text { very unpopular with the } \\
\text { department : very popular } \\
\text { with the department, } 6= \\
\text { very unpopular with the } \\
\text { department : very popular } \\
\text { with the department }\end{array}$ & $\mathrm{x}$ & $\mathrm{x}$ & $\mathrm{x}$ & $\mathrm{x}$ & $\mathrm{x}$ & $\mathrm{x}$ & $\mathrm{x}$ & $\mathrm{x}$ & $\mathrm{x}$ & $\mathrm{x}$ \\
\hline
\end{tabular}




How stude

etwa zu dieser Gruppe

approximately part of

Wieviele Deiner

this group 1? - Group

Mitstudierenden gehören in

etwa zu dieser Gruppe

Choice

other.group.2.no.str

\section{2_Q12.2_1_TEXT -}

Wieviele Deiner

Mitstudierenden gehören in

etwa zu dieser Gruppe

"[Field-1]"? - Gruppe 2 -

Anzahl: - Text

other.group.2.P1

2_Q12.4_1 - Kennst Du

Mitstudierenden, der oder

die zu dieser Gruppe

"[Field-1]" gehört? Bitte

Du kannst, aber nenne nur

Personen welche zur

Gruppe gehören. - Gruppe

2 - Name 1

\section{other.group.2.activity.1}

other.group.2.activity.2
2_Q13.6_1 - Was ist

Deiner Meinung nach die hauptsächliche Tätigkeit, die diese Gruppe "[Field-1]" zusammen hält (z.B.

Sachen, die Du

Gruppenmitglieder oft

zusammen tun siehst)? -

Gruppe 2 - Was ist Deine

Meinung nach die

hauptsächliche Tätigkeit,

die diese Gruppe "[Field-1]"

zusammen hält (z.B.

Sachen, die Du

Gruppenmitglieder oft

zusammen tun siehst)? -

Selected Choice -

Lernen/Hausaufgaben

2_Q13.6_2 - Was ist

Deiner Meinung nach die

hauptsächliche Tätigkeit,

die diese Gruppe "[Field-1]"

zusammen hält (z. B.

Sachen, die Du

Gruppenmitglieder oft

zusammen tun siehst)? -

Gruppe 2 - Was ist Deine

Meinung nach die

hauptsächliche Tätigkeit,

die diese Gruppe "[Field-1]

zusammen hält (z

Sachen, die Du

Gruppenmitglieder oft

Selected Choice - Arbeit
How students from your

approximately part of

his group 1? - Group 1

Amount: - Text

Whom among your

fellow students is part of

the group

"<groupname>"? (the number of group

members who are not fellow students can be reported on the next page). Name between 0 and 20 people. - Group 2 - Name 1

In your opinion, what is the main activity that

keeps this group

"< groupname $>$ "

together (e.g. things

that you often see the

group members doing

together)? - Group 2

Selected Choice -

studying/homework

In your opinion, what is

the main activity th

keeps this group

"<groupname>"

together (e.g. things

that you often see the

group members doing

together)? - Group 2-

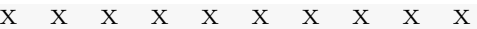

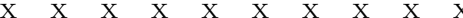

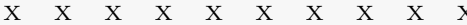




\begin{tabular}{|c|c|c|c|c|c|c|c|c|c|c|c|c|c|c|c|}
\hline VarName & VariableLabel & WordingDE & ValueLabelsDE_Linked & WordingEN & ValueLabelsEN_Linked & L1 & $\mathrm{L} 2$ & L3 & $\mathrm{L} 4$ & L5 & L6 & $\mathrm{L} 7$ & L8 & L9 & L10 L11 L12 \\
\hline other.group.2.activity.3 & & $\begin{array}{l}\text { 2_Q13.6_3 - Was ist } \\
\text { Deiner Meinung nach die } \\
\text { hauptsächliche Tätigkeit, } \\
\text { die diese Gruppe "[Field-1]" } \\
\text { zusammen hält (z.B. } \\
\text { Sachen, die Du } \\
\text { Gruppenmitglieder oft } \\
\text { zusammen tun siehst)? - } \\
\text { Gruppe 2 - Was ist Deiner } \\
\text { Meinung nach die } \\
\text { hauptsächliche Tätigkeit, } \\
\text { die diese Gruppe "[Field-1]" } \\
\text { zusammen hält (z.B. } \\
\text { Sachen, die Du } \\
\text { Gruppenmitglieder oft } \\
\text { zusammen tun siehst)? - } \\
\text { Selected Choice - Sport }\end{array}$ & & $\begin{array}{l}\text { In your opinion, what is } \\
\text { the main activity that } \\
\text { keeps this group } \\
\text { "< groupname >" } \\
\text { together (e.g. things } \\
\text { that you often see the } \\
\text { group members doing } \\
\text { together)? - Group 2- } \\
\text { Selected Choice - sports }\end{array}$ & & $\mathrm{x}$ & $\mathrm{x}$ & $\mathrm{x}$ & $\mathrm{x}$ & $\mathrm{x}$ & $\mathrm{x}$ & $\mathrm{x}$ & $\mathrm{x}$ & $\mathrm{x}$ & $\mathrm{x}$ \\
\hline other.group.2.activity. 4 & & $\begin{array}{l}\text { 2_Q13.6_4 - Was ist } \\
\text { Deiner Meinung nach die } \\
\text { hauptsächliche Tätigkeit, } \\
\text { die diese Gruppe "[Field-1]" } \\
\text { zusammen hält (z.B. } \\
\text { Sachen, die Du } \\
\text { Gruppenmitglieder oft } \\
\text { zusammen tun siehst)? - } \\
\text { Gruppe 2 - Was ist Deiner } \\
\text { Meinung nach die } \\
\text { hauptsächliche Tätigkeit, } \\
\text { die diese Gruppe "[Field-1]" } \\
\text { zusammen hält (z.B. } \\
\text { Sachen, die Du } \\
\text { Gruppenmitglieder oft } \\
\text { zusammen tun siehst)? - } \\
\text { Selected Choice - Gespräch }\end{array}$ & & $\begin{array}{l}\text { In your opinion, what is } \\
\text { the main activity that } \\
\text { keeps this group } \\
\text { "<groupname>" } \\
\text { together (e.g. things } \\
\text { that you often see the } \\
\text { group members doing } \\
\text { together)? - Group 2- } \\
\text { Selected Choice - } \\
\text { chatting }\end{array}$ & & $\mathrm{x}$ & $\mathrm{x}$ & $\mathrm{x}$ & $\mathrm{x}$ & $\mathrm{x}$ & $\mathrm{X}$ & $\mathrm{x}$ & $\mathrm{x}$ & $\mathrm{x}$ & $\mathrm{x}$ \\
\hline other.group.2.activity.5 & & $\begin{array}{l}\text { 2_Q13.6_5 - Was ist } \\
\text { Deiner Meinung nach die } \\
\text { hauptsächliche Tätigkeit, } \\
\text { die diese Gruppe "[Field-1]" } \\
\text { zusammen hält (z.B. } \\
\text { Sachen, die Du } \\
\text { Gruppenmitglieder oft } \\
\text { zusammen tun siehst)? - } \\
\text { Gruppe 2 - Was ist Deiner } \\
\text { Meinung nach die } \\
\text { hauptsächliche Tätigkeit, } \\
\text { die diese Gruppe "[Field-1]" } \\
\text { zusammen hält (z.B. } \\
\text { Sachen, die Du } \\
\text { Gruppenmitglieder oft } \\
\text { zusammen tun siehst)? - } \\
\text { Selected Choice - etwas } \\
\text { trinken gehen ("eis go } \\
\text { zieh") }\end{array}$ & & $\begin{array}{l}\text { In your opinion, what is } \\
\text { the main activity that } \\
\text { keeps this group } \\
\text { "<groupname>" } \\
\text { together (e.g. things } \\
\text { that you often see the } \\
\text { group members doing } \\
\text { together)? - Group 2- } \\
\text { Selected Choice - having } \\
\text { drinks }\end{array}$ & & $\mathrm{x}$ & $\mathrm{x}$ & $\mathrm{x}$ & $\mathrm{x}$ & $\mathrm{x}$ & $\mathrm{x}$ & $\mathrm{x}$ & $\mathrm{x}$ & $\mathrm{x}$ & $\mathrm{x}$ \\
\hline
\end{tabular}




\begin{tabular}{|c|c|c|c|c|c|c|c|c|c|c|c|c|c|c|c|}
\hline VarName & VariableLabel & WordingDE & ValueLabelsDE_Linked & WordingEN & ValueLabelsEN_Linked & L1 & $\mathrm{L} 2$ & L3 & $\mathrm{L} 4$ & L5 & $\mathrm{L} 6$ & L7 & L8 & L9 & L10 L11 L12 \\
\hline other.group.2.activity.6 & & $\begin{array}{l}\text { 2_Q13.6_6 - Was ist } \\
\text { Deiner Meinung nach die } \\
\text { hauptsächliche Tätigkeit, } \\
\text { die diese Gruppe "[Field-1]" } \\
\text { zusammen hält (z.B. } \\
\text { Sachen, die Du } \\
\text { Gruppenmitglieder oft } \\
\text { zusammen tun siehst)? - } \\
\text { Gruppe } 2 \text { - Was ist Deiner } \\
\text { Meinung nach die } \\
\text { hauptsächliche Tätigkeit, } \\
\text { die diese Gruppe "[Field-1]" } \\
\text { zusammen hält (z.B. } \\
\text { Sachen, die Du } \\
\text { Gruppenmitglieder oft } \\
\text { zusammen tun siehst)? - } \\
\text { Selected Choice - } \\
\text { gemeinsamer Weg (z.B. zur } \\
\text { Universität) }\end{array}$ & & $\begin{array}{l}\text { In your opinion, what is } \\
\text { the main activity that } \\
\text { keeps this group } \\
\text { "<groupname>" } \\
\text { together (e.g. things } \\
\text { that you often see the } \\
\text { group members doing } \\
\text { together)? - Group 2- } \\
\text { Selected Choice - } \\
\text { commute }\end{array}$ & & $\mathrm{x}$ & $\mathrm{x}$ & $\mathrm{x}$ & $\mathrm{x}$ & $\mathrm{x}$ & $\mathrm{x}$ & $\mathrm{x}$ & $\mathrm{x}$ & $\mathrm{x}$ & $\mathrm{x}$ \\
\hline other.group.2.activity.7 & & $\begin{array}{l}\text { 2_Q13.6_7 - Was ist } \\
\text { Deiner Meinung nach die } \\
\text { hauptsächliche Tätigkeit, } \\
\text { die diese Gruppe "[Field-1]" } \\
\text { zusammen hält (z.B. } \\
\text { Sachen, die Du } \\
\text { Gruppenmitglieder oft } \\
\text { zusammen tun siehst)? - } \\
\text { Gruppe 2 - Was ist Deiner } \\
\text { Meinung nach die } \\
\text { hauptsächliche Tätigkeit, } \\
\text { die diese Gruppe "[Field-1]" } \\
\text { zusammen hält (z.B. } \\
\text { Sachen, die Du } \\
\text { Gruppenmitglieder oft } \\
\text { zusammen tun siehst)? - } \\
\text { Selected Choice - } \\
\text { Rendezvous }\end{array}$ & & $\begin{array}{l}\text { In your opinion, what is } \\
\text { the main activity that } \\
\text { keeps this group } \\
\text { "< } \text { groupname>" } \\
\text { together (e.g. things } \\
\text { that you often see the } \\
\text { group members doing } \\
\text { together)? - Group 2- } \\
\text { Selected Choice - dating }\end{array}$ & & $\mathrm{x}$ & $\mathrm{x}$ & $\mathrm{x}$ & $\mathrm{x}$ & $\mathrm{x}$ & $\mathrm{x}$ & $\mathrm{x}$ & $\mathrm{x}$ & $\mathrm{x}$ & $\mathrm{x}$ \\
\hline other.group.2.activity. 8 & & $\begin{array}{l}\text { 2_Q13.6_8 - Was ist } \\
\text { Deiner Meinung nach die } \\
\text { hauptsächliche Tätigkeit, } \\
\text { die diese Gruppe "[Field-1]" } \\
\text { zusammen hält (z.B. } \\
\text { Sachen, die Du } \\
\text { Gruppenmitglieder oft } \\
\text { zusammen tun siehst)? - } \\
\text { Gruppe } 2 \text { - Was ist Deiner } \\
\text { Meinung nach die } \\
\text { hauptsächliche Tätigkeit, } \\
\text { die diese Gruppe "[Field-1]" } \\
\text { zusammen hält (z.B. } \\
\text { Sachen, die Du } \\
\text { Gruppenmitglieder oft } \\
\text { zusammen tun siehst)? - } \\
\text { Selected Choice - über } \\
\text { politische Themen sprechen }\end{array}$ & & $\begin{array}{l}\text { In your opinion, what is } \\
\text { the main activity that } \\
\text { keeps this group } \\
\text { "<groupname>" } \\
\text { together (e.g. things } \\
\text { that you often see the } \\
\text { group members doing } \\
\text { together)? - Group 2- } \\
\text { Selected Choice - } \\
\text { political discussion }\end{array}$ & & & & $\mathrm{x}$ & $\mathrm{x}$ & $\mathrm{x}$ & $\mathrm{x}$ & $\mathrm{x}$ & $\mathrm{x}$ & $\mathrm{x}$ & $\mathrm{x}$ \\
\hline
\end{tabular}




\begin{tabular}{|c|c|c|c|c|c|c|c|c|c|c|c|c|c|c|c|}
\hline VarName & VariableLabel & WordingDE & ValueLabelsDE_Linked & WordingEN & ValueLabelsEN_Linked & L1 & L2 & L3 & $\mathrm{L} 4$ & L5 & L6 & L7 & L8 & L9 & L10 L11 L12 \\
\hline other.group.2.activity.otr & & $\begin{array}{l}\text { 2_Q13.6_11 - Was ist } \\
\text { Deiner Meinung nach die } \\
\text { hauptsächliche Tätigkeit, } \\
\text { die diese Gruppe "[Field-1]" } \\
\text { zusammen hält (z.B. } \\
\text { Sachen, die Du } \\
\text { Gruppenmitglieder oft } \\
\text { zusammen tun siehst)? - } \\
\text { Gruppe 2 - Was ist Deiner } \\
\text { Meinung nach die } \\
\text { hauptsächliche Tätigkeit, } \\
\text { die diese Gruppe "[Field-1]" } \\
\text { zusammen hält (z.B. } \\
\text { Sachen, die Du } \\
\text { Gruppenmitglieder oft } \\
\text { zusammen tun siehst)? - } \\
\text { Selected Choice - Anderes }\end{array}$ & & $\begin{array}{l}\text { In your opinion, what is } \\
\text { the main activity that } \\
\text { keeps this group } \\
\text { "<groupname >" } \\
\text { together (e.g. things } \\
\text { that you often see the } \\
\text { group members doing } \\
\text { together)? - Group } 2- \\
\text { Selected Choice - other }\end{array}$ & & $\mathrm{x}$ & $\mathrm{x}$ & $\mathrm{X}$ & $\mathrm{x}$ & $\mathrm{x}$ & $\mathrm{x}$ & $\mathrm{x}$ & $\mathrm{x}$ & $\mathrm{x}$ & $\mathrm{x}$ \\
\hline other.group.2.activity.9 & & $\begin{array}{l}\text { 2_Q13.6_9 - Was ist } \\
\text { Deiner Meinung nach die } \\
\text { hauptsächliche Tätigkeit, } \\
\text { die diese Gruppe "[Field-1]" } \\
\text { zusammen hält (z.B. } \\
\text { Sachen, die Du } \\
\text { Gruppenmitglieder oft } \\
\text { zusammen tun siehst)? - } \\
\text { Gruppe } 2 \text { - Was ist Deiner } \\
\text { Meinung nach die } \\
\text { hauptsächliche Tätigkeit, } \\
\text { die diese Gruppe "[Field-1]" } \\
\text { zusammen hält (z.B. } \\
\text { Sachen, die Du } \\
\text { Gruppenmitglieder oft } \\
\text { zusammen tun siehst)? - } \\
\text { Selected Choice - Kultur }\end{array}$ & & $\begin{array}{l}\text { In your opinion, what is } \\
\text { the main activity that } \\
\text { keeps this group } \\
\text { "< groupname }> \\
\text { together (e.g. things } \\
\text { that you often see the } \\
\text { group members doing } \\
\text { together)? - Group } 2- \\
\text { Selected Choice - culture }\end{array}$ & & $\mathrm{x}$ & $\mathrm{x}$ & $\mathrm{x}$ & $\mathrm{x}$ & $\mathrm{x}$ & $\mathrm{x}$ & $\mathrm{x}$ & $\mathrm{x}$ & $\mathrm{x}$ & $\mathrm{x}$ \\
\hline other.group.2.activity.otr & & $\begin{array}{l}\text { 2_Q13.6_11_TEXT - Was } \\
\text { ist Deiner Meinung nach die } \\
\text { hauptsächliche Tätigkeit, } \\
\text { die diese Gruppe "[Field-1]" } \\
\text { zusammen hält (z.B. } \\
\text { Sachen, die Du } \\
\text { Gruppenmitglieder oft } \\
\text { zusammen tun siehst)? - } \\
\text { Gruppe 2 - Anderes - Text }\end{array}$ & & $\begin{array}{l}\text { In your opinion, what is } \\
\text { the main activity that } \\
\text { keeps this group } \\
\text { "<groupname>" } \\
\text { together (e.g. things } \\
\text { that you often see the } \\
\text { group members doing } \\
\text { together)? - Group } 2 \text { - } \\
\text { Other - TEXT }\end{array}$ & & $\mathrm{x}$ & $\mathrm{x}$ & $\mathrm{x}$ & $\mathrm{x}$ & $\mathrm{x}$ & $\mathrm{x}$ & $\mathrm{x}$ & $\mathrm{x}$ & $\mathrm{x}$ & $\mathrm{x}$ \\
\hline other.group.2.sen & & $\begin{array}{l}\text { 2_Q13.7_1 - Wie } \\
\text { empfindest Du die Gruppe } \\
\text { "[Field-1]"? - Gruppe } 2 \text { - } \\
\text { sehr negativ:sehr positiv }\end{array}$ & $\begin{array}{l}0=\text { sehr negativ:sehr positiv } \\
1=\text { sehr negativ:sehr positiv } \\
2=\text { sehr negativ:sehr positiv } \\
3=\text { sehr negativ:sehr positiv } \\
4=\text { sehr negativ:sehr positiv } \\
5=\text { sehr negativ:sehr positiv } \\
6=\text { sehr negativ:sehr positiv }\end{array}$ & $\begin{array}{l}\text { How would you } \\
\text { characterize this group } \\
2 ? \text { - Group } 2 \text { - very } \\
\text { positive : very negative }\end{array}$ & $\begin{array}{l}0=\text { very positive }: \text { very } \\
\text { negative, } 1=\text { very } \\
\text { positive }: \text { very negative, } 2 \\
=\text { very positive }: \text { very } \\
\text { negative, } 3=\text { very } \\
\text { positive }: \text { very negative, } 4 \\
=\text { very positive }: \text { very } \\
\text { negative, } 5=\text { very } \\
\text { positive }: \text { very negative, } 6 \\
=\text { very positive }: \text { very } \\
\text { negative }\end{array}$ & $\mathrm{x}$ & $\mathrm{x}$ & $\mathrm{x}$ & $\mathrm{x}$ & $\mathrm{x}$ & $\mathrm{x}$ & $\mathrm{x}$ & $\mathrm{x}$ & $\mathrm{x}$ & $\mathrm{x}$ \\
\hline
\end{tabular}




\begin{tabular}{|c|c|c|c|c|c|c|c|c|c|c|c|c|c|c|c|}
\hline VarName & VariableLabel & WordingDE & ValueLabelsDE_Linked & WordingEN & ValueLabelsEN_Linked & $\mathrm{L} 1$ & $\mathrm{~L} 2$ & L3 & $\mathrm{L} 4$ & L5 & L6 & L7 & L8 & L9 & L10 L11 L12 \\
\hline other.group.2.pop & & $\begin{array}{l}\text { 2_Q13.7_2 - Wie } \\
\text { empfindest Du die Gruppe } \\
\text { "[Field-1]"? - Gruppe } 2 \text { - } \\
\text { sehr unbeliebt am } \\
\text { Departement:sehr beliebt } \\
\text { am Departement }\end{array}$ & $\begin{array}{l}0=\text { sehr unbeliebt am } \\
\text { Departement:sehr beliebt am } \\
\text { Departement, } 1=\text { sehr } \\
\text { unbeliebt am } \\
\text { Departement:sehr beliebt am } \\
\text { Departement, } 2=\text { sehr } \\
\text { unbeliebt am } \\
\text { Departement:sehr beliebt am } \\
\text { Departement, } 3=\text { sehr } \\
\text { unbeliebt am } \\
\text { Departement:sehr beliebt am } \\
\text { Departement, } 4=\text { sehr } \\
\text { unbeliebt am } \\
\text { Departement:sehr beliebt am } \\
\text { Departement, } 5=\text { sehr } \\
\text { unbeliebt am } \\
\text { Departement:sehr beliebt am } \\
\text { Departement, } 6=\text { sehr } \\
\text { unbeliebt am } \\
\text { Departement:sehr beliebt am } \\
\text { Departement }\end{array}$ & $\begin{array}{l}\text { How would you } \\
\text { characterize this group } \\
2 ? \text { - Group } 2 \text { - very } \\
\text { unpopular with the } \\
\text { department : very } \\
\text { popular with the } \\
\text { department }\end{array}$ & $\begin{array}{l}0=\text { very unpopular with } \\
\text { the department : very } \\
\text { popular with the } \\
\text { department, } 1=\text { very } \\
\text { unpopular with the } \\
\text { department : very popular } \\
\text { with the department, } 2= \\
\text { very unpopular with the } \\
\text { department : very popular } \\
\text { with the department, } 3= \\
\text { very unpopular with the } \\
\text { department : very popular } \\
\text { with the department, } 4= \\
\text { very unpopular with the } \\
\text { department : very popular } \\
\text { with the department, } 5= \\
\text { very unpopular with the } \\
\text { department : very popular } \\
\text { with the department, } 6= \\
\text { very unpopular with the } \\
\text { department }: \text { very popular } \\
\text { with the department }\end{array}$ & $\mathrm{x}$ & $\mathrm{x}$ & $\mathrm{x}$ & $\mathrm{x}$ & $\mathrm{x}$ & $\mathrm{x}$ & $\mathrm{x}$ & $\mathrm{x}$ & $\mathrm{x}$ & $\mathrm{x}$ \\
\hline other.group.3.no & & $\begin{array}{l}\text { 3_Q12.2 - Wieviele Deiner } \\
\text { Mitstudierenden gehören in } \\
\text { etwa zu dieser Gruppe } \\
\text { "[Field-1]"? - Gruppe } 3 \text { - } \\
\text { Wieviele Deiner } \\
\text { Mitstudierenden gehören in } \\
\text { etwa zu dieser Gruppe } \\
\text { "[Field-1]"? - Selected } \\
\text { Choice }\end{array}$ & $\begin{array}{l}1=\text { Anzahl: }, 2=\text { Keine } \\
\text { Ahnung }\end{array}$ & $\begin{array}{l}\text { How students from your } \\
\text { cohort are } \\
\text { approximately part of } \\
\text { this group? - Group } 3\end{array}$ & $\begin{array}{l}1=\text { Number: }, 2=\text { No } \\
\text { idea }\end{array}$ & $\mathrm{x}$ & $\mathrm{x}$ & $\mathrm{x}$ & $\mathrm{x}$ & $\mathrm{X}$ & $\mathrm{x}$ & $\mathrm{x}$ & $\mathrm{x}$ & $\mathrm{x}$ & $\mathrm{x}$ \\
\hline other.group.3.no.str & & $\begin{array}{l}\text { 3_Q12.2_1_TEXT - } \\
\text { Wieviele Deiner } \\
\text { Mitstudierenden gehören in } \\
\text { etwa zu dieser Gruppe } \\
\text { "[Field-1]"? - Gruppe } 3 \text { - } \\
\text { Anzahl: - Text }\end{array}$ & & $\begin{array}{l}\text { How students from your } \\
\text { cohort are } \\
\text { approximately part of } \\
\text { this group? - Group } 3 \text { - } \\
\text { Amount: - Text }\end{array}$ & & $\mathrm{x}$ & $\mathrm{x}$ & $\mathrm{x}$ & $\mathrm{x}$ & $\mathrm{x}$ & $\mathrm{x}$ & $\mathrm{x}$ & $\mathrm{x}$ & $\mathrm{x}$ & $\mathrm{x}$ \\
\hline other.group.3.P1 & & $\begin{array}{l}\text { 3_Q12.4_1 - Kennst Du } \\
\text { jemanden Deiner } \\
\text { Mitstudierenden, der oder } \\
\text { die zu dieser Gruppe } \\
\text { "[Field-1]" gehört? Bitte } \\
\text { nenne so viele Personen, wie } \\
\text { Du kannst, aber nenne nur } \\
\text { Personen welche zur } \\
\text { Gruppe gehören. - Gruppe } \\
\text { 3 - Name 1 }\end{array}$ & & $\begin{array}{l}\text { Whom among your } \\
\text { fellow students is part of } \\
\text { the group } \\
\text { "<groupname>"? (the } \\
\text { number of group } \\
\text { members who are not } \\
\text { fellow students can be } \\
\text { reported on the next } \\
\text { page). Name between } 0 \\
\text { and } 20 \text { people. - Group } \\
3 \text { - Name } 1\end{array}$ & & $\mathrm{x}$ & $\mathrm{x}$ & $\mathrm{x}$ & $\mathrm{x}$ & $\mathrm{x}$ & $\mathrm{x}$ & $\mathrm{x}$ & $\mathrm{x}$ & $\mathrm{x}$ & $\mathrm{x}$ \\
\hline
\end{tabular}




\begin{tabular}{|c|c|c|c|c|c|c|c|c|c|c|c|c|c|c|c|}
\hline VarName & VariableLabel & WordingDE & ValueLabelsDE_Linked & WordingEN & ValueLabelsEN_Linked & L1 & $\mathrm{L} 2$ & L3 & $\mathrm{L} 4$ & L5 & L6 & L7 & L8 & L9 & L10 L11 L12 \\
\hline other.group.3.activity.1 & & $\begin{array}{l}\text { 3_Q13.6_1 - Was ist } \\
\text { Deiner Meinung nach die } \\
\text { hauptsächliche Tätigkeit, } \\
\text { die diese Gruppe "[Field-1]" } \\
\text { zusammen hält (z.B. } \\
\text { Sachen, die Du } \\
\text { Gruppenmitglieder oft } \\
\text { zusammen tun siehst)? - } \\
\text { Gruppe } 3 \text { - Was ist Deiner } \\
\text { Meinung nach die } \\
\text { hauptsächliche Tätigkeit, } \\
\text { die diese Gruppe "[Field-1]" } \\
\text { zusammen hält (z.B. } \\
\text { Sachen, die Du } \\
\text { Gruppenmitglieder oft } \\
\text { zusammen tun siehst)? - } \\
\text { Selected Choice - } \\
\text { Lernen/Hausaufgaben }\end{array}$ & & $\begin{array}{l}\text { In your opinion, what is } \\
\text { the main activity that } \\
\text { keeps this group } \\
\text { "<groupname>" } \\
\text { together (e.g. things } \\
\text { that you often see the } \\
\text { group members doing } \\
\text { together)? - Group 3- } \\
\text { Selected Choice - } \\
\text { studying/homework }\end{array}$ & & $\mathrm{x}$ & $\mathrm{x}$ & $\mathrm{x}$ & $\mathrm{x}$ & $\mathrm{x}$ & $\mathrm{x}$ & $\mathrm{x}$ & $\mathrm{x}$ & $\mathrm{x}$ & $\mathrm{x}$ \\
\hline other.group.3.activity.2 & & $\begin{array}{l}\text { 3_Q13.6_2 - Was ist } \\
\text { Deiner Meinung nach die } \\
\text { hauptsächliche Tätigkeit, } \\
\text { die diese Gruppe "[Field-1]" } \\
\text { zusammen hält (z.B. } \\
\text { Sachen, die Du } \\
\text { Gruppenmitglieder oft } \\
\text { zusammen tun siehst)? - } \\
\text { Gruppe } 3 \text { - Was ist Deiner } \\
\text { Meinung nach die } \\
\text { hauptsächliche Tätigkeit, } \\
\text { die diese Gruppe "[Field-1]" } \\
\text { zusammen hält (z.B. } \\
\text { Sachen, die Du } \\
\text { Gruppenmitglieder oft } \\
\text { zusammen tun siehst)? - } \\
\text { Selected Choice - Arbeit }\end{array}$ & & $\begin{array}{l}\text { In your opinion, what is } \\
\text { the main activity that } \\
\text { keeps this group } \\
\text { "< } \text { groupname>" } \\
\text { together (e.g. things } \\
\text { that you often see the } \\
\text { group members doing } \\
\text { together)? - Group 3- } \\
\text { Selected Choice - work }\end{array}$ & & $\mathrm{x}$ & $\mathrm{x}$ & $\mathrm{x}$ & $\mathrm{x}$ & $\mathrm{x}$ & $\mathrm{x}$ & $\mathrm{x}$ & $\mathrm{x}$ & $\mathrm{x}$ & $\mathrm{x}$ \\
\hline other.group.3.activity. 3 & & $\begin{array}{l}\text { 3_Q13.6_3 - Was ist } \\
\text { Deiner Meinung nach die } \\
\text { hauptsächliche Tätigkeit, } \\
\text { die diese Gruppe "[Field-1]" } \\
\text { zusammen hält (z.B. } \\
\text { Sachen, die Du } \\
\text { Gruppenmitglieder oft } \\
\text { zusammen tun siehst)? - } \\
\text { Gruppe } 3 \text { - Was ist Deiner } \\
\text { Meinung nach die } \\
\text { hauptsächliche Tätigkeit, } \\
\text { die diese Gruppe "[Field-1]" } \\
\text { zusammen hält (z.B. } \\
\text { Sachen, die Du } \\
\text { Gruppenmitglieder oft } \\
\text { zusammen tun siehst)? - } \\
\text { Selected Choice - Sport }\end{array}$ & & $\begin{array}{l}\text { In your opinion, what is } \\
\text { the main activity that } \\
\text { keeps this group } \\
\text { "< groupname >" } \\
\text { together (e.g. things } \\
\text { that you often see the } \\
\text { group members doing } \\
\text { together)? - Group } 3- \\
\text { Selected Choice - sports }\end{array}$ & & $\mathrm{x}$ & $\mathrm{x}$ & $\mathrm{x}$ & $\mathrm{x}$ & $\mathrm{x}$ & $\mathrm{x}$ & $\mathrm{x}$ & $\mathrm{x}$ & $\mathrm{x}$ & $\mathrm{x}$ \\
\hline
\end{tabular}




\begin{tabular}{|c|c|c|c|c|c|c|c|c|c|c|c|c|c|c|c|}
\hline VarName & VariableLabel & WordingDE & ValueLabelsDE_Linked & WordingEN & ValueLabelsEN_Linked & $\mathrm{L} 1$ & L2 & L3 & L4 & L5 & L6 & L7 & L8 & L9 & L10 L11 L12 \\
\hline other.group.3.activity.4 & & $\begin{array}{l}\text { 3_Q13.6_4 - Was ist } \\
\text { Deiner Meinung nach die } \\
\text { hauptsächliche Tätigkeit, } \\
\text { die diese Gruppe "[Field-1]" } \\
\text { zusammen hält (z.B. } \\
\text { Sachen, die Du } \\
\text { Gruppenmitglieder oft } \\
\text { zusammen tun siehst)? - } \\
\text { Gruppe } 3 \text { - Was ist Deiner } \\
\text { Meinung nach die } \\
\text { hauptsächliche Tätigkeit, } \\
\text { die diese Gruppe "[Field-1]" } \\
\text { zusammen hält (z.B. } \\
\text { Sachen, die Du } \\
\text { Gruppenmitglieder oft } \\
\text { zusammen tun siehst)? - } \\
\text { Selected Choice - Gespräch }\end{array}$ & & $\begin{array}{l}\text { In your opinion, what is } \\
\text { the main activity that } \\
\text { keeps this group } \\
\text { "< groupname>" } \\
\text { together (e.g. things } \\
\text { that you often see the } \\
\text { group members doing } \\
\text { together)? - Group } 3- \\
\text { Selected Choice - } \\
\text { chatting }\end{array}$ & & $\mathrm{x}$ & $\mathrm{x}$ & $\mathrm{x}$ & $\mathrm{x}$ & $\mathrm{x}$ & $\mathrm{x}$ & $\mathrm{x}$ & $\mathrm{x}$ & $\mathrm{x}$ & $\mathrm{x}$ \\
\hline other.group.3.activity.5 & & $\begin{array}{l}\text { 3_Q13.6_5 - Was ist } \\
\text { Deiner Meinung nach die } \\
\text { hauptsächliche Tätigkeit, } \\
\text { die diese Gruppe "[Field-1]" } \\
\text { zusammen hält (z.B. } \\
\text { Sachen, die Du } \\
\text { Gruppenmitglieder oft } \\
\text { zusammen tun siehst)? - } \\
\text { Gruppe } 3 \text { - Was ist Deiner } \\
\text { Meinung nach die } \\
\text { hauptsächliche Tätigkeit, } \\
\text { die diese Gruppe "[Field-1]" } \\
\text { zusammen hält (z.B. } \\
\text { Sachen, die Du } \\
\text { Gruppenmitglieder oft } \\
\text { zusammen tun siehst)? - } \\
\text { Selected Choice - etwas } \\
\text { trinken gehen ("eis go } \\
\text { zieh") }\end{array}$ & & $\begin{array}{l}\text { In your opinion, what is } \\
\text { the main activity that } \\
\text { keeps this group } \\
\text { "<groupname>" } \\
\text { together (e.g. things } \\
\text { that you often see the } \\
\text { group members doing } \\
\text { together)? - Group 3- } \\
\text { Selected Choice - having } \\
\text { drinks }\end{array}$ & & $\mathrm{x}$ & $\mathrm{x}$ & $\mathrm{x}$ & $\mathrm{x}$ & $\mathrm{x}$ & $\mathrm{x}$ & $\mathrm{x}$ & $\mathrm{x}$ & $\mathrm{x}$ & $\mathrm{x}$ \\
\hline other.group.3.activity. 6 & & $\begin{array}{l}\text { 3_Q13.6_6 - Was ist } \\
\text { Deiner Meinung nach die } \\
\text { hauptsächliche Tätigkeit, } \\
\text { die diese Gruppe "[Field-1]" } \\
\text { zusammen hält (z.B. } \\
\text { Sachen, die Du } \\
\text { Gruppenmitglieder oft } \\
\text { zusammen tun siehst)? - } \\
\text { Gruppe } 3 \text { - Was ist Deiner } \\
\text { Meinung nach die } \\
\text { hauptsächliche Tätigkeit, } \\
\text { die diese Gruppe "[Field-1]" } \\
\text { zusammen hält (z.B. } \\
\text { Sachen, die Du } \\
\text { Gruppenmitglieder oft } \\
\text { zusammen tun siehst)? - } \\
\text { Selected Choice - } \\
\text { gemeinsamer Weg (z.B. zur } \\
\text { Universität) }\end{array}$ & & $\begin{array}{l}\text { In your opinion, what is } \\
\text { the main activity that } \\
\text { keeps this group } \\
\text { "<groupname>" } \\
\text { together (e.g. things } \\
\text { that you often see the } \\
\text { group members doing } \\
\text { together)? - Group 3- } \\
\text { Selected Choice - } \\
\text { commute }\end{array}$ & & $\mathrm{x}$ & $\mathrm{x}$ & $\mathrm{x}$ & $\mathrm{x}$ & $\mathrm{x}$ & $\mathrm{x}$ & $\mathrm{x}$ & $\mathrm{x}$ & $\mathrm{x}$ & $\mathrm{x}$ \\
\hline
\end{tabular}




\begin{tabular}{|c|c|c|c|c|c|c|c|c|c|c|c|c|c|c|c|}
\hline VarName & VariableLabel & WordingDE & ValueLabelsDE_Linked & WordingEN & ValueLabelsEN_Linked & L1 & $\mathrm{L} 2$ & L3 & $\mathrm{L} 4$ & L5 & $\mathrm{L} 6$ & $\mathrm{~L} 7$ & L8 & L9 & L10 L11 L12 \\
\hline other.group.3.activity. 7 & & $\begin{array}{l}\text { 3_Q13.6_7 - Was ist } \\
\text { Deiner Meinung nach die } \\
\text { hauptsächliche Tätigkeit, } \\
\text { die diese Gruppe "[Field-1]" } \\
\text { zusammen hält (z.B. } \\
\text { Sachen, die Du } \\
\text { Gruppenmitglieder oft } \\
\text { zusammen tun siehst)? - } \\
\text { Gruppe } 3 \text { - Was ist Deiner } \\
\text { Meinung nach die } \\
\text { hauptsächliche Tätigkeit, } \\
\text { die diese Gruppe "[Field-1]" } \\
\text { zusammen hält (z.B. } \\
\text { Sachen, die Du } \\
\text { Gruppenmitglieder oft } \\
\text { zusammen tun siehst)? - } \\
\text { Selected Choice - } \\
\text { Rendezvous }\end{array}$ & & $\begin{array}{l}\text { In your opinion, what is } \\
\text { the main activity that } \\
\text { keeps this group } \\
\text { "< } \text { groupname >" } \\
\text { together (e.g. things } \\
\text { that you often see the } \\
\text { group members doing } \\
\text { together)? - Group } 3- \\
\text { Selected Choice - dating }\end{array}$ & & $\mathrm{x}$ & $\mathrm{x}$ & $\mathrm{x}$ & $\mathrm{x}$ & $\mathrm{x}$ & $\mathrm{x}$ & $\mathrm{x}$ & $\mathrm{x}$ & $\mathrm{x}$ & $\mathrm{x}$ \\
\hline other.group.3.activity.8 & & $\begin{array}{l}\text { 3_Q13.6_8 - Was ist } \\
\text { Deiner Meinung nach die } \\
\text { hauptsächliche Tätigkeit, } \\
\text { die diese Gruppe "[Field-1]" } \\
\text { zusammen hält (z.B. } \\
\text { Sachen, die Du } \\
\text { Gruppenmitglieder oft } \\
\text { zusammen tun siehst)? - } \\
\text { Gruppe } 3 \text { - Was ist Deiner } \\
\text { Meinung nach die } \\
\text { hauptsächliche Tätigkeit, } \\
\text { die diese Gruppe "[Field-1]" } \\
\text { zusammen hält (z.B. } \\
\text { Sachen, die Du } \\
\text { Gruppenmitglieder oft } \\
\text { zusammen tun siehst)? - } \\
\text { Selected Choice - über } \\
\text { politische Themen sprechen }\end{array}$ & & $\begin{array}{l}\text { In your opinion, what is } \\
\text { the main activity that } \\
\text { keeps this group } \\
\text { "<groupname>" } \\
\text { together (e.g. things } \\
\text { that you often see the } \\
\text { group members doing } \\
\text { together)? - Group 3- } \\
\text { Selected Choice - } \\
\text { political discussion }\end{array}$ & & & & $\mathrm{x}$ & $\mathrm{x}$ & $\mathrm{x}$ & $\mathrm{x}$ & $\mathrm{x}$ & $\mathrm{x}$ & $\mathrm{x}$ & $\mathrm{x}$ \\
\hline other.group.3.activity.otr & & $\begin{array}{l}\text { 3_Q13.6_11 - Was ist } \\
\text { Deiner Meinung nach die } \\
\text { hauptsächliche Tätigkeit, } \\
\text { die diese Gruppe "[Field-1]" } \\
\text { zusammen hält (z.B. } \\
\text { Sachen, die Du } \\
\text { Gruppenmitglieder oft } \\
\text { zusammen tun siehst)? - } \\
\text { Gruppe } 3 \text { - Was ist Deiner } \\
\text { Meinung nach die } \\
\text { hauptsächliche Tätigkeit, } \\
\text { die diese Gruppe "[Field-1]" } \\
\text { zusammen hält (z.B. } \\
\text { Sachen, die Du } \\
\text { Gruppenmitglieder oft } \\
\text { zusammen tun siehst)? - } \\
\text { Selected Choice - Anderes }\end{array}$ & & $\begin{array}{l}\text { In your opinion, what is } \\
\text { the main activity that } \\
\text { keeps this group } \\
\text { "< } \text { groupname>" } \\
\text { together (e.g. things } \\
\text { that you often see the } \\
\text { group members doing } \\
\text { together)? - Group } 3- \\
\text { Selected Choice - other }\end{array}$ & & $\mathrm{x}$ & $\mathrm{x}$ & $\mathrm{x}$ & $\mathrm{x}$ & $\mathrm{x}$ & $\mathrm{x}$ & $\mathrm{x}$ & $\mathrm{x}$ & $\mathrm{x}$ & $\mathrm{x}$ \\
\hline
\end{tabular}




\begin{tabular}{|c|c|c|c|c|c|c|c|c|c|c|c|c|c|c|c|}
\hline VarName & VariableLabel & WordingDE & ValueLabelsDE_Linked & WordingEN & ValueLabelsEN_Linked & $\mathrm{L} 1$ & L2 & L3 & $\mathrm{L} 4$ & L5 & L6 6 & L7 & L8 & L9 & L10 L11 L12 \\
\hline other.group.3.activity. 9 & & $\begin{array}{l}\text { 3_Q13.6_9 - Was ist } \\
\text { Deiner Meinung nach die } \\
\text { hauptsächliche Tätigkeit, } \\
\text { die diese Gruppe "[Field-1]" } \\
\text { zusammen hält (z.B. } \\
\text { Sachen, die Du } \\
\text { Gruppenmitglieder oft } \\
\text { zusammen tun siehst)? - } \\
\text { Gruppe } 3 \text { - Was ist Deiner } \\
\text { Meinung nach die } \\
\text { hauptsächliche Tätigkeit, } \\
\text { die diese Gruppe "[Field-1]" } \\
\text { zusammen hält (z.B. } \\
\text { Sachen, die Du } \\
\text { Gruppenmitglieder oft } \\
\text { zusammen tun siehst)? - } \\
\text { Selected Choice - Kultur }\end{array}$ & & $\begin{array}{l}\text { In your opinion, what is } \\
\text { the main activity that } \\
\text { keeps this group } \\
\text { "< groupname }>" \\
\text { together (e.g. things } \\
\text { that you often see the } \\
\text { group members doing } \\
\text { together)? - Group } 3- \\
\text { Selected Choice - culture }\end{array}$ & & $\mathrm{x}$ & $\mathrm{x}$ & $\mathrm{x}$ & $\mathrm{x}$ & $\mathrm{x}$ & $\mathrm{x}$ & $\mathrm{x}$ & $\mathrm{x}$ & $\mathrm{x}$ & $\mathrm{x}$ \\
\hline other.group.3.activity.otr. & & $\begin{array}{l}\text { 3_Q13.6_11_TEXT - Was } \\
\text { ist Deiner Meinung nach die } \\
\text { hauptsächliche Tätigkeit, } \\
\text { die diese Gruppe "[Field-1]" } \\
\text { zusammen hält (z.B. } \\
\text { Sachen, die Du } \\
\text { Gruppenmitglieder oft } \\
\text { zusammen tun siehst)? - } \\
\text { Gruppe } 3 \text { - Anderes - Text }\end{array}$ & & $\begin{array}{l}\text { In your opinion, what is } \\
\text { the main activity that } \\
\text { keeps this group } \\
\text { "<groupname>" } \\
\text { together (e.g. things } \\
\text { that you often see the } \\
\text { group members doing } \\
\text { together)? - Group } 3 \text { - } \\
\text { Other - TEXT }\end{array}$ & & $\mathrm{x}$ & $\mathrm{x}$ & $\mathrm{x}$ & $\mathrm{x}$ & $\mathrm{x}$ & $\mathrm{x}$ & $\mathrm{x}$ & $\mathrm{x}$ & $\mathrm{x}$ & $\mathrm{x}$ \\
\hline other.group.3.sen & & $\begin{array}{l}\text { 3_Q13.7_1 - Wie } \\
\text { empfindest Du die Gruppe } \\
\text { "[Field-1]"? - Gruppe } 3 \text { - } \\
\text { sehr negativ:sehr positiv }\end{array}$ & $\begin{array}{l}0=\text { sehr negativ:sehr positiv, } \\
1=\text { sehr negativ:sehr positiv } \\
2=\text { sehr negativ:sehr positiv, } \\
3=\text { sehr negativ:sehr positiv, } \\
4=\text { sehr negativ:sehr positiv, } \\
5=\text { sehr negativ:sehr positiv } \\
6=\text { sehr negativ:sehr positiv }\end{array}$ & $\begin{array}{l}\text { How would you } \\
\text { characterize this group? } \\
\text { - Group } 3 \text { - very positive } \\
\text { : very negative }\end{array}$ & $\begin{array}{l}0=\text { very positive }: \text { very } \\
\text { negative, } 1=\text { very } \\
\text { positive }: \text { very negative, } 2 \\
=\text { very positive }: \text { very } \\
\text { negative, } 3=\text { very } \\
\text { positive }: \text { very negative, } 4 \\
=\text { very positive }: \text { very } \\
\text { negative, } 5=\text { very } \\
\text { positive }: \text { very negative, } 6 \\
=\text { very positive }: \text { very } \\
\text { negative }\end{array}$ & $\mathrm{x}$ & $\mathrm{x}$ & $\mathrm{x}$ & $\mathrm{x}$ & $\mathrm{x}$ & $\mathrm{x}$ & $\mathrm{x}$ & $\mathrm{x}$ & $\mathrm{x}$ & $\mathrm{x}$ \\
\hline other.group.3.pop & & $\begin{array}{l}\text { 3_Q13.7_2 - Wie } \\
\text { empfindest Du die Gruppe } \\
\text { "[Field-1]"? - Gruppe } 3 \text { - } \\
\text { sehr unbeliebt am } \\
\text { Departement:sehr beliebt } \\
\text { am Departement }\end{array}$ & $\begin{array}{l}0=\text { sehr unbeliebt am } \\
\text { Departement:sehr beliebt am } \\
\text { Departement, } 1=\text { sehr } \\
\text { unbeliebt am } \\
\text { Departement:sehr beliebt am } \\
\text { Departement, } 2 \text { = sehr } \\
\text { unbeliebt am } \\
\text { Departement:sehr beliebt am } \\
\text { Departement, } 3=\text { sehr } \\
\text { unbeliebt am } \\
\text { Departement:sehr beliebt am } \\
\text { Departement, } 4=\text { sehr } \\
\text { unbeliebt am } \\
\text { Departement:sehr beliebt am } \\
\text { Departement, } 5=\text { sehr } \\
\text { unbeliebt am } \\
\text { Departement:sehr beliebt am } \\
\text { Departement, } 6=\text { sehr } \\
\text { unbeliebt am } \\
\text { Departement:sehr beliebt am } \\
\text { Departement }\end{array}$ & $\begin{array}{l}\text { How would you } \\
\text { characterize this group? } \\
\text { - Group } 3 \text { - very } \\
\text { unpopular with the } \\
\text { department : very } \\
\text { popular with the } \\
\text { department }\end{array}$ & $\begin{array}{l}0=\text { very unpopular with } \\
\text { the department : very } \\
\text { popular with the } \\
\text { department, } 1=\text { very } \\
\text { unpopular with the } \\
\text { department }: \text { very popular } \\
\text { with the department, } 2= \\
\text { very unpopular with the } \\
\text { department : very popular } \\
\text { with the department, } 3= \\
\text { very unpopular with the } \\
\text { department : very popular } \\
\text { with the department, } 4= \\
\text { very unpopular with the } \\
\text { department : very popular } \\
\text { with the department, } 5= \\
\text { very unpopular with the } \\
\text { department : very popular } \\
\text { with the department, } 6= \\
\text { very unpopular with the } \\
\text { department : very popular } \\
\text { with the department }\end{array}$ & $\mathrm{x}$ & $\mathrm{x}$ & $\mathrm{x}$ & $\mathrm{x}$ & $\mathrm{x}$ & $\mathrm{x}$ & $\mathrm{x}$ & $\mathrm{x}$ & $\mathrm{x}$ & $\mathrm{X}$ \\
\hline
\end{tabular}




\begin{tabular}{|c|c|c|c|c|c|c|c|c|c|c|c|c|c|c|c|}
\hline VarName & VariableLabel & WordingDE & ValueLabelsDE_Linked & WordingEN & ValueLabelsEN_Linked & L1 & $\mathrm{L} 2$ & L3 & L4 & L5 & L6 & L7 & L8 & L9 & L10 L11 L12 \\
\hline other.group.4.no & & $\begin{array}{l}\text { 4_Q12.2 - Wieviele Deiner } \\
\text { Mitstudierenden gehören in } \\
\text { etwa zu dieser Gruppe } \\
\text { "[Field-1]"? - Gruppe } 4 \text { - } \\
\text { Wieviele Deiner } \\
\text { Mitstudierenden gehören in } \\
\text { etwa zu dieser Gruppe } \\
\text { "[Field-1]"? - Selected } \\
\text { Choice }\end{array}$ & $\begin{array}{l}1=\text { Anzahl: , } 2=\text { Keine } \\
\text { Ahnung }\end{array}$ & $\begin{array}{l}\text { How students from your } \\
\text { cohort are } \\
\text { approximately part of } \\
\text { this group? - Group } 4\end{array}$ & $\begin{array}{l}1=\text { Number: }, 2=\text { No } \\
\text { idea }\end{array}$ & $\mathrm{x}$ & $\mathrm{x}$ & $\mathrm{x}$ & $\mathrm{x}$ & $\mathrm{x}$ & $\mathrm{x}$ & $\mathrm{x}$ & $\mathrm{x}$ & $\mathrm{x}$ & $\mathrm{x}$ \\
\hline other.group.4.no.str & & $\begin{array}{l}\text { 4_Q12.2_1_TEXT - } \\
\text { Wieviele Deiner } \\
\text { Mitstudierenden gehören in } \\
\text { etwa zu dieser Gruppe } \\
\text { "[Field-1]"? - Gruppe } 4 \text { - } \\
\text { Anzahl: - Text }\end{array}$ & & $\begin{array}{l}\text { How students from your } \\
\text { cohort are } \\
\text { approximately part of } \\
\text { this group? - Group } 4 \text { - } \\
\text { Amount: - Text }\end{array}$ & & $\mathrm{x}$ & $\mathrm{x}$ & $\mathrm{x}$ & $\mathrm{x}$ & $\mathrm{x}$ & $\mathrm{x}$ & $\mathrm{x}$ & $\mathrm{x}$ & $\mathrm{x}$ & $\mathrm{x}$ \\
\hline other.group.4.P1 & & $\begin{array}{l}\text { 4_Q12.4_1 - Kennst Du } \\
\text { jemanden Deiner } \\
\text { Mitstudierenden, der oder } \\
\text { die zu dieser Gruppe } \\
\text { "[Field-1]" gehört? Bitte } \\
\text { nenne so viele Personen, wie } \\
\text { Du kannst, aber nenne nur } \\
\text { Personen welche zur } \\
\text { Gruppe gehören. - Gruppe } \\
\text { 4- Name 1 }\end{array}$ & & $\begin{array}{l}\text { Whom among your } \\
\text { fellow students is part of } \\
\text { the group } \\
\text { "<groupname }>\text { ? (the } \\
\text { number of group } \\
\text { members who are not } \\
\text { fellow students can be } \\
\text { reported on the next } \\
\text { page). Name between } 0 \\
\text { and } 20 \text { people. - Group } \\
4 \text { - Name } 1\end{array}$ & & $\mathrm{x}$ & $\mathrm{x}$ & $\mathrm{x}$ & $\mathrm{x}$ & $\mathrm{x}$ & $\mathrm{x}$ & $\mathrm{x}$ & $\mathrm{x}$ & $\mathrm{x}$ & $\mathrm{x}$ \\
\hline other.group.4.activity. 1 & & $\begin{array}{l}\text { 4_Q13.6_1 - Was ist } \\
\text { Deiner Meinung nach die } \\
\text { hauptsächliche Tätigkeit, } \\
\text { die diese Gruppe "[Field-1]" } \\
\text { zusammen hält (z.B. } \\
\text { Sachen, die Du } \\
\text { Gruppenmitglieder oft } \\
\text { zusammen tun siehst)? - } \\
\text { Gruppe } 4 \text { - Was ist Deiner } \\
\text { Meinung nach die } \\
\text { hauptsächliche Tätigkeit, } \\
\text { die diese Gruppe "[Field-1]" } \\
\text { zusammen hält (z.B. } \\
\text { Sachen, die Du } \\
\text { Gruppenmitglieder oft } \\
\text { zusammen tun siehst)? - } \\
\text { Selected Choice - } \\
\text { Lernen/Hausaugaben }\end{array}$ & & $\begin{array}{l}\text { In your opinion, what is } \\
\text { the main activity that } \\
\text { keeps this group } \\
\text { "<groupname>" } \\
\text { together (e.g. things } \\
\text { that you often see the } \\
\text { group members doing } \\
\text { together)? - Group 4- } \\
\text { Selected Choice - } \\
\text { studying/homework }\end{array}$ & & $\mathrm{x}$ & $\mathrm{x}$ & $\mathrm{X}$ & $\mathrm{x}$ & $\mathrm{x}$ & $\mathrm{x}$ & $\mathrm{x}$ & $\mathrm{x}$ & $\mathrm{x}$ & $\mathrm{x}$ \\
\hline other.group.4.activity. 2 & & $\begin{array}{l}\text { 4_Q13.6_2 - Was ist } \\
\text { Deiner Meinung nach die } \\
\text { hauptsächliche Tätigkeit, } \\
\text { die diese Gruppe "[Field-1]" } \\
\text { zusammen hält (z.B. } \\
\text { Sachen, die Du } \\
\text { Gruppenmitglieder oft } \\
\text { zusammen tun siehst)? - } \\
\text { Gruppe } 4 \text { - Was ist Deiner } \\
\text { Meinung nach die } \\
\text { hauptsächliche Tätigkeit, } \\
\text { die diese Gruppe "[Field-1]" } \\
\text { zusammen hält (z.B. } \\
\text { Sachen, die Du } \\
\text { Gruppenmitglieder oft } \\
\text { zusammen tun siehst)? - } \\
\text { Selected Choice - Arbeit }\end{array}$ & & $\begin{array}{l}\text { In your opinion, what is } \\
\text { the main activity that } \\
\text { keeps this group } \\
\text { "< }<\text { groupname>" } \\
\text { together (e.g. things } \\
\text { that you often see the } \\
\text { group members doing } \\
\text { together)? - Group 4- } \\
\text { Selected Choice - work }\end{array}$ & & $\mathrm{x}$ & $\mathrm{x}$ & $\mathrm{x}$ & $\mathrm{x}$ & $\mathrm{x}$ & $\mathrm{x}$ & $\mathrm{x}$ & $\mathrm{x}$ & $\mathrm{x}$ & $\mathrm{x}$ \\
\hline
\end{tabular}




\begin{tabular}{|c|c|c|c|c|c|c|c|c|c|c|c|c|c|c|c|}
\hline VarName & VariableLabel & WordingDE & ValueLabelsDE_Linked & WordingEN & ValueLabelsEN_Linked & L1 & L2 & L3 & $\mathrm{L} 4$ & L5 & L6 6 & L7 & L8 & L9 & L10 L11 L12 \\
\hline other.group.4.activity. 3 & & $\begin{array}{l}\text { 4_Q13.6_3 - Was ist } \\
\text { Deiner Meinung nach die } \\
\text { hauptsächliche Tätigkeit, } \\
\text { die diese Gruppe "[Field-1]" } \\
\text { zusammen hält (z.B. } \\
\text { Sachen, die Du } \\
\text { Gruppenmitglieder oft } \\
\text { zusammen tun siehst)? - } \\
\text { Gruppe } 4 \text { - Was ist Deiner } \\
\text { Meinung nach die } \\
\text { hauptsächliche Tätigkeit, } \\
\text { die diese Gruppe "[Field-1]" } \\
\text { zusammen hält (z.B. } \\
\text { Sachen, die Du } \\
\text { Gruppenmitglieder oft } \\
\text { zusammen tun siehst)? - } \\
\text { Selected Choice - Sport }\end{array}$ & & $\begin{array}{l}\text { In your opinion, what is } \\
\text { the main activity that } \\
\text { keeps this group } \\
\text { "<groupname>" } \\
\text { together (e.g. things } \\
\text { that you often see the } \\
\text { group members doing } \\
\text { together)? - Group 4- } \\
\text { Selected Choice - sports }\end{array}$ & & $\mathrm{x}$ & $\mathrm{x}$ & $\mathrm{x}$ & $\mathrm{x}$ & $\mathrm{x}$ & $\mathrm{x}$ & $\mathrm{x}$ & $\mathrm{x}$ & $\mathrm{x}$ & $\mathrm{x}$ \\
\hline other.group.4.activity. 4 & & $\begin{array}{l}\text { 4_Q13.6_4 - Was ist } \\
\text { Deiner Meinung nach die } \\
\text { hauptsächliche Tätigkeit, } \\
\text { die diese Gruppe "[Field-1]" } \\
\text { zusammen hält (z.B. } \\
\text { Sachen, die Du } \\
\text { Gruppenmitglieder oft } \\
\text { zusammen tun siehst)? - } \\
\text { Gruppe 4 - Was ist Deiner } \\
\text { Meinung nach die } \\
\text { hauptsächliche Tätigkeit, } \\
\text { die diese Gruppe "[Field-1]" } \\
\text { zusammen hält (z.B. } \\
\text { Sachen, die Du } \\
\text { Gruppenmitglieder oft } \\
\text { zusammen tun siehst)? - } \\
\text { Selected Choice - Gespräch }\end{array}$ & & $\begin{array}{l}\text { In your opinion, what is } \\
\text { the main activity that } \\
\text { keeps this group } \\
\text { "<groupname>" } \\
\text { together (e.g. things } \\
\text { that you often see the } \\
\text { group members doing } \\
\text { together)? - Group 4- } \\
\text { Selected Choice - } \\
\text { chatting }\end{array}$ & & $\mathrm{x}$ & $\mathrm{x}$ & $\mathrm{x}$ & $\mathrm{x}$ & $\mathrm{x}$ & $\mathrm{x}$ & $\mathrm{x}$ & $\mathrm{x}$ & $\mathrm{x}$ & $\mathrm{x}$ \\
\hline other.group.4.activity.5 & & $\begin{array}{l}\text { 4_Q13.6_5 - Was ist } \\
\text { Deiner Meinung nach die } \\
\text { hauptsächliche Tätigkeit, } \\
\text { die diese Gruppe "[Field-1]" } \\
\text { zusammen hält (z.B. } \\
\text { Sachen, die Du } \\
\text { Gruppenmitglieder oft } \\
\text { zusammen tun siehst)? - } \\
\text { Gruppe 4 - Was ist Deiner } \\
\text { Meinung nach die } \\
\text { hauptsächliche Tätigkeit, } \\
\text { die diese Gruppe "[Field-1]" } \\
\text { zusammen hält (z.B. } \\
\text { Sachen, die Du } \\
\text { Gruppenmitglieder oft } \\
\text { zusammen tun siehst)? - } \\
\text { Selected Choice - etwas } \\
\text { trinken gehen ("eis go } \\
\text { zieh") }\end{array}$ & & $\begin{array}{l}\text { In your opinion, what is } \\
\text { the main activity that } \\
\text { keeps this group } \\
\text { "<groupname }>\text { " } \\
\text { together (e.g. things } \\
\text { that you often see the } \\
\text { group members doing } \\
\text { together)? - Group 4- } \\
\text { Selected Choice - having } \\
\text { drinks }\end{array}$ & & $\mathrm{x}$ & $\mathrm{x}$ & $\mathrm{x}$ & $\mathrm{x}$ & $\mathrm{x}$ & $\mathrm{x}$ & $\mathrm{x}$ & $\mathrm{x}$ & $\mathrm{x}$ & $\mathrm{x}$ \\
\hline
\end{tabular}




\begin{tabular}{|c|c|c|c|c|c|c|c|c|c|c|c|c|c|c|c|}
\hline VarName & VariableLabel & WordingDE & ValueLabelsDE_Linked & WordingEN & ValueLabelsEN_Linked & L1 & $\mathrm{L} 2$ & L3 & $\mathrm{L} 4$ & L5 & L6 & L7 & L8 & L9 & L10 L11 L12 \\
\hline other.group.4.activity. 6 & & $\begin{array}{l}\text { 4_Q13.6_6 - Was ist } \\
\text { Deiner Meinung nach die } \\
\text { hauptsächliche Tätigkeit, } \\
\text { die diese Gruppe "[Field-1]" } \\
\text { zusammen hält (z.B. } \\
\text { Sachen, die Du } \\
\text { Gruppenmitglieder oft } \\
\text { zusammen tun siehst)? - } \\
\text { Gruppe } 4 \text { - Was ist Deiner } \\
\text { Meinung nach die } \\
\text { hauptsächliche Tätigkeit, } \\
\text { die diese Gruppe "[Field-1]" } \\
\text { zusammen hält (z.B. } \\
\text { Sachen, die Du } \\
\text { Gruppenmitglieder oft } \\
\text { zusammen tun siehst)? - } \\
\text { Selected Choice - } \\
\text { gemeinsamer Weg (z.B. zur } \\
\text { Universität) }\end{array}$ & & $\begin{array}{l}\text { In your opinion, what is } \\
\text { the main activity that } \\
\text { keeps this group } \\
\text { "<groupname>" } \\
\text { together (e.g. things } \\
\text { that you often see the } \\
\text { group members doing } \\
\text { together)? - Group 4- } \\
\text { Selected Choice - } \\
\text { commute }\end{array}$ & & $\mathrm{x}$ & $\mathrm{x}$ & $\mathrm{x}$ & $\mathrm{x}$ & $\mathrm{x}$ & $\mathrm{x}$ & $\mathrm{x}$ & $\mathrm{x}$ & $\mathrm{x}$ & $\mathrm{x}$ \\
\hline other.group.4.activity. 7 & & $\begin{array}{l}\text { 4_Q13.6_7 - Was ist } \\
\text { Deiner Meinung nach die } \\
\text { hauptsächliche Tätigkeit, } \\
\text { die diese Gruppe "[Field-1]" } \\
\text { zusammen hält (z.B. } \\
\text { Sachen, die Du } \\
\text { Gruppenmitglieder oft } \\
\text { zusammen tun siehst)? - } \\
\text { Gruppe 4 - Was ist Deiner } \\
\text { Meinung nach die } \\
\text { hauptsächliche Tätigkeit, } \\
\text { die diese Gruppe "[Field-1]" } \\
\text { zusammen hält (z.B. } \\
\text { Sachen, die Du } \\
\text { Gruppenmitglieder oft } \\
\text { zusammen tun siehst)? - } \\
\text { Selected Choice - } \\
\text { Rendezvous }\end{array}$ & & $\begin{array}{l}\text { In your opinion, what is } \\
\text { the main activity that } \\
\text { keeps this group } \\
\text { "<groupname>" } \\
\text { together (e.g. things } \\
\text { that you often see the } \\
\text { group members doing } \\
\text { together)? - Group } 4- \\
\text { Selected Choice - dating }\end{array}$ & & $\mathrm{x}$ & $\mathrm{x}$ & $\mathrm{x}$ & $\mathrm{x}$ & $\mathrm{x}$ & $\mathrm{x}$ & $\mathrm{x}$ & $\mathrm{x}$ & $\mathrm{x}$ & $\mathrm{x}$ \\
\hline other.group.4.activity. 8 & & $\begin{array}{l}\text { 4_Q13.6_8 - Was ist } \\
\text { Deiner Meinung nach die } \\
\text { hauptsächliche Tätigkeit, } \\
\text { die diese Gruppe "[Field-1]" } \\
\text { zusammen hält (z.B. } \\
\text { Sachen, die Du } \\
\text { Gruppenmitglieder oft } \\
\text { zusammen tun siehst)? - } \\
\text { Gruppe } 4 \text { - Was ist Deiner } \\
\text { Meinung nach die } \\
\text { hauptsächliche Tätigkeit, } \\
\text { die diese Gruppe "[Field-1]" } \\
\text { zusammen hält (z.B. } \\
\text { Sachen, die Du } \\
\text { Gruppenmitglieder oft } \\
\text { zusammen tun siehst)? - } \\
\text { Selected Choice - über } \\
\text { politische Themen sprechen }\end{array}$ & & $\begin{array}{l}\text { In your opinion, what is } \\
\text { the main activity that } \\
\text { keeps this group } \\
\text { "<groupname>" } \\
\text { together (e.g. things } \\
\text { that you often see the } \\
\text { group members doing } \\
\text { together)? - Group 4- } \\
\text { Selected Choice - } \\
\text { political discussion }\end{array}$ & & & & $\mathrm{x}$ & $\mathrm{x}$ & $\mathrm{x}$ & $\mathrm{x}$ & $\mathrm{x}$ & $\mathrm{x}$ & $\mathrm{x}$ & $\mathrm{x}$ \\
\hline
\end{tabular}




\begin{tabular}{|c|c|c|c|c|c|c|c|c|c|c|c|c|c|c|c|}
\hline VarName & VariableLabel & WordingDE & ValueLabelsDE_Linked & WordingEN & ValueLabelsEN_Linked & L1 & L2 & L3 & $\mathrm{L} 4$ & L5 & L6 & L7 & L8 & L9 & L10 L11 L12 \\
\hline other.group.4.activity.otr & & $\begin{array}{l}\text { 4_Q13.6_11 - Was ist } \\
\text { Deiner Meinung nach die } \\
\text { hauptsächliche Tätigkeit, } \\
\text { die diese Gruppe "[Field-1]" } \\
\text { zusammen hält (z.B. } \\
\text { Sachen, die Du } \\
\text { Gruppenmitglieder oft } \\
\text { zusammen tun siehst)? - } \\
\text { Gruppe } 4 \text { - Was ist Deiner } \\
\text { Meinung nach die } \\
\text { hauptsächliche Tätigkeit, } \\
\text { die diese Gruppe "[Field-1]" } \\
\text { zusammen hält (z.B. } \\
\text { Sachen, die Du } \\
\text { Gruppenmitglieder oft } \\
\text { zusammen tun siehst)? - } \\
\text { Selected Choice - Anderes }\end{array}$ & & $\begin{array}{l}\text { In your opinion, what is } \\
\text { the main activity that } \\
\text { keeps this group } \\
\text { "<groupname>" } \\
\text { together (e.g. things } \\
\text { that you often see the } \\
\text { group members doing } \\
\text { together)? - Group 4- } \\
\text { Selected Choice - other }\end{array}$ & & $\mathrm{x}$ & $\mathrm{x}$ & $\mathrm{x}$ & $\mathrm{x}$ & $\mathrm{x}$ & $\mathrm{x}$ & $\mathrm{x}$ & $\mathrm{x}$ & $\mathrm{x}$ & $\mathrm{x}$ \\
\hline other.group.4.activity.9 & & $\begin{array}{l}\text { 4_Q13.6_9 - Was ist } \\
\text { Deiner Meinung nach die } \\
\text { hauptsächliche Tätigkeit, } \\
\text { die diese Gruppe "[Field-1]" } \\
\text { zusammen hält (z.B. } \\
\text { Sachen, die Du } \\
\text { Gruppenmitglieder oft } \\
\text { zusammen tun siehst)? - } \\
\text { Gruppe 4 - Was ist Deiner } \\
\text { Meinung nach die } \\
\text { hauptsächliche Tätigkeit, } \\
\text { die diese Gruppe "[Field-1]" } \\
\text { zusammen hält (z.B. } \\
\text { Sachen, die Du } \\
\text { Gruppenmitglieder oft } \\
\text { zusammen tun siehst)? - } \\
\text { Selected Choice - Kultur }\end{array}$ & & $\begin{array}{l}\text { In your opinion, what is } \\
\text { the main activity that } \\
\text { keeps this group } \\
\text { "< } \text { groupname }>\text { " } \\
\text { together (e.g. things } \\
\text { that you often see the } \\
\text { group members doing } \\
\text { together)? - Group } 4- \\
\text { Selected Choice - culture }\end{array}$ & & $\mathrm{x}$ & $\mathrm{x}$ & $\mathrm{x}$ & $\mathrm{x}$ & $\mathrm{x}$ & $\mathrm{x}$ & $\mathrm{x}$ & $\mathrm{x}$ & $\mathrm{x}$ & $\mathrm{x}$ \\
\hline other.group.4.activity.otk & & $\begin{array}{l}\text { 4_Q13.6_11_TEXT - Was } \\
\text { ist Deiner Meinung nach die } \\
\text { hauptsächliche Tätigkeit, } \\
\text { die diese Gruppe "[Field-1]" } \\
\text { zusammen hält (z.B. } \\
\text { Sachen, die Du } \\
\text { Gruppenmitglieder oft } \\
\text { zusammen tun siehst)? - } \\
\text { Gruppe 4 - Anderes - Text }\end{array}$ & & $\begin{array}{l}\text { In your opinion, what is } \\
\text { the main activity that } \\
\text { keeps this group } \\
\text { "<groupname>" } \\
\text { together (e.g. things } \\
\text { that you often see the } \\
\text { group members doing } \\
\text { together)? - Group } 4 \text { - } \\
\text { Other - TEXT }\end{array}$ & & $\mathrm{x}$ & $\mathrm{x}$ & $\mathrm{x}$ & $\mathrm{x}$ & $\mathrm{x}$ & $\mathrm{x}$ & $\mathrm{x}$ & $\mathrm{x}$ & $\mathrm{x}$ & $\mathrm{x}$ \\
\hline other.group.4.sen & & $\begin{array}{l}\text { 4_Q13.7_1 - Wie } \\
\text { empfindest Du die Gruppe } \\
\text { "[Field-1]"? - Gruppe } 4 \text { - } \\
\text { sehr negativ:sehr positiv }\end{array}$ & $\begin{array}{l}0=\text { sehr negativ:sehr positiv } \\
1=\text { sehr negativ:sehr positiv } \\
2=\text { sehr negativ:sehr positiv } \\
3=\text { sehr negativ:sehr positiv } \\
4=\text { sehr negativ:sehr positiv } \\
5=\text { sehr negativ:sehr positiv } \\
6=\text { sehr negativ:sehr positiv }\end{array}$ & $\begin{array}{l}\text { How would you } \\
\text { characterize this group? } \\
\text { - Group } 4 \text { - very positive } \\
\text { : very negative }\end{array}$ & $\begin{array}{l}0=\text { very positive }: \text { very } \\
\text { negative, } 1=\text { very } \\
\text { positive }: \text { very negative, } 2 \\
=\text { very positive }: \text { very } \\
\text { negative, } 3=\text { very } \\
\text { positive }: \text { very negative, } 4 \\
=\text { very positive }: \text { very } \\
\text { negative, } 5=\text { very } \\
\text { positive }: \text { very negative, } 6 \\
=\text { very positive }: \text { very } \\
\text { negative }\end{array}$ & $\mathrm{x}$ & $\mathrm{x}$ & $\mathrm{x}$ & $\mathrm{x}$ & $\mathrm{x}$ & $\mathrm{x}$ & $\mathrm{x}$ & $\mathrm{x}$ & $\mathrm{x}$ & $\mathrm{x}$ \\
\hline
\end{tabular}




\begin{tabular}{|c|c|c|c|c|c|c|c|c|c|c|c|c|c|c|c|}
\hline VarName & VariableLabel & WordingDE & ValueLabelsDE_Linked & WordingEN & ValueLabelsEN_Linked & $\mathrm{L} 1$ & $\mathrm{~L} 2$ & L3 & L4 & L5 & L6 & L7 & L8 & L9 & L10 L11 L12 \\
\hline other.group.4.pop & & $\begin{array}{l}\text { 4_Q13.7_2 - Wie } \\
\text { empfindest Du die Gruppe } \\
\text { "[Field-1]"? - Gruppe } 4 \text { - } \\
\text { sehr unbeliebt am } \\
\text { Departement:sehr beliebt } \\
\text { am Departement }\end{array}$ & $\begin{array}{l}0=\text { sehr unbeliebt am } \\
\text { Departement:sehr beliebt am } \\
\text { Departement, } 1=\text { sehr } \\
\text { unbeliebt am } \\
\text { Departement:sehr beliebt am } \\
\text { Departement, } 2=\text { sehr } \\
\text { unbeliebt am } \\
\text { Departement:sehr beliebt am } \\
\text { Departement, } 3=\text { sehr } \\
\text { unbeliebt am } \\
\text { Departement:sehr beliebt am } \\
\text { Departement, } 4=\text { sehr } \\
\text { unbeliebt am } \\
\text { Departement:sehr beliebt am } \\
\text { Departement, } 5=\text { sehr } \\
\text { unbeliebt am } \\
\text { Departement:sehr beliebt am } \\
\text { Departement, } 6=\text { sehr } \\
\text { unbeliebt am } \\
\text { Departement:sehr beliebt am } \\
\text { Departement }\end{array}$ & $\begin{array}{l}\text { How would you } \\
\text { characterize this group? } \\
\text { - Group } 4 \text { - very } \\
\text { unpopular with the } \\
\text { department : very } \\
\text { popular with the } \\
\text { department }\end{array}$ & $\begin{array}{l}0=\text { very unpopular with } \\
\text { the department : very } \\
\text { popular with the } \\
\text { department, } 1=\text { very } \\
\text { unpopular with the } \\
\text { department : very popular } \\
\text { with the department, } 2= \\
\text { very unpopular with the } \\
\text { department : very popular } \\
\text { with the department, } 3= \\
\text { very unpopular with the } \\
\text { department : very popular } \\
\text { with the department, } 4= \\
\text { very unpopular with the } \\
\text { department : very popular } \\
\text { with the department, } 5= \\
\text { very unpopular with the } \\
\text { department : very popular } \\
\text { with the department, } 6= \\
\text { very unpopular with the } \\
\text { department : very popular } \\
\text { with the department }\end{array}$ & $\mathrm{x}$ & $\mathrm{x}$ & $\mathrm{x}$ & $\mathrm{x}$ & $\mathrm{x}$ & $\mathrm{x}$ & $\mathrm{x}$ & $\mathrm{x}$ & $\mathrm{x}$ & $\mathrm{x}$ \\
\hline other.group.5.no & & $\begin{array}{l}\text { 5_Q12.2 - Wieviele Deiner } \\
\text { Mitstudierenden gehören in } \\
\text { etwa zu dieser Gruppe } \\
\text { "[Field-1]"? - Gruppe 5 - } \\
\text { Wieviele Deiner } \\
\text { Mitstudierenden gehören in } \\
\text { etwa zu dieser Gruppe } \\
\text { "[Field-1]"? - Selected } \\
\text { Choice }\end{array}$ & $\begin{array}{l}1=\text { Anzahl: }, 2=\text { Keine } \\
\text { Ahnung }\end{array}$ & $\begin{array}{l}\text { How students from your } \\
\text { cohort are } \\
\text { approximately part of } \\
\text { this group? - Group } 5\end{array}$ & $\begin{array}{l}1=\text { Number: }, 2=\text { No } \\
\text { idea }\end{array}$ & $\mathrm{x}$ & $\mathrm{x}$ & $\mathrm{x}$ & $\mathrm{x}$ & $\mathrm{x}$ & $\mathrm{x}$ & $\mathrm{x}$ & $\mathrm{x}$ & $\mathrm{x}$ & $\mathrm{x}$ \\
\hline other.group.5.no.str & & $\begin{array}{l}\text { 5_Q12.2_1_TEXT - } \\
\text { Wieviele Deiner } \\
\text { Mitstudierenden gehören in } \\
\text { etwa zu dieser Gruppe } \\
\text { "[Field-1]"? - Gruppe } 5 \text { - } \\
\text { Anzahl: - Text }\end{array}$ & & $\begin{array}{l}\text { How students from your } \\
\text { cohort are } \\
\text { approximately part of } \\
\text { this group? - Group } 5 \text { - } \\
\text { Amount: - Text }\end{array}$ & & $\mathrm{x}$ & $\mathrm{x}$ & $\mathrm{x}$ & $\mathrm{x}$ & $\mathrm{x}$ & $\mathrm{x}$ & $\mathrm{x}$ & $\mathrm{x}$ & $\mathrm{x}$ & $\mathrm{x}$ \\
\hline other.group.5.P1 & & $\begin{array}{l}\text { 5_Q12.4_1 - Kennst Du } \\
\text { jemanden Deiner } \\
\text { Mitstudierenden, der oder } \\
\text { die zu dieser Gruppe } \\
\text { "[Field-1]" gehört? Bitte } \\
\text { nenne so viele Personen, wie } \\
\text { Du kannst, aber nenne nur } \\
\text { Personen welche zur } \\
\text { Gruppe gehören. - Gruppe } \\
\text { 5 - Name 1 }\end{array}$ & & $\begin{array}{l}\text { Whom among your } \\
\text { fellow students is part of } \\
\text { the group } \\
\text { "<groupname }>\text { "? (the } \\
\text { number of group } \\
\text { members who are not } \\
\text { fellow students can be } \\
\text { reported on the next } \\
\text { page). Name between } 0 \\
\text { and } 20 \text { people. - Group } \\
5 \text { - Name } 1\end{array}$ & & $\mathrm{x}$ & $\mathrm{x}$ & $\mathrm{x}$ & $\mathrm{x}$ & $\mathrm{x}$ & $\mathrm{x}$ & $\mathrm{x}$ & $\mathrm{x}$ & $\mathrm{x}$ & $\mathrm{x}$ \\
\hline
\end{tabular}




\begin{tabular}{|c|c|c|c|c|c|c|c|c|c|c|c|c|c|c|c|}
\hline VarName & VariableLabel & WordingDE & ValueLabelsDE_Linked & WordingEN & ValueLabelsEN_Linked & L1 & $\mathrm{L} 2$ & L3 & $\mathrm{L} 4$ & L5 & L6 6 & L7 & L8 & L9 & L10 L11 L12 \\
\hline other.group.5.activity. 1 & & $\begin{array}{l}\text { 5_Q13.6_1 - Was ist } \\
\text { Deiner Meinung nach die } \\
\text { hauptsächliche Tätigkeit, } \\
\text { die diese Gruppe "[Field-1]" } \\
\text { zusammen hält (z.B. } \\
\text { Sachen, die Du } \\
\text { Gruppenmitglieder oft } \\
\text { zusammen tun siehst)? - } \\
\text { Gruppe } 5 \text { - Was ist Deiner } \\
\text { Meinung nach die } \\
\text { hauptsächliche Tätigkeit, } \\
\text { die diese Gruppe "[Field-1]" } \\
\text { zusammen hält (z.B. } \\
\text { Sachen, die Du } \\
\text { Gruppenmitglieder oft } \\
\text { zusammen tun siehst)? - } \\
\text { Selected Choice - } \\
\text { Lernen/Hausaufgaben }\end{array}$ & & $\begin{array}{l}\text { In your opinion, what is } \\
\text { the main activity that } \\
\text { keeps this group } \\
\text { "<groupname>" } \\
\text { together (e.g. things } \\
\text { that you often see the } \\
\text { group members doing } \\
\text { together)? - Group 5- } \\
\text { Selected Choice - } \\
\text { studying/homework }\end{array}$ & & $\mathrm{x}$ & $\mathrm{x}$ & $\mathrm{x}$ & $\mathrm{x}$ & $\mathrm{x}$ & $\mathrm{x}$ & $\mathrm{x}$ & $\mathrm{x}$ & $\mathrm{x}$ & $\mathrm{x}$ \\
\hline other.group.5.activity.2 & & $\begin{array}{l}\text { 5_Q13.6_2 - Was ist } \\
\text { Deiner Meinung nach die } \\
\text { hauptsächliche Tätigkeit, } \\
\text { die diese Gruppe "[Field-1]" } \\
\text { zusammen hält (z.B. } \\
\text { Sachen, die Du } \\
\text { Gruppenmitglieder oft } \\
\text { zusammen tun siehst)? - } \\
\text { Gruppe 5 - Was ist Deiner } \\
\text { Meinung nach die } \\
\text { hauptsächliche Tätigkeit, } \\
\text { die diese Gruppe "[Field-1]" } \\
\text { zusammen hält (z.B. } \\
\text { Sachen, die Du } \\
\text { Gruppenmitglieder oft } \\
\text { zusammen tun siehst)? - } \\
\text { Selected Choice - Arbeit }\end{array}$ & & $\begin{array}{l}\text { In your opinion, what is } \\
\text { the main activity that } \\
\text { keeps this group } \\
\text { "<groupname>" } \\
\text { together (e.g. things } \\
\text { that you often see the } \\
\text { group members doing } \\
\text { together)? - Group } 5- \\
\text { Selected Choice - work }\end{array}$ & & $\mathrm{x}$ & $\mathrm{x}$ & $\mathrm{x}$ & $\mathrm{x}$ & $\mathrm{x}$ & $\mathrm{x}$ & $\mathrm{x}$ & $\mathrm{x}$ & $\mathrm{x}$ & $\mathrm{x}$ \\
\hline other.group.5.activity.3 & & $\begin{array}{l}\text { 5_Q13.6_3 - Was ist } \\
\text { Deiner Meinung nach die } \\
\text { hauptsächliche Tätigkeit, } \\
\text { die diese Gruppe "[Field-1]" } \\
\text { zusammen hält (z.B. } \\
\text { Sachen, die Du } \\
\text { Gruppenmitglieder oft } \\
\text { zusammen tun siehst)? - } \\
\text { Gruppe 5 - Was ist Deiner } \\
\text { Meinung nach die } \\
\text { hauptsächliche Tätigkeit, } \\
\text { die diese Gruppe "[Field-1]" } \\
\text { zusammen hält (z.B. } \\
\text { Sachen, die Du } \\
\text { Gruppenmitglieder oft } \\
\text { zusammen tun siehst)? - } \\
\text { Selected Choice - Sport }\end{array}$ & & $\begin{array}{l}\text { In your opinion, what is } \\
\text { the main activity that } \\
\text { keeps this group } \\
\text { "<groupname }> \\
\text { together (e.g. things } \\
\text { that you often see the } \\
\text { group members doing } \\
\text { together)? - Group } 5- \\
\text { Selected Choice - sports }\end{array}$ & & $\mathrm{x}$ & $\mathrm{x}$ & $\mathrm{x}$ & $\mathrm{X}$ & $\mathrm{x}$ & $\mathrm{x}$ & $\mathrm{x}$ & $\mathrm{x}$ & $\mathrm{x}$ & $\mathrm{x}$ \\
\hline
\end{tabular}




\begin{tabular}{|c|c|c|c|c|c|c|c|c|c|c|c|c|c|c|c|}
\hline VarName & VariableLabel & WordingDE & ValueLabelsDE_Linked & WordingEN & ValueLabelsEN_Linked & $\mathrm{L} 1$ & $\mathrm{~L} 2$ & L3 & $\mathrm{L} 4$ & L5 & L6 & L7 & L8 & L9 & L10 L11 L12 \\
\hline 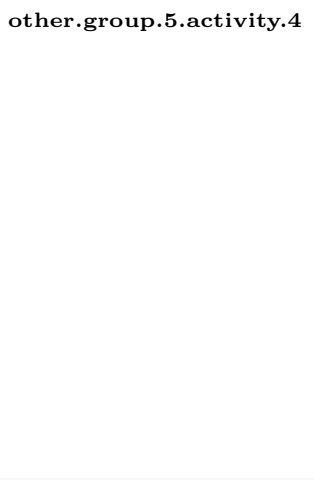 & & $\begin{array}{l}\text { 5_Q13.6_4 - Was ist } \\
\text { Deiner Meinung nach die } \\
\text { hauptsächliche Tätigkeit, } \\
\text { die diese Gruppe "[Field-1]" } \\
\text { zusammen hält (z.B. } \\
\text { Sachen, die Du } \\
\text { Gruppenmitglieder oft } \\
\text { zusammen tun siehst)? - } \\
\text { Gruppe } 5 \text { - Was ist Deiner } \\
\text { Meinung nach die } \\
\text { hauptsächliche Tätigkeit, } \\
\text { die diese Gruppe "[Field-1]" } \\
\text { zusammen hält (z.B. } \\
\text { Sachen, die Du } \\
\text { Gruppenmitglieder oft } \\
\text { zusammen tun siehst)? - } \\
\text { Selected Choice - Gespräch }\end{array}$ & & $\begin{array}{l}\text { In your opinion, what is } \\
\text { the main activity that } \\
\text { keeps this group } \\
\text { "< groupname>" } \\
\text { together (e.g. things } \\
\text { that you often see the } \\
\text { group members doing } \\
\text { together)? - Group 5- } \\
\text { Selected Choice - } \\
\text { chatting }\end{array}$ & & $\mathrm{x}$ & $\mathrm{x}$ & $\mathrm{x}$ & $\mathrm{x}$ & $\mathrm{x}$ & $\mathrm{x}$ & $\mathrm{x}$ & $\mathrm{x}$ & $\mathrm{x}$ & $\mathrm{x}$ \\
\hline other.group.5.activity.5 & & $\begin{array}{l}\text { 5_Q13.6_5 - Was ist } \\
\text { Deiner Meinung nach die } \\
\text { hauptsächliche Tätigkeit, } \\
\text { die diese Gruppe "[Field-1]" } \\
\text { zusammen hält (z.B. } \\
\text { Sachen, die Du } \\
\text { Gruppenmitglieder oft } \\
\text { zusammen tun siehst)? - } \\
\text { Gruppe 5 - Was ist Deiner } \\
\text { Meinung nach die } \\
\text { hauptsächliche Tätigkeit, } \\
\text { die diese Gruppe "[Field-1]" } \\
\text { zusammen hält (z.B. } \\
\text { Sachen, die Du } \\
\text { Gruppenmitglieder oft } \\
\text { zusammen tun siehst)? - } \\
\text { Selected Choice - etwas } \\
\text { trinken gehen ("eis go } \\
\text { zieh") }\end{array}$ & & $\begin{array}{l}\text { In your opinion, what is } \\
\text { the main activity that } \\
\text { keeps this group } \\
\text { "<groupname>" } \\
\text { together (e.g. things } \\
\text { that you often see the } \\
\text { group members doing } \\
\text { together)? - Group 5- } \\
\text { Selected Choice - having } \\
\text { drinks }\end{array}$ & & $\mathrm{x}$ & $\mathrm{x}$ & $\mathrm{x}$ & $\mathrm{x}$ & $\mathrm{x}$ & $\mathrm{x}$ & $\mathrm{x}$ & $\mathrm{x}$ & $\mathrm{x}$ & $\mathrm{x}$ \\
\hline other.group.5.activity. 6 & & $\begin{array}{l}\text { 5_Q13.6_6 - Was ist } \\
\text { Deiner Meinung nach die } \\
\text { hauptsächliche Tätigkeit, } \\
\text { die diese Gruppe "[Field-1]" } \\
\text { zusammen hält (z.B. } \\
\text { Sachen, die Du } \\
\text { Gruppenmitglieder oft } \\
\text { zusammen tun siehst)? - } \\
\text { Gruppe } 5 \text { - Was ist Deiner } \\
\text { Meinung nach die } \\
\text { hauptsächliche Tätigkeit, } \\
\text { die diese Gruppe "[Field-1]" } \\
\text { zusammen hält (z.B. } \\
\text { Sachen, die Du } \\
\text { Gruppenmitglieder oft } \\
\text { zusammen tun siehst)? - } \\
\text { Selected Choice - } \\
\text { gemeinsamer Weg (z.B. zur } \\
\text { Universität) }\end{array}$ & & $\begin{array}{l}\text { In your opinion, what is } \\
\text { the main activity that } \\
\text { keeps this group } \\
\text { "< groupname }> \\
\text { together (e.g. things } \\
\text { that you often see the } \\
\text { group members doing } \\
\text { together)? - Group 5- } \\
\text { Selected Choice - } \\
\text { commute }\end{array}$ & & $\mathrm{x}$ & $\mathrm{x}$ & $\mathrm{x}$ & $\mathrm{x}$ & $\mathrm{x}$ & $\mathrm{x}$ & $\mathrm{x}$ & $\mathrm{x}$ & $\mathrm{x}$ & $\mathrm{x}$ \\
\hline
\end{tabular}




\begin{tabular}{|c|c|c|c|c|c|c|c|c|c|c|c|c|c|c|c|}
\hline VarName & VariableLabel & WordingDE & ValueLabelsDE_Linked & WordingEN & ValueLabelsEN_Linked & $\mathrm{L} 1$ & $\mathrm{~L} 2$ & L3 & $\mathrm{L} 4$ & L5 & L6 & L7 & L8 & L9 & L10 L11 L12 \\
\hline other.group.5.activity.7 & & $\begin{array}{l}\text { 5_Q13.6_7 - Was ist } \\
\text { Deiner Meinung nach die } \\
\text { hauptsächliche Tätigkeit, } \\
\text { die diese Gruppe "[Field-1]" } \\
\text { zusammen hält (z.B. } \\
\text { Sachen, die Du } \\
\text { Gruppenmitglieder oft } \\
\text { zusammen tun siehst)? - } \\
\text { Gruppe 5 - Was ist Deiner } \\
\text { Meinung nach die } \\
\text { hauptsächliche Tätigkeit, } \\
\text { die diese Gruppe "[Field-1]" } \\
\text { zusammen hält (z.B. } \\
\text { Sachen, die Du } \\
\text { Gruppenmitglieder oft } \\
\text { zusammen tun siehst)? - } \\
\text { Selected Choice - } \\
\text { Rendezvous }\end{array}$ & & $\begin{array}{l}\text { In your opinion, what is } \\
\text { the main activity that } \\
\text { keeps this group } \\
\text { "<groupname>" } \\
\text { together (e.g. things } \\
\text { that you often see the } \\
\text { group members doing } \\
\text { together)? - Group 5- } \\
\text { Selected Choice - dating }\end{array}$ & & $\mathrm{x}$ & $\mathrm{x}$ & $\mathrm{x}$ & $\mathrm{x}$ & $\mathrm{x}$ & $\mathrm{x}$ & $\mathrm{x}$ & $\mathrm{x}$ & $\mathrm{x}$ & $\mathrm{x}$ \\
\hline other.group.5.activity. 8 & & $\begin{array}{l}\text { 5_Q13.6_8 - Was ist } \\
\text { Deiner Meinung nach die } \\
\text { hauptsächliche Tätigkeit, } \\
\text { die diese Gruppe "[Field-1]" } \\
\text { zusammen hält (z.B. } \\
\text { Sachen, die Du } \\
\text { Gruppenmitglieder oft } \\
\text { zusammen tun siehst)? - } \\
\text { Gruppe 5 - Was ist Deiner } \\
\text { Meinung nach die } \\
\text { hauptsächliche Tätigkeit, } \\
\text { die diese Gruppe "[Field-1]" } \\
\text { zusammen hält (z.B. } \\
\text { Sachen, die Du } \\
\text { Gruppenmitglieder oft } \\
\text { zusammen tun siehst)? - } \\
\text { Selected Choice - über } \\
\text { politische Themen sprechen }\end{array}$ & & $\begin{array}{l}\text { In your opinion, what is } \\
\text { the main activity that } \\
\text { keeps this group } \\
\text { "<groupname>" } \\
\text { together (e.g. things } \\
\text { that you often see the } \\
\text { group members doing } \\
\text { together)? - Group 5- } \\
\text { Selected Choice - } \\
\text { political discussion }\end{array}$ & & & & $\mathrm{x}$ & $\mathrm{x}$ & $\mathrm{x}$ & $\mathrm{x}$ & $\mathrm{x}$ & $\mathrm{x}$ & $\mathrm{x}$ & $\mathrm{x}$ \\
\hline other.group.5.activity.otr. & & $\begin{array}{l}\text { 5_Q13.6_11 - Was ist } \\
\text { Deiner Meinung nach die } \\
\text { hauptsächliche Tätigkeit, } \\
\text { die diese Gruppe "[Field-1]" } \\
\text { zusammen hält (z.B. } \\
\text { Sachen, die Du } \\
\text { Gruppenmitglieder oft } \\
\text { zusammen tun siehst)? - } \\
\text { Gruppe 5 - Was ist Deiner } \\
\text { Meinung nach die } \\
\text { hauptsächliche Tätigkeit, } \\
\text { die diese Gruppe "[Field-1]" } \\
\text { zusammen hält (z.B. } \\
\text { Sachen, die Du } \\
\text { Gruppenmitglieder oft } \\
\text { zusammen tun siehst)? - } \\
\text { Selected Choice - Anderes }\end{array}$ & & $\begin{array}{l}\text { In your opinion, what is } \\
\text { the main activity that } \\
\text { keeps this group } \\
\text { "<groupname>" } \\
\text { together (e.g. things } \\
\text { that you often see the } \\
\text { group members doing } \\
\text { together)? - Group 5- } \\
\text { Selected Choice - other }\end{array}$ & & $\mathrm{x}$ & $\mathrm{x}$ & $\mathrm{x}$ & $\mathrm{x}$ & $\mathrm{x}$ & $\mathrm{x}$ & $\mathrm{x}$ & $\mathrm{x}$ & $\mathrm{x}$ & $\mathrm{x}$ \\
\hline
\end{tabular}




\begin{tabular}{|c|c|c|c|c|c|c|c|c|c|c|c|c|c|c|c|}
\hline VarName & VariableLabel & WordingDE & ValueLabelsDE_Linked & WordingEN & ValueLabelsEN_Linked & L1 & $\mathrm{L} 2$ & L3 & $\mathrm{L} 4$ & L5 & L6 & L7 & L8 & L9 & L10 L11 L12 \\
\hline other.group.5.activity. 9 & & $\begin{array}{l}\text { 5_Q13.6_9 - Was ist } \\
\text { Deiner Meinung nach die } \\
\text { hauptsächliche Tätigkeit, } \\
\text { die diese Gruppe "[Field-1]" } \\
\text { zusammen hält (z.B. } \\
\text { Sachen, die Du } \\
\text { Gruppenmitglieder oft } \\
\text { zusammen tun siehst)? - } \\
\text { Gruppe 5 - Was ist Deiner } \\
\text { Meinung nach die } \\
\text { hauptsächliche Tätigkeit, } \\
\text { die diese Gruppe "[Field-1]" } \\
\text { zusammen hält (z.B. } \\
\text { Sachen, die Du } \\
\text { Gruppenmitglieder oft } \\
\text { zusammen tun siehst)? - } \\
\text { Selected Choice - Kultur }\end{array}$ & & $\begin{array}{l}\text { In your opinion, what is } \\
\text { the main activity that } \\
\text { keeps this group } \\
\text { "<groupname >" } \\
\text { together (e.g. things } \\
\text { that you often see the } \\
\text { group members doing } \\
\text { together)? - Group 5- } \\
\text { Selected Choice - culture }\end{array}$ & & $\mathrm{x}$ & $\mathrm{x}$ & $\mathrm{x}$ & $\mathrm{x}$ & $\mathrm{x}$ & $\mathrm{x}$ & $\mathrm{x}$ & $\mathrm{x}$ & $\mathrm{x}$ & $\mathrm{x}$ \\
\hline other.group.5.activity.otr & & $\begin{array}{l}\text { 5_Q13.6_11_TEXT - Was } \\
\text { ist Deiner Meinung nach die } \\
\text { hauptsächliche Tätigkeit, } \\
\text { die diese Gruppe "[Field-1]" } \\
\text { zusammen hält (z.B. } \\
\text { Sachen, die Du } \\
\text { Gruppenmitglieder oft } \\
\text { zusammen tun siehst)? - } \\
\text { Gruppe 5 - Anderes - Text }\end{array}$ & & $\begin{array}{l}\text { In your opinion, what is } \\
\text { the main activity that } \\
\text { keeps this group } \\
\text { "<groupname>" } \\
\text { together (e.g. things } \\
\text { that you often see the } \\
\text { group members doing } \\
\text { together)? - Group } 5 \text { - } \\
\text { Other - TEXT }\end{array}$ & & $\mathrm{x}$ & $\mathrm{x}$ & $\mathrm{x}$ & $\mathrm{x}$ & $\mathrm{X}$ & $\mathrm{x}$ & $\mathrm{x}$ & $\mathrm{x}$ & $\mathrm{x}$ & $\mathrm{x}$ \\
\hline other.group.5.sen & & $\begin{array}{l}\text { 5_Q13.7_1 - Wie } \\
\text { empfindest Du die Gruppe } \\
\text { "[Field-1]"? - Gruppe } 5 \text { - } \\
\text { sehr negativ:sehr positiv }\end{array}$ & $\begin{array}{l}0=\text { sehr negativ:sehr positiv } \\
1=\text { sehr negativ:sehr positiv } \\
2=\text { sehr negativ:sehr positiv } \\
3=\text { sehr negativ:sehr positiv } \\
4=\text { sehr negativ:sehr positiv } \\
5=\text { sehr negativ:sehr positiv } \\
6=\text { sehr negativ:sehr positiv }\end{array}$ & $\begin{array}{l}\text { How would you } \\
\text { characterize this group? } \\
\text { - Group } 5 \text { - very positive } \\
\text { : very negative }\end{array}$ & $\begin{array}{l}0=\text { very positive }: \text { very } \\
\text { negative, } 1=\text { very } \\
\text { positive }: \text { very negative, } 2 \\
=\text { very positive }: \text { very } \\
\text { negative, } 3=\text { very } \\
\text { positive }: \text { very negative, } 4 \\
=\text { very positive }: \text { very } \\
\text { negative, } 5=\text { very } \\
\text { positive }: \text { very negative, } 6 \\
=\text { very positive }: \text { very } \\
\text { negative }\end{array}$ & $\mathrm{x}$ & $\mathrm{x}$ & $\mathrm{x}$ & $\mathrm{x}$ & $\mathrm{x}$ & $\mathrm{x}$ & $\mathrm{x}$ & $\mathrm{x}$ & $\mathrm{x}$ & $\mathrm{x}$ \\
\hline other.group.5.pop & & $\begin{array}{l}\text { 5_Q13.7_2 - Wie } \\
\text { empfindest Du die Gruppe } \\
\text { "[Field-1]"? - Gruppe 5 - } \\
\text { sehr unbeliebt am } \\
\text { Departement:sehr beliebt } \\
\text { am Departement }\end{array}$ & $\begin{array}{l}0=\text { sehr unbeliebt am } \\
\text { Departement:sehr beliebt am } \\
\text { Departement, } 1=\text { sehr } \\
\text { unbeliebt am } \\
\text { Departement:sehr beliebt am } \\
\text { Departement, } 2=\text { sehr } \\
\text { unbeliebt am } \\
\text { Departement:sehr beliebt am } \\
\text { Departement, } 3=\text { sehr } \\
\text { unbeliebt am } \\
\text { Departement:sehr beliebt am } \\
\text { Departement, } 4=\text { sehr } \\
\text { unbeliebt am } \\
\text { Departement:sehr beliebt am } \\
\text { Departement, } 5=\text { sehr } \\
\text { unbeliebt am } \\
\text { Departement:sehr beliebt am } \\
\text { Departement, } 6=\text { sehr } \\
\text { unbeliebt am } \\
\text { Departement:sehr beliebt am } \\
\text { Departement }\end{array}$ & $\begin{array}{l}\text { How would you } \\
\text { characterize this group? } \\
\text { - Group } 5 \text { - very } \\
\text { unpopular with the } \\
\text { department : very } \\
\text { popular with the } \\
\text { department }\end{array}$ & $\begin{array}{l}0=\text { very unpopular with } \\
\text { the department : very } \\
\text { popular with the } \\
\text { department, } 1=\text { very } \\
\text { unpopular with the } \\
\text { department : very popular } \\
\text { with the department, } 2= \\
\text { very unpopular with the } \\
\text { department : very popular } \\
\text { with the department, } 3= \\
\text { very unpopular with the } \\
\text { department : very popular } \\
\text { with the department, } 4= \\
\text { very unpopular with the } \\
\text { department : very popular } \\
\text { with the department, } 5= \\
\text { very unpopular with the } \\
\text { department : very popular } \\
\text { with the department, } 6= \\
\text { very unpopular with the } \\
\text { department : very popular } \\
\text { with the department }\end{array}$ & $\mathrm{x}$ & $\mathrm{x}$ & $\mathrm{x}$ & $\mathrm{x}$ & $\mathrm{x}$ & $\mathrm{x}$ & $\mathrm{x}$ & $\mathrm{x}$ & $\mathrm{x}$ & $\mathrm{x}$ \\
\hline
\end{tabular}




\begin{tabular}{|c|c|c|c|c|c|c|c|c|c|c|c|c|c|c|c|c|}
\hline VarName & VariableLabel & WordingDE & ValueLabelsDE_Linked & WordingEN & ValueLabelsEN_Linked & L1 & $\mathrm{L} 2$ & L3 & $\mathrm{L} 4$ & L5 & L6 & L7 & L8 & L9 & L10 L11 & $1 \mathrm{~L} 12$ \\
\hline Ego.net.P1 & & $\begin{array}{l}\text { Q13.3_1 - Bitte nenne } \\
\text { diejenigen Personen, welche } \\
\text { im letzten halben Jahr für } \\
\text { dich wichtig waren. Dies } \\
\text { können sowohl } \\
\text { Mitstudierende als auch } \\
\text { Personen ausserhalb Deines } \\
\text { Studiums sein, und auch } \\
\text { Personen, mit denen Du } \\
\text { eventuell nicht gut } \\
\text { auskommst. Dies können } \\
\text { beispielsweise } \\
\text { Familienmitglieder, } \\
\text { Partner/Partnerin, } \\
\text { Arbeitskollegen, } \\
\text { Mitbewohner, etc. sein. } \\
\text { Bitte schreibe nur deren } \\
\text { Initialen oder Pseudonyme } \\
\text { in die folgenden Felder (eine } \\
\text { Person pro Feld, maximal } \\
\text { 10 Personen). Bitte vergib } \\
\text { keine } \\
\text { Initialen/Pseudonyme, die } \\
\text { eine Person eindeutig } \\
\text { identifizierbar machen, aber } \\
\text { stelle sicher, dass Du selbst } \\
\text { die Pseudonyme auf den } \\
\text { nächsten Seiten zuordnen } \\
\text { kannst.Nenne zwischen 0 } \\
\text { und 10 Personen. - Person } 1\end{array}$ & & $\begin{array}{l}\text { Please name the people } \\
\text { who have been } \\
\text { important to you [in the } \\
\text { last half-year/during the } \\
\text { COVID-19 crisis } \\
\text { (L11/L12)]. These may } \\
\text { be both fellow students } \\
\text { or people from outside } \\
\text { your study programme, } \\
\text { as well as people with } \\
\text { whom you do not get } \\
\text { along well. These could } \\
\text { be, for example, family } \\
\text { members, your partner, } \\
\text { work colleagues, } \\
\text { housemates, etc. Please } \\
\text { enter only their initials } \\
\text { or pseudonyms in the } \\
\text { following boxes (one } \\
\text { person per box, } \\
\text { maximum } 10 \text { people). } \\
\text { Please do not enter } \\
\text { initials or pseudonyms } \\
\text { that make a person } \\
\text { easily identifiable, but } \\
\text { ensure that you can } \\
\text { recognise the } \\
\text { pseudonyms yourself on } \\
\text { the following pages. }\end{array}$ & & $\mathrm{x}$ & & & $\mathrm{x}$ & & & & & & $\mathrm{x}$ & $\mathrm{x}$ \\
\hline studywith.P1 & & $\begin{array}{l}\text { Q13.5\#1_x1 - Bitte } \\
\text { beantworte folgende Fragen } \\
\text { zu den vorher genannten } \\
\text { Personen. - Studiert diese } \\
\text { Person mit Dir? - Person } 1\end{array}$ & $1=\mathrm{Ja}, 2=$ Nein & $\begin{array}{l}\text { This question refers to } \\
\text { the previously } \\
\text { mentioned persons. - } \\
\text { Does this person study } \\
\text { with you? - Person 1 }\end{array}$ & $1=\mathrm{Yes}, 2=\mathrm{No}$ & $\mathrm{x}$ & & & $\mathrm{x}$ & & & & & & $\mathrm{x}$ & $\mathrm{x}$ \\
\hline role.1.P1 & & $\begin{array}{l}\text { Q13.6\#1_x1_1 - - Diese } \\
\text { Person ist für mich } \\
\text {...(Mehrfachnennungen } \\
\text { möglich) - Person } 1 \text { - } \\
\text { Familie }\end{array}$ & & $\begin{array}{l}\text { To me this person is....- } \\
\text { Person 1- family }\end{array}$ & & $\mathrm{x}$ & & & $\mathrm{x}$ & & & & & & $\mathrm{x}$ & $\mathrm{x}$ \\
\hline role.2.P1 & & $\begin{array}{l}\text { Q13.6\#1_x1_2 - - Diese } \\
\text { Person ist für mich } \\
\text {...(Mehrfachnennungen } \\
\text { möglich) - Person } 1 \text { - } \\
\text { romantische/r Partner/in }\end{array}$ & & $\begin{array}{l}\text { To me this person is....- } \\
\text { Person 1- romantic } \\
\text { partner }\end{array}$ & & $\mathrm{x}$ & & & $\mathrm{x}$ & & & & & & $\mathrm{x}$ & $\mathrm{x}$ \\
\hline role.3.P1 & & $\begin{array}{l}\text { Q13.6\#1_x1_3 - - Diese } \\
\text { Person ist für mich } \\
\text { …Mehrfachnennungen } \\
\text { möglich) - Person } 1 \text { - } \\
\text { Freund/in }\end{array}$ & & $\begin{array}{l}\text { To me this person is....- } \\
\text { Person 1- friend }\end{array}$ & & $\mathrm{x}$ & & & $\mathrm{x}$ & & & & & & $\mathrm{x}$ & $\mathrm{X}$ \\
\hline role.4.P1 & & $\begin{array}{l}\text { Q13.6\#1_x1_4 - - Diese } \\
\text { Person ist für mich } \\
\text {...(Mehrfachnennungen } \\
\text { möglich) - Person } 1 \text { - } \\
\text { Mitbewohner/in }\end{array}$ & & $\begin{array}{l}\text { To me this person is....- } \\
\text { Person 1- roommate }\end{array}$ & & $\mathrm{x}$ & & & $\mathrm{x}$ & & & & & & $\mathrm{x}$ & $\mathrm{x}$ \\
\hline role.5.P1 & & $\begin{array}{l}\text { Q13.6\#1_x1_5 - - Diese } \\
\text { Person ist für mich } \\
\text {...(Mehrfachnennungen } \\
\text { möglich) - Person } 1 \text { - } \\
\text { Arbeitskolleg/in }\end{array}$ & & $\begin{array}{l}\text { To me this person is....- } \\
\text { Person 1- work colleague }\end{array}$ & & $\mathrm{x}$ & & & $\mathrm{x}$ & & & & & & $\mathrm{x}$ & $\mathrm{x}$ \\
\hline
\end{tabular}




\begin{tabular}{|c|c|c|c|c|c|c|c|c|c|c|c|c|c|c|c|c|c|}
\hline VarName & VariableLabel & WordingDE & ValueLabelsDE_Linked & WordingEN & ValueLabelsEN_Linked & L1 & $\mathrm{L} 2$ & L3 & $\mathrm{L} 4$ & L5 & L6 & L7 & L8 & L9 & & $10 \mathrm{~L} 11$ & $\mathrm{~L} 12$ \\
\hline role.6.P1 & & $\begin{array}{l}\text { Q13.6\#1_x1_6 - - Diese } \\
\text { Person ist für mich } \\
\text {...(Mehrfachnennungen } \\
\text { möglich) - Person } 1 \text { - } \\
\text { Sonstiges }\end{array}$ & & $\begin{array}{l}\text { To me this person is....- } \\
\text { Person 1- other }\end{array}$ & & $\mathrm{x}$ & & & $\mathrm{x}$ & & & & & & & $\mathrm{x}$ & $\mathrm{x}$ \\
\hline close.P1 & & $\begin{array}{l}\text { Q13.8\#1_x1 - Bitte } \\
\text { beantworte folgende Fragen } \\
\text { zu den vorher genannten } \\
\text { Personen. - Diese Person } \\
\text { und ich stehen uns sehr } \\
\text { nahe - Person 1 }\end{array}$ & $\begin{array}{l}1=\text { stimmt überhaupt nicht, } \\
2=\text { stimmt nicht, } 3=\text { stimmt } \\
\text { eher nicht, } 4=\text { weder noch, } 5 \\
=\text { stimmt eher, } 6=\text { stimmt, } 7 \\
=\text { stimmt voll und ganz }\end{array}$ & $\begin{array}{l}\text { This person and I are } \\
\text { very close. - Person } 1\end{array}$ & $\begin{array}{l}1=\text { does not apply at all, } \\
2=\text { does not apply, } 3= \\
\text { does rather not apply, } 4= \\
\text { neither, } 5=\text { rather } \\
\text { applies, } 6=\text { applies, } 7= \\
\text { applies completely (free } \\
\text { translation) }\end{array}$ & $\mathrm{x}$ & & & $\mathrm{x}$ & & & & & & & $\mathrm{x}$ & $\mathrm{x}$ \\
\hline frequ.speak.P1 & & $\begin{array}{l}\text { Q13.9\#1_x1 - - Wie oft } \\
\text { unterhältst Du Dich mit } \\
\text { dieser Person? - Person } 1\end{array}$ & $\begin{array}{l}1=\text { mindestens einmal pro } \\
\text { Jahr, } 2=\text { mehrmals pro Jahr, } \\
3=\text { mindestens einmal pro } \\
\text { Monat, } 4=\text { mehrmals pro } \\
\text { Monat, } 5=\text { mindestens } \\
\text { einmal pro Woche, } 6= \\
\text { mehrmals pro Woche, } 7= \\
\text { täglich }\end{array}$ & $\begin{array}{l}\text { How often do you speak } \\
\text { to this person? - Person } \\
1\end{array}$ & $\begin{array}{l}1=\text { at least once per year, } \\
2=\text { a few times a year, } 3 \\
=\text { at least once a month, } \\
4=\text { few times per month } \\
5=\text { at least once a week, } \\
6=\text { few times per week, } 7 \\
=\text { every day }\end{array}$ & $\mathrm{x}$ & & & $\mathrm{x}$ & & & & & & & & \\
\hline valence.P1 & & $\begin{array}{l}\text { Q13.10\#1_x1 - - Wie } \\
\text { würdest Du Deine } \\
\text { Beziehung mit dieser Person } \\
\text { beschreiben? - Person } 1\end{array}$ & $\begin{array}{l}1=\text { sehr konfliktbehaftet, } 2= \\
\text { konfliktbehaftet, } 3=\text { eher } \\
\text { konfliktbehaftet, } 4=\text { neutral, } \\
5=\text { eher harmonisch, } 6= \\
\text { harmonisch, } 7=\text { sehr } \\
\text { harmonisch }\end{array}$ & $\begin{array}{l}\text { How would you describe } \\
\text { your relationship with } \\
\text { this person? - Person } 1\end{array}$ & $\begin{array}{l}1=\text { very conflictual, } 2= \\
\text { conflictual, } 3=\text { rather } \\
\text { conflictual, } 4=\text { neutral, } 5 \\
=\text { rather harmonious, } 6= \\
\text { harmonious, } 7=\text { very } \\
\text { harmonious }\end{array}$ & $\mathrm{x}$ & & & $\mathrm{x}$ & & & & & & & $\mathrm{x}$ & $\mathrm{x}$ \\
\hline known.P1 & & $\begin{array}{l}\text { Q13.12\#1_x1_1 - Bitte } \\
\text { beantworte folgende Fragen } \\
\text { zu den vorher genannten } \\
\text { Personen. - Wie lange } \\
\text { kennst Du diese Person } \\
\text { bereits? - Person 1 - in } \\
\text { Jahren }\end{array}$ & & $\begin{array}{l}\text { This question refers to } \\
\text { the previously } \\
\text { mentioned persons. How } \\
\text { long have you known } \\
\text { this person? Person } 1 \text { - } \\
\text { in years }\end{array}$ & & $\mathrm{x}$ & & & $\mathrm{x}$ & & & & & & & $\mathrm{x}$ & $\mathrm{x}$ \\
\hline emot.support.P1 & & $\begin{array}{l}\text { Q13.13\#1_x1 - - Diese } \\
\text { Person unterstützt mich } \\
\text { wenn ich emotionale Hilfe } \\
\text { brauche (z.B. Trost, Mitleid } \\
\text { und Zuspruch) - Person } 1\end{array}$ & $\begin{array}{l}1=\text { stimmt überhaupt nicht, } \\
2=\text { stimmt nicht, } 3=\text { stimmt } \\
\text { eher nicht, } 4=\text { weder noch, } 5 \\
=\text { stimmt eher, } 6=\text { stimmt, } 7 \\
=\text { stimmt voll und ganz }\end{array}$ & $\begin{array}{l}\text { This person supports me } \\
\text { when I need emotinal } \\
\text { support (e.g. } \\
\text { consolation, sympathy } \\
\text { und encouragement) - } \\
\text { Person } 1\end{array}$ & $\begin{array}{l}1=\text { does not apply at all, } \\
2=\text { does not apply, } 3= \\
\text { does rather not apply, } 4= \\
\text { neither, } 5=\text { rather } \\
\text { applies, } 6=\text { applies, } 7= \\
\text { applies completely (free } \\
\text { translation) }\end{array}$ & $\mathrm{x}$ & & & $\mathrm{x}$ & & & & & & & $\mathrm{x}$ & $\mathrm{x}$ \\
\hline attitude.degree.P1 & & $\begin{array}{l}\text { Q13.14\#1_x1 - - Wie ist } \\
\text { die Einstellung dieser } \\
\text { Person zu einem } \\
\text { Universitätsabschluss? - } \\
\text { Person 1 }\end{array}$ & $\begin{array}{l}1=\text { sehr negativ, } 2= \\
\text { negativ, } 3=\text { eher negativ, } 4 \\
=\text { neutral, } 5=\text { eher positiv, } 6 \\
=\text { positiv, } 7=\text { sehr positiv }\end{array}$ & $\begin{array}{l}\text { What is this person's } \\
\text { attitude towards your } \\
\text { university degree? - } \\
\text { Person } 1\end{array}$ & $\begin{array}{l}1=\text { very negative, } 2= \\
\text { negative, } 3=\text { rather } \\
\text { negative, } 4=\text { neutral, } 5= \\
\text { rather positive, } 6= \\
\text { positive, } 7=\text { very positive }\end{array}$ & $\mathrm{x}$ & & & $\mathrm{x}$ & & & & & & & & \\
\hline identities. 1 & & $\begin{array}{l}\text { Q14.3 - Wie } \\
\text { starkidentifizierst Du Dich } \\
\text { mit [university name]? }\end{array}$ & $\begin{array}{l}1=1,2,3,4,5,6,7,2= \\
1,2,3,4,5,6,7,3= \\
1,2,3,4,5,6,7,4= \\
1,2,3,4,5,6,7,5= \\
1,2,3,4,5,6,7,6= \\
1,2,3,4,5,6,7,7=1,2,3,4,5,6,7\end{array}$ & $\begin{array}{l}\text { How strongly do you } \\
\text { identify with the } \\
\text { [university name]? }\end{array}$ & $\begin{array}{l}1=1,2,3,4,5,6,7,2= \\
1,2,3,4,5,6,7,3= \\
1,2,3,4,5,6,7,4= \\
1,2,3,4,5,6,7,5= \\
1,2,3,4,5,6,7,6= \\
1,2,3,4,5,6,7,7= \\
1,2,3,4,5,6,7\end{array}$ & $\mathrm{x}$ & $\mathrm{x}$ & $\mathrm{x}$ & $\mathrm{x}$ & $\mathrm{x}$ & $\mathrm{x}$ & $\mathrm{x}$ & $\mathrm{x}$ & $\mathrm{x}$ & $\mathrm{x}$ & $\mathrm{x}$ & $\mathrm{x}$ \\
\hline identities. 2 & & $\begin{array}{l}\text { Q14.4 - Wie stark } \\
\text { identifizierst Du Dich mit } \\
\text { der Gemeinschaft der } \\
\text { Studierenden an deinem } \\
\text { Departement generell? }\end{array}$ & $\begin{array}{l}1=1,2,3,4,5,6,7,2= \\
1,2,3,4,5,6,7,3= \\
1,2,3,4,5,6,7,4= \\
1,2,3,4,5,6,7,5= \\
1,2,3,4,5,6,7,6= \\
1,2,3,4,5,6,7,7=1,2,3,4,5,6,7\end{array}$ & $\begin{array}{l}\text { How strongly do you } \\
\text { identify with the } \\
\text { community of students } \\
\text { in your department? }\end{array}$ & $\begin{array}{l}1=1,2,3,4,5,6,7,2= \\
1,2,3,4,5,6,7,3= \\
1,2,3,4,5,6,7,4= \\
1,2,3,4,5,6,7,5= \\
1,2,3,4,5,6,7,6= \\
1,2,3,4,5,6,7,7= \\
1,2,3,4,5,6,7\end{array}$ & $\mathrm{x}$ & $\mathrm{x}$ & $\mathrm{x}$ & $\mathrm{x}$ & $\mathrm{x}$ & $\mathrm{x}$ & $\mathrm{x}$ & $\mathrm{x}$ & $\mathrm{x}$ & $\mathrm{x}$ & $\mathrm{x}$ & $\mathrm{x}$ \\
\hline
\end{tabular}




\begin{tabular}{|c|c|c|c|c|c|c|c|c|c|c|c|c|c|c|c|c|c|}
\hline VarName & VariableLabel & WordingDE & ValueLabelsDE_Linked & WordingEN & ValueLabelsEN_Linked & L1 & $\mathrm{L} 2$ & L3 & $\mathrm{L} 4$ & L5 & L6 & L7 & L8 & L9 & L10 & L11 & $1 \mathrm{~L} 12$ \\
\hline identities. 3 & & $\begin{array}{l}\text { Q14.5 - Wie stark } \\
\text { identifizierst Du Dich mit } \\
\text { der Wissenschaftlichen } \\
\text { Gemeinschaft generell? }\end{array}$ & $\begin{array}{l}1=1,2,3,4,5,6,7,2= \\
1,2,3,4,5,6,7,3= \\
1,2,3,4,5,6,7,4= \\
1,2,3,4,5,6,7,5= \\
1,2,3,4,5,6,7,6= \\
1,2,3,4,5,6,7,7=1,2,3,4,5,6,7\end{array}$ & $\begin{array}{l}\text { How strongly do you } \\
\text { identify with the } \\
\text { scientific community? }\end{array}$ & $\begin{array}{l}1=1,2,3,4,5,6,7,2= \\
1,2,3,4,5,6,7,3= \\
1,2,3,4,5,6,7,4= \\
1,2,3,4,5,6,7,5= \\
1,2,3,4,5,6,7,6= \\
1,2,3,4,5,6,7,7= \\
1,2,3,4,5,6,7\end{array}$ & $\mathrm{x}$ & $\mathrm{x}$ & $\mathrm{x}$ & $\mathrm{x}$ & $\mathrm{x}$ & $\mathrm{x}$ & $\mathrm{x}$ & $\mathrm{x}$ & $\mathrm{x}$ & $\mathrm{x}$ & $\mathrm{x}$ & $\mathrm{x}$ \\
\hline identities.4 & & $\begin{array}{l}\text { Q14.6 - Wie stark } \\
\text { identifizierst Du Dich mit } \\
\text { der [field of major] als } \\
\text { Wissenschaft? }\end{array}$ & $\begin{array}{l}1=1,2,3,4,5,6,7,2= \\
1,2,3,4,5,6,7,3= \\
1,2,3,4,5,6,7,4= \\
1,2,3,4,5,6,7,5= \\
1,2,3,4,5,6,7,6= \\
1,2,3,4,5,6,7,7=1,2,3,4,5,6,7\end{array}$ & $\begin{array}{l}\text { How strongly do you } \\
\text { identify with [field of } \\
\text { major] as a science? }\end{array}$ & $\begin{array}{l}1=1,2,3,4,5,6,7,2= \\
1,2,3,4,5,6,7,3= \\
1,2,3,4,5,6,7,4= \\
1,2,3,4,5,6,7,5= \\
1,2,3,4,5,6,7,6= \\
1,2,3,4,5,6,7,7= \\
1,2,3,4,5,6,7\end{array}$ & $\mathrm{x}$ & $\mathrm{x}$ & $\mathrm{x}$ & $\mathrm{x}$ & $\mathrm{x}$ & $\mathrm{x}$ & $\mathrm{x}$ & $\mathrm{x}$ & $\mathrm{x}$ & $\mathrm{x}$ & & \\
\hline identities.5 & & $\begin{array}{l}\text { Q14.7 - Wie stark } \\
\text { identifizierst Du Dich mit } \\
\text { Männern generell? }\end{array}$ & $\begin{array}{l}1=1,2,3,4,5,6,7,2= \\
1,2,3,4,5,6,7,3= \\
1,2,3,4,5,6,7,4= \\
1,2,3,4,5,6,7,5= \\
1,2,3,4,5,6,7,6= \\
1,2,3,4,5,6,7,7=1,2,3,4,5,6,7\end{array}$ & $\begin{array}{l}\text { How strongly do you } \\
\text { identify with men } \\
\text { generally? }\end{array}$ & $\begin{array}{l}1=1,2,3,4,5,6,7,2= \\
1,2,3,4,5,6,7,3= \\
1,2,3,4,5,6,7,4= \\
1,2,3,4,5,6,7,5= \\
1,2,3,4,5,6,7,6= \\
1,2,3,4,5,6,7,7= \\
1,2,3,4,5,6,7\end{array}$ & $\mathrm{x}$ & $\mathrm{x}$ & $\mathrm{x}$ & $\mathrm{x}$ & $\mathrm{x}$ & $\mathrm{x}$ & $\mathrm{x}$ & $\mathrm{x}$ & $\mathrm{x}$ & $\mathrm{x}$ & & \\
\hline identities. 6 & & $\begin{array}{l}\text { Q14.8 - Wie stark } \\
\text { identifizierst Du Dich mit } \\
\text { Frauen generell? }\end{array}$ & $\begin{array}{l}1=1,2,3,4,5,6,7,2= \\
1,2,3,4,5,6,7,3= \\
1,2,3,4,5,6,7,4= \\
1,2,3,4,5,6,7,5= \\
1,2,3,4,5,6,7,6= \\
1,2,3,4,5,6,7,7=1,2,3,4,5,6,7\end{array}$ & $\begin{array}{l}\text { How strongly do you } \\
\text { identify with women } \\
\text { generally? }\end{array}$ & $\begin{array}{l}1=1,2,3,4,5,6,7,2= \\
1,2,3,4,5,6,7,3= \\
1,2,3,4,5,6,7,4= \\
1,2,3,4,5,6,7,5= \\
1,2,3,4,5,6,7,6= \\
1,2,3,4,5,6,7,7= \\
1,2,3,4,5,6,7\end{array}$ & $\mathrm{x}$ & $\mathrm{x}$ & $\mathrm{x}$ & $\mathrm{x}$ & $\mathrm{x}$ & $\mathrm{x}$ & $\mathrm{x}$ & $\mathrm{x}$ & $\mathrm{x}$ & $\mathrm{x}$ & & \\
\hline identities.7 & & $\begin{array}{l}\text { Q14.9 - Wie stark } \\
\text { identifizierst Du Dich mit } \\
\text { der Schweiz? }\end{array}$ & $\begin{array}{l}1=1,2,3,4,5,6,7,2= \\
1,2,3,4,5,6,7,3= \\
1,2,3,4,5,6,7,4= \\
1,2,3,4,5,6,7,5= \\
1,2,3,4,5,6,7,6= \\
1,2,3,4,5,6,7,7=1,2,3,4,5,6,7\end{array}$ & $\begin{array}{l}\text { How strongly do you } \\
\text { identify with } \\
\text { Switzerland? }\end{array}$ & $\begin{array}{l}1=1,2,3,4,5,6,7,2= \\
1,2,3,4,5,6,7,3= \\
1,2,3,4,5,6,7,4= \\
1,2,3,4,5,6,7,5= \\
1,2,3,4,5,6,7,6= \\
1,2,3,4,5,6,7,7= \\
1,2,3,4,5,6,7\end{array}$ & $\mathrm{x}$ & $\mathrm{x}$ & $\mathrm{x}$ & $\mathrm{x}$ & $\mathrm{X}$ & $\mathrm{x}$ & $\mathrm{x}$ & $\mathrm{x}$ & $\mathrm{X}$ & $\mathrm{X}$ & & \\
\hline identities. 8 & & $\begin{array}{l}\text { Q14.10 - Wie stark } \\
\text { identifizierst Du Dich mit } \\
\text { deinem Herkunftskanton } \\
\text { ([QID759-ChoiceGroup- } \\
\text { SelectedChoices])? }\end{array}$ & $\begin{array}{l}1=1,2,3,4,5,6,7,2= \\
1,2,3,4,5,6,7,3= \\
1,2,3,4,5,6,7,4= \\
1,2,3,4,5,6,7,5= \\
1,2,3,4,5,6,7,6= \\
1,2,3,4,5,6,7,7=1,2,3,4,5,6,7\end{array}$ & $\begin{array}{l}\text { How strongly do you } \\
\text { identify with your } \\
\text { canton of origin? }\end{array}$ & $\begin{array}{l}1=1,2,3,4,5,6,7,2= \\
1,2,3,4,5,6,7,3= \\
1,2,3,4,5,6,7,4= \\
1,2,3,4,5,6,7,5= \\
1,2,3,4,5,6,7,6= \\
1,2,3,4,5,6,7,7= \\
1,2,3,4,5,6,7\end{array}$ & $\mathrm{x}$ & $\mathrm{x}$ & $\mathrm{x}$ & $\mathrm{x}$ & $\mathrm{x}$ & $\mathrm{x}$ & $\mathrm{x}$ & $\mathrm{x}$ & $\mathrm{x}$ & $\mathrm{x}$ & & \\
\hline identities.9 & & $\begin{array}{l}\text { Q14.11 - Wie stark } \\
\text { identifizierst Du Dich mit } \\
\text { anderen Personen Deiner } \\
\text { Nationalität } \\
\text { ([QID758-ChoiceGroup- } \\
\text { SelectedChoicesTextEntry])? }\end{array}$ & $\begin{array}{l}1=1,2,3,4,5,6,7,2= \\
1,2,3,4,5,6,7,3= \\
1,2,3,4,5,6,7,4= \\
1,2,3,4,5,6,7,5= \\
1,2,3,4,5,6,7,6= \\
1,2,3,4,5,6,7,7=1,2,3,4,5,6,7\end{array}$ & $\begin{array}{l}\text { How strongly do you } \\
\text { identify with other } \\
\text { people of your } \\
\text { nationality? }\end{array}$ & $\begin{array}{l}1=1,2,3,4,5,6,7,2= \\
1,2,3,4,5,6,7,3= \\
1,2,3,4,5,6,7,4= \\
1,2,3,4,5,6,7,5= \\
1,2,3,4,5,6,7,6= \\
1,2,3,4,5,6,7,7= \\
1,2,3,4,5,6,7\end{array}$ & $\mathrm{x}$ & $\mathrm{x}$ & $\mathrm{x}$ & $\mathrm{x}$ & $\mathrm{x}$ & $\mathrm{x}$ & $\mathrm{x}$ & $\mathrm{x}$ & $\mathrm{x}$ & $\mathrm{x}$ & & \\
\hline depression.1 & $\begin{array}{l}\text { Depression } \\
\text { Item } 1\end{array}$ & $\begin{array}{l}\text { Während der letzten Woche } \\
\text { haben mich Dinge } \\
\text { beunruhigt, die mir sonst } \\
\text { nichts ausmachen }\end{array}$ & $\begin{array}{l}0=\text { selten und überhaupt } \\
\text { nicht (weniger als einen Tag } \\
\text { lang), } 1=\text { manchmal ( ein bis } \\
\text { zwei Tage lang), } 2=\text { öfters ( } \\
\text { drei bis vier Tage lang), } 3= \\
\text { meistens, die ganze Zeit ( } \\
\text { fünf oder mehrere Tage lang) }\end{array}$ & $\begin{array}{l}\text { how often you have felt } \\
\text { this way in the past } \\
\text { week: I was bothered by } \\
\text { things that usually } \\
\text { don't bother me }\end{array}$ & $\begin{array}{l}0=\text { seldom and never } \\
\text { (less than a day), } 1= \\
\text { sometimes(one or two } \\
\text { days) }, 2=\text { often(three or } \\
\text { four days), } 3=\text { usually, } \\
\text { all the time (five or more } \\
\text { days) }\end{array}$ & $\mathrm{x}$ & $\mathrm{x}$ & $\mathrm{x}$ & $\mathrm{x}$ & $\mathrm{x}$ & $\mathrm{x}$ & $\mathrm{x}$ & $\mathrm{x}$ & $\mathrm{x}$ & $\mathrm{x}$ & $\mathrm{x}$ & $\mathrm{x}$ \\
\hline depression.2 & $\begin{array}{l}\text { Depression } \\
\text { Item } 2\end{array}$ & $\begin{array}{l}\text { Während der letzten Woche } \\
\text { hatte ich kaum Appetit }\end{array}$ & $\begin{array}{l}0=\text { selten und überhaupt } \\
\text { nicht (weniger als einen Tag } \\
\text { lang), } 1=\text { manchmal ( ein bis } \\
\text { zwei Tage lang), } 2=\text { öfters ( } \\
\text { drei bis vier Tage lang), } 3= \\
\text { meistens, die ganze Zeit ( } \\
\text { fünf oder mehrere Tage lang) }\end{array}$ & $\begin{array}{l}\text { how often you have felt } \\
\text { this way in the past } \\
\text { week: My appetite was } \\
\text { poor }\end{array}$ & $\begin{array}{l}0=\text { seldom and never } \\
\text { (less than a day) }, 1= \\
\text { sometimes(one or two } \\
\text { days) } 2=\text { often(three or } \\
\text { four days), } 3=\text { usually, } \\
\text { all the time (five or more } \\
\text { days) }\end{array}$ & $\mathrm{x}$ & $\mathrm{x}$ & $\mathrm{x}$ & $\mathrm{x}$ & $\mathrm{x}$ & $\mathrm{x}$ & $\mathrm{x}$ & $\mathrm{x}$ & $\mathrm{x}$ & $\mathrm{x}$ & $\mathrm{x}$ & $\mathrm{x}$ \\
\hline
\end{tabular}




\begin{tabular}{|c|c|c|c|c|c|c|c|c|c|c|c|c|c|c|c|c|c|}
\hline VarName & VariableLabel & WordingDE & ValueLabelsDE_Linked & WordingEN & ValueLabelsEN_Linked & L1 & $\mathrm{L} 2$ & L3 & $\mathrm{L} 4$ & L5 & L6 & L7 & L8 & L9 & L10 & L11 & L12 \\
\hline depression.3 & $\begin{array}{l}\text { Depression } \\
\text { Item } 3\end{array}$ & $\begin{array}{l}\text { Während der letzten Woche } \\
\text { konnte ich meine } \\
\text { trübsinnige Laune nicht } \\
\text { loswerden, obwohl mich } \\
\text { meine Freunde/Familie } \\
\text { versuchten, aufzumuntern }\end{array}$ & $\begin{array}{l}0=\text { selten und überhaupt } \\
\text { nicht (weniger als einen Tag } \\
\text { lang), } 1=\text { manchmal ( ein bis } \\
\text { zwei Tage lang), } 2=\text { öfters ( } \\
\text { drei bis vier Tage lang), } 3= \\
\text { meistens, die ganze Zeit ( } \\
\text { fünf oder mehrere Tage lang) }\end{array}$ & $\begin{array}{l}\text { how often you have felt } \\
\text { this way in the past } \\
\text { week: I felt that I could } \\
\text { not shake off the blues } \\
\text { even with help from my } \\
\text { family or friends }\end{array}$ & $\begin{array}{l}0=\text { seldom and never } \\
\text { (less than a day), } 1= \\
\text { sometimes(one or two } \\
\text { days) }, 2=\text { often(three or } \\
\text { four days), } 3=\text { usually, } \\
\text { all the time (five or more } \\
\text { days) }\end{array}$ & $\mathrm{x}$ & $\mathrm{x}$ & $\mathrm{x}$ & $\mathrm{x}$ & $\mathrm{x}$ & $\mathrm{x}$ & $\mathrm{x}$ & $\mathrm{x}$ & $\mathrm{x}$ & $\mathrm{x}$ & $\mathrm{x}$ & $\mathrm{x}$ \\
\hline depression. 4 & $\begin{array}{l}\text { Depression } \\
\text { Item } 4\end{array}$ & $\begin{array}{l}\text { Während der letzten Woche } \\
\text { kam ich mir genauso gut } \\
\text { vor wie andere }\end{array}$ & $\begin{array}{l}0=\text { selten und überhaupt } \\
\text { nicht (weniger als einen Tag } \\
\text { lang), } 1=\text { manchmal ( ein bis } \\
\text { zwei Tage lang), } 2=\text { öfters ( } \\
\text { drei bis vier Tage lang), } 3= \\
\text { meistens, die ganze Zeit ( } \\
\text { fünf oder mehrere Tage lang) }\end{array}$ & $\begin{array}{l}\text { how often you have felt } \\
\text { this way in the past } \\
\text { week: I felt that I was } \\
\text { just as good as other } \\
\text { people }\end{array}$ & $\begin{array}{l}0=\text { seldom and never } \\
\text { (less than a day) } 1= \\
\text { sometimes(one or two } \\
\text { days) } 2=\text { often(three or } \\
\text { four days), } 3=\text { usually, } \\
\text { all the time (five or more } \\
\text { days) }\end{array}$ & $\mathrm{x}$ & $\mathrm{x}$ & $\mathrm{x}$ & $\mathrm{x}$ & $\mathrm{x}$ & $\mathrm{x}$ & $\mathrm{x}$ & $\mathrm{x}$ & $\mathrm{x}$ & $\mathrm{x}$ & $\mathrm{x}$ & $\mathrm{x}$ \\
\hline depression.5 & $\begin{array}{l}\text { Depression } \\
\text { Item } 5\end{array}$ & $\begin{array}{l}\text { Während der letzten Woche } \\
\text { hatte ich Mühe, mich zu } \\
\text { konzentrieren }\end{array}$ & $\begin{array}{l}0=\text { selten und überhaupt } \\
\text { nicht (weniger als einen Tag } \\
\text { lang), } 1=\text { manchmal ( ein bis } \\
\text { zwei Tage lang), } 2=\text { öfters ( } \\
\text { drei bis vier Tage lang), } 3= \\
\text { meistens, die ganze Zeit ( } \\
\text { fünf oder mehrere Tage lang) }\end{array}$ & $\begin{array}{l}\text { how often you have felt } \\
\text { this way in the past } \\
\text { week: I had trouble } \\
\text { keeping my mind on } \\
\text { what I was doing }\end{array}$ & $\begin{array}{l}0=\text { seldom and never } \\
\text { (less than a day), } 1= \\
\text { sometimes(one or two } \\
\text { days) }, 2=\text { often(three or } \\
\text { four days), } 3=\text { usually, } \\
\text { all the time (five or more } \\
\text { days) }\end{array}$ & $\mathrm{x}$ & $\mathrm{x}$ & $\mathrm{x}$ & $\mathrm{x}$ & $\mathrm{x}$ & $\mathrm{x}$ & $\mathrm{x}$ & $\mathrm{x}$ & $\mathrm{x}$ & $\mathrm{x}$ & $\mathrm{x}$ & $\mathrm{x}$ \\
\hline depression.6 & $\begin{array}{l}\text { Depression } \\
\text { Item } 6\end{array}$ & $\begin{array}{l}\text { Während der letzten Woche } \\
\text { war ich } \\
\text { deprimiert/niedergeschlagen }\end{array}$ & $\begin{array}{l}0=\text { selten und überhaupt } \\
\text { nicht (weniger als einen Tag } \\
\text { lang), } 1=\text { manchmal ( ein bis } \\
\text { zwei Tage lang), } 2=\text { ofters ( } \\
\text { drei bis vier Tage lang), } 3= \\
\text { meistens, die ganze Zeit ( } \\
\text { fünf oder mehrere Tage lang) }\end{array}$ & $\begin{array}{l}\text { how often you have felt } \\
\text { this way in the past } \\
\text { week: I felt depressed }\end{array}$ & $\begin{array}{l}0=\text { seldom and never } \\
\text { (less than a day), } 1= \\
\text { sometimes(one or two } \\
\text { days) }, 2=\text { often(three or } \\
\text { four days), } 3=\text { usually, } \\
\text { all the time (five or more } \\
\text { days) }\end{array}$ & $\mathrm{x}$ & $\mathrm{x}$ & $\mathrm{x}$ & $\mathrm{x}$ & $\mathrm{x}$ & $\mathrm{x}$ & $\mathrm{x}$ & $\mathrm{x}$ & $\mathrm{x}$ & $\mathrm{x}$ & $\mathrm{x}$ & $\mathrm{x}$ \\
\hline depression.7 & $\begin{array}{l}\text { Depression } \\
\text { Item } 7\end{array}$ & $\begin{array}{l}\text { Während der letzten Woche } \\
\text { war alles anstrengend für } \\
\text { mich }\end{array}$ & $\begin{array}{l}0=\text { selten und überhaupt } \\
\text { nicht (weniger als einen Tag } \\
\text { lang), } 1=\text { manchmal ( ein bis } \\
\text { zwei Tage lang), } 2=\text { öfters ( } \\
\text { drei bis vier Tage lang), } 3= \\
\text { meistens, die ganze Zeit ( } \\
\text { fünf oder mehrere Tage lang) }\end{array}$ & $\begin{array}{l}\text { how often you have felt } \\
\text { this way in the past } \\
\text { week: I felt that } \\
\text { everything I did was an } \\
\text { effort }\end{array}$ & $\begin{array}{l}0=\text { seldom and never } \\
\text { (less than a day), } 1= \\
\text { sometimes(one or two } \\
\text { days), } 2=\text { often(three or } \\
\text { four days), } 3=\text { usually, } \\
\text { all the time (five or more } \\
\text { days) }\end{array}$ & $\mathrm{x}$ & $\mathrm{x}$ & $\mathrm{x}$ & $\mathrm{x}$ & $\mathrm{x}$ & $\mathrm{x}$ & $\mathrm{x}$ & $\mathrm{x}$ & $\mathrm{x}$ & $\mathrm{x}$ & $\mathrm{x}$ & $\mathrm{x}$ \\
\hline depression.8 & $\begin{array}{l}\text { Depression } \\
\text { Item } 8\end{array}$ & $\begin{array}{l}\text { Während der letzten Woche } \\
\text { dachte ich voller Hoffnung } \\
\text { an die Zukunft }\end{array}$ & $\begin{array}{l}0=\text { selten und überhaupt } \\
\text { nicht (weniger als einen Tag } \\
\text { lang), } 1=\text { manchmal ( ein bis } \\
\text { zwei Tage lang), } 2=\text { öfters ( } \\
\text { drei bis vier Tage lang), } 3= \\
\text { meistens, die ganze Zeit ( } \\
\text { fünf oder mehrere Tage lang) }\end{array}$ & $\begin{array}{l}\text { how often you have felt } \\
\text { this way in the past } \\
\text { week: I felt hopeful } \\
\text { about the future }\end{array}$ & $\begin{array}{l}0=\text { seldom and never } \\
\text { (less than a day), } 1= \\
\text { sometimes(one or two } \\
\text { days), } 2=\text { often(three or } \\
\text { four days), } 3=\text { usually, } \\
\text { all the time (five or more } \\
\text { days) }\end{array}$ & $\mathrm{x}$ & $\mathrm{x}$ & $\mathrm{x}$ & $\mathrm{x}$ & $\mathrm{x}$ & $\mathrm{x}$ & $\mathrm{x}$ & $\mathrm{x}$ & $\mathrm{x}$ & $\mathrm{x}$ & $\mathrm{x}$ & $\mathrm{x}$ \\
\hline depression.9 & $\begin{array}{l}\text { Depression } \\
\text { Item } 9\end{array}$ & $\begin{array}{l}\text { Während der letzten Woche } \\
\text { dachte ich, mein Leben ist } \\
\text { ein einziger Fehlschlag }\end{array}$ & $\begin{array}{l}0=\text { selten und überhaupt } \\
\text { nicht (weniger als einen Tag } \\
\text { lang), } 1=\text { manchmal ( ein bis } \\
\text { zwei Tage lang), } 2=\text { öfters ( } \\
\text { drei bis vier Tage lang), } 3= \\
\text { meistens, die ganze Zeit ( } \\
\text { fünf oder mehrere Tage lang) }\end{array}$ & $\begin{array}{l}\text { how often you have felt } \\
\text { this way in the past } \\
\text { week: I thought my life } \\
\text { had been a failure }\end{array}$ & $\begin{array}{l}0=\text { seldom and never } \\
\text { (less than a day), } 1= \\
\text { sometimes(one or two } \\
\text { days) }, 2=\text { often(three or } \\
\text { four days), } 3=\text { usually, } \\
\text { all the time (five or more } \\
\text { days) }\end{array}$ & $\mathrm{x}$ & $\mathrm{x}$ & $\mathrm{x}$ & $\mathrm{x}$ & $\mathrm{x}$ & $\mathrm{x}$ & $\mathrm{x}$ & $\mathrm{x}$ & $\mathrm{x}$ & $\mathrm{x}$ & $\mathrm{x}$ & $\mathrm{x}$ \\
\hline depression.10 & $\begin{array}{l}\text { Depression } \\
\text { Item } 10\end{array}$ & $\begin{array}{l}\text { Während der letzten Woche } \\
\text { hatte ich Angst }\end{array}$ & $\begin{array}{l}0=\text { selten und überhaupt } \\
\text { nicht (weniger als einen Tag } \\
\text { lang), } 1=\text { manchmal ( ein bis } \\
\text { zwei Tage lang), } 2=\text { öfters ( } \\
\text { drei bis vier Tage lang), } 3= \\
\text { meistens, die ganze Zeit ( } \\
\text { fünf oder mehrere Tage lang) }\end{array}$ & $\begin{array}{l}\text { how often you have felt } \\
\text { this way in the past } \\
\text { week: I felt fearful }\end{array}$ & $\begin{array}{l}0=\text { seldom and never } \\
\text { (less than a day), } 1= \\
\text { sometimes(one or two } \\
\text { days) }, 2=\text { often(three or } \\
\text { four days), } 3=\text { usually, } \\
\text { all the time (five or more } \\
\text { days) }\end{array}$ & $\mathrm{x}$ & $\mathrm{x}$ & $\mathrm{x}$ & $\mathrm{x}$ & $\mathrm{x}$ & $\mathrm{x}$ & $\mathrm{x}$ & $\mathrm{x}$ & $\mathrm{x}$ & $\mathrm{x}$ & $\mathrm{x}$ & $\mathrm{x}$ \\
\hline depression.11 & $\begin{array}{l}\text { Depression } \\
\text { Item } 11\end{array}$ & $\begin{array}{l}\text { Während der letzten Woche } \\
\text { habe ich schlecht geschlafen }\end{array}$ & $\begin{array}{l}0=\text { selten und überhaupt } \\
\text { nicht (weniger als einen Tag } \\
\text { lang), } 1=\text { manchmal ( ein bis } \\
\text { zwei Tage lang), } 2=\text { öfters ( } \\
\text { drei bis vier Tage lang), } 3= \\
\text { meistens, die ganze Zeit ( } \\
\text { fünf oder mehrere Tage lang) }\end{array}$ & $\begin{array}{l}\text { how often you have felt } \\
\text { this way in the past } \\
\text { week: My sleep was } \\
\text { restless }\end{array}$ & $\begin{array}{l}0=\text { seldom and never } \\
\text { (less than a day), } 1= \\
\text { sometimes(one or two } \\
\text { days), } 2=\text { often(three or } \\
\text { four days), } 3=\text { usually, } \\
\text { all the time (five or more } \\
\text { days) }\end{array}$ & $\mathrm{x}$ & $\mathrm{x}$ & $\mathrm{x}$ & $\mathrm{x}$ & $\mathrm{x}$ & $\mathrm{x}$ & $\mathrm{x}$ & $\mathrm{x}$ & $\mathrm{x}$ & $\mathrm{x}$ & $\mathrm{x}$ & $\mathrm{X}$ \\
\hline
\end{tabular}




\begin{tabular}{|c|c|c|c|c|c|c|c|c|c|c|c|c|c|c|c|c|c|}
\hline VarName & VariableLabel & WordingDE & ValueLabelsDE_Linked & WordingEN & ValueLabelsEN_Linked & L1 & $\mathrm{L} 2$ & L3 & $\mathrm{L} 4$ & L5 & L6 & L7 & L8 & L9 & L10 & L L11 & L12 \\
\hline depression.12 & $\begin{array}{l}\text { Depression } \\
\text { Item } 12\end{array}$ & $\begin{array}{l}\text { Während der letzten Woche } \\
\text { war ich fröhlich gestimmt }\end{array}$ & $\begin{array}{l}0=\text { selten und überhaupt } \\
\text { nicht (weniger als einen Tag } \\
\text { lang), } 1=\text { manchmal ( ein bis } \\
\text { zwei Tage lang), } 2=\text { öfters ( } \\
\text { drei bis vier Tage lang), } 3= \\
\text { meistens, die ganze Zeit ( } \\
\text { fünf oder mehrere Tage lang) }\end{array}$ & $\begin{array}{l}\text { how often you have felt } \\
\text { this way in the past } \\
\text { week: I was happy }\end{array}$ & $\begin{array}{l}0=\text { seldom and never } \\
\text { (less than a day), } 1= \\
\text { sometimes(one or two } \\
\text { days) }, 2=\text { often(three or } \\
\text { four days) } 3=\text { usually, } \\
\text { all the time (five or more } \\
\text { days) }\end{array}$ & $\mathrm{x}$ & $\mathrm{x}$ & $\mathrm{x}$ & $\mathrm{x}$ & $\mathrm{x}$ & $\mathrm{x}$ & $\mathrm{x}$ & $\mathrm{x}$ & $\mathrm{x}$ & $\mathrm{x}$ & $\mathrm{x}$ & $\mathrm{x}$ \\
\hline depression.13 & $\begin{array}{l}\text { Depression } \\
\text { Item } 13\end{array}$ & $\begin{array}{l}\text { Während der letzten Woche } \\
\text { habe ich weniger als sonst } \\
\text { geredet }\end{array}$ & $\begin{array}{l}0=\text { selten und überhaupt } \\
\text { nicht (weniger als einen Tag } \\
\text { lang), } 1=\text { manchmal ( ein bis } \\
\text { zwei Tage lang), } 2=\text { öfters ( } \\
\text { drei bis vier Tage lang), } 3= \\
\text { meistens, die ganze Zeit ( } \\
\text { fünf oder mehrere Tage lang) }\end{array}$ & $\begin{array}{l}\text { how often you have felt } \\
\text { this way in the past } \\
\text { week: I talked less than } \\
\text { usual }\end{array}$ & $\begin{array}{l}0=\text { seldom and never } \\
(\text { less than a day), } 1= \\
\text { sometimes(one or two } \\
\text { days), } 2=\text { often(three or } \\
\text { four days) } 3=\text { usually, } \\
\text { all the time (five or more } \\
\text { days) }\end{array}$ & $\mathrm{x}$ & $\mathrm{x}$ & $\mathrm{x}$ & $\mathrm{x}$ & $\mathrm{x}$ & $\mathrm{x}$ & $\mathrm{x}$ & $\mathrm{x}$ & $\mathrm{x}$ & $\mathrm{x}$ & $\mathrm{x}$ & $\mathrm{x}$ \\
\hline depression.14 & $\begin{array}{l}\text { Depression } \\
\text { Item } 14\end{array}$ & $\begin{array}{l}\text { Während der letzten Woche } \\
\text { fühlte ich mich einsam }\end{array}$ & $\begin{array}{l}0=\text { selten und überhaupt } \\
\text { nicht (weniger als einen Tag } \\
\text { lang), } 1=\text { manchmal ( ein bis } \\
\text { zwei Tage lang), } 2=\text { öfters ( } \\
\text { drei bis vier Tage lang), } 3= \\
\text { meistens, die ganze Zeit ( } \\
\text { fünf oder mehrere Tage lang) }\end{array}$ & $\begin{array}{l}\text { how often you have felt } \\
\text { this way in the past } \\
\text { week: I felt lonely }\end{array}$ & $\begin{array}{l}0=\text { seldom and never } \\
\text { (less than a day), } 1= \\
\text { sometimes(one or two } \\
\text { days) }, 2=\text { often(three or } \\
\text { four days), } 3=\text { usually, } \\
\text { all the time (five or more } \\
\text { days) }\end{array}$ & $\mathrm{x}$ & $\mathrm{x}$ & $\mathrm{x}$ & $\mathrm{x}$ & $\mathrm{x}$ & $\mathrm{x}$ & $\mathrm{x}$ & $\mathrm{x}$ & $\mathrm{x}$ & $\mathrm{x}$ & $\mathrm{x}$ & $\mathrm{x}$ \\
\hline depression.15 & $\begin{array}{l}\text { Depression } \\
\text { Item } 15\end{array}$ & $\begin{array}{l}\text { Während der letzten Woche } \\
\text { waren die Leute } \\
\text { unfreundlich zu mir }\end{array}$ & $\begin{array}{l}0=\text { selten und überhaupt } \\
\text { nicht (weniger als einen Tag } \\
\text { lang), } 1=\text { manchmal ( ein bis } \\
\text { zwei Tage lang), } 2=\text { öfters ( } \\
\text { drei bis vier Tage lang), } 3= \\
\text { meistens, die ganze Zeit ( } \\
\text { fünf oder mehrere Tage lang) }\end{array}$ & $\begin{array}{l}\text { how often you have felt } \\
\text { this way in the past } \\
\text { week: People were } \\
\text { unfriendly }\end{array}$ & $\begin{array}{l}0=\text { seldom and never } \\
\text { (less than a day) }, 1= \\
\text { sometimes(one or two } \\
\text { days) }, 2=\text { often (three or } \\
\text { four days) } 3=\text { usually, } \\
\text { all the time (five or more } \\
\text { days) }\end{array}$ & $\mathrm{x}$ & $\mathrm{x}$ & $\mathrm{x}$ & $\mathrm{x}$ & $\mathrm{x}$ & $\mathrm{x}$ & $\mathrm{x}$ & $\mathrm{x}$ & $\mathrm{x}$ & $\mathrm{x}$ & $\mathrm{x}$ & $\mathrm{x}$ \\
\hline depression.16 & $\begin{array}{l}\text { Depression } \\
\text { Item } 16\end{array}$ & $\begin{array}{l}\text { Während der letzten Woche } \\
\text { habe ich das Leben } \\
\text { genossen }\end{array}$ & $\begin{array}{l}0=\text { selten und überhaupt } \\
\text { nicht (weniger als einen Tag } \\
\text { lang), } 1=\text { manchmal ( ein bis } \\
\text { zwei Tage lang), } 2=\text { öfters ( } \\
\text { drei bis vier Tage lang), } 3= \\
\text { meistens, die ganze Zeit ( } \\
\text { fünf oder mehrere Tage lang) }\end{array}$ & $\begin{array}{l}\text { how often you have felt } \\
\text { this way in the past } \\
\text { week: I enjoyed life }\end{array}$ & $\begin{array}{l}0=\text { seldom and never } \\
(\text { less than a day) }, 1= \\
\text { sometimes (one or two } \\
\text { days), } 2=\text { often(three or } \\
\text { four days), } 3=\text { usually, } \\
\text { all the time (five or more } \\
\text { days) }\end{array}$ & $\mathrm{x}$ & $\mathrm{x}$ & $\mathrm{x}$ & $\mathrm{x}$ & $\mathrm{x}$ & $\mathrm{x}$ & $\mathrm{x}$ & $\mathrm{x}$ & $\mathrm{x}$ & $\mathrm{x}$ & $\mathrm{x}$ & $\mathrm{x}$ \\
\hline depression.17 & $\begin{array}{l}\text { Depression } \\
\text { Item } 17\end{array}$ & $\begin{array}{l}\text { Während der letzten Woche } \\
\text { musste ich weinen }\end{array}$ & $\begin{array}{l}0=\text { selten und überhaupt } \\
\text { nicht (weniger als einen Tag } \\
\text { lang), } 1=\text { manchmal ( ein bis } \\
\text { zwei Tage lang), } 2=\text { öfters ( } \\
\text { drei bis vier Tage lang), } 3= \\
\text { meistens, die ganze Zeit ( } \\
\text { fünf oder mehrere Tage lang) }\end{array}$ & $\begin{array}{l}\text { how often you have felt } \\
\text { this way in the past } \\
\text { week: I had crying spells }\end{array}$ & $\begin{array}{l}0=\text { seldom and never } \\
\text { (less than a day), } 1= \\
\text { sometimes(one or two } \\
\text { days), } 2=\text { often(three or } \\
\text { four days) } 3=\text { usually, } \\
\text { all the time (five or more } \\
\text { days) }\end{array}$ & $\mathrm{x}$ & $\mathrm{x}$ & $\mathrm{x}$ & $\mathrm{x}$ & $\mathrm{x}$ & $\mathrm{x}$ & $\mathrm{x}$ & $\mathrm{x}$ & $\mathrm{x}$ & $\mathrm{x}$ & $\mathrm{x}$ & $\mathrm{x}$ \\
\hline depression.18 & $\begin{array}{l}\text { Depression } \\
\text { Item } 18\end{array}$ & $\begin{array}{l}\text { Während der letzten Woche } \\
\text { war ich traurig }\end{array}$ & $\begin{array}{l}0=\text { selten und überhaupt } \\
\text { nicht (weniger als einen Tag } \\
\text { lang), } 1=\text { manchmal ( ein bis } \\
\text { zwei Tage lang), } 2=\text { öfters ( } \\
\text { drei bis vier Tage lang), } 3= \\
\text { meistens, die ganze Zeit ( } \\
\text { fünf oder mehrere Tage lang) }\end{array}$ & $\begin{array}{l}\text { how often you have felt } \\
\text { this way in the past } \\
\text { week: I felt sad }\end{array}$ & $\begin{array}{l}0=\text { seldom and never } \\
\text { (less than a day), } 1= \\
\text { sometimes(one or two } \\
\text { days) }, 2=\text { often(three or } \\
\text { four days) } 3=\text { usually, } \\
\text { all the time (five or more } \\
\text { days) }\end{array}$ & $\mathrm{x}$ & $\mathrm{x}$ & $\mathrm{x}$ & $\mathrm{x}$ & $\mathrm{x}$ & $\mathrm{x}$ & $\mathrm{x}$ & $\mathrm{x}$ & $\mathrm{x}$ & $\mathrm{x}$ & $\mathrm{x}$ & $\mathrm{x}$ \\
\hline depression.19 & $\begin{array}{l}\text { Depression } \\
\text { Item } 19\end{array}$ & $\begin{array}{l}\text { Während der letzten Woche } \\
\text { hatte ich das Gefühl, dass } \\
\text { mich die Leute nicht leiden } \\
\text { können }\end{array}$ & $\begin{array}{l}0=\text { selten und überhaupt } \\
\text { nicht (weniger als einen Tag } \\
\text { lang), } 1=\text { manchmal ( ein bis } \\
\text { zwei Tage lang), } 2=\text { öfters ( } \\
\text { drei bis vier Tage lang), } 3= \\
\text { meistens, die ganze Zeit ( } \\
\text { fünf oder mehrere Tage lang) }\end{array}$ & $\begin{array}{l}\text { how often you have felt } \\
\text { this way in the past } \\
\text { week: I felt that people } \\
\text { disliked me }\end{array}$ & $\begin{array}{l}0=\text { seldom and never } \\
\text { (less than a day), } 1= \\
\text { sometimes(one or two } \\
\text { days), } 2=\text { often(three or } \\
\text { four days), } 3=\text { usually, } \\
\text { all the time (five or more } \\
\text { days) }\end{array}$ & $\mathrm{x}$ & $\mathrm{x}$ & $\mathrm{x}$ & $\mathrm{x}$ & $\mathrm{x}$ & $\mathrm{x}$ & $\mathrm{x}$ & $\mathrm{x}$ & $\mathrm{x}$ & $\mathrm{x}$ & $\mathrm{x}$ & $\mathrm{X}$ \\
\hline depression. 20 & $\begin{array}{l}\text { Depression } \\
\text { Item } 20\end{array}$ & $\begin{array}{l}\text { Während der letzten Woche } \\
\text { konnte ich mich zu nichts } \\
\text { aufraffen }\end{array}$ & $\begin{array}{l}0=\text { selten und überhaupt } \\
\text { nicht (weniger als einen Tag } \\
\text { lang), } 1=\text { manchmal ( ein bis } \\
\text { zwei Tage lang), } 2=\text { öfters ( } \\
\text { drei bis vier Tage lang), } 3= \\
\text { meistens, die ganze Zeit ( } \\
\text { fünf oder mehrere Tage lang) }\end{array}$ & $\begin{array}{l}\text { how often you have felt } \\
\text { this way in the past } \\
\text { week: I could not get } \\
\text { "going" }\end{array}$ & $\begin{array}{l}0=\text { seldom and never } \\
\text { (less than a day) }, 1= \\
\text { sometimes(one or two } \\
\text { days) }, 2=\text { often(three or } \\
\text { four days) } 3=\text { usually, } \\
\text { all the time (five or more } \\
\text { days) }\end{array}$ & $\mathrm{x}$ & $\mathrm{x}$ & $\mathrm{x}$ & $\mathrm{x}$ & $\mathrm{x}$ & $\mathrm{x}$ & $\mathrm{x}$ & $x$ & $\mathrm{x}$ & $\mathrm{x}$ & $\mathrm{x}$ & $\mathrm{x}$ \\
\hline
\end{tabular}




\begin{tabular}{|c|c|c|c|c|c|c|c|c|c|c|c|c|c|c|c|c|c|}
\hline VarName & VariableLabel & WordingDE & ValueLabelsDE_Linked & WordingEN & ValueLabelsEN_Linked & L1 & L2 & L3 & $\mathrm{L} 4$ & L5 & L6 & L7 & L8 & L9 & L10 & L11 & 1. L12 \\
\hline anxiety. 1 & Anxiety Item 1 & $\begin{array}{l}\text { Wie oft fühltest Du Dich } \\
\text { im Verlauf der letzten } 2 \\
\text { Wochen durch die } \\
\text { folgenden Beschwerden } \\
\text { beeinträchtigt? Nervosität, } \\
\text { Ängstlichkeit oder } \\
\text { Anspannung }\end{array}$ & $\begin{array}{l}0=\text { Überhaupt nicht, } 1=\text { An } \\
\text { einzelnen Tagen, } 2=\text { An } \\
\text { mehr als der Hälfte der Tage, } \\
3=\text { Beinahe jeden Tag }\end{array}$ & $\begin{array}{l}\text { Over the last } 2 \text { weeks, } \\
\text { how often have you been } \\
\text { bothered by the } \\
\text { following problems? } \\
\text { Feeling nervous, } \\
\text { anxious, or on edge }\end{array}$ & $\begin{array}{l}0=\text { Not at all, } 1=\text { on } \\
\text { single days, } 2=\text { on more } \\
\text { than half of the days, } 3= \\
\text { almost every day }\end{array}$ & $\mathrm{x}$ & $\mathrm{x}$ & $\mathrm{x}$ & $\mathrm{x}$ & $\mathrm{x}$ & $\mathrm{x}$ & $\mathrm{x}$ & $\mathrm{x}$ & $\mathrm{x}$ & $\mathrm{x}$ & $\mathrm{x}$ & $\mathrm{x}$ \\
\hline anxiety.2 & Anxiety Item 2 & $\begin{array}{l}\text { Wie oft fühltest Du Dich } \\
\text { im Verlauf der letzten } 2 \\
\text { Wochen durch die } \\
\text { folgenden Beschwerden } \\
\text { beeinträchtigt? Nicht in der } \\
\text { Lage sein, Sorgen zu } \\
\text { stoppen oder zu } \\
\text { kontrollieren }\end{array}$ & $\begin{array}{l}0=\text { Überhaupt nicht, } 1=\text { An } \\
\text { einzelnen Tagen, } 2=\text { An } \\
\text { mehr als der Hälfte der Tage, } \\
3=\text { Beinahe jeden Tag }\end{array}$ & $\begin{array}{l}\text { Over the last } 2 \text { weeks, } \\
\text { how often have you been } \\
\text { bothered by the } \\
\text { following problems? Not } \\
\text { being able to stop or } \\
\text { control worrying }\end{array}$ & $\begin{array}{l}0=\text { Not at all, } 1=\text { on } \\
\text { single days, } 2=\text { on more } \\
\text { than half of the days, } 3= \\
\text { almost every day }\end{array}$ & $\mathrm{x}$ & $\mathrm{x}$ & $\mathrm{x}$ & $\mathrm{x}$ & $\mathrm{x}$ & $\mathrm{x}$ & $\mathrm{x}$ & $\mathrm{x}$ & $\mathrm{x}$ & $\mathrm{x}$ & $\mathrm{x}$ & $\mathrm{x}$ \\
\hline anxiety. 3 & Anxiety Item 3 & $\begin{array}{l}\text { Wie oft fühltest Du Dich } \\
\text { im Verlauf der letzten } 2 \\
\text { Wochen durch die } \\
\text { folgenden Beschwerden } \\
\text { beeinträchtigt? } \\
\text { Übermässige Sorgen } \\
\text { bezüglich verschiedener } \\
\text { Angelegenheiten }\end{array}$ & $\begin{array}{l}0=\text { Überhaupt nicht, } 1=\text { An } \\
\text { einzelnen Tagen, } 2=\text { An } \\
\text { mehr als der Hälfte der Tage, } \\
3=\text { Beinahe jeden Tag }\end{array}$ & $\begin{array}{l}\text { Over the last } 2 \text { weeks, } \\
\text { how often have you been } \\
\text { bothered by the } \\
\text { following problems? } \\
\text { Worrying too much } \\
\text { about different things }\end{array}$ & $\begin{array}{l}0=\text { Not at all, } 1=\text { on } \\
\text { single days, } 2=\text { on more } \\
\text { than half of the days, } 3= \\
\text { almost every day }\end{array}$ & $\mathrm{x}$ & $\mathrm{x}$ & $\mathrm{x}$ & $\mathrm{x}$ & $\mathrm{x}$ & $\mathrm{x}$ & $\mathrm{x}$ & $\mathrm{x}$ & $\mathrm{x}$ & $\mathrm{x}$ & $\mathrm{x}$ & $\mathrm{x}$ \\
\hline anxiety. 4 & Anxiety Item 4 & $\begin{array}{l}\text { Wie oft fühltest Du Dich } \\
\text { im Verlauf der letzten } 2 \\
\text { Wochen durch die } \\
\text { folgenden Beschwerden } \\
\text { beeinträchtigt? } \\
\text { Schwierigkeiten zu } \\
\text { entspannen }\end{array}$ & $\begin{array}{l}0=\text { Überhaupt nicht, } 1=\text { An } \\
\text { einzelnen Tagen, } 2=\text { An } \\
\text { mehr als der Hälfte der Tage, } \\
3=\text { Beinahe jeden Tag }\end{array}$ & $\begin{array}{l}\text { Over the last } 2 \text { weeks, } \\
\text { how often have you been } \\
\text { bothered by the } \\
\text { following problems? } \\
\text { Trouble relaxing }\end{array}$ & $\begin{array}{l}0=\text { Not at all, } 1=\text { on } \\
\text { single days, } 2=\text { on more } \\
\text { than half of the days, } 3= \\
\text { almost every day }\end{array}$ & $\mathrm{x}$ & $\mathrm{x}$ & $\mathrm{x}$ & $\mathrm{x}$ & $\mathrm{x}$ & $\mathrm{x}$ & $\mathrm{x}$ & $\mathrm{x}$ & $\mathrm{x}$ & $\mathrm{x}$ & $\mathrm{x}$ & $\mathrm{x}$ \\
\hline anxiety. 5 & Anxiety Item 5 & $\begin{array}{l}\text { Wie oft fühltest Du Dich } \\
\text { im Verlauf der letzten } 2 \\
\text { Wochen durch die } \\
\text { folgenden Beschwerden } \\
\text { beeinträchtigt? } \\
\text { Rastlosigkeit, so dass } \\
\text { Stillsitzen schwer fällt }\end{array}$ & $\begin{array}{l}0=\text { Überhaupt nicht, } 1=\text { An } \\
\text { einzelnen Tagen, } 2=\text { An } \\
\text { mehr als der Hälfte der Tage, } \\
3=\text { Beinahe jeden Tag }\end{array}$ & $\begin{array}{l}\text { Over the last } 2 \text { weeks, } \\
\text { how often have you been } \\
\text { bothered by the } \\
\text { following problems? } \\
\text { Being so restless that } \\
\text { it's hard to sit still }\end{array}$ & $\begin{array}{l}0=\text { Not at all, } 1=\text { on } \\
\text { single days, } 2=\text { on more } \\
\text { than half of the days, } 3= \\
\text { almost every day }\end{array}$ & $\mathrm{x}$ & $\mathrm{x}$ & $\mathrm{x}$ & $\mathrm{x}$ & $\mathrm{x}$ & $\mathrm{x}$ & $\mathrm{x}$ & $\mathrm{x}$ & $\mathrm{x}$ & $\mathrm{x}$ & $\mathrm{x}$ & $\mathrm{x}$ \\
\hline anxiety. 6 & Anxiety Item 6 & $\begin{array}{l}\text { Wie oft fühltest Du Dich } \\
\text { im Verlauf der letzten } 2 \\
\text { Wochen durch die } \\
\text { folgenden Beschwerden } \\
\text { beeinträchtigt? Schnelle } \\
\text { Verärgerung oder } \\
\text { Gereiztheit }\end{array}$ & $\begin{array}{l}0=\text { Überhaupt nicht, } 1=\text { An } \\
\text { einzelnen Tagen, } 2=\text { An } \\
\text { mehr als der Hälfte der Tage, } \\
3=\text { Beinahe jeden Tag }\end{array}$ & $\begin{array}{l}\text { Over the last } 2 \text { weeks, } \\
\text { how often have you been } \\
\text { bothered by the } \\
\text { following problems? } \\
\text { Becoming easily } \\
\text { annoyed or irritable }\end{array}$ & $\begin{array}{l}0=\text { Not at all, } 1=\text { on } \\
\text { single days, } 2=\text { on more } \\
\text { than half of the days, } 3= \\
\text { almost every day }\end{array}$ & $\mathrm{x}$ & $\mathrm{x}$ & $\mathrm{x}$ & $\mathrm{x}$ & $\mathrm{x}$ & $\mathrm{x}$ & $\mathrm{x}$ & $\mathrm{x}$ & $\mathrm{x}$ & $\mathrm{x}$ & $\mathrm{x}$ & $\mathrm{x}$ \\
\hline anxiety. 7 & Anxiety Item 7 & $\begin{array}{l}\text { Wie oft fühltest Du Dich } \\
\text { im Verlauf der letzten } 2 \\
\text { Wochen durch die } \\
\text { folgenden Beschwerden } \\
\text { beeinträchtigt? Gefühl der } \\
\text { Angst, so als würde etwas } \\
\text { Schlimmes passieren }\end{array}$ & $\begin{array}{l}0=\text { Überhaupt nicht, } 1=\text { An } \\
\text { einzelnen Tagen, } 2=\text { An } \\
\text { mehr als der Hälfte der Tage, } \\
3=\text { Beinahe jeden Tag }\end{array}$ & $\begin{array}{l}\text { Over the last } 2 \text { weeks, } \\
\text { how often have you been } \\
\text { bothered by the } \\
\text { following problems? } \\
\text { Feeling afraid as if } \\
\text { something awful might } \\
\text { happen }\end{array}$ & $\begin{array}{l}0=\text { Not at all, } 1=\text { on } \\
\text { single days, } 2=\text { on more } \\
\text { than half of the days, } 3= \\
\text { almost every day }\end{array}$ & $\mathrm{x}$ & $\mathrm{x}$ & $\mathrm{x}$ & $\mathrm{x}$ & $\mathrm{x}$ & $\mathrm{x}$ & $\mathrm{x}$ & $\mathrm{x}$ & $\mathrm{x}$ & $\mathrm{x}$ & $\mathrm{x}$ & $\mathrm{x}$ \\
\hline depr.diagnosis & & $\begin{array}{l}\text { Q16.3 - Hattest Du schon } \\
\text { mal eine Depression oder } \\
\text { Angststörung (Selbst- oder } \\
\text { Fremddiagnose)? }\end{array}$ & $2=\mathrm{Ja}, 3=$ Nein & $\begin{array}{l}\text { Have you ever had } \\
\text { depression or an anxiety } \\
\text { disorder (self- or } \\
\text { other-diagnosed)? }\end{array}$ & $2=\mathrm{Yes}, 3=\mathrm{No}$ & $\mathrm{x}$ & $\mathrm{x}$ & $\mathrm{x}$ & $\mathrm{x}$ & $\mathrm{x}$ & $\mathrm{x}$ & $\mathrm{x}$ & $\mathrm{x}$ & $\mathrm{x}$ & $\mathrm{x}$ & $\mathrm{x}$ & $\mathrm{x}$ \\
\hline depr.treatment & & $\begin{array}{l}\text { Q16.4 - Bist Du momentan } \\
\text { oder warst Du jemals in } \\
\text { psychologischer } \\
\text { Behandlung? }\end{array}$ & $\begin{array}{l}1=\mathrm{Ja}, \text { ich war bereits in } \\
\text { psychologischer Behandlung. } \\
, 2=\mathrm{Ja} \text {, ich bin momentan in } \\
\text { psychologischer Behandlung. } \\
, 3=\text { Nein }\end{array}$ & $\begin{array}{l}\text { Are you currently, or } \\
\text { have you even been, in } \\
\text { psychological treatment? }\end{array}$ & $\begin{array}{l}1=\text { Yes, I have been in } \\
\text { psychological treatment, } 2 \\
=\text { Yes, I am currently } \\
\text { undergoing psychological } \\
\text { treatment, } 3=\text { No }\end{array}$ & $\mathrm{x}$ & $\mathrm{x}$ & $\mathrm{x}$ & $\mathrm{x}$ & $\mathrm{x}$ & $\mathrm{x}$ & $\mathrm{x}$ & $\mathrm{x}$ & $\mathrm{x}$ & $\mathrm{x}$ & $\mathrm{x}$ & $\mathrm{x}$ \\
\hline
\end{tabular}




\begin{tabular}{|c|c|c|c|c|c|c|c|c|c|c|c|c|c|c|c|}
\hline VarName & VariableLabel & WordingDE & ValueLabelsDE_Linked & WordingEN & ValueLabelsEN_Linked & L1 & $\mathrm{L} 2$ & L3 & L4 & L5 & L6 6 & L7 & L8 & L9 & L10 L11 L12 \\
\hline extraversion.long. 1 & $\begin{array}{l}\text { Big Five Long, } \\
\text { Item } 1\end{array}$ & $\begin{array}{l}\text { Ich sehe mich selbst als } \\
\text { jemand, der gesprächig ist, } \\
\text { sich gerne unterhält }\end{array}$ & $\begin{array}{l}1=\text { trifft überhaupt nicht zu, } \\
2=\text { trifft eher nicht zu, } 3= \\
\text { weder noch, } 4=\text { eher } \\
\text { zutreffend, } 5=\text { trifft voll und } \\
\text { ganz zu }\end{array}$ & $\begin{array}{l}\text { I see myself as someone } \\
\text { who is talkative }\end{array}$ & $\begin{array}{l}1=\text { does not apply at all, } \\
2=\text { mostly does not } \\
\text { apply, } 3=\text { neither, } 4= \\
\text { mostly applies, } 5= \\
\text { applies completely (free } \\
\text { translation) }\end{array}$ & $\mathrm{x}$ & & & & & & & & & \\
\hline agreeableness.long. 1 & $\begin{array}{l}\text { Big Five Long, } \\
\text { Item } 2\end{array}$ & $\begin{array}{l}\text { dazu neigt, andere zu } \\
\text { kritisieren. }\end{array}$ & $\begin{array}{l}1=\text { trifft überhaupt nicht zu, } \\
2=\text { trifft eher nicht } \mathrm{zu}, 3= \\
\text { weder noch, } 4=\text { eher } \\
\text { zutreffend, } 5=\text { trifft voll und } \\
\text { ganz zu }\end{array}$ & $\begin{array}{l}\text { I see myself as someone } \\
\text { who tends to find fault } \\
\text { with others }\end{array}$ & $\begin{array}{l}1=\text { does not apply at all, } \\
2=\text { mostly does not } \\
\text { apply, } 3=\text { neither, } 4= \\
\text { mostly applies, } 5= \\
\text { applies completely (free } \\
\text { translation) }\end{array}$ & $\mathrm{x}$ & & & & & & & & & \\
\hline conscientiousness.long. 1 & $\begin{array}{l}\text { Big Five Long, } \\
\text { Item } 3\end{array}$ & Aufgaben gründlich erledigt & $\begin{array}{l}1=\text { trifft überhaupt nicht zu, } \\
2=\text { trifft eher nicht zu, } 3= \\
\text { weder noch, } 4=\text { eher } \\
\text { zutreffend, } 5=\text { trifft voll und } \\
\text { ganz zu }\end{array}$ & $\begin{array}{l}\text { I see myself as someone } \\
\text { who does a thorough job }\end{array}$ & $\begin{array}{l}1=\text { does not apply at all, } \\
2=\text { mostly does not } \\
\text { apply, } 3=\text { neither, } 4= \\
\text { mostly applies, } 5= \\
\text { applies completely (free } \\
\text { translation) }\end{array}$ & $\mathrm{x}$ & & & & & & & & & \\
\hline neuroticism.long. 1 & $\begin{array}{l}\text { Big Five Long, } \\
\text { Item } 4\end{array}$ & $\begin{array}{l}\text { deprimiert, } \\
\text { niedergeschlagen ist }\end{array}$ & $\begin{array}{l}1=\text { trifft überhaupt nicht } \mathrm{zu}, \\
2=\text { trifft eher nicht } \mathrm{zu}, 3= \\
\text { weder noch, } 4=\text { eher } \\
\text { zutreffend, } 5=\text { trifft voll und } \\
\text { ganz zu }\end{array}$ & $\begin{array}{l}\text { I see myself as someone } \\
\text { who is depressed, blue }\end{array}$ & $\begin{array}{l}1=\text { does not apply at all, } \\
2=\text { mostly does not } \\
\text { apply, } 3=\text { neither, } 4= \\
\text { mostly applies, } 5= \\
\text { applies completely (free } \\
\text { translation) }\end{array}$ & $\mathrm{x}$ & & & & & & & & & \\
\hline openness.long. 1 & $\begin{array}{l}\text { Big Five Long, } \\
\text { Item } 5\end{array}$ & $\begin{array}{l}\text { originell ist, neue Ideen } \\
\text { entwickelt }\end{array}$ & $\begin{array}{l}1=\text { trifft überhaupt nicht zu, } \\
2=\text { trifft eher nicht } \mathrm{zu}, 3= \\
\text { weder noch, } 4=\text { eher } \\
\text { zutreffend, } 5=\text { trifft voll und } \\
\text { ganz zu }\end{array}$ & $\begin{array}{l}\text { I see myself as someone } \\
\text { who is original, comes } \\
\text { up with new ideas } \\
6 . \text { Is reserved }\end{array}$ & $\begin{array}{l}1=\text { does not apply at all, } \\
2=\text { mostly does not } \\
\text { apply, } 3=\text { neither, } 4= \\
\text { mostly applies, } 5= \\
\text { applies completely (free } \\
\text { translation) }\end{array}$ & $\mathrm{x}$ & & & & & & & & & \\
\hline extraversion.long. 2 & $\begin{array}{l}\text { Big Five Long, } \\
\text { Item } 6\end{array}$ & $\begin{array}{l}\text { eher zurückhaltend und } \\
\text { reserviert ist }\end{array}$ & $\begin{array}{l}1=\text { trifft überhaupt nicht zu, } \\
2=\text { trifft eher nicht } \mathrm{zu}, 3= \\
\text { weder noch, } 4=\text { eher } \\
\text { zutreffend, } 5=\text { trifft voll und } \\
\text { ganz zu }\end{array}$ & $\begin{array}{l}\text { I see myself as someone } \\
\text { who is depressed, blue }\end{array}$ & $\begin{array}{l}1=\text { does not apply at all, } \\
2=\text { mostly does not } \\
\text { apply, } 3=\text { neither, } 4= \\
\text { mostly applies, } 5= \\
\text { applies completely (free } \\
\text { translation) }\end{array}$ & $\mathrm{x}$ & & & & & & & & & \\
\hline agreeableness.long.2 & $\begin{array}{l}\text { Big Five Long, } \\
\text { Item } 7\end{array}$ & $\begin{array}{l}\text { hilfsbereit und selbstlos } \\
\text { gegenüber anderen ist }\end{array}$ & $\begin{array}{l}1=\text { trifft überhaupt nicht zu, } \\
2=\text { trifft eher nicht } \mathrm{zu}, 3= \\
\text { weder noch, } 4=\text { eher } \\
\text { zutreffend, } 5=\text { trifft voll und } \\
\text { ganz zu }\end{array}$ & $\begin{array}{l}\text { I see myself as someone } \\
\text { who is helpful and } \\
\text { unselfish with others }\end{array}$ & $\begin{array}{l}1=\text { does not apply at all, } \\
2=\text { mostly does not } \\
\text { apply, } 3=\text { neither, } 4= \\
\text { mostly applies, } 5= \\
\text { applies completely (free } \\
\text { translation) }\end{array}$ & $\mathrm{x}$ & & & & & & & & & \\
\hline conscientiousness.long. 2 & $\begin{array}{l}\text { Big Five Long, } \\
\text { Item } 8\end{array}$ & etwas achtlos sein kann & $\begin{array}{l}1=\text { trifft überhaupt nicht zu, } \\
2=\text { trifft eher nicht } \mathrm{zu}, 3= \\
\text { weder noch, } 4=\text { eher } \\
\text { zutreffend, } 5=\text { trifft voll und } \\
\text { ganz zu }\end{array}$ & $\begin{array}{l}\text { I see myself as someone } \\
\text { who can be somewhat } \\
\text { careless }\end{array}$ & $\begin{array}{l}1=\text { does not apply at all, } \\
2=\text { mostly does not } \\
\text { apply, } 3=\text { neither, } 4= \\
\text { mostly applies, } 5= \\
\text { applies completely (free } \\
\text { translation) }\end{array}$ & $\mathrm{x}$ & & & & & & & & & \\
\hline neuroticism.long. 2 & $\begin{array}{l}\text { Big Five Long, } \\
\text { Item } 9\end{array}$ & $\begin{array}{l}\text { entspannt ist, sich durch } \\
\text { Stress nicht aus der Ruhe } \\
\text { bringen lässt }\end{array}$ & $\begin{array}{l}1=\text { trifft überhaupt nicht zu, } \\
2=\text { trifft eher nicht } \mathrm{zu}, 3= \\
\text { weder noch, } 4=\text { eher } \\
\text { zutreffend, } 5=\text { trifft voll und } \\
\text { ganz zu }\end{array}$ & $\begin{array}{l}\text { I see myself as someone } \\
\text { who is relaxed, handles } \\
\text { stress well }\end{array}$ & $\begin{array}{l}1=\text { does not apply at all, } \\
2=\text { mostly does not } \\
\text { apply, } 3=\text { neither, } 4= \\
\text { mostly applies, } 5= \\
\text { applies completely (free } \\
\text { translation) }\end{array}$ & $\mathrm{x}$ & & & & & & & & & \\
\hline openness.long.2 & $\begin{array}{l}\text { Big Five Long, } \\
\text { Item } 10\end{array}$ & vielseitig interessiert ist & $\begin{array}{l}1=\text { trifft überhaupt nicht zu, } \\
2=\text { trifft eher nicht } \mathrm{zu}, 3= \\
\text { weder noch, } 4=\text { eher } \\
\text { zutreffend, } 5=\text { trifft voll und } \\
\text { ganz zu }\end{array}$ & $\begin{array}{l}\text { I see myself as someone } \\
\text { who is curious about } \\
\text { many different things }\end{array}$ & $\begin{array}{l}1=\text { does not apply at all, } \\
2=\text { mostly does not } \\
\text { apply, } 3=\text { neither, } 4= \\
\text { mostly applies, } 5= \\
\text { applies completely (free } \\
\text { translation) }\end{array}$ & $\mathrm{x}$ & & & & & & & & & \\
\hline
\end{tabular}




\begin{tabular}{|c|c|c|c|c|c|c|c|c|c|c|c|c|c|c|c|}
\hline VarName & VariableLabel & WordingDE & ValueLabelsDE_Linked & WordingEN & ValueLabelsEN_Linked & $\mathrm{L} 1$ & $\mathrm{~L} 2$ & L3 & $\mathrm{L} 4$ & L5 & $\mathrm{L} 6$ & $\mathrm{~L} 7$ & L8 & L9 & L10 L11 L12 \\
\hline extraversion.long. 3 & $\begin{array}{l}\text { Big Five Long, } \\
\text { Item } 11\end{array}$ & $\begin{array}{l}\text { voller Energie und } \\
\text { Tatendrang ist }\end{array}$ & $\begin{array}{l}1=\text { trifft überhaupt nicht zu, } \\
2=\text { trifft eher nicht } \mathrm{zu}, 3= \\
\text { weder noch, } 4=\text { eher } \\
\text { zutreffend, } 5=\text { trifft voll und } \\
\text { ganz zu }\end{array}$ & $\begin{array}{l}\text { I see myself as someone } \\
\text { who is full of energy }\end{array}$ & $\begin{array}{l}1=\text { does not apply at all, } \\
2=\text { mostly does not } \\
\text { apply, } 3=\text { neither, } 4= \\
\text { mostly applies, } 5= \\
\text { applies completely (free } \\
\text { translation) }\end{array}$ & $\mathrm{x}$ & & & & & & & & & \\
\hline agreeableness.long. 3 & $\begin{array}{l}\text { Big Five Long, } \\
\text { Item } 12\end{array}$ & $\begin{array}{l}\text { häufig in Streitereien } \\
\text { verwickelt ist }\end{array}$ & $\begin{array}{l}1=\text { trifft überhaupt nicht zu, } \\
2=\text { trifft eher nicht zu, } 3= \\
\text { weder noch, } 4=\text { eher } \\
\text { zutreffend, } 5=\text { trifft voll und } \\
\text { ganz zu }\end{array}$ & $\begin{array}{l}\text { I see myself as someone } \\
\text { who is starts quarrels } \\
\text { with others }\end{array}$ & $\begin{array}{l}1=\text { does not apply at all, } \\
2=\text { mostly does not } \\
\text { apply, } 3=\text { neither, } 4= \\
\text { mostly applies, } 5= \\
\text { applies completely (free } \\
\text { translation) }\end{array}$ & $\mathrm{x}$ & & & & & & & & & \\
\hline conscientiousness.long. 3 & $\begin{array}{l}\text { Big Five Long, } \\
\text { Item } 13\end{array}$ & $\begin{array}{l}\text { zuverlässig und } \\
\text { gewissenhaft arbeitet }\end{array}$ & $\begin{array}{l}1=\text { trifft überhaupt nicht zu, } \\
2=\text { trifft eher nicht } \mathrm{zu}, 3= \\
\text { weder noch, } 4=\text { eher } \\
\text { zutreffend, } 5=\text { trifft voll und } \\
\text { ganz zu }\end{array}$ & $\begin{array}{l}\text { I see myself as someone } \\
\text { who is a reliable worker }\end{array}$ & $\begin{array}{l}1=\text { does not apply at all, } \\
2=\text { mostly does not } \\
\text { apply, } 3=\text { neither, } 4= \\
\text { mostly applies, } 5= \\
\text { applies completely (free } \\
\text { translation) }\end{array}$ & $\mathrm{x}$ & & & & & & & & & \\
\hline neuroticism.long. 3 & $\begin{array}{l}\text { Big Five Long, } \\
\text { Item } 14\end{array}$ & leicht angespannt reagiert & $\begin{array}{l}1=\text { trifft überhaupt nicht zu, } \\
2=\text { trifft eher nicht } \mathrm{zu}, 3= \\
\text { weder noch, } 4=\text { eher } \\
\text { zutreffend, } 5=\text { trifft voll und } \\
\text { ganz zu }\end{array}$ & $\begin{array}{l}\text { I see myself as someone } \\
\text { who can be tense }\end{array}$ & $\begin{array}{l}1=\text { does not apply at all, } \\
2=\text { mostly does not } \\
\text { apply, } 3=\text { neither, } 4= \\
\text { mostly applies, } 5= \\
\text { applies completely (free } \\
\text { translation) }\end{array}$ & $\mathrm{x}$ & & & & & & & & & \\
\hline openness.long.3 & $\begin{array}{l}\text { Big Five Long, } \\
\text { Item } 15\end{array}$ & $\begin{array}{l}\text { tiefsinnig ist, gerne über } \\
\text { Sachen nachdenkt }\end{array}$ & $\begin{array}{l}1=\text { trifft überhaupt nicht zu, } \\
2=\text { trifft eher nicht } \mathrm{zu}, 3= \\
\text { weder noch, } 4=\text { eher } \\
\text { zutreffend, } 5=\text { trifft voll und } \\
\text { ganz zu }\end{array}$ & $\begin{array}{l}\text { I see myself as someone } \\
\text { who is ingenious, a deep } \\
\text { thinker }\end{array}$ & $\begin{array}{l}1=\text { does not apply at all, } \\
2=\text { mostly does not } \\
\text { apply, } 3=\text { neither, } 4= \\
\text { mostly applies, } 5= \\
\text { applies completely (free } \\
\text { translation) }\end{array}$ & $\mathrm{x}$ & & & & & & & & & \\
\hline extraversion.long. 4 & $\begin{array}{l}\text { Big Five Long, } \\
\text { Item } 16\end{array}$ & $\begin{array}{l}\text { begeisterungsfähig ist und } \\
\text { andere mitreißen kann }\end{array}$ & $\begin{array}{l}1=\text { trifft überhaupt nicht zu, } \\
2=\text { trifft eher nicht } \mathrm{zu}, 3= \\
\text { weder noch, } 4=\text { eher } \\
\text { zutreffend, } 5=\text { trifft voll und } \\
\text { ganz zu }\end{array}$ & $\begin{array}{l}\text { I see myself as someone } \\
\text { who generates a lot of } \\
\text { enthusiasm }\end{array}$ & $\begin{array}{l}1=\text { does not apply at all, } \\
2=\text { mostly does not } \\
\text { apply, } 3=\text { neither, } 4= \\
\text { mostly applies, } 5= \\
\text { applies completely (free } \\
\text { translation) }\end{array}$ & $\mathrm{x}$ & & & & & & & & & \\
\hline agreeableness.long.4 & $\begin{array}{l}\text { Big Five Long, } \\
\text { Item } 17\end{array}$ & $\begin{array}{l}\text { nicht nachtragend ist, } \\
\text { anderen leicht vergibt }\end{array}$ & $\begin{array}{l}1=\text { trifft überhaupt nicht } \mathrm{zu}, \\
2=\text { trifft eher nicht } \mathrm{zu}, 3= \\
\text { weder noch, } 4=\text { eher } \\
\text { zutreffend, } 5=\text { trifft voll und } \\
\text { ganz zu }\end{array}$ & $\begin{array}{l}\text { I see myself as someone } \\
\text { who has a forgiving } \\
\text { nature }\end{array}$ & $\begin{array}{l}1=\text { does not apply at all, } \\
2=\text { mostly does not } \\
\text { apply, } 3=\text { neither, } 4= \\
\text { mostly applies, } 5= \\
\text { applies completely (free } \\
\text { translation) }\end{array}$ & $\mathrm{x}$ & & & & & & & & & \\
\hline conscientiousness.long. 4 & $\begin{array}{l}\text { Big Five Long, } \\
\text { Item } 18\end{array}$ & $\begin{array}{l}\text { dazu neigt, unordentlich zu } \\
\text { sein }\end{array}$ & $\begin{array}{l}1=\text { trifft überhaupt nicht zu, } \\
2=\text { trifft eher nicht } \mathrm{zu}, 3= \\
\text { weder noch, } 4=\text { eher } \\
\text { zutreffend, } 5=\text { trifft voll und } \\
\text { ganz zu }\end{array}$ & $\begin{array}{l}\text { I see myself as someone } \\
\text { who tends to be } \\
\text { disorganized }\end{array}$ & $\begin{array}{l}1=\text { does not apply at all, } \\
2=\text { mostly does not } \\
\text { apply, } 3=\text { neither, } 4= \\
\text { mostly applies, } 5= \\
\text { applies completely (free } \\
\text { translation) }\end{array}$ & $\mathrm{x}$ & & & & & & & & & \\
\hline neuroticism.long.4 & $\begin{array}{l}\text { Big Five Long, } \\
\text { Item } 19\end{array}$ & sich viele Sorgen macht & $\begin{array}{l}1=\text { trifft überhaupt nicht zu, } \\
2=\text { trifft eher nicht } \mathrm{zu}, 3= \\
\text { weder noch, } 4=\text { eher } \\
\text { zutreffend, } 5=\text { trifft voll und } \\
\text { ganz zu }\end{array}$ & $\begin{array}{l}\text { I see myself as someone } \\
\text { who worries a lot }\end{array}$ & $\begin{array}{l}1=\text { does not apply at all, } \\
2=\text { mostly does not } \\
\text { apply, } 3=\text { neither, } 4= \\
\text { mostly applies, } 5= \\
\text { applies completely (free } \\
\text { translation) }\end{array}$ & $\mathrm{x}$ & & & & & & & & & \\
\hline openness.long.4 & $\begin{array}{l}\text { Big Five Long, } \\
\text { Item } 20\end{array}$ & $\begin{array}{l}\text { eine lebhafte } \\
\text { Vorstellungskraft hat, } \\
\text { phantasievoll ist }\end{array}$ & $\begin{array}{l}1=\text { trifft überhaupt nicht zu, } \\
2=\text { trifft eher nicht } \mathrm{zu}, 3= \\
\text { weder noch, } 4=\text { eher } \\
\text { zutreffend, } 5=\text { trifft voll und } \\
\text { ganz zu }\end{array}$ & $\begin{array}{l}\text { I see myself as someone } \\
\text { who has an active } \\
\text { imagination }\end{array}$ & $\begin{array}{l}1=\text { does not apply at all, } \\
2=\text { mostly does not } \\
\text { apply, } 3=\text { neither, } 4= \\
\text { mostly applies, } 5= \\
\text { applies completely (free } \\
\text { translation) }\end{array}$ & $\mathrm{x}$ & & & & & & & & & \\
\hline
\end{tabular}




\begin{tabular}{|c|c|c|c|c|c|c|c|c|c|c|c|c|c|c|c|}
\hline VarName & VariableLabel & WordingDE & ValueLabelsDE_Linked & WordingEN & ValueLabelsEN_Linked & L1 & $\mathrm{L} 2$ & L3 & $\mathrm{L} 4$ & L5 & L6 & L7 & L8 & L9 & L10 L11 L12 \\
\hline extraversion.long.5 & $\begin{array}{l}\text { Big Five Long, } \\
\text { Item } 21\end{array}$ & eher still und wortkarg ist & $\begin{array}{l}1=\text { trifft überhaupt nicht } \mathrm{zu}, \\
2=\text { trifft eher nicht } \mathrm{zu}, 3= \\
\text { weder noch, } 4=\text { eher } \\
\text { zutreffend, } 5=\text { trifft voll und } \\
\text { ganz zu }\end{array}$ & $\begin{array}{l}\text { I see myself as someone } \\
\text { who tends to be quiet }\end{array}$ & $\begin{array}{l}1=\text { does not apply at all, } \\
2=\text { mostly does not } \\
\text { apply, } 3=\text { neither, } 4= \\
\text { mostly applies, } 5= \\
\text { applies completely (free } \\
\text { translation) }\end{array}$ & $\mathrm{x}$ & & & & & & & & & \\
\hline agreeableness.long.5 & $\begin{array}{l}\text { Big Five Long, } \\
\text { Item } 22\end{array}$ & anderen Vertrauen schenkt & $\begin{array}{l}1=\text { trifft überhaupt nicht zu, } \\
2=\text { trifft eher nicht zu, } 3= \\
\text { weder noch, } 4=\text { eher } \\
\text { zutreffend, } 5=\text { trifft voll und } \\
\text { ganz zu }\end{array}$ & $\begin{array}{l}\text { I see myself as someone } \\
\text { who is generally trusting }\end{array}$ & $\begin{array}{l}1=\text { does not apply at all, } \\
2=\text { mostly does not } \\
\text { apply, } 3=\text { neither, } 4= \\
\text { mostly applies, } 5= \\
\text { applies completely (free } \\
\text { translation) }\end{array}$ & $\mathrm{x}$ & & & & & & & & & \\
\hline conscientiousness.long.5 & $\begin{array}{l}\text { Big Five Long, } \\
\text { Item } 23\end{array}$ & $\begin{array}{l}\text { bequem ist und zur Faulheit } \\
\text { neigt }\end{array}$ & $\begin{array}{l}1=\text { trifft überhaupt nicht zu, } \\
2=\text { trifft eher nicht zu, } 3= \\
\text { weder noch, } 4=\text { eher } \\
\text { zutreffend, } 5=\text { trifft voll und } \\
\text { ganz zu }\end{array}$ & $\begin{array}{l}\text { I see myself as someone } \\
\text { who tends to be lazy }\end{array}$ & $\begin{array}{l}1=\text { does not apply at all, } \\
2=\text { mostly does not } \\
\text { apply, } 3=\text { neither, } 4= \\
\text { mostly applies, } 5= \\
\text { applies completely (free } \\
\text { translation) }\end{array}$ & $\mathrm{x}$ & & & & & & & & & \\
\hline neuroticism.long.5 & $\begin{array}{l}\text { Big Five Long, } \\
\text { Item } 24\end{array}$ & $\begin{array}{l}\text { ausgeglichen ist, nicht leicht } \\
\text { aus der Fassung zu bringen }\end{array}$ & $\begin{array}{l}1=\text { trifft überhaupt nicht zu, } \\
2=\text { trifft eher nicht zu, } 3= \\
\text { weder noch, } 4=\text { eher } \\
\text { zutreffend, } 5=\text { trifft voll und } \\
\text { ganz zu }\end{array}$ & $\begin{array}{l}\text { I see myself as someone } \\
\text { who is emotionally } \\
\text { stable, not easily upset }\end{array}$ & $\begin{array}{l}1=\text { does not apply at all, } \\
2=\text { mostly does not } \\
\text { apply, } 3=\text { neither, } 4= \\
\text { mostly applies, } 5= \\
\text { applies completely (free } \\
\text { translation) }\end{array}$ & $\mathrm{x}$ & & & & & & & & & \\
\hline openness.long.5 & $\begin{array}{l}\text { Big Five Long, } \\
\text { Item } 25\end{array}$ & $\begin{array}{l}\text { erfinderisch und } \\
\text { einfallsreich ist }\end{array}$ & $\begin{array}{l}1=\text { trifft überhaupt nicht zu, } \\
2=\text { trifft eher nicht zu, } 3= \\
\text { weder noch, } 4=\text { eher } \\
\text { zutreffend, } 5=\text { trifft voll und } \\
\text { ganz zu }\end{array}$ & $\begin{array}{l}\text { I see myself as someone } \\
\text { who is inventive }\end{array}$ & $\begin{array}{l}1=\text { does not apply at all, } \\
2=\text { mostly does not } \\
\text { apply, } 3=\text { neither, } 4= \\
\text { mostly applies, } 5= \\
\text { applies completely (free } \\
\text { translation) }\end{array}$ & $\mathrm{x}$ & & & & & & & & & \\
\hline extraversion.long. 6 & $\begin{array}{l}\text { Big Five Long, } \\
\text { Item } 26\end{array}$ & $\begin{array}{l}\text { durchsetzungsfähig und } \\
\text { energisch ist }\end{array}$ & $\begin{array}{l}1=\text { trifft überhaupt nicht } \mathrm{zu}, \\
2=\text { trifft eher nicht } \mathrm{zu}, 3= \\
\text { weder noch, } 4=\text { eher } \\
\text { zutreffend, } 5=\text { trifft voll und } \\
\text { ganz zu }\end{array}$ & $\begin{array}{l}\text { I see myself as someone } \\
\text { who has an assertive } \\
\text { personality }\end{array}$ & $\begin{array}{l}1=\text { does not apply at all, } \\
2=\text { mostly does not } \\
\text { apply, } 3=\text { neither, } 4= \\
\text { mostly applies, } 5= \\
\text { applies completely (free } \\
\text { translation) }\end{array}$ & $\mathrm{x}$ & & & & & & & & & \\
\hline agreeableness.long. 6 & $\begin{array}{l}\text { Big Five Long, } \\
\text { Item } 27\end{array}$ & $\begin{array}{l}\text { sich kalt und distanziert } \\
\text { verhalten kann }\end{array}$ & $\begin{array}{l}1=\text { trifft überhaupt nicht zu, } \\
2=\text { trifft eher nicht zu, } 3= \\
\text { weder noch, } 4=\text { eher } \\
\text { zutreffend, } 5=\text { trifft voll und } \\
\text { ganz zu }\end{array}$ & $\begin{array}{l}\text { I see myself as someone } \\
\text { who can be cold and } \\
\text { aloof }\end{array}$ & $\begin{array}{l}1=\text { does not apply at all, } \\
2=\text { mostly does not } \\
\text { apply, } 3=\text { neither, } 4= \\
\text { mostly applies, } 5= \\
\text { applies completely (free } \\
\text { translation) }\end{array}$ & $\mathrm{x}$ & & & & & & & & & \\
\hline conscientiousness.long. 6 & $\begin{array}{l}\text { Big Five Long, } \\
\text { Item } 28\end{array}$ & $\begin{array}{l}\text { nicht aufgibt ehe die } \\
\text { Aufgabe erledigt ist }\end{array}$ & $\begin{array}{l}1=\text { trifft überhaupt nicht zu, } \\
2=\text { trifft eher nicht zu, } 3= \\
\text { weder noch, } 4=\text { eher } \\
\text { zutreffend, } 5=\text { trifft voll und } \\
\text { ganz zu }\end{array}$ & $\begin{array}{l}\text { I see myself as someone } \\
\text { who perseveres until the } \\
\text { task is finished }\end{array}$ & $\begin{array}{l}1=\text { does not apply at all, } \\
2=\text { mostly does not } \\
\text { apply, } 3=\text { neither, } 4= \\
\text { mostly applies, } 5= \\
\text { applies completely (free } \\
\text { translation) }\end{array}$ & $\mathrm{x}$ & & & & & & & & & \\
\hline neuroticism.long. 6 & $\begin{array}{l}\text { Big Five Long, } \\
\text { Item } 29\end{array}$ & $\begin{array}{l}\text { launisch sein kann, } \\
\text { schwankende Stimmungen } \\
\text { hat }\end{array}$ & $\begin{array}{l}1=\text { trifft überhaupt nicht } \mathrm{zu}, \\
2=\text { trifft eher nicht } \mathrm{zu}, 3= \\
\text { weder noch, } 4=\text { eher } \\
\text { zutreffend, } 5=\text { trifft voll und } \\
\text { ganz zu }\end{array}$ & $\begin{array}{l}\text { I see myself as someone } \\
\text { who can be moody }\end{array}$ & $\begin{array}{l}1=\text { does not apply at all, } \\
2=\text { mostly does not } \\
\text { apply, } 3=\text { neither, } 4= \\
\text { mostly applies, } 5= \\
\text { applies completely (free } \\
\text { translation) }\end{array}$ & $\mathrm{x}$ & & & & & & & & & \\
\hline openness.long. 6 & $\begin{array}{l}\text { Big Five Long, } \\
\text { Item } 30\end{array}$ & $\begin{array}{l}\text { künstlerische und } \\
\text { ästhetische Eindrücke } \\
\text { schätzt }\end{array}$ & $\begin{array}{l}1=\text { trifft überhaupt nicht } \mathrm{zu}, \\
2=\text { trifft eher nicht } \mathrm{zu}, 3= \\
\text { weder noch, } 4=\text { eher } \\
\text { zutreffend, } 5=\text { trifft voll und } \\
\text { ganz zu }\end{array}$ & $\begin{array}{l}\text { I see myself as someone } \\
\text { who values artistic, } \\
\text { aesthetic experiences }\end{array}$ & $\begin{array}{l}1=\text { does not apply at all, } \\
2=\text { mostly does not } \\
\text { apply, } 3=\text { neither, } 4= \\
\text { mostly applies, } 5= \\
\text { applies completely (free } \\
\text { translation) }\end{array}$ & $\mathrm{x}$ & & & & & & & & & \\
\hline
\end{tabular}




\begin{tabular}{|c|c|c|c|c|c|c|c|c|c|c|c|c|c|c|c|}
\hline VarName & VariableLabel & WordingDE & ValueLabelsDE_Linked & WordingEN & ValueLabelsEN_Linked & $\mathrm{L} 1$ & $\mathrm{~L} 2$ & L3 & $\mathrm{L} 4$ & L5 & $\mathrm{L} 6$ & $\mathrm{~L} 7$ & L8 & L9 & L10 L11 L12 \\
\hline extraversion.long. 7 & $\begin{array}{l}\text { Big Five Long, } \\
\text { Item } 31\end{array}$ & $\begin{array}{l}\text { manchmal schüchtern und } \\
\text { gehemmt ist }\end{array}$ & $\begin{array}{l}1=\text { trifft überhaupt nicht zu, } \\
2=\text { trifft eher nicht zu, } 3= \\
\text { weder noch, } 4=\text { eher } \\
\text { zutreffend, } 5=\text { trifft voll und } \\
\text { ganz zu }\end{array}$ & $\begin{array}{l}\text { I see myself as someone } \\
\text { who is sometimes shy, } \\
\text { inhibited }\end{array}$ & $\begin{array}{l}1=\text { does not apply at all, } \\
2=\text { mostly does not } \\
\text { apply, } 3=\text { neither, } 4= \\
\text { mostly applies, } 5= \\
\text { applies completely (free } \\
\text { translation) }\end{array}$ & $\mathrm{x}$ & & & & & & & & & \\
\hline agreeableness.long. 7 & $\begin{array}{l}\text { Big Five Long, } \\
\text { Item } 32\end{array}$ & $\begin{array}{l}\text { rücksichtsvoll und } \\
\text { einfühlsam zu anderen ist }\end{array}$ & $\begin{array}{l}1=\text { trifft überhaupt nicht zu, } \\
2=\text { trifft eher nicht zu, } 3= \\
\text { weder noch, } 4=\text { eher } \\
\text { zutreffend, } 5=\text { trifft voll und } \\
\text { ganz zu }\end{array}$ & $\begin{array}{l}\text { I see myself as someone } \\
\text { who is considerate and } \\
\text { kind to almost everyone }\end{array}$ & $\begin{array}{l}1=\text { does not apply at all, } \\
2=\text { mostly does not } \\
\text { apply, } 3=\text { neither, } 4= \\
\text { mostly applies, } 5= \\
\text { applies completely (free } \\
\text { translation) }\end{array}$ & $\mathrm{x}$ & & & & & & & & & \\
\hline conscientiousness.long. 7 & $\begin{array}{l}\text { Big Five Long, } \\
\text { Item } 33\end{array}$ & tüchtig ist und flott arbeitet & $\begin{array}{l}1=\text { trifft überhaupt nicht zu, } \\
2=\text { trifft eher nicht zu, } 3= \\
\text { weder noch, } 4=\text { eher } \\
\text { zutreffend, } 5=\text { trifft voll und } \\
\text { ganz zu }\end{array}$ & $\begin{array}{l}\text { I see myself as someone } \\
\text { who does things } \\
\text { efficiently }\end{array}$ & $\begin{array}{l}1=\text { does not apply at all, } \\
2=\text { mostly does not } \\
\text { apply, } 3=\text { neither, } 4= \\
\text { mostly applies, } 5= \\
\text { applies completely (free } \\
\text { translation) }\end{array}$ & $\mathrm{x}$ & & & & & & & & & \\
\hline neuroticism.long. 7 & $\begin{array}{l}\text { Big Five Long, } \\
\text { Item } 34\end{array}$ & $\begin{array}{l}\text { ruhig bleibt, selbst in } \\
\text { angespannten Situationen }\end{array}$ & $\begin{array}{l}1=\text { trifft überhaupt nicht zu, } \\
2=\text { trifft eher nicht zu, } 3= \\
\text { weder noch, } 4=\text { eher } \\
\text { zutreffend, } 5=\text { trifft voll und } \\
\text { ganz zu }\end{array}$ & $\begin{array}{l}\text { I see myself as someone } \\
\text { who remains calm in } \\
\text { tense situations }\end{array}$ & $\begin{array}{l}1=\text { does not apply at all, } \\
2=\text { mostly does not } \\
\text { apply, } 3=\text { neither, } 4= \\
\text { mostly applies, } 5= \\
\text { applies completely (free } \\
\text { translation) }\end{array}$ & $\mathrm{x}$ & & & & & & & & & \\
\hline openness.long. 7 & $\begin{array}{l}\text { Big Five Long, } \\
\text { Item } 35\end{array}$ & $\begin{array}{l}\text { routinemässige und einfache } \\
\text { Aufgaben bevorzugt }\end{array}$ & $\begin{array}{l}1=\text { trifft überhaupt nicht zu, } \\
2=\text { trifft eher nicht zu, } 3= \\
\text { weder noch, } 4=\text { eher } \\
\text { zutreffend, } 5=\text { trifft voll und } \\
\text { ganz zu }\end{array}$ & $\begin{array}{l}\text { I see myself as someone } \\
\text { who prefers work that is } \\
\text { routine }\end{array}$ & $\begin{array}{l}1=\text { does not apply at all, } \\
2=\text { mostly does not } \\
\text { apply, } 3=\text { neither, } 4= \\
\text { mostly applies, } 5= \\
\text { applies completely (free } \\
\text { translation) }\end{array}$ & $\mathrm{x}$ & & & & & & & & & \\
\hline extraversion.long. 8 & $\begin{array}{l}\text { Big Five Long, } \\
\text { Item } 36\end{array}$ & $\begin{array}{l}\text { aus sich herausgeht, gesellig } \\
\text { ist }\end{array}$ & $\begin{array}{l}1=\text { trifft überhaupt nicht zu, } \\
2=\text { trifft eher nicht zu, } 3= \\
\text { weder noch, } 4=\text { eher } \\
\text { zutreffend, } 5=\text { trifft voll und } \\
\text { ganz zu }\end{array}$ & $\begin{array}{l}\text { I see myself as someone } \\
\text { who is outgoing, } \\
\text { sociable }\end{array}$ & $\begin{array}{l}1=\text { does not apply at all, } \\
2=\text { mostly does not } \\
\text { apply, } 3=\text { neither, } 4= \\
\text { mostly applies, } 5= \\
\text { applies completely (free } \\
\text { translation) }\end{array}$ & $\mathrm{x}$ & & & & & & & & & \\
\hline agreeableness.long. 8 & $\begin{array}{l}\text { Big Five Long, } \\
\text { Item } 37\end{array}$ & $\begin{array}{l}\text { schroff und abweisend zu } \\
\text { anderen sein kann }\end{array}$ & $\begin{array}{l}1=\text { trifft überhaupt nicht zu, } \\
2=\text { trifft eher nicht zu, } 3= \\
\text { weder noch, } 4=\text { eher } \\
\text { zutreffend, } 5=\text { trifft voll und } \\
\text { ganz zu }\end{array}$ & $\begin{array}{l}\text { I see myself as someone } \\
\text { who is sometimes rude } \\
\text { to others }\end{array}$ & $\begin{array}{l}1=\text { does not apply at all, } \\
2=\text { mostly does not } \\
\text { apply, } 3=\text { neither, } 4= \\
\text { mostly applies, } 5= \\
\text { applies completely (free } \\
\text { translation) }\end{array}$ & $\mathrm{x}$ & & & & & & & & & \\
\hline conscientiousness.long. 8 & $\begin{array}{l}\text { Big Five Long, } \\
\text { Item } 38\end{array}$ & $\begin{array}{l}\text { Pläne macht und diese auch } \\
\text { durchführt }\end{array}$ & $\begin{array}{l}1=\text { trifft überhaupt nicht zu, } \\
2=\text { trifft eher nicht zu, } 3= \\
\text { weder noch, } 4=\text { eher } \\
\text { zutreffend, } 5=\text { trifft voll und } \\
\text { ganz zu }\end{array}$ & $\begin{array}{l}\text { I see myself as someone } \\
\text { who makes plans and } \\
\text { follows through with } \\
\text { them }\end{array}$ & $\begin{array}{l}1=\text { does not apply at all, } \\
2=\text { mostly does not } \\
\text { apply, } 3=\text { neither, } 4= \\
\text { mostly applies, } 5= \\
\text { applies completely (free } \\
\text { translation) }\end{array}$ & $\mathrm{x}$ & & & & & & & & & \\
\hline neuroticism.long. 8 & $\begin{array}{l}\text { Big Five Long, } \\
\text { Item } 39\end{array}$ & $\begin{array}{l}\text { leicht nervös und unsicher } \\
\text { wird. }\end{array}$ & $\begin{array}{l}1=\text { trifft überhaupt nicht zu, } \\
2=\text { trifft eher nicht zu, } 3= \\
\text { weder noch, } 4=\text { eher } \\
\text { zutreffend, } 5=\text { trifft voll und } \\
\text { ganz zu }\end{array}$ & $\begin{array}{l}\text { I see myself as someone } \\
\text { who gets nervous easily }\end{array}$ & $\begin{array}{l}1=\text { does not apply at all, } \\
2=\text { mostly does not } \\
\text { apply, } 3=\text { neither, } 4= \\
\text { mostly applies, } 5= \\
\text { applies completely (free } \\
\text { translation) }\end{array}$ & $\mathrm{x}$ & & & & & & & & & \\
\hline openness.long. 8 & $\begin{array}{l}\text { Big Five Long, } \\
\text { Item } 40\end{array}$ & $\begin{array}{l}\text { gerne Überlegungen } \\
\text { anstellt, mit Ideen spielt }\end{array}$ & $\begin{array}{l}1=\text { trifft überhaupt nicht zu, } \\
2=\text { trifft eher nicht zu, } 3= \\
\text { weder noch, } 4=\text { eher } \\
\text { zutreffend, } 5=\text { trifft voll und } \\
\text { ganz zu }\end{array}$ & $\begin{array}{l}\text { I see myself as someone } \\
\text { who likes to reflect, play } \\
\text { with ideas }\end{array}$ & $\begin{array}{l}1=\text { does not apply at all, } \\
2=\text { mostly does not } \\
\text { apply, } 3=\text { neither, } 4= \\
\text { mostly applies, } 5= \\
\text { applies completely (free } \\
\text { translation) }\end{array}$ & $\mathrm{x}$ & & & & & & & & & \\
\hline
\end{tabular}




\begin{tabular}{|c|c|c|c|c|c|c|c|c|c|c|c|c|c|c|c|c|c|}
\hline VarName & VariableLabel & WordingDE & ValueLabelsDE_Linked & WordingEN & ValueLabelsEN_Linked & L1 & $\mathrm{L} 2$ & L3 & $\mathrm{L} 4$ & L5 & L6 & L7 & L8 & L9 & & L11 & $1 \mathrm{~L} 12$ \\
\hline openness.long. 9 & $\begin{array}{l}\text { Big Five Long, } \\
\text { Item } 41\end{array}$ & $\begin{array}{l}\text { nur wenig künstlerische } \\
\text { Interessen hat }\end{array}$ & $\begin{array}{l}1=\text { trifft überhaupt nicht zu, } \\
2=\text { trifft eher nicht } \mathrm{zu}, 3= \\
\text { weder noch, } 4=\text { eher } \\
\text { zutreffend, } 5=\text { trifft voll und } \\
\text { ganz zu }\end{array}$ & $\begin{array}{l}\text { I see myself as someone } \\
\text { who has few artistic } \\
\text { interests }\end{array}$ & $\begin{array}{l}1=\text { does not apply at all, } \\
2=\text { mostly does not } \\
\text { apply, } 3=\text { neither, } 4= \\
\text { mostly applies, } 5= \\
\text { applies completely (free } \\
\text { translation) }\end{array}$ & $\mathrm{x}$ & & & & & & & & & & & \\
\hline agreeableness.long. 9 & $\begin{array}{l}\text { Big Five Long, } \\
\text { Item } 42\end{array}$ & $\begin{array}{l}\text { sich kooperativ verhält, } \\
\text { Zusammenarbeit dem } \\
\text { Wettbewerb vorzieht }\end{array}$ & $\begin{array}{l}1=\text { trifft überhaupt nicht zu, } \\
2=\text { trifft eher nicht } \mathrm{zu}, 3= \\
\text { weder noch, } 4=\text { eher } \\
\text { zutreffend, } 5=\text { trifft voll und } \\
\text { ganz zu }\end{array}$ & $\begin{array}{l}\text { I see myself as someone } \\
\text { who likes to cooperate } \\
\text { with others }\end{array}$ & $\begin{array}{l}1=\text { does not apply at all, } \\
2=\text { mostly does not } \\
\text { apply, } 3=\text { neither, } 4= \\
\text { mostly applies, } 5= \\
\text { applies completely (free } \\
\text { translation) }\end{array}$ & $\mathrm{x}$ & & & & & & & & & & & \\
\hline conscientiousness.long.9 & $\begin{array}{l}\text { Big Five Long, } \\
\text { Item } 43\end{array}$ & $\begin{array}{l}\text { leicht ablenkbar ist, nicht } \\
\text { bei der Sache bleibt }\end{array}$ & $\begin{array}{l}1=\text { trifft überhaupt nicht } \mathrm{zu}, \\
2=\text { trifft eher nicht } \mathrm{zu}, 3= \\
\text { weder noch, } 4=\text { eher } \\
\text { zutreffend, } 5=\text { trifft voll und } \\
\text { ganz zu }\end{array}$ & $\begin{array}{l}\text { I see myself as someone } \\
\text { who is easily distracted }\end{array}$ & $\begin{array}{l}1=\text { does not apply at all, } \\
2=\text { mostly does not } \\
\text { apply, } 3=\text { neither, } 4= \\
\text { mostly applies, } 5= \\
\text { applies completely (free } \\
\text { translation) }\end{array}$ & $\mathrm{x}$ & & & & & & & & & & & \\
\hline openness.long.10 & $\begin{array}{l}\text { Big Five Long, } \\
\text { Item } 44\end{array}$ & $\begin{array}{l}\text { sich gut in Musik, Kunst } \\
\text { und Literatur auskennt }\end{array}$ & $\begin{array}{l}1=\text { trifft überhaupt nicht } \mathrm{zu}, \\
2=\text { trifft eher nicht } \mathrm{zu}, 3= \\
\text { weder noch, } 4=\text { eher } \\
\text { zutreffend, } 5=\text { trifft voll und } \\
\text { ganz zu }\end{array}$ & $\begin{array}{l}\text { I see myself as someone } \\
\text { who is sophisticated in } \\
\text { art, music, or literature }\end{array}$ & $\begin{array}{l}1=\text { does not apply at all, } \\
2=\text { mostly does not } \\
\text { apply, } 3=\text { neither, } 4= \\
\text { mostly applies, } 5= \\
\text { applies completely (free } \\
\text { translation) }\end{array}$ & $\mathrm{x}$ & & & & & & & & & & & \\
\hline stress.1 & $\begin{array}{l}\text { Perceived } \\
\text { Stress Scale } \\
\text { (PSS) Item } 1\end{array}$ & $\begin{array}{l}\text { Wie oft hattest Du Dich im } \\
\text { letzten Monat darüber } \\
\text { aufgeregt, dass etwas völlig } \\
\text { Unerwartetes eingetreten } \\
\text { ist? }\end{array}$ & $\begin{array}{l}0=\text { nie, } 1=\text { selten, } 2= \\
\text { manchmal, } 3=\text { häufig, } 4= \\
\text { sehr oft }\end{array}$ & $\begin{array}{l}\text { In the last month, how } \\
\text { often have you been } \\
\text { upset because of } \\
\text { something that } \\
\text { happened unexpectedly? }\end{array}$ & $\begin{array}{l}0=\text { never, } 1=\text { seldom, } 2 \\
=\text { sometimes, } 3=\text { often, } 4 \\
=\text { all the time }\end{array}$ & $\mathrm{x}$ & $\mathrm{x}$ & $\mathrm{x}$ & $\mathrm{x}$ & $\mathrm{x}$ & $\mathrm{x}$ & $\mathrm{x}$ & $\mathrm{x}$ & $\mathrm{x}$ & $\mathrm{x}$ & $\mathrm{x}$ & $\mathrm{x}$ \\
\hline stress. 2 & $\begin{array}{l}\text { Perceived } \\
\text { Stress Scale } \\
\text { (PSS) Item } 2\end{array}$ & $\begin{array}{l}\text { Wie oft hattest Du im } \\
\text { letzten Monat das Gefühl, } \\
\text { wichtige Dinge in Deinem } \\
\text { Leben nicht beeinflussen zu } \\
\text { können? }\end{array}$ & $\begin{array}{l}0=\text { nie, } 1=\text { selten, } 2= \\
\text { manchmal, } 3=\text { häufig, } 4= \\
\text { sehr oft }\end{array}$ & $\begin{array}{l}\text { In the last month, how } \\
\text { often have you felt that } \\
\text { you were unable to } \\
\text { control the important } \\
\text { things in your life? }\end{array}$ & $\begin{array}{l}0=\text { never, } 1=\text { seldom, } 2 \\
=\text { sometimes, } 3=\text { often, } 4 \\
=\text { all the time }\end{array}$ & $\mathrm{x}$ & $\mathrm{x}$ & $\mathrm{x}$ & $\mathrm{x}$ & $\mathrm{x}$ & $\mathrm{x}$ & $\mathrm{x}$ & $\mathrm{x}$ & $\mathrm{x}$ & $\mathrm{x}$ & $\mathrm{x}$ & $\mathrm{x}$ \\
\hline stress. 3 & $\begin{array}{l}\text { Perceived } \\
\text { Stress Scale } \\
\text { (PSS) Item } 3\end{array}$ & $\begin{array}{l}\text { Wie oft hattest Du Dich im } \\
\text { letzten Monat nervös und } \\
\text { "gestresst" gefühlt? }\end{array}$ & $\begin{array}{l}0=\text { nie, } 1=\text { selten, } 2= \\
\text { manchmal, } 3=\text { häufig, } 4= \\
\text { sehr oft }\end{array}$ & $\begin{array}{l}\text { In the last month, how } \\
\text { often have you felt } \\
\text { nervous and "stressed"? }\end{array}$ & $\begin{array}{l}0=\text { never, } 1=\text { seldom, } 2 \\
=\text { sometimes, } 3=\text { often, } 4 \\
=\text { all the time }\end{array}$ & $\mathrm{x}$ & $\mathrm{x}$ & $\mathrm{x}$ & $\mathrm{x}$ & $\mathrm{x}$ & $\mathrm{x}$ & $\mathrm{x}$ & $\mathrm{x}$ & $\mathrm{x}$ & $\mathrm{x}$ & $\mathrm{x}$ & $\mathrm{x}$ \\
\hline stress.4 & $\begin{array}{l}\text { Perceived } \\
\text { Stress Scale } \\
\text { (PSS) Item } 4\end{array}$ & $\begin{array}{l}\text { Wie oft hattest Du Dich im } \\
\text { letzten Monat sicher im } \\
\text { Umgang mit persönlichen } \\
\text { Aufgaben und Problemen } \\
\text { gefühlt? }\end{array}$ & $\begin{array}{l}0=\text { nie, } 1=\text { selten, } 2= \\
\text { manchmal, } 3=\text { häufig, } 4= \\
\text { sehr oft }\end{array}$ & $\begin{array}{l}\text { In the last month, how } \\
\text { often have you felt } \\
\text { confident about your } \\
\text { ability to handle your } \\
\text { personal problems? }\end{array}$ & $\begin{array}{l}0=\text { never, } 1=\text { seldom, } 2 \\
=\text { sometimes, } 3=\text { often, } 4 \\
=\text { all the time }\end{array}$ & $\mathrm{x}$ & $\mathrm{x}$ & $\mathrm{x}$ & $\mathrm{x}$ & $\mathrm{x}$ & $\mathrm{x}$ & $\mathrm{x}$ & $\mathrm{x}$ & $\mathrm{x}$ & $\mathrm{x}$ & $\mathrm{x}$ & $\mathrm{x}$ \\
\hline stress.5 & $\begin{array}{l}\text { Perceived } \\
\text { Stress Scale } \\
\text { (PSS) Item } 5\end{array}$ & $\begin{array}{l}\text { Wie oft hattest Du im } \\
\text { letzten Monat das Gefühl, } \\
\text { dass sich die Dinge nach } \\
\text { Deinen Vorstellungen } \\
\text { entwickeln? }\end{array}$ & $\begin{array}{l}0=\text { nie, } 1=\text { selten, } 2= \\
\text { manchmal, } 3=\text { häufig, } 4= \\
\text { sehr oft }\end{array}$ & $\begin{array}{l}\text { In the last month, how } \\
\text { often have you felt that } \\
\text { things were going your } \\
\text { way? }\end{array}$ & $\begin{array}{l}0=\text { never, } 1=\text { seldom, } 2 \\
=\text { sometimes, } 3=\text { often, } 4 \\
=\text { all the time }\end{array}$ & $\mathrm{x}$ & $\mathrm{x}$ & $\mathrm{x}$ & $\mathrm{x}$ & $\mathrm{x}$ & $\mathrm{x}$ & $\mathrm{x}$ & $\mathrm{x}$ & $\mathrm{x}$ & $\mathrm{x}$ & $\mathrm{x}$ & $\mathrm{X}$ \\
\hline stress.6 & $\begin{array}{l}\text { Perceived } \\
\text { Stress Scale } \\
\text { (PSS) Item } 6\end{array}$ & $\begin{array}{l}\text { Wie oft hattest Du im } \\
\text { letzten Monat das Gefühl, } \\
\text { mit all den anstehenden } \\
\text { Aufgaben und Problemen } \\
\text { nicht richtig umgehen zu } \\
\text { können? }\end{array}$ & $\begin{array}{l}0=\text { nie, } 1=\text { selten, } 2= \\
\text { manchmal, } 3=\text { häufig, } 4= \\
\text { sehr oft }\end{array}$ & $\begin{array}{l}\text { In the last month, how } \\
\text { often have you found } \\
\text { that you could not cope } \\
\text { with all the things that } \\
\text { you had to do? }\end{array}$ & $\begin{array}{l}0=\text { never, } 1=\text { seldom, } 2 \\
=\text { sometimes, } 3=\text { often, } 4 \\
=\text { all the time }\end{array}$ & $\mathrm{x}$ & $\mathrm{x}$ & $\mathrm{x}$ & $\mathrm{x}$ & $\mathrm{x}$ & $\mathrm{x}$ & $\mathrm{x}$ & $\mathrm{x}$ & $\mathrm{x}$ & $\mathrm{x}$ & $\mathrm{x}$ & $\mathrm{x}$ \\
\hline stress. 7 & $\begin{array}{l}\text { Perceived } \\
\text { Stress Scale } \\
\text { (PSS) Item } 7\end{array}$ & $\begin{array}{l}\text { Wie oft hattest Du im } \\
\text { letzten Monat das Gefühl, } \\
\text { mit Ärger in Deinem Leben } \\
\text { klar zu kommen? }\end{array}$ & $\begin{array}{l}0=\text { nie, } 1=\text { selten, } 2= \\
\text { manchmal, } 3=\text { häufig, } 4= \\
\text { sehr oft }\end{array}$ & $\begin{array}{l}\text { In the last month, how } \\
\text { often have you been able } \\
\text { to control irritations in } \\
\text { your life? }\end{array}$ & $\begin{array}{l}0=\text { never, } 1=\text { seldom, } 2 \\
=\text { sometimes, } 3=\text { often, } 4 \\
=\text { all the time }\end{array}$ & $\mathrm{x}$ & $\mathrm{x}$ & $\mathrm{x}$ & $\mathrm{x}$ & $\mathrm{x}$ & $\mathrm{x}$ & $\mathrm{x}$ & $\mathrm{x}$ & $\mathrm{x}$ & $\mathrm{x}$ & $\mathrm{x}$ & $\mathrm{x}$ \\
\hline stress. 8 & $\begin{array}{l}\text { Perceived } \\
\text { Stress Scale } \\
\text { (PSS) Item } 8\end{array}$ & $\begin{array}{l}\text { Wie oft hattest Du im } \\
\text { letzten Monat das Gefühl, } \\
\text { alles im Griff zu haben? }\end{array}$ & $\begin{array}{l}0=\text { nie, } 1=\text { selten, } 2= \\
\text { manchmal, } 3=\text { häufig, } 4= \\
\text { sehr oft }\end{array}$ & $\begin{array}{l}\text { In the last month, how } \\
\text { often have you felt that } \\
\text { you were on top of } \\
\text { things? }\end{array}$ & $\begin{array}{l}0=\text { never, } 1=\text { seldom, } 2 \\
=\text { sometimes, } 3=\text { often, } 4 \\
=\text { all the time }\end{array}$ & $\mathrm{x}$ & $\mathrm{x}$ & $\mathrm{x}$ & $\mathrm{x}$ & $\mathrm{x}$ & $\mathrm{x}$ & $\mathrm{x}$ & $\mathrm{x}$ & $\mathrm{x}$ & $\mathrm{x}$ & $\mathrm{x}$ & $\mathrm{x}$ \\
\hline
\end{tabular}




\begin{tabular}{|c|c|c|c|c|c|c|c|c|c|c|c|c|c|c|c|c|c|}
\hline VarName & VariableLabel & WordingDE & ValueLabelsDE_Linked & WordingEN & ValueLabelsEN_Linked & L1 & $\mathrm{L} 2$ & L3 & $\mathrm{L} 4$ & L5 & L6 & L7 & L8 & L9 & L10 & L11 & $1 \mathrm{~L} 12$ \\
\hline stress.9 & $\begin{array}{l}\text { Perceived } \\
\text { Stress Scale } \\
\text { (PSS) Item } 9\end{array}$ & $\begin{array}{l}\text { Wie oft hattest Du Dich im } \\
\text { letzten Monat darüber } \\
\text { geärgert, wichtige Dinge } \\
\text { nicht beeinflussen zu } \\
\text { können? }\end{array}$ & $\begin{array}{l}0=\text { nie, } 1=\text { selten, } 2= \\
\text { manchmal, } 3=\text { häufig, } 4= \\
\text { sehr oft }\end{array}$ & $\begin{array}{l}\text { In the last month, how } \\
\text { often have you been } \\
\text { angered because of } \\
\text { things that were outside } \\
\text { of your control? }\end{array}$ & $\begin{array}{l}0=\text { never, } 1=\text { seldom, } 2 \\
=\text { sometimes, } 3=\text { often, } 4 \\
=\text { all the time }\end{array}$ & $\mathrm{x}$ & $\mathrm{x}$ & $\mathrm{x}$ & $\mathrm{x}$ & $\mathrm{x}$ & $\mathrm{x}$ & $\mathrm{x}$ & $\mathrm{x}$ & $\mathrm{x}$ & $\mathrm{x}$ & $\mathrm{x}$ & $\mathrm{x}$ \\
\hline stress.10 & $\begin{array}{l}\text { Perceived } \\
\text { Stress Scale } \\
\text { (PSS) Item } 10\end{array}$ & $\begin{array}{l}\text { Wie oft hattest Du im } \\
\text { letzten Monat das Gefühl, } \\
\text { dass sich die Probleme so } \\
\text { aufgestaut haben, dass Du } \\
\text { diese nicht mehr bewältigen } \\
\text { kannst? }\end{array}$ & $\begin{array}{l}0=\text { nie, } 1=\text { selten, } 2= \\
\text { manchmal, } 3=\text { häufig, } 4= \\
\text { sehr oft }\end{array}$ & $\begin{array}{l}\text { In the last month, how } \\
\text { often have you felt } \\
\text { difficulties were piling } \\
\text { up so high that you } \\
\text { could not overcome } \\
\text { them? }\end{array}$ & $\begin{array}{l}0=\text { never, } 1=\text { seldom, } 2 \\
=\text { sometimes, } 3=\text { often, } 4 \\
=\text { all the time }\end{array}$ & $\mathrm{x}$ & $\mathrm{x}$ & $\mathrm{x}$ & $\mathrm{x}$ & $\mathrm{x}$ & $\mathrm{x}$ & $\mathrm{x}$ & $\mathrm{x}$ & $\mathrm{x}$ & $\mathrm{x}$ & $\mathrm{x}$ & $\mathrm{x}$ \\
\hline FirstClick.stress.covid & & & & & & & & & & & & & & & & $\mathrm{x}$ & $\mathrm{x}$ \\
\hline LastClick.stress.covid & & & & & & & & & & & & & & & & $\mathrm{x}$ & $\mathrm{x}$ \\
\hline PageSubmit.stress.covid & & & & & & & & & & & & & & & & $\mathrm{x}$ & $\mathrm{x}$ \\
\hline ClickCount.stress.covid & & & & & & & & & & & & & & & & $\mathrm{X}$ & $\mathrm{x}$ \\
\hline less.stress.covid & & $\begin{array}{l}\text { Welche Aspekte des Lebens } \\
\text { stressen Dich gerade } \\
\text { weniger als sonst (zu nicht } \\
\text { Corona-Zeiten)? }\end{array}$ & & $\begin{array}{l}\text { Which aspects of your } \\
\text { life stress you out less } \\
\text { than usual (during } \\
\text { non-Corona times)? }\end{array}$ & & & & & & & & & & & & $\mathrm{x}$ & $\mathrm{x}$ \\
\hline more.stress.covid & & $\begin{array}{l}\text { Welche Aspekte des Lebens } \\
\text { stressen Dich gerade mehr } \\
\text { als sonst (zu nicht } \\
\text { Corona-Zeiten)? }\end{array}$ & & $\begin{array}{l}\text { Which aspects of your } \\
\text { life stress you out more } \\
\text { than usual (during } \\
\text { non-Corona times)? }\end{array}$ & & & & & & & & & & & & $\mathrm{x}$ & $\mathrm{x}$ \\
\hline member.studyorganization. & a.L 7 & $\begin{array}{l}\text { Q19.2 - Bist Du Mitglied } \\
\text { beim [name removed]? Du } \\
\text { bist automatisch Mitglied } \\
\text { wenn Du bei Deiner } \\
\text { Einschreibung im [name } \\
\text { removed] angeklickt hast. }\end{array}$ & $1=\mathrm{Ja}, 2=$ Nein & $\begin{array}{l}\text { Are you a member of } \\
\text { [department student } \\
\text { association]? You're } \\
\text { automatically a member } \\
\text { if you clicked [name } \\
\text { removed]. }\end{array}$ & $1=\mathrm{Yes}, 2=\mathrm{No}$ & & & & & & & $\mathrm{x}$ & $\mathrm{x}$ & $\mathrm{x}$ & $\mathrm{x}$ & & \\
\hline member.studentorganizat & & $\begin{array}{l}\text { Q19.2 - Bist Du Mitglied } \\
\text { beim [name removed]? Du } \\
\text { bist automatisch Mitglied } \\
\text { wenn Du bei Deiner } \\
\text { Einschreibung im [name } \\
\text { removed] angeklickt hast. }\end{array}$ & $1=\mathrm{Ja}, 2=$ Nein & $\begin{array}{l}\text { Are you a member of } \\
\text { [department student } \\
\text { association]? You're } \\
\text { automatically a member } \\
\text { if you clicked [name } \\
\text { removed]. }\end{array}$ & $1=\mathrm{Yes}, 2=\mathrm{No}$ & $\mathrm{x}$ & $\mathrm{x}$ & $\mathrm{x}$ & $\mathrm{x}$ & $\mathrm{x}$ & $\mathrm{x}$ & $\mathrm{x}$ & $\mathrm{x}$ & $\mathrm{x}$ & $\mathrm{x}$ & & \\
\hline study. 1 & & $\begin{array}{l}\text { Q20.3 - Lernst Du } \\
\text { hauptsächlich alleine oder } \\
\text { mit anderen Leuten? }\end{array}$ & $\begin{array}{l}1=\text { alleine, } 2=\text { mit anderen } \\
\text { Leuten, } 3=\text { beides gleich viel }\end{array}$ & $\begin{array}{l}\text { Do you study primarily } \\
\text { by yourself or with } \\
\text { others? }\end{array}$ & $\begin{array}{l}1=\text { alone, } 2=\text { with } \\
\text { others, } 3=\text { both equally }\end{array}$ & $\mathrm{x}$ & $\mathrm{x}$ & $\mathrm{x}$ & $\mathrm{x}$ & $\mathrm{x}$ & $\mathrm{x}$ & $\mathrm{x}$ & $\mathrm{x}$ & $\mathrm{x}$ & $\mathrm{x}$ & $\mathrm{x}$ & $\mathrm{x}$ \\
\hline study.5 & & $\begin{array}{l}\text { Q20.4 - Warst Du ein guter } \\
\text { Schüler / eine gute } \\
\text { Schülerin in Deiner } \\
\text { vorherigen Klasse? }\end{array}$ & $\begin{array}{l}1=\text { unter den Besten, } 2= \\
\text { ganz ok, } 3=\text { nicht so gut, } 4 \\
=\text { eher bei den Schlechteren }\end{array}$ & $\begin{array}{l}\text { Were you a good student } \\
\text { in your prior class? }\end{array}$ & $\begin{array}{l}1=\text { among the best, } 2= \\
\text { quite well, } 3=\text { not so } \\
\text { well, } 4=\text { among the worst }\end{array}$ & $\mathrm{x}$ & $\mathrm{x}$ & $\mathrm{x}$ & $\mathrm{x}$ & $\mathrm{x}$ & $\mathrm{x}$ & $\mathrm{x}$ & $\mathrm{x}$ & $\mathrm{x}$ & $\mathrm{x}$ & $\mathrm{x}$ & $\mathrm{x}$ \\
\hline study. 6 & & $\begin{array}{l}\text { Q20.5 - Wie war Deine } \\
\text { Maturanote (der } \\
\text { Durchschnitt bzw. die } \\
\text { Endnote)? }\end{array}$ & & $\begin{array}{l}\text { Was was your average } \\
\text { final grade in high } \\
\text { school? }\end{array}$ & & $\mathrm{x}$ & & & & & & & & & & & \\
\hline study. 7 & & $\begin{array}{l}\text { Q20.6_1 - Ichbin sicher, } \\
\text { dass ich die Basisprüfung } \\
\text { am Ende des ersten Jahres } \\
\text { bestehen werde. - trifft } \\
\text { überhaupt nicht zu:trifft } \\
\text { voll und ganz zu }\end{array}$ & $\begin{array}{l}0=\text { trifft überhaupt nicht } \\
\text { zu:trifft voll und ganz zu, } 1= \\
\text { trifft überhaupt nicht zu:trifft } \\
\text { voll und ganz zu, } 2=\text { trifft } \\
\text { überhaupt nicht zu:trifft voll } \\
\text { und ganz zu, } 3=\text { trifft } \\
\text { überhaupt nicht zu:trifft voll } \\
\text { und ganz zu, } 4=\text { trifft } \\
\text { überhaupt nicht zu:trifft voll } \\
\text { und ganz zu, } 5=\text { trifft } \\
\text { überhaupt nicht zu:trifft voll } \\
\text { und ganz zu, } 6=\text { trifft } \\
\text { überhaupt nicht zu:trifft voll } \\
\text { und ganz zu }\end{array}$ & $\begin{array}{l}\text { I am sure that I will } \\
\text { pass the assessment } \\
\text { exam at the end of the } \\
\text { first academic year. - } \\
\text { don't agree at all:agree } \\
\text { completely }\end{array}$ & $\begin{array}{l}0=\text { don't agree at } \\
\text { all:agree completely, } 1= \\
\text { don't agree at all:agree } \\
\text { completely, } 2=\text { don't } \\
\text { agree at all:agree } \\
\text { completely, } 3=\text { don't } \\
\text { agree at all:agree } \\
\text { completely, } 4=\text { don't } \\
\text { agree at all:agree } \\
\text { completely, } 5=\text { don't } \\
\text { agree at all:agree } \\
\text { completely, } 6=\text { don't } \\
\text { agree at all:agree } \\
\text { completely }\end{array}$ & $\mathrm{x}$ & $\mathrm{x}$ & $\mathrm{x}$ & $\mathrm{x}$ & $\mathrm{x}$ & $\mathrm{x}$ & & & & & & \\
\hline
\end{tabular}




\begin{tabular}{|c|c|c|c|c|c|c|c|c|c|c|c|c|c|c|c|c|}
\hline VarName & VariableLabel & WordingDE & ValueLabelsDE_Linked & WordingEN & ValueLabelsEN_Linked & L1 & L2 & L3 & $\mathrm{L} 4$ & L5 & L6 & L7 & L8 & L9 & L10 L11 & L12 \\
\hline learn.obj.1 & $\begin{array}{l}\text { Learning } \\
\text { objective item } \\
1\end{array}$ & $\begin{array}{l}\text { Bei diesen Fragen geht es } \\
\text { um die Dinge, die dir } \\
\text { persönlich im Studium } \\
\text { wichtig sind. Im Studium } \\
\text { geht es mir darum, neue } \\
\text { Ideen zu bekommen }\end{array}$ & $\begin{array}{l}1=\text { stimmt gar nicht, } 2= \\
\text { stimmt eher nicht, } 3=\text { weder } \\
\text { noch, } 4=\text { stimmt eher, } 5= \\
\text { stimmt genau }\end{array}$ & $\begin{array}{l}\text { In my studies it is } \\
\text { important to: get new } \\
\text { ideas. }\end{array}$ & $\begin{array}{l}1=\text { don't agree at all, } 2= \\
\text { rather not agree, } 3= \\
\text { neither, } 4=\text { rather agree, } \\
5=\text { agree completely }\end{array}$ & $\mathrm{x}$ & $\mathrm{x}$ & $\mathrm{x}$ & $\mathrm{x}$ & $\mathrm{x}$ & $\mathrm{x}$ & $\mathrm{x}$ & $\mathrm{x}$ & $\mathrm{x}$ & $\mathrm{x}$ & $\mathrm{x}$ \\
\hline work.avoid.1 & $\begin{array}{l}\text { Work } \\
\text { avoidance item } \\
1\end{array}$ & $\begin{array}{l}\text { Bei diesen Fragen geht es } \\
\text { um die Dinge, die dir } \\
\text { persönlich im Studium } \\
\text { wichtig sind. Im Studium } \\
\text { geht es mir darum, keine } \\
\text { schwierigen Tests oder } \\
\text { Arbeiten zu haben }\end{array}$ & $\begin{array}{l}1=\text { stimmt gar nicht, } 2= \\
\text { stimmt eher nicht, } 3=\text { weder } \\
\text { noch, } 4=\text { stimmt eher, } 5= \\
\text { stimmt genau }\end{array}$ & $\begin{array}{l}\text { In my studies it is } \\
\text { important to have no } \\
\text { difficult tests or } \\
\text { assignments. }\end{array}$ & $\begin{array}{l}1=\text { don't agree at all, } 2= \\
\text { rather not agree, } 3= \\
\text { neither, } 4=\text { rather agree, } \\
5=\text { agree completely }\end{array}$ & $\mathrm{x}$ & $\mathrm{x}$ & $\mathrm{x}$ & $\mathrm{x}$ & $\mathrm{x}$ & $\mathrm{x}$ & $\mathrm{x}$ & $\mathrm{x}$ & $\mathrm{x}$ & $\mathrm{x}$ & $\mathrm{x}$ \\
\hline learn.obj.2 & $\begin{array}{l}\text { Learning } \\
\text { objective item } \\
2\end{array}$ & $\begin{array}{l}\text { Bei diesen Fragen geht es } \\
\text { um die Dinge, die dir } \\
\text { persönlich im Studium } \\
\text { wichtig sind. Im Studium } \\
\text { geht es mir darum, etwas } \\
\text { Interessantes zu lernen }\end{array}$ & $\begin{array}{l}1=\text { stimmt gar nicht, } 2= \\
\text { stimmt eher nicht, } 3=\text { weder } \\
\text { noch, } 4=\text { stimmt eher, } 5= \\
\text { stimmt genau }\end{array}$ & $\begin{array}{l}\text { In my studies it is } \\
\text { important to: learn } \\
\text { something interesting. }\end{array}$ & $\begin{array}{l}1=\text { don't agree at all, } 2= \\
\text { rather not agree, } 3= \\
\text { neither, } 4=\text { rather agree, } \\
5=\text { agree completely }\end{array}$ & $\mathrm{x}$ & $\mathrm{x}$ & $\mathrm{x}$ & $\mathrm{x}$ & $\mathrm{x}$ & $\mathrm{x}$ & $\mathrm{x}$ & $\mathrm{x}$ & $\mathrm{x}$ & $\mathrm{x}$ & $\mathrm{x}$ \\
\hline work.avoid.2 & $\begin{array}{l}\text { Work } \\
\text { avoidance item } \\
2\end{array}$ & $\begin{array}{l}\text { Bei diesen Fragen geht es } \\
\text { um die Dinge, die dir } \\
\text { persönlich im Studium } \\
\text { wichtig sind. Im Studium } \\
\text { geht es mir darum, zu } \\
\text { Hause keine Arbeiten } \\
\text { erledigen zu müssen }\end{array}$ & $\begin{array}{l}1=\text { stimmt gar nicht, } 2= \\
\text { stimmt eher nicht, } 3=\text { weder } \\
\text { noch, } 4=\text { stimmt eher, } 5= \\
\text { stimmt genau }\end{array}$ & $\begin{array}{l}\mathrm{n} \text { my studies it is } \\
\text { important to not have } \\
\text { to work at home. }\end{array}$ & $\begin{array}{l}1=\text { don't agree at all, } 2= \\
\text { rather not agree, } 3= \\
\text { neither, } 4=\text { rather agree, } \\
5=\text { agree completely }\end{array}$ & $\mathrm{x}$ & $\mathrm{x}$ & $\mathrm{x}$ & $\mathrm{x}$ & $\mathrm{x}$ & $\mathrm{x}$ & $\mathrm{x}$ & $\mathrm{x}$ & $\mathrm{x}$ & $\mathrm{x}$ & $\mathrm{x}$ \\
\hline learn.obj.3 & $\begin{array}{l}\text { Learning } \\
\text { objective item } \\
3\end{array}$ & $\begin{array}{l}\text { Bei diesen Fragen geht es } \\
\text { um die Dinge, die dir } \\
\text { persönlich im Studium } \\
\text { wichtig sind. Im Studium } \\
\text { geht es mir darum, später } \\
\text { knifflige Probleme lösen zu } \\
\text { können }\end{array}$ & $\begin{array}{l}1=\text { stimmt gar nicht, } 2= \\
\text { stimmt eher nicht, } 3=\text { weder } \\
\text { noch, } 4=\text { stimmt eher, } 5= \\
\text { stimmt genau }\end{array}$ & $\begin{array}{l}\text { In my studies it is } \\
\text { important to be able to } \\
\text { solve difficult problems } \\
\text { later. }\end{array}$ & $\begin{array}{l}1=\text { don't agree at all, } 2= \\
\text { rather not agree, } 3= \\
\text { neither, } 4=\text { rather agree, } \\
5=\text { agree completely }\end{array}$ & $\mathrm{x}$ & $\mathrm{x}$ & $\mathrm{x}$ & $\mathrm{x}$ & $\mathrm{x}$ & $\mathrm{x}$ & $\mathrm{x}$ & $\mathrm{x}$ & $\mathrm{x}$ & $\mathrm{x}$ & $\mathrm{x}$ \\
\hline work.avoid.3 & $\begin{array}{l}\text { Work } \\
\text { avoidance item } \\
3\end{array}$ & $\begin{array}{l}\text { Bei diesen Fragen geht es } \\
\text { um die Dinge, die dir } \\
\text { persönlich im Studium } \\
\text { wichtig sind. Im Studium } \\
\text { geht es mir darum, keine } \\
\text { schwierigen Fragen oder } \\
\text { Aufgaben lösen zu müssen }\end{array}$ & $\begin{array}{l}1=\text { stimmt gar nicht, } 2= \\
\text { stimmt eher nicht, } 3=\text { weder } \\
\text { noch, } 4=\text { stimmt eher, } 5= \\
\text { stimmt genau }\end{array}$ & $\begin{array}{l}\text { In my studies it is } \\
\text { important not to have to } \\
\text { solve difficult questions } \\
\text { or assignments. }\end{array}$ & $\begin{array}{l}1=\text { don't agree at all, } 2= \\
\text { rather not agree, } 3= \\
\text { neither, } 4=\text { rather agree, } \\
5=\text { agree completely }\end{array}$ & $\mathrm{x}$ & $\mathrm{x}$ & $\mathrm{x}$ & $\mathrm{x}$ & $\mathrm{x}$ & $\mathrm{x}$ & $\mathrm{x}$ & $\mathrm{x}$ & $\mathrm{x}$ & $\mathrm{x}$ & $\mathrm{x}$ \\
\hline learn.obj.4 & $\begin{array}{l}\text { Learning } \\
\text { objective item } \\
4\end{array}$ & $\begin{array}{l}\text { Bei diesen Fragen geht es } \\
\text { um die Dinge, die dir } \\
\text { persönlich im Studium } \\
\text { wichtig sind. Im Studium } \\
\text { geht es mir darum, } \\
\text { komplizierte Inhalte zu } \\
\text { verstehen }\end{array}$ & $\begin{array}{l}1=\text { stimmt gar nicht, } 2= \\
\text { stimmt eher nicht, } 3=\text { weder } \\
\text { noch, } 4=\text { stimmt eher, } 5= \\
\text { stimmt genau }\end{array}$ & $\begin{array}{l}\text { In my studies it is } \\
\text { important to: } \\
\text { understand difficult } \\
\text { things. }\end{array}$ & $\begin{array}{l}1=\text { don't agree at all, } 2= \\
\text { rather not agree, } 3= \\
\text { neither, } 4=\text { rather agree, } \\
5=\text { agree completely }\end{array}$ & $\mathrm{x}$ & $\mathrm{x}$ & $\mathrm{x}$ & $\mathrm{x}$ & $\mathrm{x}$ & $\mathrm{x}$ & $\mathrm{x}$ & $\mathrm{x}$ & $\mathrm{x}$ & $\mathrm{x}$ & $\mathrm{x}$ \\
\hline app.perf.3 & $\begin{array}{l}\text { Approximate } \\
\text { performance } \\
\text { goal item } 3\end{array}$ & $\begin{array}{l}\text { Bei diesen Fragen geht es } \\
\text { um die Dinge, die dir } \\
\text { persönlich im Studium } \\
\text { wichtig sind. Im Studium } \\
\text { geht es mir darum, bessere } \\
\text { Noten zu bekommen als } \\
\text { andere }\end{array}$ & $\begin{array}{l}1=\text { stimmt gar nicht, } 2= \\
\text { stimmt eher nicht, } 3=\text { weder } \\
\text { noch, } 4=\text { stimmt eher, } 5= \\
\text { stimmt genau }\end{array}$ & $\begin{array}{l}\text { In my studies it is } \\
\text { important to: get better } \\
\text { grades than others. }\end{array}$ & $\begin{array}{l}1=\text { don't agree at all, } 2= \\
\text { rather not agree, } 3= \\
\text { neither, } 4=\text { rather agree, } \\
5=\text { agree completely }\end{array}$ & $\mathrm{x}$ & $\mathrm{x}$ & $\mathrm{x}$ & $\mathrm{x}$ & $\mathrm{x}$ & $\mathrm{x}$ & $\mathrm{x}$ & $\mathrm{x}$ & $\mathrm{x}$ & $\mathrm{x}$ & $\mathrm{x}$ \\
\hline work.avoid.4 & $\begin{array}{l}\text { Work } \\
\text { avoidance item } \\
4\end{array}$ & $\begin{array}{l}\text { Bei diesen Fragen geht es } \\
\text { um die Dinge, die dir } \\
\text { persönlich im Studium } \\
\text { wichtig sind. Im Studium } \\
\text { geht es mir darum, nicht so } \\
\text { schwer zu arbeiten }\end{array}$ & $\begin{array}{l}1=\text { stimmt gar nicht, } 2= \\
\text { stimmt eher nicht, } 3=\text { weder } \\
\text { noch, } 4=\text { stimmt eher, } 5= \\
\text { stimmt genau }\end{array}$ & $\begin{array}{l}\text { In my studies it is } \\
\text { important not to have } \\
\text { to work too hard. }\end{array}$ & $\begin{array}{l}1=\text { don't agree at all, } 2= \\
\text { rather not agree, } 3= \\
\text { neither, } 4=\text { rather agree, } \\
5=\text { agree completely }\end{array}$ & $\mathrm{x}$ & $\mathrm{x}$ & $\mathrm{x}$ & $\mathrm{x}$ & $\mathrm{x}$ & $\mathrm{x}$ & $\mathrm{x}$ & $\mathrm{X}$ & $\mathrm{X}$ & $\mathrm{x}$ & $\mathrm{X}$ \\
\hline
\end{tabular}




\begin{tabular}{|c|c|c|c|c|c|c|c|c|c|c|c|c|c|c|c|c|c|}
\hline VarName & VariableLabel & WordingDE & ValueLabelsDE_Linked & WordingEN & ValueLabelsEN_Linked & L1 & $\mathrm{L} 2$ & L3 & $\mathrm{L} 4$ & L5 & L6 & L7 & L8 & L9 & L10 & L11 & $\mathrm{L} 12$ \\
\hline learn.obj.5 & $\begin{array}{l}\text { Learning } \\
\text { objective item } \\
5\end{array}$ & $\begin{array}{l}\text { Bei diesen Fragen geht es } \\
\text { um die Dinge, die dir } \\
\text { persönlich im Studium } \\
\text { wichtig sind. Im Studium } \\
\text { geht es mir darum, dass das } \\
\text { Gelernte für mich Sinn } \\
\text { ergibt }\end{array}$ & $\begin{array}{l}1=\text { stimmt gar nicht, } 2= \\
\text { stimmt eher nicht, } 3=\text { weder } \\
\text { noch, } 4=\text { stimmt eher, } 5= \\
\text { stimmt genau }\end{array}$ & $\begin{array}{l}\text { In my studies it is } \\
\text { important to: see that } \\
\text { what I learn makes } \\
\text { sense. }\end{array}$ & $\begin{array}{l}1=\text { don't agree at all, } 2= \\
\text { rather not agree, } 3= \\
\text { neither, } 4=\text { rather agree, } \\
5=\text { agree completely }\end{array}$ & $\mathrm{x}$ & $\mathrm{x}$ & $\mathrm{x}$ & $\mathrm{x}$ & $\mathrm{x}$ & $\mathrm{x}$ & $\mathrm{x}$ & $\mathrm{x}$ & $\mathrm{x}$ & $\mathrm{x}$ & & $\mathrm{x}$ \\
\hline work.avoid.5 & $\begin{array}{l}\text { Work } \\
\text { avoidance item } \\
5\end{array}$ & $\begin{array}{l}\text { Bei diesen Fragen geht es } \\
\text { um die Dinge, die dir } \\
\text { persönlich im Studium } \\
\text { wichtig sind. Im Studium } \\
\text { geht es mir darum, dass die } \\
\text { Arbeit leicht ist }\end{array}$ & $\begin{array}{l}1=\text { stimmt gar nicht, } 2= \\
\text { stimmt eher nicht, } 3=\text { weder } \\
\text { noch, } 4=\text { stimmt eher, } 5= \\
\text { stimmt genau }\end{array}$ & $\begin{array}{l}\text { In my studies it is } \\
\text { important that work is } \\
\text { easy. }\end{array}$ & $\begin{array}{l}1=\text { don't agree at all, } 2= \\
\text { rather not agree, } 3= \\
\text { neither, } 4=\text { rather agree } \\
5=\text { agree completely }\end{array}$ & $\mathrm{x}$ & $\mathrm{x}$ & $\mathrm{x}$ & $\mathrm{x}$ & $\mathrm{x}$ & $\mathrm{x}$ & $\mathrm{x}$ & $\mathrm{x}$ & $\mathrm{x}$ & $\mathrm{x}$ & & $\mathrm{x}$ \\
\hline learn.obj.6 & $\begin{array}{l}\text { Learning } \\
\text { objective item } \\
6\end{array}$ & $\begin{array}{l}\text { Bei diesen Fragen geht es } \\
\text { um die Dinge, die dir } \\
\text { persönlich im Studium } \\
\text { wichtig sind. Im Studium } \\
\text { geht es mir darum, zum } \\
\text { Nachdenken angeregt zu } \\
\text { werden }\end{array}$ & $\begin{array}{l}1=\text { stimmt gar nicht, } 2= \\
\text { stimmt eher nicht, } 3=\text { weder } \\
\text { noch, } 4=\text { stimmt eher, } 5= \\
\text { stimmt genau }\end{array}$ & $\begin{array}{l}\text { In my studies it is } \\
\text { important to: be made } \\
\text { to think about things. }\end{array}$ & $\begin{array}{l}1=\text { don't agree at all, } 2= \\
\text { rather not agree, } 3= \\
\text { neither, } 4=\text { rather agree, } \\
5=\text { agree completely }\end{array}$ & $\mathrm{x}$ & $\mathrm{x}$ & $\mathrm{x}$ & $\mathrm{x}$ & $\mathrm{x}$ & $\mathrm{x}$ & $\mathrm{x}$ & $\mathrm{x}$ & $\mathrm{x}$ & $\mathrm{x}$ & & $\mathrm{x}$ \\
\hline work.avoid.6 & $\begin{array}{l}\text { Work } \\
\text { avoidance item } \\
6\end{array}$ & $\begin{array}{l}\text { Bei diesen Fragen geht es } \\
\text { um die Dinge, die dir } \\
\text { persönlich im Studium } \\
\text { wichtig sind. Im Studium } \\
\text { geht es mir darum, } \\
\text { Aufgaben, die viel Arbeit } \\
\text { machen, nicht selber } \\
\text { erledigen zu müssen }\end{array}$ & $\begin{array}{l}1=\text { stimmt gar nicht, } 2= \\
\text { stimmt eher nicht, } 3=\text { weder } \\
\text { noch, } 4=\text { stimmt eher, } 5= \\
\text { stimmt genau }\end{array}$ & $\begin{array}{l}\text { In my studies it is } \\
\text { important to not to } \\
\text { have to do tasks myself } \\
\text { that are a lot of work. }\end{array}$ & $\begin{array}{l}1=\text { don't agree at all, } 2= \\
\text { rather not agree, } 3= \\
\text { neither, } 4=\text { rather agree, } \\
5=\text { agree completely }\end{array}$ & $\mathrm{x}$ & $\mathrm{x}$ & $\mathrm{x}$ & $\mathrm{x}$ & $\mathrm{x}$ & $\mathrm{x}$ & $\mathrm{x}$ & $\mathrm{x}$ & $\mathrm{x}$ & $\mathrm{x}$ & & $\mathrm{x}$ \\
\hline learn.obj.7 & $\begin{array}{l}\text { Learning } \\
\text { objective item } \\
7\end{array}$ & $\begin{array}{l}\text { Bei diesen Fragen geht es } \\
\text { um die Dinge, die dir } \\
\text { persönlich im Studium } \\
\text { wichtig sind. Im Studium } \\
\text { geht es mir darum, so viel } \\
\text { wie möglich zu lernen }\end{array}$ & $\begin{array}{l}1=\text { stimmt gar nicht, } 2= \\
\text { stimmt eher nicht, } 3=\text { weder } \\
\text { noch, } 4=\text { stimmt eher, } 5= \\
\text { stimmt genau }\end{array}$ & $\begin{array}{l}\text { In my studies it is } \\
\text { important to: learn as } \\
\text { much as possible. }\end{array}$ & $\begin{array}{l}1=\text { don't agree at all, } 2= \\
\text { rather not agree, } 3= \\
\text { neither, } 4=\text { rather agree, } \\
5=\text { agree completely }\end{array}$ & $\mathrm{x}$ & $\mathrm{x}$ & $\mathrm{x}$ & $\mathrm{x}$ & $\mathrm{x}$ & $\mathrm{x}$ & $\mathrm{x}$ & $\mathrm{x}$ & $\mathrm{x}$ & $\mathrm{x}$ & & $\mathrm{x}$ \\
\hline work.avoid.7 & $\begin{array}{l}\text { Work } \\
\text { avoidance item } \\
7\end{array}$ & $\begin{array}{l}\text { Bei diesen Fragen geht es } \\
\text { um die Dinge, die dir } \\
\text { persönlich im Studium } \\
\text { wichtig sind. Im Studium } \\
\text { geht es mir darum, mit } \\
\text { wenig Arbeit durch die } \\
\text { Schule zu kommen }\end{array}$ & $\begin{array}{l}1=\text { stimmt gar nicht, } 2= \\
\text { stimmt eher nicht, } 3=\text { weder } \\
\text { noch, } 4=\text { stimmt eher, } 5= \\
\text { stimmt genau }\end{array}$ & $\begin{array}{l}\text { In my studies it is } \\
\text { important to get } \\
\text { through school with } \\
\text { little work. }\end{array}$ & $\begin{array}{l}1=\text { don't agree at all, } 2= \\
\text { rather not agree, } 3= \\
\text { neither, } 4=\text { rather agree, } \\
5=\text { agree completely }\end{array}$ & $\mathrm{x}$ & $\mathrm{x}$ & $\mathrm{x}$ & $\mathrm{x}$ & $\mathrm{x}$ & $\mathrm{x}$ & $\mathrm{x}$ & $\mathrm{x}$ & $\mathrm{x}$ & $\mathrm{x}$ & & $\mathrm{x}$ \\
\hline learn.obj.8 & $\begin{array}{l}\text { Learning } \\
\text { objective item } \\
8\end{array}$ & $\begin{array}{l}\text { Bei diesen Fragen geht es } \\
\text { um die Dinge, die dir } \\
\text { persönlich im Studium } \\
\text { wichtig sind. Im Studium } \\
\text { geht es mir darum, die } \\
\text { Unterrichtsinhalte wirklich } \\
\text { zu verstehen }\end{array}$ & $\begin{array}{l}1=\text { stimmt gar nicht, } 2= \\
\text { stimmt eher nicht, } 3=\text { weder } \\
\text { noch, } 4=\text { stimmt eher, } 5= \\
\text { stimmt genau }\end{array}$ & $\begin{array}{l}\text { In my studies it is } \\
\text { important to: really } \\
\text { understand what is } \\
\text { taught. }\end{array}$ & $\begin{array}{l}1=\text { don't agree at all, } 2= \\
\text { rather not agree, } 3= \\
\text { neither, } 4=\text { rather agree, } \\
5=\text { agree completely }\end{array}$ & $\mathrm{x}$ & $\mathrm{x}$ & $\mathrm{x}$ & $\mathrm{x}$ & $\mathrm{x}$ & $\mathrm{x}$ & $\mathrm{x}$ & $\mathrm{x}$ & $\mathrm{x}$ & $\mathrm{x}$ & & $\mathrm{x}$ \\
\hline quitting.intention & & $\begin{array}{l}\text { Q22.2_10 - Inwiefern trifft } \\
\text { folgende Aussage auf Dich } \\
\text { zu? - Ich bin mir sicher, } \\
\text { dass dieses Studium am } \\
\text { [department] das Richtige } \\
\text { für mich ist }\end{array}$ & $\begin{array}{l}1=\text { trifft überhaupt nicht } \mathrm{zu}, \\
2=\text { trifft nicht zu, } 3=\text { trifft } \\
\text { eher nicht } \mathrm{zu}, 4=\text { weder } \\
\text { noch, } 5=\text { trifft eher zu, } 6= \\
\text { trifft zu, } 7=\text { trifft voll und } \\
\text { ganz zu }\end{array}$ & $\begin{array}{l}\text { Does this statement } \\
\text { apply to you? - I am } \\
\text { sure that this degree } \\
\text { program at the } \\
\text { [department] is right for } \\
\text { me }\end{array}$ & $\begin{array}{l}1=\text { does not apply at all, } \\
2=\text { does not apply, } 3= \\
\text { mostly does not apply, } 4 \\
=\text { neither, } 5=\text { applies } \\
\text { more than not, } 6= \\
\text { applies, } 7=\text { applies } \\
\text { completely (free } \\
\text { translation) }\end{array}$ & $\mathrm{x}$ & $\mathrm{x}$ & $\mathrm{x}$ & $\mathrm{X}$ & $\mathrm{x}$ & $\mathrm{x}$ & $\mathrm{x}$ & $\mathrm{x}$ & $\mathrm{x}$ & $\mathrm{x}$ & $\mathrm{x}$ & $\mathrm{x}$ \\
\hline quitting.intention.str & & $\begin{array}{l}\text { Q22.3 - Warum bist Du Dir } \\
\text { nicht sicher, dass dieses } \\
\text { Studium das Richtige für } \\
\text { Dich ist? }\end{array}$ & & $\begin{array}{l}\text { Why are you unsure } \\
\text { that this degree program } \\
\text { is right for you? }\end{array}$ & & $\mathrm{x}$ & $\mathrm{x}$ & $\mathrm{x}$ & $\mathrm{x}$ & $\mathrm{x}$ & $\mathrm{x}$ & $\mathrm{x}$ & $\mathrm{x}$ & $\mathrm{x}$ & $\mathrm{x}$ & $\mathrm{x}$ & $\mathrm{x}$ \\
\hline
\end{tabular}




\begin{tabular}{|c|c|c|c|c|c|c|c|c|c|c|c|c|c|c|c|}
\hline VarName & VariableLabel & WordingDE & ValueLabelsDE_Linked & WordingEN & ValueLabelsEN_Linked & L1 & $\mathrm{L} 2$ & L3 & $\mathrm{L} 4$ & L5 & L6 & L7 & L8 & L9 & L10 L11 L12 \\
\hline $\begin{array}{l}\text { work.values } \\
\text {.extrinsic.orientation.1 }\end{array}$ & & $\begin{array}{l}\text { Q23.2_4-Für die Arbeit } \\
\text { und die Wahl des Berufs } \\
\text { könnenunterschiedliche } \\
\text { Dinge wichtig sein. Bitte } \\
\text { gib für jeden der folgenden } \\
\text { Punktean, wie wichtig er } \\
\text { für Dich bei der Berufswahl } \\
\text { ist. Wie wichtig ist für } \\
\text { Deine Berufswahl - eine } \\
\text { sichere Berufsstellung? }\end{array}$ & $\begin{array}{l}1=\text { trifft überhaupt nicht } \mathrm{zu}, \\
2=\text { trifft nicht } \mathrm{zu}, 3=\text { trifft } \\
\text { eher nicht } \mathrm{zu}, 4=\text { weder } \\
\text { noch, } 5=\text { trifft eher } \mathrm{zu}, 6= \\
\text { trifft } \mathrm{zu}, 7=\text { trifft voll und } \\
\text { ganz zu }\end{array}$ & $\begin{array}{l}\text { The motivations for } \\
\text { work and the choice of } \\
\text { an occupation can be } \\
\text { influenced by different } \\
\text { factors. Please indicate } \\
\text { for each of the following } \\
\text { factors how important } \\
\text { they might be for } \\
\text { choosing you } \\
\text { occupation. How } \\
\text { important in your choice } \\
\text { of occupation is - secure } \\
\text { employment? }\end{array}$ & $\begin{array}{l}1=\text { don't agree at all, } 2= \\
\text { don't agree, } 3=\text { rather } \\
\text { not agree, } 4=\text { neither, } 5 \\
=\text { rather agree, } 6=\text { agree, } \\
7=\text { agree completely }\end{array}$ & $\mathrm{x}$ & $\mathrm{x}$ & $\mathrm{x}$ & $\mathrm{x}$ & $\mathrm{x}$ & $\mathrm{x}$ & $\mathrm{x}$ & $\mathrm{x}$ & $\mathrm{x}$ & $\mathrm{x}$ \\
\hline $\begin{array}{l}\text { work.values } \\
\text {.extrinsic.orientation.2 }\end{array}$ & & $\begin{array}{l}\text { Q23.2_5 - Für die Arbeit } \\
\text { und die Wahl des Berufs } \\
\text { könnenunterschiedliche } \\
\text { Dinge wichtig sein. Bitte } \\
\text { gib für jeden der folgenden } \\
\text { Punktean, wie wichtig er } \\
\text { für Dich bei der Berufswahl } \\
\text { ist. Wie wichtig ist für } \\
\text { Deine Berufswahl - ein } \\
\text { hohes Einkommen? }\end{array}$ & $\begin{array}{l}1=\text { trifft überhaupt nicht } \mathrm{zu}, \\
2=\text { trifft nicht } \mathrm{zu}, 3=\text { trifft } \\
\text { eher nicht } \mathrm{zu}, 4=\text { weder } \\
\text { noch, } 5=\text { trifft eher zu, } 6= \\
\text { trifft } \mathrm{zu}, 7=\text { trifft voll und } \\
\text { ganz zu }\end{array}$ & $\begin{array}{l}\text { The motivations for } \\
\text { work and the choice of } \\
\text { an occupation can be } \\
\text { influenced by different } \\
\text { factors. Please indicate } \\
\text { for each of the following } \\
\text { factors how important } \\
\text { they might be for } \\
\text { choosing you } \\
\text { occupation. How } \\
\text { important in your choice } \\
\text { of occupation is - a high } \\
\text { salary? }\end{array}$ & $\begin{array}{l}1=\text { don't agree at all, } 2= \\
\text { don't agree, } 3=\text { rather } \\
\text { not agree, } 4=\text { neither, } 5 \\
=\text { rather agree, } 6=\text { agree, } \\
7=\text { agree completely }\end{array}$ & $\mathrm{x}$ & $\mathrm{x}$ & $\mathrm{x}$ & $\mathrm{x}$ & $\mathrm{x}$ & $\mathrm{x}$ & $\mathrm{x}$ & $\mathrm{x}$ & $\mathrm{x}$ & $\mathrm{x}$ \\
\hline $\begin{array}{l}\text { work.values } \\
\text {.extrinsic.orientation.3 }\end{array}$ & & $\begin{array}{l}\text { Q23.2_6 - Für die Arbeit } \\
\text { und die Wahl des Berufs } \\
\text { könnenunterschiedliche } \\
\text { Dinge wichtig sein. Bitte } \\
\text { gib für jeden der folgenden } \\
\text { Punktean, wie wichtig er } \\
\text { für Dich bei der Berufswahl } \\
\text { ist. Wie wichtig ist für } \\
\text { Deine Berufswahl - gute } \\
\text { Aufstiegsmöglichkeiten? }\end{array}$ & $\begin{array}{l}1=\text { trifft überhaupt nicht } \mathrm{zu}, \\
2=\text { trifft nicht } \mathrm{zu}, 3=\text { trifft } \\
\text { eher nicht } \mathrm{zu}, 4=\text { weder } \\
\text { noch, } 5=\text { trifft eher } \mathrm{zu}, 6= \\
\text { trifft } \mathrm{zu}, 7=\text { trifft voll und } \\
\text { ganz zu }\end{array}$ & $\begin{array}{l}\text { The motivations for } \\
\text { work and the choice of } \\
\text { an occupation can be } \\
\text { influenced by different } \\
\text { factors. Please indicate } \\
\text { for each of the following } \\
\text { factors how important } \\
\text { they might be for } \\
\text { choosing you } \\
\text { occupation. How } \\
\text { important in your choice } \\
\text { of occupation is - option } \\
\text { for career advancement? }\end{array}$ & $\begin{array}{l}1=\text { don't agree at all, } 2= \\
\text { don't agree, } 3=\text { rather } \\
\text { not agree, } 4=\text { neither, } 5 \\
=\text { rather agree, } 6=\text { agree, } \\
7=\text { agree completely }\end{array}$ & $\mathrm{x}$ & $\mathrm{x}$ & $\mathrm{x}$ & $\mathrm{x}$ & $\mathrm{x}$ & $\mathrm{x}$ & $\mathrm{x}$ & $\mathrm{x}$ & $\mathrm{x}$ & $\mathrm{x}$ \\
\hline $\begin{array}{l}\text { work.values } \\
\text {.extrinsic.orientation. } 4\end{array}$ & & $\begin{array}{l}\text { Q23.2_7 - Für die Arbeit } \\
\text { und die Wahl des Berufs } \\
\text { könnenunterschiedliche } \\
\text { Dinge wichtig sein. Bitte } \\
\text { gib für jeden der folgenden } \\
\text { Punktean, wie wichtig er } \\
\text { für Dich bei der Berufswahl } \\
\text { ist. Wie wichtig ist für } \\
\text { Deine Berufswahl - ein } \\
\text { Beruf, der anerkannt ist } \\
\text { und geachtet wird? }\end{array}$ & $\begin{array}{l}1=\text { trifft überhaupt nicht zu, } \\
2=\text { trifft nicht zu, } 3=\text { trifft } \\
\text { eher nicht zu, } 4=\text { weder } \\
\text { noch, } 5=\text { trifft eher zu, } 6= \\
\text { trifft zu, } 7=\text { trifft voll und } \\
\text { ganz zu }\end{array}$ & $\begin{array}{l}\text { The motivations for } \\
\text { work and the choice of } \\
\text { an occupation can be } \\
\text { influenced by different } \\
\text { factors. Please indicate } \\
\text { for each of the following } \\
\text { factors how important } \\
\text { they might be for } \\
\text { choosing you } \\
\text { occupation. How } \\
\text { important in your choice } \\
\text { of occupation is - an } \\
\text { occupation that is } \\
\text { renowned? }\end{array}$ & $\begin{array}{l}1=\text { don't agree at all, } 2= \\
\text { don't agree, } 3=\text { rather } \\
\text { not agree, } 4=\text { neither, } 5 \\
=\text { rather agree, } 6=\text { agree, } \\
7=\text { agree completely }\end{array}$ & $\mathrm{x}$ & $\mathrm{x}$ & $\mathrm{x}$ & $\mathrm{x}$ & $\mathrm{x}$ & $\mathrm{x}$ & $\mathrm{x}$ & $\mathrm{x}$ & $\mathrm{x}$ & $\mathrm{x}$ \\
\hline
\end{tabular}




\begin{tabular}{|c|c|c|c|c|c|c|c|c|c|c|c|c|c|c|c|}
\hline VarName & VariableLabel & WordingDE & ValueLabelsDE_Linked & WordingEN & ValueLabelsEN_Linked & L1 & $\mathrm{L} 2$ & L3 & $\mathrm{L} 4$ & L5 & L6 & L7 & L8 & L9 & L10 L11 L12 \\
\hline $\begin{array}{l}\text { work.values } \\
\text {.external.orientation.1 }\end{array}$ & & $\begin{array}{l}\text { Q23.2_8 - Für die Arbeit } \\
\text { und die Wahl des Berufs } \\
\text { könnenunterschiedliche } \\
\text { Dinge wichtig sein. Bitte } \\
\text { gib für jeden der folgenden } \\
\text { Punktean, wie wichtig er für } \\
\text { Dich bei der Berufswahl ist. } \\
\text { Wie wichtig ist für Deine } \\
\text { Berufswahl - ein Beruf, der } \\
\text { einem viel Freizeit lässt? }\end{array}$ & $\begin{array}{l}1=\text { trifft überhaupt nicht } \mathrm{zu}, \\
2=\text { trifft nicht } \mathrm{zu}, 3=\text { trifft } \\
\text { eher nicht } \mathrm{zu}, 4=\text { weder } \\
\text { noch, } 5=\text { trifft eher } \mathrm{zu}, 6= \\
\text { trifft } \mathrm{zu}, 7=\text { trifft voll und } \\
\text { ganz zu }\end{array}$ & $\begin{array}{l}\text { The motivations for } \\
\text { work and the choice of } \\
\text { an occupation can be } \\
\text { influenced by different } \\
\text { factors. Please indicate } \\
\text { for each of the following } \\
\text { factors how important } \\
\text { they might be for } \\
\text { choosing you } \\
\text { occupation. How } \\
\text { important in your choice } \\
\text { of occupation is - allows } \\
\text { lots of free time? }\end{array}$ & $\begin{array}{l}1=\text { don't agree at all, } 2= \\
\text { don't agree, } 3=\text { rather } \\
\text { not agree, } 4=\text { neither, } 5 \\
=\text { rather agree, } 6=\text { agree } \\
7=\text { agree completely }\end{array}$ & $\mathrm{x}$ & $\mathrm{x}$ & $\mathrm{x}$ & $\mathrm{x}$ & $\mathrm{x}$ & $\mathrm{x}$ & $\mathrm{x}$ & $\mathrm{x}$ & $\mathrm{x}$ & $\mathrm{x}$ \\
\hline $\begin{array}{l}\text { work.values } \\
\text {.intrinsic.orientation.1 }\end{array}$ & & $\begin{array}{l}\text { Q23.2_9 - Für die Arbeit } \\
\text { und die Wahl des Berufs } \\
\text { könnenunterschiedliche } \\
\text { Dinge wichtig sein. Bitte } \\
\text { gib für jeden der folgenden } \\
\text { Punktean, wie wichtig er } \\
\text { für Dich bei der Berufswahl } \\
\text { ist. Wie wichtig ist für } \\
\text { Deine Berufswahl - eine } \\
\text { interessante Tätigkeit? }\end{array}$ & $\begin{array}{l}1=\text { trifft überhaupt nicht } \mathrm{zu}, \\
2=\text { trifft nicht } \mathrm{zu}, 3=\text { trifft } \\
\text { eher nicht } \mathrm{zu}, 4=\text { weder } \\
\text { noch, } 5=\text { trifft eher } \mathrm{zu}, 6= \\
\text { trifft } \mathrm{zu}, 7=\text { trifft voll und } \\
\text { ganz zu }\end{array}$ & $\begin{array}{l}\text { The motivations for } \\
\text { work and the choice of } \\
\text { an occupation can be } \\
\text { influenced by different } \\
\text { factors. Please indicate } \\
\text { for each of the following } \\
\text { factors how important } \\
\text { they might be for } \\
\text { choosing you } \\
\text { occupation. How } \\
\text { important in your choice } \\
\text { of occupation is - an } \\
\text { interesting subject } \\
\text { matter? }\end{array}$ & $\begin{array}{l}1=\text { don't agree at all, } 2= \\
\text { don't agree, } 3=\text { rather } \\
\text { not agree, } 4=\text { neither, } 5 \\
=\text { rather agree, } 6=\text { agree, } \\
7=\text { agree completely }\end{array}$ & $\mathrm{x}$ & $\mathrm{x}$ & $\mathrm{x}$ & $\mathrm{x}$ & $\mathrm{x}$ & $\mathrm{x}$ & $\mathrm{x}$ & $\mathrm{x}$ & $\mathrm{x}$ & $\mathrm{x}$ \\
\hline $\begin{array}{l}\text { work.values } \\
\text {.intrinsic.orientation.2 }\end{array}$ & & $\begin{array}{l}\text { Q23.2_10 - Für die Arbeit } \\
\text { und die Wahl des Berufs } \\
\text { könnenunterschiedliche } \\
\text { Dinge wichtig sein. Bitte } \\
\text { gib für jeden der folgenden } \\
\text { Punktean, wie wichtig er für } \\
\text { Dich bei der Berufswahl ist. } \\
\text { Wie wichtig ist für Deine } \\
\text { Berufswahl - eine Tätigkeit } \\
\text { bei der man selbstständig } \\
\text { arbeiten kann? }\end{array}$ & $\begin{array}{l}1=\text { trifft überhaupt nicht zu, } \\
2=\text { trifft nicht } \mathrm{zu}, 3=\text { trifft } \\
\text { eher nicht } \mathrm{zu}, 4=\text { weder } \\
\text { noch, } 5=\text { trifft eher zu, } 6= \\
\text { trifft } \mathrm{zu}, 7=\text { trifft voll und } \\
\text { ganz zu }\end{array}$ & $\begin{array}{l}\text { The motivations for } \\
\text { work and the choice of } \\
\text { an occupation can be } \\
\text { influenced by different } \\
\text { factors. Please indicate } \\
\text { for each of the following } \\
\text { factors how important } \\
\text { they might be for } \\
\text { choosing you } \\
\text { occupation. How } \\
\text { important in your choice } \\
\text { of occupation is - that I } \\
\text { can work autonomously? }\end{array}$ & $\begin{array}{l}1=\text { don't agree at all, } 2= \\
\text { don't agree, } 3=\text { rather } \\
\text { not agree, } 4=\text { neither, } 5 \\
=\text { rather agree, } 6=\text { agree, } \\
7=\text { agree completely }\end{array}$ & $\mathrm{x}$ & $\mathrm{X}$ & $\mathrm{x}$ & $\mathrm{X}$ & $\mathrm{x}$ & $\mathrm{x}$ & $\mathrm{X}$ & $\mathrm{X}$ & $\mathrm{X}$ & $\mathrm{x}$ \\
\hline $\begin{array}{l}\text { work.values } \\
\text {.social.orientation.1 }\end{array}$ & & $\begin{array}{l}\text { Q23.2_11 - Für die Arbeit } \\
\text { und die Wahl des Berufs } \\
\text { könnenunterschiedliche } \\
\text { Dinge wichtig sein. Bitte } \\
\text { gib für jeden der folgenden } \\
\text { Punktean, wie wichtig er für } \\
\text { Dich bei der Berufswahl ist. } \\
\text { Wie wichtig ist für Deine } \\
\text { Berufswahl - viel Kontakt } \\
\text { zu anderen Menschen? }\end{array}$ & $\begin{array}{l}1=\text { trifft überhaupt nicht } \mathrm{zu}, \\
2=\text { trifft nicht } \mathrm{zu}, 3=\text { trifft } \\
\text { eher nicht } \mathrm{zu}, 4=\text { weder } \\
\text { noch, } 5=\text { trifft eher } \mathrm{zu}, 6= \\
\text { trifft } \mathrm{zu}, 7=\text { trifft voll und } \\
\text { ganz zu }\end{array}$ & $\begin{array}{l}\text { The motivations for } \\
\text { work and the choice of } \\
\text { an occupation can be } \\
\text { influenced by different } \\
\text { factors. Please indicate } \\
\text { for each of the following } \\
\text { factors how important } \\
\text { they might be for } \\
\text { choosing you } \\
\text { occupation. How } \\
\text { important in your choice } \\
\text { of occupation is - lots of } \\
\text { contact with other } \\
\text { people? }\end{array}$ & $\begin{array}{l}1=\text { don't agree at all, } 2= \\
\text { don't agree, } 3=\text { rather } \\
\text { not agree, } 4=\text { neither, } 5 \\
=\text { rather agree, } 6=\text { agree, } \\
7=\text { agree completely }\end{array}$ & $\mathrm{x}$ & $\mathrm{x}$ & $\mathrm{x}$ & $\mathrm{x}$ & $\mathrm{x}$ & $\mathrm{x}$ & $\mathrm{x}$ & $\mathrm{x}$ & $\mathrm{x}$ & $\mathrm{x}$ \\
\hline
\end{tabular}




\begin{tabular}{|c|c|c|c|c|c|c|c|c|c|c|c|c|c|c|c|}
\hline VarName & VariableLabel & WordingDE & ValueLabelsDE_Linked & WordingEN & ValueLabelsEN_Linked & $\mathrm{L} 1$ & $\mathrm{~L} 2$ & L3 & $\mathrm{L} 4$ & L5 & L6 & L7 & L8 & L9 & L10 L11 L12 \\
\hline $\begin{array}{l}\text { work.values } \\
\text {.social.orientation.2 }\end{array}$ & & $\begin{array}{l}\text { Q23.2_12 - Für die Arbeit } \\
\text { und die Wahl des Berufs } \\
\text { könnenunterschiedliche } \\
\text { Dinge wichtig sein. Bitte } \\
\text { gib für jeden der folgenden } \\
\text { Punktean, wie wichtig er } \\
\text { für Dich bei der Berufswahl } \\
\text { ist. Wie wichtig ist für } \\
\text { Deine Berufswahl - ein } \\
\text { Beruf, der für die } \\
\text { Gesellschaft wichtig ist? }\end{array}$ & $\begin{array}{l}1=\text { trifft überhaupt nicht } \mathrm{zu}, \\
2=\text { trifft nicht } \mathrm{zu}, 3=\text { trifft } \\
\text { eher nicht } \mathrm{zu}, 4=\text { weder } \\
\text { noch, } 5=\text { trifft eher } \mathrm{zu}, 6= \\
\text { trifft } \mathrm{zu}, 7=\text { trifft voll und } \\
\text { ganz zu }\end{array}$ & $\begin{array}{l}\text { The motivations for } \\
\text { work and the choice of } \\
\text { an occupation can be } \\
\text { influenced by different } \\
\text { factors. Please indicate } \\
\text { for each of the following } \\
\text { factors how important } \\
\text { they might be for } \\
\text { choosing you } \\
\text { occupation. How } \\
\text { important in your choice } \\
\text { of occupation is - an } \\
\text { important contribution } \\
\text { to society? }\end{array}$ & $\begin{array}{l}1=\text { don't agree at all, } 2= \\
\text { don't agree, } 3=\text { rather } \\
\text { not agree, } 4=\text { neither, } 5 \\
=\text { rather agree, } 6=\text { agree, } \\
7=\text { agree completely }\end{array}$ & $\mathrm{x}$ & $\mathrm{x}$ & $\mathrm{x}$ & $\mathrm{x}$ & $\mathrm{x}$ & $\mathrm{x}$ & $\mathrm{x}$ & $\mathrm{x}$ & $\mathrm{x}$ & $\mathrm{x}$ \\
\hline $\begin{array}{l}\text { work.values } \\
\text {.external.orientation.2 }\end{array}$ & & $\begin{array}{l}\text { Q23.2_13 - Für die Arbeit } \\
\text { und die Wahl des Berufs } \\
\text { könnenunterschiedliche } \\
\text { Dinge wichtig sein. Bitte } \\
\text { gib für jeden der folgenden } \\
\text { Punktean, wie wichtig er } \\
\text { für Dich bei der Berufswahl } \\
\text { ist. Wie wichtig ist für } \\
\text { Deine Berufswahl - sichere } \\
\text { und gesunde } \\
\text { Arbeitsbedingungen? }\end{array}$ & $\begin{array}{l}1=\text { trifft überhaupt nicht } \mathrm{zu}, \\
2=\text { trifft nicht } \mathrm{zu}, 3=\text { trifft } \\
\text { eher nicht } \mathrm{zu}, 4=\text { weder } \\
\text { noch, } 5=\text { trifft eher zu, } 6= \\
\text { trifft zu, } 7=\text { trifft voll und } \\
\text { ganz zu }\end{array}$ & $\begin{array}{l}\text { The motivations for } \\
\text { work and the choice of } \\
\text { an occupation can be } \\
\text { influenced by different } \\
\text { factors. Please indicate } \\
\text { for each of the following } \\
\text { factors how important } \\
\text { they might be for } \\
\text { choosing you } \\
\text { occupation. How } \\
\text { important in your choice } \\
\text { of occupation is - } \\
\text { healthy and secure } \\
\text { working conditions? }\end{array}$ & $\begin{array}{l}1=\text { don't agree at all, } 2= \\
\text { don't agree, } 3=\text { rather } \\
\text { not agree, } 4=\text { neither, } 5 \\
=\text { rather agree, } 6=\text { agree, } \\
7=\text { agree completely }\end{array}$ & $\mathrm{x}$ & $\mathrm{x}$ & $\mathrm{x}$ & $\mathrm{x}$ & $\mathrm{x}$ & $\mathrm{x}$ & $\mathrm{x}$ & $\mathrm{x}$ & $\mathrm{x}$ & $\mathrm{x}$ \\
\hline $\begin{array}{l}\text { work.values } \\
\text {.external.orientation. } 3\end{array}$ & & $\begin{array}{l}\text { Q23.2_14-Für die Arbeit } \\
\text { und die Wahl des Berufs } \\
\text { könnenunterschiedliche } \\
\text { Dinge wichtig sein. Bitte } \\
\text { gib für jeden der folgenden } \\
\text { Punktean, wie wichtig er } \\
\text { für Dich bei der Berufswahl } \\
\text { ist. Wie wichtig ist für } \\
\text { Deine Berufswahl - ein } \\
\text { Beruf, der einem genügend } \\
\text { Zeit für familiäre } \\
\text { Verpflichtungen lässt? }\end{array}$ & $\begin{array}{l}1=\text { trifft überhaupt nicht } \mathrm{zu}, \\
2=\text { trifft nicht } \mathrm{zu}, 3=\text { trifft } \\
\text { eher nicht } \mathrm{zu}, 4=\text { weder } \\
\text { noch, } 5=\text { trifft eher } \mathrm{zu}, 6= \\
\text { trifft } \mathrm{zu}, 7=\text { trifft voll und } \\
\text { ganz zu }\end{array}$ & $\begin{array}{l}\text { The motivations for } \\
\text { work and the choice of } \\
\text { an occupation can be } \\
\text { influenced by different } \\
\text { factors. Please indicate } \\
\text { for each of the following } \\
\text { factors how important } \\
\text { they might be for } \\
\text { choosing you } \\
\text { occupation. How } \\
\text { important in your choice } \\
\text { of occupation is - allows } \\
\text { enough time for familial } \\
\text { obligations? }\end{array}$ & $\begin{array}{l}1=\text { don't agree at all, } 2= \\
\text { don't agree, } 3=\text { rather } \\
\text { not agree, } 4=\text { neither, } 5 \\
=\text { rather agree, } 6=\text { agree, } \\
7=\text { agree completely }\end{array}$ & $\mathrm{X}$ & $\mathrm{X}$ & $\mathrm{x}$ & $\mathrm{X}$ & $\mathrm{X}$ & $\mathrm{X}$ & $\mathrm{X}$ & $\mathrm{X}$ & $\mathrm{X}$ & $\mathrm{x}$ \\
\hline $\begin{array}{l}\text { work.values } \\
\text {.social.orientation.3 }\end{array}$ & & $\begin{array}{l}\text { Q23.2_15 - Für die Arbeit } \\
\text { und die Wahl des Berufs } \\
\text { könnenunterschiedliche } \\
\text { Dinge wichtig sein. Bitte } \\
\text { gib für jeden der folgenden } \\
\text { Punktean, wie wichtig er } \\
\text { für Dich bei der Berufswahl } \\
\text { ist. Wie wichtig ist für } \\
\text { Deine Berufswahl - ein } \\
\text { Beruf, bei dem man anderen } \\
\text { Menschen helfen kann? }\end{array}$ & $\begin{array}{l}1=\text { trifft überhaupt nicht } \mathrm{zu}, \\
2=\text { trifft nicht } \mathrm{zu}, 3=\text { trifft } \\
\text { eher nicht } \mathrm{zu}, 4=\text { weder } \\
\text { noch, } 5=\text { trifft eher } \mathrm{zu}, 6= \\
\text { trifft } \mathrm{zu}, 7=\text { trifft voll und } \\
\text { ganz zu }\end{array}$ & $\begin{array}{l}\text { The motivations for } \\
\text { work and the choice of } \\
\text { an occupation can be } \\
\text { influenced by different } \\
\text { factors. Please indicate } \\
\text { for each of the following } \\
\text { factors how important } \\
\text { they might be for } \\
\text { choosing you } \\
\text { occupation. How } \\
\text { important in your choice } \\
\text { of occupation is - } \\
\text { helping others? }\end{array}$ & $\begin{array}{l}1=\text { don't agree at all, } 2= \\
\text { don't agree, } 3=\text { rather } \\
\text { not agree, } 4=\text { neither, } 5 \\
=\text { rather agree, } 6=\text { agree, } \\
7=\text { agree completely }\end{array}$ & $\mathrm{x}$ & $\mathrm{x}$ & $\mathrm{x}$ & $\mathrm{x}$ & $\mathrm{x}$ & $\mathrm{x}$ & $\mathrm{x}$ & $\mathrm{x}$ & $\mathrm{x}$ & $\mathrm{x}$ \\
\hline
\end{tabular}




\begin{tabular}{|c|c|c|c|c|c|c|c|c|c|c|c|c|c|c|c|}
\hline VarName & VariableLabel & WordingDE & ValueLabelsDE_Linked & WordingEN & ValueLabelsEN_Linked & L1 & $\mathrm{L} 2$ & L3 & $\mathrm{L} 4$ & L5 & L6 6 & L7 & L8 & L9 & L10 L11 L12 \\
\hline gender.perceptions. 1 & & $\begin{array}{l}\text { Q24.2_16 - Im Folgenden } \\
\text { sind einige Fragen die sich } \\
\text { daraufbeziehen, ob Männer } \\
\text { und Frauen sich in } \\
\text { verschiedenen Hinsichten } \\
\text { unterscheiden. Bitte gib an, } \\
\text { inwiefern Du den folgenden } \\
\text { Aussagen zustimmst. - } \\
\text { Männer sind besser in } \\
\text { technischen und } \\
\text { naturwissenschaftlichen } \\
\text { Fächern als Frauen. }\end{array}$ & $\begin{array}{l}1=\text { stimmt überhaupt nicht, } \\
2=\text { stimmt nicht, } 3=\text { stimmt } \\
\text { eher nicht, } 4=\text { weder noch, } 5 \\
=\text { stimmt eher, } 6=\text { stimmt, } 7 \\
=\text { stimmt voll und ganz }\end{array}$ & $\begin{array}{l}\text { The following questions } \\
\text { refer to whether men } \\
\text { and women differ in } \\
\text { various aspects. Please } \\
\text { indicate to what extent } \\
\text { you agree with the } \\
\text { following statements. - } \\
\text { Men are better at } \\
\text { technical and scientific } \\
\text { subjects than women. }\end{array}$ & $\begin{array}{l}1=\text { don't agree at all, } 2= \\
\text { don't agree, } 3=\text { rather } \\
\text { not agree, } 4=\text { neither, } 5 \\
=\text { rather agree, } 6=\text { agree, } \\
7=\text { agree completely }\end{array}$ & $\mathrm{x}$ & $\mathrm{x}$ & $\mathrm{x}$ & $\mathrm{x}$ & $\mathrm{x}$ & $\mathrm{x}$ & $\mathrm{x}$ & $\mathrm{x}$ & $\mathrm{x}$ & $\mathrm{x}$ \\
\hline gender.perceptions. 2 & & $\begin{array}{l}\text { Q24.2_17 - Im Folgenden } \\
\text { sind einige Fragen die sich } \\
\text { daraufbeziehen, ob Männer } \\
\text { und Frauen sich in } \\
\text { verschiedenen Hinsichten } \\
\text { unterscheiden. Bitte gib an, } \\
\text { inwiefern Du den folgenden } \\
\text { Aussagen zustimmst. - } \\
\text { Frauen sind besser in } \\
\text { technischen und } \\
\text { naturwissenschaftlichen } \\
\text { Fächern als Männer. }\end{array}$ & $\begin{array}{l}1=\text { stimmt überhaupt nicht, } \\
2=\text { stimmt nicht, } 3=\text { stimmt } \\
\text { eher nicht, } 4=\text { weder noch, } 5 \\
=\text { stimmt eher, } 6=\text { stimmt, } 7 \\
=\text { stimmt voll und ganz }\end{array}$ & $\begin{array}{l}\text { The following questions } \\
\text { refer to whether men } \\
\text { and women differ in } \\
\text { various aspects. Please } \\
\text { indicate to what extent } \\
\text { you agree with the } \\
\text { following statements. - } \\
\text { Women are better at } \\
\text { technical and scientific } \\
\text { subjects than men. }\end{array}$ & $\begin{array}{l}1=\text { don't agree at all, } 2= \\
\text { don't agree, } 3=\text { rather } \\
\text { not agree, } 4=\text { neither, } 5 \\
=\text { rather agree, } 6=\text { agree } \\
7=\text { agree completely }\end{array}$ & $\mathrm{x}$ & $\mathrm{x}$ & $\mathrm{x}$ & $\mathrm{x}$ & $\mathrm{x}$ & $\mathrm{x}$ & $\mathrm{x}$ & $\mathrm{x}$ & $\mathrm{x}$ & $\mathrm{x}$ \\
\hline gender.perceptions. 3 & & $\begin{array}{l}\text { Q24.2_18 - Im Folgenden } \\
\text { sind einige Fragen die sich } \\
\text { daraufbeziehen, ob Männer } \\
\text { und Frauen sich in } \\
\text { verschiedenen Hinsichten } \\
\text { unterscheiden. Bitte gib an, } \\
\text { inwiefern Du den folgenden } \\
\text { Aussagen zustimmst. - } \\
\text { Männer sind besser in } \\
\text { Mathematik als Frauen. }\end{array}$ & $\begin{array}{l}1=\text { stimmt überhaupt nicht, } \\
2=\text { stimmt nicht, } 3=\text { stimmt } \\
\text { eher nicht, } 4=\text { weder noch, } 5 \\
=\text { stimmt eher, } 6=\text { stimmt, } 7 \\
=\text { stimmt voll und ganz }\end{array}$ & $\begin{array}{l}\text { The following questions } \\
\text { refer to whether men } \\
\text { and women differ in } \\
\text { various aspects. Please } \\
\text { indicate to what extent } \\
\text { you agree with the } \\
\text { following statements. - } \\
\text { Men are better than } \\
\text { women at mathematics. }\end{array}$ & $\begin{array}{l}1=\text { don't agree at all, } 2= \\
\text { don't agree, } 3=\text { rather } \\
\text { not agree, } 4=\text { neither, } 5 \\
=\text { rather agree, } 6=\text { agree, } \\
7=\text { agree completely }\end{array}$ & $\mathrm{x}$ & $\mathrm{x}$ & $\mathrm{x}$ & $\mathrm{x}$ & $\mathrm{x}$ & $\mathrm{x}$ & $\mathrm{x}$ & $\mathrm{x}$ & $\mathrm{x}$ & $\mathrm{x}$ \\
\hline gender.perceptions. 4 & & $\begin{array}{l}\text { Q24.2_19-Im Folgenden } \\
\text { sind einige Fragen die sich } \\
\text { daraufbeziehen, ob Männer } \\
\text { und Frauen sich in } \\
\text { verschiedenen Hinsichten } \\
\text { unterscheiden. Bitte gib an, } \\
\text { inwiefern Du den folgenden } \\
\text { Aussagen zustimmst. - } \\
\text { Frauen sind besser in } \\
\text { Mathematik als Männer. }\end{array}$ & $\begin{array}{l}1=\text { stimmt überhaupt nicht, } \\
2=\text { stimmt nicht, } 3=\text { stimmt } \\
\text { eher nicht, } 4=\text { weder noch, } 5 \\
=\text { stimmt eher, } 6=\text { stimmt, } 7 \\
=\text { stimmt voll und ganz }\end{array}$ & $\begin{array}{l}\text { The following questions } \\
\text { refer to whether men } \\
\text { and women differ in } \\
\text { various aspects. Please } \\
\text { indicate to what extent } \\
\text { you agree with the } \\
\text { following statements. - } \\
\text { Women are better than } \\
\text { men at mathematics. }\end{array}$ & $\begin{array}{l}1=\text { don't agree at all, } 2= \\
\text { don't agree, } 3=\text { rather } \\
\text { not agree, } 4=\text { neither, } 5 \\
=\text { rather agree, } 6=\text { agree, } \\
7=\text { agree completely }\end{array}$ & $\mathrm{x}$ & $\mathrm{x}$ & $\mathrm{x}$ & $\mathrm{x}$ & $\mathrm{x}$ & $\mathrm{x}$ & $\mathrm{x}$ & $\mathrm{x}$ & $\mathrm{x}$ & $\mathrm{x}$ \\
\hline gender.perceptions.5 & & $\begin{array}{l}\text { Q24.2_20 - Im Folgenden } \\
\text { sind einige Fragen die sich } \\
\text { daraufbeziehen, ob Männer } \\
\text { und Frauen sich in } \\
\text { verschiedenen Hinsichten } \\
\text { unterscheiden. Bitte gib an, } \\
\text { inwiefern Du den folgenden } \\
\text { Aussagen zustimmst. - } \\
\text { Männer sind besser in } \\
\text { Sprachen als Frauen. }\end{array}$ & $\begin{array}{l}1=\text { stimmt überhaupt nicht, } \\
2=\text { stimmt nicht, } 3=\text { stimmt } \\
\text { eher nicht, } 4=\text { weder noch, } 5 \\
=\text { stimmt eher, } 6=\text { stimmt, } 7 \\
=\text { stimmt voll und ganz }\end{array}$ & $\begin{array}{l}\text { The following questions } \\
\text { refer to whether men } \\
\text { and women differ in } \\
\text { various aspects. Please } \\
\text { indicate to what extent } \\
\text { you agree with the } \\
\text { following statements. - } \\
\text { Men are better than } \\
\text { women at languages. }\end{array}$ & $\begin{array}{l}1=\text { don't agree at all, } 2= \\
\text { don't agree, } 3=\text { rather } \\
\text { not agree, } 4=\text { neither, } 5 \\
=\text { rather agree, } 6=\text { agree } \\
7=\text { agree completely }\end{array}$ & $\mathrm{x}$ & $\mathrm{x}$ & $\mathrm{x}$ & $\mathrm{x}$ & $\mathrm{x}$ & $\mathrm{x}$ & $\mathrm{x}$ & $\mathrm{x}$ & $\mathrm{x}$ & $\mathrm{x}$ \\
\hline gender.perceptions.6 & & $\begin{array}{l}\text { Q24.2_21 - Im Folgenden } \\
\text { sind einige Fragen die sich } \\
\text { daraufbeziehen, ob Männer } \\
\text { und Frauen sich in } \\
\text { verschiedenen Hinsichten } \\
\text { unterscheiden. Bitte gib an, } \\
\text { inwiefern Du den folgenden } \\
\text { Aussagen zustimmst. - } \\
\text { Frauen sind besser in } \\
\text { Sprachen als Männer. }\end{array}$ & $\begin{array}{l}1=\text { stimmt überhaupt nicht, } \\
2=\text { stimmt nicht, } 3=\text { stimmt } \\
\text { eher nicht, } 4=\text { weder noch, } 5 \\
=\text { stimmt eher, } 6=\text { stimmt, } 7 \\
=\text { stimmt voll und ganz }\end{array}$ & $\begin{array}{l}\text { The following questions } \\
\text { refer to whether men } \\
\text { and women differ in } \\
\text { various aspects. Please } \\
\text { indicate to what extent } \\
\text { you agree with the } \\
\text { following statements. - } \\
\text { Women are better than } \\
\text { men at languages. }\end{array}$ & $\begin{array}{l}1=\text { don't agree at all, } 2= \\
\text { don't agree, } 3=\text { rather } \\
\text { not agree, } 4=\text { neither, } 5 \\
=\text { rather agree, } 6=\text { agree } \\
7=\text { agree completely }\end{array}$ & $\mathrm{x}$ & $\mathrm{x}$ & $\mathrm{x}$ & $\mathrm{x}$ & $\mathrm{x}$ & $\mathrm{x}$ & $\mathrm{x}$ & $\mathrm{x}$ & $\mathrm{x}$ & $\mathrm{x}$ \\
\hline
\end{tabular}




\begin{tabular}{|c|c|c|c|c|c|c|c|c|c|c|c|c|c|c|c|c|c|}
\hline VarName & VariableLabel & WordingDE & ValueLabelsDE_Linked & WordingEN & ValueLabelsEN_Linked & L1 & L2 & L3 & L4 & L5 & L6 & L7 & L8 & L9 & L10 & L11 & $\mathrm{L} 12$ \\
\hline behaviour.2 & & $\begin{array}{l}\text { Q25.2_2 - Wie oft... - ... } \\
\text { rauchst Du Tabak? }\end{array}$ & $\begin{array}{l}1=\text { nie, } 2=\text { sehr selten } \\
\text { (mindestens einmal im Jahr), } \\
3=\text { manchmal (mindestens } \\
\text { einmal im Monat), } 4= \\
\text { regelmässig (mindestens } \\
\text { einmal pro Woche), } 5=\text { oft } \\
\text { (mehrmals wöchentlich), } 6= \\
\text { jeden Tag }\end{array}$ & $\begin{array}{l}\text { How often... - ... do you } \\
\text { smoke tobacco? }\end{array}$ & $\begin{array}{l}1=\text { never, } 2=\text { very rarely } \\
\text { (at least once per year), } 3 \\
=\text { sometimes (at least } \\
\text { once per month), } 4= \\
\text { regularly (at least once } \\
\text { per week), } 5=\text { often (few } \\
\text { times per week, } 6=\text { every } \\
\text { day (free translation) }\end{array}$ & $\mathrm{x}$ & $\mathrm{x}$ & $\mathrm{x}$ & $\mathrm{x}$ & $\mathrm{x}$ & $\mathrm{x}$ & $\mathrm{x}$ & $\mathrm{x}$ & $\mathrm{x}$ & $\mathrm{x}$ & $\mathrm{x}$ & $\mathrm{x}$ \\
\hline behaviour.3 & & $\begin{array}{l}\text { Q25.2_3 - Wie oft ... - ... } \\
\text { rauchst Du Cannabis? }\end{array}$ & $\begin{array}{l}1=\text { nie, } 2=\text { sehr selten } \\
\text { (mindestens einmal im Jahr), } \\
3=\text { manchmal (mindestens } \\
\text { einmal im Monat), } 4= \\
\text { regelmässig (mindestens } \\
\text { einmal pro Woche), } 5=\text { oft } \\
\text { (mehrmals wöchentlich), } 6= \\
\text { jeden Tag }\end{array}$ & $\begin{array}{l}\text { How often... - ... do you } \\
\text { smoke cannabis? }\end{array}$ & $\begin{array}{l}1=\text { never, } 2=\text { very rarely } \\
\text { (at least once per year), } 3 \\
=\text { sometimes (at least } \\
\text { once per month), } 4= \\
\text { regularly (at least once } \\
\text { per week), } 5=\text { often (few } \\
\text { times per week, } 6=\text { every } \\
\text { day (free translation) }\end{array}$ & $\mathrm{x}$ & $\mathrm{x}$ & $\mathrm{x}$ & $\mathrm{x}$ & $\mathrm{x}$ & $\mathrm{x}$ & $\mathrm{x}$ & $\mathrm{x}$ & $\mathrm{x}$ & $\mathrm{x}$ & $\mathrm{x}$ & $\mathrm{x}$ \\
\hline behaviour.4 & & $\begin{array}{l}\text { Q25.2_4 - Wie oft... - ... } \\
\text { trinkst Du Alkohol? }\end{array}$ & $\begin{array}{l}1=\text { nie, } 2=\text { sehr selten } \\
(\text { mindestens einmal im Jahr), } \\
3=\text { manchmal (mindestens } \\
\text { einmal im Monat), } 4= \\
\text { regelmässig (mindestens } \\
\text { einmal pro Woche), } 5=\text { oft } \\
\text { (mehrmals wöchentlich), } 6= \\
\text { jeden Tag }\end{array}$ & $\begin{array}{l}\text { How often... - ... do you } \\
\text { drink alcohol? }\end{array}$ & $\begin{array}{l}1=\text { never, } 2=\text { very rarely } \\
\text { (at least once per year), } 3 \\
=\text { sometimes (at least } \\
\text { once per month), } 4= \\
\text { regularly (at least once } \\
\text { per week), } 5=\text { often (few } \\
\text { times per week, } 6=\text { every } \\
\text { day (free translation) }\end{array}$ & $\mathrm{x}$ & $\mathrm{x}$ & $\mathrm{x}$ & $\mathrm{x}$ & $\mathrm{x}$ & $\mathrm{x}$ & $\mathrm{x}$ & $\mathrm{x}$ & $\mathrm{x}$ & $\mathrm{x}$ & $\mathrm{x}$ & $\mathrm{x}$ \\
\hline freetime.org.1 & & $\begin{array}{l}\text { Q26.3_4 - Wie oft hast Du } \\
\text { Dich im letzten Monat bei } \\
\text { Aktivitäten einer der } \\
\text { folgenden Organisationen } \\
\text { oder Vereinigungen } \\
\text { beteiligt? Bitte gib auch } \\
\text { den Namen der } \\
\text { Organisation oder } \\
\text { Vereinigung an. - Bei einem } \\
\text { Sportverein? }\end{array}$ & $\begin{array}{l}1=\text { Täglich, } 2=\text { Mehrmals } \\
\text { pro Woche, } 3=\text { Mehrmals im } \\
\text { letzten Monat, } 4=\text { Einmal } \\
\text { im letzten Monat, } 5=\text { Nie }\end{array}$ & $\begin{array}{l}\text { In the last month, how } \\
\text { often have you } \\
\text { participated in activities } \\
\text { at one of the following } \\
\text { organizations or clubs? } \\
\text { Please also indicate the } \\
\text { name of the } \\
\text { organization or club. - } \\
\text { At a sports club? }\end{array}$ & $\begin{array}{l}1=\text { Daily, } 2=\text { Multiple } \\
\text { times per week, } 3= \\
\text { Multiple times in the past } \\
\text { month, } 4=\text { Once in the } \\
\text { last month, } 5=\text { Never }\end{array}$ & $\mathrm{x}$ & $\mathrm{x}$ & $\mathrm{x}$ & $\mathrm{x}$ & $\mathrm{x}$ & $\mathrm{x}$ & $\mathrm{x}$ & $\mathrm{x}$ & $\mathrm{x}$ & $\mathrm{x}$ & & \\
\hline freetime.org.1.str & & $\begin{array}{l}\text { Q26.3_4_TEXT - Wie oft } \\
\text { hast Du Dich im letzten } \\
\text { Monat bei Aktivitäten einer } \\
\text { der folgenden } \\
\text { Organisationen oder } \\
\text { Vereinigungen beteiligt? } \\
\text { Bitte gib auch den Namen } \\
\text { der Organisation oder } \\
\text { Vereinigung an. - Bei einem } \\
\text { Sportverein? - Text }\end{array}$ & & $\begin{array}{l}\text { TEXT - In the last } \\
\text { month, how often have } \\
\text { you participated in } \\
\text { activities at one of the } \\
\text { following organizations } \\
\text { or clubs? Please also } \\
\text { indicate the name of the } \\
\text { organization or club. - } \\
\text { At a sports club? }\end{array}$ & & $\mathrm{x}$ & $\mathrm{x}$ & $\mathrm{x}$ & $\mathrm{x}$ & $\mathrm{x}$ & $\mathrm{x}$ & $\mathrm{x}$ & $\mathrm{x}$ & $\mathrm{x}$ & $\mathrm{x}$ & & \\
\hline freetime.org. 2 & & $\begin{array}{l}\text { Q26.3_5 - Wie oft hast Du } \\
\text { Dich im letzten Monat bei } \\
\text { Aktivitäten einer der } \\
\text { folgenden Organisationen } \\
\text { oder Vereinigungen } \\
\text { beteiligt? Bitte gib auch } \\
\text { den Namen der } \\
\text { Organisation oder } \\
\text { Vereinigung an. - Bei einem } \\
\text { kulturellen Verein? }\end{array}$ & $\begin{array}{l}1=\text { Täglich, } 2=\text { Mehrmals } \\
\text { pro Woche, } 3=\text { Mehrmals im } \\
\text { letzten Monat, } 4=\text { Einmal } \\
\text { im letzten Monat, } 5=\text { Nie }\end{array}$ & $\begin{array}{l}\text { In the last month, how } \\
\text { often have you } \\
\text { participated in activities } \\
\text { at one of the following } \\
\text { organizations or clubs? } \\
\text { Please also indicate the } \\
\text { name of the } \\
\text { organization or club. - } \\
\text { At a cultural club? }\end{array}$ & $\begin{array}{l}1=\text { Daily, } 2=\text { Multiple } \\
\text { times per week, } 3= \\
\text { Multiple times in the past } \\
\text { month, } 4=\text { Once in the } \\
\text { last month, } 5=\text { Never }\end{array}$ & $\mathrm{x}$ & $\mathrm{x}$ & $\mathrm{x}$ & $\mathrm{x}$ & $\mathrm{x}$ & $\mathrm{x}$ & $\mathrm{x}$ & $\mathrm{x}$ & $\mathrm{x}$ & $\mathrm{x}$ & & \\
\hline freetime.org.2.str & & $\begin{array}{l}\text { Q26.3_5_TEXT - Wie oft } \\
\text { hast Du Dich im letzten } \\
\text { Monat bei Aktivitäten einer } \\
\text { der folgenden } \\
\text { Organisationen oder } \\
\text { Vereinigungen beteiligt? } \\
\text { Bitte gib auch den Namen } \\
\text { der Organisation oder } \\
\text { Vereinigung an. - Bei einem } \\
\text { kulturellen Verein? - Text }\end{array}$ & & $\begin{array}{l}\text { TEXT - In the last } \\
\text { month, how often have } \\
\text { you participated in } \\
\text { activities at one of the } \\
\text { following organizations } \\
\text { or clubs? Please also } \\
\text { indicate the name of the } \\
\text { organization or club. - } \\
\text { At a cultural club? }\end{array}$ & & $\mathrm{x}$ & $\mathrm{x}$ & $\mathrm{x}$ & $\mathrm{x}$ & $\mathrm{x}$ & $\mathrm{x}$ & $\mathrm{x}$ & $\mathrm{x}$ & $\mathrm{x}$ & $\mathrm{x}$ & & \\
\hline
\end{tabular}




\begin{tabular}{|c|c|c|c|c|c|c|c|c|c|c|c|c|c|c|c|}
\hline VarName & VariableLabel & WordingDE & ValueLabelsDE_Linked & WordingEN & ValueLabelsEN_Linked & L1 & L2 & L3 & L4 & L5 & L6 & L7 & L8 & L9 & L10 L11 L12 \\
\hline freetime.org. 3 & & $\begin{array}{l}\text { Q26.3_6 - Wie oft hast Du } \\
\text { Dich im letzten Monat bei } \\
\text { Aktivitäten einer der } \\
\text { folgenden Organisationen } \\
\text { oder Vereinigungen } \\
\text { beteiligt? Bitte gib auch } \\
\text { den Namen der } \\
\text { Organisation oder } \\
\text { Vereinigung an. - Bei einer } \\
\text { kirchlichen oder sonstigen } \\
\text { religiösen Organisation? }\end{array}$ & $\begin{array}{l}1=\text { Täglich, } 2=\text { Mehrmals } \\
\text { pro Woche, } 3=\text { Mehrmals im } \\
\text { letzten Monat, } 4=\text { Einmal } \\
\text { im letzten Monat, } 5=\text { Nie }\end{array}$ & $\begin{array}{l}\text { In the last month, how } \\
\text { often have you } \\
\text { participated in activities } \\
\text { at one of the following } \\
\text { organizations or clubs? } \\
\text { Please also indicate the } \\
\text { name of the organization } \\
\text { or club. - At a church- } \\
\text { or faith based club? }\end{array}$ & $\begin{array}{l}1=\text { Daily, } 2=\text { Multiple } \\
\text { times per week, } 3= \\
\text { Multiple times in the past } \\
\text { month, } 4=\text { Once in the } \\
\text { last month, } 5=\text { Never }\end{array}$ & $\mathrm{x}$ & $\mathrm{x}$ & $\mathrm{x}$ & $\mathrm{x}$ & $\mathrm{x}$ & $\mathrm{x}$ & $\mathrm{x}$ & $\mathrm{x}$ & $\mathrm{x}$ & $\mathrm{x}$ \\
\hline freetime.org.3.str & & $\begin{array}{l}\text { Q26.3_6_TEXT - Wie oft } \\
\text { hast Du Dich im letzten } \\
\text { Monat bei Aktivitäten einer } \\
\text { der folgenden } \\
\text { Organisationen oder } \\
\text { Vereinigungen beteiligt? } \\
\text { Bitte gib auch den Namen } \\
\text { der Organisation oder } \\
\text { Vereinigung an. - Bei einer } \\
\text { kirchlichen oder sonstigen } \\
\text { religiösen Organisation? - } \\
\text { Text }\end{array}$ & & $\begin{array}{l}\text { TEXT - In the last } \\
\text { month, how often have } \\
\text { you participated in } \\
\text { activities at one of the } \\
\text { following organizations } \\
\text { or clubs? Please also } \\
\text { indicate the name of the } \\
\text { organization or club. - } \\
\text { At a church- or faith } \\
\text { based club? }\end{array}$ & & $\mathrm{x}$ & $\mathrm{x}$ & $\mathrm{x}$ & $\mathrm{x}$ & $\mathrm{x}$ & $\mathrm{x}$ & $\mathrm{x}$ & $\mathrm{x}$ & $\mathrm{x}$ & $\mathrm{x}$ \\
\hline freetime.org.4 & & $\begin{array}{l}\text { Q26.3_7 - Wie oft hast Du } \\
\text { Dich im letzten Monat bei } \\
\text { Aktivitäten einer der } \\
\text { folgenden Organisationen } \\
\text { oder Vereinigungen } \\
\text { beteiligt? Bitte gib auch } \\
\text { den Namen der } \\
\text { Organisation oder } \\
\text { Vereinigung an. - Bei einem } \\
\text { gemeinnützigen Verein oder } \\
\text { einer Bürgerinitiative? }\end{array}$ & $\begin{array}{l}1=\text { Täglich, } 2=\text { Mehrmals } \\
\text { pro Woche, } 3=\text { Mehrmals im } \\
\text { letzten Monat, } 4=\text { Einmal } \\
\text { im letzten Monat, } 5=\text { Nie }\end{array}$ & $\begin{array}{l}\text { In the last month, how } \\
\text { often have you } \\
\text { participated in activities } \\
\text { at one of the following } \\
\text { organizations or clubs? } \\
\text { Please also indicate the } \\
\text { name of the } \\
\text { organization or club. - } \\
\text { At a social welfare- or } \\
\text { citizens' group? }\end{array}$ & $\begin{array}{l}1=\text { Daily, } 2=\text { Multiple } \\
\text { times per week, } 3= \\
\text { Multiple times in the past } \\
\text { month, } 4=\text { Once in the } \\
\text { last month, } 5=\text { Never }\end{array}$ & $\mathrm{x}$ & $\mathrm{x}$ & $\mathrm{x}$ & $\mathrm{x}$ & $\mathrm{x}$ & $\mathrm{x}$ & $\mathrm{x}$ & $\mathrm{x}$ & $\mathrm{x}$ & $\mathrm{x}$ \\
\hline freetime.org.4.str & & $\begin{array}{l}\text { Q26.3_7 T TEXT - Wie oft } \\
\text { hast Du Dich im letzten } \\
\text { Monat bei Aktivitäten einer } \\
\text { der folgenden } \\
\text { Organisationen oder } \\
\text { Vereinigungen beteiligt? } \\
\text { Bitte gib auch den Namen } \\
\text { der Organisation oder } \\
\text { Vereinigung an. - Bei einem } \\
\text { gemeinnützigen Verein oder } \\
\text { einer Bürgerinitiative? - } \\
\text { Text }\end{array}$ & & $\begin{array}{l}\text { TEXT - In the last } \\
\text { month, how often have } \\
\text { you participated in } \\
\text { activities at one of the } \\
\text { following organizations } \\
\text { or clubs? Please also } \\
\text { indicate the name of the } \\
\text { organization or club. - } \\
\text { At a social welfare- or } \\
\text { citizens' group? }\end{array}$ & & $\mathrm{x}$ & $\mathrm{x}$ & $\mathrm{x}$ & $\mathrm{x}$ & $\mathrm{x}$ & $\mathrm{x}$ & $\mathrm{x}$ & $\mathrm{x}$ & $\mathrm{x}$ & $\mathrm{x}$ \\
\hline freetime.org.5 & & $\begin{array}{l}\text { Q26.3_8 - Wie oft hast Du } \\
\text { Dich im letzten Monat bei } \\
\text { Aktivitäten einer der } \\
\text { folgenden Organisationen } \\
\text { oder Vereinigungen } \\
\text { beteiligt? Bitte gib auch } \\
\text { den Namen der } \\
\text { Organisation oder } \\
\text { Vereinigung an. - Bei einer } \\
\text { politischen Partei oder } \\
\text { einem Interessensverband? }\end{array}$ & $\begin{array}{l}1=\text { Täglich, } 2=\text { Mehrmals } \\
\text { pro Woche, } 3=\text { Mehrmals im } \\
\text { letzten Monat, } 4=\text { Einmal } \\
\text { im letzten Monat, } 5=\text { Nie }\end{array}$ & $\begin{array}{l}\text { In the last month, how } \\
\text { often have you } \\
\text { participated in activities } \\
\text { at one of the following } \\
\text { organizations or clubs? } \\
\text { Please also indicate the } \\
\text { name of the } \\
\text { organization or club. - } \\
\text { At a political party or } \\
\text { advocacy group? }\end{array}$ & $\begin{array}{l}1=\text { Daily, } 2=\text { Multiple } \\
\text { times per week, } 3= \\
\text { Multiple times in the past } \\
\text { month, } 4=\text { Once in the } \\
\text { last month, } 5=\text { Never }\end{array}$ & $\mathrm{x}$ & $\mathrm{x}$ & $\mathrm{x}$ & $\mathrm{x}$ & $\mathrm{x}$ & $\mathrm{x}$ & $\mathrm{X}$ & $\mathrm{x}$ & $\mathrm{x}$ & $\mathrm{x}$ \\
\hline
\end{tabular}




\begin{tabular}{|c|c|c|c|c|c|c|c|c|c|c|c|c|c|c|c|}
\hline VarName & VariableLabel & WordingDE & ValueLabelsDE_Linked & WordingEN & ValueLabelsEN_Linked & L1 & $\mathrm{L} 2$ & L3 & $\mathrm{L} 4$ & L5 & $\mathrm{L} 6$ & L7 & L8 & L9 & L10 L11 L12 \\
\hline freetime.org.5.str & & $\begin{array}{l}\text { Q26.3_8_TEXT - Wie oft } \\
\text { hast Du Dich im letzten } \\
\text { Monat bei Aktivitäten einer } \\
\text { der folgenden } \\
\text { Organisationen oder } \\
\text { Vereinigungen beteiligt? } \\
\text { Bitte gib auch den Namen } \\
\text { der Organisation oder } \\
\text { Vereinigung an. - Bei einer } \\
\text { politischen Partei oder } \\
\text { einem Interessensverband? - } \\
\text { Text }\end{array}$ & & $\begin{array}{l}\text { TEXT - In the last } \\
\text { month, how often have } \\
\text { you participated in } \\
\text { activities at one of the } \\
\text { following organizations } \\
\text { or clubs? Please also } \\
\text { indicate the name of the } \\
\text { organization or club. - } \\
\text { At a political party or } \\
\text { advocacy group? }\end{array}$ & & $\mathrm{x}$ & $\mathrm{x}$ & $\mathrm{x}$ & $\mathrm{x}$ & $\mathrm{x}$ & $\mathrm{x}$ & $\mathrm{x}$ & $\mathrm{x}$ & $\mathrm{x}$ & $\mathrm{x}$ \\
\hline freetime.org. 6 & & $\begin{array}{l}\text { Q26.3_9 - Wie oft hast Du } \\
\text { Dich im letzten Monat bei } \\
\text { Aktivitäten einer der } \\
\text { folgenden Organisationen } \\
\text { oder Vereinigungen } \\
\text { beteiligt? Bitte gib auch } \\
\text { den Namen der } \\
\text { Organisation oder } \\
\text { Vereinigung an. - Bei einem } \\
\text { Studierendenverein (zB. } \\
\text { beim [name removed] oder } \\
\text { einem Fachverein deines } \\
\text { Studiums)? }\end{array}$ & $\begin{array}{l}1=\text { Täglich, } 2=\text { Mehrmals } \\
\text { pro Woche, } 3=\text { Mehrmals im } \\
\text { letzten Monat, } 4=\text { Einmal } \\
\text { im letzten Monat, } 5=\mathrm{Nie}\end{array}$ & $\begin{array}{l}\text { In the last month, how } \\
\text { often have you } \\
\text { participated in activities } \\
\text { at one of the following } \\
\text { organizations or clubs? } \\
\text { Please also indicate the } \\
\text { name of the organization } \\
\text { or club. - At a student } \\
\text { association (e.g. [name } \\
\text { removed] or others)? }\end{array}$ & $\begin{array}{l}1=\text { Daily, } 2=\text { Multiple } \\
\text { times per week, } 3= \\
\text { Multiple times in the past } \\
\text { month, } 4=\text { Once in the } \\
\text { last month, } 5=\text { Never }\end{array}$ & $\mathrm{x}$ & $\mathrm{x}$ & $\mathrm{x}$ & $\mathrm{x}$ & $\mathrm{x}$ & $\mathrm{x}$ & $\mathrm{x}$ & $\mathrm{x}$ & $\mathrm{x}$ & $\mathrm{x}$ \\
\hline freetime.org.6.str & & $\begin{array}{l}\text { Q26.3_9_TEXT - Wie oft } \\
\text { hast Du Dich im letzten } \\
\text { Monat bei Aktivitäten einer } \\
\text { der folgenden } \\
\text { Organisationen oder } \\
\text { Vereinigungen beteiligt? } \\
\text { Bitte gib auch den Namen } \\
\text { der Organisation oder } \\
\text { Vereinigung an. - Bei einem } \\
\text { Studierendenverein (zB. } \\
\text { beim [name removed] oder } \\
\text { einem Fachverein deines } \\
\text { Studiums)? - Text }\end{array}$ & & $\begin{array}{l}\text { TEXT - In the last } \\
\text { month, how often have } \\
\text { you participated in } \\
\text { activities at one of the } \\
\text { following organizations } \\
\text { or clubs? Please also } \\
\text { indicate the name of the } \\
\text { organization or club. - } \\
\text { At a student association } \\
\text { (e.g. [name removed] or } \\
\text { others)? }\end{array}$ & & $\mathrm{x}$ & $\mathrm{x}$ & $\mathrm{x}$ & $\mathrm{x}$ & $\mathrm{x}$ & $\mathrm{x}$ & $\mathrm{x}$ & $\mathrm{x}$ & $\mathrm{x}$ & $\mathrm{x}$ \\
\hline freetime.act.1 & & $\begin{array}{l}\text { Q26.4_20 - Wie oft hast du } \\
\text { im letzten Monat die } \\
\text { folgenden Aktivitäten in } \\
\text { Deiner Freizeit } \\
\text { unternommen? (Wenn Du } \\
\text { andere Aktivitäten wichtig } \\
\text { findest, die nicht auf der } \\
\text { Liste stehen, spezifiziere } \\
\text { diese gerne in "Anderes") - } \\
\text { Fernsehen, DVD, Netflix, } \\
\text { oder YouTube }\end{array}$ & $\begin{array}{l}1=\text { Täglich, } 2=\text { Mehrmals } \\
\text { pro Woche, } 3=\text { Mehrmals im } \\
\text { letzten Monat, } 4=\text { Einmal } \\
\text { im letzten Monat, } 5=\text { Nie }\end{array}$ & $\begin{array}{l}\text { In the last month, how } \\
\text { often have you } \\
\text { performed these } \\
\text { activities in your free } \\
\text { time? (If you've done } \\
\text { other activities not } \\
\text { available in this list you } \\
\text { may specify these in } \\
\text { OTHER) - TV, DVD, } \\
\text { Netflix or Youtube }\end{array}$ & $\begin{array}{l}1=\text { Daily, } 2=\text { Multiple } \\
\text { times per week, } 3= \\
\text { Multiple times in the past } \\
\text { month, } 4=\text { Once in the } \\
\text { last month, } 5=\text { Never }\end{array}$ & $\mathrm{x}$ & $\mathrm{x}$ & $\mathrm{x}$ & $\mathrm{x}$ & $\mathrm{x}$ & $\mathrm{x}$ & $\mathrm{x}$ & $\mathrm{x}$ & $\mathrm{x}$ & $\mathrm{x}$ \\
\hline freetime.act.2 & & $\begin{array}{l}\text { Q26.4_21 - Wie oft hast du } \\
\text { im letzten Monat die } \\
\text { folgenden Aktivitäten in } \\
\text { Deiner Freizeit } \\
\text { unternommen? (Wenn Du } \\
\text { andere Aktivitäten wichtig } \\
\text { findest, die nicht auf der } \\
\text { Liste stehen, spezifiziere } \\
\text { diese gerne in "Anderes") - } \\
\text { Kinobesuche }\end{array}$ & $\begin{array}{l}1=\text { Täglich, } 2=\text { Mehrmals } \\
\text { pro Woche, } 3=\text { Mehrmals im } \\
\text { letzten Monat, } 4=\text { Einmal } \\
\text { im letzten Monat, } 5=\text { Nie }\end{array}$ & $\begin{array}{l}\text { In the last month, how } \\
\text { often have you } \\
\text { performed these } \\
\text { activities in your free } \\
\text { time? (If you've done } \\
\text { other activities not } \\
\text { available in this list you } \\
\text { may specify these in } \\
\text { OTHER) - Cinema }\end{array}$ & $\begin{array}{l}1=\text { Daily, } 2=\text { Multiple } \\
\text { times per week, } 3= \\
\text { Multiple times in the past } \\
\text { month, } 4=\text { Once in the } \\
\text { last month, } 5=\text { Never }\end{array}$ & $\mathrm{x}$ & $\mathrm{x}$ & $\mathrm{x}$ & $\mathrm{x}$ & $\mathrm{x}$ & $\mathrm{x}$ & $\mathrm{x}$ & $\mathrm{x}$ & $\mathrm{x}$ & $\mathrm{x}$ \\
\hline
\end{tabular}




\begin{tabular}{|c|c|c|c|c|c|c|c|c|c|c|c|c|c|c|c|}
\hline VarName & VariableLabel & WordingDE & ValueLabelsDE_Linked & WordingEN & ValueLabelsEN_Linked & L1 & L2 & L3 & $\mathrm{L} 4$ & L5 & L6 & L7 & L8 & L9 & L10 L11 L12 \\
\hline freetime.act.3 & & $\begin{array}{l}\text { Q26.4_22 - Wie oft hast du } \\
\text { im letzten Monat die } \\
\text { folgenden Aktivitäten in } \\
\text { Deiner Freizeit } \\
\text { unternommen? (Wenn Du } \\
\text { andere Aktivitäten wichtig } \\
\text { findest, die nicht auf der } \\
\text { Liste stehen, spezifiziere } \\
\text { diese gerne in "Anderes") - } \\
\text { Â«LädeleÂA/ Shopping }\end{array}$ & $\begin{array}{l}1=\text { Täglich, } 2=\text { Mehrmals } \\
\text { pro Woche, } 3=\text { Mehrmals im } \\
\text { letzten Monat, } 4=\text { Einmal } \\
\text { im letzten Monat, } 5=\mathrm{Nie}\end{array}$ & $\begin{array}{l}\text { In the last month, how } \\
\text { often have you } \\
\text { performed these } \\
\text { activities in your free } \\
\text { time? (If you've done } \\
\text { other activities not } \\
\text { available in this list you } \\
\text { may specify these in } \\
\text { OTHER) - Shopping }\end{array}$ & $\begin{array}{l}1=\text { Daily, } 2=\text { Multiple } \\
\text { times per week, } 3= \\
\text { Multiple times in the past } \\
\text { month, } 4=\text { Once in the } \\
\text { last month, } 5=\text { Never }\end{array}$ & $\mathrm{x}$ & $\mathrm{x}$ & $\mathrm{x}$ & $\mathrm{x}$ & $\mathrm{x}$ & $\mathrm{x}$ & $\mathrm{x}$ & $\mathrm{x}$ & $\mathrm{x}$ & $\mathrm{x}$ \\
\hline freetime.act. 4 & & $\begin{array}{l}\text { Q26.4_23 - Wie oft hast du } \\
\text { im letzten Monat die } \\
\text { folgenden Aktivitäten in } \\
\text { Deiner Freizeit } \\
\text { unternommen? (Wenn Du } \\
\text { andere Aktivitäten wichtig } \\
\text { findest, die nicht auf der } \\
\text { Liste stehen, spezifiziere } \\
\text { diese gerne in "Anderes") - } \\
\text { Bücher lesen }\end{array}$ & $\begin{array}{l}1=\text { Täglich, } 2=\text { Mehrmals } \\
\text { pro Woche, } 3=\text { Mehrmals im } \\
\text { letzten Monat, } 4=\text { Einmal } \\
\text { im letzten Monat, } 5=\text { Nie }\end{array}$ & $\begin{array}{l}\text { In the last month, how } \\
\text { often have you } \\
\text { performed these } \\
\text { activities in your free } \\
\text { time? (If you've done } \\
\text { other activities not } \\
\text { available in this list you } \\
\text { may specify these in } \\
\text { OTHER) - reading } \\
\text { books }\end{array}$ & $\begin{array}{l}1=\text { Daily, } 2=\text { Multiple } \\
\text { times per week, } 3= \\
\text { Multiple times in the past } \\
\text { month, } 4=\text { Once in the } \\
\text { last month, } 5=\text { Never }\end{array}$ & $\mathrm{x}$ & $\mathrm{x}$ & $\mathrm{x}$ & $\mathrm{x}$ & $\mathrm{x}$ & $\mathrm{x}$ & $\mathrm{x}$ & $\mathrm{x}$ & $\mathrm{x}$ & $\mathrm{x}$ \\
\hline freetime.act.5 & & $\begin{array}{l}\text { Q26.4_24 - Wie oft hast du } \\
\text { im letzten Monat die } \\
\text { folgenden Aktivitäten in } \\
\text { Deiner Freizeit } \\
\text { unternommen? (Wenn Du } \\
\text { andere Aktivitäten wichtig } \\
\text { findest, die nicht auf der } \\
\text { Liste stehen, spezifiziere } \\
\text { diese gerne in "Anderes") - } \\
\text { Besuch von kulturellen } \\
\text { Anlässen wie Konzerten, } \\
\text { Theateraufführungen oder } \\
\text { Ausstellungen }\end{array}$ & $\begin{array}{l}1=\text { Täglich, } 2=\text { Mehrmals } \\
\text { pro Woche, } 3=\text { Mehrmals im } \\
\text { letzten Monat, } 4=\text { Einmal } \\
\text { im letzten Monat, } 5=\text { Nie }\end{array}$ & $\begin{array}{l}\text { In the last month, how } \\
\text { often have you } \\
\text { performed these } \\
\text { activities in your free } \\
\text { time? (If you've done } \\
\text { other activities not } \\
\text { available in this list you } \\
\text { may specify these in } \\
\text { OTHER) - visiting } \\
\text { cultural events, such as } \\
\text { concerts, theater } \\
\text { performances or } \\
\text { exhibitions }\end{array}$ & $\begin{array}{l}1=\text { Daily, } 2=\text { Multiple } \\
\text { times per week, } 3= \\
\text { Multiple times in the past } \\
\text { month, } 4=\text { Once in the } \\
\text { last month, } 5=\text { Never }\end{array}$ & $\mathrm{x}$ & $\mathrm{x}$ & $\mathrm{x}$ & $\mathrm{x}$ & $\mathrm{x}$ & $\mathrm{x}$ & $\mathrm{x}$ & $\mathrm{x}$ & $\mathrm{x}$ & $\mathrm{x}$ \\
\hline freetime.act. 6 & & $\begin{array}{l}\text { Q26.4_25-Wie oft hast du } \\
\text { im letzten Monat die } \\
\text { folgenden Aktivitäten in } \\
\text { Deiner Freizeit } \\
\text { unternommen? (Wenn Du } \\
\text { andere Aktivitäten wichtig } \\
\text { findest, die nicht auf der } \\
\text { Liste stehen, spezifiziere } \\
\text { diese gerne in "Anderes") - } \\
\text { Kartenspiele, Brettspiele }\end{array}$ & $\begin{array}{l}1=\text { Täglich, } 2=\text { Mehrmals } \\
\text { pro Woche, } 3=\text { Mehrmals im } \\
\text { letzten Monat, } 4=\text { Einmal } \\
\text { im letzten Monat, } 5=\text { Nie }\end{array}$ & $\begin{array}{l}\text { In the last month, how } \\
\text { often have you } \\
\text { performed these } \\
\text { activities in your free } \\
\text { time? (If you've done } \\
\text { other activities not } \\
\text { available in this list you } \\
\text { may specify these in } \\
\text { OTHER) - card- or } \\
\text { board games }\end{array}$ & $\begin{array}{l}1=\text { Daily, } 2=\text { Multiple } \\
\text { times per week, } 3= \\
\text { Multiple times in the past } \\
\text { month, } 4=\text { Once in the } \\
\text { last month, } 5=\text { Never }\end{array}$ & $\mathrm{x}$ & $\mathrm{x}$ & $\mathrm{x}$ & $\mathrm{x}$ & $\mathrm{x}$ & $\mathrm{x}$ & $\mathrm{x}$ & $\mathrm{x}$ & $\mathrm{x}$ & $\mathrm{x}$ \\
\hline freetime.act.7 & & $\begin{array}{l}\text { Q26.4_26 - Wie oft hast du } \\
\text { im letzten Monat die } \\
\text { folgenden Aktivitäten in } \\
\text { Deiner Freizeit } \\
\text { unternommen? (Wenn Du } \\
\text { andere Aktivitäten wichtig } \\
\text { findest, die nicht auf der } \\
\text { Liste stehen, spezifiziere } \\
\text { diese gerne in "Anderes") - } \\
\text { Computerspiele }\end{array}$ & $\begin{array}{l}1=\text { Täglich, } 2=\text { Mehrmals } \\
\text { pro Woche, } 3=\text { Mehrmals im } \\
\text { letzten Monat, } 4=\text { Einmal } \\
\text { im letzten Monat, } 5=\text { Nie }\end{array}$ & $\begin{array}{l}\text { In the last month, how } \\
\text { often have you } \\
\text { performed these } \\
\text { activities in your free } \\
\text { time? (If you've done } \\
\text { other activities not } \\
\text { available in this list you } \\
\text { may specify these in } \\
\text { OTHER) - } \\
\text { Computergames }\end{array}$ & $\begin{array}{l}1=\text { Daily, } 2=\text { Multiple } \\
\text { times per week, } 3= \\
\text { Multiple times in the past } \\
\text { month, } 4=\text { Once in the } \\
\text { last month, } 5=\text { Never }\end{array}$ & $\mathrm{x}$ & $\mathrm{x}$ & $\mathrm{x}$ & $\mathrm{x}$ & $\mathrm{x}$ & $\mathrm{x}$ & $\mathrm{x}$ & $\mathrm{x}$ & $\mathrm{x}$ & $\mathrm{x}$ \\
\hline freetime.act. 8 & & $\begin{array}{l}\text { Q26.4_27-Wie oft hast du } \\
\text { im letzten Monat die } \\
\text { folgenden Aktivitäten in } \\
\text { Deiner Freizeit } \\
\text { unternommen? (Wenn Du } \\
\text { andere Aktivitäten wichtig } \\
\text { findest, die nicht auf der } \\
\text { Liste stehen, spezifiziere } \\
\text { diese gerne in "Anderes") - } \\
\text { Musik hören }\end{array}$ & $\begin{array}{l}1=\text { Täglich, } 2=\text { Mehrmals } \\
\text { pro Woche, } 3=\text { Mehrmals im } \\
\text { letzten Monat, } 4=\text { Einmal } \\
\text { im letzten Monat, } 5=\text { Nie }\end{array}$ & $\begin{array}{l}\text { In the last month, how } \\
\text { often have you } \\
\text { performed these } \\
\text { activities in your free } \\
\text { time? (If you've done } \\
\text { other activities not } \\
\text { available in this list you } \\
\text { may specify these in } \\
\text { OTHER) - listening to } \\
\text { music }\end{array}$ & $\begin{array}{l}1=\text { Daily, } 2=\text { Multiple } \\
\text { times per week, } 3= \\
\text { Multiple times in the past } \\
\text { month, } 4=\text { Once in the } \\
\text { last month, } 5=\text { Never }\end{array}$ & $\mathrm{x}$ & $\mathrm{x}$ & $\mathrm{x}$ & $\mathrm{x}$ & $\mathrm{x}$ & $\mathrm{x}$ & $\mathrm{x}$ & $\mathrm{x}$ & $\mathrm{x}$ & $\mathrm{x}$ \\
\hline
\end{tabular}




\section{freetime.act.9}

Q26.4_28 - Wie oft hast du folgenden Aktivitäten in Deiner Freizeit unternommen? (Wenn Du andere Aktivitäten wichti findest, die nicht auf der diese gerne in "Anderes") Besuch von sportlichen Anlässen als Zuschauer

freetime.act.10 Q26.4_29 - Wie oft hast im letzten Monat die folgenden Aktivitäten in Deiner Freizeit unternommen? (Wenn Du andere Aktivitäten wichti findest, die nicht auf der Liste stehen, spezifiziere diese gerne in "Anderes") Handwerkliche Arbeiten, wie Holzarbeit, Roboter bauen usw.

freetime.act.11 Q26.4_30 - Wie oft hast du im letzten Monat die olgenden Aktivitäten in Deiner Freizeit unternommen? (Wenn Du andere Aktivitäten wichti findest, die nicht auf der Liste stehen, spezifiziere diese gerne in "Anderes") Computerprogrammieren Q26.4_31 - Wie oft hast du m letzten Monat die olgenden Aktivitäten in Deiner Freizeit unternommen? (Wenn Du andere Aktivitäten wichtig findest, die nicht auf der iste stehen, spezifiziere diese gerne in "Anderes") Künstlerische Projekte, wie Malen oder Musik machen Q26.4_32 - Wie oft hast m letzten Monat die folgenden Aktivitäten in Deiner Freizeit unternommen? (Wenn Du andere Aktivitäten wichti findest, die nicht auf der Liste stehen, spezifiziere
diese gerne in "Anderes") Im Internet surfen
$1=$ Täglich, $2=$ Mehrmal pro Woche, $3=$ Mehrmals in letzten Monat, $4=$ Einmal im letzten Monat, $5=\mathrm{Ni}$

In the last month, how often have you activities in your free time? (If you've done other activities not available in this list you may specify these in OTHER) - attending sports events as a spectator

$1=$ Täglich, $2=$ Mehrmals pro Woche, $3=$ Mehrmals im letzten Monat, $4=$ Einma

In the last month, how often have you performed these activities in your free other activities not available in this list you may specify these in woodworking, building robots etc.

$1=$ Täglich, $2=$ Mehrmals pro Woche, 3 = Mehrmals i letzten Monat, $4=$ Einmal im letzten Monat, $5=\mathrm{Nie}$

the last month, how often have you performed these Dive? (If your free time? (If you've done available in this list yo may specify these in OTHER) -

Computerprogramming In the last month, how often have you performed these activities in your free time? (If you've done other activities not available in this list yo may specify these OTHER) - artistic projects like painting or making music

$1=$ Täglich, $2=$ Mehrmal pro Woche, $3=$ Mehrmals i 列 often have you performed these activities in your fre time? (If you've don other activities not available in this list yo may specify these in the internet
$1=$ Daily, $2=$ Multiple imes per week, $3=$

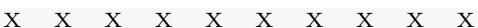
ultiple times in the past last month, $5=$ Never

$1=$ Daily, $2=$ Multiple times per week, $3=$

Multiple times in the past

month, $4=$ Once in the

last month, $5=$ Never

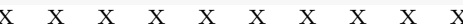

$1=$ Daily, $2=$ Multiple times per week, $3=$

Multiple times in the past month, $4=$ Once in the last month, $5=$ Never

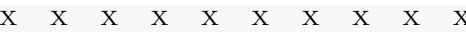

$1=$ Daily, $2=$ Multiple times per week, $3=$

Multiple times in the past

month, $4=$ Once in the

last month, $5=$ Never

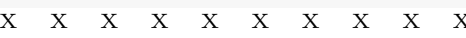

$1=$ Daily, $2=$ Multiple

times per week, $3=$

Multiple times in the past

month, $4=$ Once in the

last month, $5=$ Never 
Q26.4_33 - Wie oft hast du folgenden Aktivitäten in Deiner Freizeit unternommen? (Wenn Du findest, die nicht auf der Liste stehen, spezifiziere diese gerne in "Anderes") Sport, z.B. Besuch eines Fitness-Studios, Klettern oder Wandern

freetime.act.other.1 Q26.4 34 - Wie oft hast du im letzten Monat die folgenden Aktivitäten in Deiner Freizeit unternommen? (Wenn Du andere Aktivitäten wichti findest, die nicht auf der Liste stehen, spezifiziere diese gerne in "Anderes") Anderes 1

freetime.act.other.1.str Q26.4 34 TEXT - Wie oft hast du im letzten Monat die folgenden Aktivitäten in Deiner Freizeit

unternommen? (Wenn Du andere Aktivitäten wichtig findest, die nicht auf der Liste stehen, spezifiziere diese gerne in "Anderes") Anderes 1 - Tex

freetime.act.other.2 $26.4 \_35$ - Wie oft hast du im letzten Monat die folgenden Aktivitäten in Deiner Freizeit unternommen? (Wenn Du andere Aktivitäten wicht findest, die nicht auf der Liste stehen, spezifiziere diese gerne in "Anderes") Anderes 2

freetime.act.other.2.str 26.4_35_TEXT - Wie of hast du im letzten Monat die folgenden Aktivitäten in Deiner Freizeit unternommen? (Wenn Du andere Aktivitäten wichti findest, die nicht auf de Liste stehen, spezifiziere diese gerne in "Anderes") nderes 2 - Text

freetime.act.other.3

Q26.4 36 - Wie oft hast du
$1=$ Täglich, $2=$ Mehrmal pro Woche, $3=$ Mehrmals in letzten Monat, $4=$ Einmal im letzten Monat, $5=\mathrm{Ni}$ often have you activities in your free time? (If you've done other activities not available in this list you may specify these in OTHER) - Sports e.g. going to a gym,

climbing or hiking

$1=$ Täglich, $2=$ Mehrmals pro Woche, $3=$ Mehrmals in letzten Monat, $4=$ Einmal

In the last month, how often have you performed these time? (If you've done other activities not available in this list you may specify these in
OTHER) - Other 1

In the last month, how often have you performed these activities in your free time? (If you've done other activities not available in this list you may specify these in OTHER) - Other 1 Text

$1=$ Täglich, $2=$ Mehrmal letzten Monat, $4=$ folgenden Aktivitäten in Deiner Freizeit unternommen? (Wenn Du andere Aktivitäten wichti findest, die nicht auf der Liste stehen, spezifiziere iese gerne
nderes 3 often have you

performed these

activities in your fre

time? (If you've don

other activities not

available in this list you

may specify these in
OTHER) - Other 2

In the last month, how often have you

performed these activities in your free time? (If you've done other activities not available in this list you may specify these in Text

$1=$ Täglich, $2=$ Mehrmals pro Woche, $3=$ Mehrmals im letzten Monat, $4=$ Einmal

In the last month, how often have you performed these time? (If you've done other activities not available in this list you
In the last month, how im letzten Monat, $5=\mathrm{Nie}$

$1=$ Daily, $2=$ Multiple times per week, $3=$

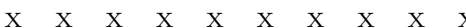
Multiple times in the past

month, 4 - Once in the

last month, $5=$ Never
$1=$ Daily, $2=$ Multiple times per week, $3=$

Multiple times in the past

month, $4=$ Once in the

$1=$ Daily, $2=$ Multiple times per week, $3=$

Multiple times in the past

month, $4=$ Once in the

last month, $5=$ Never

$1=$ Daily, $2=$ Multiple times per week, $3=$

Multiple times in the past

month, $4=$ Once in the

last month, $5=$ Never 


\begin{tabular}{|c|c|c|c|c|c|c|c|c|c|c|c|c|c|c|c|}
\hline VarName & VariableLabel & WordingDE & ValueLabelsDE_Linked & WordingEN & ValueLabelsEN_Linked & L1 & L2 & L3 & $\mathrm{L} 4$ & L5 & L6 & L7 & L8 & L9 & L10 L11 L12 \\
\hline freetime.act.other.3.str & & $\begin{array}{l}\text { Q26.4_36_TEXT - Wie oft } \\
\text { hast du im letzten Monat } \\
\text { die folgenden Aktivitäten in } \\
\text { Deiner Freizeit } \\
\text { unternommen? (Wenn Du } \\
\text { andere Aktivitäten wichtig } \\
\text { findest, die nicht auf der } \\
\text { Liste stehen, spezifiziere } \\
\text { diese gerne in "Anderes") - } \\
\text { Anderes 3 - Text }\end{array}$ & & $\begin{array}{l}\text { In the last month, how } \\
\text { often have you } \\
\text { performed these } \\
\text { activities in your free } \\
\text { time? (If you've done } \\
\text { other activities not } \\
\text { available in this list you } \\
\text { may specify these in } \\
\text { OTHER) - Other } 3 \text { - } \\
\text { Text }\end{array}$ & & $\mathrm{x}$ & $\mathrm{x}$ & $\mathrm{x}$ & $\mathrm{x}$ & $\mathrm{x}$ & $\mathrm{x}$ & $\mathrm{x}$ & $\mathrm{x}$ & $\mathrm{x}$ & $\mathrm{x}$ \\
\hline political.interest & & $\begin{array}{l}\text { Q27.2 - Wie } \\
\text { starkinteressierst Du Dich } \\
\text { für Politik? Würdest Du } \\
\text { sagen, Du bist ... }\end{array}$ & $\begin{array}{l}1=\text { sehr interessiert, } 2= \\
\text { ziemlich interessiert, } 3= \\
\text { kaum interessiert, } 4= \\
\text { überhaupt nicht interessiert }\end{array}$ & $\begin{array}{l}\text { How strongly are you } \\
\text { interested in politics? } \\
\text { Would you say you are... }\end{array}$ & $\begin{array}{l}1=\text { very interested, } 2= \\
\text { quite interested, } 3= \\
\text { barely interest, } 4=\text { not at } \\
\text { all interested }\end{array}$ & $\mathrm{x}$ & $\mathrm{x}$ & $\mathrm{x}$ & $\mathrm{x}$ & $\mathrm{x}$ & $\mathrm{x}$ & $\mathrm{x}$ & $\mathrm{x}$ & $\mathrm{x}$ & $\mathrm{x}$ \\
\hline political.info. 1 & & $\begin{array}{l}\text { Q27.4_1 - Wiehäufig... - } \\
\text {..liest Du den politischen } \\
\text { Teil in der Zeitung? }\end{array}$ & $\begin{array}{l}1=\text { Mehrmals pro Tag, } 2= \\
\text { Einmal pro Tag, } 3=5-6 \mathrm{mal} \\
\text { in der Woche, } 4=3-4 \mathrm{mal} \text { in } \\
\text { der Woche, } 5=1-2 \mathrm{mal} \text { in der } \\
\text { Woche, } 6=\text { Weniger als } 1-2 \\
\text { mal in der Woche, } 7=\mathrm{Nie}\end{array}$ & $\begin{array}{l}\text { How often do you read } \\
\text { the political section in } \\
\text { the newspaper? }\end{array}$ & $\begin{array}{l}1=\text { Multiple times a day, } \\
2=\text { Once a day, } 3=5-6 \\
\text { times a week, } 4=3-4 \\
\text { times a week, } 5=1-2 \\
\text { times a week, } 6=\text { fewer } \\
\text { than } 1-2 \text { times a week, } 7 \\
=\text { never }\end{array}$ & $\mathrm{x}$ & $\mathrm{x}$ & $\mathrm{x}$ & $\mathrm{x}$ & $\mathrm{x}$ & $\mathrm{x}$ & $\mathrm{x}$ & $\mathrm{x}$ & $\mathrm{x}$ & $\mathrm{x}$ \\
\hline political.info. 2 & & $\begin{array}{l}\text { Q27.4_2 - Wiehäufig... - } \\
\text {...siehst Du politische } \\
\text { Nachrichten am Fernsehen } \\
\text { an? }\end{array}$ & $\begin{array}{l}1=\text { Mehrmals pro Tag, } 2= \\
\text { Einmal pro Tag, } 3=5-6 \mathrm{mal} \\
\text { in der Woche, } 4=3-4 \mathrm{mal} \text { in } \\
\text { der Woche, } 5=1-2 \mathrm{mal} \text { in der } \\
\text { Woche, } 6=\text { Weniger als } 1-2 \\
\text { mal in der Woche, } 7=\mathrm{Nie}\end{array}$ & $\begin{array}{l}\text { How often do you watch } \\
\text { political news on TV? }\end{array}$ & $\begin{array}{l}1=\text { Multiple times a day, } \\
2=\text { Once a day, } 3=5-6 \\
\text { times a week, } 4=3-4 \\
\text { times a week, } 5=1-2 \\
\text { times a week, } 6=\text { fewer } \\
\text { than } 1-2 \text { times a week, } 7 \\
=\text { never }\end{array}$ & $\mathrm{x}$ & $\mathrm{x}$ & $\mathrm{x}$ & $\mathrm{x}$ & $\mathrm{x}$ & $\mathrm{x}$ & $\mathrm{x}$ & $\mathrm{x}$ & $\mathrm{x}$ & $\mathrm{x}$ \\
\hline political.info.3 & & $\begin{array}{l}\text { Q27.4_3 - Wiehäufig... - } \\
\text {..hörst Du politische } \\
\text { Nachrichten im Radio? }\end{array}$ & $\begin{array}{l}1=\text { Mehrmals pro Tag, } 2= \\
\text { Einmal pro Tag, } 3=5-6 \mathrm{mal} \\
\text { in der Woche, } 4=3-4 \mathrm{mal} \text { in } \\
\text { der Woche, } 5=1-2 \mathrm{mal} \text { in der } \\
\text { Woche, } 6=\text { Weniger als } 1-2 \\
\text { mal in der Woche, } 7=\mathrm{Nie}\end{array}$ & $\begin{array}{l}\text { How often do you listen } \\
\text { do you listen to political } \\
\text { news on the radio? }\end{array}$ & $\begin{array}{l}1=\text { Multiple times a day, } \\
2=\text { Once a day, } 3=5-6 \\
\text { times a week, } 4=3-4 \\
\text { times a week, } 5=1-2 \\
\text { times a week, } 6=\text { fewer } \\
\text { than } 1-2 \text { times a week, } 7 \\
=\text { never }\end{array}$ & $\mathrm{x}$ & $\mathrm{x}$ & $\mathrm{x}$ & $\mathrm{x}$ & $\mathrm{x}$ & $\mathrm{x}$ & $\mathrm{x}$ & $\mathrm{x}$ & $\mathrm{x}$ & $\mathrm{x}$ \\
\hline political.info. 4 & & $\begin{array}{l}\text { Q27.4_4 - Wiehäufig... liest } \\
\text { Du politische Artikel auf } \\
\text { Nachrichtenseiten im } \\
\text { Internet? }\end{array}$ & $\begin{array}{l}1=\text { Mehrmals pro Tag, } 2= \\
\text { Einmal pro Tag, } 3=5-6 \mathrm{mal} \\
\text { in der Woche, } 4=3-4 \mathrm{mal} \text { in } \\
\text { der Woche, } 5=1-2 \mathrm{mal} \text { in der } \\
\text { Woche, } 6=\text { Weniger als } 1-2 \\
\text { mal in der Woche, } 7=\mathrm{Nie}\end{array}$ & $\begin{array}{l}\text { How often do you lead } \\
\text { political articles online? }\end{array}$ & $\begin{array}{l}1=\text { Multiple times a day, } \\
2=\text { Once a day, } 3=5-6 \\
\text { times a week, } 4=3-4 \\
\text { times a week, } 5=1-2 \\
\text { times a week, } 6=\text { fewer } \\
\text { than } 1-2 \text { times a week, } 7 \\
=\text { never }\end{array}$ & $\mathrm{x}$ & $\mathrm{x}$ & $\mathrm{x}$ & $\mathrm{x}$ & $\mathrm{x}$ & $\mathrm{x}$ & $\mathrm{x}$ & $\mathrm{x}$ & $\mathrm{x}$ & $\mathrm{x}$ \\
\hline political.info.5 & & $\begin{array}{l}\text { Q27.4_5 - Wiehäufig... } \\
\text { nutzt Du Soziale Medien } \\
\text { (wie Facebook oder } \\
\text { Twitter) um politische } \\
\text { Nachrichten oder } \\
\text { Informationen zu erhalten? }\end{array}$ & $\begin{array}{l}1=\text { Mehrmals pro Tag, } 2= \\
\text { Einmal pro Tag, } 3=5-6 \text { mal } \\
\text { in der Woche, } 4=3-4 \text { mal in } \\
\text { der Woche, } 5=1-2 \text { mal in der } \\
\text { Woche, } 6=\text { Weniger als } 1-2 \\
\text { mal in der Woche, } 7=\mathrm{Nie}\end{array}$ & $\begin{array}{l}\text { How often do you use } \\
\text { social media (like } \\
\text { Facebook or Twitter) to } \\
\text { access political } \\
\text { information? }\end{array}$ & $\begin{array}{l}1=\text { Multiple times a day, } \\
2=\text { Once a day, } 3=5-6 \\
\text { times a week, } 4=3-4 \\
\text { times a week, } 5=1-2 \\
\text { times a week, } 6=\text { fewer } \\
\text { than } 1-2 \text { times a week, } 7 \\
=\text { never }\end{array}$ & $\mathrm{x}$ & $\mathrm{x}$ & $\mathrm{x}$ & $\mathrm{x}$ & $\mathrm{x}$ & $\mathrm{x}$ & $\mathrm{x}$ & $\mathrm{x}$ & $\mathrm{x}$ & $\mathrm{x}$ \\
\hline political.info. 6 & & $\begin{array}{l}\text { Q27.4_6 - Wiehäufig... } \\
\text { nutzt Du Aggregatorseiten } \\
\text { (wie Reddit oder Digg) um } \\
\text { politische Nachrichten oder } \\
\text { Informationen zu erhalten? }\end{array}$ & $\begin{array}{l}1=\text { Mehrmals pro Tag, } 2= \\
\text { Einmal pro Tag, } 3=5-6 \mathrm{mal} \\
\text { in der Woche, } 4=3-4 \mathrm{mal} \text { in } \\
\text { der Woche, } 5=1-2 \mathrm{mal} \text { in der } \\
\text { Woche, } 6=\text { Weniger als } 1-2 \\
\text { mal in der Woche, } 7=\mathrm{Nie}\end{array}$ & $\begin{array}{l}\text { How often do you use } \\
\text { aggregators (like Reddit } \\
\text { or Digg) to access } \\
\text { political information? }\end{array}$ & $\begin{array}{l}1=\text { Multiple times a day, } \\
2=\text { Once a day, } 3=5-6 \\
\text { times a week, } 4=3-4 \\
\text { times a week, } 5=1-2 \\
\text { times a week, } 6=\text { fewer } \\
\text { than } 1-2 \text { times a week, } 7 \\
=\text { never }\end{array}$ & $\mathrm{x}$ & $\mathrm{x}$ & $\mathrm{x}$ & $\mathrm{x}$ & $\mathrm{x}$ & $\mathrm{x}$ & $\mathrm{x}$ & $\mathrm{x}$ & $\mathrm{x}$ & $\mathrm{x}$ \\
\hline political.info. 7 & & $\begin{array}{l}\text { Q27.4_7 - Wiehäufig... } \\
\text { nutzt Du andere } \\
\text { Internetquellen um } \\
\text { politische Nachrichten oder } \\
\text { Informationen zu erhalten? }\end{array}$ & $\begin{array}{l}1=\text { Mehrmals pro Tag, } 2= \\
\text { Einmal pro Tag, } 3=5-6 \mathrm{mal} \\
\text { in der Woche, } 4=3-4 \mathrm{mal} \text { in } \\
\text { der Woche, } 5=1-2 \mathrm{mal} \text { in der } \\
\text { Woche, } 6=\text { Weniger als } 1-2 \\
\text { mal in der Woche, } 7=\mathrm{Nie}\end{array}$ & $\begin{array}{l}\text { How often do you use } \\
\text { other online resources to } \\
\text { access political } \\
\text { information? }\end{array}$ & $\begin{array}{l}1=\text { Multiple times a day, } \\
2=\text { Once a day, } 3=5-6 \\
\text { times a week, } 4=3-4 \\
\text { times a week, } 5=1-2 \\
\text { times a week, } 6=\text { fewer } \\
\text { than } 1-2 \text { times a week, } 7 \\
=\text { never }\end{array}$ & $\mathrm{x}$ & $\mathrm{x}$ & $\mathrm{x}$ & $\mathrm{x}$ & $\mathrm{x}$ & $\mathrm{x}$ & $\mathrm{x}$ & $\mathrm{x}$ & $\mathrm{x}$ & $\mathrm{x}$ \\
\hline
\end{tabular}




\begin{tabular}{|c|c|c|c|c|c|c|c|c|c|c|c|c|c|c|c|}
\hline VarName & VariableLabel & WordingDE & ValueLabelsDE_Linked & WordingEN & ValueLabelsEN_Linked & L1 & $\mathrm{L} 2$ & L3 & $\mathrm{L} 4$ & L5 & L6 & L7 & L8 & L9 & L10 L11 L12 \\
\hline political.info.7.other & & $\begin{array}{l}\text { Q27.5 - Du hast angegeben, } \\
\text { dass Du auch andere } \\
\text { Internetquellen benutzt um } \\
\text { politischeNachrichten oder } \\
\text { Informationen zu erhalten, } \\
\text { welche sind diese? }\end{array}$ & & $\begin{array}{l}\text { You have indicated that } \\
\text { you also use other online } \\
\text { resources to access } \\
\text { political messages and } \\
\text { information - which } \\
\text { ones? }\end{array}$ & & $\mathrm{x}$ & $\mathrm{x}$ & $\mathrm{x}$ & $\mathrm{x}$ & $\mathrm{x}$ & $\mathrm{x}$ & $\mathrm{x}$ & $\mathrm{x}$ & $\mathrm{x}$ & $\mathrm{x}$ \\
\hline political.info.main. 1 & & $\begin{array}{l}\text { Q27.6_1_1 - Bitte nenne } \\
\text { unten bis zu fünf Quellen } \\
\text { von denen Du die meisten } \\
\text { Deiner politischen } \\
\text { Informationen beziehst. } \\
\text { Beispielsweise } \\
\text { Zeitungen/Zeitschriften wie } \\
\text { die "Neue Zürcher Zeitung", } \\
\text { Radiosender wie "SRF4", } \\
\text { TV-Sendungen oder auch } \\
\text { YouTube Kanäle wie "Last } \\
\text { Week Tonight". - Quelle 1 - } \\
\text { Namen }\end{array}$ & & $\begin{array}{l}\text { Please name up to five } \\
\text { sources from which you } \\
\text { get most of your } \\
\text { political information. } \\
\text { For instance, } \\
\text { newspapers/magazines } \\
\text { such as the "Neue } \\
\text { Zürcher Zeitung", radio } \\
\text { stations such as "SRF4", } \\
\text { TV broadcasts or } \\
\text { youtube channels such } \\
\text { as "Last Week Tonight". } \\
\text { - Source 1- Name }\end{array}$ & & $\mathrm{x}$ & $\mathrm{x}$ & $\mathrm{x}$ & $\mathrm{x}$ & $\mathrm{x}$ & $\mathrm{x}$ & $\mathrm{x}$ & $\mathrm{x}$ & $\mathrm{x}$ & $\mathrm{x}$ \\
\hline political.info.main.2 & & $\begin{array}{l}\text { Q27.6_2_1 - Bitte nenne } \\
\text { unten bis zu fünf Quellen } \\
\text { von denen Du die meisten } \\
\text { Deiner politischen } \\
\text { Informationen beziehst. } \\
\text { Beispielsweise } \\
\text { Zeitungen/Zeitschriften wie } \\
\text { die "Neue Zürcher Zeitung", } \\
\text { Radiosender wie "SRF4", } \\
\text { TV-Sendungen oder auch } \\
\text { YouTube Kanäle wie "Last } \\
\text { Week Tonight". - Quelle 2 - } \\
\text { Namen }\end{array}$ & & $\begin{array}{l}\text { Please name up to five } \\
\text { sources from which you } \\
\text { get most of your } \\
\text { political information. } \\
\text { For instance, } \\
\text { newspapers/magazines } \\
\text { such as the "Neue } \\
\text { Zürcher Zeitung", radio } \\
\text { stations such as "SRF4", } \\
\text { TV broadcasts or } \\
\text { youtube channels such } \\
\text { as "Last Week Tonight". } \\
\text { - Source 2- Name }\end{array}$ & & $\mathrm{x}$ & $\mathrm{x}$ & $\mathrm{x}$ & $\mathrm{x}$ & $\mathrm{x}$ & $\mathrm{x}$ & $\mathrm{x}$ & $\mathrm{x}$ & $\mathrm{x}$ & $\mathrm{x}$ \\
\hline political.info.main.3 & & $\begin{array}{l}\text { Q27.6_3_1 - Bitte nenne } \\
\text { unten bis zu fünf Quellen } \\
\text { von denen Du die meisten } \\
\text { Deiner politischen } \\
\text { Informationen beziehst. } \\
\text { Beispielsweise } \\
\text { Zeitungen/Zeitschriften wie } \\
\text { die "Neue Zürcher Zeitung", } \\
\text { Radiosender wie "SRF4", } \\
\text { TV-Sendungen oder auch } \\
\text { YouTube Kanäle wie "Last } \\
\text { Week Tonight". - Quelle 3 - } \\
\text { Namen }\end{array}$ & & $\begin{array}{l}\text { Please name up to five } \\
\text { sources from which you } \\
\text { get most of your } \\
\text { political information. } \\
\text { For instance, } \\
\text { newspapers/magazines } \\
\text { such as the "Neue } \\
\text { Zürcher Zeitung", radio } \\
\text { stations such as "SRF4", } \\
\text { TV broadcasts or } \\
\text { youtube channels such } \\
\text { as "Last Week Tonight". } \\
\text { - Source 3- Name }\end{array}$ & & $\mathrm{x}$ & $\mathrm{x}$ & $\mathrm{x}$ & $\mathrm{x}$ & $\mathrm{x}$ & $\mathrm{x}$ & $\mathrm{x}$ & $\mathrm{x}$ & $\mathrm{x}$ & $\mathrm{x}$ \\
\hline political.info.main.4 & & $\begin{array}{l}\text { Q27.6_4_1 - Bitte nenne } \\
\text { unten bis zu fünf Quellen } \\
\text { von denen Du die meisten } \\
\text { Deiner politischen } \\
\text { Informationen beziehst. } \\
\text { Beispielsweise } \\
\text { Zeitungen/Zeitschriften wie } \\
\text { die "Neue Zürcher Zeitung", } \\
\text { Radiosender wie "SRF4", } \\
\text { TV-Sendungen oder auch } \\
\text { YouTube Kanäle wie "Last } \\
\text { Week Tonight". - Quelle 4 - } \\
\text { Namen }\end{array}$ & & $\begin{array}{l}\text { Please name up to five } \\
\text { sources from which you } \\
\text { get most of your } \\
\text { political information. } \\
\text { For instance, } \\
\text { newspapers/magazines } \\
\text { such as the "Neue } \\
\text { Zürcher Zeitung", radio } \\
\text { stations such as "SRF4", } \\
\text { TV broadcasts or } \\
\text { youtube channels such } \\
\text { as "Last Week Tonight". } \\
\text { - Source 4- Name }\end{array}$ & & $\mathrm{x}$ & $\mathrm{x}$ & $\mathrm{x}$ & $\mathrm{x}$ & $\mathrm{x}$ & $\mathrm{x}$ & $\mathrm{x}$ & $\mathrm{x}$ & $\mathrm{x}$ & $\mathrm{x}$ \\
\hline
\end{tabular}




\begin{tabular}{|c|c|c|c|c|c|c|c|c|c|c|c|c|c|c|c|}
\hline VarName & VariableLabel & WordingDE & ValueLabelsDE_Linked & WordingEN & ValueLabelsEN_Linked & $\mathrm{L} 1$ & L2 & L3 & $\mathrm{L} 4$ & L5 & L6 & L7 & L8 & L9 & L10 L11 L12 \\
\hline political.info.main.5 & & $\begin{array}{l}\text { Q27.6_5_1 - Bitte nenne } \\
\text { unten bis zu fünf Quellen } \\
\text { von denen Du die meisten } \\
\text { Deiner politischen } \\
\text { Informationen beziehst. } \\
\text { Beispielsweise } \\
\text { Zeitungen/Zeitschriften wie } \\
\text { die "Neue Zürcher Zeitung", } \\
\text { Radiosender wie "SRF4", } \\
\text { TV-Sendungen oder auch } \\
\text { YouTube Kanäle wie "Last } \\
\text { Week Tonight". - Quelle 5 - } \\
\text { Namen }\end{array}$ & & $\begin{array}{l}\text { Please name up to five } \\
\text { sources from which you } \\
\text { get most of your } \\
\text { political information. } \\
\text { For instance, } \\
\text { newspapers/magazines } \\
\text { such as the "Neue } \\
\text { Zürcher Zeitung", radio } \\
\text { stations such as "SRF4", } \\
\text { TV broadcasts or } \\
\text { youtube channels such } \\
\text { as "Last Week Tonight". } \\
\text { - Source 5- Name }\end{array}$ & & $\mathrm{x}$ & $\mathrm{x}$ & $\mathrm{x}$ & $\mathrm{x}$ & $\mathrm{x}$ & $\mathrm{x}$ & $\mathrm{x}$ & $\mathrm{x}$ & $\mathrm{x}$ & $\mathrm{x}$ \\
\hline thermometer. 1 & & $\begin{array}{l}\text { Q27.8_1 - Unten dargestellt } \\
\text { sind sogenannte } \\
\text { "Gefühlsthermometer". } \\
\text { Bitte gibt an, wie Du Dich } \\
\text { gegenüber den folgenden } \\
\text { politischen Gruppen fühlst, } \\
\text { wobei } 0 \hat{A}^{\circ} \text { die "kältesten" } \\
\text { oder negativsten Gefühle } \\
\text { darstellt, und 100Å die } \\
\text { "wärmsten" oder } \\
\text { positivsten Gefühle. } \\
\text { Neutrale Gefühle sind durch } \\
50 \hat{A}^{\circ} \text { dargestellt. - Links }\end{array}$ & $\begin{array}{l}1=0,2=10,3=20,4=30 \\
5=40,6=50,7=60,8= \\
70,9=80,10=90,11=100\end{array}$ & $\begin{array}{l}\text { Below, so-called "feeling } \\
\text { thermometers" are } \\
\text { displayed. Please } \\
\text { indicate your feelings } \\
\text { towards the following } \\
\text { political groups, where } \\
0^{\circ} \text { represents the } \\
\text { "coldest" or most } \\
\text { negative feelings, and } \\
100^{\circ} \text { represents the } \\
\text { warmest or most } \\
\text { positive feelings. } \\
\text { Neutral feelings are } \\
\text { represented by } 50^{\circ} \text {. - } \\
\text { Left }\end{array}$ & $\begin{array}{l}1=\mathrm{NA}, 2=\mathrm{NA}, 3=\mathrm{NA} \\
4=\mathrm{NA}, 5=\mathrm{NA}, 6=\mathrm{NA}, \\
7=\mathrm{NA}, 8=\mathrm{NA}, 9=\mathrm{NA} \\
10=\mathrm{NA}, 11=\mathrm{NA}\end{array}$ & $\mathrm{x}$ & $\mathrm{x}$ & $\mathrm{x}$ & $\mathrm{x}$ & $\mathrm{x}$ & $\mathrm{x}$ & $\mathrm{x}$ & $\mathrm{x}$ & $\mathrm{x}$ & $\mathrm{x}$ \\
\hline thermometer.2 & & $\begin{array}{l}\text { Q27.8_2 - Unten dargestellt } \\
\text { sind sogenannte } \\
\text { "Gefühlsthermometer". } \\
\text { Bitte gibt an, wie Du Dich } \\
\text { gegenüber den folgenden } \\
\text { politischen Gruppen fühlst, } \\
\text { wobei 0Â } 0 \text { die "kältesten" } \\
\text { oder negativsten Gefühle } \\
\text { darstellt, und } 100 \hat{A}^{\circ} \text { die } \\
\text { "wärmsten" oder } \\
\text { positivsten Gefühle. } \\
\text { Neutrale Gefühle sind durch } \\
50 \hat{A}^{\circ} \text { dargestellt. - Mitte }\end{array}$ & $\begin{array}{l}1=0,2=10,3=20,4=30 \\
5=40,6=50,7=60,8= \\
70,9=80,10=90,11=100\end{array}$ & $\begin{array}{l}\text { Below, so-called "feeling } \\
\text { thermometers" are } \\
\text { displayed. Please } \\
\text { indicate your feelings } \\
\text { towards the following } \\
\text { political groups, where } \\
0^{\circ} \text { represents the } \\
\text { "coldest" or most } \\
\text { negative feelings, and } \\
100^{\circ} \text { represents the } \\
\text { warmest or most } \\
\text { positive feelings. } \\
\text { Neutral feelings are } \\
\text { represented by } 50^{\circ} \text {. - } \\
\text { Center }\end{array}$ & $\begin{array}{l}1=\mathrm{NA}, 2=\mathrm{NA}, 3=\mathrm{NA}, \\
4=\mathrm{NA}, 5=\mathrm{NA}, 6=\mathrm{NA}, \\
7=\mathrm{NA}, 8=\mathrm{NA}, 9=\mathrm{NA}, \\
10=\mathrm{NA}, 11=\mathrm{NA}\end{array}$ & $\mathrm{x}$ & $\mathrm{x}$ & $\mathrm{x}$ & $\mathrm{x}$ & $\mathrm{x}$ & $\mathrm{x}$ & $\mathrm{x}$ & $\mathrm{x}$ & $\mathrm{x}$ & $\mathrm{x}$ \\
\hline thermometer.3 & & $\begin{array}{l}\text { Q27.8_3 - Unten dargestellt } \\
\text { sind sogenannte } \\
\text { "Gefühlsthermometer". } \\
\text { Bitte gibt an, wie Du Dich } \\
\text { gegenüber den folgenden } \\
\text { politischen Gruppen fühlst, } \\
\text { wobei } 0 \hat{A}^{\circ} \text { die "kältesten" } \\
\text { oder negativsten Gefühle } \\
\text { darstellt, und } 100 \hat{A}^{\circ} \text { die } \\
\text { "wärmsten" oder } \\
\text { positivsten Gefühle. } \\
\text { Neutrale Gefühle sind durch } \\
50 \hat{A}^{\circ} \text { dargestellt. - Rechts }\end{array}$ & $\begin{array}{l}1=0,2=10,3=20,4=30 \\
5=40,6=50,7=60,8= \\
70,9=80,10=90,11=100\end{array}$ & $\begin{array}{l}\text { Below, so-called "feeling } \\
\text { thermometers" are } \\
\text { displayed. Please } \\
\text { indicate your feelings } \\
\text { towards the following } \\
\text { political groups, where } \\
0^{\circ} \text { represents the } \\
\text { "coldest" or most } \\
\text { negative feelings, and } \\
100^{\circ} \text { represents the } \\
\text { warmest or most } \\
\text { positive feelings. } \\
\text { Neutral feelings are } \\
\text { represented by } 50^{\circ} \text {. - } \\
\text { Right }\end{array}$ & $\begin{array}{l}1=\mathrm{NA}, 2=\mathrm{NA}, 3=\mathrm{NA} \\
4=\mathrm{NA}, 5=\mathrm{NA}, 6=\mathrm{NA}, \\
7=\mathrm{NA}, 8=\mathrm{NA}, 9=\mathrm{NA}, \\
10=\mathrm{NA}, 11=\mathrm{NA}\end{array}$ & $\mathrm{x}$ & $\mathrm{x}$ & $\mathrm{x}$ & $\mathrm{x}$ & $\mathrm{x}$ & $\mathrm{x}$ & $\mathrm{x}$ & $\mathrm{x}$ & $\mathrm{x}$ & $\mathrm{x}$ \\
\hline
\end{tabular}




\begin{tabular}{|c|c|c|c|c|c|c|c|c|c|c|c|c|c|c|c|}
\hline VarName & VariableLabel & WordingDE & ValueLabelsDE_Linked & WordingEN & ValueLabelsEN_Linked & L1 & $\mathrm{L} 2$ & L3 & $\mathrm{L} 4$ & L5 & $\mathrm{L} 6$ & L7 & L8 & L9 & L10 L11 L12 \\
\hline policy. 1 & & $\begin{array}{l}\text { Q28.1\#1_30 - Im folgenden } \\
\text { Segment wollen wir gerne } \\
\text { wissen, inwieweit Du } \\
\text { verschiedene politische } \\
\text { Aussagen unter... - } \\
\text { Q28.1\#1 - Für die } \\
\text { Aufnahme von neuen } \\
\text { Asylsuchenden soll eine } \\
\text { jährliche Obergrenze gelten. }\end{array}$ & $\begin{array}{l}3=\text { stimmt überhaupt nicht, } \\
4=\text { stimmt nicht, } 5=\text { stimmt } \\
\text { eher nicht, } 6=\text { weder noch, } 7 \\
=\text { stimmt eher, } 8=\text { stimmt, } 9 \\
=\text { stimmt voll und ganz, } 10= \\
\text { Ich habe dazu keine Meinung }\end{array}$ & $\begin{array}{l}\text { There should be an } \\
\text { annual upper limit to } \\
\text { the uptake of new } \\
\text { asylum seekers. }\end{array}$ & $\begin{array}{l}3=\text { completely incorrect, } \\
4=\text { incorrect, } 5=\text { more } \\
\text { likely to be incorrect, } 6= \\
\text { neither, } 7=\text { more likely to } \\
\text { be correct, } 8=\text { correct, } 9 \\
=\text { completely correct, } 10 \\
=\text { I have no opinion on } \\
\text { this matter }\end{array}$ & $\mathrm{x}$ & $\mathrm{x}$ & $\mathrm{x}$ & $\mathrm{x}$ & $\mathrm{x}$ & $\mathrm{x}$ & $\mathrm{x}$ & $\mathrm{x}$ & $\mathrm{x}$ & $\mathrm{x}$ \\
\hline policy. 2 & & $\begin{array}{l}\text { Q28.1\#1_31 - Im folgenden } \\
\text { Segment wollen wir gerne } \\
\text { wissen, inwieweit Du } \\
\text { verschiedene politische } \\
\text { Aussagen unter... - } \\
\text { Q28.1\#1 - Die Schweiz soll } \\
\text { Kontingente für die } \\
\text { Einwanderung ausländischer } \\
\text { Arbeitskräfte festlegen } \\
\text { können. }\end{array}$ & $\begin{array}{l}3=\text { stimmt überhaupt nicht, } \\
4=\text { stimmt nicht, } 5=\text { stimmt } \\
\text { eher nicht, } 6=\text { weder noch, } 7 \\
=\text { stimmt eher, } 8=\text { stimmt, } 9 \\
=\text { stimmt voll und ganz, } 10= \\
\text { Ich habe dazu keine Meinung }\end{array}$ & $\begin{array}{l}\text { Switzerland should be } \\
\text { able to set quotas for } \\
\text { the immigration of } \\
\text { foreign workers. }\end{array}$ & $\begin{array}{l}3=\text { completely incorrect, } \\
4=\text { incorrect, } 5=\text { more } \\
\text { likely to be incorrect, } 6= \\
\text { neither, } 7=\text { more likely to } \\
\text { be correct, } 8=\text { correct, } 9 \\
=\text { completely correct, } 10 \\
=\text { I have no opinion on } \\
\text { this matter }\end{array}$ & $\mathrm{x}$ & $\mathrm{x}$ & $\mathrm{x}$ & $\mathrm{x}$ & $\mathrm{x}$ & $\mathrm{x}$ & $\mathrm{x}$ & $\mathrm{x}$ & $\mathrm{x}$ & $\mathrm{x}$ \\
\hline policy.3 & & $\begin{array}{l}\text { Q28.1\#1_32 - Im folgenden } \\
\text { Segment wollen wir gerne } \\
\text { wissen, inwieweit Du } \\
\text { verschiedene politische } \\
\text { Aussagen unter... - } \\
\text { Q28.1\#1 - Betreiber von } \\
\text { Internetseiten sollen } \\
\text { gesetzlich dazu verpflichtet } \\
\text { sein, Falschinformationen } \\
\text { ("Fake News") zu löschen, } \\
\text { auf die sie hingewiesen } \\
\text { wurden. }\end{array}$ & $\begin{array}{l}3=\text { stimmt überhaupt nicht, } \\
4=\text { stimmt nicht, } 5=\text { stimmt } \\
\text { eher nicht, } 6=\text { weder noch, } 7 \\
=\text { stimmt eher, } 8=\text { stimmt, } 9 \\
=\text { stimmt voll und ganz, } 10= \\
\text { Ich habe dazu keine Meinung }\end{array}$ & $\begin{array}{l}\text { Operators of internet } \\
\text { sites should be legally } \\
\text { mandated to remove } \\
\text { Fake News that they are } \\
\text { made aware of. }\end{array}$ & $\begin{array}{l}3=\text { completely incorrect, } \\
4=\text { incorrect, } 5=\text { more } \\
\text { likely to be incorrect, } 6= \\
\text { neither, } 7=\text { more likely to } \\
\text { be correct, } 8=\text { correct, } 9 \\
=\text { completely correct, } 10 \\
=\text { I have no opinion on } \\
\text { this matter }\end{array}$ & $\mathrm{x}$ & $\mathrm{x}$ & $\mathrm{x}$ & $\mathrm{x}$ & $\mathrm{x}$ & $\mathrm{x}$ & $\mathrm{x}$ & $\mathrm{x}$ & $\mathrm{x}$ & $\mathrm{x}$ \\
\hline policy. 4 & & $\begin{array}{l}\text { Q28.1\#1_33 - Im folgenden } \\
\text { Segment wollen wir gerne } \\
\text { wissen, inwieweit Du } \\
\text { verschiedene politische } \\
\text { Aussagen unter... - } \\
\text { Q28.1\#1 - Kinder sollen } \\
\text { gegen ansteckende } \\
\text { Krankheiten geimpft } \\
\text { werden müssen. }\end{array}$ & $\begin{array}{l}3=\text { stimmt überhaupt nicht, } \\
4=\text { stimmt nicht, } 5=\text { stimmt } \\
\text { eher nicht, } 6=\text { weder noch, } 7 \\
=\text { stimmt eher, } 8=\text { stimmt, } 9 \\
=\text { stimmt voll und ganz, } 10= \\
\text { Ich habe dazu keine Meinung }\end{array}$ & $\begin{array}{l}\text { Children must be } \\
\text { vaccinated against } \\
\text { contagious illnesses. }\end{array}$ & $\begin{array}{l}3=\text { completely incorrect, } \\
4=\text { incorrect, } 5=\text { more } \\
\text { likely to be incorrect, } 6= \\
\text { neither, } 7=\text { more likely to } \\
\text { be correct, } 8=\text { correct, } 9 \\
=\text { completely correct, } 10 \\
=\text { I have no opinion on } \\
\text { this matter }\end{array}$ & $\mathrm{x}$ & $\mathrm{x}$ & $\mathrm{x}$ & $\mathrm{x}$ & $\mathrm{x}$ & $\mathrm{x}$ & $\mathrm{x}$ & $\mathrm{x}$ & $\mathrm{x}$ & $\mathrm{x}$ \\
\hline policy.5 & & $\begin{array}{l}\text { Q28.1\#1_34 - Im folgenden } \\
\text { Segment wollen wir gerne } \\
\text { wissen, inwieweit Du } \\
\text { verschiedene politische } \\
\text { Aussagen unter... - } \\
\text { Q28.1\#1 - Alle Banken } \\
\text { sollen verstaatlicht werden. }\end{array}$ & $\begin{array}{l}3=\text { stimmt überhaupt nicht, } \\
4=\text { stimmt nicht, } 5=\text { stimmt } \\
\text { eher nicht, } 6=\text { weder noch, } 7 \\
=\text { stimmt eher, } 8=\text { stimmt, } 9 \\
=\text { stimmt voll und ganz, } 10= \\
\text { Ich habe dazu keine Meinung }\end{array}$ & $\begin{array}{l}\text { All banks should be } \\
\text { nationalized }\end{array}$ & $\begin{array}{l}3=\text { completely incorrect, } \\
4=\text { incorrect, } 5=\text { more } \\
\text { likely to be incorrect, } 6= \\
\text { neither, } 7=\text { more likely to } \\
\text { be correct, } 8=\text { correct, } 9 \\
=\text { completely correct, } 10 \\
=\text { I have no opinion on } \\
\text { this matter }\end{array}$ & $\mathrm{x}$ & $\mathrm{x}$ & $\mathrm{x}$ & $\mathrm{X}$ & $\mathrm{x}$ & $\mathrm{x}$ & $\mathrm{x}$ & $\mathrm{x}$ & $\mathrm{x}$ & $\mathrm{x}$ \\
\hline policy. 6 & & $\begin{array}{l}\text { Q28.1\#1_35 - Im folgenden } \\
\text { Segment wollen wir gerne } \\
\text { wissen, inwieweit Du } \\
\text { verschiedene politische } \\
\text { Aussagen unter... - } \\
\text { Q28.1\#1 - Es soll eine } \\
\text { Frauenquote für } \\
\text { Aufsichtsräte } \\
\text { börsennotierter } \\
\text { Unternehmen geben. }\end{array}$ & $\begin{array}{l}3=\text { stimmt überhaupt nicht, } \\
4=\text { stimmt nicht, } 5=\text { stimmt } \\
\text { eher nicht, } 6=\text { weder noch, } 7 \\
=\text { stimmt eher, } 8=\text { stimmt, } 9 \\
=\text { stimmt voll und ganz, } 10= \\
\text { Ich habe dazu keine Meinung }\end{array}$ & $\begin{array}{l}\text { There should be a quota } \\
\text { for the number of } \\
\text { women on supervisory } \\
\text { boards of listed } \\
\text { companies. }\end{array}$ & $\begin{array}{l}3=\text { completely incorrect, } \\
4=\text { incorrect, } 5=\text { more } \\
\text { likely to be incorrect, } 6= \\
\text { neither, } 7=\text { more likely to } \\
\text { be correct, } 8=\text { correct, } 9 \\
=\text { completely correct, } 10 \\
=\text { I have no opinion on } \\
\text { this matter }\end{array}$ & $\mathrm{x}$ & $\mathrm{x}$ & $\mathrm{x}$ & $\mathrm{x}$ & $\mathrm{x}$ & $\mathrm{x}$ & $\mathrm{x}$ & $\mathrm{x}$ & $\mathrm{x}$ & $\mathrm{x}$ \\
\hline
\end{tabular}




\begin{tabular}{|c|c|c|c|c|c|c|c|c|c|c|c|c|c|c|c|}
\hline VarName & VariableLabel & WordingDE & ValueLabelsDE_Linked & WordingEN & ValueLabelsEN_Linked & L1 & $\mathrm{L} 2$ & L3 & $\mathrm{L} 4$ & L5 & L6 & L7 & L8 & L9 & L10 L11 L12 \\
\hline policy. 7 & & $\begin{array}{l}\text { Q28.1\#1_36 - Im folgenden } \\
\text { Segment wollen wir gerne } \\
\text { wissen, inwieweit Du } \\
\text { verschiedene politische } \\
\text { Aussagen unter... - } \\
\text { Q28.1\#1 - Hohe Vermögen } \\
\text { sollen besteuert werden. }\end{array}$ & $\begin{array}{l}3=\text { stimmt überhaupt nicht, } \\
4=\text { stimmt nicht, } 5=\text { stimmt } \\
\text { eher nicht, } 6=\text { weder noch, } 7 \\
=\text { stimmt eher, } 8=\text { stimmt, } 9 \\
=\text { stimmt voll und ganz, } 10= \\
\text { Ich habe dazu keine Meinung }\end{array}$ & $\begin{array}{l}\text { High wealth should be } \\
\text { taxed. }\end{array}$ & $\begin{array}{l}3=\text { completely incorrect, } \\
4=\text { incorrect, } 5=\text { more } \\
\text { likely to be incorrect, } 6= \\
\text { neither, } 7=\text { more likely to } \\
\text { be correct, } 8=\text { correct, } 9 \\
=\text { completely correct, } 10 \\
=\text { I have no opinion on } \\
\text { this matter }\end{array}$ & $\mathrm{x}$ & $\mathrm{x}$ & $\mathrm{x}$ & $\mathrm{x}$ & $\mathrm{x}$ & $\mathrm{x}$ & $\mathrm{x}$ & $\mathrm{x}$ & $\mathrm{x}$ & $\mathrm{x}$ \\
\hline policy. 8 & & $\begin{array}{l}\text { Q28.1\#1_37 - Im folgenden } \\
\text { Segment wollen wir gerne } \\
\text { wissen, inwieweit Du } \\
\text { verschiedene politische } \\
\text { Aussagen unter... - } \\
\text { Q28.1\#1 - Rüstungsexporte } \\
\text { aus der Schweiz sollen } \\
\text { ausnahmslos verboten } \\
\text { werden. }\end{array}$ & $\begin{array}{l}3=\text { stimmt überhaupt nicht, } \\
4=\text { stimmt nicht, } 5=\text { stimmt } \\
\text { eher nicht, } 6=\text { weder noch, } 7 \\
=\text { stimmt eher, } 8=\text { stimmt, } 9 \\
=\text { stimmt voll und ganz, } 10= \\
\text { Ich habe dazu keine Meinung }\end{array}$ & $\begin{array}{l}\text { Arms exports from } \\
\text { Switzerland should be } \\
\text { prohibited, without } \\
\text { exception. }\end{array}$ & $\begin{array}{l}3=\text { completely incorrect, } \\
4=\text { incorrect, } 5=\text { more } \\
\text { likely to be incorrect, } 6= \\
\text { neither, } 7=\text { more likely to } \\
\text { be correct, } 8=\text { correct, } 9 \\
=\text { completely correct, } 10 \\
=\text { I have no opinion on } \\
\text { this matter }\end{array}$ & $\mathrm{x}$ & $\mathrm{x}$ & $\mathrm{x}$ & $\mathrm{x}$ & $\mathrm{x}$ & $\mathrm{x}$ & $\mathrm{x}$ & $\mathrm{x}$ & $\mathrm{x}$ & $\mathrm{x}$ \\
\hline policy. 9 & & $\begin{array}{l}\text { Q28.1\#1_38 - Im folgenden } \\
\text { Segment wollen wir gerne } \\
\text { wissen, inwieweit Du } \\
\text { verschiedene politische } \\
\text { Aussagen unter... - } \\
\text { Q28.1\#1 - Der kontrollierte } \\
\text { Verkauf von Cannabis soll } \\
\text { generell erlaubt sein. }\end{array}$ & $\begin{array}{l}3=\text { stimmt überhaupt nicht, } \\
4=\text { stimmt nicht, } 5=\text { stimmt } \\
\text { eher nicht, } 6=\text { weder noch, } 7 \\
=\text { stimmt eher, } 8=\text { stimmt, } 9 \\
=\text { stimmt voll und ganz, } 10= \\
\text { Ich habe dazu keine Meinung }\end{array}$ & $\begin{array}{l}\text { The regulated sale of } \\
\text { cannabis should be } \\
\text { generally permitted. }\end{array}$ & $\begin{array}{l}3=\text { completely incorrect, } \\
4=\text { incorrect, } 5=\text { more } \\
\text { likely to be incorrect, } 6= \\
\text { neither, } 7=\text { more likely to } \\
\text { be correct, } 8=\text { correct, } 9 \\
=\text { completely correct, } 10 \\
=\text { I have no opinion on } \\
\text { this matter }\end{array}$ & $\mathrm{x}$ & $\mathrm{x}$ & $\mathrm{x}$ & $\mathrm{x}$ & $\mathrm{x}$ & $\mathrm{x}$ & $\mathrm{x}$ & $\mathrm{x}$ & $\mathrm{x}$ & $\mathrm{x}$ \\
\hline policy.10 & & $\begin{array}{l}\text { Q28.1\#1_39 - Im folgenden } \\
\text { Segment wollen wir gerne } \\
\text { wissen, inwieweit Du } \\
\text { verschiedene politische } \\
\text { Aussagen unter... - } \\
\text { Q28.1\#1 - Das } \\
\text { Bankkundengeheimnis in } \\
\text { der Schweiz soll zur } \\
\text { Bekämpfung von } \\
\text { Steuerhinterziehung } \\
\text { gelockert werden. }\end{array}$ & $\begin{array}{l}3=\text { stimmt überhaupt nicht, } \\
4=\text { stimmt nicht, } 5=\text { stimmt } \\
\text { eher nicht, } 6=\text { weder noch, } 7 \\
=\text { stimmt eher, } 8=\text { stimmt, } 9 \\
=\text { stimmt voll und ganz, } 10= \\
\text { Ich habe dazu keine Meinung }\end{array}$ & $\begin{array}{l}\text { Bank customer secrecy } \\
\text { privileges in Switzerland } \\
\text { should be loosened to } \\
\text { combat tax evasion. }\end{array}$ & $\begin{array}{l}3=\text { completely incorrect, } \\
4=\text { incorrect, } 5=\text { more } \\
\text { likely to be incorrect, } 6= \\
\text { neither, } 7=\text { more likely to } \\
\text { be correct, } 8=\text { correct, } 9 \\
=\text { completely correct, } 10 \\
=\text { I have no opinion on } \\
\text { this matter }\end{array}$ & $\mathrm{x}$ & $\mathrm{x}$ & $\mathrm{x}$ & $\mathrm{x}$ & $\mathrm{x}$ & $\mathrm{x}$ & $\mathrm{x}$ & $\mathrm{x}$ & $\mathrm{x}$ & $\mathrm{x}$ \\
\hline policy.11 & & $\begin{array}{l}\text { Q28.1\#1_40 - Im folgenden } \\
\text { Segment wollen wir gerne } \\
\text { wissen, inwieweit Du } \\
\text { verschiedene politische } \\
\text { Aussagen unter... - } \\
\text { Q28.1\#1 - Der Staat soll } \\
\text { zum Schutz vor Terrorismus } \\
\text { stärker in die Privatsphäre } \\
\text { der Bürger eingreifen } \\
\text { dürfen. }\end{array}$ & $\begin{array}{l}3=\text { stimmt überhaupt nicht, } \\
4=\text { stimmt nicht, } 5=\text { stimmt } \\
\text { eher nicht, } 6=\text { weder noch, } 7 \\
=\text { stimmt eher, } 8=\text { stimmt, } 9 \\
=\text { stimmt voll und ganz, } 10= \\
\text { Ich habe dazu keine Meinung }\end{array}$ & $\begin{array}{l}\text { The state should be } \\
\text { allowed to invade the } \\
\text { privacy of citizens more } \\
\text { forcefully to protect } \\
\text { against terrorism. }\end{array}$ & $\begin{array}{l}3=\text { completely incorrect, } \\
4=\text { incorrect, } 5=\text { more } \\
\text { likely to be incorrect, } 6= \\
\text { neither, } 7=\text { more likely to } \\
\text { be correct, } 8=\text { correct, } 9 \\
=\text { completely correct, } 10 \\
=\text { I have no opinion on } \\
\text { this matter }\end{array}$ & $\mathrm{x}$ & $\mathrm{x}$ & $\mathrm{x}$ & $\mathrm{x}$ & $\mathrm{x}$ & $\mathrm{x}$ & $\mathrm{x}$ & $\mathrm{x}$ & $\mathrm{x}$ & $\mathrm{x}$ \\
\hline policy.12 & & $\begin{array}{l}\text { Q28.1\#1_41 - Im folgenden } \\
\text { Segment wollen wir gerne } \\
\text { wissen, inwieweit Du } \\
\text { verschiedene politische } \\
\text { Aussagen unter... - } \\
\text { Q28.1\#1 - Die } \\
\text { Videoüberwachung im } \\
\text { öffentlichen Raum soll } \\
\text { ausgeweitet werden. }\end{array}$ & $\begin{array}{l}3=\text { stimmt überhaupt nicht, } \\
4=\text { stimmt nicht, } 5=\text { stimmt } \\
\text { eher nicht, } 6=\text { weder noch, } 7 \\
=\text { stimmt eher, } 8=\text { stimmt, } 9 \\
=\text { stimmt voll und ganz, } 10= \\
\text { Ich habe dazu keine Meinung }\end{array}$ & $\begin{array}{l}\text { Video surveillance in } \\
\text { public spaces should be } \\
\text { expanded. }\end{array}$ & $\begin{array}{l}3=\text { completely incorrect, } \\
4=\text { incorrect, } 5=\text { more } \\
\text { likely to be incorrect, } 6= \\
\text { neither, } 7=\text { more likely to } \\
\text { be correct, } 8=\text { correct, } 9 \\
=\text { completely correct, } 10 \\
=\text { I have no opinion on } \\
\text { this matter }\end{array}$ & $\mathrm{x}$ & $\mathrm{x}$ & $\mathrm{x}$ & $\mathrm{x}$ & $\mathrm{X}$ & $\mathrm{x}$ & $\mathrm{x}$ & $\mathrm{x}$ & $\mathrm{X}$ & $\mathrm{x}$ \\
\hline
\end{tabular}




\begin{tabular}{|c|c|c|c|c|c|c|c|c|c|c|c|c|c|c|c|}
\hline VarName & VariableLabel & WordingDE & ValueLabelsDE_Linked & WordingEN & ValueLabelsEN_Linked & L1 & L2 & L3 & $\mathrm{L} 4$ & L5 & L6 & L7 & L8 & L9 & L10 L11 L12 \\
\hline policy.13 & & $\begin{array}{l}\text { Q28.1\#1_42 - Im folgenden } \\
\text { Segment wollen wir gerne } \\
\text { wissen, inwieweit Du } \\
\text { verschiedene politische } \\
\text { Aussagen unter... - } \\
\text { Q28.1\#1 - Radio- und } \\
\text { Fernsehgebühren sollen } \\
\text { abgeschafft und durch eine } \\
\text { kommerzielle Finanzierung } \\
\text { ersetzt werden. }\end{array}$ & $\begin{array}{l}3=\text { stimmt überhaupt nicht, } \\
4=\text { stimmt nicht, } 5=\text { stimmt } \\
\text { eher nicht, } 6=\text { weder noch, } 7 \\
=\text { stimmt eher, } 8=\text { stimmt, } 9 \\
=\text { stimmt voll und ganz, } 10= \\
\text { Ich habe dazu keine Meinung }\end{array}$ & $\begin{array}{l}\text { Radio and TV license } \\
\text { fees should be abolished } \\
\text { and replaced by } \\
\text { commerical financing. }\end{array}$ & $\begin{array}{l}3=\text { completely incorrect, } \\
4=\text { incorrect, } 5=\text { more } \\
\text { likely to be incorrect, } 6= \\
\text { neither, } 7=\text { more likely to } \\
\text { be correct, } 8=\text { correct, } 9 \\
=\text { completely correct, } 10 \\
=\text { I have no opinion on } \\
\text { this matter }\end{array}$ & $\mathrm{x}$ & $\mathrm{x}$ & $\mathrm{x}$ & $\mathrm{x}$ & $\mathrm{X}$ & $\mathrm{x}$ & $\mathrm{X}$ & $\mathrm{x}$ & $\mathrm{x}$ & $\mathrm{x}$ \\
\hline policy.14 & & $\begin{array}{l}\text { Q28.1\#1_43 - Im folgenden } \\
\text { Segment wollen wir gerne } \\
\text { wissen, inwieweit Du } \\
\text { verschiedene politische } \\
\text { Aussagen unter... - } \\
\text { Q28.1\#1 - Der Ausbau } \\
\text { erneuerbarer Energien soll } \\
\text { vom Staat dauerhaft } \\
\text { finanziell gefördert werden. }\end{array}$ & $\begin{array}{l}3=\text { stimmt überhaupt nicht, } \\
4=\text { stimmt nicht, } 5=\text { stimmt } \\
\text { eher nicht, } 6=\text { weder noch, } 7 \\
=\text { stimmt eher, } 8=\text { stimmt, } 9 \\
=\text { stimmt voll und ganz, } 10= \\
\text { Ich habe dazu keine Meinung }\end{array}$ & $\begin{array}{l}\text { The expansion of } \\
\text { renewable energy } \\
\text { sources should receive } \\
\text { permanent financial } \\
\text { support from the state. }\end{array}$ & $\begin{array}{l}3=\text { completely incorrect, } \\
4=\text { incorrect, } 5=\text { more } \\
\text { likely to be incorrect, } 6= \\
\text { neither, } 7=\text { more likely to } \\
\text { be correct, } 8=\text { correct, } 9 \\
=\text { completely correct, } 10 \\
=\text { I have no opinion on } \\
\text { this matter }\end{array}$ & $\mathrm{x}$ & $\mathrm{x}$ & $\mathrm{x}$ & $\mathrm{x}$ & $\mathrm{x}$ & $\mathrm{x}$ & $\mathrm{x}$ & $\mathrm{x}$ & $\mathrm{x}$ & $\mathrm{x}$ \\
\hline policy.15 & & $\begin{array}{l}\text { Q28.1\#1_44 - Im folgenden } \\
\text { Segment wollen wir gerne } \\
\text { wissen, inwieweit Du } \\
\text { verschiedene politische } \\
\text { Aussagen unter... - } \\
\text { Q28.1\#1 - Elektromobilität } \\
\text { soll stärker gefördert } \\
\text { werden als konventionelle } \\
\text { Mobilitäts-Technologien. }\end{array}$ & $\begin{array}{l}3=\text { stimmt überhaupt nicht, } \\
4=\text { stimmt nicht, } 5=\text { stimmt } \\
\text { eher nicht, } 6=\text { weder noch, } 7 \\
=\text { stimmt eher, } 8=\text { stimmt, } 9 \\
=\text { stimmt voll und ganz, } 10= \\
\text { Ich habe dazu keine Meinung }\end{array}$ & $\begin{array}{l}\text { Electromobility should } \\
\text { be promoted more than } \\
\text { conventional mobility } \\
\text { technologies. }\end{array}$ & $\begin{array}{l}3=\text { completely incorrect, } \\
4=\text { incorrect, } 5=\text { more } \\
\text { likely to be incorrect, } 6= \\
\text { neither, } 7=\text { more likely to } \\
\text { be correct, } 8=\text { correct, } 9 \\
=\text { completely correct, } 10 \\
=\text { I have no opinion on } \\
\text { this matter }\end{array}$ & $\mathrm{X}$ & $\mathrm{x}$ & $\mathrm{x}$ & $\mathrm{X}$ & $\mathrm{X}$ & $\mathrm{x}$ & $\mathrm{x}$ & $\mathrm{x}$ & $\mathrm{x}$ & $\mathrm{x}$ \\
\hline policy.16 & & $\begin{array}{l}\text { Q28.1\#1_45 - Im folgenden } \\
\text { Segment wollen wir gerne } \\
\text { wissen, inwieweit Du } \\
\text { verschiedene politische } \\
\text { Aussagen unter... - } \\
\text { Q28.1\#1 - Es sollen mehr } \\
\text { Fahrradwege auf } \\
\text { öffentlichen Strassen in der } \\
\text { Schweiz gebaut werden. }\end{array}$ & $\begin{array}{l}3=\text { stimmt überhaupt nicht, } \\
4=\text { stimmt nicht, } 5=\text { stimmt } \\
\text { eher nicht, } 6=\text { weder noch, } 7 \\
=\text { stimmt eher, } 8=\text { stimmt, } 9 \\
=\text { stimmt voll und ganz, } 10= \\
\text { Ich habe dazu keine Meinung }\end{array}$ & $\begin{array}{l}\text { More bike paths should } \\
\text { be built on public roads } \\
\text { in Switzerland. }\end{array}$ & $\begin{array}{l}3=\text { completely incorrect, } \\
4=\text { incorrect, } 5=\text { more } \\
\text { likely to be incorrect, } 6= \\
\text { neither, } 7=\text { more likely to } \\
\text { be correct, } 8=\text { correct, } 9 \\
=\text { completely correct, } 10 \\
=\text { I have no opinion on } \\
\text { this matter }\end{array}$ & $\mathrm{x}$ & $\mathrm{x}$ & $\mathrm{x}$ & $\mathrm{x}$ & $\mathrm{x}$ & $\mathrm{x}$ & $\mathrm{x}$ & $\mathrm{x}$ & $\mathrm{x}$ & $\mathrm{x}$ \\
\hline policy.17 & & $\begin{array}{l}\text { Q28.1\#1_46 - Im folgenden } \\
\text { Segment wollen wir gerne } \\
\text { wissen, inwieweit Du } \\
\text { verschiedene politische } \\
\text { Aussagen unter... - } \\
\text { Q28.1\#1 - } \text { A-kologische } \\
\text { Landwirtschaft soll stärker } \\
\text { gefördert werden als } \\
\text { konventionelle } \\
\text { Landwirtschaft. }\end{array}$ & $\begin{array}{l}3=\text { stimmt überhaupt nicht, } \\
4=\text { stimmt nicht, } 5=\text { stimmt } \\
\text { eher nicht, } 6=\text { weder noch, } 7 \\
=\text { stimmt eher, } 8=\text { stimmt, } 9 \\
=\text { stimmt voll und ganz, } 10= \\
\text { Ich habe dazu keine Meinung }\end{array}$ & $\begin{array}{l}\text { Organic agriculture } \\
\text { should be promoted } \\
\text { more than conventional } \\
\text { agriculture. }\end{array}$ & $\begin{array}{l}3=\text { completely incorrect, } \\
4=\text { incorrect, } 5=\text { more } \\
\text { likely to be incorrect, } 6= \\
\text { neither, } 7=\text { more likely to } \\
\text { be correct, } 8=\text { correct, } 9 \\
=\text { completely correct, } 10 \\
=\mathrm{I} \text { have no opinion on } \\
\text { this matter }\end{array}$ & $\mathrm{x}$ & $\mathrm{x}$ & $\mathrm{x}$ & $\mathrm{x}$ & $\mathrm{X}$ & $\mathrm{x}$ & $\mathrm{X}$ & $\mathrm{x}$ & $\mathrm{x}$ & $\mathrm{x}$ \\
\hline policy.18 & & $\begin{array}{l}\text { Q28.1\#1_47 - Im folgenden } \\
\text { Segment wollen wir gerne } \\
\text { wissen, inwieweit Du } \\
\text { verschiedene politische } \\
\text { Aussagen unter... - } \\
\text { Q28.1\#1 - Nahrungsmittel } \\
\text { sollen nur dann importiert } \\
\text { werden können, wenn sie } \\
\text { gemäss Schweizer Standards } \\
\text { bezüglich ökologischer } \\
\text { Nachhaltigkeit, Tierschutz } \\
\text { und Arbeitsrechten } \\
\text { produziert worden sind. }\end{array}$ & $\begin{array}{l}3=\text { stimmt überhaupt nicht, } \\
4=\text { stimmt nicht, } 5=\text { stimmt } \\
\text { eher nicht, } 6=\text { weder noch, } 7 \\
=\text { stimmt eher, } 8=\text { stimmt, } 9 \\
=\text { stimmt voll und ganz, } 10= \\
\text { Ich habe dazu keine Meinung }\end{array}$ & $\begin{array}{l}\text { Food should only be } \\
\text { allowed to be imported } \\
\text { if it meets Swiss } \\
\text { standards of production } \\
\text { regarding sustainability, } \\
\text { animal rights, and } \\
\text { workers' rights. }\end{array}$ & $\begin{array}{l}3=\text { completely incorrect, } \\
4=\text { incorrect, } 5=\text { more } \\
\text { likely to be incorrect, } 6= \\
\text { neither, } 7=\text { more likely to } \\
\text { be correct, } 8=\text { correct, } 9 \\
=\text { completely correct, } 10 \\
=\text { I have no opinion on } \\
\text { this matter }\end{array}$ & $\mathrm{x}$ & $\mathrm{x}$ & $\mathrm{x}$ & $\mathrm{x}$ & $\mathrm{x}$ & $\mathrm{x}$ & $\mathrm{x}$ & $\mathrm{x}$ & $\mathrm{x}$ & $\mathrm{x}$ \\
\hline
\end{tabular}




\begin{tabular}{|c|c|c|c|c|c|c|c|c|c|c|c|c|c|c|c|}
\hline VarName & VariableLabel & WordingDE & ValueLabelsDE_Linked & WordingEN & ValueLabelsEN_Linked & L1 & $\mathrm{L} 2$ & L3 & $\mathrm{L} 4$ & L5 & L6 & L7 & L8 & L9 & L10 L11 L12 \\
\hline policy.19 & & $\begin{array}{l}\text { Q28.1\#1_48 - Im folgenden } \\
\text { Segment wollen wir gerne } \\
\text { wissen, inwieweit Du } \\
\text { verschiedene politische } \\
\text { Aussagen unter... - } \\
\text { Q28.1\#1 - In der Schweiz } \\
\text { soll es ein bedingungsloses } \\
\text { Grundeinkommen geben. }\end{array}$ & $\begin{array}{l}3=\text { stimmt überhaupt nicht, } \\
4=\text { stimmt nicht, } 5=\text { stimmt } \\
\text { eher nicht, } 6=\text { weder noch, } 7 \\
=\text { stimmt eher, } 8=\text { stimmt, } 9 \\
=\text { stimmt voll und ganz, } 10= \\
\text { Ich habe dazu keine Meinung }\end{array}$ & $\begin{array}{l}\text { There should be a } \\
\text { universal basic income } \\
\text { in Switzerland. }\end{array}$ & $\begin{array}{l}3=\text { completely incorrect, } \\
4=\text { incorrect, } 5=\text { more } \\
\text { likely to be incorrect, } 6= \\
\text { neither, } 7=\text { more likely to } \\
\text { be correct, } 8=\text { correct, } 9 \\
=\text { completely correct, } 10 \\
=\mathrm{I} \text { have no opinion on } \\
\text { this matter }\end{array}$ & $\mathrm{x}$ & $\mathrm{x}$ & $\mathrm{x}$ & $\mathrm{x}$ & $\mathrm{x}$ & $\mathrm{x}$ & $\mathrm{x}$ & $\mathrm{x}$ & $\mathrm{x}$ & $\mathrm{x}$ \\
\hline policy.20 & & $\begin{array}{l}\text { Q28.1\#1_49 - Im folgenden } \\
\text { Segment wollen wir gerne } \\
\text { wissen, inwieweit Du } \\
\text { verschiedene politische } \\
\text { Aussagen unter... - } \\
\text { Q28.1\#1 - Der Staat soll } \\
\text { mehr Mittel für den sozialen } \\
\text { Wohnungsbau bereitstellen. }\end{array}$ & $\begin{array}{l}3=\text { stimmt überhaupt nicht, } \\
4=\text { stimmt nicht, } 5=\text { stimmt } \\
\text { eher nicht, } 6=\text { weder noch, } 7 \\
=\text { stimmt eher, } 8=\text { stimmt, } 9 \\
=\text { stimmt voll und ganz, } 10= \\
\text { Ich habe dazu keine Meinung }\end{array}$ & $\begin{array}{l}\text { The state should offer } \\
\text { more resources for the } \\
\text { construction of social } \\
\text { housing. }\end{array}$ & $\begin{array}{l}3=\text { completely incorrect, } \\
4=\text { incorrect, } 5=\text { more } \\
\text { likely to be incorrect, } 6= \\
\text { neither, } 7=\text { more likely to } \\
\text { be correct, } 8=\text { correct, } 9 \\
=\text { completely correct, } 10 \\
=\mathrm{I} \text { have no opinion on } \\
\text { this matter }\end{array}$ & $\mathrm{x}$ & $\mathrm{x}$ & $\mathrm{x}$ & $\mathrm{x}$ & $\mathrm{x}$ & $\mathrm{x}$ & $\mathrm{x}$ & $\mathrm{x}$ & $\mathrm{x}$ & $\mathrm{x}$ \\
\hline policy.21 & & $\begin{array}{l}\text { Q28.1\#1_50 - Im folgenden } \\
\text { Segment wollen wir gerne } \\
\text { wissen, inwieweit Du } \\
\text { verschiedene politische } \\
\text { Aussagen unter... - } \\
\text { Q28.1\#1 - Es soll eine } \\
\text { Obergrenze für ausländische } \\
\text { Studierende an Schweizer } \\
\text { Universitäten geben. }\end{array}$ & $\begin{array}{l}3=\text { stimmt überhaupt nicht, } \\
4=\text { stimmt nicht, } 5=\text { stimmt } \\
\text { eher nicht, } 6=\text { weder noch, } 7 \\
=\text { stimmt eher, } 8=\text { stimmt, } 9 \\
=\text { stimmt voll und ganz, } 10= \\
\text { Ich habe dazu keine Meinung }\end{array}$ & $\begin{array}{l}\text { There should be an } \\
\text { upper limit to foreign } \\
\text { students at Swiss } \\
\text { universities. }\end{array}$ & $\begin{array}{l}3=\text { completely incorrect, } \\
4=\text { incorrect, } 5=\text { more } \\
\text { likely to be incorrect, } 6= \\
\text { neither, } 7=\text { more likely to } \\
\text { be correct, } 8=\text { correct, } 9 \\
=\text { completely correct, } 10 \\
=\text { I have no opinion on } \\
\text { this matter }\end{array}$ & $\mathrm{x}$ & $\mathrm{x}$ & $\mathrm{x}$ & $\mathrm{x}$ & $\mathrm{x}$ & $\mathrm{x}$ & $\mathrm{x}$ & $\mathrm{x}$ & $\mathrm{x}$ & $\mathrm{x}$ \\
\hline policy.22 & & $\begin{array}{l}\text { Q28.1\#1_51 - Im folgenden } \\
\text { Segment wollen wir gerne } \\
\text { wissen, inwieweit Du } \\
\text { verschiedene politische } \\
\text { Aussagen unter... - } \\
\text { Q28.1\#1 - Ein } \\
\text { Universitätsstudium soll } \\
\text { grundsätzlich kostenfrei } \\
\text { sein. }\end{array}$ & $\begin{array}{l}3=\text { stimmt überhaupt nicht, } \\
4=\text { stimmt nicht, } 5=\text { stimmt } \\
\text { eher nicht, } 6=\text { weder noch, } 7 \\
=\text { stimmt eher, } 8=\text { stimmt, } 9 \\
=\text { stimmt voll und ganz, } 10= \\
\text { Ich habe dazu keine Meinung }\end{array}$ & $\begin{array}{l}\text { University studies } \\
\text { should be strictly free of } \\
\text { charge. }\end{array}$ & $\begin{array}{l}3=\text { completely incorrect, } \\
4=\text { incorrect, } 5=\text { more } \\
\text { likely to be incorrect, } 6= \\
\text { neither, } 7=\text { more likely to } \\
\text { be correct, } 8=\text { correct, } 9 \\
=\text { completely correct, } 10 \\
=\text { I have no opinion on } \\
\text { this matter }\end{array}$ & $\mathrm{x}$ & $\mathrm{x}$ & $\mathrm{x}$ & $\mathrm{x}$ & $\mathrm{x}$ & $\mathrm{X}$ & $\mathrm{x}$ & $\mathrm{x}$ & $\mathrm{X}$ & $\mathrm{x}$ \\
\hline policy.23 & & $\begin{array}{l}\text { Q28.1\#2_30 - Im folgenden } \\
\text { Segment wollen wir gerne } \\
\text { wissen, inwieweit Du } \\
\text { verschiedene politische } \\
\text { Aussagen unter... - } \\
\text { Q28.1\#2 - Für die } \\
\text { Aufnahme von neuen } \\
\text { Asylsuchenden soll eine } \\
\text { jährliche Obergrenze gelten. }\end{array}$ & $\begin{array}{l}1=\text { ich habe dazu keine } \\
\text { Meinung }\end{array}$ & $\begin{array}{l}\text { There should be an } \\
\text { annual upper limit to } \\
\text { the uptake of new } \\
\text { asylum seekers. }\end{array}$ & $\begin{array}{l}1=\mathrm{I} \text { have no opinion on } \\
\text { this matter }\end{array}$ & $\mathrm{x}$ & & & & & & & & & \\
\hline policy.24 & & $\begin{array}{l}\text { Q28.1\#2_31 - Im folgenden } \\
\text { Segment wollen wir gerne } \\
\text { wissen, inwieweit Du } \\
\text { verschiedene politische } \\
\text { Aussagen unter... - } \\
\text { Q28.1\#2 - Die Schweiz soll } \\
\text { Kontingente für die } \\
\text { Einwanderung ausländischer } \\
\text { Arbeitskräfte festlegen } \\
\text { können. }\end{array}$ & $\begin{array}{l}1=\text { ich habe dazu keine } \\
\text { Meinung }\end{array}$ & $\begin{array}{l}\text { Switzerland should be } \\
\text { able to set quotas for } \\
\text { the immigration of } \\
\text { foreign workers. }\end{array}$ & $\begin{array}{l}1=\mathrm{I} \text { have no opinion on } \\
\text { this matter }\end{array}$ & $\mathrm{x}$ & & & & & & & & & \\
\hline
\end{tabular}




\begin{tabular}{|c|c|c|c|c|c|c|c|c|c|c|c|c|c|c|c|}
\hline VarName & VariableLabel & WordingDE & ValueLabelsDE_Linked & WordingEN & ValueLabelsEN_Linked & $\mathrm{L} 1$ & $\mathrm{~L} 2$ & L3 & L4 & L5 & $\mathrm{L} 6$ & $\mathrm{~L} 7$ & L8 & L9 & L10 L11 L12 \\
\hline policy.25 & & $\begin{array}{l}\text { Q28.1\#2_32 - Im folgenden } \\
\text { Segment wollen wir gerne } \\
\text { wissen, inwieweit Du } \\
\text { verschiedene politische } \\
\text { Aussagen unter... - } \\
\text { Q28.1\#2 - Betreiber von } \\
\text { Internetseiten sollen } \\
\text { gesetzlich dazu verpflichtet } \\
\text { sein, Falschinformationen } \\
\text { ("Fake News") zu löschen, } \\
\text { auf die sie hingewiesen } \\
\text { wurden. }\end{array}$ & $\begin{array}{l}1=\text { ich habe dazu keine } \\
\text { Meinung }\end{array}$ & $\begin{array}{l}\text { Operators of internet } \\
\text { sites should be legally } \\
\text { mandated to remove } \\
\text { Fake News that they are } \\
\text { made aware of. }\end{array}$ & $\begin{array}{l}1=\mathrm{I} \text { have no opinion on } \\
\text { this matter }\end{array}$ & $\mathrm{x}$ & & & & & & & & & \\
\hline policy.26 & & $\begin{array}{l}\text { Q28.1\#2_33 - Im folgenden } \\
\text { Segment wollen wir gerne } \\
\text { wissen, inwieweit Du } \\
\text { verschiedene politische } \\
\text { Aussagen unter... - } \\
\text { Q28.1\#2 - Kinder sollen } \\
\text { gegen ansteckende } \\
\text { Krankheiten geimpft } \\
\text { werden müssen. }\end{array}$ & $\begin{array}{l}1=\text { ich habe dazu keine } \\
\text { Meinung }\end{array}$ & $\begin{array}{l}\text { Children must be } \\
\text { vaccinated against } \\
\text { contagious illnesses. }\end{array}$ & $\begin{array}{l}1=\mathrm{I} \text { have no opinion on } \\
\text { this matter }\end{array}$ & $\mathrm{x}$ & & & & & & & & & \\
\hline policy.27 & & $\begin{array}{l}\text { Q28.1\#2_34 - Im folgenden } \\
\text { Segment wollen wir gerne } \\
\text { wissen, inwieweit Du } \\
\text { verschiedene politische } \\
\text { Aussagen unter... - } \\
\text { Q28.1\#2 - Alle Banken } \\
\text { sollen verstaatlicht werden. }\end{array}$ & $\begin{array}{l}1=\text { ich habe dazu keine } \\
\text { Meinung }\end{array}$ & $\begin{array}{l}\text { All banks should be } \\
\text { nationalized }\end{array}$ & $\begin{array}{l}1=\mathrm{I} \text { have no opinion on } \\
\text { this matter }\end{array}$ & $\mathrm{x}$ & & & & & & & & & \\
\hline policy.28 & & $\begin{array}{l}\text { Q28.1\#2_35 - Im folgenden } \\
\text { Segment wollen wir gerne } \\
\text { wissen, inwieweit Du } \\
\text { verschiedene politische } \\
\text { Aussagen unter... - } \\
\text { Q28.1\#2 - Es soll eine } \\
\text { Frauenquote für } \\
\text { Aufsichtsräte } \\
\text { börsennotierter } \\
\text { Unternehmen geben. }\end{array}$ & $\begin{array}{l}1=\text { ich habe dazu keine } \\
\text { Meinung }\end{array}$ & $\begin{array}{l}\text { There should be a quota } \\
\text { for the number of } \\
\text { women on supervisory } \\
\text { boards of listed } \\
\text { companies. }\end{array}$ & $\begin{array}{l}1=\mathrm{I} \text { have no opinion on } \\
\text { this matter }\end{array}$ & $\mathrm{x}$ & & & & & & & & & \\
\hline policy.29 & & $\begin{array}{l}\text { Q28.1\#2_36 - Im folgenden } \\
\text { Segment wollen wir gerne } \\
\text { wissen, inwieweit Du } \\
\text { verschiedene politische } \\
\text { Aussagen unter... - } \\
\text { Q28.1\#2 - Hohe Vermögen } \\
\text { sollen besteuert werden. }\end{array}$ & $\begin{array}{l}1=\text { ich habe dazu keine } \\
\text { Meinung }\end{array}$ & $\begin{array}{l}\text { High wealth should be } \\
\text { taxed. }\end{array}$ & $\begin{array}{l}1=\mathrm{I} \text { have no opinion on } \\
\text { this matter }\end{array}$ & $\mathrm{x}$ & & & & & & & & & \\
\hline policy.30 & & $\begin{array}{l}\text { Q28.1\#2_37 - Im folgenden } \\
\text { Segment wollen wir gerne } \\
\text { wissen, inwieweit Du } \\
\text { verschiedene politische } \\
\text { Aussagen unter... - } \\
\text { Q28.1\#2 - Rüstungsexporte } \\
\text { aus der Schweiz sollen } \\
\text { ausnahmslos verboten } \\
\text { werden. }\end{array}$ & $\begin{array}{l}1=\text { ich habe dazu keine } \\
\text { Meinung }\end{array}$ & $\begin{array}{l}\text { Arms exports from } \\
\text { Switzerland should be } \\
\text { prohibited, without } \\
\text { exception. }\end{array}$ & $\begin{array}{l}1=\mathrm{I} \text { have no opinion on } \\
\text { this matter }\end{array}$ & $\mathrm{x}$ & & & & & & & & & \\
\hline policy.31 & & $\begin{array}{l}\text { Q28.1\#2_38 - Im folgenden } \\
\text { Segment wollen wir gerne } \\
\text { wissen, inwieweit Du } \\
\text { verschiedene politische } \\
\text { Aussagen unter... - } \\
\text { Q28.1\#2 - Der kontrollierte } \\
\text { Verkauf von Cannabis soll } \\
\text { generell erlaubt sein. }\end{array}$ & $\begin{array}{l}1=\text { ich habe dazu keine } \\
\text { Meinung }\end{array}$ & $\begin{array}{l}\text { The regulated sale of } \\
\text { cannabis should be } \\
\text { generally permitted. }\end{array}$ & $\begin{array}{l}1=\mathrm{I} \text { have no opinion on } \\
\text { this matter }\end{array}$ & $\mathrm{x}$ & & & & & & & & & \\
\hline
\end{tabular}




\begin{tabular}{|c|c|c|c|c|c|c|c|c|c|c|c|c|c|c|c|}
\hline VarName & VariableLabel & WordingDE & ValueLabelsDE_Linked & WordingEN & ValueLabelsEN_Linked & L1 & L2 & L3 & $\mathrm{L} 4$ & L5 & L6 & L7 & L8 & L9 & L10 L11 L12 \\
\hline policy.32 & & $\begin{array}{l}\text { Q28.1\#2_39 - Im folgenden } \\
\text { Segment wollen wir gerne } \\
\text { wissen, inwieweit Du } \\
\text { verschiedene politische } \\
\text { Aussagen unter... - } \\
\text { Q28.1\#2 - Das } \\
\text { Bankkundengeheimnis in } \\
\text { der Schweiz soll zur } \\
\text { Bekämpfung von } \\
\text { Steuerhinterziehung } \\
\text { gelockert werden. }\end{array}$ & $\begin{array}{l}1=\text { ich habe dazu keine } \\
\text { Meinung }\end{array}$ & $\begin{array}{l}\text { Bank customer secrecy } \\
\text { privileges in Switzerland } \\
\text { should be loosened to } \\
\text { combat tax evasion. }\end{array}$ & $\begin{array}{l}1=\mathrm{I} \text { have no opinion on } \\
\text { this matter }\end{array}$ & $\mathrm{x}$ & & & & & & & & & \\
\hline policy.33 & & $\begin{array}{l}\text { Q28.1\#2_40 - Im folgenden } \\
\text { Segment wollen wir gerne } \\
\text { wissen, inwieweit Du } \\
\text { verschiedene politische } \\
\text { Aussagen unter... - } \\
\text { Q28.1\#2 - Der Staat soll } \\
\text { zum Schutz vor Terrorismus } \\
\text { stärker in die Privatsphäre } \\
\text { der Bürger eingreifen } \\
\text { dürfen. }\end{array}$ & $\begin{array}{l}1=\text { ich habe dazu keine } \\
\text { Meinung }\end{array}$ & $\begin{array}{l}\text { The state should be } \\
\text { allowed to invade the } \\
\text { privacy of citizens more } \\
\text { forcefully to protect } \\
\text { against terrorism. }\end{array}$ & $\begin{array}{l}1=\mathrm{I} \text { have no opinion on } \\
\text { this matter }\end{array}$ & $\mathrm{x}$ & & & & & & & & & \\
\hline policy.34 & & $\begin{array}{l}\text { Q28.1\#2_41 - Im folgenden } \\
\text { Segment wollen wir gerne } \\
\text { wissen, inwieweit Du } \\
\text { verschiedene politische } \\
\text { Aussagen unter... - } \\
\text { Q28.1\#2 - Die } \\
\text { Videoüberwachung im } \\
\text { öffentlichen Raum soll } \\
\text { ausgeweitet werden. }\end{array}$ & $\begin{array}{l}1=\text { ich habe dazu keine } \\
\text { Meinung }\end{array}$ & $\begin{array}{l}\text { Video surveillance in } \\
\text { public spaces should be } \\
\text { expanded. }\end{array}$ & $\begin{array}{l}1=\mathrm{I} \text { have no opinion on } \\
\text { this matter }\end{array}$ & $\mathrm{x}$ & & & & & & & & & \\
\hline policy.35 & & $\begin{array}{l}\text { Q28.1\#2_42 - Im folgenden } \\
\text { Segment wollen wir gerne } \\
\text { wissen, inwieweit Du } \\
\text { verschiedene politische } \\
\text { Aussagen unter... - } \\
\text { Q28.1\#2 - Radio- und } \\
\text { Fernsehgebühren sollen } \\
\text { abgeschafft und durch eine } \\
\text { kommerzielle Finanzierung } \\
\text { ersetzt werden. }\end{array}$ & $\begin{array}{l}1=\text { ich habe dazu keine } \\
\text { Meinung }\end{array}$ & $\begin{array}{l}\text { Radio and TV license } \\
\text { fees should be abolished } \\
\text { and replaced by } \\
\text { commerical financing. }\end{array}$ & $\begin{array}{l}1=\mathrm{I} \text { have no opinion on } \\
\text { this matter }\end{array}$ & $\mathrm{x}$ & & & & & & & & & \\
\hline policy.36 & & $\begin{array}{l}\text { Q28.1\#2_43 - Im folgenden } \\
\text { Segment wollen wir gerne } \\
\text { wissen, inwieweit Du } \\
\text { verschiedene politische } \\
\text { Aussagen unter... - } \\
\text { Q28.1\#2 - Der Ausbau } \\
\text { erneuerbarer Energien soll } \\
\text { vom Staat dauerhaft } \\
\text { finanziell gefördert werden. }\end{array}$ & $\begin{array}{l}1=\text { ich habe dazu keine } \\
\text { Meinung }\end{array}$ & $\begin{array}{l}\text { The expansion of } \\
\text { renewable energy } \\
\text { sources should receive } \\
\text { permanent financial } \\
\text { support from the state. }\end{array}$ & $\begin{array}{l}1=\mathrm{I} \text { have no opinion on } \\
\text { this matter }\end{array}$ & $\mathrm{x}$ & & & & & & & & & \\
\hline policy.37 & & $\begin{array}{l}\text { Q28.1\#2_44 - Im folgenden } \\
\text { Segment wollen wir gerne } \\
\text { wissen, inwieweit Du } \\
\text { verschiedene politische } \\
\text { Aussagen unter... - } \\
\text { Q28.1\#2 - Elektromobilität } \\
\text { soll stärker gefördert } \\
\text { werden als konventionelle } \\
\text { Mobilitäts-Technologien. }\end{array}$ & $\begin{array}{l}1=\text { ich habe dazu keine } \\
\text { Meinung }\end{array}$ & $\begin{array}{l}\text { Electromobility should } \\
\text { be promoted more than } \\
\text { conventional mobility } \\
\text { technologies. }\end{array}$ & $\begin{array}{l}1=\mathrm{I} \text { have no opinion on } \\
\text { this matter }\end{array}$ & $\mathrm{x}$ & & & & & & & & & \\
\hline
\end{tabular}




\begin{tabular}{|c|c|c|c|c|c|c|c|c|c|c|c|c|c|c|c|}
\hline VarName & VariableLabel & WordingDE & ValueLabelsDE_Linked & WordingEN & ValueLabelsEN_Linked & L1 & $\mathrm{L} 2$ & L3 & $\mathrm{L} 4$ & L5 & L6 6 & L7 & L8 & L9 & L10 L11 L12 \\
\hline policy.38 & & $\begin{array}{l}\text { Q28.1\#2_45 - Im folgenden } \\
\text { Segment wollen wir gerne } \\
\text { wissen, inwieweit Du } \\
\text { verschiedene politische } \\
\text { Aussagen unter... - } \\
\text { Q28.1\#2 - Es sollen mehr } \\
\text { Fahrradwege auf } \\
\text { öffentlichen Strassen in der } \\
\text { Schweiz gebaut werden. }\end{array}$ & $\begin{array}{l}1=\text { ich habe dazu keine } \\
\text { Meinung }\end{array}$ & $\begin{array}{l}\text { More bike paths should } \\
\text { be built on public roads } \\
\text { in Switzerland. }\end{array}$ & $\begin{array}{l}1=\mathrm{I} \text { have no opinion on } \\
\text { this matter }\end{array}$ & $\mathrm{x}$ & & & & & & & & & \\
\hline policy.39 & & $\begin{array}{l}\text { Q28.1\#2_46 - Im folgenden } \\
\text { Segment wollen wir gerne } \\
\text { wissen, inwieweit Du } \\
\text { verschiedene politische } \\
\text { Aussagen unter... - } \\
\text { Q28.1\#2 - } \text { A-kologische } \\
\text { Landwirtschaft soll stärker } \\
\text { gefördert werden als } \\
\text { konventionelle } \\
\text { Landwirtschaft. }\end{array}$ & $\begin{array}{l}1=\text { ich habe dazu keine } \\
\text { Meinung }\end{array}$ & $\begin{array}{l}\text { Organic agriculture } \\
\text { should be promoted } \\
\text { more than conventional } \\
\text { agriculture. }\end{array}$ & $\begin{array}{l}1=\mathrm{I} \text { have no opinion on } \\
\text { this matter }\end{array}$ & $\mathrm{x}$ & & & & & & & & & \\
\hline policy.40 & & $\begin{array}{l}\text { Q28.1\#2_47 - Im folgenden } \\
\text { Segment wollen wir gerne } \\
\text { wissen, inwieweit Du } \\
\text { verschiedene politische } \\
\text { Aussagen unter... - } \\
\text { Q28.1\#2 - Nahrungsmittel } \\
\text { sollen nur dann importiert } \\
\text { werden können, wenn sie } \\
\text { gemäss Schweizer Standards } \\
\text { bezüglich ökologischer } \\
\text { Nachhaltigkeit, Tierschutz } \\
\text { und Arbeitsrechten } \\
\text { produziert worden sind. }\end{array}$ & $\begin{array}{l}1=\text { ich habe dazu keine } \\
\text { Meinung }\end{array}$ & $\begin{array}{l}\text { Food should only be } \\
\text { allowed to be imported } \\
\text { if it meets Swiss } \\
\text { standards of production } \\
\text { regarding sustainability, } \\
\text { animal rights, and } \\
\text { workers' rights. }\end{array}$ & $\begin{array}{l}1=\mathrm{I} \text { have no opinion on } \\
\text { this matter }\end{array}$ & $\mathrm{x}$ & & & & & & & & & \\
\hline policy.41 & & $\begin{array}{l}\text { Q28.1\#2_48 - Im folgenden } \\
\text { Segment wollen wir gerne } \\
\text { wissen, inwieweit Du } \\
\text { verschiedene politische } \\
\text { Aussagen unter... - } \\
\text { Q28.1\#2 - In der Schweiz } \\
\text { soll es ein bedingungsloses } \\
\text { Grundeinkommen geben. }\end{array}$ & $\begin{array}{l}1=\text { ich habe dazu keine } \\
\text { Meinung }\end{array}$ & $\begin{array}{l}\text { There should be a } \\
\text { universal basic income } \\
\text { in Switzerland. }\end{array}$ & $\begin{array}{l}1=\mathrm{I} \text { have no opinion on } \\
\text { this matter }\end{array}$ & $\mathrm{x}$ & & & & & & & & & \\
\hline policy.42 & & $\begin{array}{l}\text { Q28.1\#2_49 - Im folgenden } \\
\text { Segment wollen wir gerne } \\
\text { wissen, inwieweit Du } \\
\text { versshiedene politische } \\
\text { Aussagen unter... - } \\
\text { Q28.1\#2 - Der Staat soll } \\
\text { mehr Mittel für den sozialen } \\
\text { Wohnungsbau bereitstellen. }\end{array}$ & $\begin{array}{l}1=\text { ich habe dazu keine } \\
\text { Meinung }\end{array}$ & $\begin{array}{l}\text { The state should offer } \\
\text { more resources for the } \\
\text { construction of social } \\
\text { housing. }\end{array}$ & $\begin{array}{l}1=\mathrm{I} \text { have no opinion on } \\
\text { this matter }\end{array}$ & $\mathrm{x}$ & & & & & & & & & \\
\hline policy.43 & & $\begin{array}{l}\text { Q28.1\#2_50 - Im folgenden } \\
\text { Segment wollen wir gerne } \\
\text { wissen, inwieweit Du } \\
\text { verschiedene politische } \\
\text { Aussagen unter... - } \\
\text { Q28.1\#2 - Es soll eine } \\
\text { Obergrenze für ausländische } \\
\text { Studierende an Schweizer } \\
\text { Universitäten geben. }\end{array}$ & $\begin{array}{l}1=\text { ich habe dazu keine } \\
\text { Meinung }\end{array}$ & $\begin{array}{l}\text { There should be an } \\
\text { upper limit to foreign } \\
\text { students at Swiss } \\
\text { universities. }\end{array}$ & $\begin{array}{l}1=\mathrm{I} \text { have no opinion on } \\
\text { this matter }\end{array}$ & $\mathrm{x}$ & & & & & & & & & \\
\hline
\end{tabular}




\begin{tabular}{|c|c|c|c|c|c|c|c|c|c|c|c|c|c|c|c|c|}
\hline VariableLabel & WordingDE & ValueLabelsDE_Linked & WordingEN & ValueLabelsEN_Linked & L1 & $\mathrm{L} 2$ & L3 & $\mathrm{L} 4$ & L5 & L6 & L7 & L8 & L9 & \multicolumn{3}{|c|}{ L10 L11 L12 } \\
\hline policy.44 & $\begin{array}{l}\text { Q28.1\#2_51 - Im folgenden } \\
\text { Segment wollen wir gerne } \\
\text { wissen, inwieweit Du } \\
\text { verschiedene politische } \\
\text { Aussagen unter... - } \\
\text { Q28.1\#2 - Ein } \\
\text { Universitätsstudium soll } \\
\text { grundsätzlich kostenfrei } \\
\text { sein. }\end{array}$ & $\begin{array}{l}1=\text { ich habe dazu keine } \\
\text { Meinung }\end{array}$ & $\begin{array}{l}\text { University studies } \\
\text { should be strictly free of } \\
\text { charge. }\end{array}$ & $\begin{array}{l}1=\mathrm{I} \text { have no opinion on } \\
\text { this matter }\end{array}$ & $\mathrm{x}$ & & & & & & & & & & & \\
\hline instagram & $\begin{array}{l}\text { Q29.2 - Hast Du einen } \\
\text { Instagram-Account? }\end{array}$ & $1=\mathrm{Ja}, 2=$ Nein & $\begin{array}{l}\text { Do you have an } \\
\text { Instagram account? }\end{array}$ & $1=\mathrm{Yes}, 2=\mathrm{No}$ & $\mathrm{x}$ & $\mathrm{x}$ & & & & & & & & & & \\
\hline facebook & $\begin{array}{l}\text { Q29.3 - Hast Du einen } \\
\text { Facebook-Account? }\end{array}$ & $1=\mathrm{Ja}, 2=$ Nein & $\begin{array}{l}\text { Do you have a Facebook } \\
\text { account? }\end{array}$ & $1=\mathrm{Yes}, 2=\mathrm{No}$ & $\mathrm{x}$ & $\mathrm{x}$ & & & & & & & & & & \\
\hline feedback.1 & $\begin{array}{l}\text { Q30.3_1 - Inwiefern treffen } \\
\text { folgenden Aussagen Deiner } \\
\text { Meinungnach zu? - Ich } \\
\text { hatte Spass beim Ausfüllen } \\
\text { des Fragebogens }\end{array}$ & $\begin{array}{l}1=\text { überhaupt nicht } \\
\text { zutreffend, } 2=\text { nicht } \\
\text { zutreffend, } 3=\text { eher nicht } \\
\text { zutreffend, } 4=\text { weder noch, } 5 \\
=\text { eher zutreffend, } 6= \\
\text { zutreffend, } 7=\text { trifft voll und } \\
\text { ganz zu }\end{array}$ & $\begin{array}{l}\text { To what extent do these } \\
\text { statements apply in } \\
\text { your opinion? I had fun } \\
\text { filling out this } \\
\text { questionnaire }\end{array}$ & $\begin{array}{l}1=\text { does not apply at all, } \\
2=\text { does not apply, } 3= \\
\text { does rather not apply, } 4= \\
\text { neither, } 5=\text { rather } \\
\text { applies, } 6=\text { applies, } 7= \\
\text { applies completely (free } \\
\text { translation) }\end{array}$ & $\mathrm{x}$ & $\mathrm{x}$ & $\mathrm{x}$ & $\mathrm{x}$ & $\mathrm{x}$ & $\mathrm{x}$ & $\mathrm{x}$ & $\mathrm{x}$ & $\mathrm{x}$ & $\mathrm{x}$ & $\mathrm{x}$ & $\mathrm{x}$ \\
\hline feedback.2 & $\begin{array}{l}\text { Q30.3_2 - Inwiefern treffen } \\
\text { folgenden Aussagen Deiner } \\
\text { Meinungnach zu? - Viele } \\
\text { Fragen waren sich zu } \\
\text { ähnlich }\end{array}$ & $\begin{array}{l}1=\text { überhaupt nicht } \\
\text { zutreffend, } 2=\text { nicht } \\
\text { zutreffend, } 3=\text { eher nicht } \\
\text { zutreffend, } 4=\text { weder noch, } 5 \\
=\text { eher zutreffend, } 6= \\
\text { zutreffend, } 7=\text { trifft voll und } \\
\text { ganz zu }\end{array}$ & $\begin{array}{l}\text { To what extent do these } \\
\text { statements apply in } \\
\text { your opinion? Many } \\
\text { questions were too } \\
\text { similar }\end{array}$ & $\begin{array}{l}1=\text { does not apply at all, } \\
2=\text { does not apply, } 3= \\
\text { does rather not apply, } 4= \\
\text { neither, } 5=\text { rather } \\
\text { applies, } 6=\text { applies, } 7= \\
\text { applies completely (free } \\
\text { translation) }\end{array}$ & $\mathrm{x}$ & $\mathrm{x}$ & $\mathrm{x}$ & $\mathrm{x}$ & $\mathrm{x}$ & $\mathrm{x}$ & $\mathrm{x}$ & $\mathrm{x}$ & $\mathrm{x}$ & $\mathrm{x}$ & $\mathrm{x}$ & $\mathrm{x}$ \\
\hline feedback.3 & $\begin{array}{l}\text { Q30.3_3 - Inwiefern treffen } \\
\text { folgenden Aussagen Deiner } \\
\text { Meinungnach zu? - Ich } \\
\text { hatte technische Probleme } \\
\text { beim Ausfüllen des } \\
\text { Fragebogens }\end{array}$ & $\begin{array}{l}1=\text { überhaupt nicht } \\
\text { zutreffend, } 2=\text { nicht } \\
\text { zutreffend, } 3=\text { eher nicht } \\
\text { zutreffend, } 4=\text { weder noch, } 5 \\
=\text { eher zutreffend, } 6= \\
\text { zutreffend, } 7=\text { trifft voll und } \\
\text { ganz zu }\end{array}$ & $\begin{array}{l}\text { To what extent do these } \\
\text { statements apply in your } \\
\text { opinion? I had technical } \\
\text { problems while filling } \\
\text { out the questionnaire }\end{array}$ & $\begin{array}{l}1=\text { does not apply at all, } \\
2=\text { does not apply, } 3= \\
\text { does rather not apply, } 4= \\
\text { neither, } 5=\text { rather } \\
\text { applies, } 6=\text { applies, } 7= \\
\text { applies completely (free } \\
\text { translation) }\end{array}$ & $\mathrm{x}$ & $\mathrm{x}$ & $\mathrm{x}$ & $\mathrm{x}$ & $\mathrm{x}$ & $\mathrm{x}$ & $\mathrm{x}$ & $\mathrm{x}$ & $\mathrm{x}$ & $\mathrm{x}$ & $\mathrm{x}$ & $\mathrm{x}$ \\
\hline feedback. 4 & $\begin{array}{l}\text { Q30.3_4 - Inwiefern treffen } \\
\text { folgenden Aussagen Deiner } \\
\text { Meinungnach zu? - Ich } \\
\text { habe mir oft überlegt mit } \\
\text { dem Ausfüllen aufzuhören }\end{array}$ & $\begin{array}{l}1=\text { überhaupt nicht } \\
\text { zutreffend, } 2=\text { nicht } \\
\text { zutreffend, } 3=\text { eher nicht } \\
\text { zutreffend, } 4=\text { weder noch, } 5 \\
=\text { eher zutreffend, } 6= \\
\text { zutreffend, } 7=\text { trifft voll und } \\
\text { ganz zu }\end{array}$ & $\begin{array}{l}\text { To what extent do these } \\
\text { statements apply in } \\
\text { your opinion? I often } \\
\text { considered to stop filling } \\
\text { the questionnaire out }\end{array}$ & $\begin{array}{l}1=\text { does not apply at all, } \\
2=\text { does not apply, } 3= \\
\text { does rather not apply, } 4= \\
\text { neither, } 5=\text { rather } \\
\text { applies, } 6=\text { applies, } 7= \\
\text { applies completely (free } \\
\text { translation) }\end{array}$ & $\mathrm{x}$ & $\mathrm{x}$ & $\mathrm{x}$ & $\mathrm{x}$ & $\mathrm{x}$ & $\mathrm{x}$ & $\mathrm{x}$ & $\mathrm{x}$ & $\mathrm{x}$ & $\mathrm{x}$ & $\mathrm{x}$ & $\mathrm{x}$ \\
\hline feedback.5 & $\begin{array}{l}\text { Q30.3_5 - Inwiefern treffen } \\
\text { folgenden Aussagen Deiner } \\
\text { Meinungnach zu? - Das } \\
\text { Dankeschön von } 25 \text { CHF ist } \\
\text { fair }\end{array}$ & $\begin{array}{l}1=\text { überhaupt nicht } \\
\text { zutreffend, } 2=\text { nicht } \\
\text { zutreffend, } 3=\text { eher nicht } \\
\text { zutreffend, } 4=\text { weder noch, } 5 \\
=\text { eher zutreffend, } 6= \\
\text { zutreffend, } 7=\text { trifft voll und } \\
\text { ganz zu }\end{array}$ & $\begin{array}{l}\text { To what extent do these } \\
\text { statements apply in your } \\
\text { opinion? The thank-you } \\
\text { of } 25 \mathrm{CHF} \text { is fair }\end{array}$ & $\begin{array}{l}1=\text { does not apply at all, } \\
2=\text { does not apply, } 3= \\
\text { does rather not apply, } 4= \\
\text { neither, } 5=\text { rather } \\
\text { applies, } 6=\text { applies, } 7= \\
\text { applies completely (free } \\
\text { translation) }\end{array}$ & $\mathrm{x}$ & $\mathrm{x}$ & $\mathrm{x}$ & $\mathrm{x}$ & $\mathrm{x}$ & $\mathrm{x}$ & $\mathrm{x}$ & $\mathrm{x}$ & $\mathrm{x}$ & $\mathrm{x}$ & $\mathrm{x}$ & $\mathrm{x}$ \\
\hline experience.covid.str & & & & & & & & & & & & & & & $\mathrm{x}$ & $\mathrm{x}$ \\
\hline feedback.str & $\begin{array}{l}\text { Q30.4 - Hast Du noch } \\
\text { Vorschläge, was wir } \\
\text { amFragebogen / an der } \\
\text { Studie verbessern können? }\end{array}$ & & $\begin{array}{l}\text { Do you have suggestions } \\
\text { on how we could } \\
\text { improve the } \\
\text { questionnaire/study? }\end{array}$ & & $\mathrm{x}$ & $\mathrm{x}$ & $\mathrm{x}$ & $\mathrm{x}$ & $\mathrm{x}$ & $\mathrm{x}$ & $\mathrm{x}$ & $\mathrm{x}$ & $\mathrm{x}$ & $\mathrm{x}$ & $\mathrm{x}$ & $\mathrm{x}$ \\
\hline participate.student.intro. & $\begin{array}{l}\text { Q8.7 - Hast Du an einem } \\
\text { der [name removed] Events } \\
\text { teilgenommen? }\end{array}$ & $1=\mathrm{Ja}, 2=\mathrm{Nein}$ & $\begin{array}{l}\text { Did you participate in } \\
\text { any of the Student } \\
\text { Introduction ay events? }\end{array}$ & $1=\mathrm{Yes}, 2=\mathrm{No}$ & $\mathrm{x}$ & & & & & & & & & & & \\
\hline student.association.events.1 & $\begin{array}{l}\text { An welchen der folgenden } \\
\text { [name } \\
\text { removed]-Veranstaltungen } \\
\text { hast Du teilgenommen? }\end{array}$ & & $\begin{array}{l}\text { Which of the following } \\
\text { [name removed]-Events } \\
\text { have you attended? }\end{array}$ & & & $\mathrm{x}$ & $\mathrm{x}$ & $\mathrm{x}$ & $\mathrm{x}$ & $\mathrm{x}$ & $\mathrm{x}$ & $\mathrm{x}$ & $\mathrm{x}$ & $\mathrm{x}$ & & \\
\hline
\end{tabular}




\begin{tabular}{|c|c|c|c|c|c|c|c|c|c|c|c|c|c|c|}
\hline VariableLabel & WordingDE & ValueLabelsDE_Linked & WordingEN & ValueLabelsEN_Linked & L1 & $\mathrm{L} 2$ & L3 & $\mathrm{L} 4$ & L5 & L6 & L7 & L8 & L9 & L10 L11 L12 \\
\hline student.association.event & $\begin{array}{l}\text { An welchen der folgenden } \\
\text { [name } \\
\text { removed]-Veranstaltungen } \\
\text { hast Du teilgenommen? }\end{array}$ & & $\begin{array}{l}\text { Which of the following } \\
\text { [name removed]-Events } \\
\text { have you attended? }\end{array}$ & & & $\mathrm{x}$ & $\mathrm{x}$ & $\mathrm{x}$ & $\mathrm{x}$ & $\mathrm{x}$ & $\mathrm{x}$ & $\mathrm{x}$ & $\mathrm{x}$ & $\mathrm{x}$ \\
\hline student.association.events. 3 & $\begin{array}{l}\text { An welchen der folgenden } \\
\text { [name } \\
\text { removed]-Veranstaltungen } \\
\text { hast Du teilgenommen? }\end{array}$ & & $\begin{array}{l}\text { Which of the following } \\
\text { [name removed]-Events } \\
\text { have you attended? }\end{array}$ & & & $\mathrm{x}$ & $\mathrm{x}$ & $\mathrm{x}$ & $\mathrm{x}$ & $\mathrm{x}$ & $\mathrm{x}$ & $\mathrm{x}$ & $\mathrm{x}$ & $\mathrm{x}$ \\
\hline student.association.event & $\begin{array}{l}\text { An welchen der folgenden } \\
\text { [name } \\
\text { removed]-Veranstaltungen } \\
\text { hast Du teilgenommen? }\end{array}$ & & $\begin{array}{l}\text { Which of the following } \\
\text { [name removed]-Events } \\
\text { have you attended? }\end{array}$ & & & $\mathrm{x}$ & $\mathrm{x}$ & $\mathrm{x}$ & $\mathrm{x}$ & $\mathrm{x}$ & $\mathrm{x}$ & $\mathrm{x}$ & $\mathrm{x}$ & $\mathrm{x}$ \\
\hline student.association.events. 5 & $\begin{array}{l}\text { An welchen der folgenden } \\
\text { [name } \\
\text { removed]-Veranstaltungen } \\
\text { hast Du teilgenommen? }\end{array}$ & & $\begin{array}{l}\text { Which of the following } \\
\text { [name removed]-Events } \\
\text { have you attended? }\end{array}$ & & & $\mathrm{x}$ & $\mathrm{x}$ & $\mathrm{x}$ & $\mathrm{x}$ & $\mathrm{x}$ & $\mathrm{x}$ & $\mathrm{x}$ & $\mathrm{x}$ & $\mathrm{x}$ \\
\hline student.association.event & $\begin{array}{l}\text { An welchen der folgenden } \\
\text { [name } \\
\text { removed]-Veranstaltungen } \\
\text { hast Du teilgenommen? }\end{array}$ & & $\begin{array}{l}\text { Which of the following } \\
\text { [name removed]-Events } \\
\text { have you attended? }\end{array}$ & & & $\mathrm{x}$ & $\mathrm{x}$ & $\mathrm{x}$ & $\mathrm{x}$ & & $\mathrm{x}$ & $\mathrm{x}$ & $\mathrm{x}$ & $\mathrm{x}$ \\
\hline student.association.events. 7 & $\begin{array}{l}\text { An welchen der folgenden } \\
\text { [name } \\
\text { removed]-Veranstaltungen } \\
\text { hast Du teilgenommen? }\end{array}$ & & $\begin{array}{l}\text { Which of the following } \\
\text { [name removed]-Events } \\
\text { have you attended? }\end{array}$ & & & $\mathrm{x}$ & $\mathrm{x}$ & $\mathrm{x}$ & $\mathrm{x}$ & & $\mathrm{x}$ & $\mathrm{x}$ & $\mathrm{x}$ & $\mathrm{x}$ \\
\hline student.association.event & $\begin{array}{l}\text { An welchen der folgenden } \\
\text { [name } \\
\text { removed]-Veranstaltungen } \\
\text { hast Du teilgenommen? }\end{array}$ & & $\begin{array}{l}\text { Which of the following } \\
\text { [name removed]-Events } \\
\text { have you attended? }\end{array}$ & & & & & $\mathrm{x}$ & $\mathrm{x}$ & & $\mathrm{x}$ & $\mathrm{x}$ & $\mathrm{x}$ & $\mathrm{x}$ \\
\hline first.contact.1 & $\begin{array}{l}\text { Q9.2_1 - Mit denjenigen } \\
\text { Mitstudenten, denen ich } \\
\text { mich am nächsten fühle, } \\
\text { habe ich mich zum ersten } \\
\text { Mal unterhalten... - Selected } \\
\text { Choice - am Student } \\
\text { Introduction Day }\end{array}$ & & $\begin{array}{l}\text { I first spoke to my } \\
\text { fellow students to whom } \\
\text { I feel the closest at ... - } \\
\text { Selected Choice - the } \\
\text { Student Introduction } \\
\text { Day }\end{array}$ & & & $\mathrm{x}$ & $\mathrm{x}$ & $\mathrm{x}$ & $\mathrm{x}$ & $\mathrm{x}$ & $\mathrm{x}$ & $\mathrm{x}$ & $\mathrm{x}$ & $\mathrm{x}$ \\
\hline first.contact. 2 & $\begin{array}{l}\text { Q9.2_2 - Mit denjenigen } \\
\text { Mitstudenten, denen ich } \\
\text { mich am nächsten fühle, } \\
\text { habe ich mich zum ersten } \\
\text { Mal unterhalten... - Selected } \\
\text { Choice - in der ersten } \\
\text { Vorlesung am Erstitag }\end{array}$ & & $\begin{array}{l}\text { I first spoke to my } \\
\text { fellow students to whom } \\
\text { I feel the closest at ... - } \\
\text { Selected Choice - in the } \\
\text { first lecture on the first } \\
\text { day. }\end{array}$ & & & $\mathrm{x}$ & $\mathrm{x}$ & $\mathrm{x}$ & $\mathrm{x}$ & $\mathrm{x}$ & $\mathrm{x}$ & $\mathrm{x}$ & $\mathrm{x}$ & $\mathrm{x}$ \\
\hline first.contact. 3 & $\begin{array}{l}\text { Q9.2_3 - Mit denjenigen } \\
\text { Mitstudenten, denen ich } \\
\text { mich am nächsten fühle, } \\
\text { habe ich mich zum ersten } \\
\text { Mal unterhalten... - Selected } \\
\text { Choice - später am Erstitag }\end{array}$ & & $\begin{array}{l}\text { I first spoke to my } \\
\text { fellow students to whom } \\
\text { I feel the closest at ... - } \\
\text { Selected Choice - later } \\
\text { in the first day. }\end{array}$ & & & $\mathrm{x}$ & $\mathrm{x}$ & $\mathrm{x}$ & $\mathrm{x}$ & $\mathrm{x}$ & $\mathrm{x}$ & $\mathrm{x}$ & $\mathrm{x}$ & $\mathrm{x}$ \\
\hline first.contact.4 & $\begin{array}{l}\text { Q9.2_4 - Mit denjenigen } \\
\text { Mitstudenten, denen ich } \\
\text { mich am nächsten fühle, } \\
\text { habe ich mich zum ersten } \\
\text { Mal unterhalten... - Selected } \\
\text { Choice - in der ersten } \\
\text { Studienwoche }\end{array}$ & & $\begin{array}{l}\text { I first spoke to my } \\
\text { fellow students to whom } \\
\text { I feel the closest at ... - } \\
\text { Selected Choice - in the } \\
\text { first week of studies. }\end{array}$ & & & $\mathrm{x}$ & $\mathrm{x}$ & $\mathrm{x}$ & $\mathrm{x}$ & $\mathrm{x}$ & $\mathrm{x}$ & $\mathrm{x}$ & $\mathrm{x}$ & $\mathrm{x}$ \\
\hline first.contact.5 & $\begin{array}{l}\text { Q9.2_5 - Mit denjenigen } \\
\text { Mitstudenten, denen ich } \\
\text { mich am nächsten fühle, } \\
\text { habe ich mich zum ersten } \\
\text { Mal unterhalten... - Selected } \\
\text { Choice - am } \\
\text { Erstiwochenende }\end{array}$ & & $\begin{array}{l}\text { I first spoke to my } \\
\text { fellow students to whom } \\
\text { I feel the closest at ... - } \\
\text { Selected Choice - at the } \\
\text { First Years' weekend. }\end{array}$ & & & $\mathrm{x}$ & $\mathrm{x}$ & $\mathrm{x}$ & $\mathrm{x}$ & $\mathrm{x}$ & $\mathrm{x}$ & $\mathrm{x}$ & $\mathrm{x}$ & $\mathrm{x}$ \\
\hline
\end{tabular}




\begin{tabular}{|c|c|c|c|c|c|c|c|c|c|c|c|c|c|c|}
\hline VariableLabel & WordingDE & ValueLabelsDE_Linked & WordingEN & ValueLabelsEN_Linked & L1 & $\mathrm{L} 2$ & L3 & $\mathrm{L} 4$ & L5 & L6 & L7 & L8 & L9 & L10 L11 L12 \\
\hline first.contact.6 & $\begin{array}{l}\text { Q9.2_6 - Mit denjenigen } \\
\text { Mitstudenten, denen ich } \\
\text { mich am nächsten fühle, } \\
\text { habe ich mich zum ersten } \\
\text { Mal unterhalten... - Selected } \\
\text { Choice - in einer regulären } \\
\text { Vorlesung }\end{array}$ & & $\begin{array}{l}\text { I first spoke to my } \\
\text { fellow students to whom } \\
\text { I feel the closest at ... - } \\
\text { Selected Choice - in a } \\
\text { regular lecture. }\end{array}$ & & & $\mathrm{x}$ & $\mathrm{x}$ & $\mathrm{x}$ & $\mathrm{x}$ & $\mathrm{x}$ & $\mathrm{x}$ & $\mathrm{x}$ & $\mathrm{x}$ & $\mathrm{x}$ \\
\hline first.contact. 7 & $\begin{array}{l}\text { Q9.2_7 - Mit denjenigen } \\
\text { Mitstudenten, denen ich } \\
\text { mich am nächsten fühle, } \\
\text { habe ich mich zum ersten } \\
\text { Mal unterhalten... - Selected } \\
\text { Choice - zu einem anderen } \\
\text { Zeitpunkt: }\end{array}$ & & $\begin{array}{l}\text { I first spoke to my } \\
\text { fellow students to whom } \\
\text { I feel the closest at ... - } \\
\text { Selected Choice - at } \\
\text { another time point: }\end{array}$ & & & $\mathrm{x}$ & $\mathrm{x}$ & $\mathrm{x}$ & $\mathrm{x}$ & $\mathrm{x}$ & $\mathrm{x}$ & $\mathrm{x}$ & $\mathrm{x}$ & $\mathrm{x}$ \\
\hline first.contact.7.str & $\begin{array}{l}\text { Q9.2_7_TEXT - Mit } \\
\text { denjenigen Mitstudenten, } \\
\text { denen ich mich am nächsten } \\
\text { fühle, habe ich mich zum } \\
\text { ersten Mal unterhalten... - } \\
\text { zu einem anderen } \\
\text { Zeitpunkt: - Text }\end{array}$ & & $\begin{array}{l}\text { I first spoke to my } \\
\text { fellow students to whom } \\
\text { I feel the closest at ... - } \\
\text { Selected Choice - at } \\
\text { another time point: } \\
\text { TEXT }\end{array}$ & & & $\mathrm{x}$ & $\mathrm{x}$ & $\mathrm{x}$ & $\mathrm{x}$ & $\mathrm{x}$ & $\mathrm{x}$ & $\mathrm{x}$ & $\mathrm{x}$ & $\mathrm{x}$ \\
\hline student.association.events.1 & $\begin{array}{l}\text { An welchen der folgenden } \\
\text { [name } \\
\text { removed]-Veranstaltungen } \\
\text { hast Du teilgenommen? }\end{array}$ & & $\begin{array}{l}\text { Which of the following } \\
\text { [name removed]-Events } \\
\text { have you attended? }\end{array}$ & & & $\mathrm{x}$ & $\mathrm{x}$ & $\mathrm{x}$ & $\mathrm{x}$ & & $\mathrm{x}$ & $\mathrm{x}$ & $\mathrm{x}$ & $\mathrm{x}$ \\
\hline student.association.event & $\begin{array}{l}\text { An welchen der folgenden } \\
\text { [name } \\
\text { removed]-Veranstaltungen } \\
\text { hast Du teilgenommen? }\end{array}$ & & $\begin{array}{l}\text { Which of the following } \\
\text { [name removed]-Events } \\
\text { have you attended? }\end{array}$ & & & $\mathrm{x}$ & $\mathrm{x}$ & & $\mathrm{x}$ & & $\mathrm{x}$ & $\mathrm{x}$ & $\mathrm{x}$ & \\
\hline student.association.events.3 & $\begin{array}{l}\text { An welchen der folgenden } \\
\text { [name } \\
\text { removed]-Veranstaltungen } \\
\text { hast Du teilgenommen? }\end{array}$ & & $\begin{array}{l}\text { Which of the following } \\
\text { [name removed]-Events } \\
\text { have you attended? }\end{array}$ & & & $\mathrm{x}$ & $\mathrm{X}$ & $\mathrm{X}$ & $\mathrm{x}$ & & $\mathrm{x}$ & $\mathrm{x}$ & $\mathrm{X}$ & \\
\hline student.association.event & $\begin{array}{l}\text { An welchen der folgenden } \\
\text { [name } \\
\text { removed]-Veranstaltungen } \\
\text { hast Du teilgenommen? }\end{array}$ & & $\begin{array}{l}\text { Which of the following } \\
\text { [name removed]-Events } \\
\text { have you attended? }\end{array}$ & & & $\mathrm{x}$ & $\mathrm{x}$ & $\mathrm{x}$ & $\mathrm{x}$ & & $\mathrm{x}$ & $\mathrm{x}$ & $\mathrm{x}$ & \\
\hline student.association.events.5 & $\begin{array}{l}\text { An welchen der folgenden } \\
\text { [name } \\
\text { removed]-Veranstaltungen } \\
\text { hast Du teilgenommen? }\end{array}$ & & $\begin{array}{l}\text { Which of the following } \\
\text { [name removed]-Events } \\
\text { have you attended? }\end{array}$ & & & & $\mathrm{x}$ & & $\mathrm{x}$ & & $\mathrm{x}$ & $\mathrm{x}$ & $\mathrm{x}$ & \\
\hline student.association.event & $\begin{array}{l}\text { An welchen der folgenden } \\
\text { [name } \\
\text { removed]-Veranstaltungen } \\
\text { hast Du teilgenommen? }\end{array}$ & & $\begin{array}{l}\text { Which of the following } \\
\text { [name removed]-Events } \\
\text { have you attended? }\end{array}$ & & & & $\mathrm{x}$ & & $\mathrm{x}$ & & $\mathrm{x}$ & $\mathrm{x}$ & $\mathrm{x}$ & \\
\hline student.association.events. 7 & $\begin{array}{l}\text { An welchen der folgenden } \\
\text { [name } \\
\text { removed]-Veranstaltungen } \\
\text { hast Du teilgenommen? }\end{array}$ & & $\begin{array}{l}\text { Which of the following } \\
\text { [name removed]-Events } \\
\text { have you attended? }\end{array}$ & & & & $\mathrm{x}$ & $\mathrm{x}$ & $\mathrm{x}$ & & $\mathrm{x}$ & $\mathrm{x}$ & $\mathrm{x}$ & \\
\hline student.association.event & $\begin{array}{l}\text { An welchen der folgenden } \\
\text { [name } \\
\text { removed]-Veranstaltungen } \\
\text { hast Du teilgenommen? }\end{array}$ & & $\begin{array}{l}\text { Which of the following } \\
\text { [name removed]-Events } \\
\text { have you attended? }\end{array}$ & & & & & & $\mathrm{x}$ & & $\mathrm{x}$ & $\mathrm{x}$ & $\mathrm{x}$ & \\
\hline student.association.events.9 & $\begin{array}{l}\text { An welchen der folgenden } \\
\text { [name } \\
\text { removed]-Veranstaltungen } \\
\text { hast Du teilgenommen? }\end{array}$ & & $\begin{array}{l}\text { Which of the following } \\
\text { [name removed]-Events } \\
\text { have you attended? }\end{array}$ & & & & & & $\mathrm{x}$ & & $\mathrm{x}$ & $\mathrm{x}$ & $\mathrm{x}$ & \\
\hline student.association.event & $\begin{array}{l}\text { An welchen der folgenden } \\
\text { [name } \\
\text { removed]-Veranstaltungen } \\
\text { hast Du teilgenommen? }\end{array}$ & & $\begin{array}{l}\text { Which of the following } \\
\text { [name removed]-Events } \\
\text { have you attended? }\end{array}$ & & & & & & $\mathrm{x}$ & & $\mathrm{x}$ & $\mathrm{x}$ & $\mathrm{x}$ & \\
\hline
\end{tabular}




\begin{tabular}{|c|c|c|c|c|c|c|c|c|c|c|c|c|c|c|c|c|c|}
\hline VarName & VariableLabel & WordingDE & ValueLabelsDE_Linked & WordingEN & ValueLabelsEN_Linked & L1 & $\mathrm{L} 2$ & L3 & $\mathrm{L} 4$ & L5 & $\mathrm{L} 6$ & L7 & L8 & L9 & L10 & L11 & $1 \mathrm{~L} 12$ \\
\hline student.association.events. & & $\begin{array}{l}\text { An welchen der folgenden } \\
\text { [name } \\
\text { removed]-Veranstaltungen } \\
\text { hast Du teilgenommen? }\end{array}$ & & $\begin{array}{l}\text { Which of the following } \\
\text { [name removed]-Events } \\
\text { have you attended? }\end{array}$ & & & & & & $\mathrm{x}$ & & $\mathrm{x}$ & $\mathrm{x}$ & & & & \\
\hline student.association.event & & $\begin{array}{l}\text { An welchen der folgenden } \\
\text { [name } \\
\text { removed]-Veranstaltungen } \\
\text { hast Du teilgenommen? }\end{array}$ & & $\begin{array}{l}\text { Which of the following } \\
\text { [name removed]-Events } \\
\text { have you attended? }\end{array}$ & & & & & & $\mathrm{x}$ & & $\mathrm{x}$ & $\mathrm{x}$ & & & & \\
\hline student.association.events. & .13 & $\begin{array}{l}\text { An welchen der folgenden } \\
\text { [name } \\
\text { removed]-Veranstaltungen } \\
\text { hast Du teilgenommen? }\end{array}$ & & $\begin{array}{l}\text { Which of the following } \\
\text { [name removed]-Events } \\
\text { have you attended? }\end{array}$ & & & & & & & & $\mathrm{x}$ & $\mathrm{x}$ & & & & \\
\hline student.association.event & & $\begin{array}{l}\text { An welchen der folgenden } \\
\text { [name } \\
\text { removed]-Veranstaltungen } \\
\text { hast Du teilgenommen? }\end{array}$ & & $\begin{array}{l}\text { Which of the following } \\
\text { [name removed]-Events } \\
\text { have you attended? }\end{array}$ & & & & & & & & $\mathrm{x}$ & & & & & \\
\hline student.association.events. & .15 & $\begin{array}{l}\text { An welchen der folgenden } \\
\text { [name } \\
\text { removed]-Veranstaltungen } \\
\text { hast Du teilgenommen? }\end{array}$ & & $\begin{array}{l}\text { Which of the following } \\
\text { [name removed]-Events } \\
\text { have you attended? }\end{array}$ & & & & & & & & $\mathrm{x}$ & & & & & \\
\hline student.association.event & & $\begin{array}{l}\text { An welchen der folgenden } \\
\text { [name } \\
\text { removed]-Veranstaltungen } \\
\text { hast Du teilgenommen? }\end{array}$ & & $\begin{array}{l}\text { Which of the following } \\
\text { [name removed]-Events } \\
\text { have you attended? }\end{array}$ & & & $\mathrm{x}$ & $\mathrm{x}$ & $\mathrm{x}$ & $\mathrm{x}$ & & $\mathrm{x}$ & $\mathrm{x}$ & $\mathrm{x}$ & $\mathrm{x}$ & & \\
\hline student.association.materi & $\begin{array}{l}\text { iallsage of study } \\
\text { material }\end{array}$ & $\begin{array}{l}\text { Hast Du bereits die von der } \\
\text { [name removed] online zur } \\
\text { Verfügung gestellten } \\
\text { Materialien zur } \\
\text { Prüfungsvorbereitung } \\
\text { verwendet (Altklausuren, } \\
\text { Prüfungsprotokolle von } \\
\text { mündlichen Prüfungen } \\
\text { etc.)? }\end{array}$ & $1=\mathrm{Ja}, 2=$ Nein & $\begin{array}{l}\text { Have you already used } \\
\text { the study material } \\
\text { (previous exams, oral } \\
\text { examination protocols, } \\
\text { etc.) provided by [name } \\
\text { removed]? }\end{array}$ & $1=$ Yes, $2=$ No & & $\mathrm{x}$ & $\mathrm{x}$ & $\mathrm{x}$ & $\mathrm{x}$ & $\mathrm{x}$ & $\mathrm{x}$ & $\mathrm{x}$ & $\mathrm{x}$ & $\mathrm{x}$ & & \\
\hline learning.h & & $\begin{array}{l}\text { Wie viele Stunden lernst Du } \\
\text { in einer normalen } \\
\text { Semesterwoche (ausserhalb } \\
\text { von Vorlesungen und } \\
\text { Übungsstunden)? }\end{array}$ & & $\begin{array}{l}\text { How many hours do you } \\
\text { study in a normal week } \\
\text { during the semester } \\
\text { (excluding lectures, } \\
\text { seminars, etc.)? }\end{array}$ & & & $\mathrm{x}$ & $\mathrm{x}$ & $\mathrm{x}$ & $\mathrm{x}$ & $\mathrm{x}$ & $\mathrm{x}$ & $\mathrm{x}$ & $\mathrm{x}$ & $\mathrm{x}$ & $\mathrm{x}$ & $\mathrm{X}$ \\
\hline study.2 & Study Item 2 & $\begin{array}{l}\text { In welchem Masse würdest } \\
\text { Du den folgenden Aussagen } \\
\text { zustimmen? Ich sollte mehr } \\
\text { lernen }\end{array}$ & $\begin{array}{l}1=\text { überhaupt nicht } \\
\text { einverstanden, } 2=\text { nicht } \\
\text { einverstanden, } 3=\text { eher nicht } \\
\text { einverstanden, } 4=\text { weder } \\
\text { noch, } 5=\text { eher einverstanden, } \\
6=\text { einverstanden, } 7=\text { völlig } \\
\text { einverstanden }\end{array}$ & $\begin{array}{l}\text { To what extent would } \\
\text { you agree with the } \\
\text { following statements? I } \\
\text { should study more. }\end{array}$ & $\begin{array}{l}1=\text { don't agree at all, } 2= \\
\text { don't agree, } 3=\text { rather } \\
\text { not agree, } 4=\text { neither, } 5 \\
=\text { rather agree, } 6=\text { agree, } \\
7=\text { agree completely }\end{array}$ & & $\mathrm{x}$ & $\mathrm{x}$ & $\mathrm{x}$ & $\mathrm{x}$ & $\mathrm{x}$ & $\mathrm{x}$ & $\mathrm{x}$ & $\mathrm{x}$ & $\mathrm{x}$ & $\mathrm{x}$ & $\mathrm{x}$ \\
\hline study. 3 & Study Item 3 & $\begin{array}{l}\text { In welchem Masse würdest } \\
\text { Du den folgenden Aussagen } \\
\text { zustimmen? Ich sollte } \\
\text { effizienter lernen }\end{array}$ & $\begin{array}{l}1=\text { überhaupt nicht } \\
\text { einverstanden, } 2=\text { nicht } \\
\text { einverstanden, } 3=\text { eher nicht } \\
\text { einverstanden, } 4=\text { weder } \\
\text { noch, } 5=\text { eher einverstanden, } \\
6=\text { einverstanden, } 7=\text { völlig } \\
\text { einverstanden }\end{array}$ & $\begin{array}{l}\text { To what extent would } \\
\text { you agree with the } \\
\text { following statements? I } \\
\text { should study more } \\
\text { efficiently. }\end{array}$ & $\begin{array}{l}1=\text { don't agree at all, } 2= \\
\text { don't agree, } 3=\text { rather } \\
\text { not agree, } 4=\text { neither, } 5 \\
=\text { rather agree, } 6=\text { agree, } \\
7=\text { agree completely }\end{array}$ & & $\mathrm{x}$ & $\mathrm{x}$ & $\mathrm{x}$ & $\mathrm{x}$ & $\mathrm{x}$ & $\mathrm{x}$ & $\mathrm{x}$ & $\mathrm{x}$ & $\mathrm{x}$ & $\mathrm{x}$ & $\mathrm{x}$ \\
\hline study.4 & Study Item 4 & $\begin{array}{l}\text { In welchem Masse würdest } \\
\text { Du den folgenden Aussagen } \\
\text { zustimmen? Ich denke, dass } \\
\text { ich generell mehr lerne, als } \\
\text { die Mehrheit meiner } \\
\text { Mitstudierenden }\end{array}$ & $\begin{array}{l}1=\text { überhaupt nicht } \\
\text { einverstanden, } 2=\text { nicht } \\
\text { einverstanden, } 3=\text { eher nicht } \\
\text { einverstanden, } 4=\text { weder } \\
\text { noch, } 5=\text { eher einverstanden, } \\
6=\text { einverstanden, } 7=\text { völlig } \\
\text { einverstanden }\end{array}$ & $\begin{array}{l}\text { To what extent would } \\
\text { you agree with the } \\
\text { following statements? I } \\
\text { think that I generally } \\
\text { study more than the } \\
\text { majority of my fellow } \\
\text { students. }\end{array}$ & $\begin{array}{l}1=\text { don't agree at all, } 2= \\
\text { don't agree, } 3=\text { rather } \\
\text { not agree, } 4=\text { neither, } 5 \\
=\text { rather agree, } 6=\text { agree, } \\
7=\text { agree completely }\end{array}$ & & $\mathrm{x}$ & $\mathrm{x}$ & $\mathrm{x}$ & $\mathrm{x}$ & $\mathrm{x}$ & $\mathrm{x}$ & $\mathrm{x}$ & $\mathrm{x}$ & $\mathrm{x}$ & $\mathrm{x}$ & $\mathrm{x}$ \\
\hline
\end{tabular}




\begin{tabular}{|c|c|c|c|c|c|c|c|c|c|c|c|c|c|c|c|}
\hline VarName & VariableLabel & WordingDE & ValueLabelsDE_Linked & WordingEN & ValueLabelsEN_Linked & $\mathrm{L} 1$ & $\mathrm{~L} 2$ & L3 & $\mathrm{L} 4$ & L5 & L6 & L7 & L8 & L9 & L10 L11 L12 \\
\hline learning.where.1 & & $\begin{array}{l}\text { Wo lernst Du } \\
\text { normalerweise? }\end{array}$ & $\begin{array}{l}0=\text { Zuhause, } 1=\text { Cafés, } 0= \\
\text { Universität, } 1=\text { Bibliothek, } 0 \\
=\text { Zug, } 1=\text { bei Freunden, } 0= \\
\text { Anderes }\end{array}$ & $\begin{array}{l}\text { Where do you normally } \\
\text { study? }\end{array}$ & $\begin{array}{l}0=\text { Home, } 1=\text { Cafe, } 0= \\
\text { University, } 1=\text { Library, } 0 \\
=\text { Train, } 1=\text { At a } \\
\text { friend's, } 0=\text { Other }\end{array}$ & & $\mathrm{x}$ & $\mathrm{x}$ & $\mathrm{x}$ & $\mathrm{x}$ & $\mathrm{x}$ & $\mathrm{x}$ & $\mathrm{x}$ & $\mathrm{x}$ & $\mathrm{x}$ \\
\hline learning.where.2 & & $\begin{array}{l}\text { Wo lernst } \mathrm{Du} \\
\text { normalerweise? }\end{array}$ & $\begin{array}{l}0=\text { Zuhause, } 1=\text { Cafés, } 0= \\
\text { Universität, } 1=\text { Bibliothek, } 0 \\
=\text { Zug, } 1=\text { bei Freunden, } 0= \\
\text { Anderes }\end{array}$ & $\begin{array}{l}\text { Where do you normally } \\
\text { study? }\end{array}$ & $\begin{array}{l}0=\text { Home, } 1=\text { Cafe, } 0= \\
\text { University, } 1=\text { Library, } 0 \\
=\text { Train, } 1=\text { At a } \\
\text { friend's, } 0=\text { Other }\end{array}$ & & $\mathrm{x}$ & $\mathrm{x}$ & $\mathrm{x}$ & $\mathrm{x}$ & $\mathrm{x}$ & $\mathrm{x}$ & $\mathrm{x}$ & $\mathrm{x}$ & $\mathrm{x}$ \\
\hline learning.where.3 & & $\begin{array}{l}\text { Wo lernst Du } \\
\text { normalerweise? }\end{array}$ & $\begin{array}{l}0=\text { Zuhause, } 1=\text { Cafés, } 0= \\
\text { Universität, } 1=\text { Bibliothek, } 0 \\
=\text { Zug, } 1=\text { bei Freunden, } 0= \\
\text { Anderes }\end{array}$ & $\begin{array}{l}\text { Where do you normally } \\
\text { study? }\end{array}$ & $\begin{array}{l}0=\text { Home, } 1=\text { Cafe, } 0= \\
\text { University, } 1=\text { Library, } 0 \\
=\text { Train, } 1=\text { At a } \\
\text { friend's, } 0=\text { Other }\end{array}$ & & $\mathrm{x}$ & $\mathrm{x}$ & $\mathrm{x}$ & $\mathrm{x}$ & $\mathrm{x}$ & $\mathrm{x}$ & $\mathrm{x}$ & $\mathrm{x}$ & $\mathrm{x}$ \\
\hline learning.where.4 & & $\begin{array}{l}\text { Wo lernst Du } \\
\text { normalerweise? }\end{array}$ & $\begin{array}{l}0=\text { Zuhause, } 1=\text { Cafés, } 0= \\
\text { Universität, } 1=\text { Bibliothek, } 0 \\
=\text { Zug, } 1=\text { bei Freunden, } 0= \\
\text { Anderes }\end{array}$ & $\begin{array}{l}\text { Where do you normally } \\
\text { study? }\end{array}$ & $\begin{array}{l}0=\text { Home, } 1=\text { Cafe, } 0= \\
\text { University, } 1=\text { Library, } 0 \\
=\text { Train, } 1=\text { At a } \\
\text { friend's, } 0=\text { Other }\end{array}$ & & $\mathrm{x}$ & $\mathrm{x}$ & $\mathrm{x}$ & $\mathrm{x}$ & $\mathrm{x}$ & $\mathrm{x}$ & $\mathrm{x}$ & $\mathrm{x}$ & $\mathrm{x}$ \\
\hline learning.where.5 & & $\begin{array}{l}\text { Wo lernst Du } \\
\text { normalerweise? }\end{array}$ & $\begin{array}{l}0=\text { Zuhause, } 1=\text { Cafés, } 0= \\
\text { Universität, } 1=\text { Bibliothek, } 0 \\
=\text { Zug, } 1=\text { bei Freunden, } 0= \\
\text { Anderes }\end{array}$ & $\begin{array}{l}\text { Where do you normally } \\
\text { study? }\end{array}$ & $\begin{array}{l}0=\text { Home, } 1=\text { Cafe, } 0= \\
\text { University, } 1=\text { Library, } 0 \\
=\text { Train, } 1=\text { At a } \\
\text { friend's, } 0=\text { Other }\end{array}$ & & $\mathrm{x}$ & $\mathrm{x}$ & $\mathrm{x}$ & $\mathrm{x}$ & $\mathrm{x}$ & $\mathrm{x}$ & $\mathrm{x}$ & $\mathrm{x}$ & $\mathrm{x}$ \\
\hline learning.where.6 & & $\begin{array}{l}\text { Wo lernst Du } \\
\text { normalerweise? }\end{array}$ & $\begin{array}{l}0=\text { Zuhause, } 1=\text { Cafés, } 0= \\
\text { Universität, } 1=\text { Bibliothek, } 0 \\
=\text { Zug, } 1=\text { bei Freunden, } 0= \\
\text { Anderes }\end{array}$ & $\begin{array}{l}\text { Where do you normally } \\
\text { study? }\end{array}$ & $\begin{array}{l}0=\text { Home, } 1=\text { Cafe, } 0= \\
\text { University, } 1=\text { Library, } 0 \\
=\text { Train, } 1=\text { At a } \\
\text { friend's, } 0=\text { Other }\end{array}$ & & $\mathrm{X}$ & $\mathrm{x}$ & $\mathrm{x}$ & $\mathrm{x}$ & $\mathrm{x}$ & $\mathrm{x}$ & $\mathrm{x}$ & $\mathrm{x}$ & $\mathrm{X}$ \\
\hline learning.where.7 & & $\begin{array}{l}\text { Wo lernst Du } \\
\text { normalerweise? }\end{array}$ & $\begin{array}{l}0=\text { Zuhause, } 1=\text { Cafés, } 0= \\
\text { Universität, } 1=\text { Bibliothek, } 0 \\
=\text { Zug, } 1=\text { bei Freunden, } 0= \\
\text { Anderes }\end{array}$ & $\begin{array}{l}\text { Where do you normally } \\
\text { study? }\end{array}$ & $\begin{array}{l}0=\text { Home, } 1=\text { Cafe, } 0= \\
\text { University, } 1=\text { Library, } 0 \\
=\text { Train, } 1=\text { At a } \\
\text { friend's, } 0=\text { Other }\end{array}$ & & $\mathrm{x}$ & $\mathrm{x}$ & $\mathrm{x}$ & $\mathrm{x}$ & $\mathrm{x}$ & $\mathrm{x}$ & $\mathrm{x}$ & $\mathrm{x}$ & $\mathrm{x}$ \\
\hline learning.where.7.str & & $\begin{array}{l}\text { Wo lernst Du } \\
\text { normalerweise? (other text) }\end{array}$ & $\begin{array}{l}\mathrm{NA}=\text { Zuhause, } \mathrm{NA}=\text { Cafés, } \\
\mathrm{NA}=\text { Universität, } \mathrm{NA}= \\
\text { Bibliothek, NA = Zug, NA }= \\
\text { bei Freunden, NA = Anderes }\end{array}$ & $\begin{array}{l}\text { Where do you normally } \\
\text { study? TEXT }\end{array}$ & $\mathrm{NA}=\mathrm{NA}$ & & $\mathrm{x}$ & $\mathrm{x}$ & $\mathrm{x}$ & $\mathrm{x}$ & $\mathrm{x}$ & $\mathrm{x}$ & $\mathrm{x}$ & $\mathrm{x}$ & $\mathrm{x}$ \\
\hline like.studying & & $\begin{array}{l}\text { Wie gefällt Dir Dein } \\
\text { Studium an [university } \\
\text { name]? }\end{array}$ & $\begin{array}{l}1=\text { sehr schlecht, } 2= \\
\text { schlecht, } 3=\text { mittel, } 4=\text { gut } \\
5=\text { very good }\end{array}$ & $\begin{array}{l}\text { How do you like your } \\
\text { studies at [university } \\
\text { name]? }\end{array}$ & $\begin{array}{l}1=\text { very bad, } 2=\text { bad, } 3 \\
=\text { medium, } 4=\text { good, } 5= \\
\text { very good }\end{array}$ & & $\mathrm{x}$ & $\mathrm{x}$ & $\mathrm{x}$ & $\mathrm{x}$ & $\mathrm{x}$ & $\mathrm{x}$ & $\mathrm{x}$ & $\mathrm{x}$ & $\begin{array}{lll}x & x & x\end{array}$ \\
\hline gpa.estimate & & $\begin{array}{l}\text { Mit welcher Durchschnitts - } \\
\text { Note, denkst Du, wirst du } \\
\text { die Basisjahrprüfungen } \\
\text { abschneiden? }\end{array}$ & $\begin{array}{l}1=0.0,2=0.1,3=0.2,4= \\
0.3,5=0.4,6=0.5,7=0.6, \\
8=0.7,9=0.8,10=0.9,11 \\
=1.0,12=1.1,13=1.2,14 \\
=1.3,15=1.4,16=1.5,17 \\
=1.6,18=1.7,19=1.8,20 \\
=1.9,21=2.0,22=2.1,23 \\
=2.2,24=2.3,25=2.4,26 \\
=2.5,27=2.6,28=2.7,29 \\
=2.8,30=2.9,31=3.0,32 \\
=3.1,33=3.2,34=3.3,35 \\
=3.4,36=3.5,37=3.6,38 \\
=3.7,39=3.8,40=3.9,41 \\
=4.0,42=4.1,43=4.2,44 \\
=4.3,45=4.4,46=4.5,47 \\
=4.6,48=4.7,49=4.8,50 \\
=4.9,51=5.0,52=5.1,53 \\
=5.2,54=5.3,55=5.4,56 \\
=5.5,57=5.6,58=5.7,59 \\
=5.8,60=5.9,1=6.0\end{array}$ & $\begin{array}{l}\text { What average grade do } \\
\text { you expect to finish the } \\
\text { Basisprüfung with? }\end{array}$ & $\begin{array}{l}1=0.0,2=0.1,3=0.2, \\
4=0.3,5=0.4,6=0.5, \\
7=0.6,8=0.7,9=0.8, \\
10=0.9,11=1.0,12= \\
1.1,13=1.2,14=1.3,15 \\
=1.4,16=1.5,17=1.6, \\
18=1.7,19=1.8,20= \\
1.9,21=2.0,22=2.1,23 \\
=2.2,24=2.3,25=2.4, \\
26=2.5,27=2.6,28= \\
2.7,29=2.8,30=2.9,31 \\
=3.0,32=3.1,33=3.2, \\
34=3.3,35=3.4,36= \\
3.5,37=3.6,38=3.7,39 \\
=3.8,40=3.9,41=4.0, \\
42=4.1,43=4.2,44= \\
4.3,45=4.4,46=4.5,47 \\
=4.6,48=4.7,49=4.8, \\
50=4.9,51=5.0,52= \\
5.1,53=5.2,54=5.3,55 \\
=5.4,56=5.5,57=5.6, \\
58=5.7,59=5.8,60= \\
5.9,1=6.0\end{array}$ & & $\mathrm{x}$ & $\mathrm{x}$ & $\mathrm{x}$ & $\mathrm{x}$ & $\mathrm{x}$ & & & & \\
\hline
\end{tabular}




\begin{tabular}{|c|c|c|c|c|c|c|c|c|c|c|c|c|c|c|c|c|c|}
\hline VarName & VariableLabel & WordingDE & ValueLabelsDE_Linked & WordingEN & ValueLabelsEN_Linked & L1 & $\mathrm{L} 2$ & L3 & L4 & L5 & L6 & L7 & L8 & L9 & & 5 L11 & L12 \\
\hline Final.exam.2 & $\begin{array}{l}\text { View of final } \\
\text { exam } 2\end{array}$ & $\begin{array}{l}\text { Ich fühle mich gestresst, } \\
\text { wenn ich an die } \\
\text { Basisprüfung denke. }\end{array}$ & $\begin{array}{l}1=\text { trifft überhaupt nicht } \mathrm{zu}, \\
2=\text { trifft nicht zu, } 3=\text { trifft } \\
\text { eher nicht } \mathrm{zu}, 4=\text { weder } \\
\text { noch, } 5=\text { eher zutreffend, } 6 \\
=\text { trifft zu, } 7=\text { trifft voll und } \\
\text { ganz zu }\end{array}$ & $\begin{array}{l}\text { I feel stressed when I } \\
\text { think about the final } \\
\text { exam. }\end{array}$ & $\begin{array}{l}1=\text { does not apply at all, } \\
2=\text { does not apply, } 3= \\
\text { does rather not apply, } 4= \\
\text { neither, } 5=\text { rather } \\
\text { applies, } 6=\text { applies, } 7= \\
\text { applies completely }\end{array}$ & & $\mathrm{x}$ & $\mathrm{x}$ & $\mathrm{x}$ & $\mathrm{x}$ & $\mathrm{x}$ & & & & & & \\
\hline Final.exam.3 & $\begin{array}{l}\text { View of final } \\
\text { exam } 3\end{array}$ & $\begin{array}{l}\text { Mir ist völlig klar, welche } \\
\text { Themen ich beherrschen } \\
\text { musst, um die Basisprüfung } \\
\text { zu bestehen. }\end{array}$ & $\begin{array}{l}1=\text { trifft überhaupt nicht zu, } \\
2=\text { trifft nicht zu, } 3=\text { trifft } \\
\text { eher nicht zu, } 4=\text { weder } \\
\text { noch, } 5=\text { eher zutreffend, } 6 \\
=\text { trifft zu, } 7=\text { trifft voll und } \\
\text { ganz zu }\end{array}$ & $\begin{array}{l}\text { It is clear to me which } \\
\text { topics I have to have a } \\
\text { good command of, to } \\
\text { pass the final exam. }\end{array}$ & $\begin{array}{l}1=\text { does not apply at all, } \\
2=\text { does not apply, } 3= \\
\text { does rather not apply, } 4= \\
\text { neither, } 5=\text { rather } \\
\text { applies, } 6=\text { applies, } 7= \\
\text { applies completely }\end{array}$ & & $\mathrm{x}$ & $\mathrm{x}$ & $\mathrm{x}$ & $\mathrm{x}$ & $\mathrm{x}$ & & & & & & \\
\hline Final.exam.4 & $\begin{array}{l}\text { View of final } \\
\text { exam } 4\end{array}$ & $\begin{array}{l}\text { Die Studierenden am } \\
\text { [department name removed] } \\
\text { unterstützen sich } \\
\text { gegenseitig bei der } \\
\text { Vorbereitung auf die } \\
\text { Basisprüfung. }\end{array}$ & $\begin{array}{l}1=\text { trifft überhaupt nicht zu, } \\
2=\text { trifft nicht zu, } 3=\text { trifft } \\
\text { eher nicht zu, } 4=\text { weder } \\
\text { noch, } 5=\text { eher zutreffend, } 6 \\
=\text { trifft zu, } 7=\text { trifft voll und } \\
\text { ganz zu }\end{array}$ & $\begin{array}{l}\text { The students at } \\
\text { [department name } \\
\text { removed] support each } \\
\text { other in the preparation } \\
\text { for the final exam. }\end{array}$ & $\begin{array}{l}1=\text { does not apply at all, } \\
2=\text { does not apply, } 3= \\
\text { does rather not apply, } 4= \\
\text { neither, } 5=\text { rather } \\
\text { applies, } 6=\text { applies, } 7= \\
\text { applies completely }\end{array}$ & & $\mathrm{x}$ & $\mathrm{x}$ & $\mathrm{x}$ & $\mathrm{x}$ & $\mathrm{x}$ & & & & & & \\
\hline intention.quit & $\begin{array}{l}\text { Intention to } \\
\text { quit }\end{array}$ & $\begin{array}{l}\text { Ich habe mir oft überlegt } \\
\text { das Studium am } \\
\text { [department] abzubrechen } \\
\text { (z.B. zu einem anderen } \\
\text { [name removed] } \\
\text { Departement wechseln, die } \\
\text { Uni wechseln oder aufhören } \\
\text { zu studieren) }\end{array}$ & $\begin{array}{l}1=\text { stimmt überhaupt nicht, } \\
2=\text { stimmt nicht, } 3=\text { stimmt } \\
\text { eher nicht, } 4=\text { weder noch, } 5 \\
=\text { stimmt eher, } 6=\text { stimmt, } 7 \\
=\text { stimmt voll und ganz }\end{array}$ & $\begin{array}{l}\text { I have frequently } \\
\text { considered quitting my } \\
\text { studies at [department] } \\
\text { (e.g. to change to } \\
\text { another [name removed] } \\
\text { departement, a different } \\
\text { university or to quit } \\
\text { university) }\end{array}$ & $\begin{array}{l}1=\text { does not apply at all, } \\
2=\text { does not apply, } 3= \\
\text { does rather not apply, } 4= \\
\text { neither, } 5=\text { rather } \\
\text { applies, } 6=\text { applies, } 7= \\
\text { applies completely }\end{array}$ & & $\mathrm{x}$ & $\mathrm{x}$ & $\mathrm{x}$ & $\mathrm{x}$ & $\mathrm{x}$ & $\mathrm{x}$ & $\mathrm{x}$ & $\mathrm{x}$ & $\mathrm{x}$ & $\mathrm{x}$ & $\mathrm{x}$ \\
\hline reason.quit & $\begin{array}{l}\text { Reason for } \\
\text { intention to } \\
\text { quit }\end{array}$ & $\begin{array}{l}\text { Warum hast Du darüber } \\
\text { nachgedacht das Studium } \\
\text { am [department name } \\
\text { removed] abzubrechen? }\end{array}$ & & $\begin{array}{l}\text { Why have you } \\
\text { considered quitting your } \\
\text { studies at [department } \\
\text { name removed]? }\end{array}$ & & & $\mathrm{x}$ & $\mathrm{x}$ & $\mathrm{x}$ & $\mathrm{x}$ & $\mathrm{x}$ & $\mathrm{x}$ & $\mathrm{x}$ & $\mathrm{x}$ & $\mathrm{x}$ & $\mathrm{x}$ & $\mathrm{x}$ \\
\hline gender.perceptions.cohort. & $\begin{array}{l}\text {. Fender } \\
\text { perceptions in } \\
\text { cohort item } 1\end{array}$ & $\begin{array}{l}\text { Nun geht es darum, ob die } \\
\text { männlichen und weiblichen } \\
\text { Studenten in deinem Fach } \\
\text { sich in verschiedenen } \\
\text { Hinsichten } \\
\text { unterscheiden. Bitte gib an, } \\
\text { inwiefern Du den folgenden } \\
\text { Aussagen zustimmst. Meine } \\
\text { männlichen } \\
\text { Mitstudierenden verstehen } \\
\text { Inhalte leichter als die } \\
\text { weiblichen Studenten. }\end{array}$ & $\begin{array}{l}1=\text { stimmt überhaupt nicht, } \\
2=\text { stimmt nicht, } 3=\text { stimmt } \\
\text { eher nicht, } 4=\text { weder noch, } 5 \\
=\text { stimmt eher, } 6=\text { stimmt, } 7 \\
=\text { stimmt voll und ganz }\end{array}$ & $\begin{array}{l}\text { Now it is about whether } \\
\text { the male and female } \\
\text { students in your subject } \\
\text { differ in some regards. } \\
\text { Please indicate to what } \\
\text { extent you agree with } \\
\text { the following } \\
\text { statements: My male } \\
\text { fellow students } \\
\text { understand the contents } \\
\text { easier than the female } \\
\text { students. }\end{array}$ & $\begin{array}{l}1=\text { don't agree at all, } 2= \\
\text { don't agree, } 3=\text { rather } \\
\text { not agree, } 4=\text { neither, } 5 \\
=\text { rather agree, } 6=\text { agree, } \\
7=\text { agree completely }\end{array}$ & & $\mathrm{x}$ & $\mathrm{x}$ & $\mathrm{x}$ & $\mathrm{x}$ & $\mathrm{x}$ & $\mathrm{x}$ & $\mathrm{x}$ & $\mathrm{x}$ & $\mathrm{x}$ & & \\
\hline gender.perceptions.cohor & $\begin{array}{l}\text { Gender } \\
\text { perceptions in } \\
\text { cohort item } 2\end{array}$ & $\begin{array}{l}\text { Meine weiblichen } \\
\text { Mitstudierenden verstehen } \\
\text { Inhalte leichter als die } \\
\text { männlichen Studenten }\end{array}$ & $\begin{array}{l}1=\text { stimmt überhaupt nicht, } \\
2=\text { stimmt nicht, } 3=\text { stimmt } \\
\text { eher nicht, } 4=\text { weder noch, } 5 \\
=\text { stimmt eher, } 6=\text { stimmt, } 7 \\
=\text { stimmt voll und ganz }\end{array}$ & $\begin{array}{l}\text { My female fellow } \\
\text { students understand the } \\
\text { contents easier than the } \\
\text { male students. }\end{array}$ & $\begin{array}{l}1=\text { don't agree at all, } 2= \\
\text { don't agree, } 3=\text { rather } \\
\text { not agree, } 4=\text { neither, } 5 \\
=\text { rather agree, } 6=\text { agree, } \\
7=\text { agree completely }\end{array}$ & & $\mathrm{x}$ & $\mathrm{x}$ & $\mathrm{x}$ & $\mathrm{x}$ & $\mathrm{x}$ & $\mathrm{x}$ & $\mathrm{x}$ & $\mathrm{x}$ & $\mathrm{x}$ & & \\
\hline gender.perceptions.cohort. & $\begin{array}{l}\text {.8xender } \\
\text { perceptions in } \\
\text { cohort item } 3\end{array}$ & $\begin{array}{l}\text { Meine männlichen } \\
\text { Mitstudierenden nehmen ihr } \\
\text { Studium ernster als die } \\
\text { weiblichen Studenten (e.g. } \\
\text { lernen mehr, schwänzen } \\
\text { seltener Vorlesungen, etc.) }\end{array}$ & $\begin{array}{l}1=\text { stimmt überhaupt nicht, } \\
2=\text { stimmt nicht, } 3=\text { stimmt } \\
\text { eher nicht, } 4=\text { weder noch, } 5 \\
=\text { stimmt eher, } 6=\text { stimmt, } 7 \\
=\text { stimmt voll und ganz }\end{array}$ & $\begin{array}{l}\text { My male fellow-students } \\
\text { take their studies more } \\
\text { seriously than the } \\
\text { female students (e.g. } \\
\text { they study more, skip } \\
\text { fewer lectures, etc.) }\end{array}$ & $\begin{array}{l}1=\text { don't agree at all, } 2= \\
\text { don't agree, } 3=\text { rather } \\
\text { not agree, } 4=\text { neither, } 5 \\
=\text { rather agree, } 6=\text { agree, } \\
7=\text { agree completely }\end{array}$ & & $\mathrm{x}$ & $\mathrm{x}$ & $\mathrm{x}$ & $\mathrm{x}$ & $\mathrm{x}$ & $\mathrm{x}$ & $\mathrm{x}$ & $\mathrm{x}$ & $\mathrm{x}$ & & \\
\hline gender.perceptions.cohor & $\begin{array}{l}\text { Gender } \\
\text { perceptions in } \\
\text { cohort item } 4\end{array}$ & $\begin{array}{l}\text { Meine weiblichen } \\
\text { Mitstudierenden nehmen ihr } \\
\text { Studium ernster als die } \\
\text { männlichen Studenten (e.g. } \\
\text { lernen mehr, schwänzen } \\
\text { seltener Vorlesungen, etc.) }\end{array}$ & $\begin{array}{l}1=\text { stimmt überhaupt nicht, } \\
2=\text { stimmt nicht, } 3=\text { stimmt } \\
\text { eher nicht, } 4=\text { weder noch, } 5 \\
=\text { stimmt eher, } 6=\text { stimmt, } 7 \\
=\text { stimmt voll und ganz }\end{array}$ & $\begin{array}{l}\text { My female fellow } \\
\text { students are take their } \\
\text { studies more seriously } \\
\text { than the male students } \\
\text { (e.g. they study more, } \\
\text { skip fewer lectures, etc.) }\end{array}$ & $\begin{array}{l}1=\text { don't agree at all, } 2= \\
\text { don't agree, } 3=\text { rather } \\
\text { not agree, } 4=\text { neither, } 5 \\
=\text { rather agree, } 6=\text { agree, } \\
7=\text { agree completely }\end{array}$ & & $\mathrm{x}$ & $\mathrm{x}$ & $\mathrm{x}$ & $\mathrm{x}$ & $\mathrm{x}$ & $\mathrm{x}$ & $\mathrm{x}$ & $\mathrm{x}$ & $\mathrm{x}$ & & \\
\hline
\end{tabular}




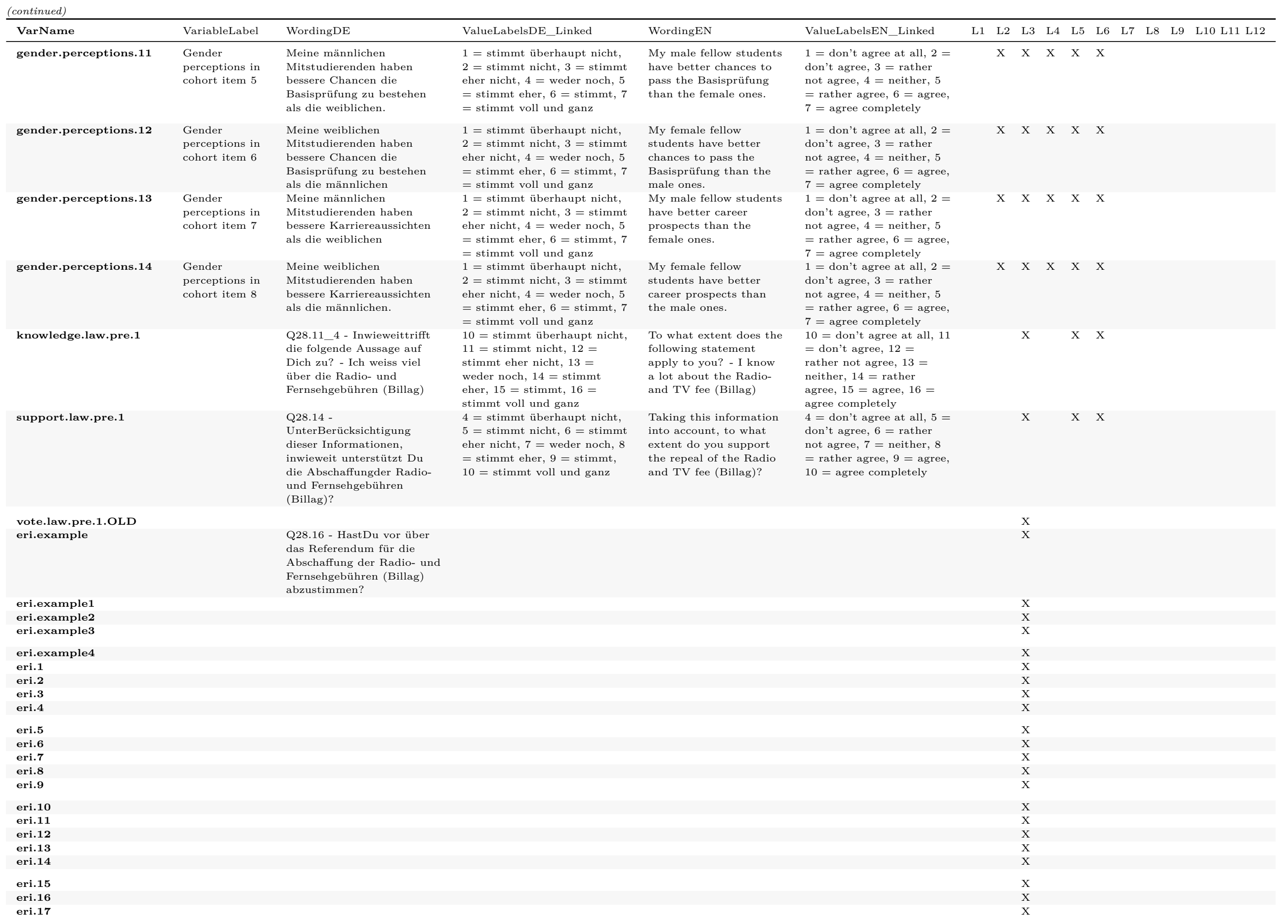




\begin{tabular}{|c|c|c|c|c|c|c|c|c|c|c|c|c|c|c|}
\hline VariableLabel & WordingDE & ValueLabelsDE_Linked & WordingEN & ValueLabelsEN_Linked & L1 & L2 & L3 & $\mathrm{L} 4$ & L5 & L6 & L7 & L8 & L9 & L10 L11 L12 \\
\hline eri.18 & & & & & & & $\mathrm{x}$ & & & & & & & \\
\hline eri.19 & & & & & & & $\mathrm{x}$ & & & & & & & \\
\hline eri.20 & & & & & & & $\mathrm{x}$ & & & & & & & \\
\hline eri.21 & & & & & & & $\mathrm{x}$ & & & & & & & \\
\hline eri.22 & & & & & & & $\mathrm{x}$ & & & & & & & \\
\hline eri.23 & & & & & & & $\mathrm{x}$ & & & & & & & \\
\hline eri.24 & & & & & & & $\mathrm{x}$ & & & & & & & \\
\hline eri.25 & & & & & & & $\mathrm{x}$ & & & & & & & \\
\hline eri.26 & & & & & & & $\mathrm{x}$ & & & & & & & \\
\hline eri. 27 & & & & & & & $\mathrm{x}$ & & & & & & & \\
\hline eri.28 & & & & & & & $\mathrm{x}$ & & & & & & & \\
\hline eri.29 & & & & & & & $\mathrm{x}$ & & & & & & & \\
\hline eri.30 & & & & & & & $\mathrm{x}$ & & & & & & & \\
\hline student.association.events.9 & $\begin{array}{l}\text { An welchen der folgenden } \\
\text { [name } \\
\text { removed]-Veranstaltungen } \\
\text { hast Du teilgenommen? - } \\
\text { [name removed] }\end{array}$ & & $\begin{array}{l}\text { Which of the following } \\
\text { [name removed]-Events } \\
\text { have you attended? - } \\
\text { Selected Choice - [name } \\
\text { removed] }\end{array}$ & & & & $\mathrm{x}$ & $\mathrm{x}$ & & & $\mathrm{x}$ & $\mathrm{x}$ & $\mathrm{x}$ & \\
\hline student.association.event & $\begin{array}{l}\text { An welchen der folgenden } \\
\text { [name } \\
\text { removed]-Veranstaltungen } \\
\text { hast Du teilgenommen? - } \\
\text { [name removed] }\end{array}$ & & $\begin{array}{l}\text { Which of the following } \\
\text { [name removed]-Events } \\
\text { have you attended? - } \\
\text { Selected Choice - [name } \\
\text { removed] }\end{array}$ & & & & $\mathrm{x}$ & & $\mathrm{x}$ & & $\mathrm{x}$ & $\mathrm{x}$ & $\mathrm{x}$ & \\
\hline student.association.events.11 & $\begin{array}{l}\text { An welchen der folgenden } \\
\text { [name } \\
\text { removed]-Veranstaltungen } \\
\text { hast Du teilgenommen? - } \\
\text { [name removed] }\end{array}$ & & $\begin{array}{l}\text { Which of the following } \\
\text { [name removed]-Events } \\
\text { have you attended? - } \\
\text { Selected Choice - [name } \\
\text { removed] }\end{array}$ & & & & $\mathrm{x}$ & & $\mathrm{x}$ & & $\mathrm{x}$ & $\mathrm{x}$ & $\mathrm{x}$ & \\
\hline student.association.event & $\begin{array}{l}\text { An welchen der folgenden } \\
\text { [name } \\
\text { removed]-Veranstaltungen } \\
\text { hast Du teilgenommen? - } \\
\text { [name removed] }\end{array}$ & & $\begin{array}{l}\text { Which of the following } \\
\text { [name removed]-Events } \\
\text { have you attended? - } \\
\text { Selected Choice - [name } \\
\text { removed] }\end{array}$ & & & & $\mathrm{x}$ & & $\mathrm{x}$ & & $\mathrm{x}$ & $\mathrm{x}$ & $\mathrm{x}$ & \\
\hline student.association.events.13 & $\begin{array}{l}\text { An welchen der folgenden } \\
\text { [name } \\
\text { removed]-Veranstaltungen } \\
\text { hast Du teilgenommen? - } \\
\text { [name removed] }\end{array}$ & & $\begin{array}{l}\text { Which of the following } \\
\text { [name removed]-Events } \\
\text { have you attended? - } \\
\text { Selected Choice - [name } \\
\text { removed] }\end{array}$ & & & & $\mathrm{x}$ & & $\mathrm{x}$ & & $\mathrm{x}$ & $\mathrm{x}$ & $\mathrm{x}$ & \\
\hline student.association.event & $\begin{array}{l}\text { An welchen der folgenden } \\
\text { [name } \\
\text { removed]-Veranstaltungen } \\
\text { hast Du teilgenommen? - } \\
\text { [name removed] }\end{array}$ & & $\begin{array}{l}\text { Which of the following } \\
\text { [name removed]-Events } \\
\text { have you attended? - } \\
\text { Selected Choice - [name } \\
\text { removed] }\end{array}$ & & & & $\mathrm{x}$ & & $\mathrm{x}$ & & $\mathrm{x}$ & $\mathrm{x}$ & $\mathrm{x}$ & \\
\hline student.association.events.15 & $\begin{array}{l}\text { An welchen der folgenden } \\
\text { [name } \\
\text { removed]-Veranstaltungen } \\
\text { hast Du teilgenommen? - } \\
\text { [name removed] }\end{array}$ & & $\begin{array}{l}\text { Which of the following } \\
\text { [name removed]-Events } \\
\text { have you attended? - } \\
\text { Selected Choice - [name } \\
\text { removed] }\end{array}$ & & & & $\mathrm{x}$ & & $\mathrm{x}$ & & $\mathrm{x}$ & $\mathrm{x}$ & $\mathrm{x}$ & \\
\hline student.association.event & $\begin{array}{l}\text { An welchen der folgenden } \\
\text { [name } \\
\text { removed]-Veranstaltungen } \\
\text { hast Du teilgenommen? - } \\
\text { [name removed] }\end{array}$ & & $\begin{array}{l}\text { Which of the following } \\
\text { [name removed]-Events } \\
\text { have you attended? - } \\
\text { Selected Choice - [name } \\
\text { removed] }\end{array}$ & & & & $\mathrm{x}$ & & $\mathrm{x}$ & & $\mathrm{x}$ & $\mathrm{x}$ & $\mathrm{x}$ & \\
\hline student.association.events. 17 & $\begin{array}{l}\text { An welchen der folgenden } \\
\text { [name } \\
\text { removed]-Veranstaltungen } \\
\text { hast Du teilgenommen? - } \\
\text { [name removed] }\end{array}$ & & $\begin{array}{l}\text { Which of the following } \\
\text { [name removed]-Events } \\
\text { have you attended? - } \\
\text { Selected Choice - [name } \\
\text { removed] }\end{array}$ & & & & $\mathrm{x}$ & & $\mathrm{x}$ & & $\mathrm{x}$ & $\mathrm{x}$ & $\mathrm{x}$ & \\
\hline
\end{tabular}




\begin{tabular}{|c|c|c|c|c|c|c|c|c|c|c|c|c|c|c|}
\hline VariableLabel & WordingDE & ValueLabelsDE_Linked & WordingEN & ValueLabelsEN_Linked & L1 & $\mathrm{L} 2$ & L3 & $\mathrm{L} 4$ & L5 & L6 & L7 & L8 & L9 & L10 L11 L12 \\
\hline student.association.event & $\begin{array}{l}\text { An welchen der folgenden } \\
\text { [name } \\
\text { removed]-Veranstaltungen } \\
\text { hast Du teilgenommen? - } \\
\text { [name removed] }\end{array}$ & & $\begin{array}{l}\text { Which of the following } \\
\text { [name removed]-Events } \\
\text { have you attended? - } \\
\text { Selected Choice - [name } \\
\text { removed] }\end{array}$ & & & & $\mathrm{x}$ & & $\mathrm{x}$ & & $\mathrm{x}$ & $\mathrm{x}$ & $\mathrm{x}$ & \\
\hline student.association.events.19 & $\begin{array}{l}\text { An welchen der folgenden } \\
\text { [name } \\
\text { removed]-Veranstaltungen } \\
\text { hast Du teilgenommen? - } \\
\text { [name removed] }\end{array}$ & & $\begin{array}{l}\text { Which of the following } \\
\text { [name removed]-Events } \\
\text { have you attended? - } \\
\text { Selected Choice - [name } \\
\text { removed] }\end{array}$ & & & & $\mathrm{x}$ & & $\mathrm{X}$ & & $\mathrm{x}$ & $\mathrm{x}$ & $\mathrm{x}$ & \\
\hline student.association.event & $\begin{array}{l}\text { An welchen der folgenden } \\
\text { [name } \\
\text { removed]-Veranstaltungen } \\
\text { hast Du teilgenommen? - } \\
\text { [name removed] }\end{array}$ & & $\begin{array}{l}\text { Which of the following } \\
\text { [name removed]-Events } \\
\text { have you attended? - } \\
\text { Selected Choice - [name } \\
\text { removed] }\end{array}$ & & & & $\mathrm{x}$ & & $\mathrm{x}$ & & $\mathrm{x}$ & $\mathrm{x}$ & $\mathrm{x}$ & \\
\hline student.association.events.21 & $\begin{array}{l}\text { An welchen der folgenden } \\
\text { [name } \\
\text { removed]-Veranstaltungen } \\
\text { hast Du teilgenommen? - } \\
\text { [name removed] }\end{array}$ & & $\begin{array}{l}\text { Which of the following } \\
\text { [name removed]-Events } \\
\text { have you attended? - } \\
\text { Selected Choice - [name } \\
\text { removed] }\end{array}$ & & & & $\mathrm{x}$ & & $\mathrm{x}$ & & $\mathrm{x}$ & $\mathrm{x}$ & $\mathrm{x}$ & \\
\hline student.association.event & $\begin{array}{l}\text { An welchen der folgenden } \\
\text { [name } \\
\text { removed]-Veranstaltungen } \\
\text { hast Du teilgenommen? - } \\
\text { [name removed] }\end{array}$ & & $\begin{array}{l}\text { Which of the following } \\
\text { [name removed]-Events } \\
\text { have you attended? - } \\
\text { Selected Choice - [name } \\
\text { removed] }\end{array}$ & & & & $\mathrm{x}$ & & $\mathrm{x}$ & & $\mathrm{x}$ & $\mathrm{x}$ & $\mathrm{x}$ & \\
\hline student.association.events. 23 & $\begin{array}{l}\text { An welchen der folgenden } \\
\text { [name } \\
\text { removed]-Veranstaltungen } \\
\text { hast Du teilgenommen? - } \\
\text { [name removed] }\end{array}$ & & $\begin{array}{l}\text { Which of the following } \\
\text { [name removed]-Events } \\
\text { have you attended? - } \\
\text { Selected Choice - [name } \\
\text { removed] }\end{array}$ & & & & $\mathrm{x}$ & & $\mathrm{x}$ & & $\mathrm{x}$ & & $\mathrm{x}$ & \\
\hline student.association.event & $\begin{array}{l}\text { An welchen der folgenden } \\
\text { [name } \\
\text { removed]-Veranstaltungen } \\
\text { hast Du teilgenommen? - } \\
\text { [name removed] }\end{array}$ & & $\begin{array}{l}\text { Which of the following } \\
\text { [name removed]-Events } \\
\text { have you attended? - } \\
\text { Selected Choice - [name } \\
\text { removed] }\end{array}$ & & & & $\mathrm{x}$ & & $\mathrm{x}$ & & $\mathrm{x}$ & & $\mathrm{x}$ & \\
\hline student.association.events. 25 & $\begin{array}{l}\text { An welchen der folgenden } \\
\text { [name } \\
\text { removed]-Veranstaltungen } \\
\text { hast Du teilgenommen? - } \\
\text { [name removed] }\end{array}$ & & $\begin{array}{l}\text { Which of the following } \\
\text { [name removed]-Events } \\
\text { have you attended? - } \\
\text { Selected Choice - [name } \\
\text { removed] }\end{array}$ & & & & $\mathrm{x}$ & & $\mathrm{x}$ & & $\mathrm{x}$ & & $\mathrm{x}$ & \\
\hline student.association.event & $\begin{array}{l}\text { An welchen der folgenden } \\
\text { [name } \\
\text { removed]-Veranstaltungen } \\
\text { hast Du teilgenommen? - } \\
\text { [name removed] }\end{array}$ & & $\begin{array}{l}\text { Which of the following } \\
\text { [name removed]-Events } \\
\text { have you attended? - } \\
\text { Selected Choice - [name } \\
\text { removed] }\end{array}$ & & & & $\mathrm{x}$ & & $\mathrm{x}$ & & $\mathrm{x}$ & & $\mathrm{x}$ & \\
\hline student.association.events.27 & $\begin{array}{l}\text { An welchen der folgenden } \\
\text { [name } \\
\text { removed]-Veranstaltungen } \\
\text { hast Du teilgenommen? - } \\
\text { [name removed] }\end{array}$ & & $\begin{array}{l}\text { Which of the following } \\
\text { [name removed]-Events } \\
\text { have you attended? - } \\
\text { Selected Choice - [name } \\
\text { removed] }\end{array}$ & & & & & & $\mathrm{x}$ & & $\mathrm{x}$ & & $\mathrm{x}$ & \\
\hline student.association.event & $\begin{array}{l}\text { An welchen der folgenden } \\
\text { [name } \\
\text { removed]-Veranstaltungen } \\
\text { hast Du teilgenommen? - } \\
\text { [name removed] }\end{array}$ & & $\begin{array}{l}\text { Which of the following } \\
\text { [name removed]-Events } \\
\text { have you attended? - } \\
\text { Selected Choice - [name } \\
\text { removed] }\end{array}$ & & & & & & $\mathrm{x}$ & & $\mathrm{x}$ & & & \\
\hline student.association.events.29 & $\begin{array}{l}\text { An welchen der folgenden } \\
\text { [name } \\
\text { removed]-Veranstaltungen } \\
\text { hast Du teilgenommen? - } \\
\text { [name removed] }\end{array}$ & & $\begin{array}{l}\text { Which of the following } \\
\text { [name removed]-Events } \\
\text { have you attended? - } \\
\text { Selected Choice - [name } \\
\text { removed] }\end{array}$ & & & & & & $\mathrm{x}$ & & $\mathrm{x}$ & & & \\
\hline
\end{tabular}




\begin{tabular}{|c|c|c|c|c|c|c|c|c|c|c|c|c|c|c|}
\hline VariableLabel & WordingDE & ValueLabelsDE_Linked & WordingEN & ValueLabelsEN_Linked & L1 & $\mathrm{L} 2$ & L3 & L4 & L5 & $\mathrm{L} 6$ & L7 & L8 & L9 & L10 L11 L12 \\
\hline student.association.event & $\begin{array}{l}\text { An welchen der folgenden } \\
\text { [name } \\
\text { removed]-Veranstaltungen } \\
\text { hast Du teilgenommen? - } \\
\text { [name removed] }\end{array}$ & & $\begin{array}{l}\text { Which of the following } \\
\text { [name removed]-Events } \\
\text { have you attended? - } \\
\text { Selected Choice - [name } \\
\text { removed] }\end{array}$ & & & & & & $\mathrm{x}$ & & $\mathrm{x}$ & & & \\
\hline student.association.events. 31 & $\begin{array}{l}\text { An welchen der folgenden } \\
\text { [name } \\
\text { removed]-Veranstaltungen } \\
\text { hast Du teilgenommen? - } \\
\text { [name removed] }\end{array}$ & & $\begin{array}{l}\text { Which of the following } \\
\text { [name removed]-Events } \\
\text { have you attended? - } \\
\text { Selected Choice - [name } \\
\text { removed] }\end{array}$ & & & & & & $\mathrm{x}$ & & $\mathrm{x}$ & & & \\
\hline student.association.event & $\begin{array}{l}\text { An welchen der folgenden } \\
\text { [name } \\
\text { removed]-Veranstaltungen } \\
\text { hast Du teilgenommen? - } \\
\text { [name removed] }\end{array}$ & & $\begin{array}{l}\text { Which of the following } \\
\text { [name removed]-Events } \\
\text { have you attended? - } \\
\text { Selected Choice - [name } \\
\text { removed] }\end{array}$ & & & & & & $\mathrm{x}$ & & $\mathrm{x}$ & & & \\
\hline student.association.events.33 & $\begin{array}{l}\text { An welchen der folgenden } \\
\text { [name } \\
\text { removed]-Veranstaltungen } \\
\text { hast Du teilgenommen? - } \\
\text { [name removed] }\end{array}$ & & $\begin{array}{l}\text { Which of the following } \\
\text { [name removed]-Events } \\
\text { have you attended? - } \\
\text { Selected Choice - [name } \\
\text { removed] }\end{array}$ & & & & & & $\mathrm{x}$ & & $\mathrm{x}$ & & & \\
\hline student.association.event & $\begin{array}{l}\text { An welchen der folgenden } \\
\text { [name } \\
\text { removed]-Veranstaltungen } \\
\text { hast Du teilgenommen? - } \\
\text { [name removed] }\end{array}$ & & $\begin{array}{l}\text { Which of the following } \\
\text { [name removed]-Events } \\
\text { have you attended? - } \\
\text { Selected Choice - [name } \\
\text { removed] }\end{array}$ & & & & & & $\mathrm{x}$ & & $\mathrm{x}$ & & & \\
\hline student.association.events. 35 & $\begin{array}{l}\text { An welchen der folgenden } \\
\text { [name } \\
\text { removed]-Veranstaltungen } \\
\text { hast Du teilgenommen? - } \\
\text { [name removed] }\end{array}$ & & $\begin{array}{l}\text { Which of the following } \\
\text { [name removed]-Events } \\
\text { have you attended? - } \\
\text { Selected Choice - [name } \\
\text { removed] }\end{array}$ & & & & & & $\mathrm{x}$ & & $\mathrm{x}$ & & & \\
\hline student.association.event & $\begin{array}{l}\text { An welchen der folgenden } \\
\text { [name } \\
\text { removed]-Veranstaltungen } \\
\text { hast Du teilgenommen? - } \\
\text { [name removed] }\end{array}$ & & $\begin{array}{l}\text { Which of the following } \\
\text { [name removed]-Events } \\
\text { have you attended? - } \\
\text { Selected Choice - [name } \\
\text { removed] }\end{array}$ & & & & & & $\mathrm{x}$ & & & & & \\
\hline student.association.events. 37 & $\begin{array}{l}\text { Q235_5 - An welchen der } \\
\text { folgenden [name } \\
\text { removed]-Veranstaltungen } \\
\text { hast Du teilgenommen? - } \\
\text { Selected Choice - Andere }\end{array}$ & $\begin{array}{l}\mathrm{NA}=\text { Veranstaltung } 1, \mathrm{NA}= \\
\text { Veranstaltung } 2, \mathrm{NA}= \\
\text { Veranstaltung } 3 \ldots .\end{array}$ & $\begin{array}{l}\text { Which of the following } \\
\text { [name removed]-Events } \\
\text { have you attended? - } \\
\text { Selected Choice - Other }\end{array}$ & $\begin{array}{l}\mathrm{NA}=\text { Event } 1, \mathrm{NA}= \\
\text { Event } 2, \mathrm{NA}=\text { Event } 3 \ldots\end{array}$ & & & & & $\mathrm{x}$ & & & & & \\
\hline student.association.event & $\begin{array}{l}\text { Q235_45_TEXT - An } \\
\text { welchen der folgenden } \\
\text { [name } \\
\text { removed]-Veranstaltungen } \\
\text { hast Du teilgenommen? - } \\
\text { Andere - Text }\end{array}$ & $\begin{array}{l}\mathrm{NA}=\text { Veranstaltung } 1, \mathrm{NA}= \\
\text { Veranstaltung } 2, \mathrm{NA}= \\
\text { Veranstaltung } 3 \ldots .\end{array}$ & $\begin{array}{l}\text { Which of the following } \\
\text { [name removed]-Events } \\
\text { have you attended? - } \\
\text { Other - Text }\end{array}$ & $\begin{array}{l}\mathrm{NA}=\text { Event } 1, \mathrm{NA}= \\
\text { Event } 2, \mathrm{NA}=\text { Event } 3 \ldots\end{array}$ & & $\mathrm{x}$ & $\mathrm{x}$ & $\mathrm{x}$ & $\mathrm{x}$ & $\mathrm{x}$ & $\mathrm{x}$ & $\mathrm{x}$ & $\mathrm{x}$ & $\mathrm{x}$ \\
\hline uni.belonging. 1 & $\begin{array}{l}\text { Q218_10 - Manchmal habe } \\
\text { ich das Gefühl, dass ich an } \\
\text { die [university name] } \\
\text { gehöre, und manchmal } \\
\text { nicht. - trifft gar nicht } \\
\text { zu:trifft voll und ganz zu }\end{array}$ & & $\begin{array}{l}\text { Sometimes I feel like I } \\
\text { belong at the [university } \\
\text { name], sometimes I } \\
\text { don't. }\end{array}$ & & & & $\mathrm{x}$ & $\mathrm{x}$ & & & & & & \\
\hline uni.belonging. 2 & $\begin{array}{l}\text { Q220_10 - Wenn es gerade } \\
\text { schlecht läuft, habe ich das } \\
\text { Gefühl, dass ich vielleicht } \\
\text { doch nicht an die } \\
\text { [university name] gehöre. - } \\
\text { trifft gar nicht zu:trifft voll } \\
\text { und ganz zu }\end{array}$ & & $\begin{array}{l}\text { When things aren't } \\
\text { going well I sometimes } \\
\text { feel like I might belong } \\
\text { at the [university name] } \\
\text { after all. }\end{array}$ & & & & $\mathrm{x}$ & $\mathrm{x}$ & & & & & & \\
\hline
\end{tabular}




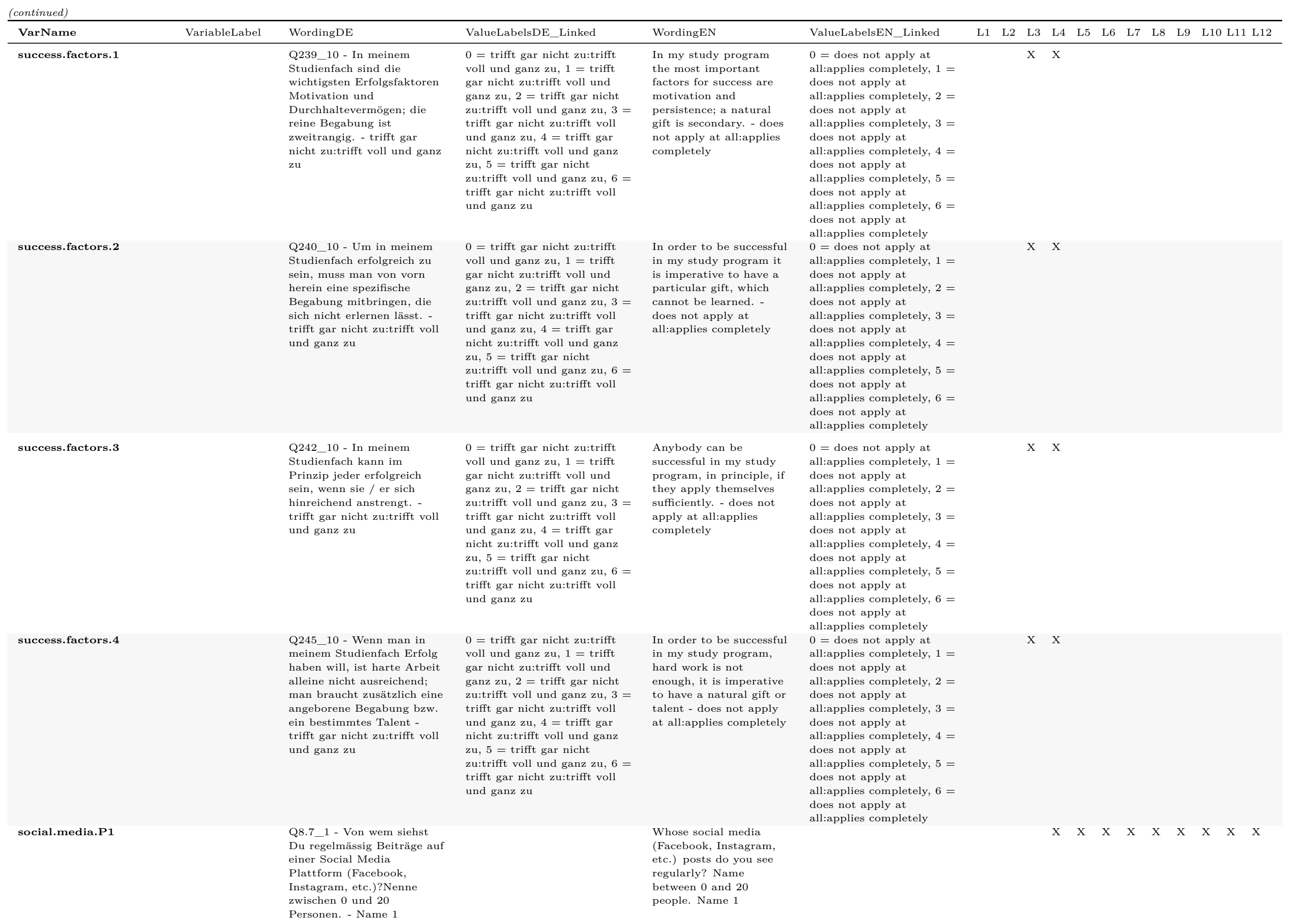




\section{vote.law.post}

Q27.19 - HastDu über

Referendum für die

Abschaffung der Radio- und

abgestimmt?

media.use.political.1

Q27.13 4 - Früher in der

Umfrage, haben wir danach

gefragt welche

Medienquellen Du nutzt um politische Informationen zu sammeln. Jetzt wollen wir wissen wie häufig, D durchschnittlich, diese Quellen genutzt hast, im Zeitraum zwischen dieser Umfrage und der Vorherigen (Mitte Dezember), um nformationen zu dem Referendum für die Abschaffung der Radio- und Fernsehgebühren (Billag-Gebühren) zu sammeln. - Wie häufig hast Du Referendum-bezogene Teile der Zeitung gelesen? Q27.13_5 - Früher in der Umfrage, haben wir danach gefragt welche

Medienquellen Du nutzt um politische Informationen zu sammeln. Jetzt wollen w wissen wie häufig, D durchschnittlich, diese Quellen genutzt hast, im Zeitraum zwischen dieser Umfrage und der Vorherige (Mitte Dezember), um Informationen zu dem Referendum für die
Abschaffung der Radio- und (Billag-Gebühren) zu

(Billag-Gebühren) zu Du dir
sammeln. - Wie hăufig Du dir

Referendum-bezogene achrichten am Fernsehe
$1=$ Mehrmals pro Tag, $2=$ Einmal pro Tag, $3=5-6 \mathrm{ma}$ in der Woche, $4=3-4 \mathrm{mal}$ in der Woche, $5=1-2$ mal in der Woche, $6=$ Weniger als $1-2$ mal in der Woche, $7=\mathrm{Nie}$

Earlier in the survey, we asked which media sources you use information. Now we would like to know how often on average you used these sources in the time period between this survey and the previous $(<$ previous referendum month $>$ ), to collect information on the referendum <closest upcoming referendum $>$. - How often did you read referendum-focused sections of the newspapers?

$1=$ Mehrmals pro Tag, $2=$ Einmal pro Tag, $3=5-6 \mathrm{ma}$ in der Woche, $4=3-4 \mathrm{mal}$ in der Woche, $5=1-2 \mathrm{mal}$ in der Woche, $6=$ Weniger als $1-2$ mal in der Woche, $7=\mathrm{Ni}$

\section{Earlier in the survey, we} asked which media

sources you use to

gather political

information. Now we would like to know how often on average you used these sources in the time period between this survey and the previous $<$ previous referendu month $>$ ), to collect information on the referendum $<$ closest
upcoming referendum $>$. upcoming referendum $>$. - How often did you watch news on the
referendum on TV?
$1=$ Multiple times a day, $2=$ Once a day, $3=5-6$

times a week, $4=3-4$
times a week, $5=1-2$

times a week, $6=$ fewer

than 1-2 times a week, 7

$=$ never
$1=$ Multiple times a day $2=$ Once a day, $3=5-6$

times a week, $4=3-4$

times a week, $5=1-2$

times a week, $6=$ fewer

than 1-2 times a week, 7 $=$ neve 
Q27.13_6 - Früher in der

Umfrage, haben wir danach gefragt welche

Medienquellen Du nutzt um politische Informationen zu sammeln. Jetzt wollen w wissen wie häufig, Du durchschnittlich, diese Quellen genutzt hast, im Ueitraum zwischen dieser (Mitte Dezember), um Informationen zu der Referendum für die

Abschaffung der Radio- und Fernsehgebühren

(Billag-Gebühren) zu sammeln. - Wie Deferendr

als pro Tag, $2=$ der Woche, $5=1-2$ mal in der mal in der Woche, $7=\mathrm{Ni}$ asked which media sources you use to

gather political would like to know how often on average you used these sources in the time period between this survey and the previous month $>$ ), to collect information on the upcoming referendum> How listen to news on the referendum on the radio? achrichten

media.use.political.4

$1=$ Mehrmals pro Tag, $2=$

Earlier in the survey, we
13_ 7 - Früher in der Q geragt welche

(um com wissen wie häufig, Du durchschnittlich, diese Quellen genutzt hast, Zeitraum zwischen Umfrage und der Vorherigen (Mitte Dezember), um Mitte Dezember), ur Referendum für die Abschaffung der Radio- und Fernsehgebühren

(Billag-Gebühren) zu sammeln. - Wie häufig hast Du Referendum-bezogene Artikel auf

Nachrichtenseiten im Internet gelesen? Einmal pro Tag, $3=5-6 \mathrm{mal}$ in der Woche, $4=3-4 \mathrm{mal}$ in information. Now we $(<$ previous referendur

$1=$ Multiple times a day $2=$ Once a day, $3=5-6$ times a week, $4=3-4$ times a week, $5=1-2$ times a week, $6=$ fewer than 1-2 times a week, 7 Einmal pro Tag, $3=5-6 \mathrm{mal}$ der Woche, $5=1-2$ mal in der Woche, $6=$ Wenige als $1-2$ mal in der Woche, $7=\mathrm{Nie}$ asked which medi sources you use to we often on average hou used these sources in $t$ time period between this survey and the previous $(<$ previous referendum month $>$ ), to collect information on the referendum <closest upcoming referendum $>$. - How often did you read articles about the referendum on news sites on the internet?

$1=$ Multiple times a day $2=$ Once a day, $3=5-6$ times a week, $5=1-2$

times a week, $5=1-2$
times a week, $6=$ fewer

than 1-2 times a week, 7

$=$ never 
media.use.political.5

media.use.political.6
Q27.13_8 - Früher in der Umfrage, haben wir danach gefragt welche

Medienquellen Du nutzt um politische Informationen zu sammeln. Jetzt wollen wir wissen wie häufig, Du

Quellen genutzt hast,

Zeitraum zwischen dieser

Umfrage und der Vorherigen

(Mitte Dezember), um

Referendum für die

Abschaffung der Radio- und

Fernsehgebühren

(Billag-Gebühren) zu

sammeln. - Wie häufig hast

Du Soziale Medien (wie

Facebook oder Twitter)

benutzt, um

Referendum-bezogene

Nachrichten ode

Informationen zu sammeln?

Q27.13_9 - Früher in der

Umfrage, haben wir danach

gefragt welche

Medienquellen Du nutzt um politische Informationen zu sammeln. Jetzt wollen wir wissen wie häufig, Du durchschnittlich, diese Quellen genutzt hast, im Zeitraum zwischen dieser

Umfrage und der Vorherigen

(Mitte Dezember), um

Informationen $\mathrm{zu}$ de

Referendum für die

Abschaffung der Radio- und

Fernsehgebühren

(Billag-Gebühren) zu

sammeln. - Wie häufig hast

Du Aggregatorseiten (wie

Reddit oder Digg) benutzt,

um Referendum-bezogene

Informationen zu sammeln?
$1=$ Mehrmals pro Tag, $2=$ Einmal pro Tag, $3=5-6 \mathrm{mal}$ in der Woche, $4=3-4 \mathrm{mal}$ in der Woche, $5=1-2 \mathrm{mal}$ in de Woche, $6=$ Weniger als 1-2 mal in der Woche, $7=\mathrm{Nie}$

arlier in the survey, we sked which media ources you use to information. Now would like to know how often on average you used these sources in the

time period between this survey and the previous $(<$ previous referendum month $>$ ), to collect information on the referendum <closest upcoming referendum $>$. - How often did you use social media sites (such as Facebook or Twitter) to gather information or messages on the

referendum?
$1=$ Mehrmals pro Tag, $2=$ Einmal pro Tag, $3=5-6 \mathrm{ma}$ in der Woche, $4=3-4 \mathrm{mal}$ in der Woche, $5=1-2 \mathrm{mal}$ in de Woche, $7=\mathrm{Nie}$ mal in der Woche, $7=$ Nie

\section{$1=$ Multiple times a day} $2=$ Once a day, $3=5-6$

times a week, $5=1-2$

times a week, $6=$ few

than 1-2 times a week, 7

$=$ never

Earlier in the survey, we asked which media sources you use to

gather political

nformation. Now we

would like to know how

often on average you

used these sources in the

time period between this

survey and the previous

$(<$ previous referendum

month $>$ ), to collect

information on the

referendum <closest

upcoming referendum $>$.

- How often did you use

content aggregator sites

(such as reddit or Digg)

to gather information or

messages on the

referendum?
$1=$ Multiple times a day, $\quad \mathrm{X} \quad \mathrm{X} \quad \mathrm{X}$ $2=$ Once a day, $3=5-6$

times a week, $4=3-4$

times a week, $5=1-2$

than $1-2$ times a week,
than

$=$ never 


\begin{tabular}{|c|c|c|c|c|c|c|c|c|c|c|c|c|c|c|c|c|c|}
\hline VarName & VariableLabel & WordingDE & ValueLabelsDE_Linked & WordingEN & ValueLabelsEN_Linked & L1 & $\mathrm{L} 2$ & L3 & $\mathrm{L} 4$ & L5 & L6 & L7 & L8 & L9 & \multicolumn{3}{|c|}{ L10 L11 L12 } \\
\hline media.use.political.7 & & $\begin{array}{l}\text { Q27.13_10 - Früher in der } \\
\text { Umfrage, haben wir danach } \\
\text { gefragt welche } \\
\text { Medienquellen Du nutzt um } \\
\text { politische Informationen zu } \\
\text { sammeln. Jetzt wollen wir } \\
\text { wissen wie häufig, Du } \\
\text { durchschnittlich, diese } \\
\text { Quellen genutzt hast, im } \\
\text { Zeitraum zwischen dieser } \\
\text { Umfrage und der Vorherigen } \\
\text { (Mitte Dezember), um } \\
\text { Informationen zu dem } \\
\text { Referendum für die } \\
\text { Abschaffung der Radio- und } \\
\text { Fernsehgebühren } \\
\text { (Billag-Gebühren) zu } \\
\text { sammeln. - Wie häufig hast } \\
\text { Du andere Internetquellen } \\
\text { benutzt, um } \\
\text { Energiegesetz-bezogene } \\
\text { Nachrichten oder } \\
\text { Informationen zu sammeln? }\end{array}$ & $\begin{array}{l}1=\text { Mehrmals pro Tag, } 2= \\
\text { Einmal pro Tag, } 3=5-6 \mathrm{mal} \\
\text { in der Woche, } 4=3-4 \mathrm{mal} \text { in } \\
\text { der Woche, } 5=1-2 \mathrm{mal} \text { in der } \\
\text { Woche, } 6=\text { Weniger als } 1-2 \\
\text { mal in der Woche, } 7=\mathrm{Nie}\end{array}$ & $\begin{array}{l}\text { Earlier in the survey, we } \\
\text { asked which media } \\
\text { sources you use to } \\
\text { gather political } \\
\text { information. Now we } \\
\text { would like to know how } \\
\text { often on average you } \\
\text { used these sources in the } \\
\text { time period between this } \\
\text { survey and the previous } \\
(<\text { previous referendum } \\
\text { month }>) \text {, to collect } \\
\text { information on the } \\
\text { referendum < closest } \\
\text { upcoming referendum }>\text {. } \\
\text { - How often did you use } \\
\text { other internet sources, } \\
\text { to gather messages or } \\
\text { information on the } \\
\text { referendum? }\end{array}$ & $\begin{array}{l}1=\text { Multiple times a day, } \\
2=\text { Once a day, } 3=5-6 \\
\text { times a week, } 4=3-4 \\
\text { times a week, } 5=1-2 \\
\text { times a week, } 6=\text { fewer } \\
\text { than } 1-2 \text { times a week, } 7 \\
=\text { never }\end{array}$ & & & & $\mathrm{x}$ & & $\mathrm{x}$ & $\mathrm{x}$ & & & & & \\
\hline media.use.political.8.text & & $\begin{array}{l}\text { Q27.14 - Du hast } \\
\text { angegeben, dass Du auch } \\
\text { andere Internetquellen } \\
\text { benutzt hast um } \\
\text { Abschaffung der Radio- und } \\
\text { Fernsehgebühren-bezogene } \\
\text { Nachrichten oder } \\
\text { Informationen zusammeln. } \\
\text { Welche sind diese? }\end{array}$ & & $\begin{array}{l}\text { You indicated that you } \\
\text { used other internet } \\
\text { sources to retrieve } \\
\text { information or messages } \\
\text { concerning the } \\
\text { referendum on } \\
\text { <upcoming referendum } \\
\text { topic }>\text {. Which were } \\
\text { these? }\end{array}$ & & & & & $\mathrm{x}$ & & $\mathrm{X}$ & $\mathrm{x}$ & & & & & \\
\hline loneliness.intimate. 1 & & $\begin{array}{l}\text { Q22.1_1 - Inwiefern treffen } \\
\text { folgende Aussagen auf Dich } \\
\text { zu? - Wie häufig hast Du } \\
\text { das Gefühl, dass Dir } \\
\text { Gesellschaft fehlt? }\end{array}$ & $\begin{array}{l}1=\text { Nie, } 2=\text { Selten, } 3= \\
\text { Manchmal, } 4=\text { Oft }\end{array}$ & $\begin{array}{l}\text { How often do you feel } \\
\text { that you lack } \\
\text { companionship? (I) }\end{array}$ & $\begin{array}{l}1=\text { Never, } 2=\text { Seldom, } 3 \\
=\text { Sometimes, } 4=\text { Often }\end{array}$ & & & & & $\mathrm{x}$ & $\mathrm{x}$ & $\mathrm{x}$ & $\mathrm{x}$ & $\mathrm{x}$ & $\mathrm{x}$ & $\mathrm{x}$ & $\mathrm{x}$ \\
\hline loneliness.collective.1 & & $\begin{array}{l}\text { Q22.1_8 - Inwiefern treffen } \\
\text { folgende Aussagen auf Dich } \\
\text { zu? - Wie häufig fühlst Du } \\
\text { Dich auf einer Wellenlänge } \\
\text { mit den Menschen um Dich } \\
\text { herum? }\end{array}$ & $\begin{array}{l}1=\mathrm{Nie}, 2=\text { Selten, } 3= \\
\text { Manchmal, } 4=\mathrm{Oft}\end{array}$ & $\begin{array}{l}\text { How often do you feel } \\
\text { that you are 'in tune' } \\
\text { with the people around } \\
\text { you? (Ca) }\end{array}$ & $\begin{array}{l}1=\text { Never }, 2=\text { Seldom, } 3 \\
=\text { Sometimes, } 4=\text { Often }\end{array}$ & & & & & $\mathrm{x}$ & $\mathrm{x}$ & $\mathrm{x}$ & $\mathrm{x}$ & $\mathrm{x}$ & $\mathrm{x}$ & $\mathrm{x}$ & $\mathrm{x}$ \\
\hline loneliness.relational.1 & & $\begin{array}{l}\text { Q22.1_9 - Inwiefern treffen } \\
\text { folgende Aussagen auf Dich } \\
\text { zu? - Wie häufig hast Du } \\
\text { das Gefühl, dass es } \\
\text { Menschen gibt, mit denen } \\
\text { Du reden kannst? }\end{array}$ & $\begin{array}{l}1=\mathrm{Nie}, 2=\text { Selten, } 3= \\
\text { Manchmal, } 4=\mathrm{Oft}\end{array}$ & $\begin{array}{l}\text { How often do you feel } \\
\text { that there are people } \\
\text { you can talk to? (Ra) }\end{array}$ & $\begin{array}{l}1=\text { Never, } 2=\text { Seldom, } 3 \\
=\text { Sometimes, } 4=\text { Often }\end{array}$ & & & & & $\mathrm{x}$ & $\mathrm{x}$ & $\mathrm{x}$ & $\mathrm{x}$ & $\mathrm{x}$ & $\mathrm{x}$ & $\mathrm{x}$ & $\mathrm{X}$ \\
\hline loneliness.intimate. 2 & & $\begin{array}{l}\text { Q22.1_10 - Inwiefern treffen } \\
\text { folgende Aussagen auf Dich } \\
\text { zu? - Wie häufig fühlst Du } \\
\text { Dich ausgeschlossen? }\end{array}$ & $\begin{array}{l}1=\mathrm{Nie}, 2=\text { Selten, } 3= \\
\text { Manchmal, } 4=\text { Oft }\end{array}$ & $\begin{array}{l}\text { How often do you feel } \\
\text { left out? (I) }\end{array}$ & $\begin{array}{l}1=\text { Never, } 2=\text { Seldom, } 3 \\
=\text { Sometimes, } 4=\text { Often }\end{array}$ & & & & & $\mathrm{x}$ & $\mathrm{x}$ & $\mathrm{x}$ & $\mathrm{x}$ & $\mathrm{x}$ & $\mathrm{x}$ & $\mathrm{x}$ & $\mathrm{x}$ \\
\hline loneliness.relational.2 & & $\begin{array}{l}\text { Q22.1_11 - Inwiefern } \\
\text { treffen folgende Aussagen } \\
\text { auf Dich zu? - Wie häufig } \\
\text { fühlst Du, dass es Menschen } \\
\text { gibt, an die Du Dich } \\
\text { wenden kannst? }\end{array}$ & $\begin{array}{l}1=\text { Nie, } 2=\text { Selten, } 3= \\
\text { Manchmal, } 4=\text { Oft }\end{array}$ & $\begin{array}{l}\text { How often do you feel } \\
\text { that there are people } \\
\text { you can turn to? (Ra) }\end{array}$ & $\begin{array}{l}1=\text { Never, } 2=\text { Seldom, } 3 \\
=\text { Sometimes, } 4=\text { Often }\end{array}$ & & & & & $\mathrm{x}$ & $\mathrm{x}$ & $\mathrm{x}$ & $\mathrm{x}$ & $\mathrm{x}$ & $\mathrm{x}$ & $\mathrm{x}$ & $\mathrm{x}$ \\
\hline
\end{tabular}




\begin{tabular}{|c|c|c|c|c|c|c|c|c|c|c|c|c|c|c|c|c|c|}
\hline VarName & VariableLabel & WordingDE & ValueLabelsDE_Linked & WordingEN & ValueLabelsEN_Linked & L1 & $\mathrm{L} 2$ & L3 & $\mathrm{L} 4$ & L5 & L6 6 & L7 & L8 & L9 & L10 & L L11 & $\mathrm{L} 12$ \\
\hline loneliness.collective.2 & & $\begin{array}{l}\text { Q22.1_12 - Inwiefern } \\
\text { treffen folgende Aussagen } \\
\text { auf Dich zu? - Wie häufig } \\
\text { hast Du das Gefühl, dass } \\
\text { Du mit den Menschen um } \\
\text { Dich herum vieles } \\
\text { gemeinsam hast? }\end{array}$ & $\begin{array}{l}1=\text { Nie, } 2=\text { Selten, } 3= \\
\text { Manchmal, } 4=\text { Oft }\end{array}$ & $\begin{array}{l}\text { How often do you feel } \\
\text { that you have a lot in } \\
\text { common with the people } \\
\text { around you? (Ca) }\end{array}$ & $\begin{array}{l}1=\text { Never, } 2=\text { Seldom, } 3 \\
=\text { Sometimes, } 4=\text { Often }\end{array}$ & & & & & $\mathrm{x}$ & $\mathrm{x}$ & $\mathrm{x}$ & $\mathrm{x}$ & $\mathrm{x}$ & $\mathrm{x}$ & $\mathrm{x}$ & $\mathrm{x}$ \\
\hline loneliness.relational.3 & & $\begin{array}{l}\text { Q22.1_13 - Inwiefern } \\
\text { treffen folgende Aussagen } \\
\text { auf Dich zu? - Wie häufig } \\
\text { fühlst Du Dich anderen } \\
\text { Menschen nah? }\end{array}$ & $\begin{array}{l}1=\text { Nie, } 2=\text { Selten, } 3= \\
\text { Manchmal, } 4=\text { Oft }\end{array}$ & $\begin{array}{l}\text { How often do you feel } \\
\text { close to people? (Ra) }\end{array}$ & $\begin{array}{l}1=\text { Never, } 2=\text { Seldom, } 3 \\
=\text { Sometimes, } 4=\text { Often }\end{array}$ & & & & & $\mathrm{x}$ & $\mathrm{x}$ & $\mathrm{x}$ & $\mathrm{x}$ & $\mathrm{x}$ & $\mathrm{x}$ & $\mathrm{x}$ & $\mathrm{x}$ \\
\hline loneliness.intimate.3 & & $\begin{array}{l}\text { Q22.1_14 - Inwiefern } \\
\text { treffen folgende Aussagen } \\
\text { auf Dich zu? - Wie häufig } \\
\text { fühlst Du Dich isoliert von } \\
\text { anderen Menschen? }\end{array}$ & $\begin{array}{l}1=\mathrm{Nie}, 2=\text { Selten, } 3= \\
\text { Manchmal, } 4=\mathrm{Oft}\end{array}$ & $\begin{array}{l}\text { How often do you feel } \\
\text { isolated from others? (I) }\end{array}$ & $\begin{array}{l}1=\text { Never, } 2=\text { Seldom, } 3 \\
=\text { Sometimes, } 4=\text { Often }\end{array}$ & & & & & $\mathrm{x}$ & $\mathrm{x}$ & $\mathrm{x}$ & $\mathrm{x}$ & $\mathrm{x}$ & $\mathrm{x}$ & $\mathrm{x}$ & $\mathrm{x}$ \\
\hline loneliness.collective.3 & & $\begin{array}{l}\text { Q22.1_15 - Inwiefern } \\
\text { treffen folgende Aussagen } \\
\text { auf Dich zu? - Wie häufig } \\
\text { hast Du das Gefühl, zu } \\
\text { einer Gruppe von Freunden } \\
\text { dazu zu gehören? }\end{array}$ & $\begin{array}{l}1=\mathrm{Nie}, 2=\text { Selten, } 3= \\
\text { Manchmal, } 4=\text { Oft }\end{array}$ & $\begin{array}{l}\text { How often do you feel } \\
\text { part of a group of } \\
\text { friends? (Ca) }\end{array}$ & $\begin{array}{l}1=\text { Never, } 2=\text { Seldom, } 3 \\
=\text { Sometimes, } 4=\text { Often }\end{array}$ & & & & & $\mathrm{x}$ & $\mathrm{x}$ & $\mathrm{x}$ & $\mathrm{x}$ & $\mathrm{x}$ & $\mathrm{x}$ & $\mathrm{x}$ & $\mathrm{x}$ \\
\hline close.no.all & $\begin{array}{l}\text { Feeling close } \\
\text { to - number of } \\
\text { people in total }\end{array}$ & $\begin{array}{l}\text { Manche Menschen fühlen } \\
\text { sich vielen Menschen sehr } \\
\text { nahe, andere nur wenigen } \\
\text { oder niemandem. Wie } \\
\text { vielen Menschen (innerhalb } \\
\text { und ausserhalb der } \\
\text { [university name]) fühlst Du } \\
\text { Dich sehr nahe? }\end{array}$ & & $\begin{array}{l}\text { Some people feel close } \\
\text { to many people, others } \\
\text { only to few or nobody. } \\
\text { How many people } \\
\text { (within and outside of } \\
\text { [university name]) do } \\
\text { you feel very close to? }\end{array}$ & & & & & & $\mathrm{x}$ & $\mathrm{x}$ & $\mathrm{x}$ & $\mathrm{x}$ & $\mathrm{x}$ & $\mathrm{x}$ & $\mathrm{x}$ & $\mathrm{x}$ \\
\hline close.no.classmates & $\begin{array}{l}\text { Feeling close } \\
\text { to - number of } \\
\text { classmates }\end{array}$ & $\begin{array}{l}\text { Wieviele dieser Menschen } \\
\text { sind Mitstudierende? }\end{array}$ & & $\begin{array}{l}\text { How many of these } \\
\text { people are fellow } \\
\text { students? }\end{array}$ & & & & & & $\mathrm{x}$ & $\mathrm{x}$ & $\mathrm{x}$ & $\mathrm{x}$ & $\mathrm{x}$ & $\mathrm{x}$ & $\mathrm{x}$ & $\mathrm{x}$ \\
\hline att.degree.classmates & $\begin{array}{l}\text { Attitude of } \\
\text { people towards } \\
\text { degree - } \\
\text { friends among } \\
\text { classmates }\end{array}$ & $\begin{array}{l}\text { Wie ist die Einstellung von } \\
\text { Freunden unter deinen } \\
\text { Mitstudierenden zu einem } \\
\text { Universitätsabschluss? }\end{array}$ & $\begin{array}{l}1=\text { sehr negativ, } 2= \\
\text { negativ, } 3=\text { eher negativ, } 4 \\
=\text { neutral, } 5=\text { eher positiv, } 6 \\
=\text { positiv, } 7=\text { sehr positiv, } 8 \\
=\text { nicht zutreffend }\end{array}$ & $\begin{array}{l}\text { What is the attitude } \\
\text { towards a university } \\
\text { degree among your } \\
\text { fellow students? }\end{array}$ & $\begin{array}{l}1=\text { very negative, } 2= \\
\text { negative, } 3=\text { rather } \\
\text { negative, } 4=\text { neutral, } 5= \\
\text { rather positive, } 6= \\
\text { positive, } 7=\text { very } \\
\text { positive, } 8=\text { not } \\
\text { applicable }\end{array}$ & & & & & $\mathrm{x}$ & $\mathrm{x}$ & $\mathrm{x}$ & $\mathrm{x}$ & $\mathrm{x}$ & $\mathrm{x}$ & & \\
\hline att.degree.friends & $\begin{array}{l}\text { Attitude of } \\
\text { people towards } \\
\text { degree - } \\
\text { friends not } \\
\text { among } \\
\text { classmates }\end{array}$ & $\begin{array}{l}\text { Wie ist die Einstellung von } \\
\text { Freunden die nicht mit dir } \\
\text { studieren zu einem } \\
\text { Universitätsabschluss? }\end{array}$ & $\begin{array}{l}1=\text { sehr negativ, } 2= \\
\text { negativ, } 3=\text { eher negativ, } 4 \\
=\text { neutral, } 5=\text { eher positiv, } 6 \\
=\text { positiv, } 7=\text { sehr positiv, } 8 \\
=\text { nicht zutreffend }\end{array}$ & $\begin{array}{l}\text { What is the attitude } \\
\text { towards a university } \\
\text { degree among your } \\
\text { friends who do not } \\
\text { study with you? }\end{array}$ & $\begin{array}{l}1=\text { very negative, } 2= \\
\text { negative, } 3=\text { rather } \\
\text { negative, } 4=\text { neutral, } 5= \\
\text { rather positive, } 6= \\
\text { positive, } 7=\text { very } \\
\text { positive, } 8=\text { not } \\
\text { applicable }\end{array}$ & & & & & $\mathrm{x}$ & $\mathrm{x}$ & $\mathrm{x}$ & $\mathrm{x}$ & $\mathrm{x}$ & $\mathrm{x}$ & & \\
\hline att.degree.partner & $\begin{array}{l}\text { Attitude of } \\
\text { people towards } \\
\text { degree - your } \\
\text { partner }\end{array}$ & $\begin{array}{l}\text { Wie ist die Einstellung von } \\
\text { deinem Partner/deiner } \\
\text { Partnerin zu einem } \\
\text { Universitätsabschluss? }\end{array}$ & $\begin{array}{l}1=\text { sehr negativ, } 2= \\
\text { negativ, } 3=\text { eher negativ, } 4 \\
=\text { neutral, } 5=\text { eher positiv, } 6 \\
=\text { positiv, } 7=\text { sehr positiv, } 8 \\
=\text { nicht zutreffend }\end{array}$ & $\begin{array}{l}\text { What is the attitude } \\
\text { towards a university } \\
\text { degree of your partner? }\end{array}$ & $\begin{array}{l}1=\text { very negative, } 2= \\
\text { negative, } 3=\text { rather } \\
\text { negative, } 4=\text { neutral, } 5= \\
\text { rather positive, } 6= \\
\text { positive, } 7=\text { very } \\
\text { positive, } 8=\text { not } \\
\text { applicable }\end{array}$ & & & & & $\mathrm{x}$ & $\mathrm{x}$ & $\mathrm{x}$ & $\mathrm{x}$ & $\mathrm{x}$ & $\mathrm{x}$ & & \\
\hline att.degree.family & $\begin{array}{l}\text { Attitude of } \\
\text { people towards } \\
\text { degree - your } \\
\text { family } \\
\text { members }\end{array}$ & $\begin{array}{l}\text { Wie ist die Einstellung von } \\
\text { deinen Familienmitgliedern } \\
\text { zu einem } \\
\text { Universitätsabschluss? }\end{array}$ & $\begin{array}{l}1=\text { sehr negativ, } 2= \\
\text { negativ, } 3=\text { eher negativ, } 4 \\
=\text { neutral, } 5=\text { eher positiv, } 6 \\
=\text { positiv, } 7=\text { sehr positiv, } 8 \\
=\text { nicht zutreffend }\end{array}$ & $\begin{array}{l}\text { What is the attitude } \\
\text { towards a university } \\
\text { degree among your } \\
\text { family members? }\end{array}$ & $\begin{array}{l}1=\text { very negative, } 2= \\
\text { negative, } 3=\text { rather } \\
\text { negative, } 4=\text { neutral, } 5= \\
\text { rather positive, } 6= \\
\text { positive, } 7=\text { very } \\
\text { positive, } 8=\text { not } \\
\text { applicable }\end{array}$ & & & & & $\mathrm{x}$ & $\mathrm{x}$ & $\mathrm{x}$ & $\mathrm{x}$ & $\mathrm{x}$ & $\mathrm{x}$ & & \\
\hline
\end{tabular}




\begin{tabular}{|c|c|c|c|c|c|c|c|c|c|c|c|c|c|c|c|c|c|}
\hline VarName & VariableLabel & WordingDE & ValueLabelsDE_Linked & WordingEN & ValueLabelsEN_Linked & $\mathrm{L} 1$ & $\mathrm{~L} 2$ & L3 & $\mathrm{L} 4$ & L5 & L6 & L7 & L8 & L9 & & 0 L11 & $1 \mathrm{~L} 12$ \\
\hline knowledge.law.pre.2 & & $\begin{array}{l}\text { Q28.11_4 - Inwieweittrifft } \\
\text { die folgende Aussage auf } \\
\text { Dich zu? - Ich weiss viel } \\
\text { über [topic x] }\end{array}$ & & $\begin{array}{l}\text { To what extent does the } \\
\text { following statement } \\
\text { apply to you - I know a } \\
\text { lot about [topic } \mathrm{x} \text { ] }\end{array}$ & & & & & & $\mathrm{x}$ & $\mathrm{x}$ & & & & & & \\
\hline knowledge.law.pre.3 & & & & & & & & & & & $\mathrm{x}$ & & & & & & \\
\hline vote.law.pre.1 & & & & & & & & & & $\mathrm{x}$ & $\mathrm{x}$ & & & & & & \\
\hline vote.law.pre.2 & & & & & & & & & & & $\mathrm{x}$ & & & & & & \\
\hline vote.law.pre.3 & & & & & & & & & & & $\mathrm{x}$ & & & & & & \\
\hline support.law.pre.2 & & $\begin{array}{l}\text { Q28.14 - } \\
\text { UnterBerücksichtigung } \\
\text { dieser Informationen, } \\
\text { inwieweit unterstützt Du } \\
\text { [topic 2]? }\end{array}$ & & $\begin{array}{l}\text { Considering this } \\
\text { information, to what } \\
\text { extent do you support } \\
\text { [topic x]? }\end{array}$ & & & & & & $\mathrm{x}$ & $\mathrm{x}$ & & & & & & \\
\hline vote.law.pre.2 & & $\begin{array}{l}\text { Q28.21 - Hast Du vor über } \\
\text { das Referendum für [topic } \\
\text { 2] abzustimmen? }\end{array}$ & & $\begin{array}{l}\text { Are you planning to } \\
\text { vote on the referendum } \\
\text { [topic } \mathrm{x}] \text { ? }\end{array}$ & & & & & & $\mathrm{x}$ & & & & & & & \\
\hline attention.check & $\begin{array}{l}\text { Checking that } \\
\text { students are } \\
\text { paying } \\
\text { attention }\end{array}$ & $\begin{array}{l}\text { Um sicherzustellen, dass } \\
\text { Dein Webbrowser korrekt } \\
\text { funktioniert und dass alle } \\
\text { Antworten aufgezeichnet } \\
\text { werden, klicke bitte auf } \\
\text { "trifft zu". }\end{array}$ & & $\begin{array}{l}\text { To ensure that your web } \\
\text { browser is functioning } \\
\text { correctly and that all } \\
\text { answers are being saved, } \\
\text { please click on option } \\
<x>\text {. }\end{array}$ & & & & & & $\mathrm{x}$ & $\mathrm{x}$ & $\mathrm{x}$ & $\mathrm{x}$ & $\mathrm{x}$ & $\mathrm{x}$ & $\mathrm{x}$ & $\mathrm{x}$ \\
\hline FirstClick.policy & & & & & & & & & & & $\mathrm{x}$ & $\mathrm{x}$ & $\mathrm{x}$ & $\mathrm{x}$ & $\mathrm{x}$ & & \\
\hline support.law.pre.3 & & $\begin{array}{l}\text { Q28.14 - } \\
\text { UnterBerücksichtigung } \\
\text { dieser Informationen, } \\
\text { inwieweit unterstützt Du } \\
\text { [topic 2]? }\end{array}$ & & $\begin{array}{l}\text { Considering all this } \\
\text { information, do you } \\
\text { support [topic x]? }\end{array}$ & & & & & & & $\mathrm{x}$ & & & & & & \\
\hline knowledge.law.post.2 & & & & & & & & & & & $\mathrm{x}$ & $\mathrm{x}$ & & & & & \\
\hline support.law.post.2 & & $\begin{array}{l}\text { Q27.17 - } \\
\text { UnterBerücksichtigung } \\
\text { dieser Informationen, } \\
\text { inwieweit unterstützt Du } \\
\text { die Abschaffungder Radio- } \\
\text { und Fernsehgebühren } \\
\text { (Billag)? }\end{array}$ & & & & & & & & & $\mathrm{x}$ & $\mathrm{x}$ & & & & & \\
\hline vote.law.post.2 & & $\begin{array}{l}\text { Q27.19 - HastDu über das } \\
\text { Referendum für die } \\
\text { Abschaffung der Radio- und } \\
\text { Fernsehgebühren(Billag) } \\
\text { abgestimmt? }\end{array}$ & & & & & & & & & $\mathrm{x}$ & $\mathrm{x}$ & & & & & \\
\hline knowledge.law.post.3 & & & & & & & & & & & & $\mathrm{x}$ & & & & & \\
\hline support.law.post.3 & & & & & & & & & & & & $\mathrm{x}$ & & & & & \\
\hline vote.law.post.3 & & & & & & & & & & & & $\mathrm{x}$ & & & & & \\
\hline acc.1 & & $\begin{array}{l}\text { Ich habe einen Account - } \\
\text { Facebook }\end{array}$ & $1=\mathrm{Ja}, 2=\mathrm{Nein}$ & $\begin{array}{l}\text { I have an account - } \\
\text { Facebook }\end{array}$ & $1=\mathrm{Yes}, 2=\mathrm{No}$ & & & & & & & $\mathrm{x}$ & $\mathrm{x}$ & $\mathrm{x}$ & $\mathrm{x}$ & $\mathrm{x}$ & $\mathrm{x}$ \\
\hline acc. 2 & & $\begin{array}{l}\text { Ich habe einen Account - } \\
\text { Facebook Messenger }\end{array}$ & $1=\mathrm{Ja}, 2=$ Nein & $\begin{array}{l}\text { I have an account - } \\
\text { Facebook Messenger }\end{array}$ & $1=$ Yes, $2=\mathrm{No}$ & & & & & & & $\mathrm{x}$ & $\mathrm{x}$ & $\mathrm{x}$ & $\mathrm{x}$ & $\mathrm{x}$ & $\mathrm{x}$ \\
\hline acc.3 & & $\begin{array}{l}\text { Ich habe einen Account - } \\
\text { WhatsApp }\end{array}$ & $1=\mathrm{Ja}, 2=$ Nein & $\begin{array}{l}\text { I have an account - } \\
\text { Whatsapp }\end{array}$ & $1=\mathrm{Yes}, 2=\mathrm{No}$ & & & & & & & $\mathrm{x}$ & $\mathrm{x}$ & $\mathrm{x}$ & $\mathrm{x}$ & $\mathrm{x}$ & $\mathrm{x}$ \\
\hline acc.4 & & $\begin{array}{l}\text { Ich habe einen Account - } \\
\text { Instagram }\end{array}$ & $1=\mathrm{Ja}, 2=$ Nein & $\begin{array}{l}\text { I have an account - } \\
\text { Instagram }\end{array}$ & $1=\mathrm{Yes}, 2=\mathrm{No}$ & & & & & & & $\mathrm{x}$ & $\mathrm{x}$ & $\mathrm{x}$ & $\mathrm{x}$ & $\mathrm{x}$ & $\mathrm{x}$ \\
\hline acc.5 & & $\begin{array}{l}\text { Ich habe einen Account - } \\
\text { Twitter }\end{array}$ & $1=\mathrm{Ja}, 2=$ Nein & $\begin{array}{l}\text { I have an account - } \\
\text { Twitter }\end{array}$ & $1=\mathrm{Yes}, 2=\mathrm{No}$ & & & & & & & $\mathrm{x}$ & $\mathrm{x}$ & $\mathrm{x}$ & $\mathrm{x}$ & $\mathrm{x}$ & $\mathrm{x}$ \\
\hline acc.6 & & $\begin{array}{l}\text { Ich habe einen Account - } \\
\text { Snapchat }\end{array}$ & $1=\mathrm{Ja}, 2=\mathrm{Nein}$ & $\begin{array}{l}\text { I have an account - } \\
\text { Snapchat }\end{array}$ & $1=\mathrm{Yes}, 2=\mathrm{No}$ & & & & & & & $\mathrm{x}$ & $\mathrm{x}$ & $\mathrm{x}$ & $\mathrm{x}$ & $\mathrm{x}$ & $\mathrm{x}$ \\
\hline acc. 7 & & $\begin{array}{l}\text { Ich habe einen Account - } \\
\text { Reddit }\end{array}$ & $1=\mathrm{Ja}, 2=$ Nein & $\begin{array}{l}\text { I have an account - } \\
\text { Reddit }\end{array}$ & $1=\mathrm{Yes}, 2=\mathrm{No}$ & & & & & & & $\mathrm{x}$ & $\mathrm{x}$ & $\mathrm{x}$ & $\mathrm{x}$ & $\mathrm{x}$ & $\mathrm{x}$ \\
\hline acc. 8 & & $\begin{array}{l}\text { Ich habe einen Account - } \\
\text { Linkedin }\end{array}$ & $1=\mathrm{Ja}, 2=$ Nein & $\begin{array}{l}\text { I have an account - } \\
\text { LinkedIn }\end{array}$ & $1=\mathrm{Yes}, 2=\mathrm{No}$ & & & & & & & $\mathrm{x}$ & $\mathrm{x}$ & $\mathrm{x}$ & $\mathrm{x}$ & $\mathrm{x}$ & $\mathrm{x}$ \\
\hline
\end{tabular}




\begin{tabular}{|c|c|c|c|c|c|c|c|c|c|c|c|c|c|c|c|c|c|}
\hline VarName & VariableLabel & WordingDE & ValueLabelsDE_Linked & WordingEN & ValueLabelsEN_Linked & $\mathrm{L} 1$ & $\mathrm{~L} 2$ & L3 & $\mathrm{L} 4$ & L5 & $\mathrm{L} 6$ & L7 & L8 & L9 & L10 & L11 & $\mathrm{L} 12$ \\
\hline acc. 9 & & $\begin{array}{l}\text { Ich habe einen Account - } \\
\text { Signal }\end{array}$ & $1=\mathrm{Ja}, 2=$ Nein & $\begin{array}{l}\text { I have an account - } \\
\text { Signal }\end{array}$ & $1=\mathrm{Yes}, 2=\mathrm{No}$ & & & & & & & $\mathrm{x}$ & $\mathrm{x}$ & $\mathrm{x}$ & $\mathrm{x}$ & $\mathrm{x}$ & $\mathrm{x}$ \\
\hline acc.10 & & $\begin{array}{l}\text { Ich habe einen Account - } \\
\text { Andere }\end{array}$ & $1=\mathrm{Ja}, 2=$ Nein & $\begin{array}{l}\text { I have an account - } \\
\text { Other }\end{array}$ & $1=\mathrm{Yes}, 2=\mathrm{No}$ & & & & & & & $\mathrm{x}$ & $\mathrm{x}$ & $\mathrm{x}$ & $\mathrm{x}$ & $\mathrm{x}$ & $\mathrm{x}$ \\
\hline acc.10.str & & $\begin{array}{l}\text { Ich habe einen Account - } \\
\text { Andere }\end{array}$ & & $\begin{array}{l}\text { I have an account - } \\
\text { Other TEXT }\end{array}$ & & & & & & & & $\mathrm{x}$ & $\mathrm{x}$ & $\mathrm{x}$ & $\mathrm{x}$ & $\mathrm{x}$ & $\mathrm{x}$ \\
\hline acc.11 & & $\begin{array}{l}\text { Ich habe einen Account - } \\
\text { Andere }\end{array}$ & $1=\mathrm{Ja}, 2=$ Nein & $\begin{array}{l}\text { I have an account - } \\
\text { Other }\end{array}$ & $1=\mathrm{Yes}, 2=\mathrm{No}$ & & & & & & & $\mathrm{x}$ & $\mathrm{x}$ & $\mathrm{x}$ & $\mathrm{x}$ & $\mathrm{x}$ & $\mathrm{x}$ \\
\hline acc.11.str & & $\begin{array}{l}\text { Ich habe einen Account - } \\
\text { Andere }\end{array}$ & & $\begin{array}{l}\text { I have an account - } \\
\text { Other TEXT }\end{array}$ & & & & & & & & $\mathrm{x}$ & $\mathrm{x}$ & $\mathrm{x}$ & $\mathrm{x}$ & $\mathrm{x}$ & $\mathrm{x}$ \\
\hline acc.12 & & $\begin{array}{l}\text { Ich habe einen Account - } \\
\text { Andere }\end{array}$ & $1=\mathrm{Ja}, 2=$ Nein & $\begin{array}{l}\text { I have an account - } \\
\text { Other }\end{array}$ & $1=\mathrm{Yes}, 2=\mathrm{No}$ & & & & & & & $\mathrm{x}$ & $\mathrm{x}$ & $\mathrm{x}$ & $\mathrm{x}$ & $\mathrm{x}$ & $\mathrm{x}$ \\
\hline acc.12.str & & $\begin{array}{l}\text { Ich habe einen Account - } \\
\text { Andere }\end{array}$ & & $\begin{array}{l}\text { I have an account - } \\
\text { Other TEXT }\end{array}$ & & & & & & & & $\mathrm{x}$ & $\mathrm{x}$ & $\mathrm{x}$ & $\mathrm{x}$ & $\mathrm{x}$ & $\mathrm{x}$ \\
\hline acc.1.is.sm & & $\begin{array}{l}\text { Ich würde diese Technologie } \\
\text { als "Soziale Medien / Social } \\
\text { Media" bezeichnen }\end{array}$ & $1=\mathrm{Ja}, 2=$ Nein & $\begin{array}{l}\text { I would consider this } \\
\text { technology "social } \\
\text { media". }\end{array}$ & $1=\mathrm{Yes}, 2=\mathrm{No}$ & & & & & & & $\mathrm{x}$ & $\mathrm{x}$ & $\mathrm{x}$ & $\mathrm{x}$ & $\mathrm{x}$ & $\mathrm{x}$ \\
\hline acc.2.is.sm & & $\begin{array}{l}\text { Ich würde diese Technologie } \\
\text { als "Soziale Medien / Social } \\
\text { Media" bezeichnen }\end{array}$ & $1=\mathrm{Ja}, 2=$ Nein & $\begin{array}{l}\text { I would consider this } \\
\text { technology "social } \\
\text { media". }\end{array}$ & $1=\mathrm{Yes}, 2=\mathrm{No}$ & & & & & & & $\mathrm{x}$ & $\mathrm{x}$ & $\mathrm{x}$ & $\mathrm{x}$ & $\mathrm{x}$ & $\mathrm{X}$ \\
\hline acc.3.is.sm & & $\begin{array}{l}\text { Ich würde diese Technologie } \\
\text { als "Soziale Medien / Social } \\
\text { Media" bezeichnen }\end{array}$ & $1=\mathrm{Ja}, 2=$ Nein & $\begin{array}{l}\text { I would consider this } \\
\text { technology "social } \\
\text { media". }\end{array}$ & $1=\mathrm{Yes}, 2=\mathrm{No}$ & & & & & & & $\mathrm{x}$ & $\mathrm{x}$ & $\mathrm{x}$ & $\mathrm{x}$ & $\mathrm{x}$ & $\mathrm{x}$ \\
\hline acc.4.is.sm & & $\begin{array}{l}\text { Ich würde diese Technologie } \\
\text { als "Soziale Medien / Social } \\
\text { Media" bezeichnen }\end{array}$ & $1=\mathrm{Ja}, 2=$ Nein & $\begin{array}{l}\text { I would consider this } \\
\text { technology "social } \\
\text { media". }\end{array}$ & $1=\mathrm{Yes}, 2=\mathrm{No}$ & & & & & & & $\mathrm{x}$ & $\mathrm{x}$ & $\mathrm{x}$ & $\mathrm{x}$ & $\mathrm{x}$ & $\mathrm{x}$ \\
\hline acc.5.is.sm & & $\begin{array}{l}\text { Ich würde diese Technologie } \\
\text { als "Soziale Medien / Social } \\
\text { Media" bezeichnen }\end{array}$ & $1=\mathrm{Ja}, 2=$ Nein & $\begin{array}{l}\text { I would consider this } \\
\text { technology "social } \\
\text { media". }\end{array}$ & $1=\mathrm{Yes}, 2=\mathrm{No}$ & & & & & & & $\mathrm{x}$ & $\mathrm{x}$ & $\mathrm{x}$ & $\mathrm{x}$ & $\mathrm{x}$ & $\mathrm{x}$ \\
\hline acc.6.is.sm & & $\begin{array}{l}\text { Ich würde diese Technologie } \\
\text { als "Soziale Medien / Social } \\
\text { Media" bezeichnen }\end{array}$ & $1=\mathrm{Ja}, 2=$ Nein & $\begin{array}{l}\text { I would consider this } \\
\text { technology "social } \\
\text { media". }\end{array}$ & $1=\mathrm{Yes}, 2=\mathrm{No}$ & & & & & & & $\mathrm{x}$ & $\mathrm{x}$ & $\mathrm{x}$ & $\mathrm{x}$ & $\mathrm{x}$ & $\mathrm{x}$ \\
\hline acc.7.is.sm & & $\begin{array}{l}\text { Ich würde diese Technologie } \\
\text { als "Soziale Medien / Social } \\
\text { Media" bezeichnen }\end{array}$ & $1=\mathrm{Ja}, 2=$ Nein & $\begin{array}{l}\text { I would consider this } \\
\text { technology "social } \\
\text { media". }\end{array}$ & $1=\mathrm{Yes}, 2=\mathrm{No}$ & & & & & & & $\mathrm{x}$ & $\mathrm{x}$ & $\mathrm{x}$ & $\mathrm{x}$ & $\mathrm{x}$ & $\mathrm{x}$ \\
\hline acc.8.is.sm & & $\begin{array}{l}\text { Ich würde diese Technologie } \\
\text { als "Soziale Medien / Social } \\
\text { Media" bezeichnen }\end{array}$ & $1=\mathrm{Ja}, 2=\mathrm{Nein}$ & $\begin{array}{l}\text { I would consider this } \\
\text { technology "social } \\
\text { media". }\end{array}$ & $1=\mathrm{Yes}, 2=\mathrm{No}$ & & & & & & & $\mathrm{x}$ & $\mathrm{x}$ & $\mathrm{x}$ & $\mathrm{x}$ & $\mathrm{x}$ & $\mathrm{x}$ \\
\hline acc.9.is.sm & & $\begin{array}{l}\text { Ich würde diese Technologie } \\
\text { als "Soziale Medien / Social } \\
\text { Media" bezeichnen }\end{array}$ & $1=\mathrm{Ja}, 2=$ Nein & $\begin{array}{l}\text { I would consider this } \\
\text { technology "social } \\
\text { media". }\end{array}$ & $1=\mathrm{Yes}, 2=\mathrm{No}$ & & & & & & & $\mathrm{x}$ & $\mathrm{x}$ & $\mathrm{x}$ & $\mathrm{x}$ & $\mathrm{x}$ & $\mathrm{x}$ \\
\hline acc.10.is.sm & & $\begin{array}{l}\text { Ich würde diese Technologie } \\
\text { als "Soziale Medien / Social } \\
\text { Media" bezeichnen }\end{array}$ & $1=\mathrm{Ja}, 2=$ Nein & $\begin{array}{l}\text { I would consider this } \\
\text { technology "social } \\
\text { media". }\end{array}$ & $1=\mathrm{Yes}, 2=\mathrm{No}$ & & & & & & & $\mathrm{x}$ & $\mathrm{x}$ & $\mathrm{x}$ & $\mathrm{x}$ & $\mathrm{x}$ & $\mathrm{x}$ \\
\hline acc.10.is.sm.str & & $\begin{array}{l}\text { Ich würde diese Technologie } \\
\text { als "Soziale Medien / Social } \\
\text { Media" bezeichnen }\end{array}$ & & $\begin{array}{l}\text { I would consider this } \\
\text { technology "social } \\
\text { media". }\end{array}$ & & & & & & & & $\mathrm{x}$ & $\mathrm{x}$ & $\mathrm{x}$ & $\mathrm{x}$ & $\mathrm{x}$ & $\mathrm{x}$ \\
\hline acc.11.is.sm & & $\begin{array}{l}\text { Ich würde diese Technologie } \\
\text { als "Soziale Medien / Social } \\
\text { Media" bezeichnen }\end{array}$ & $1=\mathrm{Ja}, 2=\mathrm{Nein}$ & $\begin{array}{l}\text { I would consider this } \\
\text { technology "social } \\
\text { media". }\end{array}$ & $1=\mathrm{Yes}, 2=\mathrm{No}$ & & & & & & & $\mathrm{x}$ & $\mathrm{x}$ & $\mathrm{x}$ & $\mathrm{x}$ & $\mathrm{x}$ & $\mathrm{x}$ \\
\hline acc.11.is.sm.str & & $\begin{array}{l}\text { Ich würde diese Technologie } \\
\text { als "Soziale Medien / Social } \\
\text { Media" bezeichnen }\end{array}$ & & $\begin{array}{l}\text { I would consider this } \\
\text { technology "social } \\
\text { media". }\end{array}$ & & & & & & & & $\mathrm{x}$ & $\mathrm{x}$ & $\mathrm{x}$ & $\mathrm{x}$ & $\mathrm{x}$ & $\mathrm{x}$ \\
\hline acc.12.is.sm & & $\begin{array}{l}\text { Ich würde diese Technologie } \\
\text { als "Soziale Medien / Social } \\
\text { Media" bezeichnen }\end{array}$ & $1=\mathrm{Ja}, 2=$ Nein & $\begin{array}{l}\text { I would consider this } \\
\text { technology "social } \\
\text { media". }\end{array}$ & $1=\mathrm{Yes}, 2=\mathrm{No}$ & & & & & & & $\mathrm{x}$ & $\mathrm{x}$ & $\mathrm{x}$ & $\mathrm{x}$ & $\mathrm{x}$ & $\mathrm{x}$ \\
\hline acc.12.is.sm.str & & $\begin{array}{l}\text { Ich würde diese Technologie } \\
\text { als "Soziale Medien / Social } \\
\text { Media" bezeichnen }\end{array}$ & & $\begin{array}{l}\text { I would consider this } \\
\text { technology "social } \\
\text { media". }\end{array}$ & & & & & & & & $\mathrm{x}$ & $\mathrm{x}$ & $\mathrm{x}$ & $\mathrm{x}$ & $\mathrm{x}$ & $\mathrm{x}$ \\
\hline acc.1.freq & & $\begin{array}{l}\text { Wie oft bist Du pro Tag auf } \\
\text { dieser Plattform? }\end{array}$ & & $\begin{array}{l}\text { How often, per day, are } \\
\text { you on this platform? }\end{array}$ & & & & & & & & $\mathrm{x}$ & $\mathrm{x}$ & $\mathrm{x}$ & $\mathrm{x}$ & $\mathrm{x}$ & $\mathrm{x}$ \\
\hline
\end{tabular}




\begin{tabular}{|c|c|c|c|c|c|c|c|c|c|c|c|c|c|c|c|c|c|}
\hline VarName & VariableLabel & WordingDE & ValueLabelsDE_Linked & WordingEN & ValueLabelsEN_Linked & L1 & $\mathrm{L} 2$ & L3 & $\mathrm{L} 4$ & L5 & L6 6 & L7 & L8 & L9 & L10 & L11 & $1 \mathrm{~L} 12$ \\
\hline acc.2.freq & & $\begin{array}{l}\text { Wie oft bist Du pro Tag auf } \\
\text { dieser Plattform? }\end{array}$ & & $\begin{array}{l}\text { How often, per day, are } \\
\text { you on this platform? }\end{array}$ & & & & & & & & $\mathrm{x}$ & $\mathrm{x}$ & $\mathrm{x}$ & $\mathrm{x}$ & $\mathrm{x}$ & $\mathrm{x}$ \\
\hline acc.3.freq & & $\begin{array}{l}\text { Wie oft bist Du pro Tag auf } \\
\text { dieser Plattform? }\end{array}$ & & $\begin{array}{l}\text { How often, per day, are } \\
\text { you on this platform? }\end{array}$ & & & & & & & & $\mathrm{x}$ & $\mathrm{x}$ & $\mathrm{x}$ & $\mathrm{x}$ & $\mathrm{x}$ & $\mathrm{x}$ \\
\hline acc.4.freq & & $\begin{array}{l}\text { Wie oft bist Du pro Tag auf } \\
\text { dieser Plattform? }\end{array}$ & & $\begin{array}{l}\text { How often, per day, are } \\
\text { you on this platform? }\end{array}$ & & & & & & & & $\mathrm{x}$ & $\mathrm{x}$ & $\mathrm{x}$ & $\mathrm{x}$ & $\mathrm{x}$ & $\mathrm{x}$ \\
\hline acc.5.freq & & $\begin{array}{l}\text { Wie oft bist Du pro Tag auf } \\
\text { dieser Plattform? }\end{array}$ & & $\begin{array}{l}\text { How often, per day, are } \\
\text { you on this platform? }\end{array}$ & & & & & & & & $\mathrm{x}$ & $\mathrm{x}$ & $\mathrm{x}$ & $\mathrm{x}$ & $\mathrm{x}$ & $\mathrm{x}$ \\
\hline acc.6.freq & & $\begin{array}{l}\text { Wie oft bist Du pro Tag auf } \\
\text { dieser Plattform? }\end{array}$ & & $\begin{array}{l}\text { How often, per day, are } \\
\text { you on this platform? }\end{array}$ & & & & & & & & $\mathrm{x}$ & $\mathrm{x}$ & $\mathrm{x}$ & $\mathrm{X}$ & $\mathrm{x}$ & $\mathrm{x}$ \\
\hline acc.7.freq & & $\begin{array}{l}\text { Wie oft bist Du pro Tag auf } \\
\text { dieser Plattform? }\end{array}$ & & $\begin{array}{l}\text { How often, per day, are } \\
\text { you on this platform? }\end{array}$ & & & & & & & & $\mathrm{x}$ & $\mathrm{x}$ & $\mathrm{x}$ & $\mathrm{x}$ & $\mathrm{x}$ & $\mathrm{x}$ \\
\hline acc.8.freq & & $\begin{array}{l}\text { Wie oft bist Du pro Tag auf } \\
\text { dieser Plattform? }\end{array}$ & & $\begin{array}{l}\text { How often, per day, are } \\
\text { you on this platform? }\end{array}$ & & & & & & & & $\mathrm{x}$ & $\mathrm{x}$ & $\mathrm{x}$ & $\mathrm{x}$ & $\mathrm{x}$ & $\mathrm{x}$ \\
\hline acc.9.freq & & $\begin{array}{l}\text { Wie oft bist Du pro Tag auf } \\
\text { dieser Plattform? }\end{array}$ & & $\begin{array}{l}\text { How often, per day, are } \\
\text { you on this platform? }\end{array}$ & & & & & & & & $\mathrm{x}$ & $\mathrm{x}$ & $\mathrm{x}$ & $\mathrm{x}$ & $\mathrm{x}$ & $\mathrm{x}$ \\
\hline acc.10.freq.str & & $\begin{array}{l}\text { Wie oft bist Du pro Tag auf } \\
\text { dieser Plattform? }\end{array}$ & & $\begin{array}{l}\text { How often, per day, are } \\
\text { you on this platform? }\end{array}$ & & & & & & & & $\mathrm{x}$ & $\mathrm{x}$ & $\mathrm{x}$ & $\mathrm{x}$ & $\mathrm{x}$ & $\mathrm{x}$ \\
\hline acc.10.freq & & $\begin{array}{l}\text { Wie oft bist Du pro Tag auf } \\
\text { dieser Plattform? }\end{array}$ & & $\begin{array}{l}\text { How often, per day, are } \\
\text { you on this platform? }\end{array}$ & & & & & & & & $\mathrm{x}$ & $\mathrm{x}$ & $\mathrm{x}$ & $\mathrm{X}$ & $\mathrm{x}$ & $\mathrm{x}$ \\
\hline acc.11.freq.str & & $\begin{array}{l}\text { Wie oft bist Du pro Tag auf } \\
\text { dieser Plattform? }\end{array}$ & & $\begin{array}{l}\text { How often, per day, are } \\
\text { you on this platform? }\end{array}$ & & & & & & & & $\mathrm{x}$ & $\mathrm{x}$ & $\mathrm{x}$ & $\mathrm{x}$ & $\mathrm{x}$ & $\mathrm{x}$ \\
\hline acc.freq. 11 & & $\begin{array}{l}\text { Wie oft bist Du pro Tag auf } \\
\text { dieser Plattform? }\end{array}$ & & $\begin{array}{l}\text { How often, per day, are } \\
\text { you on this platform? }\end{array}$ & & & & & & & & $\mathrm{x}$ & $\mathrm{x}$ & $\mathrm{x}$ & $\mathrm{x}$ & $\mathrm{x}$ & $\mathrm{x}$ \\
\hline acc.12.freq.str & & $\begin{array}{l}\text { Wie oft bist Du pro Tag auf } \\
\text { dieser Plattform? }\end{array}$ & & $\begin{array}{l}\text { How often, per day, are } \\
\text { you on this platform? }\end{array}$ & & & & & & & & $\mathrm{x}$ & $\mathrm{x}$ & $\mathrm{x}$ & $\mathrm{x}$ & $\mathrm{x}$ & $\mathrm{x}$ \\
\hline acc.12.freq & & $\begin{array}{l}\text { Wie oft bist Du pro Tag auf } \\
\text { dieser Plattform? }\end{array}$ & & $\begin{array}{l}\text { How often, per day, are } \\
\text { you on this platform? }\end{array}$ & & & & & & & & $\mathrm{x}$ & $\mathrm{x}$ & $\mathrm{x}$ & $\mathrm{x}$ & $\mathrm{x}$ & $\mathrm{x}$ \\
\hline acc.1.duration & & $\begin{array}{l}\text { Wieviel Zeit verbringst Du } \\
\text { auf dieser Plattform? }\end{array}$ & & $\begin{array}{l}\text { How much time do you } \\
\text { spend on this platform? }\end{array}$ & & & & & & & & $\mathrm{x}$ & $\mathrm{x}$ & $\mathrm{x}$ & $\mathrm{x}$ & $\mathrm{x}$ & $\mathrm{x}$ \\
\hline acc.2.duration & & $\begin{array}{l}\text { Wieviel Zeit verbringst Du } \\
\text { auf dieser Plattform? }\end{array}$ & & $\begin{array}{l}\text { How much time do you } \\
\text { spend on this platform? }\end{array}$ & & & & & & & & $\mathrm{x}$ & $\mathrm{x}$ & $\mathrm{x}$ & $\mathrm{x}$ & $\mathrm{x}$ & $\mathrm{x}$ \\
\hline acc.3.duration & & $\begin{array}{l}\text { Wieviel Zeit verbringst Du } \\
\text { auf dieser Plattform? }\end{array}$ & & $\begin{array}{l}\text { How much time do you } \\
\text { spend on this platform? }\end{array}$ & & & & & & & & $\mathrm{x}$ & $\mathrm{x}$ & $\mathrm{x}$ & $\mathrm{x}$ & $\mathrm{x}$ & $\mathrm{x}$ \\
\hline acc.4.duration & & $\begin{array}{l}\text { Wieviel Zeit verbringst Du } \\
\text { auf dieser Plattform? }\end{array}$ & & $\begin{array}{l}\text { How much time do you } \\
\text { spend on this platform? }\end{array}$ & & & & & & & & $\mathrm{x}$ & $\mathrm{x}$ & $\mathrm{x}$ & $\mathrm{x}$ & $\mathrm{x}$ & $\mathrm{x}$ \\
\hline acc.5.duration & & $\begin{array}{l}\text { Wieviel Zeit verbringst Du } \\
\text { auf dieser Plattform? }\end{array}$ & & $\begin{array}{l}\text { How much time do you } \\
\text { spend on this platform? }\end{array}$ & & & & & & & & $\mathrm{x}$ & $\mathrm{x}$ & $\mathrm{x}$ & $\mathrm{x}$ & $\mathrm{x}$ & $\mathrm{x}$ \\
\hline acc.6.duration & & $\begin{array}{l}\text { Wieviel Zeit verbringst Du } \\
\text { auf dieser Plattform? }\end{array}$ & & $\begin{array}{l}\text { How much time do you } \\
\text { spend on this platform? }\end{array}$ & & & & & & & & $\mathrm{x}$ & $\mathrm{x}$ & $\mathrm{x}$ & $\mathrm{x}$ & $\mathrm{x}$ & $\mathrm{X}$ \\
\hline acc.7.duration & & $\begin{array}{l}\text { Wieviel Zeit verbringst Du } \\
\text { auf dieser Plattform? }\end{array}$ & & $\begin{array}{l}\text { How much time do you } \\
\text { spend on this platform? }\end{array}$ & & & & & & & & $\mathrm{x}$ & $\mathrm{x}$ & $\mathrm{x}$ & $\mathrm{x}$ & $\mathrm{x}$ & $\mathrm{x}$ \\
\hline acc.8.duration & & $\begin{array}{l}\text { Wieviel Zeit verbringst Du } \\
\text { auf dieser Plattform? }\end{array}$ & & $\begin{array}{l}\text { How much time do you } \\
\text { spend on this platform? }\end{array}$ & & & & & & & & $\mathrm{x}$ & $\mathrm{x}$ & $\mathrm{x}$ & $\mathrm{x}$ & $\mathrm{x}$ & $\mathrm{x}$ \\
\hline acc.9.duration & & $\begin{array}{l}\text { Wieviel Zeit verbringst Du } \\
\text { auf dieser Plattform? }\end{array}$ & & $\begin{array}{l}\text { How much time do you } \\
\text { spend on this platform? }\end{array}$ & & & & & & & & $\mathrm{x}$ & $\mathrm{x}$ & $\mathrm{x}$ & $\mathrm{x}$ & $\mathrm{x}$ & $\mathrm{x}$ \\
\hline acc.10.duration.str & & $\begin{array}{l}\text { Wieviel Zeit verbringst Du } \\
\text { auf dieser Plattform? }\end{array}$ & & $\begin{array}{l}\text { How much time do you } \\
\text { spend on this platform? }\end{array}$ & & & & & & & & $\mathrm{x}$ & $\mathrm{x}$ & $\mathrm{x}$ & $\mathrm{x}$ & $\mathrm{x}$ & $\mathrm{x}$ \\
\hline acc.10.duration & & $\begin{array}{l}\text { Wieviel Zeit verbringst Du } \\
\text { auf dieser Plattform? }\end{array}$ & & $\begin{array}{l}\text { How much time do you } \\
\text { spend on this platform? }\end{array}$ & & & & & & & & $\mathrm{x}$ & $\mathrm{x}$ & $\mathrm{x}$ & $\mathrm{x}$ & $\mathrm{x}$ & $\mathrm{x}$ \\
\hline acc.11.duration.str & & $\begin{array}{l}\text { Wieviel Zeit verbringst Du } \\
\text { auf dieser Plattform? }\end{array}$ & & $\begin{array}{l}\text { How much time do you } \\
\text { spend on this platform? }\end{array}$ & & & & & & & & $\mathrm{x}$ & $\mathrm{x}$ & $\mathrm{x}$ & $\mathrm{x}$ & $\mathrm{x}$ & $\mathrm{x}$ \\
\hline acc.11.duration & & $\begin{array}{l}\text { Wieviel Zeit verbringst Du } \\
\text { auf dieser Plattform? }\end{array}$ & & $\begin{array}{l}\text { How much time do you } \\
\text { spend on this platform? }\end{array}$ & & & & & & & & $\mathrm{x}$ & $\mathrm{x}$ & $\mathrm{x}$ & $\mathrm{x}$ & $\mathrm{x}$ & $\mathrm{x}$ \\
\hline acc.12.duration.str & & $\begin{array}{l}\text { Wieviel Zeit verbringst Du } \\
\text { auf dieser Plattform? }\end{array}$ & & $\begin{array}{l}\text { How much time do you } \\
\text { spend on this platform? }\end{array}$ & & & & & & & & $\mathrm{x}$ & $\mathrm{x}$ & $\mathrm{x}$ & $\mathrm{x}$ & $\mathrm{x}$ & $\mathrm{x}$ \\
\hline acc.12.duration & & $\begin{array}{l}\text { Wieviel Zeit verbringst Du } \\
\text { auf dieser Plattform? }\end{array}$ & & $\begin{array}{l}\text { How much time do you } \\
\text { spend on this platform? }\end{array}$ & & & & & & & & $\mathrm{x}$ & $\mathrm{x}$ & $\mathrm{x}$ & $\mathrm{X}$ & $\mathrm{x}$ & $\mathrm{x}$ \\
\hline
\end{tabular}




\begin{tabular}{|c|c|c|c|c|c|c|c|c|c|c|c|c|c|c|c|c|}
\hline VarName & VariableLabel & WordingDE & ValueLabelsDE_Linked & WordingEN & ValueLabelsEN_Linked & $\mathrm{L} 1$ & L2 & L3 & L4 L5 & L6 & L7 & L8 & L9 & L10 & L11 & L12 \\
\hline acc.1.post & & $\begin{array}{l}\text { Wie oft postest Du eigene } \\
\text { Inhalte auf dieser Plattform } \\
\text { ? }\end{array}$ & & $\begin{array}{l}\text { How often do you post } \\
\text { your own content on } \\
\text { this platform? }\end{array}$ & & & & & & & $\mathrm{x}$ & $\mathrm{x}$ & $\mathrm{x}$ & $\mathrm{x}$ & $\mathrm{x}$ & $\mathrm{x}$ \\
\hline acc.2.post & & $\begin{array}{l}\text { Wie oft postest Du eigene } \\
\text { Inhalte auf dieser Plattform } \\
?\end{array}$ & & $\begin{array}{l}\text { How often do you post } \\
\text { your own content on } \\
\text { this platform? }\end{array}$ & & & & & & & $\mathrm{x}$ & $\mathrm{x}$ & $\mathrm{x}$ & $\mathrm{x}$ & $\mathrm{x}$ & $\mathrm{x}$ \\
\hline acc.3.post & & $\begin{array}{l}\text { Wie oft postest Du eigene } \\
\text { Inhalte auf dieser Plattform } \\
?\end{array}$ & & $\begin{array}{l}\text { How often do you post } \\
\text { your own content on } \\
\text { this platform? }\end{array}$ & & & & & & & $\mathrm{x}$ & $\mathrm{x}$ & $\mathrm{x}$ & $\mathrm{x}$ & $\mathrm{x}$ & $\mathrm{x}$ \\
\hline acc.4.post & & $\begin{array}{l}\text { Wie oft postest Du eigene } \\
\text { Inhalte auf dieser Plattform } \\
?\end{array}$ & & $\begin{array}{l}\text { How often do you post } \\
\text { your own content on } \\
\text { this platform? }\end{array}$ & & & & & & & $\mathrm{x}$ & $\mathrm{x}$ & $\mathrm{x}$ & $\mathrm{x}$ & $\mathrm{x}$ & $\mathrm{x}$ \\
\hline acc.5.post & & $\begin{array}{l}\text { Wie oft postest Du eigene } \\
\text { Inhalte auf dieser Plattform } \\
?\end{array}$ & & $\begin{array}{l}\text { How often do you post } \\
\text { your own content on } \\
\text { this platform? }\end{array}$ & & & & & & & $\mathrm{x}$ & $\mathrm{x}$ & $\mathrm{x}$ & $\mathrm{x}$ & $\mathrm{x}$ & $\mathrm{x}$ \\
\hline acc.6.post & & $\begin{array}{l}\text { Wie oft postest Du eigene } \\
\text { Inhalte auf dieser Plattform } \\
?\end{array}$ & & $\begin{array}{l}\text { How often do you post } \\
\text { your own content on } \\
\text { this platform? }\end{array}$ & & & & & & & $\mathrm{x}$ & $\mathrm{x}$ & $\mathrm{x}$ & $\mathrm{x}$ & $\mathrm{x}$ & $\mathrm{x}$ \\
\hline acc.7.post & & $\begin{array}{l}\text { Wie oft postest Du eigene } \\
\text { Inhalte auf dieser Plattform } \\
?\end{array}$ & & $\begin{array}{l}\text { How often do you post } \\
\text { your own content on } \\
\text { this platform? }\end{array}$ & & & & & & & $\mathrm{x}$ & $\mathrm{x}$ & $\mathrm{x}$ & $\mathrm{x}$ & $\mathrm{x}$ & $\mathrm{x}$ \\
\hline acc.8.post & & $\begin{array}{l}\text { Wie oft postest Du eigene } \\
\text { Inhalte auf dieser Plattform } \\
?\end{array}$ & & $\begin{array}{l}\text { How often do you post } \\
\text { your own content on } \\
\text { this platform? }\end{array}$ & & & & & & & $\mathrm{x}$ & $\mathrm{x}$ & $\mathrm{x}$ & $\mathrm{x}$ & $\mathrm{x}$ & $\mathrm{x}$ \\
\hline acc.9.post & & $\begin{array}{l}\text { Wie oft postest Du eigene } \\
\text { Inhalte auf dieser Plattform } \\
?\end{array}$ & & $\begin{array}{l}\text { How often do you post } \\
\text { your own content on } \\
\text { this platform? }\end{array}$ & & & & & & & $\mathrm{x}$ & $\mathrm{x}$ & $\mathrm{x}$ & $\mathrm{x}$ & $\mathrm{x}$ & $\mathrm{x}$ \\
\hline acc.10.post.str & & $\begin{array}{l}\text { Wie oft postest Du eigene } \\
\text { Inhalte auf dieser Plattform } \\
?\end{array}$ & & $\begin{array}{l}\text { How often do you post } \\
\text { your own content on } \\
\text { this platform? }\end{array}$ & & & & & & & $\mathrm{x}$ & $\mathrm{x}$ & $\mathrm{x}$ & $\mathrm{x}$ & $\mathrm{x}$ & $\mathrm{x}$ \\
\hline acc.10.post & & $\begin{array}{l}\text { Wie oft postest Du eigene } \\
\text { Inhalte auf dieser Plattform } \\
?\end{array}$ & & $\begin{array}{l}\text { How often do you post } \\
\text { your own content on } \\
\text { this platform? }\end{array}$ & & & & & & & $\mathrm{x}$ & $\mathrm{x}$ & $\mathrm{x}$ & $\mathrm{x}$ & $\mathrm{x}$ & $\mathrm{x}$ \\
\hline acc.11.post.str & & $\begin{array}{l}\text { Wie oft postest Du eigene } \\
\text { Inhalte auf dieser Plattform } \\
?\end{array}$ & & $\begin{array}{l}\text { How often do you post } \\
\text { your own content on } \\
\text { this platform? }\end{array}$ & & & & & & & $\mathrm{x}$ & $\mathrm{x}$ & $\mathrm{x}$ & $\mathrm{x}$ & $\mathrm{x}$ & $\mathrm{x}$ \\
\hline acc.11.post & & $\begin{array}{l}\text { Wie oft postest Du eigene } \\
\text { Inhalte auf dieser Plattform } \\
?\end{array}$ & & $\begin{array}{l}\text { How often do you post } \\
\text { your own content on } \\
\text { this platform? }\end{array}$ & & & & & & & $\mathrm{x}$ & $\mathrm{x}$ & $\mathrm{x}$ & $\mathrm{x}$ & $\mathrm{x}$ & $\mathrm{x}$ \\
\hline acc.12.post.str & & $\begin{array}{l}\text { Wie oft postest Du eigene } \\
\text { Inhalte auf dieser Plattform } \\
?\end{array}$ & & $\begin{array}{l}\text { How often do you post } \\
\text { your own content on } \\
\text { this platform? }\end{array}$ & & & & & & & $\mathrm{x}$ & $\mathrm{x}$ & $\mathrm{x}$ & $\mathrm{x}$ & $\mathrm{x}$ & $\mathrm{x}$ \\
\hline acc.12.post & & $\begin{array}{l}\text { Wie oft postest Du eigene } \\
\text { Inhalte auf dieser Plattform } \\
?\end{array}$ & & $\begin{array}{l}\text { How often do you post } \\
\text { your own content on } \\
\text { this platform? }\end{array}$ & & & & & & & $\mathrm{x}$ & $\mathrm{x}$ & $\mathrm{x}$ & $\mathrm{x}$ & $\mathrm{x}$ & $\mathrm{x}$ \\
\hline acc.1.comm & & $\begin{array}{l}\text { Ich verwende diese } \\
\text { Plattform um mit } \\
\text { Mitstudierenden zu } \\
\text { kommunizieren }\end{array}$ & $1=\mathrm{Ja}, 2=\mathrm{Nein}$ & $\begin{array}{l}\text { I use this platform to } \\
\text { communicate with fellow } \\
\text { students }\end{array}$ & $1=\mathrm{Yes}, 2=\mathrm{No}$ & & & & & & $\mathrm{x}$ & $\mathrm{x}$ & $\mathrm{x}$ & $\mathrm{x}$ & $\mathrm{x}$ & $\mathrm{x}$ \\
\hline acc.2.comm & & $\begin{array}{l}\text { Ich verwende diese } \\
\text { Plattform um mit } \\
\text { Mitstudierenden zu } \\
\text { kommunizieren }\end{array}$ & $1=\mathrm{Ja}, 2=$ Nein & $\begin{array}{l}\text { I use this platform to } \\
\text { communicate with fellow } \\
\text { students }\end{array}$ & $1=\mathrm{Yes}, 2=\mathrm{No}$ & & & & & & $\mathrm{x}$ & $\mathrm{x}$ & $\mathrm{x}$ & $\mathrm{x}$ & $\mathrm{x}$ & $\mathrm{x}$ \\
\hline acc.3.comm & & $\begin{array}{l}\text { Ich verwende diese } \\
\text { Plattform um mit } \\
\text { Mitstudierenden zu } \\
\text { kommunizieren }\end{array}$ & $1=\mathrm{Ja}, 2=$ Nein & $\begin{array}{l}\text { I use this platform to } \\
\text { communicate with fellow } \\
\text { students }\end{array}$ & $1=\mathrm{Yes}, 2=\mathrm{No}$ & & & & & & $\mathrm{x}$ & $\mathrm{x}$ & $\mathrm{x}$ & $\mathrm{x}$ & $\mathrm{X}$ & $x$ \\
\hline acc.4.comm & & $\begin{array}{l}\text { Ich verwende diese } \\
\text { Plattform um mit } \\
\text { Mitstudierenden zu } \\
\text { kommunizieren }\end{array}$ & $1=\mathrm{Ja}, 2=$ Nein & $\begin{array}{l}\text { I use this platform to } \\
\text { communicate with fellow } \\
\text { students }\end{array}$ & $1=\mathrm{Yes}, 2=\mathrm{No}$ & & & & & & $\mathrm{x}$ & $\mathrm{x}$ & $\mathrm{x}$ & $\mathrm{x}$ & $\mathrm{x}$ & $\mathrm{x}$ \\
\hline
\end{tabular}




\begin{tabular}{|c|c|c|c|c|c|c|c|c|c|c|c|c|c|c|c|c|c|}
\hline VarName & VariableLabel & WordingDE & ValueLabelsDE_Linked & WordingEN & ValueLabelsEN_Linked & L1 & L2 & L3 & $\mathrm{L} 4$ & L5 & $\mathrm{L} 6$ & L7 & L8 & L9 & L10 & L11 & $\mathrm{L} 12$ \\
\hline acc.5.comm & & $\begin{array}{l}\text { Ich verwende diese } \\
\text { Plattform um mit } \\
\text { Mitstudierenden zu } \\
\text { kommunizieren }\end{array}$ & $1=\mathrm{Ja}, 2=$ Nein & $\begin{array}{l}\text { I use this platform to } \\
\text { communicate with fellow } \\
\text { students }\end{array}$ & $1=$ Yes, $2=$ No & & & & & & & $\mathrm{x}$ & $\mathrm{x}$ & $\mathrm{x}$ & $\mathrm{x}$ & $\mathrm{x}$ & $\mathrm{x}$ \\
\hline acc.6.comm & & $\begin{array}{l}\text { Ich verwende diese } \\
\text { Plattform um mit } \\
\text { Mitstudierenden zu } \\
\text { kommunizieren }\end{array}$ & $1=\mathrm{Ja}, 2=$ Nein & $\begin{array}{l}\text { I use this platform to } \\
\text { communicate with fellow } \\
\text { students }\end{array}$ & $1=\mathrm{Yes}, 2=\mathrm{No}$ & & & & & & & $\mathrm{x}$ & $\mathrm{x}$ & $\mathrm{x}$ & $\mathrm{x}$ & $\mathrm{x}$ & $\mathrm{x}$ \\
\hline acc.7.comm & & $\begin{array}{l}\text { Ich verwende diese } \\
\text { Plattform um mit } \\
\text { Mitstudierenden zu } \\
\text { kommunizieren }\end{array}$ & $1=\mathrm{Ja}, 2=$ Nein & $\begin{array}{l}\text { I use this platform to } \\
\text { communicate with fellow } \\
\text { students }\end{array}$ & $1=\mathrm{Yes}, 2=\mathrm{No}$ & & & & & & & $\mathrm{x}$ & $\mathrm{x}$ & $\mathrm{x}$ & $\mathrm{x}$ & $\mathrm{x}$ & $\mathrm{x}$ \\
\hline acc.8.comm & & $\begin{array}{l}\text { Ich verwende diese } \\
\text { Plattform um mit } \\
\text { Mitstudierenden zu } \\
\text { kommunizieren }\end{array}$ & $1=\mathrm{Ja}, 2=$ Nein & $\begin{array}{l}\text { I use this platform to } \\
\text { communicate with fellow } \\
\text { students }\end{array}$ & $1=\mathrm{Yes}, 2=\mathrm{No}$ & & & & & & & $\mathrm{x}$ & $\mathrm{x}$ & $\mathrm{x}$ & $\mathrm{x}$ & $\mathrm{x}$ & $\mathrm{x}$ \\
\hline acc.9.comm & & $\begin{array}{l}\text { Ich verwende diese } \\
\text { Plattform um mit } \\
\text { Mitstudierenden zu } \\
\text { kommunizieren }\end{array}$ & $1=\mathrm{Ja}, 2=$ Nein & $\begin{array}{l}\text { I use this platform to } \\
\text { communicate with fellow } \\
\text { students }\end{array}$ & $1=\mathrm{Yes}, 2=\mathrm{No}$ & & & & & & & $\mathrm{x}$ & $\mathrm{x}$ & $\mathrm{x}$ & $\mathrm{x}$ & $\mathrm{x}$ & $\mathrm{x}$ \\
\hline acc.10.comm & & $\begin{array}{l}\text { Ich verwende diese } \\
\text { Plattform um mit } \\
\text { Mitstudierenden zu } \\
\text { kommunizieren }\end{array}$ & $1=\mathrm{Ja}, 2=$ Nein & $\begin{array}{l}\text { I use this platform to } \\
\text { communicate with fellow } \\
\text { students }\end{array}$ & $1=\mathrm{Yes}, 2=\mathrm{No}$ & & & & & & & $\mathrm{x}$ & $\mathrm{x}$ & $\mathrm{x}$ & $\mathrm{x}$ & $\mathrm{x}$ & $\mathrm{x}$ \\
\hline acc.10.comm.str & & $\begin{array}{l}\text { Ich verwende diese } \\
\text { Plattform um mit } \\
\text { Mitstudierenden zu } \\
\text { kommunizieren }\end{array}$ & & $\begin{array}{l}\text { I use this platform to } \\
\text { communicate with fellow } \\
\text { students }\end{array}$ & & & & & & & & $\mathrm{x}$ & $\mathrm{x}$ & $\mathrm{x}$ & $\mathrm{x}$ & $\mathrm{x}$ & $\mathrm{x}$ \\
\hline acc.11.comm & & $\begin{array}{l}\text { Ich verwende diese } \\
\text { Plattform um mit } \\
\text { Mitstudierenden } \mathrm{zu} \\
\text { kommunizieren }\end{array}$ & $1=\mathrm{Ja}, 2=$ Nein & $\begin{array}{l}\text { I use this platform to } \\
\text { communicate with fellow } \\
\text { students }\end{array}$ & $1=\mathrm{Yes}, 2=\mathrm{No}$ & & & & & & & $\mathrm{x}$ & $\mathrm{x}$ & $\mathrm{x}$ & $\mathrm{x}$ & $\mathrm{x}$ & $\mathrm{x}$ \\
\hline acc.11.comm.str & & $\begin{array}{l}\text { Ich verwende diese } \\
\text { Plattform um mit } \\
\text { Mitstudierenden zu } \\
\text { kommunizieren }\end{array}$ & & $\begin{array}{l}\text { I use this platform to } \\
\text { communicate with fellow } \\
\text { students }\end{array}$ & & & & & & & & $\mathrm{x}$ & $\mathrm{x}$ & $\mathrm{x}$ & $\mathrm{x}$ & $\mathrm{x}$ & $\mathrm{x}$ \\
\hline acc.12.comm & & $\begin{array}{l}\text { Ich verwende diese } \\
\text { Plattform um mit } \\
\text { Mitstudierenden zu } \\
\text { kommunizieren }\end{array}$ & $1=\mathrm{Ja}, 2=$ Nein & $\begin{array}{l}\text { I use this platform to } \\
\text { communicate with fellow } \\
\text { students }\end{array}$ & $1=\mathrm{Yes}, 2=\mathrm{No}$ & & & & & & & $\mathrm{x}$ & $\mathrm{x}$ & $\mathrm{x}$ & $\mathrm{x}$ & $\mathrm{x}$ & $\mathrm{x}$ \\
\hline acc.12.comm.str & & $\begin{array}{l}\text { Ich verwende diese } \\
\text { Plattform um mit } \\
\text { Mitstudierenden zu } \\
\text { kommunizieren }\end{array}$ & & $\begin{array}{l}\text { I use this platform to } \\
\text { communicate with fellow } \\
\text { students }\end{array}$ & & & & & & & & $\mathrm{x}$ & $\mathrm{x}$ & $\mathrm{x}$ & $\mathrm{x}$ & $\mathrm{x}$ & $\mathrm{x}$ \\
\hline sm.perception.1 & & $\begin{array}{l}\text { Soziale Medien sind wichtig, } \\
\text { um soziale Events zwischen } \\
\text { den Studierenden des } \\
\text { Departements zu } \\
\text { organisieren }\end{array}$ & $\begin{array}{l}1=\text { trifft überhaupt nicht zu, } \\
2=\text { trifft eher nicht zu, } 3= \\
\text { weder noch, } 4=\text { eher } \\
\text { zutreffend, } 5=\text { trifft voll und } \\
\text { ganz zu }\end{array}$ & $\begin{array}{l}\text { Social media are } \\
\text { important for organizing } \\
\text { social events between } \\
\text { the students in the } \\
\text { department. }\end{array}$ & $\begin{array}{l}1=\text { does not apply at all, } \\
2=\text { mostly does not } \\
\text { apply, } 3=\text { neither, } 4= \\
\text { mostly applies, } 5= \\
\text { applies completely (free } \\
\text { translation) }\end{array}$ & & & & & & & $\mathrm{x}$ & $\mathrm{x}$ & $\mathrm{x}$ & $\mathrm{x}$ & $\mathrm{x}$ & $\mathrm{x}$ \\
\hline sm.perception.2 & & $\begin{array}{l}\text { Soziale Medien sind wichtig, } \\
\text { um [name removed] } \\
\text { Lernmaterialien } \\
\text { auszutauschen und } \mathrm{zu} \\
\text { diskutieren }\end{array}$ & $\begin{array}{l}1=\text { trifft überhaupt nicht zu, } \\
2=\text { trifft eher nicht } \mathrm{zu}, 3= \\
\text { weder noch, } 4=\text { eher } \\
\text { zutreffend, } 5=\text { trifft voll und } \\
\text { ganz zu }\end{array}$ & $\begin{array}{l}\text { Social media are } \\
\text { important to exchange } \\
\text { and discuss study } \\
\text { materials. }\end{array}$ & $\begin{array}{l}1=\text { does not apply at all, } \\
2=\text { mostly does not } \\
\text { apply, } 3=\text { neither, } 4= \\
\text { mostly applies, } 5= \\
\text { applies completely (free } \\
\text { translation) }\end{array}$ & & & & & & & $\mathrm{x}$ & $\mathrm{x}$ & $\mathrm{x}$ & $\mathrm{x}$ & $\mathrm{x}$ & $\mathrm{x}$ \\
\hline sm.perception.3 & & $\begin{array}{l}\text { Soziale Medien sind wichtig, } \\
\text { um Freundschaften } \\
\text { innerhalb des Departements } \\
\text { zu pflegen }\end{array}$ & $\begin{array}{l}1=\text { trifft überhaupt nicht } \mathrm{zu}, \\
2=\text { trifft eher nicht } \mathrm{zu}, 3= \\
\text { weder noch, } 4=\text { eher } \\
\text { zutreffend, } 5=\text { trifft voll und } \\
\text { ganz zu }\end{array}$ & $\begin{array}{l}\text { Social media are } \\
\text { important to maintain } \\
\text { friendships within the } \\
\text { department. }\end{array}$ & $\begin{array}{l}1=\text { does not apply at all, } \\
2=\text { mostly does not } \\
\text { apply, } 3=\text { neither, } 4= \\
\text { mostly applies, } 5= \\
\text { applies completely (free } \\
\text { translation) }\end{array}$ & & & & & & & $\mathrm{x}$ & $\mathrm{x}$ & $\mathrm{x}$ & $\mathrm{x}$ & $\mathrm{x}$ & $\mathrm{x}$ \\
\hline
\end{tabular}




\begin{tabular}{|c|c|c|c|c|c|c|c|c|c|c|c|c|c|c|c|c|c|}
\hline VarName & VariableLabel & WordingDE & ValueLabelsDE_Linked & WordingEN & ValueLabelsEN_Linked & $\mathrm{L} 1$ & L2 & L3 & $\mathrm{L} 4$ & L5 & $\mathrm{L} 6$ & L7 & L8 & L9 & L10 & 0 L11 & $1 \mathrm{~L} 12$ \\
\hline sm.perception. 4 & & $\begin{array}{l}\text { Soziale Medien sind wichtig, } \\
\text { um Freundschaften } \\
\text { ausserhalb der [name } \\
\text { removed] zu pflegen }\end{array}$ & $\begin{array}{l}1=\text { trifft überhaupt nicht zu, } \\
2=\text { trifft eher nicht } \mathrm{zu}, 3= \\
\text { weder noch, } 4=\text { eher } \\
\text { zutreffend, } 5=\text { trifft voll und } \\
\text { ganz zu }\end{array}$ & $\begin{array}{l}\text { Social media are } \\
\text { important to maintain } \\
\text { friendships outside of } \\
\text { the university. }\end{array}$ & $\begin{array}{l}1=\text { does not apply at all, } \\
2=\text { mostly does not } \\
\text { apply, } 3=\text { neither, } 4= \\
\text { mostly applies, } 5= \\
\text { applies completely (free } \\
\text { translation) }\end{array}$ & & & & & & & $\mathrm{x}$ & $\mathrm{x}$ & $\mathrm{x}$ & $\mathrm{x}$ & $\mathrm{x}$ & $\mathrm{x}$ \\
\hline sm.perception.5 & & $\begin{array}{l}\text { Wenn ich einen Tag lang } \\
\text { keinen Zugang zu Sozialen } \\
\text { Medien habe, fühle ich mich } \\
\text { gestresst }\end{array}$ & $\begin{array}{l}1=\text { trifft überhaupt nicht zu, } \\
2=\text { trifft eher nicht } \mathrm{zu}, 3= \\
\text { weder noch, } 4=\text { eher } \\
\text { zutreffend, } 5=\text { trifft voll und } \\
\text { ganz zu }\end{array}$ & $\begin{array}{l}\text { When I don't have } \\
\text { access to social media } \\
\text { for a day, I feel stressed }\end{array}$ & $\begin{array}{l}1=\text { does not apply at all, } \\
2=\text { mostly does not } \\
\text { apply, } 3=\text { neither, } 4= \\
\text { mostly applies, } 5= \\
\text { applies completely (free } \\
\text { translation) }\end{array}$ & & & & & & & $\mathrm{x}$ & $\mathrm{x}$ & $\mathrm{x}$ & $\mathrm{x}$ & $\mathrm{x}$ & $\mathrm{x}$ \\
\hline sm.perception. 6 & & $\begin{array}{l}\text { Wenn ich einen Tag lang } \\
\text { keinen Zugang zu Sozialen } \\
\text { Medien habe fühle ich mich } \\
\text { erleichtert }\end{array}$ & $\begin{array}{l}1=\text { trifft überhaupt nicht zu, } \\
2=\text { trifft eher nicht } \mathrm{zu}, 3= \\
\text { weder noch, } 4=\text { eher } \\
\text { zutreffend, } 5=\text { trifft voll und } \\
\text { ganz zu }\end{array}$ & $\begin{array}{l}\text { When I don't have } \\
\text { access to social media } \\
\text { for a day, I feel relieved }\end{array}$ & $\begin{array}{l}1=\text { does not apply at all, } \\
2=\text { mostly does not } \\
\text { apply, } 3=\text { neither, } 4= \\
\text { mostly applies, } 5= \\
\text { applies completely (free } \\
\text { translation) }\end{array}$ & & & & & & & $\mathrm{x}$ & $\mathrm{x}$ & $\mathrm{x}$ & $\mathrm{x}$ & $\mathrm{x}$ & $\mathrm{x}$ \\
\hline sm.more.less & & $\begin{array}{l}\text { Ich würde Soziale Medien } \\
\text { gerne... }\end{array}$ & $\begin{array}{l}1=\text { viel mehr nutzen, } 2= \\
\text { etwas mehr nutzen, } 3= \\
\text { unverändert nutzen, } 4= \\
\text { etwas weniger nutzen, } 5= \\
\text { viel weniger nutzen }\end{array}$ & $\begin{array}{l}\text { I would like to use social } \\
\text { media... }\end{array}$ & $\begin{array}{l}1=\mathrm{a} \text { lot more, } 2=\mathrm{a} \text { bit } \\
\text { more, } 3=\text { an unchanged } \\
\text { amount, } 4=\mathrm{a} \text { bit less, } 5 \\
=\mathrm{a} \text { lot less }\end{array}$ & & & & & & & $\mathrm{x}$ & $\mathrm{x}$ & $\mathrm{x}$ & $\mathrm{x}$ & $\mathrm{x}$ & $\mathrm{x}$ \\
\hline sm.better.worse & & $\begin{array}{l}\text { Durch Soziale Medien ist } \\
\text { mein Leben insgesamt... }\end{array}$ & $\begin{array}{l}1=\text { viel besser, } 2=\text { etwas } \\
\text { besser, } 3=\text { unverändert, } 4= \\
\text { etwas schlechter, } 5=\text { viel } \\
\text { schlechter }\end{array}$ & $\begin{array}{l}\text { On the whole, social } \\
\text { media have made my } \\
\text { life... }\end{array}$ & $\begin{array}{l}1=\text { much better, } 2=\mathrm{a} \\
\text { bit better, } 3= \\
\text { unchanged, } 4=\mathrm{a} \text { bit } \\
\text { worse, } 5=\text { much worse }\end{array}$ & & & & & & & $\mathrm{x}$ & $\mathrm{x}$ & $\mathrm{x}$ & $\mathrm{x}$ & $\mathrm{x}$ & $\mathrm{x}$ \\
\hline sm.comm.P1 & & $\begin{array}{l}\text { Mit welchen Deiner } \\
\text { Mitstudierenden } \\
\text { kommunizierst Du } \\
\text { regelmässig über Soziale } \\
\text { Medien? (ausgenommen } \\
\text { Messaging-Apps). Nenne } \\
\text { zwischen 0 und } 20 \text { Personen }\end{array}$ & & $\begin{array}{l}\text { With which of your } \\
\text { fellow students do you } \\
\text { regularly communicate } \\
\text { over social media? } \\
\text { (excluding messaging } \\
\text { apps). Name between } 0 \\
\text { and } 20 \text { people. }\end{array}$ & & & & & & & & $\mathrm{x}$ & $\mathrm{x}$ & $\mathrm{x}$ & $\mathrm{x}$ & $\mathrm{x}$ & $\mathrm{x}$ \\
\hline msg.comm.P1 & & $\begin{array}{l}\text { Mit welchen Deiner } \\
\text { Mitstudierenden } \\
\text { kommunizierst } \\
\text { Duregelmässig über } \\
\text { Messaging-Apps (z.B. } \\
\text { Whatsapp, Signal, SMS)? } \\
\text { Nenne bitte zwischen 0 und } \\
20 \text { Personen. }\end{array}$ & & $\begin{array}{l}\text { With which of your } \\
\text { fellow students do you } \\
\text { regularly communicate } \\
\text { over messaging apps? } \\
\text { (for instance Whatsapp, } \\
\text { Signal, SMS). Name } \\
\text { between } 0 \text { and } 20 \\
\text { people. }\end{array}$ & & & & & & & & $\mathrm{x}$ & $\mathrm{x}$ & $\mathrm{x}$ & $\mathrm{x}$ & $\mathrm{x}$ & $\mathrm{x}$ \\
\hline sm.good.P1 & & $\begin{array}{l}\text { Wer postet auf Sozialen } \\
\text { Medien Inhalte, die Du } \\
\text { besonders gut findest? }\end{array}$ & & $\begin{array}{l}\text { Who posts content on } \\
\text { social media that you } \\
\text { find particularly good? }\end{array}$ & & & & & & & & $\mathrm{x}$ & $\mathrm{x}$ & $\mathrm{x}$ & $\mathrm{x}$ & $\mathrm{x}$ & $\mathrm{x}$ \\
\hline sm.bad.P1 & & $\begin{array}{l}\text { Wer postet auf Sozialen } \\
\text { Medien Inhalte, die Du } \\
\text { besonders schlecht findest? }\end{array}$ & & $\begin{array}{l}\text { Who posts content on } \\
\text { social media that you } \\
\text { find particularly bad? }\end{array}$ & & & & & & & & $\mathrm{x}$ & $\mathrm{x}$ & $\mathrm{x}$ & $\mathrm{x}$ & $\mathrm{x}$ & $\mathrm{x}$ \\
\hline phys.comm.covid.P1 & & $\begin{array}{l}\text { Mit wem interagierst } \mathrm{Du} \\
\text { persönlich (ihr seid physisch } \\
\text { beieinander)? }\end{array}$ & & $\begin{array}{l}\text { With whom do you } \\
\text { interact in person (you } \\
\text { are together physically)? }\end{array}$ & & & & & & & & & & & & $\mathrm{x}$ & $\mathrm{x}$ \\
\hline tel.comm.covid.P1 & & $\begin{array}{l}\text { Mit wem interagierst Du } \\
\text { telefonisch (via Telefon, } \\
\text { Skype, FaceTime, etc.)? }\end{array}$ & & $\begin{array}{l}\text { With whom do you } \\
\text { interact by phone (by } \\
\text { telephone, Skype, } \\
\text { FaceTime, etc.)? }\end{array}$ & & & & & & & & & & & & $\mathrm{x}$ & $\mathrm{x}$ \\
\hline quarantine.covid.P1 & & $\begin{array}{l}\text { Falls eine Ausgangssperre } \\
\text { verhängt wird, mit welchen } \\
5 \text { Personen des Studiums } \\
\text { würdest Du Dich gerne in } \\
\text { Quarantäne befinden? }\end{array}$ & & $\begin{array}{l}\text { If a curfew were to be } \\
\text { imposed, which } 5 \text { people } \\
\text { from your degree would } \\
\text { you like to be } \\
\text { quarantined with? }\end{array}$ & & & & & & & & & & & & $\mathrm{x}$ & $\mathrm{x}$ \\
\hline
\end{tabular}




\begin{tabular}{|c|c|c|c|c|c|c|c|c|c|c|c|c|c|c|c|c|}
\hline VarName & VariableLabel & WordingDE & ValueLabelsDE_Linked & WordingEN & ValueLabelsEN_Linked & L1 & $\mathrm{L} 2$ & L3 & $\mathrm{L} 4$ & L5 & $\mathrm{L} 6$ & L7 & L8 & L9 & L10 L11 & L12 \\
\hline health.covid.1 & & $\begin{array}{l}\text { Das Risiko für meine } \\
\text { Gesundheit ist gross, wenn } \\
\text { ich mich mit COVID-19 } \\
\text { infiziere. }\end{array}$ & $\begin{array}{l}1=\text { stimmt überhaupt nicht, } \\
2=\text { stimmt nicht, } 3=\text { stimmt } \\
\text { eher nicht, } 4=\text { weder noch, } 5 \\
=\text { stimmt eher, } 6=\text { stimmt, } 7 \\
=\text { stimmt voll und ganz }\end{array}$ & $\begin{array}{l}\text { The risk to my health } \\
\text { would be high if I were } \\
\text { to be infected with } \\
\text { COVID-19 }\end{array}$ & $\begin{array}{l}1=\text { does not apply at all, } \\
2=\text { does not apply, } 3= \\
\text { does rather not apply, } 4= \\
\text { neither, } 5=\text { rather } \\
\text { applies, } 6=\text { applies, } 7= \\
\text { applies completely (free } \\
\text { translation) }\end{array}$ & & & & & & & & & & $\mathrm{x}$ & $\mathrm{x}$ \\
\hline health.covid.2 & & $\begin{array}{l}\text { Das Risiko für die } \\
\text { Gesundheit meiner Familie } \\
\text { und Freunde ist gross, wenn } \\
\text { sie sich mit COVID-19 } \\
\text { infizieren. }\end{array}$ & $\begin{array}{l}1=\text { stimmt überhaupt nicht, } \\
2=\text { stimmt nicht, } 3=\text { stimmt } \\
\text { eher nicht, } 4=\text { weder noch, } 5 \\
=\text { stimmt eher, } 6=\text { stimmt, } 7 \\
=\text { stimmt voll und ganz }\end{array}$ & $\begin{array}{l}\text { The risk to the health of } \\
\text { my family or friends } \\
\text { would be high if they } \\
\text { were infected with } \\
\text { COVID-19 }\end{array}$ & $\begin{array}{l}1=\text { does not apply at all, } \\
2=\text { does not apply, } 3= \\
\text { does rather not apply, } 4= \\
\text { neither, } 5=\text { rather } \\
\text { applies, } 6=\text { applies, } 7= \\
\text { applies completely (free } \\
\text { translation) }\end{array}$ & & & & & & & & & & $\mathrm{x}$ & $\mathrm{x}$ \\
\hline health.covid.3 & & $\begin{array}{l}\text { Das Risiko für die } \\
\text { Gesundheit von Menschen } \\
\text { im Allgemeinen ist gross, } \\
\text { wenn sie sich mit } \\
\text { COVID-19 infizieren. }\end{array}$ & $\begin{array}{l}1=\text { stimmt überhaupt nicht, } \\
2=\text { stimmt nicht, } 3=\text { stimmt } \\
\text { eher nicht, } 4=\text { weder noch, } 5 \\
=\text { stimmt eher, } 6=\text { stimmt, } 7 \\
=\text { stimmt voll und ganz }\end{array}$ & $\begin{array}{l}\text { The risk to the health of } \\
\text { people in general would } \\
\text { be high if they were } \\
\text { infected with COVID-19 }\end{array}$ & $\begin{array}{l}1=\text { does not apply at all, } \\
2=\text { does not apply, } 3= \\
\text { does rather not apply, } 4= \\
\text { neither, } 5=\text { rather } \\
\text { applies, } 6=\text { applies, } 7= \\
\text { applies completely (free } \\
\text { translation) }\end{array}$ & & & & & & & & & & $\mathrm{x}$ & $\mathrm{x}$ \\
\hline close.infected.covid & & $\begin{array}{l}\text { Gibt es eine Person, der Du } \\
\text { nahe stehst und an } \\
\text { COVID-19 erkrankt ist? }\end{array}$ & $1=\mathrm{Ja}, 2=$ Nein & $\begin{array}{l}\text { Is there anyone you are } \\
\text { close to who is infected } \\
\text { with COVID-19? }\end{array}$ & $1=\mathrm{Yes}, 2=\mathrm{No}$ & & & & & & & & & & $\mathrm{x}$ & $\mathrm{x}$ \\
\hline close.risk.covid & & $\begin{array}{l}\text { Gibt es eine Person, der Du } \\
\text { nahe stehst und die zur } \\
\text { COVID-19 Risikogruppe } \\
\text { gehört? }\end{array}$ & $1=\mathrm{Ja}, 2=$ Nein & $\begin{array}{l}\text { Is there anyone you are } \\
\text { close to who is in a } \\
\text { group considered } \\
\text { 'high-risk' for } \\
\text { COVID-19? }\end{array}$ & $1=\mathrm{Yes}, 2=\mathrm{No}$ & & & & & & & & & & $\mathrm{x}$ & $\mathrm{x}$ \\
\hline test.covid & & $\begin{array}{l}\text { Wurdest Du auf COVID-19 } \\
\text { getestet? }\end{array}$ & $1=\mathrm{Ja}, 2=\mathrm{Nein}$ & $\begin{array}{l}\text { Have you been tested for } \\
\text { COVID-19? }\end{array}$ & $1=\mathrm{Yes}, 2=\mathrm{No}$ & & & & & & & & & & $\mathrm{x}$ & $\mathrm{x}$ \\
\hline test.covid.when & & $\begin{array}{l}\text { Wann? (Bitte gib das } \\
\text { Datum an: TT/MM/JJJJ) }\end{array}$ & & & & & & & & & & & & & $\mathrm{x}$ & $\mathrm{x}$ \\
\hline test.covid.pos & & $\begin{array}{l}\text { Hast Du ein positives } \\
\text { COVID-19-Testergebnis } \\
\text { erhalten? }\end{array}$ & $1=\mathrm{Ja}, 2=$ Nein & $\begin{array}{l}\text { Have you received a } \\
\text { positive COVID-19 test } \\
\text { result }\end{array}$ & $1=\mathrm{Yes}, 2=\mathrm{No}$ & & & & & & & & & & $\mathrm{x}$ & $\mathrm{x}$ \\
\hline symptom.covid.1 & & $\begin{array}{l}\text { Hast Du in letzter Zeit eines } \\
\text { oder mehrere der folgenden } \\
\text { Symptome festgestellt, die } \\
\text { mit COVID-19 verbunden } \\
\text { sind? Fieber }\end{array}$ & & $\begin{array}{l}\text { Have you had any of the } \\
\text { following symptoms } \\
\text { associated with } \\
\text { COVID-19? Fever }\end{array}$ & & & & & & & & & & & $\mathrm{x}$ & $\mathrm{x}$ \\
\hline symptom.covid.2 & & $\begin{array}{l}\text { Hast Du in letzter Zeit eines } \\
\text { oder mehrere der folgenden } \\
\text { Symptome festgestellt, die } \\
\text { mit COVID-19 verbunden } \\
\text { sind? Husten }\end{array}$ & & Coughing & & & & & & & & & & & $\mathrm{x}$ & $\mathrm{x}$ \\
\hline symptom.covid.3 & & $\begin{array}{l}\text { Hast Du in letzter Zeit eines } \\
\text { oder mehrere der folgenden } \\
\text { Symptome festgestellt, die } \\
\text { mit COVID-19 verbunden } \\
\text { sind? Geschmacksverlust }\end{array}$ & & Loss of sense of taste & & & & & & & & & & & $\mathrm{x}$ & $\mathrm{x}$ \\
\hline symptom.covid.4 & & $\begin{array}{l}\text { Hast Du in letzter Zeit eines } \\
\text { oder mehrere der folgenden } \\
\text { Symptome festgestellt, die } \\
\text { mit COVID-19 verbunden } \\
\text { sind? Kurzatmigkeit }\end{array}$ & & Shortness of breath & & & & & & & & & & & $\mathrm{x}$ & $\mathrm{x}$ \\
\hline symptom.covid.5 & & $\begin{array}{l}\text { Hast Du in letzter Zeit eines } \\
\text { oder mehrere der folgenden } \\
\text { Symptome festgestellt, die } \\
\text { mit COVID-19 verbunden } \\
\text { sind? Halsschmerzen }\end{array}$ & & Sore throat & & & & & & & & & & & $\mathrm{x}$ & $\mathrm{x}$ \\
\hline
\end{tabular}




\begin{tabular}{|c|c|c|c|c|c|c|c|c|c|c|c|c|c|c|c|c|}
\hline VarName & VariableLabel & WordingDE & ValueLabelsDE_Linked & WordingEN & ValueLabelsEN_Linked & L1 & $\mathrm{L} 2$ & L3 & $\mathrm{L} 4$ & L5 & L6 & L7 & L8 & L9 & L10 L11 & $1 \mathrm{~L} 12$ \\
\hline symptom.covid.6 & & $\begin{array}{l}\text { Hast Du in letzter Zeit eines } \\
\text { oder mehrere der folgenden } \\
\text { Symptome festgestellt, die } \\
\text { mit COVID-19 verbunden } \\
\text { sind? Muskelschmerzen }\end{array}$ & & Muscle ache & & & & & & & & & & & $\mathrm{x}$ & $\mathrm{x}$ \\
\hline symptom.covid.7 & & $\begin{array}{l}\text { Hast Du in letzter Zeit eines } \\
\text { oder mehrere der folgenden } \\
\text { Symptome festgestellt, die } \\
\text { mit COVID-19 verbunden } \\
\text { sind? Andere }\end{array}$ & & Other & & & & & & & & & & & $\mathrm{x}$ & $\mathrm{x}$ \\
\hline symptom.covid.7.text & & $\begin{array}{l}\text { Hast Du in letzter Zeit eines } \\
\text { oder mehrere der folgenden } \\
\text { Symptome festgestellt, die } \\
\text { mit COVID-19 verbunden } \\
\text { sind? Andere Text }\end{array}$ & & Other (text box) & & & & & & & & & & & $\mathrm{x}$ & $\mathrm{x}$ \\
\hline symptom.covid.when & & $\begin{array}{l}\text { Wann trat das erste dieser } \\
\text { Symptome auf? (Bitte gib } \\
\text { das Datum an: } \\
\text { TT/MM/JJJJ) }\end{array}$ & & $\begin{array}{l}\text { When did you notice the } \\
\text { first of these symptoms } \\
\text { (Please give the date: } \\
\text { DD/MM/YYYY) }\end{array}$ & & & & & & & & & & & $\mathrm{x}$ & $\mathrm{x}$ \\
\hline effective.rules.covid & & $\begin{array}{l}\text { Inwieweit glaubst Du, dass } \\
\text { die vom Bundesamt für } \\
\text { Gesundheit empfohlenen } \\
\text { vorbeugenden Massnahmen } \\
\text { die Ausbreitung von } \\
\text { COVID-19 wirksam } \\
\text { reduzieren (häufiges } \\
\text { Händewaschen, Abstand } \\
\text { von } 2 \text { Metern zu Anderen, } \\
\text { Vermeidung von } \\
\text { Gruppentreffen, Husten / } \\
\text { Niesen in die Ellbogen, } \\
\text { Vermeidung von } \\
\text { Gesichtsberührungen)? }\end{array}$ & & $\begin{array}{l}\text { To what extent do you } \\
\text { think the preventive } \\
\text { measures recommended } \\
\text { by the Federal Office of } \\
\text { Public Health are } \\
\text { effective in reducing the } \\
\text { spread of COVID-19 } \\
\text { (frequent hand washing, } \\
\text { two-metre distance to } \\
\text { others, } \\
\text { coughing/sneezing into } \\
\text { the elbow, avoiding } \\
\text { touching your face) }\end{array}$ & & & & & & & & & & & $\mathrm{x}$ & $\mathrm{x}$ \\
\hline adherence.self.covid & & $\begin{array}{l}\text { Inwieweit befolgst Du diese } \\
\text { empfohlenen Massnahmen? }\end{array}$ & $\begin{array}{l}1=\text { gar nicht, } 2=\text { manchmal }, \\
3=\text { ungefähr zur Hälfte, } 4= \\
\text { meistens, } 5=\text { immer }\end{array}$ & $\begin{array}{l}\text { To what extent do you } \\
\text { follow these measures? }\end{array}$ & $\begin{array}{l}1=\text { not at all, } 2= \\
\text { sometimes, } 3=\text { about half } \\
\text { the time, } 4=\text { usually, } 5= \\
\text { always }\end{array}$ & & & & & & & & & & $\mathrm{x}$ & $\mathrm{x}$ \\
\hline adherence.others.covid & & $\begin{array}{l}\text { Inwieweit glaubst } \mathrm{Du} \text {, dass } \\
\text { andere Personen deines } \\
\text { Studiums die empfohlenen } \\
\text { Massnahmen befolgen? }\end{array}$ & $\begin{array}{l}1=\text { gar nicht, } 2=\text { manchmal, } \\
3=\text { ungefähr zur Hälfte, } 4= \\
\text { meistens, } 5=\text { immer }\end{array}$ & $\begin{array}{l}\text { To what extent do you } \\
\text { think others in your } \\
\text { degree follow the } \\
\text { recommended measures? }\end{array}$ & $\begin{array}{l}1=\text { not at all, } 2= \\
\text { sometimes, } 3=\text { about half } \\
\text { the time, } 4=\text { usually, } 5= \\
\text { always }\end{array}$ & & & & & & & & & & $\mathrm{x}$ & $\mathrm{X}$ \\
\hline br.conf.covid & & $\begin{array}{l}\text { Wie viele der } \\
\text { Pressekonferenzen des } \\
\text { Bundesrates hast du } \\
\text { gesehen? }\end{array}$ & & $\begin{array}{l}\text { How many of the } \\
\text { Federal Council's press } \\
\text { conferences have you } \\
\text { seen? }\end{array}$ & & & & & & & & & & & $\mathrm{x}$ & $\mathrm{x}$ \\
\hline discuss.covid.P1 & & $\begin{array}{l}\text { Mit wem innerhalb der } \\
\text { Kohorte tauschst Du Dich } \\
\text { regelmässig über COVID-19 } \\
\text { aus? Dies kann jede } \\
\text { Diskussion im } \\
\text { Zusammenhang mit dem } \\
\text { Virus umfassen, z. B. wie } \\
\text { sich COVID-19 auf die } \\
\text { Welt, Staaten oder Dich } \\
\text { selbst auswirkt, den } \\
\text { wissenschaftlichen } \\
\text { Fortschritt, aktualisierte } \\
\text { Richtlinien zur Bekämpfung } \\
\text { des Virus usw. }\end{array}$ & & $\begin{array}{l}\text { With whom within the } \\
\text { cohort do you regularly } \\
\text { exchange information } \\
\text { about COVID-19? This } \\
\text { can include any } \\
\text { discussion related to the } \\
\text { virus, such as how } \\
\text { COVID-19 is impacting } \\
\text { the world, states, or } \\
\text { yourself, scientific } \\
\text { progress, updated } \\
\text { guidelines to combat the } \\
\text { virus, etc. }\end{array}$ & & & & & & & & & & & $\mathrm{x}$ & $\mathrm{x}$ \\
\hline
\end{tabular}




\begin{tabular}{|c|c|c|c|c|c|c|c|c|c|c|c|c|c|c|c|c|}
\hline VarName & VariableLabel & WordingDE & ValueLabelsDE_Linked & WordingEN & ValueLabelsEN_Linked & L1 & $\mathrm{L} 2$ & L3 & $\mathrm{L} 4$ & L5 & L6 6 & L7 & L8 & L9 & L10 L11 & $1 \mathrm{~L} 12$ \\
\hline info.share.P1 & & $\begin{array}{l}\text { Von wem innerhalb der } \\
\text { Kohorte erhältst Du } \\
\text { nützliche Informationen zu } \\
\text { COVID-19? (in } \\
\text { Diskussionen, über soziale } \\
\text { Medien, Gruppenchats, } \\
\text { usw.) Nenne zwischen 0 } \\
\text { und } 20 \text { Personen. }\end{array}$ & & $\begin{array}{l}\text { From whom within the } \\
\text { cohort do you receive } \\
\text { useful information about } \\
\text { COVID-19? (in } \\
\text { discussions, via social } \\
\text { media, group chats, } \\
\text { etc.) Name between } 0 \\
\text { and } 20 \text { people. }\end{array}$ & & & & & & & & & & & $\mathrm{x}$ & $\mathrm{x}$ \\
\hline misinfo.share.P1 & & $\begin{array}{l}\text { Von wem innerhalb der } \\
\text { Kohorte erhältst Du } \\
\text { Informationen zu } \\
\text { COVID-19, die Du für } \\
\text { ungenau oder falsch hältst? } \\
\text { (in einer Diskussion, über } \\
\text { soziale Medien, } \\
\text { Gruppenchats, usw.) }\end{array}$ & & $\begin{array}{l}\text { From whom within the } \\
\text { cohort do you receive } \\
\text { information about } \\
\text { COVID-19 that you } \\
\text { believe is inaccurate or } \\
\text { incorrect? (in a } \\
\text { discussion, via social } \\
\text { media, group chats, etc.) }\end{array}$ & & & & & & & & & & & $\mathrm{x}$ & $\mathrm{x}$ \\
\hline misinfo.report.1 & & $\begin{array}{l}\text { Während der derzeitigen } \\
\text { COVID-19-Krise findet in } \\
\text { der Gesellschaft ein reger } \\
\text { Informationsaustausch über } \\
\text { verfügbare Behandlungen, } \\
\text { empfohlene } \\
\text { Verhaltensweisen, } \\
\text { wirtschaftliche } \\
\text { Auswirkungen, } \\
\text { Verfügbarkeit von Gütern } \\
\text { usw. statt. Auch innerhalb } \\
\text { der Universität tauschen } \\
\text { Studierende aktuelle } \\
\text { Informationen aus, z.B. } \\
\text { über geänderte Prüfungen, } \\
\text { Kurse oder den Zugang zu } \\
\text { Materialien. Manchmal } \\
\text { erweisen sich diese } \\
\text { ausgetauschten } \\
\text { Informationen als richtig, } \\
\text { manchmal sind sie } \\
\text { inkorrekt. Kannst Du } \\
\text { Beispiele nennen für solche } \\
\text { Themen oder Gerüchte, die } \\
\text { zwischen Studierenden } \\
\text { kontrovers diskutiert } \\
\text { werden, und bei denen } \\
\text { unklar ist oder unklar war, } \\
\text { ob sie korrekt sind? Bitte } \\
\text { beschreibe 1-5 solche } \\
\text { Themen oder Informationen } \\
\text { in kurzen Sätzen oder } \\
\text { Schlüsselwörtern. }\end{array}$ & & $\begin{array}{l}\text { During the current } \\
\text { COVID } 19 \text { crisis, there } \\
\text { is a lot of information } \\
\text { exchange in society } \\
\text { about available } \\
\text { treatments, } \\
\text { recommended } \\
\text { behaviours, economic } \\
\text { impact, availability of } \\
\text { goods, etc. Within the } \\
\text { university, students also } \\
\text { exchange up-to-date } \\
\text { information, e.g. about } \\
\text { changed exams, courses } \\
\text { or access to materials. } \\
\text { Sometimes this } \\
\text { exchanged information } \\
\text { turns out to be correct, } \\
\text { sometimes it is } \\
\text { incorrect. Can you give } \\
\text { examples of such topics } \\
\text { or rumours that are } \\
\text { controversial between } \\
\text { students and where it is } \\
\text { or was unclear whether } \\
\text { they are correct? Please } \\
\text { describe } 1-5 \text { such issues } \\
\text { or information in short } \\
\text { sentences or keywords. }\end{array}$ & & & & & & & & & & & $\mathrm{x}$ & $\mathrm{x}$ \\
\hline misinfo.report.2 & & $\begin{array}{l}\text { Bitte beschreibe 1-5 solche } \\
\text { Themen oder Informationen } \\
\text { in kurzen Sätzen oder } \\
\text { Schlüsselwörtern. }\end{array}$ & & $\begin{array}{l}\text { Please describe } 1-5 \text { such } \\
\text { issues or information in } \\
\text { short sentences or } \\
\text { keywords. }\end{array}$ & & & & & & & & & & & $\mathrm{x}$ & $\mathrm{x}$ \\
\hline misinfo.report.3 & & $\begin{array}{l}\text { Bitte beschreibe 1-5 solche } \\
\text { Themen oder Informationen } \\
\text { in kurzen Sätzen oder } \\
\text { Schlüsselwörtern. }\end{array}$ & & $\begin{array}{l}\text { Please describe } 1-5 \text { such } \\
\text { issues or information in } \\
\text { short sentences or } \\
\text { keywords. }\end{array}$ & & & & & & & & & & & $\mathrm{x}$ & $\mathrm{x}$ \\
\hline misinfo.report.4 & & $\begin{array}{l}\text { Bitte beschreibe } 1-5 \text { solche } \\
\text { Themen oder Informationen } \\
\text { in kurzen Sätzen oder } \\
\text { Schlüsselwörtern. }\end{array}$ & & $\begin{array}{l}\text { Please describe } 1-5 \text { such } \\
\text { issues or information in } \\
\text { short sentences or } \\
\text { keywords. }\end{array}$ & & & & & & & & & & & $\mathrm{x}$ & $\mathrm{x}$ \\
\hline
\end{tabular}




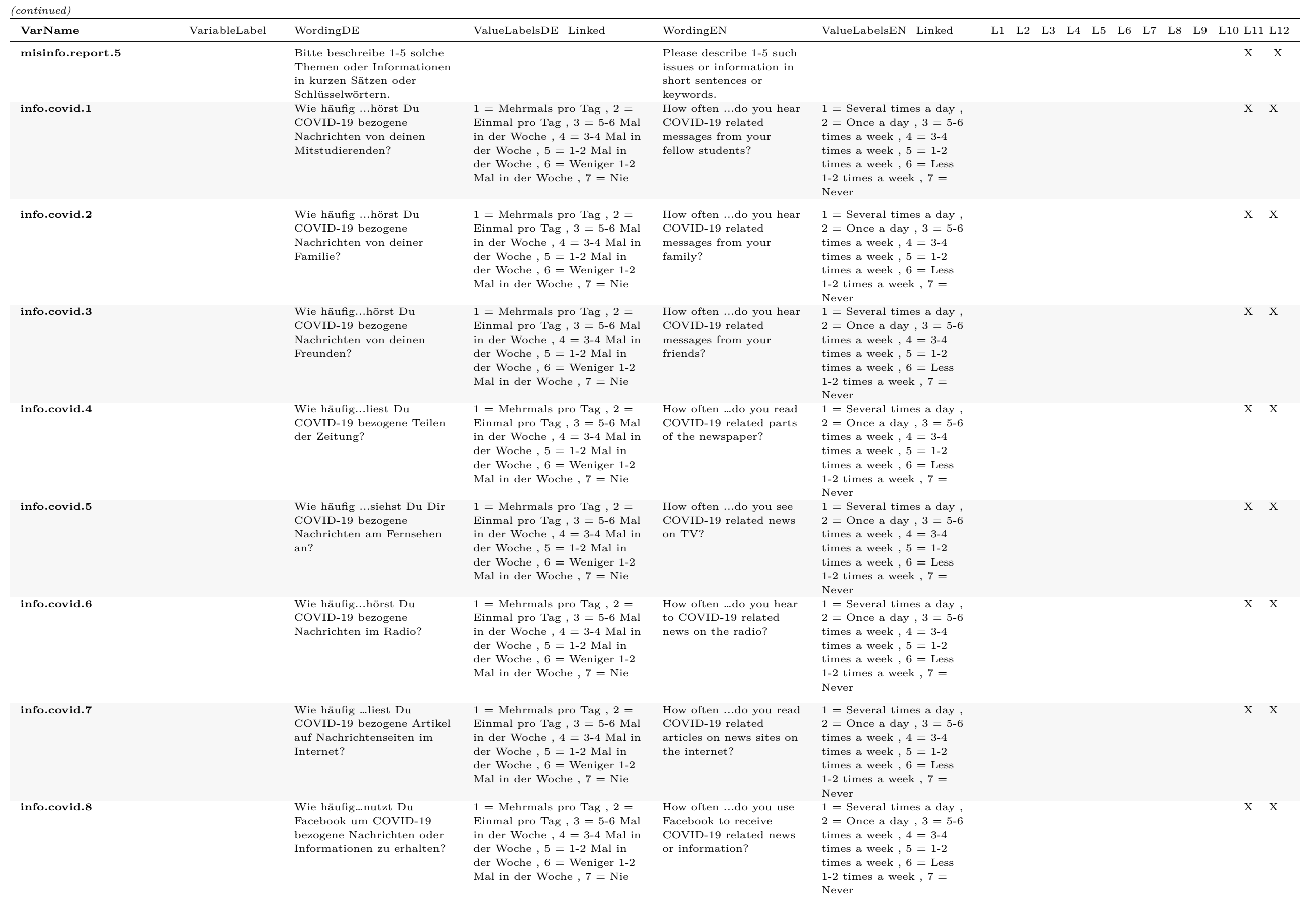




\begin{tabular}{|c|c|c|c|c|c|c|c|c|c|c|c|c|c|c|c|c|}
\hline VarName & VariableLabel & WordingDE & ValueLabelsDE_Linked & WordingEN & ValueLabelsEN_Linked & $\mathrm{L} 1$ & $\mathrm{~L} 2$ & L3 & $\mathrm{L} 4$ & L5 & $\mathrm{L} 6$ & L7 & $\mathrm{L} 8$ & L9 & L10 L11 & $1 \mathrm{~L} 12$ \\
\hline info.covid.9 & & $\begin{array}{l}\text { Wie häufig ...nutzt Du } \\
\text { Twitter um COVID-19 } \\
\text { bezogene Nachrichten oder } \\
\text { Informationen zu erhalten? }\end{array}$ & $\begin{array}{l}1=\text { Mehrmals pro Tag, } 2= \\
\text { Einmal pro Tag, } 3=5-6 \mathrm{Mal} \\
\text { in der Woche, } 4=3-4 \mathrm{Mal} \text { in } \\
\text { der Woche, } 5=1-2 \mathrm{Mal} \text { in } \\
\text { der Woche, } 6=\text { Weniger } 1-2 \\
\text { Mal in der Woche, } 7=\mathrm{Nie}\end{array}$ & $\begin{array}{l}\text { How often ...do you use } \\
\text { Twitter to receive } \\
\text { COVID- } 19 \text { related news } \\
\text { or information? }\end{array}$ & $\begin{array}{l}1=\text { Several times a day } \\
2=\text { Once a day }, 3=5-6 \\
\text { times a week, } 4=3-4 \\
\text { times a week, } 5=1-2 \\
\text { times a week, } 6=\text { Less } \\
1-2 \text { times a week, } 7= \\
\text { Never }\end{array}$ & & & & & & & & & & $\mathrm{x}$ & $\mathrm{x}$ \\
\hline info.covid.10 & & $\begin{array}{l}\text { Wie häufig ...nutzt Du } \\
\text { YouTube um COVID-19 } \\
\text { bezogene Nachrichten oder } \\
\text { Informationen zu erhalten? }\end{array}$ & $\begin{array}{l}1=\text { Mehrmals pro Tag, } 2= \\
\text { Einmal pro Tag, } 3=5-6 \mathrm{Mal} \\
\text { in der Woche, } 4=3-4 \mathrm{Mal} \text { in } \\
\text { der Woche, } 5=1-2 \mathrm{Mal} \text { in } \\
\text { der Woche, } 6=\text { Weniger } 1-2 \\
\text { Mal in der Woche, } 7=\mathrm{Nie}\end{array}$ & $\begin{array}{l}\text { How often ...do you use } \\
\text { YouTube to receive } \\
\text { COVID- } 19 \text { related news } \\
\text { or information? }\end{array}$ & $\begin{array}{l}1=\text { Several times a day } \\
2=\text { Once a day }, 3=5-6 \\
\text { times a week }, 4=3-4 \\
\text { times a week, } 5=1-2 \\
\text { times a week, } 6=\text { Less } \\
1-2 \text { times a week, } 7= \\
\text { Never }\end{array}$ & & & & & & & & & & $\mathrm{x}$ & $\mathrm{x}$ \\
\hline info.covid.11 & & $\begin{array}{l}\text { Wie häufig ... nutzt Du } \\
\text { Instagram um COVID-19 } \\
\text { bezogene Nachrichten oder } \\
\text { Informationen zu erhalten }\end{array}$ & $\begin{array}{l}1=\text { Mehrmals pro Tag, } 2= \\
\text { Einmal pro Tag, } 3=5-6 \mathrm{Mal} \\
\text { in der Woche, } 4=3-4 \mathrm{Mal} \text { in } \\
\text { der Woche, } 5=1-2 \mathrm{Mal} \text { in } \\
\text { der Woche, } 6=\text { Weniger } 1-2 \\
\text { Mal in der Woche, } 7=\mathrm{Nie}\end{array}$ & $\begin{array}{l}\text { How often ...do you use } \\
\text { Instagram to receive } \\
\text { COVID- } 19 \text { related news } \\
\text { or information? }\end{array}$ & $\begin{array}{l}1=\text { Several times a day } \\
2=\text { Once a day }, 3=5-6 \\
\text { times a week, } 4=3-4 \\
\text { times a week, } 5=1-2 \\
\text { times a week, } 6=\text { Less } \\
1-2 \text { times a week }, 7= \\
\text { Never }\end{array}$ & & & & & & & & & & $\mathrm{x}$ & $\mathrm{x}$ \\
\hline info.covid.12 & & $\begin{array}{l}\text { Wie häufig ...nutzt Du } \\
\text { Reddit um COVID-19 } \\
\text { bezogene Nachrichten oder } \\
\text { Informationen zu erhalten? }\end{array}$ & $\begin{array}{l}1=\text { Mehrmals pro Tag, } 2= \\
\text { Einmal pro Tag, } 3=5-6 \mathrm{Mal} \\
\text { in der Woche }, 4=3-4 \mathrm{Mal} \text { in } \\
\text { der Woche, } 5=1-2 \mathrm{Mal} \text { in } \\
\text { der Woche, } 6=\text { Weniger } 1-2 \\
\text { Mal in der Woche, } 7=\mathrm{Nie}\end{array}$ & $\begin{array}{l}\text { How often ...do you use } \\
\text { Reddit to receive } \\
\text { COVID- } 19 \text { related news } \\
\text { or information? }\end{array}$ & $\begin{array}{l}1=\text { Several times a day } \\
2=\text { Once a day }, 3=5-6 \\
\text { times a week }, 4=3-4 \\
\text { times a week, } 5=1-2 \\
\text { times a week, } 6=\text { Less } \\
1-2 \text { times a week }, 7= \\
\text { Never }\end{array}$ & & & & & & & & & & $\mathrm{x}$ & $\mathrm{x}$ \\
\hline info.covid.13 & & $\begin{array}{l}\text { Wie häufig ...nutzt Du } \\
\text { andere Internetquellen um } \\
\text { COVID-19 bezogene } \\
\text { Nachrichten oder } \\
\text { Informationen zu erhalten? }\end{array}$ & $\begin{array}{l}1=\text { Mehrmals pro Tag, } 2= \\
\text { Einmal pro Tag, } 3=5-6 \mathrm{Mal} \\
\text { in der Woche, } 4=3-4 \mathrm{Mal} \text { in } \\
\text { der Woche, } 5=1-2 \mathrm{Mal} \text { in } \\
\text { der Woche, } 6=\text { Weniger } 1-2 \\
\text { Mal in der Woche, } 7=\mathrm{Nie}\end{array}$ & $\begin{array}{l}\text { How often ...do you use } \\
\text { other online sources to } \\
\text { receive COVID-19 } \\
\text { related news or } \\
\text { information? }\end{array}$ & $\begin{array}{l}1=\text { Several times a day } \\
2=\text { Once a day }, 3=5-6 \\
\text { times a week, } 4=3-4 \\
\text { times a week, } 5=1-2 \\
\text { times a week, } 6=\text { Less } \\
1-2 \text { times a week }, 7= \\
\text { Never }\end{array}$ & & & & & & & & & & $\mathrm{x}$ & $\mathrm{x}$ \\
\hline info.covid.13.text & & $\begin{array}{l}\text { Wie häufig ...nutzt } \mathrm{Du} \\
\text { andere Internetquellen um } \\
\text { COVID-19 bezogene } \\
\text { Nachrichten oder } \\
\text { Informationen zu erhalten? } \\
\text { Text }\end{array}$ & & $\begin{array}{l}\text { How often ...do you use } \\
\text { other online sources to } \\
\text { receive COVID-19 } \\
\text { related news or } \\
\text { information? (text box) }\end{array}$ & & & & & & & & & & & $\mathrm{x}$ & $\mathrm{x}$ \\
\hline info.main.covid.1 & & $\begin{array}{l}\text { Bitte nenne unten bis zu } \\
\text { fünf Quellen von denen Du } \\
\text { die meisten Deiner } \\
\text { COVID-19 bezogene } \\
\text { Informationen beziehst. } \\
\text { Beispielsweise } \\
\text { Zeitungen/Zeitschriften wie } \\
\text { die "Neue Zürcher Zeitung", } \\
\text { Radiosender wie "SRF4", } \\
\text { TV-Sendungen oder auch } \\
\text { YouTube Kanäle wie "Last } \\
\text { Week Tonight". }\end{array}$ & & $\begin{array}{l}\text { Please list below up to } \\
\text { five sources from which } \\
\text { you get most of your } \\
\text { COVID-19 related } \\
\text { information. For } \\
\text { example, } \\
\text { newspapers/magazines } \\
\text { like the "Neue Zürcher } \\
\text { Zeitung", radio stations } \\
\text { like "SRF4", TV } \\
\text { programmes or YouTube } \\
\text { channels like "Last } \\
\text { Week Tonight". }\end{array}$ & & & & & & & & & & & $\mathrm{x}$ & $\mathrm{x}$ \\
\hline
\end{tabular}


inforid

example,

newspapers/magazines like the "Neue Zürcher Zeitung", radio station like "SRF4", TV

programmes or YouTube

channels like "La

info.main.covid.3

Bitte nenne unten bis zu ünf Quellen von denen D

die meisten Deiner

Informationen beziehst.

info.main.covid.4

nenne unten bis zu ünf Quellen von denen Du die meisten Deiner

COVID-19 bezogene Informationen beziehst.

\section{info.main.covid.5}

misinfo.covid.1
Bitte nenne unten bis zu fünf Quellen von denen D die meisten Deiner

Informationen beziehst.
Wie häufig ...erhältst Du alsche COVID-19 bezoge Nachrichten von deinen
$1=$ Mehrmals pro Tag , $2=$ Einmal pro Tag, $3=5-6 \mathrm{Ma}$ in der Woche, $4=3-4 \mathrm{Mal}$ der Woche, $5=1-2$ Mal in Mal in der Woche, $7=$ Nie
Please list below up to five sources from which you get most of your COVID-19 related

information. Fo

example,

newspapers/magazines like the "Neue Zürcher Zeitung", radio station like "SRF4", TV

programmes or YouTube channels like "Last

Week Tonight".

Please list below up to five sources from which you get most of your COVID-19 related information. For example,

newspapers/magazines like the "Neue Zürche Zeitung", radio station like "SRF4", TV

programmes or YouTube channels like "Last

Week Tonight".

Please list below up to five sources from whic you get most of your

information. Fo example,

newspapers/magazines like the "Neue Zürche Zeitung", radio statio like "SRF4", TV

programmes or YouTube channels like "La

Week Tonight".

How often ...do you hear false COVID-19 relate messages from your

$1=$ Several times a day

. Once day, $3=5$

times a week, $6=1-2$

$1-2$ times a week, $7=$

Never 


\section{misinfo.covid.3}

Wie häufig...erhältst Du falsche COVID-19 bezogene Nachrichten von deine

Freunden?

Wie häufig ...liest Du falsche COVID-19 bezogene Informationen in der Zeitung?

misinfo.covid.5

Wie häufig ...siehst Du falsche COVID-19 bezogene Nachrichten am Fernsehen

misinfo.covid.6

Wie häufig... hörst Du alsche COVID-19 bezogene Nachrichten im Radio?

misinfo.covid.7

Wie häufig ...liest Du falsche COVID-19 bezogene Artike auf Nachrichtenseiten im Internet?

misinfo.covid. 8

Wie häufig... erhältst $\mathrm{Du}$ auf Facebook falsche

Nachrichten oger

Informationen?

Wiehäufig... siehst Du auf Twitter falsche COVID-19 bezogene Nachrichten Informationen?

Wie häufig... siehst Du auf YouTube falsche COVID-19 bezogene Nachrichten oder Informationen?
$1=$ Mehrmals pro Tag, $2=$ Einmal pro Tag, $3=5-6 \mathrm{Mal}$ in der Woche, $4=3-4 \mathrm{Mal}$ der Woche, $5=1-2 \mathrm{Mal}$ in
der Woche, $6=$ Weniger $1-2$ der Woche, $6=$ Weniger $1-2$
Mal in der Woche, $7=\mathrm{Nie}$

$1=$ Mehrmals pro Tag, $2=$ Einmal pro Tag, $3=5-6 \mathrm{Mal}$ in der Woche, $4=3-4 \mathrm{Mal}$ in der Woche, $5=1-2 \mathrm{Mal}$ in der Woche, $6=$ Weniger $1-2$ Mal in der Woche, $7=\mathrm{Nie}$

$1=$ Mehrmals pro Tag , $2=$ Einmal pro Tag, $3=5-6 \mathrm{Ma}$ in der Woche , $4=3-4 \mathrm{Mal}$ in der Woche, $5=1-2 \mathrm{Mal}$ in der Woche, $6=$ Weniger $1-2$

rmals pro Tag, $2=$ in der Woche, $4=3-4$ Mal Woche, $4=3-4$ Mal in der Woche, $5=1-2 \mathrm{Mal}$ in Mal in der Woche, $7=\mathrm{Nie}$

$1=$ Mehrmals pro Tag, $2=$ Einmal pro Tag, $3=5-6 \mathrm{M}$ in der Woche , $4=3-4 \mathrm{Mal}$ der Woche, $5=1-2 \mathrm{Mal}$ in der Woche, $6=$ Weniger $1-2$ Mal in der Woche, $7=\mathrm{Nie}$

$1=$ Mehrmals pro Tag, $2=$ Einmal pro Tag, $3=5-6 \mathrm{Ma}$ in der Woche, $5=1-2$ Mal in der Woche, $6=$ Weriger in Mal in der Woche $7=$ Nie

$1=$ Mehrmals pro Tag, $2=\quad$ How often $\ldots$ do you see

How often ...do you hear lse COVID-19 related messages from your friends?

How often ...do you read false COVID-19 related parts of the newspape

$1=$ Several times a day $2=$ Once a day, $3=5-6$ times a week, $4=3-4$ times a week, $5=1-2$
times a week, $6=$ Les $1-2$ times a week, $7=$ Never

$1=$ Several times a day $2=$ Once a day , $3=5-6$ times a week, $4=3-4$ times a week, $5=1-2$ times a week, $6=$ Less 1-2 times a week, $7=$ Never

How often ...do you se false COVID-19 related news on TV

$2=$ Once a day , $3=5-6$ times a week, $4=3-4$ times a week, $5=1-2$ times a week, $6=$ Less 1-2 times a week, $7=$ Never

How often ...do you hea alse COVID-19 news on the radio?

$1=$ Several times a day times a week, $5=1-2$ times a week , $6=$ Less 1-2 times a week, $7=$ Never

How often ...do you read articles on news sites on the internet?

Several times a day $2=$ Once a day , $3=5-6$ times a week, $4=3-4$ times a week, $5=1-2$ times a week, $6=$ Less 1-2 times a week, $7=$ Never

How often ...do you $=$ Once a day, $3=5-6$ times a week, $5=1-2$ times a week, $6=$ Less 1-2 times a week, $7=$ Never Einmal pro Tag, $3=5-6 \mathrm{Mal}$ in der Woche, $4=3-4 \mathrm{Mal}$ in der Woche, $5=1-2 \mathrm{Mal}$ in der Woche, $6=$ Weniger $1-2$

$1=$ Mehrmals pro Tag , $2=$ Einmal pro Tag, $3=5-6 \mathrm{Ma}$ in der Woche, $4=3-4 \mathrm{Mal}$ in der Woche, $5=1-2 \mathrm{Mal}$ in der Woche, $6=$ Weniger 1-2 $\mathrm{Mal}$ in der Woche, $7=\mathrm{Nie}$
How often ...do you see false COVID-19 related times a week, $4=3-4$ times a week, $5=1-2$ times a week, $6=$ Less 1-2 times a week, $7=$ Never How often ...do you see news or information on YouTube?

$=$ Several times a day times a week, $4=3-4$ times a week, $6=$ Les 1-2 times a week, $7=$ Never $2=$ Once a day , $3=5-6$ $2=$ Once a day , $3=5-6$ 
$2=$ Once a day , $3=5-6$

times a week, $4=3-4$

times a week, $5=1-2$

times a week , $6=$ Less

1-2 times a week, 7

dal Woche, $6=$ Weniger 1 - 2

misinfo.covid.13

Q12.19_13 - Wiehäufig siehst Du auf andere Internetquellen falsche oder Informationen?

$1=$ Mehrmals pro Tag , $2=$ Einmal pro Tag , $3=5-6 \mathrm{Mal}$ How often ...do you see in der Woche, $4=3-4 \mathrm{Mal}$ in news or info-19 related der Woche, $5=1-2 \mathrm{Mal}$ in der Woche, $6=$ Weniger $1-2$ $\mathrm{Mal}$ in der Woche, $7=\mathrm{Nie}$

misinfo.covid.13.text

Du hast angegeben, dass Du auch von andere

Internetquellen falsche oder ungenaue COVID-19

bezogene Nachrichten oder Informationen erhältst,

welche sind diese?

misinfo.main.covid.

Bitte nenne unten bis zu ünf Quellen von denen Du die meisten Deiner falschen oder ungenauen COVID-19 bezogene Informationen erhälten hast.

Beispielsweis

Zeitungen/Zeitschriften wie die "Neue Zürcher Zeitung", Radiosender wie "SRF4", TV-Sendungen oder auch YouTube Kanäle wie "Last Week Tonight". - Quelle 1 . Namen

misinfo.main.covid.2

ne unten bis zu

ünf Quellen von denen $\mathrm{Du}$ die meisten Deiner falschen oder ungenauen COVID-19 ezogene Informatione erhälten hast.

Beispielsweise Zeitungen/Zeitschriften wie die "Neue Zürcher Zeitung", Radiosender wie "SRF4", TV-Sendungen oder auch YouTube Kanale wie "Last Week Tonight". your false or inaccurat Zeitung", radio station like the "Neue Zürcher
$1=$ Several times a day times a week, $4=3-4$ times a week, $5=1-2$ times a week, $6=$ Less 1-2 times a week, $7=$ Never

You have stated that you also receive incorrect or inaccurate or information from which internet sources, box)

Please list below up to five sources from which you received most of COVID-19 related information. Fo example

newspapers/magazines like the "Neue Zürcher like "SRF4", TV

programmes or YouTube channels like "Las

Week Tonight".

Please list below up to five sources from whic you received most of your false or inaccurate COVID-19 related information. Fo example,

newspapers/magazines Zeitung", radio station like "SRF4", TV programmes or YouTube channels like "La 


\begin{tabular}{|c|c|c|c|c|c|c|c|c|c|c|c|c|c|c|c|c|}
\hline VarName & VariableLabel & WordingDE & ValueLabelsDE_Linked & WordingEN & ValueLabelsEN_Linked & L1 & $\mathrm{L} 2$ & L3 & $\mathrm{L} 4$ & L5 & L6 & L7 & L8 & L9 & L10 L11 & $1 \mathrm{~L} 12$ \\
\hline misinfo.main.covid.3 & & $\begin{array}{l}\text { Bitte nenne unten bis zu } \\
\text { fünf Quellen von denen Du } \\
\text { die meisten Deiner falschen } \\
\text { oder ungenauen COVID-19 } \\
\text { bezogene Informationen } \\
\text { erhälten hast. } \\
\text { Beispielsweise } \\
\text { Zeitungen/Zeitschriften wie } \\
\text { die "Neue Zürcher Zeitung", } \\
\text { Radiosender wie "SRF4", } \\
\text { TV-Sendungen oder auch } \\
\text { YouTube Kanäle wie "Last } \\
\text { Week Tonight". - Quelle } 3 \text { - } \\
\text { Namen }\end{array}$ & & $\begin{array}{l}\text { Please list below up to } \\
\text { five sources from which } \\
\text { you received most of } \\
\text { your false or inaccurate } \\
\text { COVID-19 related } \\
\text { information. For } \\
\text { example, } \\
\text { newspapers/magazines } \\
\text { like the "Neue Zürcher } \\
\text { Zeitung", radio stations } \\
\text { like "SRF4", TV } \\
\text { programmes or YouTube } \\
\text { channels like "Last } \\
\text { Week Tonight". }\end{array}$ & & & & & & & & & & & $\mathrm{x}$ & $\mathrm{x}$ \\
\hline misinfo.main.covid.4 & & $\begin{array}{l}\text { Bitte nenne unten bis zu } \\
\text { fünf Quellen von denen Du } \\
\text { die meisten Deiner falschen } \\
\text { oder ungenauen COVID-19 } \\
\text { bezogene Informationen } \\
\text { erhälten hast. } \\
\text { Beispielsweise } \\
\text { Zeitungen/Zeitschriften wie } \\
\text { die "Neue Zürcher Zeitung", } \\
\text { Radiosender wie "SRF4", } \\
\text { TV-Sendungen oder auch } \\
\text { YouTube Kanäle wie "Last } \\
\text { Week Tonight". - Quelle 4 - } \\
\text { Namen }\end{array}$ & & $\begin{array}{l}\text { Please list below up to } \\
\text { five sources from which } \\
\text { you received most of } \\
\text { your false or inaccurate } \\
\text { COVID-19 related } \\
\text { information. For } \\
\text { example, } \\
\text { newspapers/magazines } \\
\text { like the "Neue Zürcher } \\
\text { Zeitung", radio stations } \\
\text { like "SRF4", TV } \\
\text { programmes or YouTube } \\
\text { channels like "Last } \\
\text { Week Tonight". }\end{array}$ & & & & & & & & & & & $\mathrm{x}$ & $\mathrm{x}$ \\
\hline misinfo.main.covid.5 & & $\begin{array}{l}\text { Bitte nenne unten bis zu } \\
\text { fünf Quellen von denen Du } \\
\text { die meisten Deiner falschen } \\
\text { oder ungenauen COVID-19 } \\
\text { bezogene Informationen } \\
\text { erhälten hast. } \\
\text { Beispielsweise } \\
\text { Zeitungen/Zeitschriften wie } \\
\text { die "Neue Zürcher Zeitung", } \\
\text { Radiosender wie "SRF4", } \\
\text { TV-Sendungen oder auch } \\
\text { YouTube Kanäle wie "Last } \\
\text { Week Tonight". - Quelle 5- } \\
\text { Namen }\end{array}$ & & $\begin{array}{l}\text { Please list below up to } \\
\text { five sources from which } \\
\text { you received most of } \\
\text { your false or inaccurate } \\
\text { COVID-19 related } \\
\text { information. For } \\
\text { example, } \\
\text { newspapers/magazines } \\
\text { like the "Neue Zürcher } \\
\text { Zeitung", radio stations } \\
\text { like "SRF4", TV } \\
\text { programmes or YouTube } \\
\text { channels like "Last } \\
\text { Week Tonight". }\end{array}$ & & & & & & & & & & & $\mathrm{x}$ & $\mathrm{x}$ \\
\hline study.covid.1 & & $\begin{array}{l}\text { Ich habe Schwierigkeiten, } \\
\text { mich während der } \\
\text { Vorlesungen zu } \\
\text { konzentrieren }\end{array}$ & $\begin{array}{l}1=\text { Viel weniger als zuvor, } 2 \\
=\text { Weniger als zuvor, } 3=\text { Ein } \\
\text { bisschen weniger als zuvor, } 4 \\
=\text { Gleichermassen, } 5=\text { Ein } \\
\text { bisschen mehr als zuvor, } 6= \\
\text { Mehr als zuvor, } 7=\text { Viel } \\
\text { mehr als zuvor }\end{array}$ & $\begin{array}{l}\text { I have difficulties } \\
\text { concentrating during } \\
\text { lectures }\end{array}$ & $\begin{array}{l}1=\text { Much less than before } \\
, 2=\text { Less than before }, 3 \\
=\text { A little less than before } \\
, 4=\text { Equal }, 5=\mathrm{A} \text { little } \\
\text { more than before, } 6= \\
\text { More than before }, 7= \\
\text { Much more than before }\end{array}$ & & & & & & & & & & $\mathrm{x}$ & $\mathrm{x}$ \\
\hline study.covid.2 & & $\begin{array}{l}\text { Ich habe Schwierigkeiten, } \\
\text { mich fürs Studium zu } \\
\text { motivieren }\end{array}$ & $\begin{array}{l}1=\text { Viel weniger als zuvor, } 2 \\
=\text { Weniger als zuvor, } 3=\text { Ein } \\
\text { bisschen weniger als zuvor, } 4 \\
=\text { Gleichermassen, } 5=\text { Ein } \\
\text { bisschen mehr als zuvor, } 6= \\
\text { Mehr als zuvor, } 7=\text { Viel } \\
\text { mehr als zuvor }\end{array}$ & $\begin{array}{l}\text { I have difficulties } \\
\text { motivating myself to } \\
\text { work }\end{array}$ & $\begin{array}{l}1=\text { Much less than before } \\
, 2=\text { Less than before }, 3 \\
=\text { A little less than before } \\
, 4=\text { Equal }, 5=\text { A little } \\
\text { more than before, } 6= \\
\text { More than before, } 7= \\
\text { Much more than before }\end{array}$ & & & & & & & & & & $\mathrm{x}$ & $\mathrm{x}$ \\
\hline study.covid.3 & & Ich lerne effizient & $\begin{array}{l}1=\text { Viel weniger als zuvor, } 2 \\
=\text { Weniger als zuvor, } 3=\text { Ein } \\
\text { bisschen weniger als zuvor, } 4 \\
=\text { Gleichermassen, } 5=\text { Ein } \\
\text { bisschen mehr als zuvor, } 6= \\
\text { Mehr als zuvor, } 7=\text { Viel } \\
\text { mehr als zuvor }\end{array}$ & I am learning efficiently & $\begin{array}{l}1=\text { Much less than before } \\
, 2=\text { Less than before }, 3 \\
=\text { A little less than before } \\
, 4=\text { Equal }, 5=\mathrm{A} \text { little } \\
\text { more than before, } 6= \\
\text { More than before }, 7= \\
\text { Much more than before }\end{array}$ & & & & & & & & & & $\mathrm{x}$ & $\mathrm{x}$ \\
\hline
\end{tabular}


Ich kann gut mit anderen Studenten an

Gruppenarbeiten arbeiten

study.covid.5

study.covid.6

study.covid.7

study.covid.8

community.covid.2

community.covid.3

worries.covid.1
Ich schätze die höhere Online-Lernen habe

Es ist möglich, die Anforderungen der Kurse zu erfüllen

Die Studierenden unterstützen sich gegenseitig

Es herrscht Konkurrenzdenken unter den Studierenden

Für unsere Kohorte ist es im Vergleich zu

Studierenden in früheren Jahren einfacher, die

Studienziele zu erreichen

Mein Heimarbeitsplatz ist genauso gut ausgestattet wie der von anderer

Studierenden (z. B. WLAN, Schreibtisch, Materialien).

Jetzt da von zuhause

gelernt wird, ist es einfache die Kurse zu bestehen, auch für Studierende, die weniger hart arbeiten

Ich fühle mich sozial isoliert
$1=$ Viel weniger als zuvor, 2 $=$ Weniger als zuvor, $3=$ Ein bisschen weniger als zuvor, 4 $=$ Gleichermassen, $5=$ Ein bisschen mehr als zuvor, $6=$ Mehr als zuvor, $7=\mathrm{Viel}$

mehr als zuvor

$=$ Viel weniger als zuvor, 2 = Weniger als zuvor, $3=$ Ei bisschen weniger als zuvor, $=$ Gleichermassen, $5=\mathrm{Ei}$ bisschen mehr als zuvor, 6 Mehr als zuvor, $7=$ Viel mehr als zuvo

$1=$ Viel weniger als zuvor, 2 $=$ Weniger als zuvor, $3=\mathrm{Ein}$ bisschen weniger als zuvor, 4 $=$ Gleichermassen, $5=$ Ein bisschen mehr als zuvor, 6 Mehr als zuvor, $7=$ Viel mehr als zuvor

$1=$ Viel weniger als zuvor, 2 $=$ Weniger als zuvor, $3=$ Ei bisschen weniger als zuvor, 4 $=$ Gleichermassen, $5=$ Ein bisschen mehr als zuvor, $6=$ Mehr als zuvor, $7=$ Vie mehr als zuvor

$1=$ Viel weniger als zuvor, 2 = Weniger als zuvor, $3=\mathrm{Ei}$ bisschen weniger als zuvor, $=$ Gleichermassen, $5=\mathrm{Ei}$ bisschen mehr als zuvor, $6=$ Mehr als zuvor, $7=$ Viel mehr als zuvor

$1=$ Trifft überhaupt nicht zu $2=$ Trifft nicht $\mathrm{zu}, 3=$ Trifft eher nicht zu, $4=$ Weder

noch, $5=$ Trifft eher zu, $6=$ Trifft zu, $7=$ Trifft voll und ganz zu

$1=$ Trifft überhaupt nicht $\mathrm{zu}$ $2=$ Trifft nicht $\mathrm{zu}, 3=$ Triff eher nicht zu, $4=$ Weder

noch, $5=$ Trifft eher zu, $6=$ Trifft zu, $7=$ Trifft voll und ganz zu

Trifft überhaupt nicht zu, eher nicht $z w, 4=$ We noch, $5=$ Trifft eher zu, $6=$ Trifft zu, $7=$ Trifft voll und ganz zu

$1=$ Viel weniger als zuvor, 2 $=$ Weniger als zuvor, $3=$ Ei bisschen weniger als zuver, $=$ Gleichermassen, $5=\mathrm{E}$, bisschen mehr als zuvor, 6 Mehr als zuvor, $7=$ Viel mehr als zuvor
I can work well with $\quad 1=$ Much less than before $\begin{array}{ll} & , 2=\text { Less than before }, 3 \\ \text { collaborative projects } & =\mathrm{A} \text { little less than before }\end{array}$ $=$ A little less than before more than before $6=$ More than before $7=$ Much more than before $\begin{array}{ll}\text { I appreciate the higher } & 1=\text { Much less than before } \\ \text { flexibility I have due to } & 2=\text { Less than before }, 3\end{array}$ online learning due to $\quad=$ A little less than before 4 - Equal, $5=$ A little more than before, $6=$ More than before, $7=$ Much more than before $1=$ Much less than before

It is possible to meet the expectations of the courses

$2=$ Less than before, 3 $=\mathrm{A}$ little less than before , $4=$ Equal, $5=\mathrm{A}$ little more than before, $6=$ More than before, $7=$ Much more than before

Students support each $1=$ Much less than before $2=$ Less than before, 3 $=\mathrm{A}$ little less than before $4=$ Equal, $5=\mathrm{A}$ little more than before, $6=$ More than before, $7=$ Much more than before Students compete with each other

before $2=$ Less than before, 3 $=$ A little less than before , $4=$ Equal, $5=\mathrm{A}$ little more than before, $6=$ More than before, $7=$ Much more than before

It is easier for our cohort to achieve the study goals compared to $1=$ don't agree at all, $2=$ ton't agree, $3=$ rather $=$ rather agree, $6=$ agree, $7=$ agree completely My home office is just as $\quad 1=$ don't agree at all, $2=$ well equipped as that not agree, $4=$ nither, 5 materials)

Now that learning is done from home, it is easier to pass the students who work less hard.

I feel socially isolated

$7=$ agre agree, $6=$ ag

$1=$ don't agree at all, $2=$

don't agree, $3=$ rather

$=$ rather agree, $6=$ agree,

$7=$ agree completely

$1=$ Much less than before $=\mathrm{A}$ little less than before $4=$ Equal, $5=$ A little more than before, $6=$ More than before, $7=$ Much more than before 


I feel stressed

Weniger als zuvor, $3=$ Ei

Glen weniger als zuvor, 4 Geichermassen, 5 = Ein Mehro mehr als zuvor

worries.covid.3

ich fühle mich entspannt

worries.covid.4

Ich habe das Gefühl, dass ich etwas verpasse

Ich habe das Gefühl, dass andere Tolleres erleben als ch (FoMO; Fear of missin out) (

Ich mache mir Sorgen um meine Familie und Freund

Ich mache mir Sorgen um meine eigene Gesundheit

ch mache mir Sorgen um die Wirtschaft

Ich mache mir Sorgen um meine eigene finanzielle Situatio

Ich mache mir Sorgen um meine zukünftige Karrier (z. B. einen Platz im Masterstudiengang finden, berufliche Planung).
$1=$ Viel weniger als zuvor, 2 $=$ Weniger als zuvor, $3=$ Ein bisschen weniger als zuvor, $=$ Gleichermassen, $5=$ Ein bisschen mehr als zuvor, $6=$ Mehr als zuvor,
mehr als zuvo

$1=$ Viel weniger als zuvor, 2 = Weniger als zuvor, $3=$ Ein bisschen weniger als zuvor, $=$ Gleichermassen, $5=$ Ein bisschen mehr als zuvor, 6 Mehr als zuvor, $7=$ Viel mehr als zuvo

$1=$ Viel weniger als zuvor, 2 $=$ Weniger als zuvor, $3=$ Ein bisschen weniger als zuvor, 4 $=$ Gleichermassen, $5=$ Ein bisschen mehr als zuvor, $6=$ Mehr als zuvor, $7=$ Vie mehr als zuvor

$1=$ Viel weniger als zuvor, 2 = Weniger als zuvor, $3=$ Ein bisschen weniger als zuvor, 4 $=$ Gleichermassen, $5=\mathrm{Ei}$ bisschen mehr als zuvor, $6=$ Mehr als zuvor, $7=$ Vie

mehr als zuvor

$1=$ Viel weniger als zuvor, 2 = Weniger als zuvor, $3=$ Ein bisschen weniger als zuvor, $=$ Gleichermassen, $5=$ Ein bisschen mehr als zuvor, $6=$ Mehr als zuvor, $7=$ Viel mehr als zuvo

$1=$ Viel weniger als zuvor $=$ Weniger als zuvor, $3=$ Ei =Weniger als zuvor, $3=$ Ei bisschen weniger als zuvor, $=$ Gleichermassen, $5=$ Ein Mehr als zuvor, $7=\mathrm{Viel}$ mehr als zuvo

$1=$ Viel weniger als zuvor, = Weniger als zuvor, 3 = Ei bisschen weniger als zuver, - Gleichermassen, 5 = Ein $=$ Gleichen Mehr als zuvor, $7=$ Viel mehr als zuvo

$1=$ Viel weniger als zuvor, 2 = Weniger als zuvor, $3=\mathrm{Ein}$ bisschen weniger als zuvor, $=$ Gleichermassen, $5=$ Ein bisschen mehr als zuvor, 6 Mehr als zuvor, $7=$ Viel mehr als zuvor

, $2=$ Less than before, 3

$=\mathrm{A}$ little less than before , $4=$ Equal, $5=\mathrm{A}$ little more than before, 6 More than before, Much more than

I feel relaxed

$1=$ Much less than before $2=$ Less than before, 3 $=\mathrm{A}$ little less than before $4=$ Equal, $5=$ A little more than before, $6=$ More than before, $7=$ Much more than before

I feel that I am missing out on things

$1=$ Much less than before

$2=$ Less than before, 3

$=\mathrm{A}$ little less than before $4=$ Equal, $5=$ A little more than before, $6=$ More than before, $7=$ Much more than before $1=$ Much less than before $2=$ Less than before, 3

feel that others are having more rewarding out)

$=\mathrm{A}$ little less than before , $4=$ Equal, $5=\mathrm{A}$ little More than before, $7=$ Much more than before

am worried about my family and friends

before $2=$ Less than before, 3 $=$ A little less than before $4=$ Equal, $5=\mathrm{A}$ little more than before, $6=$ More than before, $7=$ Much more than before

am worried about my own health

than before $2=$ Less than before, 3 A little less than before $4=$ Equal, $5=\mathrm{A}$ little more than before, $6=$ More than before, $7=$ Much more than before

am worried about the $1=$ Much less than before $2=$ Less than before, 3 $=$ A little less than before more than before, $6=$ More than before $7=$ Much more than before $1=$ Much less than before $2=$ Less than before, 3 $=\mathrm{A}$ little less than before $4=$ Equal, $5=$ A little more than before, $6=$ More than before, $7=$ Much more than before

am worried about my 1 = Much less than $2=$ Less than before, 3 $=\mathrm{A}$ little less than before , $4=$ Equal, $5=$ A little more than before, $6=$ More than before, $7=$ Much more than before masters p
situation) 
bisschen weniger als zuvor, 4

$=$ Gleichermassen, $5=$ Ein

bisschen mehr als zuvor, 6

Mehr als zuvor
mehr als zuvor

teach.covid.1

"Zuvor" bezieht sich hier auf die Zeit vor der COVID-19-Krise. Die removed] versuche removed] versuchen
sicherzustellen, dass wir so sicherzustellen, dass wir so
viel lernen, wie wir sollten

teach.covid.2 Die Dozierenden [name removed] versuchen sicherzustellen, dass wir eine faire Chance haben, das Semester zu bestehen

$1=$ Viel weniger als zuvor, 2 $=$ Weniger als zuvor, $3=\mathrm{Ei}$ bisschen weniger als zuvor, $=$ Gleichermassen, $5=$ Ein bisschen mehr als zuvor, 6 Mehr als zuvor,
mehr als zuvor

$1=$ Viel weniger als zuvor, 2 = Weniger als zuvor, $3=$ Ein bisschen weniger als zuvor, $=$ Gleichermassen, $5=$ Ein bisschen mehr als zuvor, $6=$ Mehr als zuvor, $7=$ Viel mehr als zuvor

teach.covid.3

Die Dozierenden an [name removed] unterstützen un

= Viel weniger als zuvor, 2 $=$ Weniger als zuvor, $3=$ Ein $=$ Gleich weniger als zuvor, $=$ Gleichermassen, $5=$ Ein bisschen mehr als zuvor, 6 mehr als zuvor

uni.covid.1

Die Gesundheits- und Sicherheitsmassnahmen [name removed] wurden kla kommunizier

upt nicht zu, $2=$ Trifft nicht $\mathrm{zu}, 3=$ Triff eher nicht zu, $4=$ Weder noch, $5=$ Trifft eher zu, $6=$
Trifft zu, $7=$ Trifft voll und ganz zu

uni.covid.2

Die studienbezogenen Regelungen der [name removed] wurden klar kommuniziert

uni.covid.3

Die studienbezogene Regelungen [name removed] sind konsistent und die Studierenden können gut vorausplanen

uni.covid.4

Die [name

removed]-Schulleitung hat auf die COVID-19 K reagiert $2=$ Trifft nicht zu, $3=$ Trifft eher nicht zu, $4=$ Weder noch, $5=$ Trifft eher zu, $6=$ Trifft zu, $7=$ Trifft voll und ganz zu

$1=$ Trifft überhaupt nicht $\mathrm{z}$ $2=$ Trifft nicht $\mathrm{zu}, 3=$ Triff eher nicht zu, $4=$ Weder noch, $5=$ Trifft eher zu, $6=$
Trifft zu, $7=$ Trifft voll und Trifft zu,
ganz zu $2=$ Trift nicht zu $3=$ Treft eher nicht zu, $4=$ Weder noch, $5=$ Trifft eher zu, 6 Trifft zu, $7=$ Trifft voll $6=$ ganz zu

Studierende erhalten psychologische Unterstützung von der
[name removed], falls sie diese während der COVID-19 Krise benötigen

$1=$ Trifft überhaupt nicht zu $2=$ Trifft nicht $\mathrm{zu}, 3=$ Trifft eher nicht zu, $4=$ Weder noch, $5=$ Trifft eher zu, $6=$ Trifft zu, $7=$ Trifft voll und ganz zu

The lecturers at university name removed] try to ensure that we learn
as we should

The lecturers at [university name removed] try to ensure that we have a fair chance of passing the semeste

The lecturers at [university name

The health and safety measures of [university name removed] were clearly communicated

The degree-related regulations of the university name removed] have been clearly communicated

The [university name removed]'s study-relate arrangements are consistent and student can plan ahead well

The [university name removed] executive board has responded crisis.

Students receive psychological support from the [university name removed] if they need it during the COVID-19 crisis
, 2 = Less than before, 3

$=$ A little less than before , $4=$ Equal, $5=\mathrm{A}$ little more than before, $6=$ More than before, $7=$ Much more than before $1=$ Much less than before , $2=$ Less than before, 3 $=$ A little less than before , $4=$ Equal, $5=\mathrm{A}$ little more than before, $6=$ Much more than before

$1=$ Much less than before $2=$ Less than before, 3 $=\mathrm{A}$ little less than before , $4=$ Equal, $5=\mathrm{A}$ little more than before, $6=$ More than before, $7=$ Much more than before $1=$ Much less than before $2=$ Less than before, 3 $=\mathrm{A}$ little less than before , $4=$ Equal , $5=$ A little more than before, $6=$ More than before, $7=$ Much more than before $1=$ don't agree at all, $2=$ don't agree, $3=$ rather not agree, $4=$ neither, 5 $=$ rather agree, $6=$ agree, $7=$ agree completely

$1=$ don't agree at all, $2=$ don't agree, $3=$ rather not agree, $4=$ neither, 5 $=$ rather agree, $6=$ agree, $7=$ agree completely

$1=$ don't agree at all, $2=$ don't agree, $3=$ rather not agree, $4=$ neither, 5 $=$ rather agree, $6=$ agree, $7=$ agree completely

$1=$ don't agree at all, $2=$ don't agree, $3=$ rather

$=$ rather agree, $6=$ agree,

7 = agree completely

$1=$ don't agree at all, $2=$ don't agree, $3=$ rather not agree, $4=$ neither, 5 $=$ rather agree, $6=$ agree,

7 = agree completely 

Personen, die von COVID-19 betroffen sind, finanzielle Unterstïtzung anbieten. $2=$ Trifft nicht $\mathrm{zu}, 3=$ Tr
eher nicht $\mathrm{zu}, 4=$ Weder verhindern

policy.covid.3

Es ist wichtig, dass die name removed], alle ihre Gebäude schliesst.

policy.covid.4

Unser Jahrgang ist aufgrund der Reaktion der [name removed] auf das Coronavirus gegenübe anderen Jahrgängen benachteiligt.

policy.covid.5 Alle [name removed] -Kurse usschliesslich online unterrichtet werden.

policy.covid.6

Die Regierung sollte ersonenbezogene Date wie den Standort aller Schweizer Mobiltelefon nutzen können um die Verbreitung des Virus zu verhindern.

policy.covid.7

Die Regierung sollte sich auf das Prinzip de Herdenimmunität stütze und COVID-19 ohne vorbeugende Massnahmen ausbreiten lassen, um eine kollektive Resistenz gegen das Virus zu fördern Die Regierung sollte Unternehmen, die von COVID-19 negativ betroffen sind, finanzielle Unterstützung anbieten.

Other countries should have done more to prevent the spread of the virus beyond their ganz z

$1=$ Trifft überhaupt nicht zu $2=$ Trifft nicht $\mathrm{zu}, 3=$ Triff eher nicht zu, $4=$ Weder noch, $5=$ Trift eher zu, $6=$ ganz zu

$1=$ Trifft überhaupt nicht zu, $2=$ Trifft nicht $\mathrm{zu}, 3=$ Trifft eher nicht zu, $4=$ Weder noch, $5=$ Trifft eher zu, $6=$ Trifft zu, $7=$ Trifft voll und ganz zu

$1=$ Trifft überhaupt nicht zu $2=$ Trifft nicht $\mathrm{zu}, 3=$ Trift eher nicht $\mathrm{zu}, 4=$ Weder noch, $5=$ Trifft eher zu, $6=$ Trifft zu, $7=$ Trifft voll und ganz zu

$1=$ Trifft überhaupt nicht $\mathrm{zu}$ $2=$ Trifft nicht $\mathrm{zu}, 3=$ Triff eher nicht $\mathrm{zu}, 4=$ Weder noch, $5=$ Trifft eher zu, $6=$ Trifft zu, $7=$ Trifft voll und ganz zu

$1=$ Trifft überhaupt nicht $\mathbf{z}$ $2=$ Trifft nicht $\mathrm{zu}, 3=$ Trifft eher nicht $\mathrm{zu}, 4=$ Weder noch, $5=$ Trifft eher zu, $6=$ Trifft zu, $7=$ Trifft voll und ganz zu

$1=$ Trifft überhaupt nicht z $2=$ Trifft nicht $\mathrm{zu}, 3=$ Triff eher nicht zu, $4=$ Weder noch, $5=$ Trifft eher zu, $6=$
Trifft zu, $7=$ Trifft voll und Trifft zu,
ganz zu

policy.covid.9
It is important that the [university name closes all its uildings.

Our year's cohort is at a disadvantage to other cohorts because of the [university name removed]'s response to the coronavirus. All [university name removed] courses should be taught exclusively online this semester.

The government should be able to use personal data such as the location of all Swiss mobile phones to prevent the spread of the virus.

The government should rely on the principle of herd immunity and allow COVID-19 to spread without preventive measures to promote collective resistance to the virus. The government should offer financial support to companies negative ffected by COVID-19.

The government should offer financial support to persons affected by COVID-19.
$1=$ Trifft überhaupt nicht zu $2=$ Trifft nicht $z \mathbf{u}, 3=$ Trifft eher nicht zu, $4=$ Weder noch, $5=$ Trifft eher zu, $6=$ Trifft zu, $7=$ Trifft voll und ganz zu
$=$ rather agree, $6=$ agree,

$7=$ agree completely

$1=$ don't agree at all, $2=$ don't agree, $3=$ rather not agree, $4=$ neither, 5 $=$ rather agree, $6=$ agree

$=$ don't agree at all, $2=$ don't agree, $3=$ rather not agree, $4=$ neither, 5 $7=$ agrece $6=$ agree not agree, $4=$ neither, 5 $=$ rather agree, $6=$ agree, $7=$ agree completely

$1=$ don't agree at all, $2=$ don't agree, $3=$ rather not agree, $4=$ neither, 5 don't agree, $3=$ rather not agree, $4=$ neither, 5 $=$ rather agree, $6=$ agree, $7=$ agree completely

$1=$ don't agree at all, $2=$ don't agree, $3=$ rather not agree, $4=$ neither, 5 $=$ rather agree, $6=$ agree, $7=$ agree completely

$1=$ don't agree at all, $2=$ don't agree, $3=$ rather not agree, $4=$ neither, 5 $=$ rather agree, $6=$ agree, $7=$ agree completely

$1=$ don't agree at all, $2=$ don't agree, $3=$ rather $=$ rather agree, $6=$ agree, 7 = agree completely 


\begin{tabular}{|c|c|c|c|c|c|c|c|c|c|c|c|c|c|c|c|c|}
\hline VarName & VariableLabel & WordingDE & ValueLabelsDE_Linked & WordingEN & ValueLabelsEN_Linked & L1 & L2 & $\mathrm{L} 3$ & L4 & L5 & $\mathrm{L} 6$ & L7 & L8 & L9 & L10 L11 & L12 \\
\hline policy.covid.10 & & $\begin{array}{l}\text { Krankenhäuser und } \\
\text { Kliniken sollten angesichts } \\
\text { der aktuellen } \\
\text { COVID-19-Situation die } \\
\text { Versorgung aller } \\
\text { Nicht-Notfallpatienten } \\
\text { verweigern können. }\end{array}$ & $\begin{array}{l}1=\text { Trifft überhaupt nicht } \mathrm{zu}, \\
2=\text { Trifft nicht } \mathrm{zu}, 3=\text { Trifft } \\
\text { eher nicht } \mathrm{zu}, 4=\text { Weder } \\
\text { noch, } 5=\text { Trifft eher zu, } 6= \\
\text { Trifft zu, } 7=\text { Trifft voll und } \\
\text { ganz zu }\end{array}$ & $\begin{array}{l}\text { Hospitals and clinics } \\
\text { should be allowed to } \\
\text { refuse care to all } \\
\text { non-emergency patients } \\
\text { given the current } \\
\text { COVID-19 situation. }\end{array}$ & $\begin{array}{l}1=\text { don't agree at all, } 2= \\
\text { don't agree, } 3=\text { rather } \\
\text { not agree, } 4=\text { neither, } 5 \\
=\text { rather agree, } 6=\text { agree } \\
7=\text { agree completely }\end{array}$ & & & & & & & & & & $\mathrm{x}$ & $\mathrm{x}$ \\
\hline policy.covid.12 & & $\begin{array}{l}\text { Die Menschen sollten } \\
\text { wieder arbeiten, um die } \\
\text { wirtschaftlichen Kosten der } \\
\text { COVID-19 Krise zu } \\
\text { reduzieren. }\end{array}$ & $\begin{array}{l}1=\text { Trifft überhaupt nicht zu, } \\
2=\text { Trifft nicht zu, } 3=\text { Trifft } \\
\text { eher nicht zu, } 4=\text { Weder } \\
\text { noch, } 5=\text { Trifft eher zu, } 6= \\
\text { Trifft zu, } 7=\text { Trifft voll und } \\
\text { ganz zu }\end{array}$ & $\begin{array}{l}\text { People should return to } \\
\text { work to reduce the } \\
\text { economic costs of the } \\
\text { COVID- } 19 \text { crisis. }\end{array}$ & $\begin{array}{l}1=\text { don't agree at all, } 2= \\
\text { don't agree, } 3=\text { rather } \\
\text { not agree, } 4=\text { neither, } 5 \\
=\text { rather agree, } 6=\text { agree } \\
7=\text { agree completely }\end{array}$ & & & & & & & & & & $\mathrm{x}$ & $\mathrm{x}$ \\
\hline policy.covid.13 & & $\begin{array}{l}\text { Unwesentliche Reisen } \\
\text { zwischen der Schweiz und } \\
\text { anderen Ländern sollten } \\
\text { verboten werden. }\end{array}$ & $\begin{array}{l}1=\text { Trifft überhaupt nicht zu, } \\
2=\text { Trifft nicht zu, } 3=\text { Trifft } \\
\text { eher nicht } \mathrm{zu}, 4=\text { Weder } \\
\text { noch, } 5=\text { Trifft eher zu, } 6= \\
\text { Trifft zu, } 7=\text { Trifft voll und } \\
\text { ganz zu }\end{array}$ & $\begin{array}{l}\text { Non-essential travel } \\
\text { between Switzerland } \\
\text { and other countries } \\
\text { should be banned. }\end{array}$ & $\begin{array}{l}1=\text { don't agree at all, } 2= \\
\text { don't agree, } 3=\text { rather } \\
\text { not agree, } 4=\text { neither, } 5 \\
=\text { rather agree, } 6=\text { agree, } \\
7=\text { agree completely }\end{array}$ & & & & & & & & & & $\mathrm{x}$ & $\mathrm{x}$ \\
\hline policy.covid.14 & & $\begin{array}{l}\text { Reisende, die über } \\
\text { Flughäfen in die Schweiz } \\
\text { einreisen, sollten in jedem } \\
\text { Fall auf COVID-19 getestet } \\
\text { werden. }\end{array}$ & $\begin{array}{l}1=\text { Trifft überhaupt nicht zu, } \\
2=\text { Trifft nicht } \mathrm{zu}, 3=\text { Trifft } \\
\text { eher nicht } \mathrm{zu}, 4=\text { Weder } \\
\text { noch, } 5=\text { Trifft eher zu, } 6= \\
\text { Trifft zu, } 7=\text { Trifft voll und } \\
\text { ganz zu }\end{array}$ & $\begin{array}{l}\text { Travellers entering } \\
\text { Switzerland through } \\
\text { airports should be } \\
\text { tested for COVID-19 in } \\
\text { all cases. }\end{array}$ & $\begin{array}{l}1=\text { don't agree at all, } 2= \\
\text { don't agree, } 3=\text { rather } \\
\text { not agree, } 4=\text { neither, } 5 \\
=\text { rather agree, } 6=\text { agree } \\
7=\text { agree completely }\end{array}$ & & & & & & & & & & $\mathrm{x}$ & $\mathrm{x}$ \\
\hline policy.covid.15 & & $\begin{array}{l}\text { Die COVID-19-Krise hat } \\
\text { positive Effekte auf das } \\
\text { Klima. }\end{array}$ & $\begin{array}{l}1=\text { Trifft überhaupt nicht zu, } \\
2=\text { Trifft nicht zu, } 3=\text { Trifft } \\
\text { eher nicht zu, } 4=\text { Weder } \\
\text { noch, } 5=\text { Trifft eher zu, } 6= \\
\text { Trifft zu, } 7=\text { Trifft voll und } \\
\text { ganz zu }\end{array}$ & $\begin{array}{l}\text { The COVID- } 19 \text { crisis } \\
\text { has positive effects on } \\
\text { the climate. }\end{array}$ & $\begin{array}{l}1=\text { don't agree at all, } 2= \\
\text { don't agree, } 3=\text { rather } \\
\text { not agree, } 4=\text { neither, } 5 \\
=\text { rather agree, } 6=\text { agree } \\
7=\text { agree completely }\end{array}$ & & & & & & & & & & $\mathrm{x}$ & $\mathrm{x}$ \\
\hline policy.covid.16 & & $\begin{array}{l}\text { Die Einschränkungen und } \\
\text { Empfehlungen der } \\
\text { Schweizer Regierung sind zu } \\
\text { streng. }\end{array}$ & $\begin{array}{l}1=\text { Trifft überhaupt nicht } \mathrm{zu}, \\
2=\text { Trifft nicht } \mathrm{zu}, 3=\text { Trifft } \\
\text { eher nicht } \mathrm{zu}, 4=\text { Weder } \\
\text { noch, } 5=\text { Trifft eher zu, } 6= \\
\text { Trifft zu, } 7=\text { Trifft voll und } \\
\text { ganz zu }\end{array}$ & $\begin{array}{l}\text { The restrictions and } \\
\text { recommendations of the } \\
\text { Swiss government are } \\
\text { too strict. }\end{array}$ & $\begin{array}{l}1=\text { don't agree at all, } 2= \\
\text { don't agree, } 3=\text { rather } \\
\text { not agree, } 4=\text { neither, } 5 \\
=\text { rather agree, } 6=\text { agree, } \\
7=\text { agree completely }\end{array}$ & & & & & & & & & & & $\mathrm{x}$ \\
\hline policy.covid.17 & & $\begin{array}{l}\text { Es sollte erlaubt sein, sich } \\
\text { zu versammeln, um friedlich } \\
\text { gegen die vom Schweizer } \\
\text { Bundesrat getroffenen } \\
\text { Massnahmen zu } \\
\text { demonstrieren. }\end{array}$ & $\begin{array}{l}1=\text { Trifft überhaupt nicht zu, } \\
2=\text { Trifft nicht zu, } 3=\text { Trifft } \\
\text { eher nicht zu, } 4=\text { Weder } \\
\text { noch, } 5=\text { Trifft eher zu, } 6= \\
\text { Trifft zu, } 7=\text { Trifft voll und } \\
\text { ganz zu }\end{array}$ & $\begin{array}{l}\text { People should be } \\
\text { allowed to gather to } \\
\text { demonstrate peacefully } \\
\text { against the measures } \\
\text { taken by the Swiss } \\
\text { Federal Council. }\end{array}$ & $\begin{array}{l}1=\text { don't agree at all, } 2= \\
\text { don't agree, } 3=\text { rather } \\
\text { not agree, } 4=\text { neither, } 5 \\
=\text { rather agree, } 6=\text { agree, } \\
7=\text { agree completely }\end{array}$ & & & & & & & & & & & $\mathrm{X}$ \\
\hline policy.covid.18 & & $\begin{array}{l}\text { Die Schweizer Regierung } \\
\text { benutzt das Virus um ihre } \\
\text { Kontrolle über die } \\
\text { Bevölkerung langfristig zu } \\
\text { vergrössern. }\end{array}$ & $\begin{array}{l}1=\text { Trifft überhaupt nicht zu, } \\
2=\text { Trifft nicht zu, } 3=\text { Trifft } \\
\text { eher nicht zu, } 4=\text { Weder } \\
\text { noch, } 5=\text { Trifft eher zu, } 6= \\
\text { Trifft zu, } 7=\text { Trifft voll und } \\
\text { ganz zu }\end{array}$ & $\begin{array}{l}\text { The Swiss government is } \\
\text { using the virus to } \\
\text { increase its control over } \\
\text { the population in the } \\
\text { long term. }\end{array}$ & $\begin{array}{l}1=\text { don't agree at all, } 2= \\
\text { don't agree, } 3=\text { rather } \\
\text { not agree, } 4=\text { neither, } 5 \\
=\text { rather agree, } 6=\text { agree } \\
7=\text { agree completely }\end{array}$ & & & & & & & & & & & $\mathrm{x}$ \\
\hline registered & & $\begin{array}{l}\text { Bist Du momentan } \\
\text { (Frühjahrssemester 2020) } \\
\text { an der [name removed] } \\
\text { eingeschrieben? }\end{array}$ & $1=\mathrm{Ja}, 2=$ Nein & $\begin{array}{l}\text { Are you currently } \\
\text { (spring semester 2020) } \\
\text { enrolled at the } \\
\text { [university name } \\
\text { removed]? }\end{array}$ & $1=\mathrm{Yes}, 2=\mathrm{No}$ & & & & & & & & & & $\mathrm{x}$ & $\mathrm{x}$ \\
\hline courses & & $\begin{array}{l}\text { Ich besuche hauptsächlich } \\
\text { Kurse... mit Personen, } \\
\text { welche }[\mathrm{X}] \text { das Studium } \\
\text { gestartet haben }\end{array}$ & $\begin{array}{l}1=2016,2=2017,3= \\
2018,4=2019\end{array}$ & $\begin{array}{l}\text { I mainly attend } \\
\text { courses... with people } \\
\text { who have started their } \\
\text { studies in [year] }\end{array}$ & $\begin{array}{l}1=2016,2=2017,3= \\
2018,4=2019\end{array}$ & & & & & & & & & & $\mathrm{x}$ & $\mathrm{x}$ \\
\hline cohort.year & & $\begin{array}{l}\text { Ich fühle mich zugehörig } \\
\text { zum Jahrgang ... der } \\
\text { Personen, welche }[\mathrm{X}] \text { das } \\
\text { Studium gestartet haben }\end{array}$ & $\begin{array}{l}1=2016,2=2017,3= \\
2018,4=2019\end{array}$ & $\begin{array}{l}\text { I feel that I belong to } \\
\text { the cohort ... of people } \\
\text { who started their degree } \\
\text { course in [year] }\end{array}$ & $\begin{array}{l}1=2016,2=2017,3= \\
2018,4=2019\end{array}$ & & & & & & & & & & $\mathrm{x}$ & $\mathrm{x}$ \\
\hline
\end{tabular}




\begin{tabular}{|c|c|c|c|c|c|c|c|c|c|c|c|c|c|c|c|c|}
\hline VarName & VariableLabel & WordingDE & ValueLabelsDE_Linked & WordingEN & ValueLabelsEN_Linked & L1 & $\mathrm{L} 2$ & L3 & $\mathrm{L} 4$ & L5 & L6 6 & L7 & L8 & L9 & L10 L11 & $1 \mathrm{~L} 12$ \\
\hline contact.1.P1 & & $\begin{array}{l}\text { Ich habe folgenden Kontakt } \\
\text { zu dieser Person ... Im } \\
\text { selben Haushalt }\end{array}$ & & $\begin{array}{l}\text { I have the following } \\
\text { contact with this person } \\
\ldots \text { In the same } \\
\text { household }\end{array}$ & & & & & & & & & & & $\mathrm{x}$ & $\mathrm{x}$ \\
\hline contact.2.P1 & & $\begin{array}{l}\text { Ich habe folgenden Kontakt } \\
\text { zu dieser Person ... } \\
\text { Ausserhalb des Hauses }\end{array}$ & & $\begin{array}{l}\text { I have the following } \\
\text { contact with this person } \\
\text {.. Outside the house }\end{array}$ & & & & & & & & & & & $\mathrm{x}$ & $\mathrm{x}$ \\
\hline contact.3.P1 & & $\begin{array}{l}\text { Ich habe folgenden Kontakt } \\
\text { zu dieser Person ... Telefon } \\
\text { (nur Audio) }\end{array}$ & & $\begin{array}{l}\text { I have the following } \\
\text { contact with this person } \\
\ldots \text { Telephone (audio } \\
\text { only) }\end{array}$ & & & & & & & & & & & $\mathrm{x}$ & $\mathrm{x}$ \\
\hline contact.4.P1 & & $\begin{array}{l}\text { Ich habe folgenden Kontakt } \\
\text { zu dieser Person ... } \\
\text { Skype/FaceTime oder } \\
\text { ähnliches }\end{array}$ & & $\begin{array}{l}\text { I have the following } \\
\text { contact with this person } \\
\ldots \text { Skype/FaceTime or } \\
\text { similar }\end{array}$ & & & & & & & & & & & $\mathrm{x}$ & $\mathrm{x}$ \\
\hline contact.5.P1 & & $\begin{array}{l}\text { Ich habe folgenden Kontakt } \\
\text { zu dieser Person ... } \\
\text { Chat-Messaging } \\
\text { (WhatsApp, Signal, etc.) }\end{array}$ & & $\begin{array}{l}\text { I have the following } \\
\text { contact with this person } \\
\ldots \text { Chat messaging } \\
\text { (WhatsApp, Signal, } \\
\text { etc.) }\end{array}$ & & & & & & & & & & & $\mathrm{x}$ & $\mathrm{x}$ \\
\hline contact.other.P1 & & $\begin{array}{l}\text { Ich habe folgenden Kontakt } \\
\text { zu dieser Person ... Anderes }\end{array}$ & & & & & & & & & & & & & $\mathrm{x}$ & $\mathrm{x}$ \\
\hline freq.phys.P1 & & $\begin{array}{l}\text { Wie oft unterhältst Du Dich } \\
\text { mit dieser Person persönlich } \\
\text { (ihr seid physisch } \\
\text { beieinander)? }\end{array}$ & $\begin{array}{l}1=\text { nie, } 2=\text { weniger als } \\
\text { wöchentlich, } 3=\text { einmal pro } \\
\text { Woche, } 4=\text { mehrmals } \\
\text { wöchentlich, } 5=\text { fast jeden } \\
\text { Tag, } 6=\text { einmal pro Tag, } 7= \\
\text { mehrmals täglich }\end{array}$ & & $\begin{array}{l}1=\text { Never, } 2=\text { less than } \\
\text { weekly, } 3=\text { once a week, } \\
4=\text { several times a week, } \\
5=\text { almost every day, } 6= \\
\text { once a day, } 7=\text { several } \\
\text { times a day }\end{array}$ & & & & & & & & & & $\mathrm{x}$ & $\mathrm{x}$ \\
\hline freq.tel.P1 & & $\begin{array}{l}\text { Wie oft unterhältst Du Dich } \\
\text { mit dieser Person } \\
\text { telefonisch (via Telefon, } \\
\text { Skype, FaceTime, etc.)? }\end{array}$ & $\begin{array}{l}1=\text { nie, } 2=\text { weniger als } \\
\text { wöchentlich, } 3=\text { einmal pro } \\
\text { Woche, } 4=\text { mehrmals } \\
\text { wöchentlich, } 5=\text { fast jeden } \\
\text { Tag, } 6=\text { einmal pro Tag, } 7= \\
\text { mehrmals täglich }\end{array}$ & & $\begin{array}{l}1=\text { Never, } 2=\text { less than } \\
\text { weekly, } 3=\text { once a week, } \\
4=\text { several times a week, } \\
5=\text { almost every day, } 6= \\
\text { once a day, } 7=\text { several } \\
\text { times a day }\end{array}$ & & & & & & & & & & $\mathrm{x}$ & $\mathrm{x}$ \\
\hline freq.msg.P1 & & $\begin{array}{l}\text { Wie oft kommunizierst Du } \\
\text { mit dieser Person über } \\
\text { Messaging-Apps (z.B. } \\
\text { Whatsapp, Signal, SMS) }\end{array}$ & $\begin{array}{l}1=\text { nie, } 2=\text { weniger als } \\
\text { wöchentlich, } 3=\text { einmal pro } \\
\text { Woche, } 4=\text { mehrmals } \\
\text { wöchentlich, } 5=\text { fast jeden } \\
\text { Tag, } 6=\text { einmal pro Tag, } 7= \\
\text { mehrmals täglich }\end{array}$ & & $\begin{array}{l}1=\text { Never, } 2=\text { less than } \\
\text { weekly, } 3=\text { once a week, } \\
4=\text { several times a week, } \\
5=\text { almost every day, } 6= \\
\text { once a day, } 7=\text { several } \\
\text { times a day }\end{array}$ & & & & & & & & & & $\mathrm{x}$ & $\mathrm{x}$ \\
\hline sm.comm.P1 & & $\begin{array}{l}\text { Mit welchen Deiner } \\
\text { Mitstudierenden } \\
\text { kommunizierst Du } \\
\text { regelmässig über Soziale } \\
\text { Medien? (ausgenommen } \\
\text { Messaging-Apps). Nenne } \\
\text { zwischen 0 und } 20 \text { Personen }\end{array}$ & & $\begin{array}{l}\text { With which of your } \\
\text { fellow students do you } \\
\text { regularly communicate } \\
\text { over social media? } \\
\text { (excluding messaging } \\
\text { apps). Name between } 0 \\
\text { and } 20 \text { people. }\end{array}$ & & & & & & & & & & & $\mathrm{x}$ & $\mathrm{x}$ \\
\hline
\end{tabular}




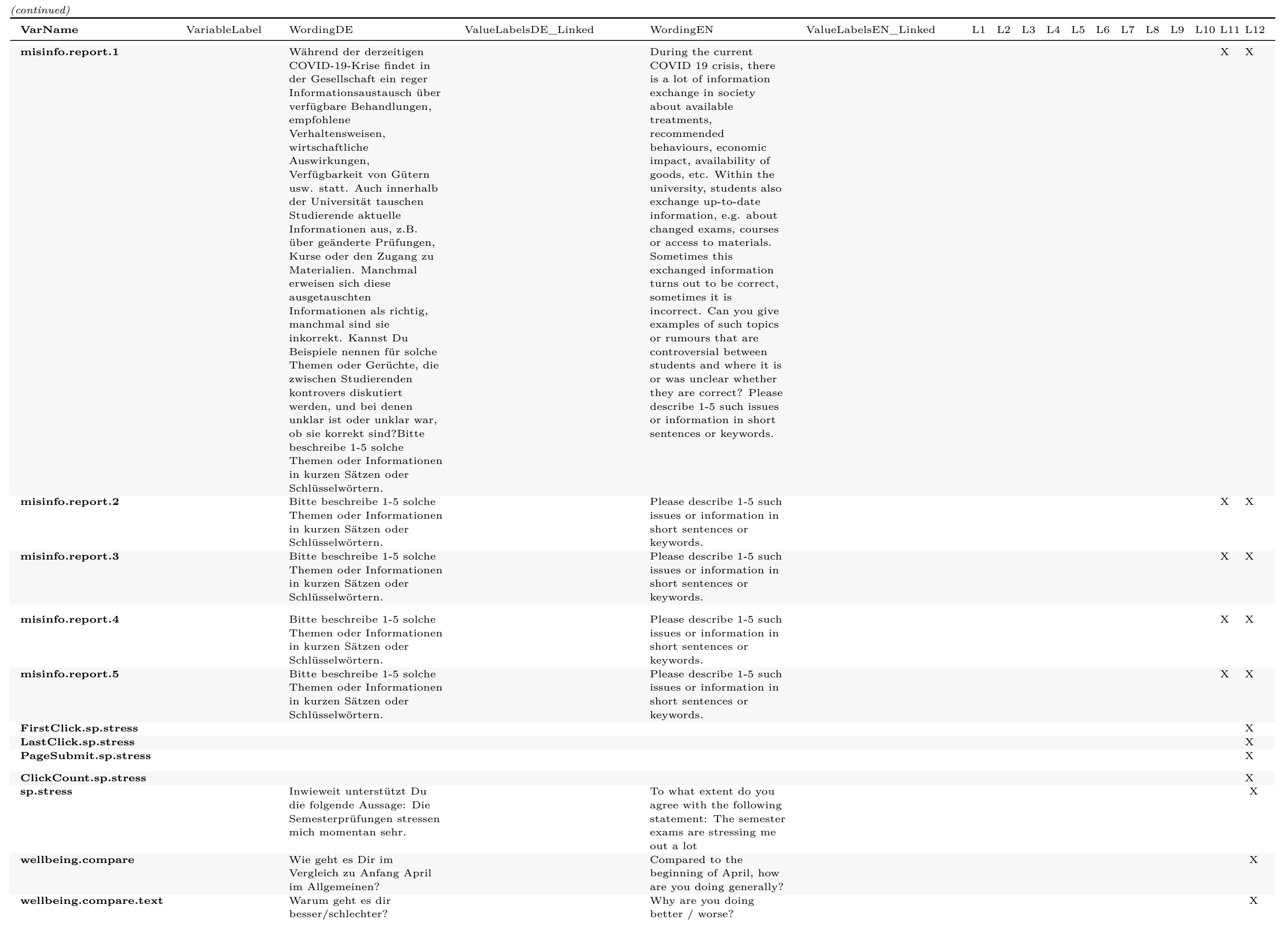




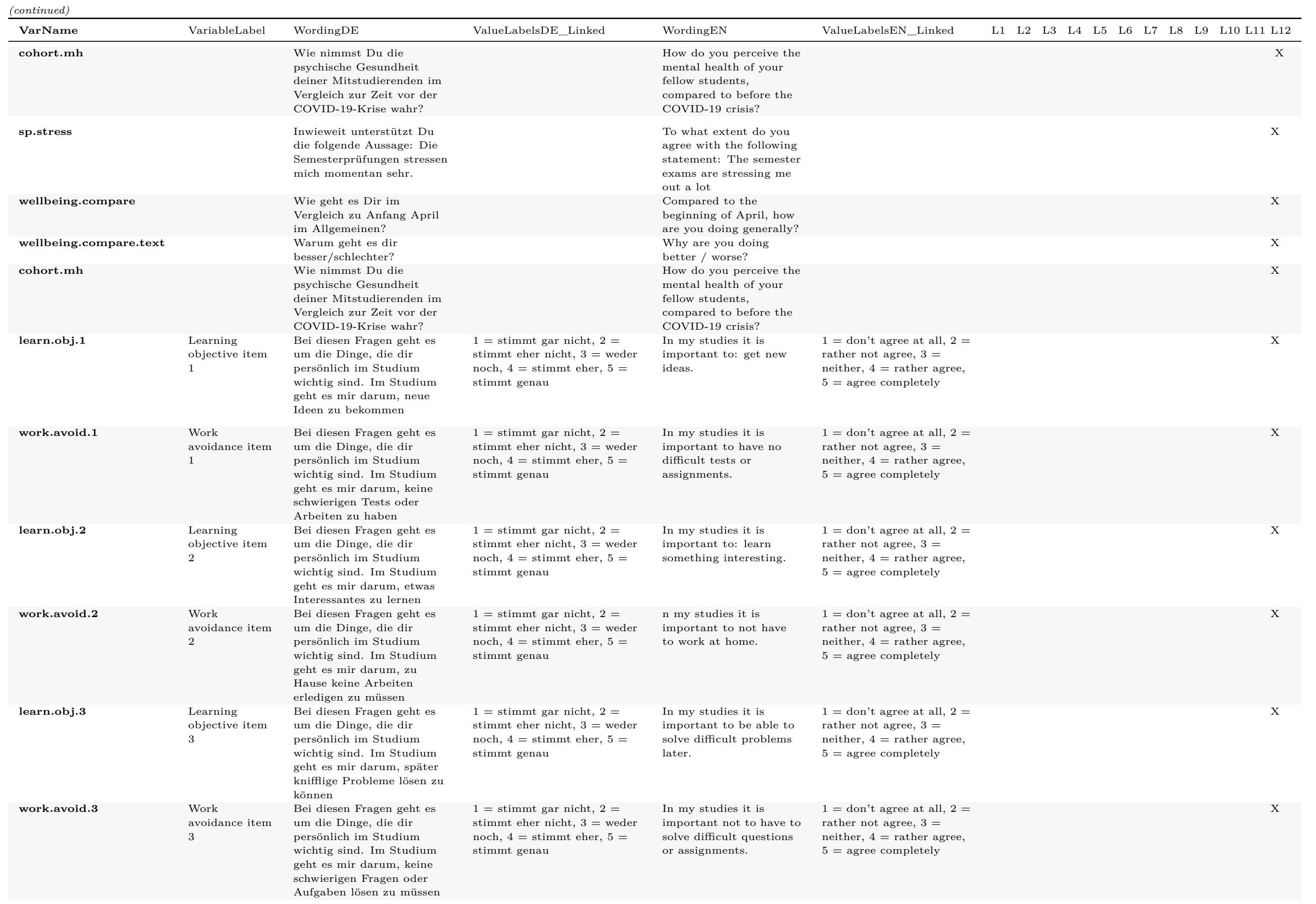




\begin{tabular}{|c|c|c|c|c|c|c|c|c|c|c|c|c|c|c|}
\hline VarName & VariableLabel & WordingDE & ValueLabelsDE_Linked & WordingEN & ValueLabelsEN_Linked & L1 & $\mathrm{L} 2$ & L3 & L4 & L5 & L6 6 & L7 L8 & L9 & L10 L11 L12 \\
\hline learn.obj.4 & $\begin{array}{l}\text { Learning } \\
\text { objective item } \\
4\end{array}$ & $\begin{array}{l}\text { Bei diesen Fragen geht es } \\
\text { um die Dinge, die dir } \\
\text { persönlich im Studium } \\
\text { wichtig sind. Im Studium } \\
\text { geht es mir darum, } \\
\text { komplizierte Inhalte zu } \\
\text { verstehen }\end{array}$ & $\begin{array}{l}1=\text { stimmt gar nicht, } 2= \\
\text { stimmt eher nicht, } 3=\text { weder } \\
\text { noch, } 4=\text { stimmt eher, } 5= \\
\text { stimmt genau }\end{array}$ & $\begin{array}{l}\text { In my studies it is } \\
\text { important to: } \\
\text { understand difficult } \\
\text { things. }\end{array}$ & $\begin{array}{l}1=\text { don't agree at all, } 2= \\
\text { rather not agree, } 3= \\
\text { neither, } 4=\text { rather agree, } \\
5=\text { agree completely }\end{array}$ & & & & & & & & & $\mathrm{x}$ \\
\hline app.perf.3 & $\begin{array}{l}\text { Approximate } \\
\text { performance } \\
\text { goal item } 3\end{array}$ & $\begin{array}{l}\text { Bei diesen Fragen geht es } \\
\text { um die Dinge, die dir } \\
\text { persönlich im Studium } \\
\text { wichtig sind. Im Studium } \\
\text { geht es mir darum, bessere } \\
\text { Noten zu bekommen als } \\
\text { andere }\end{array}$ & $\begin{array}{l}1=\text { stimmt gar nicht, } 2= \\
\text { stimmt eher nicht, } 3=\text { weder } \\
\text { noch, } 4=\text { stimmt eher, } 5= \\
\text { stimmt genau }\end{array}$ & $\begin{array}{l}\text { In my studies it is } \\
\text { important to: get better } \\
\text { grades than others. }\end{array}$ & $\begin{array}{l}1=\text { don't agree at all, } 2= \\
\text { rather not agree, } 3= \\
\text { neither, } 4=\text { rather agree, } \\
5=\text { agree completely }\end{array}$ & & & & & & & & & $\mathrm{x}$ \\
\hline work.avoid.4 & $\begin{array}{l}\text { Work } \\
\text { avoidance item } \\
4\end{array}$ & $\begin{array}{l}\text { Bei diesen Fragen geht es } \\
\text { um die Dinge, die dir } \\
\text { persönlich im Studium } \\
\text { wichtig sind. Im Studium } \\
\text { geht es mir darum, nicht so } \\
\text { schwer zu arbeiten }\end{array}$ & $\begin{array}{l}1=\text { stimmt gar nicht, } 2= \\
\text { stimmt eher nicht, } 3=\text { weder } \\
\text { noch, } 4=\text { stimmt eher, } 5= \\
\text { stimmt genau }\end{array}$ & $\begin{array}{l}\text { In my studies it is } \\
\text { important not to have } \\
\text { to work too hard. }\end{array}$ & $\begin{array}{l}1=\text { don't agree at all, } 2= \\
\text { rather not agree, } 3= \\
\text { neither, } 4=\text { rather agree, } \\
5=\text { agree completely }\end{array}$ & & & & & & & & & $\mathrm{x}$ \\
\hline learn.obj.5 & $\begin{array}{l}\text { Learning } \\
\text { objective item } \\
5\end{array}$ & $\begin{array}{l}\text { Bei diesen Fragen geht es } \\
\text { um die Dinge, die dir } \\
\text { persönlich im Studium } \\
\text { wichtig sind. Im Studium } \\
\text { geht es mir darum, dass das } \\
\text { Gelernte für mich Sinn } \\
\text { ergibt }\end{array}$ & $\begin{array}{l}1=\text { stimmt gar nicht, } 2= \\
\text { stimmt eher nicht, } 3=\text { weder } \\
\text { noch, } 4=\text { stimmt eher, } 5= \\
\text { stimmt genau }\end{array}$ & $\begin{array}{l}\text { In my studies it is } \\
\text { important to: see that } \\
\text { what I learn makes } \\
\text { sense. }\end{array}$ & $\begin{array}{l}1=\text { don't agree at all, } 2= \\
\text { rather not agree, } 3= \\
\text { neither, } 4=\text { rather agree } \\
5=\text { agree completely }\end{array}$ & & & & & & & & & $\mathrm{x}$ \\
\hline work.avoid.5 & $\begin{array}{l}\text { Work } \\
\text { avoidance item } \\
5\end{array}$ & $\begin{array}{l}\text { Bei diesen Fragen geht es } \\
\text { um die Dinge, die dir } \\
\text { persönlich im Studium } \\
\text { wichtig sind. Im Studium } \\
\text { geht es mir darum, dass die } \\
\text { Arbeit leicht ist }\end{array}$ & $\begin{array}{l}1=\text { stimmt gar nicht, } 2= \\
\text { stimmt eher nicht, } 3=\text { weder } \\
\text { noch, } 4=\text { stimmt eher, } 5= \\
\text { stimmt genau }\end{array}$ & $\begin{array}{l}\text { In my studies it is } \\
\text { important that work is } \\
\text { easy. }\end{array}$ & $\begin{array}{l}1=\text { don't agree at all, } 2= \\
\text { rather not agree, } 3= \\
\text { neither, } 4=\text { rather agree, } \\
5=\text { agree completely }\end{array}$ & & & & & & & & & $\mathrm{x}$ \\
\hline learn.obj.6 & $\begin{array}{l}\text { Learning } \\
\text { objective item } \\
6\end{array}$ & $\begin{array}{l}\text { Bei diesen Fragen geht es } \\
\text { um die Dinge, die dir } \\
\text { persönlich im Studium } \\
\text { wichtig sind. Im Studium } \\
\text { geht es mir darum, zum } \\
\text { Nachdenken angeregt zu } \\
\text { werden }\end{array}$ & $\begin{array}{l}1=\text { stimmt gar nicht, } 2= \\
\text { stimmt eher nicht, } 3=\text { weder } \\
\text { noch, } 4=\text { stimmt eher, } 5= \\
\text { stimmt genau }\end{array}$ & $\begin{array}{l}\text { In my studies it is } \\
\text { important to: be made } \\
\text { to think about things. }\end{array}$ & $\begin{array}{l}1=\text { don't agree at all, } 2= \\
\text { rather not agree, } 3= \\
\text { neither, } 4=\text { rather agree, } \\
5=\text { agree completely }\end{array}$ & & & & & & & & & $\mathrm{x}$ \\
\hline work.avoid.6 & $\begin{array}{l}\text { Work } \\
\text { avoidance item } \\
6\end{array}$ & $\begin{array}{l}\text { Bei diesen Fragen geht es } \\
\text { um die Dinge, die dir } \\
\text { persönlich im Studium } \\
\text { wichtig sind. Im Studium } \\
\text { geht es mir darum, } \\
\text { Aufgaben, die viel Arbeit } \\
\text { machen, nicht selber } \\
\text { erledigen zu müssen }\end{array}$ & $\begin{array}{l}1=\text { stimmt gar nicht, } 2= \\
\text { stimmt eher nicht, } 3=\text { weder } \\
\text { noch, } 4=\text { stimmt eher, } 5= \\
\text { stimmt genau }\end{array}$ & $\begin{array}{l}\text { In my studies it is } \\
\text { important to not to } \\
\text { have to do tasks myself } \\
\text { that are a lot of work. }\end{array}$ & $\begin{array}{l}1=\text { don't agree at all, } 2= \\
\text { rather not agree, } 3= \\
\text { neither, } 4=\text { rather agree, } \\
5=\text { agree completely }\end{array}$ & & & & & & & & & $\mathrm{x}$ \\
\hline learn.obj.7 & $\begin{array}{l}\text { Learning } \\
\text { objective item } \\
7\end{array}$ & $\begin{array}{l}\text { Bei diesen Fragen geht es } \\
\text { um die Dinge, die dir } \\
\text { persönlich im Studium } \\
\text { wichtig sind. Im Studium } \\
\text { geht es mir darum, so viel } \\
\text { wie möglich zu lernen }\end{array}$ & $\begin{array}{l}1=\text { stimmt gar nicht, } 2= \\
\text { stimmt eher nicht, } 3=\text { weder } \\
\text { noch, } 4=\text { stimmt eher, } 5= \\
\text { stimmt genau }\end{array}$ & $\begin{array}{l}\text { In my studies it is } \\
\text { important to: learn as } \\
\text { much as possible. }\end{array}$ & $\begin{array}{l}1=\text { don't agree at all, } 2= \\
\text { rather not agree, } 3= \\
\text { neither, } 4=\text { rather agree, } \\
5=\text { agree completely }\end{array}$ & & & & & & & & & $\mathrm{x}$ \\
\hline work.avoid.7 & $\begin{array}{l}\text { Work } \\
\text { avoidance item } \\
7\end{array}$ & $\begin{array}{l}\text { Bei diesen Fragen geht es } \\
\text { um die Dinge, die dir } \\
\text { persönlich im Studium } \\
\text { wichtig sind. Im Studium } \\
\text { geht es mir darum, mit } \\
\text { wenig Arbeit durch die } \\
\text { Schule zu kommen }\end{array}$ & $\begin{array}{l}1=\text { stimmt gar nicht, } 2= \\
\text { stimmt eher nicht, } 3=\text { weder } \\
\text { noch, } 4=\text { stimmt eher, } 5= \\
\text { stimmt genau }\end{array}$ & $\begin{array}{l}\text { In my studies it is } \\
\text { important to get } \\
\text { through school with } \\
\text { little work. }\end{array}$ & $\begin{array}{l}1=\text { don't agree at all, } 2= \\
\text { rather not agree, } 3= \\
\text { neither, } 4=\text { rather agree, } \\
5=\text { agree completely }\end{array}$ & & & & & & & & & $\mathrm{x}$ \\
\hline
\end{tabular}


wichtig sind. Im Studium $1=$ stimmt gar nicht, $2=$

In my studies it is

ValueLabelsEN_Linked

L1 $\quad$ L2

stimmt eher nicht, $3=$ wede

In my studies it is
important to: really

$1=$ don't agree at all, 2

noch, $4=$ stimmt eher, $5=\quad$ understand what is

rather not agree, $3=$

geht es mir darum, die

taught.

$5=$ agree completely

zu verstehen 


\section{Meta}

Specific information related to students' academic status at each wave in Cohort II is contained in data.frames with the following variables:

\begin{tabular}{|c|c|c|}
\hline VarName & Type & Description \\
\hline student_id & character & identifier of the student (used in other tables) \\
\hline is_invited & boolean & $\begin{array}{l}\text { indicator for whether the student received an invitation at this } \\
\text { specific wave }\end{array}$ \\
\hline is_alter & boolean & $\begin{array}{l}\text { indicator for whether the student was mentionned as a posisble } \\
\text { alter in network items at this specific wave }\end{array}$ \\
\hline is_in_cohort & boolean & $\begin{array}{l}\text { indicator for whether the student is considered to be part of the } \\
\text { cohort at this specific wave (having at least one course } \\
\text { registration with another member of the cohort) }\end{array}$ \\
\hline is_enrolled & boolean & $\begin{array}{l}\text { indicator for whether the student was officially enrolled in the } \\
\text { program at this specific wave }\end{array}$ \\
\hline number_courses_total & numeric & $\begin{array}{l}\text { number of courses to which the student was registered at this } \\
\text { specific wave }\end{array}$ \\
\hline number_courses_department & numeric & $\begin{array}{l}\text { number of courses of the department attached to the study } \\
\text { program to which the student was registered at this specific wave }\end{array}$ \\
\hline $\begin{array}{l}\text { number_courses_year1_mandatory } \\
\text { _program1 }\end{array}$ & numeric & $\begin{array}{l}\text { number of courses that were mandatory in the first year of the } \\
\text { first subprogram to which the student was registered at this } \\
\text { specific wave }\end{array}$ \\
\hline $\begin{array}{l}\text { number_courses_year1_mandatory } \\
\text { _program } 2\end{array}$ & numeric & $\begin{array}{l}\text { number of courses that were mandatory in the first year of the } \\
\text { second subprogram to which the student was registered at this } \\
\text { specific wave }\end{array}$ \\
\hline $\begin{array}{l}\text { number_courses_year1_mandatory } \\
\text { _program3 }\end{array}$ & numeric & $\begin{array}{l}\text { number of courses that were mandatory in the first year of the } \\
\text { third subprogram to which the student was registered at this } \\
\text { specific wave }\end{array}$ \\
\hline $\begin{array}{l}\text { number_courses_year1_mandatory } \\
\text { _program } 4\end{array}$ & numeric & $\begin{array}{l}\text { number of courses that were mandatory in the first year of the } \\
\text { fourth subprogram to which the student was registered at this } \\
\text { specific wave }\end{array}$ \\
\hline $\begin{array}{l}\text { number_courses_year2_mandatory } \\
\text { _program1 }\end{array}$ & numeric & $\begin{array}{l}\text { number of courses that were mandatory in the second year of the } \\
\text { first subprogram to which the student was registered at this } \\
\text { specific wave }\end{array}$ \\
\hline $\begin{array}{l}\text { number_courses_year2_mandatory } \\
\text { _program2 }\end{array}$ & numeric & $\begin{array}{l}\text { number of courses that were mandatory in the second year of the } \\
\text { second subprogram to which the student was registered at this } \\
\text { specific wave }\end{array}$ \\
\hline $\begin{array}{l}\text { number_courses_year2_mandatory } \\
\text { _program } 3\end{array}$ & numeric & $\begin{array}{l}\text { number of courses that were mandatory in the secdon year of the } \\
\text { third subprogram to which the student was registered at this } \\
\text { specific wave }\end{array}$ \\
\hline $\begin{array}{l}\text { number_courses_year2_mandatory } \\
\text { _program } 4\end{array}$ & numeric & $\begin{array}{l}\text { number of courses that were mandatory in the second year of the } \\
\text { fourth subprogram to which the student was registered at this } \\
\text { specific wave }\end{array}$ \\
\hline
\end{tabular}




\begin{tabular}{|c|c|c|}
\hline VarName & Type & Description \\
\hline number_students_coregistered & numeric & $\begin{array}{l}\text { number of other students with whom the student had at least } \\
\text { one course in common }\end{array}$ \\
\hline number_coregistrations_total & numeric & $\begin{array}{l}\text { number of co-registrations with all other students (i.e., the sum } \\
\text { over all other students of the number of common courses) }\end{array}$ \\
\hline number_exams_year1_total & numeric & $\begin{array}{l}\text { number of exams offered in first year to which the student was } \\
\text { registered at this specific wave }\end{array}$ \\
\hline $\begin{array}{l}\text { number_exams_year1_mandatory } \\
\text { _program1 }\end{array}$ & numeric & $\begin{array}{l}\text { number of exams that were mandatory in the first year of the } \\
\text { first subprogram to which the student was registered at this } \\
\text { specific wave }\end{array}$ \\
\hline $\begin{array}{l}\text { number_exams_year1_mandatory } \\
\text { _program2 }\end{array}$ & numeric & $\begin{array}{l}\text { number of exams that were mandatory in the first year of the } \\
\text { second subprogram to which the student was registered at this } \\
\text { specific wave }\end{array}$ \\
\hline $\begin{array}{l}\text { number_exams_year1_mandatory } \\
\text { _program3 }\end{array}$ & numeric & $\begin{array}{l}\text { number of exams that were mandatory in the first year of the } \\
\text { third subprogram to which the student was registered at this } \\
\text { specific wave }\end{array}$ \\
\hline $\begin{array}{l}\text { number_exams_year1_mandatory } \\
\text { _program4 }\end{array}$ & numeric & $\begin{array}{l}\text { number of exams that were mandatory in the first year of the } \\
\text { fourth subprogram to which the student was registered at this } \\
\text { specific wave }\end{array}$ \\
\hline number_exams_year2_total & numeric & $\begin{array}{l}\text { number of exams offered in second year to which the student was } \\
\text { registered at this specific wave }\end{array}$ \\
\hline $\begin{array}{l}\text { number_exams_year2_mandatory } \\
\text { _program1 }\end{array}$ & numeric & $\begin{array}{l}\text { number of exams that were mandatory in the first year of the } \\
\text { first subprogram to which the student was registered at this } \\
\text { specific wave }\end{array}$ \\
\hline $\begin{array}{l}\text { number_exams_year2_mandatory } \\
\text { _program2 }\end{array}$ & numeric & $\begin{array}{l}\text { number of exams that were mandatory in the first year of the } \\
\text { second subprogram to which the student was registered at this } \\
\text { specific wave }\end{array}$ \\
\hline $\begin{array}{l}\text { number_exams_year2_mandatory } \\
\text { _program } 3\end{array}$ & numeric & $\begin{array}{l}\text { number of exams that were mandatory in the first year of the } \\
\text { third subprogram to which the student was registered at this } \\
\text { specific wave }\end{array}$ \\
\hline $\begin{array}{l}\text { number_exams_year2_mandatory } \\
\text { _program } 4\end{array}$ & numeric & $\begin{array}{l}\text { number of exams that were mandatory in the first year of the } \\
\text { fourth subprogram to which the student was registered at this } \\
\text { specific wave }\end{array}$ \\
\hline number_labs_year2 & numeric & $\begin{array}{l}\text { number of exams considered as lab exams offered in second year } \\
\text { to which the student was registered at this specific wave }\end{array}$ \\
\hline number_exams_year1_passed & numeric & $\begin{array}{l}\text { number of exams offered in first year that the student passed in } \\
\text { the semester of this specific wave }\end{array}$ \\
\hline number_exams_year2_passed & numeric & $\begin{array}{l}\text { number of exams offered in second year that the student passed } \\
\text { in the semester of this specific wave }\end{array}$ \\
\hline
\end{tabular}




\begin{tabular}{lll}
\hline VarName & Type & Description \\
\hline block_year1_passed & boolean & $\begin{array}{l}\text { indicator for whether the student passed the exam block offered } \\
\text { in first year (i.e., qualification exam) in the semester of this } \\
\text { specific wave } \\
\text { number of exam blocks offered in second year that the student } \\
\text { passed in the semester of this specific wave }\end{array}$ \\
\hline
\end{tabular}

And similarly for Cohort III:

\begin{tabular}{|c|c|c|}
\hline VarName & Type & Description \\
\hline student_id & character & identifier of the student (used in other tables) \\
\hline is_invited & boolean & $\begin{array}{l}\text { indicator for whether the student received an invitation at this } \\
\text { specific wave }\end{array}$ \\
\hline is_alter & boolean & $\begin{array}{l}\text { indicator for whether the student was mentionned as a posisble } \\
\text { alter in network items at this specific wave }\end{array}$ \\
\hline is_in_cohort & boolean & $\begin{array}{l}\text { indicator for whether the student is considered to be part of the } \\
\text { cohort at this specific wave (having at least one course } \\
\text { registration with another member of the cohort) }\end{array}$ \\
\hline is_enrolled & boolean & $\begin{array}{l}\text { indicator for whether the student was officially enrolled in the } \\
\text { program at this specific wave }\end{array}$ \\
\hline number_courses_total & numeric & $\begin{array}{l}\text { number of courses to which the student was registered at this } \\
\text { specific wave }\end{array}$ \\
\hline number_courses_department & numeric & $\begin{array}{l}\text { number of courses of the department attached to the study } \\
\text { program to which the student was registered at this specific wave }\end{array}$ \\
\hline number_courses_year1_mandatory & numeric & $\begin{array}{l}\text { number of courses that were mandatory in the first year to } \\
\text { which the student was registered at this specific wave }\end{array}$ \\
\hline number_courses_year2_mandatory & numeric & $\begin{array}{l}\text { number of courses that were mandatory in the second year to } \\
\text { which the student was registered at this specific wave }\end{array}$ \\
\hline number_students_coregistered & numeric & $\begin{array}{l}\text { number of other students with whom the student had at least } \\
\text { one course in common }\end{array}$ \\
\hline number_coregistrations_total & numeric & $\begin{array}{l}\text { number of co-registrations with all other students (i.e., the sum } \\
\text { over all other students of the number of common courses) }\end{array}$ \\
\hline number_exams_year1_total & numeric & $\begin{array}{l}\text { number of exams offered in first year to which the student was } \\
\text { registered at this specific wave }\end{array}$ \\
\hline number_exams_year1_mandatory & numeric & $\begin{array}{l}\text { number of exams that were mandatory in the first year to which } \\
\text { the student was registered at this specific wave }\end{array}$ \\
\hline number_exams_year2_total & numeric & $\begin{array}{l}\text { number of exams offered in second year to which the student was } \\
\text { registered at this specific wave }\end{array}$ \\
\hline number_exams_year2_mandatory & numeric & $\begin{array}{l}\text { number of exams that were mandatory in the first year to which } \\
\text { the student was registered at this specific wave }\end{array}$ \\
\hline
\end{tabular}




\begin{tabular}{|c|c|c|}
\hline VarName & Type & Description \\
\hline number_labs_year2 & numeric & $\begin{array}{l}\text { number of exams considered as lab exams offered in second year } \\
\text { to which the student was registered at this specific wave }\end{array}$ \\
\hline number_exams_year1_passed & numeric & $\begin{array}{l}\text { number of exams offered in first year that the student passed in } \\
\text { the semester of this specific wave }\end{array}$ \\
\hline block_year1_passed & boolean & $\begin{array}{l}\text { indicator for whether the student passed the exam block offered } \\
\text { in first year (i.e., qualification exam) in the semester of this } \\
\text { specific wave }\end{array}$ \\
\hline number_blocks_year2_passed & numeric & $\begin{array}{l}\text { number of exam blocks offered in second year that the student } \\
\text { passed in the semester of this specific wave }\end{array}$ \\
\hline
\end{tabular}

General information on students of Cohort II and Cohort III contain the following:

\begin{tabular}{|c|c|c|}
\hline VarName & Type & Description \\
\hline student_id & character & identifier of the student (used in other tables) \\
\hline birthdate & date & date of birth of the student (format: yyyy-mm-dd) \\
\hline gender & character & gender of the student ( $M=$ male, $W=$ female) \\
\hline country_of_origin & character & $\begin{array}{l}\text { country provided as residence of the student when entering the } \\
\text { university (in German) }\end{array}$ \\
\hline entry_semester & character & $\begin{array}{l}\text { semester in which the student entered the university (can be in } \\
\text { any program) }\end{array}$ \\
\hline qualification_exam_semester & character & $\begin{array}{l}\text { semester in which the student last took the first year } \\
\text { qualification exam in the program of interest (empty if the } \\
\text { student did not took the exam) }\end{array}$ \\
\hline qualification_exam_program & character & $\begin{array}{l}\text { program in which the student last took the first year } \\
\text { qualification exam in the program of interest (for cohorts } 1 \text { and } 2 \text {, } \\
\text { this value can be } 1,2,3 \text {, or } 4 \text { depending on the sub-program they } \\
\text { are enrolled in the main program, for cohort } 3 \text { it can only be } 1 \text {, } \\
\text { and the variable is empty if the student did not took the exam) }\end{array}$ \\
\hline qualification_exam_grade & numeric & $\begin{array}{l}\text { grade obtained when the student last took the first year } \\
\text { qualification exam in the program of interest (passing the exam } \\
\text { requires a value above } 3 \text {, the variable is empty if the student did } \\
\text { not took the exam) }\end{array}$ \\
\hline first_program & character & $\begin{array}{l}\text { program in which the student entered the university (for cohorts } \\
1 \text { and } 2 \text {, this value can be } 1,2,3,4 \text {, depending on the } \\
\text { sub-program they are enrolled in the main program, for cohort } 3 \\
\text { it can only be } 1 \text {, and the variable is "other" if the student } \\
\text { entered in another program) }\end{array}$ \\
\hline
\end{tabular}




\begin{tabular}{|c|c|c|}
\hline VarName & Type & Description \\
\hline last_program & character & $\begin{array}{l}\text { program in which the student was at the end of the study, i.e. } \\
\text { Fall } 2019 \text { (for cohorts } 1 \text { and } 2 \text {, this value can be } 1,2,3,4 \text {, } \\
\text { depending on the sub-program they are enrolled in the main } \\
\text { program, for cohort } 3 \text { it can only be } 1 \text {, and the variable is "other" } \\
\text { if the student entered in another program) }\end{array}$ \\
\hline leaving_date & date & $\begin{array}{l}\text { date at which the student officially left the university (can be } \\
\text { empty if the student was still registered in Fall 2019) }\end{array}$ \\
\hline
\end{tabular}

The following objects are available to describe the academic paths of students and the cohort boundaries in both cohorts II and III:

\begin{tabular}{|c|c|c|}
\hline Object & Type & Description \\
\hline student_general_information_cohort2 & data frame & $\begin{array}{l}\text { table containing general information related to the academic } \\
\text { path of each student who was invited to participate in the study }\end{array}$ \\
\hline student_information_wave_cohort2 & $\begin{array}{l}\text { list of } 10 \\
\text { data frames }\end{array}$ & $\begin{array}{l}\text { list containing } 10 \text { data frames (one for each wave of } \\
\text { questionnaire) containing the information related to the students } \\
\text { academic status at the time the questionnaires were sent }\end{array}$ \\
\hline course_information_cohort 2 & data frame & $\begin{array}{l}\text { table containing information related to the courses and exams } \\
\text { students could register to }\end{array}$ \\
\hline registration_information_wave_cohort 2 & $\begin{array}{l}\text { list of } 10 \\
\text { matrices }\end{array}$ & $\begin{array}{l}\text { list containing } 10 \text { matrices (one for each wave of questionnaire) } \\
\text { representing the bipartite network of students registrations to } \\
\text { different couses (in this network, } 0=\text { no registration, } 1= \\
\text { registration) }\end{array}$ \\
\hline exam_information_wave_cohort 2 & $\begin{array}{l}\text { list of } 10 \\
\text { matrices }\end{array}$ & $\begin{array}{l}\text { list containing } 10 \text { matrices (one for each wave of questionnaire) } \\
\text { representing the bipartite network of students registrations to } \\
\text { different couses }\end{array}$ \\
\hline student_general_information_cohort3 & data frame & $\begin{array}{l}\text { table containing general information related to the academic } \\
\text { path of each student who was invited to participate in the study }\end{array}$ \\
\hline student_information_wave_cohort3 & $\begin{array}{l}\text { list of } 10 \\
\text { data frames }\end{array}$ & $\begin{array}{l}\text { list containing } 10 \text { data frames (one for each wave of } \\
\text { questionnaire) containing the information related to the students } \\
\text { academic status at the time the questionnaires were sent }\end{array}$ \\
\hline course_information_cohort3 & data frame & $\begin{array}{l}\text { table containing information related to the courses and exams } \\
\text { students could register to }\end{array}$ \\
\hline registration_information_wave_cohort3 & $\begin{array}{l}\text { list of } 10 \\
\text { matrices }\end{array}$ & $\begin{array}{l}\text { list containing } 10 \text { matrices (one for each wave of questionnaire) } \\
\text { representing the bipartite network of students registrations to } \\
\text { different couses (in this network, } 0=\text { no registration, } 1= \\
\text { registration) }\end{array}$ \\
\hline
\end{tabular}




\begin{tabular}{lll}
\hline Object & Type & Description \\
\hline exam_information_wave_cohort3 & $\begin{array}{l}\text { list of 10 } \\
\text { matrices }\end{array}$ & $\begin{array}{l}\text { list containing 10 matrices (one for each wave of questionnaire) } \\
\text { representing the bipartite network of students registrations to } \\
\text { different couses }\end{array}$ \\
\hline
\end{tabular}

Information related to courses and exams offered for cohort II can be found in the following table:

\begin{tabular}{|c|c|c|}
\hline VarName & Type & Description \\
\hline course_code & character & $\begin{array}{l}\text { identifier of a course and the exam linked to this course (if it } \\
\text { exists) }\end{array}$ \\
\hline is_exam & boolean & indicator of whether an exam is linked to the course \\
\hline department_course & boolean & $\begin{array}{l}\text { indicator of whether the course was proposed in the department } \\
\text { attached to the study program }\end{array}$ \\
\hline present_in_year1 & boolean & $\begin{array}{l}\text { indicator of whether the exam linked to the course was proposed } \\
\text { to first year students }\end{array}$ \\
\hline mandatory_in_year1_program1 & boolean & $\begin{array}{l}\text { indicator of whether the course was mentionned as mandatory in } \\
\text { first year in the official curriculum of the first sub-program }\end{array}$ \\
\hline mandatory_in_year1_program 2 & boolean & $\begin{array}{l}\text { indicator of whether the course was mentionned as mandatory in } \\
\text { first year in the official curriculum of the second sub-program }\end{array}$ \\
\hline mandatory_in_year1_program 3 & boolean & $\begin{array}{l}\text { indicator of whether the course was mentionned as mandatory in } \\
\text { first year in the official curriculum of the third sub-program }\end{array}$ \\
\hline mandatory_in_year1_program4 & boolean & $\begin{array}{l}\text { indicator of whether the course was mentionned as mandatory in } \\
\text { first year in the official curriculum of the fourth sub-program }\end{array}$ \\
\hline present_in_year2 & boolean & $\begin{array}{l}\text { indicator of whether the exam linked to the course was proposed } \\
\text { to second year students }\end{array}$ \\
\hline mandatory_in_year2_program 1 & boolean & $\begin{array}{l}\text { indicator of whether the course was mentionned as mandatory in } \\
\text { second year in the official curriculum of the first sub-program }\end{array}$ \\
\hline mandatory_in_year2_program 2 & boolean & $\begin{array}{l}\text { indicator of whether the course was mentionned as mandatory in } \\
\text { second year in the official curriculum of the second sub-program }\end{array}$ \\
\hline mandatory_in_year2_program 3 & boolean & $\begin{array}{l}\text { indicator of whether the course was mentionned as mandatory in } \\
\text { second year in the official curriculum of the third sub-program }\end{array}$ \\
\hline mandatory_in_year2_program 4 & boolean & $\begin{array}{l}\text { indicator of whether the course was mentionned as mandatory in } \\
\text { second year in the official curriculum of the fourth sub-program }\end{array}$ \\
\hline lab_in_year2 & boolean & $\begin{array}{l}\text { indicator of whether the exam linked to the course was } \\
\text { considered as a lab exam in second year }\end{array}$ \\
\hline
\end{tabular}

And similarly for cohort III: 


\begin{tabular}{|c|c|c|}
\hline VarName & Type & Description \\
\hline course_code & character & $\begin{array}{l}\text { identifier of a course and the exam linked to this course (if it } \\
\text { exists) }\end{array}$ \\
\hline is_exam & boolean & indicator of whether an exam is linked to the course \\
\hline department_course & boolean & $\begin{array}{l}\text { indicator of whether the course was proposed in the department } \\
\text { attached to the study program }\end{array}$ \\
\hline present_in_year1 & boolean & $\begin{array}{l}\text { indicator of whether the exam linked to the course was proposed } \\
\text { to first year students }\end{array}$ \\
\hline mandatory_in_year1 & boolean & $\begin{array}{l}\text { indicator of whether the course was mentionned as mandatory in } \\
\text { first year in the official curriculum of the first sub-program }\end{array}$ \\
\hline present_in_year2 & boolean & $\begin{array}{l}\text { indicator of whether the exam linked to the course was proposed } \\
\text { to second year students }\end{array}$ \\
\hline mandatory_in_year2 & boolean & $\begin{array}{l}\text { indicator of whether the course was mentionned as mandatory in } \\
\text { second year in the official curriculum of the first sub-program }\end{array}$ \\
\hline lab_in_year 2 & boolean & $\begin{array}{l}\text { indicator of whether the exam linked to the course was } \\
\text { considered as a lab exam in second year }\end{array}$ \\
\hline
\end{tabular}

Version 1.0 | 18 February, 2022

\section{References}

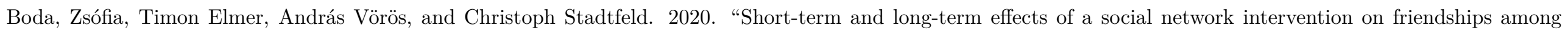
university students." Scientific Reports 10 (1): 1-12. https://doi.org/10.1038/s41598-020-59594-z.

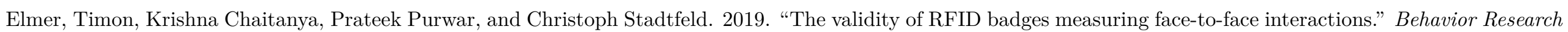
Methods, 1-19. https://doi.org/10.3758/s13428-018-1180-y.

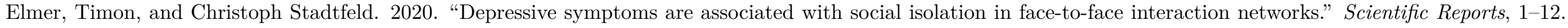
https://doi.org/10.1038/s41598-020-58297-9.

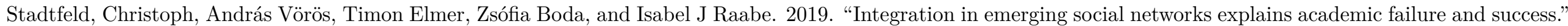
Proceedings of the National Academy of Sciences of the United States of America 116 (3): 792-97. https://doi.org/10.1073/pnas.1811388115.

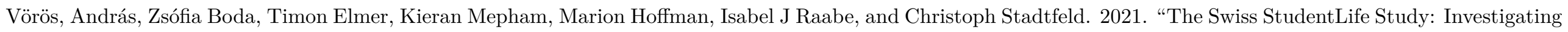
the emergence of an undergraduate community through dynamic, multidimensional social network data." Social Networks, no. 65: 71-84. 